LA CALIDAD DE LA INFORMACIÓN TELEMÁTICA

EVALUACIÓN DE SERVICIOS PÚBLICOS DE REFERENCIA DIGITAL 



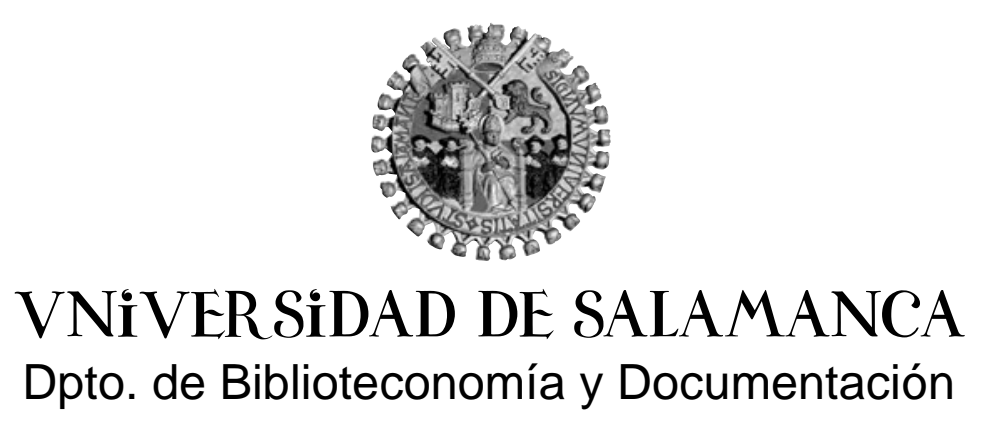

\title{
LA CALIDAD DE LA INFORMACIÓN TELEMÁTICA EVALUACIÓN DE SERVICIOS PÚBLICOS DE REFERENCIA DIGITAL
}

\author{
TESIS DOCTORAL
}

presentada para la obtención del grado de Doctor en Documentación

José Antonio Merlo Vega Doctorando
José Antonio Frías Montoya

Director 


\section{TESIS DOCTORAL}

Título

La calidad de la información telemática: evaluación de servicios públicos de referencia digital

Doctorando

José Antonio Merlo Vega

Director

José Antonio Frías Montoya

Departamento

Biblioteconomía y Documentación

\section{Programa}

Metodología y líneas de investigación en Biblioteconomía y

Documentación

\section{Descriptores}

Servicios de referencia / Referencia digital / Evaluación de bibliotecas

Pregunte: las bibliotecas responden 


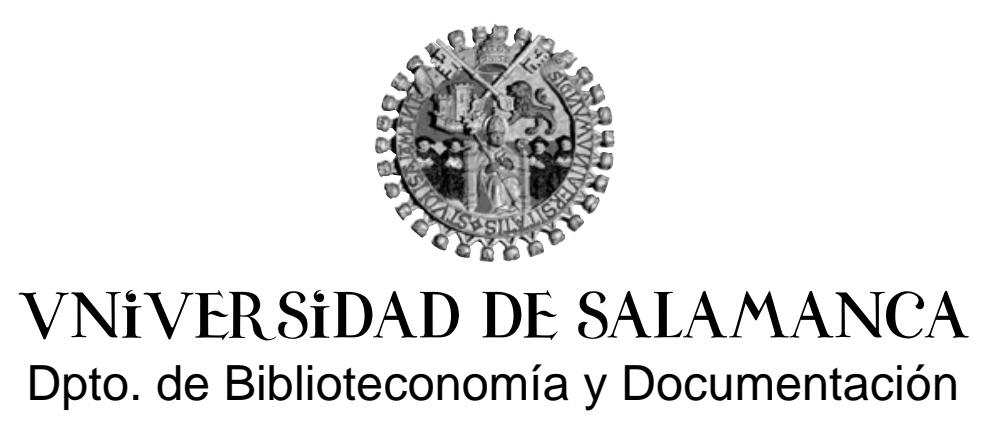

\section{LA CALIDAD DE LA INFORMACIÓN TELEMÁTICA} EVALUACIÓN DE SERVICIOS PÚBLICOS DE REFERENCIA DIGITAL

\section{TESIS DOCTORAL}

José Antonio Merlo Vega

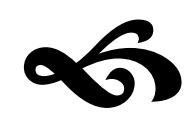

Salamanca, 2008 



\section{Índice}

Introducción. INFORMACIÓN TELEMÁTICA Y SERVICIOS DE REFERENCIA: INVESTIGACIÓN TEÓRICO-PRÁCTICA

0. Objetivos y contexto de la tesis doctoral

0.1. Objetivos: metodología de la investigación

0.2 . Contenidos: servicios de referencia y referencia digital

0.3. Aplicación: evaluación de un servicio público de referencia digital

1. El estudio de los servicios de referencia digital

1.1. La producción bibliográfica sobre servicios de referencia

1.2. Recursos para la investigación en referencia digital

1.3. Tendencias en la investigación en referencia digital

Parte I. LOS SERVICIOS BIBLIOTECARIOS DE INFORMACIÓN Y REFERENCIA

2. El servicio de referencia en la biblioteca

2.1. La información en la biblioteca

2.2. Fundamentos del servicio de referencia 57

2.3. Un servicio para los usuarios $\quad 58$

2.4. Tipología de los servicios de información 60

3. Organización del servicio de referencia 63

3.1. Perfil profesional del referencista 63

3.2. El entorno espacial en los servicios de referencia 66

3.3. Instrumentos para la prestación del servicio de referencia $\quad 67$

3.4. Formación de usuarios y servicios de referencia 68 
4. Las demandas de información 71

4.1. Tipología de las demandas de información 71

4.2. Información general $\quad 76$

4.3. Información de respuesta rápida $\quad 79$

4.4. Información bibliográfica $\quad 81$

5. El proceso de referencia 85

5.1. La recepción de las consultas $\quad 85$

5.2. La entrevista de referencia 86

5.3. La resolución de las consultas 90

5.4. Productos informativos elaborados por la biblioteca 93

6. La colección de referencia 95

6.1. Las fuentes de información 95

6.2. Tipología de los recursos de referencia 98

6.3. Esquema de la Clasificación Funcional/Formal 115

6.4. Internet como recurso para la referencia 119

$\begin{array}{ll}\text { 7. Evaluación de los servicios de referencia } & 127\end{array}$

7.1. Características de la evaluación 127

7.2. Evaluación de las consultas 130

7.3. Evaluación de la colección de referencia 133

7.4. Indicadores de evaluación 135

7.5. Métodos de evaluación 145

Parte II. SERVICIOS DE REFERENCIA DIGITAL: DESARROLLO Y EVALUACIÓN

8. El servicio bibliotecario de referencia digital 155

8.1. Contexto conceptual de la referencia digital 155

8.2. Tipología de los servicios de referencia digital 167

8.3. Tecnologías de comunicación para la referencia digital 178

9. Desarrollo de servicios de referencia digital 205

9.1. Planificación y creación de un servicio de referencia 205 digital

9.2. Competencias profesionales para la referencia digital 215

9.3. Servicios públicos de referencia digital 224

9.4. Servicios de referencia digital en España 242 
10. Pautas y normas para el ejercicio de la referencia digital

10.1. Recomendaciones de la IFLA

10.2. Pautas de la RUSA/ALA

258

10.3. Normas de la Virtual Reference Desk Network

264

11. Evaluación de los servicios de referencia digital

11.1. Evaluación de la información telemática

11.2. Metodologías de evaluación de la referencia digital

11.3. Propuestas para la evaluación de servicios públicos de 294 referencia digital

Parte III. APLICACIÓN PRÁCTICA: EVALUACIÓN DE «PREGUNTE: LAS BIBLIOTECAS RESPONDEN»

12. El servicio «Pregunte: las bibliotecas responden»

12.1. Estudio de «Pregunte: las bibliotecas responden»:

metodología y objetivos

12.2. Desarrollo histórico del servicio «Pregunte: las bibliotecas responden»

12.3. Descripción del funcionamiento del servicio

13. Evaluación del servicio de referencia digital «Pregunte: las bibliotecas responden»

13.1. Estudios y metodología

13.2. Estudio de profesionales

13.3. Estudio de usuarios

13.4. Estudio de incidencias

413

13.5. Estudio de preguntas y respuestas $\quad 419$

13.5.1. Estadísticas generales $\quad 420$

13.5.2. Análisis por clasificación 421

13.5.3. Análisis de respuestas 426

13.5.4. Homogeneidad de las respuestas $\quad 434$

13.6. Estudio de visibilidad

13.7. Estudio bibliográfico

13.8. Propuestas de mejora 442

14. El servicio público de referencia digital «Pregunte: las 451

bibliotecas responden» en la actualidad

14.1. Bibliotecas participantes: datos generales 452

14.2. Manuales de procedimiento y otros documentos 458

14.3. Estadísticas del servicio de referencia digital «Pregunte: 465 las bibliotecas responden»: 2000-2007 
Parte IV. RECURSOS DE INFORMACIÓN

16. Servicios de referencia: recursos bibliográficos

16.1. Manuales sobre servicios de referencia

16.2. Evaluación de servicios de referencia

16.3. Servicios de referencia en entornos digitales

492

16.4. Recursos y tecnología web en los servicios de

16.5. Bibliografía complementaria sobre servicios de

502 referencia

17. Fuentes de información: recursos bibliográficos

17.1. Manuales sobre fuentes de información y colecciones de referencia

17.2. Evaluación de fuentes de información

17.3. Bibliografía complementaria sobre fuentes de información

18. Referencia digital: recursos bibliográficos

18.1. Manuales y bibliografía esencial sobre referencia digital

18.2. Evaluación de la referencia digital

18.3. Conceptualización de la referencia digital

18.4. Procesos de la referencia digital

18.5. Sistemas de referencia digital

18.6. Servicios públicos de referencia digital

18.7. Servicios especializados de referencia digital

560

\section{Anexos. DOCUMENTOS COMPLEMENTARIOS}

Anexo 1. Encuestas empleadas en la evaluación de «Pregunte: las bibliotecas responden»

Cuestionario 1: Coordinadores

Anexo 2. Consultas realizadas en la evaluación de «Pregunte: las 


\section{Introducción}

\section{Información telemática y servicios de referencia: investigación teórico-práctica}

Los servicios de referencia digital son aquellos que ofrecen las bibliotecas para responder consultas de sus usuarios por medios telemáticos. La evaluación de estos servicios es el tema principal de la presente investigación, que se concreta en la metodología de análisis de los sistemas de consulta que suministran administraciones públicas con responsabilidad bibliotecaria nacional, los que se han denominado «Servicios públicos de referencia digital». En esta parte introductoria, se quiere mostrar la metodología seguida y presentar el estado de la cuestión relativo a la referencia digital. Así pues, el primer capítulo está destinado a describir el contenido de la tesis doctoral. El capítulo inicial, que se presenta como cero, ya que no trata de referencia, sino de la propia tesis, quiere servir de resumen de los contenidos que se desarrollan en las distintas partes de este trabajo de investigación. En este bloque introductorio, se ha incluido como capítulo uno el destinado a analizar la producción bibliográfica sobre servicios de referencia digital. En él, se comentan las monografías y autores más importantes sobre servicios de referencia ofrecidos en línea. También se describen los recursos de información más útiles para la investigación en servicios de información telemáticos. Además, se ha realizado un estudio bibliográfico a partir de los documentos que se recogen en las diferentes relaciones de recursos documentales que se ofrecen en la parte cuarta de la tesis. El análisis bibliométrico sirve para contextualizar la tesis doctoral y conocer las tendencias de la investigación sobre referencia digital, un incipiente campo de estudio. 
Introducción. INFORMACIÓN TELEMÁTICA Y SERVICIOS DE REFERENCIA: INVESTIGACIÓN TEÓRICO-PRÁCTICA

0. Objetivos y contexto de la tesis doctoral

0.1. Objetivos: metodología de la investigación

0.2. Contenidos: servicios de referencia y referencia digital

0.3. Aplicación: evaluación de un servicio público de referencia digital

1. El estudio de los servicios de referencia digital

1.1. La producción bibliográfica sobre servicios de referencia

1.2. Recursos para la investigación en referencia digital

1.3. Tendencias en la investigación en referencia digital 


\section{Objetivos y contexto de la tesis doctoral}

Los sistemas de referencia digital se han ido incorporando a la oferta de servicios que las bibliotecas facilitan a los ciudadanos. En los inicios del siglo $\mathrm{XXI}$, las bibliotecas comenzaron a ofrecer servicios de información por medios telemáticos, dando respuesta a las consultas que los usuarios les planteaban, como tradicionalmente hizo la biblioteca, pero con la atractiva novedad de que los usuarios no estaban presentes en el momento de formular sus cuestiones, ya que se emplean tecnologías de la información y telecomunicaciones. La natural incorporación de Internet a los procedimientos bibliotecarios derivó en la creación de servicios específicos de consulta, en los que la referencia tradicional ampliaba su horizonte, permitiendo que el personal especializado de una biblioteca pudiera ser interrogado por cualquier medio digital. Los servicios de consulta atendidos por bibliotecas que ofrecen la posibilidad de ser interrogados en línea y que ofrecen sus respuestas también de forma telemática son los denominados servicios de referencia digital, objeto de estudio de esta tesis doctoral.

El objetivo fundamental de esta investigación es analizar la evolución de los servicios bibliotecarios de referencia, describiendo los métodos empleados en la actualidad para ofrecer servicios de información a los ciudadanos y examinando los sistemas empleados para evaluar la calidad de dichos servicios. Siendo más precisos, el tema principal de la investigación es la evaluación de los servicios públicos de referencia digital, aquellos que prestan organismos bibliotecarios de autoridad nacional. Son servicios de consulta ofrecidos a través de Internet, para todos los ciudadanos y sobre cualquier tema. Una definición estricta de este tipo de instituciones se ofrece en el apartado 9.3. de la investigación. En definitiva, se ha pretendido determinar el contexto teórico de la referencia digital, para, en primer lugar, establecer metodologías de evaluación, y, a continuación, ponerlas en práctica.

Se ha considerado útil incluir un capítulo cero de carácter introductorio. En los tres subapartados en los que se ha dividido este capítulo inicial se quiere situar la tesis doctoral, explicando sus objetivos y la metodología seguida para la redacción de la misma. Además, también en esta sección, se explicarán de forma resumida los contenidos de las diferentes partes en las que se ha dividido la tesis, para que se pueda disponer de una visión global de los temas tratados en los diferentes capítulos en los que se ha organizado el contenido. Asimismo, se expondrá de forma sucinta la aplicación práctica que se realizó para evaluar el servicio público de referencia digital «Pregunte: las bibliotecas responden», que fue analizado de forma exhaustiva a partir de los criterios propuestos en esta investigación, que se recogen en el capítulo 11.3.

Este capítulo cero es, por tanto, una panorámica de los contenidos que se desarrollan en la tesis doctoral y su redacción obedece a la intención de servir de ayuda para una mejor y más rápida comprensión de los temas que se han estudiado en esta investigación. 


\subsection{Objetivos: metodología de la investigación}

La investigación que se está presentando ha querido alcanzar de manera positiva cinco grandes objetivos:

1/ Describir la evolución de los servicios bibliotecarios de referencia.

2/ Conceptualizar los servicios de referencia digital.

3/ Analizar las circunstancias especiales de los servicios públicos de referencia digital.

4/ Establecer la metodología de evaluación idónea para los servicios de referencia digital.

5/ Aplicar los procedimientos de evaluación a los servicios públicos de referencia digital.

Para alcanzar estas pretensiones, se siguió una metodología de trabajo propia de toda investigación científica. Desde que se inscribió la tesis doctoral hasta que se estableció la redacción definitiva, se han empleado, analizado y sintetizado todos los recursos de información específicos de interés sobre las materias estudiadas: referencia, evaluación y sistemas digitales. El proyecto de la presente tesis doctoral se inscribió en la Universidad de Salamanca en 1999, con una orientación inicial hacia la evaluación de la información que se ofrecía en línea, sobre todo a través de sitios web institucionales. Durante los años 2003 y 2004 se realizó un avance en los contenidos de la tesis, cuyo esquema ya estaba totalmente volcado hacia los servicios de referencia digital, pero con una necesaria base teórica en los servicios de referencia tradicionales, en los que se asientan las nuevas formas de ofrecer la referencia. La redacción tuvo que interrumpirse y no fue hasta 2007 cuando se finalizó la investigación. En el segundo semestre de este año, se actualizaron todos los datos obtenidos, se redactó el texto definitivo y se pudo conseguir una panorámica completa de la referencia digital, en general, y de los servicios públicos, en particular.

La investigación se centró, por tanto, en los servicios que ofrecen los organismos bibliotecarios públicos para dar respuesta a consultas de cualquier ciudadano y tema. Se ha empleado la denominación «Servicios públicos de referencia digital» para expresar claramente que son servicios de consulta abiertos, a diferencia de muchos servicios de consulta que se ofrecen de forma exclusiva para comunidades concretas, como ocurre frecuentemente en las bibliotecas universitarias.

Se ha establecido un desarrollo gradual de los contenidos, a fin de ofrecer, en primer lugar, las informaciones básicas que son necesarias para presentar la evaluación del servicio público de referencia digital que se ha analizado en esta investigación. Así, a medida que se avance en la lectura de esta tesis doctoral se podrán encontrar los siguientes temas: 
a) Revisión bibliográfica. Análisis de la producción bibliográfica sobre servicios de referencia en general, fuentes de información y referencia digital. Se ofrece una panorámica de los principales recursos de información para la investigación en referencia digital, así como un estudio bibliométrico en el que se pueden observar las tendencias en la investigación en estos campos científicos. Este apartado introductorio está localizado en el capítulo 1 de la tesis doctoral y distribuido en tres subapartados en los que se analizan los principales documentos de interés, se comentan los recursos de información y se dan los resultados del análisis bibliométrico realizado.

b) Servicios de referencia. Los servicios de referencia digital se asientan sobre los servicios de consulta que tradicionalmente ofrecían las bibliotecas, por lo que se ha dedicado una parte de la tesis a estudiar la referencia en la biblioteca, sus fundamentos, tipologías de servicios y de demandas de información, organización del servicio y proceso que se lleva a cabo desde que se recibe una pregunta hasta que se contesta. Estos aspectos son estudiados en los capítulos 2 a 5, que se encuentran en la Parte I de la tesis doctoral. También se analizarán las colecciones de referencia. En el capítulo 6 se estudian los tipos de fuentes de información, estableciéndose una clasificación nueva y dedicando un amplio espacio a Internet como recurso para la referencia. También se estudian de forma específica, en el capítulo 7, los métodos de evaluación de los servicios de referencia tradicionales.

c) Referencia digital. Una vez establecidos los conceptos relacionados con los servicios de referencia tradicionales y estudiados todos los aspectos afines a los mismos, la investigación se centra en aquellos servicios que ofrecen las bibliotecas para responder consultas de los usuarios a través de Internet, es decir, en los servicios de referencia digital. En primer lugar, se establece el marco teórico, definiendo y delimitando qué se debe entender por este tipo de servicios, explicando cómo deben planificarse y ponerse en práctica, estudiando las competencias profesionales de los nuevos referencistas, así como las tecnologías de información disponibles. De igual forma, se presentan los servicios de referencia digital nacionales que existen en la actualidad, así como las directrices internacionales sobre las que se asienta el trabajo de referencia digital. Todos estos asuntos son tratados en los capítulos 8, 9 y 10, pertenecientes a la Parte II de la tesis doctoral. También en este bloque, se ha incluido un apartado específico, el capítulo 11, para estudiar la evaluación de los servicios de referencia digital, donde se ofrece la metodología propuesta en la investigación, que se aplicará posteriormente.

d) Evaluación práctica. A partir de los criterios ofrecidos en el capítulo 11, se ha realizado la evaluación del servicio público de referencia digital «Pregunte: las bibliotecas responden», que ofrece una sólida red de bibliotecas públicas españolas, coordinadas por el Ministerio de Cultura. El análisis se realizó con la colaboración de la Subdirección General de Coordinación Bibliotecaria, quien puso a disposición del doctorando 
todos los datos y recursos necesarios. La evaluación se ofrece en la Parte III, dividida en diferentes capítulos. En el capítulo 12 se ofrece la historia del servicio español de referencia digital y se analiza su funcionamiento. El capítulo 13 muestra los resultados obtenidos en la aplicación de las diferentes metodologías de evaluación, incluyendo, al final del mismo, las propuestas de mejora que se deducen del análisis realizado. En el capítulo 14 se examina la situación del servicio, tal y como se encontraba en el mes de agosto de 2007. El capítulo 15, el último de esta parte, recoge las conclusiones que se derivan de los estudios realizados y sirven, asimismo, como conclusiones de la tesis doctoral. En los anexos que aparecen al final de la tesis, se recogen algunos materiales empleados para la evaluación.

e) Recursos de información. Las diferentes referencias bibliográficas empleadas para la redacción de esta investigación componen la Parte IV de la tesis doctoral. No obstante, no se ha querido ofrecer una única relación, ya que impediría su manejo y mezclaría documentos de diferentes temas y desigual calidad. Por este motivo, se han realizado tres capítulos bibliográficos diferentes, en los que se recogen, por este orden, los recursos sobre servicios de referencia, sobre fuentes de información y sobre referencia digital. Se trata de los capítulos 16 a 18. Cada uno de ellos está subdividido en función de los temas que tratan, especialmente en el caso de los textos sobre referencia digital, que se han organizado en siete grupos diferentes. En los tres capítulos, se ha realizado una categoría para los manuales y la bibliografía esencial y otra para los aspectos relativos a la evaluación.

\subsection{Contenidos: servicios de referencia y referencia digital}

Como se ha adelantado, en este capítulo cero se quiere realizar una síntesis de los contenidos de la tesis doctoral, para aportar una perspectiva general de los diferentes temas que se tratan en el grueso de la investigación. Por ese motivo, se comentará en los siguientes párrafos la información que se contiene en las distintas partes en las que se ha dividido el texto y en sus correspondientes capítulos. De esta manera, cuando se inicie la lectura del cuerpo de la tesis doctoral, ya se dispondrá de datos suficientes que ayuden a su comprensión.

Este trabajo doctoral está estructurado en una introducción, cuatro partes y un bloque de anexos. En la introducción, se ofrece, además de esta panorámica general de la tesis doctoral, el estado de la investigación en referencia digital, así como la recopilación de las fuentes necesarias para su estudio y un análisis bibliográfico de la producción científica internacional sobre el tema. La Parte I está dedicada a los servicios de referencia tradicionales, a los servicios de información que las bibliotecas llevan ofreciendo desde finales del siglo XIX. La Parte II se centra en la referencia digital, propia del siglo XXI, estudiándose su definición, técnicas, planificación, evaluación, etc. En la Parte III, se realiza la evaluación práctica del servicio público de referencia digital español, que se llevó a cabo para aplicar las teorías expuestas en el bloque anterior. La Parte IV recoge las referencias bibliográficas empleadas para la elaboración de la 
tesis, que se han organizado en tres grandes apartados: servicios de referencia, fuentes de información y referencia digital. Los anexos aportan materiales que se han empleado para la investigación práctica, es decir, en la evaluación de «Pregunte: las bibliotecas responden». Los contenidos de cada capítulo son los siguientes:

Capítulo 0. Objetivos y contexto de la tesis doctoral. Resumen de la tesis doctoral, en el que se explican los objetivos, la metodología y los recursos empleados. Se trata de una panorámica global de la investigación realizada, que quiere servir de síntesis de los contenidos.

Capítulo 1. El estudio de los servicios de referencia digital. Análisis de la producción bibliográfica sobre servicios de referencia y presentación de los recursos necesarios y disponibles para la investigación en referencia digital. Se ofrece un estudio bibliométrico, realizado a partir de la base de datos creada para la tesis doctoral, en la que se observan las tendencias en la investigación en referencia digital.

Capítulo 2. El servicio de referencia en la biblioteca. Introducción a los servicios de consulta en las bibliotecas, desde un punto de vista tradicional. Se estudia la función informativa de las bibliotecas, los fundamentos en los que se asientan los servicios de referencia, su adecuación a los usuarios y la tipología de los servicios de información existentes.

Capítulo 3. Organización del servicio de referencia. Este apartado continúa desarrollando aspectos de los servicios de referencia tradicionales. En este caso se analiza el perfil profesional del referencista, el entorno espacial de los servicios de referencia, los instrumentos necesarios para la prestación del servicio de referencia, así como la relación entre los servicios de referencia y la alfabetización informacional.

Capítulo 4. Las demandas de información. Los servicios de referencia resuelven demandas de información. En esta sección se establecen tipologías de consultas, a partir de diversas aportaciones teóricas, además de incorporar una clasificación propia de las consultas, que son divididas en demandas de información general, demandas de información de respuesta rápida y demandas de información bibliográfica.

Capítulo 5. El proceso de referencia. Los aspectos relacionados con los procedimientos que se siguen desde que se recibe una consulta hasta que ésta es satisfecha son el objeto de este capítulo. Se estudian los métodos de recepción de las consultas, se examinan las particularidades de la denominada entrevista de referencia y se analizan los aspectos relativos a la resolución de las consultas. Además, se aporta información sobre los productos informativos que elaboran las bibliotecas como apoyo a este proceso de resolución de demandas de información.

Capítulo 6. La colección de referencia. La calidad de los servicios de referencia dependerá de los recursos de información que empleen. En este capítulo se estudian las fuentes de información y se establece una tipología de los 
recursos de referencia. Se ha querido aportar una nueva organización de los recursos informativos que fuera válida para los diferentes productos en los que hoy se puede encontrar información. En este capítulo se desarrolla la Clasificación Funcional/Formal de las fuentes de información, propuesta por el doctorando. También se estudia Internet como recurso para la referencia.

Capítulo 7. Evaluación de los servicios de referencia. Dado que la evaluación es el tema central de esta tesis, se ha querido incluir un capítulo sobre evaluación de servicios de referencia tradicionales, en los que se ha estudiado las características de la evaluación, la evaluación de las consultas y de la colección de referencia, así como indicadores y métodos para la evaluación de servicios bibliotecarios de información. También se aporta una síntesis de las técnicas de investigación social que pueden aplicarse a los servicios de referencia. La evaluación de la referencia digital, dado su interés específico en esta tesis doctoral, se recoge en el capítulo 11.

Capítulo 8. El servicio bibliotecario de referencia digital. Primer capítulo de la parte dedicada a la referencia digital, donde se ofrece el contexto conceptual de la referencia digital, se establece una tipología de los servicios de referencia digital y se explican las tecnologías de comunicación empleadas para la referencia digital. Este capítulo es novedoso dentro de la investigación internacional, ya que supone una revisión de las teorías aportadas por científicos de todo el mundo y una sistematización de las prácticas actuales.

Capítulo 9. Desarrollo de servicios de referencia digital. La planificación y la puesta en marcha de un servicio de referencia digital son aspectos estudiados en este capítulo, donde se ha dedicado un espacio significativo a las competencias profesionales para la referencia digital. Es destacable la exposición que se realiza sobre los diferentes servicios públicos de referencia digital existentes en el mundo, ya que se han conseguido datos que hasta ahora no aparecen en fuente alguna. También se aporta la nómina de servicios de referencia digital disponibles en España hasta diciembre de 2007.

Capítulo 10. Pautas y normas para el ejercicio de la referencia digital. La referencia digital se asienta sobre directrices internacionales. En este apartado se describen las que han aprobado organismos como la IFLA o la RUSA, filial de la ALA especializada en servicios de información. También se estudian las normas de la Virtual Reference Desk Network, de carácter pionero y que fueron tenidas en cuenta por un elevado número de instituciones y bibliotecas para la puesta en marcha de sus servicios de referencia en línea.

Capítulo 11. Evaluación de los servicios de referencia digital. La evaluación de la información telemática, entendida como aquella que se ofrece a través de web, es el primer apartado estudiado en este capítulo. Las metodologías de evaluación de la referencia digital son expuestas de forma detallada en otra de las secciones, ya que se quiere ofrecer una síntesis de los sistemas de evaluación ofrecidos por teóricos y que son empleados por bibliotecas. Dado que en esta investigación se realiza una evaluación práctica que requería el establecimiento de una metodología específica, se realizan propuestas para la 
evaluación de servicios públicos de referencia digital, que después se aplicarán en los capítulos siguientes.

Capítulo 12. El servicio «Pregunte: las bibliotecas responden». El servicio de referencia digital español es el protagonista de la tercera parte de la tesis, compuesta por éste y los tres capítulos siguientes. Aquí se realiza un estudio de este servicio, ofreciendo su desarrollo histórico y describiendo su funcionamiento. Se trata de informar acerca de en qué consiste este servicio, por qué fases ha pasado, qué bibliotecas lo integran y cuál era su estado en el momento de realizar la investigación que se explica en el capítulo 13.

Capítulo 13. Evaluación del servicio de referencia digital «Pregunte: las bibliotecas responden». El análisis realizado, los datos obtenidos y las sugerencias de mejora se detallan en este apartado. Se explican y comentan los resultados de los diferentes estudios llevados a cabo: encuestas para el estudio de profesionales y de usuarios, estudio de las incidencias a partir de los registros de las mismas, estudio de preguntas y respuestas, estudio de visibilidad y estudio bibliográfico. Al final de este capítulo se ofrecen una serie de propuestas organizadas por ámbitos diferentes, que sirvan para solucionar los aspectos negativos detectados.

Capítulo 14. El servicio público de referencia digital «Pregunte: las bibliotecas responden» en la actualidad. Tras la evaluación realizada, el servicio público español sufrió diferentes reformas. En este capítulo, se informa de la situación del mismo en agosto de 2007, explicando cuáles son las bibliotecas participantes y aportando datos generales del servicio. Asimismo, se analizan los nuevos manuales de procedimiento y otros documentos redactados después de la evaluación. También se actualizan a 2007 las estadísticas del servicio de referencia digital «Pregunte: las bibliotecas responden».

Capítulo 15. Análisis de resultados: conclusiones. El capítulo ofrece de forma independiente el análisis conjunto de los resultados. Tras las diferentes exposiciones teóricas realizadas para contextualizar los servicios de referencia digital, establecer un modelo de análisis de servicios públicos y aplicar la propuesta metodológica de evaluación, se pueden destacar una serie de conclusiones sobre «Pregunte: las bibliotecas responden», que permiten ofrecer un diagnóstico del servicio público de referencia digital español.

Capítulo 16. Servicios de referencia: recursos bibliográficos. Los últimos tres capítulos recogen las referencias bibliográficas empleadas para la elaboración de la tesis doctoral. En este apartado se ofrecen los documentos que tratan sobre referencia tradicional, estableciéndose cinco grandes grupos en función de su importancia o de su tema: manuales sobre servicios de referencia; evaluación de servicios de referencia; servicios de referencia en entornos digitales; recursos y tecnología web en los servicios de referencia; y bibliografía complementaria sobre servicios de referencia.

Capítulo 17. Fuentes de información: recursos bibliográficos. Este capítulo ofrece una selección de recursos sobre fuentes de información. Se han seleccionado sólo aquellas obras que están relacionadas directamente con la 
tesis doctoral, por lo que no se trata de una recopilación exhaustiva, sino selectiva de documentos. En este caso, la separación en grupos es menor, estableciéndose una categoría para los manuales sobre fuentes de información y colecciones de referencia, otra para los documentos que tratan sobre la evaluación de fuentes de información y un amplio grupo con la bibliografía complementaria sobre fuentes de información.

Capítulo 18. Referencia digital: recursos bibliográficos. En este capítulo se encuentra la bibliografía específica sobre referencia digital. Dada la importancia que tiene para la investigación, el nivel de especificidad es mayor que en las otras dos agrupaciones bibliográficas. En este caso se han establecido siete temas, comenzando por los manuales y la bibliografía esencial sobre referencia digital y continuando por aquellos documentos que tratan sobre la evaluación de la referencia digital. Apartados específicos se dedican a la conceptualización de la referencia digital, a los agentes y procesos de la referencia digital y a los sistemas tecnológicos. Las experiencias prácticas se han agrupado en dos categorías: servicios públicos y servicios especializados de referencia digital.

\subsection{Aplicación: evaluación de un servicio público de referencia digital}

La tesis doctoral pretende ser un compendio teórico-práctico sobre referencia digital, concretamente sobre servicios públicos de referencia digital. A lo largo de la primera y segunda parte se exponen los diferentes contenidos teóricos sobre los servicios bibliotecarios de consulta y sobre cómo se están proporcionando en la actualidad, apoyados en tecnologías de la información y en diferentes servicios de telecomunicaciones. La base teórica podría haber sido suficiente para un trabajo como éste, pero se prefirió llevar a la práctica las teorías que se aportan en esta investigación, sobre todo cuando se llegó a la conclusión de que las metodologías de evaluación de servicios de referencia digital demostraron ser insuficientes para aquellos servicios de consulta que se ofrecían públicamente, de forma abierta y sin tener un control previo de la masa de usuarios potenciales.

Las teorías y prácticas de evaluación de servicios de referencia digital no servían por entero para el análisis de los servicios públicos de referencia digital. Por ese motivo, se proponen una serie de métodos y ámbitos de evaluación, que son explicados en el capítulo 11.3 y llevados a la práctica en la Parte III. En los siguientes párrafos se resume la evaluación que se llevó a cabo y que se describe pormenorizadamente en el capítulo 13. La evaluación práctica se realizó tomando como base el servicio «Pregunte: las bibliotecas responden», desde el que bibliotecas públicas españolas, a través de Internet y mediante un sistema de turnos, resuelven las consultas de cualquier persona, independientemente de que sea ciudadano español o no. El único requisito es que se empleen algunas de las lenguas oficiales de España.

Por una parte, en la evaluación se quiso poner en práctica una metodología de análisis específica para aquellos servicios de referencia digitales que no se ofrecían para un colectivo concreto. Cuando las bibliotecas saben a quien se dirigen, la evaluación es más sencilla, pero en los servicios públicos de 
referencia digital, por el hecho de ser abiertos, los posibles usuarios no están determinados, por lo que los métodos de evaluación deben ser diferentes, adaptándose a sus propias circunstancias. Por otra parte, el doctorando había sido requerido por el Ministerio de Cultura, como investigador en servicios de referencia, para analizar la situación de «Pregunte: las bibliotecas responden», ya que se había detectado un descenso en su uso. La convergencia entre los intereses del doctorando y de los responsables ministeriales hizo que se planteara esta investigación desde una doble perspectiva: como estudio académico de carácter doctoral y como informe de consultoría.

La evaluación práctica está sujeta a una estricta metodología de investigación, a la que se suma la intención de obtener resultados de aplicación inmediata. Así se planteó esta tesis doctoral, en la que la evaluación realizada ha servido para que se reformaran determinados aspectos del servicio estudiado, que se ha renovado profundamente tras el análisis y que en estos momentos incluso sigue planteándose novedades, como la introducción de referencia sincrónica.

Aunque los datos están actualizados a agosto de 2007, el grueso de los estudios que componen la evaluación de «Pregunte: las bibliotecas responden» se realizaron en 2004. La metodología propuesta sigue siendo válida para este tipo de servicios. Puesto que la evaluación se detalla en el capítulo 13, aquí simplemente se ofrece un resumen de los métodos que se llevaron a cabo, que fueron los siguientes:

- Estudio de profesionales. Encuesta redactada con la intención de conocer el perfil de los bibliotecarios referencistas, que fue cumplimentada por cerca del $77 \%$ de los trabajadores implicados en el servicio en el momento de realizarse, lo que asegura índices muy altos de fiabilidad. La encuesta estaba compuesta por cincuenta preguntas y recogía información sobre datos laborales, formación, procedimientos, opiniones del servicio, calidad de las respuestas y posibles reformas.

- Estudio de usuarios. El sistema español dispone de una base de datos de usuarios registrados, quienes se han dado de alta voluntariamente en el servicio. Empleando esta base de datos se envió por correo electrónico una encuesta en la que se preguntaba por su perfil, opinión del servicio y posibles mejoras. En este caso se trabajó con una población correspondiente al 14\% de los usuarios registrados.

- Estudio de incidencias. Análisis de los registros de las incidencias del sistema correspondientes al año 2003, así como de las diferentes comunicaciones profesionales relacionadas con el funcionamiento anormal del servicio. Se estudiaron las incidencias para determinar los principales problemas técnicos con los que se encontraba el servicio. También se incluyeron en este subestudio las quejas y reclamaciones hechas por los usuarios. 
- Estudio de preguntas y respuestas. En este bloque se integran diferentes análisis realizados para conocer la cantidad y calidad de las preguntas y respuestas. En primer lugar, se realizó una evaluación cuantitativa, para conocer el número de preguntas recibidas, su evolución cronológica y su distribución temática. Además, se realizó un análisis de las preguntas resueltas en un turno completo, correspondiente al mes de marzo de 2004, estudiando el tipo de respuesta, sus fuentes, el cumplimiento de plazos y la validez de la respuesta. Se efectuó también un estudio discreto (el analista como usuario) para evaluar la homogeneidad de las respuestas, a partir de preguntas idénticas realizadas por el doctorando en diferentes fechas.

- Estudio de visibilidad y bibliográfico. Empleo de técnicas de minería de datos para conocer el grado de penetración del servicio en Internet. Se quería relacionar el grado de conocimiento de este servicio con el número de enlaces hacia el mismo que existían en el momento de realizar la investigación. De igual forma, se realizaron consultas en las bases de datos profesionales, analizando los resultados obtenidos pormenorizadamente, para disponer de información sobre la difusión de este servicio en las publicaciones especializadas en Biblioteconomía y su índice de cita en la literatura profesional.

Todos los datos correspondientes a las diferentes evaluaciones realizadas se encuentran disponibles en el capítulo 13 de la tesis doctoral. Tras la evaluación global se establecen una serie de propuestas de mejora, que se describen, por ámbitos, en el capítulo 13.8. Dado que los estudios se realizaron en 2004 se consideró necesario incluir la información más actual que fuera posible, por lo que en el capítulo 14 se incorporan las estadísticas correspondientes al periodo 2000-2007, que corresponde a los siete primeros años completos de actividad de este servicio, que fue pionero a nivel internacional y sigue siendo un ejemplo de cooperación interadministrativa, ya que están implicados en el mismo organismos bibliotecarios de la administración central, regional y local. Las conclusiones que se extrajeron de los resultados se detallan en el capítulo 15 y actúan, asimismo, como conclusiones de la investigación. 


\section{El estudio de los servicios de referencia digital}

El servicio bibliotecario de referencia, en relación al resto de las secciones de las bibliotecas, es relativamente moderno. Desde la Antigüedad se conservan testimonios de bibliotecas y documentos sobre la organización de las mismas, pero no es hasta finales del siglo XIX cuando se comienza a hablar de la biblioteca como entidad informadora y no sólo conservadora de documentos ni facilitadora de recursos. En este apartado, se pretende realizar un estado de la cuestión sobre la producción bibliográfica relativa a los servicios de referencia en general y sobre los servicios de referencia digital en particular. En las siguientes páginas, se ofrecerá un panorama de la producción internacional sobre servicios de referencia, con una evidente inclinación hacia los testimonios más actuales y hacia los textos que recogen de forma significativa los servicios electrónicos de información en las bibliotecas. Además, es importante destacar que se ha realizado un estudio bibliométrico sobre la investigación existente en relación a los servicios de referencia digital, que se plantea a modo de contextualización de esta tesis doctoral, orientada al análisis de la calidad de la información que se ofrece en los servicios públicos de referencia digital, especialmente del servicio español.

\subsection{La producción bibliográfica sobre servicios de referencia}

La edición de libros que tratan sobre servicios bibliotecarios de referencia es escasa, la que se dedica a los servicios de referencia digital es ínfima. Se trata de un servicio bibliotecario muy vinculado a las fuentes de información, disciplina sobre la que sí es posible encontrar un número significativo de textos y contribuciones. Si se realiza una sistematización de las obras relacionadas con la temática de esta tesis, será útil establecer categorías diferentes entre monografías sobre servicios de referencia y manuales de obras de referencia y repertorios de obras de referencia. Las primeras serían aquellas en que este servicio bibliotecario es el eje, ofreciendo contenidos sobre su desarrollo, técnicas, colecciones o evaluación. Los otros dos tipos de materiales están orientados a recoger recursos de información, ya sea incluyendo explicaciones teóricas sobre fuentes de información (manuales) o facilitando exclusivamente recursos (repertorios). En esta sección de la tesis doctoral se quieren comentar aquellas obras que se consideran de mayor utilidad sobre servicios bibliotecarios de referencia, especialmente las que incluyen capítulos sobre referencia digital o que tratan exclusivamente de esta modalidad de los servicios informativos que ofrecen las bibliotecas a través de Internet.

El panorama internacional actual de manuales de calidad sobre referencia en bibliotecas se limita a tres monografías sobresalientes: Reference and 
information services: an introduction ${ }^{1}$, Reference and information services in the 21st century: an introduction ${ }^{2}$ y el clásico Introduction to reference work ${ }^{3}$. Dada su importancia, estos tres textos se describen de forma detallada en los párrafos siguientes. Se trata de auténticos manuales de referencia, en los que se dedican capítulos tanto a los servicios de información en la biblioteca, como también a las principales fuentes de información existentes. Son las tres obras recomendables, aunque presentan el mismo problema: están orientadas de forma muy directa al usuario angloparlante, sobre todo al estadounidense, algo que sólo es un parcialmente un obstáculo, aunque se echa en falta una obra de estas características que tenga como base los recursos de información editados en España.

A las tres obras norteamericanas se les pueden añadir dos que se pueden considerar ya clásicas, la italiana Informare in biblioteca ${ }^{4}$ y la francesa Accuellir, orienter, informer ${ }^{5}$, que se puede definir como un manual íntegro de las diferentes posibilidades que tiene una biblioteca para informar a los usuarios, ya sea a petición de los mismos o por iniciativa de la biblioteca; una obra que incluso con el paso del tiempo sigue siendo recomendable, a pesar de que las cuestiones tecnológicas apenas tienen cabida en la misma.

Bopp y Smith son los editores de uno de los tres manuales básicos sobre servicios y colecciones de referencia, Reference and information services: an introduction, que ya ha llegado a su cuarta edición, de 2007, siendo la primera en 1991. Se trata de una obra colectiva, que se dedica a partes iguales tanto a los servicios de referencia como a las fuentes de información. Incluso, entre la segunda edición de 1995 y la tercera de 2001 se han añadido capítulos y se han reformado los existentes, para dar cabida a los entornos tecnológicos de la referencia. Entre los contenidos de interés que pueden ser encontrados en la primera parte, la dedicada a conceptos y procesos, están los siguientes: historia y variedades de los servicios de referencia, aspectos éticos, la entrevista de referencia, control bibliográfico, organización de la información y estrategias de búsqueda, recursos electrónicos para la referencia, sistemas electrónicos para la referencia, instrucción y formación de usuarios, profesionales, evaluación, administración y servicios de referencia para usuarios específicos. En el segundo bloque se estudian las obras de referencia, incluyendo aspectos de evaluación de las mismas y ofreciendo una descripción de recursos más útiles para cada fuente de información. Existe una traducción al español, publicada en México en el año $2000^{6}$, que se presenta como un libro de texto para estudiantes y profesores de bibliotecología, así como un manual para

\footnotetext{
${ }^{1}$ Bopp, Richard E.; Smith, Linda C. (eds.). Reference and information services: an introduction. 4th ed. Englewood, CO: Libraries Unlimited, 2007.

${ }^{2}$ Cassell, Kay Ann; Hiremath, Uma. Reference and information services in the 21st century: an introduction. London: Facet, 2006. Hay una edición del mismo año publicada en Nueva York: Neal-Schumann.

${ }^{3}$ Katz, William A. Introduction to reference work. 8th ed. New York: McGraw-Hill, 2002.

${ }^{4}$ Aghemo, Aurelio. Informare in biblioteca. Milano: Editrice Bibliografica, 1992.

${ }^{5}$ Calenge, Bertrand. Accueillir, orienter, informer: I'organisation des services aux publics dans les bibliotèques. Paris: Edition du Cercle de la librairie, 1996.

${ }^{6}$ Bopp, Richard E.; Smith, Linda C. Introducción general al servicio de consulta. México

D.F.: Universidad Nacional Autónoma de México, 2000.
} 
bibliotecarios referencistas. En la introducción realizada por el traductor se ofrecen y comentan algunas monografías sobre fuentes de información publicadas en español, sobre todo en México, aunque también en Argentina, Cuba, España y Estados Unidos. La versión en español se basa en la primera edición del original (1991), pero incluye muchas aportaciones de la segunda (1995), ya que la traducción estaba prácticamente terminada cuando se editó la segunda edición estadounidense. El traductor optó por emplear las notas para actualizar los contenidos referidos a las publicaciones comentadas. Así pues, las notas amplían los conceptos, añadiendo la información complementaria que ha considerado el traductor. Además, se ha incluido como apéndice la traducción del capítulo de la segunda edición original correspondiente a los servicios de referencia en Internet. Otra novedad es la actualización de la bibliografía comentada, que se incluye como un segundo anexo y que abarca el periodo de 1991 a 1999.

De aparición reciente y con un contenido muy actual es la monografía de Cassell e Hiremath Reference and information services in the 21st century: an introduction. La obra se editó simultáneamente en Estados Unidos y el Reino Unido y rápidamente se ha colocado entre las obras fundamentales relacionadas con los servicios de información. El planteamiento de estas dos autoras es más bibliotecario que bibliográfico, ya que, no se pretende ofrecer grandes repertorios de obras de referencia, sino que trata de describir todos los aspectos relativos a los servicios bibliotecarios de información, para, mencionar las características y utilidad de las principales fuentes de información existentes en cada categoría y tipología. Además, las fuentes señaladas se actualizan de forma periódica en la web de la editorial estadounidense Neal-Schuman ${ }^{7}$, quien publicó la edición original. La obra está dividida en cuatro partes: conceptos fundamentales, introducción a las principales fuentes de referencia, aspectos especiales del servicio de información y referencia y desarrollo y gestión de colecciones y servicios de referencia. En la última parte, se estudia el desarrollo de colecciones de referencia, la administración de los departamentos de información, la evaluación y mejora de los servicios de referencia, además de reflexionar sobre el futuro de los servicios de referencia ${ }^{8}$. Se puede destacar, asimismo, que esta obra sirve también como fuente para la selección de materiales informativos, ya que en los diversos capítulos dedicados a las fuentes de información ofrece su lista de los diez mejores recursos, su top ten en enciclopedias, diccionarios, índices, etc.

Sin duda, la obra clásica en servicios bibliotecarios de referencia es la Katz, Introduction to reference work. Este profesor e investigador estadounidense ha sido durante años el principal experto internacional en servicios y colecciones de referencia. Su manual se editó por vez primera en 1969 y ha conocido ocho ediciones, la última en 2002. William Katz falleció cuando estaba trabajando en la novena edición de su obra, de la que dejó

\footnotetext{
7 Reference and Information Services in the 21st Century: An Introduction. Updates: http://www.neal-schuman.com/reference21st/.

${ }^{8}$ Una panorámica imaginaria de cómo será la profesión de referencista en 2020 se sugiere en Lipow, Anne Grodzins. The future of reference: point-of-need reference service: no longer an afterthought. Reference Services Review, 2003, vol. 31, n. 1, p. 31-35.
} 
actualizaciones en el espacio web $^{9}$ en el que ofrecía materiales para sus alumnos. Esta obra se edita en dos volúmenes. El primero, titulado Basic Information Services, es, ante todo, un manual de fuentes de información; y el segundo, Reference services and Reference Processes, está especialmente centrado en servicios de referencia. En el primer volumen, aunque, como se ha dicho, se trata de un manual de obras y recursos de referencia, se dedican sendos capítulos al trabajo del bibliotecario referencista y a Internet como herramienta para el servicio de referencia. El volumen dedicado a los servicios y procesos de referencia se divide en cuatro grandes apartados, en los que trata sobre los usuarios del servicio de referencia, Internet dentro de los servicios de referencia, entrevista de referencia y búsqueda de información y políticas de instrucción, desarrollo del servicio y evaluación. Katz tenía preparado un nuevo capítulo para la siguiente edición, que está accesible en línea y que trata sobre la comunidad Internet, es decir, de la utilidad de listas de distribución, blogs o wikis para los profesionales de la referencia.

La edición española de monografías sobre servicios de referencia es inexistente. Solamente se pueden encontrar capítulos en determinados manuales de biblioteconomía o artículos más o menos desarrollados, pero no hay textos monográficos sobre el servicio de referencia. Entre las contribuciones a monografías más destacables hay que mencionar los capítulos de Cordón ${ }^{10}$ en el Manual de biblioteconomía coordinado por Orera y el de Magán ${ }^{11}$ en el Tratado básico de biblioteconomía del que él mismo fue editor. También es de interés el apartado dedicado a los servicios de orientación, información bibliográfica y referencia del manual Gestión de bibliotecas de Gómez ${ }^{12}$. Como artículo de síntesis sobre la organización y los procesos de los servicios de referencia presenciales hay que mencionar el publicado por el doctorando en la revista Anales de documentación ${ }^{13}$. Una relación completa de los documentos publicados en revistas españolas sobre servicios de referencia puede ser consultada en las bibliografías del apartado 16 de esta tesis doctoral.

Sin embargo, sí existen ejemplos de manuales de fuentes de información editados en España. Se trata de una serie de obras donde se analizan los diferentes tipos de recursos de información, describiendo los productos informativos y las obras de referencia de mayor utilidad para el usuario español. Por lo general, se trata de obras colectivas, con excepciones como

\footnotetext{
${ }^{9}$ Welcome to the Katz Website: Introduction to Reference Work: Volumes I \& II, 8/e: http://www.mhhe.com/socscience/katz/index.html.

${ }^{10}$ Cordón García, José Antonio. Servicios de información y referencia. En Orera Orera, Luisa (ed.). Manual de biblioteconomía. Madrid: Síntesis, 1996, p. 265-287.

${ }^{11}$ Magán Wals, José Antonio. Los servicios de información y referencia bibliográfica: situación actual y aprovechamiento de los recursos. En Magán Wals, José Antonio (ed.). Tratado básico de biblioteconomía. Madrid: Editorial Complutense, 1996, p. 341-364.

${ }^{12}$ Gómez Hernández, José Antonio. La definición de los usuarios y los servicios básicos. En Gómez Hernández, José Antonio. Gestión de bibliotecas. Murcia: DM, ICE, 2002, p. 171191.

${ }^{13}$ Merlo Vega, José Antonio. El servicio de referencia. Anales de documentación, 2000, n. 3, p. 93-126.
} 
las de Cebrián ${ }^{14}$, López Yepes ${ }^{15}$ o Martín Vega ${ }^{16}$. Las obras colectivas más destacadas dentro de la producción editorial española dedicada a fuentes de información son el Manual de investigación bibliográfica y documental ${ }^{17}$, el Manual de fuentes de información ${ }^{18}$ y la monografía Las fuentes de información: estudios teóricos-prácticos ${ }^{19}$. Otros manuales de fuentes de información editados en España, pero con una temática más especializada son las escritas por Alía Miranda ${ }^{20}$ y Carrizo Sainero ${ }^{21}$, dentro del campo de las humanidades, y la editada por el CINDOC con el título La información especializada en Internet ${ }^{22}$, que es uno de los repertorios más útiles sobre fuentes de información accesibles de forma telemática. Existen muchos otros recursos bibliográficos, que se han recogido en el apartado 17 de esta investigación, donde se relacionan las referencias bibliográficas de obras sobre fuentes de información.

El mercado editorial latinoamericano ofrece publicaciones de desigual interés sobre servicios de referencia y fuentes de información. Una obra clásica, que se ha visto reeditada, es la mexicana El servicio de consulta ${ }^{23}$, una de las escasas monografías en castellano sobre el servicio bibliotecario de información. Otras obras publicadas en América Latina sobre el tema son la argentina Principios de referencia: fuentes y servicios de consulta ${ }^{24}$ y la colombiana Servicio de referencia ${ }^{25}$, si bien esta última es una traducción de una obra australiana. También está editada en México la obra de Calva ${ }^{26}$ en la que teoriza sobre los fundamentos y tipos de las necesidades de la información. Dentro del clásico Manual de bibliotecología se publicó un útil capítulo de Sabor $^{27}$ sobre servicios de referencia. Aunque también se menciona en otros apartados de la tesis, es preciso constatar también aquí que es en el ámbito latinoamericano donde se ha publicado la única obra

\footnotetext{
${ }^{14}$ Cebrián, Bernandino. J. Fuentes de consulta para la documentación informativa. Madrid: Universidad Europea CEEE, 1997.

${ }^{15}$ López Yepes, José. Los caminos de la información. Madrid: Fragua, 1997.

${ }^{16}$ Martín Vega, Arturo. Fuentes de información general. Gijón: Trea, 1995.

${ }^{17}$ Cordón García, José Antonio; López Lucas, Jesús; Vaquero Pulido, Raúl. Manual de investigación bibliográfica y documental. Madrid: Pirámide, 2001.

${ }^{18}$ Carrizo, Gloria; Irureta-Goyena, Pilar; López de Quintana, Eugenio. Manual de Fuentes de Información. Madrid: CEGAL, 1994.

19 Torres, Isabel de (dir.). Las fuentes de Información: estudios teórico-prácticos. Madrid: Síntesis, 1998.

${ }^{20}$ Alía Miranda, Francisco. Fuentes de información para historiadores: obras de referencia y bibliografías. Gijón: Trea, 1998.

${ }^{21}$ Carrizo Sainero, Gloria. La información en ciencias sociales. Gijón: Trea, 2000.

22 Maldonado Martínez, Ángeles; Rodríguez Yunta, Luis (coords.). La información especializada en Internet: directorio de recursos de interés académico y profesional. 2 a ed. corr. y aum. Madrid: CSIC, 2006.

${ }^{23}$ Morales Campos, Estela. El servicio de consulta. 2. ed. corr. y aum. Mexico, D.F.: Universidad Nacional Autonoma de México, 1993.

${ }^{24}$ Melnik, Diana. Principios de referencia: fuentes y servicios de consulta. Buenos Aires: Alfagrama, 2005.

${ }^{25}$ Gosling, Mary. Servicio de referencia. Bogotá: Rojas Eberhard, 2001.

${ }^{26}$ Calva González, Juan José. Las necesidades de información: fundamentos teóricos y métodos. México: UNAM, 2004.

${ }^{27}$ Sabor, Josefa E. Servicio de referencia. En Manual de bibliotecología. México D.F.: Kapelusz, 1984, p. 191-213.
} 
monográfica en castellano sobre servicios digitales de referencia ${ }^{28}$. También es justo añadir que en América Latina se han editado excelentes repertorios de fuentes de información, como son los de Garza Mercado ${ }^{29}$ o Romanos de Tirate $^{30}{ }^{0}$, ambas obras de extraordinario interés para conocer recursos de información sobre ciencias humanas y sociales, aunque entre las obras del autor mexicano se encuentran otros repertorios multidisciplinares.

En relación con los servicios de referencia digital, se han editado diferentes monografías en las que se estudian de forma específica los diversos aspectos relacionados con esta actividad bibliotecaria. Como es de suponer, la mayoría de los textos son recientes, ya que en los últimos años es cuando se han comenzado a desarrollar estos servicios. Algunos de los principales textos publicados en el mundo sobre servicios bibliotecarios de información basados en tecnologías de la información y en sistemas telemáticos de comunicación son los siguientes:

- Coffman, Steve. Going live: Starting and running a virtual reference service. Chicago: American Library Association, 2003.

- Janes, Joseph. Introduction to reference work in the digital age. New York: NealSchuman, 2003.

- Lipow, Anne Grodzins. The Virtual Reference Librarian's Handbook. New York: Neal-Schuman, 2003.

- Meola, Marc; Stormont, Sam. Starting and Operating Live Virtual Reference Services: A How-to-Do-It Manual for Librarians. New York: Neal-Schuman, 2002.

- Rodríguez Briz, Fernanda. Los servicios de referencia virtual: surgimiento, desarrollo y perspectivas a futuro. Buenos Aires: Alfagrama, 2005.

La obra de Janes es fundamental para comprender este tipo de servicios de información, su evolución, sus técnicas o los sistemas tecnológicos que se pueden emplear. Es una de las obras más completas en cuanto a su contenido, ya que incluye aspectos como la entrevista de referencia, el personal, las políticas, las tecnologías o la planificación de un servicio de este tipo. Por otra parte, es importante la obra de Coffman, que cuenta con colaboradores importantes, como Sloan. Se trata de un manual sobre cómo poner en funcionamiento -paso a paso- un servicio de referencia digital, mantenerlo y promocionarlo. Lipow quiso ofrecer con su manual una herramienta bibliográfica de utilidad práctica, que sirviera para transformar un servicio de referencia tradicional en digital, aportando técnicas, recursos y aconsejando sobre el uso de los sistemas más adecuados. Incluso, la maquetación de la obra, que sigue el esquema de los How-to-Do-lt de NealSchuman, permite que el lector tenga esta obra como un cuaderno de nota, además de ofrecerle documentos de texto que puede extraer del cederrón adjunto para la práctica de la referencia digital. Esta obra se puede completar con la Meola y Stormon, que se concibe como un manual práctico y que ofrece diferentes líneas de implantación de servicios de referencia digital en función del tipo de biblioteca y del nivel que se quiera poner en

\footnotetext{
${ }^{28}$ Rodríguez Briz, Fernanda. Los servicios de referencia virtual: surgimiento, desarrollo y perspectivas a futuro. $1^{\mathrm{a}}$ ed., $1^{\mathrm{a}}$ reimp. Buenos Aires: Alfagrama, 2006.

${ }^{29}$ Garza Mercado, Ario. Obras de consulta para estudiantes de ciencias sociales y humanidades. México: El Colegio de México, 1992.

30 Romanos de Tiratel, Susana. Guía de fuentes de información especializadas: Humanidades y Ciencias Sociales. Buenos Aires: EB Publicaciones, 2001.
} 
marcha, desde los servicios de información electrónica más básicos o los más elaborados.

En el año 2007 se han publicado algunas obras significativas relacionadas con la referencia digital. Además de la coordinada por Lankes, que se comenta al final de este epígrafe, hay que reseñar dos monografías de interés y actualidad:

- Kovacs, Diane K. The virtual reference handbook: interview and information delivery techniques for the chat and e-mail environments. London: Facet, 2007.

- Jia, Liu. The evaluation of worldwide digital reference services in libraries. Oxford: Chandos Publishing, 2007.

La obra de Kovacs se centra en las competencias del personal referencista, mientras que la de Jia estudia sistemas de evaluación de la referencia digital. Antes de comenzar con los comentarios a estos dos títulos hay que mencionar que, en relación a las obras que tratan sobre evaluación, también es conveniente mencionar en este repaso de monografías importantes el texto realizado por $\mathrm{McClure}^{31}$ y su equipo de investigadores, que ofrece una metodología para la evaluación de servicios de referencia digital realizada con un rigor admirable y que ha sido tenida muy en cuenta en el apartado 11.2 de la tesis doctoral dedicado a este tema. Volviendo a The virtual reference handbook, de Kovacs, hay que entender este título como un estudio sobre los conocimientos y habilidades que debe poseer un bibliotecario referencista digital. La autora realiza una diagnosis exhaustiva de cuáles son las competencias en materia de comunicación, destrezas informacionales y habilidades tecnológicas que un profesional debe poseer, Se describen estas competencias y se ofrecen pautas para adquirlas. En cuanto a la obra de Jia, se ofrecen los resultados de una investigación internacional sobre referencia digital, Ilevado a cabo entre Alemania y China. El estudio se realizó de forma simultánea y empleando la misma metodología, la cual será comentada en el apartado 11.2. de esta tesis doctoral. Como monografía específica esta obra es interesante, ya que en sus primeros capítulos se ofrece un contexto general de la referencia digital.

Además, en este estado de la cuestión bibliográfica que se está realizado, habría que mencionar como documentos genéricos destacados los estudios monográficos de Nguyen $^{32}$, que realizó como trabajo de investigación de finalización de carrera, el de Maxwell ${ }^{33}$, editado en la excelente colección de informes sobre impacto de las tecnologías en las bibliotecas que publica la American Library Association, así como The AskA Starter Kit, publicación del

${ }^{31}$ McClure, Charles R.; Lankes, R. David; Gross, Melissa; Choltco-Devlin, Beverly. Statistics, Measures and Quality Standards for Assessing Digital Reference Library Services: Guidelines and Procedures. Syracuse, New York; Tallahassee, Florida: Information Institute of Syracuse; School of Information Studies, 2002.

${ }^{32}$ Nguyen, Claire. Mettre en place et développer un service de référence virtuelle dans une perspective d'integration ŕ un réseau collaboratif: Analysis comparées et propositions ŕ partir de l'exemple de l'Université de Montréal: Mémoirte d'étude. Villeurbanne: ENSSIB, 2006.

${ }^{33}$ Maxwell, Nancy Kalikov. Establishing and mantaining live online reference service. Library Technology Reports, 2002, vol. 38, n. 4, p. 1-68. 
proyecto Virtual Reference Desk $^{34}$ que fue de gran ayuda para iniciar servicios de información digital en muchos centros de Estados Unidos. También se pueden incluir aquí algunas obras que tratan de tipos específicos de ofrecer referencia digital, como el correo electrónico $\left(\right.$ Pantry ${ }^{35}$ ) o el chat $\left(\right.$ Ronan $\left.^{36}\right)$. Por último, hay que hacer mención especial de la obra de Rodríguez Briz, que ha sabido introducir este tipo de servicios en la biblioteconomía en español, realizando una labor de síntesis para tratar sobre la evolución de los servicios de referencia, los aspectos que hay que tener en cuenta para el intercambio de preguntas y respuestas, los diferentes sistemas que es posible emplear para la referencia digital, así como una reflexión sobre el cambio de orientación del servicio y la panorámica latinoamericana.

Las principales editoriales americanas especializadas en referencia han publicado colecciones de escritos sobre servicios de referencia digital. Por una parte, The Hatworth Information Press aprovecha muchos de los números monográficos de su revista The Reference Librarian para editar dichos volúmenes como monografías, en las que se reproduce de forma íntegra, y hasta con la misma maquetación y compaginación, los artículos publicados en dicha revista profesional. Así ha ocurrido con la siguiente relación de títulos, todos ellos de importancia para el estudio de los servicios de referencia digital:

- Anderson, Byron; Webb, Paul T. (eds.). New directions in reference. Binghamton, NY: The Haworth Information Press, 2006.

- Katz, William A. (ed.). Digital Reference Services. Binghamton, NY: The Haworth Information Press, 2004.

- Kimmel, Stacey; Heise, Jennifer (eds.). Virtual reference services: Issues and trends. Binghamton, NY: The Haworth Information Press, 2003.

- Novotny, Eric (ed.). Assessing reference and user services in a digital age. Binghamton, NY: The Haworth Information Press, 2006.

- West, Jessamyn (ed.). Digital versus non-digital reference: ask a librarian online and offline. Binghamton, NY: The Haworth Information Press, 2004.

Algunos de los números monográficos de Hatworth que se relacionan más arriba merecen especial atención, ya que trataron temas de actualidad en el mismo momento en el que se estaba reflexionando sobre ellos y coincidiendo con los proyectos de muchas bibliotecas para lanzar un servicio de referencia digital. Las obras coordinadas por Anderson y Webb, por Kimmen y Heise o por West son colecciones de artículos en las que se recogen los puntos de vista de teóricos y profesionales, que exponen sus pareceres sobre el presente y el futuro de los servicios de referencia. Pero entre todas destaca, para los fines de esta tesis, la obra dirigida por Katz, que es uno de los textos esenciales sobre referencia digital, donde, primero desde una perspectiva teórica, y después mediante la aportación de buenas prácticas, se puede obtener una panorámica significativa de los servicios de referencia digitales. De igual forma, la obra coordinada por Novotny es un

\footnotetext{
${ }^{34}$ Lankes, R. David; Kasowitz, Abby S. The AskA starter kit: How to build and maintain digital reference services. Syaracuse, New York: Syracuse University, 1998.

${ }^{35}$ Pantry, Sheila. Creating a successful e-information service. London: Facet, 2002.

${ }^{36}$ Ronan, Jana Smith. Chat reference: a guide to live virtual reference services. Westport, Conn.: Libraries Unlimited, 2003.
} 
texto que aporta importantes claves a los investigadores que trabajan sobre evaluación de servicios y sistemas de referencia digital, como es el caso de esta tesis doctoral. Todos los artículos recogidos en las monografías anteriores han sido analizados por el doctorando, aplicados en diversas partes de esta investigación y de los mismos se ofrecen referencias bibliográficas en los apartados correspondientes del capítulo 18 de la tesis.

Asimismo, la otra gran editorial especialista en referencia, Neal-Schuman, cuyas obras son editadas con frecuencia por la británica Facet para el mercado europeo, ha publicado diversas obras colectivas, donde los principales autores estadounidenses aportan sus reflexiones y experiencias. Como se podrá comprobar en la relación que se reproduce a continuación, en ellas participa David Lankes, probablemente el mayor especialista en referencia digital en la actualidad, tanto por sus investigaciones como por los proyectos que ha dirigido. Las obras más notables de esta editorial sobre referencia digital, presentadas por orden cronológico de publicación, son las siguientes:

- Lankes, R. David; Collins, John W.; Kasowitz, Abby S. (eds.). Digital reference service in the new millennium: planning, management, and evaluation. New York, London: Neal-Schuman, 2000.

- Lankes, R. David; McClure, Charles R.; Gross, Melissa; Pomerantz, Jeffrey (eds.). Implementing digital reference services: setting standards and making it real. New York: Neal-Schuman, 2003.

- Lankes, R. David; Janes, Joseph; Smith, Linda C.; Finneran, Christina M. (eds.). The virtual reference experience: integrating theory into practice. New York: NealSchuman, 2004.

- Lankes, R. David; Abels, Eileen; White, Marilyn; Haque, Saira N. (eds.). The virtual reference desk: creating a reference future. New York: Neal-Schuman, $2005^{37}$.

- Lankes, R. David; Nicholson, Scott; Radford, Marie L.; Westbrook, Lynn; Silverstein, Joanne L.; Nast, Philip (eds.). Virtual reference service: From competencies to assessment. New York: Neal-Schuman, $2007^{38}$.

La obra del año 2000 supuso una nueva conceptualización de los servicios de referencia digital, ya que sus autores, aunque conscientes de la base tradicional sobre la que asientan estos servicios, ofrecen una perspectiva más tecnológica. Recoge gran parte de las comunicaciones presentadas a la conferencia del proyecto Virtual Reference Desk (VRD) celebrada en 1999. En la primera parte se introducen los conceptos y características de la referencia digital, para continuar con ponencias sobre la creación de servicios de este tipo, su gestión, evaluación y, por último, la integración de los servicios de referencia con la tecnología, a partir de experiencias concretas. La monografía de 2003 también recopila contribuciones presentas a una conferencia anual de VRD, en este caso la celebrada en 2001. Está dividida en seis partes, en las que se agrupan las comunicaciones en función de los temas tratados: necesidad de los servicios de referencia digital, gestión de estos servicios, referencia en tiempo real, servicios cooperativos, investigación en referencia digital y evaluación. De igual forma, la obra de

${ }^{37}$ Existe una edición europea: Lankes, R. David; Abels, Eileen; White, Marilyn; Haque, Saira N. (eds.). The virtual reference desk: creating a reference future. New York: NealSchuman, 2005. London: Facet, 2006.

${ }^{38}$ Está prevista la edición en Europa (London: Facet) para diciembre de 2007. 
2004 contiene las actas de la cuarta conferencia anual de VRD. Las ponencias se agrupan en cuatro partes. La primera parte recoge ponencias sobre los usuarios de los servicios de referencia digital, mientras que la segunda está dedicada a los profesionales, la tercera a las políticas y la cuarta al contexto legal y social de la referencia a través de Internet.

Como en los casos anteriores, la obra editada a finales de 2005 en Estados Unidos y en 2006 en el Reino Unido, recoge las principales contribuciones a la quinta conferencia anual de VRD. En esta ocasión, se incluyen experiencias que van más allá del ámbito anglosajón, como era común en los textos anteriores; así, se trata de Biblioteksvagten, el servicio danés de referencia digital. Por último, la obra más reciente, Virtual reference service, editada en 2007, es la última obra que recoge los trabajos presentados a la conferencia anual de Virtual Reference Desk, ya que este proyecto ha finalizado y no se convocarán más encuentros de este tipo. El contenido de este último volumen de ponencias sigue un esquema similar al de los anteriores, estableciéndose cuatro grande apartados en los que distribuyen los trabajos presentados, que en esta ocasión tratan de aspectos como consorcios de referencia digital, con una experiencia sobre cómo poner en marcha una red en seis meses; el uso de la mensajería instantánea para la referencia digital; prácticas de evaluación de este tipo de servicios; y ejemplos de actividades de formación profesional e instrucción para usuarios.

Esta colección de textos, en la que se difunden las comunicaciones más significativas de los diferentes encuentros del proyecto VRD, constituye una fuente de información bibliográfica de excepcional interés para profesionales de la referencia digital, así como para investigadores en este campo. Por este motivo, estas publicaciones han sido tenidas en cuenta y analizadas para la redacción de este trabajo doctoral de investigación.

\subsection{Recursos para la investigación en referencia digital}

Los investigadores especializados en servicios de referencia emplean las mismas fuentes de información que quienes trabajan en documentación en general, ya que los recursos principales, como las bases de datos o las publicaciones periódicas suelen integrar contenidos relativos a los servicios de información junto a otros aspectos técnicos o teóricos sobre las ciencias de la documentación. Así, bases de datos como LISA o LISTA son recursos con los que hay que trabajar de forma necesaria para obtener información bibliográfica sobre servicios de referencia en general y sobre referencia digital en particular. La base de datos Library and Information Science Abstracts (LISA) es la que cuenta con una mayor trayectoria en la investigación bibliotecológica. Es elaborada por Cambridge Scientific Abstracts (CSA) ${ }^{39}$, en la actualidad perteneciente al grupo ProQuest. A través de LISA se pueden obtener referencias bibliográficas y resúmenes de 440 publicaciones periódicas de todo el mundo, así como actas de

\footnotetext{
${ }^{39}$ Library and Information Science Abstracts: http://www.csa.com/factsheets/lisa-set-c.php.
} 
congresos. Su cobertura comienza en 1969, lo que la convierte en una fuente excepcional por alcance y su volumen, ya más de 300.000 registros. De concepción similar es Library, Information Science and Technology Abstracts (LISTA), uno de los pocos recursos gratuitos que elabora la empresa Ebsco ${ }^{40}$. Indiza más de 600 revistas, así como documentos procedentes de reuniones científicas. Su cobertura cronológica comienza a mediados de los años 60. Estas dos bases de datos son la primera opción para un investigador en biblioteconomía, ya que ambas tienen ámbito internacional y los resultados de sus consultas pueden ser exportados a los principales gestores de referencias bibliográficas. Así se ha actuado para la elaboración de esta tesis doctoral.

También hay que tener en cuenta otras bases de datos en las que se puede encontrar información complementaria. En el ámbito internacional, conviene trabajar también con Library Literature and Information Science Index, de la empresa HW Wilson ${ }^{41}$, que se presenta además en las modalidades de texto completo y base retrospectiva (1905-1983). Otras bases de datos bibliográficas, de extensión internacional, en este caso elaboradas en Europa, son las que realiza el INIST francés: Francis ${ }^{42}$ y ArticleSciences ${ }^{43}$. La primera, de pago, recoge más de un millón y medio de referencias bibliográficas de ciencias sociales y humanas, con un elevado número de documentos relacionados con bibliotecas; la segunda, gratuita, supone la base de datos de su servicio de acceso al documento y alcanza los diez millones de referencias de todos los campos de la ciencia. Otro servicio de provisión de documentos cuyo catálogo es una buena herramienta para la recuperación de información bibliográfica es el Document Supply de la British Library ${ }^{44}$, que permite consultar de forma gratuita su base de nueve millones de artículos de todas las disciplinas. En el ámbito latinoamericano será útil Infobila, base de datos bibliográfica alimentada por el Colegio Universitario de Investigaciones Bibliotecológicas (CUIB) ${ }^{45}$ de la UNAM. Las bases de datos elaboradas en España son varias. Es imprescindible la consulta a ISOC-Biblioteconomía y Documentación ${ }^{46}$, realizada por el CINDOC, instituto del CSIC que analiza la producción española en Archivística, Biblioteconomía y Documentación. Las reformas orgánicas que ha experimentado este centro indican que esta base será alimentada por el nuevo Centro de Ciencias Humanas y Sociales (CCHS) ${ }^{47}$. También pueden

\footnotetext{
${ }^{40}$ Library, Information Science and Technology Abstracts: http://www.libraryresearch.com.

${ }^{41}$ Library Literature and Information Science Index:

http://www.hwwilson.com/Databases/liblit.htm.

${ }^{42}$ Francis está distribuida por la empresa OVID: http://www.ovid.com.

${ }^{43}$ ArtcicleSciences: http://articlesciences.inist.fr.

${ }^{44}$ El catálogo de la British Library permite buscar directamente en su base de datos de artículos: http://www.bl.uk.

${ }^{45}$ Infobila: http://cuib.unam.mx/infobila.htm.

${ }^{46}$ ISOC-Biblioteconomía y Documentación: http://bddoc.csic.es:8080/index.jsp.

${ }^{47}$ El 30 de octubre de 2007 la Junta de Gobierno del Consejo Superior de Investigaciones Científicas acordó la creación del Centro de Ciencias Humanas y Sociales (CCHS). Dicho centro está formado por siete Institutos del CSIC, entre ellos el antiguo CINDOC, que pasó a denominarse Instituto de Estudios Documentales sobre Ciencia y Tecnología (IEDCYT), que pasó a desempeñar otras actividades, más relacionadas con investigación científica y transferencia de conocimientos. Las bases de datos ICYT e ISOC pasaron a formar parte de unidades o servicios de apoyo del CCHS.
} 
aportar referencias Bedoc $^{48}$, de la empresa Inforarea, Documents in Information Sciencies (DOIS) ${ }^{49}$, en la que intervienen diferentes centros europeos y Datathéke ${ }^{50}$, elaborada en la Universidad de Salamanca.

Las editoriales que publican monografías sobre bibliotecas también disponen de títulos sobre servicios bibliotecarios de referencia. Como se puede comprobar en las diferentes secciones de la parte cuarta de esta tesis en las que se recopilan los manuales de servicios de referencia (16.1), fuentes de información y colecciones de referencia (17.1) y referencia digital (18.1), los editores de estos textos son los mismos que suelen publicar sobre cuestiones relacionadas con las bibliotecas. No obstante, existen algunas empresas que destacan por su dedicación a los servicios de referencia. Entre ellas sobresale The Haworth Information Press ${ }^{51}$, editora estadounidense que cuenta en su haber con el catálogo más extenso de libros sobre referencia. Como se podrá comprobar más adelante, es también la responsable de las principales publicaciones periódicas sobre el tema. Una de sus revistas estrella, The reference librarian, es el origen de muchas de sus monografías, ya que acostumbra a editar sus volúmenes monográficos de forma simultánea, como número de la revista y monografía. En este sentido, en el caso de la referencia digital, destacan títulos que ya han sido comentados en el apartado anterior, como, por ejemplo, New directions in reference ${ }^{52}$ (The Reference Librarian, 2006, vol. 45, n. 93), Digital Reference Services ${ }^{53}$ (The Reference Librarian, 2004, vol. 38, n. 79/80), Virtual reference services: Issues and trends ${ }^{54}$ (Internet Reference Services Quarterly, 2003, vol. 8, n. 1/2) o Assessing reference and user services in a digital age ${ }^{55}$ (The Reference Librarian, 2006, vol. 46, n. 95/96).

La otra editorial, también estodounidense, que hay que destacar entre aquellas que publican más títulos sobre servicios de referencia y que dedican textos de su catálogo a la referencia digital es Neal-Schuman Publishers ${ }^{56}$, quien tiene el acuerdo con la británica Facet Publishing para editar en Europa gran parte de los textos que publica la empresa norteamericana. De esta forma, muchos de los títulos de interés sobre referencia digital se encuentran disponibles en dos ediciones. Algunos ejemplos de títulos publicados por una de estas dos editoriales o por las dos fueron expuestos en el apartado anterior. Otras editoriales estadounidenses han editado obras sobre servicios de referencia, como Libraries Unlimited ${ }^{57} 0$

\footnotetext{
${ }^{48}$ Bedoc: http://www.inforarea.es/bedoc.htm.

49 DOIS: http://wotan.liu.edu/dois.

50 Datathéke: http://milano.usal.es/dtt.htm.

${ }^{51}$ The Haworth Information Press: http://www.haworthpress.com.

52 Anderson, Byron; Webb, Paul T. (eds.). New directions in reference. Binghamton, NY: The Haworth Information Press, 2006. (The Reference Librarian, Vol. 45, N. 93).

53 Katz, William A. (ed.). Digital Reference Services. Binghamton, NY: The Haworth Information Press, 2004. (The Reference Librarian, Vol. 38, N. 79/80.).

54 Kimmel, Stacey; Heise, Jennifer (eds.). Virtual reference services: Issues and trends. Binghamton, NY: The Haworth Information Press, 2003. (Internet Reference Services Quarterly, Vol. 8, No 1/2.).

${ }^{55}$ Novotny, Eric (ed.). Assessing reference and user services in a digital age. Binghamton, NY: The Haworth Information Press, 2006. (The Reference Librarian, Vol. 46, N. 95/96.).

${ }_{56}$ Neal-Schuman Publishers: http://www.neal-schuman.com.

57 Libraries Unlimited: http://www.lu.com
} 
Information Today ${ }^{58}$, aunque no se puede dejar de mencionar la labor editorial de la American Library Association ${ }^{59}$, que ha publicado algunos títulos específicos sobre referencia digital, como se podrá comprobar en la bibliografía del apartado 16.1 de esta tesis doctoral. La oferta en lenguas no inglesas es prácticamente inexistente. El único ejemplo de monografía sobre referencia digital en español, como ya se ha mencionado, es el título que editó la editorial argentina Alfagrama ${ }^{60}$ y que vio una reimpresión al año siguiente de su comercialización; se trata de la ya mencionada monografía de Rodríguez Briz, Los servicios de referencia virtual: surgimiento, desarrollo y perspectivas a futuro (Buenos Aires: Alfagrama, 2005).

La oferta de publicaciones periódicas especializadas en referencia es mayor. Al igual que ocurría en la edición de monografías, los principales títulos de revistas sobre esta materia son responsabilidad de la empresa estadounidense The Haworth Information Press, que tiene en el mercado las publicaciones más importantes en el área de la referencia digital, que son The reference librarian (ISSN 0276-3877) e Internet Reference Services Quaterly (ISSN 1087-5301). La primera de ellas, de carácter semestral, nació en 1981 y acoge artículos sobre servicios y colecciones de referencia. A menudo ha dedicado monográficos a los aspectos tecnológicos de la referencia. La segunda publicación es la respuesta de esta editorial a la necesidad de crear una revista profesional específica para la referencia digital. Es trimestral, lleva el subtítulo de "a journal of innovative information practice, technologies, and resources" y su primer número es de 1996. Esta misma editorial publica revistas sobre referencia especializadas en diferentes áreas, como son Journal of library administration (ISSN 01930826), Legal Reference Services Quarterly (ISSN 0270-319X), Medical Reference Services Quarterly (ISSN 0276-3869), Music Reference Services Quarterly (ISSN 1058-8167), Resource Sharing \& Information Networks (ISSN 0737-7797) y Slavic \& East European Information Resources (ISSN 1522-8886). Además, esta editora americana ha anunciado el lanzamiento de una nueva publicación trimestal, Journal of Electronic Resources Librarianship, que contempla todos los ámbitos y procesos de las colecciones bibliotecarias digitales, por lo que es prever contenidos sobre referencia digital. Esta nueva publicación, cuyo primer número está estimado que se publique en la primavera de 2008, tomará el relevo de The Acquisitions Librarian (ISSN: 0896-3576), que se edita desde 1989.

Existen otras importantes revistas cuyo contenido debe ser consultados por los investigadores en referencia digital, como son Reference Services Review (ISSN 0090-7324), publicada trimestralmente por la editorial estadounidense Pierian Press desde 1973; Reference Reviews (ISSN 09504125 ), de carácter trimestral, editada desde 1987 por el grupo británico Longman; y Reference and user services quarterly (ISSN 1094-9054), también trimestral, creada en 1997 y editada por la Reference and User Services Association, afiliada a la American Library Association.

\footnotetext{
58 Information Today: http://www.infotoday.com.

${ }^{59}$ El catálogo de la ALA está accesible en http://www.alastore.ala.org.

${ }^{60}$ Alfagrama: http://www.alfagrama.com.ar.
} 
Aunque no estén centradas en servicios de referencia o en referencia digital, existen una serie de publicaciones periódicas que, de forma regular, incluyen en sus contenidos colaboraciones sobre aspectos relacionados con las tecnologías y los servicios bibliotecarios de consulta. Entre las revistas profesionales que tienen una mayor frecuencia de artículos sobre referencia digital destacan The electronic library (ISSN 0264-0473), trimestral, desde 1983 y editada por la británica Learned Information; Information technology and libraries (ISSN 0730-9295), trimestral, desde 1982, responsabildiad de la Information Technology Association (LITA), división de la American Library Association; esta revista continúa la actividad de Journal of Library Automation (ISSN 0022-2240), que se editó entre 1968 y 1981.; Computers in libraries (ISSN 1041-7915), mensual, desde 1988 y de la editorial estadounidense Meckler; The Journal of academic librarianship (ISSN 00991333), bimestral, desde 1975, publicada en Estados Unidos por Elsevier; Library journal (ISSN 0363-0277), quincenal, desde 1976, de la editorial estadounidense del mismo nombre; o Library trends (ISSN 0024-2594), una de las revistas pioneras en biblioteconomía, ya que se edita desde 1952, con carácter trimestral, desde la University of Illinois Library School.

Para la realización de un trabajo de investigación es conveniente estar informado de las noticias profesionales y académicas relacionadas con el tema objeto de estudio. De igual forma, es muy productivo intercambiar información con otros investigadores que trabajen en el mismo área o en disciplinas afines. Para ello, son de una excepcional utilidad las listas de distribución. Como viene sucediendo en las fuentes de información mostradas hasta el momento, los principales foros sobre el tema tienen su principal comunidad entre bibliotecarios de Estados Unidos y, a continuación en Gran Bretaña. También hay una fuerte presencia de profesionales australianos. La principal lista sobre tecnologías y bibliotecas, no sólo sobre referencia digital, es Web4Lib Electronic Discussion ${ }^{61}$, que nació en mayo de 1994 con el objetivo de intercambiar información acerca de las implicaciones de Internet en el trabajo bibliotecario. Los archivos de Web4Lib son públicos y suponen una importante fuente de información para los investigadores en referencia digital. Otra lista de temática amplia, que trata sobre tecnologías y bibliotecas es Electronic Resources in Libraries (ERIL-L) ${ }^{62}$, administrada desde la Universidad de Binghamton en Nueva York y creada en abril de 2005.

Entre las listas específicas, que tratan exclusivamente de referencia digital, hay que mencionar tres foros de forma especial. Digital Reference List (Dig_Ref) se creó en 1998, a partir de una iniciativa del Virtual Reference Desk y en la actualidad sigue bastante activa, aunque en otro servidor difererente al de Yahoo Groups donde comenzó. En estos momentos es una de listas de la comunidad Wenjunction, donde se han volcado los mensajes enviados desde $2001^{63}$. Otra importante lista sobre referencia digital es

\footnotetext{
${ }^{61}$ Web4Lib Electronic Discussion: http://lists.webjunction.org/web4lib/.

${ }^{62}$ Electronic Resources in Libraries ERIL-http://listserv.binghamton.edu/archives/eril-I.html

${ }^{63}$ Los mensajes pueden encontrarse en http://digref.org/archive/. En el sitio de Webjunction se informa de cómo suscribirse: http://www.webjunction.org. Los archivos originales están disponibles en http://finance.groups.yahoo.com/group/dig_ref/.
} 
Livereference, Group on live reference services for librarians ${ }^{64}$. Está formada por cerca de mil profesionales que atienden servicios de referencia sincrónicos. Inició su andadura en junio de 2000. Por último, es de interés la lista de distribución Discussion of Library Reference Issues ${ }^{65}$ (LIBREF-L), accesible de forma abierta desde diciembre de 1995 en el servidor de listas de la Universidad de Kent, en Ohio.

Hay varios profesionales e investigadores que ofrecen sitios web públicos desde los que difunden sus publicaciones, investigaciones, ya sea de forma estática o de blogs dinámicos, a través de los que se comunican con otros profesionales. Uno de los principales ejemplos y sitios web más útiles es el David Lankes ${ }^{66}$, director del Information Institute of Syracuse, un autor de lectura obligada y uno de los investigadores más productivos en relación a los servicios de referencia digital. Otro investigador con una producción significativa en el campo de la referencia digital es Jeffrey Pomerantz ${ }^{67}$, profesor en la School of Information and Library Science de la Universidad de Carolina del Norte en Chapel Hill. Desde su web se puede acceder a publicaciones, presentaciones y proyectos sobre el tema de esta tesis doctoral, en los que ha participado este docente. También existen buenos ejemplos de profesionales que disponen de un sitio web de utilidad para quien trabaja en referencia digital; uno de ellos es Stephen Francoeur ${ }^{68}$, bibliotecario referencista en el Biblioteca Newman de Nueva York y autor de un sitio web especializado en referencia, así como el administrador de un activo blog sobre esta temática. Por último, es necesario mencionar el servidor de Diane Kovacs ${ }^{69}$, consultora y experta en referencia digital, quien es la autora de importantes manuales sobre recursos electrónicos de información y de otras obras que se pueden consultar en la bibliografía, así como en sus páginas.

Junto a la información facilitada por los profesionales y los investigadores hay que mencionar la que ofrecen en sus webs las asociaciones profesionales que trabajan en servicios de referencia. En primer lugar, hay que mencionar a la Sección de Servicios de Información y Referencia de la IFLA $^{70}$ autora de las importantes pautas sobre referencia digital. Asimismo, la Reference and User Services Association ${ }^{71}$, filial de la American Library Association, ofrece importantes documentos, normativas, experiencias, noticias, artículos, etc. sobre referencia digital. Su relación de pautas, comentadas en el apartado 10.2 de esta tesis doctoral son de obligada referencia para los servicios bibliotecarios de consulta, así como su revista,

\footnotetext{
${ }^{64}$ Group on live reference services for librarians http://groups.yahoo.com/group/ livereference.

${ }_{65}^{6}$ Discussion of Library Reference Issues: http://listserv.kent.edu/archives/libref-I.html.

${ }^{66}$ David Lankes: http://www.DavidLankes.org.

67 Jeffrey Pomerantz: http://sils.unc.edu/ -jpom.

${ }^{68}$ Stephen Francoeur es el autor de The teaching librarian:

http://www.teachinglibrarian.org/digref.htm y de la bitácora Digital reference:

http://www.teachinglibrarian.org/weblog/blogger.html.

${ }^{69}$ Diane Kovacs http://www.kovacs.com.

${ }^{70}$ IFLA. Sección de Servicios de Información y Referencia:

http://www.ifla.org/VII/s36/index.htm

${ }^{71}$ Reference and User Services Association: http://www.ala.org/rusa/.
} 
Reference and user services quarterly, ahora accesible a través de un nuevo blog. También ofrecen iniciativas de formación interesantes, como Virtual Reference Adventure: Choose Your Own Experience ${ }^{72}$ o RUSA toolkit ${ }^{73}$. Además, se puede incluir en este apartado el servidor de la comunidad profesional WebJunction $^{74}$, en el que se dedica un espacio a la referencia digital, muy bien provisto documentalmente. Además de artículos, noticias y listas de distribución, recoge la documentación de los diferentes congresos de la red Virtual Reference Desk, que han sido decisivos en el desarrollo tecnológico y teórico de la referencia por medios telemáticos.

Para terminar este apartado y este capítulo previo a la descripción de los servicios de referencia en general y a la práctica de la referencia digital, se quiere dejar constancia de una serie de sitios web de diferente tipología y demostrada utilidad. Dos son los directorios de bibliotecas que emplean servicios de referencia digital: Libsuccess $^{75}$ y Liswiki $^{76}$, ambos basados en tecnología wiki, con la que construyen sendos directorios de recursos de biblioteconomía y documentación, sumando entre los dos una buena nómina de bibliotecas que emplean el correo electrónico, chat, mensajería instantánea, SMS o un software específico para recibir y responder consultas de sus usuarios. Otro recurso web de interés es UCLA 245 Information Access ${ }^{77}$, en el que se puede consultar un conato de enciclopedia sobre servicios de referencia, incluyendo personas y términos. También desde el punto de vista terminológico es útil el Question Point Glossary $^{78}$, en el que se definen, en inglés, los principales conceptos relativos a la referencia digital. Dentro de los recursos de esta entidad estadounidense de proyección internacional, también es importante citar como fuente de información Question Point Blog ${ }^{79}$, iniciado en noviembre de 2005, para actuar de boletín informativo para los clientes de esta aplicación y para los miembros de su red de referencia digital. Los contenidos son útiles para la investigación en este ámbito, ya que sus noticias tienen un amplio alcance, siempre dentro de los servicios de información que se prestan por medios telemáticos. Por último, hay que incluir dentro de los recursos web especializados en referencia digital el tutorial Anytime, Anywhere Answers: Building Skills for Virtual Reference ${ }^{80}$, que fue desarrollado como material de formación del Statewide Virtual Reference Project, la red de referencia digital del estado de Washington. El tutorial sirvió de base para la obra que posteriormente editó la American Library Association ${ }^{81}$, en la que se recogen los mismos materiales de la versión electrónica, pero mucho más

\footnotetext{
${ }^{72}$ Virtual Reference Adventure: Choose Your Own Experience: http://cs.ala.org/ra/vr_adventure/

${ }^{73}$ RUSA toolkit: http://wikis.ala.org/rusatoolkit/

${ }^{74}$ Webjunction: http://webjunction.org.

75 Libsuccess: http://www.libsuccess.org.

76 Liswiki: http://liswiki.org.

${ }^{77}$ UCLA 245 Information Access: http://ucla245.pbwiki.com.

${ }^{78}$ Question Point Glossary:

http://www.oclc.org/americalatina/es/support/documentation/glossary/questionpoint/default.htm.

${ }^{79}$ Question Point Blog: http://questionpoint.blogs.com.

${ }^{80}$ Anytime, Anywhere Answers: Building Skills for Virtual Reference: http://vrstrain.spl.org.

${ }^{81}$ Hirko, Buff; Ross, Mary Bucher. Virtual reference training: the complete guide to providing anytime, anywhere answers. Chicago: American Library Association, 2004.
} 
desarrollados e incorporando nuevos contenidos, como textos teóricos y el análisis del trabajo realizado a partir del tutorial. El proyecto consistió en un plan de formación en referencia digital que se desarrollaba en cinco semanas, proponiendo en este plazo lecturas y actividades de forma gradual. El objetivo fue formar a los profesionales de esta red estadounidense, pero todos los materiales y documentos elaborados para este fin siguen en línea para quien desee adquirir conocimientos y competencias en estos temas. El proyecto se llevó a cabo entre 2002 y 2006, por lo que los últimos recursos incluidos son de esta fecha final; no obstante, por la validez de sus contenidos como material formativo, sigue siendo un recurso recomendable.

\subsection{Tendencias en la investigación en referencia digital}

La investigación en referencia digital es muy reciente, como es de prever, tanto como lo son las tecnologías que se emplean para su realización. Sloan $^{82}$ opina que la primera vez que una revista profesional publicó un artículo sobre la aplicación de medios telemáticos para ofrecer referencia fue en 1986, por lo que estamos ante un área de estudio que apenas sobrepasa las dos décadas de existencia. El artículo ${ }^{83}$ al que se refiere Sloan explicaba el servicio experimental llevado a cabo por la biblioteca de la University of Health Sciences de Washington mediante el cual ofrecía referencia a través de correo electrónico.

Se ha querido realizar un estudio bibliométrico/bibliográfico básico que permitiera establecer, a grandes rasgos, las principales características de la investigación sobre referencia digital, en la que se pudieran determinar los temas, autores o publicaciones más significativas. No se trata de un estudio exhaustivo ni contempla el rigor deseado en un análisis científico específico, algo que hubiese supuesto una tesis doctoral por sí misma. Se trata de una aproximación a las tendencias en referencia digital a partir de los datos numéricos extraídos por el doctorando siguiendo la metodología que se expone a continuación.

El punto de partida es una base de datos bibliográfica que se ha elaborado para esta tesis y en la que se han introducido referencias de documentos monográficos, publicaciones periódicas y contribuciones a congresos y reuniones científicas. En dicha base se han integrado referencias de documentos escritos en lenguas que pudiese comprender el doctorando: español, catalán, gallego, inglés, francés, portugués e italiano. También se ha recogido algunos documentos en otras lenguas, siempre que presentaran resúmenes amplios en alguno de los idiomas anteriormente mencionados. Como se apreciará en la bibliografía, el porcentaje más elevado es el de los documentos escritos en inglés.

${ }^{82}$ Sloan, Bernie. Twenty years of virtual reference. Internet Reference Services Quarterly, 2006, vol. 11, n. 2, p. 91-95.

${ }^{83}$ Howard, Ellen H.; Jankowski, Terry Ann. Reference services via electronic mail. Bulletin of the Medical Library Association, 1986, vol. 74, n. 1, p. 300-204. 
La elaboración de la base de datos que se ha empleado para la tesis doctoral, cuya relación aparece agrupada en diferentes subdivisiones en la parte cuarta de la investigación, ha seguido los siguientes pasos:

- Empleo de la aplicación de gestión de referencias bibliográficas Pro Cite, versión 5.0.3 para Windows, como gestor de referencias bibliográficas.

- Uso de los programas RefWorks y End Note de forma complementaria.

- Consulta a las principales bases de datos nacionales e internacionales con contenidos de Biblioteconomía y Documentación: LISA. LISTA, Francis, ISOC, ERIC, etc.

- Consulta a los principales proveedores de revistas electrónicas con publicaciones especializadas en Biblioteconomía y Documentación: Emerald Full Text, Science Direct, Ebsco, Swetswise, Willey, etc.

- Consulta a los principales catálogos colectivos nacionales e internacionales y a catálogos de bibliotecas nacionales con colecciones significativas: WorldCat, Rebiun, Library of Congress, Biblioteca Nacional de España, etc.

- Consulta a bases de datos bibliográficas: Global Books in Print, ISBN, etc.

- Selección manual de los registros relacionados con servicios de referencia, en general, y sobre referencia digital, en particular.

- Exportación de los registros seleccionados en los diferentes recursos electrónicos a los diferentes gestores bibliográficos, en función de las características de cada base o catálogo.

- Unificación de todos los registros en Pro Cite.

- Supervisión, control de duplicados y corrección manual de todos los registros incorporados.

- Codificación en formato RIS de la bibliografía elaborada por el doctorando de forma manual e importación de la misma a Pro Cite.

- Incorporación manual de los registros recuperados por el doctorando a partir de investigaciones y lecturas.

- Verificación de la pertinencia de los registros y de su adecuación a la temática de la tesis doctoral.

- Localización y supervisión de los registros.

- Eliminación de los imprecisos y carentes de valor.

- Control de autoridades.

- Categorización de los documentos en función de su temática.

- Configuración de las opciones de salida de Pro Cite para adaptarla a la ISO 690, para realizar la bibliografía y las notas.

- Análisis bibliométrico.

El proceso de investigación bibliográfica dio como resultado un total de $\mathbf{1 . 3 1 5}$ referencias afines al tema de la tesis doctoral, de forma directa o muy próxima. Todos los registros se organizaron en tres grandes categorías, aunque en algunos casos a los documentos se les asignó dos clasificaciones temáticas, por lo que la suma del total de documentos analizados no es la misma que la del total de documentos por categorías. Esto se debe a que un mismo artículo o monografía puede estar contabilizado doblemente, ya que, 
como se ha comentado, una treintena de documentos ha sido sistematizados en dos categorías diferentes. Normalmente, los documentos han sido clasificados bajo una de las quince categorías temáticas establecidas, pero en ocasiones se han asignado dos temas, al tratarse de documentos con contenidos que así lo aconsejaban. Nunca se han establecido más de dos categorías. Los resultados cuantitativos de los documentos que han sido recogidos en cada bloque temático son los siguientes:

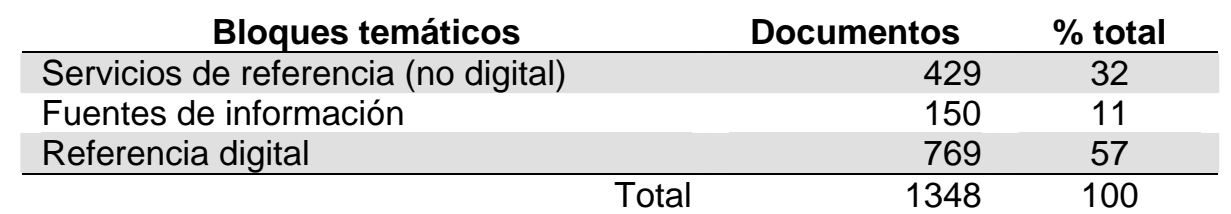

Fig. 0.1. Distribución temática de la base de datos bibliográfica

En el siguiente gráfico se muestra de forma visual la distribución de los artículos empleados para la tesis en los tres grandes bloques temáticos empleados para la redacción de la misma.

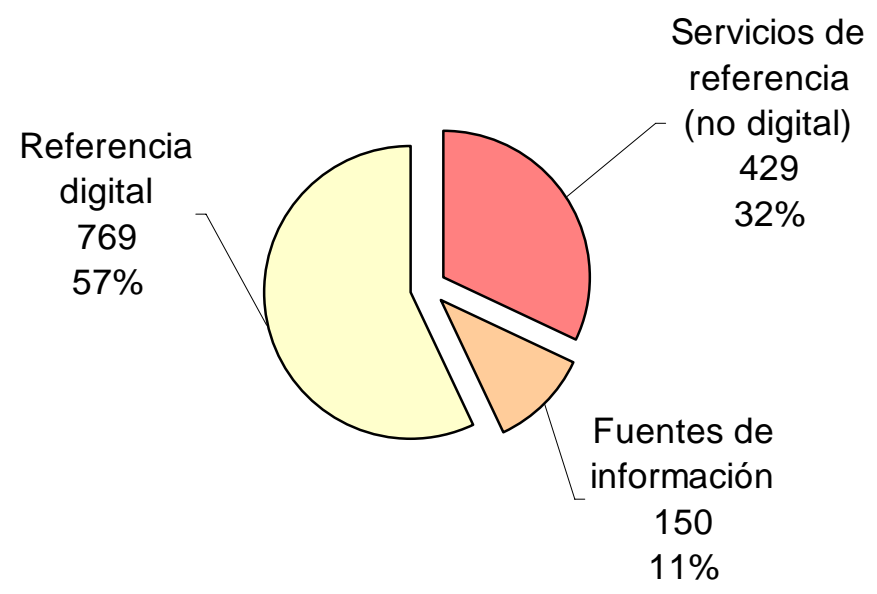

Fig. 0.2. Número y porcentaje de las referencias totales

De forma premeditada se ofrece un mayor número de documentos sobre referencia digital (57\% del total), ya que es el tema de la tesis y en el que la recopilación bibliográfica ha sido realizada de forma muy exhaustiva. Como se observa en el gráfico, los tres grandes bloques han tenido un tratamiento desigual, ya que se ha prestado mayor atención a la recogida exhaustiva de información sobre referencia digital, habiéndose limitado el número de documentos que tratan sobre servicios de referencia (32\%) y sobre fuentes de información (11\%) a aquellos que se han considerado más importantes.

Es por eso, por lo que la estructuración de estos tres bloques en un segundo nivel se ha realizado de manera más detallada en aquellos aspectos en los que las tecnologías estaban presentes en la práctica de los servicios de referencia. Además, en estos tres grandes grupos, se han querido reunir de forma independiente las referencias que estudiaban aspectos evaluativos, por tratarse de un tema especialmente analizado en esta tesis doctoral. 
El primer bloque de referencias bibliográficas incluidas en la base de datos es el que trata sobre servicios de referencia en general, entre las que no se incluyen los documentos específicos acerca de cualquier aspecto relativo a la referencia digital. La descripción de contenidos de cada uno de los epígrafes de esta parte se encuentra en el apartado 16, en la parte cuarta de la tesis doctoral. Las categorías realizadas en torno a estos documentos y las cifras de las referencias recopiladas y analizadas son las siguientes:

\begin{tabular}{|c|c|c|}
\hline Temas (Servicio de referencia) & $\begin{array}{c}\mathrm{N}^{\circ} \text { de } \\
\text { documentos }\end{array}$ & $\begin{array}{c}\% \\
\text { categoría }\end{array}$ \\
\hline 1. Manuales sobre servicios de referencia & 95 & 22 \\
\hline 2. Evaluación de servicios de referencia & 59 & 14 \\
\hline $\begin{array}{l}\text { 3. Servicios de referencia en entornos } \\
\text { digitales }\end{array}$ & 113 & 26 \\
\hline $\begin{array}{l}\text { 4. Recursos y tecnología web en los } \\
\text { servicios de referencia }\end{array}$ & 51 & 12 \\
\hline $\begin{array}{l}\text { 5. Bibliografía complementaria sobre } \\
\text { servicios de referencia }\end{array}$ & 111 & 26 \\
\hline
\end{tabular}

Fig. 0.3. Distribución temática de las referencias sobre Servicios de referencia

Como se puede apreciar en el siguiente gráfico el número mayor de referencias seleccionadas con las que tratan sobre servicios de referencia en entornos digitales ( $26 \%$ de la categoría), es decir, aquellas que tratan de las tecnologías como herramienta para los servicios bibliotecarios de consulta. También tiene el mismo porcentaje (26\%) el grupo en el que se recogen las referencias de los artículos que estudian aspectos relacionados con Internet y los servicios de referencia. No se incluyen aquí las referencias relacionadas con la prestación de la referencia digital.

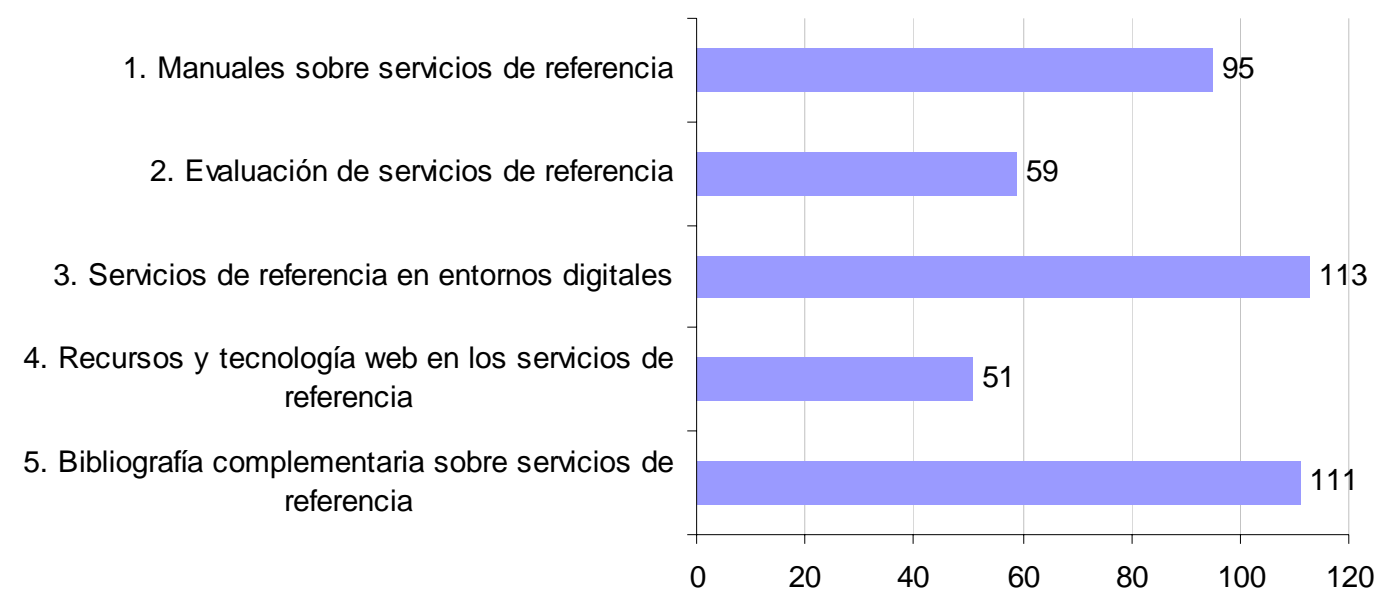

Fig. 0.4. Número de documentos sobre Servicios de referencia (no digital)

El segundo núcleo de documentos lo constituyen los que tratan sobre fuentes y colecciones de referencia. En este caso, ya que no era éste el tema de la investigación, a pesar de que existen muchas obras de interés que están relacionadas con el asunto de la investigación, se han seleccionado exclusivamente y de forma muy crítica las obras que se han 
incluido en la base de datos y, por tanto, en la bibliografía de la tesis doctoral. Los contenidos a los que se refiere cada epígrafe están desarrollados en el apartado 17 de la tesis doctoral. En este caso, los temas y los números de documentos son los siguientes:

\begin{tabular}{lcc} 
Temas (Fuentes de información) & $\begin{array}{c}\mathbf{N}^{\circ} \text { de } \\
\text { documentos }\end{array}$ & $\begin{array}{c}\% \\
\text { categoría }\end{array}$ \\
\hline $\begin{array}{c}\text { 6. Manuales sobre fuentes de información y } \\
\text { colecciones de referencia }\end{array}$ & 56 & 37 \\
7. Evaluación de fuentes de información & 23 & 15 \\
$\begin{array}{l}\text { 8. Bibliografía complementaria sobre } \\
\text { fuentes de información }\end{array}$ & 71 & 48 \\
\hline \multicolumn{1}{|c|}{ Total categoría } & 150 & 100
\end{tabular}

Fig. 0.5. Distribución temática de las referencias sobre Fuentes de información

Como se ha dicho más arriba, no se pretendía aquí recoger toda la producción sobre fuentes de información, sino solamente aquellas obras o documentos que fueran de interés para la investigación doctoral, por lo que se ha restringido el volumen de las referencias a centenar y medio, aunque existen muchos más monografías, artículos de publicaciones periódicas y contribuciones a congresos sobre este tema. La imagen de las cifras expuestas en la tabla anterior es la que se ofrece a continuación.

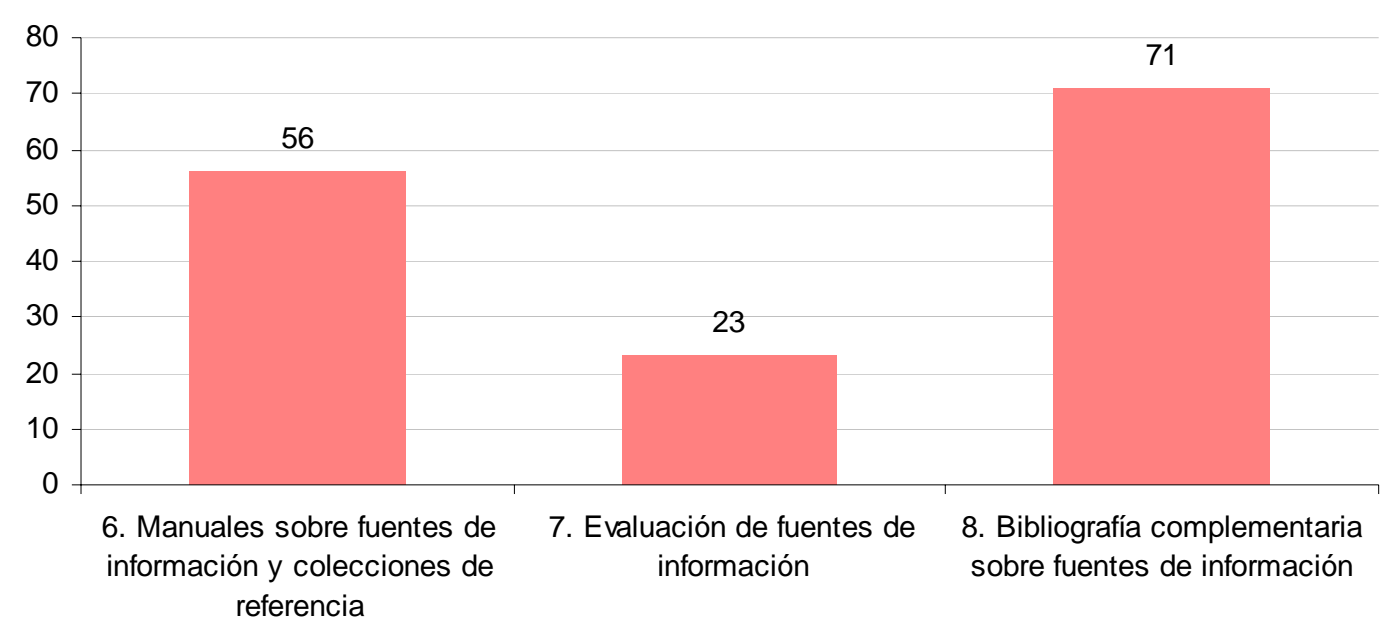

Fig. 0.6. Número de documentos sobre Fuentes de información

Por último, el tercer bloque recoge la bibliografía específica sobre servicios de referencia digital. La exhaustividad en la recopilación, el análisis detallado de su pertinencia, la sistematización adecuada y la aplicación de estos recursos a la tesis doctoral se ha hecho con sumo cuidado y especial dedicación, ya que esta sección bibliográfica es la base documental sobre la que se asienta este trabajo de investigación. Las categorías temáticas son explicadas de forma detallada -para éste y los otros dos bloques anterioresen la parte cuarta de la investigación, donde se reproducen las referencias bibliográficas.

Los temas con los que se ha trabajado en cuanto a servicios de referencia digital y las cifras correspondientes a cada subcategoría son los que se exponen a continuación: 


\begin{tabular}{|c|c|c|}
\hline Temas (Referencia digital) & $\begin{array}{c}\mathrm{N}^{\circ} \text { de } \\
\text { documentos }\end{array}$ & $\begin{array}{c}\% \\
\text { categoría }\end{array}$ \\
\hline $\begin{array}{l}\text { 9. Manuales y bibliografía esencial sobre } \\
\text { referencia digital }\end{array}$ & 33 & 4 \\
\hline 10. Evaluación de la referencia digital & 76 & 10 \\
\hline $\begin{array}{l}\text { 11. Conceptualización de la referencia } \\
\text { digital }\end{array}$ & 158 & 21 \\
\hline 12. Procesos de la referencia digital & 125 & 16 \\
\hline 13. Sistemas de referencia digital & 132 & 17 \\
\hline 14. Servicios públicos de referencia digital & 140 & 18 \\
\hline \multirow[t]{2}{*}{$\begin{array}{l}\text { 15. Servicios especializados de referencia } \\
\text { digital }\end{array}$} & 105 & 14 \\
\hline & 769 & 100 \\
\hline
\end{tabular}

Fig. 0.7. Distribución temática de las referencias sobre Referencia digital

Los contenidos que se han recogido en cada uno de los epígrafes anteriores están desarrollados en el apartado 18 de la tesis doctoral. Como puede apreciarse, los porcentajes están muy igualados, habiéndose encontrado un mayor número de documentos teóricos, sobre todo artículos que reflexionan sobre referencia digital ( $21 \%$ de la categoría). También es notable el número de referencias que tratan sobre los servicios de referencia digital en bibliotecas públicas (18\%), así como el volumen de documentos que estudian las tecnologías de la información para la referencia digital (17\%). En el siguiente gráfico se ofrece una presentación visual de los documentos pertenecientes a cada categoría.

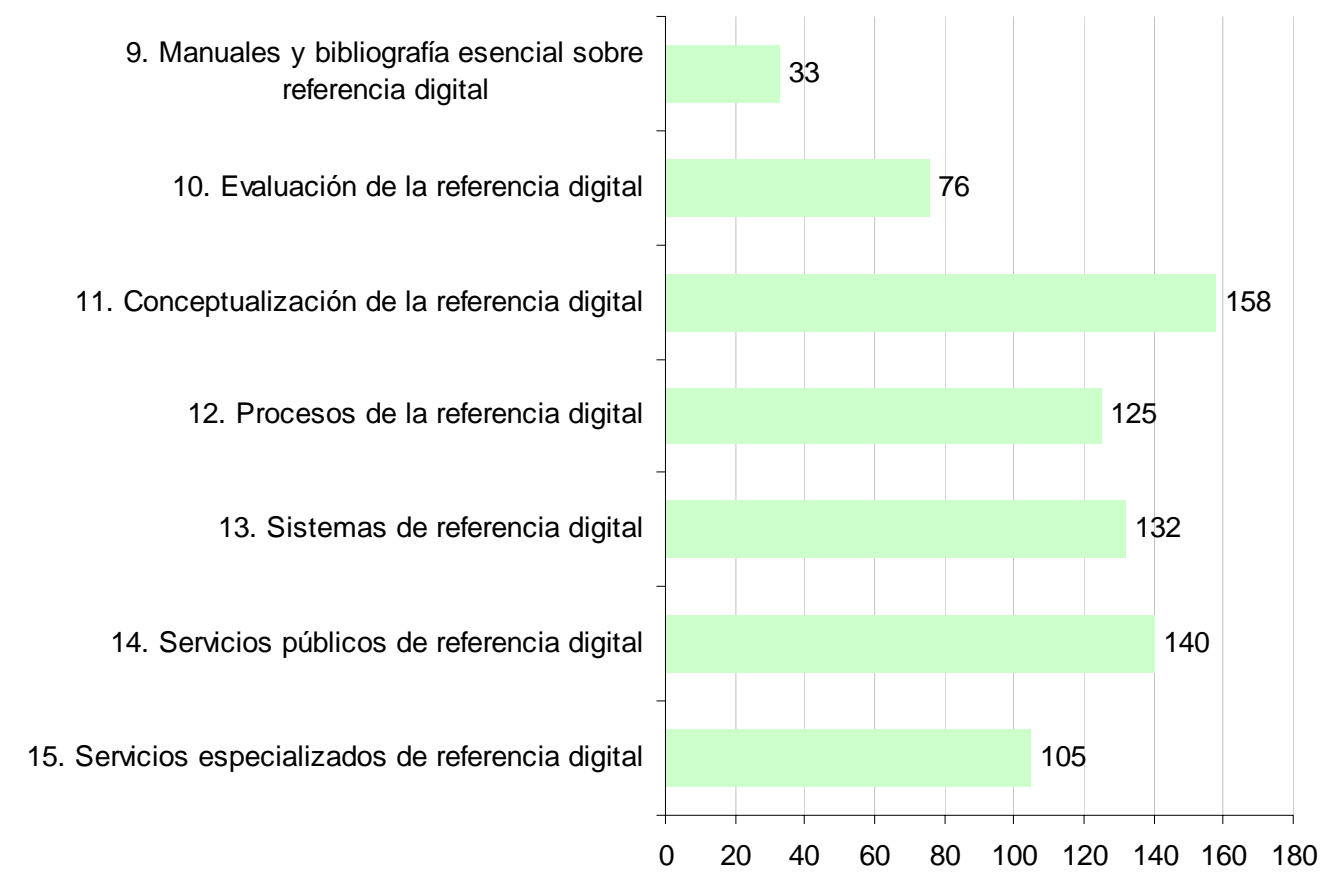

Fig. 0.8. Número de documentos sobre Referencia digital

Tomando como elemento de comparación la tipología documental se pueden encontrar las siguientes clases de documentos con las que se ha trabajado: libros y documentos monográficos, capítulos de monografías, artículos de publicaciones periódicas y ponencias o presentaciones de congresos. Como 
se ha comentado anteriormente, la selección de documentos ha sido más precisa y amplia en temas relacionados con la referencia digital, como se puede apreciar en la siguiente tabla, donde también se evidencia la presencia mayoritaria de documentos publicados como artículos en revistas especializadas.

\begin{tabular}{|c|c|c|}
\hline $\begin{array}{r}\text { Tipología } \\
\end{array}$ & $\mathrm{N}^{\circ}$ de documentos & $\%$ del total \\
\hline $\begin{array}{l}\text { Libros o documentos } \\
\text { monográficos }\end{array}$ & 201 & 15 \\
\hline Capítulos de monografías & 17 & 1 \\
\hline Ponencias de congresos & 60 & 5 \\
\hline $\begin{array}{l}\text { Artículos de revistas } \\
\text { profesionales }\end{array}$ & 1036 & 79 \\
\hline
\end{tabular}

Fig. 0.9. Distribución tipológica de las referencias de la base de datos

En la tabla anterior, se aprecia como el número mayor de documentos pertenece a artículos publicados en revistas profesionales. En este caso, y como es lógico, sólo se ha asignado una tipología por documentos, por lo que el total con el que se obtiene equivale al total de la base de datos con la que se ha trabajado para la tesis doctoral y para este análisis bibliométrico. Si se desea desglosar la tipología documental por lo grandes grupos temáticos, el resultado sería el que se ofrece en la tabla siguiente:

\begin{tabular}{rccc}
$\mathbf{N}^{\circ}$ de documentos & $\begin{array}{c}\text { Servicios de } \\
\text { Referencia }\end{array}$ & $\begin{array}{c}\text { Fuentes de } \\
\text { Información }\end{array}$ & $\begin{array}{c}\text { Referencia } \\
\text { Digital }\end{array}$ \\
\hline $\begin{array}{r}\text { Libros o documentos } \\
\text { monográficos }\end{array}$ & 102 & 59 & 50 \\
$\begin{array}{r}\text { Capítulos de monografías } \\
\text { Ponencias de congresos }\end{array}$ & 5 & 3 & 9 \\
Artículos de revistas & 318 & 2 & 52 \\
profesionales & & 86 & 652 \\
\hline
\end{tabular}

Fig. 0.10. Distribución tipológica y temática de las referencias de la base de datos

El gráfico siguiente muestra estos mismos datos, reflejando visualmente cómo las cifras mayores corresponden a los documentos que tratan sobre servicios de referencia digital que han sido editados en publicaciones periódicas.

Como se ha mencionado, la selección bibliográfica prioritaria ha sido la relativa a aquellos documentos que trataban sobre los servicios de consulta que las bibliotecas ofrecen en línea, es decir, a los servicios de referencia digital.

En esta línea de investigación, como en cualquier disciplina, la comunicación científica predominante se realiza a través de las revistas. En el gráfico siguiente se deja constancia del elevado porcentaje de artículos recogidos, en relación a las otras tipologías documentales. 


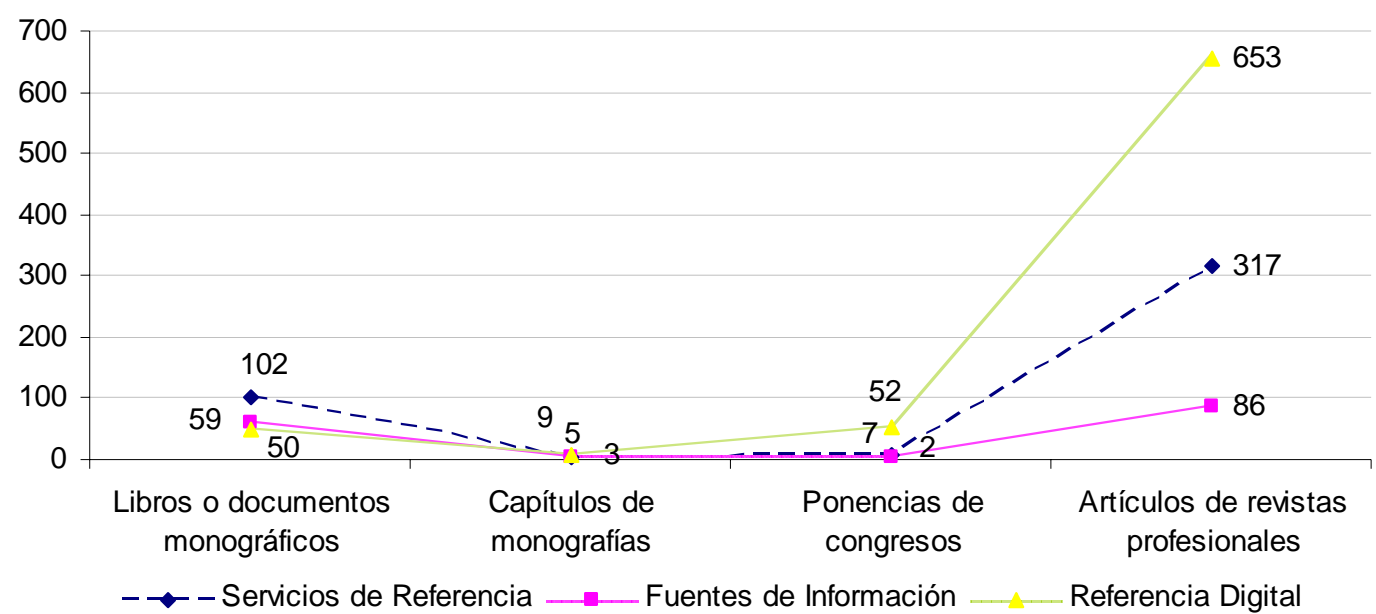

Fig. 0.11. Número de documentos según su tipología y temática

Un dato esperado, aunque se puede constatar de forma fehaciente en la base de datos que se ha producido para la tesis doctoral, es la preponderancia del idioma inglés en la producción científica sobre servicios de referencia y sobre servicios bibliotecarios de consulta por medios telemáticos. Teniendo en cuenta íntegramente la base de datos empleada, los datos totales y porcentuales son los siguientes:

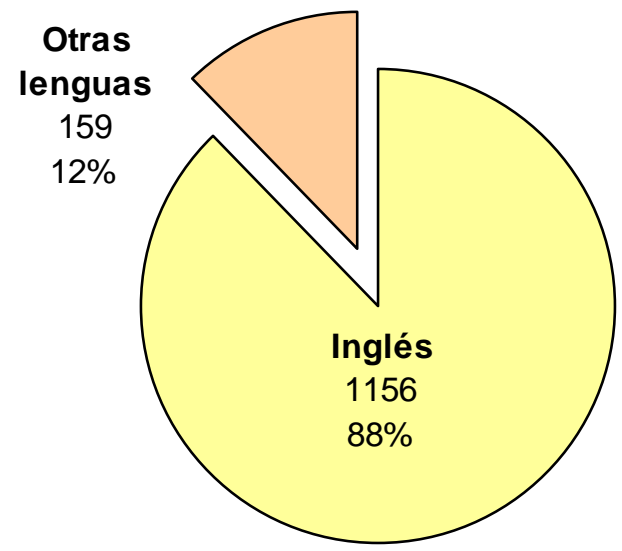

Fig. 0.12. Lenguas de los documentos (número de documentos y porcentaje del total)

Si se desglosa por las principales lenguas incorporadas a la base de datos bibliográfica según el bloque temático al que pertenecen, los datos cuantitativos serían los que se muestran a continuación:

\begin{tabular}{ll} 
Idiomas & \multicolumn{1}{c}{$\begin{array}{c}\text { Número de } \\
\text { documentos }\end{array}$} \\
\hline Inglés & 1156 \\
\hline Español & 78 \\
\hline Francés & 33 \\
\hline Holandés & 15 \\
\hline Italiano & 11 \\
\hline
\end{tabular}




\begin{tabular}{|c|c|}
\hline Portugués & 6 \\
\hline Alemán & 5 \\
\hline Danés & 4 \\
\hline Catalán & 2 \\
\hline Croata & 1 \\
\hline Finlandés & 1 \\
\hline Húngaro & 1 \\
\hline Islandés & 1 \\
\hline Turco & 1 \\
\hline & 1315 \\
\hline
\end{tabular}

Fig. 0.13. Distribución por idiomas de las referencias de la base de datos

Los documentos en español, como puede apreciarse son todavía escasos, aunque supone el segundo número en volumen de documentos por idiomas, muy lejos de la cantidad que aportan los documentos en inglés. No obstante, en España y los países de habla hispana, se aprecia cierto interés en la profesión en torno a la referencia digital. Como muestra se pueden citar las actividades de formación que realizan organismos bibliotecarios, para capacitar a sus profesionales en técnicas de referencia en línea. Algunos ejemplos son los planes de formación del Ministerio de Cultura, quien, a través de la Subdirección General de Coordinación Bibliotecaria colabora en la instrucción de los bibliotecarios españoles. En noviembre de 2007 el Ministerio de Cultura ha organizado un curso sobre referencia digital para el personal bibliotecario que participa en el proyecto «Pregunte: las bibliotecas responden».

Asimismo, algunas redes de bibliotecas municipales han llevado a cabo actividades de formación en este mismo sentido, como ocurrió en noviembre de 2007 en el Ayuntamiento de Zaragoza, quien convocó el curso "Servicios de referencia digital en las bibliotecas públicas". Este interés se observa también en las bibliotecas universitarias. Por ejemplo, en el VII Workshop REBIUN sobre proyectos digitales, denominado "La estrategia digital: ¿hacia dónde?" y celebrado en Madrid los días 18 y 19 de octubre de 2007, se incluyó la ponencia titulada Gestión del conocimiento en un servicio de referencia virtual: diseño de un programa para la atención de consultas, presentada por Patricia Riera, de la Universitat Oberta de Catalunya.

La edad de los documentos también es un dato que permite conocer datos cualitativos de la producción científica especializada. En ese caso, se ofrecen dos tipos de análisis numérico, uno con periodos más amplios y divididos en los tres grandes bloques temáticos y otro, en el que se sólo se han contemplado las categorías relacionadas con referencia digital y en el que se quiere representar la evolución cronológica pormenorizada de cada tema.

En cuanto a las fechas de publicación de los documentos contenidos en la base de datos bibliográfica, organizadas por periodos de tres años, estructurando la información en las tres secciones que se vienen manejando a lo largo de este apartado y en las que se ha dividido la bibliografía, los resultados serían los siguientes: 


\begin{tabular}{rccc}
$\begin{array}{r}\text { Fecha de } \\
\text { publicación }\end{array}$ & $\begin{array}{c}\text { Servicios de } \\
\text { Referencia }\end{array}$ & $\begin{array}{c}\text { Fuentes de } \\
\text { Información }\end{array}$ & $\begin{array}{c}\text { Referencia } \\
\text { Digital }\end{array}$ \\
\hline Antes de 1980 & 4 & 0 & 1 \\
$1981-1983$ & 8 & 1 & 0 \\
$1984-1986$ & 15 & 1 & 2 \\
$1987-1989$ & 14 & 2 & 6 \\
$1990-1992$ & 21 & 2 & 21 \\
\hline $1993-1995$ & 9 & 12 & 35 \\
$1996-1998$ & 45 & 33 & 40 \\
$1999-2001$ & 86 & 31 & 139 \\
\hline $2002-2004$ & 100 & 22 & 321 \\
\hline $2005-2007$ & 103 & 45 & 245 \\
\hline
\end{tabular}

Fig. 0.14. Distribución cronológica y temática de las referencias de la base de datos

Para el estudio que se lleva a cabo en esta tesis doctoral es mucho más importante conocer la evolución de la producción científica especializada en referencia digital, por ese motivo se ofrecen de forma desagregada las edades de los documentos que corresponden a las subcategorías del tercer bloque, detallando de manera anual el número de documentos que se han publicado cada año. De esta manera, se aprecia cuantitativamente en qué sentido está evolucionando la investigación en referencia digital. Los datos son los que se ofrecen a continuación:

\begin{tabular}{rcccccccccc} 
Referencia digital (RD) & $<1999$ & 2000 & 2001 & 2002 & 2003 & 2004 & 2005 & 2006 & 2007 \\
\hline $\begin{array}{r}\text { Manuales y bibliografía } \\
\text { esencial }\end{array}$ & 4 & 3 & 1 & 3 & 7 & 6 & 3 & 2 & 4 \\
Evaluación & 4 & 4 & 4 & 7 & 13 & 6 & 6 & 25 & 8 \\
Conceptualización & 15 & 5 & 22 & 29 & 32 & 20 & 16 & 17 & 6 \\
Procesos de la RD & 14 & 10 & 12 & 20 & 22 & 8 & 13 & 20 & 8 \\
Sistemas de RD & 13 & 6 & 10 & 11 & 17 & 15 & 21 & 16 & 27 \\
Servicios públicos & 12 & 8 & 14 & 19 & 31 & 21 & 19 & 13 & 9 \\
Servicios especializados & 17 & 10 & 8 & 19 & 21 & 15 & 8 & 10 & 2 \\
\hline
\end{tabular}

Fig. 0.15. Distribución cronológica de los documentos sobre Referencia digital

La evolución cronológica se percibe gráficamente en la siguiente ilustración, en la que se observa cómo el mayor número de documentos corresponden a los artículos que tratan de conceptualizar la referencia digital, estableciendo definiciones, reflexionando sobre sus ventajas o determinando las diferentes variantes que es posible encontrarse en los servicios bibliotecarios que ofrecen servicios de consulta a través de Internet. Un dato que resalta es que en 2003 se encuentran los índices mayores en varias de las subcategorías temáticas en las que se han dividido los documentos que estudian la referencia digital.

También es destacable que en 2006 se publicaron un número de documentos sobre evaluación de servicios electrónicos de referencia superior a los que se editaron en años anteriores. Esto puede deberse a que ya ha existen muchos servicios con trayectoria suficiente como para disponer de los datos indispensables para evaluarlos. La evolución cronológica de los documentos específicos sobre referencia digital es el objeto del siguiente gráfico. 


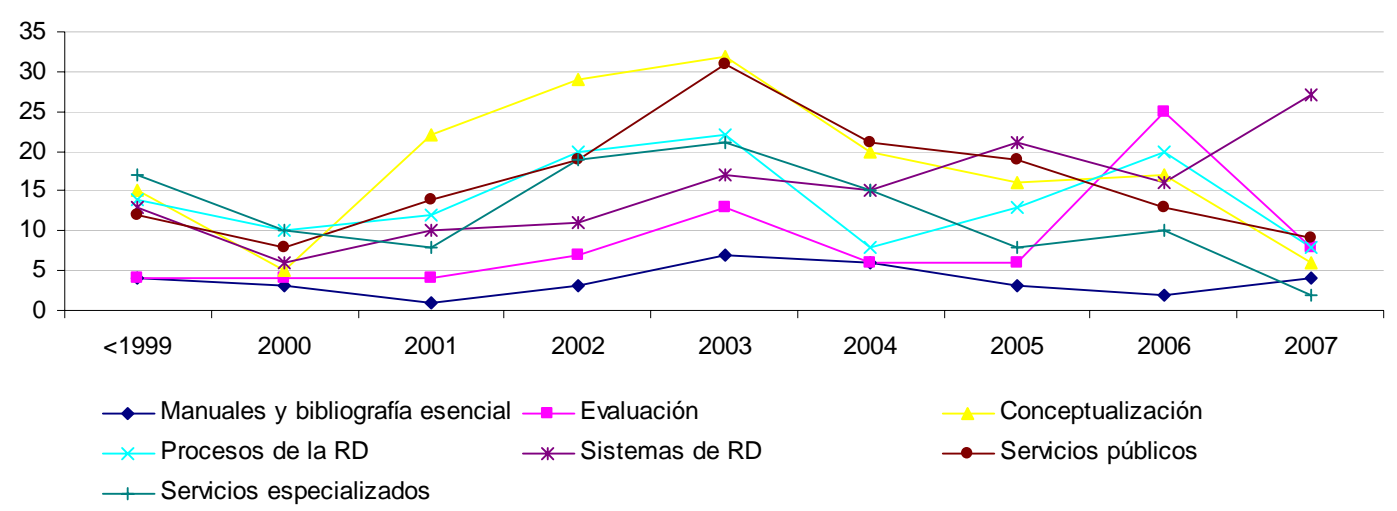

Fig. 0.16. Evolución cronológica de los documentos sobre Referencia digital

A partir de esta base de datos se pueden conocer también quienes son los autores que más investigaciones han aportado a las investigaciones sobre referencia digital y cuáles han sido las revistas más productivas sobre el tema. Los datos de los autores que se ofrecen corresponden a la integridad de la base bibliográfica, ya que se ha querido mostrar la trayectoria de estos investigadores que en casos significativos ya trabajaban en servicios de referencia antes de la propagación de las tecnologías en las bibliotecas. La relación de los autores de los que se han recogido más de cinco referencias en la base de datos bibliográfica de la tesis doctoral es la siguiente:

\begin{tabular}{rc} 
Autorla & $\begin{array}{c}\mathbf{N}^{\mathbf{0}} \text { de } \\
\text { referencias }\end{array}$ \\
\hline Lankes, R. David & 32 \\
Katz, William & 29 \\
Pomerantz, Jeffrey & 16 \\
Kresh, Diane Nester & 13 \\
Fraley, Ruth A. & 11 \\
Janes, Joseph & 10 \\
McClure, Charles & 10 \\
Tenopir, Carol & 9 \\
Nilsen, Kirsti & 8 \\
Wasik, Joann M. & 8 \\
Accart, Jean-Philippe & 7 \\
Gross, Melissa & 7 \\
Merlo Vega, José A. & 7 \\
Ward, David & 7 \\
Ronan, Jana & 6 \\
Sloan, Bernie & 6 \\
Whitlatch, Jo Bell & 6 \\
Hirko, Buff & 5 \\
Kasowitz, Abby & 5 \\
Moyo, Lesley M. & 5 \\
Radford, Marie & 5 \\
\hline
\end{tabular}

Fig. 0.17. Autores con más de cinco artículos en la base de datos bibliográfica

Por último, se quiere destacar la labor de las publicaciones periódicas que más páginas han dedicado a los servicios de referencia en general, sobre todo a la referencia digital, a la que se dedica esta investigación. Igual que en el caso anterior, se toma como base el total de las referencias 
recopiladas, cualquiera que sea la categoría temática asignada. De esta forma, se puede conocer la cifra global de documentos, ya traten de aspectos generales de la referencia, ya sea sobre aspectos tecnológicos relacionados con la referencia o bien sean documentos que analizan los servicios y sistemas de referencia digital en su sentido estricto. La relación de revistas profesionales recogidas en la base de datos y que han publicado más de diez artículos sobre los temas tratados en esta investigación es la que se presenta seguidamente:

\begin{tabular}{rc} 
Publicación periódica & $\begin{array}{c}\mathbf{N}^{\mathbf{0}} \text { de } \\
\text { referencias }\end{array}$ \\
The Reference Librarian & 135 \\
Reference Services Review & 86 \\
Internet Reference Services Quarterly & 56 \\
Reference and User Services Quarterly & 42 \\
Annual Digital Reference Conference, & 28 \\
Library Journal & 24 \\
Computers in Libraries & 23 \\
The Electronic Library & 21 \\
The Journal of Academic Librarianship & 18 \\
Journal of Library Administration & 17 \\
Library Review & 16 \\
Library trends & 15 \\
Information Technology and Libraries & 14 \\
New Library World & 13 \\
College and Undergraduate Libraries & 12 \\
Medical reference services quarterly & 12 \\
Online & 11 \\
Searcher & 11 \\
The Virtual Reference Desk & 11 \\
BibliotheekBlad & 10 \\
D-Lib Magazine & 10 \\
Library Hi Tech News & 10 \\
Library and information science rearch & 10 \\
Public Services Quarterly & 10 \\
\hline
\end{tabular}

Fig. 0.18. Publicaciones periódicas con más de diez referencias en la base de datos

Como era de esperar, las dos revistas especializadas en servicios de referencia con mayor trayectoria internacional son las que destacan en esta bibliografía. The Reference Librarian y Reference Services Review son las publicaciones periódicas de mayor importancia en el tema que se ha tratado en esta tesis doctoral. Otras dos revistas destacan por el número de artículos aportados: Internet Reference Services Quarterly, una de las publicaciones profesionales más recientes, y Reference and User Services Quarterly, también de dilatada trayectoria. Es un dato importante que estas cuatro revistas suman la cuarta parte del total de los documentos que forman parte de este estudio. En cuanto a las publicaciones periódicas españolas, la revista que más artículos sobre servicios de referencia ha publicado es el Boletín de la Asociación Andaluza de Bibliotecarios, donde han aparecido cinco artículos; asimismo, la Revista Española de Documentación Científica ha publicado cinco contribuciones sobre referencia o evaluación de fuentes de información. 


\section{Parte I}

\section{Los servicios bibliotecarios de información y referencia}

Tras el bloque introductorio, la primera parte de la tesis doctoral está conformada por el marco teórico de los servicios de referencia. El objetivo del módulo primero es ofrecer los contenidos sobre los que se asientan los servicios de referencia digitales, partiendo de la teoría y la práctica bibliotecaria tradicional, sobre la que se han construido los nuevos servicios telemáticos. Por esa razón se considera necesario ofrecer una panorámica acerca de este tipo de secciones bibliotecarias, así como sus bases teóricas y los fundamentos de su organización. Asimismo, se detallan los tipos de demandas de información que atienden las bibliotecas, se presentan las diferentes etapas del proceso de consulta/respuesta y se dedica un amplio apartado a estudiar la colección de referencia, aportando una nueva concepción de las fuentes de información, agrupadas en la denominada Clasificación Funcional-Formal de los recursos informativos. También se ha querido incluir en esta sección un apartado relacionado con Internet como herramienta del servicio de referencia, ya que la aparición de la red universal ha modificado sustancialmente los servicios bibliotecarios de consulta. 
Parte I. LOS SERVICIOS BIBLIOTECARIOS DE INFORMACIÓN Y REFERENCIA

2. El servicio de referencia en la biblioteca

2.1. La información en la biblioteca

2.2. Fundamentos del servicio de referencia

2.3. Un servicio para los usuarios

2.4. Tipología de los servicios de información

3. Organización del servicio de referencia

3.1. Perfil profesional del referencista

3.2. El entorno espacial en los servicios de referencia

3.3. Instrumentos para la prestación del servicio de referencia

3.4. Formación de usuarios y servicios de referencia

4. Las demandas de información

4.1. Tipología de las demandas de información

4.2. Información general

4.3. Información de respuesta rápida

4.4. Información bibliográfica

5. El proceso de referencia

5.1. La recepción de las consultas

5.2. La entrevista de referencia

5.3. La resolución de las consultas

5.4. Productos informativos elaborados por la biblioteca

6. La colección de referencia

6.1. Las fuentes de información

6.2. Tipología de los recursos de referencia

6.3. Esquema de la Clasificación Funcional/Formal

6.4. Internet como recurso para la referencia

7. Evaluación de los servicios de referencia

7.1. Características de la evaluación

7.2. Evaluación de las consultas

7.3. Evaluación de la colección de referencia

7.4. Indicadores de evaluación

7.5. Métodos de evaluación 


\section{2: El servicio de referencia en la biblioteca}

Una vez analizada la situación de la investigación sobre referencia digital se quiere ofrecer el contexto de este tipo de servicios bibliotecarios, comenzando por los conceptos tradicionales sobre los que se asientan los nuevos sistemas bibliotecarios de información. Los servicios de referencia son aquellos que ofertan las bibliotecas para solventar las necesidades de información de los usuarios. En este apartado se delimita la terminología relativa a este servicio y se analizan los objetivos que debe perseguir la sección de referencia de una entidad bibliotecaria. No todas las bibliotecas son iguales, por lo que tampoco lo serán sus servicios de información. Es necesario adecuar los servicios de referencia a los diferentes tipos de usuarios, lo cual también se estudia en este apartado de la tesis doctoral. Además, se recogen diferentes teorías sobre la tipología de los servicios de información, realizando una síntesis de las distintas formas en las que se materializan los servicios de referencia.

La experiencia docente del doctorando se refleja en este trabajo de investigación. Así, entre las materias que ha impartido el autor de esta tesis doctoral se encuentra la asignatura optativa Servicio de referencia e información bibliográfica, que se ofrecía en el plan de estudios de 1993 de la Diplomatura en Biblioteconomía y Documentación de la Universidad de Salamanca. Los contenidos que se presentan en los apartados siguientes eran tratados en dicha asignatura, que sirvió de primer acercamiento a los servicios bibliotecarios de consulta. Asimismo, parte del programa impartido en la materia mencionada fue publicado como artículo científico en la revista Anales de Documentación ${ }^{84}$, siendo uno de los artículos más citados sobre este tema. Tanto los textos empleados en la asignatura, como el mencionado artículo, han servido como base para los diferentes aspectos tratados en esta parte de la tesis doctoral, que se han completado y actualizando con los conocimientos aprehendidos de las distintas monografías y documentos que se han ido publicando sucesivamente sobre los temas tratados en los párrafos que se ofrecen a continuación, además de las propias reflexiones y teorías que el doctorando ha ido desarrollado desde que comenzó a impartir e investigar materias relativas a los servicios y las fuentes de información.

\subsection{La información en la biblioteca}

Todos los teóricos de la Biblioteconomía coinciden en que las principales funciones de la biblioteca son formar, informar y entretener. Estos tres objetivos se desarrollarán de manera distinta en virtud de los tipos de bibliotecas existentes. Lógicamente, las bibliotecas de centros de enseñanza (escolares y universitarias) deberán centrar su actividad en la formación,

\footnotetext{
${ }^{84}$ Merlo Vega, José Antonio. El servicio bibliotecario de referencia. Anales de documentación, 2000, vol. 3, p. 93-126. Disponible también en línea: <http://www.um.es/fccd/anales/ad03/ad0300.html>. [Consulta 15 julio 2007]
} 
mientras que otras bibliotecas, como las públicas o las especiales (hospitales, prisiones, etc.), se preocupan más del ocio de sus usuarios. Pero todas las bibliotecas, sea cual sea su tipología, cuentan con un servicio de información que atiende las consultas de los usuarios, aunque el grado de importancia de este servicio dependerá del modelo de biblioteca, de la política bibliotecaria seguida y de los objetivos de la misma.

Las colecciones bibliotecarias están formadas por fondos de distintas características, soportes y temáticas, siempre orientados a satisfacer los tres objetivos mencionados: formación, información y entretenimiento. Por ello, en una biblioteca pueden encontrarse documentos útiles para la formación académica y profesional de los usuarios, así como obras de consulta. Del mismo modo, se incluyen obras de esparcimiento. La distribución de la colección dependerá del tipo de biblioteca: en bibliotecas universitarias primará la colección de formación, en las especializadas la de información y en las públicas la de ocio, por ejemplo.

Aunque pueden encontrarse ejemplos de actividades de información en las bibliotecas desde que éstas existen, lo cierto es que el servicio de información, tal y como hoy se concibe, nace a finales del siglo $\mathrm{XIX}^{85}$ y se generaliza a mediados del siglo XX. La propia evolución de la educación y la cultura ha convertido a la biblioteca en un centro dinámico, más preocupado por la difusión de sus fondos y de la información en ellos contenida, que por la conservación y el almacenamiento de los mismos. Esta concepción de la biblioteca como centro difusor de documentos ha provocado el aumento de acciones dirigidas a informar al usuario y el afianzamiento de los servicios de información como parte indispensable del trabajo bibliotecario.

Janes $^{86}$ ofrece una breve historia de la referencia en una de las pocas monografías sobre referencia digital que se han considerado fundamentales en esta tesis doctoral. En todo caso, el autor se centra excesivamente en la trayectoria de las bibliotecas estadounidenses, ignorando la realidad europea. De igual forma, la trayectoria histórica de los servicios bibliotecarios de referencia se recoge en el capitulo primero del excelente manual de Bopp y Smith $^{87}$.

Los distintos servicios de información que prestan las bibliotecas varían según las informaciones que se ofrezcan. Por este motivo, se emplean diferentes términos para denominar la actividad consistente en facilitar información a los usuarios. Así, se habla de servicio de referencia, servicio de información bibliográfica, servicio de orientación, de consulta, de

\footnotetext{
${ }^{85}$ Son muchos los teóricos que mencionan a Samuel Swett Green como el primer autor que habla de los servicios bibliotecarios de información para ayudar a los usuarios. Green publicó en 1876 en Library Journal un artículo titulado "Personal relations between librarians and readers" en el que defendía esta idea. Véase Tyckoson, David A. What is the best model of reference service? Library trends, 2001, vol. 50, n. 2, p. 183-196.

${ }^{86}$ Janes, Joseph. Introduction to reference work in the digital age. New York: NealSchuman, 2003, p. 6-19.

${ }^{87}$ Bunge, Charles A.; Bopp, Richard E. History and varieties of reference services. En Bopp, Richard E.; Smith, Linda C. (eds. ). Reference and information services: an introduction . $3^{\text {th }}$ ed. Englewood, CO: Libraries Unlimited, 2000, .p. 3-27.
} 
búsquedas documentales, etc. Por ejemplo, las Pautas sobre los servicios de las bibliotecas públicas ${ }^{88}$ incluyen dentro de los que se consideran esenciales el Servicio de información general y de orientación e información bibliográfica.

Sobre todas las denominaciones empleadas se ha impuesto el término «referencia», neologismo aceptado por el uso entre los profesionales bibliotecarios, aunque no oficialmente, ya que no ha recibido aún el beneplácito de la Real Academia Española. La acepción bibliotecaria de la palabra referencia procede del inglés reference, que se emplea como sinónimo de consulta. El peso de la tradición biblioteconómica anglosajona es el causante de que se haya realizado una traducción impropia. No obstante, el término «referencia» está plenamente admitido dentro de la terminología bibliotecaria de la lengua española y, del mismo modo, la denominación Servicio de referencia es la que se ha impuesto para mencionar a la sección de la biblioteca encargada de informar al usuario sobre cuestiones diversas. No obstante, en el dominio hispanoamericano sí es habitual que se emplee Servicio de consulta con la misma frecuencia que Servicio de referencia.

En algunos manuales de Biblioteconomía se hace una diferencia entre el servicio de referencia y el de información bibliográfica. La explicación consistía en que estos servicios atendían consultas distintas. Mientras que el servicio de referencia resolvía cuestiones de respuesta inmediata y sencilla, el servicio de información bibliográfica estaba especializado en ofrecer información más compleja y elaborada, como relaciones bibliográficas o búsquedas en bases de datos. Esta diferenciación, que apenas se utiliza en la actualidad, puesto que todo tipo de consultas son resueltas por el mismo servicio, es la causa de que todavía hoy se utilice la denominación Servicio de referencia e información bibliográfica.

En definitiva, es necesario entender el servicio de referencia como la unidad de la biblioteca que da respuesta a las consultas de los usuarios, resolviendo cuestiones inmediatas (pregunta/respuesta), ofreciendo información bibliográfica específica, suministrando documentos externos y orientando acerca de fuentes de información y sistemas de interrogación de los recursos informativos.

Los aspectos que se deben estudiar en relación al servicio de referencia deben girar en torno a los agentes que intervienen en el mismo: usuarios y bibliotecarios, así como a las técnicas específicas que se emplean en el servicio. Del mismo modo, en sus contenidos habrá que incluir los recursos de información que se manejan, tanto la colección de referencia como los productos informativos elaborados por la biblioteca u otras instituciones. Además, será necesario analizar también los aspectos relativos a la gestión del servicio: diseño, planificación, evaluación, etc. De forma gráfica los elementos integrantes de un servicio de referencia pueden ser expresados de esta manera:

${ }^{88}$ Pautas sobre los servicios de las bibliotecas públicas. Madrid: Ministerio de Educación, Cultura y Deporte, 2002, p. 15-16. 


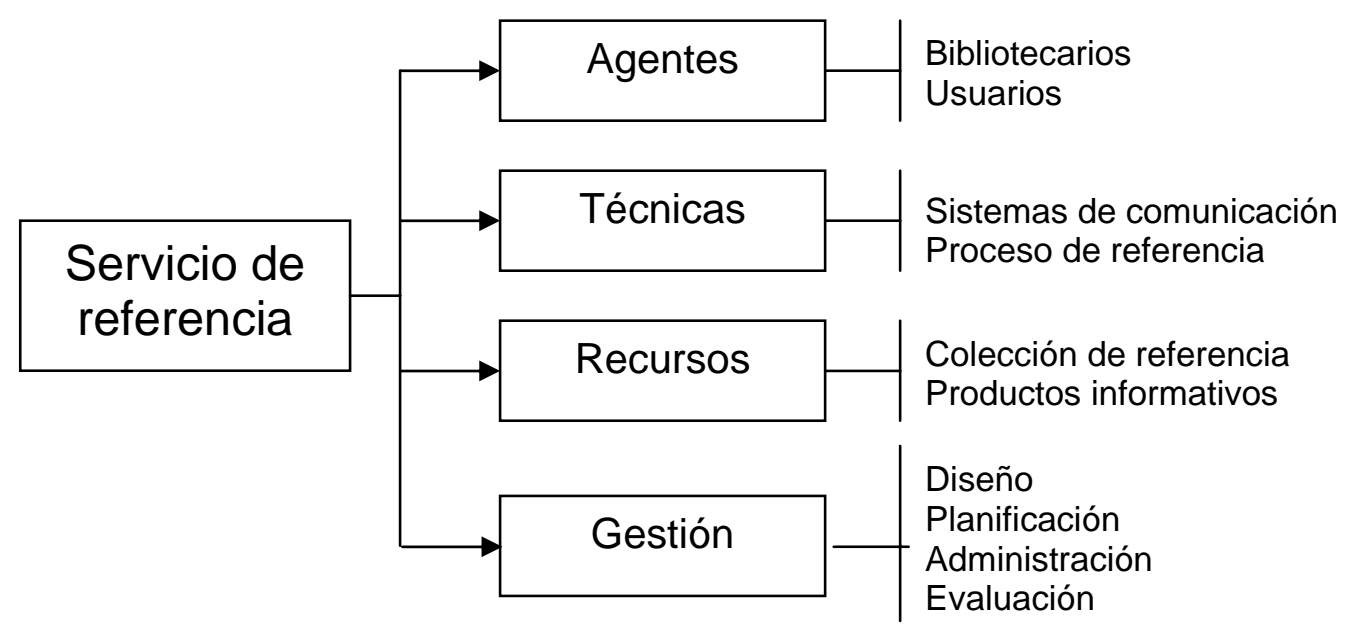

Fig. 1.1. Elementos de un servicio de referencia

Partiendo de este esquema pueden desarrollarse los elementos definitorios del servicio de información de una biblioteca. El estudio global de los servicios de referencia, presenciales o digitales, deberá incluir los siguientes ámbitos:

1. Bibliotecarios. Perfil del bibliotecario de referencia. Características profesionales y personales. Formación continua.

2. Usuarios. Necesidades de información de los usuarios. Adecuación a los usuarios en virtud de determinadas características como la edad o el tipo de biblioteca a la que acuden. Actividades de instrucción en información de los usuarios.

3. Sistemas de comunicación. Recepción de las consultas. Atención al usuario. Tipos de consultas. Sistemas de información. Entrevista de referencia. Tecnologías de comunicación para la referencia. Aplicaciones informáticas para el servicio de referencia

4. Proceso de referencia. Fases por las que pasa una demanda de información desde que se realiza hasta que se solventa. Técnicas de búsqueda. Habilidades de información. Destrezas de comunicación.

5. Colección de referencia. Fuentes de información de que dispone la biblioteca para la resolución de las consultas. Desarrollo de colecciones. Valoración de obras de referencia. Fuentes automatizadas y electrónicas. Recursos de información en entornos telemáticos.

6. Productos informativos. Materiales elaborados por la biblioteca para informar a los usuarios incluso adelantándose a sus peticiones. Tutoriales y guías de recursos. Servicios de alerta y difusión selectiva de la información. 
7. Diseño. Aspectos relacionados con la infraestructura y el mobiliario del servicio, así como con la distribución de las áreas de trabajo y las condiciones físicas y ambientales. Selección del modelo de servicio.

8. Planificación. Distribución de los recursos económicos, documentales y de personal. Organización de los servicios y actividades informativas. Desarrollo de las políticas específicas.

9. Administración. Control de la planificación. Gestión económica y de los recursos humanos. Automatización de los servicios. Cooperación interbibliotecaria en materia de referencia. Redes y consorcios.

10. Evaluación. Análisis del rendimiento del servicio. Valor y uso de la colección. Satisfacción de los usuarios. Calidad de la información. Gestión del cambio.

\subsection{Fundamentos del servicio de referencia}

Si una de la funciones de la biblioteca es informar, el principal objetivo del servicio de referencia será conseguir que todas las informaciones requeridas sean satisfechas. Por este motivo, la biblioteca deberá contar con una sección específica, con personal especializado en la búsqueda de información y con una colección de consulta útil. Además, deberá desarrollar las iniciativas y procedimientos que considere necesarios para facilitar al usuario el acceso a la información.

La IFLA ya mencionaba en sus Pautas para bibliotecas públicas ${ }^{89}$ una serie de aspectos relativos a la oferta de información, entre los que sobresalían los siguientes:

- Aceptar la responsabilidad de dar respuestas precisas actualizadas de manera rápida e imparcial.

- Estar preparada para buscar fuera de la biblioteca cuando sea necesario, así como para atender consultas de usuarios de otras bibliotecas.

- Dar a conocer el papel informativo de la biblioteca mediante la publicidad u otros medios.

- Instruir en el uso de las fuentes informativas.

- Proporcionar información mediante tablones de anuncios.

- Compilar bibliografías y guías de lectura.

- Ofrecer servicios de actualización.

En la nueva edición de estas pautas ${ }^{90}$, la IFLA continúa incluyendo la oferta informativa entre los servicios básicos a los usuarios:

${ }^{89}$ IFLA. Pautas para bibliotecas públicas. Madrid: Dirección General del Libro y Bibliotecas, 1988, p. 20-21. 
- servicios de información con medios impresos y electrónicos

- servicios de asesoramiento a los lectores

- servicios de información a la comunidad

Es posible establecer unas bases sobre qué metas debe cumplir el servicio de información de cualquier biblioteca, sea del tipo que sea. En resumen, un servicio de referencia debe partir de los siguientes objetivos:

1.- El servicio debe ser empleado por los usuarios, lo que se puede conseguir a través de sistemas publicitarios y de formación de usuarios. Para alcanzar este objetivo la biblioteca debe contar con espacios e infraestructuras adecuados y desarrollar sistemas sencillos para la recepción de las consultas.

2. Todas las consultas deben ser solucionadas satisfactoriamente, lo cual implica la posesión de una buena colección de referencia y el dominio de los sistemas de consulta de cada fuente de información. Además, será necesario desarrollar sistemas de acceso al documento cuando la información requerida no se encuentre en la colección propia.

3. La colección de consulta debe ser empleada directamente por los usuarios, por lo que será necesario organizar actividades específicas de formación de usuarios en el manejo de las obras de referencia y demás fuentes de información.

\subsection{Un servicio para los usuarios}

Los usuarios son uno de los elementos que determinan diferencias tipológicas entre las bibliotecas. Cada grupo de usuarios tiene sus necesidades informativas específicas, lo que implica una colección distinta y unos servicios bibliotecarios diferentes. Por este motivo, el servicio de referencia variará según las características particulares de los usuarios, estando la biblioteca obligada a adecuar su colección y sus servicios informativos según la tipología bibliotecaria.

Así, el servicio de información de las bibliotecas nacionales debe constituirse en un centro nacional de información bibliográfica, produciendo bases de datos, elaborando repertorios, catálogos y productos similares, tanto de sus fondos como de colecciones externas. El servicio de información de una biblioteca nacional debe poseer una colección especializada en la producción artística e intelectual nacional, ya que sus usuarios serán, en un alto porcentaje, investigadores.

En las bibliotecas universitarias el servicio de referencia deberá adecuarse a varios tipos de usuarios. En primer lugar al estudiante, que requerirá sus servicios para completar los contenidos de las asignaturas y para realizar los

90 IFLA/UNESCO. Directrices IFLA/UNESCO para el desarrollo de bibliotecas públicas. Madrid: Ministerio de Educación, Cultura y Deporte, 2001, p. 28. 
trabajos encomendados por los profesores. Para atender a este tipo de usuario el personal encargado de la referencia debe conocer la colección propia para orientar al usuario en el uso de las mismas. Otros tipos de usuarios de las bibliotecas universitarias son los docentes e investigadores, quienes no requieren información concreta sino información bibliográfica sobre sus campos de investigación o docencia. La adecuación en este caso será facilitar información propia y ajena y posibilitar el acceso a documentos externos.

Los servicios de información más variados se encuentran en las bibliotecas públicas. Este tipo de centros bibliotecarios atiende a usuarios de características muy distintas y de necesidades de información muy dispares. Por un parte, se encuentra el usuario en edad escolar, quien solicita información de utilidad para su formación. Por otra parte, están los estudiantes superiores, que requieren informaciones más elaboradas. Además, la biblioteca pública atiende a usuarios adultos que consultan informaciones de muy diferente tipología. Por ello, la colección de referencia y los servicios de información de una biblioteca pública deben ser muy variados, de carácter enciclopédico y genéricos. La IFLA recomienda que en bibliotecas que atiendan a poblaciones mayores de 5.000 habitantes la colección de referencia sea el $10 \%$ del total ${ }^{91}$.

En cuanto a las bibliotecas escolares, sus servicios de referencia deben apoyar la función educativa, de ahí que su colección se divida entre un $70 \%$ de obras de formación e información y un 30\% de obras de ficción ${ }^{92}$. En todo momento, la sección de referencia de las bibliotecas escolares se planteará desde una perspectiva pedagógica, como complemento de las enseñanzas recibidas en las aulas ${ }^{93}$. En muchos casos, el servicio de referencia participará también en la formación de los estudiantes, prestando sus instalaciones y fondos para la explicación de ciertos temas.

El servicio de referencia de las bibliotecas especiales apenas difiere del que se realiza en las bibliotecas públicas. En todo caso, la tipología de las informaciones requeridas estará en función de los usuarios concretos de cada biblioteca especial. En las bibliotecas de centros hospitalarios no es necesario destinar muchos fondos a la referencia, ya que los usuarios prefieren utilizar la colección de ocio. En otros tipos de bibliotecas, como son las bibliotecas de prisiones, la colección de referencia sí es importante, ya que estos centros desarrollan una actividad educativa y cultural, que debe verse apoyada por la biblioteca.

El servicio de referencia más exhaustivo se lleva a cabo en las bibliotecas especializadas. Dado el perfil de los usuarios y la función de suministro de

\footnotetext{
${ }^{91}$ IFLA. Pautas para bibliotecas públicas. Madrid: Dirección General del Libro y Bibliotecas, 1988.

92 Baró, M.; Mañá, T, Formarse para informarse. Madrid: Celeste, M.E.C., 1996. Este porcentaje se recoge asimismo en las Directrices IFLA/UNESCO para la biblioteca escolar, de 2002, disponibles en http://www.ifla.org/VII/s11/pubs/sguide02-s.pdf.

93 Torres Ramírez, Isabel de; Montes Montes, M. José. El servicio de referencia en la biblioteca escolar. Educación y biblioteca, feb. 1991, n. 14, p. 57-60.
} 
información de estas bibliotecas, será necesario disponer de múltiples servicios de información para atender las consultas y para facilitar documentación de interés antes de que ésta sea requerida. El personal de referencia de las bibliotecas especializadas debe dominar las fuentes de información sobre el campo temático de la biblioteca, ya que es habitual que las informaciones solicitadas por los usuarios no se encuentren en la propia biblioteca sino en colecciones externas. El responsable del servicio de información de bibliotecas especializadas deberá conocer qué fuentes existen en su disciplina, cuáles son las estrategias de consulta de cada recurso, dónde están los servicios de suministro de documentos más ágiles en su campo y cuáles son las bibliotecas o centros de orientación similar que puedan cooperar con las mismas.

\subsection{Tipología de los servicios de información}

Uno de los estudios de sistematización más completos acerca de los distintos servicios de información es el realizado por Bunge y Bopp ${ }^{94}$, cuyas teorías fueron resumidas por Magán ${ }^{95}$. Estos autores dividen los servicios de referencia en tres bloques: servicios de información, servicios de formación y servicios de orientación. En la siguiente tabla se reflejan las teorías de estos autores estadounidenses, empleando una traducción propia:

\begin{tabular}{|c|l|l|}
\hline Tipo de servicios & \multicolumn{1}{|c|}{ Descripción } & \multicolumn{1}{|c|}{ Ejemplos } \\
\hline Información & $\begin{array}{l}\text { Resuelven las consultas } \\
\text { de los usuarios }\end{array}$ & $\begin{array}{l}\text { Preguntas de respuesta } \\
\text { rápida, consultas } \\
\text { bibliográficas, obtención } \\
\text { de un documento }\end{array}$ \\
\hline Formación & $\begin{array}{l}\text { Tratan de educar al } \\
\text { usuario en el uso de la } \\
\text { biblioteca y de la } \\
\text { colección de referencia }\end{array}$ & Formación de usuarios \\
\hline Orientación & $\begin{array}{l}\text { Asesoran al usuario en la } \\
\text { elección de una obra o de } \\
\text { una fuente de información }\end{array}$ & $\begin{array}{l}\text { Actividades llevadas a } \\
\text { cabo por la biblioteca para } \\
\text { recomendar o dar a } \\
\text { conocer documentos }\end{array}$ \\
\hline
\end{tabular}

Fig. 1.2. Tipología de los servicios de referencia (Bunge; Bopp)

Una teoría coherente y bien argumentada sobre la tipología de los servicios de consulta bibliotecarios es la que defiende Bertrand Calenge ${ }^{96}$. El autor francés opina que los servicios de información en la biblioteca están

\footnotetext{
${ }^{94}$ Bunge, Charles A.; Bopp, Richard E. History and varieties of reference services. En Bopp, Richard E.; Smith, Linda C. (eds.). Reference and information: an introduction. $3^{\text {rd }}$ ed. Englewood: Libraries Unlimited, 2001, p. 3-27.

95 Magán Wals, José Antonio. Los servicios de información y referencia bibliográfica: situación actual y aprovechamiento de los recursos. En Tratado básico de biblioteconomía. $2^{a}$ ed. Madrid: Editorial Complutense, 1996, p. 343-366. Magán toma la referencia de la segunda edición: Bopp, Richard E. History and varieties of reference services. En Reference and information services: an introduction. $2^{\text {nd }}$ ed. Englewood: Libraries Unlimited, 1995, p. 3-35.

${ }_{96}$ Calenge, Bertrand. Accueillir, orienter, informer: I'organisation des services aux publics dans les biblioteques. Paris: Cercle de la Librairie, 1996.
} 
relacionados con las actividades desarrolladas para acoger al usuario y por las iniciativas que se plantean para orientarle en el espacio, en las técnicas bibliotecarias y en el uso de la colección. Acoger, orientar e informar son los tres pilares de los servicios al público en las bibliotecas según este autor. Para él, la concepción habitual de los servicios de información no es válida, por lo que relaciona la información al usuario, con la recepción y la orientación en la biblioteca. Probablemente por expresar sus argumentos en una lengua diferente de la inglesa las teorías de Calenge no han sido excesivamente recogidas por los teóricos. Se quiere dejar constancia del valor de la monografía de este reputado bibliotecario francés, de la solidez de su enfoque y del práctico desarrollo que hace de las diferentes tipologías de servicios informativos bibliotecarios.

Teniendo en cuenta éstas y otras aportaciones de los diferentes teóricos que han expuesto su categorización de los servicios de consulta, es posible agrupar lo distintos servicios de información que se desarrollan en las bibliotecas en virtud de factores diversos. Una propuesta de sistematización de las distintas formas en las que se traduce la información al usuario es la siguiente:

\begin{tabular}{|l|l|}
\hline Servicio de información & Descripción \\
\hline Consultas de respuesta rápida & $\begin{array}{l}\text { Resolución de cuestiones sencillas } \\
\text { utilizando obras de consulta de/desde la } \\
\text { biblioteca }\end{array}$ \\
\hline Consultas bibliográficas & $\begin{array}{l}\text { Elaboración de repertorios bibliográficos } \\
\text { sobre temas específicos y } \\
\text { comprobaciones bibliográficas }\end{array}$ \\
\hline Acceso al documento & $\begin{array}{l}\text { Préstamo interbibliotecario, } \\
\text { fotodocumentación, envío electrónico, etc. }\end{array}$ \\
\hline Información sobre novedades & $\begin{array}{l}\text { Boletines informativos, de adquisiciones, } \\
\text { novedades editoriales, etc. }\end{array}$ \\
\hline $\begin{array}{l}\text { Difusión Selectiva de la } \\
\text { Información }\end{array}$ & $\begin{array}{l}\text { Entrega de información sobre novedades } \\
\text { según los temas elegidos por los usuarios }\end{array}$ \\
\hline $\begin{array}{l}\text { Orientación bibliográfica y } \\
\text { documental }\end{array}$ & $\begin{array}{l}\text { Guías de lectura, selecciones de } \\
\text { documentos, asesoramiento bibliográfico, } \\
\text { etc. }\end{array}$ \\
\hline Asesoramiento técnico & $\begin{array}{l}\text { Preparación de informes y recopilación de } \\
\text { información sobre un tema }\end{array}$ \\
\hline Alfabetización informacional & $\begin{array}{l}\text { Formación de usuarios en el uso del } \\
\text { servicio, de la colección, etc. }\end{array}$ \\
\hline
\end{tabular}

Fig. 1.3. Tipología de los servicios de referencia (Merlo Vega)

La existencia de los anteriores tipos de servicios de información puede constarse en cualquier servicio de referencia. Por ejemplo, si se toma como ejemplo la base de datos de preguntas y respuestas de «Pregunte: las bibliotecas responden» sería posible localizar cuestiones planteadas en línea que se corresponden con los tipos anteriormente expuestos. Igualmente, se localizarían ejemplos de cada grupo en los servicios de referencia que tienen abiertas su base de datos de cuestiones satisfechas, como ocurre con la red global de Question Point o los servicios públicos de Finlandia o Gales, por 
ejemplo. A continuación, se muestran algunos ejemplos de preguntas que se corresponden con los grupos que se han descrito en párrafos anteriores.

Consultas de respuesta rápida:

- Preguntas sobre el intérprete de la versión de la canción "La Ilorona" que aparece en la banda sonora de la película Frida.

- Teléfono de la estación de autobuses de Salamanca.

Consultas bibliográficas:

- Año en que se publicó la primera edición de "Cien años de soledad".

- Traducciones de obras poéticas de Ben Clark.

Acceso al documento:

- Localización del artículo "Web social y educación” publicado en la revista Educación y biblioteca en octubre de 2007.

- El presidente de una comunidad de vecinos pide una copia de Ley de Propiedad Horizontal.

Información sobre novedades:

- Un usuario pregunta por las últimas novelas compradas por la biblioteca.

- Un usuario pregunta si se ha adquirido el último premio Nadal.

Difusión Selectiva de la Información:

- Un opositor a cuerpos del Ministerio de Hacienda necesita información periódica sobre legislación tributaria.

- Un profesor de filología requiere bibliografía actualizada de forma constante sobre didáctica del español como lengua extranjera.

Orientación bibliográfica y documental:

- Un estudiante de Psicología pregunta por títulos sobre trastornos emocionales.

- Un usuario solicita ayuda para localizar películas de directores del movimiento Dogma.

Asesoramiento técnico:

- Un empresario quiere abrir una papelería en una nueva zona residencial y necesita datos estadísticos sobre la población.

- Un representante sindical solicita información sobre condicionales laborales en países de la Unión Europea para una negociación.

Alfabetización informacional:

- Preguntas sobre el manejo del catálogo automatizado

- Consultas sobre recuperación avanzada en buscadores 


\section{Organización del servicio de referencia}

Los servicios de referencia -presenciales o telemáticos- deben contemplar una serie de elementos en su planificación y gestión para un correcto desarrollo de los mismos. En los apartados que se incluyen en esta sección se analizarán las competencias de los profesionales referencistas, así como los espacios que deben ocupar los servicios de consulta en las bibliotecas. Además, se describirán los instrumentos necesarios para que el personal dedicado a esta sección pueda desempeñar su trabajo con calidad y eficiencia. Por último, en este bloque se estudian también elementos relativos a la alfabetización informacional en relación a los servicios de referencia, basados en la formación de usuarios en el uso de la colección informativa y en la instrucción en el manejo de los recursos electrónicos, catálogos y otras fuentes de información empleadas por la biblioteca.

\subsection{Perfil profesional del referencista}

Dadas las características de los servicios de información de una biblioteca, es necesario que éstos estén atendidos por profesionales especializados en la atención y resolución de las demandas de información. Por ello, es más aconsejable que los servicios de referencia estén gestionados por personal específico, que se encargue de formar y mantener la colección de referencia, recibir las consultas, resolverlas y desarrollar los instrumentos que se consideren necesarios para informar a los usuarios. El personal referencista debe reunir una serie de características, como ser una persona con formación biblioteconómica, puesto que es necesario que se conozcan las técnicas y servicios bibliotecarios para informar adecuadamente sobre el uso de la biblioteca, los productos bibliotecarios y la colección, así como ser un profesional conocedor de la colección propia, tanto del fondo de referencia como del general, para saber donde encontrar la información buscada. Por otra parte, un bibliotecario referencista deberá estar informado de las fuentes de referencia externas, para obtener datos que no puedan extraerse de la colección de la biblioteca.

Es importante que los encargados de los servicios informativos de las bibliotecas $^{97}$ tengan capacidad de análisis y síntesis, para delimitar las consultas de los usuarios y para que las respuestas se ajusten a las preguntas; además deben ser expertos en los sistemas de búsqueda y acceso a la información de las distintas fuentes empleadas para la referencia, para conseguir las respuestas pertinentes en el menor tiempo posible. Esto obliga a la familiarización con las nuevas tecnologías, para utilizar las fuentes de referencia electrónicas, para emplear procedimientos

\footnotetext{
${ }^{97}$ Simmonds analiza las formas más comunes de organización interna de los servicios de referencia y establece las responsabilidades de los coordinadores de estos departamentos. Véase Simmonds, Patience L. The 21st Century Reference Department: Working to Provide Quality: Service to Users. The Reference Librarian, 2003, vol. 39, n. 81, p. 89-103.
} 
de información automatizados y para elaborar información electrónica (bases de datos, repertorios hipertextuales, herramientas de la web social, etc.).

Un buen referencista debe conocer las necesidades informativas de los usuarios, a fin de poder elaborar bibliografías, guías, etc., con temas e informaciones de interés; además, debe ser activo, ya que será necesario desarrollar métodos de información adecuados a los usuarios: correo electrónico, actualización bibliográfica, bitácoras, etc.

Como características personales, es necesario que se demuestre objetividad, para utilizar todas las fuentes de información disponibles y responder verazmente a las consultas sin omisiones ni errores deliberados; otro requisito es un nivel cultural medio/alto, que permita poder atender y satisfacer todas las demandas de información que reciba el servicio. Por último, se requiere una personalidad afable, que posibilite relacionarse con usuarios de cualquier tipo. Para Gorman ${ }^{98}$, el referencista debe cumplir una serie de valores: administración, servicio, libertad intelectual, racionalismo, alfabetización y aprendizaje, igualdad de acceso, privacidad y democracia. De manera similar se expresan Hirko y Ross ${ }^{99}$, quienes tras realizar un estudio para la formación de los bibliotecarios del servicio de referencia digital de Washington, establecen catorce competencias básicas de los profesionales de los servicios digitales de referencia.

Mary M. Nofsinger ofreció en $1999^{100}$ una visión muy acertada de las competencias del personal referencista en el siglo XXI. Para esta autora, la formación de los bibliotecarios referencistas debe estar en constante desarrollo, debido sobre todo a los avances tecnológicos ${ }^{101}$. Ella divide las nuevas competencias en varios grupos: habilidades para la referencia y conocimiento de esta materia, comunicación y habilidades interpersonales, destrezas tecnológicas, habilidades para el análisis y el pensamiento crítico, así como destrezas para la gestión y la supervisión. También es importante la visión de $\mathrm{Osa}^{102}$, quien establece una serie de competencias para los directivos de los actuales servicios de referencia, ya que los constantes cambios en los servicios de información requieren profesionales activos que sepan adaptarse a las nuevas circunstancias y organizar los equipos necesarios para la prestación de estos servicios en entornos digitales.

\footnotetext{
${ }^{98}$ Gorman, Michael. Values for human-to-human reference. Library trends, 2001, vol. 50, n. 2, p. 168-182.

${ }^{99}$ Hirko, Buff; Ross, Mary Bucher. Virtual reference training: the complete guide to providing anytime, anywhere answers. Chicago: American Library Association, 2004. 10-11.

100 Nofsinger, Mary M. Training and Retraining Reference Professionals: Core Competencies for the 21st Century. The Reference Librarian, 1999, no. 64, p. 9-19. También publicado en Zlatos, Christy (ed.). Coming of Age in Reference Services: A Case History of the Washington State University Libraries. New York: The Haworth Press, Inc., 1999, p. 919.

${ }^{101}$ Kupersmith introduce el concepto de tecnoestrés en la profesión del referencista, enfermedad producida por las tecnologías y caracterizada por la ansiedad del servicio, el exceso de información, las situaciones conflictivas y motivos organizacionales. Véase Kupersmith, John. Technostress and the reference librarian. Reference Services Review, 1992, vol. 20, n. 2, p. 7-14,50.

${ }_{102}$ Osa, Justina O. Managing the 21st Century Reference Department: Competencies. The Reference Librarian, 2003, vol. 39, n. 81, p. 33-50.
} 
Los servicios de referencia están siguiendo modelos muy diversos, en función de las políticas generales que planteen las bibliotecas, así como a partir de las políticas concretas de información que persigan. Una buena sistematización de los modelos aplicados en los servicios de referencia es la que aportan Cassel e Hiremath ${ }^{103}$ en su excelente manual de 2006 sobre los servicios de información y referencia en el siglo XXI. En la siguiente tabla se describen los modelos de organización de los servicios de referencia en las bibliotecas, con especial atención a los aspectos relativos al personal que los atiende, indicando sus pros y contras, según los criterios de las autoras.

\begin{tabular}{|c|c|c|c|}
\hline Tipo & Descripción & Pros & Contras \\
\hline $\begin{array}{l}\text { Mostrador de } \\
\text { referencia tradicional }\end{array}$ & $\begin{array}{l}\text { El bibliotecario sirve } \\
\text { al usuario desde el } \\
\text { mostrador de } \\
\text { referencia }\end{array}$ & $\begin{array}{l}\text { Fácil para el } \\
\text { personal: un punto } \\
\text { de servicio }\end{array}$ & $\begin{array}{l}\text { Sólo sirve a los } \\
\text { usuarios que van al } \\
\text { mostrador }\end{array}$ \\
\hline $\begin{array}{l}\text { Modelo de } \\
\text { referencia de } \\
\text { consulta }\end{array}$ & $\begin{array}{l}\text { Las preguntas } \\
\text { complejas son } \\
\text { remitidas al servicio } \\
\text { de consulta }\end{array}$ & $\begin{array}{l}\text { Utiliza bibliotecarios } \\
\text { para las cuestiones } \\
\text { complejas }\end{array}$ & $\begin{array}{l}\text { Limita el número de } \\
\text { usuarios a los que } \\
\text { puede servir }\end{array}$ \\
\hline $\begin{array}{l}\text { Servicio de } \\
\text { referencia por } \\
\text { niveles }\end{array}$ & $\begin{array}{l}\text { Tres niveles de } \\
\text { servicio: mostrador } \\
\text { de información, } \\
\text { mostrador de } \\
\text { referencia general y } \\
\text { servicios de consulta }\end{array}$ & $\begin{array}{l}\text { Utiliza bibliotecarios } \\
\text { para las cuestiones } \\
\text { complejas }\end{array}$ & $\begin{array}{l}\text { Debe preparar al } \\
\text { personal para remitir } \\
\text { adecuadamente y } \\
\text { limita el número de } \\
\text { usuarios a los que } \\
\text { puede servir }\end{array}$ \\
\hline Equipo de personal & $\begin{array}{l}\text { Trabajo bibliotecario } \\
\text { y paraprofesional } \\
\text { juntos en el } \\
\text { mostrador de } \\
\text { referencia }\end{array}$ & $\begin{array}{l}\text { El bibliotecario está } \\
\text { disponible para } \\
\text { constestar preguntas } \\
\text { más difíciles }\end{array}$ & $\begin{array}{l}\text { Los trabajadores } \\
\text { paraprofesionales } \\
\text { pueden remitir } \\
\text { adecuadamente al } \\
\text { bibliotecario }\end{array}$ \\
\hline $\begin{array}{l}\text { Concepto de punto } \\
\text { de servicio integrado }\end{array}$ & $\begin{array}{l}\text { Integración de los } \\
\text { mostradores de } \\
\text { referencia y } \\
\text { circulación }\end{array}$ & $\begin{array}{l}\text { Un punto único para } \\
\text { atender a los } \\
\text { usuarios }\end{array}$ & $\begin{array}{l}\text { Requiere formación } \\
\text { continua del } \\
\text { personal }\end{array}$ \\
\hline Itinerancia & $\begin{array}{l}\text { Los bibliotecarios se } \\
\text { mueven por todas } \\
\text { las secciones del } \\
\text { área de referencia }\end{array}$ & $\begin{array}{l}\text { Se alcanza a } \\
\text { usuarios que no se } \\
\text { acercan al } \\
\text { mostrador de } \\
\text { referencia }\end{array}$ & $\begin{array}{l}\text { Requiere personal } \\
\text { adicional }\end{array}$ \\
\hline Referencia virtual & $\begin{array}{l}\text { Los bibliotecarios } \\
\text { responden } \\
\text { cuestiones por } \\
\text { correo electrónico y } \\
\text { chat }\end{array}$ & $\begin{array}{l}\text { Usuarios ayudados } \\
\text { sin visitar la } \\
\text { biblioteca }\end{array}$ & $\begin{array}{l}\text { Tecnología lenta y } \\
\text { muy fría para } \\
\text { comunicarse con los } \\
\text { usuarios }\end{array}$ \\
\hline $\begin{array}{l}\text { Modelo de alcance } \\
\text { externo }\end{array}$ & $\begin{array}{l}\text { Los bibliotecarios } \\
\text { salen de sus } \\
\text { departamentos, } \\
\text { grupos y } \\
\text { organizaciones }\end{array}$ & $\begin{array}{l}\text { Se puede llegar a } \\
\text { nuevos destinatarios }\end{array}$ & $\begin{array}{l}\text { Requiere personal } \\
\text { adicional }\end{array}$ \\
\hline
\end{tabular}

Fig. 1.4. Modelos de los servicios de referencia (Cassel; Hiremath)

${ }^{103}$ Cassell, Kay Ann; Hiremath, Uma. Reference and information services in the 21st century: an introduction. London: Facet, 2006, 340. 


\subsection{El entorno espacial en los servicios de referencia}

El diseño de un servicio de referencia requiere delimitar claramente tres aspectos: localización, condiciones físicas y equipamiento. Los servicios de información de la biblioteca deben contar con un espacio específico para la sección de referencia. Este espacio debe estar bien señalizado y fácilmente localizable, por lo que se aconseja su ubicación cerca de la entrada principal de la biblioteca, así como de los catálogos y de la colección de referencia. La biblioteca debe tener un lugar para atender al usuario. Este punto se denomina mostrador de referencia y deberá estar diseñado para que albergue de manera cómoda todo el equipamiento necesario para el funcionamiento de esta sección: mesas, sillas, ordenadores, etc. Por lo general, se opta por un mostrador para recibir las consultas rápidas y por una mesa con sus correspondientes sillas para recoger las preguntas más complejas, como las búsquedas bibliográficas.

Dadas las características de este servicio el espacio tendrá dos zonas con su respectivo equipamiento: la zona de atención al usuario, en la que se encuentra el mostrador de referencia y la zona de trabajo del personal, en la cual estará el mobiliario y los documentos utilizados por los bibliotecarios referencistas cuando no estén atendiendo al público. Este carácter mixto deberá ser tenido en cuenta por los arquitectos y diseñadores, dadas las particulares condiciones de comodidad, iluminación, temperatura, etc. Dependiendo de cómo esté orientado el servicio de referencia los espacios pueden estar unidos o ser independientes. Si la biblioteca considera oportuno separar la sección de atención al usuario de la unidad de información entonces habrá que situar un mostrador a la entrada, desde el cual se orientará al usuario sobre los requisitos para utilizar la biblioteca, sus secciones, servicios, etc. En este caso la sección de información podría ubicarse en otra parte de la biblioteca, a ser posible alejada de las sección de lectura en sala. El motivo es que la sección de referencia genera mucho tráfico, ya que los usuarios necesitan utilizar documentación constantemente y recibir indicaciones del personal referencista.

La colección de referencia estará dentro de esta sección o muy cerca de ella. Es importante que este fondo sea de libre acceso, para que los usuarios la utilicen de manera independiente según sus necesidades. De igual manera, es aconsejable que los terminales de consulta a los catálogos, a las fuentes de información en cederrón y en línea también sean de libre acceso, aunque, debido a las características de los equipos necesarios para su uso, es conveniente llevar un control de los ordenadores u otros equipos empleados en esta sección.

Una parte de la colección de referencia deberá ser custodiada por el personal bibliotecario: fondo antiguo, ejemplares raros, literatura gris, folletos, etc. La causa de que estos documentos no sean de libre acceso es protegerlos de un eventual deterioro o daño que pudieran ocasionar su pérdida definitiva. La digitalización de este tipo de documentos y su correspondiente acceso telemático son la solución correcta para poder ofrecer libremente estas colecciones. 


\subsection{Instrumentos para la prestación del servicio de referencia}

Para que el servicio de referencia pueda cumplir sus objetivos es necesario que la biblioteca disponga de determinados instrumentos, tanto para el trabajo interno como para la recogida de consultas, la resolución de las mismas y su posterior entrega.

En cuanto al trabajo interno el número de herramientas dependerá de la especialización del servicio. Un equipamiento completo estará formado por:

- instrumentos de comunicación (teléfono, fax, correo electrónico)

- instrumentos de consulta (colección profesional y de referencia)

- instrumentos de difusión (digitalización, correo electrónico).

Por lo que respecta a los instrumentos necesarios para la atención al usuario, las herramientas más comunes son los formularios de toma de datos, en los cuales se consignarán las informaciones necesarias para que todos los aspectos de la consulta queden recogidos.

Generalmente, las preguntas de respuesta rápida no requieren ningún tipo de formulario, a no ser que se quiera llevar una estadística. El usuario formula su pregunta y el bibliotecario referencista la contesta. Sin embargo, este procedimiento es fundamental en las consultas bibliográficas, ya que es el mejor sistema para delimitar la demanda y poder resolverla correctamente.

Este tipo de formularios recogen los siguientes datos:

- Identificación del usuario: por si es necesario ponerse en contacto con el mismo para aclarar algún aspecto de la consulta o para cualquier otra cuestión

- Datos temáticos: tema principal de la consulta y aspectos relacionados

- Datos económicos: en el caso de que el servicio no sea gratuito será necesario indicar la forma de pago, número de cuenta, datos fiscales, etc.

- Datos complementarios: límites cronológicos, idiomas, número de referencias, aspectos que no interesan, etc.

Lógicamente, el instrumento fundamental en el servicio de referencia será la colección de referencia, concepto muy amplio que reúne a todas las fuentes de información que se empleen para responder las consultas de los usuarios. La colección de consulta será un tema tratado de forma específica en el apartado sexto de esta misma sección de la tesis doctoral. 


\subsection{Formación de usuarios y servicios de referencia}

El fin último de toda biblioteca es que su colección se utilice. Para alcanzar este objetivo es necesario que los usuarios conozcan la oferta de servicios y la organización de la biblioteca. Por ello, se deben desarrollar acciones de alfabetización informacional ${ }^{104}$; en primer lugar, se plantearán sistemas para informar a los usuarios sobre la propia biblioteca, tanto sobre sus características generales, como sobre sus servicios concretos. Además se organizarán otras actividades para informar acerca de servicios y colecciones específicas.

Todas las iniciativas que lleve a cabo la biblioteca para dar a conocer sus departamentos, su colección, sus instalaciones, etc., se engloban dentro de la denominada formación de usuarios, que puede plantearse de manera genérica, para dar a conocer la biblioteca: servicios, colección, etc. en sentido amplio. Las actividades más comunes de formación de usuarios desde esta perspectiva son:

- Folletos informativos: en los cuales se explicará los aspectos generales de la biblioteca: condiciones de acceso, localización, horarios, servicios, reglamentos, etc.

- Folletos específicos: para las distintas secciones o servicios: préstamos, colección local, información y referencia, fonoteca, etc., donde se expliquen los principales datos de las secciones o servicios.

- Visitas guiadas a la biblioteca: para conocer la disposición, los servicios y cualquier tema de interés para los usuarios.

- Vídeos: donde se expliquen los aspectos más interesantes de la biblioteca.

- Cursos de formación de usuarios: organización de cursos breves en los que se explique la organización de la biblioteca, las técnicas bibliotecarias, el uso de la colección, los servicios, etc.

- Campañas publicitarias: uso de técnicas de marketing: carteles, anuncios publicitarios, aparición en la prensa y medios de comunicación, etc.

De la misma manera, la formación de usuarios se plantea para objetivos más concretos, como son el uso de determinados servicios o colecciones bibliotecarias. En este caso, se desarrollan actividades como las siguientes:

- Guías de la sección o servicio: donde se explique con detalle todo lo relativo a ese departamento: usuarios, normativa, colección, horarios, etc.

\footnotetext{
${ }^{104}$ La importancia de la alfabetización informacional en los servicios de referencia es desarrollada por Rader. Véase Rader, Hannelore B. Information literacy in the reference environment: preparing for the future. The Reference Librarian, 2000, n. 71, p. 25-33. Esta autora realiza una recopilación de experiencias donde los servicios de referencia incluyen la instrucción dentro de su actividad.
} 
- Guías de uso de los productos bibliotecarios: catálogos, bases de datos propias, etc.

- Tutoriales de determinados documentos y recursos: obras de referencia, CD-ROM, Internet, etc.

- Boletines bibliográficos y guías de lectura: selecciones temáticas de obras extraídas de la colección, ofreciendo su referencia, localización y breves comentarios.

- Boletines de adquisiciones: recoger los fondos que se han incorporado recientemente para darlos a conocer.

- Selecciones de obras: ofrecer críticas de obras recomendadas, sobre todo de novedades editoriales, a fin de que los usuarios las conozcan y utilicen.

- Exposición de novedades: disponer en un expositor las últimas obras incorporadas al fondo.

- Exposiciones bibliográficas: extraer de las estanterías obras con una característica común (autor, tema, lengua, etc.) para difundirlas.

- Cursos especializados de formación de usuarios: aprendizaje de aspectos concretos: uso de obras de referencia, catálogos, manejo de herramientas automatizadas, etc.

- Dinamizaciones: animaciones a la lectura, organización de actividades en torno a una obra concreta.

- Extensión bibliotecaria: organización de actividades diversas: presentaciones de libros, encuentros con el autor, proyecciones, representaciones teatrales, etc. Todas ellas encaminadas a dar a conocer la colección de la biblioteca.

Estas actividades específicas de formación de usuarios pueden aplicarse al servicio de referencia e información bibliográfica. En concreto, las actividades de formación de usuarios más útiles y las más empleadas en el servicio de referencia son los folletos explicativos del servicio, las guías de uso de las herramientas bibliotecarias (catálogos, sistemas automatizados), los tutoriales de uso de fuentes de información, los boletines bibliográficos, guías de lectura y recomendaciones de documentos. No obstante, cualquiera de las actividades anteriores puede ser llevada a cabo por el servicio de referencia para difundir su colección y potenciar el uso de la misma.

En muchas ocasiones las actividades de formación de usuarios sirven, no sólo para difundir los fondos y servicios, sino también para mejorarlos, ya que se da la oportunidad al usuario para que opine sobre cualquier cuestión que afecte a la biblioteca. Por ello, es conveniente desarrollar sistemas de 
recepción de sugerencias, a fin de adaptar la biblioteca a las necesidades de los usuarios en cuanto a la disposición de las colecciones, la adquisición de obras, las normativas, la organización de actividades de formación, etc. La realización de actividades de formación de usuarios debe plantearse de manera organizada, especificándose una serie de aspectos:

- Finalidad de la actividad: qué se pretende conseguir

- Usuarios: a quién va dirigida

- Circunstancias: aspectos que influirán en la actividad (medios, tiempo, número de personas, nivel académico, etc.)

- Actividades: acciones que se llevarán a cabo a partir de los criterios anteriores

Es aconsejable informarse de qué actividades de formación de usuarios se han realizado en otras bibliotecas, para tomarlas como ejemplo o imitarlas. En Biblioteconomía es lícito, recomendable y útil basarse en las experiencias positivas realizadas en otros centros para ser puestas en práctica de nuevo en otras bibliotecas. Por lo general, si una actividad de formación de usuarios, en particular, o un plan de alfabetización informacional, en general, han tenido éxito en una biblioteca, puede asegurarse que, en condiciones similares, tendrá también buenos resultado en centros parecidos. Las buenas prácticas son modelos que se deben aplicar en bibliotecas que tengan espacios, colecciones, servicios y usuarios similares. 


\section{Las demandas de información}

Las consultas son la esencia del servicio de referencia. Las preguntas que los usuarios plantean al servicio de referencia son muy variadas en cuanto a su temática, motivación, nivel de profundidad, sencillez en la respuesta, etc. Los servicios presenciales y los telemáticos reciben cuestiones muy similares. En los subapartados de este cuarto capítulo se analizan los tipos de demanda de información, a partir de las sistematizaciones realizadas por los principales teóricos, además de incluir una clasificación propia que sirve para sistematizar todo tipo de consultas. Así, tal y como se desarrolla en este apartado, en un servicio bibliotecario de referencia se recibirán preguntas de información general, sobre todo relativas a la biblioteca y a los recursos de información, además de preguntas de respuesta rápida, que son en sentido estricto las que se responden con contestaciones concretas y delimitadas. Además, se expone un tercer tipo de preguntas, las bibliográficas, que tienen el denominador común de que la respuesta esperada está compuesta de documentos, ya sean a texto completo o referencias bibliográficas. En esta sección de la tesis doctoral, se exponen los tipos de demandas de información, a las que se acompaña de ejemplos reales extraídos de diferentes servicios de referencia digital.

\subsection{Tipología de las demandas de información}

Las preguntas que los usuarios realizan en el servicio de referencia pueden ser de tipos muy diversos. Distintos autores han establecido categorías de demandas de información planteadas en las bibliotecas.

Para Josefa E. Sabor ${ }^{105}$ "las preguntas que el público formula son, en esencia, de seis clases:

1. Sobre condiciones de admisión en la biblioteca, préstamo, uso de formularios, (...) y, en general, la conducta a seguir y la manera de formular con corrección las demandas

2. Sobre el manejo de los catálogos

3. Sobre el uso de las materiales bibliográficos

4. Sobre datos concretos que necesita conocer, pertenecientes a las más diversas materias

5. Sobre lecturas que debe o quiere realizar, sean para el estudio de un tema de su interés, para el aumento de sus conocimientos, o de carácter formativo y recreativo

\footnotetext{
${ }^{105}$ Sabor, J..A. Servicio de referencia. En Manual de bibliotecología. $2^{\mathrm{a}}$ ed. México D.F.: Kapelusz, 1984, p. 191.
} 
6. Sobre la forma de realizar tareas intelectuales: búsqueda de datos, investigaciones o tareas bibliográficas"

Otros autores, como Bunge y Bopp ${ }^{106}$, reúnen las distintas demandas planteadas por los usuarios en tres grupos:

a) información: el usuario pregunta al personal referencista cuestiones variadas con la intención de obtener una información. Las preguntas pueden ser: de respuesta rápida, consultas bibliográficas, solicitudes de préstamo interbibliotecario, servicios de información de entidades, preguntas de investigación, servicios de pago e información comercial.

b) orientación: recomendación de obras, biblioterapia, informes y asesoramiento documental, difusión selectiva de la información.

c) instrucción: formación individual, formación en grupos.

Otra tipología de las demandas que se plantean en un servicio de referencia es la que propone Grogan ${ }^{107}$ :

- Preguntas administrativas y de orientación: se trataría de cuestiones sobre la propia biblioteca, como el horario, el uso de determinados servicios, la localización de las secciones, etc.

- Preguntas de autor/título: los usuarios preguntan por si una determinada obra está en la biblioteca.

- Preguntas factuales: el usuario necesita conocer un dato o un hecho.

- Preguntas sobre determinadas materias: la consulta se centra en qué documentos posee la biblioteca sobre un tema de interés para el usuario.

- Preguntas mutables: se denominan así las cuestiones planteadas cuando el usuario no sabe exactamente lo que necesita, por lo que la pregunta irá transformándose o delimitándose a medida que el personal ofrezca documentos o respuestas.

- Preguntas de investigación: demandas especializadas que requieren una búsqueda exhaustiva para poder ser resueltas convenientemente.

- Otras preguntas: preguntas inconsistentes, ilógicas, absurdas, etc. Los usuarios pueden plantear preguntas a las cuales es imposible responder, aún contando con una buena colección de referencia, ya

${ }^{106}$ Bunge, Charles A.; Bopp, Richard E. History and varieties of reference services. En Bopp, Richard E.; Smith, Linda C. (eds.). Reference and information: an introduction. $3^{\text {rd }}$ ed. Englewood: Libraries Unlimited, 2001, p. 3-27.

${ }^{107}$ Grogan, D. Practical reference work. $2^{\text {nd }}$ ed. London: Library Association, 1992, p. 36-49. 
sea por el contenido de la consulta o porque la pregunta no tiene una respuesta sencilla.

- Preguntas sin respuesta: a pesar de que el servicio de referencia debe intentar contestar a todas las consultas que se formulen a veces no es posible resolverlas, ya sea por el carácter de la propia pregunta o porque no se poseen fuentes de información para responderlas.

Todas las teorías anteriormente expuestas se refieren a consultas muy parecidas, variando únicamente la sistematización de los tipos de preguntas que cada autor menciona. Se puede añadir una clasificación más actual, orientada específicamente a las preguntas que reciben los servicios de referencia digital. Fue establecida por Charles R. McClure y otros en su manual de evaluación de los servicios electrónicos de referencia ${ }^{108}$. Divide en las siguientes categorías los tipos de preguntas que se reciben en un servicio de referencia digital ${ }^{109}$.

Bibliográficas: preguntas relacionadas con cualquier aspecto sobre el autor o publicación de un trabajo. Puede incluir la verificación de una cita, nombres de autores, información sobre series, sobre una edición, copyright, etc.

De instrucción: se trata de las cuestiones que se reciben para ayudar a usar recursos electrónicos, para usarlos o para encontrar la respuesta a una pregunta de referencia. Algunos ejemplos podrían ser aprender a buscar en una base de datos de publicaciones periódicas, emplear el OPAC, cómo pedir materiales localizados en el catálogo, cómo limitar búsquedas en un motor concreto, cómo emplear la lógica booleana, etc.

Búsquedas bibliográficas: consultas sobre publicaciones sobre un tema o de un autor. Puede ser limitada a un periodo, fecha, etc.

Otras: preguntas que son válidas y que pueden ser atendidas por el servicio, pero que no se pueden clasificar en las diferentes categorías.

Fuera de ámbito: preguntas que no se contestan porque no se ajustan a los criterios del servicio. A menudo son derivadas a otros servicios.

\footnotetext{
${ }^{108}$ Mac Clure, Charles R.; Lankes, R. David; Gross, Melissa; Choltco-Devlin, Beverly. Statistics, Measures and Quality Standards for Assessing Digital Reference Library Services: Guidelines and Procedures. Syracuse, New York: Information Institute of Syracuse; Tallahassee, Florida: School of Information Studies, 2002, p. 24-25.

${ }^{109}$ La relación que se ofrece aquí se presenta en el mismo orden que en su fuente original, organizada alfabéticamente a partir del nombre de las categorías en inglés. Esta clasificación se empleará en la sección específica de la tesis en la que se analiza la evaluación, como uno de los documentos con estándares aplicables para evaluar servicios de referencia, aunque más adelante se variará el orden, para disponer en último lugar las categorías menos importantes.
} 
Asesoramiento bibliográfico: consejos acerca de recursos que pueden ser útiles al usuario. A menudo consisten en sugerir otros títulos similares a uno ya conocido o leído, otros libros de una misma colección, disponibilidad de una publicación en diferentes formatos, obras en una lengua determinada 0 información sobre los contenidos de un libro determinado.

Referencia rápida: preguntas con una respuesta sencilla y concreta. Es el tipo de preguntas que se responden con almanaques, enciclopedias, directorios, atlas, tesauros y anuarios de estados del mundo. Muchos servicios de referencia atienden únicamente este tipo de cuestiones.

Búsquedas temáticas: investigaciones bibliográficas solicitadas por un usuario sobre un tema concreto. Este tipo de búsquedas requiere localizar información en fuentes muy diversas: publicaciones periódicas, libros, citas, ensayos, estadísticas, datos en bruto, etc. Asimismo, las respuestas serán de formatos diversos: correos electrónicos, textos completos de artículos, citas. sitios web, documentos, presentaciones, imágenes, vídeos, etc.

Consultas técnicas: son preguntas relacionadas con la tecnología que permite emplear el servicio de referencia digital $u$ otros aspectos acerca del acceso al sitio web de la biblioteca.

La biblioteca de la Penn State University realizó un estudio ${ }^{110}$ sobre el tipo de demandas de información que recibía, ya fuera de forma presencial o bien a través de medios electrónicos. Para esta evaluación dividió los tipos de consultas en diferentes grupos, que son los que se exponen a continuación:

¿Dónde está? Ayuda en la localización de un servicio, instalaciones, personas o recursos dentro de la biblioteca; puede requerir el uso de recursos electrónicos. Algunos ejemplos: ¿me puede prestar una grapadora?, ¿dónde está el servicio más cercano?, tengo que ver a esta persona ¿dónde la puedo encontrar?, he recibido este aviso ¿dónde tengo que ir?

Políticas y procedimientos. Explicaciones sobre los servicios disponibles en la biblioteca. Ejemplos de este tipo son: ¿cómo examino un libro?, ¿puedo pedir libros prestado aunque hace tiempo que me terminé mis estudios?, recibí un aviso de demora en un préstamo, pero ya lo devolví, ¿cómo puedo reservar un artículo?

Solución de problemas y equipamiento. Demandas de ayuda para usar un equipo o resolver problemas con el mismo o bien con un recurso en red. Como ejemplos de preguntas de este tipo estarían: se

${ }^{110}$ Fennewald, Joseph. Same Questions, Different Venue: An Analysis of In-Person and Online Questions. The Reference Librarian, 2006, no. 95/96, 2006, p. 21-35. 
ha atascado la fotocopiadora, no puedo copiar estos archivos en un disco, ¿se puede imprimir a doble cara?

Consulta. Preguntas que requieren conocimientos de las colecciones de la biblioteca o de sus servicios, especialización temática o de otro tipo. El tipo de preguntas pueden variar desde búsquedas básicas en el catálogo a necesidades más complejas que requieren desarrollar estrategias de búsquedas. Ejemplos: ¿cómo puedo acceder al catálogos desde casa?, ¿cómo encuentro un vídeo en el catálogo?, ¿tienen algún libro escrito por $X X$ ?, estoy realizando un trabajo sobre XX y necesito bibliografía sobre el tema, voy a realizar mi tesis y quiero información preliminar sobre XX.

En el caso de esta biblioteca, la distribución de las preguntas presenciales, por correo electrónico o mediante su sistema web de recogida de preguntas fue la siguiente ${ }^{111}$ :

\begin{tabular}{|l|c|c|c|}
\hline & $\begin{array}{c}\text { Referencia } \\
\text { presencial }\end{array}$ & $\begin{array}{c}\text { Correo } \\
\text { Electrónico }\end{array}$ & $\begin{array}{c}\text { Referencia } \\
\text { digital }\end{array}$ \\
\hline ¿Dónde está? & $42 \%$ & $5 \%$ & $13 \%$ \\
\hline $\begin{array}{l}\text { Políticas } y \\
\text { procedimientos }\end{array}$ & $14 \%$ & $12 \%$ & $6 \%$ \\
\hline $\begin{array}{l}\text { Solución de } \\
\text { problemas }\end{array}$ & $6 \%$ & $16 \%$ & $5 \%$ \\
\hline Consulta & $38 \%$ & $60 \%$ & $72 \%$ \\
\hline Otros & NA & $7 \%$ & $4 \%$ \\
\hline
\end{tabular}

Fig.1.5. Evaluación de la biblioteca de la Penn State University

En este mismo grupo se puede incluir el estudio presentado por Diamond y Pease $^{112}$, realizado a partir de 450 transacciones de referencia digital realizadas entre 1997 y 1999 en la Biblioteca Meriam de la California State University. Las preguntas se recibieron por correo electrónico y fueron clasificadas en cuatro grandes grupos: uso de los catálogos; políticas de la biblioteca y alcance de las colecciones; cuestiones de conectividad o acceso a recursos; y mecánicas de las bases de datos. Lo interesante de este artículo es que ofrece una lista de frecuencia de los temas; curiosamente, las preguntas más demandadas (97) fueron aquellas cuya contestación requirieron recursos de referencia tradicionales, seguido de orientaciones de información (76) para comenzar trabajos.

Además de las aportaciones presentadas hasta el momento, puede establecerse una última división de las demandas de información que se reciben en una biblioteca, tomando como elemento de distinción el tipo de información demandada; de esta forma se podrían clasificar las consultas en demandas de información general, demandas de información de respuesta rápida y demandas de información bibliográfica. En los siguientes epígrafes de esta investigación doctoral se desarrolla esta clasificación triple.

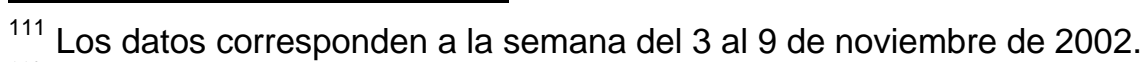

${ }^{112}$ Diamond, Wendy; Pease, Barbara. Digital reference: a case study of question types in an academic library. Reference Services Review, 2001, vol. 29, n. 3, p. 210-219. 


\subsection{Información general}

Todas las cuestiones que se reciban acerca de la biblioteca pueden incluirse dentro del apartado de información general. Como se ha mencionado anteriormente, la información que los usuarios requieren acerca de la biblioteca suelen tratar de:

- organización de la biblioteca: horarios, secciones, condiciones, etc.

- uso de los productos bibliotecarios: catálogos, CD-ROM, etc.

- sistemas de consulta de la colección de referencia

- localización de la colección: disposición de los fondos, signaturas, centros de interés, etc.

Este tipo de preguntas son muy habituales en cualquier biblioteca. Deben ser atendidas con diligencia, para conseguir que el usuario utilice la biblioteca y consulte los fondos. Como ejemplo de este tipo de preguntas pueden ponerse los siguientes:

¿Tienen folletos de la biblioteca?

¿A qué edad puedo hacerme socio?

¿Puedo usar el carné de mi hermano?

¿Cierran a mediodía?

¿Dónde están los servicios de caballeros?

¿Cuántas obras se prestan simultáneamente?

¿Cómo se busca un autor en el catálogo?

¿Cómo se consulta esta enciclopedia?

¿Cómo se visualizan los registros en el OPAC?

¿Dónde están las guías turísticas?

¿Coloco las obras después de consultarlas?

A continuación se presentan ejemplos extraídos del archivo de consultas del servicio «Pregunte: las bibliotecas responden».

Información general: Ejemplo 1

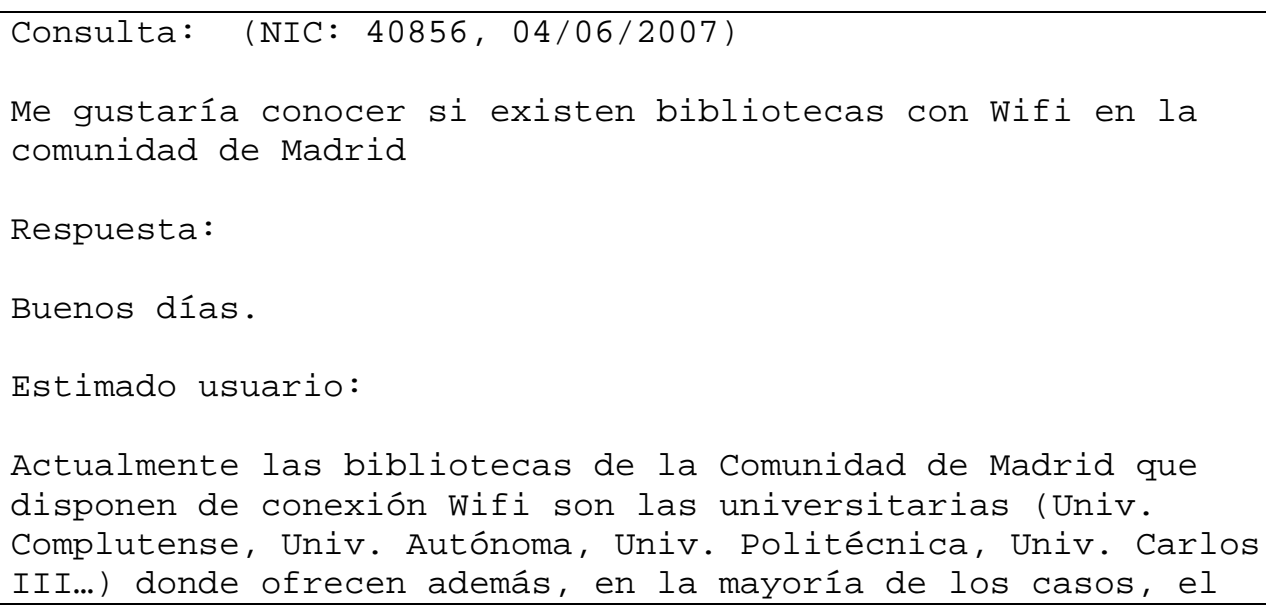


préstamo de ordenadores portátiles para su uso en las salas de la biblioteca correspondiente.

En las bibliotecas dependientes del Ayuntamiento de Madrid no existe acceso hasta el momento. En la Red de Bibliotecas

Públicas de la Comunidad se encuentra en fase de proyecto y experimentación, y es probable que a medio plazo pueda ofrecerse también este servicio a nuestros usuarios.

Fuentes utilizadas en la respuesta:

http://WWW. upm. es/laupm/servicios/bibliotecas/biblio_portatil.p df

http://WWW. ucm . es/BUCM/servicios/5841.php

http: //asyc . uc3m.es/index.php? Id=68

http ://WWW. uam.es/innovacion/zonas_inalambricas.htm

Tema: INFORMÁTICA E INTERNET

Fig. 1.6. Ejemplo de Pregunta/Respuesta: Información general

\section{Información general: Ejemplo 2}

Consulta: (NIC: 17757, 25/02/2003)

Soy investigador del fútbol modesto en el periodo alrededor de la guerra. Mucha de la información la saco a través del préstamo interbibliotecario pero la BPE Santander no presta ciertas obras que podrían dame esta información que busco. Deseo saber las clasificaciones de la Primera Regional de fútbol de Cantabria en las temporadas 40-41 y 41-42. Esta información se encuentra muy probablemente en este libro que tienen ustedes en su Biblioteca:

Gómez Samperio, Raúl

1926-2001 Rayo Cantabria / Raúl Gómez Samperio. -- [S.1.] : [s.n.], D.L. 2002 (Santander : Calima)

200 p.: il., fot. ; $30 \mathrm{~cm}$

D.L. SA 195-2002

ISBN 84-607-4967-3

Rayo Cantabria-Historia

Mil novecientos veintiseis-Dos mil uno Rayo Cantabria

796.332 Rayo Cantabria (091)

Código Barras Sucursal Localización Signatura

1060360 B.P.E. CANTABRIA DEPOSITO LEGAL DL 3 1366/A

NO SE PRESTA Disponible

1060361 B.P.E. CANTABRIA DEPOSITO LEGAL DL 3 1366/B

NO SE PRESTA Disponible

Muchas gracias por su esfuerzo y quedo a la espera de su respuesta

Respuesta:

La BPE en Santander si realiza préstamo interbibliotecario de la mayoría de sus fondos, con ciertas excepciones como documentos de difícil adquisición o de referencia. Es posible que usted haya sacado la conclusión de que no se presta la obra que necesita al interpretar la información 'NO SE PRESTA' hace referencia al préstamo a domicilio no al préstamo 
interbibliotecario ya que este ultimo se realiza entre bibliotecas.

En cuanto a la información que usted necesita, puede consultar los siguientes libros por préstamo intebibliotecario: 84-404-2588-๑ - Racing de Santander /Alba Ingelmo, Teodosio Gumersindo; 1998

84-95054-85-X - Hacia el centenario de la Real Gimnástica de Torrelavega / Gómez Samperio, Raúl Tantín ; 1998

84-607-4967-3 - Rayo Cantabria, 75 Aniversario, vivero Real Racing Club /Gómez Samperio, Raúl Rayo Cantabria; 2002 84-920051-1-4 Archivo deportivo de Santander / Fermín Sánchez González

75 aniversario Cultural Deportiva Guarnizo / Jose Manuel Ruamayor Guarnizo : Cultural Deportiva Guarnizo, 1997

Fuentes para ampliar: El diario montañes C La Prensa s/n 39012 Santander ( WWw.eldiariomontanes.es/)

FEDERACION CANTABRA DE FUTBOL Dirección: Marqués Hermida 14 10 Tlf.: 942 - 21.63.50 Fax: 942 - 31.31.47 C.P.: 39009 Santander

Tema: LUGARES Y GENTES

Fig. 1.7. Ejemplo de Pregunta/Respuesta: Información general

\section{Información general: Ejemplo 3}

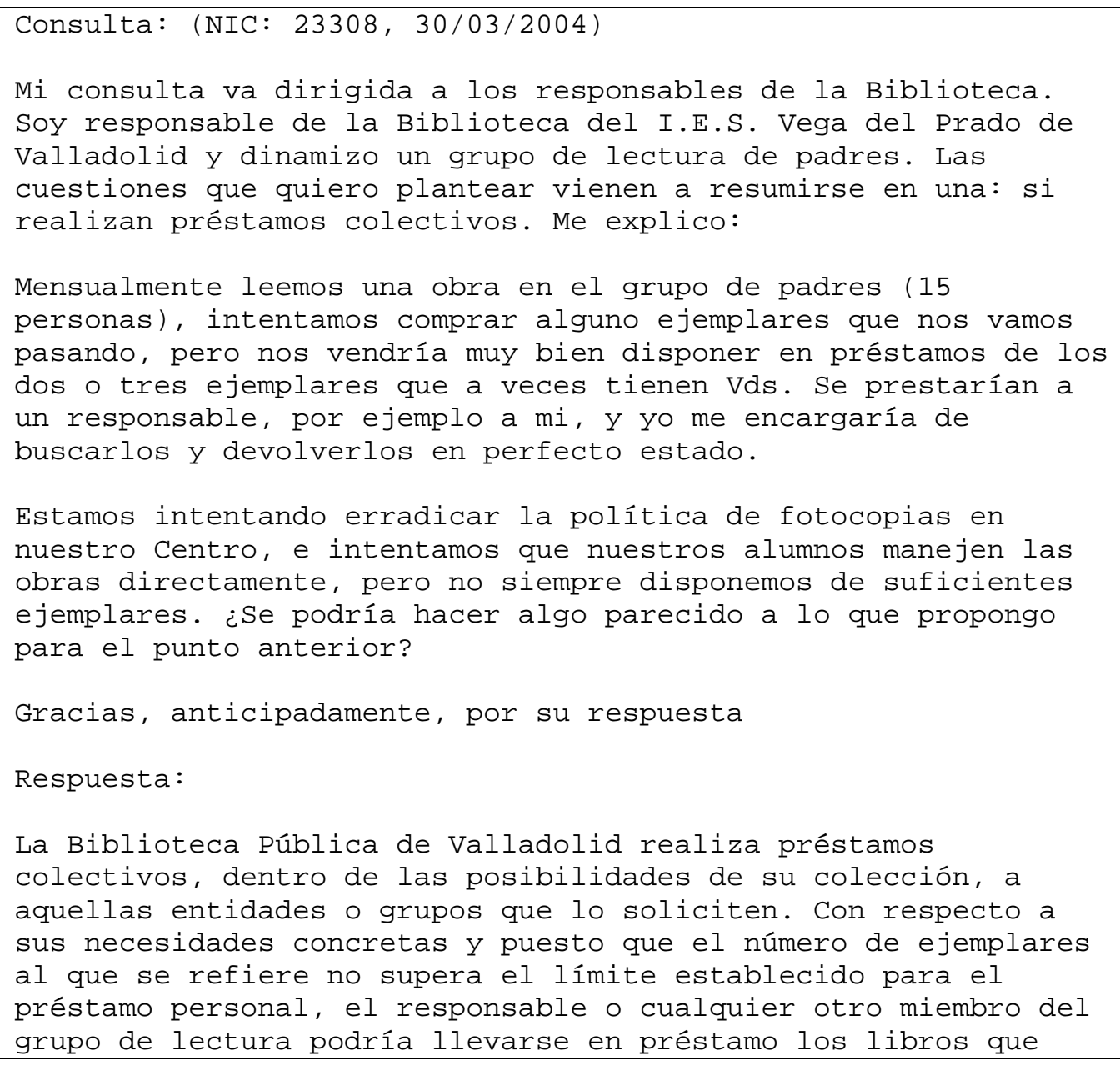




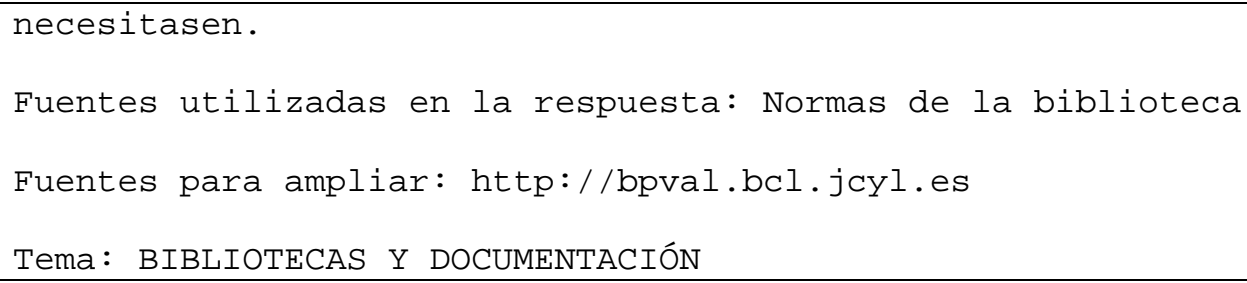

Fig. 1.8. Ejemplo de Pregunta/Respuesta: Información general

\subsection{Información de respuesta rápida}

Como demandas de respuesta rápida se conocen aquellas preguntas acerca de temas ajenos a la biblioteca que solicitan datos concretos, los cuales pueden ofrecerse de inmediato consultando una fuente de información.

Por lo general, corresponden a un esquema sencillo de interrogación (quién, qué, dónde, cuál, cómo, etc.). Incluso, muchas de ellas se responden simplemente con un sí o un no. Lo habitual es que estas preguntas sean formuladas por estudiantes, quienes las necesitan para sus trabajos; aunque pueden ser planteadas por cualquier usuario de la biblioteca. Ejemplos de este tipo de demandas son:
¿Quién pisó la luna por primera vez?
¿Qué significa RFID?
¿Dónde desemboca el Tormes?
¿Cuál es el animal que corre más rápido?
¿Se puede traducir "notice" como "noticia"?
¿Quién inventó el lapicero?
¿Cuáles son las farmacias de guardia de hoy?

Este tipo de consultas son las estrictamente consideradas como de referencia y son las que abundan en los servicios presenciales y en los digitales, como es el caso de «Pregunte: las bibliotecas responden», de donde se han extraído los siguientes ejemplos:

Información de respuesta rápida: Ejemplo 1

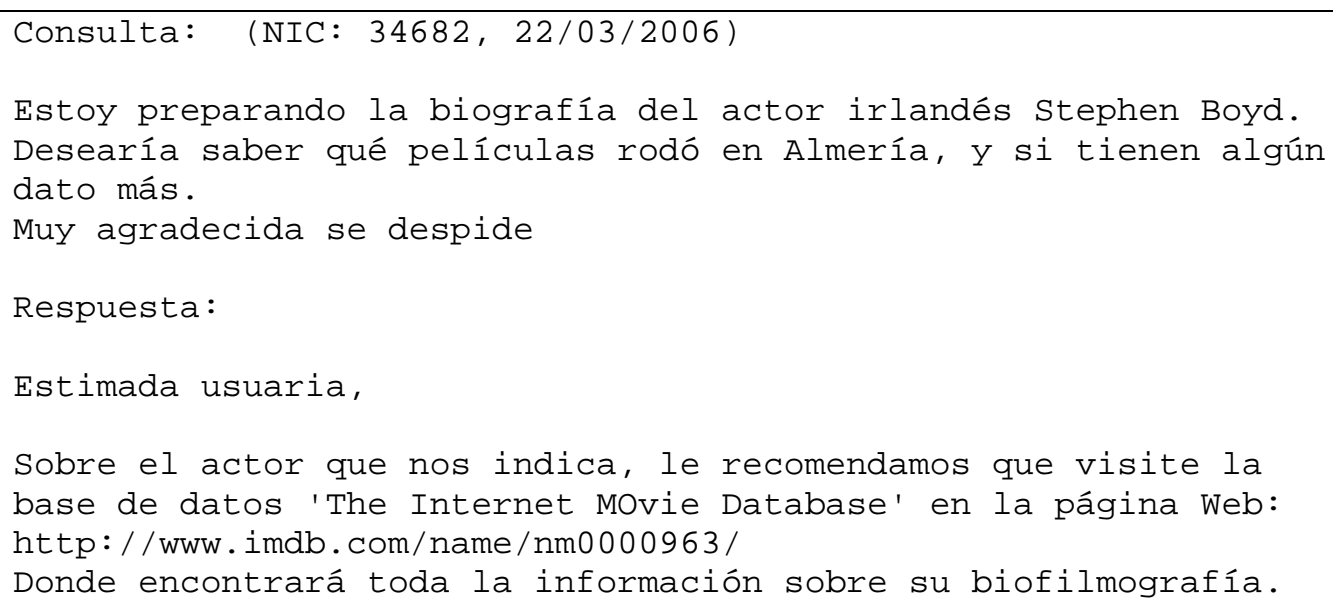




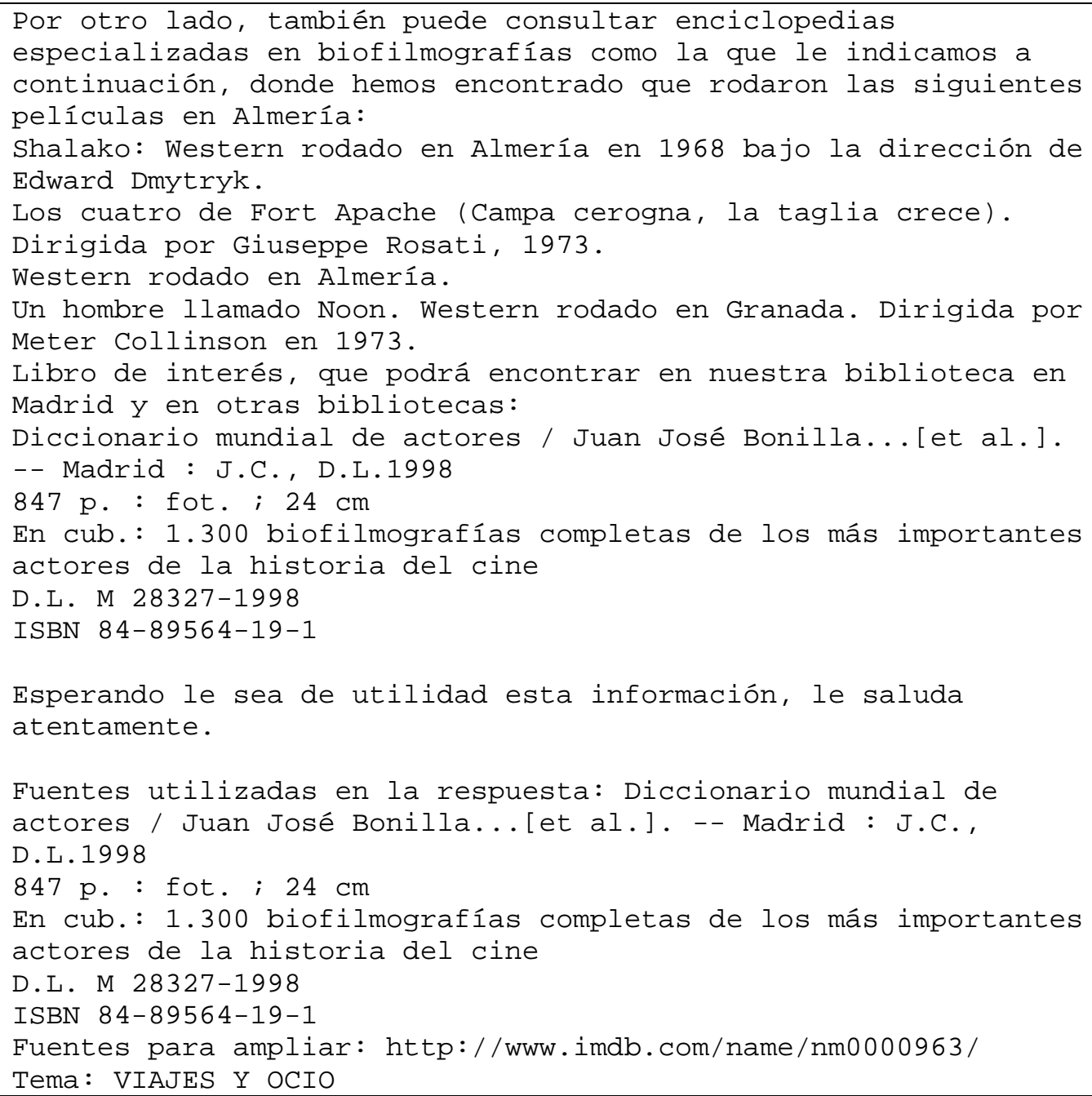

Fig. 1.9. Ejemplo de Pregunta/Respuesta: Información de respuesta rápida

\section{Información de respuesta rápida: Ejemplo 2}

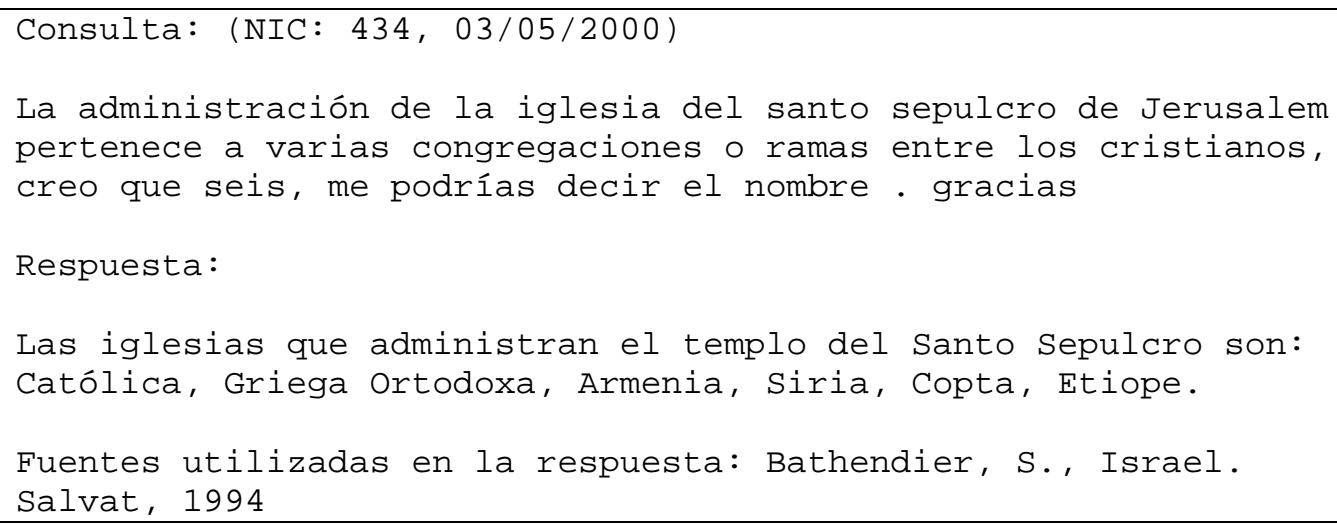

Fig. 1.10. Ejemplo de Pregunta/Respuesta: Información de respuesta rápida

\section{Información de respuesta rápida: Ejemplo 3}




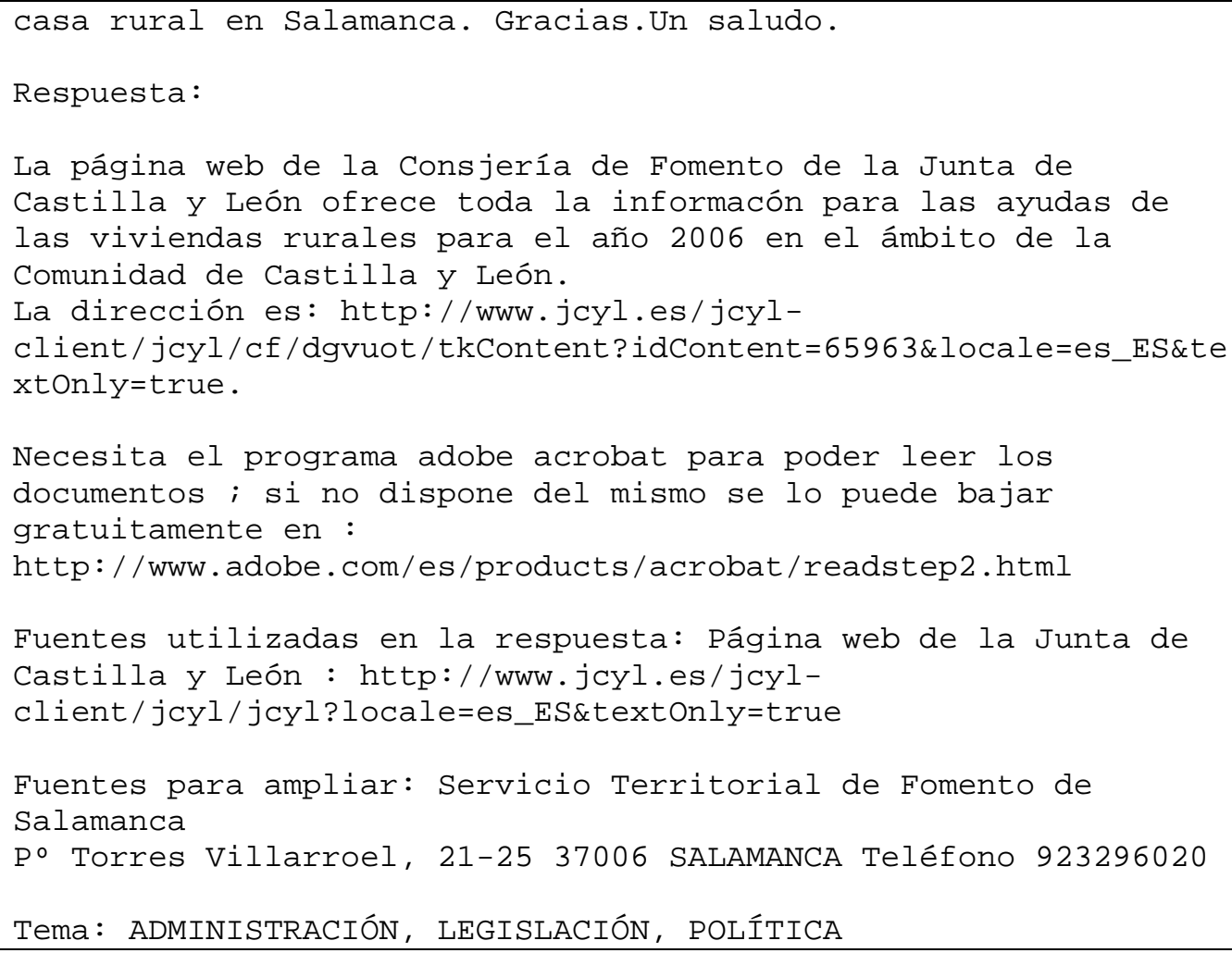

Fig. 1.11. Ejemplo de Pregunta/Respuesta: Información de respuesta rápida

\subsection{Información bibliográfica}

En el tercer tipo, la información bibliográfica, se incluyen todas las preguntas que requieran una información más elaborada y el uso de distintas fuentes de información para poder contestar al usuario. La información bibliográfica es un servicio bibliotecario muy arraigado, consistente en ofrecer al usuario relaciones de documentos acerca del tema de su consulta. Tradicionalmente, estas relaciones son bibliografías en las que se recogen monografías, artículos de publicaciones periódicas, etc.

En la actualidad, esta información se debe completar con informaciones extraídas de bases de datos y páginas web. Las consultas de información bibliográfica requieren una entrevista con el usuario, como se trató en un apartado anterior, para delimitar la consulta al máximo, a fin de ofrecer información de utilidad para el mismo.

La información bibliográfica suele plantearse por motivos académicos o profesionales. Algunos ejemplos de este tipo de demandas son:

Información sobre Internet y bibliotecas

Obras sobre la vida social de Salamanca en el siglo XVI

Estudios sobre Augusto Roa Bastos

Artículos y libros sobre fútbol y psicología de masas

Bibliografía sobre el euro 
A continuación se ofrecen algunos ejemplos reales extraídos de «Pregunte: las bibliotecas responden», que sirven para ilustrar este apartado.

\section{Información bibliográfica: Ejemplo 1}

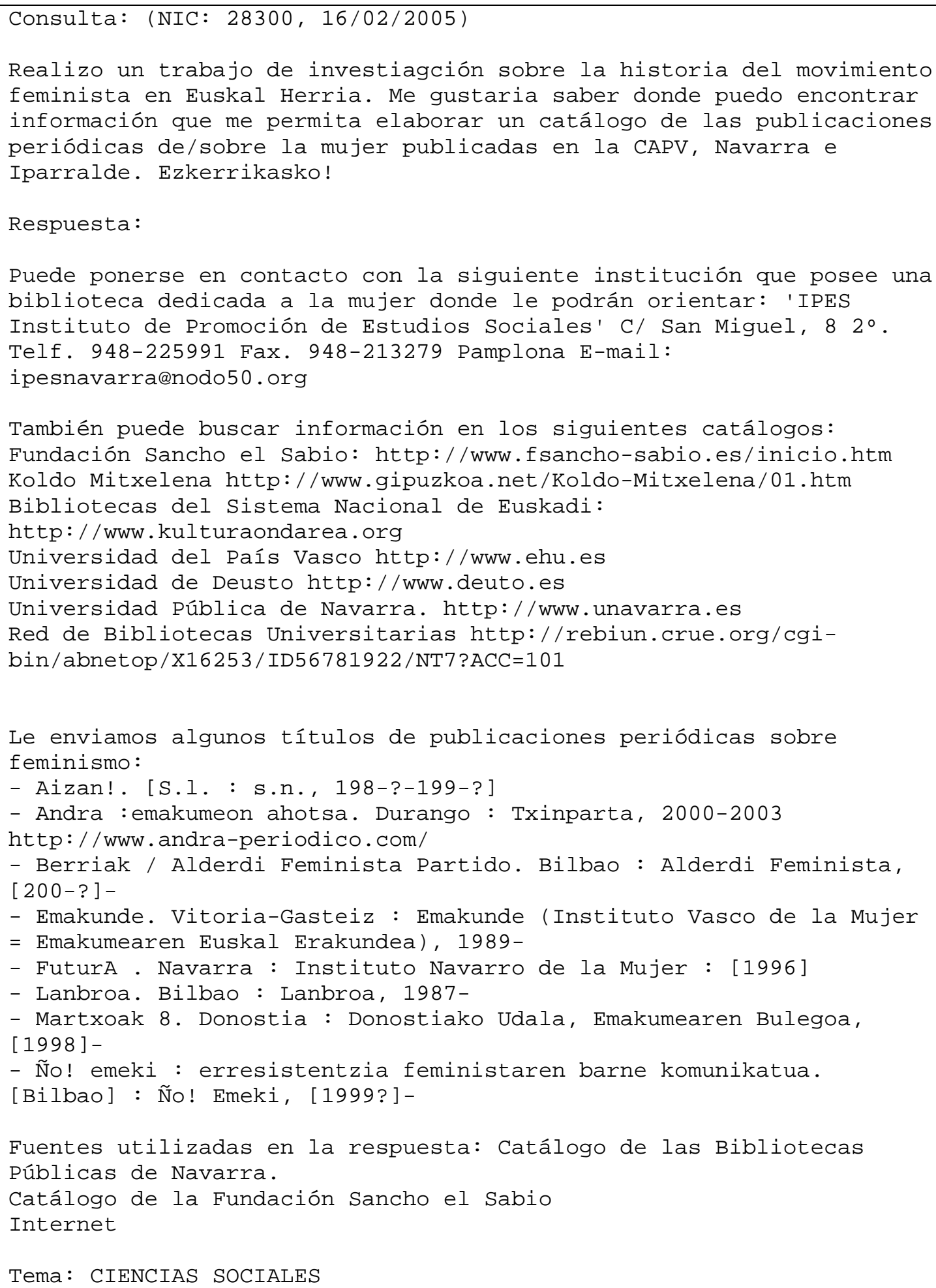

Fig. 1.12. Ejemplo de Pregunta/Respuesta: Información bibliográfica 
Información bibliográfica: Ejemplo 2

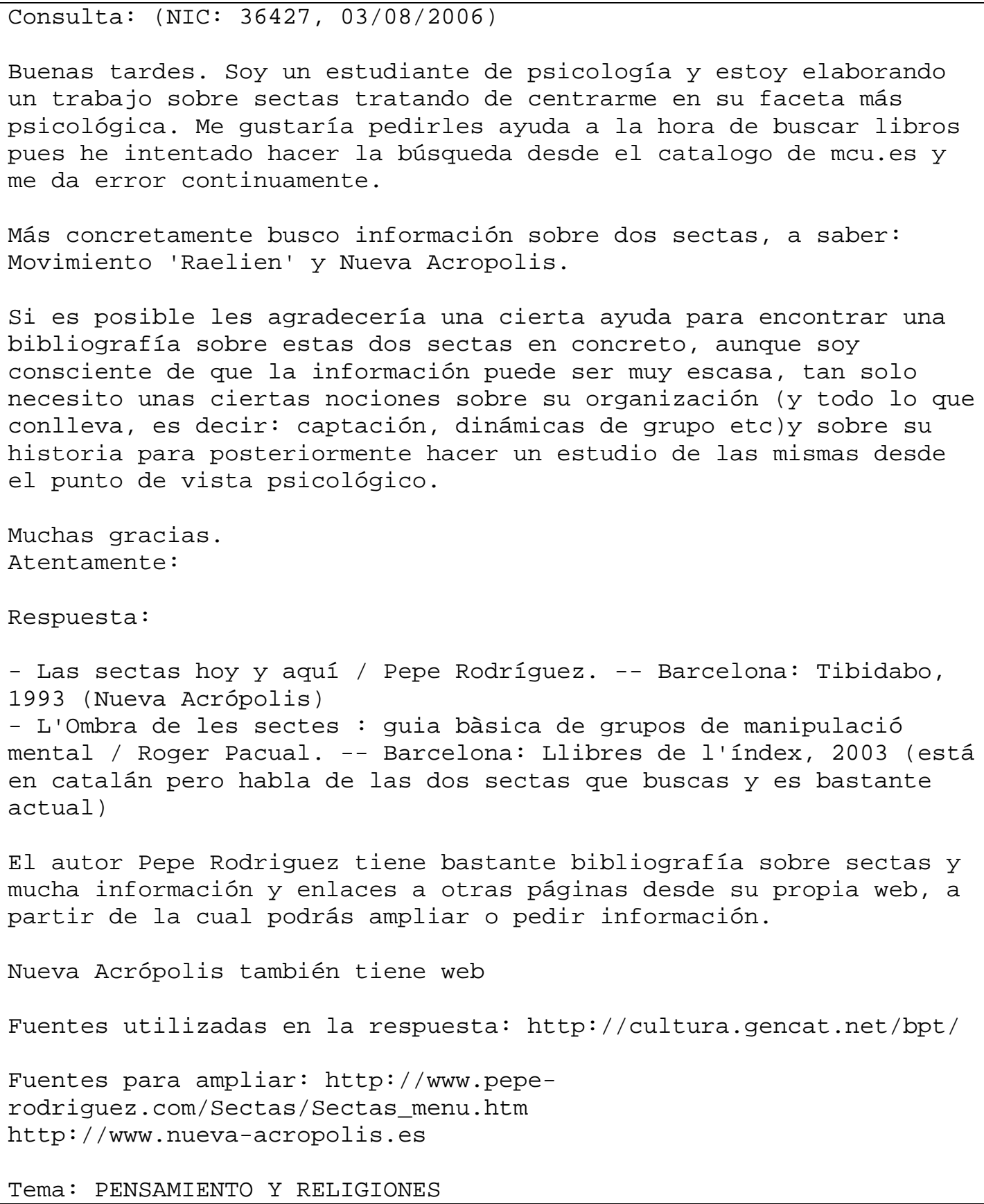

Fig. 1.13. Ejemplo de Pregunta/Respuesta: Información de respuesta bibliográfica

También pueden ser consideradas como información bibliográfica las preguntas que los usuarios realizan con la intención de recibir asesoramiento a la hora de seleccionar documentos entre la colección de la biblioteca. En este caso la consulta puede ser genérica, es decir, para solicitar la recomendación de una obra sin especificar preferencias, o bien más concreta, detallando las materias u otros elementos sobre los que se quiere recibir asesoramiento. Ejemplos de estos tipos de preguntas son: 
¿Y qué libro leo ahora?

¿Qué discos tenéis de música brasileña que estén bien?

¿Merece la pena algún otro libro de esta colección?

¿Cuáles son las mejores bases de datos legislativas?

¿En qué revistas encontraré algo sobre poesía española actual?

Información bibliográfica: Ejemplo 3

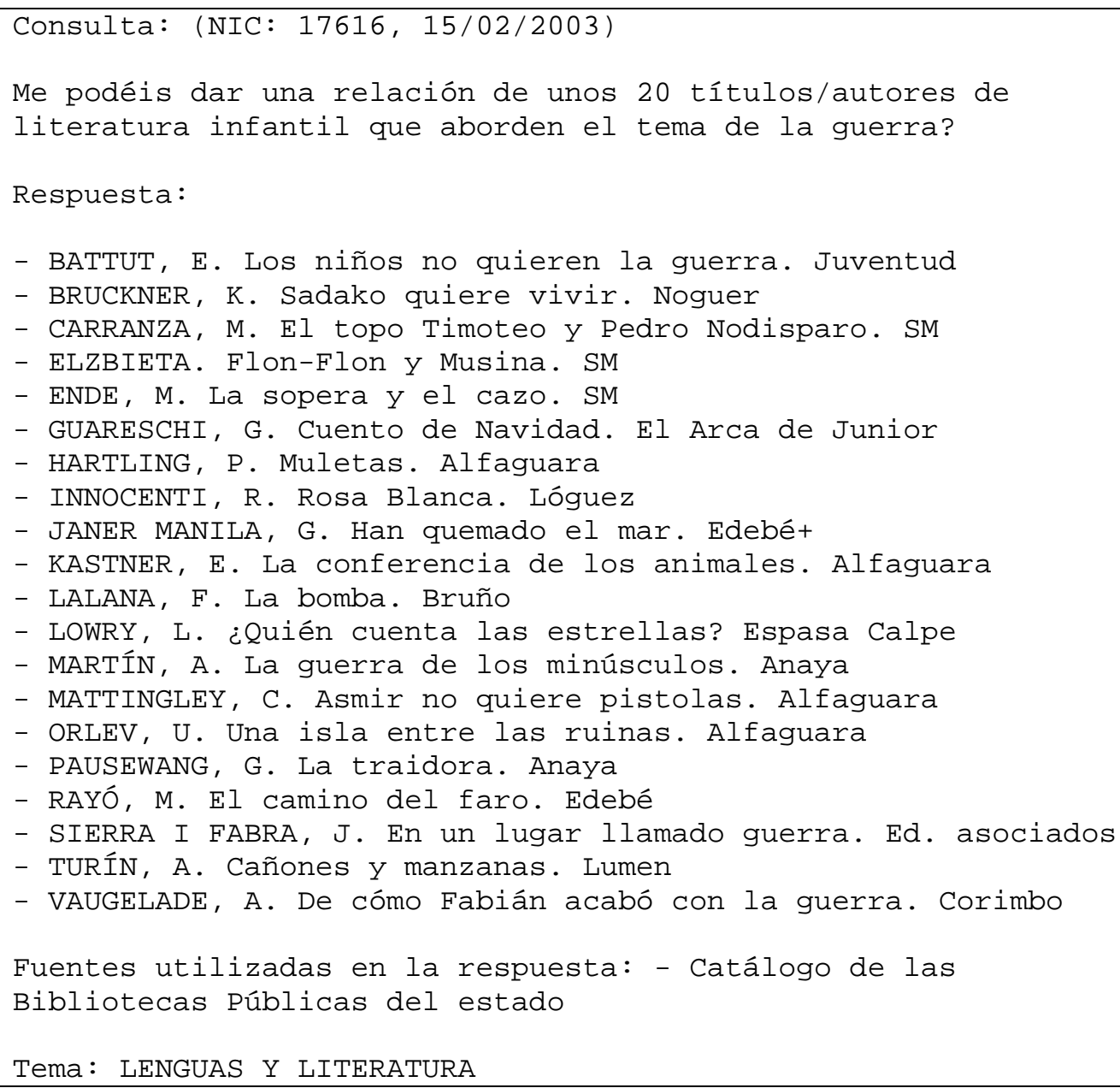

Fig. 1.14. Ejemplo de Pregunta/Respuesta: Información de respuesta bibliográfica 


\section{El proceso de referencia}

La práctica del servicio de referencia conlleva un proceso que comienza en el momento que se plantea una pregunta y que finaliza cuando se ha entregado la misma. La biblioteca debe disponer de un manual de procedimiento para guiarse en este proceso, tanto si se trata de un servicio presencial, como si se ofrece de forma telemática. Para ello, serán de gran utilidad las pautas y directrices que se presentan en el capítulo 10 de la tesis doctoral, que pueden ser adaptadas por las bibliotecas a partir de sus circunstancias particulares. En este proceso, es esencial la entrevista de referencia, que se constituye en el guión de la comunicación con el usuario para delimitar qué información se necesita. En este quinto capítulo también se estudiarán los medios de que dispone una biblioteca para resolver las consultas, que han sido sistematizados según la visión del doctorando. Por último, se expondrán una serie de productos informativos que las bibliotecas pueden elaborar para completar el trabajo de referencia, adelantándose a las consultas que los usuarios quieran plantear.

\subsection{La recepción de las consultas}

La biblioteca debe garantizar que cualquier consulta o duda de los usuarios sea recogida. No todas se reciben de la misma manera, ya que, dependiendo de la demanda de información, se atenderá al usuario en un espacio u otro, se empleará más o menos tiempo y serán necesarios útiles diferentes para la resolución de las preguntas.

Las preguntas generales sobre el uso de la biblioteca (horarios, reglamento, sistema de inscripción, etc.) se suelen atender en el mostrador de recepción de la biblioteca. Son preguntas de fácil solución, por lo que no es necesario utilizar formularios para recogerlas ni emplear fuentes de información para responderlas.

Se trata de cuestiones que se reciben de manera oral y se contestan de igual forma, aunque en ocasiones vayan acompañadas de folletos explicativos. Por ejemplo:

¿A qué hora cierra la biblioteca?

¿Abren los sábados por la mañana?

¿A qué edad puedo ser socio?

Las cuestiones que se planteen sobre la colección, el catálogo, etc. se reciben generalmente cerca de los fondos, los catálogos o los servicios bibliotecarios. Los usuarios interrogan al personal sobre el sistema de búsqueda del catálogo, la ubicación de los fondos, el método de consulta de una obra, las normas de préstamo, etc. cuando están al lado de los objetos o servicios que provocan la consulta. 
En estos casos a veces es el personal quien debe preguntar sutilmente a los usuarios si necesitan información. Como los anteriores, este tipo de preguntas suelen realizarse oralmente y responderse de la misma manera. Ejemplo son:

¿Dónde están las obras de gastronomía?

¿Cómo se busca una obra?

¿Cuántas obras se prestan a la vez?

Cuando las preguntas son más complejas se debe poner especial atención en la recepción de la consulta. Las demandas de información que no tengan por objeto la biblioteca, su colección o sus servicios deben ser atendidas en la sección de referencia. Allí se preguntará al usuario por su consulta mediante la denominada entrevista de referencia. Si las demandas son de respuesta rápida no será necesario emplear formularios para recoger las preguntas, a no ser que se quiera llevar un control o una estadística del tipo de demandas de información que se reciben en el servicio.

Las cuestiones más elaboradas requieren un formulario específico donde el personal irá anotando los distintos aspectos que delimiten el tema de la consulta. En muchas ocasiones las consultas especializadas pueden hacerse a distancia: correo postal, fax, teléfono o correo electrónico.

Algunos ejemplos son la petición de bibliografías, datos estadísticos o factuales o la solicitud de Difusión Selectiva de la Información.

\subsection{La entrevista de referencia}

La mejor manera de recoger las consultas es mediante la entrevista de referencia; se trata de la conversación que el personal referencista mantiene con el usuario con la intención de delimitar y clarificar las demandas de información de éste ${ }^{113}$. En esta entrevista, el referencista va anotando las distintas facetas del tema de interés para que la respuesta se ajuste al tema de la consulta. El grado de profundidad de la entrevista de referencia dependerá de la consulta. Cuanto más especializado sea el tema planteado por el usuario más detallada será la entrevista.

Una entrevista de referencia completa deberá incluir las siguientes cuestiones:

- Tema principal de la búsqueda y tema relacionados con el mismo. El tema debe ser delimitado al máximo, excluyendo todos aquellos sobre los

\footnotetext{
${ }^{113}$ Curry hace un completo repaso a la literatura profesional sobre la entrevista de referencia desde 1995 a 2005, periodo en el que este proceso se ha modificando debido a las tecnologías. En su estudio incluye autores, años y aportaciones más significativas. Véase Curry, Evelyn L. The reference interview revisited: Librarian-patron interaction in the virtual environment. SIMILE: Studies in Media \& Information Literacy Education, 2005, vol. 5, n. 1. Disponible en línea en http://www.utpjournals.com/simile/indexj.html (consulta 25 agosto 2007).
} 
que el usuario no muestre interés. Es muy común que el usuario no tenga una idea clara acerca de qué es lo que le interesa y qué no, por lo que el personal debe hacer todas las preguntas necesarias hasta que la consulta esté perfectamente especificada.

- Información que ya conoce el usuario. Es importante saber qué datos, obras o autores ha manejado el usuario, ya que de lo contrario la biblioteca podría darle información redundante.

- Objeto de la demanda. Saber para qué quiere el usuario la información será útil para determinar el grado de especialización y en qué fuentes se realizará la búsqueda.

- Profundidad o nivel de la información. Hay que preguntar qué tipo de información va a ser útil para el usuario, a fin de eliminar aquella que por defecto o por exceso no se ajuste a las necesidades del usuario, ya sea por su nivel científico, por la exhaustividad de los datos, el grado de especialización o por cualquier otro motivo.

- Cantidad de información. En este punto se demandará sobre el número de respuestas que requiere el usuario. En unas ocasiones simplemente bastará con un número limitado de documentos, mientras que en otras se necesitarán todas las referencias o datos que se encuentren.

- Idiomas de la información. En las búsquedas que se realicen aparecerán documentos en varias lenguas, por lo que habrá que preguntar al usuario qué idiomas quiere y cuáles no, a fin de eliminar directamente aquellas referencias que no va a emplear.

- Límites cronológicos. Dependiendo del tema de la búsqueda la fecha de la información será útil o no, por lo que habrá que establecer a partir de qué año quiere el usuario que se haga la búsqueda.

- Formato de las respuestas y modo de recepción. Preguntar si la respuesta se entregará en papel o en disquete y si el usuario la recogerá en la biblioteca o se le enviará por correo postal, fax o correo electrónico.

- Importe económico. Muchas consultas se resuelven únicamente en bases de datos o en servicios de información de pago, por ello hay que preguntar al usuario cuánto está dispuesto a gastar para la resolución de su consulta.

- Tiempo de repuesta. Urgencia del usuario por recibir la información y disponibilidad de la biblioteca para entregarla.

En la mayoría de estos apartados pueden ser empleadas dos tipos de preguntas: abiertas y cerradas. Las abiertas son aquellas en las que el usuario puede expresarse libremente para comunicar sus necesidades de información; mientras que en las cerradas únicamente podrá contestar a una de las opciones que le plantee como alternativa el personal referencista. 
Ejemplos de preguntas abiertas son las siguientes:

¿Qué tema le interesa?

¿Qué autores conoce?

¿Para qué necesita la información?

Ejemplos de respuestas cerradas serían:

Objeto de la consulta (personal / estudios / profesional)

Número de referencias (1 a 10 / 10 a 50 / más de 50)

Forma de recepción (biblioteca /envío postal / correo electrónico).

No todas las entrevistas de referencia deben realizarse de la misma manera, ya que las consultas que se reciben son muy distintas entre sí. La entrevista debe adecuarse a la demanda de información ${ }^{114}$.

- consulta rápida: la entrevista se centrará en delimitar con la mayor precisión la consulta. Al tratarse de datos concretos se puede prescindir de formularios complejos, empleándose otros más sencillos en los que se anote un breve resumen de la consulta, si se cree necesario.

- búsquedas especializadas: en muchos casos las consultas requieren realizar una búsqueda compleja para localizar la información demandada. Este tipo de consulta necesita de una entrevista exhaustiva, en la que se delimiten todos los aspectos de la misma.

- difusión selectiva de la información: la entrevista de referencia para la recogida de un perfil para difusión selectiva de la información debe ser realizada con detalle, ya que los datos aportados por el usuario serán utilizados con frecuencia. Para establecer los temas de interés es necesario emplear los mismos tesauros o listas de encabezamientos de materias con los que se trabaje en la biblioteca para la descripción de los documentos, a fin de garantizar que se envía la información sobre temas que realmente interesan al usuario.

- orientación bibliográfica: la entrevista de referencia que tiene por finalidad orientar al usuario sobre títulos concretos debe centrarse en conocer los gustos de los usuarios y sus criterios de evaluación. En estos casos es útil preguntar por lecturas anteriores o autores predilectos. Si la orientación bibliográfica se realiza sobre obras que no son de ficción entonces será necesario conocer, además, el objeto de la consulta: lectura personal, trabajo, investigación, etc.

\footnotetext{
${ }^{114}$ Sutton, E. D.; Holt, L. E. The reference interview. En Reference and information services. $2^{\text {nd }}$ ed. Englewood: Libraries Unlimited, 1995, p. 36-54. En la tercera edición de este manual, el capítulo dedicado a la entrevista de referencia fue abordado directamente por uno de los dos editores de la obra: Bopp, Richard E. The reference interview. En Bopp, Richard E.; Smith, Linda C. (eds.). Reference and information: an introduction. $3^{\text {rd }}$ ed. Englewood: Libraries Unlimited, 2001, p. 47-68.
} 
- información a la comunidad: los servicios de referencia atienden frecuentemente consultas sobre la vida administrativa, económica o sociocultural de la localidad ${ }^{115}$. En estos casos es importante clarificar qué información se pretende, para evitar confundirse de entidad. La entrevista de referencia dejará claro qué organismo es el que se busca y que datos se requieren sobre el mismo: dirección, horarios, gestiones, etc.

- formación de usuarios: cuando la entrevista de referencia se realiza para enseñar al usuario los servicios y técnicas bibliotecarios se partirá de una explicación del personal para, a continuación, responder las cuestiones que les vayan planteando los usuarios.

- búsqueda en bases de datos: la principal cuestión en la entrevista de referencia que se realice para consultar una base de datos es traducir el tema de la consulta a descriptores, empleando el lenguaje controlado de la base de datos que se esté interrogando. Además, se preguntarán todos los datos que delimiten la consulta: lenguas, periodo cronológico, número de referencias, etc. En el caso de que sea el usuario quien realice la búsqueda, la entrevista se orientará hacia aspectos técnicos y los sistemas de recuperación de la información.

- atención telefónica y referencia sincrónica: cuando la consulta se realiza por teléfono, chat ${ }^{116}$ o procedimientos similares la entrevista de referencia se debe comenzar por la identificación del usuario. Es preferible que, cuando sea posible, las preguntas sean cerradas, para delimitar cuanto antes las consultas. La estructura de este tipo de entrevista no difiere demasiado de las que se hacen en persona. Dado que pocas veces la consulta puede ser respondida en el momento, habrá que preguntar al usuario cómo se entrega la respuesta: con una nueva comunicación, por fax, correo electrónico, etc.

- atención mediante referencia asincrónica: los usuarios tienen la posibilidad de comunicarse con la biblioteca mediante procedimientos telemáticos, ya sea a través del correo electrónico o mediante formularios en páginas web. Si la información se solicita por correo electrónico, entonces la biblioteca sólo debe esperar a que el usuario haga su consulta. Si su mensaje no es lo suficientemente claro entonces la biblioteca preguntará todas aquellas cuestiones que necesite aclarar. En esta entrevista se debe determinar también cómo se entregarán las respuestas en caso de que sean voluminosas o de que la búsqueda requiera tiempo. Cuando la biblioteca

\footnotetext{
${ }^{115}$ Un buen ejemplo es el servicio de estadísticas locales Colorado Statistical Abstracts, que se describe en Hollis, Deborah R.; Jobe, Margaret M. Publishing on the Web: creating a local reference tool. Library Hi Tech, 1999, vol. 17, n. 1, p. 63-74. En España, son buenos ejemplos los del servicio de información comunitaria de la Biblioteca Pública de Tarragona y el Servidor de Información Local (SILO) que ofrece la Biblioteca Municipal de Peñaranda de Bracamonte (Salamanca) y donde se han reunido estadísticas relacionadas a la comarca producidas por organismos diversos para que se puedan consultar mediante una única interfaz. Más información en http://www.citafgsr.com/silo/index.php.

${ }^{116}$ Westbrook analiza las fórmulas de cortesía en las entrevistas de referencia realizadas a través de chat. Véase Westbrook, Lynn. Chat reference communication patterns and implications: applying politeness theory. Journal of Documentation, 2007, vol. 63, n. 5, p. 638-658.
} 
pone en línea formularios para que el usuario realice sus preguntas, la formulación de la consulta se llevará a cabo rellenando cada uno de los apartados del formulario. A diferencia de los formularios impresos, los electrónicos son completados por los usuarios, por lo que es necesario que indiquen su dirección de correo electrónico o teléfono, por si se necesitase solicitar datos complementarios o especificar los que introdujo el usuario. Como en otras ocasiones, además del tema de la búsqueda, se deberá preguntar por el modo de recepción de la respuesta.

\subsection{La resolución de las consultas}

Una vez recogida la consulta a través de la entrevista de referencia se deberá proceder a su resolución. El sistema elegido para solventar la pregunta dependerá de la intensidad de la misma. No obstante se pueden marcar una serie de etapas en todo el proceso de consulta. De esta forma, el periodo que transcurre desde que el usuario plantea su pregunta hasta que ésta es respondida, aunque puede haber excepciones, pasa generalmente por las fases que se describen a continuación:

Análisis de la consulta

Determinación exacta de la pregunta formulada por el usuario

Traducción de la consulta a términos de búsqueda

Elección de los descriptores, encabezamientos de materia, clasificaciones, etc. por las que puede localizarse la información requerida

Selección de las fuentes de información

Elección de los documentos o sistemas de información que se consideren más apropiados para resolver la demanda

Traducción de los términos de búsqueda al lenguaje documental

Comparar los descriptores, encabezamientos o clasificaciones extraídas por la biblioteca con las empleadas en la fuente de información que se está consultando y emplear los términos que más se ajusten

$\downarrow$

Búsqueda en las distintas fuentes seleccionadas

Uso de los sistemas de consulta o recuperación de la información de las distintas fuentes seleccionadas para realizar la consulta

Extracción de las respuestas que se ajusten a la consulta

Recopilación de las respuestas pertinentes de cada una de las fuentes

Síntesis de las respuestas encontradas

Organización de la información válida para la resolución de la demanda, eliminando la superflua y la que no se ajuste a la solicitud

Preparación del documento de respuesta

Materialización del resultado en un impreso o mediante cualquier otro sistema empleado para la entrega al usuario

Fig. 1.15. Proceso de resolución de una pregunta 
En todo este proceso juegan un papel fundamental las fuentes de información de que disponga la biblioteca. Para que la sección de referencia sea eficiente se debe contar con una completa colección de referencia, además de tener destreza en el manejo de las mismas. Los útiles y procedimientos que habitualmente se emplean para resolver las preguntas de los usuarios son:

1/ Productos de la propia biblioteca. Los catálogos, boletines informativos, bibliografías, guías de lectura y cualquier otro producto elaborado por la biblioteca serán de utilidad para resolver cuestiones planteadas por los usuarios. El archivo de las consultas que ya fueron respondidas será empleado para ofrecer esas respuestas a nuevos usuarios y para planificar actividades de formación de usuarios. Cuando las consultas versen sobre alguno de los productos bibliotecarios (catálogo, por ejemplo) el proceso de resolución consistirá en la formación en el uso de dicho producto o en la elaboración de materiales explicativos para el manejo de los mismos.

2/ Colección de referencia impresa. Enciclopedias, diccionarios, anuarios, etc. son fundamentales para resolver cuestiones concretas (datos o hechos). Dependiendo de la especialización de la pregunta se utilizarán otras fuentes de información como las bibliografías o los índices. En todos estos casos los sistemas de consulta dependerán de la obra en cuestión y de la forma en que se tenga organizada la información. Será necesario conocer todos los aspectos relativos al uso de estos documentos y familiarizarse con el manejo de los mismos.

3/ Colección electrónica. Las fuentes de información electrónicas, sobre todo aquellas que utilizan soportes ópticos y los libros electrónicos ${ }^{117}$, son de especial interés en los centros de información, debido a su capacidad de almacenamiento y a la facilidad para la recuperación de la información. Este tipo de fuentes de información son válidas sobre todo en las consultas especializadas, particularmente en las bibliográficas. Los sistemas automatizados de recuperación son cada vez más sencillos de manejar. Por lo general, emplean sistemas de consulta intuitivos y permiten el uso de técnicas avanzadas de búsqueda, como los operadores booleanos o el truncamiento. Dada la variedad de software de recuperación existentes es necesario que el personal referencista conozca los que se utilicen en el centro, a fin de encontrar la información más útil en el menor tiempo posible.

4/ Sistemas basados en las telecomunicaciones. Si la pregunta planteada por el usuario puede ser resuelta con una llamada de teléfono, el envío de un fax o un correo electrónico y la biblioteca no posee en su colección ninguna obra con la que responder la demanda, entonces se aconseja el empleo de estos sistemas de comunicación como una herramienta del servicio de referencia. Estos procedimientos se utilizarán para trasladar

117 La edición electrónica de productos para la referencia es amplia, ya que, por su contenido y finalidad, las obras de consulta en formato de libro electrónico presentan muchas ventajas para los usuarios. Se pueden ver ejemplo en Bronshteyn, Karen. Using NetLibrary eBooks at the reference desk. Reference Services Review, 2007, vol. 35, n. 4, p. 560-570. 
preguntas a organismos, servicios de información, empresas, etc. cuando el usuario requiera de ellos poca información: dirección, gestiones, productos informativos, etc.

5/ Sistemas basados en Internet. Internet es una gran fuente de información, de la que el personal referencista podrá valerse a menudo. En la actualidad hay millones de páginas web con información de utilidad. Las bibliotecas están utilizando esta información como parte de su colección, ya que es de acceso libre y universal en su gran mayoría. Entre las aplicaciones de Internet al servicio de referencia destacan la web y las listas de distribución.

La web es un sistema de acceso a la información muy simple que posibilita que cualquier persona u organismo introduzca documentos (páginas web) en Internet y que los mismos estén enlazados con otros documentos. El WWW está convirtiendo a Internet en un gran catálogo de recursos enciclopédicos donde encontrar información de cualquier tipo sobre cualquier tema. Por otra parte, las listas de distribución (también llamadas listas de discusión y listas de correo) se basan en la suscripción a un mismo grupo temático de varios usuarios de correo electrónico. Cada vez que alguno de esos usuarios mande un mensaje a la lista lo recibirán todos los demás. Al tratarse de listas centradas en un tema éstas se convierten en un buen lugar al que acudir cuando se quiera obtener información sobre el tema que ha provocado la lista.

Para obtener mejor provecho de estos métodos de información por procedimientos telemáticos es necesario conocer los sistemas de uso de los mismos. En el caso de la consulta de páginas web habrá que saber manejar un navegador, emplear los sistemas de búsqueda y los principales directorios y recursos. Para participar en las listas de distribución es necesario conocer el sistema de suscripción a la lista, de envío de mensajes y las distintas opciones que se ofrecen en estos servicios.

6/ Sistemas informales. Cualquier fuente de información es válida para responder una consulta. Es posible que el personal prefiera emplear métodos menos profesionales pero igualmente efectivos para obtener la información demandada. Toda fuente de información no incluida en los apartados anteriores podría considerarse como informal: preguntas a otros profesionales o a otras personas ajenas a la profesión, ingreso en redes sociales presentes en Internet, archivo de folletos y publicidad, etc. La información encontrada de esta manera es válida, aunque deberá ser contrastada para evitar ofrecer al usuario una respuesta equivocada. 


\subsection{Productos informativos elaborados por la biblioteca}

La biblioteca debe adelantarse a las consultas de los usuarios. Para ello se elaborarán una serie de productos informativos que se ajusten a las demandas recibidas en el servicio de referencia. El tipo de productos dependerá del grado de especialización de la biblioteca y, por tanto, de las necesidades informativas de los usuarios. Los productos que se pueden elaborar en este sentido son:

- Boletines de novedades y/o adquisiciones: listados de los últimos documentos incorporados a la biblioteca y/o aparecidos en el mercado. La diferencia consiste en que los boletines de adquisiciones recogen únicamente documentos que están en la biblioteca, mientras que en los de novedades no tiene por qué, ya que puede tratarse de recomendaciones u orientaciones bibliográficas sobre obras que aún no han sido adquiridas por la biblioteca.

- Bibliografías impresas y guías de lectura: realización de repertorios bibliográficos sobre temas de interés para los usuarios o de actualidad (conmemoraciones, acontecimientos históricos, científicos o literarios, etc.). Estas bibliografías pueden realizarse por indicación de los usuarios o por propia iniciativa del personal. Las guías de lectura suelen ser más informales, recogiendo sólo obras seleccionadas, mientras que las bibliografías son más exhaustivas y especializadas.

- Dossiers de prensa: recopilación de noticias sobre un tema. Son de gran utilidad cuando tratan temas de actualidad, sobre los cuales no hay producción bibliográfica.

- Tablones de anuncios: información local, institucional, cultural, etc. Este sistema de suministro de información tiene muy buena acogida, ya que suele ser un medio útil para ofrecer informaciones muy demandadas por los usuarios.

- Difusión selectiva de la información: la biblioteca puede comprometerse a ofrecer periódicamente información sobre distintos temas a los usuarios que estén interesados. Para ello, se recogerán los perfiles informativos del usuario, en los cuales se expondrán cuáles son los aspectos de los que quiere ser informado.

- Folletos de la biblioteca: la propia biblioteca suele ser un tema de los más demandados por los usuarios, por lo que es conveniente realizar folletos explicativos sobre la misma, sus servicios, el uso de los catálogos, etc.

- Preguntas frecuentes: la biblioteca puede ofrecer al usuario un archivo de FAQ (Frequently Asked Questions) o preguntas frecuentemente plateadas. La función de las FAQ es informar sobre temas muy diversos ofreciendo preguntas planteadas por distintos usuarios, pero que pueden ser útiles para todos. Las FAQ pueden 
realizarse por escrito o bien ofrecerse dentro de la información web de la biblioteca.

- Selección de recursos web: con la implantación del acceso a Internet como un servicio bibliotecario más se ha hecho necesario recopilar las páginas y servicios de mayor interés para los usuarios, ya sea por su contenido o porque desde las mismas se pueda localizar otras informaciones.

- Sistemas de comunicación: si la biblioteca dispone de correo electrónico para comunicarse con sus usuarios, como ocurre en las bibliotecas universitarias, otro medio de ofrecer información son las listas de distribución o de correo. Los usuarios suscritos a estas listas recibirían la información que la biblioteca quisiese enviar: novedades, información bibliográfica, búsquedas temáticas, direcciones web de interés, etc. Asimismo, la presencia en redes sociales ${ }^{118}$ y el establecimiento de canales profesionales de chat y mensajería instantánea son soluciones prácticas.

\footnotetext{
${ }^{118}$ Las redes sociales profesionales están siendo utilizadas por los profesionales de las bibliotecas como herramienta de comunicación e intercambio de información. Para conocer el funcionamiento de este tipo de servicios será útil la lectura del siguiente documento: Moral, José Antonio del. Redes sociales y wikis. En Rojas Orduña, Octavio Isaac (coord.). Web 2.0: manual (no oficial) de uso. Madrid: ESIC, 2007, p. 17-59. Desde una perspectiva más bibliotecaria es recomendable: En Mathews, Brian S. Online social networking. En Courtney, Nancy (ed.). Library 2.0 and beyond: innovative technologies and tomorrow's user. Westport: Libraries Unlimited, 2007, p. 75-89. Por último, se recomienda la lectura de los capítulos sexto (comunidades en línea) y séptimo (redes sociales) de Farkas, Meredith G. Social software in libraries. Medford: Informarion Today, 2007, p. 85-124.
} 


\section{La colección de referencia}

Los servicios de referencia emplean fuentes de información de todo tipo para resolver la variedad de consultas que recibe. Como se ha visto en los apartados anteriores, la información requerida en un servicio de referencia bibliotecario es tan variada que el profesional referencista necesita realizar un gran esfuerzo para conocer la oferta de recursos existentes, la información contenida en los mismos, así como los sistemas de interrogación específicos para cada fuente ${ }^{119}$. En este sexto capítulo el doctorando hace un análisis de las fuentes de información, ofreciendo una tipología de los recursos de referencia que se adapta a la oferta informativa que se puede encontrar un profesional de la información. Para ello se parte de una clasificación propia, basada en dos grandes criterios: la función de una fuente de información, es decir, qué tipo de dudas resuelve, y la forma de la misma, esto es, cómo se materializa en un producto informativo concreto. En el apartado 6.2. se detalla esta clasificación, exponiendo sus características y aportando ejemplos; mientras que en la sección 6.3. se resumen los diferentes tipos de fuentes según la función y según la forma. También se incluye en este capítulo un apartado para analizar la importancia de Internet como recurso para la referencia, que se centra exclusivamente en la aplicación de la red como recurso informativo, aportando una importante selección de recursos, que sirvan de ejemplo a esta concepción de Internet como herramienta para la referencia, tanto presencial como digital.

\subsection{Las fuentes de información}

La expresión «fuentes de información» es empleada comúnmente en la literatura profesional, a pesar de que no existe coincidencia sobre su sentido exacto. Isabel de Torres opina que «con el término fuente tomado en sentido amplio puede nombrarse cualquier material o producto, ya sea original o elaborado, que tenga potenciabilidad para aportar noticias o informaciones 0 que pueda usarse como testimonio para acceder al conocimiento» ${ }^{120}$. En un sentido más estricto, Isabel Villaseñor, partiendo de la definición de "fuente" que se realiza en el Diccionario de autoridades de la Real Academia Española, indica que «el término "fuentes de información" se identifica con el concepto de principio, fundamento y origen de la información, es decir, el punto del que se parte y al que se accede para conseguirla» ${ }^{121}$.

\footnotetext{
${ }^{119}$ Landesman opina que, a pesar de que los presupuestos de adquisiciones en colecciones de referencia siguen siendo elevados, no obstante, cada vez es más frecuente que se empleen recursos distintos de las colecciones propias para resolver las demandas de información. Véase Landesman, Margaret. Getting it right: the evolution of reference collections. The Reference Librarian, 2005, vol. 44, n. 91/92, p. 5-22. El doctorando coincide con esta autora en la necesidad de ampliar el concepto de colección de referencia.

${ }^{120}$ Torres Ramírez, Isabel de. Las fuentes de información: metodología del repertorio bibliográfico. En López Yepes, José (coor.). Manual de Ciencias de la Documentación. Madrid: Pirámide, 2002, p. 317.

${ }^{121}$ Villaseñor, Isabel. Las fuentes de información. En López Yepes, José (ed.). Manual de información y documentación. Madrid: Pirámide, 1996, p. 201.
} 
Tomando las opiniones de estas dos autoras, es posible entender "fuentes de información", en un sentido amplio, como cualquier recurso empleado para satisfacer una demanda de información. No obstante, es necesario matizar este concepto, ya que, a partir de esta definición tan amplia, podrían entenderse como fuentes tanto determinados documentos, como personas o instituciones. Por este motivo, y partiendo de una perspectiva restringida a la ciencia bibliográfica, habría que describir el concepto de "fuentes de información", en un sentido estricto, como los recursos informativos creados para facilitar datos sobre un persona, institución, documento o asunto.

Según José Antonio Cordón (et al.) «es preciso diferenciar entre "obra de referencia", cuyo concepto nos remite a una obra concebida con el exclusivo fin de proporcionar unas informaciones específicas de la manera más eficaz posible, y "fuente de referencia", que son distintos elementos que sin haber sido concebidos para suministrar una información específica pueden, en un determinado momento, constituirse en instrumentos fundamentales para responder una consulta» ${ }^{122}$. Esta idea equivale a la definición que se hizo en el párrafo anterior de fuentes de información en sentido amplio (fuentes de referencia) y en sentido estricto (obra de referencia).

Los autores anteriores ${ }^{123}$ realizan una clasificación de las obras de referencia basándose en la información que proporcionan:

- obras de referencia de información directa o inmediata: son aquellas que proporcionan directamente la información sin necesidad de tener que recurrir a otra fuente.

- obras de referencia de información indirecta o diferida: no proporcionan directamente la información, sino la descripción de los documentos susceptibles de contenerla.

Para Cordón (y otros), las obras de referencia de información directa son: enciclopedias, diccionarios, fuentes de información biográfica, directorios (listas de personas o instituciones), guías (fondos de archivos); mientras que en las obras de referencia de información indirecta se incluyen los siguientes tipos: repertorios bibliográficos, catálogos (de bibliotecas), boletines de sumarios, índices (de descriptores).

Isabel de Torres ofrece una sistematización más amplia de las fuentes de información ${ }^{124}$ : «Entre las obras de referencia de carácter inmediato o directo es preciso mencionar: enciclopedias, diccionarios enciclopédicos, diccionarios de la lengua, repertorios biográficos, anuarios, almanaques, guías o directorios, cronologías, atlas y otras fuentes de información geográfica, diccionarios varios (frases famosas, hechos curiosos), manuales y tratados. Dentro de las obras referenciales o indirectas se integran:

\footnotetext{
${ }^{122}$ Cordón García, José Antonio (et al.). Las obras de referencia. En Cordón García, José Antonio (et al.). Manual de investigación bibliográfica y documental: teoría y práctica. Madrid: Pirámide, 2001, p. 27.

${ }^{123}$ Cordón García, José Antonio (et al.). op. cit., p. 28-32.

${ }^{124}$ Torres Ramírez, Isabel de. op. cit., p. 320.
} 
bibliografías, catálogos de bibliotecas, catálogos colectivos, índices de artículos de publicaciones periódicas, revistas de resúmenes, índices de citas, boletines de sumarios y bibliografías de bibliografías».

También es necesario reflejar la diferencia entre fuentes de información y servicios de información, ya que aunque los servicios pueden ser también considerados como recursos de información es preferible entenderlos de forma diferente. Así, para el doctorando, estos dos conceptos pueden definirse de la siguiente forma:

- Fuentes de información: los recursos que se emplean para localizar datos de cualquier tipo, ya sea para cuestiones personales, formativas, administrativas u otra finalidad.

- Servicios de información: los sistemas que ofrecen determinados organismos para resolver consultas de los usuarios a los que atiende en función de su actividad.

Es difícil realizar clasificaciones a partir de los distintos tipos de fuentes de información existentes. Son muchos los autores que se han atrevido a sistematizar las obras y las fuentes de referencia, siempre partiendo de criterios específicos: temática, estructura, soporte, sistemas de acceso, etc., pero no existe una clasificación definitiva, debido a la heterogeneidad de los recursos de información disponibles, de los procedimientos y medios surgidos con la difusión de la redes y las nuevas tecnologías y, además, a causa del carácter híbrido de muchas fuentes de información, ya que es frecuente que los recursos informativos pueden adscribirse a varias categorías simultáneamente.

Las teorías tradicionales sobre fuentes de información -las existentes antes del desarrollo de Internet- han comenzado a dejar de ser útiles, dada la variedad de recursos de información existentes y la constante aparición de productos basados en las tecnologías que pueden ser empleados como recursos informativos. Por este motivo, se propone en esta tesis doctoral una nueva clasificación de los productos que se emplean en las secciones de referencia con fines informativos. Dicha clasificación se desarrolla en el apartado siguiente y está basada en el establecimiento de dos grandes categorías para clasificar los diferentes recursos de información. El primer grupo que se hace tiene en cuenta la función de la fuente de información, es decir, el tipo de demanda informativa que resuelve. El segundo grupo que se establece es a partir de la forma del documento, de su presentación como producto informativo. El doctorando encuentra que existen quince grandes categorías de fuentes de información, a partir de la función de las mismas, las cuales se subdividen en productos con distintas formas, a menudo coincidentes, tal y como se expone en los epígrafes siguientes. Para establecer claramente los conceptos, se ofrecen a continuación las definiciones en las que se asienta las tipologías que se desarrollan en el apartado 6.2. y que se sintetizan en el esquema del apartado 6.3. 
- Recursos de referencia: producto informativo de utilidad para resolver una consulta u ofrecer una información.

- Fuentes de información: de forma general, es un sinónimo tanto de recursos de información, como de recursos u obras de referencia; de forma estricta, es el producto concebido para facilitar datos.

- Clasificación funcional de los recursos de información: sistematización de las fuentes de información a partir del tipo de consulta que resuelvan.

- Clasificación formal de los recursos de información: sistematización de las fuentes de información a partir de la estructura del producto informativo.

\subsection{Tipología de los recursos de referencia}

Los recursos de información pueden clasificarse a partir de diversos criterios. De forma genérica, las fuentes pueden estructurarse en función del tipo de información que recogen, es decir, de la clase de demandas informativas que resuelven. Se trataría de una clasificación que parte de la función del recurso de información, es decir, de qué tipo de necesidad de información cubre. Desde esta perspectiva, existirían los siguientes tipos de fuentes de información:

\begin{tabular}{|c|c|}
\hline Informativas & Información sobre recursos de información \\
\hline Personales & Información sobre personas \\
\hline Institucionales & Información sobre organizaciones \\
\hline Bibliográficas & $\begin{array}{l}\text { Información sobre monografías, publicaciones } \\
\text { seriadas y otros documentos editados }\end{array}$ \\
\hline Documentales & $\begin{array}{l}\text { Información sobre documentos con acceso a su } \\
\text { texto completo }\end{array}$ \\
\hline Terminológicas & Información lexicográfica \\
\hline Geográficas & Información sobre lugares \\
\hline Históricas & Información sobre acontecimientos \\
\hline Estadísticas & Información estadística \\
\hline Normativas & Información legislativa, jurídica y normativa \\
\hline Temáticas & $\begin{array}{l}\text { Información sobre cualquier rama del } \\
\text { conocimiento }\end{array}$ \\
\hline Técnicas & Información sobre documentos técnicos \\
\hline Inéditas & Información sobre documentos no publicados \\
\hline Multimedia & Información sobre documentos audiovisuales \\
\hline Telemáticas & $\begin{array}{l}\text { Información sobre sitios web y otros recursos } \\
\text { accesibles en línea }\end{array}$ \\
\hline
\end{tabular}

Fig. 1.16. Tipología de las fuentes de información 
Muchas fuentes de información son híbridas, es decir, que podrían clasificarse en dos o más categorías de las que se acaban de exponer.

Dentro de cada uno de estos grandes tipos habría que realizar otras subdivisiones, partiendo de la forma bajo lo que se presentan las diferentes fuentes de información: bibliografías, manuales, sitios web,... Partiendo de la clasificación funcional de las fuentes de fuentes de información es posible desglosar los distintos tipos pertenecientes a cada una de las categorías, según la forma de cada recurso. En los siguientes párrafos se presentan los diferentes tipos de fuentes de información, los cuales se resumen en un cuadro clasificatorio en el apartado siguiente de esta sección de la tesis doctoral.

\section{Fuentes informativas}

Se emplean para localizar otras fuentes de información. Sirven, por tanto, para saber en qué obra o recurso puede ser localizado determinado dato o información necesitada. En esta categoría se encuentran los manuales y repertorios de obras de referencia, las bibliografías de bibliografías, los repertorios de bases de datos, los directorios de buscadores y los directorios analíticos de documentos web.

En los manuales y repertorios de obras de referencia se comentan las diferentes enciclopedias, diccionarios, manuales, etc., que existen sobre un tema. La diferencia consiste en que en los manuales se dan explicaciones acerca de cada tipología de fuentes de información, aparte de recopilar y comentar las existentes.

En este tipo de fuentes de información destacan en el ámbito anglosajón Reference and information services: an introduction ${ }^{125}$, de Libraries Unlimited; Reference and information services in the 21st century: an introduction $^{126}$, editado tanto por Neal-Schumman como por Facet; así como el clásico Introduction to reference work $^{127}$, publicado por McGraw-Hill. En la actualidad, el repertorio más completo, que todavía que no ha visto finalizada su edición, ya que están publicados sólo dos de los tres volúmenes previstos, es New Walfords Guide to Reference Sources ${ }^{128}$, editado en Europa por Facet y en Estados Unidos por Neal-Schuman.

Por lo que respecta a obras de este tipo sobre documentos de lengua francesa son interesantes Développer un fonds de référence en bibliothèque: imprimés, cédéroms, sites Internet ${ }^{129}$, de la editorial Cercle de la Librairie, que de alguna manera continúa la labor del repertorio clásico Ouvrages de

\footnotetext{
${ }^{125}$ Bopp, Richard E.; Smith, Linda C. (eds. ). Reference and information services: an introduction . $4^{\text {th }}$ ed. Englewood, CO: Libraries Unlimited, 2007.

${ }^{126}$ Cassell, Kay Ann; Hiremath, Uma. Reference and information services in the 21st century: an introduction. London: Facet, 2006.

${ }^{127}$ Katz, William A. Introduction to reference work. $8^{\text {th }}$ ed. New York: McGraw-Hill, 2002.

${ }^{128}$ Lester, Ray (ed.). New Walfords Guide to Reference Sources. London: Facet, 2005-.

${ }^{129}$ Béthery, Annie (dir.). Développer un fonds de référence en bibliothèque: imprimés, cédéroms, sites Internet. $5^{\mathrm{eme}}$. Paris: Cercle de la Librairie, 2001.
} 
réference pour les bibliothèques ${ }^{130}$, publicado en la misma editorial Cercle de la Librairie.

En España son pocas las obras que pueden considerarse dentro de esta categoría de información; entre las mismas destacan Obras de referencia: repertorio bibliográfico para bibliotecas públicas ${ }^{131}$, publicada por la Asociación Educación y Biblioteca. No obstante, sí existen algunos manuales de fuentes de información, como son: Las fuentes de información ${ }^{132}$, Manual de fuentes de información ${ }^{133}$ o Fuentes de información general ${ }^{134}$.

También pueden considerarse como repertorios de obras de referencia las recopilaciones de fuentes de información presentes en Internet. En este caso, se reúnen enciclopedias, diccionarios, directorios, etc., que son de libre acceso a través de Internet. Entre los distintos ejemplos existentes se pueden mencionar la Biblioteca de referencia en línea: <http://www.uned.es/biblioteca/referencia/PAGINAINICIO.HTML>

Las bibliografías de bibliografías son repertorios en los que se recopilan listados de bibliografías, por lo general ordenadas por temas. Un ejemplo es The bibliographic index: a cumulative bibliography of bibliographies, que publica la editorial estadounidense Wilson. La editorial ofrece información sobre este producto, que ahora edita como base de datos en http://www.hwwilson.com/Databases/biblio.htm.

Los repertorios de bases de datos son una buena fuente de información en la que se pueden encontrar las bases de datos públicas y comerciales que pueden consultarse sobre distintos temas. El más conocido a nivel internacional es Gale's directory of databases. Para las bases de datos accesibles en Internet es de gran utilidad Internet invisible, disponible en la dirección <http://www.internetinvisible.com>.

Los directorios de buscadores son una excelente herramienta para localizar fuentes de información presentes en Internet. Son recopilaciones que dan acceso a sistemas de búsqueda de Internet, por lo general, buscadores. Entre ellos destaca Buscopio, el cual se puede consultar en $<$ http://www.buscopio.net>.

Los directorios analíticos son otra importante fuente de información para la localización de páginas web de interés sobre un tema. Consisten en selecciones comentadas de sitios web, ordenados de forma temática. Existen múltiples ejemplos, entre los cuales destacan Internet Public Library

\footnotetext{
${ }^{130}$ Beaudiquez, Marcelle; Béthery, Annie; Albaric, Michel. Ouvrages de référence pour les bibliothèques: répertoire bibliographique. $4^{\mathrm{eme}}$ ed. Paris: Cercle de la Librairie, 1995.

${ }^{131}$ Asociación Educación y Bibliotecas. Obras de referencia: repertorio bibliográfico para bibliotecas públicas. $2^{\mathrm{a}}$ ed. Madrid: Tilde Servicios Editoriales, 1996.

${ }^{132}$ Torres, Isabel de (dir.). Las fuentes de Información: estudios teórico-prácticos. Madrid: Síntesis, 1998.

${ }^{133}$ Carrizo, Gloria; Irureta-Goyena, Pilar; López de Quintana, Eugenio. Manual de Fuentes de Información. Madrid: CEGAL, 1994.

${ }^{134}$ Martín Vega, Arturo. Fuentes de información general. Gijón: Trea, 1995.
} 
$<$ http://www.ipl.org>, Intute <http://www.intute.ac.uk> o BUBL <http://bubl.ac. uk/link $>$.

\section{Fuentes personales}

Este tipo de recursos se utilizan para conocer datos referentes a personas: vida, obra, información laboral, etc. En este grupo pueden incluirse las biografías, las enciclopedias y diccionarios biográficos, las enciclopedias generales y especializadas, las bases de datos de biografías, los denominados "Quién es quién" y los directorios de personas.

Las biografías son las monografías en las que se estudia la vida de una persona. Al tratarse de obras especializadas se convierten en las mejores fuentes de información sobre un determinado autor o personaje.

En muchos casos, las biografías aparecen en obras conjuntas; es lo que conoce como enciclopedias y diccionarios biográficos, dependiendo de si la ordenación es sistemática o alfabética, respectivamente. Uno de los mejores ejemplos de este tipo de obras es el Diccionario biográfico de autores Bompiani.

También pueden ser incluidas en esta categoría las enciclopedias, tanto las generales como las especializadas, que se explicarán más adelante, ya que todas incluyen información biográfica, además de temática.

Las bases de datos de biografías también pueden ser consideradas, de alguna forma, como diccionarios o repertorios biográficos, ya que el contenido es el mismo que en las fuentes mencionadas en el párrafo anterior; la única diferencia es que en las bases de datos la información es electrónica, y no está impresa, como ocurre con las enciclopedias y diccionarios biográficos. Como ejemplos pueden mencionarse algunas de las más significativas accesibles desde Internet: Biography <http://www.biography.com>, Busca biografías <http://buscabiografias.com> o Biographical dictionary <http://www.s9.com/biography>.

Los Quién es quién son una fuente de información similar a los diccionarios biográficos. Por lo general se estructuran por disciplinas o áreas geográficas. Entre los múltiples ejemplos destaca The International Who's who. Existen muchas obras dedicadas a colectivos concretos, como por ejemplo el Directorio de Expertos en el Tratamiento de la Información (EXIT) $<$ http://www.directorioexit.info $>$.

Por último, hay que mencionar los directorios de personas, también llamados "páginas blancas". Estas fuentes se distinguen por facilitar los datos de las personas que están vinculadas a una determinada institución o empresa. Un ejemplo es el directorio de la Universidad de Salamanca, que puede ser consultado desde la página principal de esta entidad <http://www.usal.es>, y que ofrece los datos de localización y puesto de trabajo del personal de esta universidad. 


\section{Fuentes institucionales}

Las fuentes de información institucionales son aquellas que aportan datos sobre empresas y entidades, ya sean históricos, de localización, de estructura, de su actividad o de cualquier otro tipo. Pueden considerarse pertenecientes a esta categoría los directorios de instituciones, las memorias, las guías institucionales y los anuarios.

Los directorios de instituciones, también llamados "páginas amarillas", son aquellos recursos en los que se facilitan datos de diversas empresas o entidades, sean del tipo que sean. Por lo general, son informaciones para la localización, como la dirección, el teléfono o el correo electrónico, aunque también se pueden incluir aquí las que tratan de su actividad, organización, etc. La forma de presentación de este tipo de fuentes varía entre las impresas, como The world of learning, directorio de centros educativos y de investigación de todo el mundo; las electrónicas, como el CD-ROM Directorio de telecomunicaciones e informática: empresas proveedoras; o a las que se accede en línea, como las Páginas Amarillas <http://www.paginasamarillas. es> o el directorio de administraciones Admiweb <http://www.admiweb.org>.

Otras fuentes de información sobre entidades son las memorias institucionales, en las que se explica la actividad desarrollada por las mismas en un período determinado, generalmente durante un año. Por ejemplo, Memoria del Ministerio de Cultura. También, las quías institucionales, publicaciones en cualquier soporte, en las que a grandes rasgos se presenta una entidad: historia, organización, actividades, etc. En muchos casos son folletos que aportan la información básica sobre la institución.

También se pueden incluir como fuentes de este tipo los anuarios institucionales, aunque en muchos casos son fuentes temáticas. Consisten en publicaciones que ofrecen datos sobre empresas 0 actividades económicas en un determinado año. Cuando se trata de los datos de una empresa, habría que hablar de memorias, pero sí es de un colectivo, entonces se suelen presentar como anuarios. Un ejemplo es el Anuario de empresas agrícolas de Andalucía.

\section{Fuentes bibliográficas}

Todo recurso que ofrezca información acerca de una publicación puede ser considerado como fuente de información bibliográfica. En sentido estricto se incluyen en esta categoría las fuentes que facilitan descripciones o referencias de monografías, partes de monografías, contribuciones a congresos, artículos de publicaciones periódicas, etc. No obstante, estas fuentes deben extenderse a cualquier tipo de documento en cualquier soporte. Partiendo de esta idea, es posible encontrarse con bases de datos bibliográficas, bibliografías, bibliografías analíticas, boletines de sumarios, boletines de resúmenes, índices acumulativos, repertorios de publicaciones periódicas, índices de citas, catálogos de bibliotecas, catálogos comerciales, boletines de críticas y reseñas, guías de archivos y catálogos de archivos. 
Las bases de datos bibliográficas permiten obtener información sobre monografías, artículos de publicaciones periódicas, etc. Las de mayor interés son las que realizan las agencias del ISBN, responsables del control de las publicaciones en venta en un país. Es importante la base Global books in print, que recoge información bibliográfica del ámbito anglosajón. En España la base de datos ISBN puede se consultada desde <http://www.mcu.es/comun/bases/isbn/ISBN.html>. Las bases de datos bibliográficas pueden ser identificadas a menudo con las bibliografías, ya que el contenido es el mismo, lo que difiere es la forma de acceso a la información.

Las bibliografías son repertorios de referencias bibliográficas. Existen diversos tipos, dependiendo de su contenido (generales y especializadas), del ámbito geográfico (nacionales, internacionales), de la fecha de publicación de los documentos incluidos (retrospectivas, corrientes), etc. Existen múltiples ejemplos de bibliografías, como es el caso de la Bibliografía española, una buena muestra del concepto de bibliografía nacional, que es aquella que se elabora para recoger toda la producción bibliográfica de un país o en una lengua. Está producida por la Biblioteca Nacional e integrada por los registros bibliográficos que han sido entregados a través del depósito legal.

También es importante destacar la existencia de las bibliografías analíticas. Se denomina así a una serie de fuentes de información en las que se puede encontrar de forma periódica los resúmenes de artículos aparecidos en revistas de todo el mundo. Por lo general, se agrupan por temas, como lo demuestran estos ejemplos: Psychological abstracts, Chemical abstracts, Historical abstracts, etc. También se pueden incluir aquí los Current contents, que recogen referencias y resúmenes de artículos de publicaciones periódicas.

En cuanto a las fuentes bibliográficas relativas a las publicaciones periódicas hay que destacar los boletines de sumarios, como aquella fuente que recoge los índices de varias revistas; los boletines de resúmenes, que consisten en repertorios en los que se pueden consultar el contenido de publicaciones periódicas, junto con un resumen de los artículos en ellas publicados; y los índices acumulativos, como un buen recurso para conocer en un solo documento qué artículos se han publicado en una determinada revista.

Por otra parte, para encontrar datos sobre publicaciones seriadas, la mejor fuente son las bases de datos y repertorios de publicaciones periódicas, en los que se organizan y describen los diarios, revistas y las restantes publicaciones en serie existentes. Estos repertorios se pueden presentar, una vez más, en forma impresa o electrónica.

El repertorio impreso más famoso es el Ulrich's international periodicals directory; en formato electrónico destaca la base de datos ISSN, publicada en soporte óptico y en línea <http://www.issn.org>. En esta categoría habría que incluir a los directorios de revistas electrónicas, como Latindex 
<http://www.latindex. unam.mx> o la Red de Revistas Científicas Españolas $<$ http://www.revicien. net>.

Los índices de citas también sirven para la recuperación de información bibliográfica, aunque su principal función es reunir en un mismo repertorio a los autores de los artículos publicados en revistas científicas con los autores que son citados por los mismos. Saber qué autor cita a quién y en qué artículo se produce la cita es un excelente recurso de información. Los índices de citas más destacados los realiza el "Institute for Scientific Information", responsable del Social Science Citation Index, del Science Citation Index y del Art \& Humanities Citation Index, entre otros.

A diferencia de las bibliografías, los catálogos de bibliotecas presentan la localización de las publicaciones que describen. De esta forma, además de disponer de información bibliográfica, se puede saber qué biblioteca tiene una obra. De especial valor son los catálogos colectivos, ya que reúnen colecciones de varias bibliotecas, indicando siempre, junto a los datos de un documento, en qué centro está y cuál es su signatura, es decir, la identificación de su localización. Catálogos de bibliotecas de todo el mundo pueden ser localizados desde Libdex <http://www.libdex.com>. Para España puede ser útil el directorio Bibliotecas españolas y de todo el mundo $<$ http://exlibris.usal.es/bibesp>, desde el que se indica qué bibliotecas tienen su catálogo en Internet.

Otras fuentes de información bibliográfica de gran interés son los catálogos comerciales, que editan librerías, editoriales y distribuidores y los $\underline{\text { boletines }}$ de críticas y reseñas. Por lo general, son recursos publicados por iniciativa privada y comercial, por lo que la información contenida en los mismos debe ser analizada. Estos boletines se realizan en papel o bien se ponen en línea a través de los webs de estas empresas, como ocurre, por ejemplo, con Amazon <http://www.amazon.com>. Son interesantes los servicios de alerta, a través de los cuales se envía por correo electrónico las reseñas de las novedades editoriales. Un buen ejemplo es el servicio de actualización bibliográfica de la empresa Díaz de Santos <http://www.diazdesantos.es>

Para obtener información bibliográfica de fondos archivísticos existen fuentes de información muy valiosas, como son las guías de archivos, también denominadas "guías del investigador". Se trata de una herramienta para conocer qué documentos están depositados en los mismos. Entre los múltiples ejemplos se pueden mencionar algunos importantes como el Censo-Guía de Archivos de España e Iberoamérica <http://aer.mcu.es/ sgae/index_censo_guia.jsp>.

Junto a estas guías están los catálogos de archivos, en los que se ofrece un mayor nivel de descripción de los documentos albergados en un archivo. En muchos casos los catálogos de archivos se diferencian de los catálogos bibliotecarios en que no recogen toda la colección, sino una determinada sección del archivo. Ejemplos de catálogos de archivos son el Catálogo del Archivo Histórico de la Universidad de Sevilla, accesible desde 
<http://publius.cica.esmanuscrito/fconsulta.catalogo.html> o el Catálogo de mapas y planos de la Sección Nobleza del Archivo Histórico Nacional.

\section{Fuentes documentales}

En determinados casos, sobre todo para investigaciones de carácter humanístico, es necesario informarse acerca de un documento concreto, pero también poder consultarlo. Para esto sirven las fuentes documentales: antologías, catálogos o colecciones documentales y bibliotecas digitales. Desde ellas se podrán conocer datos de diferentes escritos y, además, examinar su contenido.

Las antologías son un recurso de información consistente en la recopilación de textos seleccionados de un autor, época, género, tema, etc. Un ejemplo es la obra Teoría y crítica de la traducción: antología, con unos cien textos sobre traductología.

Por otra parte, los catálogos documentales o colecciones documentales recopilan también textos, ya sean facsímiles o no, de los documentos de uno o varios archivos. Un ejemplo es el Catálogo documental del Archivo de la Real Sociedad Económica de Amigos del País de Valencia 1877-1940. En este tipo de obras, a diferencia de los catálogos de archivos tradicionales, no sólo se recoge la descripción de un documento, sino también su texto íntegro.

Habría que incluir también en este apartado a las bibliotecas digitales, que suponen una forma sencilla de poder acceder en línea al texto completo de determinadas obras del pensamiento universal. Se trata de colecciones de documentos en formato digital, descritos a partir de técnicas documentales y disponibles para su consulta. Destacan en el ámbito internacional el Proyecto Gutenberg <http://www.gutenberg.org> y en el nacional la Biblioteca Virtual Miguel de Cervantes <http://www.cervantesvirtual.com>, entre las decenas existentes en Internet.

Por último, los repositorios también son una fuente de información documental, ya que alojan en servidores de uso compartido, textos electrónicos, artículos, informes, actas de congreso, etc., generalmente especializados en un tema. Los repositorios pueden ser localizados desde recursos como The Directory of Open Access Repositories (OpenDOAR) $<$ http://www.opendoar.org $>$.

\section{Fuentes terminológicas}

Los diccionarios son las fuentes de información lexicográfica por excelencia. Pueden ser considerados como tales aquellas obras en las que se da información sobre las voces o expresiones de una determinada lengua, ya sea para definirlas o para ofrecer su traducción a otros idiomas. Existen numerosas clasificaciones de los tipos de diccionarios existentes. Todas ellas parten de divisiones similares a los que desarrolla José Martínez de 
Sousa, quien en uno de sus diccionarios técnicos ${ }^{135}$, sistematiza las tipologías de los diccionarios a partir de criterios léxicos (generales, normativos, de autoridades, etimológicos, de argot, etc.), sintagmáticos (de construcción, de modismos, de refranes, de citas, etc.), paradigmáticos (onomasiológicos, ideológicos, de sinónimos, etc.), terminológicos (especializados, tecnológicos, de abreviaciones, de dudas, de incorrecciones, de topónimos, etc.) y enciclopédicos (de materias, regionales, etc.). Además, este autor incluye otras clasificaciones de los diccionarios basadas en aspectos históricos (diacrónicos y sincrónicos), de la lengua (monolingües, bilingües, multilingües), de la presentación (alfabéticos, sistemáticos, etc.), de la forma (abreviados, básicos, escolares, etc.), de la edición (actuales, prácticos, razonados, etc.), formato (breve, bolsillo, etc.) y de la publicación (por entregas, informático, etc.).

En la actualidad los diccionarios se presentan en diversos soportes: impresos, CD-ROM, en línea, etc. Una buena fuente de información es La página de los diccionarios alojada en <http://www.jamillan.com/dicciona. $\mathrm{htm}>$. Como directorio de diccionarios en línea destaca Your dictionary $<$ http://www.yourdictionary.com>, que ofrece múltiples enlaces a diccionarios de la lengua, especializados, vocabularios, etc.

También las enciclopedias pueden ser consideradas como fuentes de información lexicográficas, ya que suelen describir los términos contenidos en las mismas. De igual forma podrían ser incluidos aquí los tesauros, entendidos como vocabularios o listados de términos agrupados por familias semánticas, empleados para el análisis documental y la recuperación de la información, y los glosarios, que son relaciones de palabras seleccionadas ya sea por su tema, origen o cualquier otra circunstancia y que están acompañadas de breves descripciones de su significado, uso, historia, etc. Muchos de los tesauros y vocabularios empleados para el análisis de contenido y la recuperación de información pueden ser localizados y consultados desde el directorio especializado en clasificación y tesauros Controlled vocabularies <http://www.imresources.fit.qut.edu.au/vocab/>.

\section{Fuentes geográficas}

Las fuentes de información geográficas se emplean para obtener datos acerca de un lugar determinado: país, región, localidad, etc. Las obras más habituales de este tipo de fuentes son los mapas, planos y callejeros, los atlas, las guías geográficas, los denominados "estado del mundo", los diccionarios geográficos y las enciclopedias generales. También hay que incluir como una fuente de información de reciente aparición los servidores de información geográfica. Por lo general, en todos estos tipos de fuentes son muy importantes las imágenes; en muchos casos, más que los textos, dada la información que facilitan.

Las fuentes de información geográficas básicas son los mapas, representaciones más o menos detalladas de un área. Por lo general, los

\footnotetext{
${ }^{135}$ Martínez de Sousa, J. Diccionario de lexicografía práctica. Barcelona: Bibliograf, 1995,
} p. 116-117. 
planos son equivalentes a los mapas, pero con una doble acepción. Por una parte, pueden ser considerados mapas con un mayor nivel de detalle o escala $\mathrm{y}$, por otra parte, se entiende también como plano la imagen esquematizada de un lugar, ya sea para destacar su relieve, hidrografía, comunicaciones o cualquier otro aspecto.

Además, los callejeros son mapas o planos en los que se representa la ordenación urbana de una determinada localidad. Sin embargo, la fuente de información geográfica más común son los atlas, obras formadas por conjuntos de mapas, planos e, incluso, callejeros. El contenido y la precisión de los atlas dependerán de la intención de sus editores, ya que pueden abarcar toda la tierra, un determinado continente, país, región, etc., así como ser más generales u ofrecer escalas muy detalladas de las diferentes áreas recogidas.

Una fuente importante para obtener información sobre un país o área son las guías geográficas. Son monografías en las que se estudia todo lo referente a una zona: historia, geografía, costumbres, accesos, cultura y turismo, etc. Al tratarse de fuentes editoriales, la calidad de las mismas dependerá de la institución que las publica y de la orientación bajo la que se haya redactado la obra: turística, divulgativa, académica, ... La presentación de estas guías también es muy diferente, ya que pueden difundirse bajo la forma de libros, folletos, CD-ROM o como páginas web.

Los estados del mundo, también llamados «facts», son fuentes de información que recogen todos los datos relativos a un país en un momento concreto. Son de sumo interés porque reúnen información histórica (acontecimientos principales, bandera, himno, etc.) y geográfica (extensión, clima, etc.), junto a datos de actualidad (gobierno, población, economía, etc.). En español se publica de forma regular la obra El estado del mundo de la editorial Akal, que supone un buen ejemplo de este tipo de obras de referencia. En el ámbito internacional destaca CIA world fact book, accesible desde <http://www.theodora.com/wfb/>.

Los diccionarios geográficos o «gazetteers» son obras en las que se disponen los topónimos en orden alfabético. Ofrecen información de cada uno de los lugares incluidos e, incluso, mapas o ilustraciones. En la actualidad se ofrecen también en forma de base de datos. Una fuente similar son los tesauros geográficos, en los que se ofrecen los nombres de los lugares, junto a sus variantes lingüísticas y las formas relacionadas. Entre los más importantes internacionalmente está el Getty Thesaurus of Geographic Names <http://www.getty.edu>.

También las enciclopedias generales pueden ser consideradas fuentes de referencia geográficas, ya que, junto a las entradas temáticas y a las lingüísticas, se incluyen en las mismas informaciones sobre lugares.

Los servidores de información geográfica son otro excelente recurso para recuperar datos o imágenes sobre un país o área determinada. Por lo general, presentan diferentes categorías: información sobre lugares, mapas, 
datos turísticos, etc. Como ejemplos destacados están Mapquest $<$ http://www.mapquest.com>, The Virtual Tourist <http://www.virtualtourist. com> o Geographic <http://www.geographic.org>.

\section{Fuentes históricas}

Las fuentes de información histórica sirven para conocer los acontecimientos sucedidos a lo largo del tiempo. Aunque podrían ser consideradas fuentes temáticas, es preferible contemplarlas como una tipología independiente, ya que las fuentes históricas pueden referirse a cualquier disciplina, aparte de la historia, como una de las ciencias sociales. Pueden considerarse dentro de este grupo de obras de referencia las cronologías, los anuarios, los almanaques, los atlas históricos, las enciclopedias generales y las monografías especializadas.

Las cronologías son obras en las que se recogen los datos históricos ocurridos durante un período de tiempo determinado. Su principal característica es que la información se dispone cronológicamente, desde la fecha de partida de la obra hasta los acontecimientos más recientes. Si la obra trata de un único año, entonces se denominan anuarios. Existen muchas obras que utilizan estas formas para presentar la historia internacional, local, de una disciplina, etc. En España son famosas las distintas obras editadas por Plaza \& Janés, como Crónica del siglo $X X$, Crónica de la Humanidad o Crónica de España; también hay que destacar otros anuarios como los editados por diarios como El País y El Mundo o el Anuario de los hechos, de la editorial Difusora Internacional.

Los almanaques son obras de contenido similar; se presentan bajo la forma de calendarios e incluyen datos meteorológicos, astronómicos, religiosos, además de las efemérides históricas. Un ejemplo es The Hispanic American Almanac, de la editorial Gale.

Sin duda, los atlas históricos también son una excelente fuente de referencia histórica. Se distinguen porque explican la historia mediante mapas y gráficos, algo que es de mayor utilidad para comprender el desarrollo de batallas, migraciones, procesos de colonización y descolonización, etc.

Como fuentes de información amplias también útiles como recurso histórico hay que considerar a las enciclopedias generales y a las monografías especializadas, redactadas desde una perspectiva histórica.

\section{Fuentes estadísticas}

Las estadísticas son indispensables para conocer datos numéricos correspondientes a una actividad o institución. Si la presentación se realiza de forma anual, entonces se denominan anuarios estadísticos. Un ejemplo es el Anuario estadístico de Castilla y León, que edita la Junta de Castilla y León. Las estadísticas pueden estar elaboradas por empresas especializadas o por organismos públicos, como ocurre en España con el Instituto Nacional de Estadística, que difunde sus estadísticas a través del 
servicio denominado Banco de datos Tempus <http://www.ine.es> y en la Unión Europea con Eurostat, oficina de la Comisión Europea para la realización de informes estadísticos, siendo muchos de ellos de pago: $<$ http://www.europa.eu.int/comm/eurostat/>. Sus estudios son los principales recursos para conocer estadísticas en España y Europa, respectivamente.

\section{Fuentes normativas}

Las publicaciones generadas por los órganos legislativos y judiciales son de gran valor e interés. Existen múltiples recursos para localizar este tipo de información. Como fuentes primarias o directas destacan los boletines oficiales y los textos legislativos $y$, entre las fuentes de información secundarias o indirectas, se incluirían las bases de datos jurídicas y los repertorios legislativos. También hay que considerar como una fuente de información normativa los portales jurídicos, accesibles en Internet.

Los boletines oficiales son las publicaciones que editan las distintas administraciones para difundir las normas y decisiones aprobadas por las mismas. Se editan en papel, aunque también existen versiones de muchos de ellos en soporte óptico (CD-ROM) y telemático (Internet). Un buen directorio de boletines oficiales está accesible desde <http://www.internenes. com/ boletines>.

Los textos legales también son una fuente de información de primer orden, ya que recogen la legislación en vigor en un país o área geográfica. Existen muchas editoriales especializadas en estas materias. En España sobresalen Tecnos, La Ley y Civitas.

Las referencias de las leyes, normas y sentencias, e incluso sus textos completos, se recogen en las bases de datos jurídicas y en los repertorios legislativos. Una vez más, las diferencias estriban en la forma de acceso a la información recopilada en estas fuentes. Mientras que las bases están automatizadas, los repertorios se editan en papel. No obstante, son las mismas empresas las que se dedican a la información legal y a la edición de las mismas fuentes en formato impreso (repertorios) y automatizado (bases de datos).

En España destacan las bases de datos y repertorios Aranzadi, La Ley y El Derecho. También hay que destacar en cuanto a las bases de datos legislativas, las que edita el Boletín Oficial del Estado <http://www.boe.es/g/es/iberlex/>, sobre todo Iberlex, que contiene la legislación española. Además hay que mencionar como una importante fuente normativa a Eurlex, base de datos que realiza la Unión Europea con las normas en vigor en los estados pertenecientes a la Unión Europea $<$ http://eur-lex.europa.eu/es/index.htm>.

Han aparecido en Internet muchos portales jurídicos gratuitos. Actúan por una parte como bases de datos, desde las que localizar las referencias de normas legales y/o de sentencias; pero, por otra parte, facilitan el acceso a los textos íntegros de las leyes, decretos, normas, etc., recogidos en los 
mismos. Se denominan portales porque, además de la información legal, ofrecen servicios complementarios: directorios de personas e instituciones, información bibliográfica especializada, etc. Sin duda, son una buena muestra de fuente de información híbrida. En España existen distintos portales de este tipo, entre los que pueden citarse Todalaley <http://www. todalaley.com> o Jurisweb <http://www.jurisweb.com>.

\section{Fuentes temáticas}

Las informaciones sobre un tema o disciplina se podrán encontrar en enciclopedias, manuales y tratados, monografías especializadas y recursos web.

Las enciclopedias son los compendios del saber por definición, ya que acumulan el conocimiento y lo presentan de forma sistematizada. Es posible encontrar diferente tipos de enciclopedias, según se atienda a su ordenación (alfabética, por materias), su contenido (generales, especializadas), su formato (impresas, CD-ROM, Internet) o en virtud de otros criterios (cobertura cronológica, destinatarios, área geográfica, etc.).

No obstante, lo que identifica a cualquier enciclopedia es el objetivo de ofrecer de forma organizada el saber acerca de un tema o sobre múltiples temas. Ejemplos de enciclopedias universales o generales son la Britannica, la Espasa y la Larousse. En cuanto a las enciclopedias en CD-ROM, tienen una gran difusión la Encarta y la Enciclopedia Universal Micronet. Está última tiene su correlato en Internet bajo el nombre de Enciclonet $<$ http://www.enciclonet.com>.

Los manuales y tratados son otra excelente fuente de información sobre un tema. Se denominan así a las monografías que tratan de recoger todo el conocimiento sobre un tema. Los tratados se diferencian por su carácter exhaustivo, ya que intentan recoger todos los conocimientos habidos sobre una materia; mientras que los manuales parten de una intención más didáctica.

Por otra parte, las monografías especializadas, que muchas veces pueden confundirse con los manuales y los tratados, son las obras que tratan aspectos concretos de un tema, pero desde una visión limitada del mismo, ya que las monografías estudian un tema, pero parcialmente, sin intención de estudiar todo sobre el mismo (tratados) ni de explicar los diferentes aspectos relativos a esa materia (manuales).

Del mismo modo, una fuente temática puede ser una publicación periódica, sobre todo si son de tipo especializado. También se pueden incluir como fuentes especializadas los informes, estudios que aportan una visión sintética y actual sobre un determinado tema o asunto. Si los informes no han sido publicados, como ocurre en la mayoría de las ocasiones, entonces habría que incluir este tipo de documentos entre las fuente inéditas. 
En las fuentes de información temáticas cabrían muchas variantes, ya que existen multitud de posibilidades para informarse sobre un asunto 0 disciplina. Además de las anteriormente citadas, habría que incluir a los recursos web, englobando bajo esta denominación a cualquier documento accesible en línea en el que se encuentre información sobre un tema.

\section{Fuentes técnicas}

Existen diferentes tipos de información especializada, necesaria sobre todo con fines tecnológicos y empresariales. Se trata de las patentes, marcas y las normas técnicas. Las patentes son los documentos que dan derecho a la explotación de un invento; las marcas adjudican la propiedad del uso del nombre de un producto o servicio y las normas son las especificaciones de tipo nacional o internacional que regulan de forma oficial la realización de una determinada actividad o producto. Junto a este tipo de documentos hay que estudiar las fuentes inéditas, ya que a menudo son recogidas de forma conjunta en bases de datos y repertorios. Existen diferentes bases de datos y repertorios de patentes, marcas y normas.

La información que facilitan es la misma, pero no la forma de acceso a los datos. Las bases de datos emplean procedimientos automatizados, mientras que los repertorios son obras impresas. No obstante, estos dos tipos de fuentes pueden ser considerados como una misma, ya que en ambas se recopila información similar. Para la patentes existen fuentes internacionales, muchas de ellas accesibles en línea, como las que selecciona la Organización Mundial de la Propiedad Intelectual en su Intellectual Property Digital Library <http://ipdl.wipo.int> o las de la base de datos Questel-Orbit.

En España, son escenciales las bases de datos de la Oficina Española de Patentes y Marcas (OEPM) <http://www.oepm.es/internet/bases_datos.htm>, sobre todo Oepmpat, en la cual se encuentran las patentes y los modelos de utilidad españoles. Para conocer qué normas existen lo mejor es consultar los catálogos de normas y bases de datos elaborados por los distintos organismos responsables, como son el ISO Catalogue, de la International Organization for Standardization (ISO) <http://www.iso.ch>, en el ámbito internacional, y el Catálogo de Normas UNE, de la Asociación Española de Normalización y Certificación (AENOR) <http://www.aenor.es>, en el terreno nacional.

\section{Fuentes inéditas}

Las fuentes de información inéditas son aquellas que ofrecen datos acerca de la denominada "literatura gris", es decir, documentos que no han sido publicados y que, por tanto, no han sido distribuidos por los canales editoriales tradicionales. Como literatura gris se conocen los informes, actas de congresos, proyectos de investigación y las traducciones no editadas. Además, se incluyen otras categorías vistas en el apartado anterior, como son las patentes y las normas. La mejor fuente de información de este género son las bases de datos y repertorios de literatura gris, ya sean generales o por tipos de documentos (actas, tesis, traducciones, etc.). 
Entre las la principales bases de datos de literatura gris destaca OpenSIGLE $<$ http://opensigle.inist.fr>, que continúa la labor del System for Information on Grey Literature in Europe (SIGLE), realizada de forma cooperativa por varias entidades europeas, coordinadas por The European Association for Grey Literature in Europe (EAGLE) y que tiene información sobre informes, comunicaciones a congresos, tesis doctorales y estadísticas. Entre las fuentes especializadas en alguna de las tipologías de los documentos inéditos, es necesario destacar la Base de Datos de Transferencia de Resultados de Investigacion (DATRI), donde se pueden conocer los grupos de investigación españoles y sus líneas de trabajo. La base de datos del National Technical Information Service (NTIS) <http://www.ntis.gov> es un buen recurso para localizar informes técnicos, sobre todo elaborados en Estados Unidos. De igual forma existen importantes fuentes para localizar actas de congresos; entre ellas sobresalen los ISI Proceedings, elaborados por el Institute for Scientific Information (ISI).

Para la localización de tesis doctorales leídas en universidades españolas es fundamental la base de datos Teseo, elaborada por el Ministerio de Educación y Ciencia y accesible desde la dirección de Internet <http://teseo.mec.es/teseo/jsp/teseo.jsp>. Las bases de datos más importantes para la localización de tesis doctorales y otros trabajos de investigación son las que desarrolla la empresa UMI, hoy perteneciente al grupo ProQuest, <http://www.umi.com/hp/Products/Dissertations.html>. Se trata de las bases de datos Dissertation Express y ProQuest Digital Dissertations, que, además de dar las informaciones básicas de los documentos, ofrecen la posibilidad de acceder al texto completo de los mismos.

En los repertorios y bases de datos de literatura gris también se recogen traducciones de documentos técnicos. No obstante, existen fuentes de referencia específicas, como es el repertorio World translation index, del International Translation Centre (ITC). Como fuentes de información de traducciones también están los catálogos y bases de datos en línea de centros de suministro de documentos, como el del British Library Document Supply Service o el del Institut de I'Information Scientifique et Technique (INIST).

Todos los tipos de documentos que se conciben como literatura gris tendrían su ubicación en este grupo de fuentes de información. Así, habría que hablar de varias categorías. Los informes son documentos que aportan información sintética y actual sobre un tema. Los proyectos de investigación son documentos en los que se presentan las conclusiones de estudios realizados por equipos de investigadores acreditados. Las tesis son trabajos de investigación presentados para conseguir grados académicos, tanto el título de doctor como estudios superiores.

Las comunicaciones científicas son documentos presentados a congresos especializados y reuniones científicas, en las que se ofrecen innovaciones y experiencias sobre determinadas ramas de conocimiento o actividades profesionales. El documento que reúne los trabajos presentados a un 
congreso se denomina actas. En muchos casos, estos productos informativos se encuentran publicados, por lo que no se incluirían en este apartado de la clasificación de las fuentes, sino como monografías, dentro de las fuentes temáticas.

\section{Fuentes multimedia}

En muchas ocasiones será necesario localizar documentos de imagen y/o sonido. Cuando ocurra esto se deberán emplear fuentes de información similares a las anteriormente vistas, en cuanto a la descripción y sistema de acceso a la información, pero especializadas en documentos audiovisuales. Las fuentes de información multimedia son muy similares entre sí, por lo que pueden englobarse en las bases de datos y repertorios de documentos multimedia, aunque también se pueden incluir los buscadores especializados, como un tipo de base de datos de documentos audiovisuales disponibles en Internet.

Las bases de datos y repertorios de documentos multimedia identifican documentos de imagen, sonido, etc. En muchos casos forman parte de las fuentes de información bibliográfica, por lo que es habitual que las bases de datos bibliográficas o los catálogos de bibliotecas, por ejemplo, incluyan entre sus documentos a los vídeos, CD-ROM, DVD y demás documentos multimedia. No obstante, existen fuentes desde las que se pueden localizar de forma independiente estos tipos de documentos, como, por ejemplo, The multimedia and CD-ROM directory, que edita TFPL Publishing, La Guía del vídeo-cine, de la editorial Cátedra o la Base de datos Cederrón, de la Fundación Germán Sánchez Ruipérez <http://www.fundaciongsr.es/cdrom>.

Entre este tipo de fuentes de información se pueden incluir los buscadores especializados. Esta denominación se aplicaría a las fuentes de recuperación telemática desde las que se localizan documentos multimedia accesibles en Internet. Algunos ejemplos son Altavista Image Search $<$ http://www.altavista.com/image>, para imágenes; The classical music archives <http://www.classicalarchives.com>, para archivos de audio o el web OjoTV <http://www.ojotv.com>, para cámaras web que transmiten directo vía Internet.

\section{Fuentes telemáticas}

Las fuentes de información telemáticas se emplean recuperar documentos presentes en Internet, ya sean páginas web o de otro tipo. Es importante dejar constancia de que estos recursos son complementarios a muchos de los analizados anteriormente, pero que se diferencian de ellos porque las telemáticas son fuentes que están en Internet y que han sido creadas para localizar documentos que también están en la red.

Las categorías de las fuentes que pueden ser consideradas telemáticas son los buscadores, los índices, los portales, los repertorios de recursos telemáticos, los servidores y sitios web en sus múltiples formatos y los sistemas de mensajería. 
Los buscadores son bases de datos de documentos existentes en Internet, sobre todo páginas web. Dado su carácter de bases de datos, se trata de un recurso donde la información se recupera de forma automatizada, partiendo de búsquedas por términos. Pero, lo habitual es que vayan acompañados de índices, en los cuales se parte de grandes categorías temáticas que se irán delimitando hasta encontrar las informaciones que más se ajusten al tema de la búsqueda. Los mejores ejemplos de buscadores, que a su vez incorporan índices temáticos, son los de Google <http://www.google.com> y Yahoo <http://www.yahoo.com>.

Junto a estas dos fuentes hay que mencionar a los portales, que son fuentes telemáticas que cuentan con buscadores e índices, pero a los que añaden otros recursos de información: noticias, servicios de comunicaciones, directorios de personas e instituciones, traductores, etc. Un ejemplo de portal horizontal, es decir, el que trata de todo tipo de disciplinas, es Terra $<$ http://www.terra.es> y, como portal vertical o especializado, en este caso en veterinaria, puede ponerse como ejemplo Portal Veterinaria $<$ http://www.portalveterinaria.com>.

Los repertorios de recursos telemáticos son selecciones de documentos en línea sobre un tema. Por lo general, los realizan personas muy relacionadas con la materia objeto de la selección. Son muy importantes las recopilaciones que junto a los enlaces incluyen información acerca de la autoría, del contenido y sobre su calidad. Como muestra de los repertorios de recursos telemáticos pueden citarse los que elaboran los servicios bibliotecarios de las universidades, por ejemplo el que realiza la Universidad Complutense de Madrid <http://www.ucm.es/BUCM/frames07.htm>.

En muchas ocasiones la mejor fuente de información sobre tema son los sitios web especializados en esa materia. A través de los buscadores e índices se pueden localizar centenares de sitios en Internet que recopilan toda la información posible sobre un tema. Este tipo de recursos no sólo ofrecen enlaces a otros recursos, sino que destacan por la gran cantidad de información que ponen a disposición de cualquier usuario de Internet. Como un ejemplo significativo puede considerarse el servidor del Ministerio de Administraciones Públicas <http://www.map.es>, útil para localizar todo lo relacionado con información administrativa en España. Dentro de los sitios web se incluyen múltiples recursos: bitácoras o weblogs, wikis, páginas personales, etc. Todos se ellos se presentan bajo tecnología HTML o similar, por lo que se incluyen en esta gran categoría.

Otro recurso telemático son los sistemas de mensajería, entendiendo por tales los servicios que permiten enviar un mensaje para que lo reciban de forma simultánea un conjunto de usuarios. Entre estos sistemas destacan los grupos de noticias y las listas de distribución, en ambos casos compuestos por usuarios interesados en intercambiar información sobre un tema. En las listas de distribución, el usuario se suscribe mediante correo electrónico a una lista determinada y, cada vez que un miembro de la misma envíe un mensaje, éste será reenviado de forma automática a todos los integrantes de la lista de distribución. Como ejemplos pueden mencionarse 
las listas de distribución españolas que aloja RedIRIS, red científica y académica española y que pueden ser localizadas desde su directorio: $<$ http://www.rediris.es/list/tema/tematic.es.html>.

Por último, entre los recursos telemáticos habría que incluir las redes

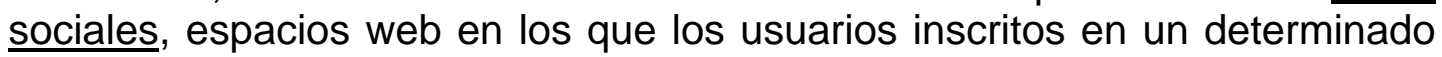
colectivo intercambian informaciones y documentos. Se tratan de redes cerradas, a las que se accede mediante la invitación de un miembro del grupo. En muchos casos son agrupaciones profesionales, por lo que suponen un sistema de intercambio de información útil para los servicios de referencia. Ejemplos de redes sociales profesionales son Facebook <http://www.facebook.com>, Linkedin <http://www.linkedin.com> o Xing $<$ http://www.xing.com>.

\subsection{Esquema de la Clasificación Funcional/Formal}

Para disponer de una presentación más gráfica y sintética de los diferentes tipos de fuentes de información tratados en los apartados anteriores, se ha elaborado esta tabla, como sinopsis de las diferentes fuentes de información existentes a partir de la función que desempeñan, junto a las diferentes manifestaciones en las que se pueden consultar, según la forma en la que se han editado o se presentan.

Función
Fuentes informativas

Fuentes personales

Fuentes institucionales

Fuentes bibliográficas

\section{Forma}

Manuales de obras de referencia

Repertorios de obras de referencia

Bibliografías de bibliografías

Repertorios de bases de datos

Directorios de buscadores

Directorios analíticos

\section{Biografías}

Enciclopedias biográficas

Diccionarios biográficos

Enciclopedias

Bases de datos de biografías

Quién es quién

Directorios de personas

Directorios de instituciones

Memorias institucionales

Guías institucionales

Anuarios institucionales

Bases de datos bibliográficas

Bibliografías

Bibliografías analíticas

Boletines de sumarios

Boletines de resúmenes

Índices acumulativos

Repertorios de publicaciones periódicas

Bases de datos de publicaciones periódicas

Índices de citas

Catálogos de bibliotecas 
Fuentes documentales

Fuentes terminológicas

Fuentes geográficas

Fuentes históricas

Fuentes estadísticas

Fuentes normativas

Fuentes temáticas

Fuentes técnicas

Fuentes inéditas
Catálogos comerciales

Boletines de críticas y reseñas

Guías de archivos

Catálogos de archivos

Antologías

Catálogos documentales

Bibliotecas digitales

Repositorios

Diccionarios

Enciclopedias

Tesauros

Glosarios

Mapas

Planos

Callejeros

Atlas

Guías geográficas

Estados del mundo

Diccionarios geográficos

Enciclopedias

Tesauros geográficos

Servidores de información geográfica

Cronologías

Anuarios

Almanaques

Atlas históricos

Enciclopedias

Monografías especializadas

Estadísticas

Anuarios estadísticos

Boletines oficiales

Textos legales

Bases de datos jurídicas

Repertorios legislativos

Portales jurídicos

Enciclopedias

Manuales

Tratados

Monografías especializadas

Publicaciones periódicas

Informes

Recursos web

Bases de datos de patentes, marcas y normas

Repertorios de patentes, marcas y normas

Bases de datos de literatura gris

Repertorios de literatura gris

Informes

Proyectos de investigación

Tesis

Comunicaciones científicas

Actas 


\section{Fuentes multimedia}

Fuentes telemáticas
Bases de datos de documentos multimedia Repertorios de documentos multimedia Buscadores especializados

\author{
Buscadores \\ Índices \\ Portales \\ Repertorios de recursos telemáticos \\ Servidores web \\ Sistemas de mensajería \\ Redes sociales
}

Asimismo, esta clasificación se puede ofrecer de forma inversa, partiendo de la forma de las fuentes de información. En este caso, la relación de tipos de recursos de información sería la siguiente:

\section{Forma}

\section{Actas}

Almanaques

Antologías

Anuarios

Anuarios estadísticos

Anuarios institucionales

Atlas

Atlas históricos

Bases de datos bibliográficas

Bases de datos de biografías

Bases de datos de documentos multimedia

Bases de datos de literatura gris

Bases de datos de patentes, marcas y

normas

Bases de datos de publicaciones periódicas

Bases de datos jurídicas

Bibliografías

Bibliografías analíticas

Bibliografías de bibliografías

Bibliotecas digitales

Biografías

Boletines de críticas y reseñas

Boletines de resúmenes

Boletines de sumarios

Boletines oficiales

Buscadores

Buscadores especializados

Callejeros

Catálogos comerciales

Catálogos de archivos

Catálogos de bibliotecas

Catálogos documentales

Comunicaciones científicas

Cronologías

Diccionarios

Diccionarios biográficos

Diccionarios geográficos

\section{Función}

Fuentes inéditas

Fuentes históricas

Fuentes documentales

Fuentes históricas

Fuentes estadísticas

Fuentes institucionales

Fuentes geográficas

Fuentes históricas

Fuentes bibliográficas

Fuentes personales

Fuentes multimedia

Fuentes inéditas

Fuentes técnicas

Fuentes bibliográficas

Fuentes normativas

Fuentes bibliográficas

Fuentes bibliográficas

Fuentes informativas

Fuentes documentales

Fuentes personales

Fuentes bibliográficas

Fuentes bibliográficas

Fuentes bibliográficas

Fuentes normativas

Fuentes telemáticas

Fuentes multimedia

Fuentes geográficas

Fuentes bibliográficas

Fuentes bibliográficas

Fuentes bibliográficas

Fuentes documentales

Fuentes inéditas

Fuentes históricas

Fuentes terminológicas

Fuentes personales

Fuentes geográficas 
Directorios analíticos

Directorios de buscadores

Directorios de instituciones

Directorios de personas

Enciclopedias

Enciclopedias biográficas

Estadísticas

Estados del mundo

Glosarios

Guías de archivos

Guías geográficas

Guías institucionales

Índices

Índices acumulativos

Índices de citas

Informes

Manuales

Manuales de obras de referencia

Mapas

Memorias institucionales

Monografías especializadas

Monografías especializadas

Planos

Portales

Portales jurídicos

Publicaciones periódicas

Proyectos de investigación

Quién es quién

Recursos web

Redes sociales

Repertorios de bases de datos

Repertorios de documentos multimedia

Repertorios de literatura gris

Repertorios de obras de referencia

Repertorios de patentes, marcas y normas

Repertorios de publicaciones periódicas

Repertorios de recursos telemáticos

Repertorios legislativos

Repositorios

Servidores de información geográfica

Servidores web

Sistemas de mensajería

Tesauros

Tesauros geográficos

Tesis

Textos legales

Tratados
Fuentes informativas

Fuentes informativas

Fuentes institucionales

Fuentes personales

Fuentes temáticas

Fuentes personales

Fuentes geográficas

Fuentes históricas

Fuentes terminológicas

Fuentes personales

Fuentes estadísticas

Fuentes geográficas

Fuentes terminológicas

Fuentes bibliográficas

Fuentes geográficas

Fuentes institucionales

Fuentes telemáticas

Fuentes bibliográficas

Fuentes bibliográficas

Fuentes inéditas

Fuentes temáticas

Fuentes temáticas

Fuentes informativas

Fuentes geográficas

Fuentes institucionales

Fuentes temáticas

Fuentes históricas

Fuentes geográficas

Fuentes telemáticas

Fuentes normativas

Fuentes temáticas

Fuentes inéditas

Fuentes personales

Fuentes temáticas

Fuentes telemáticas

Fuentes informativas

Fuentes multimedia

Fuentes inéditas

Fuentes informativas

Fuentes técnicas

Fuentes bibliográficas

Fuentes telemáticas

Fuentes normativas

Fuentes documentales

Fuentes geográficas

Fuentes telemáticas

Fuentes telemáticas

Fuentes terminológicas

Fuentes geográficas

Fuentes inéditas

Fuentes normativas

Fuentes temáticas 


\subsection{Internet como recurso para la referencia}

Internet es el medio que hace posible la referencia digital. A través de sus servicios las bibliotecas y los usuarios pueden comunicarse e intercambiarse datos y documentos. Pero Internet también es la gran base de consulta a la que acudirán constantemente los profesionales referencistas ${ }^{136}$, incluso antes a que a sus propias obras de referencia. Los recursos gratuitos se entremezclan con los comerciales; los recursos propios y los externos se unen; los centros y las personas están relacionados entre sí. Todo parece estar al alcance del ratón, sobre todo en la actualidad, donde la web social está convirtiendo Internet en una plataforma en constante crecimiento, donde los conocimientos se comparten, a menudo desinteresadamente ${ }^{137}$.

Desde los orígenes de Internet, muchos fueron los que percibieron su potencial como herramienta para los servicios bibliotecarios de referencia ${ }^{138}$, aunque en un principio se encontraran reticencias sobre el valor de la información disponible en Internet ${ }^{139}$. Pero rápidamente Internet se convierte en la primera fuente de información de la referencia y así se aprecia en la abundante bibliografía sobre el tema publicada en revistas profesionales. Prueba del rápido reconocimiento del uso de Internet en la referencia es la obra coordinada por Kinder ${ }^{140}$, que ya recopilaba en 1994 opiniones y experiencias de profesionales que estaban comenzando a trabajar con Internet en los servicios de referencia. Esta obra, que fue publicada simultáneamente como el número $41 / 42$ de la revista The Reference Librarian, sirve ahora como fuente para la historia de la referencia digital, ya que en ella se trata de sistemas ya desaparecidos o en desuso. Poco después, en 1996, se edita otra obra que quiere ofrecer las pautas para integrar Internet en el trabajo de referencia. Se trata del manual de Thomsen ${ }^{141}$, de corte práctico y centrada en la explicación de tecnologías como las listas de correo y grupos de noticias, las FAQ o los incipientes

\footnotetext{
${ }^{136}$ En un estudio realizado en la Stetson University se constató que la ratio entre fuentes en línea e impresas empleadas por los bibliotecarios referencistas era de 6 a 1, para las digitales. Véase: Bradford, Jane T.; Costello, Barbara; Lenholt, Robert. Reference service in the digital age: an analysis of sources used to answer reference questions. The Journal of Academic Librarianship, 2005, vol. 31, n. 3, p. 263-272.

${ }^{137}$ Mizzy y Mahoney realizaron un estudio sobre los recursos de Internet de utilidad para la referencia, en el que ofrecen tanto criterios de evaluación, como selecciones de sitios de interés. Véase Mizzy, Danianne; Mahoney, Elizabeth Tillapaugh. Stocking the Virtual Ready Reference Collection. The Reference Librarian, 2002, vol. 38, n. 79-80, p. 67-99. En los apéndices de este artículo se podrán encontrar otros estudios similares, así como directorios de recursos de referencia en Internet, índices de recursos seleccionados y servicios de información.

${ }^{138}$ Cannon realiza una buena síntesis de los servicios de Internet más útiles para la referencia en Cannon, Nancy. Yahoo! Do you Google? Virtual reference overview. The Reference Librarian, 2002, vol. 38, n. 77, p. 31-37. En este artículo realiza un panorámica de buscadores, directorios temáticos, web invisible, servicios de referencia digital, etc.

${ }^{139}$ Zumalt, Joseph R.; Pasicznyuk, Robert W. The Internet and reference services: a realworld test of Internet utility. Reference and User Services Quarterly, 1998, vol. 38, n. 2, p. 165-172.

${ }^{140}$ Kinder, Robin (ed.). Librarians on the Internet: impact on reference services. Binghamton, NY: The Haworth Information Press, 1994.

${ }^{141}$ Thomsen, Elizabeth. Reference collection development on the Internet: A how-to-do-it manual. New York: Neal-Schuman, 1996.
} 
OPAC en línea. En 1997 Diaz $^{142}$ coordina otro número de la productiva revista The Reference Librarian sobre fuentes de información en Internet, que también se convierte en monografía. De ese mismo año es Biblioteconomía y Documentación en Internet ${ }^{143}$, dedicada exclusivamente a los recursos telemáticos de interés para los profesionales de la información. Más reciente es la monografía de Sauers ${ }^{144}$, donde se recogen aspectos como la evaluación de recursos web para la referencia, la elaboración de estrategias de consulta, el estudio de directorios y motores de búsqueda o la aplicación de la red al servicio de referencia ${ }^{145}$. Entre las últimas monografías dedicadas a Internet como recurso para la referencia están las obras de Frost $^{146}$ (2005), Miller y Pellen ${ }^{147}$ (2006) y la excelente La información especializada en Internet ${ }^{148}$ (2006).

Como es lógico, los principales manuales de referencia editados de forma internacional ofrecen multitud de recursos de referencia presentes en Internet. Se trata de manuales teórico-prácticos, en los que las descripciones teóricas de los tipos de fuentes de información son acompañadas de relaciones de los recursos más útiles para cada categoría. En otros casos, se trata de repertorios, en los que ofrecen de forma sistemática las reseñas de las fuentes de información más valiosas. Son especialmente recomendables los siguientes manuales y repertorios ${ }^{149}$.

- Bopp, Richard E.; Smith, Linda C. (eds. ). Reference and information services: an introduction . $4^{\text {th }}$ ed. Englewood, CO: Libraries Unlimited, 2006.

- Cassell, Kay Ann; Hiremath, Uma. Reference and information services in the $21^{\text {st }}$ century: an introduction. London: Facet, 2006.

- Katz, William A. Introduction to reference work. $8^{\text {th }}$ ed. New York: McGraw-Hill, 2002.

- Lester, Ray (ed.). New Walfords Guide to Reference Sources. London: Facet, 2005-.

- Maldonado Martínez, Ángeles; Rodríguez Yunta, Luis (coords.). La información especializada en Internet: directorio de recursos de interés académico y profesional. $2^{\mathrm{a}}$ ed. corr. y aum. Madrid: CSIC, 2006.

\footnotetext{
${ }^{142}$ Diaz, Karen R. (ed.). Reference sources on the Internet: off the shelf and onto the Web. Binghamton, NY: The Haworth Information Press, 1997.

${ }^{143}$ Merlo Vega, José Antonio; Sorli Rojo, Ángela. Biblioteconomía y Documentación en Internet. Madrid: CSIC, CINDOC, 1997.

${ }_{144}$ Sauers, Michael P. Using the internet as a reference tool: a how-to-do-it manual for librarians. New York: Neal-Schuman, 2001.

${ }^{145}$ Véase, por ejemplo, Hundie, Kebede. Library operations and Internet resources. The Electronic Library, 2003, vol. 21, n. 6, p. 555-564.

${ }^{146}$ Frost, William J. (ed.). The reference collection: from the shelf to the Web. Binghamton, NY: The Haworth Information Press, 2005.

${ }^{147}$ Miller, William; Pellen, Rita M. (eds.). Evolving Internet Reference Resources.

Binghamton, NY: The Haworth Information Press, 2006.

148 Maldonado Martínez, Ángeles; Rodríguez Yunta, Luis (coords.). La información especializada en Internet: directorio de recursos de interés académico y profesional. 2a ed. corr. y aum. Madrid: CSIC, 2006.

${ }^{149}$ Sólo se mencionan los manuales y repertorio más actuales y de mayor calidad, en los que se puedan conocer recursos web de utilidad para la referencia.
} 
Los profesionales de la referencia están comenzando a emplear aplicaciones informáticas específicas para la recuperación de información. Se trata de diferentes modalidades de herramientas que, bien se utilizan de forma independiente, bien se integran en los navegadores web, ya sea como barras complementarias o como ventanas desde las que se puede acceder directamente a recursos de referencia. Los programas diseñados para el acceso a la información a través de Internet son motores de búsqueda que actúan como metabuscadores y que permiten consultas avanzadas para conseguir resultados precisos. Uno de los ejemplos más empleados en bibliotecas es Copernic, programa que ha perdido terreno ante la eficacia de barras de herramientas como Google Toolbar, MSM Toolbar o Yahoo Toolbar $^{150}$. Se trata de complementos que se integran en el navegador y que permiten realizar consultas en uno o varios buscadores. Otros programas de localización de información, tanto en ordenadores locales o en Internet son Google Desktop y Microsoft Windows Desktop.

Una excelente opción para la recuperación de información en Internet son las extensiones que ofrecen navegadores como Mozilla Firefox, que cuenta con una ventana para acceder directamente a los recursos que se seleccionen. En estos momentos, además de los grandes buscadores, se pueden integrar en el navegador recursos como enciclopedias, diccionarios, bases de datos bibliográficas, de imágenes o factuales, así como cientos de sistemas $^{151}$ que se pueden interrogar directamente desde la ventana del navegador. Junto a estas aplicaciones hay que mencionar los servicios externos que permiten personalizar los recursos que un usuario desea consultar de forma frecuente, como noticias y bitácoras, diccionarios y enciclopedias o utilidades para la referencia rápida: conversores, localizadores de mapas, efemérides, etc. El usuario selecciona sus recursos preferidos, que quedarán almacenados en el servidor del servicio que se esté empleado. Es lo que se denominan aplicaciones de escritorio o páginas de inicio personalizadas, entre las que destacan Netvibes, iGoogle y Windows Live ${ }^{152}$.

También son muchos los sitios de Internet, concebidos especialmente como directorios de recursos para la referencia ${ }^{153}$, desde lo que se pueden localizar fuentes específicas para la referencia factual, bibliográfica 0 documental $^{154}$. En la siguiente relación se mencionan aquellos directorios

\footnotetext{
${ }^{150}$ Un estudio sobre el tema, con selección de herramientas y comentario de las mismas puede fue realizada en Brown, Mitchell. Library toolbars for use and development. Library Hi Tech News, 2007, n. 8, p. 33-35.

151 Mozdev, comunidad de desarrolladores de Mozilla, mantiene un directorio de las extensiones posibles en la dirección http://mycroft.mozdev.org.

${ }^{152}$ Este tipo de herramientas se inscriben dentro del denominado software social, que es estudiado con detalle en el dossier que la revista Educación y biblioteca dedicó a la web social y sus aplicaciones en las bibliotecas: Merlo Vega, José Antonio (coor.). Bibliotecas y web social. Educación y biblioteca, sept./oct. 2007, n. 161, p. 62-124.

${ }^{153}$ Adamson, Shaun; Weingart, Sandra. Creation and evolution of a Web-based reference collection for an academic community. Campus-Wide Information Systems, 1999, vol. 16, n. 5, p. 157-161. En este artículo se ofrece un modelo de cómo desarrollar un sitio web específico para la referencia para atender a una comunidad universitaria.

${ }^{154}$ Véase Morse, Lori. 100 best free reference websites: a selected list. The Reference Librarian, 2005, vol. 44, n. 91/92, p. 279-295.
} 
que se consideran más útiles en función de su trayectoria (permanencia en Internet), mantenimiento (actualizaciones) y contenidos para la referencia (variedad y gratuidad) ${ }^{155}$.

- Alcove 9: http://www.loc.gov/rr/main/alcove9/

- Best Free Reference Web Sites ${ }^{156}$ : http://www.ala.org/ala/rusa/rusaourassoc/rusasections/mars/marspubs /MARSBESTIndex.htm

- Biblioteca de Referencia en Línea: http://www.uned.es/biblioteca/referencia/PAGINAINICIO.HTML

- Internet Library for Librarians: http://www.itcompany.com/inforetriever/

- Librarians' Internet Index: http://lii.org/pub/topic/reference

- Libray Spot: http://www.libraryspot.com

- Refdesk: http://www.refdesk.com

- The Internet Public Library / Ready Reference: http://www.ipl.org/div/subject/browse/ref00.00.00

- Virtual Reference Shelf: http://www.loc.gov/rr/askalib/virtualref.html

Como recursos generales para la obtención de información en Internet también habría que mencionar a los directorios analíticos, entiendo como tales los índices temáticos de sitios web, que han sido seleccionados por especialistas partir de determinados criterios de evaluación. Algunos ejemplos significativos y de probada utilidad son:

- BUBL LINK: http://bubl.ac.uk/link

- Ciberoteca: http://www.ciberoteca.com

- Intute: http://www.intute.ac.uk

- Librarians' index to the Internet: http://lii.org

- Tecnociencia: http://www.tecnociencia.es

- The Internet Public Library: http://www.ipl.org

- The Open Directory Project: http://dmoz.org

- The WWW Virtual Library: http://vlib.org

Los recursos web son herramientas informativas de primer orden para los servicios de referencia. Navarrete-Cortés y otros ${ }^{157}$ han aplicado métodos bibliométricos para la creación de directorios electrónicos de recursos informativos externos. Los recursos de Internet que pueden ser de utilidad para el trabajo de la referencia digital se pueden agrupar en cuatro categorías: recursos para la referencia factual, recursos para referencia bibliográfica, recursos para el acceso al documento y recursos para la

\footnotetext{
${ }^{155}$ Sowards analiza la calidad de cien sitios web de referencia gratuitos, a partir de una veintena de criterios. Véase Sowards, Steven W. Structures and Choices for Ready Reference Web Sites. The Reference Librarian, 2005, vol. 44, n. 91/92, p. 117-138.

${ }^{156}$ La RUSA realiza anualmente su lista de los mejores recursos gratuitos de referencia, que publica en su revista y que reúne en su web. La lista número ocho corresponde a 2006. Véase, por ejemplo, RUSA, Machine-Assisted Reference Section. Best free reference Web sites: eighth annual list. Reference and User Services Quarterly, 2006, vol. 46, n. 1, p. 34-39.

${ }^{157}$ Navarrete-Cortés, José; Fernández López, Juan Antonio; Chaichio, Juan Antonio. Recursos informativos en la web: aplicación de técnicas bibliométricas para medir su uso. Revista española de documentación científica, 2007, vol. 30, n. 4, p. 492-502.
} 
comunicación.. En los siguientes párrafos se describirán las aplicaciones de cada uno de estos grupos y se ofrecerán algunas direcciones de servidores que destacan en sus diferentes categorías ${ }^{158}$.

a) Recursos para la referencia factual. Son las fuentes de información por excelencia, a las que se acude para conseguir datos concretos, ya sean históricos, biográficos, estadísticos o terminológicos. Son los recursos tradicionales de la referencia rápida, pero ofrecidos a través de Internet. Corresponden a categorías como acrónimos, atlas, biografías, diccionarios, enciclopedias, estadísticas, etc. Algunas muestras de este tipo de recursos de referencia son:

- Acronym finder: http://www.acronymfinder.com

- Acronym search: http://acronymsearch.com

- Biography Center: http://www.biography-center.com/

- Biography.com: http://www.biography.com

- Born Today: http://www.born-today.com

- Busca biografias: http://buscabiografias.com

- Conversion and Calculation Center: http://www.convertit.com/Go/Convertlt/

- Martindale's Calculators on-line Center: http://www.martindalecenter.com/Calculators.html

- Calendar Zone: http://www.calendarzone.com

- Davidson Web Conversion Utility: http://www.davidson.com.au/tools/convert/

- Xe.com: Conversor universal de divisas: http://www.xe.com/ucc/es/

- Demographic and Social Statistics: http://unstats.un.org/unsd/demographic/default.htm

- Diccionarios.com: http://www.diccionarios.com

- DictSearch: http://www.foreignword.com/es/Tools/dictsrch.htm

- Lexicool: http://www.lexicool.com

- One look: http://www.onelook.com

- Real Academia Española: http://www.rae.es

- Your dictionary: http://www.yourdictionary.com

- Earth calendar: http://www.earthcalendar.net

- Efemerides: http://www.educar.org/comun/efemerides/

- Columbia Encyclopedia: http://www.bartleby.com/65/

- Encarta: http://es.encarta.msn.com

- Enciclonet: http://www.enciclonet.com

- Enciclopedia Libre Universal: http://enciclopedia.us.es

- Encyclopedia Britannica: http://www.britannica.com

- Wikipedia: http://www.wikipedia.org

- Servidores estadísticos: http://www.ine.es/serv/estadist.htm

- Eurostat: http://europa.eu.int/comm/eurostat/

- GeoHive: Global data: http://www.geohive.com

- Heraldaria: http://www.heraldaria.com

- Heráldica de apellidos: http://www.heraldicadeapellidos.com

158 Todas las direcciones estaban plenamente operativas el 20 de junio de 2007 
- World Genealogy Portal:

http://www.dieminger.com/genealogy/index.html

- Time and Date: http://www.timeanddate.com

- Perry-Castañeda Library Map Collection: http://www.lib.utexas.edu/maps/index.html

- Maps of the World: http://www.theodora.com/maps/

- Map machine: http://plasma.nationalgeographic.com/mapmachine/

- Guía del mundo: http://www.guiadelmundo.org.uy

- The World Fact Book: http://www.cia.gov/cia/publications/factbook/index.html

b) Recursos para la referencia bibliográfica. La orientación bibliográfica, la búsqueda de información sobre monografías, artículos de revistas, tesis doctorales, etc. es frecuente en los servicios de referencia, por lo que entre el personal referencista tienen que realizar una buena selección entre aquellos que ofrezcan catálogos de editoriales, librerías y bibliotecas, directorios de revistas, bases de datos bibliográficas, servidores comerciales, etc., como los que se relacionan a continuación.

- Portal de archivos españoles (PARES): http://pares.mcu.es

- CompletePlanet (bases de datos): http://www.completeplanet.com

- Internet invisible: http://www.internetinvisible.com

- Repertoire de bases de donnés gratuites disponibles sur Internet: http://dadi.enssib.fr

- Bibliotecas españolas y de todo el mundo: http://exlibris.usal.es/bibesp

- Libdex: http://www.libdex.com

- Unesco Libraries Portal: http://www.unesco.org/webworld

- CBUC: http://www.cbuc.es

- REBIUN - catálogos colectivos: http://rebiun.crue.org

- WorldCat: http://www.worldcat.org

- Buscaeditorial: http://www.bibliotecagodella.com/buscaeditorial/

- Guía de Editores de España: http://www.guia-editores.org

- ISBN editoriales: http://www.mcu.es/comun/bases/isbn/EDIT.html

- Publishers' catalogues: http://www.lights.com/publisher

- Amazon: http://www.amazon.com

- Books of the World: http://www.booksfactory.com

- Casa del Libro: http://www.casadellibro.com

- FNAC: http://www.fnac.es

- Iberlibro: http://www.iberlibro.com

- ISBN: http://www.mcu.es/comun/bases/isbn/ISBN.html

- Isbn.nu: http://www.isbn.nu

- Isbndb: http://isbndb.com

- Repertorio Integrado de Libros en Venta en Iberoamérica (RILVI):

- http://www.cerlalc.org/rilvi/index.php

- SOL: http://www.sol-e.com

- Directory of Open Access Journals (DOAJ): http://www.doaj.org

- Latindex: http://www.latindex.org

- News directory: http://www.newsdirectory.com

- Revicien: http://www.revicien.net

- Tecnociencia: revistas electrónicas: http://www.tecnociencia.es/e-revistas/ 
c) Recursos para el acceso al documento. Las consultas que se reciben en el servicio de referencia se refieren en muchos casos al suministro de documentos concretos que necesitan los usuarios. Por tanto, el personal debe conocer con soltura las diferentes posibilidades y servicios disponibles para este fin, tanto desde recursos comerciales, como desde centros de suministro de documentos. Además, en la actualidad existen muchos servidores que almacenan documentos en diversos formatos para su consulta y descarga de forma libre; las bibliotecas tienen que conocer y saber consultar estas bibliotecas digitales y repositorios ${ }^{159}$, ya que serán de gran ayuda en un servicio de referencia digital. A continuación, se recogen algunas direcciones de servicios comerciales, centros de suministro de documentos, bibliotecas digitales y repositorios, a fin de mostrar ejemplos de este tipo de recursos de utilidad para la referencia.

- Biblioteca Virtual Miguel de Cervantes: http://www.cervantesvirtual.com

- Digital libraries: resources and projects: http://www.ifla.org/II/diglib.htm

- El Aleph: http://elaleph.com

- The European Library: http://www.theeuropeanlibrary.org

- Project Gutenberg: http://www.gutenberg.org

- Directorio/Recolector de colecciones digitales: http://www.mcu.es/roai/es/inicio/inicio.cmd

- Directory of Open Access Repositories: http://www.opendoar.org

- Registry of Open Access Repositories: http://archives.eprints.org

- Metalist: http://metalis.cilea.it

- OAlster: http://www.oaister.org

- Ebsco: http://ejournals.ebsco.com

- Emerald Fulltext: http://www.emeraldinsight.com/ft/

- Ovid: https://gateway.ovid.com

- Science Direct: http://www.sciencedirect.com

- Swetwise: https://www.swetswise.com

- Ingenta Connect: http://www.ingentaconnect.com

- CINDOC-Servicio de Acceso al Documento: http://marte.cindoc.csic.es/cindoc/servicios.htm

- British Library's document supply service: http://www.bl.uk/services/document/dsc.html

- ArticleScience INIST: http://articlesciences.inist.fr

- FirstSearch: http://www.oclc.org/firstsearch/

- ProQuest Digital Dissertations: http://wwwlib.umi.com/dissertations

- Tesis doctorales en red: http://www.tdr.cesca.es

d) Recursos para la comunicación. Los referencistas deben acudir con frecuencia a otros profesionales para preguntar por la posible respuesta a una pregunta para cuya solución se tienen problemas. Por eso motivo, es importante que se conozcan las listas de distribución existentes y se participe en ellas. En muchos casos, hará falta consultar directorios de personas o entidades, sobre todo de la administración, para ponerse en contacto con las mismas para resolver las cuestiones que se les plantee.

\footnotetext{
${ }^{159}$ Véase, por ejemplo, Jacsó, Péter. Open access ready reference suites. Online Information Review, 2006, vol. 30, n. 6, p. 737-743.
} 
También se pueden incluir aquí los servicios de referencia de otras bibliotecas y los web de expertos. En la siguiente lista se ofrece una breve selección de recursos centrados en la comunicación, sobre todo relativos a directorios de las administraciones y de empresas, así como recursos sobre listas de distribución, redes sociales, servicios de expertos y otras bibliotecas que ofrecen referencia digital.

- Admiweb: http://www.admiweb.org

- Canal Aytos: http://www.aytos.org

- El portal del ciudadano: http://www.administracion.es

- Agenda de la comunicación: http://www.lamoncloa.es/ServiciosdePrensa/Agendadelacomunicacion/default.htm

- EU Who is who: http://europa.eu/whoiswho/

- Governments on the WWW: http://www.gksoft.com/govt/en/

- Baintrack University Index: http://www.braintrack.com

- Universities Worldwide: http://univ.cc/

- Camerdata: http://www.camerdata.es

- Guías amarillas: http://www.guiasamarillas.es/

- Guías naranjas: empresas: http://www.guiasnaranjas.com/es/

- Logismarket: http://www.logismarket.es

- Páginas amarillas: http://www.paginasamarillas.es

- Páginas amarillas.com: http://www.paginasamarillas.com

- QDQ: http://www.qdq.com

- Infobel: http://www.infobel.com/World/

- RedIRIS: http://www.rediris.es/list/

- Tile.net: http://tile.net

- Topica: http://lists.topica.com

- Facebook: http://www.facebook.com

- Linkedin: http://www.linkedin.com

- Neurona: http://www.neurona.com

- Xing: http://www.xing.com

- Pregunte: las bibliotecas responden: http://www.pregunte.es

- Información en vivo: http://www.nypl.org/branch/questions/index2.html

- Ask a librarian, Library of Congress: http://www.loc.gov/rr/askalib/

- Library Success: http://www.libsuccess.org

- LIS wiki: http://liswiki.org

- Yahoo Answers: http://es.answers.yahoo.com

- Answers.com: http://www.answers.com

- Xpertia: http://www.xpertia.com

- Todo Expertos: http://uclue.com

- Mis respuestas.com: http://misrespuestas.com/

- Te ayudo.es: http://teayudo.es/Inicio.asp

- Live QnA: http://qna.live.com

- Wiki answers: http://wiki.answers.com 


\section{Evaluación de los servicios de referencia}

La evaluación de la información ofrecida por los servicios de referencia digital es la esencia de esta tesis doctoral. No obstante, es necesario analizar primero las características de la evaluación de un servicio de referencia tradicional, ya que sobre los mismos se asientan los que se practican en entornos digitales. En este capítulo, por tanto, se analizarán los aspectos fundamentales de la evaluación que se deber realizar de un servicio bibliotecario de consulta, ya se ofrezca de forma presencial o en línea, para después estudiar la evaluación de las consultas y, a continuación de la colección de referencia. Los indicadores de evaluación ocupan otro apartado de este capítulo, dándole un espacio detallado a este punto, ya que se considera de esencial importancia. Por último, en este capítulo se examinan los diferentes métodos de evaluación que es posible aplicar en los servicios de referencia, incluyéndose las pautas que se comenzarán a aplicar en breve en las bibliotecas públicas españolas para recoger los datos cuantitativos para el análisis de los servicios de referencia. La evaluación de los servicios de referencia digitales es objeto del capítulo 11, que se ofrece en la parte siguiente de la tesis, ya que se ha considerado que era más conveniente reunir en esta primera parte todos los aspectos de los servicios de referencia más tradicionales, mientras que en la parte segunda se estudian todas las circunstancias de la referencia digital, entre ellas las que rodean a los procesos de evaluación.

\subsection{Características de la evaluación}

Todos los servicios y actividades llevadas a cabo en una biblioteca pueden y deben ser evaluados. El servicio de referencia es uno de los que con mayor motivo debe someterse a constante evaluación, ya que así se podrán corregir los defectos y se conseguirá más eficacia en el servicio.

Existen varias razones por las cuales es aconsejable la evaluación del servicio de referencia.

- asegurar que las tareas propias del servicio se están realizando correctamente

- necesidad de obtener el máximo rendimiento del servicio, tanto de cara a la institución de la que se depende, como hacia el usuario

- avance de las nuevas tecnologías, que provocan cambios en las formas de trabajar

Martín Vega, quien resume de esta manera la necesidad de la evaluación ${ }^{160}$ : «La evaluación tiene como objetivos principales, desde el punto de vista científico, obtener un conocimiento del funcionamiento general del servicio

\footnotetext{
${ }^{160}$ Martín Vega, Arturo. La colección de referencia. Boletín de la Asociación Andaluza de Bibliotecarios, sept. 1997, n. 48, p. 81.
} 
(observar si los resultados de las búsquedas son positivos o negativos), medir el grado de satisfacción de los usuarios y, desde el punto de vista administrativo, justificar las actividades realizadas». Desde una perspectiva similar, Lamy ${ }^{161}$ ofrece una metodología sencilla para la evaluación de los servicios de referencia, ofreciendo diecinueve medidas de análisis, que divide en cuatro grandes grupos: los fondos, los medios, los costes y los usos.

Se puede concluir, en definitiva, que la evaluación del servicio de referencia debe efectuarse, por una parte, para controlar la actividad que se está desarrollando en el servicio $y$, por otra, la utilidad de la colección de referencia. Una vez extraídos y analizados los datos que controlan estos dos ámbitos de evaluación se contará con elementos para tomar decisiones, modificar los puntos débiles y aumentar la calidad del servicio. Además de los elementos que van a ser evaluados (servicio y colección), la biblioteca debe establecer claramente quién realizará la evaluación y cuándo es conveniente que se lleve a cabo.

Para que la evaluación sea más efectiva debe ser coordinada por un equipo de trabajo, por lo que una de las primeras acciones de la evaluación es formar el equipo evaluador. Cuando puedan existir problemas de relaciones laborales o se quiera tener una evaluación más objetiva es conveniente contar con los servicios de profesionales externos, que tengan conocimientos demostrados sobre la materia. La dirección del servicio también juega un papel importante en la evaluación, ya que a la misma le corresponde la coordinación del proceso. Es habitual que los órganos de dirección sean ajenos a los equipos de evaluación, a fin de garantizar la objetividad y neutralidad en el trabajo realizado. No obstante, deben estar presentes en el proceso, mediante las labores de coordinación y supervisión de las diferentes etapas del análisis.

El momento de iniciar la evaluación dependerá de la biblioteca, de la actividad del servicio de referencia y del uso que se esté realizando de la colección de referencia. Es aconsejable llevar un control periódico de ciertas actividades, como el número de consultas, aunque otras no es necesario evaluarlas más que en momentos concretos. La evaluación debe ser planificada convenientemente, estableciendo un periodo de tiempo mínimo y máximo para llevarla a cabo. Esto es necesario para que el servicio esté más centrado en los objetivos que se pretenden conseguir y para que los datos obtenidos no pierdan actualidad.

Los ámbitos que deben ser evaluados en un servicio de referencia de forma preferente son:

- Servicio: espacio, infraestructura, atención en el mostrador, consultas recibidas por otros procedimientos, suministro de documentos, formación de usuarios, etc.

\footnotetext{
${ }^{161}$ Lamy, Jean-Philippe. Evaluer un service de référence: quelques outils. Bulletin des Bibliothèques de France, 2001, vol. 46, n. 4, p. 82-88.
} 
- Consultas: cantidad, pertinencia, satisfacción de los usuarios.

- Colección: calidad, actualidad, costes, soportes, etc.

- Personal: aptitud, actitud, interés, etc.

Todos estos campos pueden ser evaluados de forma independiente, para lo que habría que establecer planes de evaluación específicos. También cabe la posibilidad de realizar una evaluación general del servicio, donde se controlasen todos los aspectos anteriores, aunque esto, por el tiempo y la dedicación que exige, es sólo aconsejable cuando esté manifiestamente demostrado que el servicio de referencia necesita un cambio de orientación.

El servicio de referencia puede ser evaluado de forma genérica mediante parámetros como el número de usuarios que emplean el servicio, en relación al número de usuarios reales y del número de usuarios potenciales; el número de preguntas realizadas en un período de tiempo y el grado de satisfacción del usuario en cuanto a la actividad general del servicio.

Los autores del excelente manual Statistics, Measures and Quality Standards for Assessing Digital Reference Library Services: Guidelines and Procedures ${ }^{162}$ indican las causas por las que un servicio de referencia debe evaluarse, refiriéndose específicamente a los servicios de referencia digitales. En otro apartado de la tesis doctoral se tratará de los diferentes indicadores de evaluación establecidos en esta obra. En definitiva, un servicio de referencia digital debe ser evaluado por las siguientes causas:

- Determinar el grado en los objetivos de un servicio de referencia digital están siendo cumplidos.

- Evaluar de qué forma los servicios de la referencia digitales están apoyando los objetivos generales de la biblioteca u organismo.

- Supervisar el estado de los servicios y su funcionamiento para hacer mejoras constantemente y las modificaciones del servicio necesarias.

- Producir datos que describen el empleo, los usuarios y los usos de la referencia digital a lo largo del tiempo.

- Determinar el grado en que están satisfaciéndose las necesidades de información de un usuario a través del servicio.

- Justificar los costos y beneficios del servicio y demostrar la justificación general de las actividades de la referencia digital.

${ }^{162}$ Mac Clure, Charles R.; Lankes, R. David; Gross, Melissa; Choltco-Devlin, Beverly. Statistics, Measures and Quality Standards for Assessing Digital Reference Library Services: Guidelines and Procedures. Syracuse, New York: Information Institute of Syracuse; Tallahassee, Florida: School of Information Studies, 2002, p. 3. 
- Comparar los costos relativos y los beneficios de los servicios de referencia digitales con los servicios de referencia tradicionales.

- Proporcionar datos para una planificación continuada y el desarrollo de los servicios de referencia digitales.

- Determinar los tipos de personal de formación y apoyo que podría ser necesario.

- Informar a los directivos y organizaciones de la naturaleza y éxitos de los servicios de la referencia digitales.

- Identificar aquellos aspectos de los servicios de referencia digitales que necesitan ser revisados o mejorados.

- Animar al personal de la referencia digital piense en términos de resultados e impacto de los servicios de referencia digitales.

\subsection{Evaluación de las consultas}

Uno de los principales aspectos que se deben evaluar en los servicios de referencia son las demandas de información que los usuarios plantean. Según Lancaster ${ }^{163}$ «Dicha actividad se puede analizar de maneras distintas: número y tipo de preguntas recibidas; distribución de las preguntas por horas y días de la semana; tiempo empleado en proporcionar las respuestas; requisitos de personal para atender el servicio; fuentes utilizadas para responder las preguntas, etc. No obstante, una auténtica evaluación intentaría determinar el número de las preguntas que, entre las planteadas, se responden completa y correctamente.»

En la evaluación de las consultas se valorarán una serie de aspectos cuantitativos:

- número de preguntas recibidas

- número de preguntas buscadas

- número de preguntas que se contestan

- número de preguntas que se contestan completa y correctamente

El control de estas cuestiones es complejo en algunas ocasiones, sobre todo en lo que respecta al grado de satisfacción del usuario. Para anotar estas informaciones se debe contar con un formulario en el que se constate rápida y claramente datos descriptivos de la consulta (fecha, hora, procedimiento, tema, fuentes, tiempo de respuesta) y del usuario (nivel académico y grado de satisfacción).

Los sistemas de evaluación mediante formularios plantean problemas como la actitud forzada del personal, que se sabe evaluado, o el tiempo que un

${ }^{163}$ Lancaster, F. W. Evaluación de la biblioteca. Madrid: ANABAD, 1996, p. 167. 
usuario requiere para saber si la respuesta aportada es la que necesitaba. Por ello, se emplean otros sistemas como el estudio discreto. Se denomina así a la técnica que evalúa la capacidad de resolución de las preguntas por parte del personal y el grado de adecuación de las mismas a las expectativas de los usuarios. Este método parte del estudio previo de las consultas, contrastándolas con la colección, y con la participación de usuarios que, de acuerdo con los evaluadores, formulan las preguntas al personal, que desconoce que se le está evaluando, para después tomar nota de una serie de criterios de evaluación: rapidez en la respuesta, selección de las fuentes de información, adecuación de la respuesta, actitud y comportamiento, satisfacción del usuario, etc. Lógicamente, éste es un sistema que debe ser realizado con tacto, a fin de no provocar malestar entre el personal ${ }^{164}$.

Para la evaluación de las consultas contestadas correctamente por el servicio de referencia es muy útil el indicador que a tal efecto recoge la norma ISO 11620:1998(E) sobre indicadores de rendimiento en las bibliotecas $^{165}$. Entre los indicadores propuestos interesa el B.2.6, sobre las preguntas realizadas en el servicio de referencia. El objetivo de este sistema de evaluación es calcular si el personal es capaz de cumplir los requisitos básicos para un servicio de referencia, es decir, de dar respuestas correctas a las preguntas que se le plantee. El alcance de este indicador es general, aunque, dada su metodología y los requisitos que implica, se está limitando a grandes bibliotecas, bibliotecas universitarias y científicas y a sistemas bibliotecarios.

La norma ISO 11620 define ${ }^{166}$ este indicador como «el número de consultas contestadas correctamente divididas entre el total de las consultas planteadas.» El método propuesto se basa en los denominados estudios discretos. Como ya se expuso, este sistema se articula en función de un grupo de usuarios instruidos por el equipo evaluador para que planteen una serie de cuestiones seleccionadas a los encargados del servicio de información, quienes no sabrán que las preguntas son simuladas. Esto tiene la ventaja de que las consultas se atenderán de la forma habitual, ya que el personal desconoce que está siendo probado. El método discreto obliga a que los usuarios sean elegidos en representación a la comunidad de usuarios de la biblioteca. Del mismo modo, las consultas también deben ser seleccionadas convenientemente, sobre todo porque en ocasiones es difícil determinar si una consulta ha sido respondida correctamente o no. Las preguntas que pueden provocar respuestas ambiguas no deben ser

\footnotetext{
${ }^{164}$ Una muestra es la evaluación que se realizó en la Universidad de California y que se puede consultar en Kawakami, Alice; Swartz, Pauline. Digital reference: training and assessment for service improvement. Reference Services Review, 2003, vol. 31, n. 3, p. 227-236.

165 ISO. ISO 11620: Information and documentation. Library performance indicators. Genève: ISO, 1998. Esta norma tiene su correspondencia en España en la norma UNE 50137:2000 Información y documentación. Indicadores de rendimiento bibliotecario. Se aprobaron como norma española UNE 50137:2000/1M:2005 los indicadores adicionales de la ISO 11620/A1.

${ }^{166}$ ISO. op. cit., p. 40.
} 
planteadas en este modelo de evaluación, ya que implicaría inexactitudes en la tasa final.

La tasa de consultas contestadas correctamente se determina mediante la fórmula siguiente, redondeando la cifra final hacia el número más cercano:

Número de consultas contestadas correctamente

$$
\times 100 \%
$$

Número total de consultas planteadas

Existen una serie de parámetros para medir la efectividad de las respuestas $^{167}$ :

- Tasa de acierto o exhaustividad: porcentaje de documentos pertinentes encontrados en relación al número de documentos existentes sobre esa consulta.

- Tasa de precisión o pertinencia: relación entre el número de respuestas ofrecidas y las que son válidas o pertinentes.

- Tiempo de respuesta: tiempo transcurrido desde la formulación de la demanda hasta la resolución de la misma.

- Costes: valor de la información, tanto económico como temporal.

- Grado de eficiencia: calidad de la información ofrecida y su relación con los aspectos anteriores.

La norma ISO 11620 ha sido tomada como punto de partida para el establecimiento de indicadores de rendimiento para los servicios bibliotecarios electrónicos. El resultado ha sido la norma ISO/TR 20983: 2003 (E) cuyo título completo es Información y Documentación. Indicadores de Rendimiento para Servicios Bibliotecarios Electrónicos ${ }^{168}$. En esta norma específica de servicios digitales también se incluyen algunos aspectos relacionados con las consultas, ya que se incluye el indicador Porcentaje de peticiones de información realizadas de forma electrónica. No obstante, no trata en ningún apartado sobre la calidad de las respuestas, por lo que el estudio de esta norma se realiza en el apartado 7.5 de la tesis doctoral, en donde se describen los métodos de evaluación.

\footnotetext{
${ }^{167}$ Rimland realiza un exhaustivo análisis sobre la producción bibliográfica relativa a la efectividad de los servicios de referencia bibliotecarios. Véase Rimland, Emily L. Do We Do It Well? A Bibliographic Essay on the Evaluation of Reference Effectiveness. The Reference Librarian, 2007, vol. 47, n. 98, p. 41-55.

${ }^{168}$ Es la norma española UNE-ISO/TR 20983:2006 IN, vigente desde el 26 de julio de 2006. AENOR. UNE-ISO/TR 20983 IN: Información y documentación: Indicadores para los servicios bibliotecarios electrónicos (ISO/TR 20983:2003). Madrid: AENOR, 2006.
} 


\subsection{Evaluación de la colección de referencia}

En buena parte, la calidad del servicio de referencia dependerá de su colección, entendida en sentido amplio, es decir, como la suma de las fuentes de información que el servicio puede utilizar para resolver una consulta. Por ello, la colección de referencia debe evaluarse a fin de conocer si el fondo de información es el adecuado en cuanto a su volumen, calidad, soportes y organización.

El volumen de la colección de referencia debe ser evaluado en relación al fondo total y al número de consultas recibidas. El porcentaje respecto al fondo total dependerá del tipo de biblioteca y del número de usuarios de la misma. Por ejemplo, en bibliotecas escolares se recomienda que los materiales de consulta asciendan al $70 \%$ de la colección ${ }^{169}$, mientras que en las bibliotecas públicas se recomienda que, en circunstancias generales, los libros de consulta sean el $10 \%$ de la colección total ${ }^{170}$.

Lo esencial en la evaluación de la colección de referencia es examinar la utilidad de los documentos con los que se cuenta para informar. Uno de los sistemas de análisis de las obras de referencia mejor estructurados es el que propone Marcelle Beaudique $z^{171}$, quien divide el análisis en dos aspectos: análisis material y análisis intelectual. Se desarrollan a continuación los distintos aspectos relacionados con estos tipos de análisis:

1. Análisis material de la obra

1.1. Encuadernación: seleccionar preferentemente las encuadernaciones en tapa dura

1.2. Manejabilidad y peso: la obra no debe ser demasiado voluminosa (que se pueda coger bien en la mano), ni demasiado pesada (para evitar riesgos de caída), ni demasiado grande (necesitan una instalación particular o atriles).

1.3. Lomo legible: las obras en varios volúmenes deben llevar en el lomo indicaciones precisas sobre el corte de las palabras o las fechas.

1.4. Tipografía: comprobar la legibilidad de los caracteres, títulos de cabecera que faciliten la consulta, paginación, etc. Habrá que verificar las erratas tipográficas.

1.5. Puesta al día: problemas por la intercalación de las actualizaciones y por el espacio que ocuparán los posibles suplementos.

\footnotetext{
169 IFLA. Directrices IFLA/UNESCO para la biblioteca escolar. The Hague: IFLA, 2002. Disponible en <http://www.ifla.org/VII/s11/pubs/sguide02-s.pdf>.

170 IFLA/FIAB. Pautas para bibliotecas públicas. Madrid: Dirección General del Libro y Bibliotecas, 1988, p. 70.

${ }^{171}$ Beaudiquez, M. Guide de bibliographie général: méthologie et pratique. München: Saur, 1989. Traducido en Educación y biblioteca, 1992, n. 30.
} 
2. Análisis del contenido intelectual de la obra

2.1. Conocimiento del autor y del editor: analizar las informaciones biográficas que aparezcan; estudiar las funciones del autor $y$ colaboradores; en especial de los capítulos de los que son responsables. Es recomendable que el editor sea especialista en la materia.

2.2. Examen de los elementos constitutivos de la obra: habrá que analizar el prefacio o introducción, las notas de utilización, los índices, anexos, fuentes, abreviaturas, ilustraciones, mapas, gráficos, notas a pie de página, bibliografía.

2.3. Conocimiento interno mediante la lectura de algunas partes de la obra:

2.3.1. Estilo: en relación al nivel de la obra y al público al que se dirige

2.3.2. Organización del contenido: lectura seguida 0 fragmentada; remisiones de sustitución o complemento; tipos de clasificación; índices (esenciales en obras no alfabéticas); notas bibliográficas y remisión a otras lecturas (en este caso hay que examinar el número de citas, su actualidad, su lengua, ...); analizar las ilustraciones: número, tamaño, calidad documental, colocación y fiabilidad de las explicaciones.

2.3.3. Fiabilidad y exhaustividad del contenido: objetividad en el tono, en las omisiones y en las distorsiones de la información. Comprobar los errores.

2.3.4. Actualidad y puesta al día del contenido: indicación de las fechas de publicación de cada volumen; forma de la puesta al día: reediciones; suplementos aleatorios; complementos periódicos, hojas sueltas.

Estos criterios de análisis son muy útiles para conocer si una obra de referencia puede ser adquirida y si sigue siendo útil o, por el contrario, es susceptible de expurgo. Asimismo, los parámetros anteriores permitirán elegir entre distintas fuentes de información con contenidos similares y optar por el soporte más adecuado a las necesidades del servicio de referencia de la biblioteca ${ }^{172}$.

${ }^{172}$ Stewart estudia los criterios de selección de la colección de referencia impresa y electrónica, ofreciendo indicaciones que permitan escoger entre unos y otros formatos. Véase Stewart, Lou Ann. Choosing Between Print and Electronic Resources: The Selection Dilemma. The Reference Librarian, 2000, vol. 34, n. 71, p. 79-97. 
Una interesante opinión acerca de la evaluación de la colección de referencia es la aportada por Nolan ${ }^{173}$, quien propone una serie de sistemas para esta labor. En primer lugar, habla de la reacción del usuario de referencia, es decir, de si el usuario está contento con el fondo de este servicio. Otro sistema propuesto es la comparación de la colección que se posee con las listas de obras de referencia recomendadas por asociaciones e instituciones. Un tercer procedimiento es la comparación con la colección de referencia de otras bibliotecas. El último método de evaluación propuesto son los estudios de uso.

\subsection{Indicadores de evaluación}

La evaluación del servicio de referencia puede basarse en indicadores, que pueden definirse como "un elemento informativo del control del funcionamiento de una actividad"174. Los indicadores cumplen una doble función, ya que, de un lado, tienen un carácter descriptivo, pues permiten comprobar el estado y evolución de la actividad y, por otro lado, tienen un carácter evaluador, ya que permiten valorar las causas y efectos que de ellos se derivan.

Los indicadores son indispensables para evaluar el rendimiento de la biblioteca y, por tanto, para establecer planes de mejora. Por lo general, los indicadores proceden de medidas cuantitativas, que ayudan a establecer los elementos que indican la efectividad de la biblioteca. Los indicadores de rendimiento se obtienen a partir de las medidas, que en realidad son indicadores de número, calidad, uso, utilidad, etc. A grandes rasgos, las medidas del rendimiento que se pueden establecer son ${ }^{175}$ :

- Medidas del coste de inversión de servicios. Permiten medir cuánto cuesta ofrecer un determinado nivel de servicio: cantidad de recursos, cantidad de dinero, características relevantes de los recursos destinados a los servicios.

- Medidas de la producción de los servicios. Permiten medir la producción de un servicio: cantidad, calidad, oportunidad, disponibilidad, accesibilidad.

- Medidas de la efectividad de los servicios. Son formas de medir la efectividad de las producciones de la biblioteca desde la perspectiva de los usuarios: cantidad de uso, percepción por parte de los usuarios, satisfacción de los usuarios, importancia para el usuario, propósito de uso, consecuencias del uso.

\footnotetext{
${ }^{173}$ Nolan, C.W. Managing the reference collection. Chicago: American Library Association, 1999, p. 153-159.

${ }^{174}$ Peón Pérez, J. L. Definición y planificación de la gestión bibliotecaria. En Manual de biblioteconomía, Madrid: Síntesis, 1996, p. 304.

${ }^{175}$ Claves para el éxito: indicadores de rendimiento para bibliotecas públicas. Barcelona. Eumo, 1995.
} 
- Medidas del ámbito de los servicios. Son formas de medir las dimensiones y características del área y de la población que sirve la biblioteca: población general, población usuaria, área geográfica, necesidades de información.

De estas medidas se extraen los indicadores de rendimiento:

1. Indicadores de rendimiento operacional: relacionan la inversión con la producción. Se emplean para la asignación de recursos a actividades, servicios y productos.

2. Indicadores de efectividad: relacionan la producción con el uso. Se utilizan para conocer el rendimiento de la biblioteca: satisfacción de los usuarios, volumen de uso, etc. desde la perspectiva de los usuarios.

3. Indicadores de coste-efectividad: relacionan la inversión con el uso. Sirven para conocer en qué medida los recursos empleados en los servicios o usuarios están siendo efectivos.

4. Indicadores de impacto: relacionan el uso que se hace de la biblioteca, sus servicios o productos y el uso potencial que se puede hacer de ellos. Analizan el número de usuarios potenciales en comparación al de los reales y el grado de satisfacción de la comunidad a la que sirve.

En la mencionada obra ${ }^{176}$ se recogen una serie de medidas e indicadores específicos para el servicio de consulta e información. En cuanto a las medidas se detallan la de coste de inversión en servicios, de la producción de servicios y de la efectividad de los servicios. Por lo que respecta a los indicadores se ofrecen ejemplos de los cuatro tipos anteriormente expuestos. A continuación, se reproducen los diferentes indicadores de rendimiento específicos para los servicios de consulta e información que se recogen en la mencionada obra, siempre teniendo presente que se están ofreciendo indicadores para la evaluación de estos servicios en las bibliotecas públicas.

\section{Medidas del coste de inversión en servicios}

- Cantidad de recursos de servicios de consulta e información. Esta medida incluye el coste de ofrecer los servicios de consulta e información. Puede incluir una asignación de personal, espacio, equipamiento, existencias, etc. asociada con la oferta del servicio.

- Cantidad de recursos de las búsquedas en línea a bases de datos. Ésta es una medida de los costes asociados a la búsqueda en línea, incluyendo el personal, el equipamiento, el precio de la suscripción, la consulta y el acceso a las bases de datos (telecomunicaciones), etc.

${ }^{176}$ Op. cit. p. 112-115. 
Medidas de la producción de servicios

- Número de demandas de consulta e información recibidas. Es una medida del número de demandas de consulta e información recibidas que se responden en un determinado período de tiempo.

- Número de demandas de consulta e información satisfechas. Es una medida del número de demandas de consulta e información que se contestan en un determinado período de tiempo.

- Número de búsquedas en línea realizadas. Es una medida del número de búsquedas en línea realizadas para satisfacer una demanda de consulta o de información. Puede darse el caso de que el usuario haya pedido la búsqueda, o bien que el personal de la biblioteca crea que es la mejor manera de tratar una demanda. Nótese que la definición de búsqueda en línea puede variar considerablemente. Las definiciones de búsqueda van desde la cantidad total de búsquedas que hay que hacer para responder a una demanda del usuario, hasta la aplicación de una estrategia de búsqueda para una sola base de datos.

- Número de referencias bibliográficas recuperadas mediante la búsqueda en línea. Es el total de referencias bibliográficas recuperadas mediante la búsqueda en línea. De nuevo, la definición de referencias recuperadas puede variar desde el número de referencias identificadas por medio de la búsqueda hasta el número de referencias seleccionadas/vistas en pantalla/examinadas por el usuario.

- Precisión de la respuesta a la consulta. Esta medida corresponde a la exactitud de la respuesta que se ha dado a la demanda, se obtiene mediante la evaluación experta sobre una escala predeterminada.

- Exhaustividad de la respuesta a la consulta. Mide el grado en que la respuesta que se ha dado a la demanda es completa. Se mide mediante la evaluación experta sobre una escala predeterminada.

- Nivel de complejidad de la respuesta a la consulta. Es una medida del nivel de complejidad/exhaustividad de la respuesta a la consulta. Algunos usuarios quieren respuestas muy simples, mientras que otros quieren respuestas muy técnicas a sus demandes. Eso se puede medir mediante la evaluación de un experto que compare la complejidad de las respuestas respecto a un estándar.

- Relevancia de la respuesta a la consulta. La adecuación de la respuesta dada a una demanda. A veces la información puede parecer relevante a una demanda, pero en realidad puede no serlo. Esta medida se puede obtener mediante la comparación respecto a un estándar por parte de expertos o de usuarios. 
- Oportunidad de la respuesta a la consulta. Se puede medir de dos maneras. En primer lugar, mediante el tiempo transcurrido entre que un usuario hace una petición hasta que recibe una respuesta. En segundo lugar, mediante el tiempo que transcurre desde que el usuario indica para cuándo necesita una respuesta hasta que se recibe la respuesta.

- Disponibilidad de los servicios de consulta e información. Esta medida corresponde a las horas durante las que están disponibles los servicios de consulta e información.

- Accesibilidad de los servicios de consulta e información. Esta medida corresponde al período de tiempo durante el que los servicios de consulta e información son accesibles cuando se necesitan. También se puede medir como el tiempo medio que tiene que esperar un usuario para que sea atendido.

Medidas de la efectividad de los servicios

- Cantidad de uso de los servicios de consulta e información.

- Propósito de uso de los servicios de consulta e información.

Indicadores de rendimiento operacional

- Coste de cada demanda satisfecha.

- Coste de cada búsqueda en línea.

- Coste de cada referencia recuperada.

- Coste medio del nivel de oportunidad de la respuesta.

- Coste medio del nivel de precisión de la respuesta.

- Coste medio del nivel de exhaustividad de la respuesta.

- Coste medio del nivel de complejidad de la respuesta.

- Coste medio del nivel de relevancia de la respuesta.

- Coste medio del nivel de disponibilidad de los servicios de consulta e información.

- Coste medio del nivel de accesibilidad de los servicios de consulta e información.

Indicadores de efectividad

- Satisfacción del usuario con la oportunidad de la respuesta. 
- Satisfacción del usuario con la precisión de la respuesta.

- Satisfacción del usuario con la exhaustividad de la respuesta.

- Satisfacción del usuario con el nivel de complejidad de la respuesta.

- Satisfacción del usuario con la relevancia de la respuesta.

- Satisfacción del usuario con el número de referencias recuperadas.

- Satisfacción del usuario con la disponibilidad de los servicios de consulta e información.

- Satisfacción del usuario con la accesibilidad de los servicios de consulta e información.

- Promedio de demandas de consulta hechas/nivel de satisfacción del usuario.

- Promedio de usuarios de los servicios de consulta e información/nivel de satisfacción del usuario.

- Frecuencia media de uso de los servicios de consulta e información/nivel de satisfacción del usuario.

- Promedio de demandas de consulta hechas/nivel de disponibilidad.

- Promedio de usuarios de los servicios de consulta e información/nivel de disponibilidad.

- Frecuencia media de uso de los servicios de consulta e información/nivel de disponibilidad.

- Promedio de demandas de consulta hechas/nivel de accesibilidad.

- Promedio de usuarios de los servicios de consulta e información/nivel de accesibilidad.

- Frecuencia media de uso de los servicios de consulta e información/nivel de accesibilidad.

Indicadores de coste-efectividad

- Coste de cada demanda recibida.

- Coste de cada uso del servicio de consulta e información.

- Coste de cada usuario del servicio de consulta e información.

- Coste per capita de los servicios de consulta e información. 
- Coste medio/nivel de satisfacción del usuario.

Indicadores de impacto

- Número de demandas de consulta recibidas per capita.

- Número de demandas de consulta satisfechas per capita.

- Número de búsquedas en línea realizadas per capita.

- Número de demandas de consulta satisfechas/número de demandas de consulta recibidas.

Otros indicadores obtenidos

- Número de búsquedas en línea realizadas/número de demandas de consultas satisfechas.

Es importante comentar en esta sección de la tesis doctoral aquellas normas que afectan a la evaluación de los servicios de referencia y que establecen indicadores relacionados con el tema de esta investigación doctoral. Por ejemplo, en Estados Unidos fue aprobada el 6 de octubre de 2004 la norma ANSI/NISO Z39.7-2004: Information Services and Use: Metrics \& statistics for libraries and information providers, a la que se ha dado en llamar Emetrics ${ }^{177}$. Esta norma fue publicada por primera vez en 1968, reconfirmada en 1974 y revisada en 1983 y 1995. El estándar de 2004 es, por tanto, la tercera revisión, que se debe en este caso a la necesidad de incluir aquellos aspectos del trabajo bibliotecario que se realiza a través de web. El objetivo principal de la norma, según se explica en su introducción, es ayudar a los bibliotecarios e investigadores, estableciendo y definiendo la información cuantificable más útil, para medir los recursos y el desarrollo de las bibliotecas, para proveerlas de un corpus de datos que permita la comparación.

La norma Z39.7-2004 incluye un práctico diccionario de datos, en los que se definen una gran cantidad de conceptos. La nueva estructura es realmente útil y en todos los casos la información se ofrece de esta forma:

- Elemento o ámbito que se va a medir

- Definición en la que se describe claramente de qué se trata

- Método aplicable para su medición

- Fuente de los datos, generalmente la propia biblioteca

- Ámbito geográfico de aplicación

- Tipo de biblioteca a la que afecta el indicador

- Indicación de si la cifra es un total

177 http://www.niso.org/emetrics/ 
En relación a los recursos y servicios electrónicos, la NISO Z39.7-2004 establece cuatro grandes grupos de datos ${ }^{178}$ :

- Número de sesiones

- Número de búsquedas (preguntas)

- Número de unidades o registros examinados (incluidas descargas)

- Número de visitas virtuales

Además, se añaden una serie de elementos cuyo control se considera importante:

- Número de sesiones rechazadas ${ }^{179}$

- Número de selecciones del menú180

- Número de transacciones de referencia virtual

Entre los elementos que se recogen en el desarrollo de los indicadores emetrics se encuentra el número de transacciones de referencia digital, cuya información se reproduce a continuación ${ }^{181}$ :

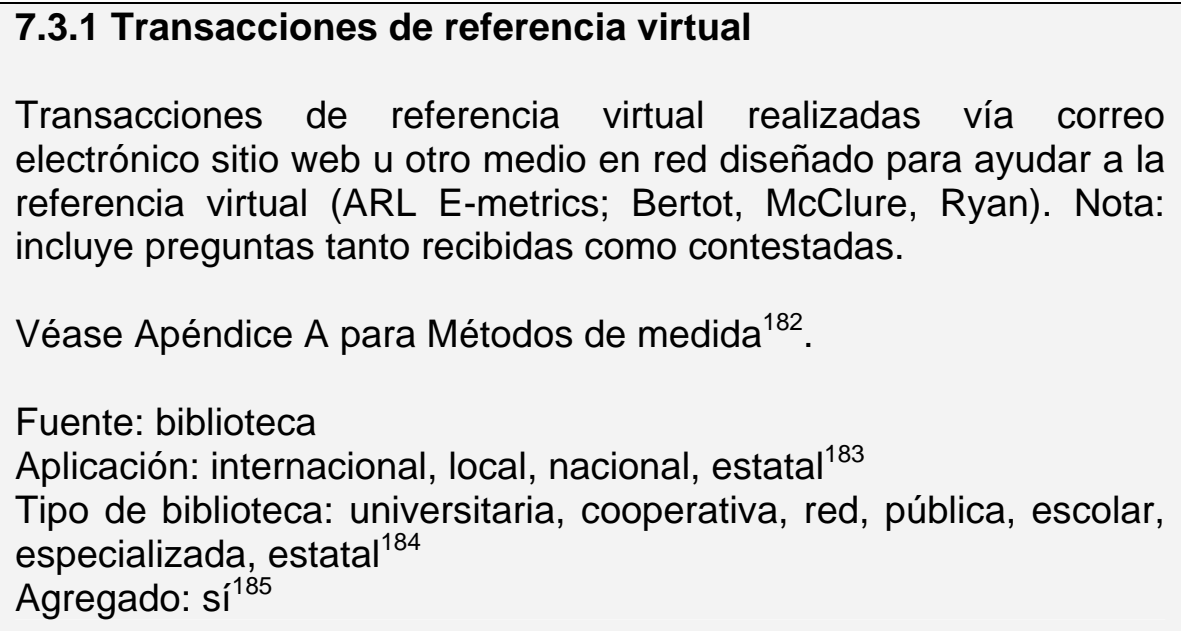
electrónico sitio web u otro medio en red diseñado para ayudar a la referencia virtual (ARL E-metrics; Bertot, McClure, Ryan). Nota: incluye preguntas tanto recibidas como contestadas.

Véase Apéndice A para Métodos de medida ${ }^{182}$.

Fuente: biblioteca

Aplicación: internacional, local, nacional, estatal ${ }^{183}$

Tipo de biblioteca: universitaria, cooperativa, red, pública, escolar, especializada, estatal ${ }^{184}$

Agregado: sí ${ }^{185}$

Fig. 1.17. Indicador para la referencia digital (NISO Z39.7-2004)

\footnotetext{
${ }^{178}$ Welch hace un estudio de la norma en un reciente artículo: Welch, Jeanie M. Click and Be Counted: A New Standard for Reference Statistics. The Reference Librarian, 2007, vol. 47, n. 97, p. 95-104.

${ }^{179}$ También denominados turnaway. Son los intentos fallidos de acceso a los lugares en lo que es necesarios entrar con identificación (login).

${ }^{180}$ Número de usuarios que han realizado consultas a través de las opciones alfabéticas y sistemáticas del menú.

${ }^{181}$ La traducción es del doctorando.

${ }^{182}$ En este apéndice se incluye un método específico para la medición de la referencia digital: el número total de transacciones de referencia digital en una semana típica, es decir en periodos donde no haya sobreactividad ni escasez de visitas, por lo que deben evitarse periodos de vacaciones o en aquellos en los que la biblioteca no esté cumpliendo su horario completo.

${ }^{183}$ Hay que tener en cuenta la división geográfica en estados de Estados Unidos.

${ }^{184}$ Todas las tipologías están definidas en la propia norma.

${ }^{185}$ Agregado se refiere a si es un valor absoluto.
} 
Este elemento es el único que trata de la referencia digital. Se inscribe en el bloque específico de la medición de los servicios, dentro de los indicadores que miden las peticiones de información. En la tabla que aparece a continuación se indican los datos que es útil recoger según esta norma en relación a los servicios electrónicos de información:

\begin{tabular}{|c|c|c|c|}
\hline & $\begin{array}{c}\text { Desde dentro } \\
\text { de la biblioteca }\end{array}$ & $\begin{array}{c}\text { Desde otra } \\
\text { parte dentro de } \\
\text { la institución }\end{array}$ & $\begin{array}{c}\text { Desde fuera } \\
\text { de la } \\
\text { institución }\end{array}$ \\
\hline Número de sesiones ${ }^{186}$, OPAC & $\mathrm{X}$ & $\mathrm{X}$ & $\mathrm{X}$ \\
\hline Número de sesiones, servicios comerciales & $\mathrm{X}$ & $\mathrm{X}$ & $\mathrm{X}$ \\
\hline Número de sesiones rechazadas & $\mathrm{X}$ & $\mathrm{X}$ & $\mathrm{X}$ \\
\hline $\begin{array}{c}\text { Número de búsquedas } \\
\text { de la biblioteca }\end{array}$ & $\mathrm{X}$ (consultas), colección \\
\hline $\begin{array}{c}\text { Número de búsquedas (consultas), servicios } \\
\text { comerciales }\end{array}$ & $\mathrm{X}$ & $\mathrm{X}$ & $\mathrm{X}$ \\
\hline Número de búsquedas (consultas), OPAC & $\mathrm{X}$ & $\mathrm{X}$ & $\mathrm{X}$ \\
\hline $\begin{array}{c}\text { Número de unidades/registros examinados } \\
\text { total colección de la biblioteca- } \\
\text { unidades de contenido }\end{array}$ & $\mathrm{X}$ & $\mathrm{X}$ & $\mathrm{X}$ \\
\hline $\begin{array}{c}\text { Número de unidades/registros examinados, } \\
\text { total servicios comerciales -unidades } \\
\text { de contenido }\end{array}$ & $\mathrm{X}$ & $\mathrm{X}$ & $\mathrm{X}$ \\
\hline $\begin{array}{c}\text { Número de unidades/registros examinados, } \\
\text { registros descriptivos de la colección } \\
\text { de la biblioteca }\end{array}$ & $\mathrm{X}$ & $\mathrm{X}$ & $\mathrm{X}$ \\
\hline $\begin{array}{c}\text { Número de unidades/registros examinados, } \\
\text { registros descriptivos de servicios } \\
\text { comerciales }\end{array}$ & $\mathrm{X}$ & $\mathrm{X}$ & $\mathrm{X}$ \\
\hline $\begin{array}{c}\text { Número de unidades/registros examinados, } \\
\text { registros descriptivos del OPAC }\end{array}$ & $\mathrm{X}$ & $\mathrm{X}$ & $\mathrm{X}$ \\
\hline Número de visitas virtuales & & $\mathrm{X}$ & $\mathrm{X}$ \\
\hline Número de selecciones de menú & & & $\mathrm{X}$ \\
\hline Número de transacciones de referencia virtual & & & $\mathrm{X}$ \\
\hline
\end{tabular}

Fig. 1.18. Datos para la evaluación de servicios electrónicos (NISO Z39.7-2004)

Como se aprecia, la única medida específica es el número de transacciones de referencia digital habidas en una semana común. La transacción de referencia se define como un contacto informativo que incluye conocimiento, uso, recomendación, interpretación o instrucción en el uso de una o más fuentes de información por un miembro de la plantilla de la biblioteca. Las fuentes de información serán tanto impresas como no, bases de datos, catálogos, reenvíos o comunicación con otras bibliotecas, instituciones o personas, de dentro o fuera de la biblioteca. Las remisiones a otras fuentes también se deben considerar como transacciones de referencia. De igual forma, si el referencista emplea fuentes obtenidas en una sesión anterior, se deben contabilizar tantas veces como se haga de ellas para resolver nuevas consultas.

\footnotetext{
${ }^{186}$ Una sesión es una consulta exitosa a un catálogo o una base de datos.

187 Una búsqueda debe entender como la representación intelectual única de una consulta.

188 Registros en los que el usuario ha entrado realmente, a partir de los que ha localizado en su búsqueda.

189 Una unidad de contenido es un recurso electrónico: un título de revista, un libro, una obra de referencia, una imagen, etc.
} 
La ISO también ha aprobado una norma en la que se establecen métodos para la evaluación de servicios bibliotecarios que se ofrecen mediante dispositivos digitales. Se trata de la ISO 20983 sobre indicadores de rendimiento para servicios bibliotecarios electrónicos ${ }^{190}$, que complementa a la ISO 11620:1998 sobre indicadores de rendimiento bibliotecario. En España fue aprobada por la AENOR y es la norma española UNE-ISO/TR 20983:2003 ${ }^{191}$. Como se puede comprobar en la siguiente tabla, donde se recogen los servicios que se analizan y los indicadores específicos, se contemplan también los servicios de referencia digital, aunque sólo se mide el número de peticiones de información realizadas por medios telemáticos.

\begin{tabular}{|c|c|}
\hline $\begin{array}{l}\text { Servicio, actividad } \\
\text { o aspecto medido }\end{array}$ & Indicador de rendimiento \\
\hline \multicolumn{2}{|c|}{ Servicios al público } \\
\hline General & $\begin{array}{l}\text { Porcentaje de población a la que llegan los } \\
\text { servicios electrónicos }\end{array}$ \\
\hline $\begin{array}{l}\text { Oferta de servicios bibliotecarios } \\
\text { electrónicos }\end{array}$ & $\begin{array}{l}\text { Porcentaje de gastos en provisión de } \\
\text { información asignados a la colección } \\
\text { electrónica }\end{array}$ \\
\hline \multirow[t]{6}{*}{ Obtención de documentos } & $\begin{array}{l}\text { Número de documentos descargados por } \\
\text { sesión }\end{array}$ \\
\hline & Coste por sesión de base de datos \\
\hline & Coste por documento descargado \\
\hline & Porcentaje de sesiones rechazadas \\
\hline & Porcentaje de sesiones remotas del OPAC \\
\hline & $\begin{array}{l}\text { Visitas virtuales como porcentaje sobre el total } \\
\text { de visitas }\end{array}$ \\
\hline $\begin{array}{l}\text { Servicios de referencia y } \\
\text { preguntas }\end{array}$ & $\begin{array}{l}\text { Porcentaje de peticiones de información } \\
\text { realizadas de forma electrónica }\end{array}$ \\
\hline Formación de usuarios & $\begin{array}{l}\text { Número de asistencias a sesiones de formación } \\
\text { sobre servicios electrónicos per cápita }\end{array}$ \\
\hline \multirow[t]{3}{*}{ Equipamiento } & $\begin{array}{l}\text { Horas de estaciones de trabajo disponibles per } \\
\text { cápita }\end{array}$ \\
\hline & $\begin{array}{l}\text { Población por estaciones de trabajo de acceso } \\
\text { público }\end{array}$ \\
\hline & Ratio de uso de las estaciones de trabajo \\
\hline \multicolumn{2}{|c|}{ Disponibilidad y uso de recursos humanos } \\
\hline Formación de personal & $\begin{array}{l}\text { Número de asistencias a sesiones formales de } \\
\text { formación sobre tecnologías de la información o } \\
\text { relacionadas por miembro del personal }\end{array}$ \\
\hline Despliegue de personal & $\begin{array}{l}\text { Porcentaje de personal de la biblioteca que } \\
\text { suministra y desarrolla servicios electrónicos }\end{array}$ \\
\hline
\end{tabular}

Fig. 1.19. Indicadores de servicios bibliotecarios electrónicos (UNE-ISO/TR 20983: 2003)

190 ISO/TR 20983:2003. Information and documentation - Performance indicators for electronic library services.

${ }^{191}$ AENOR. UNE-ISO/TR 20983 IN: Información y documentación: Indicadores para los servicios bibliotecarios electrónicos (ISO/TR 20983:2003). Madrid: AENOR, 2006. 
Esta norma recomienda medir el uso que hace de los medios electrónicos para realizar consultas, por lo que añade un indicador específico, basado en un dato porcentual. Las siguientes líneas pertenecen al anexo de la norma en el que se desarrolla este indicador.

Porcentaje de peticiones de información realizadas de forma electrónica

\title{
Objetivo
}

Establecer el uso hecho de medios electrónicos para realizar consultas.

\author{
Alcance \\ Todas las bibliotecas. \\ Definición del indicador \\ El número de peticiones de información realizadas de forma electrónica \\ durante un período de tiempo determinado como porcentaje del número total \\ de peticiones de información recibidas durante el mismo período.
}

\section{Método}

Se registran todas las peticiones de información recibidas por todo el personal de la biblioteca en un período de tiempo representativo (muestra), anotando los medios de presentación. Se cuenta, como una subdivisión, el número de peticiones de información realizadas electrónicamente, bien por correo electrónico a los puntos de servicio de la biblioteca, bien directamente al personal bibliotecario o a través de la Web.

El porcentaje de peticiones de información realizadas de forma electrónica es

$$
A / B \times 100 \%
$$

donde

A es el número de peticiones de información realizadas electrónicamente durante un período de tiempo determinado

B es el número total de peticiones de información recibidas durante el mismo período de tiempo

Se redondea al número entero más cercano.

\section{Interpretación y factores que afectan al indicador}

El indicador es un número entero entre 0 y 100. Esta cifra da una indicación de hasta qué punto los usuarios están utilizando los medios electrónicos de comunicación. Un número alto puede indicar que una alta proporción de usuarios de la biblioteca están familiarizados con los medios electrónicos y los usan para acceder a los servicios de la biblioteca.

El nivel puede verse afectado por un bajo nivel de personal en el mostrador de consultas.

Un número bajo puede indicar la necesidad de formación de usuarios o de una mejor promoción de los servicios electrónicos de consulta. El resultado puede verse afectado por el nivel de uso del sitio Web de la biblioteca. 


\subsection{Métodos de evaluación}

Dependiendo del tipo de evaluación que se esté llevando a cabo y del producto, servicio o aspecto que se esté controlando, la evaluación deberá seguir unos procedimientos más generales o, por el contrario, desarrollar sistemas más específicos. Kuruppu ${ }^{192}$ realizó en 2007 un análisis muy exhaustivo de las metodologías que se habían empleado para la evaluación de servicios de referencia, empleando la bibliografía profesional y haciendo una completa revisión de la misma, incluyendo los estudios sobre evaluación de servicios de referencia digital. Como métodos empleados para la evaluación cuantitativa incluye los siguientes: estadísticas de referencia y las encuestas y cuestionarios; en cuanto a los métodos de evaluación cualitativa menciona: observación, entrevistas, grupos de discusión y estudios de casos. Jia ${ }^{193}$ también sintetiza los métodos más empleados para la evaluación de los servicios de referencia, especialmente aquellos que se prestan a través de Internet. En su obra recoge que los métodos más frecuentemente mencionados por los teóricos e investigadores son las encuestas y cuestionarios, la observación, las entrevistas y los estudios de casos.

Todo proceso de evaluación comporta una serie de etapas que se establecerán en la planificación de la actividad ${ }^{194}$. Antes de iniciar el proceso será necesario crear el equipo de evaluación o bien contratar a quien se vaya a encargar de la misma. Aquí se iniciará un periodo de preparación, a fin de delimitar las características del servicio y acordar todos los pasos y acciones que se llevarán a cabo. En la siguiente etapa se definirán los aspectos que se van a evaluar y se establecerán las medidas e indicadores que se van a utilizar. A continuación, se estudiará el sistema más adecuado para la obtención de los datos y se fijará un periodo de tiempo para la ejecución de la actividad evaluadora.

En la mayor parte de las evaluaciones se utilizan formularios para la toma de datos, tanto para los aspectos estrictamente cuantitativos como para las cuestiones que recogen las impresiones de los usuarios. En este caso habrá que adaptar los impresos al objeto de la evaluación. Los formularios son útiles cuando se quieren obtener datos numéricos como el número de usuarios que utilizan el servicio, el número de consultas o las bases de datos que se han empleado. La dificultad estriba en cómo plasmar las expectativas y la satisfacción del usuario. En este caso, las preguntas deben plantearse de forma sencilla y clara mediante respuestas cerradas, es decir, aportando variantes para que el usuario elija la que mejor se acomode a sus impresiones.

Los impresos que recogen información cualitativa (no numérica) pueden sustituirse por entrevistas directas con los usuarios, en los cuales se

\footnotetext{
${ }^{192}$ Kuruppu, Pali U. Evaluation of Reference Services: A Review. The Journal of Academic Librarianship, 2007, vol. 33, n. 3, p. 368-381.

${ }^{193} \mathrm{Jia}$, Liu. The evaluation of worldwide digital reference services in libraries. Oxford: Chandos Publishing, 2007, p. 58-59.

194 Massissimo, À. op. cit., p. 111-113.
} 
interrogará acerca de la colección, la organización del servicio, el personal, aspectos relativos a la situación del usuario, como su nivel académico, además de por las cuestiones relacionadas con el espacio y la infraestructura del servicio. En los servicios de referencia digital, esta evaluación puede realizarse al entregar la respuesta, ya sea mediante un texto que acompañe a la misma al final del mensaje, en caso de correo electrónico, o de una ventana o página web preparada para este fin. Por ejemplo, las bibliotecas que emplean el sistema Question Point disponen de una evaluación automática, en la que el usuario sólo debe seleccionar las sus opciones para pregunta: Negativa o No, Neutra o N/A, Positivo o Sí. Las preguntas que efectúan a sus usuarios a través del formulario automático son las siguientes:

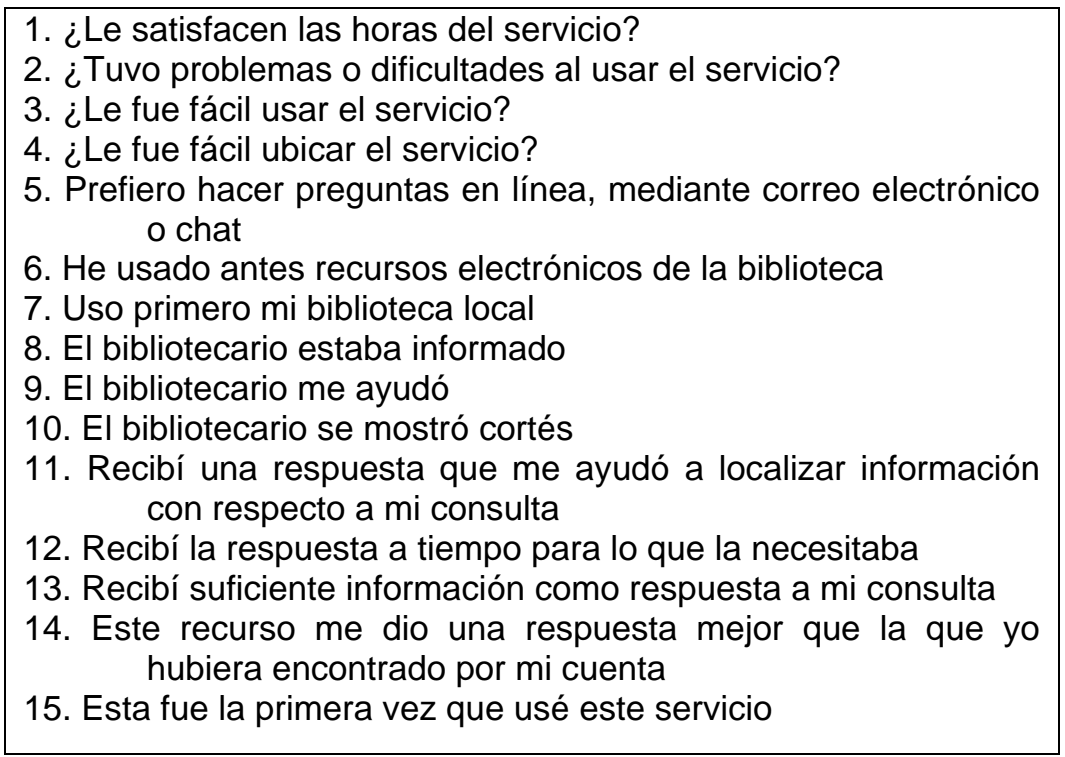

Fig. 1.20. Preguntas de la encuesta de satisfacción de Question Point

Por lo general, la toma de datos para la posterior evaluación de los servicios de referencia se realiza a partir de plantillas, en las que el personal indica simplemente el número de usos del sistema, a veces especificando el tipo de consulta. Este método sólo es válido para una evaluación cuantitativa, para obtener datos en bruto acerca del número de consultas. Por ejemplo, el grupo de trabajo de estadísticas de las bibliotecas públicas españolas trabaja en un borrador de sistema de anotación de consultas, en el se trata de registrar diariamente el número y tipo de preguntas que se reciben en los servicios de referencia de una biblioteca pública. Las indicaciones que se hacen llegar al personal responsable del registro de datos son las siguientes $^{195}$ :

\footnotetext{
${ }^{195}$ El Grupo de Trabajo de Estadísticas de Bibliotecas Públicas está integrado por personal de diferentes bibliotecas públicas españolas y coordinado por la Subdirección General de Coordinación Bibliotecaria del Ministerio de Cultura. Ha elaborado las recomendaciones para el control de las consultas de referencia que se reciben en una biblioteca, cuyas indicaciones se reproducen en este apartado de la tesis doctoral. La versión que se ha empleado corresponde al documento que se presentó en las XI Jornadas de Cooperación Bibliotecaria, celebradas en Mérida en marzo de 2007. En estas jornadas se aprobó que las
} 


\section{PETICIONES DE INFORMACIÓN}

Se incluyen en la recogida de datos

1. Recuperación de documentos específicos (en la biblioteca o en catálogos, bases de datos o bibliografías

2. Consultas de referencia : los usuarios solicitan datos concretos de su interés (búsqueda de datos realizada por el bibliotecario)

3. Demandas de información bibliográfica:elaboración de búsquedas bibliográficas sobre un tema determinado o la verificación de datos bibliográficos.

4. Servicios de formación: preguntas tendentes a educar a los usuarios en el uso de la biblioteca y de sus recursos.

5. Servicios de información de valor añadido (normalmente de pago y que exceden un tiempo límite)

- En caso de que se combinen varios de estos aspectos en la misma petición de información debería indicarse el principal y contabilizarse como una única petición de información.

- Las bibliotecas que formen parten en el servicio Pregunte: la biblioteca responde, deberán reflejar estos datos.

- Se contabilizarán todas las demandas recibidas: en la biblioteca, por teléfono, fax, correo electrónico, web,...)

No se incluyen en la recogida de datos

1. Demandas de orientación general: Consultas relativas a los servicios y horarios de la biblioteca, así como las relacionadas con la localización de salas y fondos.

2. Preguntas que se hacen con el objetivo de localizar obras de la colección que ya se han identificado bibliográficamente.

3. No se contabilizarán las peticiones de información inapropiadas, es decir, aquéllas cuya resolución no es objetivo de la biblioteca pública: preguntas que requieren una investigación científica, solicitudes de opinión o consejo sobre cualquier tema, preguntas malintencionadas, etc. 


\title{
TIPOS DE RESPUESTAS
}

1. Demanda de información resuelta. La que se ajusta a los requerimientos de la pregunta, es decir, cuando se ha resuelto la demanda de forma adecuada o bien aunque no se disponga de la información, se pueda enviar al usuario a otro centro donde la encontrará. En el caso de que se haya satisfecho parte de la demanda y se redirecciona después al usuario a otro centro especializado en el que podrá completar la información, también se contabilizará como resuelta.

2. Demanda de información no resuelta. Cuando no se ha podido proporcionar una respuesta o redireccionar al usuario a la fuente adecuada para encontrar su respuesta.

\section{RECOGIDA DE DATOS}

- Recogida diaria. Es la más fiable.

- Muestreo. Aunque los datos estadísticos tradicionales de las bibliotecas se toman durante todo el período de recogida de datos, esto no es posible en todos los servicios de la biblioteca como, por ejemplo, el uso interno o preguntas de referencia. Por lo tanto se permite la aplicación de métodos de muestreo allí donde no se pueden recoger datos de los sistemas automatizados o donde la recogida de datos llevaría mucho tiempo. Para el cálculo del tamaño de la muestra se deberían consultar los manuales de procedimientos estadísticos. (ISO 2789:2003)

El formulario que se emplea recoge, a través de marcas manuales (una por consulta), el número de demandas que se reciben, separando las resueltas de las no resueltas. En otra sección se anotan las búsquedas bibliográficas, ya sea en el catálogo de la biblioteca o en otros catálogos, marcando también si han sido resueltas o no dichas peticiones de información. En resumen, los datos que se recomienda anotar en el sistema de control de consultas propuesto por el grupo de trabajo de estadísticas de bibliotecas públicas son los siguientes:

\author{
Demandas de información \\ Resueltas \\ No resueltas \\ Búsquedas bibliográficas \\ Catálogo \\ Resueltas \\ No resueltas \\ Otros catálogos \\ Resueltas \\ No resueltas
}


Existen diversas técnicas que se pueden utilizar para evaluar una biblioteca. En realidad, los diferentes métodos de investigación social son aplicables al análisis de la actividad bibliotecaria y del comportamiento de sus usuarios. Por lo que se refiere a la evaluación de los servicios bibliotecarios de referencia, en general, y del servicio de referencia digital, en particular, las técnicas pueden ser las mismas empleadas en Sociología y en otras disciplinas de las Ciencias Sociales; incluso, algunos de los sistemas empleados siguen criterios muy estrictos basados en métodos de organización empresarial.

No obstante, se ha considerado que se necesitan métodos complementarios y específicos para algunos servicios de referencia digital, especialmente para aquellos cuya población usuaria no está definida, como ocurre con los servicios públicos nacionales e internacionales, que se ofrecen de manera abierta, sin establecerse un colectivo vinculado a una biblioteca o a una red bibliotecaria concretas, algo que dificulta los posibles estudios de usuarios. Por este motivo, se ofrecen en el apartado 11.3. algunas propuestas para la evaluación de servicios públicos de referencia digital, las cuales, además, han sido aplicadas en la tercera parte de esta tesis doctoral.

Por lo que respeta a los métodos que se están empleando para evaluar los servicios de referencia, y sin intención de detenerse detalladamente en los mismos, se enumeran en los siguientes párrafos las diferentes técnicas que se mencionan en la literatura profesional y que se han empleado en evaluaciones de bibliotecas, como se podrá comprobar en las referencias que se recogen en las bibliografías de la parte cuarta de la tesis (apartados $16.2,17.2$ y 18.2).

En la actualidad, ya se dispone de una base bibliográfica a la que acudir para conocer las técnicas de investigación cuantitativas y cualitativas que se pueden aplicar en las bibliotecas ${ }^{196}$, aunque aquí se hace un resumen sucinto en función de su utilidad en la evaluación de servicios de referencia digital. Los métodos más frecuentes en evaluación cuantitativa y cualitativa son los siguientes:

- Entrevistas. Conjunto de preguntas que se realizan a los usuarios para conocer su opinión sobre determinadas cuestiones. En el caso de los servicios de referencia las encuestas suelen incidir en la satisfacción con la respuesta recibida, su conformidad con el trato recibido o el grado de cumplimiento de sus expectativas, por ejemplo. Se trata de una técnica muy desarrollada y empleada en un porcentaje muy alto de las evaluaciones

\footnotetext{
${ }^{196}$ Algunos ejemplos recientes de monografías sobre técnicas de investigación en biblioteconomía son: Pickard, Alison Jane. Research methods in information. London: Facet, 2007; Powell, Ronald R.; Connaway, Lynn Silipigni. Basic research methods for librarians. $4^{\text {th }}$ ed. Westport (Connecticut); London: Libraries Unlimited, 2004; y Delgado López-Cózar, Emilio. La investigación en biblioteconomía y documentación. Gijón: Trea, 2002. En cuanto a técnicas específicas para la evaluación cualitativa son recomendables: Matus Sepúlveda, Gladys; Molina Luque, Fidel. Metodología cualitativa: un aporte de la Sociología para investigar en Bibliotecología. Valparaíso: Universidad de Playa Ancha, 2006; y Valentim, Marta Ligia Pomim. Métodos cualitativos de pesquisa em Ciencia da informaçao. Sao Paulo: Polis, 2005.
} 
realizadas en bibliotecas. Este método se ha empleado también para el análisis de los servicios de referencia digital, aunque no se puede aplicar apenas en los servicios públicos nacionales, ya que no se tiene información de los usuarios.

- Cuestionarios electrónicos. Método afín a las encuestas, pero con orientación plenamente evaluadora. El usuario responde a cuestiones cerradas sobre los servicios que acaba de recibir. Muchos servicios de referencia digital lo emplean, empleando ventanas emergentes en muchos casos, que contienen formularios en los que el usuario sólo tiene que elegir la opción de su respuesta y enviar los resultados. Es, como se vio unos párrafos antes, el método empleado por importantes servicios para recoger la satisfacción del usuario, como es el caso de Question Point o el ejemplo que se muestra en la figura 1.21.
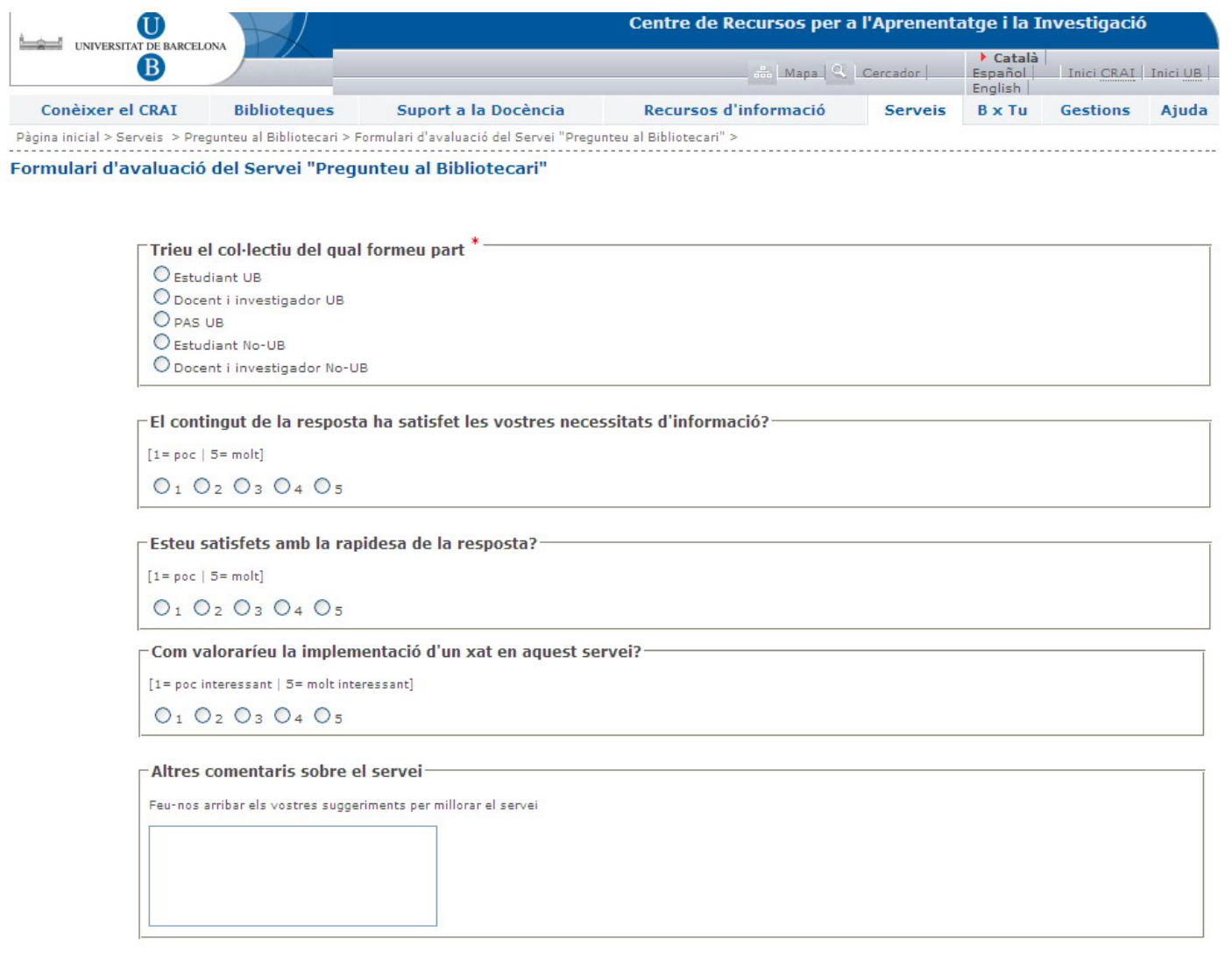

* Camp obligatori

Enviar

Fig. 1.21. Preguntas de la encuesta de satisfacción de la Universitat de Barcelona

- Observación no participante. Se trata de estudiar los hábitos de los usuarios: cuándo preguntan más, cómo utilizan la colección, cuánto tardan en encontrar un dato, etc. La observación ofrece pautas para conocer el comportamiento de los usuarios del servicio y, por tanto, para reenfocar aquellos procedimientos que no sean efectivos. Esta técnica sólo servirá a efectos orientativos, ya que aporta pocos datos tangibles, además de requerir mucho tiempo y personal. No obstante, ofrece importante pautas de 
comportamiento acerca de los usuarios y su relación con la información: cómo, cuándo, dónde y qué buscan.

- Observación participante. Consisten en el uso de los servicios por parte del personal evaluador de forma anónima, sin que los profesionales sepan que están siendo evaluados. Los evaluadores pertenecen también a la biblioteca. En el caso de la referencia, el evaluador realiza diferentes consultas de forma intencionada, para analizar determinados factores de las respuestas, como la pertinencia o el tiempo transcurrido. Se trata de un método que hay que aplicar con precaución y que requiere una detallada planificación. En algunas obras sobre evaluación este método se denomina estudio discreto, que es una traducción de unobtrusive study.

- Análisis de los registros del sistema (logs) o de las transcripciones de las sesiones. Todos los sistemas automatizados registran internamente las operaciones que ejecutan. Es importante, a la hora de elegir o desarrollar un sistema automatizado de gestión de la referencia, que se conozcan las capacidades del mismo para registrar información, ya que de ello dependerá que se puedan extraer datos para la evaluación del servicio, tales como el número de preguntas, los tipos, las horas y días de consulta, etc. En el apartado 11.2 de esta tesis doctoral se menciona con frecuencia el uso de los registros del sistema como medio para la obtención de datos para indicadores de rendimiento de los servicios de referencia digital. Se trata de un procedimiento esencial en los servicios de referencia digitales.

- Grupos de discusión (focus groups). Se trata de reunir a un grupo de personas para que debatan aspectos de la calidad del servicio, ya sea sobre el personal, la gestión, el sistema automatizado, las respuestas ofrecidas, etc. Los integrantes de estos grupos variarán en función de qué se quiera evaluar. En algunos caso, conviene que sean personas que trabajen en la biblioteca, a fin de evaluar cuestiones como la organización o la comunicación interna; en otros casos, los grupos estarán formados por usuarios, que opinarán sobre las expectativas cumplidas, la satisfacción o la accesibilidad del servicio, por ejemplo. También se deberán formar grupos de ciudadanos poco o nada relacionados con la biblioteca, para debatir sobre el conocimiento del servicio o los ámbitos que cubre, por ejemplo. Son también una herramienta importante para la evaluación cualitativa de un servicio de referencia

- Estudio de casos. Recopilación y examen de prácticas ejemplares de servicios similares a los que se están ofreciendo. Los evaluadores recogen testimonios, documentación y datos de otras bibliotecas y servicios de orientación afín, que hayan demostrado un buen funcionamiento, y analizan los elementos que de su éxito, para trasladarlos a los servicios propios. Las historias de éxitos, buenas prácticas o cualquier terminología similar que se quiera emplear son una buena opción para iniciar servicios de información en una biblioteca, tomando como ejemplo experiencias destacables, basándose en el principio de que, en condiciones similares, un servicio con éxito en una biblioteca, también lo tendrá en otra parecida. 
En ocasiones las bibliotecas optan por encargar la evaluación a personas o entidades externas, facilitando los recursos, pero no participando directamente en la recogida de datos ni en parte alguna del proceso de análisis. Las dos principales formas de materializar la evaluación independiente son la revisión por pares y los análisis externos, que se explican someramente en los párrafos siguientes.

- Revisión por pares (peer review). Técnica relacionada con los grupos de discusión. Se trata de seleccionar personas, ya sean profesionales de la biblioteca, usuarios o colaborares externos, que realizarán las labores de análisis de aquellos elementos que se deseen evaluar: calidad de las respuestas, trato de los profesionales, fuentes empleadas, capacidad del sistema, etc. Ha demostrado ser un excelente método de evaluación aplicable a los servicios de referencia, tanto presenciales como telemáticos Se deben normalizar algunas cuestiones de procedimiento y criterios de actuación ya que se trabajará de forma independiente, antes de la puesta en común definitiva, de la que se extraerán los resultados de la evaluación que se esté llevando a cabo.

- Análisis externos, encargados a personas o empresas especializados, es un método que tiene que tener en cuenta las bibliotecas para evaluar determinadas cuestiones. Por ejemplo, este sistema será muy útil para evaluar las especificaciones técnicas de una aplicación que se quiera emplear o esté usando para la referencia digital. De igual modo, el trabajo con consultores puede ser empleado para el análisis de la calidad de las respuestas.

Muchos de los criterios, indicadores y métodos expuestos en este apartado son de aplicación tanto en lo servicios de referencia tradicionales como en los digitales. No obstante, estos últimos servicios requieren, en muchos casos, una metodología particular, así como el empleo de indicadores específicos, incluso diferenciados en función del sistema o medio que se utilice para prestar los servicios de referencia sincrónicos y asincrónicos. Todos estos aspectos son examinados en el capítulo 11 de la tesis doctoral, una vez analizados los diferentes elementos relativos a los servicios de referencia digital, que se describen en las páginas siguientes. 


\section{Servicios de referencia digital: desarrollo y evaluación}

Existen diferentes modelos para prestar servicios de referencia a través de redes de telecomunicación. En este segundo bloque se delimitan los conceptos relacionados con la referencia digital, se estudian los diferentes procedimientos empleados hasta el momento dentro y fuera de España y se ofrece una descripción de los diversos servicios públicos de referencia que existen en la actualidad en todo el mundo. A continuación, se analizan las directrices que distintas organizaciones bibliotecarias han elaborado para la prestación de servicios digitales de referencia, que son útiles para cualquier biblioteca. Una vez ofrecida esta información, el resto del módulo se dedica a la evaluación de las consultas y los servicios de referencia, comenzando por las características de los métodos empleados para analizar los servicios telemáticos de referencia y concluyendo con la metodología propuesta por el doctorando, ya que, en el último apartado de esta sección, se aportan planteamientos sobre la evaluación de servicios públicos de referencia digital, que después se llevarán a la práctica, según se podrá comprobar en la parte tercera de la tesis doctoral. 
Parte II. SERVICIOS DE REFERENCIA DIGITAL: DESARROLLO Y EVALUACIÓN

8. El servicio bibliotecario de referencia digital

8.1. Contexto conceptual de la referencia digital

8.2. Tipología de los servicios de referencia digital

8.3. Tecnologías de comunicación para la referencia digital

9. Desarrollo de servicios de referencia digital

9.1. Planificación y creación de un servicio de referencia digital

9.2. Competencias profesionales para la referencia digital

9.3. Servicios públicos de referencia digital

9.4. Servicios de referencia digital en España

10. Pautas y normas para el ejercicio de la referencia digital

10.1. Recomendaciones de la IFLA

10.2. Pautas de la RUSA/ALA

10.3. Normas de la Virtual Reference Desk Network

11. Evaluación de los servicios de referencia digital

11.1. Evaluación de la información telemática

11.2. Metodologías de evaluación de la referencia digital

11.3. Propuestas para la evaluación de servicios públicos de referencia digital 


\section{El servicio bibliotecario de referencia digital}

Los servicios de referencia digital son una realidad reciente. Las primeras iniciativas de servicios de consulta ofrecidos por las bibliotecas a través de redes de telecomunicación tienen poco más veinte años. Desde entonces, la referencia digital se ha asentado, aunque todavía dista mucho de ser un servicio extendido y consolidado. En este capítulo, se desarrollarán los diferentes aspectos relativos a los servicios de referencia digital, analizando la literatura profesional, presentando el estado de la cuestión y aportando una definición de qué se debe entender en sentido estricto por un servicio bibliotecario de referencia digital. En el segundo apartado se realizará una extensa clasificación de las diferentes manifestaciones que es posible encontrarse dentro de las secciones de consulta en línea de las bibliotecas; se trata de una sistematización de los servicios de referencia digital en función de criterios y perspectivas diferentes. El capítulo finaliza con la descripción detallada de los sistemas que se emplean para la referencia digital. Se ofrece un análisis de los métodos que utilizan las bibliotecas para que los usuarios les hagan llegar sus preguntas y los profesionales referencistas puedan devolverle la respuesta pertinente. Como se verá en este tercer apartado, hay una amplia gama de tecnologías y aplicaciones por las que pueden optar una biblioteca. De todas ellas se explican las características básicas y su utilidad para la práctica de la referencia digital, indicando sus ventajas y desventajas, así como sus tendencias, principales programas empleados y los aspectos que hay que tener en cuenta para su uso como herramienta en la que basar la referencia digital.

\subsection{Contexto conceptual de la referencia digital}

Aunque parezca una perogrullada, los servicios bibliotecarios de referencia digital son, ante todo, servicios bibliotecarios de referencia, es decir, las secciones de las bibliotecas desde las que se atienden las consultas bibliográficas e informativas de los usuarios. A partir de aquí, sólo resta completar la definición con el matiz semántico que añade el calificativo «digital». El concepto de los servicios bibliotecarios de referencia no es homogéneo. Según autores, bibliotecas o áreas geográficas las secciones que las bibliotecas destinan a informar a sus usuarios tienen mayor o menor cobertura. En algunos casos, como ocurre fundamentalmente en las teorías y bibliotecas anglosajonas, los servicios de consulta responden a cuestiones cerradas, que se ajustan a un esquema estricto de pregunta-respuesta. En otros ámbitos, como en Francia ${ }^{197}$, tal como señala Nguyen ${ }^{198}$, este tipo de

\footnotetext{
${ }^{197}$ Según Lamy los servicios bibliotecarios de referencia son de reciente aparición en Francia, al menos como servicios específico. Solamente, a finales de los años 90 se comienzan a publicar obras dedicadas a estudiar la función informadora de la biblioteca. Véase Lamy, Jean-Philippe. Les espaces d'information: éléments de programmation. Bulletin des Bibliothéques de France, 2000, vol. 45, n. 3, p. 83-88.

${ }^{198}$ Nguyen, Claire. Mettre en place et développer un service de référence virtuelle dans une perspective d'integration à un réseau collaboratif. Villeurbanne: ENSSIB, 2006, p. 13.
} 
servicios se identifican con la búsqueda bibliográfica. Otros autores, entre los que se encuentra el doctorando, consideran más adecuado asignar a los servicios de referencia todas las cuestiones relacionadas con la provisión de información a los usuarios, como se ha visto en el apartado 2.4. de esta tesis doctoral.

Por tanto, se pueden ofrecer varias definiciones de los servicios bibliotecarios de referencia -digital o no- ya sea partiendo de un sentido más amplio o más estricto. En todo caso, merece la pena insistir en que la incorporación de la etiqueta «digital», «electrónica» o «virtual», no cambia la función de los servicios bibliotecarios de consulta, simplemente afecta a los procedimientos de trabajo y a los medios de comunicación con los usuarios. Para la IFLA, la delimitación de los conceptos debe partir de las políticas que se establezcan en cada centro. En sus pautas coinciden con el servicio Virtual Reference Canada ${ }^{199}$, para quien "los términos referencia virtual, referencia digital, servicios de información en Internet, referencia permanente y referencia en tiempo real son intercambiables para describir los servicios de referencia que utilizan tecnología digital de una u otra forma". Ciertamente, los sinónimos empleados para denominar este servicio son múltiples, tanto en español, como en otras lenguas próximas. Sirva de ejemplo, la siguiente relación:

Inglés

- 24/7 Reference

- Ask a librarian

- AskA services

- Digital reference service

- Electronic information service

- Electronic reference

- E-Reference

- Internet Information Services

- Live online reference service

- Live reference

- Online reference

- Q\&A services

- Question point

- Virtual reference

- Virtual reference desk

- Real time reference
Español

- Servicio de referencia digital

- Servicio de referencia virtual

- Servicios de referencia en línea

- Servicios digitales de referencia

- Servicios electrónicos de referencia

- Pregunte a un bibliotecario

- Referencia en línea

\section{Italiano}

- Reference digitale

- Servizi di consulenza online

- Chiedi al bibliotecario

\section{Francés}

- Référence numérique

- Référence virtuel/le

- Guichet virtuel

- Bureau d'information

- Service de questions / résponses

- Services de réponse à distance

\section{Portugués}

- Serviço de referência digital

- Serviço de referência virtual

- Balcão de referência virtual

\section{Catalán}

- Servei de referència Virtual

- Servei de referència digital

Fig. 2.1. Denominaciones de los servicios de referencia digital

\footnotetext{
199 Virtual Reference Canada <http://www.collectionscanada.ca/vrc-rvc/s34-150-e.html> es un servicio que presta la Biblioteca Nacional de Canadá a las bibliotecas de este país, para resolver cuestiones de referencia de forma cooperativa.
} 
Como puede apreciarse, es común el intercambio de los términos «virtual» y «digital», así como el empleo de denominaciones como «electrónico» o «en línea». Entre todas ellas, en esta tesis doctoral se ha optado deliberadamente por emplear la expresión «referencia digital», como el concepto que ofrece una definición más afín a la realidad que representa, además de ser en estos momentos la forma más empleada en la literatura profesional. El calificativo «virtual», tan empleado en biblioteconomía en los primeros momentos de las aplicaciones de la telemática a las bibliotecas ${ }^{200}$, incluye acepciones ambiguas, que definen de forma poco limitada cualquier realidad a la que se quiere aplicar. De esta forma, «virtual» es aquello que no es real, algo que no es cierto en los servicios bibliotecarios de referencia, puesto que es palpable la existencia de unos agentes (usuarios y bibliotecarios), unos procesos (preguntas, búsquedas, respuestas) y unos medios (equipos, fuentes de información).

En conjunto implican la prestación de un servicio que, aunque se realice de forma telemática, es real ${ }^{201}$. De igual forma es impreciso el calificativo «electrónico», que tampoco se ajusta a las características definitorias de la referencia, ya que no todos los medios electrónicos son digitales. Referencia electrónica es el fax o el teléfono, que no se deben incluir, por lo general, como sistemas de la referencia digital ${ }^{202}$. Por último, la expresión «en línea» (mucho menos el anglicismo «online») tampoco es certera para denominar al servicio remoto de consultas que prestan las bibliotecas. El uso ha hecho de la expresión «en línea» un sinónimo de «telemático», por lo que podría ser válido para la referencia digital; pero, por el mismo motivo que se descartaba el calificativo «electrónico», no parece precisa esta terminología, que puede aplicarse a cualquier sistema de telecomunicaciones. En definitiva, en esta investigación se ha considerado que la forma más adecuada es referencia digital, cuya descripción y características se comentan en los párrafos siguientes.

Una primera definición que merece la pena ser destacada es la que ofrece la RUSA en sus Guidelines for implementing and maintaining virtual reference

\footnotetext{
${ }^{200}$ Sigue siendo habitual encontrarse este calificativo como sinónimo de trabajo en línea. Algunos autores, como Lindblomm y otros, prefieren el concepto de referencia virtual para los servicios de información sincrónicos que se prestan a los usuarios. Véase Lindbloom, Mary-Carol; Yackle, Anna; Burhans, Skip; Peters, Tom; Bell, Lori. Virtual Reference: A Reference Question Is a Reference Question? Or Is Virtual Reference a New Reality? New Career Opportunities for Librarians. The Reference Librarian, 2006, vol. 45, n. 93, p. 3-22. ${ }^{201}$ No obstante, muchos autores anglosajones defienden el calificativo virtual, ya que en inglés es sinónimo de telemático. Así ocurre con Moyo, quien considera que por el carácter de servicio desempeñado en línea es preferible emplear el denominación virtual reference. Véase Moyo, L. M. Reference anytime anywhere: towards virtual reference services at Penn State. The Electronic Library, 2002, vol. 20, n. 1, p. 22-28. No obstante, el doctorando considera que en español se trata de un caso de falsos amigos y que no es conveniente traducir este término de forma literal como referencia virtual.

${ }^{202}$ Muchas bibliotecas ofrecen servicios de referencia digital combinados con los presenciales y digitales. Es interesante destacar servicios como Page Us, en la biblioteca de la Universidad de Carolina del Norte, donde los referencistas atienden llamadas telefónicas o responden a las consultas por mensajería instantánea, en función del método elegido por el usuario. Véase VanScoy, Amy. Page us: combining the best of in-person and virtual reference service to meet in-library patron needs. Internet Reference Services Quarterly, 2006, vol. 11, n. 2, p. 15-25.
} 
services $^{203}$, para quien «Referencia virtual» es el servicio de referencia iniciado electrónicamente, a menudo en tiempo real, en el que los usuarios emplean ordenadores u otra tecnología de Internet para comunicarse con el personal de referencia, sin que exista presencia física. En este mismo sentido se dirige la definición aportada por Jamen McGranahan ${ }^{204}$, para quien «Referencia virtual» se refiere a la habilidad de los bibliotecarios para la provisión de consultas y búsquedas con la ayuda de Internet. En ambos casos, como se puede apreciar, se hace mención a Internet como medio de comunicación para la referencia. Una definición importante, es la que aporta Janes $^{205}$, para quien «Referencia digital» es el uso de tecnologías y recursos digitales para proporcionar directamente ayuda profesional a las personas que buscan información, donde y cuando la necesiten ${ }^{206}$.

Es posible definir «referencia digital» en sentido amplio, entendiendo por tal el servicio que una biblioteca presta a usuarios remotos para ofrecerles información. Desde esta perspectiva, es una condición que el servicio se preste desde una biblioteca, que atienda a usuarios que se hallan fuera del edificio y que se les informe de datos o documentos que sean de su interés. Esta concepción implica que un servicio como éste responde a las cuestiones que planteen los usuarios, además de realizar y ofrecer recursos de información que consideran que pueden ser útiles, sin esperar a que sean solicitados por los destinatarios del servicio. Así, las guías de fuentes de información, los tutoriales, actividades y materiales de alfabetización informacional, las selecciones de recursos web o los productos informativos impresos y electrónicos que elabore la biblioteca y que difunda por medios electrónicos podrían ser considerados como propios de un servicio de referencia digital. No obstante, se debe ser preciso a la hora de definir un servicio de referencia digital. El doctorando propone la siguiente definición, en sentido estricto, de referencia digital:

\section{Servicio de referencia digital \\ El servicio bibliotecario que atiende peticiones de información de forma telemática, empleando tecnologías digitales para la comunicación con los usuarios.}

La definición es pretendidamente sintética y contiene importantes elementos definitorios de un servicio de referencia digital:

- es un servicio bibliotecario, prestado por las bibliotecas en el desempeño de sus objetivos básicos.

- es un servicio que atiende consultas, es decir, que responde a cuestiones planteadas por los destinatarios del servicio.

\footnotetext{
203 RUSA. Guidelines for Implementing and Maintaining Virtual Reference Services. Chicago: ALA, RUSA, 2004. La traducción es del doctorando.

${ }^{204}$ McGranahan, Jamen. Virtual reference. Library Mosaics, 2005, vol. 16, n. 1, p. 16.

${ }^{205}$ Janes, Joseph. Introduction to reference work in the digital age. New York: Neal-

Schuman, 2003, p. 29.

${ }^{206}$ La traducción es del doctorando.
} 
- $\quad$ es un servicio que se presta en línea, a partir de Internet.

- es un servicio que emplea tecnologías de la información para la recepción de las consultas y el envío de las respuestas, así como para todas las comunicaciones necesarias para el proceso.

Esta definición está en sintonía con la opinión de García Delgado ${ }^{207}$, autora de una de las escasas aportaciones teóricas sobre el tema escritas en castellano. Para ella, "el servicio de referencia virtual está basado más en la forma que en el fondo, es decir, que toda la transacción de referencia es llevada a cabo de modo virtual siguiendo la máxima de Taylor "en cualquier sitio, espacio, a cualquier ritmo y en cualquier momento". Aquí radica lo novedoso de este servicio: se ofrece total libertad de acceso al mismo". En el documento que se está citando, García hace una síntesis de las características de un servicio de este tipo, así como una tipología de los más empleados y una descripción de experiencias destacadas.

La relación de los servicios de referencia con los medios electrónicos ha sido muy bien sintetizada por Straw ${ }^{208}$, para quienes los referencistas han pasado de "magos a maestros". Este autor realiza una aproximación histórica del desarrollo de la referencia electrónica desde las primeras iniciativas hasta la actualidad. Según Straw habría que hablar de una primera etapa, que oscila entre 1930 y 1970, donde tienen su aparición y consolidación las telecomunicaciones. Se trata de un periodo caracterizado por la experimentación y el diseño de prototipos de sistemas de recuperación automática de documentos. La llegada de los sistemas automatizados a las bibliotecas se produce en la segunda etapa de la que habla este investigador, situada entre 1970 y 1985. Las bases de datos tienen pleno desarrollo y se convierten en algo habitual en las grandes bibliotecas, formando parte de los recursos empleados por los referencistas para resolver demandas de información. La tercera etapa es la que se localiza entre 1985 y 1994, que está caracterizada por la expansión de la informática y por el desarrollo de los soportes ópticos. El cederrón se convertirá en el sistema de almacenamiento más útil para los profesionales de la referencia. Por último, hay que hablar de la etapa actual, iniciada en 1993 y que Straw limita al año 2000. Como era de esperar, esta fase se caracteriza por la aparición y propagación de Internet, que transforma la naturaleza del trabajo de referencia, además de modificar la relación entre bibliotecarios y usuarios $^{209}$. Las bibliotecas se convierten en instructoras de información, en docentes especializados en enseñar dónde y cómo encontrar la información deseada. Los servicios de referencia comienzan a hacerse cargo de la necesaria alfabetización informacional. De ahí el cambio de perfil del referencista, que ha pasado de experto en localización de información a instructor en técnicas de documentación, de mago a maestro, en términos de Straw.

\footnotetext{
${ }^{207}$ García Delgado, Purificación. El servicio de referencia digital. El profesional de la información, 2003, vol. 12, n. 4, p. 320-330.

${ }^{208}$ Straw, Joseph E. From magicians to teachers: The development of electronic reference in libraries: 1930-2000. The Reference Librarian, 2001, n. 74, p. 1-12.

${ }^{209}$ Straw, op. cit., p. 9.
} 
La rápida puesta en marcha de servicios de referencia digital en las bibliotecas, sobre todo en Estados Unidos, donde la cifra creció de forma exponencial en muy pocos años, ha hecho que algunos autores fueran muy escépticos en relación a estos servicios. Buena prueba de ello son McKinzie y Lauer, quienes en varios trabajos ${ }^{210}$ han puesto en duda la necesidad de la referencia digital, servicio que consideran sobreestimado. Su opinión sirvió de base a una profusa discusión que tuvo lugar en la lista de distribución Web4lib en diciembre de 2002 y cuyas intervenciones más significativas fueron reproducidas en el Bulletin des Bibliothèques de France ${ }^{211}$.

Entre las opiniones sobresalieron algunas como la Bernie Sloan, quien ha estudiado en diversas ocasiones aspectos de la referencia digital, para quien las bibliotecas deben saber dar prioridad a unos servicios $u$ otros, ya que hay usuarios que prefieren desplazarse hasta el mostrador de referencia, otros que prefieren realizar la consulta por teléfono y otros que se deciden por el uso de su ordenador para plantear preguntas a la biblioteca. McKinzie y Lauer sugieren en varias ocasiones que la referencia digital es una cuestión de moda, que deslumbra a los bibliotecarios tecnófilos, algo que ha sido muy contestado por quienes intervinieron en la discusión que generó su artículo. El doctorando opina que la referencia digital no es un servicio innovador, aunque obliga a las bibliotecas a cambiar de metodología de trabajo. Se trata de ampliar los servicios de información que ya se ofrecían, para dar apoyo informativo -una razón de ser de toda biblioteca- a quienes no pueden o no quieren desplazarse hasta la sede física de la misma. La referencia digital es, pues, otro método para ofrecer servicios de información; se trata de emplear las posibilidades de la tecnología para poder informar a usuarios remotos.

Uno de los autores más productivos en relación a la referencia digital es R. David Lankes ${ }^{212}$, quien ha sido responsable de importantes proyectos como el Virtual Reference Desk. Este investigador ha sido el autor de la redacción de la voz Digital reference de la Encyclopedia of Library and Information Science $^{213}$. En esta entrada Lankes ofrece el marco conceptual, así como el desarrollo histórico de la referencia digital y las tendencias actuales. Para él referencia digital se refiere a una red de especialización, intermediación y recursos puestos a disposición de personas que buscan respuestas en entornos telemáticos. También se conoce como referencia virtual ( $y$ a menudo referencia en chat o referencia en tiempo real) e incluye diversos

\footnotetext{
${ }^{210}$ McKinzie, Steve; Lauer, Jonathan D. Virtual reference: overrated, inflated, and not even real. Charleston Advisor, 2002, vol. 4, n. 2, p. 56-57. Versión en francés: Le travail de reference virtuel: un service surestime, gonfle et pas meme reel. Bulletin des Bibliothèques de France, 2003, vol. 48, n. 4, p. 63-65. Se recomienda también la lectura del artículo de los mismos autores: Digital reference: a new library paradigm or the emperor's new clothes. Against the Grain, 2002, vol. 14, n. 4, p. 34-38.

${ }^{211}$ Tennant, Roy (et al.). Que reproche-t-on au travail de référence virtuel ? Bulletin des Bibliothèques de France, 2003, vol. 48, n. 4, p. 66-71.

${ }^{212}$ La trayectoria de este autor y muchas de sus publicaciones pueden ser consultadas en su sitio web Virtual Dave Lankes, disponible en <http://quartz.syr.edu/rdlankes> [consulta 14 de julio de 2007]. También se da acceso a su bitácora personal y profesional.

${ }^{213}$ Lankes, R. David. Digital Reference. En Miriam Drake (Ed.). Encyclopedia of Library and Information Science. $2^{\text {nd }}$ ed. New York: Marcel Dekker, 2003.
} 
procedimientos, incluyendo correo electrónico, formularios web, chat $^{214}$ y mensajería instantánea. Los programas informáticos de referencia más avanzados pueden incorporar videoconferencia, navegación web compartida e incluso que el bibliotecario de forma remota tome el control del ordenador de un usuario. Las tecnologías sirven al propósito fundamental de proveer intermediación humana a usuarios que están en línea. Para Lankes, los aspectos más relevantes que hay que tener presentes a la hora de afrontar servicios de referencia digital son: la elección del mejor método para interactuar con el usuario; el desarrollo de una política para la referencia digital; proveer de personal el mostrador virtual de referencia; integrar la referencia digital en las iniciativas generales de la biblioteca; programas informáticos y estándares para facilitar la referencia digital; y evaluación de costes y beneficios de la referencia digital.

Como se decía unas líneas antes, Lankes es uno de los autores que más han aportado a la referencia digital, su experiencia como investigador, director del Information Institute of Syracuse y responsable de importantes proyectos de referencia digital, lo convierten en un referente en este campo. Entre sus trabajos cobra especial importancia el denominado The Digital Reference Research Agenda ${ }^{215}$, puesto que en el mismo define la referencia digital y ofrece un modelo para su prestación. En esta agenda se entiende como referencia digital el uso de intermediación humana para responder preguntas en un entorno digital. Además, el autor ofrece otras definiciones significativas, como la de Pomerantz ${ }^{216}$, otro gran experto en referencia digital, cuyo enfoque es prácticamente idéntico: referencia digital es el servicio que se presta a los usuarios mediante respuesta a preguntas en un medio automatizado ${ }^{217}$. Lankes, entre otros investigadores, participó en un seminario celebrado en la Universidad de Harvard en agosto de 2002 en el que se quería asentar las bases de la referencia digital ${ }^{218}$, donde se aportó un modelo que ha sido defendido por diversos autores, como Pomerant ${ }^{219}$, quien también participó en su elaboración. Lankes construye su Modelo general de referencia digital a partir de este seminario. El modelo de Lankes se basa en cinco componentes: conocimientos humanos; eficiencia y

\footnotetext{
${ }^{214}$ Pomerantz ha realizado un estudio sobre las cuestiones más importantes que debe afrontar la investigación biblioteconómica en relación a la referencia vía chat. Véase Pomerantz, Jeffrey. A conceptual framework and open research questions for chat-based reference service. Journal of the American Society for Information Science and Technology, 2005 , vol. 56 , n. 12 , p. $1288-1302$.

${ }^{215}$ Lankes, R. David. The digital reference research agenda. Journal of the American Society for Information Science and Technology, 2004, vol. 55, n. 4, p. 301-311.

${ }^{216}$ Pomerantz, Jeffrey. Integrating Digital Reference Service into the Digital Library Environment. En Lankes, R. D.; Nicholson, S.; Goodrum, A. (eds.). The Digital Reference Research Agenda. Chicago: Association of College and Research Libraries, 2003, p. 23-47. ${ }^{217}$ La traducción es del doctorando.

${ }^{218}$ Puede consultarse el informe final en Lankes, R. D.; Nicholson, S.; Goodrum, A. (eds.). The Digital Reference Research Agenda. Chicago: Association of College and Research Libraries, 2003. Además, está en línea un resumen de dicho simposio, al que se puede acceder desde la dirección <http://quartz.syr.edu/symposium/agenda.html> [consulta 24 de junio de 2007].

${ }^{219}$ Pomerantz, Jeffrey; Nicholson, Scott; Belanger, Yvonne; Lankes, David R. The current state of digital reference: validation of a general digital reference model through a survey of digital reference services. Information Processing and Management, 2004, vol. 40, n. 2, p. 347-363.
} 
efectividad, sistemas de información, preguntas; y respuestas. El autor estadounidense desarrolla su modelo de forma esquemática en las diferentes versiones de su Agenda ${ }^{220}$. El proceso comienza cuando el usuario (User) realiza una consulta (Question Acquisition) a un centro de información (Triage Center). Es interesante el término empleado por Lankes, ya que triage pertenece al vocabulario médico y suele corresponden al proceso de selección, de separación, de examen, que se realiza antes de atender a un paciente. En el sentido empleado en este modelo, el siguiente paso sería el examen (Triage) de la pregunta por el personal referencista especializado (Experts), quien, por una parte, enviará al usuario la respuesta (Answer Formulation) y, por otra parte, la archivará (Q\&A Archive), para que pueda ser empleada como fuente de información interna o como recurso informativo a través de Internet (Web Resources). El esquema aportado por Lankes es el siguiente:

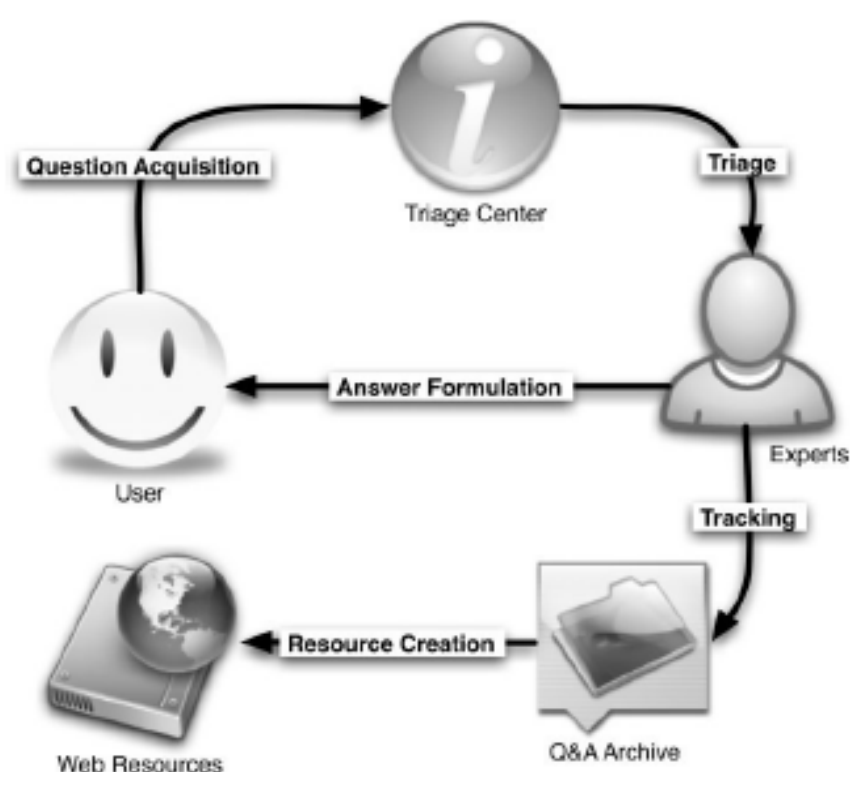

Fig. 2.2. Modelo General de la Referencia Digital (Lankes)

El modelo parte de dos presupuestos: 1) es útil incorporar la experiencia humana en los sistemas de información y 2) la naturaleza digital de los sistemas de referencia digital proporcionan un contexto significativamente diferente. El marco de la investigación en referencia digital supone asumir estos presupuesto de partida y enfocar su trabajo hacia los siguientes focos: políticas, sistemas, evaluación y conocimiento. Además, la referencia digital no puede ignorar que tiene unos precedentes (la referencia bibliotecaria y los servicios de preguntas o Ask $A$ ) y que tiene relación estrecha con seis ámbitos de la información: bibliotecas digitales, recuperación de información, referencia y biblioteconomía, comunicación por medios electrónicos, teoría

\footnotetext{
${ }^{220}$ La traducción y la adaptación son del doctorando. Véase Lankes, R. D.; Nicholson, S.; Goodrum, A. (eds.). The Digital Reference Research Agenda. Chicago: Association of College and Research Libraries, 2003; Lankes, R. David. The digital reference research agenda. Journal of the American Society for Information Science and Technology, 2004, vol. 55, n. 4, p. 301-311; y Lankes, R. D. Digital Reference Research - Fusing Research and Practice. Reference and User Services Quarterly, 2005, vol. 44, n. 4, p. 320-326.
} 
de sistemas y educación. A partir de estas bases, Lankes desarrolla la agenda o marco conceptual y ejecutivo que fundamenta la referencia digital. Además, desarrolla una matriz en la que contempla las cuestiones que hay que desarrollar en la investigación en este ámbito, que es una excelente base para el diseño de sistemas de referencia digital. Las diferentes ramas y focos de atención de la referencia digital, a partir de las teorías de Lankes, fueron representadas de forma gráfica por este autor estadounidense:

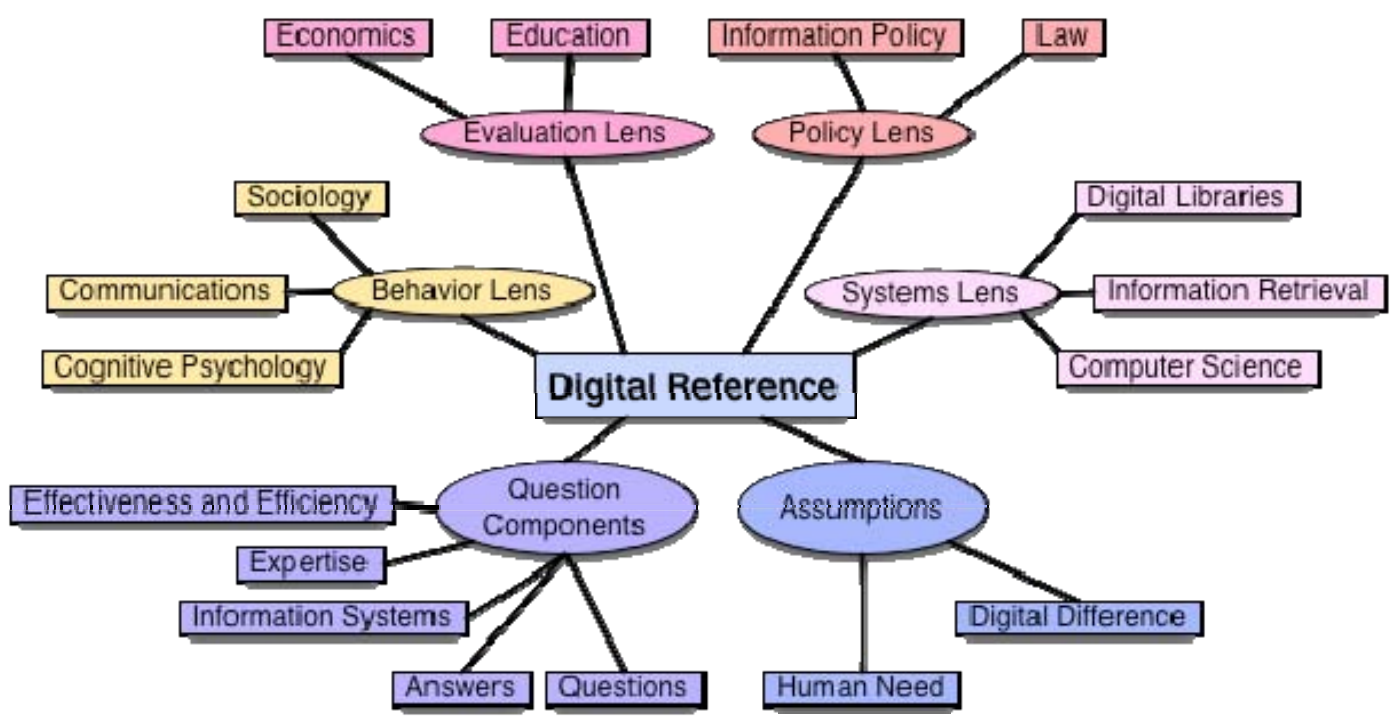

Fig. 2.3. Focos del Modelo general de la referencia digital (Lankes)

Lankes, partiendo de la teoría de sistemas, entiende que en la referencia digital intervienen diferentes elementos que hay que tener en cuenta para su análisis y desarrollo. Por una parte, establece una serie de objetivos o focos (Lens), como son los relacionados con el comportamiento (Behavior Lens), en donde intervienen disciplinas como la sociología, la comunicación y la psicología cognitiva. El siguiente elemento es el relativo a la evaluación (Evaluation Lens), en este caso atendiendo a factores económicos y educativos. El tercer objetivo es el de las normas (Politics Lens), que incluyen los aspectos de las políticas de información y los jurídicos. A continuación, se reúnen los aspectos que atañen a los sistemas de información (Systems Lens) y que reúnen materias, como bibliotecas digitales, recuperación de información e informática. Por otra parte, el modelo incluye una serie de presupuestos de partida (Assumptions), con los que es necesario estar de acuerdo para comprender la referencia digital, como son el hecho diferencial que supone el trabajo digital y la necesidad de intervención humana en los servicios de consulta. Pero, para Lankes ${ }^{221}$, la cuestión central de la referencia digital es el grado de participación humana en el servicio. Este eje de la referencia digital se puede desgranar en una serie de componentes (Question Elements), como son la eficiencia y la efectividad del servicio, la habilidad del referencista, las tecnologías

${ }^{221}$ Lankes, R.D. Op. cit., p. 303. 
empleadas, el tipo de preguntas atendidas y la calidad de las respuestas entregadas.

Para otros autores, como Alves y Meneses $^{222}$, el concepto de servicio de referencia e información es una fusión de todos los sectores, servicios y recursos humanos existentes en una biblioteca, para atender las necesidades informacionales de los usuarios. Para estas autoras, los servicios de referencia digital surgen como una alternativa a los medios y necesidades actuales. Según las mismas, la palabra "cambio" es la que mejor define a la biblioteconomía actual.

Por otra parte, Lauer y McKinzie ${ }^{223}$ insisten en que los cambios tecnológicos no se deben sobrevalorar ni infraestimar el factor humano de los bibliotecarios y su experiencia. De igual forma, Anderson ${ }^{224}$ ofrece su visión acerca de cuáles son los principales cambios que ha experimentado la profesión de referencista, para él centrados en el desarrollo del trabajo en red y de las redes neuronales, la realidad virtual y la inteligencia artificial, así como la nanotecnología. Se trata de nuevas tecnologías que inciden en las estructuras organizativas de los servicios de referencia y en las formas de prestar dichos servicios.

Es útil el documento que la Public Library Association, adscrita a la ALA, dedicó a la referencia digital, que fue redactado por Richard W. Boss ${ }^{225}$. Para este autor ${ }^{226}$, "referencia virtual, también conocida como e-referencia, es el servicio de referencia en línea, que ayuda a los usuarios ofreciendo respuestas a las preguntas más frecuentes (FAQs) en el sitio web de una biblioteca, montando herramientas seleccionadas para la referencia, facilitando un correo electrónico o un formulario web para que los usuarios planteen sus preguntas de referencia y/o proveyendo asistencia en tiempo real usando programas de chat o mensajería instantánea". Boss considera que uno de los primeros hitos de la referencia digital fue en 1995, cuando se puso en marcha Internet Public Library, siendo a finales de los años 90 cuando muchas bibliotecas lanzan sus servicios de referencia en línea, ya sea de forma individual o cooperativa ${ }^{227}$. Las teorías de Boss se pueden

\footnotetext{
${ }^{222}$ Alves, Ana Paula Meneses; Vidotti, Silvana Aparecida Borsetti Gregório. O serviço de referęncia e informaçăo digital. Biblionline, 2006, vol. 2, n. 2.

${ }^{223}$ Lauer, Jonathan D.; McKinzie, Steve. Bad Moon Rising: A Candid Examination of Digital Reference and What It Means to the Profession. The Reference Librarian, 2002-2003, vol. 38, n. 79-80, p. 45-56.

${ }^{224}$ Anderson, Charles R. Reference librarianship: a guides for the 21st Century. The Reference Librarian, 2006, vol. 34, n. 72, p. 5-19.

${ }^{225}$ Boss, Richard W. Virtual Reference. Public Library Association Tech Notes, 2004, n. 30 dec.

${ }^{226}$ La traducción es del doctorando.

227 Las teorías de Boss se ven apoyadas por el resultado de la investigación de Tenopir en la que analiza la creación de servicios electrónicos de información en las bibliotecas pertenecientes a las Association of Research Libraries (ARL). En su estudio Tenopir refleja cómo la década de los 90 fue en la que se popularizaron los servicios de referencia digital en las bibliotecas académicas y de investigación. Véase Tenopir, Carol. Electronic reference and reference librarians: a look through the 1990s. Reference Services Review, 1999, vol. 27, n. 3, p. 276-280.
} 
resumir, de forma general, sintetizando qué se puede entender por referencia digital según este autor:

- la información estática que, a modo de FAQ, ofrecen las bibliotecas en sus páginas web

- las selecciones de recursos de referencia realizadas por bibliotecas

- los servicios bibliotecarios que atienden las consultas de los usuarios ya sea de forma asíncrona o en tiempo real.

Fritch y Mandernack ${ }^{228}$ opinan que se está asistiendo a la emergencia de un nuevo paradigma ${ }^{229}$, en el medio informativo en general y en los servicios de referencia en particular. Ambos realizan una revisión histórica del servicio de referencia hasta llegar al momento actual de la información, para ellos caracterizado por el uso de las tecnologías, el acceso a Internet, los medios de comunicación electrónicos y otros aspectos similares que están llevando hacia un nuevo paradigma en la referencia, en el cual ya se está viviendo. Ofrecen una serie de indicaciones acerca de los nuevos ámbitos informacionales. Entre los temas que componen el nuevo marco de la referencia estarían: servicios de referencia digital, portales web, bases de datos de FAQ, tutoriales en línea, referencia distribuida (roving reference), sesiones de orientación para investigadores, revisiones por pares, programas cooperativos, personal, etc.

Entre los autores que están exponiendo sus teorías sobre el futuro de la referencia y la llegada de la referencia digital es necesario mencionar a Janes $^{230}$. En un breve artículo resume las tendencias en las que se encuentra el trabajo de referencia desde finales de los 90 y principios del siglo XXI. Para él, ha habido un incremento en el número y variedad de recursos de información disponibles, incluyendo, aunque no exclusivamente, a los que se ofrecen en las bibliotecas; además, estos recursos se han hecho más complejos y, por tanto, más difíciles de manejar para localizar una información. Otra característica es el aumento de las personas que usan las bibliotecas, que tienen perfiles muy diversos y que solicitan una amplia gama de servicios de información. Janes considera que las bibliotecas deben ofrecer un "mix de servicios", diversos en contenidos y en sistemas, conteniendo servicios sincrónicos (en persona, por teléfono, mediante tecnologías), así como asincrónicos (correo postal y electrónico y web). En este mismo sentido, $\mathrm{Katz}^{231}$, en el artículo que enmarca el número especial

\footnotetext{
${ }^{228}$ Fritch, John W.; Mandernack, Scott B. The emerging reference paradigm: a vision of reference services in a complex information environment. Library trends, 2001, vol. 50, n. 2 , p. 286-305.

${ }^{229}$ La mención a un cambio de paradigma en la referencia digital en relación a los servicios tradicionales de referencia en bibliotecas es un hecho común en la bibliografía profesional. Véase, por ejemplo, Moyo, L. M. Electronic Libraries and the Emergence of New Service Paradigms. The Electronic Library, 2004, vol. 22, n. 3, p. 220-230; y Reenstjerna, Frederick R. Thinking About Reference Service Paradigms and Metaphors. The Reference Librarian, 2001, vol. 34, n. 72, p. 97-111, además de la referencia anterior.

${ }^{230}$ Janes, Joseph. What is reference for? Reference Services Review, 2003, vol. 31, n. 1, p. 22-25.

${ }^{231}$ Katz, Bill. Digital reference: an overview. The Reference Librarian, 2002-2003, vol. 38, n. $79 / 80$, p. 1-17. Este importante autor también aborda las tendencias en referencia digital en
} 
dedicado a referencia digital en The Reference Librarian, también analiza los principales aspectos que están marcando los actuales servicios de referencia. Los tipos de preguntas que se están recibiendo, la disponibilidad de los servicios durante 24 horas al día y 7 días a la semana, la necesidad de adaptar las metodologías de evaluación o la aparición de los servicios comerciales son los principales ámbitos de desarrollo de la referencia digital, según este autor. En esta misma línea se sitúa LaGuardia ${ }^{232}$, para quien el bibliotecario referencista debe hacer énfasis en el uso de las tecnologías como fin para conseguir las necesidades, en lugar de como un juguete o un fin en sí mismo. Para esta autora, hay cinco ámbitos a los que la referencia actual debe prestar especial atención: diseño de los sistemas correctos; mantener una visión local de las necesidades de los usuarios; obtener una perspectiva realista en la instrucción bibliotecaria; reconocer un cambio de paradigma en la complejidad de las demandas de información; y los aspectos relativos a las relaciones públicas de los servicios de referencia.

Diane Kresh, responsable de una de las primeras redes cooperativas de referencia creadas, el Collaborative Digital Reference Service (CDRS), realizó una sintética historia de este tipo de servicios de información ${ }^{233}$, partiendo de sus datos y de las aportaciones de diversos investigadores. En su artículo se menciona al Electronic Access to Reference Service (EARS) de la Maryland's Health Services Library como el primer servicio de referencia digital, ya que se inicia en 1984. El servicio se ofrecía a través de la compañía Telebase. Los servicios de referencia mediante correo electrónico arrancan en los primeros años 90, en algunas bibliotecas universitarias y públicas. En muchos casos se trataba de servicios especializados, como Joan of Art (1993) en arte o Ask Eric (1992), en educación. El primer servicio de referencia a través de chat datado es el de la biblioteca Bill Drew en Suny Morrisville, Nueva York, que se comenzó a ofrecer en otoño de 1998 y que sirvió de modelo al que arrancó la Temple University en noviembre de ese mismo año. A finales de los años 90 comienzan a crearse consorcios para la prestación conjunta de este servicio mediante chat. Entre los primeros grupos destaca el Metropolitan Cooperative Library System de California, que se inició el 1 de julio de 2000. Antes, en 1999, la Biblioteca del Congreso había puesto en marcha el CDRS, que en 2001 pasa a ser QuestionPoint, a partir de un acuerdo con OCLC. En enero de 2003 nace Virtual Reference Canada, otro de los grandes servicios de referencia digital. Ese mismo año nace Ask Us en Australia ${ }^{234}$.

Katz, Bill. Long live old reference services and new technologies. Libraries trends, 2001, vol. 50, n. 2, p. 263-285.

${ }^{232}$ LaGuardia, Cheryl. The future of reference: get real! Reference Services Review, 2003, vol. 31, n. 1, p. 39-42.

${ }^{233}$ Kresh, Diane. Virtually yours: thoughts on where we have been and where we are going with virtual reference services in libraries. The Reference Librarian, 2002-2003, vol. 38, n. $79 / 80$, p. $19-34$.

${ }^{234} \mathrm{La}$ autora omite que desde agosto de 2002 el servicio australiano ya estaba operativo, aunque de forma experimental. Asimismo, ignora servicios europeos más antiguos, como el inglés, de 1997, los de Finlandia o Dinamarca, de 1999 o el español, que nació en junio de 2000. 


\subsection{Tipología de los servicios de referencia digital}

Los servicios bibliotecarios de referencia digital se pueden clasificar en función de diversos criterios, como son la tipología de las bibliotecas que responden a los usuarios, el tipo de consultas que atienden, los medios tecnológicos que emplean, la especialización temática, etc. Autores, como Manso $^{235}$, han aportado su clasificación de los servicios de referencia digital. Este autor cubano realiza una aproximación bibliográfica al concepto de la referencia digital, analizando los elementos que intervienen en su proceso, así como otros aspectos relacionados: modelos, organización, tecnología y evaluación. Asimismo, ofrece una clasificación de los servicios que él denomina de referencia virtual, que presenta en función de diferentes criterios:

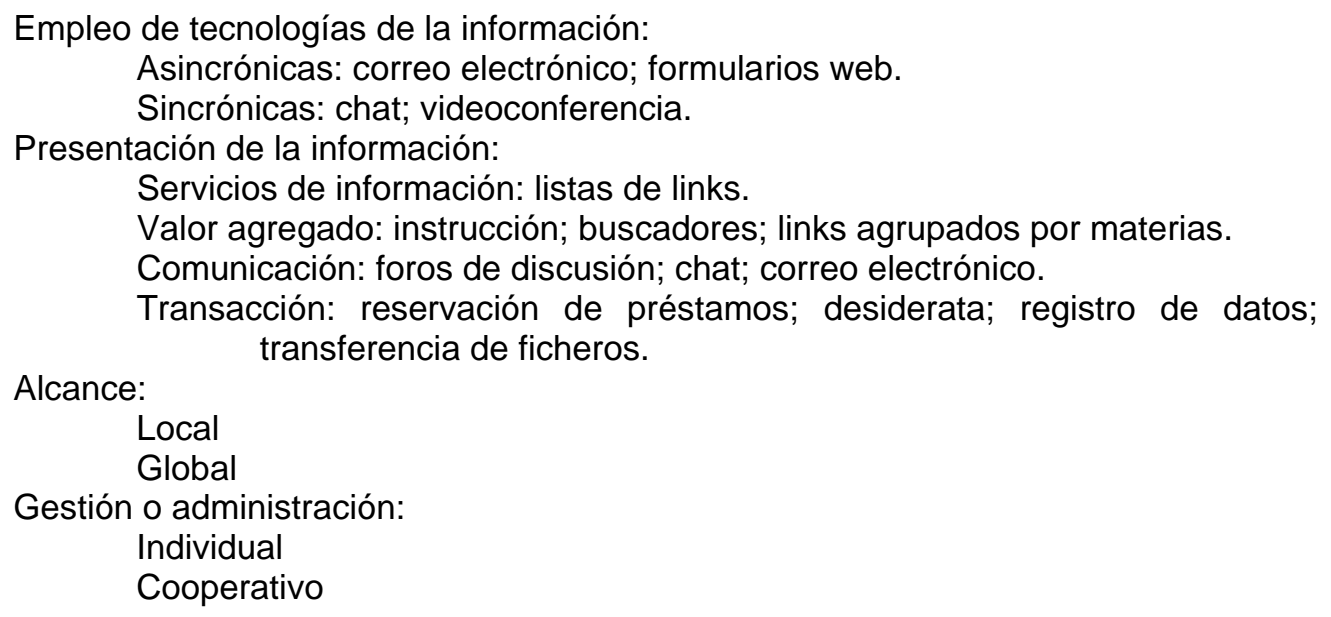

El doctorando quiere ofrecer en este apartado una sistematización de los servicios de referencia digital, partiendo de puntos de vista diferentes y siempre intentando reflejar la diversidad de servicios de este tipo que se pueden encontrar en estos momentos en todo el mundo. La siguiente estructuración parte, por tanto, de servicios de referencia digital reales, los cuales se agrupan a partir de criterios diversos, por lo que esta clasificación no implica incompatibilidad entre unas categorías y otras, sino que quiere ofrecer la suma de las distintas vertientes a partir de las que se pueden clasificar los servicios bibliotecarios de referencia digital.

Los servicios de referencia digital existentes se pueden clasificar en los tipos que a continuación se relacionan (ordenación alfabética), partiendo de los criterios que se exponen en los grupos que se detallan en los siguientes párrafos (ordenación alfanumérica). Tras la descripción de las tipologías de servicios bibliotecarios de referencia digital que ha encontrado el doctorando, se ofrece un esquema a modo de resumen.

\footnotetext{
${ }^{235}$ Manso Rodríguez, Ramón Alberto. Del escritorio tradicional al virtual: nuevas posibilidades para el servicio de referencia. ACIMED [en línea], febrero 2007, vol. 15, n. 2. Disponible en <http://bvs.sld.cu/revistas/aci/vol15_02_07/aci08207.htm> [consulta 12 junio 2007].
} 
A/ Según la tipología bibliotecaria, sobre todo partiendo de los usuarios a los que se atienda y/o de las colecciones que se posean, es posible encontrarse con los siguientes servicios de referencia digital:

A1. Servicios de referencia de bibliotecas nacionales: aquellos que ofrecen las bibliotecas nacionales, regionales o centrales de un país o demarcación geográfica. Suelen atender exclusivamente cuestiones sobre la cultura de la zona sobre la que tienen jurisdicción bibliográfica. Un buen ejemplo es el Service d'Information des Bibliothécaires a Distance (SINDBAD) ${ }^{236}$ de la Biblioteca Nacional de Francia, que ofrece tanto datos de sus colecciones, como informaciones factuales.

A2. Servicios de referencia de bibliotecas públicas: los que prestan las bibliotecas que tienen fondo enciclopédico y que están abiertas a cualquier tipo de usuario ${ }^{237}$. Sus servicios de referencia digital son genéricos, ya que atienden consultas de cualquier temática, aunque no suelen ser exhaustivos, ya que no realizan búsquedas bibliográficas complejas o especializadas. El servicio de referencia digital de la Biblioteca Pública de Nueva York ${ }^{238}$ o el de Biblioteca Municipal de Lyon $^{239}$ son dos buenos ejemplos. Muchos de estos servicios se ofrecen desde entidades de coordinación de bibliotecas públicas en un estado o región, como es el caso del servicio australiano VISioN ${ }^{240}$ en Victoria.

A3. Servicios de referencia de bibliotecas universitarias: los servicios que ofrecen las entidades de enseñanza superior a su comunidad de estudiantes, profesores, investigadores y trabajadores ${ }^{241}$. Suelen ser avanzados y están muy centrados en el uso de las colecciones especializadas, recursos electrónicos o apoyo a la enseñanza en línea. Como una excelente muestra está el servicio de regencia digital

\footnotetext{
${ }^{236}$ Service d'Information des Bibliothécaires a Distance (SINDBAD) http://www.bnf.fr/PAGES/zNavigat/frame/version_espagnole.htm?ancre=espagnol.htm ${ }^{237}$ Un ejemplo de implantación de servicio de referencia en línea en una biblioteca pública de una localidad pequeña es el de la Winter Park Public Library, que inició su servicio de referencia vía chat en febrero de 2002. Véase Ward, Joyce; Mervar, Dana; Loving, Matthew; Kronen, Steve. Going It Alone: can a small/medium-sized library manage live online reference? The Reference Librarian, 2002-2003, vol. 38, n. 79-80, p. 311-322. ${ }^{238}$ New York Public Library: Ask librarians online: http://www.nypl.org/questions.

${ }^{239}$ Bibliothèque municipale de Lyon: http://www.bm-lyon.fr.

240 Victorian Information Service Network, ahora denominado Information Victoria: http://www.information.vic.gov.au/info_serv/index.html. Se puede obtener más información sobre este servicio en Murray, Janet; Tschernitz, Cindy. The impact of electronic information delivery on reference enquiries. Online Information Review, 2005, vol. 29, n. 2, p. 157-167. En este artículo se ofrece además una evaluación del impacto del servicio en su comunidad y un estudio de los presupuestos asignados.

${ }^{241}$ Véase Nguyen, Claire. Les services de reférénce virtuels en bibliothèque universitaire:

Enjeux, perspectives, debats. Bulletin des bibliothèques de France, 2006, vol. 51, n. 3, p. 5457. También será útil consultar la experiencia de InfoPoint, el sistema de referencia digital de la University of Minnesota Twin Cities Libraries, que se describe detalladamente en Stemper, James A.; Butler, John T. Developing a model to provide digital reference services. Reference Services Review, 2001, vol. 29, n. 3, p. 172-189.
} 
creado por la CREPUQ ${ }^{242}$, la institución que agrupa a los rectores de las universidades del Canadá francófono.

A4. Servicios de referencia de bibliotecas escolares: son los servicios de referencia digital que prestan los colegios de enseñanza primaria y los centros de enseñanza secundaria. Están muy centrados en el apoyo a los currículos de sus respectivos centros, por lo que se ofrecen solamente a sus estudiantes. Suelen estar acompañados de recursos de información complementarios, donde el estudiante puede localizar las respuestas a sus consultas de forma independiente. En Estados Unidos, gracias a la red Virtual Reference Desk se crearon un gran número de servicios de referencia digital en escuelas, que trabajaban de forma cooperativa. Un ejemplo en España es el servicio de referencia a través de formulario web que ofrece el Instituto de Educación Secundaria El Escorial ${ }^{243}$.

A5. Servicios de referencia de bibliotecas especializadas: aquellos que ofrecen las bibliotecas de centros de investigación y las pertenecientes a organismos públicos o privados que sólo atienden al personal vinculados a sus respectivas instituciones: administraciones públicas, empresas, colegios profesionales, organismos científicos, hospitales, parlamentos, etc. Sus colecciones son especializadas, de igual forma que lo son sus servicios de referencia digital. Una muestra es el Agriculture Network Information Center ${ }^{244}$ (AgNIC), cuyo servicio de referencia digital está especializado en ciencias agrarias.

A6. Servicios de referencia de bibliotecas especiales: los servicios que se ofrecen en bibliotecas de centros hospitalarios, penitenciarios o los destinados a usuarios en condiciones particulares (discapacitados, ancianos, inmigrantes, colectivos sociales). Son bibliotecas con colecciones de tipo general, similar a las de una biblioteca pública, pero que atiende sólo a los usuarios vinculados a ese centro. Los servicios de referencia digital en este tipo de bibliotecas son muy escasos, excepto en aquellas que también cumplen con funciones educativas, como son las bibliotecas de cárceles o las que tienen programas de formación de adultos. Un excelente ejemplo es el servicio Infoeyes ${ }^{245}$, que ofrece información y referencia para ciegos.

A7. Servicios de referencia de bibliotecas digitales. Algunas bibliotecas no tienen sede física, pero prestan igualmente servicios de información y

\footnotetext{
${ }^{242}$ CREPUQ, Conférence des recteurs et des principaux des universités du Québec: http://www.crepuq.qc.ca.

${ }^{243}$ Instituto de Educación Secundaria El Escorial:

http://www.educa.madrid.org/web/ies.elescorial.elescorial/webbiblio/bibliotecario.html

${ }_{244}^{244}$ Agriculture Network Information Center: http://www.agnic.org.

245 Infoeyes: http://www.infoeyes.org. Este servicio nació en 2004 y es ofrecido de forma conjunta por una quincena de servicios de referencia estadounidenses. Desde su nacimiento hasta agosto de 2007 había atendido un millar de cuestiones planteadas tanto a través de Question Point como del software de reconocimiento de voz tcConference, que también permite la conavegación.
} 
acceso a colecciones documentales ${ }^{246}$. Se puede entender como biblioteca digital aquella que reúne colecciones en formatos electrónicos, las organiza a partir de normas biblioteconómicas y las difunde a través de servicios dirigidos a usuarios. Es habitual que las bibliotecas digitales incluyan servicios de referencia. Un ejemplo de este modelo es la Biblioteca Virtual Cervantes, que dispone de un servicio de referencia en línea, denominado El bibliotecario ${ }^{247}$, que atiende las consultas de los usuarios.

B/ A partir de la existencia o no de cooperación se pueden distinguir dos tipos de servicios de referencia digital:

B1. Servicios individuales: aquellos servicios de referencia digital que presta una biblioteca de forma independiente, tomando como base sus propias colecciones y personal. En las bibliotecas públicas, cumplen una función relevante como servicio de información local y, en las universitarias, son un importante apoyo para los estudiantes, para su orientación bibliográfica y la alfabetización informacional ${ }^{248}$.

B2. Servicios cooperativos: los servicios de referencia digital en los que intervienen diferentes bibliotecas, ya sean del mismo organismo y tipología o de otras instituciones ${ }^{249}$. Este grupo de servicios de referencia digital son los más frecuentes, sobre todo los que pertenecen a un tipo de bibliotecas similar, como son, por ejemplo, las redes de bibliotecas públicas. También son abundantes las muestras de servicios cooperativos entre campus, en las bibliotecas universitarias, y los que afectan a los consorcios de bibliotecas especializadas, sobre todo en salud ${ }^{250}$.

\footnotetext{
${ }^{246}$ Véase Choi, Youngok. Reference services in digital collections and projects. Reference Services Review, 2006, vol. 34, n. 1, p. 129-147. El autor realizó un estudio sobre los servicios ofrecidos en 60 bibliotecas digitales, de los que un 75\% (40) disponían de referencia digital, fundamentalmente a través de correo electrónico. Es interesante también Chowdhury, Gobinda G. Digital libraries and reference services: present and future. Journal of Documentation, 2002, vol. 58, n. 3, p. 258-283. En este artículo la autora analiza los servicios personalizados de las bibliotecas digitales, incluyendo los de referencia.

${ }^{247}$ Biblioteca Virtual Miguel de Cervantes, El bibliotecario: http://www.cervantesvirtual.com/bibliotecario/index.jsp.

${ }^{248}$ Un excelente ejemplo de biblioteca que emplea los servicios de referencia digital para el apoyo educativo es la Brooklyn Public Library, cuyo servicio Live Homework Help <http://www.brooklynpubliclibrary.org/homework_help.jsp> ofrece ayuda en línea para la realización de trabajos para estudiantes que sean usuarios de la biblioteca. Otro ejemplo similar es Homework Help, de las bibliotecas públicas de Arlington

$<$ http://www.arlingtonva.us/Departments/Libraries/LibrariesMain.aspx>, que también atiende en español.

${ }^{249}$ Un interesante estudio sobre la mejora del rendimiento en la pertenencia a un servicio cooperativo es: Breidenbaugh, Andrew. Budget planning and performance measures for virtual reference services. The Reference Librarian, 2006, vol. 46, n. 95/96, p. 113-124. Informa de la evaluación realizada por la Tampa-Hillsborough County Public Library comparando sus estadísticas de referencia digital en solitario y desde su pertenencia al Ask a Librarian de Florida El aumento de su efectividad tuvo relación directa en la asignación de presupuestos para el servicio de referencia digital.

${ }^{250}$ La cooperación es la base de la referencia digital, como opina Pomerantz, uno de los teóricos más prestigiosos en esta disciplina. Véase Pomerantz, Jeffrey. Collaboration as the Norm in Reference Work. Reference and User Services Quarterly, 2006, vol. 46, n. 1, p. 45-
} 
C/ La temática sirve también como un criterio de distinción de los servicios de referencia digitales, ya que es posible localizar:

C1. Servicios generales: que atienden a consultas de cualquier disciplina, como suele ocurrir en los servicios públicos de referencia digital, es decir, los que ofrecen los sistemas bibliotecarios públicos de un estado para todos sus ciudadanos. Son los servicios de referencia digital más comunes, sobre todo cuando son ofertados por bibliotecas públicas. Los servicios comentados en el apartado 9.3. son buena prueba de esta tipología.

C2. Servicios especializados: los que sólo responden consultas sobre una materia específica ${ }^{251}$. Esto ocurre en todas las bibliotecas especializadas y en muchas bibliotecas universitarias, que restringen las temáticas a las materias que se imparten en sus facultades de influencia. También se pueden incluir aquí los servicios de referencia no bibliotecarios, que son atendidos por expertos en diferentes asuntos. Los servicios de referencia temática de la Universidad de Sevilla $^{252}$ son una muestra de este tipo de referencia digital.

D/ Los destinatarios de los servicios de información ofrecen una división de los servicios de referencia digital en dos grupos:

D1. Servicios abiertos: Ios que atienden a cualquier usuario, sea miembro o no de la biblioteca o red de bibliotecas que da el servicio. Los servicios públicos de referencia en línea que ofrecen las responsables de un estado o región suelen pertenecer a esta categoría, ya que suelen poner cómo única norma que se empleen las lenguas oficiales de ese área geográfica. Este tipo de servicios públicos son los más destacados sistemas de referencia digital, al no restringir su actividad a destinatario alguno.

D2. Servicios restringidos: los que sólo atienden consultas de los usuarios vinculados a sus bibliotecas. Esto plantea problemas añadidos de autenticación y autorización, ya que son necesarios sistemas de reconocimiento de direcciones IP, para permitir la consulta sólo desde terminales de una red institucional o a través de procedimientos de identificación, como los números que acompañan al código de barras del carnet de usuario de una biblioteca. Son servicios habituales en bibliotecas especializadas y universitarias. Los sistemas de referencia digital de muchas redes públicas estadounidenses también restringen el uso a quienes tengan un número de usuarios o vivan en su área de influencia.

55. En este artículo analiza los diferentes ámbitos y procedimientos relacionados con la referencia digital en los la colaboración entre bibliotecas y profesionales es esencial.

${ }^{251}$ Lankes ofrece una descripción de los primeros servicios de este tipo que existieron en Estados Unidos, como Ask a Volcanologist, Ask Shamu, Dr. Math o el National Museum of American Art Reference Desk. Véase Lankes, R. David. Building and maintaining Internet information services. Syracuse, New York: Syracuse University, 1998.

${ }^{252}$ Universidad de Sevilla. Pregunte a un bibliotecario:

http://bib.us.es/neo/servicios/pregunte/index-ides-idweb.html 
Desde la perspectiva del modelo del servicio que se presta, es posible encontrarse con las siguientes realidades en los servicios de información:

E1. Servicios de bibliotecas: Ios servicios de referencia digital que prestan las bibliotecas, sean del tipo que sea. Son los servicios de referencia propiamente dichos, los que deben ser considerados así en sentido estricto. También son los más abundantes, ya que es habitual que los ofrezcan las bibliotecas universitarias y las públicas. Es importante insistir en la idea de que deben ser considerados como los verdaderos servicios de referencia digital.

E2. Servicios de información: aquellos que facilitan centros de documentación, archivos o servicios de información, habitualmente pertenecientes a organismos de la administración pública. Son habituales los servicios de información al ciudadano, a los consumidores o colectivos específicos. Un buen ejemplo es Europe Direct $^{253}$, servicio de consultas de la Comisión Europea, que ofrece información sobre la Unión Europea, especialmente sobre sus webs, y que se presta por teléfono, correo electrónico o mediante conversación vía chat con conavegación.

E3. Servicios de expertos: tipología de servicios de información en la que diferentes personas, especialistas en una materia, se agrupan en torno a un servicio o plataforma web. En muchos casos son independientes y gratuitos para el usuario, pero en otros casos conllevan el pago de una cantidad. No son servicios de referencia en sentido estricto ${ }^{254}$. Algunos ejemplos son los servicios españoles Todo expertos $^{255}$ o Xpertia ${ }^{256}$. También se incluyen aquí los directorios de expertos de determinadas instituciones, sobre todo científicas, como es el caso de RedIRIS ${ }^{257}$.

E4. Servicios de respuestas: módulos o servicios que ofrecen algunos buscadores para que los usuarios realicen consultas y éstas sean atendidas, bien por personal vinculado a la empresa dueña del buscador, bien por otros usuarios. Algunos de estos sistemas no prosperaron, como el puesto en marcha por Googe bajo el nombre de Google Answers ${ }^{258}$, aunque éste mantiene su archivo de respuestas; pero otros, como Yahoo Answers ${ }^{259}$ o Live $Q n A^{260}$ siguen en activo, siendo los usuarios los que atienden las consultas.

\footnotetext{
253 Europe Direct: http://ec.europa.eu/europedirect 1, p. 11-16.

${ }^{255}$ Todo expertos: http://www.todoexpertos.com

256 Xpertia; http://www.xpertia.com

${ }^{257}$ Guía de expertos de Redlris: http://expertos.rediris.es

258 Google Answers: http://answers.google.com

259 Yahoo Answers: http://es.answers.yahoo.com
}

254 Lochore realiza una interesante comparación entre servicios bibliotecarios y servicios de expertos. Véase Lochore, Stephen. How good are the free digital reference services? A comparison of library-based and expert services. Library Review, 2004, vol. 53, n. 1, p. 2429. Otra evaluación similar es la que se describe en McCrea, Richard. Evaluation of two library-based and one expert reference service on the Web. Library Review, 2004, vol. 53, n. 
E5. Buscadores inteligentes: programas de recuperación de información en Internet que poseen un desarrollo informático que les permite interpretar el lenguaje natural y ofrecer resultados afines a los temas demandados por el usuario. En algunos casos se emplean robots con capacidad de diálogo (verbots), que actúan como asistentes virtuales en la consultas de los usuarios, orientándoles en sus búsquedas y ofreciéndoles resultados que consideran ajustados a sus peticiones $^{261}$. Algunos buscadores que actúan de forma similar a los servicios de información atendidos por humanos son Chacha ${ }^{262}$, Brainboost $^{263}$ o Hakia ${ }^{264}$.

F/ Tomando como elemento diferenciador la dependencia institucional existen dos tipos de servicios de información:

F1. Servicios públicos: los que prestan entidades dependientes de las diferentes administraciones públicas, normalmente ofrecidos por bibliotecas, pero también por centros de documentación y servicios de información. Su principal característica definitoria es la gratuidad por el uso del servicio, ya que son servicios al ciudadano. Solamente se consideran servicios bibliotecarios de referencia digital los que ofrezcan las bibliotecas de cualquier tipo, no los que faciliten los servicios de documentación o de información de las administraciones locales, regionales, estatales o supranacionales.

F2. Servicios comerciales: aquellos que ofrecen empresas u entidades privadas, no pertenecientes a organismos de la administración; conllevan un beneficio económico, a veces a cambio de las respuestas y otras veces, a través de la publicidad que aparece en las páginas del servicio o en la respuesta que se envía al usuario, no teniendo éste que abonar cantidad alguna por la respuesta. Suele tratarse de servicios que ofrecen las grandes empresas de contenidos de Internet, como Yahoo, o servicios que atiende expertos. No pueden considerarse servicios bibliotecarios de referencia digital.

G/ Una división empleada con frecuencia es la que se basa en la tecnología que se usa para la prestación del servicio de referencia digital; en este caso, es posible encontrar dos grandes tipos de sistemas ${ }^{265}$ :

G1. Servicios sincrónicos: los que se comunican con el usuario en tiempo real, estableciéndose una interacción en vivo, en donde el usuario realiza su consulta, que es atendida en el momento por el personal de

\footnotetext{
${ }^{260}$ Live QnA: http://qna.live.com

261 Uno de los mejores ejemplos de verbot es Pregúntale a Ana, asistente virtual de la empresa Ikea: http://www.ikea.es.

262 Chacha: http://www.chacha.com

263 Brainboost: http://www.brainboost.com

264 Hakia; http://www.hakia.com

${ }^{265}$ Para Lankes es un error concebir de forma diferente los servicios de referencia asíncronos y los sincrónicos. Propone un modelo general único teniendo en cuenta el tiempo de retraso. Véase Lankes, R. David. The digital reference fallacy. The Reference Librarian, 2002-2003, vol. 38, n. 79/80, p. 35-44.
} 
la biblioteca ${ }^{266}$. Son los servicios de referencia digital que se realizan por chat, telefonía IP, videoconferencia, sistemas de mensajería instantánea o a través de plataformas o aplicaciones informáticas que contemplan alguna de estas posibilidades.

G2. Servicios asincrónicos: aquellos servicios de referencia que emplean tecnología de la información pero donde la comunicación se hace de forma diferida, no en tiempo real. El usuario envía la consulta, sobre todo a través de correo electrónico, formularios web o mensaje corto de teléfono móvil y la biblioteca le ofrece la respuesta por los mismos medios. Los programas informáticos para la referencia digital sincrónica pueden actuar también de forma asíncrona, recogiendo las consultas y almacenando las respuestas y los materiales complementarios para el acceso posterior por parte del demandante.

G3. Servicios mixtos: sistemas que permiten la comunicación sincrónica o asincrónica en función de la elección del usuario. Se trata de las aplicaciones informáticas diseñadas para la prestación de la referencia digital, en las que el usuario puede emplear la plataforma para dejar su consulta y esperar la repuesta por correo electrónico o entablar una entrevista de referencia en tiempo real. A menudo, este tipo de servicios se inician de forma sincrónica, a través de sus módulos de chat o mensajería instantánea, pero se resuelven de manera asíncrona, a través de correo electrónico, ya que se necesita algún tiempo para la localización de la información solicitada.

H/ Se puede establecer otra clasificación en virtud del área geográfica sobre la que se informa o desde la que se informa. En este caso se hablaría de:

H1. Servicios internacionales: no restringidos a ningún país o procedencia geográfica de los usuarios. Suelen trabajar en inglés o en la lengua común de los países a los que pertenezcan las bibliotecas participantes. Un ejemplo es el servicio Ask a librarian de la Biblioteca del Congreso de Estados Unidos ${ }^{267}$, que atiende a usuarios de todo el mundo y que también se ofrece en español, desde la División Hispánica.

H2. Servicios nacionales: aquéllos que sólo dan información sobre un estado concreto; son habituales en las bibliotecas nacionales, donde informan de la cultura, lengua, producción bibliográfica, etc. de sus respectivos países. Esto ocurre, por ejemplo, con el servicio Pregunte

\footnotetext{
${ }^{266}$ Martseller y Schmitt-Martseller ofrecen un amplio conjunto de aplicaciones específicas de la referencia en tiempo real para organizaciones bibliotecarias, sobre todo de tipo académico. Véase Marsteller, Matthew R.; Schmitt-Marsteller, Jackie. Opportunities for real-time digital reference service. The Reference Librarian, 2002, vol. 38, n. 79/80, p. 163181. También, en este sentido, es importante consultar Marsteller, Matthew R.; Mizzy, Danianne. Exploring the synchronous digital reference interaction for query types, question negotiation, and patron response. Internet Reference Services Quarterly, 2003, vol. 8, n. 1/2, p. 149-165.

${ }^{267}$ Library of Congress: Ask a librarian: http://www.loc.gov/rr/askalib.
} 
al bibliotecario de la Biblioteca Nacional de España ${ }^{268}$, aunque su enfoque es sobre todo relativo a las colecciones y servicios de esta biblioteca nacional.

H3. Servicios regionales: son los servicios de referencia digital que atienden preguntas sobre un área geográfica menor que un estado y mayor que una provincia o una ciudad. Están especializados en autores, cultura e información de esa zona. Un ejemplo perfecto es el servicio La biblioteca responde, que ofrece la Biblioteca de Andalucía ${ }^{269}$ y que atiende consultas sobre esta Comunidad Autónoma.

H4. Servicios locales: aquellos que ofrecen información sobre una localidad o una provincia. Habitualmente están gestionados por las bibliotecas públicas de esta localidad o provincia y, en muchos casos, trabajan en red, contestando de forma colectiva a preguntas de disciplinas de todo tipo y de forma individual para las cuestiones locales, que suelen ser tipo histórico, turístico, administrativo o cultural. Una muestra es el Servicio de Información Local de la Biblioteca Pública de Tarragona $^{270}$.

I/ Otra clasificación que se puede realizar en relación a los servicios de información es en función del sistema de atención al usuario, es decir, de quién y cómo se responda a las cuestiones planteadas por los usuarios. Existen dos procedimientos en este sentido:

I1. Personal o atención intelectual, por parte de personas. Las demandas son recibidas por profesionales, que reciben al usuario, le realizan las preguntas necesarias para matizar la cuestión y asegurarse de que se va a responder aquello que de verdad se está requiriendo. Son los verdaderos servicios bibliotecarios de referencia y como ejemplo se podrían poner la inmensa mayoría de los comentados en las notas a pie de página.

12. Automática o atención por parte de sistemas automatizados. Los usuarios realizan sus consultas en formularios disponibles en la web del servicio de información. Las cuestiones son analizadas mediante sistemas de procesamiento del lenguaje natural y son respondidas también empleando una sintaxis humana. Se utilizan sobre todo para informar acercar de los contenidos de un sitio web, como medio para localizar páginas o información de interés para el usuario. Suelen emplear algún icono o imagen humana, pero no pueden ser considerados servicios de referencia, sino herramientas de apoyo para la localización de la información ${ }^{271}$.

\footnotetext{
${ }^{268}$ Biblioteca Nacional de España: Pregunte al Bibliotecario:

http://www.bne.es/esp/servicios/pregunte.htm.

269 Biblioteca de Andalucía: La biblioteca responde:

http://www.juntadeandalucia.es/cultura/ba.

${ }^{270}$ Biblioteca Pública de Tarragona: http://cultura.gencat.net/BPT.

${ }^{271}$ Un buen ejemplo es el Asistente virtual del Ministerio de Cultura español, que se emplea para las búsquedas en sus páginas: http://www.mcu.es.
} 
J/ Un último criterio de clasificación posible es a partir del medio empleado para el envío de la consulta y la recepción de la misma ${ }^{272}$. Es posible utilizar los siguientes sistemas:

J1. Ordenador personal: las transacciones de referencia digital que se realizan empleando computadores, los cuales dispondrán de las aplicaciones necesarias para comunicarse con la biblioteca, realizar la consulta, realizar la entrevista de referencia y recibir la respuesta. Es el medio más empleado en referencia digital.

J2. Tablet $P C$ o pizarras electrónicas. Ordenadores portátiles inalámbricos de pequeñas dimensiones, que se sitúan entre un ordenador personal y una PDA. Su principal característica es que permite la escritura a través de una pantalla táctil. Su diseño está muy orientado hacia la educación, donde profesores y alumnos comparten servidor, siendo los tablet $P C$ los terminales con los que se trabaja. Las bibliotecas que están empleando esta herramienta prestan a los usuarios los PC para darles información y comunicarse con ellos ${ }^{273}$.

J3. PDA o Personal Digital Assistant: ordenadores de dimensiones reducidas, que actúan como agendas electrónicas, pero que tienen las funcionalidades básicas de un ordenador personal. Algunas bibliotecas ofrecen servicios para enviar información directamente a los PDA de los usuarios ${ }^{274}$. Se trata de un servicio apenas desarrollado por las bibliotecas, aunque sí es frecuente entre los proveedores de información electrónica.

J4. Teléfono móvil: empleo del servicio de mensajes cortos o Short Message Service (SMS) para la referencia digital. Normalmente se combina con el uso de ordenadores personales, desde donde se realizan las consultas. No obstante, las bibliotecas que ofrecen este servicio permiten que se les interrogue a través de un SMS y se reciba la respuesta de la misma forma. Un ejemplo pionero en ese sentido es Biblioteksvar ${ }^{275}$, el servicio público de referencia en línea de Noruega.

En la siguiente relación se muestra un resumen de la clasificación que se acaba de desarrollar y que puede servir para representar la variedad de los servicios de información que se prestan por medios telemáticos en la actualidad, ya sean bibliotecarios o no. En esta tesis doctoral, interesan los servicios bibliotecarios de referencia digital, particularmente los servicios públicos, aunque en este apartado se ha querido ofrecer una amplia panorámica, que permita distinguir las diferencias entre las diferentes ofertas

\footnotetext{
${ }^{272}$ Sobre los dispositivos electrónicos de bolsillo de utilidad en bibliotecas es interesante: Strauber, Christopher. Handhled computers in libraries. En Courtney, Nancy (ed.). Library 2.0 and beyond: innovative technologies and tomorrow's user. Westport: Libraries Unlimited, 2007, p. 49-61.

${ }^{273}$ Un ejemplo de su uso está descrito en Hibner, Holly. The Wireless Librarian: Using Tablet PCs for Ultimate Reference and Customer Service: A Case Study. Library Hi Tech News, 2005, vol. 22, n. 5, p. 19-22.

${ }^{274}$ Ríos, Gabriel R. PDA librarian. Reference Services Review, 2004. vol. 32, n. 1, p. 16-20.

${ }^{275}$ Biblioteksvar: http://biblioteksvar.no.
} 
que un usuario se puede encontrar a la hora de plantear una pregunta a una institución por medios digitales. En resumen, el cuadro clasificatorio es el siguiente:

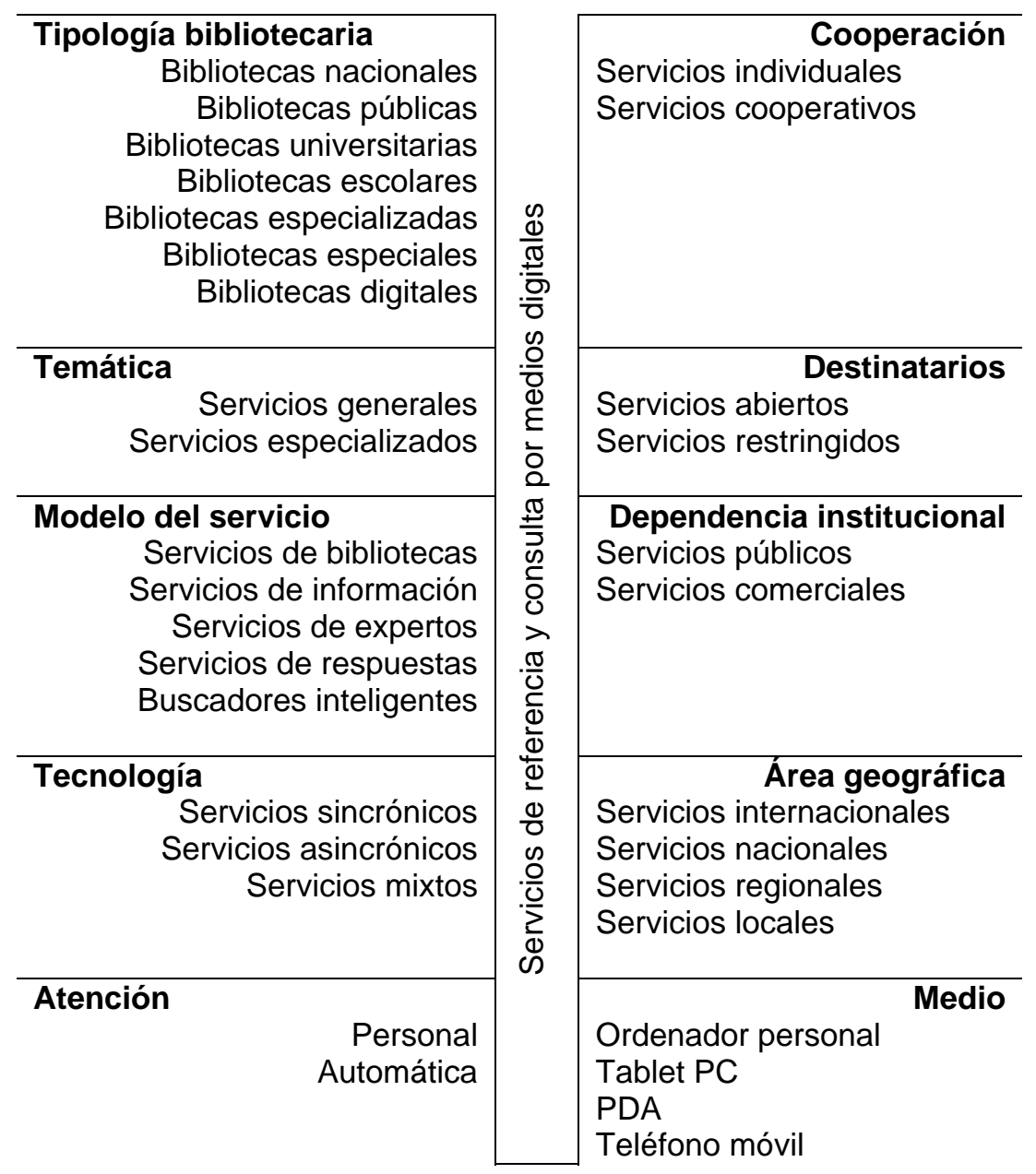

Fig. 2.4. Clasificación de los tipos de servicios de referencia digital 


\subsection{Tecnologías de comunicación para la referencia digital}

La referencia digital, por el hecho de ser electrónica, basa su existencia en las distintas herramientas informáticas existentes para poder operar en red. Además de los sistemas de telecomunicaciones, que no se van a desarrollar de forma exhaustiva en esta tesis doctoral, por no ser un aspecto específico de la misma, será necesario disponer de equipos informáticos y de aplicaciones que permitan la comunicación entre el usuario y la biblioteca. Los medios técnicos fueron comentados de forma somera en el apartado anterior: ordenadores personales, PDA y teléfonos móviles, pero en este apartado se describirán de forma más precisa las diferentes sistemas empleados por las bibliotecas para ofrecer sus servicios de referencia digital. Hay que tener presente que esta relación está basada en los medios que se están utilizando en la realidad, aunque puedan existir otras formas de comunicación.

Se trata de ofrecer una panorámica sobre las aplicaciones que se usan para la referencia digital; además, de cada una de ellas se ofrecerán algunas informaciones definitorias y los programas más comunes entre los empleados por las bibliotecas. Se comentan también aquí las aplicaciones informáticas comerciales especialmente diseñadas para la referencia en línea. Para este aspecto han sido muy enriquecedoras las aportaciones de Fagan $^{276}$, Hirko ${ }^{277}$ y Roberts ${ }^{278}$, entre otros autores. También son recomendables las columnas de Steven Bell ${ }^{279}$ en The reference librarian donde, bajo el título común de Pencils never crash, ofrece sus impresiones sobre el desarrollo tecnológico aplicable en los servicios de referencia digital.

Existe una buena fuente de información para conocer qué sistemas emplean las bibliotecas para sus servicios de referencia. Se trata de LIS wiki ${ }^{280}$, directorio que emplea la tecnología de los wikis para ofrecer información sobre biblioteconomía. Ofrece una relación de servicios de todo el mundo, sobre todo de Estados Unidos y Canadá, especificando en muchos casos el sistema que emplean y el nombre del programa. En estos momentos, es el directorio más actualizado de servicios de referencia digital existentes en todo el mundo, a pesar de poseer amplias lagunas en cuanto a los servicios de referencia digital que no se desarrollaran en países angloparlantes.

Las categorías que se muestran a continuación ofrecen de forma completa información tanto sobre sistemas sincrónicos como asíncronos, división que se explicó en el apartado anterior. En esta sección se pretende incidir en las

\footnotetext{
${ }^{276}$ Fagan, Jody Condit. Site search and instant messaging reference: a comparative study. Internet Reference Services Quarterly, 2003, vol. 8, n. 1/2, p. 167-182.

${ }^{277}$ Hirko, Buff. Live, Digital Reference Marketplace. Library Journal Net Connect, 15 oct. 2002.

${ }^{278}$ Roberts, Lisa. Choosing a Chat Reference Software Solution: The Devil Is in the Details. En Information Strategies 2001. Fort Myers, FL: Florida Gulf Coast University, 2001. Disponible en http://library.fgcu.edu/Conferences/infostrategies01/presentations/2001/ roberts.htm [consultado el 17/07/2007].

${ }^{279}$ Bell, Steven. Thinking Thoughtfully: About Reference Technology. The Reference Librarian, 2007, vol. 47, n. 97, p. 125-128.

${ }^{280}$ LIS wiki: http://liswiki.org
} 
diferentes tecnologías o sistemas empleados en la referencia, que se han agrupado en once tipos, que se describen y comentan en los párrafos siguientes.

\section{Correo electrónico}

El correo electrónico o e-mail es el servicio consistente en el envío de mensajes a través de una red de telecomunicaciones. Es uno de los servicios de Internet más empleados. Basa su funcionamiento en la existencia de un protocolo específico, el SMTP, que permite el intercambio de mensajes entre dos ordenadores que disponen del mismo programa cliente. Para su uso es necesario la existencia de direcciones de correo electrónico, con la que enviar los mensajes y desde la que recibirlos. Es necesario también un proveedor de correo, en cuyas máquinas o servidores se registran las direcciones y que actúan como intermediarios en el proceso de envío/recepción de los mensajes.

El correo electrónico emplea programas cliente específicos, ya estén instalados en los ordenadores de los emisores y receptores o bien se encuentren en funcionamiento en los servidores de los proveedores, para su consulta a través de web. Los programas cliente más empleados en la actualidad son Evolution para Linux, Mail, para MacOS, Microsoft Outlook Express, para Windows, Eudora, para Windows y MacOS y Mozilla Thunderbird, para Windows, Linux y MacOS. Los programas servidores de correo más utilizados son Microsoft Exchange Server y MailEnable, para Windows, y Exim, Sendmail, Qmail y Postfix, para Unix.

Las bibliotecas que emplean el correo electrónico como medio para la referencia digital son la inmensa mayoría ${ }^{281}$. Se debe considerar que se ofrece este servicio desde el momento en que la biblioteca difunde una dirección de correo electrónico para que los usuarios se dirijan a ella con la finalidad de solicitar información. Es habitual que la dirección de correo electrónico se incluya junto a otros medios para la referencia digital, ya que es la opción preferida por muchos usuarios. El uso del correo electrónico también es común para continuar sesiones de referencia iniciadas por otros procedimientos -presenciales o telemáticos- que aconsejan un tiempo de búsqueda por parte del personal para poder conseguir la respuesta pertinente a la consulta del usuario. Asimismo, se emplea para el envío de materiales que resuelven una demanda de información, pero que no es

\footnotetext{
${ }^{281}$ Un ejemplo de biblioteca con trayectoria en este tipo de servicios está explicado en Fullerton, Vera. E-mail Reference: Refocus and Revise. Experiences from Gelman Library. En IFLA General Conference and Council (67. Boston. 2001). Boston: IFLA, 2001. Disponible en http://www.ifla.org/IV/ifla67/papers/056-98e.pdf [consultado el 17/07/2007]. Sobre este mismo tema véase también Garnsey, A. Beth; Powel, Ronald R. Los servicios de referencia a través del correo electrónico en la biblioteca pública. Boletín de la Asociación Andaluza de Bibliotecarios, 2003, vol. 18, n. 71, p. 57-76. Se ofrecen los resultados de un estudio realizado en Estados Unidos sobre bibliotecas que ofrecían referencia por correo electrónico. También es interesante la experiencia de la Northern Illinois University descrita en VandeCreek, Leanne. E-Mail reference evaluation: using the results of a satisfaction survey. The Reference Librarian, 2006, vol. 45, n. 93, p. 99-108.
} 
posible o conveniente enviar por otros procedimientos, como la mensajería instantánea, por ejemplo.

Los servicios de referencia digital a través de correo electrónico se complementan con otros servicios de información de la biblioteca, que empleará listas de distribución (basadas en la tecnología del correo electrónico) para ofrecer alertas, difusión selectiva de la información, boletines de novedades, etc. Hay que recordar que la referencia digital en sentido estricto debe entenderse a partir de la existencia de una consulta planteada por el usuario. Los servicios de referencia digital a través de correo electrónico deben formar parte de los servicios de información de cualquier biblioteca ${ }^{282}$.

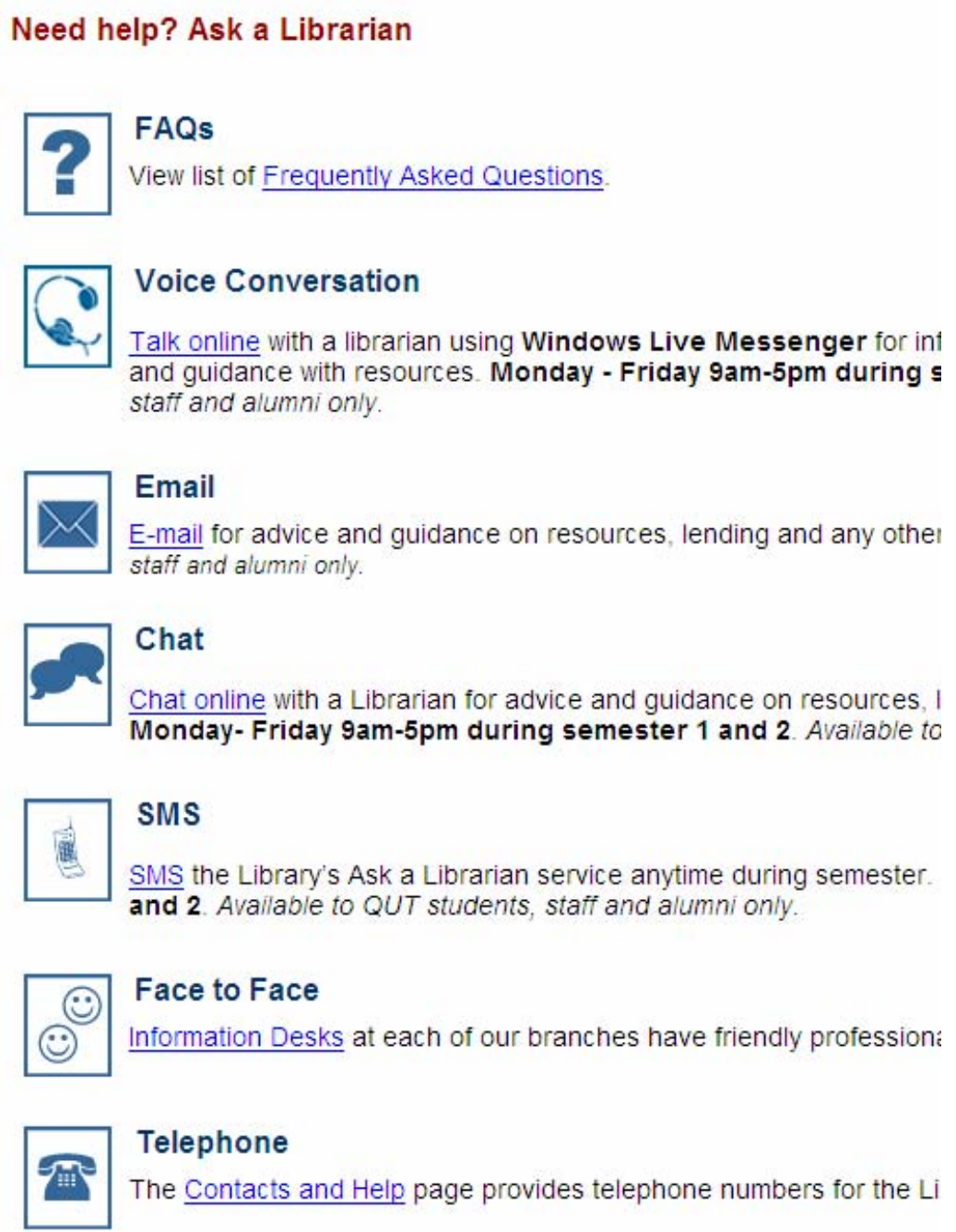

Fig. 2.5. Servicios de referencia digital de la Queensland University of Technology

\footnotetext{
${ }^{282}$ Sobre el correo electrónico como medio para la referencia es útil la monografía Kovacs, Diane K. The virtual reference handbook: interview and information delivery techniques for the chat and e-mail environments. London: Facet, 2007. De igual forma, véanse los artículos Croft, Rosie; Eichenlaub, Naomi. E-mail reference in a distributed learning environment: best practices, user satisfaction, and the reference services continuum. Journal of Library Administration, 2006, vol. 45, n. 1/2, p. 117-147; y Lederer, Naomi. E-mail reference: who, when, where, and what is asked. The Reference Librarian, 2001, n. 74, p. 55-73.
} 


\section{Formularios web}

La programación de páginas web en HTML y lenguajes derivados incluye la posibilidad de crear formularios en los que el diseñador decide los campos y qué acciones se realizarán en función del comportamiento de los usuarios ante dicho formulario. Desde un punto del uso externo, el formulario es sencillo de emplear, por su carácter intuitivo y adaptable. El usuario simplemente debe completar los campos y confirmar el envío mediante el elemento encargado de transferir los datos al servidor. Desde un punto de vista interno o de programación, los formularios presentan diferentes niveles de complejidad, ya que pueden consistir en código HTML sencillo, programándose todo el formulario para que se reciba un correo electrónico con la información cumplimentada, pero también admite altos grados de complejidad, al combinarse con otros programas y lenguajes (scripts) para que se realicen operaciones más avanzadas.

Habitualmente, el código en HTML o en XML se combina con lenguajes como Java, PHP, Perl, ASP o ColdFusion. En la actualidad son muy frecuentes los formularios que emplean PHP como lenguaje de programación común desde el servidor, ya que puede mostrar la información en páginas independientes, guardar un registro o log de la comunicación, enviar los datos a una base en mySQL o ASCII, por ejemplo, guardar la información en una cookie o generar un correo electrónico, incluso con archivos adjuntos. Son varios los lenguajes de programación que insertan los códigos de formularios en su lenguaje de diseño web, gracias a que el World Wide Web Consortium (W3C) ha delimitado perfectamente la estructura de los mismos ${ }^{283}$.

El número de bibliotecas que emplean formularios para recoger las consultas es abundante. Este método es habitual en los servicios públicos de referencia en línea, como se podrá comprobar en el capítulo 9.3. de esta misma parte. Se trata de un sistema más elaborado que el correo electrónico y que posibilita que la biblioteca comience la entrevista de referencia de forma pasiva. En el correo electrónico, es el usuario el que redacta su consulta de forma libre, aunque la biblioteca dé algunas indicaciones en su sitio web. En los formularios web, la biblioteca ha dispuesto una serie de casillas para que el usuario las vaya completando. En cada parte del formulario, la biblioteca recoge datos esenciales y complementarios. Los esenciales serán, al menos, la consulta y la dirección de correo electrónico; mientras que los complementarios pueden ser el motivo de la consulta (estudios, trabajo, etc.), la edad del usuario, la localidad de domicilio, la urgencia de la respuesta, la información que ya conoce el usuario, etc.

Los formularios web permiten programar preguntas abiertas y cerradas. Las abiertas se emplean para la redacción libre, como la pregunta misma, mientras que en las cerradas se pretende ofrecer una lista estricta de posibles contestaciones, como franjas de edad, motivos de consulta, área de residencia, etc. Desde el punto de visto estadístico las preguntas cerradas

283 Puede verse la estructura HTML de los formularios en el manual del W3C: http://www.w3.org/TR/html4/interact/forms.html 
recibidas en un formulario son más fáciles de clasificar. El sistema para elegir una respuesta cerrada varía entre la lista desplegable y la selección de opciones, mediante la activación de casillas. El diseño del formulario web debe realizarse de forma muy meditada, ya que supone la primera comunicación con el usuario antes de que formule su consulta; por este motivo, deben estar bien elegidas las diferentes casillas, así como la información textual que se acompañe a las mismas, ofreciendo las opciones de ayuda y las páginas de información complementaria que se consideren necesarias para una correcta comprensión del sistema y del servicio.

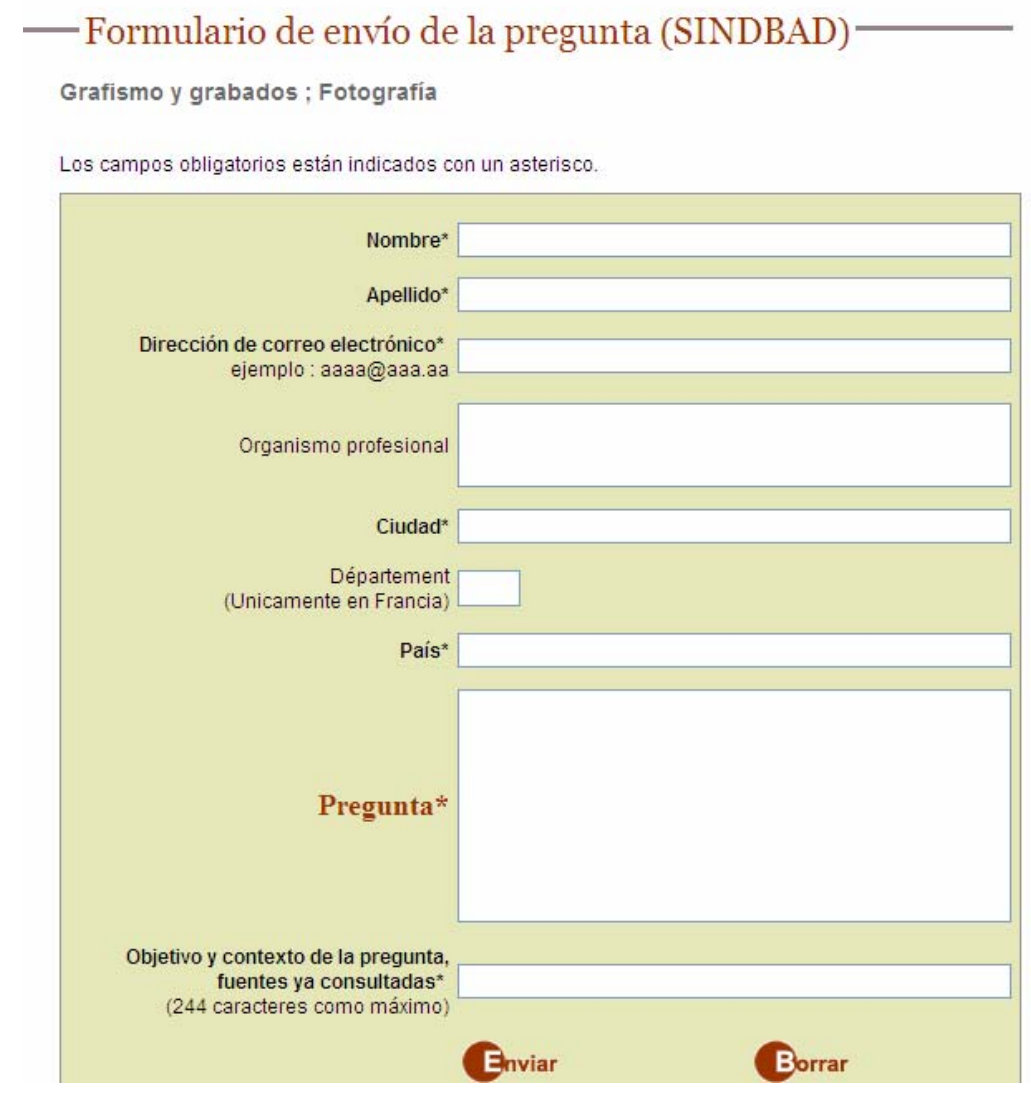

Fig. 2.6. Formulario web de la Biblioteca Nacional de Francia

La respuesta a las consultas recibidas a través de formularios web se realiza siempre a través de programas cliente de correo electrónico, por lo que es importante insistir en la comprobación de que la dirección ofrecida por el usuario ha sido bien tecleada. Como solución ante posibles pérdidas o devoluciones de mensajes de respuesta, las bibliotecas crean páginas web donde copian las consultas extraviadas por problemas con las direcciones de correo de los usuarios, además de disponer de un archivo donde se almacenan las transacciones realizadas, que se pueden consultar a partir de un buscador específico. 


\section{Chat}

El anglicismo chat, cuya traducción literal sería «charla» se emplea para identificar al servicio de Internet que permite la conversación entre dos o más personas, mediante mensajes de texto que se intercambian en tiempo real. Se trata, pues, de una actividad que se realiza de forma sincrónica, estando presentes el emisor y el receptor al mismo tiempo. Para que la comunicación sea posible es necesario emplear programas cliente específicos $^{284}$, como $X$-Chat, ChatZilla o mIRC, que trabajan a partir del protocolo IRC o Internet Relay Chat. Aunque parezcan tecnologías similares y lo sean en cuanto a los usos que se realizan de las mismas, técnicamente los servicios de chat son diferentes de los de mensajería instantánea, que emplean protocolos diferentes.

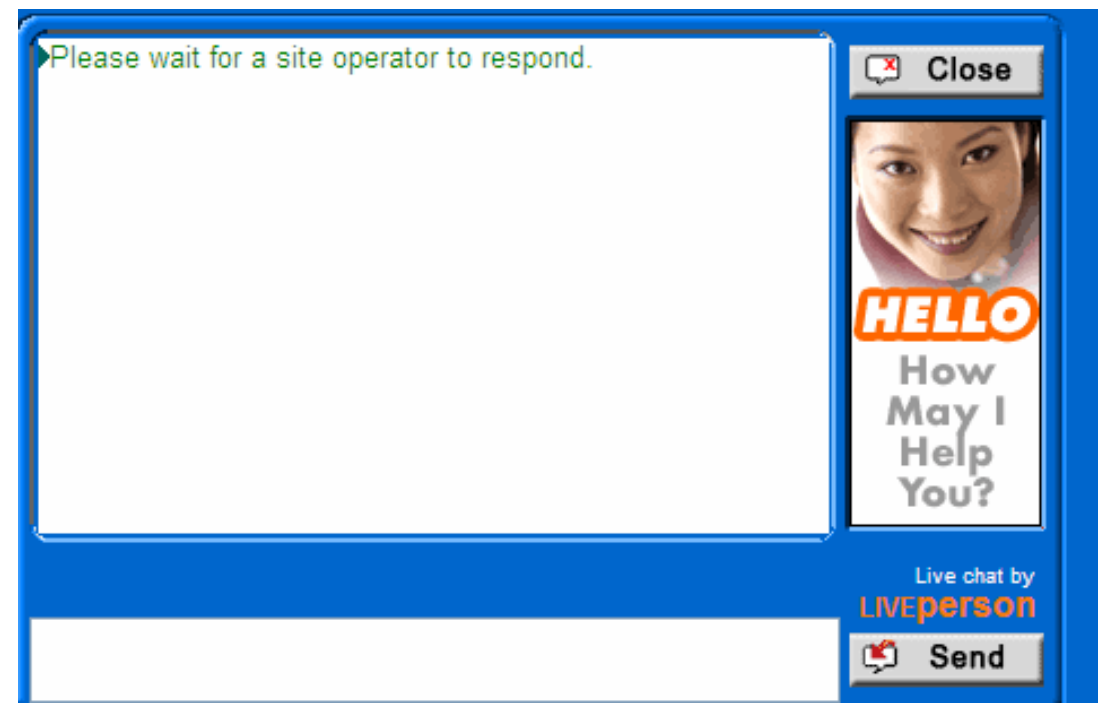

Fig. 2.7. Referencia digital mediante chat en la Cardinal Stritch University Library

El chat implica un grado mayor de desarrollo en los servicios de referencia digital $^{285}$, ya que parten de los mismos esquemas que los servicios que se prestan de forma presencial en los mostradores de referencia, pero añadiendo las condiciones de frescura ${ }^{286}$, agilidad e inmediatez que implica la prestación de un servicio como éste. Por eso, la referencia digital a través de chat implica personal muy preparado, entrevistas de referencia predefinidas, técnicas de comunicación fluidas y un gran manejo de los

\footnotetext{
${ }^{284}$ Sobre la elección de un programa informático para realizar referencia vía chat es muy útil la consulta del siguiente artículo: Roberts, Lisa. Choosing a Chat Reference Software Solution: The Devil Is in the Details. En Information Strategies 2001. Fort Myers, FL: Florida Gulf Coast University, 2001. Disponible en <http://library.fgcu.edu/Conferences/infostrategies01/presentations/2001/roberts.htm> [consultado 17 julio 2007].

${ }^{285}$ Francoeur, Stephen. An analytical survey of chat reference services. Reference Services Review, 2001, vol. 29, n. 3, p. 189-204. El autor ofrece un estudio sobre referencia vía chat, indicando programas más empleados y consideraciones para la práctica de este servicio.

${ }^{286}$ Véase Caufield, James. Tricky devil: a humorous training technique for the chat reference environment. The Electronic Library, 2005, vol. 23, n. 4, p. 377-382. Se comenta una experiencia de referencia mediante chat en una biblioteca universitaria, en la que la conversación de referencia se realiza empleando recursos humorísticos.
} 
recursos de información ${ }^{287}$. Las bibliotecas que ofrecen chat para la recepción de consultas suelen emplear programas en los que la comunicación se basa en texto ${ }^{288}$. De manera habitual se limita su horario a determinados días y horas, lo mismo que cualquier servicio bibliotecario. Es habitual que la referencia vía chat sólo se ofrezca algunas horas al día o a la semana. No obstante, en los países donde la referencia digital se ha desarrollado completamente es muy frecuente encontrarse con servicios de este tipo, que se ofrecen desde los sitios web de las bibliotecas en horarios amplios; así ocurre en Estados Unidos, Canadá, Australia o Reino Unido, donde existen servicios públicos de referencia en línea o en muchos países europeos, como Dinamarca, Noruega o Suecia. En España esta iniciativa es todavía muy tímida, destacándose casos como el de El bibliotecario en línea ${ }^{289}$, de la Universidad de Murcia, que ofrece este servicio durante tres horas de la mañana para contestar cuestiones sobre la propia biblioteca.

Algunas bibliotecas están optando por la implantación de software libre, de código fuente abierto, por tanto, para realizar la referencia digital a través de chat. Entre los programas empleados para la conversación destaca Rakim $^{290}$, que usan bibliotecas como las de las Universidades de Winnipeg en Estados Unidos o las de Hamburgo, Hannover o Düsseldorf en Alemania. Otro de los programas empleados para el chat del servicio bibliotecario de referencia es LivePerson. En este caso, se trata de software propietario, que está en funcionamiento en bibliotecas de universidades como la Open University en el Reino Unido, Carnegie Mellon en Estados Unidos o Dortmund en Alemania ${ }^{291}$.

\section{Mensajería instantánea}

A semejanza del chat, la mensajería instantánea es un servicio que se realiza en red y mediante el cual dos o varias personas intercambian mensajes en tiempo real; por tanto, también es un servicio que se realiza de forma sincrónica. Se diferencia del chat en que se emplean protocolos de comunicación distintos, aparte de que la mensajería instantánea ofrece otra serie de posibilidades, como conocer cuando un determinado usuario está conectado a la red. Para ello, es necesario que la persona que quiere intercambiar mensajes esté dada de alta en el sistema, con un nick o identificación personal. Se inspiran en los chat en cuanto a su manera de

\footnotetext{
${ }^{287}$ Véase Carter, David S. Hurry up and wait: observations and tips about the practice of chat reference. The Reference Librarian, 2002-2003, vol. 38, n. 79/80, p. 113-120.

${ }^{288}$ Véase Ovadia, Steven. Real-time chat reference and the importance of text-chat. The Reference Librarian, 2002-2003, vol. 38, n. 79/80, p. 157-161.

${ }^{289}$ El bibliotecario en línea: https://bibliotalk.um.es/bibliotalk/indexUsuario.jsp

290 Sobre este software es ilustrativo el artículo: Carraway, Shawn; Payne, Susan. Implementing RAKIM open source chat reference software. Computers in Libraries, 2005, vol. 25 , n. 5, p. 10, 12, 14-15. Una evaluación de servicio de referencia digital ofrecido con esta aplicación puede consultarse en Jane, Catherine; McMillan, Dawn. Online in real-time? Deciding whether to offer a real-time virtual reference service: Winds of change: libraries in the twenty-firt century. The Electronic Library, 2003, vol. 21, n. 3, p. 240-246.

${ }^{291}$ Porter describe la evaluación llevada a cabo en el servicio de referencia digital de La Trobe University, que se ofrece vía chat mediante LivePerson. Véase Porter, Susan. Chat: from the desk of a subject librarian. Reference Services Review, 2003, vol. 31, n. 1, p. 5767.
} 
trabajar y su aplicación, pero ambos sistemas emplean tecnologías diferentes, por eso deben ser tratados como medios distintos de prestar la referencia digital ${ }^{292}$.

Existe una amplia variedad de programas cliente hábiles para el intercambio simultáneo de mensajes. Las grandes compañías de informática e Internet han desarrollado los suyos propios, siendo los más empleados en la actualidad ICQ, Windows Live Messenger, Yahoo! Messenger, AOL Instant Messenger $^{293}$ y Google Talk; éste último emplea el protocolo abierto Jabber, siendo los demás aplicaciones y protocolos cerrados.

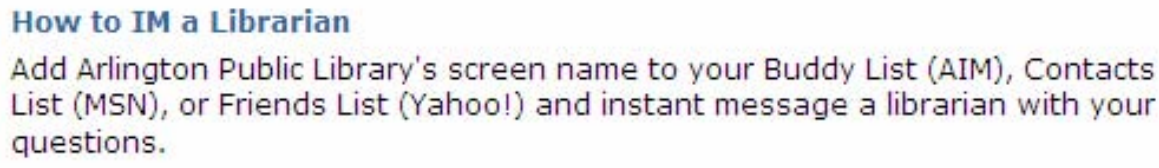

\begin{tabular}{|c|c|c|}
\hline & IM Service & Arlington Library's Screen Name \\
\hline & AOL Instant Messenger (AIM) & iqueryarlib \\
\hline & iChat (Mac) & iqueryarlib (AIM Account) \\
\hline & MSN Messenger & iqueryarlib@hotmail.com \\
\hline & Yahoo! Messenger & iqueryarlib \\
\hline V & ased Instant Messaging & \\
\hline $\begin{array}{l}\text { You ca } \\
\text { Intern } \\
\text { service }\end{array}$ & $\begin{array}{l}\text { use IQuery without installing } \\
\text { t access. Use your AIM, MSN, c } \\
\text { 5: }\end{array}$ & $\begin{array}{l}\text { oftware on any computer with } \\
\text { hoo! account with these web-based }\end{array}$ \\
\hline & IM Service & Arlington Library's Screen Name \\
\hline & AIM Express & iqueryarlib \\
\hline & MSN Web Messenger & iqueryarlib@hotmail.com \\
\hline$\ddot{B}$ & Yahoo! Web Messenger & iqueryarlib \\
\hline
\end{tabular}

Fig. 2.8. Referencia digital mediante mensajería instantánea en Arlington (Virginia)

\footnotetext{
${ }^{292}$ Véase Oberhelman, David D. Reference service and resources in the age of instant messaging. Reference Reviews, 2007, vol. 21, n. 2, p. 7-8.

${ }^{293}$ Para Lukasiewicz, AOL IM es una aplicación perfecta para la referencia digital en una biblioteca universitaria. La autora opina que es una solución barata, ya que los programas específicos son costosos, además de que los alumnos están familiarizados con este software. Véase Lukasiewicz, Adrianna. Exploring the role of digital academic libraries: Changing student needs demand innovative service approach. Library Review, 2007, vol. 56, n. 9, p. 821-827. Sin embargo, en opinión del doctorando, el uso de AOL IM no es tan interesante para las bibliotecas españolas, ya que no se trata de un cliente empleando en nuestro país. No obstante, es interesante disponer de diferentes aplicaciones gratuitas para que el usuario se comunique con el servicio de referencia digital con la que suela emplear.
} 
Entre las bibliotecas que emplean la mensajería instantánea en sus servicios de referencia digital es muy común que se emplee el programa Trillian, ya que es una aplicación multiprotocolo, que opera en Windows y que permite el acceso desde un único programa cliente a los principales servicios de mensajería instantánea, además de a redes de intercambio de ficheros. De esta manera, las bibliotecas posibilitan que los usuarios empleen sus programas de mensajería habituales para comunicarse con la biblioteca, que usará este software compatible con la práctica totalidad de los programas desarrollados para la mensajería en tiempo real ${ }^{294}$.

Una vez más, los ejemplos hay que buscarlos preferentemente en Estados Unidos, donde se emplea en servicios como Morris Messenger ${ }^{295}$ en Illinois, Ask A Librarian de la Biblioteca del Estado de Indiana, en la biblioteca de la Universidad de Ohio o en el Providence College de Rhode Island, por mencionar ejemplos de tipologías bibliotecarias diferentes. Otra aplicación multiprotocolo, es decir, que permite el acceso a/desde diferentes sistemas de mensajería es instantánea es Pidgin ${ }^{296}$, anteriormente conocido como Gaim. Este software es empleado para la referencia digital en, por ejemplo, las bibliotecas de la Universidad de Florida.

Recientemente las bibliotecas están comenzando a instalar tecnologías de la web social en sus sitios de Internet ${ }^{297}$. Hay bastantes ejemplos de bibliotecas que incluyen en sus webs un sistema de chat que no necesita abrir una aplicación específica en página aparte. Entre los sistemas elegidos para insertar o embeber el programa de chat entre las páginas de las bibliotecas destaca Meebome, una extensión de Meebo, programa de mensajería instantánea que permite comunicarse en redes como ICQ, Yahoo, MSN y Gtalk sin instalar ni abrir estos programas en el ordenador personal. La ventaja de esta nueva versión es que el formulario de consulta se inserta en el sitio web de la biblioteca y permite que los usuarios se comuniquen con

\footnotetext{
${ }^{294}$ Steiner y Long realizaron un estudio con opiniones de bibliotecarios en el que se recogían razones para ofrecer o no servicios de referencia digital mediante mensajería instantánea. Véase Steiner, Sarah K.; Long, Casey M. What Are We Afraid of? A Survey of Librarian Opinions and Misconceptions Regarding Instant Messenger. The Reference Librarian, 2007, vol. 47, n. 97, p. 31-50.

${ }^{295}$ Un estudio comparativo entre servicio de referencia digital ofrecido por mensajería instantánea y el que se presta presencialmente en la misma biblioteca puede ser consultado en Desai, Christina M. Instant messaging reference: how does it compare? The Electronic Library, 2003, vol. 21, n. 1, p. 21-30. Esta misma autora ha publicado diferentes estudios sobre el tema, como, por ejemplo, Desai, Christina M; Fagan, Jody; Nixon, Carol. Instant messaging reference. En Annual Computers in Libraries Conference (17. 2002.

Washington). Medford, NJ: Information Today, 2002, p. 52-59. La evaluación de este servicio por parte de los usuarios se publicó en Ruppel, Margie; Fagan, Jody Condit. Instant messaging reference: users' evaluation of library chat. Reference Services Review, 2002, vol. 30, n. 3, p. 183-197. La actualización de la evaluación de Morris Messenger, analizando también los resultados de la conavegación se publicó en Graves, Stephanie J.; Desai, Christina M. Instruction via chat reference: does co-browse help? Reference Services Review, 2006, vol. 34, n. 3, p. 340-357.

${ }^{296}$ Pidgin: http://www.pidgin.im

${ }^{297}$ La oferta de tecnologías es mayor que el uso que se está haciendo de las mismas. Por ejemplo, no existen casos de bibliotecas que usen wikis para la referencia digital. Más información sobre esta tecnología y su aplicación bibliotecaria en: Bell, Steven J. Time to Lose the Sticky and Try a Wiki. The Reference Librarian, 2007, vol. 47, n. 98, p. 101-105.
} 
ella en tiempo real, siempre que haya personal bibliotecario presente, como es lógico. La biblioteca recibe los mensajes a través del servicio de mensajería instantánea gratuito que la empresa Meebo ofrece y que permite trabajar también con los principales operadores de mensajería instantánea. Este sistema se creó pensando en los weblogs, para que los lectores de las bitácoras pudieran dialogar con los autores de las mismas, pero bibliotecas como la Exeter Public Library, el Illinois Institute of Technology o la Kansas State University Library han sabido adaptar esta tecnología para ofrecer referencia digital en tiempo real. Otros programas que cumplen la misma función son Chatango, empleado para la referencia digital en las universidades de Calgary y del Estado de Oregon, y Plugoo, que utiliza la biblioteca de derecho de la Universidad de Wisconsin y algunas facultades de la Universidad de Sevilla, donde se combina con Meebome, según los servicios elegidos por cada centro.

Biblioteca de Química

Recursos | Aprendizaje e Investigación | Servicios | Sobre la Biblioteca_ [versión imprimir]

Pregunte al bibliotecario de Inicio ₹ Biblioteca de Quimica * Servicios * Pregunte al bibliotecario

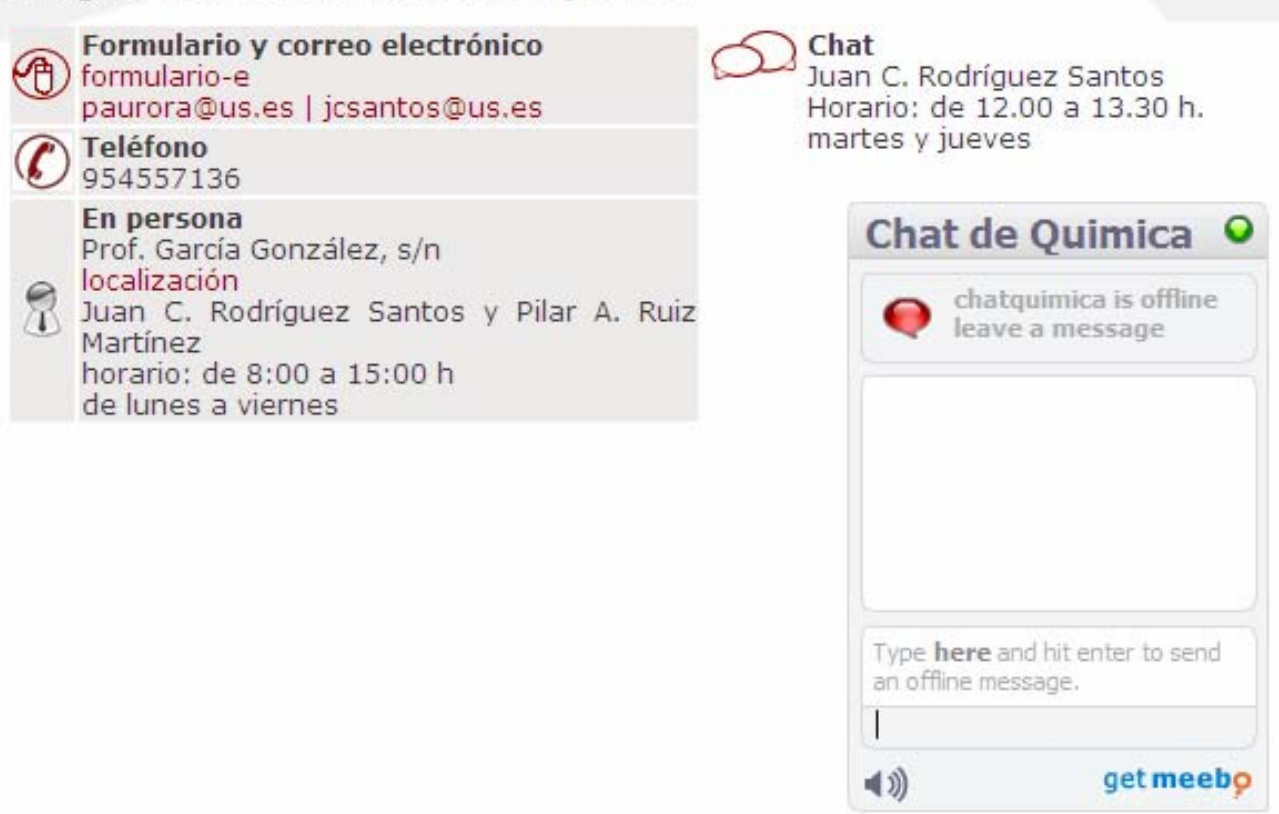

Fig. 2.9. Referencia digital mediante mensajería (Meebome en la Universidad de Sevilla)

\section{Weblogs}

Los cuadernos de bitácora, weblogs o blogs son sitios web que emplean una tecnología específica para la creación de contenidos, de tal forma que se puedan ir publicando y almacenando en el servidor informaciones, que son accesibles de forma abierta desde cualquier navegador, apareciendo siempre en primer lugar la última actualización realizada. El devenir de los weblogs ha sido muy rápido, habiéndose creado como un servicio dirigido a particulares, para el que no era necesario disponer de conocimientos especializados. La aparición de diversos servicios gratuitos de alojamiento 
de blogs ha hecho que su número se incrementara de forma espectacular. Se estima que los primeros weblogs nacieron en torno a 2001. El crecimento ha sido tan rápido que, en agosto de 2007, Technorati ${ }^{298}$, el principal buscador de blogs, indizaba cerca de cien millones de bitácoras de todo el mundo. Existen variantes en función de sus contenidos, ya que es posible clasificarlos como weblogs (texto), fotologs (imágenes), vlogs (vídeo), audioblogs (sonido) o moblogs (blogs en los teléfonos móviles). También se pueden incluir como bitácora los que incorporan podcast, archivos de audio, generalmente emitidos o diseñados como programas de radio.

Varios son los factores que han hecho experimentar el rápido crecimiento de este servicio. En primer lugar, la facilidad para crear una bitácora. Existen programas específicos, que se instalan en un servidor propio y desde el mismo se inician los blogs que se desee utilizar. Los programas más empleados para esta función son WordPress y Movable Type. Pero el éxito se debe a la variedad de sitios que ofrecen creación y alojamiento gratuito, entre los que destacan Blogger, Wordpress, La coctelera, Bitacoras.com, Blogia, Blogspirit y Blogalia. Todas estas empresas permiten la creación gratuita de blogs, que se alojan en sus servidores y que se almacenan de forma cronológica y sistemática.

Todas las noticias publicadas dispondrán de una única dirección permanente (permalink), lo que permite que sean enlazadas y citadas de forma particular. Además, los weblogs disponen de un mecanismo, los trackback, para conocer qué otras bitácoras enlazan con alguno de sus mensajes, ya que es común que se produzca intercambio o reenvío de informaciones y textos entre blogs afines; es lo que se está denominando en castellano la blogosfera.

Otro de los factores que ha causado esta revolución de los blogs ha sido la posibilidad de sindicar contenidos, es decir, de conocer de forma automática las actualizaciones que se realicen en otros blogs o sitios web que empleen los protocolos específicos para la sindicación (RSS, ATOM, por ejemplo). La sindicación de contenidos permite que, a partir de lectores de noticias se puedan seleccionar los canales de información más interesantes para un usuario.

Para la lectura de sitios sindicados se pueden emplear programas cliente, opciones de los navegadores o servidores que actúan como clientes. En cuando a los programas cliente útiles para la lectura de noticias RSS, también llamados agregadores, destacan FeedReader, FeedDemon, Feed Navigator y RSS Fácil. Las últimas versiones de los navegadores más empleados también permiten leer también en el propio navegador los canales RSS elegidos, así lo hacen Mozilla Firefox, Opera o Internet Explorer. Además, cada vez es más frecuente la lectura de los contenidos sindicados seleccionados desde servidores externos al ordenador personal del usuario; para ello son servicios muy empleados Bloglines, Google Reader o My Yahoo.

${ }^{298}$ Technorati: http://www.technorati.com 
Para muchas bibliotecas, la aparición de la tecnología blog ha supuesto una solución para crear contenidos y albergarlos en Internet sin apenas presupuesto ni tampoco conocimientos de diseño web ni redes de telecomunicaciones. La sencillez en la creación y mantenimiento de contenidos ha dado como resultado que el sitio web de la biblioteca se pueda construir con programas de weblogs, ya sea en un servidor local o externo. En ocasiones, las bibliotecas han empleado CMS o gestores de contenidos libres, que son más complicados de instalar y desarrollar, pero que ofrecen resultados totalmente profesionales. Pero, cuando las bibliotecas han optado por los blogs estaban permitiendo, además, que los usuarios participaran en la construcción del sitio, con sus aportaciones y sugerencias. Esto se debe a que la tecnología blog permite interacción, al dar la posibilidad a los lectores para dejar su opinión o incluso crear informaciones. Los medios posibilitan que, en la actualidad, se incorporen sistemas de comunicación en vivo, integrados en la web estática, para poder mantener diálogos en tiempo real. Estas posibilidades ya se comentaron en el apartado dedicado al chat.

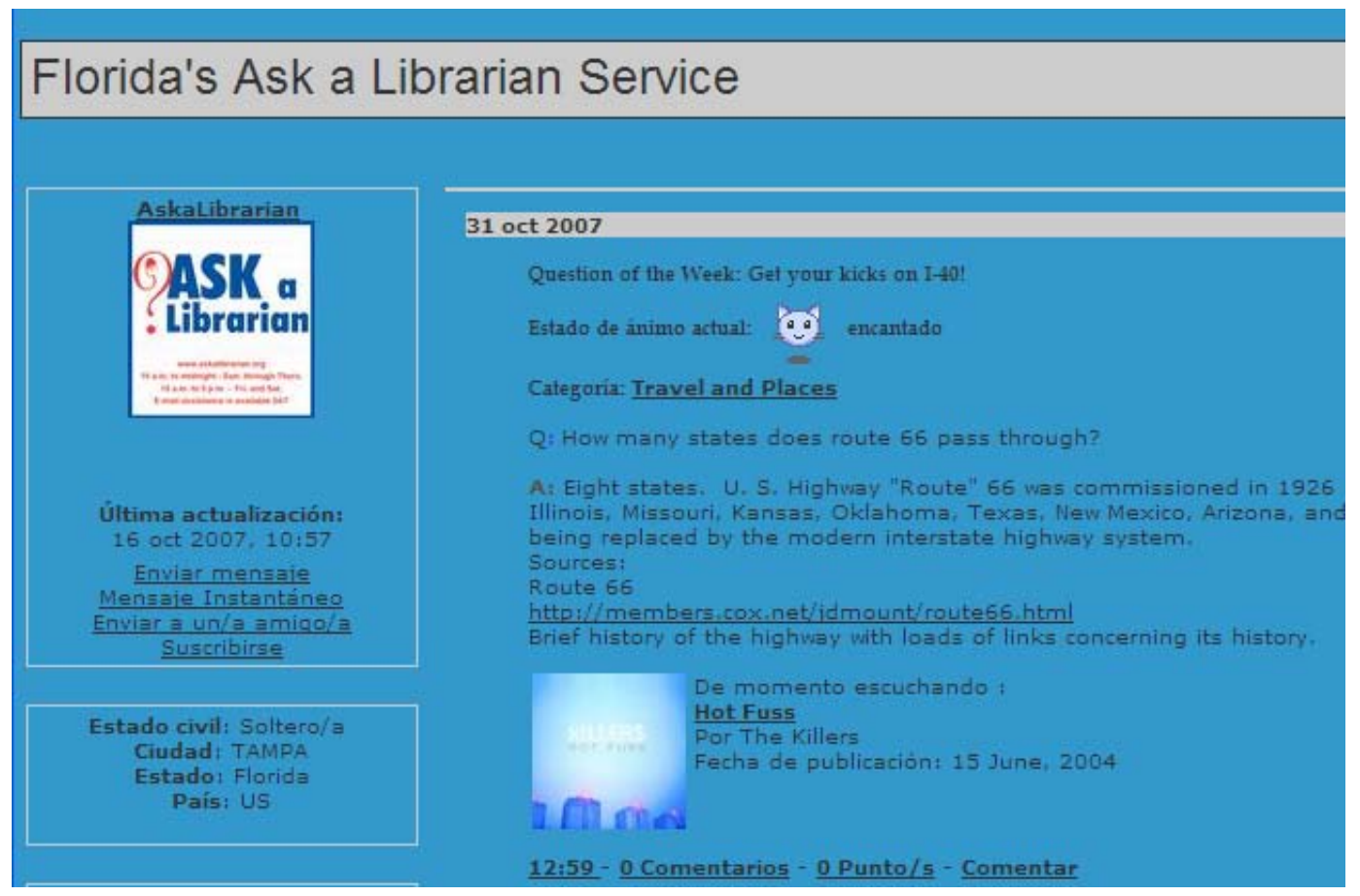

Fig. 2.10. Referencia digital mediante redes sociales y weblogs en Ask a Librarian (Florida)

Algunos autores como Pomeranzt y Stutzman ${ }^{299}$ han investigado acerca de las ventajas de la blogosfera -comunidad de responsables de weblogs- para la práctica del trabajo de referencia. Ellos son conscientes de que el uso bibliotecario de los blogs ha comenzado siendo un mero espacio informativo, un boletín de noticias, pero sus posibilidades son mayores, sobre todo aplicadas al servicio de referencia.

299 Pomerantz, Jeffrey; Stutzman, Frederic. Collaborative reference work in the blogosphere. Reference Services Review, 2006, vol. 34, n. 2, p. 200-212. 
El trabajo de referencia siempre se ha basado en la actividad cooperativa, algo que se potencia y simplifica con los weblogs, ya que, a partir de un mensaje, diferentes colaboradores pueden expresar su opinión, que van siendo sumadas como un conjunto, anidadas, dentro del mismo contexto. Los blogs permiten que un usuario dirija una pregunta a la biblioteca y que ésta sea respondida en ese mismo espacio web. Se trataría, por tanto, de otro servicio asincrónico, que puede también integrar otros sistemas del mismo tipo, como los formularios web, o sincrónicos, como el chat, a partir de programas embebidos o insertados en el blog de la biblioteca, como Meebome, Chatango o Plugoo.

También existe un programa específico para la referencia digital basado en la tecnología blog. Se trata de Lyceum $^{300}$, una aplicación de código fuente abierto, que parte de WordPress y que está orientado hacia la administración de manera sencilla de recursos de referencia, así como hacia la gestión de preguntas y respuestas. Algunas instituciones lo han adoptado para su servicio de blogs, como la Universidad Johns Hopkins ${ }^{301}$.

Para ejemplificar el uso que se realiza de los weblogs por parte de las bibliotecas es una buena muestra la aplicación que se lleva a cabo en la red de bibliotecas escolares de Galicia $^{302}$, donde un buen número de centros educativos han creado blogs en sus bibliotecas escolares y ofrecen la posibilidad de contactar con la misma para recoger las consultas y comentarios de sus estudiantes.

\section{Redes sociales}

Con el término amplio de red social o comunidad virtual se debe entender al conjunto de personas que están registradas en un espacio web que está diseñado para la interactuación de sus miembros, quienes se crean una identificación específica para operar dentro de ese grupo. Los servidores que ofrecen la posibilidad de crear redes disponen de un software específico para esta función, registrando las identidades de sus usuarios, en algunos casos con apariencia en tres dimensiones. Los miembros de una red establecen sus propias relaciones, invitando a otras personas a participar en sus grupos y aceptando o denegando la entrada de nuevos miembros.

Este sistema de relaciones se emplea también en la investigación, para la que existen servicios especializados mediante los que crear redes de investigadores en un área; ejemplos de estas aplicaciones profesionales son Academici $^{303}$, Econozco ${ }^{304}$, Neurona ${ }^{305}$ o Linkedin ${ }^{306}$. Las redes sociales o comunidades virtuales más numerosas en la actualidad son Orkut ${ }^{307}$,

\footnotetext{
300 The Lyceum Project: http://lyceum.ibiblio.org

${ }^{301}$ Hopkins Weblogs: http://blogs.jhu.edu/portal.php

302 Bibliotecas escolares de Galicia: http://www.edu.xunta.es/biblioteca/blog/

${ }^{303}$ Academici: http://www.academici.net

304 eConozco: http://www.econozco.com

${ }^{305}$ Neurona.com: http://www.neurona.com

${ }^{306}$ Linkedin: http://www.linkedin.com

${ }^{307}$ Orkut: http://www.orkut.com
} 
MySpace ${ }^{308}$, Facebook ${ }^{309}$, Xing ${ }^{310}$ y Second Life $^{311}$, donde ya están presentes muchas bibliotecas ${ }^{312}$, algunas ofreciendo desde este espacio virtual servicios de referencia digital ${ }^{313}$. Al igual que ocurre con otros servicios de Internet, existen servidores que permiten la creación gratuita de redes sociales, como son $\mathrm{Ning}^{314}$, Nexo ${ }^{315}$, Xing ${ }^{316}$ o My Opera ${ }^{317}$, por poner sólo algunos ejemplos.

Las bibliotecas ya se han introducido en las redes sociales, sobre todo en aquellas que basan su funcionamiento en la creación de personalidades paralelas a las reales, ya sea de manera individual o pertenecientes a entidades. Servidores como Second Life construyen realidades virtuales en las que existen personas, ciudades y relaciones y, como en la vida real, las personas se comunican entre sí, ya sea conversando, realizando actividades en común, que trasladan desde la vida física, como realizar compras, asistir a un espectáculo o visitar una biblioteca.

Algunas bibliotecas han querido estar también presente en estos mundos paralelos, bien de forma testimonial, para estar cerca de los usuarios o bien para ampliar su oferta de servicios. Incluso, ya ha habido autores como Evans $^{318}$ o Nybraten y Arantzen ${ }^{319}$ que han querido transmitir a la comunidad bibliotecaria cómo pueden trabajar en estas comunidades virtuales. Evans expone la experiencia de la biblioteca del Brooklyn College, quien ha decidido estar presente en MySpace, dada la popularidad de esta red entre los estudiantes que atiende esta biblioteca. En su artículo se ofrecen algunas direcciones de bibliotecas que tienen su espacio en estas redes, como la Albany County Public Library ${ }^{320}$, que informa de sus servicios y permite la recepción de consultas desde MySpace.

Algunos otros ejemplos de bibliotecas en esta red son la biblioteca de la Universidad Francisco Marroquín de Guatemala ${ }^{321}$ o la Biblioteca Comunal Palagonia $^{322}$ en Catania (Italia). También es posible encontrar en Second

\footnotetext{
308 MySpace: http://www.myspace.com

${ }^{309}$ Facebook: http://www.facebook.com

${ }^{310}$ Xing: http://www.xing.com

${ }^{311}$ Second Life: http://www.secondlife.com

${ }^{312}$ Webb, Paula. Prevailing Practices for Libraries on MySpace. College and Undergraduate Libraries, vol. 14, n. 2, p. 39-44.

${ }^{313}$ Erdman, Jacquelyn. Reference in a 3-D Virtual World: Preliminary Observations on

Library Outreach in "Second Life". The Reference Librarian, 2007, vol. 47, n. 98, p. 29-39.

314 Ning: http://www.ning.com

${ }^{315}$ Nexo: http://www.nexo.com

${ }^{316}$ Xing: http://www.xing.com

317 My Opera: http://my.opera.com/community/

${ }^{318}$ Evans, Beth. Your Space or MySpace? Library Journal Net Connect, 2006, vol. 131, p. 812.

319 Nybraten, Frank Robert; Arantzen, Jonas Svartberg. Participation and interaction. Scandinavian Public Library Quarterly, 2007, vol. 40, n. 1, p. 14-15.

${ }^{320}$ La dirección en MySpace de la Albany County Public Library es http://www.myspace.com/acplwy

${ }^{321}$ Biblioteca Ludwig von Mises: http://www.myspace.com/bibliotecaufm

${ }^{322}$ Biblioteca Comunale Palagonia: http://www.myspace.com/palica1
} 
Life bibliotecas que prestan sus servicios, como la Biblioteca Pública de Amsterdam $^{323}$ o las bibliotecas de la Universidad de California ${ }^{324}$.

La filosofía es, pues, estar donde están los usuarios, ofreciendo los mismos servicios. Este medio es sobre todo aconsejable en bibliotecas que trabajan con jóvenes ${ }^{325}$, ya que son los principales usuarios de estas redes sociales. Si la biblioteca tiene su espacio virtual está abriendo una posibilidad más a que se acceda a sus servicios y está permitiendo que sus usuarios les hagan llegar consultas por este medio. Los espacios virtuales se pueden configurar, de tal forma, que la biblioteca incluya un sistema para la recepción de consultas. En las redes más sencillas, las posibilidades de comunicación con el usuario son sencillas, ofreciendo una dirección de correo electrónico, una ventana de chat o mensajería instantánea o un weblogs para dejar la consulta. En las comunidades más avanzadas, como Second Life, la biblioteca puede tener sus salas y su propio mostrador de referencia, atendido por un bibliotecario que conversa con el usuario como lo haría en persona.

\section{Grupos de noticias}

Los grupos de noticias o newsgroups son sistemas de mensajería, por lo general asíncronos, que permiten el intercambio de mensajes entre las diferentes personas miembros de un determinado foro. El esquema de funcionamiento es similar al de las listas de distribución, ya que diversas personas interesadas en un mismo tema se reúnen en un grupo para intercambiar mensajes. Pero existen grandes diferencias, una vez más debidas a la tecnología. Las listas de distribución se basan en el correo electrónico, por lo que se debe cumplir el protocolo SMTP; emplean, además, un software específico para la redifusión de los mensajes que un miembro de una lista quiere hacer llegar al resto.

En los grupos de noticias se utilizan programas cliente específicos -aunque los de correo electrónico son por lo general también compatibles- y un protocolo propio, el denominado NNTP. Los usuarios no necesitan estar dados de alta, simplemente suscribirse al grupo y, en muchos casos, ni siquiera eso. Esto último ocurre sobre todo en los grupos que operan a través de web, donde son los servidores que alojan al grupo los que cumplen los protocolos, limitándose el usuario a conectarse con un navegador web, para leer los mensajes enviados y remitir los suyos si lo desea.

No es ésta una tecnología pensada para la referencia digital, pero hay notables ejemplos de bibliotecas que la están empleando para ofrecer este servicio de consulta. Así ocurre con la Biblioteca Municipal de Lyon, cuyo

\footnotetext{
${ }^{323}$ Bibliotheek Amsterdam OBA Openbare: http://slurl.com/secondlife/OBA/154.438/203.188 (Acceso desde Second Life)

324 UCLA Libraries: http://slurl.com/secondlife/Cybrary\%20City/231.315/109.746 (acceso desde Second Life)

${ }^{325}$ Puede consultarse el resultado de un estudio sobre servicios de referencia para jóvenes en Henley, Caroline. Digital reference services for young library users: a comparison of four services. Library Review, 2004, vol. 53, n. 1, p. 30-36.
} 
servicio Le Guichet du savoir ${ }^{326}$ (ventanilla del saber) emplea un sistema de noticias para que los usuarios depositen sus consultas y para que los bibliotecarios las respondan, quedando ambas, preguntas y respuestas, almacenadas en el grupo de noticias.

\begin{tabular}{|c|c|c|c|}
\hline$*$ & Le Guichet du & Savoir $®$ & $\begin{array}{r}\text { Bibliothèque municipale de } \\
\text { Lyon }\end{array}$ \\
\hline Support · Charte \& Règles & $\theta$ Aide & O Recherche & Evénements \\
\hline Bienvenue invité ( Connexi & ( Inscription ) & \multicolumn{2}{|c|}{ Recevoir à nouveau l'email de validation } \\
\hline
\end{tabular}

Services $\rightarrow$ Accès thématique aux Questions / Réponses $\rightarrow$ Arts $\rightarrow$ Architecture - Urbanisme

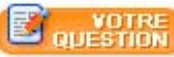

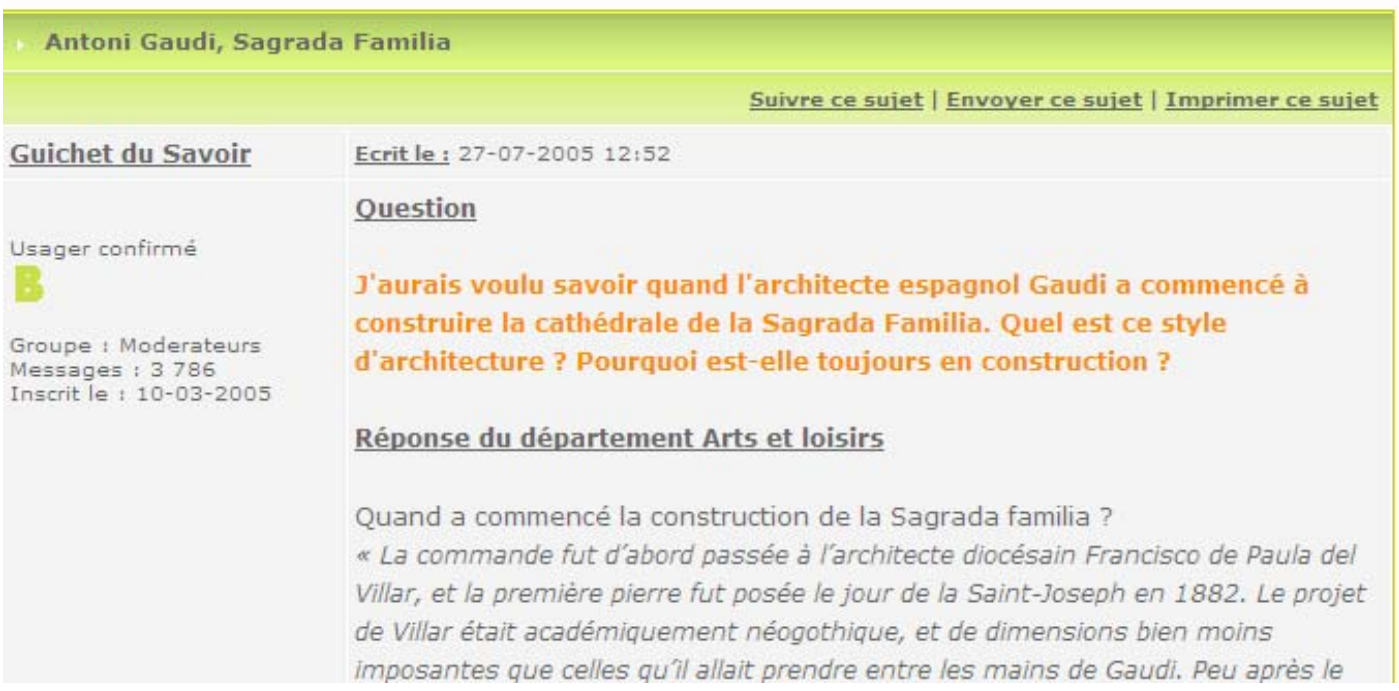

Fig. 2.11. Referencia mediante grupos de noticias en la Biblioteca Municipal de Lyon

\section{Telefonía IP}

La conversación telefónica usando Internet recibe las denominaciones de Voz sobre Protocolo de Internet, Voz sobre IP, VozIP, VolP o Telefonía IP. Consiste en la posibilidad de emitir y recibir señales de voz empleando el protocolo IP, el mismo que se utiliza para la transmisión de datos en Internet. La voz se convierte en señal digital y se envía por paquetes, en vez de por circuitos, forma tradicional utilizada por las compañías telefónicas. En definitiva, se trata de emplear la tecnología de la conmutación de paquetes, base de la transferencia de información en Internet, para el envío de voz en tiempo real. El uso de VoIP empleando ordenadores requiere de la instalación de software específico. En la actualidad, los más empleados son Skype y Google Talk. Algunos sistemas de mensajería instantánea también están permitiendo esta funcionalidad, como Windows Live Messenger o Yahoo. Además del programa de telefonía, es necesario un micrófono y auriculares, como es lógico. Una vez reunidas las condiciones necesarias,

${ }^{326}$ Le Gichet du savoir: http://www.guichetdusavoir.org 
es necesario registrarse en el servicio que se quiera emplear, para que se le asigne su identificación, el equivalente al número de teléfono. Por lo general, estas conversaciones son gratuitas, aunque algunas empresas cobran determinadas cuotas. El uso de estas tecnologías por parte de las bibliotecas es tímido, aunque existen suficientes ejemplos como para demostrar que son experiencias eficaces y que tiene sentido ofrecer esta vía de comunicación con los usuarios. Por lo general, las bibliotecas que ofrecen esta posibilidad prestan este servicio simultaneando tecnologías, frecuentemente de forma simultánea con el chat y la mensajería instantánea. Las secciones de referencia digital de las bibliotecas abren una cuenta en los servicios de telefonía sobre IP, que difunden públicamente en sus webs. De esta manera, informan a los usuarios de que pueden comunicarse con la biblioteca, para hacer llegar sus consultas por las diferentes vías disponibles, incluyendo los alias, números o identificaciones necesarias para cada servicio, así como los horarios en los que se puede encontrar personal para atender las consultas.

Un ejemplo notable es el servicio Skype a librarian ${ }^{327}$, que prestan a los usuarios las bibliotecas de la Universidad de Ohio. Esta red de bibliotecas universitarias ofrece un completo servicio de referencia, ya que a los sistemas tradicionales (referencia presencial y teléfono convencional) añade las posibilidades de consultas por correo electrónico y formulario web, chat (Meebo), mensajería instantánea (AOL Instant Messenger, Yahoo! Messenger y MSN Messenger) y telefonía IP (Skype). La red de bibliotecas facilita a los usuarios su cuenta o Skype ID, así como la conexión al proveedor para que el usuario cree una cuenta si no dispone de ella y descargue el software si es necesario. Se trata de un servicio que esta universidad ofrece en un horario semanal muy amplio.

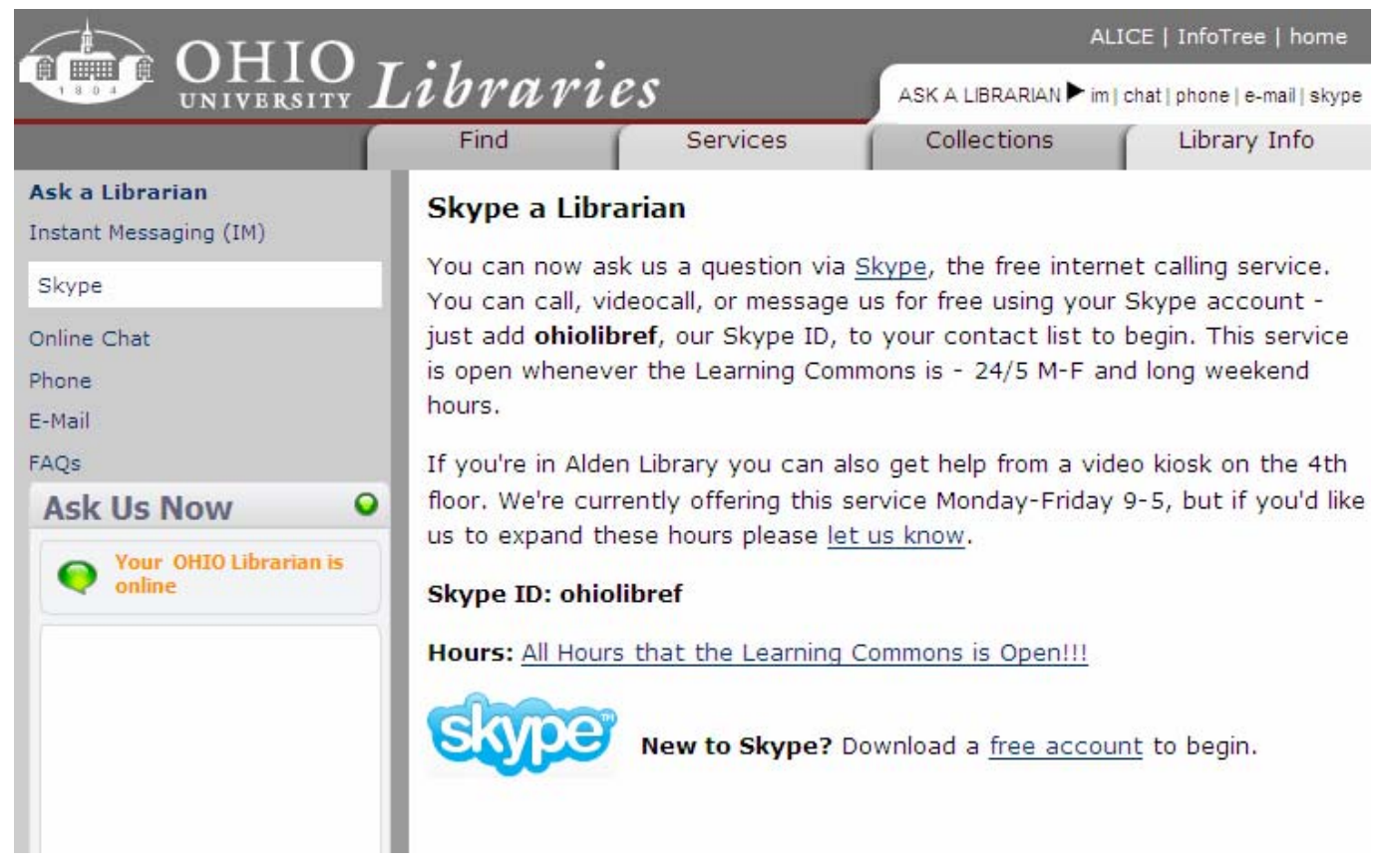

Fig. 2.12. Referencia digital mediante telefonía IP en la Ohio University

${ }^{327}$ Skype a librarian: http://www.library.ohiou.edu/ask/skype.html 


\section{Videoconferencia}

La videoconferencia es la posibilidad de transmitir audio y vídeo en tiempo real a través de Internet. Existen estándares específicos para la transmisión de elementos audiovisuales, aunque en sentido amplio se puede englobar bajo este término a todas las tecnologías capaces de enviar imagen y sonido simultáneamente y en tiempo real. En muchas ocasiones, cuando esto ocurre no se trata exactamente de una videoconferencia, sino de telefonía con vídeo o de chat con imágenes y sonido, por ejemplo. En este caso, se deberá disponer, además del software específico, de una cámara web (webcam) y de un micrófono, que servirán para transmitir las imágenes y sonidos de las personas que intervengan en la transmisión. La calidad en la recepción dependerá del tipo de conexión que se esté empleando y de los medios de que se dispongan. Los equipos y canales específicos para videoconferencia siempre darán mejores resultados que las conexiones que emplean webcams y conexiones domésticas.

Programas informáticos ya mencionados en otras categorías soportan videoconferencia; así ocurre con Yahoo Messenger, AOL Instant Messenger (AIM), Windows Live Messenger o Skype, por ejemplo. Por este motivo, este medio de comunicación se podría haber integrado en los bloques anteriores, ya que estas tecnologías se completan con la videoconferencia cuando en la conexión también se está transmitiendo imagen y sonido simultáneos, en tiempo real. No obstante, se ha preferido explicar este medio en otro apartado, a fin de representar de forma más precisa las posibilidades de la referencia digital.

Los servicios de referencia digital pueden emplear esta tecnología como un complemento más a los servicios que ofrecen en línea. La similitud entre el mostrador de referencia presencial y telemático es mayor si los usuarios pueden comunicarse con un bibliotecario a quien están viendo y oyendo. Ciertamente, esta tecnología tiene muchas desventajas, como la ubicación del referencista, que debe situarse en una zona de la biblioteca donde la conversación sea posible. Pero estos medios tampoco aportan demasiadas ventajas a otros que están siendo empleados, sobre todo al chat o la mensajería instantánea, por lo que, en caso de ofrecer un servicio de referencia digital con imagen y sonido en directo, lo conveniente es prestarlo junto a los restantes sistemas sincrónicos.

El doctorando no tiene constancia de que este servicio se esté ofreciendo desde las bibliotecas para la referencia digital de forma individual, aunque sí dentro de las posibilidades de aquellas bibliotecas que prestan servicios de información a través de tecnologías compatibles con vídeo, como son la mensajería instantánea, el chat o la telefonía IP. El ejemplo de la red de bibliotecas de la Universidad de Ohio, que se ha comentado unas líneas más arriba, es una muestra de esta aplicación en la práctica, ya que permite a sus usuarios que se realicen preguntas a los bibliotecarios desde su "vídeo quiosco", un espacio multimedia a disposición de la comunidad universitaria. 


\section{SMS}

El servicio de mensajes cortos o Short Message Service (SMS) es una aplicación de la telefonía móvil que permite el envío de informaciones para su lectura como un mensaje de texto o multimedia. Los SMS son uno de los servicios más empleados por los usuarios de telefonía móvil, ya que su precio es inferior a una llamada y permite la transmisión de información suficiente para una comunicación fluida.

La popularización de los SMS dio pie a una nueva vía de negocio, en la cual a los clientes que demandaban un servicio por esta vía se les cobraba diferentes tarifas en función de la transacción que hubiese realizado. Las compañías telefónicas son las encargadas de cobrar a los clientes y de pagar a los proveedores de servicios. Las propias compañías de telefonía móvil se convirtieron rápidamente en proveedoras de información vía SMS, ya que permitían a los usuarios recibir o descargar mensajes de las temáticas que desearan: noticias, deportes, espectáculos, etc. En la mayoría de estos casos los usuarios deben pagar por los mensajes que reciben. También ha supuesto un hito importante en la difusión de los servicios de mensajes cortos como sistemas de información, la creación de programas informáticos de envío de SMS, que permiten su uso de forma masiva, pero también personalizada. De esta manera, los usuarios o clientes que deseen recibir una información de un determinado proveedor sólo deberán suscribirse al servicio deseado, con los posibles desembolsos que esto pueda implicar.

Las bibliotecas se han querido unir a las entidades que ofrecen servicios de información vía SMS. Dentro de las limitadas experiencias que todavía existen, es relativamente frecuente el número de bibliotecas que prestan servicios a través del teléfono móvil, por lo general vinculados a la difusión de información, eventos, novedades o noticias, así como a la comunicación de plazos de vencimiento o disponibilidad de publicaciones reservadas. Un ejemplo cercano puede ser el de las Bibliotecas Municipales de La Coruña, que avisan a sus usuarios por SMS de las actividades que se realizan en sus centros. Los usuarios deben registrarse en el sistema municipal de información ${ }^{328}$ y seleccionar el canal de noticias de la biblioteca.

Existe una serie de ejemplos destacados de bibliotecas que ofrecen servicios de referencia en línea vía SMS. Entre los más importantes se encuentra Biblioteksvar ${ }^{329}$, el servicio público de referencia en línea noruego. El usuario puede mandar preguntas de menos de 160 caracteres y la biblioteca responderá con otro mensaje corto. Si la respuesta es larga o la pregunta requiere información complementaria se remitirá al usuario al formulario web o al chat del servicio. Para realizar preguntas se debe enviar la palabra svar y la pregunta al número 1980, siendo el importe el mismo que el del envío de un SMS normal y no debiéndose pagar nada por recibir la respuesta. Normalmente, los mensajes se contestan antes del siguiente día

\footnotetext{
${ }^{328}$ Portal de Suscripción a Canales de Información Ayuntamiento de A Coruña: http://sms.coruna.es

${ }^{329}$ Biblioteksvar: http://biblioteksvar.no
} 
laborable. Recientemente, en verano de 2007, este sistema se ha unido a los medio de la referencia digital por chat y formulario web que ofrecía Biblioteksvagten $^{330}$, el servicio público de referencia digital danés.

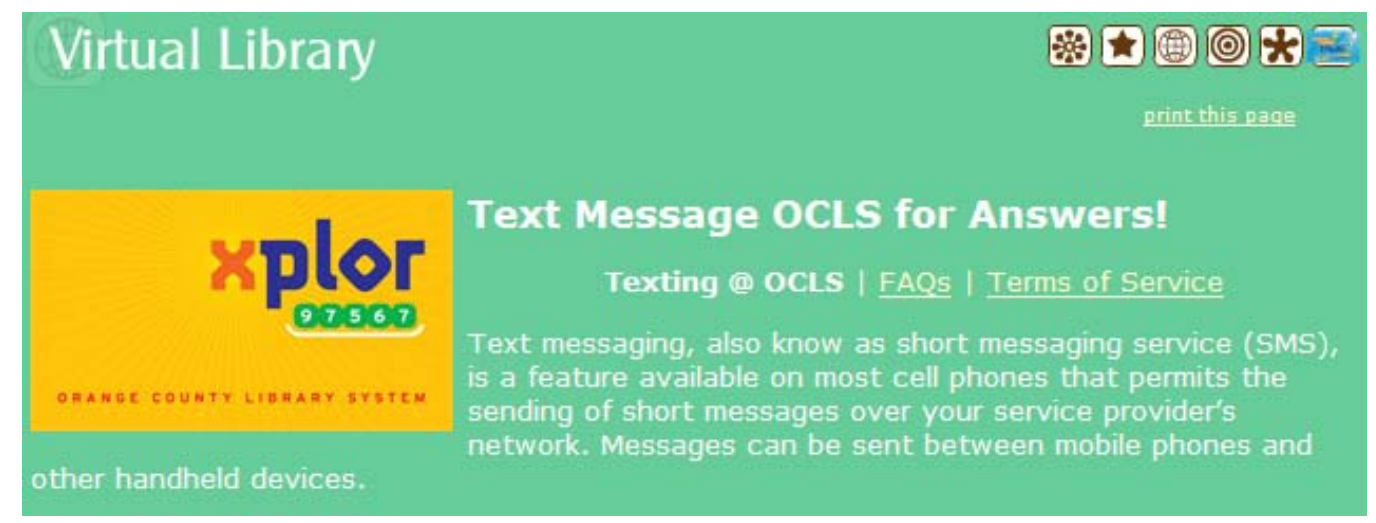

Fig. 2.13. Referencia digital mediante SMS en la Biblioteca Pública del Condado de Orange

Otro buen ejemplo de servicio público es $X p{ }^{331}{ }^{33}$, prestado por el sistema bibliotecario del condado de Orange en Florida; el funcionamiento es similar al de otros servicios, es decir, hay que enviar el término adecuado (xplor, en este caso) al número del servicio. La particularidad es que disponen de un término general para el servicio de información y otros para cuestiones más concretas, como la petición de un código postal o una dirección postal. Los mensajes también pueden ser enviados a otros dispositivos que acepten SMS, como los PDA, por ejemplo. En este caso, las tarifas también son únicamente las que cobre la compañía telefónica, porque la biblioteca presta este servicio de forma gratuita.

Algunas otras bibliotecas, de diferentes tipologías, que ofertan este servicio son la Universidad de Queensland ${ }^{332}$ en Australia, limitado a la comunidad universitaria, que incluye este sistema dentro de la amplia variedad de métodos para la referencia digital. Otro ejemplo de biblioteca universitaria que utiliza el SMS para la referencia digital es el de la Curtin University of Technology en Sydney. Este servicio fue detallado en el congreso de la ALIA ${ }^{333}$ de 2005, es gratuito y está limitado a su comunidad universitaria. Un último ejemplo es el de la National Library Board ${ }^{334}$ de Singapur ${ }^{335}$, que también ofrece respuestas a través de mensajes cortos de teléfono móvil ${ }^{336}$.

\footnotetext{
${ }^{330}$ Biblioteksvagten: http://www.biblioteksvagten.dk

${ }^{331}$ Orange County Library System. Xplor: http://www.ocls.info/xplor/

${ }^{332}$ Universidad de Queensland. Ask a librarian: http://www.library.qut.edu.au/ask.jsp

${ }^{333}$ Algunos estudios sobre SMS en la referencia digital son; Giles, Nicola; Grey-Smith, Sue. Txting librarians @ Curtin. En Information Online 2005. Sydney: Australian Library and Information Association, $2005 . \quad$ Disponible en http://conferences.alia.org.au/online2005/papers/a12.pdf [consultado el 01/08/2007]; Hill, J. B.; Madarash-Hill, Cherie; Sherman, Dayne. Text Messaging in an Academic Library: Integrating SMS into Digital Reference. The Reference Librarian, 2007, vol. 47, n. 97, p. 1729.

${ }^{334}$ National Library Board, Singapore, Lee Kong Chian Reference Library: http://www.nlb.gov.sg

${ }^{335}$ Más información sobre este servicio en Ngian, Lek Choh. The re-invention of the reference enquiry service: a case study of the National Library Board, Singapore. En IFLA
} 


\section{Programas cliente}

Las aplicaciones o programas cliente son productos que están diseñados para la realización de tareas específicas. Los usuarios los instalan en sus ordenadores personales para ejecutarlos y utilizarlos con finalidades diversas. Este tipo de programas pueden ser propietarios, es decir, con un código de programación que pertenece a una persona, empresa o entidad, que es la única que puede efectuar variaciones sobre el mismo; o bien, distribuirse de forma abierta, con su código fuente abierto, para que pueda ser modificado por quien esté interesado.

Junto al concepto de código abierto hay que hablar del de software libre, que se refiere al movimiento que aboga por la ejecución, análisis, modificación y distribución de aplicaciones de forma abierta. Los programas de software libre están sujetos a la legislación de propiedad intelectual, pero los beneficiarios de sus derechos ceden algunos, para que sus programas puedan ser empleados libremente. Existe un colectivo organizado internacionalmente para la gestión del software libre, la recopilación de recursos y documentos, así como de los derechos que llevan aparejados. Se trata de la Free Software Foundation (FSF) ${ }^{337}$, que tiene diferentes ramas en virtud de las lenguas y de las áreas geográficas. La FSF mantiene un directorio con la Unesco, accesible desde su sitio web, desde el que se pueden localizar aplicaciones libres, incluyendo algunas de las que se emplean para la referencia digital.

Las bibliotecas, como todas las entidades corporativas, son usuarias de aplicaciones informáticas, en muchos casos generales, como las relativas a cuestiones ofimáticas o contables y, en otras, particulares, especialmente los programas empleados para el control de los usuarios, las colecciones y las transacciones entre ambos. Asimismo, las bibliotecas son expertas en el manejo de software para la recuperación de información, tanto en sus catálogos, como en las diversas colecciones electrónicas que albergan, así como en los recursos a los que tienen acceso. En ocasiones, las bibliotecas utilizan aplicaciones específicas para operaciones o servicios concretos, como ocurre con los servicios de referencia digital.

Muchas bibliotecas han optado por el uso de una aplicación informática para la gestión del servicio de referencia digital, que sea capaz de establecer una comunicación con el usuario, ya sea en tiempo real o de forma asíncrona, que permita el almacenamiento de las consultas o la explotación de estadísticas. Para ello, las soluciones por las que se opta suelen ser las siguientes:

General Conference and Council (71. 2005. Oslo). Oslo: IFLA, 2005. Disponible en <http://www.ifla.org/IV/ifla71/papers/031e-Ngian.pdf> [consulta 17 julio 2007].

${ }^{336}$ Véase también el ejemplo de la Southbank Library en Brisbane (Australia), descrito en Herman, Sonia. SMS reference: keeping up with your clients. The Electronic Library, 2007, vol. 25 , n. 4 , p. 401-408.

${ }^{337}$ Free Software Foundation: http://www.fsf.org 
- Desarrollo de un programa propio. La biblioteca realiza un estudio de las funcionalidades que se deben exigir a un sistema de gestión de referencia digital y encarga la aplicación a una empresa informática. Este es el modelo empleado, por ejemplo, por Pregunte ${ }^{338}$, el servicio público de referencia en línea que ofrecen las bibliotecas españolas. El principal motivo para optar por esta solución es que permite un diseño a la carta, disponiendo de tantos módulos como desee la biblioteca y realizando las operaciones que la biblioteca considere que se van a emplear. Tiene como principales desventajas que requiere un servicio de mantenimiento particularizado y que es poco útil para el trabajo en red, a no ser que todas las bibliotecas que formen parte de un supuesto consorcio empleasen esta misma aplicación.

- Empleo de un software de atención a clientes. Existen aplicaciones comerciales, diseñadas para la venta electrónica y la atención a clientes por medios telemáticos que se ajustan a los requisitos del servicio de referencia. Se trata de tomar como base un producto no pensado para la biblioteca, pero totalmente compatible con la actividad de la referencia digital. En muchos casos se emplea el denominado Call Center Software, que aglutina programas hábiles para la comunicación en tiempo real a través de Internet. Algunos ejemplos de este tipo de software son RightNow y Siebel, que se emplean normalmente en grandes empresas y entidades, aunque se pueden encontrar en bibliotecas universitarias, por ejemplo ${ }^{339}$. También se deben incluir aquí las soluciones de comunicación en tiempo real usadas en las bibliotecas, que derivan de programas de enseñanza en línea y de otros con alta interactividad, como los juegos, especialmente los programados con sistemas MultiUser Object Oriented (MOO). Estos programas fueron empleados en referencia digital en los primeros años de existencia de la misma ${ }^{340}$.

- Uso de un software para la referencia digital. Existen en el mercado diversas aplicaciones informáticas específicamente concebidas para ofrecer servicios de referencia digital. Se trata de productos diseñados pensando en las bibliotecas $y$, por lo general, proceden de entidades vinculadas a la profesión bibliotecaria. Son productos que cumplen los estándares empleados en las bibliotecas y que se integran con las colecciones y servicios electrónicos. Tienen la ventaja de que pueden ser instalados nada más tomarse la decisión de iniciar un servicio de referencia digital y de que se ajustan perfectamente a la referencia digital cooperativa. Además, al tratarse de productos comerciales, se dispondrá del respaldo del vendedor para su mantenimiento. La principal desventaja

\footnotetext{
${ }^{338}$ Pregunte: las bibliotecas responden: http://www.pregunte.org

${ }^{339}$ Dilevko analiza el modelo del servicio de referencia digital basado en Call-centers. Opina que suponen las desprofesionalización de la función de referencista, así como la pérdida en las habilidades de los bibliotecarios referencistas. De igual forma, relaciona los hábitos de lectura con la calidad de los servicios de referencia. Véase Dilevko, Juris. An ideological analysis of digital reference service models. Library Trends, 2001, vol. 50, n. 2, p. 218-244.

${ }^{340}$ Se trata de una tecnología pensada para los juegos interactivos en tiempo real, que se emplea también para la formación a distancia. Su uso en la referencia digital fue analizado por García Delgado, Purificación. El servicio de referencia digital. El profesional de la información, 2003, vol. 12, n. 4, p. 320-330.
} 
es que pueden no ajustarse realmente a las necesidades de una biblioteca concreta, aunque algunos productos realizan adaptaciones según la demanda del cliente. Para un conocimiento completo de la oferta existente en la actualidad, es muy útil el exhaustivo análisis que Fagan $^{341}$ realizó de los siete principales programas empleados en el mundo: elibrarian (Digi-Net), Live Assistance (Live Assistance), OnDemand Basic (Convey Systems), Question Point 24/7 Reference (OCLC), Timpani SB Chat (Live Person), Virtual Reference Toolkit (Tutor.com; antes de LSSI) y VRLplus (Docutek).

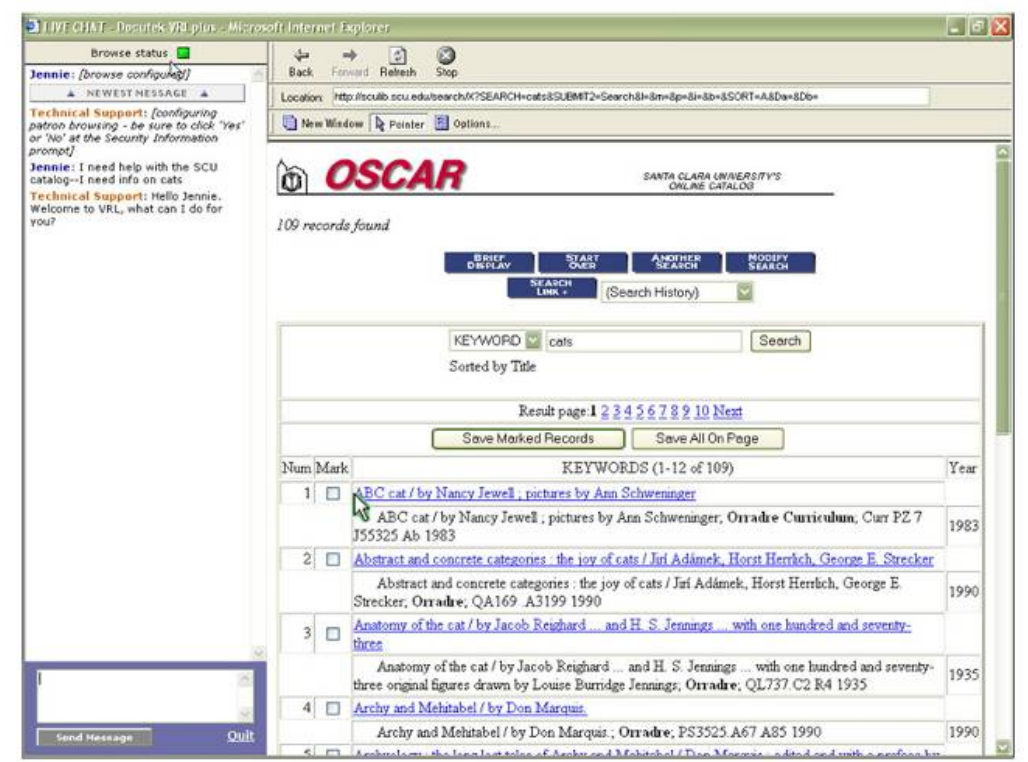

Fig. 2.14. Interfaz del programa de referencia digital Docutek VRL Plus (sesión sincrónica)

Los sistemas de comunicación y transacción de preguntas/respuestas empleados en los programas de referencia digital son similares. Se ofrece una puerta de entrada diseñada de tal forma que el usuario decida cuál es la vía de consulta que desee emplear. Estas aplicaciones integran la información web estática de la biblioteca junto con las posibilidades de consulta en tiempo real. Así pues, el usuario decide si consulta directamente los recursos de información disponibles, si envía su consulta a través del correo electrónico o formulario web, o bien si conecta con el personal referencista. En este caso, las aplicaciones disponen de servicios de chat o mensajería instantánea. A partir de aquí el proceso suele consistir en una entrevista de referencia sincrónica, para la que el sistema divide la pantalla de consulta en dos áreas, la de comunicación y la de visualización de información.

\footnotetext{
${ }^{341}$ Fagan, Jody Condit. Virtual reference software comparative review. The Charleston Advisor, 2004, vol. 6, n. 4, p. 16. En este artículo sintetiza el análisis que realizó a siete aplicaciones informáticas para la referencia digital y que presentó al encuentro anual de la red Virtual Reference Desk de 2004. Se puede descargar una tabla con la comparativa que realizó esta autora desde http://peregrin.jmu.edu/ faganjc/presentations/VRD2004/ChatRefProductsFinal.xls.
} 
Por una parte, la biblioteca interroga al usuario, mientras que en el área de mayor dimensión va mostrando páginas o documentos, que respondan a la consulta del usuario. Según los programas empleados, los métodos pueden ser diferentes, en función de si la biblioteca dirige la búsqueda o si se comparte con el demandante de información. Lo habitual es que las aplicaciones empleen la conavegación (co-browsing), tecnología que conecta los dos terminales (usuario/biblioteca) para visualizar la misma información simultáneamente.

La conavegación o co-browsing se puede realizar de diferentes formas en función de la tecnología que se emplee para que el personal referencista vaya mostrando la información necesaria al usuario, que la visualiza en la interfaz de la aplicación que se esté empleando o, incluso, en el propio navegador, en el caso de los sistemas que trabajar a partir de web e integran sistemas de chat o mensajería instantánea y páginas web. En la conavegación, usuario y personal bibliotecario visualizan la información de forma simultánea y cualquiera de los dos puede hacer uso de sus teclados o ratones para abrir nuevas páginas o realizar consultas, mientras que la otra parte podrá ir siguiendo el proceso en su propio ordenador.

Rodríguez Briz $^{342}$ resume las variantes de los posibles sistemas de navegación compartida en su monografía, la única sobre el tema escrita en castellano. También es útil el glosario de OCLC ${ }^{343}$ para delimitar la terminología relativa a este tema. Una de las variantes es el uso de aplicaciones compartidas (application sharing), que consiste en el uso de forma conjunta de un programa, que permite a los dos partes escribir o moverse de forma independiente y remota, pero simultáneamente, de manera que las acciones de cada uno se visualizan en tiempo real.

Otra posibilidad es el sistema de escolta (escorting) en el que el bibliotecario realiza las consultas a través de la web, al tiempo que en el navegador del usuario se van viendo las páginas que va abriendo el referencista. Además, es posible encontrarse con tecnologías de envío de páginas (page pushing), empleada en sesiones de chat y mediante la cual el bibliotecario copia direcciones web en el sistema que se abren en el navegador del usuario al dar la orden de envío desde el programa cliente del referencista.

Por último, es posible encontrarse con sistemas de URL compartidas (URL sharing) que se basa en la sincronización de los navegadores del usuario y el bibliotecario, para realizar las consultas al mismo tiempo. Cuando una de los dos partes abre una página web, ésta se visualiza también en la otra parte.

\footnotetext{
${ }^{342}$ Rodríguez Briz, Fernanda. Los servicios de referencia virtual: surgimiento, desarrollo y perspectivas a futuro. Buenos Aires: Alfagrama, 2005, p. 110.

${ }_{343}$ OCLC glossaries: Question Point glossary: http://www.oclc.org/americalatina/es/support/ documentation/glossary/default.htm
} 


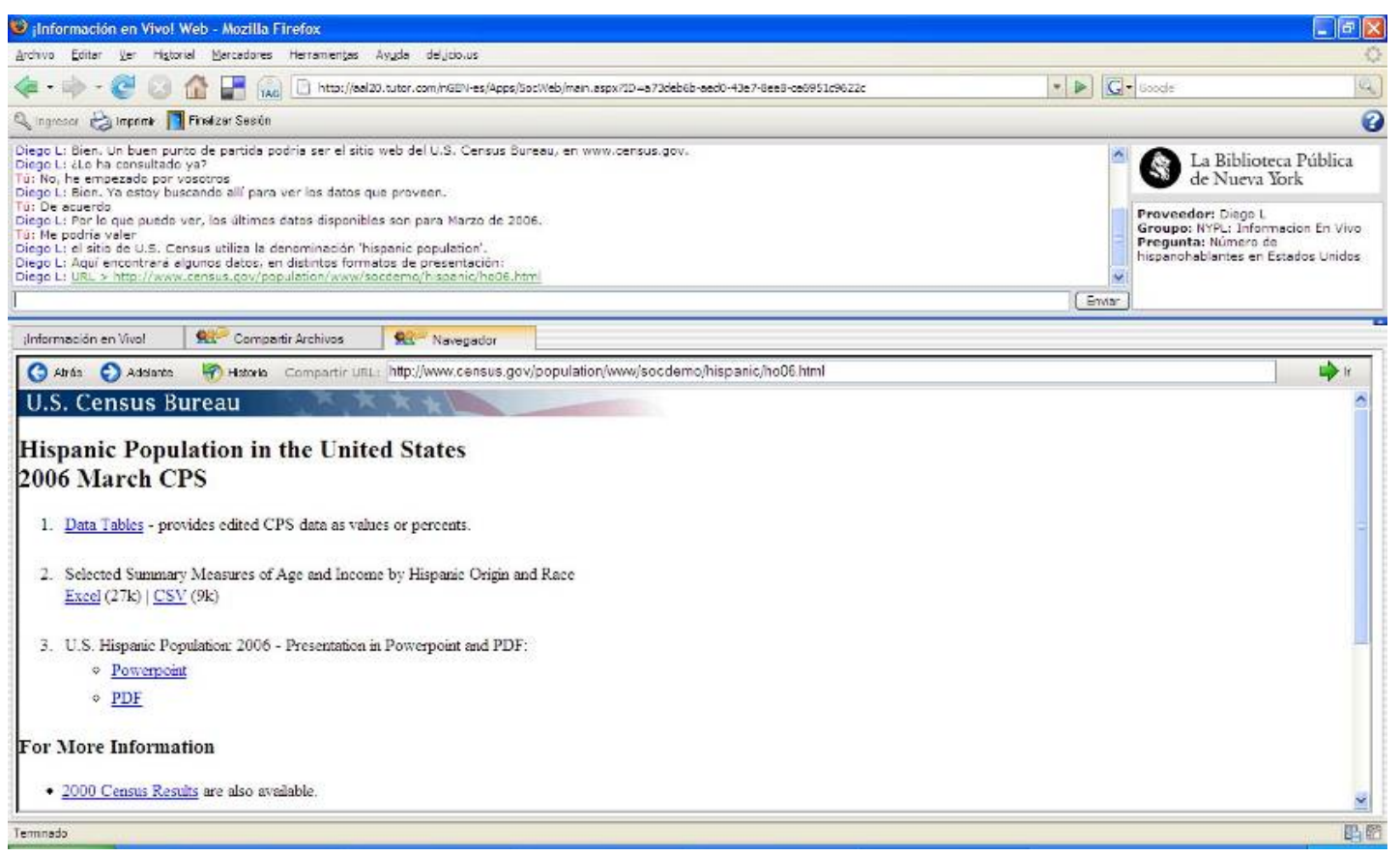

Fig. 2.15. Interfaz del programa de referencia digital Tutor (sesión de conavegación)

Una de las características que se debe exigir a las aplicaciones informáticas especialmente concebidas para la gestión de transacciones de referencia por medios digitales es el cumplimiento de estándares y protocolos. La mayoría de los métodos de comunicación utilizados emplean protocolos generalizados, ya sea por el uso o porque son normas ISO o aprobadas por organismos oficiales de normalización, como la NISO en Estados Unidos. La NISO ha creado un estándar específico para la referencia digital. Se trata de la norma Networked reference services: Question/Answer Transaction Protocol $^{344}$, cuya versión definitiva es de 2006. La NISO es la entidad acreditada por la ANSI, organismo estadounidense de normalización, para el desarrollo de normas relativas al intercambio de información.

La NISO creó el Comité AZ, en el que trabaja activamente la Biblioteca del Congreso, para desarrollar un estándar específico para la referencia digital. El primer borrador del Protocolo de Transacción de Pregunta/Respuesta o Question/Answer Transaction Protocol (QAT) fue presentado en septiembre de 2003. Posteriormente, se estableció un periodo de prueba, de abril de 2004 a abril de 2005, en el que se recogieron las enmiendas oportunas. Finalmente, la NISO publica el protocolo QAT en diciembre de 2006, como un informe técnico que sirva de base a los sistemas diseñados para la administración de usuarios, recursos, preguntas y respuestas en los servicios de referencia digital, de tal manera, que los sistemas puedan estar interconectados y trabajar de forma cooperativa.

La norma NISO identifica todos los elementos del proceso y los organiza de forma uniforme, codificándolos en XML para su posterior intercambio y gestión. Se trata de un documento que se debe tener como base para el

\footnotetext{
${ }^{344}$ NISO. Networked reference services: Question/Answer Transaction Protocol. Bethesda: NISO Press, 2006
} 
diseño informático de un servicio de referencia digital, dada la excelente identificación que realiza de los agentes implicados en el proceso, de la descripción de los modelos y topologías y de la codificación normalizada que propone de todas las secuencias posibles.

Entre las aplicaciones informáticas empleadas para la referencia digital destaca Question Point ${ }^{345}$ por su implantación y sus prestaciones. Por una parte, se trata de una aplicación que permite la recepción de consultas y su respuesta de forma asincrónica. El usuario cumplimenta un formulario con su consulta, recibe una notificación por correo electrónico para confirmarle que la pregunta ha sido recibida $y$, posteriormente, para informarle de que tiene la respuesta en el sistema. Además, la última versión del programa permite la conversación mediante chat tradicional o bien una fórmula ampliada en la que la conversación en tiempo real se realiza de forma conjunta con la conavegación.

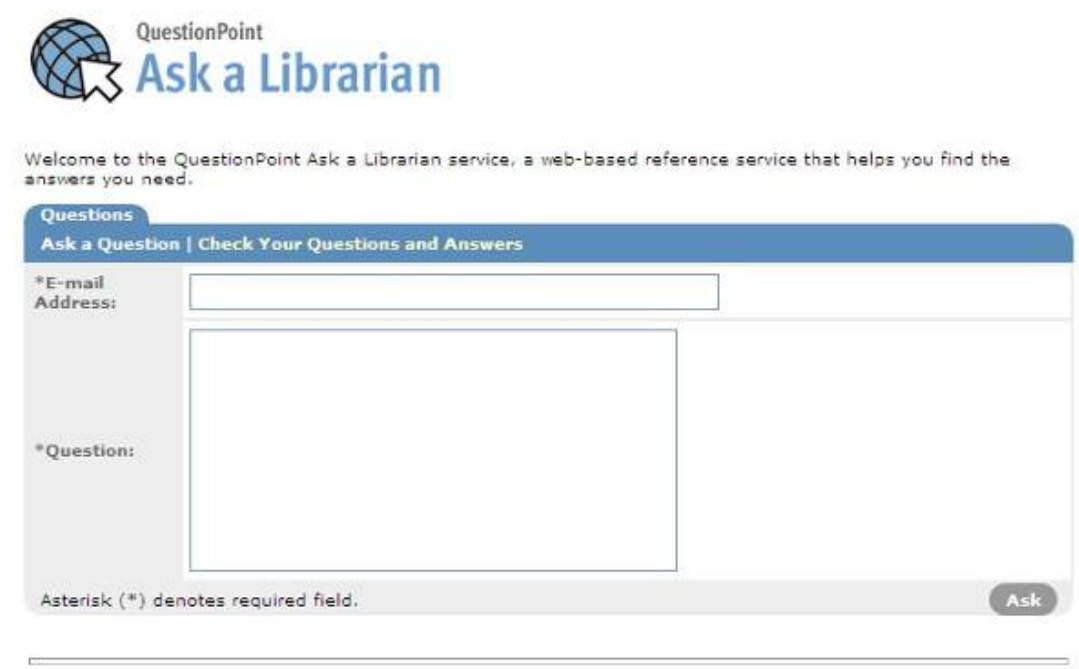

Fig. 2.16. Interfaz del programa de referencia digital Question Point (formulario básico)

Por otra parte, Question Point es también un servicio cooperativo de referencia en línea. En función de lo que contrate la biblioteca, se puede acceder a una base de datos común y a servicios de apoyo para remitir aquellas cuestiones que no pueda resolver una biblioteca. Esta herramienta es la empleada por la mayor red de referencia digital del mundo, la que coordina la Biblioteca del Congreso de Estados Unidos ${ }^{346}$, así como por los servicios públicos de referencia digital de países como Alemania, Eslovenia o los Países Bajos. La red cooperativa dispone de un gran archivo de preguntas y respuestas, que puede ser consultado de forma abierta.

\footnotetext{
${ }^{345}$ Question Point: http://www.questionpoint.org

${ }^{346}$ En la Red Global que trabaja con Question Point participan algunos centros de información españoles, en concreto, el Centro de Documentación Info-Sud de la Universidad de Valencia y la biblioteca de la Universidad de Cádiz.
} 
Record Detail:

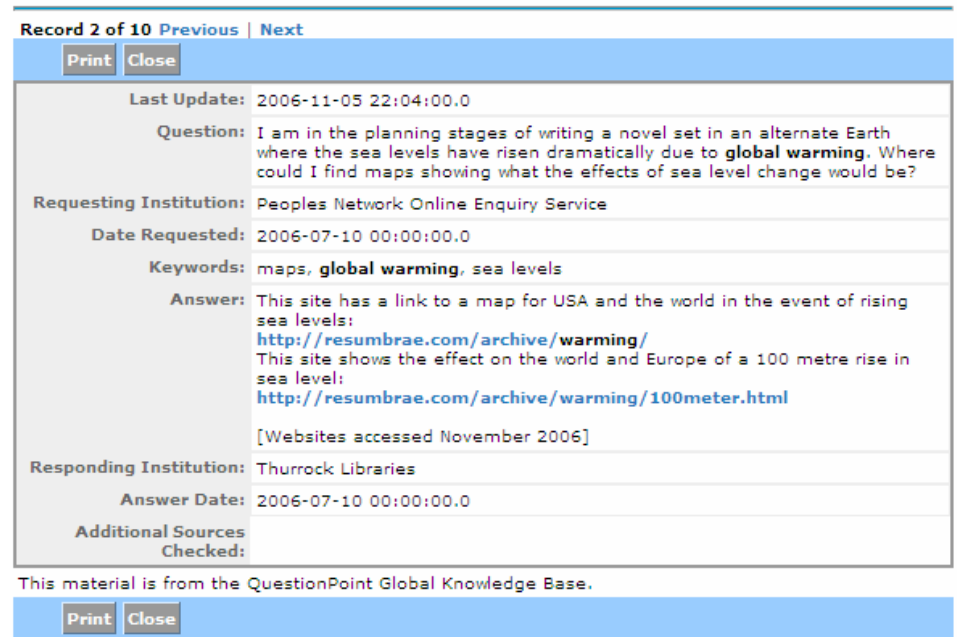

Fig. 2.17. Interfaz del programa de referencia digital Question Point (archivo de respuestas) 


\section{Desarrollo de servicios de referencia digital}

Crear un servicio de referencia implica tener en cuenta los aspectos de planificación comunes a cualquier unidad de información, con las particularidades propias de un trabajo que se realiza en línea, por lo que se debe estar especialmente atento a cuestiones tecnológicas. En este capítulo, se describirán, en primer lugar, las aportaciones de diferentes teóricos sobre la planificación y creación de un servicio de referencia digital, ofreciendo, asimismo, una relación detallada de los diferentes elementos que es necesario contemplar para la puesta en marcha de un servicio de este tipo. En el segundo apartado, se estudian las competencias profesionales necesarias para la referencia digital, estructurándose en tres bloques, las capacidades de comunicación esenciales, las habilidades relativas a las tecnologías y las destrezas necesarias para la recuperación de información y manejo de obras y fuentes de referencia. El capítulo finaliza disertando sobre los servicios públicos de referencia digital. Se ha querido dedicar un apartado específico para aquellos servicios de referencia que están abiertos para todos los ciudadanos y que son atendidos por organismos bibliotecarios, normalmente de la administración general de un estado. Se examinan este tipo de servicios públicos, identificando sus características definitorias y realizando un panorama internacional de los mismos. Se ha pretendido reunir la nómina completa de los servicios públicos de referencia que existen en el mundo, incluyendo los datos más relevantes de cada uno. La información que facilitan estos servicios públicos, especialmente el que se presta a nivel nacional en España, es el eje de esta tesis doctoral, motivo por el cual se hace tanto hincapié en los mismos.

\subsection{Planificación y creación de un servicio de referencia digital}

La puesta en funcionamiento del servicio de referencia digital requiere un detallado proceso en el que se analicen todas las circunstancias que rodean la actividad de la referencia digital: personal, espacios, equipamientos, aplicaciones, recursos, políticas, presupuesto, etc. Las bibliotecas que deseen implantar una sección de este tipo tienen que tener en cuenta una extensa relación de ámbitos en los que debe definir claramente cuál es la opción más conveniente para el tipo de biblioteca y para el tipo de servicio que se quiere prestar. Las condiciones no serán idénticas para una biblioteca pública que para una universitaria; como tampoco serán igual para un centro que quiere ofrecer el servicio de manera individual, que para aquellos que lo ofrecen de forma cooperativa. Asimismo, si lo que se está planificando es un servicio público de referencia digital de alcance nacional o territorial, entonces los aspectos que hay que valorar y sobre los que tiene que recaer la planificación y mantenimiento del servicio son también muy diferentes a los que se prestan en una biblioteca o red de bibliotecas.

Muchos son los autores que han difundido sus teorías acerca de cómo implantar un servicio de referencia; también existen muchas experiencias 
publicadas $^{347}$ sobre el desarrollo de servicios desde su creación; aunque, los documentos más prácticos y aconsejables son los elaborados por los responsables de proyectos que ya han sido puestos en marcha o en que su momento estaban en fase de estudio. Éste es el ejemplo de uno de los textos más completos, que sirven de muestra ejemplar sobre cómo se debe realizar el estudio de un nuevo servicio antes de ponerlo en marcha; se trata del informe preparado por el Grupo de trabajo de referencia a distancia de la Conférence des Recteurs et des Principaux des Universités du Quebec $(\text { CREPUQ) })^{348}$. El estudio tenía como finalidad la creación de un servicio de referencia digital cooperativo para las bibliotecas universitarias francófonas de Canadá y en el mismo se realiza un análisis del contexto de los sistemas de consulta en línea, así como de la tipología de los servicios telemáticos de referencia y de los sistemas informáticos útiles para este fin. El informe aporta sus conclusiones o recomendaciones, junto a unos útiles anexos en los que se comparan los programas cliente más empleados en la actualidad, así como las tecnologías de mensajería instantánea, a partir de aplicaciones específicas y de agregadores de servicios.

Una aportación teórica bien estructurada es la que presenta Nguyen $^{349}$, como parte de un trabajo más amplio sobre los servicios de referencia digitales. Para la autora francesa, la puesta en marcha de un servicio de este tipo pasa por cuatro grandes etapas: fase preparatoria, definición de la política del servicio, definición de la organización del trabajo y difusión y evaluación. En la fase inicial se debe realizar un análisis de necesidades, para lo que es importante formar un grupo de trabajo que recoja la información necesaria y elabore los documentos previos. La política del servicio debe ser claramente delimitada, teniendo en cuenta aspectos como la confidencialidad de los datos y los permisos para explotar recursos electrónicos comerciales, así como cuáles serán los destinatarios y qué nivel de servicio se ofrecerá. En este aspecto, hay que definir qué tipo de consultas se atenderán, si sólo serán generales, sobre la biblioteca, si también sobre recursos y colecciones o bien sobre cualquier tema. Asimismo, será necesario acordar cómo será el contenido y la estructura de las respuestas que se ofrezcan. El modelo de organización se debe determinar en función del modelo de biblioteca o de institución, que determinará si se opta por un sistema integrado en el servicio presencial, por un servicio independiente 0 , todo lo contrario, prestado en red ${ }^{350}$. Es importante, dentro de la definición del modelo de organización, determinar las herramientas que se van a emplear, ya que serán los intermediarios entre el usuario y el bibliotecario. Una vez decidido cómo será el servicio, la

\footnotetext{
${ }^{347}$ Un ejemplo es Beard, Jill; Bottomley, Neil; Geeson, Rachel; Spencer, Stuart. ASK: a virtual enquiry desk - a case study. The Electronic Library, 2003, vol. 21, n. 6, p. 601-608. ${ }^{348}$ CREPUQ. Un service de référence virtuelle pour les bibliothèques universitaires québécoises. Montréal: CREPUQ, 2006.

${ }^{349}$ Nguyen, Claire. Mettre en place et développer un service de référence virtuelle dans une perspective d'integration à un réseau collaboratif. Villeurbanne: ENSSIB, 2006, p. 46-70.

${ }^{350}$ Sobre los modelos de colaboración en los servicios de referencia digital es interesante la lectura de Yi, Jin; Min, Huang; Haoming, Lin; Jing, Guo. Study on the collaboration mechanism of the virtual reference service. The Electronic Library, 2007, vol. 25, n. 6, p. 733-740, donde se establecen tres fórmulas de cooperación: las bibliotecas son tratadas como iguales, existencia de un centro coordinador de la red y sistemas híbridos.
} 
siguiente fase será la promoción del mismo y su posterior evaluación, necesaria para modificar las primeras decisiones o para redefinir los objetivos del servicio.

En muchos casos, las políticas se basan en recomendaciones mínimas, que se deben atender para la correcta prestación del servicio. En el capítulo 10 de esta tesis doctoral se analizan las principales normas emanadas de organismos bibliotecarios de referencia internacional. Aún así, existen muchos ejemplos de políticas individuales, como el modelo implantado en la Universidad de Minnesota ${ }^{351}$ o la lista de comprobación (checklist) propuesta por Breznay y Haas $^{352}$, que aparece también en una de las primeras monografías editadas sobre servicios de referencia digitales, Digital Reference Services ${ }^{353}$, coordinada por William Katz. Para estas autoras, si se quiere poner en funcionamiento un servicio de referencia digital hay tener presentes aspectos relacionados con el equipo de trabajo, el software, los horarios de prestación de servicio, el márketing y la evaluación. Algunas aportaciones realizadas en la bibliografía profesional son más prácticas, como la llevada a cabo en la Universidad de Illinois ${ }^{354}$, la del servicio AskUsQuestions ${ }^{355}$ de Ohio o la que presentan Nilsen y Ross ${ }^{356}$, quienes han redactado una relación de pautas para tener en cuenta a la hora de ofrecer servicios de referencia digitales. Se trata de una serie de conclusiones extraídas de la investigación que ambas realizaron con el nombre de The Library Visit Study durante más de una década en la University of Western Ontario. El proyecto se realizó en varias fases y en la última de ellas se analizó la satisfacción de los usuarios en el uso de los servicios de referencia digitales. El grueso de los datos de las sesiones de referencia digital analizadas corresponde al periodo comprendido entre febrero y mayo de 2005. A partir de los resultados obtenidos, las autoras ofrecen una serie de consejos que pueden ser de utilidad para la práctica de los servicios de referencia digitales, que se exponen en las siguientes líneas.

\section{Indicaciones para todo tipo de servicios de referencia digitales}

- Asegurarse de que la tecnología funciona y comprobarlo con frecuencia.

- Facilitar una respuesta automática que asegure a los usuarios que su pregunta se ha recibido.

- Asegurarse de que la página principal de la biblioteca indica que el servicio está disponible. El sitio del servicio de referencia no debe estar a

\footnotetext{
${ }^{351}$ Stemper, James A.; Butler, John T. Developing a model to provide digital reference services. Reference Services Review, 2001, vol. 29, n. 3, p. 172-189.

${ }^{352}$ Breznay, Ann Marie; Haas, Leslie M. A checklist for starting and operating a digital reference desk. The Reference Librarian, 2002-2003, vol. 38, n. 79/80, p. 101-112.

${ }^{353}$ Katz, William A. (ed.). Digital Reference Services. Binghamton, NY: The Haworth Information Press, 2004. Como es habitual en The Haworth Information, ésta monografía recoge el número 79/80 de The Reference Librarian.

${ }^{354}$ Kibbee, Jo; Ward, David; Wei, Ma. Virtual service, real data: results of a pilot study.

Reference Services Review, 2002, vol. 30, n. 1, p. 25-36.

${ }^{355}$ Kloss, Louise; Zhang, Yin. An evaluative case study of a real-time online reference service. The Electronic Library, 2003, vol. 21, n. 6, p. 565-575.

${ }^{356}$ Nilsen, Kirsti; Ross, Catherine Sheldrick. Evaluating Virtual Reference from the Users' Perspective. The Reference Librarian, 2006, no. 95/96, 2006, p. 53-79
} 
más de dos clics de la página principal de bienvenida. Informar a los usuarios del tipo de preguntas que pueden ser respondidas, incluyendo ejemplos.

- No dar por hecho que se trata de usuarios cercanos, que pueden desplazarse fácilmente a la biblioteca para una ayuda adicional, para consultar una obra de referencia o un determinado documento impreso. Esperar preguntas de usuarios que están lejos, incluso cuando se indica que el servicio está limitado para usuarios de la institución.

- Trasladar los buenos comportamientos del servicio presencial de referencia al entorno digital.

- $\quad$ No dar por hecho que la entrevista de referencia es innecesaria.

- Prestar atención a los aspectos comunicativos en la relación con los usuarios mientras dura la consulta.

- Comprobar las URLS a las que se remite y si los sitios web podrán resolver la pregunta del usuario.

- Hacer preguntas que permitan la continuación del proceso.

Indicaciones para los servicios de referencia por correo electrónico

- Proporcionar un formulario que el usuario pueda completar.

- Indicar el plazo en el que una respuesta puede ser entregada.

- Dirigirse al usuario por su nombre y firmar el mensaje de respuesta con el nombre del bibliotecario que elaboró la contestación.

- Tomar especial precaución en hacer el mensaje amistoso.

- Enviar la respuesta a la pregunta en la primera contestación, pero preguntar al usuario si se está respondiendo a la que se había demandado. Animar al usuario a que vuelva a ponerse en contacto con quien redacta la contestación si necesita que se envíe más información o ayuda.

Indicaciones para los servicios de referencia a través de chat

- Indicar las horas en las que el servicio está atendido.

- Tomarse tiempo para clarificar la pregunta. No pensar que la rapidez es más importante que la calidad.

- Dejar que el usuario sepa qué se está haciendo mientras se está trabajando en la pregunta.

- Cuando se envíen páginas web, explicar al usuario qué hacer con ellas.

- Si la comunicación está durando demasiado tiempo, informar al usuario de que se está de acuerdo.

La puesta en funcionamiento de los servicios de referencia digital, paso a paso, se recoge detalladamente en la monografía The AskA Starter Kit: How to Build and Maintain Digital Reference Services ${ }^{357}$. Se trata de un manual que se inscribe en el proyecto Virtual Reference Desk (VRD), del Departamento de Educación de Estados Unidos, que tenía como finalidad crear un sistema nacional cooperativo de referencia para la educación. Se trató de una iniciativa de la Biblioteca Nacional de Educación y del Eric

${ }^{357}$ Lankes, R. David; Kasowtz, Abby S. The AskA starter kit: How to build and maintain digital reference services. Syaracuse, NY: Syracuse University, 1998. 
Clearinghouse on Information and Techonology, que contaba con el apoyo de la White House Office of Science and Technology Policy. El manual constituyó una herramienta para la creación de servicio de referencia (Ask A) en centros educativos, a partir de una política común, ya que se iba a trabajar en red. La metodología propuesta por Lankes y Kasowitz ${ }^{358}$ en el documento anterior, también recogida en otros textos y autores, como Wasik ${ }^{359}$, integrante de la plantilla del VRD, se organiza en torno a seis pasos:

1. Información: recogida de datos

2. Planificación: desarrollo del servicio

3. Formación:

4. Prototipo:

5. Contribución: programas de capacitación fase experimental del servicio

6. Evaluación: análisis de la calidad del servicio

El objetivo de la primera fase es recopilar información general relacionada con los servicios de referencia digital; se trata de poder definir qué se entiende por referencia digital, identificando tendencias, características y usuarios potenciales. En el segundo módulo de esta metodología se deberá establecer un plan de creación del servicio de referencia digital deseado, determinando la mejor manera para ponerlo en marcha y mantenerlo. Para ello, se establecerán los objetivos del servicio y los agentes que intervendrán en su estructura, tanto internos como externos. La formación del personal que atenderá el servicio es esencial para el correcto funcionamiento del mismo, por lo que se deberá planificar también un programa de capacitación, aspectos analizados en el siguiente bloque de esta metodología, a los que se dedican bastantes recursos, ofreciendo técnicas y ejemplos para alcanzar las competencias específicas de los bibliotecarios de la referencia digital ${ }^{360}$. Llevar a cabo una fase piloto, de forma experimental, es otra iniciativa recomendada por el manual del VRD; se trata de identificar los elementos comunes en los procesos, estableciendo las tendencias en los tipos y contenidos de las consultas y revisando las políticas iniciales ${ }^{361}$. En esta etapa, es esencial el rendimiento de las aplicaciones informáticas elegidas, ya que es el momento de analizar su calidad antes de su implantación definitiva. La fase quinta consiste en la prestación del servicio de forma abierta, que tiene que ir precedida de una campaña de difusión en la que se publicite la existencia del servicio. En esta etapa se debe consolidar el

\footnotetext{
${ }^{358}$ Esta autora también es responsable de las pautas para referencistas de servicios digitales orientados a niños: Kasowitz, Abby S. Guidelines for Information Specialists of $K$ 12 Digital Reference Services. Syracuse, NY: Virtual Reference Desk, 1998.

${ }^{359}$ Wasik, Joann M. Building and Maintaining Digital Reference Services. Syracuse, NY: ERIC Clearinghouse on Information and Technology, 1999.

${ }^{360}$ Ellis y Francoeur estudian la normalización de las competencias inforrmacionales en la referencia digital. Véase Ellis, Lisa; Francoeur, Stephen. Applying Information Competency to Digital Reference. En IFLA General Conference and Council (67. 2001. Boston). Boston: IFLA, 2001. Disponible en http://www.ifla.org/IV/ifla67/papers/057-98e.pdf [consultado el 17/07/2007].

${ }^{361}$ Los servicios de referencia digital pueden encontrarse con algunos problemas relativos a sus usuarios. Una categorización de los mismos ha sido realizada por Borin, Jacqueline. EProblems, E-Solutions: electronic reference and the problem patron in the academic library. The Reference Librarian, 2002, vol. 36, n. 75-76, p. 149-162.
} 
servicio, aprendiendo de la experiencia cotidiana y buscando posibles aliados para conseguir un espectro más amplio de usuarios y mayores recursos de información. El módulo final de esta metodología está dedicado a la evaluación. Es necesario medir la efectividad y la eficiencia del servicio de referencia digital, por lo que se debe establecer un plan de evaluación por áreas, estableciendo qué normas se emplearán y por qué métodos se obtendrá la información. El manual del VRD es uno de los primeros, ya que se trata de un servicio pionero en el mundo, que sigue siendo válido como punto de partida y herramienta de apoyo para cualquier biblioteca que quiera poner en marcha un servicio de este tipo o que quiera evaluar su experiencia $^{362}$.

El centro británico de expertos en gestión de la información digital UKOLN encargó un informe a Linda Berube sobre el estado de la cuestión y las tendencias de la referencia digital. Berube ha sido y es responsable de servicios públicos de referencia digital en el Reino Unido, como el desparecido Ask a librarian o el actual Enquire. En su informe ${ }^{363}$, Berube realiza un rápido repaso por la terminología, los modelos de servicio y los aspectos más relevantes para las bibliotecas públicas. Es interesante su relación de recomendaciones para la planificación de un servicio de referencia digital, que se reproduce a continuación, dada la excelente síntesis que se realiza, al recoger todos los puntos de análisis previos a la creación de un servicio bibliotecario de consulta en línea. Berube sintetiza en los siguientes elementos los aspectos que hay que tener en cuenta para la puesta marcha de los servicios de referencia digital:

- Localización física del servicio (en un área de servicios públicos; en una área de colecciones especiales; en una oficina; próximo a los recurso impresos, etc.)

- Localización del servicio virtual (espacio del servidor; proveedor de servicios de Internet, etc.)

- Formación en técnicas web avanzadas, entrevista de referencia y procedimientos

- Conocimientos de programación y web (diseño web, gestión de bases de datos, etc.)

- Gestión y coordinación del servicio (quién hace qué cuándo)

- Plazo de entrega para las consultas (las preguntas serán respondidas en uno/dos días, una semana, etc.)

- Control de calidad (normas básicas para consultas de investigación, tipos de fuentes usadas, estructura de las respuestas, remisión a otros recursos o servicios, etc.)

- Destinatarios del servicio (disponible para usuarios de una biblioteca local o para cualquiera)

- Recogida de datos para la evaluación

- Promoción del servicio

${ }^{362}$ La versión íntegra del manual puede descargarse desde: http://www.webjunction.org, comunidad profesional que está actuando como repositorio de los documentos generados en el proyecto Virtual Reference Desk.

${ }_{363}$ Berube, Linda. Digital Reference Overview. Bath: UKOLN, Networked Services Policy Task Group, 2003. 
- Hardware y software (ordenador, impresora, escáner, cliente de correo, formulario web, software de chat, sistema de autenticación, etc.)

- Equipamiento adicional (cámara web, equipo de vídeo, etc.)

- Mobiliario

Los aspectos que se deben tener en cuenta para iniciar y mantener un servicio de referencia digital coinciden en un alto porcentaje con las circunstancias que rodean la toma de decisiones de cualquier servicio bibliotecario. En el apartado 2.1. de esta tesis doctoral se realizó un esquema de los elementos que intervienen en cualquier sección de información de una biblioteca: agentes (bibliotecarios, usuarios), técnicas (sistemas de comunicación, proceso de referencia), recursos (colección de referencia, productos informativos) y gestión (diseño, planificación, administración, evaluación). Estos mismos elementos sirven de partida para la organización de los servicios de referencia digitales y son los que se emplean a continuación para resumir los principales aspectos que se deben tener en cuenta en la referencia digital, que se presentan aquí como una lista de recomendaciones.

\section{AGENTES}

\section{Bibliotecarios}

1. El personal responsable de la referencia digital debe tener una formación biblioteconómica sólida, superior a la necesaria en otras secciones de la biblioteca, que debe estar en continuo reciclaje.

2. Las competencias de los bibliotecarios de la referencia digital deben abarcar aspectos comunicativos, tecnológicos e informacionales.

3. La especialización de los profesionales en disciplinas o recursos específicos aumenta la calidad del servicio.

4. El bibliotecario es un intermediario entre el usuario y la información, por lo que debe conocer dónde está y cómo se accede a la misma.

5. Se deben establecer niveles de responsabilidad, estableciendo quien tiene la autoridad para confirmar la calidad de las respuestas.

6. El bibliotecario referencista debe estar integrado en el colectivo profesional, participando en sus foros y difundiendo su experiencia en publicaciones y reuniones científicas.

\section{Usuarios}

7. La biblioteca deberá decidir a qué usuarios permite el uso de sus servicios de referencia por procedimientos remotos. 
8. Si se limita el servicio de referencia digital a usuarios específicos se deben elegir sistemas sencillos de autenticación y autorización.

9. Los usuarios que no se atiendan porque se excluyan en la política del servicio deben ser remitidos a los servicios de referencia digitales disponibles.

10. Es conveniente recoger algunos datos básicos del usuario que ayuden a ofrecer una respuesta más ajustada a sus necesidades, tales como finalidad de la consulta, edad o lugar de residencia.

11. Se debe articular un sistema de quejas y sugerencias, para recoger las opiniones de los usuarios.

\section{TÉCNICAS}

\section{Sistemas de comunicación}

12. La elección del sistema de recepción de consultas y envío de respuestas debe tener en cuenta la disponibilidad del personal de la biblioteca.

13. El servicio se presentará mediante sistemas sincrónicos, asincrónicos o mixtos que permitan un uso generalizado del mismo, a través de aplicaciones comunes y que cumplan los estándares básicos

14. Los programas informáticos de gestión global de las transacciones de referencia digital son una solución eficaz, por lo que es recomendable la adquisición de un producto comercial, el diseño de una aplicación o la elaboración de una interfaz integral.

15. La conavegación es la mejor herramienta para mostrar en tiempo real la información que puede ser útil al usuario y conseguir resultados satisfactorios de forma inmediata.

Proceso de referencia

16. El referencista debe mostrar actitud amable, de servicio público, así como predisposición para informar. Un usuario mal atendido es un usuario perdido.

17. Se debe transmitir en la entrevista de referencia que se está siendo atendido por profesionales de la información.

18. Se debe marcar una norma sobre la duración de las entrevistas en tiempo real. La referencia sincrónica puede continuarse de forma asíncrona.

19. Se debe tener un archivo de mensajes preescritos, para incluir ante situaciones o consultas similares y para ofrecer instrucción de forma ágil y meditada. 
20. La comunicación debe ser fluida, informando al usuario de las operaciones que se están realizando y empleando un lenguaje que evite los tecnicismos.

21. Todas las consultas tienen que tener una respuesta.

\section{RECURSOS}

\section{Colección de referencia}

22. La colección física es muy útil para la referencia digital, por lo que sus responsables deben tener fácil acceso a la misma.

23. Internet es una excelente herramienta para los bibliotecarios de la referencia digital, por lo que deben conocer detalladamente su potencial, incluyendo nociones de programación web.

24. Se deben emplear técnicas avanzadas de recuperación, extensiones de los navegadores y programas específicos de búsqueda de datos.

25. Se debe disponer de una red de colaboración, formal o informal, que se empleará como recurso de información.

26. Se debe remitir al usuario a las fuentes, instituciones o personas adecuadas cuando la biblioteca no tenga la respuesta.

\section{Productos informativos}

27. La biblioteca debe ser productora de información. Selecciones de recursos, guías informativas, tutoriales, boletines, alertas, etc. deben ser elaborados por los servicios de información.

28. Se deben poner a disposición del usuario ejemplos de consultas, tanto para indicar el tipo de cuestiones que se atienden, como para orientar sobre la estructura idónea de una pregunta.

29. Las respuestas ofrecidas por el servicio son una buena base de datos de conocimientos, por lo que deben emplearse y difundirse en el sitio web de la biblioteca, eliminando la información personal.

\section{GESTIÓN}

\section{Diseño}

30. El servicio de referencia digital debe tener un espacio adecuado, con un mobiliario que contemple las cuestiones de ergonomía que requiere el trabajo de referencia digital. 
31. Los servicios que ofrezcan la posibilidad de realizar la entrevista de referencia con imagen y sonido requieren condiciones espaciales específicas para esta actividad.

32. El equipamiento informático y los dispositivos periféricos deben estar interconectados y cercanos, para permitir realizar todas las operaciones sin desplazamientos.

33. Las redes de telecomunicaciones empleadas en el servicio de referencia digital deben ser consistentes, seguras y rápidas.

\section{Planificación}

34. Se deben planificar servicios sostenibles a medio y largo plazo.

35. El servicio de referencia digital debe integrarse en la política general del centro y la entidad, aunque deberá tener una política específica, que se aprobará en función de la orientación que se quiera dar al mismo.

36. El servicio de referencia digital debe ofrecer, difundir y cumplir una política específica de privacidad y salvaguarda de la propiedad intelectual e industrial.

37. Se debe establecer un modelo claro de servicio de referencia digital, como parte del servicio presencial, como una unidad independiente de la biblioteca, como un servicio de apoyo o como miembro de un sistema cooperativo.

38. Se deben redactar manuales de procedimientos para todas las áreas de trabajo del servicio de referencia digital.

39. Se deben establecer los niveles de información que se atenderán: básica sobre la biblioteca, orientación e instrucción sobre servicios y recursos, información factual general o específica, investigación bibliográfica y documental.

40. Se debe establecer el modelo de respuesta: sistema de identificación, estilo, respuesta u orientación, inclusión de fuentes.

41. Se debe determinar la política de suministro de documentos, especificando si se enviarán archivos, de qué tipos, por qué medios y en qué condiciones.

42. Se deben planificar y poner en práctica actividades de promoción y difusión del servicio.

\section{Administración}

43. El servicio de referencia digital debe estructurarse en un organigrama en el que se definan jerarquía, responsabilidades, funciones y tareas. 
44. El servicio debe organizarse mediante un sistema de turnos y de asignación de consultas, que tendrá en cuenta la frecuencia de la renovación y los descansos en función del tipo de atención que presten a los usuarios, en tiempo real o en diferido.

45. Los horarios de atención de servicios y los plazos de entrega de respuestas deben ser acordados en función de las posibilidades de la biblioteca y comunicados a los usuarios potenciales a través del sitio web del servicio.

46. Se debe disponer de una partida presupuestaria específica, que se empleará para el mantenimiento de la actividad, renovación de equipos, acceso a recursos de información y necesidades de servicios externos.

\section{Evaluación}

47. Se debe establecer qué datos es necesario recoger para su posterior análisis.

48. Se deben establecer métodos cuantitativos y cualitativos de evaluación del servicio.

49. Se deben analizar el funcionamiento del servicio, las capacidades de los profesionales, la utilidad de los recursos empleados para la referencia y la calidad de las informaciones facilitadas.

50. Se redactarán informes periódicos del servicio de referencia digital, que se emplearán como documentos informativos y para la toma de decisiones.

\subsection{Competencias profesionales para la referencia digital}

El personal que atiende los servicios de referencia digital se ha convertido en el verdadero artífice del éxito de estos servicios. De nada servirán los proyectos bien delimitados, documentados, reflexionados y presupuestados si las capacidades de los bibliotecarios referencistas no son las que se esperan de ellos. Al perfil tradicional del bibliotecario del servicio de referencia, que se vio en el apartado 3.1., se le añaden una serie de conocimientos y habilidades que hace aún mucho más especializado este puesto de trabajo.

El bibliotecario referencista debe estar preparado en fuentes de información, sistemas de recuperación, técnicas de comunicación y tecnologías digitales, toda una suma de conocimientos que requieren una capacitación inicial sólida y una formación constante. 
La revista The Reference Librarian dedicó uno de sus números de 1999, también editado como monografía ${ }^{364}$, a reflexionar sobre la evolución de los servicios de referencia. En una de las colaboraciones, Nofsinger ${ }^{365}$ disertaba sobre los cambios futuros en los servicios de referencia, que continuarían a los que habían experimentado en las dos últimas décadas, debido a la aparición de las tecnologías. Para la autora, el paradigma habitual de los servicios de referencia en los años 80 estaba marcado por las técnicas de la entrevista de referencia, la ayuda informativa, empleado principalmente recursos impresos, el desarrollo de colecciones por especialistas en diferentes materias, la formación de usuarios y ocasionalmente la intermediación en búsquedas en bases de datos. En los años 90 comienzan los cambios, con la penetración de los ordenadores y la automatización, así como con la aparición de nuevos recursos de información en línea y en cederrón. Desde entonces, los profesionales de la información, especialmente los referencistas, han tenido que adquirir nuevas competencias, como el desarrollo de habilidades interpersonales y de comunicación, destrezas en tecnología, técnicas de pensamiento analítico y sintético o capacidades de gestión y supervisión. El futuro, para esta autora, pasa por el desarrollo de excelentes habilidades de comunicación, sólidos servicios de orientación y una intensiva formación y "reformación".

Diane Kovacs, recoge en su The virtual reference handbook ${ }^{366}$, unas de las últimas monografías editadas sobre referencia digital, una amplia relación descriptiva de las competencias que se deben poseer para el trabajo de la referencia digital. Esta autora de prestigio consolidado ha sistematizado en tres grandes bloques las técnicas que debe dominar un bibliotecario que presta servicio de referencia a través de chat, mensajería instantánea o correo electrónico. Para ella, las competencias se distribuyen entre habilidades técnicas, de comunicación y de referencia. Las destrezas técnicas están relacionadas con los conocimientos y habilidades necesarios en tecnologías, tanto sobre el funcionamiento de equipos como de los programas necesarios para poner en marcha y desarrollar un servicio de referencia digital. Las competencias comunicativas se refieren a las técnicas que se deberán emplear para el intercambio de mensajes con el usuario, tanto para el proceso de referencia, como para conseguir que la comunicación sea fluida, ágil y precisa. Por último, las competencias de referencia hacen alusión a todos los conocimientos necesarios para la localización de información, desde el manejo fluido de las fuentes hasta los sistemas de recuperación específicos. Los siguientes párrafos están basados en la mencionada obra ${ }^{367}$, extrayendo de la misma las diferentes

364 Zlatos, Christy (ed.). Coming of age in reference services: a case history of the Washington State University Libraries. Binghamton, NY: The Haworth Information Press, 1999.

365 Nofsinger, Mary M. Training and Retraining Reference Professsionals: Core Competencies for the 21st Century. The Reference Librarian, 1999, n. 64, p. 9-19.

${ }^{366}$ Kovacs, Diane $\mathrm{K}$. The virtual reference handbook: interview and information delivery techniques for the chat and e-mail environments. London: Facet, 2007. Existe otra edición, la original estadounidense, publicada en New York: Neal-Schumann, 2007.

${ }^{367}$ La relación de competencias y las observaciones que se realizan de las mismas son traducción libre del doctorando, quien asimismo describe de forma resumida contenidos de esta monografía. 
competencias que estima necesarias para los responsables de los servicios de referencia digital. Su relación de competencias sirve, asimismo, para comprobar el nivel de formación de los referencistas ${ }^{368}$.

\section{A/ Competencias técnicas}

Adquirir y profundizar en habilidades y conocimientos técnicos para la referencia digital es el primera bloque de competencias que reúne Kovacs, todas relacionadas con las destrezas necesarias en el uso de ordenadores, periféricos y aplicaciones informáticas. El bibliotecario referencista debe ser un experto en el hardware y el software que se maneja en los entornos de la referencia digital y que esta autora describe en esta relación de conocimientos. Las competencias técnicas son las siguientes:

A.1. Habilidad para escribir en el teclado de un ordenador y hacer uso de otros dispositivos relacionados, como el ratón tradicional o derivados del mismo, como el trackball (ratón de bola) o el touchpad (alfombra táctil). Es necesario disponer de soltura en el manejo de estas herramientas, ya que el personal tiene que trabajar en situaciones en las que se debe atender de forma rápida a cada usuario.

A.2. Habilidad para trabajar de forma simultánea con varias aplicaciones, teniendo varias ventanas abiertas y realizando a la vez distintas actividades: conversación con chat, búsquedas en documentos impresos y fuentes electrónicas, etc. El referencista digital debe ser capaz de trabajar en situaciones multitarea.

A.3. Conocimiento funcional avanzado de cómo acceder a Internet, usar el correo electrónico y conectarse a sitios web. Se trata de una competencia obvia, ya que sin saber trabajar con Internet no se puede desempeñar la referencia digital.

A.4. Conocimiento funcional avanzado de al menos un navegador web. El referencista debe conocer de forma detallada las posibilidades y la configuración del navegador que se emplee en el trabajo de referencia digital. En muchos casos, se deberá guiar al usuario por las opciones del navegador, por lo que es preciso conocerlas bien.

A.5. Conocimiento demostrado de las tecnologías básicas que puedan ser empleadas por un usuario del servicio de referencia digital. Las condiciones de acceso de un usuario o sus grados de instrucción variarán considerablemente, por lo que el personal debe estar familiarizado con las tecnologías para orientar al usuario en el proceso de la referencia.

\footnotetext{
${ }^{368}$ En este tema es también interesante la lectura de Chandler, quien analiza las tendencias en formación de profesionales bibliotecarios, en especial la necesaria en los referencistas. Véase Chandler, Yvonne J. Reference in library and information science education. Library trends, 2001, vol. 50, n. 2, p. 245-262.
} 
A.6. Conocimiento demostrado de las aplicaciones de chat específicas que se empleen. La formación del referencista digital pasa por el aprendizaje de los programas más empleados para la conversación por Internet, por lo que es recomendable la consulta a los manuales u opciones de ayuda de los mismos. El conocimiento del software de chat por el que se opte en la biblioteca debe ser completo.

A.7. Conocimiento demostrado de cómo conectarse y conversar con software de chat basado en web, mensajería instantánea, etc. Se trata, sobre todo, de saber manejar los programas de mensajería instantánea, de conversación en tiempo real, ya que es una modalidad de referencia digital sincrónica que se presta con frecuencia en las bibliotecas.

A.8. Conocimiento demostrado de las posibilidades para suministrar documentos o información. Los formatos de envío de documentos en la referencia digital no son iguales que en la presencial. Las secciones de referencia en línea de las bibliotecas envían los documentos por fax, como adjuntos de correo electrónico, transferencia de ficheros 0 mediante sistemas de archivos compartidos.

A.9. Conocimiento demostrado de la forma de envío de archivos adjuntos a través de correo electrónico. Se trata de un proceso simple, pero que requiere atención y un sistema organizado para el almacenamiento local y la transmisión de los documentos. El personal referencista debe saber cómo hacerlo y cómo archivar la información enviada.

A.10.Conocimiento demostrado de los sistemas de transferencia de ficheros, ya sea mediante mensajería instantánea, como por FTP o colocando la información en web. En función del sistema de chat o de correo electrónico que se emplee para la referencia digital se debe conocer las funciones específicas para el envío directo de los documentos a los usuarios. Si se utilizan sistemas más avanzados para transferir o compartir ficheros, los conocimientos deberán cubrir también estos aspectos.

A.11.Conocimiento demostrado de los tipos de formatos de ordenador comunes. Los responsables de los servicios de referencia digital de una biblioteca manejarán diferentes formatos de texto, imagen, audio, vídeo, compresión, etc., por lo que es necesario que se identifiquen con precisión los mismos. Posiblemente, en ocasiones se encuentren con formatos especiales, por lo que se deben conocer las fuentes de consulta que permitan su descripción.

A.12.Conocimiento demostrado del sistema empleado para el correo electrónico y sus limitaciones. Es necesario evitar problemas que pueden surgir con el programa que se va a usar para el correo electrónico, como son tamaño de mensajes y de archivos adjuntos, filtros antispam, formatos de archivo que soporta, etc. Cada aplicación de correo es diferente, por lo que hay que conocer bien las 
posibilidades y la configuración de la que se vaya a emplear para el servicio de referencia digital.

A.13. Conocimiento demostrado de otros sistemas de correo electrónico y sus limitaciones. Es importante conocer el funcionamiento de otros programas de correo distintos al que emplee la biblioteca, ya que los usuarios los emplearán y, al saber cómo funcionan, la biblioteca puede orientar al usuario en posibles problemas. En ocasiones, el personal será quien tenga que indicar al usuario qué debe hacer con su propio ordenador para recibir documentos, para descargar archivos 0 cualquier otra acción derivada de su consulta.

A.14.Conocimiento demostrado de las opciones de descarga, instalación y uso de barras de herramientas, motores de búsqueda, plug-ins y otras extensiones de ayuda para el navegador. Los navegadores ofrecen en la actualidad diferentes posibilidades para la búsqueda en fuentes de información concretas; los sistemas son diversos, por lo general barras de búsqueda, extensiones o formularios. Es muy útil que los referencistas conozcan y empleen estas posibilidades.

A.15. Habilidad para usar un escáner, digitalizar documentos impresos, enviarlos por fax y/o guardarlos para su envío, como adjuntos de un correo electrónico o por transferencia de ficheros, por ejemplo. El escáner es un dispositivo esencial del servicio de referencia digital, por lo que será imprescindible saber manejar el programa de digitalización instalado y las posibilidades que presenta para guardar o enviar directamente el documento escaneado.

\section{B/ Competencias comunicativas}

Poseer, poner en práctica y desarrollar conocimientos y habilidades de comunicación es otro de los grandes apartados en los que se pueden agrupar las competencias de los profesionales de la referencia digital. Los responsables de la referencia en línea tienen que poseer las mismas habilidades comunicativas que quienes ejercen la referencia presencial, pero existen algunas destrezas que tienen que sumarse a las habituales en la referencia digital, ya que en ésta no existe la comunicación no verbal, además de necesitarse técnicas que permitan un contacto fluido en el que la distancia sea suplida por un trato idéntico al que se ofrecería en persona ${ }^{369}$. En esta ocasión Kovacs no pretende ofrecer un listado exhaustivo de competencias, sino que reúne aquellas que considera más importantes, basándose en su experiencia y de sus investigaciones sobre entrevistas de referencia. En este bloque, la autora señala una docena de habilidades y conocimientos que deben demostrar los referencistas digitales. Las competencias comunicativas son las que se exponen a continuación:

\footnotetext{
${ }^{369}$ Buckley alude a la "regla de oro" para aumentar la calidad en el trato con los usuarios. Se trata de un principio ético basado en tratar a las personas como le gustaría ser tratado a uno mismo. Según este autor las relaciones con los usuarios mejorarían si se aplica esta regla habitual en culturas y religiones. Véase: Buckley, Chad E. Golden rule reference: Face-toface and virtual. The Reference Librarian, 2006, n. 93, p. 129-136.
} 
B.1. Habilidad y conocimiento de las necesidades de formación continua en cuestiones técnicas, comunicativas y de referencia. El bibliotecario debe estar formándose de forma permanente. Es necesario adaptarse a los cambios generados por la industria de la información, la infraestructura técnica y los dinámicos cambios sociales. Reconocer la necesidad del aprendizaje permanente y poner en práctica programas de formación continua, son características del personal que trabaja en referencia digital.

B.2. Conocimiento y comprensión de las habilidades para la correcta entrevista de referencia y de las técnicas para el servicio de referencia digital. La práctica, experiencia, observación de referencistas expertos y atención a los retos específicos del chat y la comunicación por correo electrónico son las estrategias más eficaces para la formación de bibliotecarios que atienden los servicios de referencia digital.

B.3. Habilidad para identificarse con los usuarios de la referencia digital mientras sucede la entrevista de referencia y para comprender los aspectos de la cultura y el entorno social de Internet. El bibliotecario debe conseguir la empatía del usuario, lo que no se consigue tecleando más rápido, sino haciendo sentir al usuario que se está presente, que la conversación es real. Además, el personal referencista debe saber situarse en el entorno de Internet, donde las relaciones no son exactamente igual que en las comunicaciones físicas.

B.4. Habilidad para explicar los procesos y técnicas bibliotecarias sin emplear la jerga profesional. La terminología bibliotecaria debe ser evitada para conseguir comunicaciones claras y concisas, así como para asegurarse de que los usuarios comprenden la ayuda que se les facilita y hagan uso de ella. Hay que recordar que los principales destinatarios de las bibliotecas, los usuarios, no entienden el vocabulario bibliotecario.

B.5. Estar convencido de la necesidad de identificarse y proyectarse como un profesional y como parte de la contribución de la biblioteca a la comunidad de Internet (el espacio de la biblioteca en la web). Las bibliotecas deben promover la creación de una cultura web bibliotecaria; los bibliotecarios cumplen una función como profesionales de la información y así deben actuar. De igual forma que los bibliotecarios forman parte de la red social para la que trabajan de forma presencial, asimismo, deben integrarse en la estructura de base de la web.

B.6. Habilidad para proveer información sin hacer juicios de valor, manteniendo y demostrando objetividad profesional. Es posible que el usuario no quiera facilitar la información necesaria para poder responder satisfactoriamente, ante lo que se deberá ser educado e intentar reconducir la entrevista hacia la oferta de orientación en los recursos que puedan ser útiles al usuario. En otras ocasiones, el personal se encuentra con que el usuario no tiene la información 
necesaria, comparte información personal o se encuentra incómodo en la entrevista. En todos los casos, se debe actuar de manera educada, objetiva y profesional.

B.7. Habilidad para leer rápida y cuidadosamente el texto escrito por el usuario y visualizarlo en la pantalla del ordenador, comunicando al usuario que se está "escuchando". Es importante mostrar la presencia del personal bibliotecario en la entrevista, enviando mensajes breves o emoticonos mientras se comprende la consulta y respondiendo cuando se está seguro de haber entendido la cuestión. Es útil emplear textos preescritos $^{370}$, que muchos programas de chat permiten almacenar. Hay que intentar evitar algunos problemas, como la sensación de que no se está trabajando en los momentos de ausencia de mensajes, malos entendidos en el tema de consulta o el uso de lenguaje que no se entienda.

B.8. Comprender la necesidad y la habilidad de "estar aquí" para el usuario de la referencia virtual, evitando "silencios". Para Kovacs, la estrategia de comunicación más importante es mantener la comunicación, informando en todo momento de lo que se está haciendo y diciéndole al usuario cómo actuar. Siempre se deberá comunicar que se están abriendo o enviando páginas (conavegación). Si no es así, los usuarios no sabrán qué se está haciendo o qué se va a hacer. Manifestar la presencia y verificar al usuario que se está comprendiendo es esencial en la referencia digital.

B.9. Comprender cuándo y en qué se debe instruir al usuario en una entrevista de referencia digital. Habitualmente, los bibliotecarios referencistas disponen de recursos seleccionados y preparados para consultar; de igual forma, tienen preparadas diferentes explicaciones de los mismos para presentar de forma sencilla a los usuarios. Pero se debe distinguir cuándo el usuario puede necesitar explicación de cuándo se quiere únicamente una respuesta. Lo más adecuado será preguntar al usuario si desea o no que se le expliqué cómo consultar determinada fuente de información.

B.10. Conocimiento demostrado de cuándo y cómo ofrecer continuación de la consulta, reenvíos o consultas a otros profesionales. En la entrevista de referencia puede ocurrir que la consulta requiera más tiempo y dedicación de lo habitual, por lo que se deberá ofrecer más información por otras vías, como el correo electrónico. Por tanto, la consulta continuará por medios asíncronos. En ocasiones, la mejor respuesta es enviar al usuario a la persona o servicio adecuados; en ese caso, se debe explicar claramente a quien se remite y por qué. Una buena manera de conseguir la respuesta a una consulta, es compartiéndola con otros profesionales, ya sea particularmente o a través de foros.

\footnotetext{
${ }^{370}$ Falcato ha realizado un estudio sobre los mensajes que es conveniente tener redactados para una mayor fluidez en el servicio de referencia digital. Véase Falcato, Pedro. Sistema de ayuda para la redacción de mensajes en un servicio de referencia por correo electrónico. Información, cultura y sociedad, 2005, n. 13, p. 11-28.
} 
B.11. Habilidad para trabajar con varios usuarios en un único entorno de referencia digital. El personal responsable de la referencia digital puede encontrarse con varios usuarios que realizan sus peticiones al mismo tiempo o con una pregunta que aparece mientras se está dentro del proceso de resolución de otra consulta. Se deberá disponer de técnicas y recursos para informar al nuevo usuario de que se está presente y de que se le atenderá rápidamente.

B.12.Conocimientos funcionales para teclear rápida y fluidamente en el teclado de un ordenador con el objetivo de comunicarse, es decir, teclear con soltura. Esta competencia tiene que ver con las tecnológicas, pero en este caso se trata no sólo de velocidad, sino de saber emplear técnicas de abreviación, símbolos y otros elementos habituales en el chat, como los «emoticonos».

\section{$\mathrm{Cl}$ Competencias en referencia}

Estrechamente unidas a las competencias comunicativas están las habilidades necesarias para trabajar con información, saber seleccionar los recursos, emplear los sistemas específicos de consulta de las diferentes fuentes, utilizar sistemas de búsqueda, extraer de forma crítica los contenidos adecuados a la consulta que se está resolviendo, etc.; es decir, realizar el trabajo de referencia de forma conveniente. Un bibliotecario referencista competente debe saber cómo está organizada la colección de la biblioteca, cómo identificar y localizar información, cómo navegar, buscar y extraer información en cualquier fuente, cómo, dónde y quién almacena determinada información, qué información está accesible y bajo qué términos, costes, restricciones, formatos y otras condiciones de acceso a la información que pueda ser necesaria. Como en el bloque anterior, Kovacs no ofrece una relación exhaustiva de competencias relacionadas con el ejercicio de la referencia, sino una lista selectiva, que también se resume en las líneas siguientes, dado que se trata de un acertado conjunto de capacidades que debe demostrar un profesional de la referencia digital. Seguidamente, se detallan las competencias en referencia:

C.1. Capacidad para ser accesible, para mantener y transmitir una actitud acogedora y predispuesta para prestar el servicio de referencia, a través de comunicaciones basadas en texto. Hacer sentir al usuario que es bienvenido al servicio de referencia digital es tarea del personal referencista.

C.2. Demostrar el conocimiento y ser capaz de aplicar las políticas de la organización pertinentes para un usuario específico del servicio de referencia digital. Se trata de establecer los límites adecuados en función de los perfiles marcados para el uso del servicio y para la información que se puede facilitar.

C.3. Conocimiento funcional detallado de las fuentes de referencia rápida, tales como enciclopedias, almanaques, índices, bibliografías y las principales obras de referencia impresas y electrónicas. 
C.4. Demostrar el conocimiento de las mejores o principales fuentes de referencia disponibles en formato impreso y electrónico y el tipo de recursos de información que pueden ser usados para ofrecer servicios de referencia en temas especializados y la referencia general.

C.5. Capacidad para conducir de forma adecuada las entrevistas de referencia y analizar preguntas, empleando los conocimientos de las formas de organización y acceso a la información de las fuentes impresas y digitales.

C.6. Demostrar el conocimiento de la necesidad y la capacidad de evaluar los recursos de información, en función del nivel, alcance y forma apropiados para un usuario concreto.

C.7. Capacidad para desarrollar estrategias de búsqueda efectivas, empleando palabras clave y búsquedas booleanas en catálogos de bibliotecas, bases de datos comerciales y buscadores de Internet, así como conocer cuándo usar las opciones avanzadas de búsqueda.

C.8. Conocimiento demostrado del alcance y las limitaciones de los motores de búsqueda en la web.

C.9. Habilidad para llevar a cabo búsquedas avanzadas en al menos uno de los principales motores de búsqueda de Internet.

C.10. Conocimiento demostrado del alcance y limitaciones de las fuentes, así como capacidad para usar los recursos de referencia web gratuitos.

C.11. Conocimiento demostrado de la necesidad de evaluar la información web de calidad y ser capaz de hacerlo, siendo críticos con las fuentes de información.

C.12. Conocimiento demostrado de las bases de datos de pago 0 contratadas accesibles para el personal referencista y para los usuarios del servicio de referencia.

C.13. Conocimiento demostrado de cómo y dónde buscar información en la colección local en recursos impresos y electrónicos.

C.14. Conocimiento demostrado de cuándo y dónde buscar en catálogos de otras bibliotecas y organismos bibliotecarios.

C.15. Conocimiento demostrado de las posibilidades disponibles para remitir a un usuario a las personas o entidades pertinentes. 


\subsection{Servicios públicos de referencia digital}

Una vez examinados los diferentes tipos de servicios de referencia digital, la tecnología que se puede emplear para su gestión, los aspectos que se deben tener en cuenta para la planificación de estos servicios y las competencias específicas de los referencistas, aspectos que se han ido describiendo en apartados anteriores, es el momento de enfocar esta investigación hacia los servicios públicos de referencia digital, los cuales se definirán y describirán en el presente apartado y sobre cuya evaluación se tratará en el capítulo 11. Hay que tener presente que los servicios públicos de referencia digital son muy especiales, ya que no se ajustan a las mismas condiciones que los que prestan bibliotecas concretas, al tratarse de servicios para toda la ciudadanía, por tanto, abiertos, y que suelen ser atendidos de forma descentralizada, de manera distribuida implicando a personal de diferentes centros bibliotecarios. La calidad de su trabajo, motivo de esta tesis doctoral, requiere metodologías de análisis específicas, como se comprobará en el capítulo dedicado a la evaluación de los servicios de referencia digital. No se puede evaluar un servicio con usuarios no identificados y atendido por personal de diferentes centros, de la misma manera que se analiza la calidad de un servicio concreto, que atiende a usuarios específicos y que está prestado por personal de la misma organización. Por eso, se han querido dar ciertas indicaciones de cómo se deben evaluar este tipo de servicios bibliotecarios de referencia, además de poner en práctica la metodología de evaluación propuesta por el doctorando.

Son escasos los documentos en los que se hayan estudiado los servicios de referencia que los gobiernos nacionales ofrecen a los ciudadanos de un país. Desde hace tiempo, éste es un tema de interés para el doctorando, quien ha publicado sendos artículos ${ }^{371}$ en los que se recogían y comentaban los servicios públicos de referencia digital existentes en el mundo. Hay que entender como servicios públicos de referencia digital los servicios de consulta que se prestan de forma gratuita a través de Internet y que son atendidos por organismos bibliotecarios públicos. En los siguientes párrafos se toma como punto de partida la información que se ha ido reuniendo y difundiendo y se ha realizado una exhaustiva actualización, consiguiendo reunir datos y cifras que no se presentan en ninguna otra fuente de información, con la intención de poder ofrecer una panorámica actual acerca de qué países disponen de este tipo de servicios de referencia y de qué forma los prestan.

Para la realización de esta sección ha sido esencial la colaboración del personal de cada uno de los servicios descritos, a quienes se ha interrogado y con los que se ha mantenido y se mantiene una fluida relación profesional para el intercambio conjunto de información. Gracias a la tesis, se ha creado

\footnotetext{
${ }^{371}$ Merlo Vega, José Antonio; Sorli Rojo, Ángela. Pregunte a un bibliotecario: servicios de referencia en línea. Revista Española de Documentación Científica, enero-marzo 2003, vol. 26, n. 1, p. 91-101. Disponible también en línea <http://www.cindoc.csic.es/redc/redc.html>. Merlo Vega, José Antonio. Servicios públicos de referencia en línea. BiD: textos universitaris de Biblioteconomia i Documentació [en línea], jun. 2005 [consulta: 15 julio 2007], núm. 14. Disponible en <http://www.ub.es/bid/>.
} 
una red informal de referencistas con los que se intercambia información acerca de los servicios de referencia digital propios de cada área geográfica.

Cada vez es mayor el número de países en los que se están llevado a cabo iniciativas estatales o de ámbito nacional para el desarrollo de servicios de referencia que, apoyados o no en bibliotecas, respondan cualquier cuestión que planteen los usuarios de Internet. Por lo general, se trata de servicios que parten de las entidades estatales con competencias en materia bibliotecaria, aunque en muchos casos consisten en iniciativas de bibliotecas o consorcios, que deciden extender sus servicios de información a la comunidad nacional o internacional. En poco tiempo, estos servicios se han consolidado e, incluso, han ampliado sus posibilidades, ofreciendo conexiones en directo a través de chat desde donde plantear las consultas. Estos proyectos se están viendo completados por otros similares gestionados por instituciones públicas o privadas, que han puesto en línea sus servicios Ask a librarian (pregunte a un bibliotecario), también llamados $Q$ \& A Services (servicios de preguntas y respuestas).

En este epígrafe de la investigación se comentarán los servicios de referencia de tipo público, por tanto gratuitos, que se han creado con la idea de servir de medio de información de referencia para los ciudadanos de un determinado país, aunque también respondan a preguntas planteadas por usuarios extranjeros. La condición de servicios públicos de referencia digital se debe limitar a los que cumplan las siguientes condiciones:

- Servicios de consulta dirigidos a la población en general, que no hagan excepciones para su uso por la pertenencia o afiliación a una determinada biblioteca, institución científica o académica o por la residencia en un país determinado.

- Servicios cooperativos en los que la presencia de las instituciones bibliotecarias nacionales es prioritaria, especialmente en los aspectos de gestión y coordinación del servicio.

- Servicios ilimitados en cuanto al tipo de preguntas que atiende, con las obligadas excepciones de los servicios de referencia en cuanto a interpretación de informaciones legales y médicas, por ejemplo.

- Servicios gratuitos, dependientes de organismos bibliotecarios, que se ofrecen desinteresadamente a los ciudadanos, como un servicio público.

- Servicios que se prestan en línea, ya sea a través de formularios web, correo electrónico, chat, sistemas de mensajería, comunicaciones telefónicas IP, videoconferencias o plataformas de referencia.

En la siguiente relación se comentarán -como se indicaba algunas líneas más arriba- los servicios de referencia nacionales, ofrecidos por entidades bibliotecarias, que se ofrecen de forma abierta a través de Internet a cualquier usuario, independientemente de si está o no registrado como socio en la/s biblioteca/s que ofrece/n el servicio. No se han comentado muchos 
servicios de referencia de tipo público que se limitan a un área geográfica concreta de un país específico. De alguna manera, los servicios de referencia telemáticos que aquí se incluyen actúan como los centros nacionales responsables de esta labor, bien porque estén avalados por un organismo ministerial o bien porque se trata de bibliotecas que han asumido esa labor.

Cada uno de los proyectos se ofrece encabezado por algunos datos básicos de identificación, como son el país desde el que se ofrecen, el nombre bajo el que se difunde el servicio y la dirección principal de acceso a través de Internet. En los contenidos se comentan los sistemas telemáticos que utilizan para que los usuarios realicen sus consultas: chat, formulario web, interfaz para envío de correo electrónico u otros sistemas de comunicación, así como su desarrollo histórico, sus principales características y algunos datos estadísticos. Para conseguir homogeneidad en las estadísticas, se solicitó a cada uno de los servicios comentados que aportaran los datos referentes a 2006, ya que se trataba del último año completo antes de la fecha de finalización de la redacción de la tesis doctoral.

Muchas de las informaciones que se ofrecen en las siguientes páginas han sido facilitadas al doctorando por personal de estos servicios de referencia, con quienes se ha contactado para disponer de datos originales y actuales. Cuando las fuentes han sido personales se indican en nota a pie de página. La ordenación de los servicios se ha realizado de forma alfabética, por el nombre oficial del estado en castellano.

\section{Alemania}

Deutsche Internetbibliothek

http://www.internetbibliothek.de

Deutsche Internetbibliothek (Biblioteca Alemana Internet) es un proyecto nacido el 1 de enero de 2002, iniciado por la Fundación Bertelsmann y por la Deutschen Bibliotheksverband (Federación Alemana de Bibliotecas), en donde participan noventa bibliotecas públicas. Trabaja con una aplicación informática propia, creada por SISIS Informationssysteme $\mathrm{GmbH}$, pero que desde 2005 ya no ofrece servicio técnico, al desaparecer esta empresa. Desde ese año reside en el servidor del servicio central de bibliotecas en Konstanz. Se trata de un portal de recursos informativos, en el que las direcciones más útiles de Internet han sido seleccionadas y comentadas por bibliotecarios. Los recursos están perfectamente organizados, descritos en pequeñas fichas informativas y evaluados a partir de criterios básicos, como el contenido, la navegación o el diseño. La cifra de recursos seleccionados y comentados supera los 6.500. Una de las opciones de este portal de recursos informativos es permitir que se envíen cuestiones de todo tipo (menos médicas y legales) a través de un formulario, en el que se piden datos obligatorios (tema, nombre y correo) y otros opcionales (código postal, propósito de la consulta y fuentes ya empleadas). El servicio indica que ofrecerá la respuesta a lo largo del siguiente día de trabajo. En la actualidad es atendido por setenta y tres bibliotecas públicas y veinte privadas, sobre 
todo especializadas, de Alemania, Austria y Suiza. En el año $2006^{372}$ el servicio recibió 3,5 millones de visitas y atendió cerca de seis mil consultas por correo electrónico; este cifra de preguntas supuso un incremento de un $22 \%$ sobre el año anterior. Aproximadamente hay 200 bibliotecarios y colaboradores en este servicio de referencia. Desde principios de 2007 todas las preguntas son recibidas por la biblioteca pública de Dresde, quien se encarga de la coordinación del servicio y de la distribución de las preguntas $^{373}$.

\section{Alemania \\ InfoPoint}

http://www.zlb.de/fragen_sie_uns/ask_a_librarian

La Biblioteca Central y Regional de Berlín ofrece el Servicio InfoPoint / Question Point ${ }^{374}$, como parte de la red internacional de centros que trabajan en este servicio cooperativo internacional que puede ser consultado en dieciocho lenguas, ya que existen acuerdos con bibliotecas de China, República Checa, Estonia, Finlandia, Francia, Grecia, Hungría, Corea, Letonia, Polonia, Rumanía, Rusia y Suecia, de tal forma que las preguntas que lleguen en las lenguas de las bibliotecas de estos países serán resueltas por las mismas directamente, sin la necesidad de intermediación de la biblioteca alemana. Además, el servicio está accesible en otras lenguas. Tras los contactos establecidos en la Conferencia de la IFLA de agosto de 2007, el servicio incluyó también el español entre los idiomas de pregunta/respuesta. Las cuestiones en castellano son contestadas por la Biblioteca de Castilla-La Mancha ${ }^{375}$. Para las consultas se ofrece un formulario web, en el que la mayoría de los campos son obligatorios. Se pide autorización al usuario para poder archivar sus preguntas. El plazo de respuesta es un día laborable. El servicio multilingüe comenzó en el verano de 2005, a partir de una reunión celebrada en París en 2004. En un principio, el servicio se ofrecía sólo en alemán, inglés y turco. Además, la Biblioteca Central de Berlín ofrece servicios de referencia presenciales, a través del teléfono, por correo electrónico y a través de chat. El crecimiento en el número de centros ha sido constante; en agosto de 2007 participaban en la red dieciséis bibliotecas de diferentes países, de las cuales la gran mayoría son públicas, aunque también hay especializadas y universitarias. En noviembre de 2007 el número de bibliotecas e idiomas era de veintitrés. Durante 2006 InfoPoint contestó más de quinientas preguntas en alemán, ya

\footnotetext{
372 Datos facilitados por Sabine Conrad, de la Städtische Bibliotheken Dresden.

373 Puede consultarse información más detallada sobre los servicios de referencia digital en Alemania en Rösch, Hermann. Digital Reference in Germany: an overview and experiences on the need for qualifications. En IFLA General Conference and Council (69. 2003. Berlín).

Berlín: IFLA, 2003. Disponible en <http://www.ifla.org/IV/ifla69/papers/107e_trans-

Roesch.pdf> [consulta 17 julio 2007].

${ }^{374}$ Puede ampliarse información sobre este servicio en: McGlamery, Susan; Ulrich, Paul S. Serving Patrons in Their Language, Not Just Ours. En IFLA General Conference and Council 73. 2007. Durban). Durban: IFLA, 2007. Disponible en http://www.ifla.org/IV/ifla73/ papers/128-McGlamery_Ulrich-en.pdf [consultado el 17/07/2007]. Hay una traducción al castellano realizada por Gloria Pérez Salmerón.

${ }^{375}$ Véase esta información ampliada en Notario Urango, Juan. La Biblioteca de Castilla-La Mancha colaborará con la Biblioteca Central y Regional de Berlín en la prestación de servicios multilíngües de referencia virtual. Anaquel, 2007, n. 39, p. 26.
} 
que las que se reciben en otros idiomas son resueltas por las bibliotecas de la red. También colaboran con el servicio Deutsche Internetbibliothek, resolviendo cuestiones que le son derivadas desde esta otra red cooperativa íntegramente alemana.

\section{Australia y Nueva Zelanda}

AskNow!

http://www.asknow.gov.au

El Council of Australian State Libraries (CASL) ha puesto en marcha este proyecto, a partir del cual todo ciudadano australiano o de cualquier parte del mundo puede enviar sus preguntas, sean del tema que sean. Dichas cuestiones serán respondidas por un equipo de cerca de un centenar de personas integrado por el personal de las bibliotecas participantes en esta experiencia, fundamentalmente bibliotecas públicas estatales, tanto nacionales, como centrales o regionales o bien públicas de una ciudad; entre ellas se encuentran: National Library of Australia, ACT Library and Information Service, State Library of New South Wales, Northern Territory Library and Information Service, State Library of Queensland, State Library of South Australia, State Library of Tasmania, State Library of Victoria, State Library of Western Australia, National Library of New Zealand y National Library Board of Singapore. Las consultas se realizan por chat en tiempo real, empleando un software que permite que el referencista muestre al usuario páginas web de su interés, al tiempo que se van contestando las cuestiones planteadas. Algunas de las bibliotecas participantes ofrecen este mismo servicio de forma independiente, para preguntas relacionadas con su comunidad. Esta iniciativa comenzó con una fase experimental en agosto de 2002 y ya está totalmente consolidada. Hasta finales de $2006^{376}$ había contestado más de 130.000 peticiones, teniendo en la actualidad una media de tres mil consultas al mes. En el año 2005 atendió 33.396 conexiones. Como es lógico en los servicios que se prestan vía chat, limita su servicio a un horario y unos días concretos (lunes a viernes). Comenzó empleando el software 24/7, como la mayoría de los servicios de este tipo que nacieron por las mismas fechas en Estados Unidos. En la actualidad trabaja con Question Point, siendo una de las redes más activas de la versión internacional de este servicio. Desde noviembre de 2006 simultaneó su servicio vía chat con la oferta de la referencia a través de servicios de mensajería instantánea, servicio que se ha consolidado en junio de 2007, dada la aceptación por parte de los usuarios. Si un usuario prefiere emplear un formulario de correo electrónico entonces el servicio deriva hacia la Biblioteca Nacional de Australia, quien se compromete a responder en cinco días laborables.

\section{Canadá}

Ask a Librarian (Toronto Public Library)

http://www.tpl.toronto.on.ca/ask_index.jsp

Ask Ontario

http://knowledgeontario.ca/ASK_ONTARIO/

\footnotetext{
${ }^{376}$ Información ofrecida por Carmel McInerny, Manager de Information Services en la National Library of Australia.
} 
La Biblioteca Pública de Toronto dispone de un servicio de referencia en línea que amplía el que ya venía ofreciendo. Aunque parte de una biblioteca específica, no limita el acceso a nadie, por lo que cualquier persona puede enviar sus cuestiones, ya sea a través de los formularios realizados a tal efecto o a partir de un chat con el personal referencista. Además, se ofrece la posibilidad de preguntar mediante una llamada de teléfono. El servicio de referencia se plantea de forma diferenciada dependiendo de la edad de los demandantes, existiendo un formulario específico para niños y jóvenes y otro para adultos. Como viene siendo habitual, el chat está limitado a unos días (lunes a sábados) y horas. Sin embargo, si se prefiere realizar las consultas a través del formulario, entonces no hay restricciones horarias. En este caso, la biblioteca se compromete a responder en 24 horas, excepto las cuestiones realizadas en fin de semana. En el año 2006 su Virtual Reference Desk atendió 4.200 cuestiones $^{377}$. Por otra parte, en el servicio Ask Ontario participan bibliotecas públicas y académicas, así como entidades relacionadas con el patrimonio cultural. Es un servicio que se ofrece dentro del proyecto Knowledge Ontario, centrado en la difusión de la información digital relativa a este territorio. En Canadá destaca, además, la iniciativa Virtual Reference Canada / Référence Virtuelle Canada, que están llevando a cabo de forma conjunta distintas bibliotecas, coordinadas por la Biblioteca Nacional de Canadá. No obstante, este servicio canadiense de referencia cooperativa está restringido a las bibliotecas que pertenecen a esta red. Asimismo, la Biblioteca y Archivos Nacionales de Quebec ofrece un formulario de referencia para la comunidad francófona.

\section{China}

\section{Virtual Reference Desk}

http://www.library.sh.cn/english/service/index.htm

Collaborative Online Reference Service (CORS)

http://zsdh.library.sh.cn:8080/

La Biblioteca Central de Shangai facilita desde mayo de 2001 el primer servicio de referencia digital de China, que presta en cooperación con otras bibliotecas académicas y de investigación. El servicio chino responde directamente las cuestiones precisas, las denominadas de referencia rápida, mientras que ofrece las fuentes de información para aquellas cuestiones más complejas. El plazo estimado de respuesta oscila entre 1 y 7 días. Las restricciones del servicio son las habituales, insistiendo en que no se desarrollarán los temas que requieran investigación bibliográfica ni se ofrecerán comentarios acerca de temas legales, médicos o financieros. Aunque en un principio se ofrecía la posibilidad de preguntar en tiempo real, a través de un sistema de mensajería basado en ICQ, el servicio se presta en la actualidad a través de un formulario web. El usuario puede elegir a qué miembro del personal realiza una pregunta, en función de la especialización de los referencistas. El servicio se inició en mayo de 2001, cambiando de plataforma en julio de 2005. Junto a la Queen's Library de Nueva York y bibliotecas de otros seis países forman el Collaborative Online Reference Service (CORS), en el que están integradas veinticuatro bibliotecas e instituciones y desde el que responden a las preguntas que se envíen a su

\footnotetext{
377 Información facilitada por Norma Grech, Department Head, Toronto Reference Library, Information and Operations.
} 
servicio en chino. A lo largo de $2006^{378}$, CORS recibió y contestó 9.243 consultas. En este país asiático, también hay que tener en cuenta el servicio de referencia digital que presta el China Academic Library and Information System $^{379}$, en el que participan más de medio centenar de universidades de todo el país. Cinco bibliotecas de esta red, ofrecen de forma cooperativa servicios de referencia digital, aunque éste no se desarrolla aquí, al tratarse de un servicio orientado a informar a un colectivo concreto: la comunidad universitaria e investigadora de China ${ }^{380}$.

\section{Dinamarca}

Biblioteksvagten / Net Librarian

http://www.biblioteksvagten.dk

Dinamarca es uno de los países que antes ha desarrollado eficaces servicios nacionales de referencia en línea, ya que su servicio de referencia digital nació en octubre de 1999. Biblioteksvagten es el mejor ejemplo de cómo organismos públicos pueden poner en marcha iniciativas para que sus ciudadanos, o cualquier persona que lo desee, planteen sus preguntas y éstas sean atendidas de forma rápida y eficaz. El servicio de referencia danés se ofrece tanto en tiempo real, a través de un chat, como de forma diferida, a partir de un formulario en el que el usuario realiza su consulta. El chat está limitado a un horario (de lunes a domingo), pero no a temáticas ni personas. Las únicas cuestiones de las que este servicio no informa son las relacionadas con algunos aspectos legales o jurídicos. Se ofrece un servicio de referencia en línea desde bibliotecas públicas y otro desde bibliotecas de investigación. El servicio es gratuito, aunque si se requiere algún tipo de documentación, como fotocopias, el pago de los gastos corresponderá al usuario. Además del chat y del formulario, los usuarios pueden plantear sus dudas por teléfono. Colaboran en el proyecto bibliotecas públicas, que componen el grueso de la tipología bibliotecaria, pero también hay bibliotecas universitarias y especializadas. Este servicio de referencia se completa con otros dos servidores que mantiene la misma institución, The Danish National Library Authority; en uno de ellos, accesible desde $<$ http://www.bibliotekernesnetguide.dk>, se ofrecen recursos seleccionados para usuarios de bibliotecas públicas y, en el otro, que se puede consultar desde <http://www.bibliotek.dk>, se ofrecen los datos de las bibliotecas danesas, así como la consulta a los catálogos de las que dependen de instituciones públicas. Recientemente, ha añadido la posibilidad de enviar consultas a través de SMS. En el año 2005 habían recibido 22.817 preguntas, mientras que en el año $2006^{381}$ atendieron 27.956 preguntas, de las cuales, 22.956 fueron respondidas por bibliotecas públicas y 5.401 por universitarias. En la actualidad, integran el servicio cincuenta y dos

\footnotetext{
${ }^{378}$ Datos facilitados por Marshall Chang del CORS Administration Centre.

${ }^{379}$ CALIS: http://www.calis.edu.cn. Información sobre este consorcio y sobre su referencia de referencia digital puede ser consultada en Xiaoxia, Yao; Chen, Ling. Exploring the services provided by CALIS: meeting the needs of member libraries. Library Management, 2005, vol. 26, n. 8/9, p. 471-477.

${ }_{380}$ Para obtener más información sobre los servicios de referencia digital en China véase

Songhui, Zheng. Virtual reference services in China: helping the information-poor. The Electronic Library, 2006, vol. 24, n. 6, p. 763-773.

${ }^{381}$ Información provista por Vera Daugaard, bibliotecaria de la Herning County Library y Project Manager de Biblioteksvagten.dk.
} 
bibliotecas públicas, tres escolares y quince universitarias 0 de investigación ${ }^{382}$.

\section{Eslovenia}

Vprasaj knjiznicarja

http://home.izum.si/izum/qp/default.htm

El servicio de referencia esloveno se inicia el 1 de enero de 2005 y en la actualidad participan en él cinco bibliotecas universitarias, cinco bibliotecas públicas y una especializada, la del IZUM, el instituto de investigación en información y documentación que actúa como administrador del proyecto, así como responsable del servicio técnico y de la organización de las actividades de formación. La base del servicio de referencia es el programa Question Point, por lo que ofrecen la posibilidad de que las consultas se realicen a través de un formulario web o bien vía chat. El servicio de conversación en tiempo real está disponible durante cinco días a la semana y durante seis horas diarias; el formulario web que se remite por correo electrónico y recibe preguntas que se contestan en 24 horas en días laborables. Las bibliotecas eslovenas emplean Question Point en su software, además de como recurso de información y sistema de control estadístico. Cada día una biblioteca pública y una universitaria se encargan de contestar las preguntas remitidas a través de este sistema. Todas se apoyan en los servicios y recursos de OCLC para ofrecer las respuestas, ya que participa activamente en su red cooperativa internacional. En el año $2006^{383}$ el servicio público de referencia en línea de Eslovenia recibió un total de 2.834 consultas, de la cuales 1.421 se realizaron vía chat y las otras 1.413 a través de su formulario web. Este servicio también participa en el proyecto InfoPoint, que coordina la Biblioteca Central y Regional de Berlín y que presta un servicio de referencia multilingüe, distribuyéndose las preguntas en función del idioma en que se formule.

\section{España}

Pregunte: las bibliotecas responden

http://www.pregunte.es

Pregunte es el mejor ejemplo de trabajo cooperativo entre bibliotecas públicas del que se puede hablar en España. Inició su actividad en junio de 2000, por lo que es uno de los servicios de este tipo más antiguos internacionalmente. En el proyecto participan cuarenta y dos bibliotecas, fundamentalmente Bibliotecas Públicas del Estado, aunque también intervienen algunas redes municipales. Asimismo, están integradas en el proyecto varias bibliotecas regionales. Para conseguir dar respuesta a todas las preguntas de carácter local se han seleccionado bibliotecas de la práctica totalidad de las comunidades autónomas españolas; algunas de las bibliotecas integrantes, como es el caso de la Biblioteca de Andalucía, tienen su propio servicio de referencia en línea. Las preguntas se realizan a través de un formulario y se contestan mediante correo electrónico. Durante los primeros años de funcionamiento, el servicio de referencia en línea español ha mantenido una media anual de unas cinco mil preguntas contestadas

\footnotetext{
${ }^{382}$ Para ampliar información sobre este servicio, véanse los diferentes artículos de Vera Daugaard que aparecen en la bibliografía del capítulo 18.6.

${ }^{383}$ Datos facilitados por Davor Bračko, del IZUM (Institute of Information Science).
} 
satisfactoriamente La administración técnica y la coordinación se lleva a cabo en la Subdirección General de Coordinación Bibliotecaria, del Ministerio de Cultura. El servicio se presta a cualquier usuario que plantee sus preguntas en una de las lenguas españolas. El usuario también puede elegir el idioma de la respuesta: castellano, catalán, gallego o vasco. Las bibliotecas participantes responden en un plazo máximo de tres días desde que se formula la pregunta, independientemente de si las consultas se realizan en día laboral o festivo. El servicio dispone de un buscador en el que se permite recuperar por palabras o temas las preguntas realizadas desde el inicio del servicio. Desde su puesta en funcionamiento, hasta mediados de 2007, Pregunte había atendido algo más de cuarenta mil consultas.

\section{Estados Unidos}

24/7 Reference Cooperative

http://www.questionpoint.org/community/TransitionTaskForce/FAQ_247.htm

Ask Now (California)

http://www.asknow.org

¡Información en vivo! (Nueva York)

http://www.nypl.org/questions/index.cfm

QandNJ (Nueva Jersey)

http://www.qandanj.org/

El programa 24/7 fue muy empleado en bibliotecas estadounidenses para ofrecer servicios de referencia sincrónicos. En 2005 las comunidades de usuarios de 24/7 y de Question Point se integran para crear una red cooperativa, con la finalidad de prestar servicios 24 horas al día, de tal forma que las bibliotecas compartan usuarios y recursos, con la excepción de las preguntas locales, que son atendidas por las bibliotecas correspondientes. En la actualidad esta red cooperativa se distribuye en dos grupos, uno para bibliotecas públicas y otro para universitarias. En Estados Unidos existen diversos servicios de referencia digital estatales. En las siguientes líneas se describen algunos de estos sistemas ofrecidos por bibliotecas o entidades públicas estadounidenses de forma abierta, como el servicio de referencia de California, uno de los primeros que ofertaron referencia digital de forma pública. Comenzó como 24/7 Reference, nombre de un programa informático creado y empleado originariamente por el Metropolitan Cooperative Library System (MCLS) del sur de California. El sistema, hoy reemplazado por QuestionPoint, permitía que se mantuviera una conversación con el personal responsable del servicio en tiempo real, a través de la conavegación, para ir orientando al usuario y mostrándole en una parte de la pantalla páginas o documentos de utilidad para su consulta. Cerca de un centenar de bibliotecas integran este servicio, que en muchos casos también puede ser interrogado en español. La red de bibliotecas del MCLS permite que cualquier persona que quiera hacer una pregunta la plantee en tiempo real, ya sea en castellano o en inglés, sin poner límites a los horarios ni a la temática de las preguntas. Desde agosto de 2004, este servicio está combinado con Question Point, sistema de referencia de OCLC, aunque ambos servicios mantienen sus usuarios diferenciados. No obstante, se puede realizar consultas de forma gratuita a partir de las bibliotecas pertenecientes a la red, como la Biblioteca Pública de Los 
Ángeles <http://www.lapl.org>, quien también atiende en español, mediante chat o formulario. Otro ejemplo importante es el de la Biblioteca Pública de Nueva York, que ofrece diferentes posibilidades para la referencia digital. Recibe preguntas y ofrece respuestas en español, en tiempo real, empleado el software Tutor, que permite la conversación y la conavegación. El sistema envía una copia de la sesión al correo electrónico del usuario. También se pueden realizar preguntas por correo electrónico. Además, en Estados Unidos destaca QandNJ, un servicio de referencia digital consolidado ofrecido desde Nueva Jersey. Ofrece la posibilidad de preguntar a una biblioteca pública o una escolar, aunque es necesario pertenecer a una de sus bibliotecas, para lo cual solicitan el número de código de barras de su tarjeta de usuario. También están presentes en MySpace, en la dirección $<$ http://myspace.com/qandanj>. Existen otras grandes redes estatales en Estados Unidos; para su localización es muy útil el directorio que realiza LISwiki <http://liswiki.org> bajo los epígrafes de referencia digital (virtual reference, chat reference, etc.)

\section{Estados Unidos}

Ask a librarian (Library of Congress)

http://www.loc.gov/rr/askalib

Global Reference Network

http://www.loc.gov/rr/digiref/

La Biblioteca del Congreso de Estados Unidos ofrece la posibilidad de responder a las preguntas que se envíen a sus servicios de referencia. Dada la amplitud de colecciones y departamentos de esta biblioteca, los servicios de referencia son diferentes en función de los temas o colecciones en los que se especializan. De esta forma, es posible encontrarse con servicios de referencia de colecciones generales (economía, ciencias sociales, derecho, etc.), colecciones internas (áreas geográficas) y formatos especiales (manuscritos, música, etc.). Algunas de estas secciones permiten las consultas en tiempo real mediante un chat en horario limitado (lunes a viernes), pero todas ofrecen un formulario a partir del cual enviar las preguntas. Esta biblioteca participa en proyectos cooperativos, por lo que algunas consultas serán respondidas por bibliotecas externas. En su política de actuación indica qué preguntas no se atienden: bibliografías extensas, trabajos académicos o para estudiantes, traducciones o cuestiones relacionadas con genealogía o heráldica, por ejemplo. También existe la posibilidad de plantear preguntas en español, pero sólo sobre cultura hispánica. En este caso las respuestas se recibirán antes de cinco días hábiles, aunque en otras secciones la resolución de las preguntas se hace en menos tiempo. Según su estadísticas ${ }^{384}$, en el año 2006 este servicio atendió 47.630 consultas, mientras que el total de las transacciones de referencia que hizo la Biblioteca del Congreso, por todos los medios (también presencialmente, por teléfono y por correo electrónico) fueron 633.396. La Biblioteca del Congreso, junto a OCLC, lidera también el proyecto Global Reference Network (GRN), en el que participan centros que emplean Question Point y que se ofrece como un servicio para las bibliotecas que emplean este software. GNR es el sucesor de Collaborative

\footnotetext{
${ }^{384}$ Datos ofrecidos por Digital Reference Team, Ask A Librarian Service, The Library of Congress.
} 
Digital Reference Service, grupo constituido formalmente en junio de 2000, también coordinado por la Biblioteca del Congres ${ }^{385}$. En la actualidad es un servicio para entidades, no para usuarios, en el que participan 1.800 bibliotecas de 23 países, que atienden una media de 3.500 consultas semanales, en 26 idiomas. Las bibliotecas que participan en este sistema se favorecen del apoyo del resto de los miembros, a los que se pueden enviar consultas de difícil resolución, así como de una gran base de datos de recursos. En esta red participan dos bibliotecas españolas, la del Centro de Documentación Info-Sud de la Universidad de Valencia y la biblioteca de la Universidad de Cádiz.

\section{Finlandia}

\section{Ask a librarian}

http://www.libraries.fi/en-GB/ask_librarian

Las bibliotecas públicas finlandesas disponen de servidores específicos en tres idiomas (finlandés, sueco e inglés) que emplean para la difusión de la información que consideran de interés para sus usuarios. Entre los servicios informativos que desarrollan desde Libraries.fi, además de las selecciones de recursos y de las páginas de acceso y consulta a las colecciones de las bibliotecas públicas, están las dedicadas al servicio de referencia en línea, que se presta a partir de un formulario. En un plazo máximo de tres días laborales los usuarios dispondrán de las respuestas a las preguntas que hayan formulado en este servicio. Además, pueden consultar por materias 0 automáticamente el archivo con las cuestiones ya contestadas. Más de medio centenar de bibliotecas participan en el proyecto, de las que 39 son públicas, una universitaria y catorce especializadas. La iniciativa nació en 1999, está coordinada por la Biblioteca Pública de Helsinki y en ella participan todas las bibliotecas regionales. Su uso ha ido en constante crecimiento; en 2003, recibió 2.928 consultas, 3.514 en 2004, 4.000 en 2005 y 5.029 en $2006^{386}$. En este último año, en 2006, 415 profesionales diferentes enviaron respuestas a las consultas de los usuarios. En las normas de uso apenas se ponen limitaciones, excepto que sólo se plantee una pregunta cada vez que se rellene el formulario y que para cuestiones bibliográficas se empleen los catálogos. Se informa de que las fuentes que se utilizarán para la resolución de las consultas son tanto los recursos propios de las bibliotecas participantes, como las bases de datos e Internet y que las respuestas serán un resumen de los resultados obtenidos en la búsqueda en las mismas. Paralelamente, desde 2001 la Biblioteca Pública de Helsinki presta el servicio Information Gas Station (iGS), que dispone de puntos móviles para la recogida de preguntas en diferentes lugares de la ciudad.

\footnotetext{
${ }^{385}$ Para conocer la trayectoria de este proyecto véanse sendos artículos de su directora: Kresh, Diane Nester. Library quality reference meets the World Wide Web. En IFLA General Conference and Council (67. 2001. Boston). Boston: IFLA, 2001. Disponible en http://www.ifla.org//V/ifla67/papers/131-151e.pdf [consultado el 17/07/2007] y Kresh, Diane Nester. Offering high quality reference service on the Web. The Collaborative Digital Reference Service (CDRS). D-Lib Magazine, 2000, vol. 6, n. 6.

${ }^{386}$ Datos facilitados por Nina Granlund, responsable del servicio finlandés de referencia en línea.
} 


\section{Francia}

Le guichet du savoir

http://www.guichetdusavoir.org

La Biblioteca Municipal de Lyon puso en marcha a principios de 2004 un servicio de referencia en línea atendido por sus bibliotecarios y abierto a cualquier ciudadano, independientemente de si está inscrito o no en la biblioteca y del lugar desde el que se hagan las preguntas. Para ello emplea un programa de gestión de noticias, en el que los usuarios se incorporan al foro, con un apodo y un correo electrónico, para realizar sus consultas. El servicio ofrece respuestas breves o fuentes de información y no atiende consultas médicas ni jurídicas. La "ventanilla del saber" recibe sobre todo cuestiones bibliográficas y de tipo factual. Las respuestas se envían en un plazo de tres días, excepto festivos. El usuario recibirá un correo electrónico en el que se indica que ya tiene su respuesta en el foro de noticias. Es importante destacar que se trata de una iniciativa local, no gubernamental, en la que una biblioteca municipal decide dar un servicio de información global, no restringido únicamente a sus usuarios. El servicio que ofrece la Biblioteca Municipal de Lyon tiene una buena acogida entre la población francesa, como lo demuestran sus datos de $2006^{387}$, año en el que recibieron 5.600 consultas, 651.042 visitas a las páginas de Le Guichet $d u$ Savoir y más de tres millones de páginas vistas.

\section{Francia}

\section{Bibliothèque publique d'information / BiblioSés@me}

http://www.bpi.fr

La Bibliothèque publique d'information (BPI) del Centro Pompidou ofrece desde su creación en 1977 un servicio de información que paulatinamente ha ido incorporando tecnologías de la información, comenzando por teléfono, correo postal, fax, videotexto (el minitel francés) y hoy correo electrónico y chat. El alcance del servicio es internacional y en su presentación apuntan que responden a consultas bibliográficas y factuales o de referencia rápida, pero no atienden cuestiones sobre suministro de documentos, peticiones de bibliografías, trabajos de investigación o de clase, consultas médicas, legales o genealógicas, ni aquellas preguntas referidas al funcionamiento del Centro Pompidou. El servicio se presta a través de chat, cuatro días de la semana y sólo durante dos horas de la mañana; por teléfono, las consultas se reciben durante toda la semana, excepto martes, en un horario muy amplio. Las peticiones que se atienden por correo electrónico son las que se reciben a través de un formulario, en el que es obligatorio completar datos como el objetivo de la demanda o el nivel de estudios. En $2006^{388}$, el servicio de preguntas/respuestas del centro Pompidou atendió 1.798 consultas de referencia, de las cuales 1.295 fueron recibidas por correo electrónico y 70 mediante sesiones de chat, en el horario establecido a tal efecto: 10 a 12 horas; tres consultas fueron hechas por correo electrónico desde otras vías. Por otra parte, la BPI está integrada en la red BiblioSés@me, formada por bibliotecas públicas del país. A mediados de 2007, la red estaba integrada

\footnotetext{
${ }^{387}$ Datos facilitados por Bertrand Calenge, responsable de Evaluation prospective communication interne de la Bibliothèque municipale de Lyon.

${ }^{388}$ Datos facilitados por Marie Montano, Section Bibliothèque à distance, Service Accueil des publics. Bpi, Georges Pompidou.
} 
por nueve bibliotecas públicas y dos más entrarán en el proyecto próximamente. Las bibliotecas de la red están especializadas en materias concretas y son las encargadas de responder todas las preguntas que se reciban sobre sus campos de especialización. Trabajan mediante formulario web a partir del programa Question Point, con la excepción de la BPI, que también ofrece chat. En el año 2006, BiblioSés@me estaba integrado por la BPI de París y las bibliotecas públicas de Marsella, Troyes, Montpellier, Lille, Valenciennes y Limoges y en total respondieron a 1.724 preguntas.

\section{Hungría}

Linlnfo

http://libinfo.oszk.hu

El servicio de referencia en línea húngaro nace en 1999 con el nombre de MIT-HOL (qué-dónde). Desde comienzos de 2001 el servicio se redefine y se integran en él importantes bibliotecas y especialistas. En agosto de 2002 participaban en el mismo 124 personas, de 59 bibliotecas, expertas en 67 disciplinas. En la actualidad el más de medio centenar de bibliotecas adscritas al proyecto trabajan en forma de consorcio, coordinadas por la National Széchényi Library. En el proyecto participan una veintena de bibliotecas públicas, pero también de educación superior y especializadas; incluso cuenta con expertos independientes. Para recoger las respuestas se emplea un formulario, en el que se solicitan datos del usuario, tanto obligatorios como voluntarios. También se pregunta por el tipo de fuentes que se quieren recibir, las lenguas de los documentos, etc. Las respuestas se enviarán por correo electrónico en un tiempo de dos días laborales. Existen una serie de cuestiones que no se atienden, como son las relacionadas con asuntos médicos o legales, investigaciones para trabajos universitarios, información empresarial (para negocios), información heráldica extensa, cuestiones hipotéticas, etc. Según sus estadísticas ${ }^{389}$, en el año 2003 recibieron 4.031 consultas, a las que ofrecieron 4.574 respuestas.

\section{Italia}

\section{SegnaWeb / Chiedi @lla tua biblioteca}

http://www.segnaweb.it

SegnaWeb es un directorio de recursos de Internet puesto en línea en mayo de 2003. Bibliotecarios de todo el país seleccionan aquellos sitios web que consideran de mayor interés y utilidad para los usuarios de Internet italianos. Para ello, emplean una serie de criterios de selección, como la regida de sitios de interés general, no especializados, los que no tratan de temas locales, informaciones primarias, preferentemente en italiano, por ejemplo. En marzo de 2006 incluyó en su contenido la sección denominada Pregunta a tu biblioteca ${ }^{390}$, desde la que se han recopilado enlaces a servicios de información públicos, no limitados a colectivos concretos ni especializados. En la relación facilitada aparecen unas cuarenta bibliotecas o redes de

\footnotetext{
${ }^{389}$ La información ha sido facilitada directamente por el servicio de referencia húngaro.

390 Más información en Pacillo, Angela. Chiedi @lla tua biblioteca. Biblioteche Oggi, ottobre 2006, vol. 24, n. 8, p. 45-54.
} 
bibliotecas, sobre todo universitarias, aunque también se encuentran algunas bibliotecas públicas, comunales o provinciales ${ }^{391}$.

\section{Noruega}

Biblioteksvar

http://biblioteksvar.no

Biblioteksvar (Pregunte a la biblioteca) es la fusión de dos servicios de referencia en línea que se venían prestando en Noruega: Bibliotekvakten, servicio cooperativo y Spør Biblioteket de la Biblioteca Pública de Oslo. El servicio de referencia más antiguo es Bibliotekvakten que, a su vez, parte de un proyecto anterior, denominado Bibliotekvakten i Vestfold, llevado a cabo con éxito entre los meses de enero y junio de 2002, en el cual se pretendía experimentar la eficacia de un servicio nacional de referencia en tiempo real, ya que estaba asentado el uso del correo electrónico como medio para resolver las preguntas de los usuarios de Internet en este país nórdico. Bibliotekvakten pasó a ser una iniciativa del Statens bibliotektilsyn, máxima entidad bibliotecaria estatal y participaron en el proyecto catorce bibliotecas, coordinadas por la biblioteca pública de Vestfold, quien se actuaba además como una biblioteca para bibliotecas, ya que ofrece servicios de planificación y desarrollo bibliotecarios. Biblioteksvar, el servicio actual, presenta tres posibilidades de consulta: vía formulario web (respuesta por correo electrónico), chat y mensajes de teléfono móvil. Las sesiones de chat son realizadas por el personal de las bibliotecas participantes, quienes cambian de turno cada noventa minutos. Las respuestas que se envían por correo electrónico son contestadas por la Biblioteca Pública de Oslo. Biblioteksvar es el primer servicio de este tipo que permite preguntar o recibir la contestación mediante SMS, sistema para el que se ha habilitado un número específico y cuyo coste es el mismo de un mensaje de móvil. El plazo para la respuesta de las preguntas realizadas vía mensaje es un día laboral, que es el mismo periodo en el que contestan las preguntas realizadas mediante el formulario web. En la actualidad hay medio centenar de bibliotecas en el proyecto, sobre todo públicas, aunque también entidades bibliotecarias de alcance regional y algunas musicales y especiales, como la de la Oficina Nacional de Estadística o la del principal hospital de Oslo. El servicio es atendido por unos 250 profesionales; normalmente, 4 o 5 personas trabajan al mismo tiempo con las preguntas. En el año $2006^{392}$ el servicio público de referencia digital noruego atendió 13.500 consultas por chat, cerca de 10.000 por correo electrónico y 3.500 por $\mathrm{SMS}^{393}$.

\section{Países Bajos \\ Al@din \\ http://aladin.bibliotheek.nl}

\footnotetext{
${ }^{391}$ Una visión de los servicios actuales de referencia en Italia que están basados en Internet puede ser consultada en Longo, Brunella. I servizi di reference nell'era dell'accesso. Biblioteche Oggi, 2001, vol. 19, n. 3, p. 42-58.

${ }^{392}$ Información facilitada por Jørn Helge B. Dahl, Leder Biblioteksvar.no.

${ }^{393}$ Más información sobre los servicios de referencia en Noruega en Høivik, Tord. Public libraries in the Norwegian reference market. New Library World, 2007, vol. 108, n. 9/10, p. 396-406.
} 
Dentro del portal de recursos bibliotecarios Bibliotheek.nl se encuentra Al@din, servicio de consulta de las bibliotecas públicas en Internet. El proyecto admite preguntas de cualquier tema, excepto los asuntos relacionados con préstamos de obras de las bibliotecas participantes, consejos médicos o jurídicos ni problemas relacionados con los ordenadores de los usuarios. A través de un formulario, el usuario realiza la consulta, antes de enviarla puede comprobar que no fue hecha anteriormente; cuando se cerciora de que la consulta no ha sido realizada, el sistema le pedirá una serie de datos obligatorios (sexo, edad, correo electrónico, pertenencia a una biblioteca pública) y otros voluntarios (cómo conoció el servicio, tema, fuentes previas empleadas). Además, el usuario puede consultar en vivo el servicio, a través de chat, limitado a un cierto número de días y horas y para el que se usa el software Chatfone. El portal se completa con una sección educativa y de noticias; con una interfaz de búsqueda en catálogos bibliotecarios y en la bases de datos de recursos web seleccionados por las bibliotecas participantes; y con otra opción para localizar información de bibliotecas públicas holandesas. El servicio es atendido por bibliotecarios públicos de todo el país, que responden hasta en cinco días laborales, aunque si van a tardar más de un día se lo comunican al usuario por correo electrónico. En el año $2006^{394}$ el servicio recibió 720.647 visitantes, de los cuales un $43 \%$ consultó la base de datos de recursos que ofrece. El número de preguntas de referencia digital que atendió fue 128.551.

\section{Reino Unido}

Ask a librarian

http://www.ask-a-librarian.org.uk

Aunque en estos momentos el servicio está desactivado, merece la pena incluir la pionera experiencia inglesa de referencia digital en esta relación. Las bibliotecas públicas británicas también ofrecían un servicio de referencia en línea a través de Internet, creado para ciudadanos del Reino Unido, pero que permitía ser utilizado por cualquier persona que lo considere un medio adecuado para obtener una información. En sus completas páginas informativas se especificaban las limitaciones temáticas, como eran las cuestiones legales, los problemas informáticos 0 las búsquedas bibliográficas extensas. Otra limitación era el número de preguntas que se podían realizar por persona y día, que se restringía a tres. También se incluían una serie de consejos para preguntar y ejemplos de consultas recientes, a fin de que el usuario supiera qué tipo de cuestiones se podían realizar y cómo debían ser formuladas. Alrededor de setenta bibliotecas públicas eran las responsables de solventar las dudas recibidas por correo electrónico a través del formulario creado para este fin. El tiempo de respuesta estimado era de dos días. El servicio Ask a librarian ${ }^{395}$ fue puesto en marcha en 1997 y desde octubre de 2001, en su última etapa, estaba

\footnotetext{
${ }^{394}$ Datos provistos por Harriet de Man, Servicemanager Aladin. Vereniging Openbare Bibliotheken.

${ }^{395}$ Berube, Linda. Collaborative digital reference: an Ask a Librarian (UK) overview. Program, 2004, vol. 38, n. 1, p. 29-41. Éste y otros artículos de esta misma autora, disponibles en la bibliografía 18.6 podrán servir para obtener una panorámica del servicio de referencia original del Reino Unido.
} 
coordinado por Co-East ${ }^{396}$, consorcio de bibliotecas del este de Inglaterra. En la actualidad, este servicio ha sido reemplazado por People's Network, que se comenta a continuación.

\section{Reino Unido}

The People's Network - Enquire

http://www.peoplesnetwork.gov.uk

Servicio de preguntas y respuestas en línea del Museums, Libraries and Archives Council (MLA), agencia que se encarga de la política en materia de centros culturales en Inglaterra ${ }^{397}$. El servicio se realiza a través de chat, aunque previamente el usuario debe cumplimentar una serie de datos en un formulario. El horario de consulta es de lunes a viernes, de 9 a 17 horas, aunque después de la última hora las preguntas son atendidas por referencistas estadounidenses. Preferentemente los destinatarios del servicio son los ciudadanos ingleses; para ciudadanos de otras áreas geográficas se facilitan direcciones de otros sistemas de referencia similares. Se trata de un servicio de reciente creación, ya que se lanzó de forma experimental en la primavera de 2005, a partir de la experiencia de Ask a librarian, uno de los sistemas de referencia digital pioneros internacionalmente, que fue comentado más arriba. Destaca su sistema de financiación, ya que se mantiene gracias a fondos de la lotería. Se trata de una ambiciosa iniciativa en la que están implicadas las bibliotecas públicas del Reino Unido y que ha ido mejorándose desde su inicio en el mes de mayo de 2005. En la actualidad trabaja con el software Question Point de OCLC. El primer año completo del nuevo sistema fue 2006 y en los doce meses de ese periodo se recibieron 15.026 preguntas $^{398}$.

\section{Reino Unido (Gales)}

Ask Cymru/Wales

http://www.askcymru.org.uk

Los ciudadanos de Gales disponen de un servicio de referencia propio, que pueden emplear en inglés o galés. Vinculado al desparecido Ask a librarian británico, fue diseñado y desarrollado por el consorcio Co-East, quien también era responsable de su mantenimiento. Es un servicio cooperativo en el que interviene personal de bibliotecas públicas, universitarias, escolares y de la Biblioteca Nacional de Gales. El servicio de referencia digital galés se inició en septiembre 2004, empleando la misma aplicación que el servicio de consultas en línea inglés. En la actualidad, se trata de una plataforma independiente, en la que están implicados más de medio centenar de profesionales. El sistema de envío de las preguntas es a través de un formulario web. Aunque el servicio está especializado en Gales, su lengua y su cultura, responden a cuestiones de cualquier tema y nivel de especialización, ya sea para un trabajo escolar, una tesis doctoral o la

\footnotetext{
${ }^{396}$ Para conocer con mayor desarrollo la desaparecida experiencia inglesa es muy útil el siguiente artículo: Berube, Linda. Collaborative digital reference: an Ask a Librarian (UK) overview. Program: electronic library and information systems, 2004, vol. 38, no. 1, p. 29-41.

${ }^{397}$ Se presenta más adelante el servicio de referencia digital galés. Para conocer la situación en Escocia es útil: Chowdhury, Gobinda; Margariti, Simone. Digital reference services: a snapshot of the current practices in Scottish libraries. Library Review, 2004, vol. 53 , n. 1, p. 50-60.

${ }^{398}$ Datos facilitados por Joanne John, Enquire Administrator.
} 
resolución de un pasatiempos, como indican en su presentación. El plazo de respuesta máximo que se marcan es de dos días. El servicio incluye algunas limitaciones, como el envío de un máximo de tres preguntas por día o la respuesta únicamente a cuestiones factuales, no aquellas que contemplen una interpretación de la información, como los asuntos legales o médicos; también inciden en que no realizan investigaciones, sino que ofrecen fuentes para su redacción, así como que tampoco responden preguntas sobre problemas informáticos. Los referencistas de este servicio solicitan al usuario que ofrezcan alguna información complementaria a su consulta, como el motivo de la misma o los datos que ya conoce sobre el tema. El sistema de consulta se abre directamente con el casilla para la introducción de la pregunta y, tras el envío de la cuestión, se piden otros datos, como el nombre y el correo electrónico, además de preguntar al usuario acerca de que si permite que su consulta se exponga en el sitio web del servicio, ya que en la página principal del mismo aparece siempre el último mensaje que se ha contestado. El servicio de referencia galés atendió en 2006651 consultas y, en los ocho primeros meses de 2007 el número de preguntas era de $359^{399}$.

\section{Suecia}

\section{Fråga Biblioteket}

http://www.eref.se

El sistema de referencia digital de Suecia es uno de los que más ha cambiado desde sus inicios. Bajo el nombre común de Fråga Biblioteket (Pregunta a una biblioteca) se ofrecen servicios de consulta a través de bibliotecas públicas o universitarias, siendo elección del usuario interrogar un servicio u otro. Además, ofrecen tres servicios especiales, que son la referencia digital para niños, consulta en otros idiomas o referencia sobre aspectos de tecnología. El servicio de referencia de las bibliotecas públicas comenzó en 1998 y desde 2003 está coordinado por la Biblioteca Municipal de Örebro. El actual Fråga Biblioteket, atendido por bibliotecas públicas, es la iniciativa que sucede a Bibliotekarie direkt, servicio de referencia en línea en el que colaboraron cinco bibliotecas públicas. Desde el 1 de julio de 2006, el servicio es coordinado por organismos bibliotecarios de Malmö, Estocolmo y Umeå, en nombre de Kulturrådet, el consejo estatal de cultura. Unas setenta bibliotecas públicas están integradas en la referencia digital sueca en la actualidad. El servicio de referencia específico de las bibliotecas universitarias se inicia en septiembre de 2003, con un proyecto denominado Jourhavande bibliotekarie (El bibliotecario de guardia). Su función era resolver cuestiones de tipo pedagógico y necesidades de información de universitarios y otros estudiantes. Este servicio académico es coordinado desde 2005 por la Biblioteca Nacional de Suecia y participan en él cerca de veinte bibliotecas universitarias. Desde 2007 los dos servicios comienzan a operar bajo la denominación común de Fråga Biblioteket (Pregunta a una biblioteca). Se ofrece por chat y mediante formulario web; en este segundo caso intentan responder al día siguiente. Para la gestión del servicio emplean el programa Docutek VRLplus. En el año 2006 el servicio respondió 22.491 preguntas, de las cuales, 6.357 se resolvieron por chat y 16.134 a

\footnotetext{
${ }^{399}$ Información obtenida a través de la consulta al servicio de referencia galés y ofrecida por los responsables de la biblioteca de la University of Wales en Aberystwyth.
} 
través de correo electrónico. El servicio sueco es multilingüe desde primeros de octubre de 2006. Permite preguntar en una docena de lenguas, entre ellas el español. Según sus estadísticas ${ }^{400}$, desde el 1 de octubre de 2006 hasta el 1 de marzo de 2007 respondieron 281 consultas en lenguas distintas al sueco, 84 de ellas en español. La sede del Instituto Cervantes colabora en este servicio. Cada lengua está atendida por al menos cinco bibliotecarios, que pertenecen a diferentes bibliotecas del país.

\section{Suiza}

SwissInfoDesk

http://www.snl.admin.ch/swissinfodesk/

La Biblioteca Nacional Suiza ha creado un portal de información sobre su país y su cultura, para servir de apoyo a quienes trabajen o investiguen en relación a la Confederación Helvética ${ }^{401}$. No se trata en sentido estricto de un servicio público de referencia digital, ya que las consultas están limitada a un tema: Suiza. No obstante, se incluye en esta relación, como parte de la los servicios públicos que se han reunido en la tesis doctoral, ya que ofrece servicios gratuitos y porque permite que las consultas sean de cualquier disciplina, siempre con el tema suizo como fin. Por una parte, el usuario puede localizar información por sí mismo, ya que se presenta un directorio estructurado por temas, con recursos brevemente comentados. A los enlaces también puede accederse a través de los diferentes índices de palabras clave, tanto por personas como por materias. La consulta directa al personal referencista requiere el uso de un extenso formulario en el que se solicitan los siguientes datos sobre la pregunta: pregunta, motivo de la consulta, palabras clave, área geográfica de la cuestión, lengua, tipo de información (bibliografía, imágenes, fotocopias, etc.), servicio deseado (gratuito, pago, rápido), precio estimado máximo, fecha deseada de envío y modo de recepción. Además, es obligatorio cumplimentar la información relativa al usuario: nombre, institución, direcciones, etc. El servicio de información sobre Suiza se lanzó en 2003, sólo en inglés, aunque en la actualidad responde en las diferentes lenguas oficiales del territorio suizo. El servicio es gratuito cuando la consulta se puede responder en menos de media hora, aunque existen tarifas para búsquedas que impliquen más tiempo. Además de la biblioteca nacional, participan en el proyecto bibliotecas públicas y cantonales, así como una veintena de bibliotecas especializadas. En el año 2006 el servicio suizo recibió 918 preguntas.

\footnotetext{
${ }^{400}$ Datos facilitados por Leena Månsson, Bibliotekskonsulent de la Regionbibliotek Skåne.

${ }^{401}$ Véase Accart, J.-P. A question about Switzerland? SwissInfoDesk. IFLA Council and General Conference $(71,2005$. Oslo). Libraries - A voyage of discovery. Disponible en $<$ http://www.ifla.org/IV/ifla71/papers/030e_trans-Accart.pdf>. En la bibliografía 18.6 se encontrarán más documentos de este mismo autor en los que se explica el servicio de referencia nacional suizo. El doctorando agradece la colaboración del señor Accart en la tesis doctoral, al aportar la información estadística que le solicitó y responder a las preguntas que se le hicieron.
} 


\subsection{Servicios de referencia digital en España}

Como complemento a este capítulo se quiere hacer un rápido repaso a los las bibliotecas españolas que están ofreciendo servicios de referencia a través de Internet. La nómina es breve y los servicios ofrecidos muy limitados. Excepto en el caso ya mencionado en el apartado anterior de «Pregunte: las bibliotecas responden», el resto de los centros sólo informan a sus propios usuarios o sobre temas específicos. Por tanto, no son servicios públicos, aunque sí son servicios bibliotecarios de información. En un estudio realizado por Frías y Lorente ${ }^{402}$ sobre la información web de las bibliotecas públicas catalanas encontraron que sólo el 1,83\% de las 109 bibliotecas analizadas ofrecían servicios de referencia a través de Internet. Un estudio similar fue realizado por García Gómez ${ }^{403}$, pero no aporta datos concretos sobre la oferta de referencia digital desde las web de las bibliotecas públicas españolas, aunque sí comenta las experiencias de los "Pregunte" nacional y andaluz. Un estudio más que hay que tener en cuenta es el de Jiménez López ${ }^{404}$, quien analiza los servicios de referencia digital en las bibliotecas universitarias españolas existentes en enero de 2004, así como la producción científica sobre el tema publicada en España entre 1995 y 2003.

Una característica común de los servicios de referencia digital españoles es que apenas ofrecen referencia sincrónica. Únicamente las universidades de Granada, Murcia y Sevilla incluyen este servicio, a través de chat, en horarios limitados y para usuarios registrados. También existe un ejemplo de biblioteca especializada que atiende vía chat, el del Centro de Documentación Sud-Nort de la Universidad de Valencia. En España, todavía no se han introducido de forma generalizada los servicios digitales de referencia sincrónica y es muy limitada la que se realiza de forma asíncrona. En los siguientes párrafos se han querido agrupar los servicios de este tipo que se ofrecen en nuestro país en el momento de redactar estas páginas (agosto de 2007), con indicación del sistema que emplean, del tipo de usuario a los que atiende y de temática de las consultas a que responde. Es una panorámica, por tanto, de la todavía incipiente presencia de lo servicios de referencia digital que se encuentran en España, para cuya elaboración ha sido muy útil el apartado que sobre este tema dedica el anuario que la revista Mi biblioteca publicará en 2008 sobre las bibliotecas españolas y al que ha tenido acceso el doctorando, ya que participa en el mismo, cooperando, supervisando y como comité científico.

\footnotetext{
${ }^{402}$ Frías, Amparo; Lorente, Magdalena. La web de la biblioteca como escaparate de la biblioteca física: análisis de las webs de las bibliotecas públicas. BiD: textos universitaris de biblioteconomia i documentació, 2003, n. 10.

${ }^{403}$ García Gómez, Francisco Javier. Las bibliotecas públicas españolas en Internet: ¿qué servicios ofrecen? Boletín de la Asociación Andaluza de Bibliotecarios, 2002, n. 68, p. $22-$ 36.

${ }^{404}$ Jiménez López, Angels. Servicios de referencia virtuales: consideraciones generales y estado de desarrollo en las bibliotecas universitarias españolas. En Info: Congreso Internacional de Información (5. 2004. La Habana). La Habana: INFO, 2004. Disponible en http://www.congreso-info.cu/UserFiles/File/Info/Info2004/Ponencias/017.pdf [consultado el 17/07/2007].
} 
Tomando como fecha septiembre de 2007, los servicios de referencia digital que se ofrecen en España son los siguientes:

Institución: Ministerio de Cultura y Comunidades Autónomas

Servicio: Pregunte: las bibliotecas responden

Dirección: http://www.pregunte.es

Usuarios: Cualquier ciudadano

Temática: Cualquier tema

Sistema: Formulario web

Plazo: $\quad 72$ horas

Institución: Biblioteca Nacional de España

Servicio: Pregunte al bibliotecario

Dirección: http://www.bne.es/esp/servicios/pregunte.htm

Usuarios: Cualquier ciudadano

Temática: Servicios y colecciones de la biblioteca

Sistema: $\quad$ Formulario web y correo electrónico

Plazo: $\quad$ No se establece

Institución: Biblioteca de Andalucía

Servicio: La biblioteca responde

Dirección: http://www.juntadeandalucia.es/cultura/ba/responde

Usuarios: Cualquier ciudadano

Temática: Andalucía y cultura andaluza

Sistema: Formulario web

Plazo: $\quad 72$ horas

Institución: Biblioteca Pública del Estado en Tarragona

Servicio: Servei d'Informació Local / Servei d'nformació Bibliográfica

Dirección: http://cultura.gencat.net/bpt/

Usuarios: Cualquier ciudadano

Temática: Información comunitaria sobre Tarragona; búsquedas

Sistema: Formulario web, correo electrónico

Plazo: $\quad$ No se establece

Institución: Instituto de Filosofía (CSIC)

Servicio: Pregunte al bibliotecario

Dirección: http://www.ifs.csic.es/biblioteca/serv/pre_bib.htm

Usuarios: Cualquier ciudadano

Temática: Servicios y colecciones de la biblioteca

Sistema: Formulario web

Plazo: $\quad 24$ horas

Institución: Biblioteca Virtual Miguel de Cervantes

Servicio: El bibliotecario

Dirección: http://www.cervantesvirtual.com/bibliotecario/index.jsp

Usuarios: Cualquier ciudadano

Temática: Servicios y colecciones de la biblioteca; búsquedas

Sistema: Formulario web

Plazo: $\quad$ No se establece 
Institución: Centro de Documentación Sud-Nort, Universidad de Valencia

Servicio: $\quad$ Servicio de referencia virtual, INFOSUD.

Dirección: http://www.uv.es/infosud/cas/formularioscas.html

Usuarios: Cualquier ciudadano

Temática: Temáticas especializados (sociología, economía)

Sistema: Formulario web, chat / QuestionPoint

Plazo: $\quad 48$ horas (formulario), inmediato (web)

Institución: IES El Escorial

Servicio: Pregunte al bibliotecario

Dirección: http://www.educa.madrid.org/web/ies.elescorial.elescorial/webbiblio/bibliotecario.html

Usuarios: Comunidad escolar

Temática: Servicios y colecciones de la biblioteca

Sistema: Formulario web

Plazo: $\quad$ No se establece

Institución: Universidad de Alcalá de Henares

Servicio: Información bibliográfica

Dirección: http://www.uah.es/servi/biblioteca/servicios_bibliotecas/infor_biblio.htm

Usuarios: Comunidad universitaria

Temática: Servicios y colecciones de la biblioteca

Sistema: Formulario web

Plazo: $\quad$ No se establece

Institución: Universidad de Alicante

Servicio: $\quad$ Punt BiU. Punto Bibliotecario de Información al Usuario

Dirección: http://www.ua.es/es/bibliotecas/SIBID/centrales/neo_puntbiu/presentacion.htm

Usuarios: Comunidad universitaria

Temática: Servicios y colecciones de la biblioteca

Sistema: $\quad$ Formulario web, correo electrónico

Plazo: $\quad$ No se establece

Institución: Universidad de Barcelona

Servicio: $\quad$ Pregunteu al bibliotecari

Dirección: http://www.bib.ub.edu/serveis/pab/

Usuarios: Comunidad universitaria

Temática: Servicios y colecciones de la biblioteca; búsquedas

Sistema: Formulario web

Plazo: $\quad 24$ horas

Institución: Universidad Cardenal Herrera - CEU

Servicio: La biblioteca responde

Dirección: http://www.uch.ceu.es/principal/biblioteca/faq.asp?op=faq\&menusuperior=alumnos

Usuarios: Comunidad universitaria

Temática: $\quad$ Servicios y colecciones de la biblioteca

Sistema: Correo electrónico

Plazo: $\quad$ No se establece 
Institución: Universidad Carlos III de Madrid

Servicio: Pregunte al bibliotecario

Dirección: http://biblioteca.uc3m.es/uhtbin/cgisirsi///UC3M/0/63/1751/X

Usuarios: Comunidad universitaria

Temática: Servicios y colecciones de la biblioteca; búsquedas.

Sistema: Formulario web

Plazo: $\quad 48$ horas

Institución: Universidad Complutense de Madrid

Servicio: Consulte al bibliotecario

Dirección: http://www.ucm.es/BUCM/servicios/5958.php

Usuarios: Comunidad universitaria

Temática: Servicios y colecciones de la biblioteca; búsquedas.

Sistema: Formulario web

Plazo: $\quad$ No se establece

Institución: Universidad de Cádiz

Servicio: Vía Virtual: consulte al bibliotecario.

Dirección: http://biblioteca.uca.es/vv/acercade.htm

Usuarios: Comunidad universitaria

Temática: Servicios y colecciones de la biblioteca; búsquedas

Sistema: Formulario web, chat / Programa QuestionPoint

Plazo: Inmediato

Institución: Universidad de Córdoba (Ciencias del Trabajo)

Servicio: Pregunte al bibliotecario.

Dirección: http://www.uco.es/webuco/buc/centros/tra/Pregunte-al-Bibliotecario.html

Usuarios: Comunidad universitaria

Temática: Servicios y colecciones de la biblioteca; búsquedas

Sistema: Formulario web

Plazo: $\quad 48$ horas

Institución: Universidad de La Coruña

Servicio: Búsqueda bibliográfica

Dirección: http://www.udc.es/biblioteca/FPI/formubusq.htm

Usuarios: Comunidad universitaria

Temática: Información bibliográfica

Sistema: Formulario web

Plazo: $\quad$ No se establece

Institución: Universidad de Gerona

Servicio: El bibliotecari respon

Dirección: http://biblioteca.udg.edu/serveis/bibliorespon/index.asp

Usuarios: Comunidad universitaria

Temática: Servicios y colecciones de la biblioteca; búsqueda

Sistema: Formulario web

Plazo: $\quad 24$ horas 
Institución: Universidad de Granada

Servicio: La biblioteca responde.

Dirección: http://www.ugr.es/ biblio/biblioteca_responde/index.html

Usuarios: Comunidad universitaria

Temática: Servicios y colecciones de la biblioteca

Sistema: $\quad$ Formulario web, chat

Plazo: $\quad$ No se establece (formulario), inmediato (chat)

Institución: Universidad de Huelva

Servicio: Información bibliográfica

Dirección: http://www.uhu.es/biblioteca/inforbiblio/infbibl.html

Usuarios: Comunidad universitaria

Temática: Servicios y colecciones de la biblioteca

Sistema: Formulario web, correo electrónico

Plazo: $\quad$ No se establece

Institución: Universidad de Las Palmas de Gran Canaria

Servicio: Pregúntanos.

Dirección: http://biblioteca.ulpgc.es/?q=preguntanos

Usuarios: Comunidad universitaria

Temática: Servicios y colecciones de la biblioteca

Sistema: Formulario web

Plazo: $\quad$ No se establece

Institución: Universidad de León

Servicio: Consulte al bibliotecario. La biblioteca responde

Dirección: http://www5.unileon.es/bibportal/contacto/La\%20Biblioteca\%20responde

Usuarios: Comunidad universitaria

Temática: Servicios y colecciones de la biblioteca

Sistema: Formulario web

Plazo: $\quad 24$ horas

Institución: Universidad de Murcia

Servicio: Pregunte al bibliotecario

Dirección: http://www.um.es/biblioteca/formularios/formConsulta.htm

Servicio: Pregunte al bibliotecario

Dirección: http://https://bibliotalk.um.es/bibliotalk/indexUsuario.jsp

Usuarios: Comunidad universitaria

Temática: Servicios y colecciones de la biblioteca

Sistema: $\quad$ Formulario web, correo electrónico y chat

Plazo: $\quad$ No se establece (formulario), inmediato (chat

Institución: Universidad de Navarra

Servicio: Consulte al bibliotecario.

Dirección: http://www.unav.es/biblioteca/consultealbibliotecario.html

Usuarios: Comunidad universitaria

Temática: Servicios y colecciones de la biblioteca

Sistema: Formulario web

Plazo: $\quad 48$ horas 
Institución: Universidad Pontificia de Comillas

Servicio: Consultas y sugerencias

Dirección: http://www.upcomillas.es/portales/Biblioteca/consultas/consultas.asp

Usuarios: Comunidad universitaria

Temática: Información bibliográfica

Sistema: Formulario web

Plazo: $\quad$ No se establece

Institución: Universidad Pompeu Fabra

Servicio: Consultas al personal bibliotecario

Dirección: http://www.upf.edu/bib/cast/consultes/consultes.htm?opcio=0

Usuarios: Comunidad universitaria

Temática: Servicios y colecciones de la biblioteca

Sistema: Formulario web

Plazo: $\quad 48$ horas

Institución: Universidad de Salamanca (Traducción y Documentación)

Servicio: Referencia en línea

Dirección: http://sabus.usal.es/docu/formulario.htm

Usuarios: Comunidad universitaria

Temática: Información bibliográfica

Sistema: Formulario web

Plazo: $\quad$ No se establece

Institución: Universidad de Sevilla

Servicio: Pregunte al bibliotecario.

Dirección: http://bib.us.es/neo/servicios/pregunte/index-ides-idweb.html

Usuarios: Comunidad universitaria

Temática: Servicios y colecciones de la biblioteca

Sistema: Formulario web, chat

Plazo: $\quad$ No se establece (formulario), inmediato (chat)

Institución: Universidad de Zaragoza

Servicio: Pregunta al bibliotecario.

Dirección: http://biblioteca.unizar.es/pregbiblio.php

Usuarios: Comunidad universitaria

Temática: Servicios y colecciones de la biblioteca

Sistema: Formulario web

Plazo: Una semana

Institución: Universitat Jaume I

Servicio: Ask a librarian - Pregunta al bibliotecario.

Dirección: http://www.uji.es/CA/cd/info/biblio.html

Usuarios: Comunidad universitaria

Temática: Servicios y colecciones de la biblioteca

Sistema: Formulario web / Programa Question Point

Plazo: 24 horas. 
Algunas bibliotecas españolas están empleando la aplicación Question Point, que comercializa OCLC y que, además de ser una plataforma que integra chat y formularios web, es una red cooperativa en la que las preguntas pueden ser derivadas a los otros miembros participantes. En España, están ya empleando este servicio. Actualmente están trabando con este servicio el Centro de Documentación Info-Sud de la Universidad de Valencia y la Biblioteca de la Universidad de Cádiz. En el momento de redactar estas líneas (septiembre de 2007) se está implantando en el Consorcio de Bibliotecas Universitarias de Cataluña y en la Biblioteca de Catalunya. Además, será una realidad en breve en otros centros bibliotecarios: Universidad Pablo de Olavide de Sevilla (noviembre 2007), Universidad Autónoma de Madrid (noviembre 2007) y Biblioteca Nacional (diciembre 2007) $^{405}$.

405 Información facilitada por Federico Peiró, Director Comercial de Doc6, empresa que tiene la licencia para la distribución exclusiva en España de los productos de OCLC. 


\section{Pautas y normas para el ejercicio de la referencia digital}

Los servicios de referencia digital disponen de una serie de recomendaciones que pueden emplearse como documentos de trabajo, tanto para iniciar un servicio de este tipo, como para su desarrollo y evaluación. Las pautas para este servicio bibliotecario han sido elaboradas por los organismos bibliotecarios más reconocidos internacionalmente. Por una parte, la IFLA aprobó y difunde sus Recomendaciones para el servicio de referencia digital, que han sido traducidas a varios idiomas. Por otra parte, la Reference and User Services Association (RUSA), integrada en la American Lilbrary Association (ALA) ha aprobado una serie de pautas vinculadas con los servicios referencia digitales, sobre las que se han asentado muchos de los servicios de referencia digital existentes, especialmente de universidades de Estados Unidos, así como servicios públicos de diferentes estados de esta país norteamericano. En los siguientes epígrafes se comentan estas directrices, junto a otras que se consideran de interés por su autoridad, utilidad y calidad, como son las de la Virtual Reference Desk Network, que sirvieron de base a los servicios de referencia digital de centros educativos de Estados Unidos y muchos países angloparlantes.

\subsection{Recomendaciones de la IFLA}

La sección de trabajo de referencia, de la Federación Internacional de Asociaciones de Bibliotecarios y Bibliotecas se comenzó a reunir en 1998 con la intención de debatir acerca de las implicaciones de las tecnologías en los servicios de referencia. En 2002 se crea un grupo específico para la redacción de las pautas que sirvieran de marco para los servicios de referencia que se prestaban en línea. En el comité permanente hubo presencia española desde 2003. En el plan estratégico del grupo de trabajo de referencia de la IFLA para 2004 y para 2005 se incluyó la importancia de estas pautas para acercar los servicios presenciales a los telemáticos.

La versión original de estas Recomendaciones para el servicio de referencia digital $^{406}$ se aprobó en 2003, mientras que la edición en español es de 2004. En la introducción de las mismas se intenta delimitar el concepto de referencia digital, además de ofrecer el marco en el que se inscribe e informar de los dos ámbitos a los que se dirige; por un parte, se quiere contribuir a una mejor administración de los servicios de referencia digital y, por otra, se quieren articular normas para la práctica de estos servicios, pensando especialmente en el trabajo cooperativo. Como se dice en la introducción: "El objetivo de estas recomendaciones o directrices es promover las mejores prácticas de referencia digital a escala internacional. El entorno en línea está singularmente adaptado para trabajar

\footnotetext{
${ }^{406}$ La edición en castellano ha sido publicada por ANABAD: IFLA. Reference Work Section. Recomendaciones para el servicio de referencia digital. Madrid: ANABAD, 2004.
} 
cooperativamente y compartir recursos. Las bibliotecas de diferentes países pueden tener distintas tradiciones de servicio público que afecten tanto a sus prácticas de referencia actuales como a las expectativas de sus clientes. Sin embargo, se debe reconocer que las nuevas tecnologías harán posible que los bibliotecarios redefinan el ámbito de sus servicios públicos. Estas recomendaciones son un intento de crear pautas comunes a partir de diferentes tradiciones, con la esperanza de que la comunidad internacional de bibliotecarios pueda explorar libremente sus posibilidades". Sin duda, la labor realizada en estas pautas es útil para las entidades que disponen de servicios de referencia digital.

Para la delimitación de los conceptos parten de las políticas del servicio Virtual Reference Canada ${ }^{407}$, para quien "los términos referencia virtual, referencia digital, servicios de información en Internet, referencia permanente y referencia en tiempo real son intercambiables para describir los servicios de referencia que utilizan tecnología digital de una u otra forma".

El primer bloque de las recomendaciones se centra en la administración de los servicios de referencia digital. En este apartado se ofrece pautas sobre la política del servicio y su planificación, el personal que lo atenderá, la formación que deben tener estos profesionales, el diseño de la interfaz, aspectos legales y de promoción, así como cuestiones relativas a la evaluación, la calidad del servicio y la cooperación con otros centros. Para no eliminar información de interés en el contexto de esta tesis doctoral se reproducen las pautas ofrecidas en los diferentes apartados de esta primera parte de las recomendaciones de la IFLA. No se incluyen algunos comentarios que son desarrollados en los indicadores posteriores, contenido principal que se quiere exponer en esta investigación, ya que se han tenido en cuenta para la evaluación realizada en la parte tercera de esta tesis doctoral.

\section{Política de Referencia}

- Proponer los objetivos para este nuevo servicio de referencia.

- Elaborar normas que se puedan aplicar combinando las políticas y procedimientos existentes con estos objetivos, asegurándose de que están en consonancia con el propósito general de la institución.

- Establecer un grupo supervisor, responsable de crear prácticas mejores, definir una conducta aceptable y articular un código de conducta teniendo en cuenta las consecuencias de su infracción.

- Establecer la periodicidad con que estas políticas se deben revisar, describir el procedimiento y asignar responsabilidades

- Asegurarse de que se respetan los derechos de autor y demás restricciones legales aplicables.

\footnotetext{
${ }^{407}$ Virtual Reference Canada <http://www.collectionscanada.ca/vrc-rvc/s34-150-e.html> es un servicio que coordina la Biblioteca Nacional de Canadá y en el que están integradas las bibliotecas de este país; su objetivo es compartir información y apoyo, para resolver cuestiones de referencia de forma cooperativa.
} 
- Establecer quién puede utilizar el servicio. Definir y delimitar la población destinataria primaria. Si se presta servicio a cualquier persona sin tener en cuenta su edad, raza, sexo, preferencia sexual, religión, etc., se debe decir. Si se excluye a ciertas personas (por ejemplo, usuarios ajenos a una comunidad particular), la aplicación de la norma debe ser uniforme ${ }^{408}$.

- Establecer si existen tipos de preguntas que la institución responderá o no. Por ejemplo: "Responderemos preguntas sobre datos y preguntas sobre referencias. No responderemos preguntas relativas a consejo médico o jurídico, etc."

- Los usuarios deberían utilizar el servicio de acuerdo con los propósitos y funciones de dicho servicio.

\section{Planificación}

- Crear un grupo de trabajo de administradores y profesionales de la institución para investigar las opciones de servicio posibles y establecer prioridades.

- Elaborar objetivos concretos: ¿Cómo atenderá este servicio las necesidades de la comunidad? ¿Cómo podría evolucionar este servicio con el transcurso del tiempo?

- Elaborar propuestas de actuación.

- Evaluar los servicios y programas informáticos disponibles.

- Determinar los servicios y programas informáticos necesarios.

- Establecer las fuentes de financiación más seguras

- Solicitar información a los usuarios.

- Comprobar si otras instituciones (locales, regionales, etc.) podrían estar interesadas en aunar los recursos para fomentar un servicio cooperativo.

- Volver a evaluar las propuestas de actuación iniciales basado en los logros obtenidos a partir de los pasos anteriores.

- Presentar un plan de acción y asegurarse el apoyo de la dirección.

\section{Personal}

- Seleccionar personal participativo atendiendo al interés (aspecto clave), capacidades, disponibilidad, conocimientos informáticos y aptitudes de comunicación interpersonal. Defina claramente sus responsabilidades y tareas específicas.

- Estimar cuántos bibliotecarios se necesitan a jornada completa para distribuir y responder preguntas, así como cuantos técnicos o informáticos, si procede.

- Tener la suficiente flexibilidad en cuestiones de personal como para incorporar miembros que expresen interés en participar una vez que hayan asumido los objetivos. Recordar que el

\footnotetext{
${ }^{408}$ Sobre este aspecto véase Hiller, Steve; Schillie, Jane; Self, Jim. Evaluación de la Comunidad: Parte esencial de las herramientas del bibliotecario referencista. En IFLA General Conference and Council (70. 2004. Buenos Aires). Buenos Aires: IFLA, 2004. Disponible en http://www.ifla.org/IV/ifla70/papers/029s_trans-Hiller_Schillie_Self.pdf [consultado el 17/07/2007].
} 
futuro del proyecto depende de fomentar el interés más que desalentar al personal.

- En caso de que no se pueda conseguir o no se desee un servicio de 24 horas, hacer un calendario del personal durante las horas que mejor se adapten a las necesidades de información y expectativas de los usuarios, lo que se debe tener especialmente en cuenta si se emplean herramientas de referencia por chat.

- Examinar y evaluar la planificación y distribución de la carga de trabajo de los bibliotecarios basándose en información actual. Realizar ajustes cuando sea necesario y posible.

- Elaborar un calendario de turnos de trabajo centralizado para el personal estable, así como para sustitutos y/o auxiliares.

- Establecer quién proporcionará el apoyo técnico necesario dentro de la institución o consorcio (un grupo de soporte técnico organizado es fundamental para el éxito del servicio de referencia digital).

- Decidir quiénes serán los miembros del personal que controlarán el cumplimiento de las restricciones de uso.

- Decidir quiénes serán los miembros del personal responsables de asegurar que las "Normas para el Servicio de Referencia Digital" se cumplan.

- Planificar la integración del "Servicio" en los procedimientos diarios y el flujo de trabajo. Normalizar los procedimientos para que cuando haya personal ausente, no se pierdan preguntas de referencia.

Formación: aspectos básicos

- Establecer quién formará al personal y dedicar tiempo a la formación, orientación y desarrollo profesional del mismo.

- Las aptitudes más importantes que un bibliotecario de referencia digital debería poseer son las siguientes:

- Multitarea.

- Clara capacidad de comunicación, sobre todo escrita.

- Conocimientos para realizar búsquedas en recursos convencionales y bases de datos en línea.

- Capacidad para entrevistar a distancia, con la dificultad que añade la falta de indicaciones visuales o auditivas.

- Conocimiento de los recursos de referencia.

- Estar familiarizado con los programas informáticos seleccionados.

- Actualizar la formación según sea necesario. Animar y dar facilidades para que el personal se mantenga al día de los nuevos avances en este ámbito.

\section{El diseño de la interfaz}

- Ilustrar con ejemplos la interfaz "fácil de usar" y la navegación sencilla.

- Elaborar una estructura y diseño estándares y utilizarlos de un modo coherente en todo el sitio, con el fin de que un usuario 
que entre por primera vez pueda comprender cómo navegar por el sitio después de emplear una o dos pantallas. Colocar el vínculo al "Servicio" [el botón "Pregunte al bibliotecario"] de un modo coherente en todas las páginas web de la institución.

- Emplear tantos iconos e imágenes como necesite para orientar al usuario. Intentar no llenar la página con grandes bloques de texto.

- Indicar claramente el nombre de la institución y colocar un vínculo hacia la página principal de la biblioteca.

- Incluir un breve párrafo en el que se explique el ámbito de los servicios de referencia de la institución y se mencione el tiempo que tarda una respuesta a sus preguntas (p.ej. "... todas las preguntas que se realicen a este servicio se responderán en un plazo de cinco días laborables...").

- Proporcionar información para orientar al usuario en el formulario. (En el campo de "Recursos consultados" debería figurar al menos un ejemplo que muestre al usuario que es importante incluir el número de volumen, el número de página, fecha, título, información del autor, etc...).

- Se pueden añadir campos comunes de información a su formulario web que son básicos, como " Dirección de correo electrónico" y "Texto de la pregunta", así como campos optativos como: "Nombre", "Número de teléfono", "Nivel de estudios", y "Motivo de la búsqueda", etc.

- Insertar vínculos para recursos en línea que sean importantes, tanto internos como externos (revisados y actualizados periódicamente): Páginas principales, Catálogos en línea, Bases de datos y Preguntas frecuentes.

- Insertar un vínculo para información sobre políticas generales de referencia y correspondencia de la institución.

- Señalar y proporcionar información de contacto por cualquier medio con el personal bibliotecario: por servicio de chat en directo, correo electrónico, formulario web, fax, correo postal, teléfono, etc...

- Tener en cuenta las posibles limitaciones del equipo informático y la sofisticación técnica de los usuarios finales a la hora de planificar un sitio. Deben estar claramente especificadas las necesidades mínimas para el funcionamiento del servicio.

- Incorporar las políticas y cumplir con las leyes que aseguran a todos los usuarios el acceso al servicio.

- Indicar claramente quién responde las preguntas y señalar lo que el servicio no hará.

- Declaración de Privacidad, Reclamaciones, etc... de conformidad con el normativa legal local ${ }^{409}$.

- Establecer el período por el que se guardarán transcripciones de chat y preguntas y quién tendrá acceso a las mismas.

\footnotetext{
${ }^{409}$ En relación con este tema véase Gorman, Michael. Privacy in the Digital environment: issues for libraries. En IFLA General Conference and Council (67. 2001. Boston). Boston: IFLA, 2001. Disponible en http://www.ifla.org/IV/ifla67/papers/145-083e.pdf [consultado el 17/07/2007].
} 
- Decidir si es necesario mantener el anonimato del usuario suprimiendo toda la información personal.

- Establecer un proceso y calendario de mantenimiento de los archivos.

- Ofrecer los medios para que el usuario proporcione contestación a las encuestas, buzón de sugerencias, correos electrónicos, etc...

Aspectos legales

- Referencia digital y libertad de información/cultura local.

- Políticas nacionales de información. ¿Cuál es el panorama político?

- Legislación sobre información pública.

- Legislación relacionada.

- Derechos de autor.

- Privacidad y confidencialidad.

- Contratos de licencia.

- Relaciones con el consorcio.

Publicidad y Promoción

- Identificar claves de audiencia

- Desarrollar una descripción identificativa del proyecto y un nombre o logo que conecte con los objetivos de la comunidad a la que se dirige.

- Fomentar la comunicación directa entre el personal y los patrocinadores.

- Crear enlaces estratégicos en el sitio web de la Biblioteca, y en los sitios de posibles colaboradores institucionales.

- Entrar en contacto con los medios de comunicación locales, publicaciones periódicas de amigos de la biblioteca, emisoras de radio locales, centros educativos.

- Enviar información a las listas de distribución profesionales o de especial interés.

\section{Evaluación y calidad}

- Efectuar encuestas tanto a usuarios como a trabajadores. Supervisar sus problemas y preguntas.

- Recoger y hacer una evaluación de las estadísticas de la actividad del servicio, así como asuntos técnicos o políticos, si es posible.

- Introducir los cambios a los servicios basándose en el análisis de las estadísticas y las respuestas de bibliotecarios y usuarios.

\section{Colaboración}

- Establecer una visión común de los servicios que prestará la nueva entidad.

- Elaborar normas comunes de práctica y procedimientos.

- Crear confianza entre los socios, establecer responsabilidades.

- Reflexionar sobre las cuestiones que puedan surgir en el uso de recursos compartidos, lo que incluye: ley de derechos de autor, 
contratos de licencia, responsabilidad, políticas de información nacional, etc.

El segundo ámbito de aplicaciones está redactado para contribuir a la práctica de la referencia digital; se ofrecen recomendaciones generales para el servicio, así como otras específicas referentes al contenido, pautas para los servicios ofrecidos a través de chat y directrices específicas para las sesiones de referencia a través de chat. Con el primer bloque de estas pautas de la IFLA, se reproducen los argumentos correspondientes al documento en español, que también fueron tenidos en cuenta para la evaluación realizada en la parte tercera de esta tesis doctoral, así como para los epígrafes dedicados a las metodologías de evaluación de esta misma sección de la investigación. Las pautas de la IFLA insisten en que los servicios de referencia digital deberían cumplir las mismas normas que los servicios de referencia tradicional.

Recomendaciones generales para la práctica de la referencia digital

- Comprometerse a prestar la ayuda más eficaz.

- Mostrar cortesía y respeto profesional a la hora de responder preguntas.

- Respetar los principios de libertad intelectual.

- Acusar recibo de las preguntas de usuarios y responderles a la mayor brevedad posible. Las cartas y otros tipos de comunicación se deberían responder de un modo rápido y educado.

- Elaborar y seguir una política de cambio en las respuestas.

- Cumplir los contratos de licencia, tanto para material electrónico como impreso, así como las restricciones específicas de uso y las leyes de derecho de autor que aplican al material en cuestión.

- Poner en práctica buenas estrategias de búsqueda.

- Responder a todas las preguntas que se asignen, aunque sea sólo para decir "Lo siento, no sé pero puede intentar..."

- Para preguntas que requieran respuestas más detalladas, se puede prestar ayuda si procede. El tiempo de búsqueda debería limitarse al tiempo recomendado por el supervisor, siempre que ello sea posible.

Recomendaciones referentes al contenido

- El "Servicio de Referencia Digital" debería ser informativo, fomentar la capacidad de informarse mostrando a sus usuarios cómo encontrar respuesta a sus preguntas.

- Mantener la objetividad y no emitir juicios de valor sobre la cuestión o la naturaleza de la pregunta durante la operación.

- Emplear una técnica neutral de entrevista para concretar "la pregunta real" y cuando se haya determinado, responder a los usuarios de un modo preciso y adecuado en cuanto a duración y nivel para satisfacer su demanda. Incluir la notificación de que la pregunta se puede remitir a otros socios del consorcio si procede.

- Una respuesta bien estructurada se compone de introducción, cuerpo y conclusión. 
- Encabezamiento: Salude al usuario, incluya una expresión de agradecimiento general por utilizar el servicio y mencione directamente el asunto de la pregunta del usuario: Ejemplo: "Puede encontrar información sobre en ," Para saber más sobre , le recomendamos "

- Cuerpo: Mencione las fuentes íntegramente y describa todo el material (si procede) que se envía por separado o adjunto. Explique cómo encontró la información y su ubicación con respecto al recurso recomendado, en caso de que no sea evidente.

- Firma: Debería formar parte de toda conclusión y se debería guardar anotada por el bibliotecario. La firma del bibliotecario puede contener su nombre o iniciales, cargo, institución e información de contacto, según establezca el supervisor.

- Evitar el uso de jergas, acrónimos o abreviaturas de Internet.

- Escribir con claridad todas las respuestas y relacionarlas con el nivel de la pregunta (en la medida de lo posible).

- Ofrecer respuestas precisas, comprobar los hechos y evaluar las fuentes.

- Comprobar la ortografía y validar la URL.

- Seleccionar y citar sólo recursos con autoridad:

- Criterios de evaluación para recursos impresos: Autor, Fecha de Publicación, Edición o Revisión, Editor, Título, Público Destinatario, Difusión, Estilo.

- Criterios de evaluación para revistas, Precisión, Autoridad, Actualidad, Objetividad.

- Criterios de evaluación para recursos web: Autor, Contenido, Nombre del Dominio, Fecha de la última Revisión, Objetividad, Autoridad y Precisión.

- Citar siempre las fuentes de información íntegras, ya sean páginas web, obras de referencia, bases de datos u otras. Si es posible, emplear un estilo de citas coherente a escala institucional.

- Si la información de una fuente no es útil, el bibliotecario debería aumentar su valor con análisis, descripciones, palabras clave, referencias o paráfrasis. Evitar manipular la información de manera que pueda llevar a equívocos.

- El bibliotecario debería esforzarse por señalar o recomendar al menos un recurso para cada pregunta.

Recomendaciones generales para el servicio de chat o foro de consulta ${ }^{410}$.

- El diálogo o charla con un usuario se debería iniciar tan pronto como el usuario entre en la lista del foro.

- Las preguntas del foro se deberían responder en el orden en que se reciben.

\footnotetext{
${ }^{410}$ Sobre este mismo aspecto son importantes las conclusiones del siguiente estudio: Fagan, Jody Condit; Desai, Christina M. Communication strategies for instant messaging and chat reference services. The Reference Librarian, 2002-2003, vol. 38, n. 79/80, p. 121155. Las autoras ofrecen indicaciones basadas en sesiones de referencia en tiempo real.
} 
- Los bibliotecarios que sirven a usuarios por medio del chat deberían identificarse inmediatamente al inicio de la conversación. Esta introducción debe estar en las guías del bibliotecario.

- Los resultados de investigaciones realizadas en varios proyectos de chat afirman que la sesión media suele durar en torno a 15 minutos. Los bibliotecarios utilizarán su sentido común a este respecto. Sea consciente de que otros usuarios están esperando.

- Se recomiendan intervalos de 45 segundos o menos entre respuestas para confirmar al usuario que no se ha desconectado.

- Los registros de URL se emplean a menudo.

- Utilizar la ortografía, gramática y mayúsculas de un modo apropiado, y ser conscientes de que "el lenguaje del chat" suele ser más familiar que la prosa formal escrita.

- Elaborar guías institucionales generales para ayudar a los bibliotecarios a ahorrar tiempo y prestar un servicio coherente dentro de la institución. El administrador de servicios deberá aprobar las guías institucionales.

- Animar a los bibliotecarios a que elaboren su propia guía individual según sea necesario. Es probable que un bibliotecario quiera utilizar guías si: 1. recibe preguntas que exigen respuestas similares sobre asuntos que otros no han tratado; 2. tiene una especialidad que requiere una guía personalizada; 3 . realiza a menudo la misma referencia a otra institución, asociación, recurso o sitio web; 4. desea establecer una forma coherente de saludo o conclusión que sea diferente de la guía institucional o del grupo; 5 . si la sesión no se puede cerrar en un período razonable de tiempo y/o hay otro usuario en espera, ofrézcale enviarle por correo electrónico la respuesta mencionando el tiempo que tardará, por ejemplo "Continuaré buscando una respuesta y se la enviaré por correo electrónico dentro de X horas o minutos", "¿Es suficiente con esto para empezar?", "¿Podría enviarle una respuesta por correo electrónico?".

- Trabajar con más de un usuario a la vez. Si se considera adecuado, se puede recoger también al segundo usuario (se recomienda emplear un navegador por separado). Por ejemplo "Ahora mismo estoy trabajando con otro usuario. Volveré a esta sesión de chat tan pronto como pueda." "¿Podría esperar cinco minutos?"

\section{Recomendaciones para sesiones de chat}

- Aclarar qué información necesita el usuario. Permitir que el usuario explique la información que necesita antes de responder.

- Usar técnicas de preguntas con final abierto para animar al usuario a ampliar su pregunta, por ejemplo: "Dígame algo más sobre el tema de su interés", ¿Me puede dar algún tipo de información adicional?" o "¿Cuánta información necesita?"

- Emplear preguntas para refinar la búsqueda. Por ejemplo: "¿Ha encontrado ya algo?", "¿Qué tipo de información necesita (libros, artículos, etc.)?" o "¿Necesita información histórica o actual?" 
- Dividir las respuestas largas en bloques (por ejemplo. 30 palabras por bloque) con el fin de evitar largas pausas y para que el usuario pueda empezar a leer su respuesta mientras termina de escribirla.

- Explicar su proceso de búsqueda al usuario y describir lo que encuentra cuando sea posible. Recordar que el usuario no puede verle. Hacer saber al usuario que está realizando una búsqueda y el lugar en que la realiza.

- Si hay que comprobar fuentes impresas o la pregunta llevará un tiempo, se puede proporcionar al usuario el recurso para que lo consulte o la opción del seguimiento por correo electrónico.

- Usar citas completas.

- Si hay que remitir la pregunta a otro bibliotecario, informar detalladamente al usuario sobre a quién debe dirigirse, cómo ponerse en contacto con esta persona y qué preguntarle.

- Comportamiento inadecuado: si el comportamiento del usuario es inapropiado (según establecen las normas institucionales), enviarle un mensaje de advertencia o finalizar la llamada. Se deberá enviar un informe de los usuarios incorrectos que se reiteren en su comportamiento.

- Escribir como se habla, de un modo informal.

- Utilizar el nombre del usuario y hacerle preguntas cuando proceda.

- Evitar respuestas del tipo sílno, puesto que se pueden interpretar como frías y poco amigables, al igual que en persona.

- Aclarar la terminología confusa y evite el exceso de jerga. Utilizar terminología que el usuario pueda entender.

\subsection{Pautas de la RUSAIALA}

Las pautas más empleadas internacionalmente no son las de la IFLA, sino las elaboradas por la Reference and User Services Association (RUSA), sección que agrupa a los bibliotecarios referencistas dentro de la American LIbrary Association (ALA). La RUSA ha elaborado diferentes directrices, que entiende como documentos autorizados que sirven de guía para la prestación de servicios y la toma de decisiones. Dentro de esta sección se han aprobado diferentes normativas, que se ofrecen a continuación, organizadas por temas y con la indicación de la fecha de aprobación o de su revisión más actual:

- Desarrollo de colecciones: Elements for Basic Reviews: A Guide for Writers and Readers of Reviews of Works in All Mediums and Genres (2006).

- Servicios electrónicos: Guidelines for the Introduction of Electronic Information Resources to Users (2006); Guidelines for Implementing and Maintaining Virtual Reference Services (2004).

- Genealogía e historia: Guidelines for a Unit or Course of Instruction in Genealogical Research at Schools of Library and Information Science (1996); Guidelines for Developing Beginning Genealogical Collections (1999); Guidelines for Editors of Historical and Genealogical Bulletins 
and Family Newsletters (1997); Guidelines for Establishing Local History Collections (2006); Guidelines for Preservation, Conservation, and Restoration of Local History and Local Genealogical Materials (1992).

- Préstamo interbibliotecario: Interlibrary Loan Code for the United States (2001); Interlibrary Loan Code for the United States Explanatory Supplement.

- Servicios de referencia/información: Guidelines for Behavioral Performance of Reference and Information Service Providers (2004); Guidelines for Cooperative Reference Services (2006); Guidelines for Implementing and Maintaining Virtual Reference Services (2004); Guidelines for Information Services (2000); Guidelines for Liaison Work in Managing Collections and Services (2001); Guidelines for Medical, Legal, and Business Responses (2001); Guidelines for Preparation of a Bibliography (2001); Professional Competencies for Reference and User Services Librarians (2003).

- Colectivos de usuarios: Guidelines for the Development and Promotion of Multilingual Collections and Services (2007); Guidelines for Library Services to Older Adults (1999); Guidelines for Library Services to Spanish-Speaking Library Users (2007).

Como puede apreciarse hay varias normas que se refieren a los servicios de consulta electrónicos; concretamente, para el ámbito de esta tesis doctoral interesan las Guidelines for Implementing and Maintaining Virtual Reference Services, de 2004; como complementarias, hay que tener en cuenta algunas otras, como las Guidelines for Behavioral Performance of Reference and Information Service Providers ${ }^{411}$, de 2004 y las que tratan de los servicios de referencia en general.

Las pautas para la puesta en práctica y mantenimiento de servicios virtuales de referencia fueron redactadas por un comité específico y aprobadas por el comité ejecutivo de la RUSA/ALA en junio de 2004. Para la primera versión se basaron en uno de los trabajos del especialista Bernie Sloan ${ }^{412}$, experto internacional que ha producido un elevado número de investigaciones sobre los servicios de referencia. El propósito de las directrices fue ayudar a las bibliotecas y consorcios que están desarrollando servicios de referencia digitales, orientando sobre los procedimientos que se deben seguir, sin pretender normalizar de forma estricta el trabajo de la referencia digital, ya que las condiciones particulares de cada servicio hace que las pautas tengan que ser personalizadas. El esquema de los contenidos de estas pautas es el siguiente:

\footnotetext{
${ }^{411}$ Estas normas son tomadas también como base para el evaluación de la actividad de los referencistas, así como para la detección de sus carencias formativas. Véase, por ejemplo, Ward, David. Using virtual reference transcripts for staff training. Reference Services Review, 2003, vol. 31, n. 1, p. 46-56.

${ }_{412}$ Sloan, Bernie, Electronic reference services: some suggested guidelines. Reference and User Services Quarterly, summer 1998, vol. 38, no. 1, p.77-81.
} 
1. Definición de referencia virtual

2. Preparación para los servicios de referencia virtual

3. Prestación del servicio: usuarios, parámetros, conducta, cooperación

4. Organización del servicio: integración, infraestructura, presupuestos, personal, márketing, evaluación y mejora

\section{Privacidad}

En una dirección diferente a la IFLA, que emplea el término «referencia digital», la RUSA utiliza en sus pautas el concepto de «referencia virtual», que define como el servicio de referencia que se inicia electrónicamente, a menudo en tiempo real, en el que los usuarios emplean ordenadores $u$ otras tecnologías de Internet para comunicarse con el personal referencista, sin que éste esté físicamente presente. Para la RUSA; los canales de comunicación usados en la referencia virtual incluyen chat, videoconferencia, voz a través de IP, conavegación ${ }^{413}$, correo electrónico y mensajería instantánea. Las indicaciones de la RUSA dejan claro que el hecho de manejar recursos electrónicos para ofrecer una respuesta no implica por sí mismo la existencia de referencia digital; de igual forma, constatan que la referencia virtual a menudo es continuada por comunicaciones telefónicas, envíos de fax o la visita del usuario en persona, aunque estos modos de referencia no se deben incluir en la consideración de referencia digital.

Tras las cuestiones introductorias, las pautas de la RUSA ofrecen algunas indicaciones sobre los elementos previos a la implantación de un servicio de referencia digital. Es interesante la primera indicación que ofrece en este apartado, dedicado a los preparativos del servicio, en la que insiste en la necesidad de concebir el servicio de referencia digital como una parte más de los servicios de la biblioteca o red, nunca como un servicio distinto. Es esencial que los órganos de administración conozcan de antemano todos los gastos que implica el arranque y mantenimiento de un servicio y que lo doten económicamente para su desarrollo en un plazo largo. Asimismo, todos los estamentos de la biblioteca o red deben conocer los detalles del nuevo servicio. Un número representativo del personal de administración y del servicio de referencia deben formar parte del equipo encargado de la planificación, formación, puesta en funcionamiento y promoción del servicio de referencia virtual; este comité también será encargado de seleccionar las aplicaciones informáticas que se emplearán para el desarrollo del nuevo servicio. También es necesario que un número significativo de personas pertenecientes a la población destinatarias del servicio estén integradas en la planificación y difusión del servicio de referencia digital. El personal informático también tiene que formar parte del equipo que tome las decisiones en cuanto a la infraestructura necesaria, la selección del software y las compras, sobre todo en lo relativo a la compatibilidad con los sistemas que ya existen en las bibliotecas. Las pautas de la RUSA también insisten en que el servicio de referencia digital tiene que ser tenido en cuenta para el desarrollo de las colecciones y selección de recursos electrónicos,

${ }^{413}$ El concepto de conavegación está relacionado con el sistema de trabajo de las plataformas creadas para el desarrollo de la referencia digital y se basa en que el personal referencista va abriendo páginas web que el usuario puede ir consultando simultáneamente. 
especialmente en lo relativo a sus licencias de acceso. Además, se hace imprescindible la evaluación constante de los servicios de referencia en línea, que puede partir de criterios similares a los que se emplean para la evaluación de los servicios de referencia tradicionales.

El tercer apartado de las pautas de la RUSA está dedicado a la provisión del servicio, es decir, a la puesta en práctica y desarrollo del mismo. Las diferentes indicaciones que se ofrecen en este bloque se organizan en cuatro grandes temas: destinatarios, parámetros del servicio, comportamiento y cooperación. En cuanto a los aspectos relativos a los usuarios, se establecen sugerencias como que la biblioteca debe definir la población objeto y difundir su política dentro de su sitio web, además de en cualquier lugar que se considere oportuno. Se deben articular sistemas técnicos para autentificar a los usuarios, además de ser estricto con la política de acceso al servicio. Los usuarios deben conocer los procedimientos, por lo que se debe difundir claramente la política institucional, así como publicitar claramente el servicio y a quien va dirigido. En cuanto al subapartado relativo a los parámetros del servicio, la RUSA incluye aquí algunas notas sobre la difusión del tipo de demandas de información que se atenderán, si se facilitarán documentos o archivos y se cobrará por este servicio. Además, será necesario establecer plazos de entrega de la respuesta, marcando periodos de respuesta en la referencia asíncrona y tiempo de conexión por sesión en la sincrónica. Es importante incluir enlaces externos e internos, que atraigan la atención del servicio.

Además de disponer de pautas específicas sobre las competencias profesionales $^{414}$ y el comportamiento del personal de los servicios de referencia en general ${ }^{415}$, la RUSA incluye en estas directrices algunas indicaciones sobre cómo se debe actuar en los servicios electrónicos de referencia. Se insiste en que el personal de esta sección tiene que tener una comunicación fluida entre sí, además de demostrar habilidades en las otras formas de referencia. Dado que no hay una relación presencial, el bibliotecario tiene que desarrollar formación y destrezas complementarias para proporcionar un servicio de calidad, similar al que se ofrece en persona. La RUSA recomienda tener en cuenta sus pautas sobre los profesionales de la referencia. Es necesario que el personal posea habilidades para la comunicación en línea, ya que se deberá realizar telemáticamente las entrevistas de referencia. Se deberá ofrecer una formación inicial y al principio del servicio, hasta que se hagan efectivos los conocimientos. Una indicación más de la RUSA es que el personal debe tratar como privadas y

\footnotetext{
${ }^{414}$ RUSAIALA. Professional Competencies for Reference and User Services Librarians, aprobadas en 2003 y disponibles en <http://www.ala.org/ala/rusa/rusaprotools/ referenceguide/professional.htm>. Existe una traducción al catalán publicada en la revista electrónica BiD: RUSA. Competències professionals per als bibliotecaris dels serveis de referència i atenció a l'usuari. Presentació i traducció de Nora Vela. BiD: textos universitaris de biblioteconomia i documentació, 2003, n. 11. Disponible en $<$ http://www.ub.es/bid/bid11.htm> [consulta 13 junio 2007].

${ }^{415}$ RUSA/ALA. Guidelines for Behavioral Performance of Reference and Information Services Professionals, aprobadas en2 004 y disponibles en <http://www.ala.org/ala/rusa/ rusaprotools/referenceguide/guidelinesbehavioral.htm>.
} 
confidenciales todas las comunicaciones realizadas, así como las transcripciones de las mismas.

En los servicios digitales de referencia son muy comunes los consorcios o la prestación cooperativa de este servicio. Las pautas que se están exponiendo en esta sección de la tesis doctoral incluyen una docena de recomendaciones para las bibliotecas integrantes de estas redes. Es lícito que las bibliotecas se asocien con otras entidades similares para extender el servicio y hacerlo más rentable, en sentido económico y de uso. No obstante, se deberá articular un sistema de administración y coordinación, así como definir claramente la responsabilidad de cada biblioteca participante $^{416}$. Todas las bibliotecas enlazarán con el proyecto cooperativo, detallando qué va a encontrar un usuario en el mismo. Es necesario que se desarrollen procedimientos de comunicación entre los participantes. La red debe designar un nivel mínimo de participación en el servicio cooperativo para cada biblioteca. En la referencia sincrónica, se establecerá un número indispensable de horas de atención, mientras que en la referencia asíncrona, la participación puede basarse en el número de preguntas que se deben responder $o$ en el tiempo mínimo de disponibilidad. La administración organizará los calendarios, según la disponibilidad de las bibliotecas. La RUSA aboga por la existencia de una fuente de información que centralice los recursos relativos a las políticas, operaciones, procedimientos y normativas, así como los datos de las bibliotecas participantes. Las políticas deberán establecer prioridades en cuanto al tipo de preguntas que responderán, así como unas pautas claras sobre las licencias de acceso a los recursos electrónicos y garantías de privacidad. Para que los medios técnicos empleados en la red se ejecuten de forma correcta la RUSA recomienda que se siga la norma NISO Question/Answer Transaction Protocol $^{417}$, que ha supuesto todo un avance en la prestación de servicios de referencia en red.

El siguiente apartado de las directrices de la RUSA sobre la práctica de servicios virtuales de referencia trata acerca de la organización del servicio. Se incluyen aquí diferentes notas acerca de la integración del servicio de referencia digital dentro de los tradicionales, aspectos relacionados con la infraestructura, el mantenimiento económico, el personal, la promoción y la evaluación de los servicios electrónicos de consulta. En cuanto a la integración, se vuelve a incidir en la necesidad de que el servicio digital se conciba como un parte del servicio bibliotecario de referencia, ya que, aunque se planteen sistemas distintos de provisión, los objetivos serán coincidentes. Los fines y el funcionamiento del servicio deben ser conocidos por todo el personal de la biblioteca. El servicio debe contar con espacio, mobiliario, hardware y software adecuados y deben ser apoyados por el

\footnotetext{
${ }^{416}$ Sennema describe un sistema de comunicación entre bibliotecarios pertenecientes a una misma red de referencia digital, basado en tres herramientas distintas, todas ellas accesibles en web. Véase Sennema, Greg. Managing the reference desk online. Reference Services Review, 2003, vol. 31, n. 3, p. 257-263.

${ }^{417}$ NISO. Networked reference services: Question/Answer Transaction Protocol. Bethesda: NISO Press, 2006. Sobre este protocolo véase el apartado 8.3. Tecnologías de comunicación para la referencia digital, en esta misma parte de la tesis doctoral. En los párrafos dedicados al software específico para la referencia digital se describe esta norma.
} 
personal de administración e informática. En relación a la financiación, se debe contar con una asignación presupuestaria específica, que se dedicará al personal, equipamiento informática, aplicaciones electrónicas, conexiones, mobiliario, formación, publicidad y espacios del servicio. El personal debe compartir la responsabilidad del servicio de referencia digital, a fin de garantizar su continuidad. En la medida de lo posible, la plantilla debe estar formada en referencia presencial y digital, a fin de poder disponer de flexibilidad en los puestos de trabajo. La selección del personal que se encargará de la referencia digital se basará en sus habilidades, interés y disponibilidad. La formación continua es obligada en esta sección de la biblioteca o consorcio.

Siguiendo con la descripción de estas importantes directrices, la RUSA aborda, como no podía ser menos, dos cuestiones de importancia: el marketing y la evaluación. La promoción del servicio de referencia digital tendrá que ser realizada a través de un plan específico, determinando el grupo de destinatarios a los que se quiere informar, dedicando un presupuesto a esta actividad y analizando los resultados al final de la campaña. La evaluación del servicio de referencia digital se realizará de forma regular, empleando tanto al personal como a los usuarios. Se trata de conocer la efectividad y la eficiencia del servicio. Existen varios métodos de evaluación que pueden ser aplicados, como el uso de las estadísticas, las opiniones de los usuarios o la revisión de las transcripciones. Las evaluaciones serán equivalentes a las del servicio de referencia tradicional; sus resultados servirán para la mejora del servicio en cuanto a ajustes de personal, parámetros o política del servicio, formación, etc.

Las directrices de la RUSA finalizan con una sección dedicada a la privacidad, un aspecto de crucial importancia en cualquier servicio de información que se preste por medios electrónicos. Las comunicaciones entre usuarios y biblioteca serán privadas, con excepción de lo que determinen las leyes. Los datos generados y mantenidos con fines de evaluación serán confidenciales. Se recomienda eliminar la información de los usuarios, tales como nombre o correo electrónico. Será necesario establecer un calendario de conservación de los archivos. El usuario debe saber si sus datos van a ser retenidos, por lo que habrá que difundir públicamente la política de privacidad que aplique el servicio. Las preguntas y respuestas pueden ser empleadas para la creación de una base de datos de consultas y FAQ, siempre manteniendo la confidencialidad de los usuarios que realizaron las preguntas e informándoles de la posibilidad del almacenamiento de las cuestiones que hayan planteado al servicio. De igual forma, deben tratarse confidencialmente las preguntas que se empleen para la formación y publicidad del servicio. 


\subsection{Normas de la Virtual Reference Desk Network}

Se ha querido incluir entre los principales documentos que incorporan pautas para la prestación de los servicios de consulta electrónicos el denominado Aspectos de calidad para los servicios de referencia ${ }^{418}$ redactado por los expertos de la red Virtual Reference Desk (VRD). EI VRD se inició en 1997, como un proyecto especial del ERIC Clearinghouse on Information \& Technology. En enero de 2002 pasó a formar parte de la Education Digital Library Initiative. Su actividad cesó en marzo de $2005^{419}$. El "mostrador de referencia virtual" formaba parte de un proyecto del Departamento de Educación de los Estados Unidos, cuyo principal objetivo fue crear recursos y servicios basados en Internet, pero en el que el trabajo intelectual fuera el sustento de la calidad de los productos creados. A partir de este proyecto, se promovieron servicios como una lista de distribución para docentes, un directorio analítico de recursos web y una base de datos, además del servicio de referencia digital, en el que participan diversas bibliotecas e instituciones. Anualmente, el grupo de expertos se reunía para debatir acerca de las cuestiones relativas a la referencia digital, siendo muchas de las comunicaciones presentadas, aportaciones fundamentales en la investigación sobre servicios de referencias electrónicos ${ }^{420}$.

Al tratarse de un servicio cooperativo consideraron necesario establecer unas directrices comunes, a fin de ofrecer un servicio de calidad. Por este motivo nacen sus Facets of Quality for Digital Reference Services, cuya quinta y última versión fue finalizada en junio de 2003. El documento original data de 1997 y fue revisado en 1999 y en 2003, donde recibió significativas contribuciones. Se trata, por tanto, de un documento pionero, ya que, como se vio en esta misma sección de la tesis doctoral, las otras dos directrices importantes, las de la IFLA y las de la RUSA/ALA son de 2003. La versión definitiva de la VRD también son de ese año, aunque la primera edición de la mismas es de 1997, como se acaba de explicar. Con estas pautas, la red del VRD quería facilitar un documento que fuera aplicable a cualquier servicio de este tipo, ya fuera académico, escolar o público.

Los aspectos de calidad tratados en este documento se han estructurado en dos grandes bloques: la comunicación con el usuario y el desarrollo/gestión del servicio. La categoría dedicada al usuario incluye los componentes que se suceden durante el proceso de pregunta-respuesta, como accesibilidad, rapidez de los plazos, claridad de la política, interactividad o instrucción. El apartado de la gestión trata de la toma de decisiones a la hora de crear y

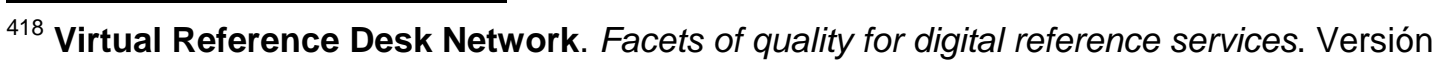
5. VRDN, 2003.

${ }^{419}$ Las fechas de la actividad del Virtual Reference Desk han sido facilitadas por David Lankes, quien fue su director. El doctorado agradece la colaboración del Doctor Lankes de manera especial, ya que no hay constancia de estos datos en ninguna fuente documental. Incluso, se realizó una consulta en este sentido al servicio de referencia de la Biblioteca del Congreso, quienes no pudieron ofrecer la respuesta, al no localizar las fechas solicitadas.

${ }^{420}$ Algunas de las ponencias de los encuentros anuales del VRD fueron editadas en forma de monografías, siempre coordinadas por David Lankes. Muchos de los materiales empelados en las presentaciones de cada conferencia anual pueden consultarse desde Webjunction: http://www.webjunction.org.
} 
mantener el servicio, para conseguir la calidad esperada y la satisfacción del usuario. El VRD es consciente de que los servicios de referencia digitales difieren unos de otros, por lo que ofrece dos niveles de recomendaciones de calidad, para que las bibliotecas las adapten a sus circunstancias. Por una parte, se encuentran las pautas esenciales, las que todos los miembros de una red deben cumplir y, por otra, las recomendaciones que cada biblioteca cumplirá en función de su situación actual y sus objetivos. Con todo, las pautas del VRD se presentan como un modelo aplicable a cualquier consorcio que ofrezca servicios de referencia en línea y para aquellas instituciones que las quieran tener como base para la creación de sus propias directrices, como hizo la IFLA, por ejemplo. A continuación, se describen las diferentes recomendaciones de la VRD, a partir de la estructura y numeración de la quinta versión, aunque el texto que se incorpora a la tesis no es una traducción de la misma, sino un resumen de los contenidos del documento. Tras cada aspecto tratado se incorpora la norma que se considera esencial.

\section{Comunicación con el usuario}

1. Accesibilidad. Los servicios de referencia digital deben presentar facilidad para su acceso y navegación por cualquier usuario de Internet, sin tener en cuenta el equipamiento, las discapacidades físicas o la barrera del idioma. Esencial: asegurarse de que el servicio es accesible y navegable por correo electrónico y formularios web.

2. Rapidez en los plazos. Las preguntas deben ser contestadas tan rápido como sea posible. Los tiempos dependerán de la política del servicio y de la disponibilidad de recursos (personal, presupuestos, tecnología, etc.). Esencial: responder al menos al $10 \%$ de las preguntas en dos días laborables.

3. Política de respuesta clara. La claridad en la comunicación debe presentarse antes o al inicio de cada sesión de referencia, para reducir las posibilidades de confusión del usuario o la recepción de preguntas inapropiadas. Esencial: crear y cumplir una política de respuesta clara.

4. Interactividad. Los servicios de referencia digitales deben posibilitar que la entrevista de referencia sea efectiva, para que los usuarios puedan comunicar sus necesidades de información y clarificar cuestiones vagas. Esencial: solicitar al usuario que facilite información como su edad o nivel académico y la materia de su consulta, a través de un formulario web o una comunicación posterior por correo electrónico.

5. Instrucción. Los servicios de referencia digitales proveen información actual y especializada. Los servicios de referencia digital de calidad ofrecen más a los usuarios que las respuestas factuales, ya que les guían en cómo formular preguntas, en organización del conocimiento y en alfabetización informacional. Esencial: ofrecer respuestas o fuentes de información para la contestación; cuando no sea posible dar una respuesta es necesario contestar al usuario con la comunicación apropiada. 


\section{Desarrollo y gestión del servicio}

6. Autoridad. Los expertos en referencia digital deben tener el conocimiento necesario y la formación académica del área temática que atiendan. Se deberán determinar niveles específicos, destrezas y experiencia necesaria en función de las disciplinas o campos. Esencial: asegurarse de que entre el personal hay al menos un experto cualificado que pueda supervisar la calidad y exactitud de las respuestas de la plantilla.

7. Formación de expertos. Los servicios deben ofrecer una orientación efectiva, por lo que hay que preparar al personal para responder usando un lenguaje claro y efectivo, siempre siguiendo las políticas y procedimientos. La formación de los referencistas es uno de los aspectos fundamentales en la planificación y práctica del servicio de referencia digital. Esencial: organizar alguna actividad de formación para todo el personal del servicio de referencia, aunque sea de manera informal.

8. Privacidad. Todas las comunicaciones entre los usuarios y los referencistas deben mantenerse en completa confidencialidad. Esencial: impedir el acceso público a los nombres de los usuarios, correos electrónicos, direcciones postales o preguntas, a menos que se haya informado previamente de que esta información puede estar disponible, a través de un formulario web, por ejemplo.

9. Revisión. Los servicios de referencia digitales deben evaluar regularmente sus procedimientos y servicios. La revisión continuada y la evaluación aseguran la calidad, eficiencia y fiabilidad de las comunicaciones, así como la satisfacción general del usuario. Esencial: comprobar periódicamente las respuestas dadas a los usuarios, para mejorar la calidad, exactitud, cumplimiento de las políticas y destrezas informacionales.

10. Ofrecer información relacionada. Además de dar la respuesta directa a las preguntas de los usuarios, los servicios de referencia digital pueden ofrecer el acceso a recursos de información y ayuda. Se podrán reutilizar los resultados de los procesos de pregunta-respuesta almacenados en los archivos o en las FAQ. Esencial: incluir recursos básicos en el sitio web como un complemento al servicio de preguntas y respuestas.

11. Publicidad. Se debe informar a los posibles usuarios de las ventajas del servicio. Un plan de relaciones públicas definido puede asegurar una estrategia de promoción. La publicidad no puede crear más demanda de la que el servicio sea capaz de manejar. Esencial: crear y difundir públicamente una descripción de la finalidad y la práctica del servicio. 


\section{Evaluación de los servicios de referencia digital}

La evaluación de la información que se ofrece en línea es el tema central de esta tesis doctoral. En primer lugar, se ha presentado el contexto teórico y práctico de los servicios bibliotecarios de referencia, para centrarse posteriormente en los que se prestan en línea por medio de redes y aplicaciones de comunicación, para, por fin, disertar acerca de la evaluación de la información y los servicios de referencia telemáticos. En el capítulo 7 se trató de la evaluación de los servicios de referencia, pero en éste se estudian los aspectos relativos al análisis de la referencia en línea. En primer lugar, se dedica un apartado a la metodología de evaluación de la información web, recurso de importancia esencial para la prestación de la referencia digital. Se describirán procedimientos y teorías de diferentes investigadores, al tiempo que se resumen los principales indicadores ofrecidos por estos teóricos. A continuación, se recogen metodologías de evaluación de la referencia digital, tomando como base el resultado de afamados y contundentes proyectos de investigación realizados en los Estados Unidos, país donde la referencia digital tiene mayor trayectoria y penetración. Además, el doctorando aporta sus planteamientos acerca de cómo se deben evaluar servicios públicos de información, un aspecto que no se ha contemplado en la literatura profesional, ya que todas las experiencias corresponde a servicios locales, aunque telemáticos, que prestan bibliotecas o consorcios bibliotecarios. En la parte tercera de esta tesis, se evalúa un servicio público de referencia digital, pero, antes, se ha establecido una metodología de evaluación adecuada para este tipo de servicios, que es la que se presenta en el último capítulo de este bloque.

\subsection{Evaluación de la información telemática}

La calidad de la información telemática es también evaluable. Son muchas las aportaciones teóricas y las experiencias prácticas que se pueden consultar sobre la información disponible a través de redes de información. El doctorando recogió muchas de las mismas y las sintetizó en una presentación llevada a cabo en la Universidad de Extremadura y publicada por dicha entidad ${ }^{421}$. Ese texto se ha retomado también para esta sección de la tesis doctoral, dada su adecuación con los contenidos que aquí se están desarrollando. Se parte de que todo tipo de información es susceptible de ser evaluada, sobre todo si se requiere reunir una colección de utilidad para los usuarios de un centro de información y de un servicio de referencia. La información almacenada en los soportes tradicionales, e incluso en los electrónicos, cuenta desde hace tiempo con un corpus teórico contrastado relativo a los criterios que se deben aplicar para la evaluación de la misma.

${ }^{421}$ Merlo Vega, José Antonio. La evaluación de la calidad de la información web: aportaciones teóricas y experiencias prácticas. En Recursos informativos: creación, descripción y evaluación. Mérida: Junta de Extremadura, 2003, p. 101-110. (Sociedad de la información, 8). 
Sin embargo, la información telemática, especialmente la accesible a través de Internet, todavía está siendo objeto de reflexión e investigación, a fin de ofrecer una serie de parámetros y procedimientos que sirvan de forma definitiva para analizar la calidad de la información accesible en línea. En los siguientes párrafos se expondrán los principales aspectos referidos a los criterios y métodos de evaluación del principal tipo de información telemática: aquella que se difunde a través de páginas web.

La información web es aquella que está elaborada en cualquiera de los lenguajes derivados del SGML y cuya característica más notable es ser documentos hipertextuales y multimedia. La unidad básica de los documentos de este tipo es la página web, entendida como el documento escrito en un lenguaje de marcado, con una localización única dentro de un servidor. El contenido de una página web puede ser independiente o bien estar vinculado a otras páginas web, entre las que existen enlaces hipertextuales y las cuales completan su información. En este caso, se denomina sitio web, al tratarse del conjunto de páginas web relacionadas entre sí por su autoría y porque su contenido sólo cobra sentido cuando se entiende de forma global, distribuido entre varias páginas web complementarias e interdependientes. Esta delimitación de conceptos es importante, ya que el proceso de evaluación de información telemática muchas veces podrá realizarse sobre páginas aisladas aunque, en la mayoría de los casos, el objeto será un sitio web en su conjunto.

La evaluación de sitios web es necesaria por motivos cuantitativos y cualitativos. El elevado número de páginas existentes -la base de datos de Google ya ha sobrepasado los diez mil millones de documentos- obliga a contar con criterios desde los que se extraiga la información de calidad de la abultada cifra de recursos inservibles, inoperantes y desdeñables. Asimismo, cualquier fuente de información sólo es válida si aporta contenidos útiles y si los mismos son localizados de forma sencilla. Por este motivo, también es necesario recurrir a parámetros que ayuden a identificar la información imprescindible y separarla de la que nada aporta. Es evidente que disponer de indicadores para aplicar en el proceso de evaluación es, sin lugar a dudas, necesario, sobre todo para los especialistas de los servicios de referencia digital, quienes utilizan los recursos de Internet como primera fuente de información.

La evaluación de la información telemática, como la de cualquier otro tipo, requiere una planificación concreta en la que se establecerán los criterios que se aplicarán y los métodos mediante los que se pondrán en práctica dichos criterios. Los criterios se materializarán mediante el uso de parámetros e indicadores de evaluación; mientras que los métodos se desarrollan a través de procedimientos concretos y la ayuda de los recursos necesarios para la realización positiva de los métodos ideados para llevar a cabo el proceso de evaluación. Parámetros, indicadores, procedimientos y recursos son, por tanto, los cuatro elementos clave del proceso de evaluación de la información web. 
- Los parámetros son los aspectos genéricos que serán evaluados. Se trata de establecer una serie de grandes bloques sobre los que se realizará el análisis y los cuales serán desarrollados en indicadores concretos que dan la información necesaria para cada uno de estos grupos. Existe un elevado número de propuestas o criterios genéricos, como puede observarse en las recopilaciones realizadas por Alastair Smith $^{422}$ o Robert Sebek ${ }^{423}$, muchas de ellas coincidentes.

- Los indicadores son los elementos que desarrollan cada uno de los parámetros establecidos para el análisis de la información. Son las cuestiones concretas que se evaluarán. Como ocurre con los parámetros, existen múltiples componentes que pueden ser considerados como un índice de la calidad de una página o de un sitio web. Como muestra puede citarse el estudio que Oliver, Wilkinson y Bennet ${ }^{424}$ realizaron en la Universidad de Georgia en el que reunieron más de quinientos criterios o indicadores válidos para el análisis de la información web.

- Los procedimientos son los métodos que se emplean para hacer efectiva la aplicación de parámetros e indicadores. Éste es el aspecto del proceso de evaluación que presenta un menor grado de desarrollo en cuanto a aportaciones teóricas o experiencias prácticas, ya que sólo hay propuestas aisladas y parciales. La planificación de cualquier proceso de evaluación no puede limitarse a delimitar qué se debe analizar sino también debe decir cómo se debe obtener la información relativa a los elementos que se están evaluando. La evaluación de información web adolece, en estos momentos, de una definición y sistematización de los procedimientos que se deberán aplicar.

- Los recursos son los materiales necesarios para el proceso de evaluación. Conocidos qué aspectos serán evaluados y cómo se procederá a su análisis será necesario establecer qué medios humanos, instrumentales y documentales son necesarios. Como ocurría con los procedimientos, los recursos también están poco estructurados y, por lo general, en la planificación y ejecución de la evaluación, sólo se contemplan los recursos humanos y algunos documentales como las listas de parámetros e indicadores y los formularios o plantillas de análisis. Sin embargo, un correcto proceso de análisis de la calidad de la información web debería dejar constancia, antes de comenzar con la evaluación, de todos los recursos que serán necesarios para el desarrollo del mismo.

\footnotetext{
${ }^{422}$ Smith, Alastair. Criteria for evaluation of Internet information resources [en línea]. Disponible en <http://www.vuw.ac.nz/staff/alastair_smith/evaln/index.htm> [Consulta: 15 julio 2007]

${ }^{423}$ Sebek; Robert. Bibliography on evaluating web information [en línea]. Disponible en <http://www.lib.vt.edu/help/instruct/evaluate/evalbiblio.html> [Consulta: 15 julio 2007]. Continúa la recopilación realizada por Nicole Auer.

${ }^{424}$ Oliver, K.M.; Wilkinson, G.L. Bennet, L.T. Evaluating the quality of Internet information sources [en línea]. Disponible en <http://www.eric.ed.gov/>. [Consulta: 17 julio 2007].
} 
Como se adelantó en los párrafos precedentes, existe un elevado número de aportaciones en cuanto a los parámetros e indicadores que se deben aplicar para la evaluación de recursos telemáticos. A continuación, se expondrán algunas de las que se consideran más significativas, ya sea por el rigor con el que se presentan, por la evidente utilidad de las mismas o por haber sido desarrolladas por autores de contrastada relevancia en el estudio de la calidad de la información web. Las teorías que aquí se presentan han sido publicadas en fuentes impresas o digitales y la identificación de todas ellas se expone en las citas bibliográficas que se mencionan a pie de página. Se pretende dejar constancia de los principales estudios, difundiendo los trabajos de singular relevancia y las conclusiones a las que han llegado los autores de los mismos.

Las aportaciones teóricas más importantes en España se deben al profesor Codina, quien en dos ocasiones ha publicado sus teorías sobre qué criterios deben aplicarse en cualquier proceso de análisis de la información digital. En la primera de ellas ${ }^{425}$, aunque indica que toda evaluación puede centrarse únicamente en el estudio del contenido y la autoría, establece catorce parámetros con sus correspondientes indicadores, los cuales divide en tres niveles de interés. Se exponen a continuación los catorce criterios genéricos sobre los que este autor va a desarrollar su primer esquema de indicadores:

1. Calidad y volumen de la información

2. Autoría: responsabilidad y solvencia

3. Legibilidad y ergonomía

4. Navegación y representación de la información

5. Recuperabilidad

6. Interactividad/Computabilidad

7. Velocidad de descarga

8. Servicios adicionales

9. Luminosidad

10. Calidad de los enlaces

11. Actualización de los enlaces

12. Descripción, selección y evaluación

13. Visibilidad

14. Autodescripción

Con acierto, este autor retoma sus teorías en otra publicación editada el mismo año ${ }^{426}$ (Codina 2000b), en la cual agrupa los criterios propuestos en sólo seis parámetros, que desarrolla con los correspondientes indicadores y con la novedad de que se facilitan algunas notas aclaratorias, que pueden ser útiles para el proceso de aplicación de los criterios expuestos. En esta segunda aportación de Codina los indicadores son los siguientes:

\footnotetext{
${ }^{425}$ Codina, Luis. Evaluación de recursos digitales en línea: conceptos, indicadores y métodos. Revista Española de Documentación Científica, 2000, vol. 23, n. 1, p. 9-44.

${ }^{426}$ Codina, Luis. Parámetros e indicadores de calidad para la evaluación de recursos digitales. En Jornadas Españolas de Documentación (7. 2000. Bilbao). La gestión del conocimiento: retos y soluciones de los profesionales de la información. Bilbao: Universidad del País Vasco, 2000, p. 135-144.
} 
1. Autoría: adecuación y solvencia de la fuente

2. Contenido: valor intrínseco y volumen de la información

3. Acceso a la información: navegación y recuperación

4. Ergonomía: comodidad y facilidad de utilización

5. Luminosidad: presencia y calidad de enlaces externos

6. Visibilidad: número de enlaces que recibe de otros recursos

En el mercado en español existe una monografía específica sobre evaluación de sitios web, publicada por Trea en $2007^{427}$. En esta obra se realiza un estado de la cuestión sobre la evaluación de la calidad de la información telemática, así como la metodología que se puede emplear para medir y comparar sitios web. Una buena aportación de este trabajo es que puede servir de base a los gestores de contenidos y diseñadores de sitios web, ya que ofrece los elementos fundamentales en los que una sede web asienta su calidad.

Siguiendo con las aportaciones teóricas, también es útil la sistematización de criterios que realiza Nicole Auer ${ }^{428}$, quien, además, era responsable de una de las recopilaciones más completas de artículos y proyectos relacionados con la calidad de la información web. Para dicha autora, quien se basa en estudios previos de otros investigadores, los parámetros para evaluar información accesible en Internet son cinco: autoría, cobertura, objetividad, exactitud y actualidad. Para cada uno de los parámetros Auer desarrollaba una serie de indicadores, una exposición razonada de por qué es necesario cada parámetro y los métodos que se podían emplear para aplicar los indicadores sugeridos.

El mismo número de parámetros, en gran medida coincidentes, son los que se deben emplear en opinión de Janet Alexander y Marsha Tate, autoras de uno de los pocos manuales impresos ${ }^{429}$ sobre cómo evaluar la información web. Un dato interesante del estudio realizado por ambas autoras es que, antes de desarrollar los parámetros de calidad de la información web, comentan estos mismos criterios aplicados al análisis de las fuentes de información tradicionales. Esta perspectiva de la evaluación de las páginas web como fuente de referencia, dota a las teorías de estas autoras de un grado extraordinario de interés para quienes trabajan en unidades de información, tal y como ocurre con el esquema propuesto años antes por Carolyn Caywood ${ }^{430}$. Los cinco criterios de Alexander y Tate son, una vez más, autoridad, exactitud, objetividad, actualidad y cobertura y destinatarios.

${ }^{427}$ Jiménez Piano, Marina; Ortiz-Repiso Jiménez, Virginia. Evaluación y calidad de sedes web. Gijón: Trea, 2007.

${ }^{428} \mathrm{El}$ artículo de Nicole Auer en el que se defendían estas teorías era Evaluating internet information y estaba accesible en línea en el servidor de la Universidad Virgina Tech, en la dirección <http://www.lib.vt.edu/research/libinst/idle/evaluating.html>.

${ }^{429}$ Alexander, Janet.; Tate, Marsha. Web wisdom: how to evaluate and create information quality on the Internet. Mahwah: Lawrence Erlbaum Associates, 1999.

${ }^{430}$ Caywood, Carolyn. Library selection criteria for WWW resources. Public libraries, may/june 1996, p. 169. Disponible originalmente en línea, desde 1995. En la actualidad desde la siguiente dirección <http://www.keele.ac.uk/depts/aa/landt/lt/Internet/criteria.htm>. [Consulta 15 julio 2007]. 
Otra monografía de interés sobre el tema es la que firma Alison Cooke ${ }^{431}$ y que se presenta como un guía para evaluar la información accesible en Internet. Esta autora prefiere no establecer una lista única de elementos de análisis, sino que desarrolla distintas relaciones de criterios para aplicar en función del tipo de información o servicio que se esté evaluando: sitios web institucionales, páginas personales, directorios temáticos, publicaciones electrónicas, bases de datos, sitios de transferencia de ficheros, etc. No obstante, pueden entenderse como parámetros generales los que expone para cualquier fuente de información de Internet, los cuales vienen acompañados de sus correspondientes listas de indicadores, una vez explicado el porqué de cada parámetro o aspecto general de análisis. En definitiva, estos son los criterios propuestos:
1. Propósito
2. Cobertura
3. Autoridad y reputación
4. Exactitud
5. Actualidad y mantenimiento
6. Accesibilidad
7. Presentación y organización de la información
8. Facilidad en el uso
9. Comparación con otras fuentes
10. Calidad global del recurso

Las teorías de Jim Kapoun ${ }^{432}$ también inciden en los aspectos hasta ahora expuestos, ya que este autor habla de exactitud, autoridad, objetividad, actualidad y cobertura como los cinco criterios que se deben aplicar en la evaluación de documentos web. Para cada uno de ellos se aportan dos o tres indicadores que los desarrollan.

Similar es la opinión de Alastair Smith ${ }^{433}$, responsable además de otra de las importantes colecciones de recursos sobre evaluación de información telemática accesibles en Internet y cuya localización ya se ha mencionado en nota. En este caso se habla de siete criterios: cobertura, contenido, diseño gráfico y multimedia, propósito, reseñas, usabilidad y costes. De forma muy resumida este autor apunta los indicadores que integran cada uno de los parámetros.

\footnotetext{
${ }^{431}$ Cooke, Alison. Neal-Schuman authoritative guide to evaluating information on the Internet. New York: Neal-Schuman, 1999.

${ }^{432}$ Kapoun, Jim. Teaching undergrads WEB evaluation: A guide for library instruction, $C \& R L$ News, July/August 1998, Vol. 59 No. 7. Disponible en línea en <http://www.ala.org/ala/acrl/ acrlpubs/crlnews/backissues1998/julyaugust6/teachingundergrads.htm>. [Consulta 17 julio 2007].

${ }^{433}$ Smith, Alastair. Criteria for evaluation of Internet information resources [en línea]. <http://www.vuw.ac.nz/ agsmith/evaln/index.htm>. [Consulta: 17 julio 2007]. Otra versión de estas teorías fue publicada en el artículo: Smith, Alastair G. Testing the Surf: Criteria for Evaluating Internet Information Resources. The Public-Access Computer Systems Review,1997, vol. 8, no. 3, disponible en <http://epress.lib.uh.edu/pr/v8/n3/smit8n3.html>. [Consulta: 17 julio 2007]
} 
Por último, uno de los proyectos sobre la evaluación de la calidad de las fuentes de información en Internet mejor llevados a cabo es el que desarrollaron Gene Wilkinson, Lisa Bennet y Kevin Oliver ${ }^{434}$ en la Universidad de Georgia entre 1996 y 1998. En las fases previas de su trabajo se llegaron a manejar decenas de indicadores, los cuales quedaron reducidos a 125 en la última versión presentada y que se agrupan en los siguientes once parámetros:

1. Accesibilidad y usabilidad del sitio

2. Identificación del recurso y documentación sobre el mismo

3. Identificación del autor

4. Autoridad del autor

5. Diseño y estructura de la información

6. Relevancia y alcance del contenido

7. Validez del contenido

8. Exactitud y fiabilidad del contenido

9. Navegación dentro del documento

10. Calidad de los enlaces

11. Aspectos estéticos y afectivos

Aparte de estas teorías existen decenas de artículos y proyectos que han establecido patrones de calidad de la información web. No obstante, las aquí reflejadas son algunas de las de mayor trascendencia o importancia en la investigación sobre este tema. Hasta el momento, se han incluido los textos que dieron lugar a los primeros resultados de las investigaciones sobre este asunto, especialmente los relacionados con las colecciones de referencia o de interés para bibliotecas, a pesar de que existen decenas de estudios en los que se analiza la calidad de la información web. Por incluir uno de los más recientes, actualizado en junio de 2007, es interesante comentar la lista CARS de Robert Harris ${ }^{435}$, quien establece una serie de parámetros de análisis para la evaluación de fuentes de información en Internet. Su lista de evaluación de recursos web parte de cuatro grandes parámetros: credibilidad (credibility), exactitud (accuracy), sensatez (reasonableness) y ayuda (support). Cada uno de estos parámetros se desarrollan en indicadores específicos, que se reproducen de forma resumida a continuación:

- credibilidad: credenciales del autor, muestras del control de la calidad, metainformación, indicadores de carencia de credibilidad (anonimato, mala expresión, etc.)

- exactitud: atemporalidad, amplitud, destinatarios y propósito, indicadores de falta de precisión (ausencia de fecha, generalidades, etc.)

\footnotetext{
${ }^{434}$ Oliver, K.M.; Wilkinson, G.L. Bennet, L.T. Evaluating the quality of Internet information sources [en línea]. Disponible en <http://www.eric.ed.gov/>. [Consulta: 17 julio 2007].

${ }^{435}$ Harris, Robert. Evaluating Internet Research Sources [en línea]. Versión 15 junio 2007. Disponible en <http://www.virtualsalt.com/evalu8it.htm>. [Consulta 15 julio 2007].
} 
- sensatez: imparcialidad, objetividad, moderación, consistencia, opiniones, indicadores de ausencia de sensatez (tono, tendencia, incumplimiento de expectativas, etc.)

- ayuda: fuentes y bibliografía, comprobación, comparación con otras fuentes, indicadores de carencia de ayuda (fuentes no identificadas, ausencia de fuentes, etc.)

Los indicadores de exactitud aplicables a la referencia fueron analizados por Frické y Fallis ${ }^{436}$. Estos autores ofrecen una útil panorámica de la investigación en evaluación de la calidad de la información web especializada en referencia y ofrecen una metodología propia ideada para comprobar la exactitud de un recurso. En su investigación emplean indicadores propuestos por diversos autores, que someten a un análisis en el que intervienen herramientas como buscadores o barras de búsquedas.

En España es de interés el trabajo de Ayuso y Martínez ${ }^{437}$ sobre evaluación de calidad de fuentes y recursos digitales. Las profesoras de la Universidad de Murcia ofrecen una guía de buenas prácticas a partir de una propuesta de protocolo de actuación para analizar la calidad de fuentes de información publicadas en Internet. Las autoras han elaborado un instrumento evaluativo basado en tres secciones: micronavegación, donde se examinan los aspectos de organización y estructura de la web; macronavegación, en donde se analiza la importancia del recurso dentro de contexto general de la web, así como su luminosidad y visibilidad; y usabilidad, para la que se examinan aspectos como la facilidad de uso o las posibilidades de relación. Su protocolo es llevado a la práctica en el mencionado artículo, ofreciendo la evaluación de una serie de sitios web que cumplen los parámetros establecidos en este estudio.

También es conveniente reflejar algunas de las aplicaciones prácticas de evaluación de recursos web. La evaluación de la calidad de la información web es especialmente importante para los servicios o instituciones que mantienen directorios de recursos en Internet, así como para los servicios de referencia digitales, como avanzados usuarios de información web. Estos organismos necesitan basarse en criterios cualitativos objetivos para formar sus colecciones de documentos digitales. Por ese motivo, administradores de contenidos web, responsables de portales, índices o directorios y agencias de evaluación recurren a distintos parámetros, normalmente establecidos por ellos mismos, para analizar y escoger la información que contendrán sus servidores. En otros casos, la selección se realiza de forma más subjetiva, partiendo de los intereses específicos de la institución que realiza la recopilación de los recursos. Por último, es importante destacar cómo algunos de los directorios más consultados de la red, como WWW

\footnotetext{
${ }^{436}$ Frické, Martin; Fallis, Don. Indicators of Accuracy for Answers to Ready Reference Questions on the Internet. Journal of the American Society for Information Science and Technology, 2004, vol. 55, n. 3, p. 238-245.

${ }^{437}$ Ayuso García, María Dolores; Martínez Navarro, Victoria. Evaluación de calidad de fuentes y recursos digitales: guía de buenas prácticas. Anales de documentación, 2006, n. 9, p. 17-42.
} 
Virtual Library <http://vlib.org> o BUBL <http://bubl.ac.uk> no poseen criterios específicos de evaluación y parten de elementos personales para la creación de sus índices de recursos telemáticos.

Uno de los servicios de análisis de contenidos web más laureado fue Argus Clearinghouse, proyecto de la Universidad de Michigan iniciado en 1993 y posteriormente dependiente de Internet Public Library ${ }^{438}$. En este directorio sólo se incluían guías o directorios de recursos. La evaluación de los mismos se hacía partiendo de los cinco criterios generales que a continuación se exponen:

- Descripción del recurso: explicación de los contenidos, acceso y alcance de los enlaces seleccionados.

- Evaluación del recurso: comentarios acerca de la tipología de los sitios analizados, su utilidad y autoría.

- Diseño: aspectos estéticos y de usabilidad.

- Organización del contenido: métodos empleados para sistematizar las páginas incluidas en las distintas guías de recursos.

- Metainformación: datos acerca de cuáles son los objetivos del directorio, cómo es elaborado y por quién, periodicidad de sus actualizaciones, etc.

Un buen ejemplo de directorio temático que aplica criterios de evaluación de forma estricta fue SOSIG, Social Science Information Gateway quien dividía el análisis de los sitios incluidos en su índice en tres aspectos: el contenido, la navegación y las características del web. En cuanto al contenido se evaluaba su validez (exactitud, fiabilidad, etc.), su autoría y reputación de la fuente y la importancia de la información incluida en el recurso, así como su exactitud, exhaustividad, unicidad y organización de la misma. En cuanto a la navegación por el web se analizaban aspectos como la facilidad de uso, las ayudas que ofrece, el uso de las normas aprobadas, el uso apropiado de la tecnología y la estética. Por último, se evaluaba el sitio web de forma general, comprobando la actualidad de la información, la autoridad del administrador del web y el funcionamiento del sistema.

SOSIG está ahora incluido en Intute ${ }^{439}$, directorio analítico que ha unido los esfuerzos y contenidos de las principales selecciones de recursos efectuadas en diferentes disciplinas.

\footnotetext{
${ }^{438}$ Internet Public Library: http://www.ipl.org

${ }^{439}$ Intute: http://www.intute.ac.uk. Intute se presentó el 13 de julio de 2006, recogiendo el testigo de algunos de los tradicionales directorios analíticos existentes hasta el momento, que se fusionaron en esta excelente fuente de información, como SOSIG (ciencias sociales), Humbul (humanidades), EEVL (ingeniería y matemáticas) o Psygate (física) entre otros.
} 
Uno de los recursos de información francófonos más interesante es Sapristi! ${ }^{440}$, quien aplica también una serie de criterios de calidad antes de incluir sitios web a su directorio. En este caso, los parámetros que se analizan son el contenido, el organismo y autor responsables, el punto de vista del que se parte para la elaboración del web, la información previa que hay sobre el sitio y la veracidad de los datos incluidos en el directorio. También merece la pena incluir en este panorama de aplicación de criterios de calidad para la selección de recursos web, el esquema que sigue la Commission "Français et Informatique"441, quien basa el análisis que realiza de los recursos informativos que integran su directorio temático en las siguientes cuestiones:

- ¿quién?: autoría

- ¿qué?: contenido

- ¿dónde?: área geográfica

- ¿cuándo?: actualidad

- ¿cómo?: exposición de los datos

- ¿por qué?: finalidad del web

También es destacar el Internet Scout Project ${ }^{442}$, que se convirtió en todo un referente de los directorios analíticos existentes en Internet. Como criterios fundamentales para la selección y posterior análisis de recursos web se emplearon los siguientes: contenido (alcance, usuarios, propósito, actualización, exactitud), autoridad de los responsables en la materia, mantenimiento de la información, presentación (navegabilidad, usabilidad, organización de la información), disponibilidad o validez de los enlaces seleccionados y coste de la información (gratuidad o pago).

Existen numerosos ejemplos de criterios de los que se parte para la selección de sitios o páginas web, aunque muy pocos han sido desarrollados con rigor o están siendo aplicados con propiedad. Esto se debe a que hay escasas entidades encargadas de la evaluación de recursos y menos aún las que no tienen intereses comerciales. Los ejemplos de Intute o de Internet Public Library, como directorios analíticos de recursos web de calidad, son de los pocos existentes en los que se toman en cuenta criterios de análisis antes de seleccionar y recomendar recursos de utilidad para los usuarios de sus directorios. De igual forma, los servicios bibliotecarios de referencia deben crearse colecciones de recursos telemáticos, que puedan ser útiles para responder las preguntas de los usuarios. Para ello, es conveniente disponer de criterios de evaluación que ayuden a su selección.

Para finalizar este apartado se quiere incluir una aportación específica relativa a los estándares de calidad en los servicios de referencia digitales, que se incluye en el excelente trabajo de Charles McClure y otros que se comenta en el siguiente apartado de la tesis. Los autores del manual Statistics, Measures and Quality Standards for Assessing Digital Reference

\footnotetext{
${ }^{440}$ Sapristi!: http://docinsa.insa-lyon.fr/sapristi

${ }^{441}$ Commission "Français et Informatique":

http://users.skynet.be/ameurant/francinfo/index.html

${ }^{442}$ Internet Scout Project: http://scout.cs.wisc.edu
} 
Library Services ${ }^{443}$ proponen los siguientes estándares de calidad en la provisión de servicios de referencia digitales:

1. Cortesía: percepción del usuario en cuanto al trato recibido.

2. Precisión: corrección de la respuesta.

3. Satisfacción: nivel de satisfacción general con el servicio.

4. Usuarios que repiten: porcentaje de personas que vuelven a emplear el servicio.

5. Conocimiento del servicio: porcentaje de la población que conoce el servicio.

6. Costes: gasto que supone la provisión del servicio.

7. Tiempo de finalización: media de tiempo que se tarda en satisfacer una demanda de información.

8. Accesibilidad: sencillez en el manejo y adecuación del sistema a los estándares de usabilidad.

\subsection{Metodologías de evaluación de la referencia digital}

En los apartados anteriores de esta tesis doctoral se han desarrollado los contenidos generales sobre la evaluación de los servicios de referencia, aplicables sobre todo los que se prestan de forma presencial, los denominados servicios de referencia tradicionales. Asimismo, se ha querido incidir en la evaluación de la calidad de la información web, aquella que se obtiene en Internet a través de navegadores, que es un recurso esencial para los servicios de consulta electrónicos. No obstante, es necesario precisar aún más y exponer estándares para el análisis de servicios digitales de referencia, que se empleen de forma exclusiva en aquellas bibliotecas que reciben consultas por medios digitales y las responden por los mismos medios. Aunque la bibliografía profesional no es extensa en este tema, sí existen publicaciones que merecen la pena ser destacadas ${ }^{444}$ y tomadas como punto de partida para el establecimiento de indicadores de evaluación de la referencia digital. Son especialmente importantes las aportaciones del proyecto de la red UNISON en Australia ${ }^{445}$, que ofrece una relación de indicadores clave para el análisis de la referencia digital.

\footnotetext{
${ }^{443}$ Mac Clure, Charles R.; Lankes, R. David; Gross, Melissa; Choltco-Devlin, Beverly. Statistics, Measures and Quality Standards for Assessing Digital Reference Library Services: Guidelines and Procedures. Syracuse, New York: Information Institute of Syracuse; Tallahassee, Florida: School of Information Studies, 2002, p. 60-61.

${ }^{444}$ Es útil el trabajo aportado por Gilbert, Lauren Miranda; Mengxiong, Liu; Matoush, Toby; Whitlatch, Jo Bell. Assessing Digital Reference and Online Instructional Services in an Integrated Public/University Library. The Reference Librarian, 2006, vol. 46, n. 95, p. 149172. Se explican las metodologías seguidas para la evaluación de servicios de referencia mediante correo electrónico y de chat, así como el análisis de la calidad de tutoriales en línea. También la aportación de Hodges, Ruth A. Assessing digital reference. Libri: International Journal of Libraries and Information Services, 2002, vol. 52, n. 3, p. 157-168. ${ }^{445}$ Los indicadores de UNISON son expuestos en Rigby, Alison; Smithers, Amanda. From sercive to survey: The UNISON Digital Reference Key Performance Indicators Project. En Information Online 2007 [en línea]. Australia Library and Information Association, 2007. Disponible en <http://www.information-online.com.au/docs/Presentations/oncon.pdf> [consulta 12 septiembre 2007].
} 
Rösch ${ }^{446}$, además de establecer su propia clasificación de los medios asíncronos y sincrónicos mediante los que se puede prestar referencia digital, sistematiza los criterios de calidad que se deben aplicar en la práctica de la referencia digital, que divide en siete categorías: organización del proceso de referencia; eficiencia; extensión o alcance del servicio; proceso de comunicación; calidad de la respuestas; uso del servicio; y evaluación del servicio. Por otro lado, Gross ${ }^{447}$, analizó las aportaciones más importantes para tomarlas como base en el proyecto del Information Institute de Syracuse, que se comentará seguidamente y del que se puede afirmar que es la metodología más completa realizada para la evaluación de la referencia digital.

Muchas de las experiencias de interés relacionadas con la evaluación de los servicios de referencia digitales fueron recogidas en el número especial de The Reference Librarian ${ }^{448}$, titulado Assessing Reference and User Services in a Digital Age; pero, sin duda, la principal aportación realizada en relación a la evaluación de los servicios de referencia digitales es la que corresponde al manual Statistics, Measures and Quality Standards for Assessing Digital Reference Library Services: Guidelines and Procedures ${ }^{449}$. La obra es el resultado de un proyecto de investigación con el mismo título que tiene su origen en la Virtual Reference Desk Conference, celebrada en 2000 en Seattle. En dicho congreso se constató la necesidad de disponer de elementos para la evaluación de los emergentes servicios de referencia digital. En marzo de 2001 se inició el proyecto, que fue concluido en mayo de 2002. En la investigación participaron diferentes bibliotecas e instituciones de Estados Unidos y de Gran Bretaña. El manual producto de la investigación ofrece una relación completa para aplicar en la evaluación de los diferentes ámbitos de la referencia digital. Además, se describen los procedimientos necesarios para analizar los servicios y compararlos con los de otras bibliotecas.

Los autores reúnen treinta y cinco medidas, estadísticas y estándares para la evaluación de servicios de referencia digitales. Cada uno de estos indicadores se presenta bajo un mismo esquema, que comienza con la definición de la medida, estadística o norma, que continúa con los fundamentos de las mismas, para describir posteriormente los procedimientos de recopilación de los datos correspondientes a cada indicador, además de incluir observaciones y comentarios. En los siguientes párrafos se resumen las informaciones más relevantes sobre los distintos

\footnotetext{
${ }^{446}$ Rösch, Herman. Digital reference services: state of the art in the focus of quality. En IFLA General Conference and Council (72. 2006. Seúl). Seúl: IFLA, 2006. Disponible en $<$ http://www.ifla.org/IV/ifla72/papers/098-Roesch-en.pdf> [consulta 17 julio 2007]. ${ }^{447}$ Gross, Melissa. Assessing Quality in Digital Reference Services: Overview of Key Literature on Digital Reference. Syracuse, NY: Information Institute of Syracuse, 2001.

${ }_{448}$ Novotny, Eric (ed.). Assessing Reference and User Services in a Digital Age. The Reference Librarian, 2006, no 95/96. Este número doble también fue publicado como monografía: Binghamton, New York: The Haworth Press, 2007.

${ }^{449}$ Mac Clure, Charles R.; Lankes, R. David; Gross, Melissa; Choltco-Devlin, Beverly. Statistics, Measures and Quality Standards for Assessing Digital Reference Library Services: Guidelines and Procedures. Syracuse, New York: Information Institute of Syracuse; Tallahassee, Florida: School of Information Studies, 2002.
} 
sistemas propuestos en el mencionado manual. Los diferentes indicadores se organizan en siete grupos: estadísticas y medidas descriptivas, análisis del sistema, medidas de satisfacción de los usuarios, costes, tiempo empleado por el personal, otras opciones de evaluación y estándares de calidad. Cada indicador va acompañado de una serie de recursos que pueden ser tomados como ejemplos o materiales para la evaluación y que se presentan como anexos al final de este documento, el más completo en su género dentro de la bibliografía profesional internacional.

Las medidas que pueden ser empleadas para una completa evaluación de los servicios de referencia que se prestan por medios digitales son las siguientes:

1. Número de preguntas de referencia digital recibidas. Se trata de contabilizar el número de cuestiones que se recibieron por vía electrónica: correo electrónico, formularios web, chat, etc. No se deben incluir aquí las recibidas por teléfono, fax o correo postal. Es conveniente contar de forma independiente cada una de las preguntas recibidas, aunque hayan sido hechas en el mismo mensaje de correo electrónico, por ejemplo. Con esta medida se conoce el volumen de trabajo del servicio. Este indicador podrá se comparado con el número de preguntas respondidas. También podrán desagregarse las preguntas recibidas por cada uno de los medios puestos a disposición del usuario (correo electrónico, chat, formularios, telefonía IP, etc.). Los datos se extraerán del sistema, aunque el personal debe completarlos manualmente. La frecuencia de recogida de datos debe ser diaria, aunque es conveniente que sean tabulados en periodos quincenales.

2. Número de contestaciones del servicio de referencia digital. Número de veces que el personal de la biblioteca se ha dirigido a un usuario para contestar una pregunta realizada al servicio de referencia digital. No se incluyen aquí las veces que el usuario se ha puesto en contacto con el personal. Los contactos entre el personal y los usuarios pueden ocurrir por correo electrónico, formularios web, sesiones de vídeo interactivo, voz IP, chat o a través de software específico para la referencia digital. Se debe contabilizar por separada cada acción de contacto, aunque se inicie con un procedimiento, por ejemplo chat, y se continúe con otro, por ejemplo correo electrónico. Esta medida se combina necesariamente con la anterior. También se emplea para analizar cuestiones como los posibles fallos tecnológicos, la efectividad de la entrevista de referencia digital o el grado de esfuerzo que supone contestar una pregunta. Los periodos y sistemas de recogida de datos son los mismos que en el estándar anterior.

3. Número de respuestas del servicio de referencia digital. Cifra de las respuestas que proporcionan la información que el usuario está buscando para su pregunta. El conjunto de las respuestas está compuesto por las comunicaciones con el usuario para dar una respuesta a su pregunta, las direcciones de recursos que pueden servirle para satisfacer su demanda y el envío a otros agentes que puedan ayudarle en su pregunta. Se contabilizan todas las respuestas dadas por medios digitales, aunque la pregunta haya sido hecha por a través de otros sistemas. Esta medida se combinará con la 
correspondiente a la que mide el tiempo de respuesta, así como con las dos primeras. También conviene recoger estos datos diariamente y tabularlos de forma quincenal.

4. Número de preguntas recibidas digitalmente pero no contestadas o respondidas completamente por medios digitales. Esta medida se refiere únicamente a aquellas preguntas que se han recibido por medios digitales, pero que se han contestado con los métodos tradicionales o usando una combinación de ambos. En ocasiones una pregunta realizada por correo electrónico se puede contestar mediante una llamada de teléfono o el envío de un documento por fax, por ejemplo; por eso conviene separar este tipo de preguntas de las que se reciben y responden completamente por procedimientos digitales. Se trata de tener conocimiento de la proporción de este tipo de usos del servicio, para planificar el personal, su formación, los gastos de materiales, la organización de los servicios presenciales y telemáticos, etc. Los periodos de recogida de estos datos son los mismos que hasta ahora se están proponiendo.

5. Actividad total de la referencia - Preguntas recibidas. La actividad total de la referencia se refiere al número íntegro de preguntas recibidas y se calculará sumando el número de preguntas recibido, el número de preguntas recibidas digitalmente pero no respondidas completamente por medios digitales y el número de preguntas recibidas en los servicios tradicionales de referencia. Esta medida es útil en la evaluación del servicio de referencia en general. La recogida de los datos será diaria y la tabulación cada dos semanas.

6. Porcentaje de las preguntas de la referencia digital del total de las preguntas de referencia. Se trata de dividir el número de preguntas recibidas por medios electrónicos entre el total de las preguntas de referencia recibidas por cualquier medio. El resultado es multiplicado por 100 para conocer el porcentaje. Este dato servirá para la planificación del servicio general de referencia. Se realizará el informe anualmente, aunque la consulta al sistema se deberá realizar cada día y la tabulación de los datos semanalmente. Se requiere una coordinación estrecha entre el personal que atiende el servicio de referencia tradicional y el que se encarga del digital.

7. Tasa de respuestas completadas de forma correcta. Se trata de obtener el porcentaje de preguntas contestadas correctamente y por completo en relación al total de respuestas dadas. La manera de hallar este índice es dividir el número de respuestas correctas entre el número total de respuestas dadas y multiplicar el resultado por 100. Esta medida sirve para saber si se están cumpliendo los objetivos. Este dato debe ser recogido por el coordinador del servicio, en principio de forma anual, aunque puede ser recomendable obtener en periodos más breves. Existen diferentes formas de obtener este indicador. Una fórmula es establecer un grupo de revisión por pares, que analice de forma individual un cierto número de cuestiones o un periodo concreto. Los resultados de cada miembro se cruzarían con los de los demás, para quedarse con aquellos en los que hubiese habido consenso. Otro método es el estudio discreto, en el que se plantean preguntas de las 
que ya se conocen las respuestas, para comprobar el grado de acierto ${ }^{450}$. También se puede acudir al análisis de un observador externo.

8. Tiempo de conclusión de la referencia digital. Esta medida se refiere al tiempo medio que se tarda en dar una respuesta por medios digitales a una pregunta recibida por los mismos medios. Esta medida sirve tanto para conocer si se está respondiendo en un tiempo razonable como establecer los plazos que se indicarán a los usuarios. Esta información se recogerá de forma diaria y se tabulará de manera quincenal. Anualmente se informará de este dato. No se debe descontar el tiempo que el personal no ha estado trabajado en la pregunta. Se debe incluir todo el tiempo que haya transcurrido entre la pregunta y la respuesta.

9. Número de preguntas del servicio de referencia digital sin responder. Se incluyen aquí las preguntas que no han podido ser satisfechas y las que se han contestado de forma incompleta. Se entiende como incompletas las preguntas que no han podido ser contestadas porque el usuario no ha respondido a las cuestiones planteadas por el personal para poder contestar su pregunta. También se incluyen las preguntas que no se han contestado por incapacidad de la biblioteca (medios o recursos). De igual forma se contabilizan aquí las preguntas que no tienen respuesta y las que fueron contestadas pero, por error técnico o humano, nunca fueron enviadas a los usuarios.

10. Tipo de preguntas recibidas en el servicio de referencia digital. Es necesario asignar un tipo concreto a cada pregunta. Las categorías propuestas son: cuestiones bibliográficas, preguntas de instrucción, búsqueda de literatura, asesoramiento bibliográfico, referencia rápida, cuestiones de investigación, aspectos técnicos, fuera de ámbito, otras preguntas. Conocer el número de preguntas correspondiente a cada tipo servirá para desarrollar las colecciones de forma conveniente, así como para planificar el servicio, formar conveniente al personal y realizar las modificaciones que se consideren necesarias. Como en otras medidas, los datos de este indicador deberán ser recogidos diariamente, tabulados quincenalmente e incluidos en el informe anual.

11. Número de reenvíos. Se trata de contabilizar el número de ocasiones en las que un usuario ha sido remitido a otro punto de información dentro de la biblioteca, del servicio de referencia digital o de un agente externo. Los reenvíos pueden deberse a diversas causas: usuarios no registrados, preguntas inapropiadas para el servicio o falta de los recursos de información necesarios. No se incluyen aquí los envíos al usuario a fuentes de información donde puede encontrar la respuesta independientemente. Esta medida sirve para apoyar el desarrollo equilibrado de las colecciones.

\footnotetext{
${ }^{450}$ Un ejemplo de estudio discreto, llevado a cabo en la biblioteca de la Southeastern Lousiana University puede consultarse en Hill, J. B.; Madarash-Hill, Cherie; Bich, Ngoc Pham Thi. Digital Reference Evaluation: Assessing the Past to Plan for the Future. Electronic Journal of Academic and Special Librarianship [en línea], Fall 2003, vol. 4, n. 2-3. Disponible en http://southernlibrarianship.icaap.org/content/v04n03/Hill_j01.htm [consulta 18 agosto 2007].
} 
También es útil para planificar el alcance del servicio de referencia digital. Cuando los reenvíos son internos este indicador se empleará para reorganizar el personal. En cuanto a los reenvíos externos, con este dato se podrán seleccionar posibles entidades colaboradoras para la prestación del servicio.

12. Tasa de saturación. Medida de la ratio de los usuarios del servicio de referencia digital que son miembros de la población objeto del servicio del número total de los miembros de la población destinataria. El dato se obtiene dividiendo el número de usuarios entre el total de la población y multiplicando el resultado por cien. Esta tasa indica el grado de exhaustividad o penetración del servicio entre los habitantes de la zona de influencia de la biblioteca o de la población potencial a quien va dirigido el servicio de referencia digita. Esta medida ayudará en la toma de decisiones relativas a publicidad, nivel de penetración, dotación de recursos, etc. Esta estadística es responsabilidad de la dirección ${ }^{451}$ o coordinación del servicio y se debe realizar de forma mensual o anual.

13. Recursos empleados por pregunta. Esta medida identificará el número de fuentes empleadas para responder a una cuestión planteada en el servicio de referencia digital. Se deben incluir todo tipo de recursos empleados, tanto electrónicos como impresos. También aquellos recursos que han sido creados por el propio personal del servicio. La importancia de esta medida estriba en un mejor conocimiento de la colección que se emplea y la posible mejora de la misma. El nivel de detalle de este indicador dependerá de lo que necesite la biblioteca. Se puede simplificar haciendo una categorización sencilla, dividiendo los tipos de recursos en: gratuitos, creados por la biblioteca, recursos de pago, colección tradicional, otros.

14. Tasa de retorno. Número de usuarios que emplean el servicio más de una vez. El número de usuarios que repiten es una medida que indica satisfacción con el servicio. Este indicador puede combinarse con el número de usuarios nuevos. La frecuencia de recogida del dato será mensual. Se trata de una medida difícil de recopilar y aún más difícil de analizar. Este indicador no proporciona por sí mismo información cualitativa acerca de por qué los usuarios repiten, por lo que debe combinarse con otro indicador posterior, relativo a las razones para usar el servicio de referencia digital.

15. Número de sesiones de referencia digital. Esta medida consiste en conocer el número total de sesiones registradas en el servicio, empleado su página web, software de charla en tiempo real, vídeo digital interactivo, etc., anotadas en el sistema. También se deben incluir las sesiones de consulta a las FAQ y a los archivos del sistema. Sin embargo, se excluyen los accesos a la página de bienvenida del sitio web de la biblioteca que no

\footnotetext{
${ }^{451}$ Para profundizar sobre los perfiles de los responsables de los servicios de referencia es muy útil el siguiente artículo: Howze, Philip C. Training the New Head of Reference:

Focusing on the Supervising Relationship as Technique. The Reference Librarian, 2003, vol. 39 , n. 81, p. 51-58.
} 
corresponde directamente al servicio de referencia digital. Para tener constancia de este dato se depende íntegramente de los registros del sistema (logs).

16. Uso del servicio de referencia digital por día de la semana. Se trata de medir el uso del servicio cada día de la semana durante un periodo de tiempo determinado. La razón principal de este indicador es organizar convenientemente los calendarios de trabajo del personal del servicio de referencia digital. Conviene extraer mensualmente estos datos de los registros del sistema que se emplee en el servicio. Este dato se combina con la que da a conocer las consultas por horas del día.

17. Uso del servicio de referencia digital por hora del día. Se quieren conocer los momentos del día en el que hay más tráfico de preguntas, cuál es la hora punta del servicio o cuales son los momentos en los que hay menos actividad. El motivo fundamental, como ocurría en el indicador anterior, es organizar convenientemente los horarios y calendarios del personal que atiende las consultas de la referencia digital. La frecuencia y procedimiento de recolección de este dato es la misma que en el indicador anterior: conviene obtener el indicador cada mes, empleando los registros del sistema.

18. Navegador del usuario. Tipo de navegador empleado por el usuario para acceder al servicio de referencia digital. Se trata de conocer la tecnología que emplean los usuarios para adecuar el software de la biblioteca, a fin de que no haya problemas en la recepción de preguntas y envío de las respuestas. Esta información también es útil para el personal, que podrá adecuar las sesiones de explicaciones técnicas a las herramientas de las que dispone el usuario. Asimismo, este dato sirve para el desarrollo del sitio web del servicio de referencia digital, aunque lo idóneo es que fuera compatible con todos los navegadores. La extracción de este dato se debe realizar de forma mensual, a partir de los registros del sistema.

19. Plataforma del usuario. Identificación del sistema operativo que utiliza el usuario en su ordenador. Si se precisa, se puede llegar a niveles de detalle muy completos, en los que se indique la plataforma y la versión con la que se está accediendo al servicio de referencia digital. Se trata de conocer posibles dificultades técnicas en el uso del servicio, por incompatibilidades o necesidades de configuración específicas. La referencia digital ideal debe ser compatible con cualquier sistema operativo. Este dato se obtendrá de forma mensual a partir de los registros del sistema, aunque puede ser necesaria la ayuda de los departamentos de tecnologías.

20. Conocimiento del servicio. Primera medida de satisfacción de los usuarios. Consiste en determinar si la población destinataria sabe que el servicio está disponible. Este dato se necesita para los posibles programas de marketing que la biblioteca quiera llevar a cabo. Será necesario emplear procedimientos de recogida de datos como encuestas, cuestionarios, entrevistas o grupos de discusión de usuarios. Se realizará de forma anual, 
determinando los parámetros de la población objeto del servicio, seleccionando cuáles son los procedimientos más adecuados, qué cuestiones se recogerán y cómo se llevarán a cabo las encuestas. Los cuestionarios se emplearán también para otras medidas, pero se deben incluir preguntas acerca de cómo el usuario conoció el servicio, con respuestas predeterminadas: a través de una web, en la biblioteca, en una publicación, publicidad, recomendación, etc.

21. Accesibilidad del servicio. Este indicador mide el grado de facilidad de uso del servicio, para que pueda ser empleado directamente por los usuarios. Incluye diversos factores como la disponibilidad temporal, el diseño del sitio web, con especial atención a la sencillez de la interfaz, cumplimiento de los estándares web para discapacitados, facilidad de uso, jerarquías en la que se organiza la información y se coloca el formulario web de consulta al servicio de referencia, uso de metaetiquetas o las posibilidades de acceso en diversas lenguas si es necesario para la población a la que se atiende. Para obtener esta información se deberán emplear encuestas, cuestionarios o entrevistas, además de otros medios, como la selección de un grupo de usuarios para probar con ellos el sistema o la revisión del mismo por parte de expertos en accesibilidad. Se trata de una medida que se debe obtener anualmente.

22. Expectativas del servicio. Se trata de medir las expectativas que los usuarios tienen cuando emplean el servicio. En este indicador pueden incluir diferentes cuestiones: tipos de preguntas que esperan que sean resueltas, formato de las respuestas, tiempo en el que considera que será entregada la respuesta, grado de compromiso para encontrar las respuestas, respuestas correctas, definitivas o exhaustivas. Los procedimientos para conseguir estos datos se basarán en encuestas, cuestionarios, entrevistas o a partir de grupos de usuarios o foros de debate. Este indicador es aconsejable cuando el servicio de referencia es limitado y necesita saber qué ámbitos son demandados y no está cubriendo. Los tipos de preguntas que el usuario espera que sean atendidas corresponden a los expresados en la medida número diez. El formato de las respuestas se refiere a la entrega de información elaborada o a la posibilidad de entregar textos completos, por ejemplo. El tiempo de respuesta sirve para determinar cuales son los plazos que se consideran razonables, lo que permitirá organizar de forma conveniente los horarios del personal. El grado de responsabilidad o compromiso está limitado por los recursos con los que cuente el servicio de referencia, tanto de personal como en lo relacionado con las fuentes de información. El servicio debe intentar ofrecer siempre respuestas correctas, además de definitivas y exhaustivas, algo que no es sencillo, ya que muchas cuestiones son abiertas y nunca pueden considerarse respondidas de forma completa.

23. Otras fuentes empleadas por el usuario. Esta medida determina en qué otros recursos el usuario ha intentado encontrar la respuesta a su consulta. Aquí se pueden incluir otros servicios de referencia digital y de referencia presencial y búsquedas de forma autónoma a través de la web, empleando motores de búsqueda, bases de datos, catálogos en línea, directorios, etc. 
El procedimiento para conocer estos datos es a través de la entrevista de referencia, ya sea por correo electrónico, chat u otros procedimientos. La frecuencia será cada vez que se reciba una pregunta.

24. Razones para el uso. Se pregunta por qué un usuario emplea el servicio de referencia digital por primera vez o por qué repite en el uso del mismo. En esta medida se incluyen cuestiones como el boca a boca, la reputación de la biblioteca o del servicio de referencia tradicional, la publicidad, reseñas del servicio, distancia de acceso a la biblioteca física, satisfacción con un uso anterior, ninguna otra alternativa, etc. Esta medida puede servir como indicador de éxito si se obtienen buenos resultados en las razones que parten de la recomendación mediante el boca a boca o a través de reseñas del servicio, por ejemplo. La toma de datos se realizará a partir de encuestas, cuestionarios y entrevistas.

25. Razones para el no uso. Esta medida se refiere a la valoración de por qué nunca se ha usado el servicio de referencia digital o por qué se ha empleado previamente pero no se ha vuelto a consultar. Para las personas que nunca han usado el servicio, esta medida puede incluir aspectos como: se desconocía el servicio, la persona está incómoda con la tecnología, no se dispone de los recursos tecnológicos necesarios para emplear el servicio o preferencia del servicio presencial. Para aquéllos que han usado el servicio previamente pero no lo usan actualmente, esta medida puede incluir razones como: el usuario quedó satisfecho con el uso anterior, pero no ha vuelto a tener necesidad de emplear de nuevo el servicio, el usuario quedó descontento en su experiencia anterior, el usuario encuentra la información por sí mismo, el usuario no ha encontrado la política de uso del servicio. Como en el indicador anterior, para obtener estas informaciones se deberá recurrir a encuestas, cuestionarios o entrevistas.

26. Mejoras necesarias y servicios adicionales que se deben ofrecer. Se describen las áreas en las que el servicio puede ser modificado de forma positiva, a partir de las sugerencias de los usuarios y de sus quejas. También se incluyen las posibles novedades que se aconseja incorporar al servicio. Además de las sugerencias de los usuarios se deben incluir aquí las realizadas por el personal que atiende el servicio. Las posibles mejoras incidirán en la reducción de los plazos de respuesta y en los sistemas de comunicación entre el personal. Las novedades irán en el sentido de ampliar horarios, aumentar los tipos de consultas que se atienden, adaptación de las tecnologías a usuarios con necesidades especiales, etc. Como en otras medidas que se están incluyendo en esta parte de la tesis doctoral, en este indicador serán necesarias encuestas, cuestionarios y entrevistas o la creación de grupos de usuarios. También se tendrán en cuenta los comentarios espontáneos de los usuarios.

27. Satisfacción con el personal del servicio. Medida que consiste en determinar la percepción del usuario acerca de cómo el personal del servicio de referencia digital ha satisfecho sus necesidades de información. La satisfacción con la plantilla incluye los siguientes elementos: percepción de tratamiento personalizado, a partir de contestaciones individualizadas; 
actitud y conducta del personal para ser útiles y responder con calidad; percepción de los periodos de respuesta, atendiendo a que el personal respondió en los plazos pensados o si lo hizo con premura. Con esta medida se puede formar al personal en el trato con los usuarios, además de contar con una base para realizar posibles cambios en los plazos, por ejemplo. Las encuestas y las entrevistas son los dos procedimientos para la recolección de estos datos.

28. Satisfacción con el sistema de respuesta. Se trata de una medida para conocer si el usuario está satisfecho con el modo de entrega de una respuesta. Este indicador da pautas para conocer si el correo electrónico, chat, formularios web o cualquier otro medio empleado para ofrecer la contestación a una demanda de referencia digital satisface a los usuarios. Con esta información se tienen datos para ampliar los sistemas de entrega de respuestas, incluyendo métodos adicionales a los que suele emplear la biblioteca en su servicio de referencia digital. También se obtienen datos de esta forma para conocer la tecnología que emplea el usuario.

29. Impacto del servicio en el usuario. Este indicador describe cómo un usuario ha sido afectado por el uso del servicio. El impacto en el usuario se mide con estos efectos: se ha resuelto un problema de información, se ha respondido una necesidad de información, se ha ahorrado tiempo y se ha accedido a recursos que el usuario no hubiese podido consultar por otros medios. También se incluyen otros aspectos como la incidencia positiva en cuestiones personales, académicas o laborales del usuario. Esta medida de satisfacción es esencial, ya que da a conocer el valor del servicio reflejado en la vida de sus usuarios. Los medios de obtención de datos, una vez más, son las encuestas y las entrevistas, ya sean de forma personal o a través de grupos de usuarios; también serán muy útiles las informaciones que los usuarios ofrecen de forma voluntaria.

30. Datos demográficos de los usuarios. Se trata de definir las características de la población a la que se atiende. Se tendrán en cuenta la edad, raza, género, educación/formación, empleo/desempleo y profesión. Última de las medidas relacionadas con la satisfacción de los usuarios. En servicios de referencia académicos también habrá que recoger datos sobre el tipo de usuario: profesor, personal o estudiante, describiendo que nivel de estudios. Estos datos indican los patrones habituales en los usuarios, lo que puede servir a la biblioteca para orientar mejor el servicio. Las encuestas son el mejor medio para conocer esta información.

31. Coste del servicio de referencia digital. Consiste en determinar el coste total de la provisión del servicio, incluyendo salarios del personal, gastos producidos por los recursos digitales, infraestructura, publicidad, formación, materiales impresos, etc. Primera de las tres medidas relacionadas con el valor económico del servicio. En caso de que el servicio de referencia digital esté integrado en el servicio de referencia presencial se deberán prorratear los costes. Este dato es esencial para confeccionar los presupuestos y tomar decisiones relativas a la asignación de los recursos. 
Esta medida es responsabilidad de la dirección de la biblioteca y se elabora a partir de las nóminas y las facturas.

32. Porcentaje del coste del servicio de referencia digital en relación al presupuesto total del servicio de referencia. Esta medida determina el porcentaje que supone la referencia digital dentro del presupuesto total del servicio de referencia, ya sea presencial, híbrido o digital. Al tratarse de un tanto por ciento, la fórmula para hallar este dato consiste en dividir el coste de la referencia digital entre el presupuesto total de la referencia y multiplicar por cien el resultado. Es importante conocer esta información, para una mejor distribución de los recursos. Hay que tener en cuenta que el coste de este servicio siempre será relativamente alto.

33. Porcentaje del coste del servicio de referencia digital en relación al presupuesto total de la biblioteca. Este indicador ofrece el porcentaje del presupuesto de gestión de una biblioteca que es dedicado a la referencia digital. Se calcula dividiendo el coste de la referencia digital entre el presupuesto total de la biblioteca y multiplicando el resultado por cien. Conocer el porcentaje relativo es esencial para entender el grado de importancia de un servicio dentro de la organización general de la biblioteca. Esta medida puede ser empleada para conocer si es necesario asignar más recursos al servicio de referencia digital.

34. Porcentaje de tiempo dedicado por el personal para supervisar la tecnología. Las dos últimas medidas propuestas están relacionadas con el tiempo empleado por el personal para cuestiones técnicas. En este primer indicador se quiere conocer comparar el tiempo invertido en el control de la tecnología en relación al tiempo total dedicado al servicio de referencia. De esta forma, el dato se consigue dividiendo el tiempo invertido en la supervisión tecnológica entre el tiempo total dedicado al servicio y multiplicando por cien el resultado obtenido. Existen muchas tareas que el personal debe realizar para mantener en perfecto estado los sistemas automatizados con los que se trabaja en la referencia digital, lo que redundará en la calidad de la prestación del servicio. Esta medida será empleada para la toma de decisiones, configuración de los puestos de trabajo y análisis de la satisfacción laboral.

35. Porcentaje de tiempo dedicado por el personal a ayudar a los usuarios con la tecnología. Este indicador consiste en medir el tiempo invertido por el personal en comunicaciones informales, no programadas y personalizadas para orientarles y formales en el uso del sistema automatizado del servicio de referencia digital. Se halla dividiendo este tiempo entre el tiempo total dedicado al servicio de referencia $y$ multiplicando el resultado por cien. En este tiempo hay que incluir el dedicado a enseñar a descargar archivos, visualizar documentos en formato pdf, importar registros de una base de datos, etc. Como métodos para conocer esta información están los muestreos, encuestas y entrevistas, así como el análisis de los registros del sistema. 
Además de esta batería de indicadores, es interesante conocer otros propuestas. Por ejemplo, para la evaluación de sesiones de referencia atendidas a través de chat, es muy útil el sistema ideado por las bibliotecas integrantes del Oregon's Collaborative Statewide Virtual Reference Project $^{452}$, que se basa en las pautas de la RUSA, aunque las adapta a su situación particular. Se trata de un servicio cooperativo en el que intervienen veintitrés sistemas de bibliotecas y que se ofrece para todos los ciudadanos de forma abierta. El servicio de referencia a través de chat se ofrece durante 48 horas a la semana, mientras que el que se realiza por correo electrónico está disponibles todos los días y a todas las horas. La serie de pautas e indicadores que se ofrecen a continuación se determinaron para la evaluación de 228 sesiones de referencia vía chat y 159 cuestiones planteadas por correo electrónico, todas ellas correspondientes a un periodo de un año, el que va de octubre de 2003 a septiembre de 2004. Para su evaluación partieron de la lista de indicadores del servicio de referencia New

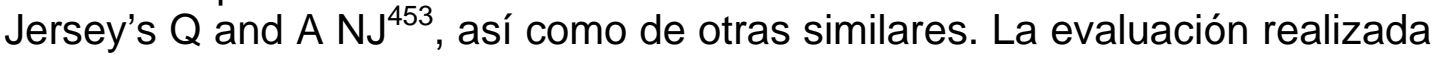
en Oregón se circunscribía a la aplicación de una lista de indicadores, indicando si la acción se realizaba, si no se llevaba a cabo o si la medida no era aplicable. Además, se elaboraron unas pautas, en las que se relacionaban posibles actividades que se podían evaluar y el indicador oportuno para ellas. A continuación, se reproducen los indicadores empleados por esta red para la evaluación de su servicio de referencia digital:

- El bibliotecario entabló una entrevista de referencia.

- El bibliotecario charló de una manera amistosa y profesional, por ejemplo, evitando jergas y absteniéndose de interponer los juicios de valor sobre la naturaleza de la pregunta.

- El bibliotecario dio señas de un entendimiento inicial sobre las necesidades del usuario.

- El bibliotecario reescribió la pregunta o petición y pidió confirmación para asegurarse de que la había entendido.

- El bibliotecario preguntó cuestiones indefinidas y animó al usuario a que ampliara la información u ofreciera otra adicional.

- El bibliotecario empleó preguntas cerradas y/o clarificadoras para refinar la búsqueda o aclarar terminología confusa.

- El bibliotecario arrancó la búsqueda en las cuestiones específicas.

- El bibliotecario identificó y empleó delimitadores de la búsqueda que podrían limitar los resultados, como fecha, lengua, exhaustividad, etc.

- El bibliotecario animó al usuario a contribuir con ideas durante la búsqueda.

- El bibliotecario envió mensajes al usuario mientras el indica páginas web.

- El bibliotecario y el usuario mantuvieron una conversación a dos bandas.

\footnotetext{
${ }^{452}$ El resultado de la evaluación de esta red cooperativa puede ser consultado en Hyde, Loree; Tucker-Raymond, Caleb. Benchmarking Librarian Performance in Chat Reference. The Reference Librarian, 2006, no 95/96, p. 5-19.

${ }^{453} \mathrm{Q}$ and $\mathrm{A} N \mathrm{NJ}$ es un servicio de referencia digital adminitrado por la South Jersey Regional Library Cooperative. Está disponible en http://www.qandanj.org.
} 
- El bibliotecario envió información en pequeños bloques.

- El bibliotecario ofreció o proporcionó algunas pautas de instrucción, incluyendo el proceso o la estrategia de búsqueda.

- El bibliotecario citó completamente los recursos, a menos que la autoría quedara reflejada en otra parte (no es necesario citar las páginas web que se envían).

- El usuario indicó su grado de satisfacción al terminar la sesión.

- No se interpretó la información legal, médica o estadística.

- Las cuestiones requieren información detallada y se remitió al usuario a la página principal de la biblioteca.

- Las cuestiones requirieren información detalla no disponible y se reenvía al usuario a otra fuente.

- Si el bibliotecario está muy ocupado para iniciar la sesión, la pregunta es reenviada.

Como se dijo más arriba, los indicadores de evaluación empleados por el servicio cooperativo de Oregón parten del método de evaluación que se emplea en una de las redes más activas, que es la que está administrada por la South Jersey Regional Library Cooperative, perteneciente a la New Jersey Library Network. Esta red emplea una lista de comprobación para la evaluación de su servicio de referencia digital, que se traduce a continuación. Se trata de indicar únicamente si la respuesta a cada epígrafe es positiva, negativa o no aplicable.

Lista de comprobación para la evaluación de sesiones de referencia

\begin{tabular}{|l|l|l|l|}
\hline \multicolumn{2}{|c|}{ SoftwarelAspectos técnicos } \\
\hline Sí & No & N/A & \\
\hline & & & El bibliotecario envía una página web y no sólo la URL \\
\hline & & & El bibliotecario envía lo que ha anunciado \\
\hline & & & El bibliotecario envía con éxito archivos o pantallazos \\
\hline & & & El bibliotecario usa con éxito bases de datos comerciales \\
\hline & & & El punto de vista del usuario estaba claro cuando el bibliotecario finalizaba la sesión \\
\hline \multicolumn{7}{|c|}{ Investigación/Búsqueda } \\
\hline Sí & No & N/A & \\
\hline & & & El recurso o ítem enviado contesta o parcialmente responde la pregunta \\
\hline & & & El bibliotecario ha evaluado suficientemente el ítem antes de enviarlo \\
\hline & & & El bibliotecario ha comprobado que el recurso está operativo antes de enviarlo \\
\hline & & & Se han empleado los recursos apropiados para responder la consulta \\
\hline & & & Se asignó un código interno a la contestación \\
\hline Sí & No & N/A & \multicolumn{2}{|c|}{ Comunicación y modelo de conducta de la referencia } \\
\hline & & & El bibliotecario emplea cuestiones indefinidas para conseguir la pregunta específica del usuario \\
\hline & & & El bibliotecario mantuvo un diálogo ininterrumpido con el usuario \\
\hline & & & El bibliotecario mantuvo informado al usuario de su actividad \\
\hline & & & El bibliotecario comunicó al usuario cuáles eran los próximos pasos previstos \\
\hline & & & El bibliotecario hizo un uso apropiado de los mensajes escritos \\
\hline & & & El bibliotecario informó al usuario antes de enviar un ítem \\
\hline & & & El bibliotecario explicó al usuario lo que enviaba \\
\hline & & & El bibliotecario facilitó instrucción sobre el recurso enviado, si se necesitaba \\
\hline & & & El bibliotecario explicó donde encontrar la respuesta en el ítem enviado \\
\hline & & & El bibliotecario reenvió convenientemente la sesión \\
\hline & & & El bibliotecario se responsabilizó apropiadamente para retomar el contacto con el usuario \\
\hline & & & El bibliotecario preguntó al usuario si se había contestado complemente a la pregunta \\
\hline
\end{tabular}

Fig. 2.18. Lista de comprobación de la South Jersey Regional Library Cooperative 
Entre los proyectos realizados para evaluar servicios de referencia digital ocupa un lugar destacado el llevado a cabo en el seno del Statewide Virtual Reference Project, una iniciativa de la Biblioteca del Estado de Washington. Después de un largo periodo de discusión, en otoño de 2004 difunden el documento The Virtual Evaluation Toolkit (VET) ${ }^{454}$, que ofrece toda una serie de herramientas para ser aplicadas en la evaluación de los servicios digitales de referencia. El manual proporciona recursos para realizar análisis más someros o detallados, según el nivel de profundidad de la evaluación que se requiera.

En el primer nivel, se analiza el sitio web, las comunicaciones, la política y la satisfacción del usuario; mientras que, en el segundo nivel, se plantean sistemas de autoevaluación y el uso del sitio web; además, existe un tercer nivel, donde se incluyen revisiones de las transcripciones de las sesiones realizadas por el sistema de pares, análisis descriptivo de las sesiones, grupos de discusión, pruebas de usabilidad y análisis de costes.

Para cada uno de los niveles, se ofrece la descripción de la metodología específica, su propósito y se dan las herramientas necesarias, a menudo cuestionarios y listas de comprobación. Siempre se detalla el proceso que se debe seguir, además de ofrecer ejemplos de evaluaciones ya aplicadas a distintos servicios digitales de referencia.

Otra autora que ha abordado la evaluación de los servicios de referencia desde la perspectiva de los usuarios es Kirsti Nilsen ${ }^{455}$, quien ha estudiado la bibliografía profesional y ha realizado diferentes evaluaciones sobre la satisfacción final de los usuarios que emplean los servicios de referencia digital. Nilsen ${ }^{456}$ encuentra tres problemas que se repiten de forma habitual y que suelen ser expresados por los usuarios como negativos: 1) evitar preguntas al usuario, que provoca que se deje sin resolver la cuestión que realmente planteó el usuario, ya que no se estableció la entrevista de referencia necesaria; 2) no ofrecer instrucción sobre los recursos a los que se remitió al usuario ni comprobar si la información está realmente en la fuente a la que se envía; y 3) no proponer la posibilidad de realizar un seguimiento de las preguntas, indicando al usuario la disponibilidad del servicio para ampliar o completar las respuestas. También desde la

\footnotetext{
${ }^{454}$ El documento completo puede ser descargado desde <http://www.secstate.wa.gov/ library/libraries/projects/virtualRef/textdocs/VETmanual.pdf>. Se puede tener una completa información sobre el contenido de este manual de evaluación de servicios de referencia en el siguiente artículo: Hirko, Buff. VET: The Virtual Evaluation Toolkit. The Reference Librarian, 2006, no. 95/96, 2006, p. 125-148.

${ }^{455}$ Entre otros estudios de esta autora destacan: Nilsen, Kirsti; Ross, Catherine Sheldrick. Evaluating Virtual Reference from the Users' Perspective. The Reference Librarian, 2006, vol. 46, n. 95/96, p. 53-79. En el apartado 9.1. de esta tesis doctoral se hace relación a Library Visit Study, importante estudio de satisfacción de usuarios, que se desarrolla en este artículo. Véase también Nilsen, Kirsti. Virtual versus Face-to-Face Reference: Comparing Users' Perspectives on Visits to Physical and Virtual Reference Desks in Public and Academic Libraries. En IFLA General Conference and Council (71. 2005. Oslo). Oslo: IFLA, 2005. Disponible en <http://www.ifla.org/IV/ifla71/papers/027e-Nilsen.pdf> [consulta 17 julio 2007].

${ }^{456}$ Nilsen, Kirsti. Comparing users' perspectives of in-person and virtual reference. New Library World, 2006, vol. 107, n. 3/4, p. 91-104.
} 
perspectiva de los usuarios, Pomerantz y $\mathrm{Luo}^{457}$ realizan un estudio de usuarios en el que combinan las técnicas tradicionales de evaluación con los resultados del análisis de la satisfacción mostrada tras el empleo de servicios de información vía chat.

Es conveniente recoger la aportación de Novotny, experto en evaluación de servicios de referencia digital y editor de la monografía ${ }^{458}$ más reciente sobre el tema. En un importante artículo publicado en 2001, este autor realiza una síntesis de los métodos que se pueden emplear para la evaluación de los servicios bibliotecarios de información que se ofrecen en entornos digitales:

- estudios de casos

- análisis de coste-beneficio

- grupos de discusión

- entrevistas personales

- observación

- encuestas

- estudios de usabilidad

- análisis/estadísticas de registros web

Además, este autor reúne las principales medidas cuantitativas y cualitativas que se pueden emplear, así como los criterios de evaluación aportados por otros autores y por entidades como la RUSA, por lo que la consulta de sus investigaciones se convierte en una etapa fundamental de cualquier estudio sobre el tema, como ha ocurrido en la elaboración de la presente tesis doctoral. Estos mismos métodos de análisis de los servicios de referencia digital son los tratados por Whitlatch ${ }^{459}$, que se basa en los sistemas de evaluación tradicionales, para adaptarlos a los medios digitales, que esta autora expuso en un manual de prestigio publicado en $2000^{460}$. Esta investigadora insiste en la validez de encuestas y cuestionarios, la observación, entrevistas individuales y focos de discusión y los estudios de casos como métodos para el análisis de los servicios de referencia digital.

Por último, hay que mencionar el estudio publicado por Jia $\mathrm{Liu}^{461}$ en el que se evaluaron servicios de referencia digital que se ofrecieran por correo electrónico o formulario web. Se formaron dos grupos de investigación en Alemania y China, que siguieron una metodología común para analizar servicios de referencia digital de diversos países. La metodología se basó en la aplicación de cuestionarios y en la observación, como métodos de investigación social. Los datos de ambos análisis fueron comparados en un

${ }^{457}$ Pomerantz, Jeffrey; Luo, Lili. Motivations and uses: evaluating virtual reference service from the users' perspective. Library and Information Science Research, 2006, vol. 28, n. 3, p. 350-373.

${ }^{458}$ Novotny, Eric (ed.). Assessing reference and user services in a digital age. Binghamton, NY: The Haworth Information Press, 2006.

${ }^{459}$ Whitlatch, Jo Bell. Evaluating reference services in the electronic age. Library Trends, 2001, vol. 50, n. 2, p. 207-217.

${ }^{460}$ Whitlatch, Jo Bell. Evaluating Reference Services: A Practical Guide. Chicago: American Library Association, 2000.

${ }^{461} \mathrm{Jia}$, Liu. The evaluation of worldwide digital reference services in libraries. Oxford:

Chandos Publishing, 2007. 
estudio híbrido, realizado a partir de los resultados cuantitativos y cualitativos (informaciones de los cuestionarios y conclusiones del proceso de observación); además, se realizó una comparación de los datos y se recogió el estado internacional de la referencia digital. El equipo de investigación alemán incluyó en su estudio 147 bibliotecas, de África, Australia, Asia, América y Europa, sobre todo universitarias, aunque también se evaluaron bibliotecas nacionales. El equipo de investigación chino realizó su encuesta y su observación a 136 bibliotecas, en las que el porcentaje mayor también correspondió a las universitarias, pero donde también se incluyeron bibliotecas nacionales y algunas de tipo público, al tratarse de bibliotecas regionales. La evaluación partía de un cuestionario idéntico, donde se analizaron las siguientes cuestiones:

- Accesibilidad, entendida como suma de factores que facilitan el acercamiento o la localización del servicio de referencia digital, para hacer más cercano y sencillo su uso.

- Interés, referido a las indicaciones que permiten conocer la aptitud de la biblioteca y de su personal para transmitir que las preguntas son bien recibidas y que se trata de un servicio abierto.

- Criterios formales, que tienen que ver con la forma en la que se ofrece la referencia digital, ya sea a través de correo electrónico o de formulario web, así como de si se utilizan directrices para su prestación.

- Preguntas, recogiendo toda la información sobre los plazos, el respeto a la confidencialidad, entrevista de referencia a través de comunicaciones con los usuarios, etc.

- Amigabilidad, estudiando la forma en que el personal trata a los usuarios, la personalización de los mensajes, la identificación de quien redacta la respuesta, etc.

- Respuestas, incluyendo la calidad de las mismas, el cumplimiento de expectativas de los usuarios, la adecuación de las respuestas y la intención de volver a emplear el servicio.

- Seguimiento, relación posterior con quienes han sido usuarios del servicio.

Se ofrecen a continuación algunos resultados de esta evaluación correspondientes a las cinco preguntas que analizaban la forma de acercamiento del servicio. Las cuestiones evaluadas fueron las siguientes:

1. Existencia de un enlace directo al servicio de referencia desde la página principal de la biblioteca. Los resultados difieren entre los datos obtenidos por los equipos de investigación. El grupo alemán detectó que sí había enlace en un $66 \%$, mientras que los resultados afirmativos del grupo chino fueron del $38 \%$. 
2. Existencia de un icono específico para el servicio de referencia digital. Los resultados concluyeron que un $71,3 \%$ de las bibliotecas analizadas por el grupo chino disponen de una imagen propia para identificar el servicio de referencia digital, mientras que esta cifra desciende al $19 \%$ en el equipo alemán.

3. Denominación del servicio de referencia digital. El $40 \%$ de las bibliotecas evaluadas por los investigadores alemanes llama a su servicio de referencia digital "Pregunte a un bibliotecario" (Ask a librarian). Esta cifra se sitúa en el $36 \%$ en la evaluación hecha en China.

4. Existencia de indicaciones de uso del servicio o FAQ. Solamente el $29,3 \%$ de las bibliotecas analizadas en Alemania disponía de FAQ. Menos de la mitad de las bibliotecas estudiadas por el grupo chino disponían de información relativa al uso del servicio, mientras que el 53,7\% no incluían ayuda alguna.

5. Número de clicks necesarios para acceder al servicio. En el $49,6 \%$ de las bibliotecas estudiadas por el equipo alemán el servicio de referencia digital estaba accesible a un sólo paso, mientras que en las investigadas en China el porcentaje fue del $61,8 \%$.

Como se dijo, la evaluación también incluyó una serie de preguntas para conocer el interés del servicio, es decir la actitud de las bibliotecas para la atracción de demandas de información, en donde se analizaron cuestiones como la receptividad o la preocupación por almacenar las consultas resueltas. También se formularon cuestiones como la existencia de formularios web o la incorporación de recursos de autoservicio, para que los usuarios pudieran encontrar las respuestas a sus consultas de forma autónoma.

El proceso de envío de las preguntas fue igualmente evaluado. En este caso se recogió información sobre el periodo de tiempo de respuesta, las garantías de privacidad, la existencia de acuses de recibo de las preguntas o la interacción biblioteca-usuario para concretar las preguntas recibidas.

Otros criterios seguidos para la evaluación fueron la forma de comunicación con el usuario, en relación a la manera de dirigirse al mismo, la firma de las respuestas, el cumplimiento de los plazos establecidos, la satisfacción de los usuarios o la adecuación de la respuesta. Puede afirmarse que ésta es la evaluación de servicios de referencia digital más importante realizada de forma internacional. 


\subsection{Propuestas para la evaluación de servicios públicos de referencia digital}

Los servicios públicos de referencia en línea presentan condiciones particulares que no permiten que se les evalúe como el resto de los servicios bibliotecarios de información, ya sean presenciales o telemáticos. Este tipo de servicios públicos se prestan de forma cooperativa, con el trabajo organizado de diferentes instituciones que deben coordinar su actividad. La diversidad de personas e instituciones implicadas obliga a procedimientos de análisis particularizados. Asimismo, la población destinataria es amplia y, hasta cierto punto, indefinida, por lo que se hace muy complicada una evaluación de la satisfacción de los usuarios. En los siguientes párrafos se ofrecen metodologías aplicables a los servicios de referencia que cumplan las condiciones que se expusieron en el apartado 9.3. de esta tesis doctoral y que se mencionan ahora nuevamente, para la contextualización de los sistemas de análisis que se muestran a continuación.

Se entiende por servicios públicos de referencia digital aquellos que están dirigidos a la población en general, en los que la presencia de las instituciones bibliotecarias nacionales es prioritaria, especialmente en los aspectos de gestión y coordinación del servicio; que son ilimitados en cuanto al tipo de preguntas que atiende -con las obligadas excepciones-, que son suministrados por bibliotecas u organismos bibliotecarios y que se prestan en línea.

Los servicios presentados en el apartado 9.3 de esta tesis doctoral cumplen estas condiciones. Servicios como Pregunte: las bibliotecas responden, en España, o sus correlatos en Dinamarca, Noruega, Finlandia o Suecia, por ejemplo, son los que podrían ser evaluados partiendo de las metodologías que se proponen en este epígrafe de la investigación. En la tercera parte de la tesis, dedicada a evaluar el sistema de referencia digital público español, se han empleado estas técnicas de evaluación, en muchos casos planteadas específicamente para el análisis de la calidad del servicio de referencia en línea de las bibliotecas públicas españolas. Hay que tener en cuenta que el servicio español trabaja mediante formulario web y correo electrónico, por lo que algunos aspectos de análisis propios del chat o de sistemas sincrónicos no se han tenido en cuenta.

Los ámbitos que se deben evaluar en un servicio público de referencia digital son los siguientes:

- Profesionales: datos cuantitativos, formación, satisfacción.

- Usuarios: perfiles, motivos para el uso, satisfacción, repetición.

- Sistema: funcionamiento, incidencias, registros estadísticos.

- Preguntas: tipos, lenguas, temas.

- Respuestas: calidad, fuentes, redacción, homogeneidad.

- Visibilidad: conocimiento, penetración, enlaces, reseñas.

- Costes: gastos, beneficios, porcentaje presupuestario. 
Para obtener información cuantitativa y cualitativa de todos estos temas se pueden emplear las metodologías de evaluación que se desarrollan a continuación.

\section{Estudio de profesionales}

Las técnicas de recogidas de datos más apropiadas son grupos de debate, entrevistas y encuestas. Los grupos o foros de debate consisten en la selección de un número de personas representativo del colectivo, con las que se intercambiarán pareceres acerca de los temas de la evaluación. Dada la configuración que habitualmente presentan los servicios públicos de referencia en línea, habitualmente distribuidos geográficamente, este tipo de métodos requieren conversaciones por medios telemáticos, a través de sistemas de mensajería, instantánea o diferida. Las entrevistas presentan este mismo problema, ya que se trataría de realizar visitas a los profesionales que atienden el servicio, que siempre son numerosos. Por lo tanto, la forma más eficaz de obtener datos sobre el personal es a través de los cuestionarios de encuestas.

El responsable de la evaluación prepara un formulario, fundamentalmente compuesto por preguntas cerradas, para agilizar la toma de datos, aunque siempre se debe tener en cuenta que algunas preguntas deben estar abiertas, para anotar sugerencias y comentarios. La realización de la encuesta se puede hacer mediante un formulario electrónico, depositado en el mismo servidor del sistema de referencia o en alguno de los que existen y que están especializados en la recogida de datos. También puede realizarse por correo electrónico o a través de impresos.

Un estudio de profesionales debe incluir las cuestiones que permitan reunir la información relativa a estos temas: perfil de los trabajadores: número de personas, categoría laboral, responsabilidad en el servicio, experiencia en el servicio, exclusividad en la tarea de referencia, formación biblioteconómica, habilidades de información, opinión del sistema, procedimientos que sigue, valoración de las fuentes, opinión de la política del servicio, opinión de la organización del servicio, valoración de la calidad de las respuestas y el servicio, satisfacción laboral, posibles modificaciones en el servicio.

\section{Estudio de usuarios}

Las técnicas de análisis de los usuarios también pueden ser las mismas que para los profesionales. Existen una serie de datos cuantitativos que se extraerán de los registros del sistema y de los procedimientos de control que emplee la red para las consultas al servicio de referencia. Normalmente, las bibliotecas que participan en redes cooperativas de referencia digital también ofrecen sus propios servicios locales de referencia, tanto digital como presencial. Estas bibliotecas suelen tener métodos de registro de las consultas, para sus estadísticas internas. Para la obtención de los datos numéricos no suele haber problemas, ya que se pueden utilizar sencillos procedimientos manuales o automatizados para esta labor. Los registros de los sistemas automatizados (logs) permiten contabilizar el número de 
sesiones, lo que puede equivaler al número de usuarios. Si se trabaja con formularios web, se pueden crear diferentes campos previos, que ofrezcan el perfil del usuario (edad, área geográfica, motivo de la consulta), así como su posterior satisfacción con la respuesta entregada y el cumplimiento de expectativas $^{462}$.

Pero los datos cualitativos son más complicados de obtener. Para ello, sigue siendo un buen sistema la creación de grupos de discusión, foros en los que se conversa con los usuarios sobre los temas de la evaluación. No obstante, este método, aunque válido, es difícil de llevar a cabo, puesto que los usuarios de los servicios de referencia digital están menos identificados que los que acuden a un servicio presencial, además de estar menos implicados en la actividad de la biblioteca. Por ello, vuelve a convertirse en una herramienta esencial el uso de cuestionarios.

Los servicios de referencia digitales identifican al usuario a través del correo electrónico, que es necesario para poder interactuar con las bibliotecas en el proceso de la referencia. Además, algunos servicios ofrecen la posibilidad de registrarse, para poder acceder a ventajas complementarias. Si el servicio cooperativo cuenta con usuarios registrados, éste será un buen colectivo para realizar la evaluación por encuestas. Si no es así, se emplearán las direcciones de correo electrónico, teniendo un cuidado extremo en no contravenir la legislación relativa al uso de datos almacenados por medios electrónicos.

Los estudios de usuarios deben permitir obtener información sobre estos asuntos: edad, nivel académico, área de residencia, actividad, conocimiento del servicio, motivos para el uso o repetición, medio por el que conoció la existencia del servicio, intentos previos de obtención de la información demandada, valoración de la respuesta, valoración del tiempo de respuesta, valoración del trato recibido, problemas con el sistema, cumplimiento de expectativas, satisfacción global.

\section{Estudio del sistema}

El análisis del sistema es crucial para mantener la calidad del servicio. Los fallos debidos a causas tecnológicas redundarán negativamente en la calidad del servicio y en la percepción que se tenga del mismo. Por eso, es necesario realizar un análisis previo de los medios y los procedimientos técnicos, antes de decidir qué tecnología se emplea y de ofrecer el servicio. Habitualmente, los sistemas electrónicos empleados en la referencia digital no causan problemas, ya que se trata de tecnologías estables y comunes, como el correo electrónico, los formularios web o el chat. A medida que se emplean tecnologías que requieren más medios pueden aparecer problemas, como son las conexiones vía telefonía IP o a través de videoconferencia. Por último, si se decide trabajar con plataformas

\footnotetext{
${ }^{462}$ Uno de los escasos estudios llevados a la práctica sobre este tema en servicios públicos de referencia digital es el que se describe en Kwon, Nahyun. User satisfaction with referrals at a collaborative virtual reference service. Information Research [en línea], 2006, vol. 11, n. 2. Disponible en <http://informationr.net/ir/11-2/paper246.html> [consulta 30 julio 2007].
} 
específicas para el servicio de referencia, es necesario realizar las suficientes comprobaciones como para demostrar que el funcionamiento es correcto y los errores nulos.

Para analizar el sistema se puede partir del uso de sistema mismo. Es decir, realizar pruebas con una dificultad creciente, hasta asegurarse de que el rendimiento es óptimo. Para conocer el grado de usabilidad del sistema, es decir, para comprobar si es sencillo de manejar y su organización es lógica, lo más adecuado es contar con colaboradores externos, que no estén habituados con el sistema, para analizar su comportamiento al emplearlo y obtener información independientemente sobre su percepción. Asimismo, el sistema puede ser analizado por un experto para conocer si se cumplen los requisitos y estándares de accesibilidad.

El propio sistema automatizado debería informar de los datos estadísticos que sirvan para la evaluación cuantitativa, como son el número de sesiones, días y horas de consulta, número de usuarios diferentes, plazos en los que se sirven las respuestas, perfiles de usuarios, clasificación de las preguntas, valoración de los usuarios, etc. El tipo de datos que se pueden obtener dependerá de la configuración del sistema, de qué datos se han programado para que se queden registrados en el servidor.

El estudio del sistema puede ser ampliado con el análisis de las incidencias. A efectos de este apartado de la tesis, se considera incidencia cualquier indicación, generada por el sistema, que registre un error en el mismo, así como las diferentes comunicaciones, recibidas por correo electrónico o cualquier otro medio, de los usuarios o de los profesionales que atienden el servicio, en las que informan de problemas de conexión, recepción, organización o gestión de las preguntas. Es una práctica recomendable que quien ostente la coordinación técnica de un servicio cooperativo de referencia en línea reúna en un archivo común las diferentes incidencias que se presenten, ya que a partir de las mismas se detectarán los aspectos que se deben mejorar.

Habitualmente, las incidencias que se reciban tratarán de cuestiones como: problemas técnicos (conexiones, descargas, etc.), organización interna (modificación de turnos, cuestiones de procedimiento, estadísticas, etc.), redirecciones (preguntas locales o especializadas), aclaraciones (preguntas que requieren explicaciones complementarias), reclamaciones (plazos expirados, preguntas mal contestadas, etc.), sugerencias (modificaciones, comentarios) 0 agradecimientos (comunicaciones de gratitud de los usuarios).

\section{Estudio de las preguntas}

Los servicios cooperativos de referencia digital se crean con una política definida, en la que se establecen los tipos de cuestiones que serán atendidas por el personal referencista. Con frecuencia, estas políticas insisten en que se responden preguntas de cualquier tema, sin entrar en interpretaciones acerca de datos médicos, legales o estadísticos; tampoco 
suelen responden íntegramente a las demandas de investigaciones bibliográficas exhaustivas, aunque en estos casos es común facilitar las principales fuentes de información. Por lo tanto, las bibliotecas saben qué tipos de preguntas quieren recibir, por lo general de la misma tipología que las que responden en los servicios presenciales, aunque algunas bibliotecas limitan el uso de la referencia digital a cuestiones de información comunitaria o local o aspectos relativos a los servicios bibliotecarios y sus recursos de información.

Las limitaciones en la política bibliotecaria no suponen que los usuarios vayan a cumplir con las normativas aprobadas o con las orientaciones facilitadas. Es común que los usuarios empleen el servicio se utilice sin haber conocido antes su reglamento y que se reciban cuestiones de todo tipo, nivel de profundidad y temática. La biblioteca deberá tomar las decisiones oportunas sobre qué tipo de preguntas responde y cuáles no, aunque todas deberán ser siempre contestadas, aunque sea para informar al usuario de que su pregunta no es procedente o de que no se dispone de los recursos necesarios para conseguir la respuesta.

Para obtener datos de las preguntas recibidas se pueden utilizar los registros del sistema (logs) y los archivos de preguntas. Es conveniente que o bien el usuario que hace una pregunta o bien el profesional que la responde describan someramente la cuestión, asignándole una materia e identificando algunos aspectos como la lengua. Además, el profesional debería asignar también un tipo concreto a la demanda, en función de si se trata de una pregunta de referencia rápida, orientación, información bibliográfica, etc. Es necesario que el servicio haya normalizado los tipos de preguntas, como se hizo en el apartado 4.1. de esta tesis doctoral, en el que se estudiaron las demandas de información. El análisis de los datos de las preguntas habitualmente debe realizarse de forma manual, examinando la base de datos o una muestra representativa de la misma.

En la evaluación de las preguntas los datos que es necesario recoger son los siguientes: número de preguntas, número de preguntas recibidas por horas y días, tipología de la demanda, lengua de la pregunta, temática general de la pregunta (clasificación).

Los datos referentes al número de preguntas por franjas horarias y días de la semana son muy útiles para una mejor organización del personal, reforzando la plantilla en las horas punta y permitiendo realizar otras tareas en las horas o días de menos afluencia. Los tipos de demanda incidirán en el desarrollo de colecciones especializadas, así como en la posible cooperación con otros organismos para la resolución de cuestiones concretas. La recogida de los datos sobre la lengua en la que se hace la pregunta y se pide la respuesta es sobre todo importante en las áreas geográficas con más de una lengua oficial. En cuanto a la clasificación, es esencial que el servicio de referencia trabaje con una sistematización del conocimiento, con el nivel de detalle que se precise, a fin de poder conocer qué temas son los más demandados y proveer a la biblioteca de los recursos necesarios. 
Asimismo, el uso de las clasificaciones es importante en las redes cooperativas en las que las preguntas se distribuyen entre las bibliotecas miembros en función de la temática de las cuestiones recibidas.

\section{Estudio de las respuestas}

La calidad del servicio de referencia es directamente proporcional a la calidad de las respuestas que ofrece. Si un usuario ve cumplidas sus expectativas volverá a usar el servicio, además de promocionarlo en su entorno. La evaluación de las respuestas es una de las actividades de análisis más complejas, ya que en la misma se integran aspectos cuantitativos y cualitativos. Los aspectos estadísticos más fáciles de cuantificar corresponden a las cifras de respuestas entregadas. Para conocerlos simplemente se deberán analizar los registros del sistema, aunque a menudo hay que revisar manualmente las comunicaciones y extraer de las mismas las que corresponden a respuestas a demandas de información, contabilizando de forma independiente las relativas a incidencias y otros contenidos. También a partir de los registros del sistema se puede conocer el tiempo de demora en la respuesta, para saber si se actúa en plazo o se ha contestado en un periodo mayor del establecido.

Combinando los sistemas automatizados y los manuales se puede obtener el dato del nivel de resolución alcanzado. Se trata de articular métodos para asignar a cada pregunta la información relativa a si se respondió total o parcialmente, si se ofreció la respuesta correcta, si se cerró el proceso, si fue necesario enviar al usuario a otra fuente o si no se pudo responder. Los sistemas empleados por la red cooperativa deberían permitir que el personal, una vez entregada la respuesta la describa como contestada o no y como parcial o total; también es necesario que se identifique por qué una pregunta no fue contestada: por considerarla inapropiada, por no disponer de los recursos de información o porque se reenvió a la entidad idónea.

Las fuentes de información empleadas para la contestación también deben ser analizadas. Puede necesitarse un nivel detallado de estudio, para conocer las fuentes esenciales y las menos empleadas, aunque normalmente los datos que se necesitan recoger se centran en el tipo de recursos, identificando si se trata de fuentes de información impresas, electrónicas o de otros tipos. De igual forma, interesa controlar si los recursos de información empleados están o no en la colección de la biblioteca y si son gratuitos o comerciales.

La homogeneidad en la respuesta es otro elemento que se debe evaluar. Se trata de comparar si se sigue o no un mismo patrón de contestación, tanto en el esquema general de las respuestas (encabezamiento, cuerpo del mensaje, despedida, notas aclaratorias, declaración de privacidad), como en el estilo, como en el tipo de respuesta (datos o fuentes) y en la identificación de las fuentes.

La evaluación de respuestas es una actividad esencialmente cualitativa, por lo que hay que emplear técnicas basadas en el estudio directo de las 
preguntas. Para ello, se puede contar con evaluadores externos, crear grupos de análisis por pares o formar foros de debate entre profesionales; se trata de elegir una metodología individualizada que se aplicará a un conjunto de preguntas, cuyo número dependerá del total de las respuestas enviadas. Un procedimiento será extraer las respuestas correspondientes a un periodo representativo o bien un número al azar entre el total. Al volumen de respuestas seleccionado se le ejecutará un análisis común, consiste en examinar los siguientes datos:

- tipo de respuesta: respuesta textual, remisión a fuentes, combinación de texto y fuentes, pregunta no contestada.

- fuentes empleadas: impresas, electrónicas, personales, varias, recursos propios elaborados por la institución.

- fuentes para ampliar: ofrecimiento o no de fuentes complementarias

- tiempo de respuestas: horas/días transcurridos desde que se recibió

la pregunta hasta que se envía la respuesta

- validez de la respuesta: contenido ajustado o no a la pregunta

- homogeneidad: cumplimiento o no o de las indicaciones de procedimiento en cuanto a contenido, estilo y fuentes.

Los análisis cualitativos de las respuestas requieren emplear métodos de evaluación más avanzados y específicos de las técnicas de mercado e investigación social. Por ejemplo, en este aspecto son muy útiles los estudios discretos. Se trata de enviar una serie de preguntas cuyas respuestas se conocen, a fin de valorar la contestación recibida. Los estudios de este tipo más eficaces pueden ser:

- estudio discreto de cumplimiento de la política: envío de preguntas que no se ajusten a los reglamentos: cuestiones legales, médicas, preguntas imprecisas, investigaciones bibliográficas, etc; también se enviarán preguntas apropiadas, que impliquen sucesivas comunicaciones con el personal, a fin de comprobar sus comportamiento y procedimientos.

- estudio discreto de la calidad de las respuestas: selección de preguntas de diversos tipos (instrucción, orientación, bibliográficas, de referencia rápida, etc.) para evaluar el grado de corrección; en este método también se puede analizar la validez de la respuesta, es decir, la adecuación a la pregunta, por lo que se deberán elegir también temas que permitan esta comprobación; en la calidad también hay que medir el tiempo transcurrido hasta la recepción de la respuesta.

- estudio discreto de homogeneidad de las respuestas: análisis del grado de correspondencia entre preguntas similares; la manera más eficaz es enviar la misma pregunta en diversas fechas, para comparar los resultados; éste método también sirve para comprobar el grado de uso de los archivos del servicio.

- estudio discreto de las comunicaciones: análisis del estilo, sintaxis, protocolo, lenguaje, organización del contenido, exposición, 
condiciones de privacidad, etc.; se enviarán preguntas variadas, en diferentes días y horas, previendo que sean contestadas por personal diferente, con la finalidad de comprobar si se siguen los mismos procedimientos y estilo de comunicación.

Todos estos estudios se pueden realizar a partir de los archivos generados en el uso del servicio, examinando los diferentes aspectos que se han ido exponiendo en los párrafos anteriores. No obstante, los estudios discretos requieren una inversión menor, sobre todo de tiempo, y ofrecen garantías de que los resultados se ajustan a la realidad del servicio que se está prestando.

\section{Estudio de visibilidad}

Saber el grado de conocimiento del servicio permite disponer de elementos para tomar decisiones relativas a su promoción, relanzamiento, reorientación o clausura del mismo. En este tipo de estudios se quiere conocer si el servicio se conoce o no y hasta qué punto ha penetrado entre la población destinataria. En los estudios de usuarios se debe preguntar por qué medios se conoció el servicio, ya que este dato da pautas para actuar en la difusión del sistema en medios u ámbitos concretos.

Existen varias fórmulas que se pueden aplicar para tener datos sobre el conocimiento del servicio, como son las encuestas, aunque para servicios de referencia digitales pueden ser empleados otros más específicos como:

- estudio de visibilidad: consulta a través de los sistemas avanzados de los motores de búsqueda, para conocer el número de páginas que enlazan con la del servicio; en este tipo de estudios conviene reflejar no sólo el número de enlaces, sino también el área geográfica del servidor que enlaza con el servicio de referencia digital y el tipo de institución de que depende.

- estudio bibliográfico: consulta a las bases de datos profesionales para conocer el número de documentos en los que se hace referencia al servicio específico que se está evaluando; también se incluyen aquí las posibles noticias y reseñas aparecidas en medios de comunicación.

Los resultados de los estudio de penetración son la base para las campañas publicitarias, ya que se identifican sectores, se concretan estrategias de actuación y se deciden asignaciones presupuestas, de personal o de recursos.

\section{Estudio de costes}

El análisis económico del servicio de referencia digital también debe ser incluido dentro de la evaluación de este tipo de organizaciones. Es indispensable conocer el valor económico del servicio para ajustarlo a las condiciones de las bibliotecas integrantes. Hay que partir de que los 
servicios de referencia digitales no son rentables económicamente ${ }^{463}$. En términos de beneficios monetarios, todos los servicios de referencia cuestan más de lo que ingresan. De hecho, los servicios de este tipo que cobran por dar respuestas han ido cesando en su negocio, ya que no se conseguían los beneficios estimados. La rentabilidad de los servicios de referencia digitales es ante todo social: el uso generalizado del mismo justifica los gastos que se deriven de la prestación del servicio.

La evaluación económica se hace para conocer cuáles deben ser los fondos que anualmente se asignen al servicio y cuál va a ser la distribución del presupuesto entre las entidades participantes. Los servicios cooperativos de referencia trabajan sobre todo en redes. Por una parte, es posible encontrarse con redes estatales, asentadas en las bibliotecas públicas; y, por otra, con redes académicas, en las que participan universidades y organismos de investigación. El análisis económico del servicio es necesario para conocer las aportaciones de cada una de las partes.

Es habitual que apenas haya gastos comunes, excepto en algunas redes donde existe un sistema de gerencia cooperativo, que se financia entre todas las bibliotecas miembros del proyecto. Lo frecuente, por tanto, es que cada biblioteca asuma los gastos que le corresponden, sobre todo relativos al personal, a los recursos de información y a la infraestructura tecnológica. También es cotidiano que los servicios de referencia digitales estén atendidos por las secciones presenciales de referencia de las bibliotecas de una red. Por ello, es difícil conocer la aportación con la que cada biblioteca colabora en el sistema cooperativo.

El análisis económico se debe hacer a partir de los datos específicos del servicio de referencia digital de cada biblioteca o bien prorrateando los mismos, si coinciden los recursos, cuando los servicios presenciales y telemáticos se prestan indistintamente. Los datos económicos que es necesario recopilar son los correspondientes a: nóminas y pagos de personal, compra de colecciones para la biblioteca, acceso a recursos electrónicos de pago, instalaciones de telecomunicaciones, equipamiento informático, mantenimiento de la tecnología, elaboración de productos informativos y tutoriales, reprografía y consumibles, material de promoción, gastos de gestión del consorcio, formación del personal, mobiliario, compañías de comunicaciones.

Los sistemas de análisis expuestos en los párrafos anteriores, cuando eran aplicables, se han puesto en práctica para la evaluación del servicio de referencia «Pregunte: las bibliotecas responden», que se desarrolla en el parte tercera de esta investigación, núcleo principal de esta tesis doctoral.

\footnotetext{
${ }^{463}$ No obstante, muchos servicios de este tipo tampoco suponen pérdidas económicas a las instituciones que los ofrecen, en muchos casos debido a que están patrocinados por entidades, por lo general privadas, como ocurre en la mayoría de los servicios públicos de referencia digital que se ofrecen en Estados Unidos. Un ejemplo, es el servicio inglés de referencia digital, sostenido con fondos procedentes de la lotería nacional.
} 


\section{Aplicación práctica: evaluación de «Pregunte: las bibliotecas responden»}

España cuenta con uno de los primeros servicios de referencia digitales aparecidos en todo el mundo. Se trata de «Pregunte: las bibliotecas responden», un proyecto en el que participan bibliotecas públicas de las diferentes comunidades autónomas y que coordina el Ministerio de Cultura. Para poner en práctica las diferentes metodologías de evaluación expuestas en el último apartado del bloque anterior se ha tomado este servicio como base para realizar un estudio en el que se analizaron diferentes componentes, a fin de conocer el funcionamiento de este servicio, detectar sus debilidades y ofrecer propuestas de mejora. Esta parte de la tesis se ha elaborado con el apoyo de la Subdirección General de Coordinación Bibliotecaria, quien ha tenido en cuenta los resultados de la investigación para mejorar este servicio cooperativo. En esta tercera sección, se presenta el servicio público de referencia digital español, se realiza un diagnóstico del mismo, se detallan propuestas de mejora y se ofrece el estado del mismo tras la introducción de varios de los cambios sugeridos. 
Parte III. APLICACIÓN PRÁCTICA: EVALUACIÓN DE «PREGUNTE: LAS BIBLIOTECAS RESPONDEN»

12. El servicio «Pregunte: las bibliotecas responden»

12.1. Estudio de «Pregunte: las bibliotecas responden»: metodología y objetivos

12.2. Desarrollo histórico del servicio «Pregunte: las bibliotecas responden »

12.3. Descripción del funcionamiento del servicio

13. Evaluación del servicio de referencia digital «Pregunte: las bibliotecas responden»

13.1. Estudios y metodología

13.2. Estudio de profesionales

13.3. Estudio de usuarios

13.4. Estudio de incidencias

13.5. Estudio de preguntas y respuestas

13.5.1. Estadísticas generales

13.5.2. Análisis por clasificación

13.5.3. Análisis de respuestas

13.5.4. Homogeneidad de las respuestas

13.6. Estudio de visibilidad

13.7. Estudio bibliográfico

13.8. Propuestas de mejora

14. El servicio público de referencia digital «Pregunte: las bibliotecas responden» en la actualidad

14.1. Bibliotecas participantes: datos generales

14.2. Manuales de procedimiento y otros documentos

14.3. Estadísticas del servicio de referencia digital «Pregunte: las bibliotecas responden»: 2000-2007

15. Análisis de resultados: conclusiones 


\section{El servicio «Pregunte: las bibliotecas responden»}

La tercera parte de la tesis doctoral, como se puede apreciar, representa la aplicación práctica de esta investigación. En los dos bloques anteriores, el doctorando ha querido recoger los principales contenidos relativos a los servicios de referencia, tanto presenciales como telemáticos, además de establecer las diferentes metodologías de evaluación que pueden ser aplicadas a los servicios públicos de referencia digitales. No obstante, la utilidad de esta tesis quedaría en entredicho si sólo se tratara de una investigación teórica, donde se expusiera el estado de la cuestión y nada más. No es ésa la intención del doctorando. Una vez asentados los conceptos de forma exhaustiva y situado el momento actual en el que se encuentran los servicios de referencia, se han querido poner en práctica los métodos propuestos en el bloque anterior, a partir de un excelente ejemplo: el servicio «Pregunte: las bibliotecas responden», que ofrecen bibliotecas públicas españolas, bajo la supervisión de la Subdirección General de Coordinación Bibliotecaria, del Ministerio de Cultura español.

En este apartado se explican los objetivos y la metodología empleada en la evaluación del servicio, incorporando una relación cronológica del mismo, desde que se concibe en 1999 hasta los últimos cambios habidos en el año 2007. Esta síntesis histórica es una amplia guía sobre los diferentes estados por los que ha pasado «Pregunte» y sobre cómo ha sido su evolución. Se podrán observar una serie de etapas en las que el servicio ha tenido que reaccionar ante situaciones de exceso de actividad o de pasividad, ya que «Pregunte» ha experimentado momentos en ambos sentidos. La descripción exhaustiva de los datos históricos efectuada en la tesis se cierra en marzo de 2007, cuando se inicia la etapa actual, caracterizada por el traslado del servidor al Ministerio de Cultura, responsable único de toda la coordinación desde esas fechas. No obstante, se incorporan algunas informaciones posteriores a esa fecha, por considerarlas significativas en la prestación del servicio «Pregunte».

Tras la relación cronológica se ofrecen las cifras que identificaban al servicio en general y cada una de las bibliotecas que participaban en el mismo en el momento de la investigación. No se ofrecen los datos actualizados en este apartado, ya que, para una mejor pertinencia de los resultados de las evaluaciones realizadas era necesario ofrecer los datos estadísticos del periodo en el que se llevaron a cabo los diferentes análisis. No obstante, la relación cronológica está actualizada y las estadísticas últimas se recogen en el apartado 14.3., de esta parte, una vez presentada la evaluación y las propuestas de mejora derivadas de la investigación.

También se ha incluido en esta sección una descripción pormenorizada acerca de la organización del servicio. Antes de proceder a cualquier evaluación es necesario conocer de forma detallada cómo funciona una entidad o un servicio. En este caso, se ha querido dar a conocer todos y cada uno de los procedimientos que se emplean en «Pregunte». Se incluye 
la información relativa al sistema de turnos, documentación empleada, sistemas de recepción de consultas y proceso de respuesta, interacción con los usuarios, control estadístico, etc.

\subsection{Estudio de «Pregunte»: metodología y objetivos}

Una tesis doctoral en la que se ofrecen métodos para evaluar servicios de información digitales carecería de fundamento si no hubiesen aplicado los mismos. Por este motivo, el autor, de común acuerdo con la Subdirección General de Coordinación Bibliotecaria, realizó un estudio sobre el servicio público de referencia en línea español. Por una parte, se trataba de ejercitar las teorías que se estaban elaborando para esta tesis doctoral y, por otra, partir de ese corpus teórico para el análisis minucioso de "Pregunte: las bibliotecas responden". Hay que situarse a finales de 2003, periodo en que se establecen los contactos y se llega a un acuerdo entre el doctorando y el Ministerio de Cultura para aplicar la investigación sobre la calidad de los servicios de referencia digitales al servicio Pregunte.

Tras algunas conversaciones previas, para delimitar el alcance del estudio se realizó una propuesta de trabajo, que se presentó a la Subdirección General de Coordinación bibliotecaria el 20 de enero de 2004. Asimismo, un primer avance del análisis fue presentado a los miembros del Grupo de Trabajo de «Pregunte» el 10 de febrero de 2004. En esta fecha se expusieron los objetivos de la investigación y las principales acciones que se estaban llevando a cabo para la evaluación del servicio. De igual forma, se recogieron sugerencias de los asistentes a esta reunión para que el enfoque del estudio y el resultado final fuese aplicable a la situación actual del servicio. Efectivamente, se trataba de poner en práctica los resultados que se derivaran de la investigación, como así fue, ya que, una vez entregado el estudio, se han realizado mejoras que se explican en otro apartado de este bloque de la tesis doctoral. En definitiva, se ha podido conseguir la meta de toda investigación, ya que los resultados de la misma han podido ser aplicados y han servido para la mejora de la calidad de este servicio público de información, que las bibliotecas españolas prestan gratuitamente.

Es importante destacar que esta investigación nació como un proyecto de tesis doctoral, que fue apoyado por el Ministerio de Cultura dada su aplicación real. Esta tercera parte de la tesis es la única que contó con la financiación de la Subdirección General de Coordinación Bibliotecaria. El contenido de esta parte sigue inédito.

La raíz de la parte práctica del estudio -efectuado en 2004- fue que, desde que el servicio de referencia en línea «Pregunte: las bibliotecas responden» se inició en junio de 2000, el empleo del mismo por los usuarios a los que va dirigido había ido menguando paulatinamente, a pesar de contar con un mayor número de bibliotecas en el proyecto y, por supuesto, de disponer de mayor experiencia. Contra toda lógica, el volumen de consultas fue descendiendo de manera sucesiva, como demuestran las estadísticas que periódicamente se realizan. Tomando datos de las estadísticas elaboradas 
por la coordinación técnica del servicio este hecho se pudo constatar de forma objetiva, como lo demuestras estas cifras, extraídas de la sección de estadísticas de la actual intranet de «Pregunte».

\begin{tabular}{|c|c|}
\hline \multicolumn{1}{|c|}{ Periodo } & Preguntas realizadas \\
\hline 1 junio 2000 / 30 mayo 2001 & 7835 \\
\hline 1 junio 2001 / 30 mayo 2002 & 5988 \\
\hline 1 junio 2002 / 30 mayo 2003 & 4583 \\
\hline 1 junio 2003 / 30 mayo 2004 & 5405 \\
\hline 1 junio 2004 / 30 mayo 2005 & 5661 \\
\hline 1 junio 2005 / 30 mayo 2006 & 5549 \\
\hline 1 junio 2006 / 30 mayo 2007 & 4542 \\
\hline
\end{tabular}

Se hacía necesario estudiar esa tendencia a la baja, para conocer cuáles eran las causas de que un servicio útil y gratuito hubiese ido descendiendo en su uso. Para ello, la Subdirección General de Coordinación Bibliotecaria y el Grupo de Trabajo de «Pregunte», integrado por la Biblioteca Regional de Murcia, como coordinadora del proyecto, y otras bibliotecas participantes en este programa, dieron su apoyo decidido a la investigación del doctorando, que se concretaría en el estudio acerca del funcionamiento del servicio, del que se derivaron propuestas de mejora, que han sido directamente aplicadas en su mayor parte, sin necesidad de variar sustancialmente la estructura desde la que ahora se trabaja.

Los objetivos de los que se partieron fueron los siguientes:

- análisis del funcionamiento del servicio en el momento del estudio

- análisis de las fortalezas y debilidades del servicio

- análisis de la visibilidad y conocimiento del servicio

- propuestas de mejora del funcionamiento del servicio

- propuestas de mejora de la información facilitada por el servicio

- propuestas para la difusión y publicidad del servicio

En definitiva, hay tres grandes propósitos que marcan el contenido de la investigación y que sintetizan los aspectos citados en las líneas anteriores:

$\Rightarrow$ Describir el sistema de organización y sus procedimientos

$\Rightarrow$ Evaluar la calidad del servicio y de la información

$\Rightarrow$ Ofrecer propuestas para la mejora de su rendimiento

Para conseguir estos objetivos se actuó de forma muy diferente, en función de qué informaciones se pretendiese conseguir: perfiles de los profesionales que atienden el servicio, usuarios del mismo, tipos de preguntas, incidencias en la coordinación, difusión del servicio y visibilidad en la bibliografía profesional y en los recursos telemáticos afines, etc.

El grueso de la información necesaria para la evaluación que se presenta en esta parte de la tesis doctoral fue recogida entre los meses de febrero y abril de 2004, aunque algunos datos han sido actualizados. En todo caso, en cada uno de los estudios parciales (encuestas, búsquedas bibliográficas, 
preguntas realizadas al servicio, etc.) se indica el periodo en el que se realizaron los mismos.

Una investigación de estas características requería un análisis pormenorizado de los distintos elementos que intervienen en «Pregunte». Por una parte, se hacía necesario conocer la opinión de los agentes (profesionales y usuarios), pero también era obligatorio comprobar los procedimientos y, como no, la calidad de las informaciones dadas. Además, habría que valorar de igual forma el grado de difusión que el servicio de referencia de las bibliotecas públicas españolas ha alcanzado en los años que lleva prestándose. Por tanto, se hacía necesaria una metodología de trabajo compuesta por distintas submetodologías, en función de la evaluación particular que se estuviese realizando.

Como se ha visto en el bloque de la tesis dedicado a la evaluación de servicios de referencia digitales, hay editados algunos trabajos interesantes acerca de cómo evaluar este tipo de un unidades de información. Entre estos estudios destaca la obra Statistics, Measures and Quality Standards for Assessing Digital Reference Library Services: Guidelines and Procedures, dirigida por el profesor Charles R. McClure en el Information Institute of Syracuse y que puede ser consultado íntegramente en línea en la dirección <http://quartz.syr.edu/quality>. Esta guía, junto a otros estudios parciales realizados para evaluar servicios de referencia telemáticos, fueron tenidos en cuenta para establecer una metodología específica aplicable a esta evaluación concreta de «Pregunte: las bibliotecas responden». Pero, sobre todo, además de planificar el proceso evaluativo como parte práctica de la tesis doctoral, se ha partido de la idea de evaluar para mejorar, por lo que todos los análisis efectuados pretendieron recoger los indicadores necesarios para sugerir acciones concretas de mejora.

Aunque en un apartado posterior de esta tesis doctoral se describen de forma independiente los diferentes estudios realizados y la metodología específica aplicada en cada caso, se quiere ofrecer en esta sección una panorámica general de cómo se ha enfocado el estudio. En los siguientes párrafos se resumen las distintas acciones realizadas para conseguir la información que finalmente sirvió para conocer el estado de la cuestión del servicio y para el establecimiento de las conclusiones y propuestas que se plantearon seguidamente. Los sistemas de evaluación empleados han sido los siguientes:

- Recopilación de información: los datos sobre «Pregunte» se encuentran muy dispersos. Apenas se han publicado artículos en revistas profesionales en los que se estudie este servicio de referencia en línea. Además, son escasos los informes internos generados en los años de existencia del servicio. Por este motivo, la primera acción que se llevó a cado fue la recopilación de documentos e informaciones relativos a «Pregunte». Se recogió toda la documentación generada desde la Biblioteca Regional de Murcia, impulsora y coordinadora del servicio, así como desde la Subdirección General de Coordinación 
Bibliotecaria, encargada de coordinar los distintos grupos de trabajo formados por las Bibliotecas Públicas de Estado españolas. La colaboración de los responsables de la Biblioteca Regional de Murcia y de la Subdirección General de Coordinación Bibliotecaria ha sido esencial para poder redactar el apartado en el que se ofrece una visión cronológica de «Pregunte», que se estima necesaria, tanto para quienes participan en el proyecto desde su origen, como para quienes se han ido incorporando al mismo.

- Encuestas: se realizaron tres tipos de encuestas. La principal ha sido la efectuada a los profesionales que trabajan o han trabajado en «Pregunte» en labores de coordinación, resolución de preguntas o apoyo en el proceso de elaboración de respuestas. Las cuestiones por las que se preguntaba pretendían conocer el perfil de los bibliotecarios, su formación, sus procedimientos como referencistas y su opinión sobre el servicio. La segunda encuesta se envió a los coordinadores de cada biblioteca participante y en ella se interrogaba sobre cuestiones específicas, como el número de personas que trabajan en «Pregunte» y sus categorías laborales. Con la segunda encuesta se pudieron obtener datos hasta ahora no disponibles. Por último, se envió otra encuesta, esta vez a usuarios registrados en «Pregunte». El sistema permite que los usuarios se registren, para poder conocer el estado de sus consultas. Se empleó la base de datos de usuarios registrados para hacer llegar a los mismos una serie de preguntas sobre su opinión sobre el servicio. En todo momento se respetó la legislación sobre protección de datos personales. Todas las encuestas han sido enviadas y recibidas por correo electrónico.

- Procedimientos: para conocer si los procedimientos que se siguen en «Pregunte» eran correctos o mejorables, se estudió pormenorizadamente la organización del servicio: cómo se coordina, cómo se distribuyen los turnos, cómo se realizan las preguntas, cómo se resuelven, cómo se pueden realizar reclamaciones y qué incidencias se presentan con más asiduidad. Para ello se analizaron los manuales y los documentos complementarios redactados para quienes atienden «Pregunte». Asimismo, se han estudiado las incidencias recibidas a lo largo del año 2003 por el coordinador de «Pregunte». También se examinó el proceso de pregunta-respuesta, es decir, las distintas fases por las que una pregunta pasa desde que es planteada por un usuario hasta que éste recibe por correo electrónico la respuesta.

- Preguntas y respuestas: la mejor manera de conocer la calidad del servicio es comprobarlo directamente. Se remitieron distintas cuestiones a «Pregunte» a lo largo de varios días, incluso repitiendo las preguntas. Se trataba de conocer la calidad de las respuestas, la utilidad de las mismas, la homogeneidad en los contenidos y la uniformidad en la exposición de las respuestas. Para ello, se ha empleado un método discreto, basado en la selección de las 
preguntas y en que el personal no sabe que está siendo interrogado con fines evaluativos. De esta forma se consiguen datos más fiables y objetivos. La pretensión de este método fue analizar la calidad de las respuestas, no evaluar la formación del personal de las bibliotecas participantes. Además, se analizaron las respuestas ofrecidas a las cuestiones recibidas a lo largo de un turno completo, para conocer el tipo de respuesta dada, las fuentes manejadas y otras informaciones. En el examen de las preguntas también se ha dedicado un estudio a las temáticas más frecuentes a las que se refieren las consultas.

- Difusión: la eficiencia de un servicio público, además de por su nivel de su uso, también se mide por su grado de conocimiento. Para saber la difusión de «Pregunte» se han realizado dos estudios particulares. En uno de ellos se han interrogado bases de datos especializadas en bibliotecología, tanto españolas como extranjeras. A los datos obtenidos por este procedimiento se han unido las referencias facilitadas por los responsables de «Pregunte» sobre noticias aparecidas en medios informativos locales o nacionales. El segundo análisis ha sido efectuado para conocer la visibilidad de«Pregunte» en Internet, es decir, cuántas webs enlazaban con alguno de los servidores del servicio y quiénes eran las instituciones que facilitaban estos enlaces. Para ello se emplearon las opciones avanzadas de los principales buscadores. El estudio de visibilidad aportó cifras sobre el número de servidores que enlazan con «Pregunte» y el tipo de instituciones a las que pertenecen: bibliotecas, organismos públicos, empresas, etc.

Un estudio de estas características no hubiese sido posible sin la colaboración de un gran número de personas, sin cuya participación no se podría ofrecer tanta información como la que aquí se ha conseguido recopilar. El doctorando quiere dejar constancia de su agradecimiento a quienes han contribuido a que esta parte de la tesis doctoral haya podido realizarse. Es de agradecer la colaboración de los coordinadores y profesionales de las bibliotecas públicas que participan en el proyecto, quienes han respondido a todas las cuestiones que se les han planteado, dejando parte de su tiempo para apoyar este estudio y lograr que el informe llegara a buen puerto.

También hay que agradecer el apoyo de los usuarios que respondieron a la encuesta, quienes demostraron tomarse «Pregunte» como un servicio propio, además de transmitir sus ganas de que el proyecto siguiera adelante. De forma especial hay que mencionar a los responsables presentes y pasados de la Biblioteca Regional de Murcia, al personal de la Subdirección General de Coordinación Bibliotecaria y al Grupo de Trabajo de «Pregunte», quienes trataron al doctorando como "alguien de casa", facilitándole toda la documentación necesaria, respondiendo a las preguntas que se les fueron planteando, ofreciendo orientaciones y dando soluciones a los problemas que fueron surgiendo. No se puede dejar pasar en estas línea la gratitud más sincera a María Luisa Martínez Conde, de la Subdirección General de Coordinación Bibliotecaria, que apoyó en todo momento la investigación, por 
su interés en conseguir un servicio de referencia efectivo y por la amabilidad de comprender las circunstancias que conllevan la elaboración de un trabajo de estas características. De igual forma, es necesario agradecer el interés, la colaboración y la implicación en el estudio de Ángel Peñalver Martínez, de la Biblioteca Regional de Murcia, experto referencista, quien ha puesto a disposición de la tesis todos los materiales que se le pidieron, quien atendió las llamadas de auxilio que periódicamente le llegaban y sin cuya colaboración la investigación no hubiese obtenido los mismos resultados. Se ha comprobado, una vez más, que para el colectivo bibliotecario la palabra "cooperación" es un valor indiscutible.

\subsection{Desarrollo histórico del servicio «Pregunte: las bibliotecas responden»}

La descripción del desarrollo de «Pregunte» a lo largo de sus años de existencia se hace necesaria para la mejor comprensión de la evaluación que posteriormente se presenta. En este apartado se exponen los principales datos históricos, como son la sucesiva incorporación de bibliotecas, el momento actual y la presentación de las estadísticas de estos años de funcionamiento. La intención es situar el servicio desde sus orígenes hasta el presente, algo necesario antes de proceder a su evaluación y a la presentación de las conclusiones y las serie de mejoras.

Por lo tanto, se exponen a continuación los principales hechos de relevancia en el desarrollo del servicio «Pregunte: las bibliotecas responden», desde su concepción hasta la actualidad. Los acontecimientos que se mencionan en los siguientes párrafos son sólo una muestra de los periodos vividos en el servicio. Ha sido difícil obtener información acerca de algunos hechos, por lo que el grado de precisión es el más elevado que se ha podido conseguir. Hay que plantear esta secuencia cronológica como un esfuerzo por hilvanar datos esparcidos en documentos de trabajo, notas de prensa, actas de reuniones, documentos internos e incluso informaciones inéditas. En esta cronología está representada toda la historia del servicio público de referencia en línea español.

1999

- Documento "La Biblioteca Responde". Proyecto que tiene el objetivo de crear un servicio de información público, mediante correo electrónico y web, gestionado de forma cooperativa entre bibliotecas de las diferentes Comunidades Autónomas y la Subdirección General de Coordinación Bibliotecaria. En dicho documento se dan indicaciones sobre el reglamento de uso, la metodología las normas de estilo, la coordinación del servicio, así como de su desarrollo técnico. Éste es el documento sobre el que construirá el proyecto «Pregunte».

- Adquisición de lotes bibliográficos (43.469.773 pesetas / 261.259,60 euros) 
- 15 de septiembre de 1999. Incorporación oficial al proyecto de la Biblioteca Regional de Murcia / Biblioteca Pública del Estado en Murcia.

- 20 de septiembre de 1999. Incorporación oficial al proyecto de la Biblioteca Central de Cantabria / Biblioteca Pública del Estado en Santander.

- 30 de septiembre de 1999. Presentación de la beta del sistema.

- 10 de diciembre de 1999. Incorporación oficial al proyecto de la Biblioteca de Andalucía y de la Biblioteca Pública del Estado en Zaragoza.

- 13 de diciembre de 1999. Presentación del servicio en la Secretaría de Estado de Cultura. Asisten los miembros del Grupo Pregunte, el Director General del Libro Archivos y Bibliotecas y representantes de las Comunidades Autónomas, excepto de Galicia y de Castilla y León.

- 13 de diciembre de 1999. Incorporación oficial al proyecto de la Biblioteca Pública del Estado en Valencia.

- 15 de diciembre de 1999. Incorporación oficial al proyecto de la Biblioteca de Castilla-La Mancha / Biblioteca Pública del Estado en Toledo; del Servei de Biblioteques i Patrimoni Bibliogràfic de la Generalitat de Catalunya; de la Biblioteca Central de La Rioja / Biblioteca Pública del Estado en Logroño; de la Biblioteca Pública del Estado en Vitoria; y de la Biblioteca de Asturias.

- 21 de diciembre de 1999. Incorporación oficial al proyecto de la Biblioteca General de Navarra.

- 22 de diciembre de 1999. Incorporación oficial al proyecto de la Biblioteca Central de Madrid.

- Diciembre de 1999. Incorporación oficial al proyecto de la Biblioteca Pública del Estado en Las Palmas de Gran Canaria.

- Diciembre de 1999. Inicio de la fase experimental, en la que las distintas bibliotecas participantes realizan pruebas del sistema. El periodo de pruebas se alargará hasta el mes de junio de 2000. Participan en esta fase -en mayor o menor medida- las siguientes bibliotecas: Biblioteca Regional de Murcia/Biblioteca Pública del Estado en Murcia; Biblioteca Central de Cantabria/Biblioteca Pública del Estado en Santander; Biblioteca de Andalucía; Biblioteca Pública del Estado en Zaragoza; Biblioteca Pública del Estado en Valencia; Biblioteca de Castilla-La Mancha/Biblioteca Pública del Estado en Toledo; Servei de Biblioteques i del Patrimoni Bibliogràfic, Generalitat de Catalunya; Biblioteca Central de La Rioja/Biblioteca Pública del Estado en Logroño; Biblioteca Pública del Estado en Vitoria; Biblioteca de Asturias; Biblioteca General de Navarra; Biblioteca Central de Madrid; Biblioteca Pública del Estado en Mahón; Biblioteca Pública del Estado en Cáceres; Biblioteca Pública del Estado en León; Biblioteca Pública 
del Estado en Tarragona; Biblioteca Municipal Central de San Sebastián; Biblioteca Pública del Estado en Las Palmas y Biblioteca Pública del Estado en Castellón.

\section{0}

- 17 de enero de 2000. Incorporación oficial al proyecto de la Biblioteca Pública del Estado en Mahón y de la Biblioteca Pública del Estado en Cáceres.

- 3 de febrero de 2000. Incorporación oficial al proyecto de la Biblioteca Pública del Estado en León.

- 14 de marzo de 2000. Informe del Coordinador del Grupo de Trabajo «Pregunte: las bibliotecas responden» en el que explica las actividades llevadas a cabo en 1999 por el Grupo. Informa de los siguientes puntos: definición de los objetivos del proyecto; reparto de tareas previas; elección de la plataforma y herramientas informáticas; diseño del programa de gestión y de la base de datos y selección del desarrollador; supervisión del desarrollo del producto; desarrollo del resto de actividades; inicio de la fase final; presentación del programa e inicio de la fase de pruebas; presentación final.

- 30 de marzo de 2000. El Secretario de Estado de Cultura presenta el Plan de Impulso de las Bibliotecas Públicas Españolas: "Las bibliotecas públicas, puertas de entrada a una Sociedad de la Información para todos", de la Dirección General del Libro, Archivos y Bibliotecas. En el apartado 5, «Medidas y proyectos incluidos en el Plan», se incluye la creación de un "Servicio cooperativo de información en Internet", con la siguiente descripción:

El servicio, cuyo nombre será Pregunte: las bibliotecas responden, atenderá todo tipo de consultas y peticiones de información a través de Internet, tanto de carácter práctico, de tipo bibliográfico o cultural o de índole general, y sobre todas las materias. Cualquier persona podrá enviar sus consultas mediante un formulario disponible en una página web y recibirá la respuesta por correo electrónico en un plazo máximo de tres días. Atenderán el servicio de forma cooperativa varias bibliotecas dependientes de las Comunidades Autónomas, en turnos diarios.

- 6 abril de 2000. Anexo al informe sobre el Grupo el Proyecto «Pregunte» elaborado por el coordinador del grupo de trabajo. La Subdirección General de Coordinación Bibliotecaria informa de que el servicio será multilingüe, en los idiomas oficiales del estado, tanto para realizar las preguntas como para recibir las respuestas.

- 9 de mayo de 2000. Incorporación oficial al proyecto de la Biblioteca Pública del Estado en Tarragona; de la Biblioteca Municipal Central de San Sebastián; y de la Biblioteca Central de Terrasa. 
- 17 de mayo de 2000. La Ministra de Educación, Cultura y Deporte presenta en el Congreso de los Diputados el Plan de Impulso de las Bibliotecas Públicas Españolas, en el que se encuentra «Pregunte».

- Mayo de 2000. Continúan las pruebas en 15 bibliotecas

- 8 de junio de 2000. Puesta en marcha del servicio. La Biblioteca Pública del Estado en León inaugura el sistema de turnos y, por tanto, es la primera biblioteca que atiende las preguntas de los usuarios.

- 8 de junio de 2000. Mensaje en las listas de distribución Públicas e Iwetel en el que se difunde la noticia de la puesta en marcha del servicio.

- Junio de 2000. Incorporación oficial al proyecto de la Biblioteca Pública del Estado en Castellón.

- Junio de 2000. Noticia en Correo Bibliotecario. Informa de la puesta en marcha del servicio, que se inscribe en el ámbito de cooperación establecido entre el Ministerio de Educación, Cultura y Deporte y las Comunidades Autónomas y que se incluye en el "Plan de Impulso de las Bibliotecas Públicas Españolas". Se informa de que participan 20 Bibliotecas Públicas, pertenecientes a 16 Comunidades Autónomas. La Subdirección General de Coordinación Bibliotecaria se encargará del patrocinio y la coordinación, mientras que las labores de gestión técnica recaerán en la Biblioteca Regional de Murcia.

- 18 de octubre de 2000. Incorporación oficial al proyecto del Centro Superior Bibliográfico de Galicia.

- 15 de noviembre de 2000. Incorporación oficial al proyecto de la Biblioteca Pública del Estado en Salamanca.

- Diciembre de 2000. La Biblioteca Pública del Estado en Castellón abandona el proyecto. Se había incorporado al mismo en el mes de junio de ese mismo año.

- Adquisición de lotes bibliográficos (26.587.452 pesetas / 159.793,80 euros)

2001

- 10 de enero de 2001. Informe sobre el servicio «Pregunte: las bibliotecas responden», elaborado por la Subdirección General de Coordinación Bibliotecaria. Se informa de que se puso en marcha el 8 de junio de 2000, con 21 bibliotecas participantes (20 bibliotecas y la SGCB). El informe se centra en la necesidad de conseguir la dirección www.pregunte.es.

- 25 de enero de 2001. Incorporación oficial al proyecto de la Biblioteca Pública del Estado en Córdoba. 
- Enero de 2001. Incorporación oficial al proyecto de la Biblioteca Pública del Estado en Jaén.

- Mayo de 2001. La Biblioteca Pública del Estado en Jaén abandona el proyecto. Se había incorporado al mismo en el mes de enero de 2001.

- 6 de junio de 2001. Reunión sobre el Proyecto Pregunte: las Bibliotecas Responden (Servicio Cooperativo de Información por Internet) celebrada en Madrid en la Secretaría de Estado de Cultura. Se analizan los principales aspectos del primer año del servicio: exceso de preguntas (se decide ampliar el número de bibliotecas para poder dar respuestas en tres días); problemas con las preguntas inadecuadas (se decide preparar procedimientos comunes de respuesta ante preguntas no procedentes); estadísticas (se decide la emisión de informes trimestrales); necesidad de modificaciones en el sistema información; estudio y depuración de las preguntas y respuestas, listados de fuentes, etc.; traspaso de la coordinación técnica a la SGCB; cursos de formación. Se nombra una Comisión Permanente formada por los siguientes centros: Biblioteca de Andalucía, Biblioteca Pública del Estado en Barcelona, Biblioteca Municipal Central de San Sebastián, Biblioteca Pública del Estado en Las Palmas, Biblioteca Pública del Estado en Santander, Biblioteca Pública del Estado en Zaragoza y Biblioteca Regional de Murcia. La Biblioteca Regional de Murcia, en calidad de coordinador técnico, presenta el informe del primer año de servicio.

- 29 de junio de 2001. Incorporación oficial al proyecto de la Biblioteca Pública del Estado en Huesca y de la Biblioteca Pública del Estado en Santa Cruz de Tenerife.

- 4 de septiembre de 2001. Incorporación oficial al proyecto de la Biblioteca Pública del Estado en Huelva.

- 12 de septiembre de 2001. Incorporación oficial al proyecto de la Biblioteca Pública del Estado en Alicante.

- 15 a 18 y 22 a 25 de octubre de 2001. Curso "El servicio de información en la biblioteca pública", celebrado en Toledo, con una duración de 21 horas. Fue organizado por la Subdirección General de Coordinación Bibliotecaria para quienes fueran a atender «Pregunte: las bibliotecas responden».

- 22 de octubre de 2001. Incorporación oficial al proyecto del Servicio Municipal de Lectura Pública de La Coruña y de la Red de Biblioteca Municipales de Bilbao.

- Diciembre de 2001. La Biblioteca Pública del Estado en Las Palmas deja de participar en «Pregunte». Fue una de las bibliotecas que iniciaron el proyecto, ya que llevaba en el mismo desde diciembre de 1999. 
- Adquisición de lotes bibliográficos (79.701,57 euros) para las BPE de Tarragona, Salamanca y Córdoba

2002

- Febrero de 2002. "Informe sobre Coordinación técnica del servicio «Pregunte»", presentado por Tomás Saorín Pérez, Coordinador Técnico del servicio. Se resumen los problemas y las actuaciones correspondientes a 2001.

- Febrero de 2002. Especificaciones para la mejora del servidor «Pregunte: las bibliotecas responden». Información de la Biblioteca Regional de Murcia para la elaboración del presupuesto por el área de informática de la Universidad de Murcia.

- Febrero de 2002. Cambio del coordinador técnico. Deja el puesto Tomás Saorín Pérez y pasa a desempeñarlo Ángel Peñalver Martínez, también de la Biblioteca Regional de Murcia.

- Julio de 2002. Cambio en la clasificación temática

- Contrato con la Universidad de Murcia para llevar a cabo nuevas funcionalidades del software de gestión

- Adquisición de lotes bibliográficos (134.100,25 euros) para las BPE de Alicante, Huelva, Huesca y Santa Cruz de Tenerife

\section{3}

- 24 de junio de 2003. Reunión sobre el Proyecto celebrada en la Secretaría de Estado de Cultura. Se comprueba que muchos de los puntos aprobados en la reunión anterior (6 junio 2001) no han sido puestos en práctica: envío de preguntas inadecuadas para decidir procedimientos, informes estadísticos, etc. Se decide la revisión del manual de procedimiento. Se trata del descenso del uso del servicio y se apuntan, como posibles causas, la falta de difusión y el mayor conocimiento de Internet por parte de los usuarios. Se discute la posibilidad de ampliar el espacio de respuesta y de adjuntar archivos. Se discuten, además, los siguientes asuntos: delimitación del tipo de respuestas que se dan; posibilidad de ampliar los servicios (chat); recogida de datos del usuario (edad, finalidad de la consulta); medición de la satisfacción del usuario; problemas con las preguntas sin respuesta; modificación de la clasificación; problemas con los lotes que envía la SGCB (existencia de duplicados); suscripciones a bases de datos; propuesta de evaluación del servicio; cursos de formación ofrecidos por la SGCB. Se nombra una Comisión Permanente.

- 7 de julio de 2003. "Informe sobre tareas de gestión/coordinación del servicio «Pregunte: las bibliotecas responden»", redactado por Ángel Peñalver Martínez. Se realiza un estudio de las consultas y de las 
incidencias destinadas al coordinador del sistema entre enero y junio de 2003.

- 24 a 27 de noviembre de 2003. Curso de formación "El servicio de información en la biblioteca pública", para bibliotecas participantes en «Pregunte», celebrado en Toledo, en la Biblioteca Regional de Castilla-La Mancha.

- 1 de diciembre de 2003. Incorporación oficial al proyecto de la Biblioteca de Castilla y León / Biblioteca Pública del Estado en Valladolid; de la Biblioteca Pública del Estado en Albacete; de la Biblioteca Pública del Estado en Cuenca; de la Biblioteca Pública del Estado en Lérida; de la Biblioteca Pública del Estado en Mérida; y de la Biblioteca de Latina "Antonio Mingote" de Madrid.

- 8 de enero de 2004. Incorporación oficial al proyecto de la Biblioteca Pública del Estado en Burgos.

- 20 de enero de 2004. Presentación de la propuesta del informe "El servicio de referencia en línea «Pregunte: las bibliotecas responden»: análisis de su funcionamiento y propuestas de mejora", encargado por la Subdirección General de Coordinación Bibliotecaria.

- 26 de enero de 2004. Incorporación oficial al proyecto de la Biblioteca Pública del Estado en Almería.

- 1 de febrero de 2004. La Biblioteca Central de Terrassa dejó de participar en el servicio «Pregunte». Llevaba en el proyecto desde el 9 de mayo de 2000.

\section{4}

- 10 de febrero de 2004. Reunión de la Comisión de seguimiento, en la Secretaría de Estado de Cultura. Se presenta el estudio de evaluación que está en fase de realización. Se decide aplazar cualquier decisión hasta la entrega del informe. Se acuerda hacer un nuevo manual de procedimiento, con información elaborada u orientaciones. Otras cuestiones tratadas fueron: modificación de los tramos de edad; problemas con las preguntas sin respuesta; necesidad de un coordinador que valide las preguntas; uso de la lista interna.

- Mayo de 2004. Avance del estudio "El servicio de referencia en línea «Pregunte: las bibliotecas responden»: análisis de su funcionamiento y propuestas de mejora", realizado por José Antonio Merlo Vega, profesor del Departamento de Biblioteconomía y Documentación de la Universidad de Salamanca.

- Junio de 2004.Primeros pasos para el traslado del servidor y de la coordinación técnica a la Subdirección General de Coordinación Bibliotecaria. Integración del Grupo de Trabajo de «Pregunte: las 
bibliotecas responden» en el Grupo de Trabajo de Referencia Virtual, formado por las siguientes instituciones: Biblioteca de Andalucía, Biblioteca Pública del Estado en Gijón, Biblioteca de Castilla y León / Biblioteca Pública del Estado en Valladolid, Biblioteca de Castilla-La Mancha / Biblioteca Pública del Estado en Toledo, Biblioteca Pública del Estado en Cáceres, Biblioteca Regional de Madrid, Subdirección General de Coordinación Bibliotecaria, Biblioteca Regional de Murcia / Biblioteca Pública del Estado en Murcia y Biblioteca Pública del Estado en Valencia. La decisión de la integración en el Grupo de Trabajo de Referencia Virtual se recoge en la conclusión número 12 de las Jornadas de Cooperación Bibliotecaria MEC /CCAA, celebradas en Valencia los días 2, 3 y 4 de junio de 2004.

- Septiembre de 2004. Finalización y entrega del informe "El servicio de referencia en línea «Pregunte: las bibliotecas responden»: análisis de su funcionamiento y propuestas de mejora", realizado por José Antonio Merlo Vega, profesor del Departamento de Biblioteconomía y Documentación de la Universidad de Salamanca.

- 28 de septiembre de 2004. Reunión del grupo Pregunte en el Ministerio de Cultura. Se presenta el nuevo grupo, en el que ya no están los representantes de Barcelona y Asturias. José Antonio Merlo Vega expone los aspectos más destacados del informe "El servicio de referencia en línea «Pregunte: las bibliotecas responden»: análisis de su funcionamiento y propuestas de mejora", los principales problemas detectados, las conclusiones más importantes y las propuestas de mejora. Se debate el informe y se decide asumir el informe como un documento propio del Grupo, que servirá de base para tomar decisiones.

- 8 de diciembre de 2005. Jornada sobre servicios de referencia virtual, celebrada en Lyon (Francia). Pablo Gallo realiza una presentación sobre Pregunte.

- Adquisición de lotes bibliográficos (128.277,97 euros) para las BPE de Albacete, Almería, Badajoz, Cuenca, Lérida y Burgos

- Contratación de 25 licencias Ocenet (30.000 euros) para los usuarios de «Pregunte: las bibliotecas responden»:

\section{5}

- 23 de febrero de 2005. Convocatoria de reunión del Grupo Pregunte, que debe ser anulada por las circunstancias meteorológicas.

- 30 de marzo de 2005. Reunión del Grupo Pregunte en la Sala Velázquez del Ministerio de Cultura, con el objetivo de revisar las propuestas que se van a llevar a una reunión general de todos los participantes en Pregunte. Se tratan temas como: licencias de Ocenet, problemas con 
el servidor, traslado del mismo, propuestas de mejora que se pueden aplicar a corto plazo y tareas pendientes.

- 30 de abril de 2005. El Servei de Biblioteques i del Patrimoni Bibliogràfic de la Generalitat de Catalunya abandona el proyecto. Se había incorporado al mismo en el mes de diciembre de 1999.

- 12 de mayo de 2005. Reunión sobre el servicio cooperativo de información Pregunte, que se celebra en la sala de prensa del Ministerio de Cultura. Se debaten las propuestas de la comisión delegada del Grupo Pregunte. Se plantean una serie de propuestas generales y algunas concretas de realización inmediata. Los resultados del debate son los siguientes:

- se acepta incorporar a otras bibliotecas

- no se aprueba modificar el tiempo máximo de respuesta

- se decide ampliar el número de bibliotecas del turno en catalán, dado el número de consultas que se reciben en esta lengua

- se decide estudiar las funciones de un centro que coordine el servicio

- se decide estudiar la inclusión obligatoria de datos del usuario: edad, motivo de la consulta, localidad de residencia.

- 10 de junio de 2005. Conclusiones finales de las IX Jornadas de Cooperación Bibliotecaria MEC / CCAA, celebradas en Tarragona, los días 8, 9 y 10 de junio de 2005. Se acuerda que la coordinación del Grupo de Trabajo de Referencia Virtual recaiga en la Biblioteca de Andalucía. En la primera de las conclusiones se dice: 1. El Grupo de Trabajo de Referencia Virtual continuará estudiando las posibilidades de mejora del servicio Pregunte, las Bibliotecas Responden. Elaborará un manual de procedimiento, propondrá la ampliación del número de bibliotecas participantes, especialmente municipales, y abrirá la participación a las bibliotecas públicas iberoamericanas.

- 13 de octubre de 2005: Incorporación oficial al proyecto de la Biblioteca Regional de Madrid "Joaquín Leguina".

- 23, 24 y 25 de noviembre de 2005. Curso del sistema cooperativo Pregunte. Biblioteca de Castilla-La Mancha, Toledo. 20 horas de duración.

- 14 de diciembre de 2005: Incorporación oficial al proyecto de la Biblioteca Pública del Estado en Badajoz.

- 15 de diciembre de 2005: Reunión del Grupo de Trabajo de Referencia Virtual. Análisis del servicio, traslado del servidor, modificaciones efectuadas, revisión del manual de procedimiento, reactivación del foro, posible participación de archivos y museos. Acude a la reunión el Jefe de la Sección de Archivos de la Subdirección General de los 
Archivos Estatales, quien manifiesta la disponibilidad de su servicio para incorporarse a Pregunte.

2006

- Renovación de 15 licencias de Ocenet por importe de 17.500 euros.

- 2 de febrero de 2006. Incorporación oficial al proyecto de la Biblioteca Pública del Estado en Teruel y de la Biblioteca Pública del Estado en Segovia.

- 22 de febrero de 2006. Incorporación oficial al proyecto de la Biblioteca Pública del Estado en Soria.

- 1 de marzo de 2006. Incorporación oficial al proyecto de la Biblioteca Pública del Estado en Gerona.

- 21 de marzo de 2006. Reunión del Grupo de Trabajo de Referencia Virtual para la revisión del manual del servicio. Propuesta de estructura y distribución de los contenidos entre los integrantes del grupo. La reunió se celebró en Madrid, en la sede del Ministerio de Cultura, y en la misma se estableció la estructura del manual de procedimiento de Pregunte, que quedó establecida de la siguiente forma: 1. Introducción; 2. Uso del programa; 3. Gestión de preguntas/ respuestas; 4. Pautas de estilo de las respuestas; 5. Fuentes y herramientas; 6 . Directorio de bibliotecas participantes.

- 28 de marzo de 2006. Últimas respuestas ofrecidas por el Centro Superior Bibliográfico de Galicia, que abandona el servicio.

- 29, 30 y 31 de marzo de 2006. Curso sobre el sistema cooperativo Pregunte. Biblioteca de Castilla-La Mancha ,Toledo. 20 horas.

- 26 de mayo de 2006. Informe sobre el módulo estadístico accesible desde la coordinación del servicio. Documento sobre las posibilidades de explotación de estadísticas que permite el servidor de Pregunte.

- 14, 15 y 16 de junio de 2006. X Jornadas de Cooperación Bibliotecaria, celebradas en Santiago de Compostela. Presentación del informe del Grupo de Trabajo de Referencia Virtual, en el que se describen las reuniones celebradas en el año anterior.

- 20 de junio de 2006. Primera versión en pruebas del nuevo servidor del servicio, para que fuera revisada por los participantes en el proyecto. Se inicia el proceso de transformación de la nueva herramienta informática, adaptando los requisitos de la Subdirección General de Coordinación Bibliotecaria y del Grupo de Trabajo de Referencia Virtual. Se establecen dos fases de prueba, finalizando este periodo el 31 de enero de 2007. 
- 22 de junio de 2006. Reunión del Grupo de Trabajo de Referencia Virtual en la Biblioteca Regional de Madrid. Aprobación del nuevo manual del servicio. Se alcanzan algunos acuerdos relativos a la mejora en la recuperación y en el sistema de evaluación.

- 23 de junio de 2006. Cambios en la herramienta de Pregunte. Propuesta de modificaciones en los sistemas de evaluación del servicio, así como otras mejoras de tipo técnico: quejas, posteriores comunicaciones con el usuario, métodos de búsqueda

- Prevista la adquisición de lotes bibliográficos por valor de 120.0000 euros

2007

20, 21 y 22 de marzo de 2007. XI Jornadas de Cooperación Bibliotecaria, celebradas en Mérida. Informe del Grupo de Trabajo de Referencia Virtual en el que se describe el proceso de reforma de los manuales y se actualiza la relación de los miembros del grupo, que está coordinado por Alfonso Ramos Torres, Jefe del Departamento de Referencia, Información y Documentación de la Biblioteca de Andalucía.

- 26 de marzo de 2007. Lanzamiento del nuevo diseño de Pregunte. El servidor se traslada definitivamente al Ministerio de Cultura, comenzándose una nueva etapa en el servicio.

- 30 de abril de 2007. La Biblioteca Nodal de Pontevedra se incorpora al servicio, respondiendo a sus primeras preguntas el 6 de junio de 2007.

- 10 de abril de 2007. La Biblioteca de Estudos Locais de A Coruña realiza las primeras pruebas para unirse al servicio y reforzar el turno en gallego. Se incorporó al servicio el 30 de marzo de 2007.

- 15 de junio de 2007. Primer día de turno para la Biblioteca Pública del Estado en Palma de Mallorca, que se incorporó al servicio el 5 de junio de 2007.

- 28 de junio de 2007. Turno para la Biblioteca Valenciana, incorporada al servicio el 5 de junio de 2007.

- Octubre-diciembre 2007. Campaña de promoción del servicio, mediante la difusión de elementos publicitarios (alfombrillas, marcapáginas, bolsas, etc.) y la inserción de banners en prensa digital. El lema de la campaña fue "Si tienes una pregunta, ya tienes respuesta" al que se precedía de las frases "24 horas, 365 días al año", "Preguntas sobre cualquier tema", "En 72 horas obtienes respuesta".

- 28, 29 y 30 de noviembre de 2007. Curso sobre el servicio de información cooperativo Pregunte. Madrid, Biblioteca Regional de Madrid. El 
programa está centrado en la comparación entre los servicios de referencia tradicionales y los digitales, además de ofrecer una panorámica de servicios similares en otros países.

- Diciembre de 2007. El Ministerio de Cultura inicia el estudio de métodos de referencia en tiempo real para incorporar a la plataforma de Pregunte.

Aunque en la actualidad hay 42 bibliotecas y/o instituciones trabajando en el servicio, era 34 el número de las que participan en «Pregunte: las bibliotecas responden» en el momento de la evaluación que se presenta como aplicación práctica de esta tesis doctoral. A las mismas habría que sumar a la Subdirección General de Coordinación Bibliotecaria, que siempre ha actuado como coordinadora, aunque no participa en los turnos de resolución de preguntas. Además de las bibliotecas que en ese periodo estaban integradas en el proyecto, formaron parte del mismo las siguientes: Biblioteca Pública del Estado en Castellón (junio - diciembre 2000), Biblioteca Pública del Estado en Jaén (enero - mayo 2001), Biblioteca Pública del Estado en Las Palmas (diciembre 1999 - diciembre 2001) y Biblioteca Central de Terrasa (mayo 2000 - febrero 2004). Con posterioridad al estudio abandonaron el proyecto el Servei de Biblioteques i del Patrimoni Bibliogràfic de la Generalitat de Catalunya (diciembre 1999-abril 2005) y Centro Superior Bibliográfico de Galicia (octubre 2000-marzo 2006). Una vez finalizado el estudio se incorporaron otras bibliotecas al servicio: Biblioteca Regional de Madrid (octubre 2005), Biblioteca Pública del Estado en Badajoz (diciembre 2005), Biblioteca Pública del Estado en Teruel (febrero 2006), Biblioteca Pública del Estado en Segovia (febrero 2006), Biblioteca Pública del Estado en Soria (febrero 2006), Biblioteca Pública del Estado en Gerona (marzo 2006), Biblioteca de Estudos Locais de A Coruña (abril 2007), Biblioteca Nodal de Pontevedra (junio 2007), Biblioteca Pública del Estado en Palma de Mallorca (junio 2007) y Biblioteca Valenciana (junio 2007).

A continuación, se ofrece la relación de las instituciones que estaban integradas en «Pregunte» en el momento de la investigación, junto a la fecha (año/mes/día) en la que oficialmente se incorporaron al servicio.

\begin{tabular}{ll}
\hline $1999 / 09 / 15$ & \begin{tabular}{l} 
Biblioteca Regional de Murcia/Biblioteca Pública del Estado en Murcia \\
\hline $1999 / 09 / 20$
\end{tabular} \\
\hline $\begin{array}{l}\text { Biblioteca Central de Cantabria/Biblioteca Pública del Estado en } \\
\text { Santander }\end{array}$ \\
\hline $1999 / 12 / 10$ & Biblioteca de Andalucía \\
\hline $1999 / 12 / 10$ & Biblioteca Pública del Estado en Zaragoza \\
\hline $1999 / 12 / 13$ & Biblioteca Pública del Estado en Valencia \\
\hline $1999 / 12 / 15$ & $\begin{array}{l}\text { Biblioteca de Castilla-La Mancha/Biblioteca Pública del Estado en } \\
\text { Toledo }\end{array}$ \\
\hline $1999 / 12 / 15$ & $\begin{array}{l}\text { Servei de Biblioteques i del Patrimoni Bibliogràfic, Generalitat de } \\
\text { Catalunya }\end{array}$ \\
\hline $1999 / 12 / 15$ & $\begin{array}{l}\text { Biblioteca Central de La Rioja/Biblioteca Pública del Estado en } \\
\text { Logroño }\end{array}$ \\
\hline $1999 / 12 / 15$ & Biblioteca Pública del Estado en Vitoria \\
\hline $1999 / 12 / 15$ & Biblioteca de Asturias \\
\hline
\end{tabular}




\begin{tabular}{ll}
\hline $1999 / 12 / 21$ & Biblioteca General de Navarra \\
\hline $1999 / 12 / 22$ & Biblioteca Central de Madrid \\
\hline $2000 / 01 / 17$ & Biblioteca Pública del Estado en Mahón \\
\hline $2000 / 01 / 17$ & Biblioteca Pública del Estado en Cáceres \\
\hline $2000 / 02 / 03$ & Biblioteca Pública del Estado en León \\
\hline $2000 / 05 / 09$ & Biblioteca Pública del Estado en Tarragona \\
\hline $2000 / 05 / 09$ & Biblioteca Municipal Central de San Sebastián \\
\hline $2000 / 10 / 18$ & Centro Superior Bibliográfico de Galicia \\
\hline $2000 / 11 / 15$ & Biblioteca Pública del Estado en Salamanca \\
\hline $2001 / 01 / 25$ & Biblioteca Pública del Estado en Córdoba \\
\hline $2001 / 06 / 29$ & Biblioteca Pública del Estado en Huesca \\
\hline $2001 / 06 / 29$ & Biblioteca Pública del Estado en Santa Cruz de Tenerife \\
\hline $2001 / 09 / 04$ & Biblioteca Pública del Estado en Huelva \\
\hline $2001 / 09 / 12$ & Biblioteca Pública del Estado en Alicante \\
\hline $2001 / 10 / 22$ & Servicio Municipal de Lectura Pública de La Coruña \\
\hline $2001 / 10 / 22$ & Red de Bibliotecas Municipales de Bilbao \\
\hline $2003 / 12 / 01$ & Biblioteca de Castilla y León \\
\hline $2003 / 12 / 01$ & Biblioteca Pública del Estado en Albacete \\
\hline $2003 / 12 / 01$ & Biblioteca Pública del Estado en Cuenca \\
\hline $2003 / 12 / 01$ & Biblioteca Pública del Estado en Lérida \\
\hline $2003 / 12 / 01$ & Biblioteca Pública del Estado en Mérida \\
\hline $2003 / 12 / 01$ & Biblioteca de Latina “Antonio Mingote" (Madrid) \\
\hline $2004 / 01 / 08$ & Biblioteca Pública del Estado en Burgos \\
\hline $2004 / 01 / 26$ & Biblioteca Pública del Estado en Almería \\
\hline 20
\end{tabular}

Todas estas bibliotecas formaban el Turno general. Los turnos específicos en lenguas distintas al castellano lo integraban las siguientes instituciones:

Turno catalán: - Biblioteca Pública del Estado en Lérida - Biblioteca Pública del Estado en Mahón

- Biblioteca Pública del Estado en Tarragona

- Biblioteca Pública del Estado en Valencia

- Servei de Biblioteques i del Patrimoni Bibliogràfic, Generalitat de Catalunya

Turno gallego: - Centro Superior Bibliográfico de Galicia - Servicio Municipal de Lectura Pública de La Coruña

Turno vasco: $\quad$ - Biblioteca General de Navarra

- Biblioteca Municipal Central de San Sebastián

- Biblioteca Pública del Estado en Vitoria

- Red de Bibliotecas Municipales de Bilbao 
Es importante conocer cuáles eran las condiciones de partida de la evaluación que se quería realizar para esta tesis doctoral, por lo que se ofrece el resumen de los datos más significativos, correspondientes al 8 de abril de 2004, momento en el que se estaban recogiendo la mayor parte de las informaciones correspondientes a las encuestas y al resto de las evaluaciones parciales efectuadas.

Preguntas gestionadas:

Plazo de las respuestas:

Respuestas en plazo:

Respuestas fuera de plazo:

$1.955(8,37 \%)$

Tipo de respuestas:

Respuestas positivas:

Respuestas negativas:

Respuestas inapropiadas:

$20.719(88,67 \%)$

Respuestas incompletas:

$837(3,58 \%)$

$817(3,50 \%)$

Usuarios:

15.189

Máximo de consultas en un día:

97

Media de consultas por día:

15,56

Tiempo medio de respuesta (días):

1,67

Número de bibliotecas (Turno general):

Turno en catalán:

Turno en gallego:

Turno en vasco:

34 (35 hasta 01-02-04)

5

2

4

Promedio de días con turno (general):

44,57

Bibliotecas y días que han tenido turno:

Entre 1 y 10 días de turno:

Entre 11 y 20 días de turno:

$8(22,86 \%)$

Entre 21 y 30 días de turno:

$0(0 \%)$

$0(0 \%)$

Entre 31 y 40 días de turno:

$5(14,29)$

Entre 41 y 50 días de turno:

$2(5,71 \%)$

Entre 51 y 60 días de turno:

$4(11,43 \%)$

Entre 61 y 70 días de turno:

$16(45,71 \%)$

Total de profesionales en el servicio:

Categorías laborales:

Profesionales Grupo A:

$27(18,24 \%)$

Profesionales Grupo B:

$92(62,16 \%)$

Profesionales Grupo C:

$21(14,19 \%)$

Profesionales Otros grupos:

$8(5,41 \%)$ 
Las estadísticas que se ofrecen seguidamente corresponden a las bibliotecas que atendieron el servicio a lo largo de 2004, por lo que se encuentran las 34 bibliotecas y entidades que colaboraban en esos momentos en «Pregunte», más la Biblioteca Central de Terrassa, que dejó de participar en el mismo en febrero de 2004. La intención de constatar estas informaciones fue la de reunir una serie de datos que estaban dispersos. Por una parte, se incluyen los relativos a las bibliotecas que integraban el proyecto y que se podían conocer únicamente en el directorio de las páginas internas. De esta fuente se han obtenido las fechas de incorporación a «Pregunte».

Los datos globales de cada biblioteca se tomaron de las estadísticas de cada centro participante, consultando una por una las cifras desde la opción de "Estadísticas" del sistema, al que se pudo tener acceso para realizar la investigación.

La información sobre el número de personas que trabajan en cada biblioteca y sus categorías laborales fue consultada a los coordinadores de las mismas, a través de una breve entrevista/cuestionario que se distribuyó por correo electrónico y que se completó, en algunos casos, vía telefónica. La consulta de las estadísticas se realizó el 8 de abril de 2004, entre las 16:00 y las 17:20 horas, a fin de conseguir los datos más homogéneos posibles. A continuación se reproducen esta información, que sirvió de base para establecer la situación real del servicio en el momento en el que se realizó la evaluación. 


\section{BIBLIOTECA DE ANDALUCÍA}

Fecha de incorporación:

$N^{\circ}$ de días de turno:

Total de preguntas recibidas:

Porcentaje preguntas recibidas / totales:

Media de preguntas por turno:
10/12/1999

64

816

3,49

12,75

Personal en «Pregunte»:

\begin{tabular}{|c|c|c|c|c|}
\hline Total & Grupo A & Grupo B & Grupo C & Otros \\
\hline 5 & 3 & 2 & 0 & 0 \\
\hline
\end{tabular}

Preguntas gestionadas:

\begin{tabular}{|c|c|c|c|c|}
\hline Total & $\begin{array}{c}\text { Respuestas } \\
\text { en plazo }\end{array}$ & $\begin{array}{c}\text { \% en plazo / } \\
\text { total }\end{array}$ & $\begin{array}{c}\text { Respuestas } \\
\text { fuera de plazo }\end{array}$ & $\begin{array}{c}\% \text { fuera de } \\
\text { plazo / total }\end{array}$ \\
\hline 816 & 769 & 92.24 & 47 & 5,76 \\
\hline
\end{tabular}

Tipos de respuesta:

\begin{tabular}{|c|c|c|c|}
\hline Positiva & Negativa & Inapropiada & Incompleta \\
\hline 739 & 24 & 16 & 37 \\
\hline
\end{tabular}

\section{BIBLIOTECA DE ASTURIAS}

Fecha de incorporación:

$\mathrm{N}^{\circ}$ de días de turno:

Total de preguntas recibidas:

Porcentaje preguntas recibidas / totales:

Media de preguntas por turno:
$15 / 12 / 1999$

65

948

4,05

14,58

Personal en «Pregunte»:

\begin{tabular}{|c|c|c|c|c|}
\hline Total & Grupo A & Grupo B & Grupo C & Otros \\
\hline 4 & 2 & 2 & 0 & 0 \\
\hline
\end{tabular}

Preguntas gestionadas:

\begin{tabular}{|c|c|c|c|c|}
\hline Total & $\begin{array}{c}\text { Respuestas } \\
\text { en plazo }\end{array}$ & $\begin{array}{c}\% \text { en plazo / } \\
\text { total }\end{array}$ & $\begin{array}{c}\text { Respuestas } \\
\text { fuera de plazo }\end{array}$ & $\begin{array}{c}\% \text { fuera de } \\
\text { plazo / total }\end{array}$ \\
\hline 948 & 766 & 80,8 & 182 & 19,2 \\
\hline
\end{tabular}

Tipos de respuesta:

\begin{tabular}{|c|c|c|c|}
\hline Positiva & Negativa & Inapropiada & Incompleta \\
\hline 790 & 51 & 52 & 55 \\
\hline
\end{tabular}




\section{BIBLIOTECA DE CASTILLA-LA MANCHA BIBLIOTECA PÚBLICA DEL ESTADO EN TOLEDO}

Fecha de incorporación:

$\mathrm{N}^{\mathrm{O}}$ de días de turno:

Total de preguntas recibidas:

Porcentaje preguntas recibidas / totales:

Media de preguntas por turno:
$15 / 12 / 1999$

63

923

3,95

14,65

Personal en «Pregunte»:

\begin{tabular}{|c|c|c|c|c|}
\hline Total & Grupo A & Grupo B & Grupo C & Otros \\
\hline 6 & 0 & 2 & 2 & 2 \\
\hline
\end{tabular}

Preguntas gestionadas:

\begin{tabular}{|c|c|c|c|c|}
\hline Total & $\begin{array}{c}\text { Respuestas } \\
\text { en plazo }\end{array}$ & $\begin{array}{c}\text { \% en plazo / } \\
\text { total }\end{array}$ & $\begin{array}{c}\text { Respuestas } \\
\text { fuera de plazo }\end{array}$ & $\begin{array}{c}\% \text { fuera de } \\
\text { plazo / total }\end{array}$ \\
\hline 923 & 894 & 96,86 & 29 & 3,14 \\
\hline
\end{tabular}

Tipos de respuesta:

\begin{tabular}{|c|c|c|c|}
\hline Positiva & Negativa & Inapropiada & Incompleta \\
\hline 854 & 34 & 27 & 8 \\
\hline
\end{tabular}

\section{BIBLIOTECA DE CASTILLA Y LEÓN}

Fecha de incorporación:

$\mathrm{N}^{\circ}$ de días de turno:

Total de preguntas recibidas:

Porcentaje preguntas recibidas / totales:

Media de preguntas por turno:

Personal en «Pregunte»:
$01 / 12 / 2003$

4

54

0,23

13,5

\begin{tabular}{|c|c|c|c|c|}
\hline Total & Grupo A & Grupo B & Grupo C & Otros \\
\hline 3 & 1 & 2 & 0 & 0 \\
\hline
\end{tabular}

Preguntas gestionadas:

\begin{tabular}{|c|c|c|c|c|}
\hline Total & $\begin{array}{c}\text { Respuestas } \\
\text { en plazo }\end{array}$ & $\begin{array}{c}\text { \% en plazo / } \\
\text { total }\end{array}$ & $\begin{array}{c}\text { Respuestas } \\
\text { fuera de plazo }\end{array}$ & $\begin{array}{c}\% \text { fuera de } \\
\text { plazo / total }\end{array}$ \\
\hline 54 & 52 & 96,30 & 2 & 3,70 \\
\hline
\end{tabular}

Tipos de respuesta:

\begin{tabular}{|c|c|c|c|}
\hline Positiva & Negativa & Inapropiada & Incompleta \\
\hline 51 & 0 & 1 & 2 \\
\hline
\end{tabular}




\section{BIBLIOTECA CENTRAL DE CANTABRIA BIBLIOTECA PÚBLICA DEL ESTADO EN SANTANDER}

Fecha de incorporación:

No de días de turno:

Total de preguntas recibidas:

Porcentaje preguntas recibidas / totales:

Media de preguntas por turno:

Personal en «Pregunte»:
20/09/1999

66

798

3,41

12,09

\begin{tabular}{|c|c|c|c|c|}
\hline Total & Grupo A & Grupo B & Grupo C & Otros \\
\hline 1 & 0 & 0 & 0 & 1 \\
\hline
\end{tabular}

Preguntas gestionadas:

\begin{tabular}{|c|c|c|c|c|}
\hline Total & $\begin{array}{c}\text { Respuestas } \\
\text { en plazo }\end{array}$ & $\begin{array}{c}\% \text { en plazo / } \\
\text { total }\end{array}$ & $\begin{array}{c}\text { Respuestas } \\
\text { fuera de plazo }\end{array}$ & $\begin{array}{c}\% \text { fuera de } \\
\text { plazo / total }\end{array}$ \\
\hline 792 & 686 & 86,62 & 106 & 13,38 \\
\hline
\end{tabular}

Tipos de respuesta:

\begin{tabular}{|c|c|c|c|}
\hline Positiva & Negativa & Inapropiada & Incompleta \\
\hline 703 & 32 & 26 & 31 \\
\hline
\end{tabular}

\section{BIBLIOTECA CENTRAL DE LA RIOJA \\ BIBLIOTECA PÚBLICA DEL ESTADO EN LOGROÑO}

Fecha de incorporación:

$\mathrm{N}^{\circ}$ de días de turno:

Total de preguntas recibidas:

Porcentaje preguntas recibidas / totales:

Media de preguntas por turno:
$15 / 12 / 1999$

65

913

3,9

14,05

Personal en «Pregunte»:

\begin{tabular}{|c|c|c|c|c|}
\hline Total & Grupo A & Grupo B & Grupo C & Otros \\
\hline 4 & 0 & 4 & 0 & 0 \\
\hline
\end{tabular}

Preguntas gestionadas:

\begin{tabular}{|c|c|c|c|c|}
\hline Total & $\begin{array}{c}\text { Respuestas } \\
\text { en plazo }\end{array}$ & $\begin{array}{c}\text { \% en plazo / } \\
\text { total }\end{array}$ & $\begin{array}{c}\text { Respuestas } \\
\text { fuera de plazo }\end{array}$ & $\begin{array}{c}\% \text { fuera de } \\
\text { plazo / total }\end{array}$ \\
\hline 913 & 908 & 99,45 & 5 & 0,55 \\
\hline
\end{tabular}

Tipos de respuesta:

\begin{tabular}{|c|c|c|c|}
\hline Positiva & Negativa & Inapropiada & Incompleta \\
\hline 849 & 23 & 35 & 6 \\
\hline
\end{tabular}




\section{BIBLIOTECA CENTRAL DE MADRID}

Fecha de incorporación:

$\mathrm{N}^{\circ}$ de días de turno:

Total de preguntas recibidas:

Porcentaje preguntas recibidas / totales:

Media de preguntas por turno:

Personal en «Pregunte»:
22/12/1999

65

843

3,61

12,97

\begin{tabular}{|c|c|c|c|c|}
\hline Total & Grupo A & Grupo B & Grupo C & Otros \\
\hline 4 & 0 & 4 & 0 & 0 \\
\hline
\end{tabular}

Preguntas gestionadas:

\begin{tabular}{|c|c|c|c|c|}
\hline Total & $\begin{array}{c}\text { Respuestas } \\
\text { en plazo }\end{array}$ & $\begin{array}{c}\text { \% en plazo / } \\
\text { total }\end{array}$ & $\begin{array}{c}\text { Respuestas } \\
\text { fuera de plazo }\end{array}$ & $\begin{array}{c}\% \text { fuera de } \\
\text { plazo / total }\end{array}$ \\
\hline 843 & 800 & 94,9 & 43 & 5,1 \\
\hline
\end{tabular}

Tipos de respuesta:

\begin{tabular}{|c|c|c|c|}
\hline Positiva & Negativa & Inapropiada & Incompleta \\
\hline 794 & 16 & 12 & 21 \\
\hline
\end{tabular}

\section{BIBLIOTECA CENTRAL DE TERRASSA}

Fecha de incorporación:

Fecha de baja:

$N^{\circ}$ de días de turno:

Total de preguntas recibidas:

Porcentaje preguntas recibidas / totales:

Media de preguntas por turno:

Personal en «Pregunte»:
$09 / 05 / 2000$

$01 / 02 / 2004$

56

1275

5,45

22,77

\begin{tabular}{|c|c|c|c|c|}
\hline Total & Grupo A & Grupo B & Grupo C & Otros \\
\hline 6 & 0 & 6 & 0 & 0 \\
\hline
\end{tabular}

Preguntas gestionadas:

\begin{tabular}{|c|c|c|c|c|}
\hline Total & $\begin{array}{c}\text { Respuestas } \\
\text { en plazo }\end{array}$ & $\begin{array}{c}\% \text { en plazo / } \\
\text { total }\end{array}$ & $\begin{array}{c}\text { Respuestas } \\
\text { fuera de plazo }\end{array}$ & $\begin{array}{c}\% \text { fuera de } \\
\text { plazo / total }\end{array}$ \\
\hline 1275 & 1210 & 94,90 & 65 & 5,10 \\
\hline
\end{tabular}

Tipos de respuesta:

\begin{tabular}{|c|c|c|c|}
\hline Positiva & Negativa & Inapropiada & Incompleta \\
\hline 1100 & 59 & 67 & 49 \\
\hline
\end{tabular}




\section{BIBLIOTECA GENERAL DE NAVARRA}

Fecha de incorporación:

$N^{\circ}$ de días de turno:

Total de preguntas recibidas:

Porcentaje preguntas recibidas / totales:

Media de preguntas por turno:
$21 / 12 / 1999$

67

867

3,71

12,94

Personal en «Pregunte»:

\begin{tabular}{|c|c|c|c|c|}
\hline Total & Grupo A & Grupo B & Grupo C & Otros \\
\hline 4 & 2 & 2 & 0 & 0 \\
\hline
\end{tabular}

Preguntas gestionadas:

\begin{tabular}{|c|c|c|c|c|}
\hline Total & $\begin{array}{c}\text { Respuestas } \\
\text { en plazo }\end{array}$ & $\begin{array}{c}\text { \% en plazo / } \\
\text { total }\end{array}$ & $\begin{array}{c}\text { Respuestas } \\
\text { fuera de plazo }\end{array}$ & $\begin{array}{c}\% \text { fuera de } \\
\text { plazo / total }\end{array}$ \\
\hline 867 & 772 & 89,04 & 95 & 10,96 \\
\hline
\end{tabular}

Tipos de respuesta:

\begin{tabular}{|c|c|c|c|}
\hline Positiva & Negativa & Inapropiada & Incompleta \\
\hline 836 & 13 & 7 & 11 \\
\hline
\end{tabular}

\section{BIBLIOTECA DE LATINA “ANTONIO MINGOTE” (Madrid)}

Fecha de incorporación:

$\mathrm{N}^{\circ}$ de días de turno:

Total de preguntas recibidas:

Porcentaje preguntas recibidas / totales:

Media de preguntas por turno:

Personal en «Pregunte»:

\begin{tabular}{|c|c|c|c|c|}
\hline Total & Grupo A & Grupo B & Grupo C & Otros \\
\hline 7 & 0 & 7 & 0 & 0 \\
\hline
\end{tabular}

Preguntas gestionadas:

\begin{tabular}{|c|c|c|c|c|}
\hline Total & $\begin{array}{c}\text { Respuestas } \\
\text { en plazo }\end{array}$ & $\begin{array}{c}\% \text { en plazo / } \\
\text { total }\end{array}$ & $\begin{array}{c}\text { Respuestas } \\
\text { fuera de plazo }\end{array}$ & $\begin{array}{c}\% \text { fuera de } \\
\text { plazo / total }\end{array}$ \\
\hline 43 & 41 & 95,35 & 2 & 4,65 \\
\hline
\end{tabular}

Tipos de respuesta:

\begin{tabular}{|c|c|c|c|}
\hline Positiva & Negativa & Inapropiada & Incompleta \\
\hline 39 & 2 & 2 & 0 \\
\hline
\end{tabular}




\section{BIBLIOTECA MUNICIPAL CENTRAL DE SAN SEBASTIÁN}

Fecha de incorporación:

$\mathrm{N}^{\circ}$ de días de turno:

Total de preguntas recibidas:

Porcentaje preguntas recibidas / totales:

Media de preguntas por turno:

Personal en «Pregunte»:
$09 / 05 / 2000$

56

1102

4,71

19,68

\begin{tabular}{|c|c|c|c|c|}
\hline Total & Grupo A & Grupo B & Grupo C & Otros \\
\hline 1 & 0 & 1 & 0 & 0 \\
\hline
\end{tabular}

Preguntas gestionadas:

\begin{tabular}{|c|c|c|c|c|}
\hline Total & $\begin{array}{c}\text { Respuestas } \\
\text { en plazo }\end{array}$ & $\begin{array}{c}\% \text { en plazo / } \\
\text { total }\end{array}$ & $\begin{array}{c}\text { Respuestas } \\
\text { fuera de plazo }\end{array}$ & $\begin{array}{c}\% \text { fuera de } \\
\text { plazo / total }\end{array}$ \\
\hline 1101 & 1033 & 93,82 & 68 & 6,18 \\
\hline
\end{tabular}

Tipos de respuesta:

\begin{tabular}{|c|c|c|c|}
\hline Positiva & Negativa & Inapropiada & Incompleta \\
\hline 929 & 70 & 62 & 40 \\
\hline
\end{tabular}

\section{BIBLIOTECA REGIONAL DE MURCIA}

\section{BIBLIOTECA PÚBLICA DEL ESTADO EN MURCIA}

Fecha de incorporación:

$\mathrm{N}^{\circ}$ de días de turno:

Total de preguntas recibidas:

Porcentaje preguntas recibidas / totales:

Media de preguntas por turno:

Personal en «Pregunte»:
$15 / 09 / 1999$

66

840

3,59

12,73

\begin{tabular}{|c|c|c|c|c|}
\hline Total & Grupo A & Grupo B & Grupo C & Otros \\
\hline 4 & 1 & 0 & 3 & 0 \\
\hline
\end{tabular}

Preguntas gestionadas:

\begin{tabular}{|c|c|c|c|c|}
\hline Total & $\begin{array}{c}\text { Respuestas } \\
\text { en plazo }\end{array}$ & $\begin{array}{c}\% \text { en plazo / } \\
\text { total }\end{array}$ & $\begin{array}{c}\text { Respuestas } \\
\text { fuera de plazo }\end{array}$ & $\begin{array}{c}\% \text { fuera de } \\
\text { plazo / total }\end{array}$ \\
\hline 835 & 800 & 95,81 & 35 & 4,19 \\
\hline
\end{tabular}

Tipos de respuesta:

\begin{tabular}{|c|c|c|c|}
\hline Positiva & Negativa & Inapropiada & Incompleta \\
\hline 785 & 13 & 10 & 27 \\
\hline
\end{tabular}




\section{BIBLIOTECA PÚBLICA DEL ESTADO EN ALBACETE}

Fecha de incorporación:

$N^{\circ}$ de días de turno:

Total de preguntas recibidas:

Porcentaje preguntas recibidas / totales:

Media de preguntas por turno:
$01 / 12 / 2003$

7

132

0,56

18,86

Personal en «Pregunte»:

\begin{tabular}{|c|c|c|c|c|}
\hline Total & Grupo A & Grupo B & Grupo C & Otros \\
\hline 9 & 0 & 5 & 2 & 2 \\
\hline
\end{tabular}

Preguntas gestionadas:

\begin{tabular}{|c|c|c|c|c|}
\hline Total & $\begin{array}{c}\text { Respuestas } \\
\text { en plazo }\end{array}$ & $\begin{array}{c}\% \text { en plazo / } \\
\text { total }\end{array}$ & $\begin{array}{c}\text { Respuestas } \\
\text { fuera de plazo }\end{array}$ & $\begin{array}{c}\% \text { fuera de } \\
\text { plazo / total }\end{array}$ \\
\hline 132 & 131 & 99,24 & 1 & 0,76 \\
\hline
\end{tabular}

Tipos de respuesta:

\begin{tabular}{|c|c|c|c|}
\hline Positiva & Negativa & Inapropiada & Incompleta \\
\hline 130 & 1 & 1 & 0 \\
\hline
\end{tabular}

\section{BIBLIOTECA PÚBLICA DEL ESTADO EN ALICANTE}

Fecha de incorporación:

No de días de turno:

Total de preguntas recibidas:

Porcentaje preguntas recibidas / totales:

Media de preguntas por turno:

Personal en «Pregunte»:

\begin{tabular}{|c|c|c|c|c|}
\hline Total & Grupo A & Grupo B & Grupo C & Otros \\
\hline 1 & 1 & 0 & 0 & 0 \\
\hline
\end{tabular}

Preguntas gestionadas:

\begin{tabular}{|c|c|c|c|c|}
\hline Total & $\begin{array}{c}\text { Respuestas } \\
\text { en plazo }\end{array}$ & $\begin{array}{c}\% \text { en plazo / } \\
\text { total }\end{array}$ & $\begin{array}{c}\text { Respuestas } \\
\text { fuera de plazo }\end{array}$ & $\begin{array}{c}\% \text { fuera de } \\
\text { plazo / total }\end{array}$ \\
\hline 364 & 328 & 90,11 & 36 & 9,89 \\
\hline
\end{tabular}

Tipos de respuesta:

\begin{tabular}{|c|c|c|c|}
\hline Positiva & Negativa & Inapropiada & Incompleta \\
\hline 305 & 33 & 7 & 19 \\
\hline
\end{tabular}




\section{BIBLIOTECA PÚBLICA DEL ESTADO EN ALMERÍA}

Fecha de incorporación:

$\mathrm{N}^{\circ}$ de días de turno:

Total de preguntas recibidas:

Porcentaje preguntas recibidas / totales:

Media de preguntas por turno:

Personal en «Pregunte»:
$26 / 01 / 2004$

3

40

0,17

13,33

\begin{tabular}{|c|c|c|c|c|}
\hline Total & Grupo A & Grupo B & Grupo C & Otros \\
\hline 3 & 1 & 2 & 0 & 0 \\
\hline
\end{tabular}

Preguntas gestionadas:

\begin{tabular}{|c|c|c|c|c|}
\hline Total & $\begin{array}{c}\text { Respuestas } \\
\text { en plazo }\end{array}$ & $\begin{array}{c}\% \text { en plazo / } \\
\text { total }\end{array}$ & $\begin{array}{c}\text { Respuestas } \\
\text { fuera de plazo }\end{array}$ & $\begin{array}{c}\% \text { fuera de } \\
\text { plazo / total }\end{array}$ \\
\hline 40 & 34 & 85 & 6 & 15 \\
\hline
\end{tabular}

Tipos de respuesta:

\begin{tabular}{|c|c|c|c|}
\hline Positiva & Negativa & Inapropiada & Incompleta \\
\hline 31 & 4 & 1 & 4 \\
\hline
\end{tabular}

\section{SERVEI DE BIBLIOTEQUES I DEL PATRIMONI BIBLIOGRÀFIC, GENERALITAT DE CATALUNYA}

Fecha de incorporación:

$\mathrm{N}^{\circ}$ de días de turno:

Total de preguntas recibidas:

Porcentaje preguntas recibidas / totales:

Media de preguntas por turno:

Personal en «Pregunte»:
$15 / 12 / 1999$

64

1065

4,55

16,64

\begin{tabular}{|c|c|c|c|c|}
\hline Total & Grupo A & Grupo B & Grupo C & Otros \\
\hline 6 & 0 & 6 & 0 & 0 \\
\hline
\end{tabular}

Preguntas gestionadas:

\begin{tabular}{|c|c|c|c|c|}
\hline Total & $\begin{array}{c}\text { Respuestas } \\
\text { en plazo }\end{array}$ & $\begin{array}{c}\% \text { en plazo / } \\
\text { total }\end{array}$ & $\begin{array}{c}\text { Respuestas } \\
\text { fuera de plazo }\end{array}$ & $\begin{array}{c}\% \text { fuera de } \\
\text { plazo / total }\end{array}$ \\
\hline 1065 & 1002 & 94,08 & 63 & 5,92 \\
\hline
\end{tabular}

Tipos de respuesta:

\begin{tabular}{|c|c|c|c|}
\hline Positiva & Negativa & Inapropiada & Incompleta \\
\hline 983 & 13 & 35 & 34 \\
\hline
\end{tabular}




\section{BIBLIOTECA PÚBLICA DEL ESTADO EN BURGOS}

Fecha de incorporación:

$N^{\circ}$ de días de turno:

Total de preguntas recibidas:

Porcentaje preguntas recibidas / totales:

Media de preguntas por turno:
$08 / 01 / 2004$

3

38

0,16

12,66

Personal en «Pregunte»:

\begin{tabular}{|c|c|c|c|c|}
\hline Total & Grupo A & Grupo B & Grupo C & Otros \\
\hline 7 & 2 & 2 & 3 & 0 \\
\hline
\end{tabular}

Preguntas gestionadas:

\begin{tabular}{|c|c|c|c|c|}
\hline Total & $\begin{array}{c}\text { Respuestas } \\
\text { en plazo }\end{array}$ & $\begin{array}{c}\% \text { en plazo / } \\
\text { total }\end{array}$ & $\begin{array}{c}\text { Respuestas } \\
\text { fuera de plazo }\end{array}$ & $\begin{array}{c}\% \text { fuera de } \\
\text { plazo / total }\end{array}$ \\
\hline 32 & 32 & 100 & 0 & 0 \\
\hline
\end{tabular}

Tipos de respuesta:

\begin{tabular}{|c|c|c|c|}
\hline Positiva & Negativa & Inapropiada & Incompleta \\
\hline 27 & 0 & 0 & 5 \\
\hline
\end{tabular}

\section{BIBLIOTECA PÚBLICA DEL ESTADO EN CÁCERES}

Fecha de incorporación:

$\mathrm{N}^{\circ}$ de días de turno:

Total de preguntas recibidas:

Porcentaje preguntas recibidas / totales:

Media de preguntas por turno:

Personal en «Pregunte»:

\begin{tabular}{|c|c|c|c|c|}
\hline Total & Grupo A & Grupo B & Grupo C & Otros \\
\hline 5 & 0 & 5 & 0 & 0 \\
\hline
\end{tabular}

Preguntas gestionadas:

\begin{tabular}{|c|c|c|c|c|}
\hline Total & $\begin{array}{c}\text { Respuestas } \\
\text { en plazo }\end{array}$ & $\begin{array}{c}\% \text { en plazo / } \\
\text { total }\end{array}$ & $\begin{array}{c}\text { Respuestas } \\
\text { fuera de plazo }\end{array}$ & $\begin{array}{c}\% \text { fuera de } \\
\text { plazo / total }\end{array}$ \\
\hline 1131 & 1038 & 91,78 & 93 & 8,22 \\
\hline
\end{tabular}

Tipos de respuesta:

\begin{tabular}{|c|c|c|c|}
\hline Positiva & Negativa & Inapropiada & Incompleta \\
\hline 955 & 91 & 44 & 41 \\
\hline
\end{tabular}




\section{BIBLIOTECA PÚBLICA DEL ESTADO EN CÓRDOBA}

Fecha de incorporación:

$\mathrm{N}^{\circ}$ de días de turno:

Total de preguntas recibidas:

Porcentaje preguntas recibidas / totales:

Media de preguntas por turno:

Personal en «Pregunte»:
$25 / 01 / 2001$

49

665

2,84

13,37

\begin{tabular}{|c|c|c|c|c|}
\hline Total & Grupo A & Grupo B & Grupo C & Otros \\
\hline 1 & 1 & 0 & 0 & 0 \\
\hline
\end{tabular}

Preguntas gestionadas:

\begin{tabular}{|c|c|c|c|c|}
\hline Total & $\begin{array}{c}\text { Respuestas } \\
\text { en plazo }\end{array}$ & $\begin{array}{c}\% \text { en plazo / } \\
\text { total }\end{array}$ & $\begin{array}{c}\text { Respuestas } \\
\text { fuera de plazo }\end{array}$ & $\begin{array}{c}\% \text { fuera de } \\
\text { plazo / total }\end{array}$ \\
\hline 665 & 517 & 77,74 & 148 & 22,26 \\
\hline
\end{tabular}

Tipos de respuesta:

\begin{tabular}{|c|c|c|c|}
\hline Positiva & Negativa & Inapropiada & Incompleta \\
\hline 615 & 17 & 20 & 13 \\
\hline
\end{tabular}

\section{BIBLIOTECA PÚBLICA DEL ESTADO EN CUENCA}

Fecha de incorporación:

$N^{\circ}$ de días de turno:

Total de preguntas recibidas:

Porcentaje preguntas recibidas / totales:

Media de preguntas por turno:

Personal en «Pregunte»:
$01 / 12 / 2003$

4

35

0,15

8,75

\begin{tabular}{|c|c|c|c|c|}
\hline Total & Grupo A & Grupo B & Grupo C & Otros \\
\hline 5 & 0 & 1 & 4 & 0 \\
\hline
\end{tabular}

Preguntas gestionadas:

\begin{tabular}{|c|c|c|c|c|}
\hline Total & $\begin{array}{c}\text { Respuestas } \\
\text { en plazo }\end{array}$ & $\begin{array}{c}\% \text { en plazo / } \\
\text { total }\end{array}$ & $\begin{array}{c}\text { Respuestas } \\
\text { fuera de plazo }\end{array}$ & $\begin{array}{c}\% \text { fuera de } \\
\text { plazo / total }\end{array}$ \\
\hline 35 & 34 & 97,14 & 1 & 2,86 \\
\hline
\end{tabular}

Tipos de respuesta:

\begin{tabular}{|c|c|c|c|}
\hline Positiva & Negativa & Inapropiada & Incompleta \\
\hline 28 & 3 & 2 & 2 \\
\hline
\end{tabular}




\section{BIBLIOTECA PÚBLICA DEL ESTADO EN HUELVA}

Fecha de incorporación:

$N^{\circ}$ de días de turno:

Total de preguntas recibidas:

Porcentaje preguntas recibidas / totales:

Media de preguntas por turno:
$04 / 09 / 2001$

35

451

1,93

12,88

Personal en «Pregunte»:

\begin{tabular}{|c|c|c|c|c|}
\hline Total & Grupo A & Grupo B & Grupo C & Otros \\
\hline 2 & 2 & 0 & 0 & 0 \\
\hline
\end{tabular}

Preguntas gestionadas:

\begin{tabular}{|c|c|c|c|c|}
\hline Total & $\begin{array}{c}\text { Respuestas } \\
\text { en plazo }\end{array}$ & $\begin{array}{c}\text { \% en plazo / } \\
\text { total }\end{array}$ & $\begin{array}{c}\text { Respuestas } \\
\text { fuera de plazo }\end{array}$ & $\begin{array}{c}\% \text { fuera de } \\
\text { plazo / total }\end{array}$ \\
\hline 451 & 399 & 88,47 & 52 & 11,53 \\
\hline
\end{tabular}

Tipos de respuesta:

\begin{tabular}{|c|c|c|c|}
\hline Positiva & Negativa & Inapropiada & Incompleta \\
\hline 368 & 23 & 10 & 50 \\
\hline
\end{tabular}

\section{BIBLIOTECA PÚBLICA DEL ESTADO EN HUESCA}

Fecha de incorporación:

$\mathrm{N}^{\circ}$ de días de turno:

Total de preguntas recibidas:

Porcentaje preguntas recibidas / totales:

Media de preguntas por turno:

Personal en «Pregunte»:

\begin{tabular}{|c|c|c|c|c|}
\hline Total & Grupo A & Grupo B & Grupo C & Otros \\
\hline 3 & 1 & 2 & 0 & 0 \\
\hline
\end{tabular}

Preguntas gestionadas:

\begin{tabular}{|c|c|c|c|c|}
\hline Total & $\begin{array}{c}\text { Respuestas } \\
\text { en plazo }\end{array}$ & $\begin{array}{c}\% \text { en plazo / } \\
\text { total }\end{array}$ & $\begin{array}{c}\text { Respuestas } \\
\text { fuera de plazo }\end{array}$ & $\begin{array}{c}\% \text { fuera de } \\
\text { plazo / total }\end{array}$ \\
\hline 637 & 556 & 87,28 & 81 & 12,72 \\
\hline
\end{tabular}

Tipos de respuesta:

\begin{tabular}{|c|c|c|c|}
\hline Positiva & Negativa & Inapropiada & Incompleta \\
\hline 558 & 43 & 13 & 23 \\
\hline
\end{tabular}




\section{BIBLIOTECA PÚBLICA DEL ESTADO EN LEÓN}

Fecha de incorporación:

$\mathrm{N}^{\circ}$ de días de turno:

Total de preguntas recibidas:

Porcentaje preguntas recibidas / totales: $\quad 3,95$

Media de preguntas por turno:

Personal en «Pregunte»:
$03 / 02 / 2000$

64

924

14,44

\begin{tabular}{|c|c|c|c|c|}
\hline Total & Grupo A & Grupo B & Grupo C & Otros \\
\hline 4 & 2 & 2 & 0 & 0 \\
\hline
\end{tabular}

Preguntas gestionadas:

\begin{tabular}{|c|c|c|c|c|}
\hline Total & $\begin{array}{c}\text { Respuestas } \\
\text { en plazo }\end{array}$ & $\begin{array}{c}\text { \% en plazo / } \\
\text { total }\end{array}$ & $\begin{array}{c}\text { Respuestas } \\
\text { fuera de plazo }\end{array}$ & $\begin{array}{c}\% \text { fuera de } \\
\text { plazo / total }\end{array}$ \\
\hline 924 & 844 & 91,34 & 80 & 8,66 \\
\hline
\end{tabular}

Tipos de respuesta:

\begin{tabular}{|c|c|c|c|}
\hline Positiva & Negativa & Inapropiada & Incompleta \\
\hline 858 & 25 & 35 & 6 \\
\hline
\end{tabular}

\section{BIBLIOTECA PÚBLICA DEL ESTADO EN LÉRIDA}

Fecha de incorporación:

$\mathrm{N}^{\circ}$ de días de turno:

Total de preguntas recibidas:

Porcentaje preguntas recibidas / totales:

Media de preguntas por turno:

Personal en «Pregunte»:
$01 / 12 / 2003$

4

57

0,24

14,25

\begin{tabular}{|c|c|c|c|c|}
\hline Total & Grupo A & Grupo B & Grupo C & Otros \\
\hline 9 & 1 & 8 & 0 & 0 \\
\hline
\end{tabular}

Preguntas gestionadas:

\begin{tabular}{|c|c|c|c|c|}
\hline Total & $\begin{array}{c}\text { Respuestas } \\
\text { en plazo }\end{array}$ & $\begin{array}{c}\% \text { en plazo / } \\
\text { total }\end{array}$ & $\begin{array}{c}\text { Respuestas } \\
\text { fuera de plazo }\end{array}$ & $\begin{array}{c}\% \text { fuera de } \\
\text { plazo / total }\end{array}$ \\
\hline 57 & 57 & 100 & 0 & 0 \\
\hline
\end{tabular}

Tipos de respuesta:

\begin{tabular}{|c|c|c|c|}
\hline Positiva & Negativa & Inapropiada & Incompleta \\
\hline 52 & 1 & 3 & 1 \\
\hline
\end{tabular}




\section{BIBLIOTECA PÚBLICA DEL ESTADO EN MAHÓN}

Fecha de incorporación:

$N^{\circ}$ de días de turno:

Total de preguntas recibidas:

Porcentaje preguntas recibidas / totales:

Media de preguntas por turno:
$17 / 01 / 2000$

65

1121

4,79

17,25

Personal en «Pregunte»:

\begin{tabular}{|c|c|c|c|c|}
\hline Total & Grupo A & Grupo B & Grupo C & Otros \\
\hline 4 & 1 & 1 & 1 & 1 \\
\hline
\end{tabular}

Preguntas gestionadas:

\begin{tabular}{|c|c|c|c|c|}
\hline Total & $\begin{array}{c}\text { Respuestas } \\
\text { en plazo }\end{array}$ & $\begin{array}{c}\% \text { en plazo / } \\
\text { total }\end{array}$ & $\begin{array}{c}\text { Respuestas } \\
\text { fuera de plazo }\end{array}$ & $\begin{array}{c}\% \text { fuera de } \\
\text { plazo / total }\end{array}$ \\
\hline 1121 & 1015 & 90,54 & 106 & 9,46 \\
\hline
\end{tabular}

Tipos de respuesta:

\begin{tabular}{|c|c|c|c|}
\hline Positiva & Negativa & Inapropiada & Incompleta \\
\hline 894 & 87 & 54 & 86 \\
\hline
\end{tabular}

\section{BIBLIOTECA PÚBLICA DEL ESTADO EN MÉRIDA}

Fecha de incorporación:

$\mathrm{N}^{\circ}$ de días de turno:

Total de preguntas recibidas:

Porcentaje preguntas recibidas / totales:

Media de preguntas por turno:

Personal en «Pregunte»:

\begin{tabular}{|c|c|c|c|c|}
\hline Total & Grupo A & Grupo B & Grupo C & Otros \\
\hline 6 & 0 & 4 & 2 & 0 \\
\hline
\end{tabular}

Preguntas gestionadas:

\begin{tabular}{|c|c|c|c|c|}
\hline Total & $\begin{array}{c}\text { Respuestas } \\
\text { en plazo }\end{array}$ & $\begin{array}{c}\% \text { en plazo / } \\
\text { total }\end{array}$ & $\begin{array}{c}\text { Respuestas } \\
\text { fuera de plazo }\end{array}$ & $\begin{array}{c}\% \text { fuera de } \\
\text { plazo / total }\end{array}$ \\
\hline 63 & 63 & 100 & 0 & 0 \\
\hline
\end{tabular}

Tipos de respuesta:

\begin{tabular}{|c|c|c|c|}
\hline Positiva & Negativa & Inapropiada & Incompleta \\
\hline 62 & 0 & 1 & 0 \\
\hline
\end{tabular}




\section{BIBLIOTECA PÚBLICA DEL ESTADO EN SALAMANCA}

Fecha de incorporación:

$\mathrm{N}^{\circ}$ de días de turno:

Total de preguntas recibidas:

Porcentaje preguntas recibidas / totales:

Media de preguntas por turno:

Personal en «Pregunte»:
$15 / 11 / 2000$

57

693

2,96

12,15

\begin{tabular}{|c|c|c|c|c|}
\hline Total & Grupo A & Grupo B & Grupo C & Otros \\
\hline 4 & 1 & 3 & 0 & 0 \\
\hline
\end{tabular}

Preguntas gestionadas:

\begin{tabular}{|c|c|c|c|c|}
\hline Total & $\begin{array}{c}\text { Respuestas } \\
\text { en plazo }\end{array}$ & $\begin{array}{c}\text { \% en plazo / } \\
\text { total }\end{array}$ & $\begin{array}{c}\text { Respuestas } \\
\text { fuera de plazo }\end{array}$ & $\begin{array}{c}\% \text { fuera de } \\
\text { plazo / total }\end{array}$ \\
\hline 693 & 625 & 90,19 & 68 & 9,81 \\
\hline
\end{tabular}

Tipos de respuesta:

\begin{tabular}{|c|c|c|c|}
\hline Positiva & Negativa & Inapropiada & Incompleta \\
\hline 632 & 15 & 36 & 10 \\
\hline
\end{tabular}

\section{BIBLIOTECA PÚBLICA DEL ESTADO EN TARRAGONA}

Fecha de incorporación:

$\mathrm{N}^{\circ}$ de días de turno:

Total de preguntas recibidas:

Porcentaje preguntas recibidas / totales:

Media de preguntas por turno:

Personal en «Pregunte»:
$09 / 05 / 2000$

62

1067

4,56

17,21

\begin{tabular}{|c|c|c|c|c|}
\hline Total & Grupo A & Grupo B & Grupo C & Otros \\
\hline 4 & 0 & 4 & 0 & 0 \\
\hline
\end{tabular}

Preguntas gestionadas:

\begin{tabular}{|c|c|c|c|c|}
\hline Total & $\begin{array}{c}\text { Respuestas } \\
\text { en plazo }\end{array}$ & $\begin{array}{c}\% \text { en plazo / } \\
\text { total }\end{array}$ & $\begin{array}{c}\text { Respuestas } \\
\text { fuera de plazo }\end{array}$ & $\begin{array}{c}\% \text { fuera de } \\
\text { plazo / total }\end{array}$ \\
\hline 1067 & 1040 & 97,47 & 27 & 2,53 \\
\hline
\end{tabular}

Tipos de respuesta:

\begin{tabular}{|c|c|c|c|}
\hline Positiva & Negativa & Inapropiada & Incompleta \\
\hline 925 & 58 & 57 & 27 \\
\hline
\end{tabular}




\section{BIBLIOTECA PÚBLICA DEL ESTADO EN SANTA CRUZ DE TENERIFE}

Fecha de incorporación:

$N^{\circ}$ de días de turno:

Total de preguntas recibidas:

Porcentaje preguntas recibidas / totales:

Media de preguntas por turno:
$29 / 06 / 2001$

38

507

2,17

13,34

Personal en «Pregunte»:

\begin{tabular}{|c|c|c|c|c|}
\hline Total & Grupo A & Grupo B & Grupo C & Otros \\
\hline 4 & 0 & 4 & 0 & 0 \\
\hline
\end{tabular}

Preguntas gestionadas:

\begin{tabular}{|c|c|c|c|c|}
\hline Total & $\begin{array}{c}\text { Respuestas } \\
\text { en plazo }\end{array}$ & $\begin{array}{c}\text { \% en plazo / } \\
\text { total }\end{array}$ & $\begin{array}{c}\text { Respuestas } \\
\text { fuera de plazo }\end{array}$ & $\begin{array}{c}\% \text { fuera de } \\
\text { plazo / total }\end{array}$ \\
\hline 507 & 406 & 80,08 & 101 & 19,92 \\
\hline
\end{tabular}

Tipos de respuesta:

\begin{tabular}{|c|c|c|c|}
\hline Positiva & Negativa & Inapropiada & Incompleta \\
\hline 472 & 1 & 0 & 34 \\
\hline
\end{tabular}

\section{BIBLIOTECA PÚBLICA DEL ESTADO EN VALENCIA}

Fecha de incorporación:

$\mathrm{N}^{0}$ de días de turno:

Total de preguntas recibidas:

Porcentaje preguntas recibidas / totales:

Media de preguntas por turno:

Personal en «Pregunte»:

\begin{tabular}{|c|c|c|c|c|}
\hline Total & Grupo A & Grupo B & Grupo C & Otros \\
\hline 8 & 2 & 4 & 0 & 2 \\
\hline
\end{tabular}

Preguntas gestionadas:

\begin{tabular}{|c|c|c|c|c|}
\hline Total & $\begin{array}{c}\text { Respuestas } \\
\text { en plazo }\end{array}$ & $\begin{array}{c}\% \text { en plazo / } \\
\text { total }\end{array}$ & $\begin{array}{c}\text { Respuestas } \\
\text { fuera de plazo }\end{array}$ & $\begin{array}{c}\% \text { fuera de } \\
\text { plazo / total }\end{array}$ \\
\hline 1331 & 1236 & 92,86 & 95 & 7,14 \\
\hline
\end{tabular}

Tipos de respuesta:

\begin{tabular}{|c|c|c|c|}
\hline Positiva & Negativa & Inapropiada & Incompleta \\
\hline 1251 & 17 & 12 & 51 \\
\hline
\end{tabular}




\section{BIBLIOTECA PÚBLICA DEL ESTADO EN VITORIA}

Fecha de incorporación:

$\mathrm{N}^{\circ}$ de días de turno:

Total de preguntas recibidas:

Porcentaje preguntas recibidas / totales:

Media de preguntas por turno:
$15 / 12 / 1999$

66

1112

4,75

16,85

Personal en «Pregunte»:

\begin{tabular}{|c|c|c|c|c|}
\hline Total & Grupo A & Grupo B & Grupo C & Otros \\
\hline 3 & 1 & 0 & 2 & 0 \\
\hline
\end{tabular}

Preguntas gestionadas:

\begin{tabular}{|c|c|c|c|c|}
\hline Total & $\begin{array}{c}\text { Respuestas } \\
\text { en plazo }\end{array}$ & $\begin{array}{c}\text { \% en plazo / } \\
\text { total }\end{array}$ & $\begin{array}{c}\text { Respuestas } \\
\text { fuera de plazo }\end{array}$ & $\begin{array}{c}\% \text { fuera de } \\
\text { plazo / total }\end{array}$ \\
\hline 1112 & 1027 & 92,36 & 85 & 7,64 \\
\hline
\end{tabular}

Tipos de respuesta:

\begin{tabular}{|c|c|c|c|}
\hline Positiva & Negativa & Inapropiada & Incompleta \\
\hline 1016 & 35 & 23 & 38 \\
\hline
\end{tabular}

\section{BIBLIOTECA PÚBLICA DEL ESTADO EN ZARAGOZA}

Fecha de incorporación:

$\mathrm{N}^{\circ}$ de días de turno:

Total de preguntas recibidas:

Porcentaje preguntas recibidas / totales:

Media de preguntas por turno:

Personal en «Pregunte»:
10/12/1999

64

699

2,99

10,92

\begin{tabular}{|c|c|c|c|c|}
\hline Total & Grupo A & Grupo B & Grupo C & Otros \\
\hline 1 & 1 & 0 & 0 & 0 \\
\hline
\end{tabular}

Preguntas gestionadas:

\begin{tabular}{|c|c|c|c|c|}
\hline Total & $\begin{array}{c}\text { Respuestas } \\
\text { en plazo }\end{array}$ & $\begin{array}{c}\% \text { en plazo / } \\
\text { total }\end{array}$ & $\begin{array}{c}\text { Respuestas } \\
\text { fuera de plazo }\end{array}$ & $\begin{array}{c}\% \text { fuera de } \\
\text { plazo / total }\end{array}$ \\
\hline 699 & 657 & 93,99 & 42 & 6,01 \\
\hline
\end{tabular}

Tipos de respuesta:

\begin{tabular}{|c|c|c|c|}
\hline Positiva & Negativa & Inapropiada & Incompleta \\
\hline 615 & 36 & 25 & 23 \\
\hline
\end{tabular}




\section{CENTRO SUPERIOR BIBLIOGRÁFICO DE GALICIA}

Fecha de incorporación:

$N^{\circ}$ de días de turno:

Total de preguntas recibidas:

Porcentaje preguntas recibidas / totales:

Media de preguntas por turno:
$18 / 10 / 2000$

56

1002

4,28

17,89

Personal en «Pregunte»:

\begin{tabular}{|c|c|c|c|c|}
\hline Total & Grupo A & Grupo B & Grupo C & Otros \\
\hline 1 & 0 & 0 & 1 & 0 \\
\hline
\end{tabular}

Preguntas gestionadas:

\begin{tabular}{|c|c|c|c|c|}
\hline Total & $\begin{array}{c}\text { Respuestas } \\
\text { en plazo }\end{array}$ & $\begin{array}{c}\text { \% en plazo / } \\
\text { total }\end{array}$ & $\begin{array}{c}\text { Respuestas } \\
\text { fuera de plazo }\end{array}$ & $\begin{array}{c}\% \text { fuera de } \\
\text { plazo / total }\end{array}$ \\
\hline 1002 & 857 & 85,53 & 145 & 14,47 \\
\hline
\end{tabular}

Tipos de respuesta:

\begin{tabular}{|c|c|c|c|}
\hline Positiva & Negativa & Inapropiada & Incompleta \\
\hline 787 & 101 & 92 & 22 \\
\hline
\end{tabular}

\section{RED DE BIBLIOTECAS MUNICIPALES DE BILBAO}

Fecha de incorporación:

$\mathrm{N}^{\circ}$ de días de turno:

Total de preguntas recibidas:

Porcentaje preguntas recibidas / totales:

Media de preguntas por turno:

Personal en «Pregunte»:

\begin{tabular}{|c|c|c|c|c|}
\hline Total & Grupo A & Grupo B & Grupo C & Otros \\
\hline 3 & 1 & 1 & 1 & 0 \\
\hline
\end{tabular}

Preguntas gestionadas:

\begin{tabular}{|c|c|c|c|c|}
\hline Total & $\begin{array}{c}\text { Respuestas } \\
\text { en plazo }\end{array}$ & $\begin{array}{c}\% \text { en plazo / } \\
\text { total }\end{array}$ & $\begin{array}{c}\text { Respuestas } \\
\text { fuera de plazo }\end{array}$ & $\begin{array}{c}\% \text { fuera de } \\
\text { plazo / total }\end{array}$ \\
\hline 422 & 412 & 97,63 & 10 & 2,37 \\
\hline
\end{tabular}

Tipos de respuesta:

\begin{tabular}{|c|c|c|c|}
\hline Positiva & Negativa & Inapropiada & Incompleta \\
\hline 382 & 11 & 19 & 10 \\
\hline
\end{tabular}




\section{SERVICIO MUNICIPAL DE LECTURA PÚBLICA DE LA CORUÑA}

Fecha de incorporación:

$\mathrm{N}^{\circ}$ de días de turno:

Total de preguntas recibidas:

Porcentaje preguntas recibidas / totales:

Media de preguntas por turno:
$22 / 10 / 2001$

33

405

1,73

12,27

Personal en «Pregunte»:

\begin{tabular}{|c|c|c|c|c|}
\hline Total & Grupo A & Grupo B & Grupo C & Otros \\
\hline 6 & 0 & 6 & 0 & 0 \\
\hline
\end{tabular}

Preguntas gestionadas:

\begin{tabular}{|c|c|c|c|c|}
\hline Total & $\begin{array}{c}\text { Respuestas } \\
\text { en plazo }\end{array}$ & $\begin{array}{c}\text { \% en plazo / } \\
\text { total }\end{array}$ & $\begin{array}{c}\text { Respuestas } \\
\text { fuera de plazo }\end{array}$ & $\begin{array}{c}\% \text { fuera de } \\
\text { plazo / total }\end{array}$ \\
\hline 405 & 369 & 91,11 & 36 & 8,89 \\
\hline
\end{tabular}

Tipos de respuesta:

\begin{tabular}{|c|c|c|c|}
\hline Positiva & Negativa & Inapropiada & Incompleta \\
\hline 304 & 40 & 30 & 31 \\
\hline
\end{tabular}




\subsection{Descripción del funcionamiento del servicio}

De igual forma que se ha expuesto el desarrollo histórico, también se ha estimado conveniente presentar el sistema de trabajo del servicio, tal y como estaba desarrollándose en el momento de la investigación doctoral, describiendo su método de organización de turnos y coordinación, detallando el proceso que se seguía desde que se recibía una pregunta hasta que se enviaba la respuesta, estudiando los materiales documentales elaborados para «Pregunte» y otras cuestiones que tenían como objetivo delimitar el sistema de funcionamiento del que se partía en ese momento para la prestación del servicio.

La base física y lógica sobre la que se sustentaba «Pregunte» era el servidor que se encontraba en la Biblioteca Regional de Murcia y cuya información y software se estaba trasladando a dependencias de la Subdirección General de Coordinación Bibliotecaria. Había una persona encargada de la coordinación técnica, cuya misión era dar respuesta a cualquier incidencia que surjiera entre los participantes del proyecto, así como atender las cuestiones de los usuarios que se recibían a través de las páginas del servicio, ya fuera desde el formulario habilitado para remitir sugerencias o mediante el correo electrónico, al que se accedía a través de iconos muy claros.
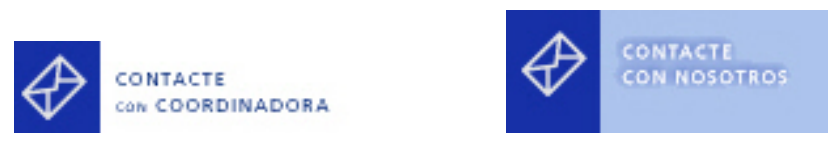

Fig. 3.1. Acceso a los sistemas de envío de correo electrónico

La Coordinación Técnica también se estaba encargando de intermediar entre el colectivo de bibliotecas e instituciones que pertenecían a «Pregunte»y los servicios informáticos de la Universidad de Murcia, antiguos responsables del desarrollo y el mantenimiento de la aplicación que empleaba el servicio.

La distribución de los turnos se realizaba dependiendo del número de centros participantes, de tal forma que el número de bibliotecas en el proyecto era también el número de días que transcurren desde que una biblioteca era responsable de atender las preguntas hasta que volvía a tener esa responsabilidad. En esos momentos la distribución era:

$\begin{array}{ll}\text { Turno general: } & \text { cada } 34 \text { días } \\ \text { Turno en catalán: } & \text { cada } 5 \text { días } \\ \text { Turno en gallego: } & \text { cada } 2 \text { días } \\ \text { Turno en vasco: } & \text { cada } 4 \text { días }\end{array}$

Los turnos eran de 24 horas (de 0 a 24 h.). El Turno general lo integraban las 34 bibliotecas participantes. Era frecuente que a las 11 bibliotecas que atendían en alguna lengua distinta al castellano les coincidiera el Turno general y el correspondiente de su lengua específica. 
Las bibliotecas comunicaban a la Coordinación Técnica qué días sería imposible atender el servicio, por coincidir con fiestas locales, obras u otras circunstancias. Si fueran a existir problemas con los turnos, la coordinación técnica modificaba el calendario, avisando a las bibliotecas que se verían afectadas por los cambios. Por lo general, los turnos se difundían con dos meses de antelación a través de las páginas internas del servicio. No obstante, el sistema enviaba un correo electrónico a la biblioteca de turno el día siguiente.

Esta información estaba restringida a los participantes en el proyecto, quienes debían identificarse con un nombre de usuario y contraseña.

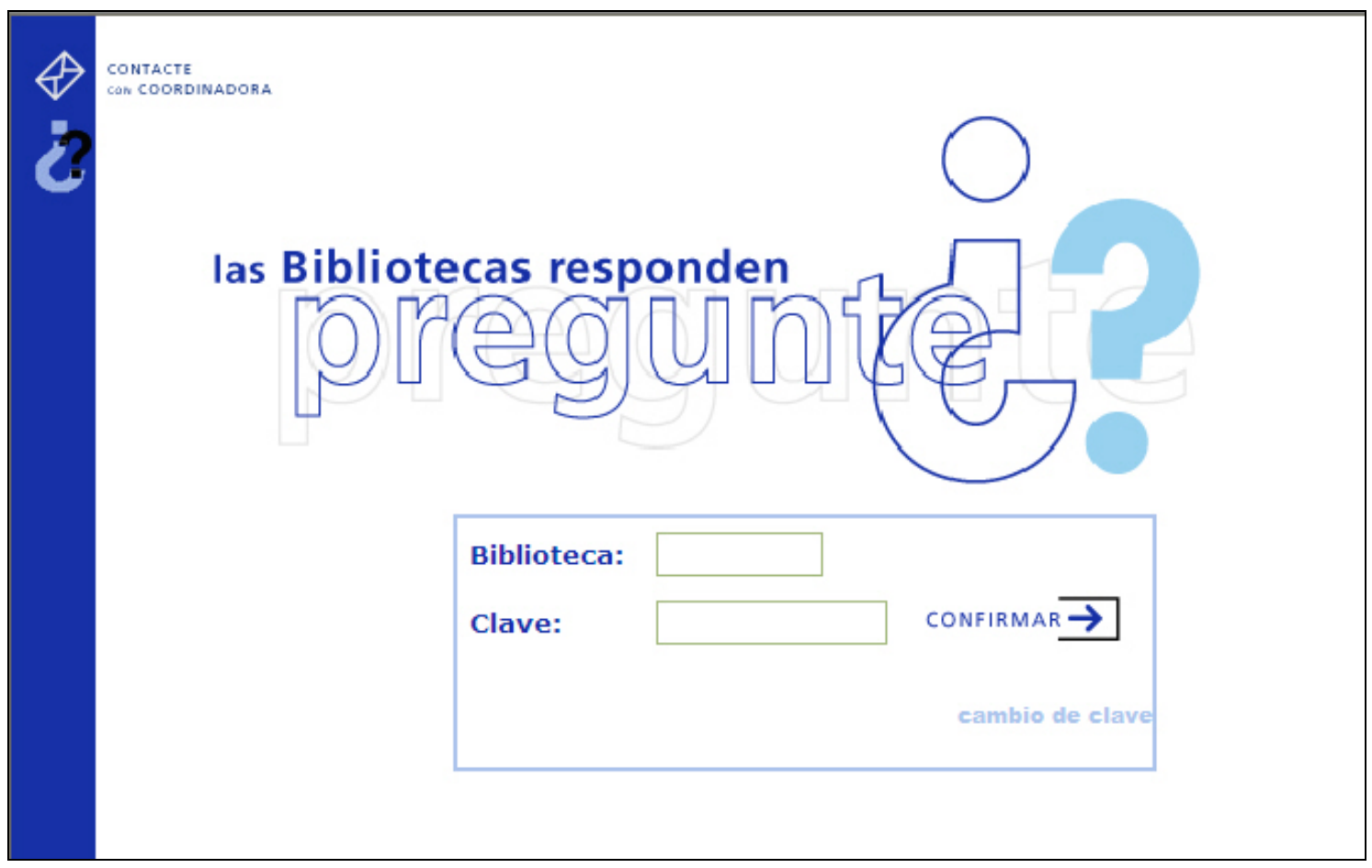

Fig. 3.2. Interfaz de acceso a la intranet

Cuando se habían introducido las claves, la información a la que se tenía acceso era la siguiente:

a/ Turnos del mes actual y del próximo. Los días que corresponde turno a la biblioteca que estaba haciendo la consulta aparecían resaltados y marcados con una cruz. Existía un calendario para el turno en general y otros para cada una de las lenguas distintas del español: catalán, gallego, vasco. 


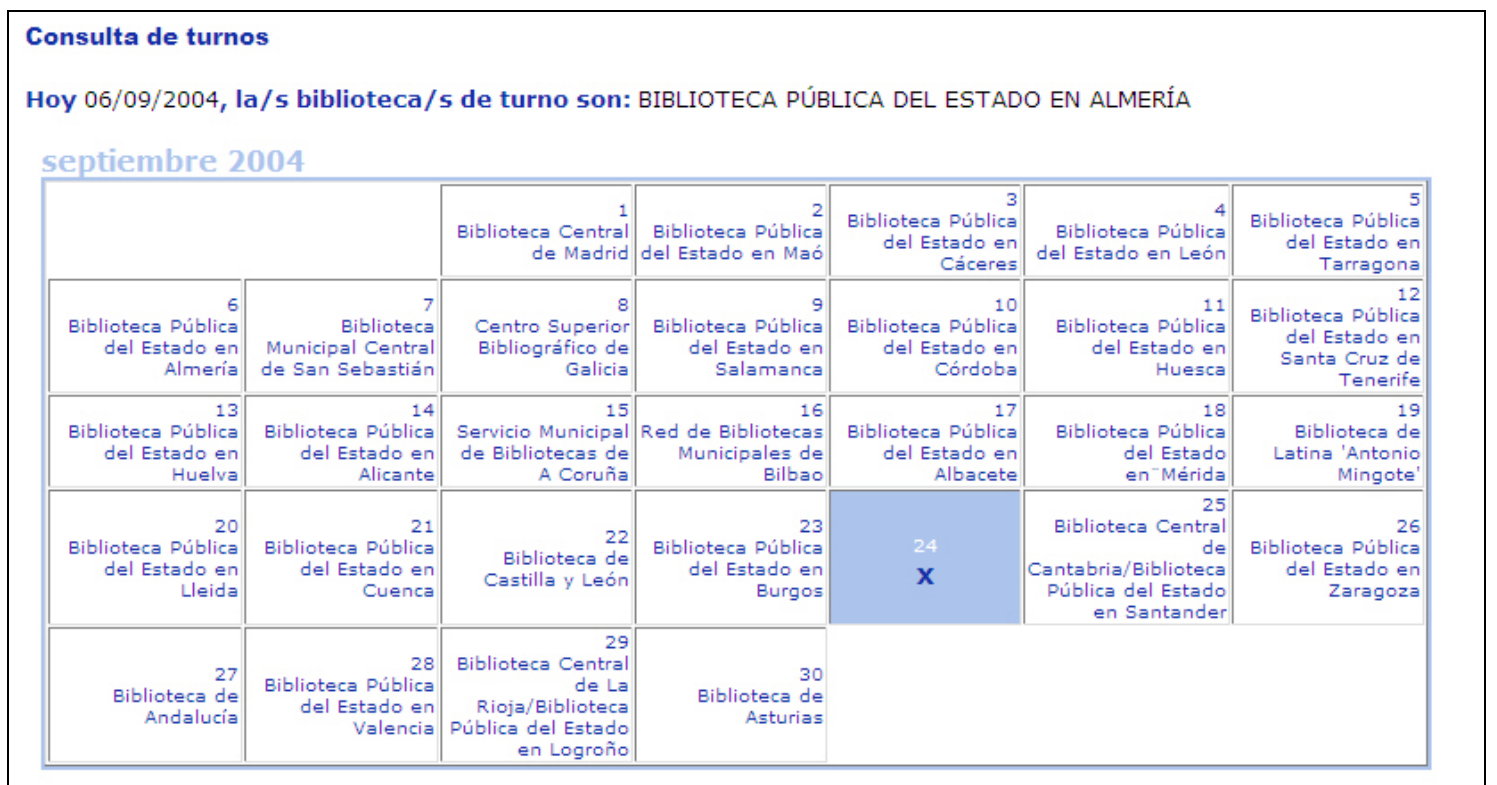

Fig. 3.3. Distribución de turnos - Turno general

\section{biblis bipliotecas responden}

Consulta de turnos catalanes

Hoy 06/09/2004, la/s biblioteca/s de turno son: BIBLIOTECA PÚBLICA DEL ESTADO EN VALENCIA

\begin{tabular}{|c|c|c|c|c|c|c|}
\hline & & $\begin{array}{r}1 \\
\text { Biblioteca } \\
\text { Pública del } \\
\text { Estado en } \\
\text { Valencia }\end{array}$ & $\begin{array}{r}2 \\
\text { Biblioteca } \\
\text { Pública del } \\
\text { Estado en } \\
\text { Lleida }\end{array}$ & $\begin{array}{r}3 \\
\text { Biblioteca } \\
\text { Pública del } \\
\text { Estado en } \\
\text { Maó }\end{array}$ & $\begin{array}{r}4 \\
\text { Biblioteca } \\
\text { Pública del } \\
\text { Estado en } \\
\text { Barcelona }\end{array}$ & $\begin{array}{r}5 \\
\text { Biblioteca } \\
\text { Pública del } \\
\text { Estado en } \\
\text { Tarragona }\end{array}$ \\
\hline $\begin{array}{r}6 \\
\text { Biblioteca } \\
\text { Pública del } \\
\text { Estado en } \\
\text { Valencia }\end{array}$ & $\begin{array}{r}7 \\
\text { Biblioteca } \\
\text { Pública del } \\
\text { Estado en } \\
\text { Lleida }\end{array}$ & $\begin{array}{r}8 \\
\text { Biblioteca } \\
\text { Pública del } \\
\text { Estado en } \\
\text { Maó }\end{array}$ & $\begin{array}{r}9 \\
\text { Biblioteca } \\
\text { Pública del } \\
\text { Estado en } \\
\text { Barcelona }\end{array}$ & $\begin{array}{r}10 \\
\text { Biblioteca } \\
\text { Pública del } \\
\text { Estado en } \\
\text { Tarragona }\end{array}$ & $\begin{array}{r}11 \\
\text { Biblioteca } \\
\text { Pública del } \\
\text { Estado en } \\
\text { Valencia }\end{array}$ & $\begin{array}{r}12 \\
\text { Biblioteca } \\
\text { Pública del } \\
\text { Estado en } \\
\text { Lleida }\end{array}$ \\
\hline $\begin{array}{r}13 \\
\text { Biblioteca } \\
\text { Pública del } \\
\text { Estado en } \\
\text { Maó }\end{array}$ & $\begin{array}{r}14 \\
\text { Biblioteca } \\
\text { Pública del } \\
\text { Estado en } \\
\text { Barcelona }\end{array}$ & $\begin{array}{r}15 \\
\text { Biblioteca } \\
\text { Pública del } \\
\text { Estado en } \\
\text { Tarragona }\end{array}$ & $\begin{array}{r}16 \\
\text { Biblioteca } \\
\text { Pública del } \\
\text { Estado en } \\
\text { Valencia }\end{array}$ & $\begin{array}{r}17 \\
\text { Biblioteca } \\
\text { Pública del } \\
\text { Estado en } \\
\text { Lleida }\end{array}$ & $\begin{array}{r}18 \\
\text { Biblioteca } \\
\text { Pública del } \\
\text { Estado en } \\
\text { Maó }\end{array}$ & $\begin{array}{r}19 \\
\text { Biblioteca } \\
\text { Pública del } \\
\text { Estado en } \\
\text { Barcelona }\end{array}$ \\
\hline $\begin{array}{r}20 \\
\text { Biblioteca } \\
\text { Pública del } \\
\text { Estado en } \\
\text { Tarragona }\end{array}$ & $\begin{array}{r}21 \\
\text { Biblioteca } \\
\text { Pública del } \\
\text { Estado en } \\
\text { Valencia }\end{array}$ & $\begin{array}{r}22 \\
\text { Biblioteca } \\
\text { Pública del } \\
\text { Estado en } \\
\text { Lleida }\end{array}$ & $\begin{array}{r}23 \\
\text { Biblioteca } \\
\text { Pública del } \\
\text { Estado en } \\
\text { Maó }\end{array}$ & $\begin{array}{r}24 \\
\text { Biblioteca } \\
\text { Pública del } \\
\text { Estado en } \\
\text { Barcelona }\end{array}$ & $\begin{array}{r}25 \\
\text { Biblioteca } \\
\text { Pública del } \\
\text { Estado en } \\
\text { Tarragona }\end{array}$ & $\begin{array}{r}26 \\
\text { Biblioteca } \\
\text { Pública del } \\
\text { Estado en } \\
\text { Valencia }\end{array}$ \\
\hline $\begin{array}{r}27 \\
\text { Biblioteca } \\
\text { Pública del } \\
\text { Estado en } \\
\text { Lleida }\end{array}$ & $\begin{array}{r}28 \\
\text { Biblioteca } \\
\text { Pública del } \\
\text { Estado en } \\
\text { Maó }\end{array}$ & $\begin{array}{r}29 \\
\text { Biblioteca } \\
\text { Pública del } \\
\text { Estado en } \\
\text { Barcelona }\end{array}$ & $\begin{array}{r}30 \\
\text { Biblioteca } \\
\text { Pública del } \\
\text { Estado en } \\
\text { Tarragona }\end{array}$ & & & \\
\hline
\end{tabular}

Fig. 3.4. Distribución de turnos - Turno catalán

b/ Manual de procedimiento. Se ofrecía información sobre: definición del servicio, explicación del funcionamiento, sugerencias para la redacción de respuestas, reglas de estilo, plazos de respuesta, sistemas de comunicación. La información que se encontraba en línea también estaba disponible en formato Adobe Acrobat y era remitida a las bibliotecas en el momento de iniciar su participación en «Pregunte». 
c/ Información de las bibliotecas. Directorio organizado por Comunidades Autónomas. Se incluía nombre de la biblioteca, correo electrónico de la misma, dirección web, datos postales y de contacto, personas vinculadas a «Pregunte» y fecha de incorporación.

\section{biblis bibliotecas responden bibliotecas}

Información completa de las bibliotecas participantes en el sistema, ordenada por comunidades autónomas.

ANDALUCIA

BIBLIOTECA DE ANDALUCIA

CORREO ELECTRÓNICO franciscoj.martin@juntadeandalucia.es

URL http://www.sba.junta-andalucia.es/

DIRECCIÓN C/ Profesor Sainz Cantero, 6-18002 Granade

TELÉFONO 958026925

FAX 958292610 PERSONAS DE CONTACTO - Francisco J. Martin Pertiñez (Dpto. Informacion Bibliografica y Referencia) 958026925 - Ascension Espinosa Wait - M.
Angeles Chacon

FECHA DE
INCORPORACIÓN $10 / 12 / 1999$

Fig. 3.5. Información sobre las bibliotecas de la red

d/ Foro. Sistema de comunicación entre participantes en el proyecto. Se trataba de un formulario desde el que se podían enviar mensajes a una biblioteca concreta o a todas de forma simultánea. Las bibliotecas recibían un correo electrónico con la identificación de quien ha enviado el mensaje. Este foro se estima una útil herramienta de distribución de información y de cooperación para la prestación del servicio, pero apenas se estaba empleando.

Foro de comunicación entre las bibliotecas participantes

Esta sección permite la comunicación entre las bibliotecas participantes en el sistema.

Seleccione la/s biblioteca/s a las que quiere enviar el correo electrónico, y rellene la información que desee enviar:

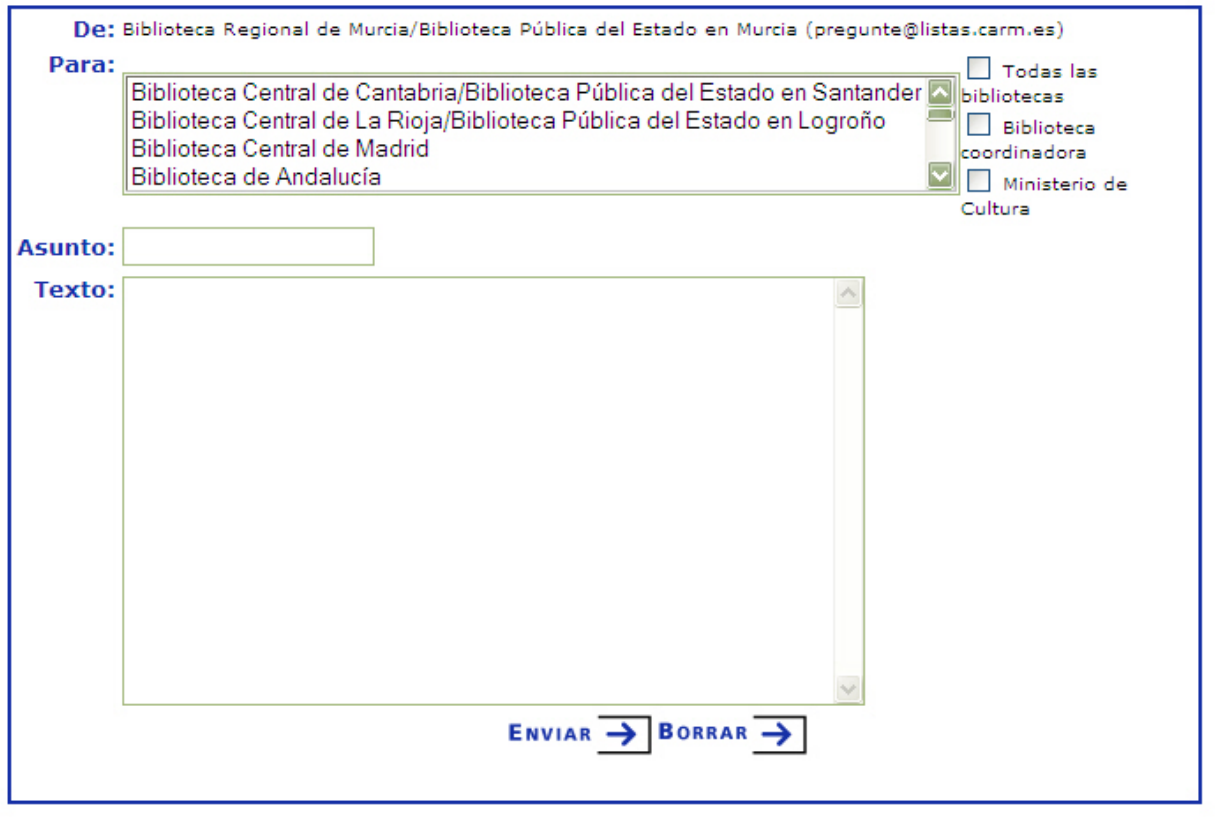

Fig. 3.6. Sistema de envío de mensajes al foro 
e/ Buscador interno. Sistema de recuperación de preguntas ya resueltas. Se trataba del archivo de preguntas y respuestas, que era posible consultar por palabras o por palabras y temas. Además, se puede delimitar por Número de Identificación de Consulta (NIC) y fechas. La visualización de los registros también podía ser definida, eligiendo si los resultados aparecerían ordenados por temas, por fecha de consulta o por fecha de resolución.

f/ Estadísticas. Sistema para conocer las estadísticas generales del servicio y las de las distintas bibliotecas. Existía la posibilidad de desglosar las estadísticas, para conocer grupos de edad de los usuarios, provincia desde la que se realizan las consultas y temas. También ofrecía datos del tipo de preguntas recibidas y del idioma en el que se hicieron.

El proceso de pregunta-respuesta comienza cuando un usuario quiere realizar una pregunta al servicio. Para ello se conecta a «Pregunte: las bibliotecas responden» a través de su dirección principal http://www.pregunte.org, donde se encontraba con la siguiente interfaz:

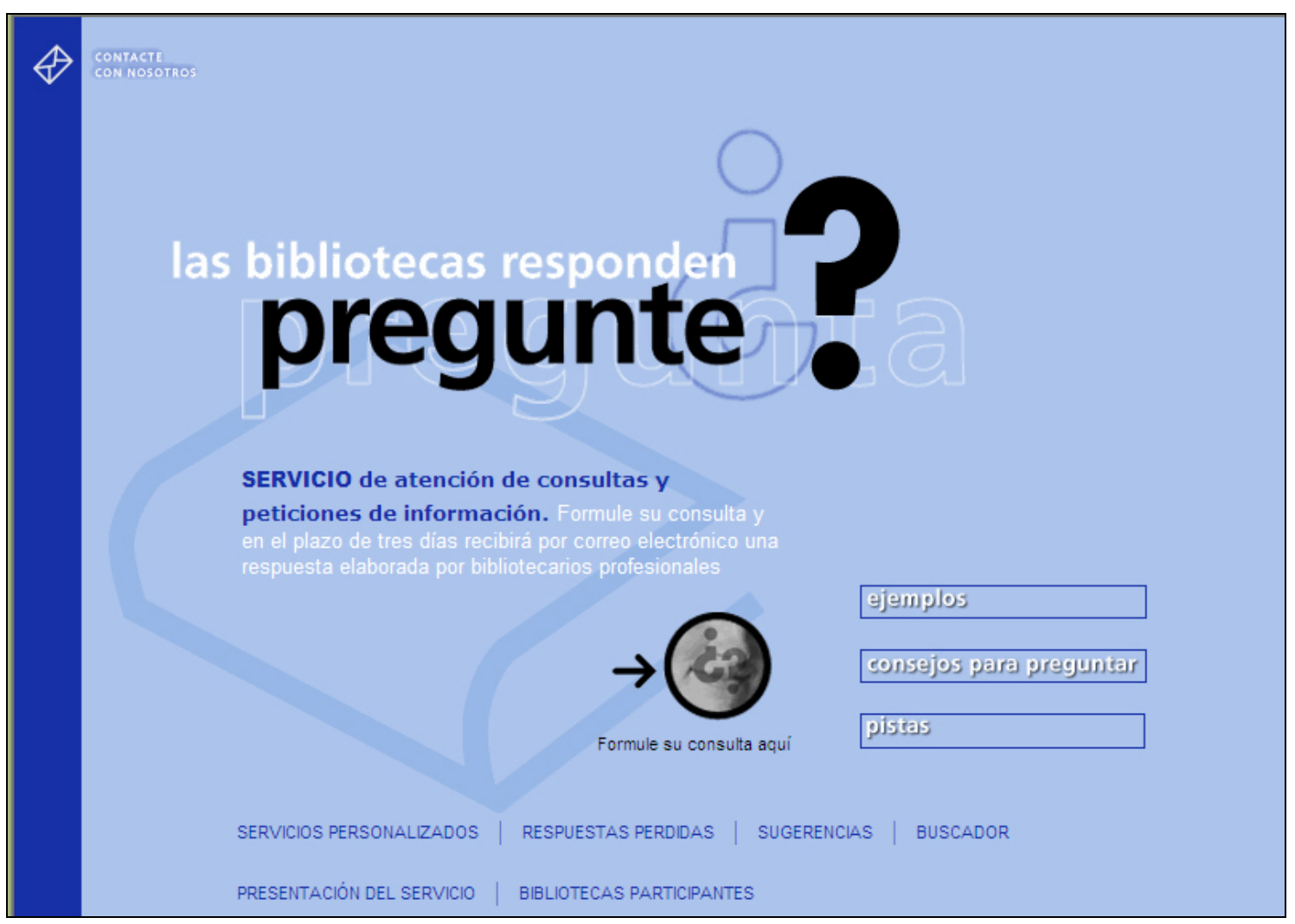

Fig. 3.7. Interfaz de usuario

Como puede apreciarse, se ofrecían ejemplos y otras informaciones útiles para realizar la consulta, además del acceso a otros servicios complementarios, como la posibilidad de registrarse como usuario o la consulta de las respuestas a las preguntas devueltas, al presentar problemas las direcciones de correo electrónico indicadas por los usuarios. También se posibilitaba la consulta al archivo de preguntas y respuestas. 
La opción para acceder al formulario de consulta estaba claramente indicada en el centro de la página principal del servicio:

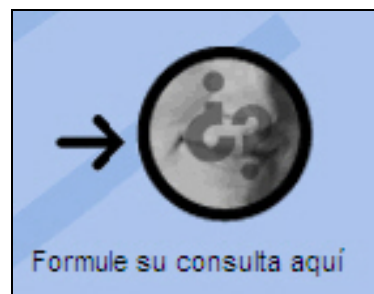

Fig. 3.8. Logo de acceso al formulario de consulta

Desde aquí se accedía al segundo nivel del sitio web, destinado a recoger las consultas y que, para que el usuario comprendiera mejor el proceso, se había dividido en tres apartados.

En el primero de ellos se pedía directamente que se realizase la consulta. A la derecha del formulario estaban los enlaces a la página de consejos para preguntar, pistas y ejemplos de consultas que también aparecían en la página principal.

\section{consejos para preguntar}

\section{Preguntas concretas}

Solamente podemos facilitarle respuestas concretas a preguntas cond documentar la fuente de la respuesta, y no podemos responder a las gran humanidad. No estudiamos un tema, esbozamos hipótesis o damos opiniones.

\section{Sitúenos ...}

Si cuando realice una pregunta nos da información de contexto, seguro que busca. Tenga en cuenta que no podemos entablar una conversación para acl pregunta, que únicamente recibiremos su correo electrónico. Explíquenos quiere los datos, dónde ha oído hablar del tema, de dónde surge su duda. Si r pista que nos encamine en nuestra búsqueda, los bibliotecarios que recoja agradecerán.

\section{Atención al correo electrónico}

Si falla el correo electrónico se rompe la cadena. Ponga atención al teclear s electrónico, y asegúrese de que es una dirección que puede recibir correos sólo desde su red local. De todas maneras, si no funcionase correctamente s electrónico, hemos previsto una página de respuestas perdidas, accesible desde donde estarán consultables durante un tiempo las preguntas-respuestas que su destinatario.

Fig. 3.9. Página de información sobre el servicio 
No obstante, el usuario podía rellenar su consulta sin pasar por las páginas de consejos y pistas para preguntar. En estas páginas era donde se encontraba el tipo de preguntas que se atendían, así como las excepciones que no se respondían. También aquí se dan ejemplos de cómo redactar la pregunta.

El formulario de consulta comenzaba con un espacio en el cual se podía redactar de forma libre el contenido de la demanda de información. El servicio aconsejaba, debajo de este espacio, que se detallara la información que se necesitaba, así como cualquier dato que fuera de utilidad para poder localizarla.

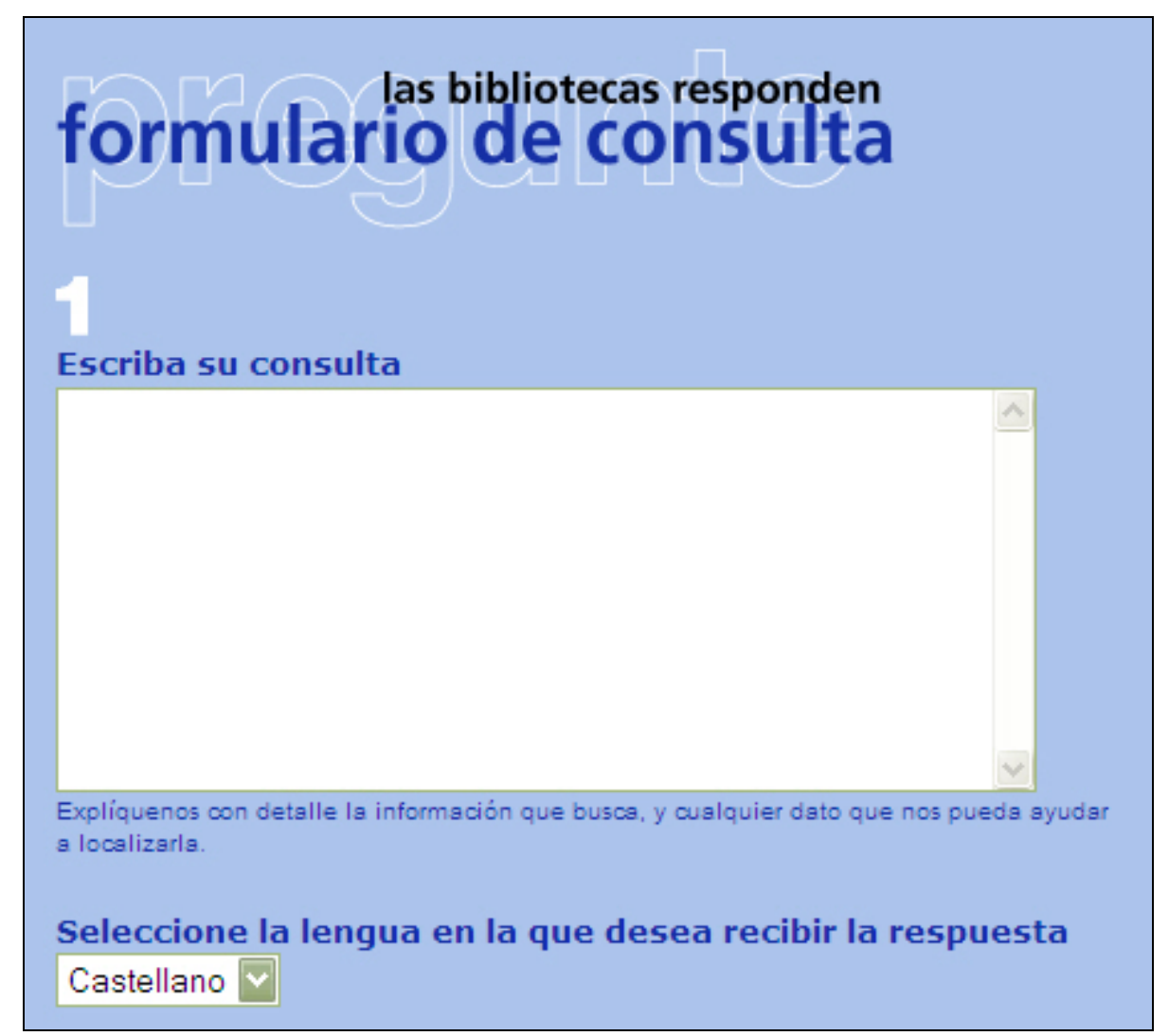

Fig. 3.10. Formulario de consulta

El usuario podía preguntar en cualquiera de las lenguas oficiales del Estado y solicitar que la respuesta se dé en esa misma lengua.

«Pregunte» basaba la comunicación con el usuario en la recepción de las preguntas mediante este formulario y el envío de la respuesta a través de un correo electrónico, dato que se pedía en el segundo paso: 


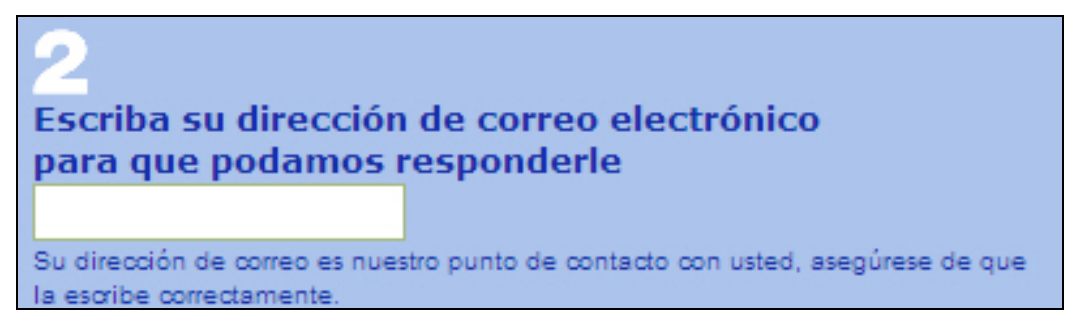

Fig. 3.11. Formulario de consulta

La tercera parte del formulario era opcional y en ella se pedían ciertos datos que permitirían conocer de forma somera el perfil del usuario que estaba realizando la consulta. A través de este sistema se podía conocer la edad del usuario y el lugar desde el que se consultaba. La edad se medía por tramos, mientras que para la localidad se utilizaba la división provincial de España, más una opción para quienes preguntan desde fuera del estado español.

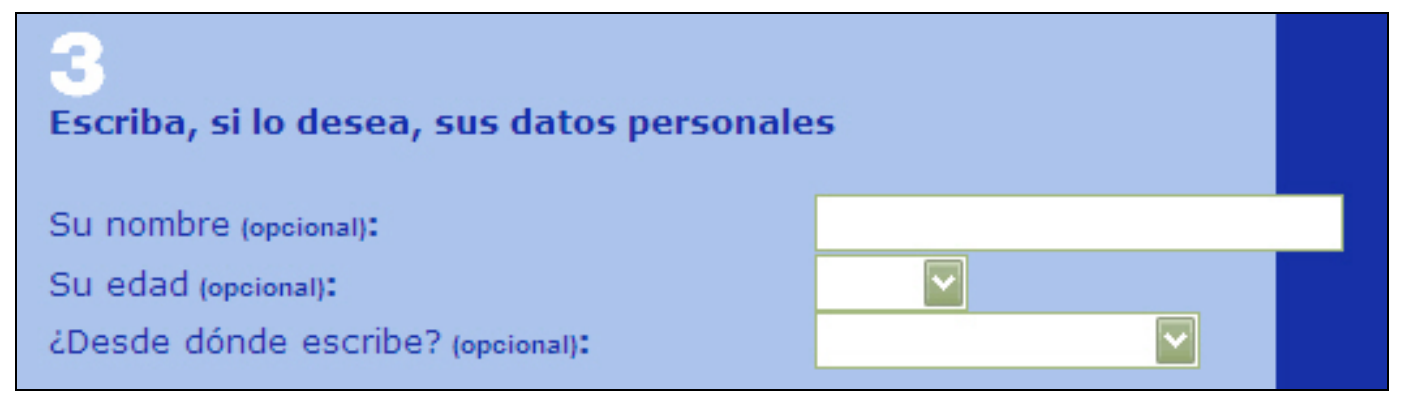

Fig. 3.12. Formulario de consulta

Una vez completada esta información, se enviaba al usuario a una página de comprobación de los datos de la consulta. Aceptados éstos, se generaba otra página donde se le indicaba que la pregunta había sido procesada correctamente y que en "el plazo máximo de tres días recibirá una respuesta concreta realizada por una de las bibliotecas colaboradoras". En esta misma página se informaba del Número de Identificación de Consulta (NIC) que se le ha asignado.

También, desde este mismo lugar, se avisaba al usuario de una serie de circunstancias:

- "Si observa que no recibe respuesta a su consulta dentro de los próximos tres días, puede usar este número para enviar una reclamación”.

- "Si su dirección de correo electrónico fuera incorrecta o no funcionase, su respuesta se depositará en la página de respuestas perdidas".

- "También puede registrarse como usuario y obtener una clave, que le permitirá consultar el estado de las preguntas/respuestas que haya enviado al sistema". 
Si el usuario lo consideraba interesante se registraba, proceso que se verá más adelante. Hasta aquí el protagonista era el usuario. Una vez enviada la pregunta, el programa informático la asignaba de forma automática a la biblioteca que estaba de turno ese día, quien, además de recibirlas por correo electrónico, podía verlas al conectarse a la página interna de las bibliotecas que participaban en «Pregunte: las bibliotecas responden», accesible entonces desde la dirección web específica $<$ http://www.pregunte.org/pregunte/bibliotecas $>$. Debajo de la relación de preguntas que la biblioteca tiene pendientes de contestar, se encontraban una serie de opciones:

$$
\text { contestar | rechazar | redingir a biblioteca local | borrar repetidas }
$$

Fig. 3.13. Opciones internas de respuesta

a/ contestar: se pasaba al formulario desde donde se redacta y envía la respuesta.

b/ rechazar: la pregunta se considera inadecuada, por lo que no se contestará.

c/ redirigir a biblioteca local: la consulta es específica de otra localidad, por lo que se envía a la biblioteca que se considere más apropiada para responderla.

d/ borrar repetidas: eliminar las consultas que se han realizado por duplicado.

Las preguntas, a través del web interno de «Pregunte» se visualizaban de la siguiente forma:

Gestión de respuestas

Total de preguntas recibidas: 103 Preguntas pendientes de contestar: 10

1. Aparte de la Biblia, ¿Que otros libros contemporáneos recogen acontecimientos o crónicas de la vida de Jesús? --06/09/2004 (13:09)

2. Soy José Becerra, coordinador de la publicación periódica 'Boletín Criminológico' del Instituto de Criminología de la Universidad de Málaga. El motivo de mi consulta es para preguntarles qué tendriamos que hacer para poder enviarles nuestra publicación por correo y que ustedes la expusieran como creyeran más conveniente. Por supuesto, es gratuíta y de divulgación científica. Pueden responder a: Boletincriminologico@uma.es Un cordial saludo José Becerra. --06/09/2004 (14:39)

3. Hola: Quisiera conocer datos sobre Cristotal Bencomo (Mencey de Taoro)en Tenerife (Islas Canarias). ¿Quienes fueron sus hijos y hacia donde emigraron?, además de cualquier otro dato que me lleve a seguir la pista de cada uno de ellos. Muchas Gracias --06/09/2004 (15:35)

4. Hola: Me gustaría conocer los pasos a seguir para realizar la evaluación de una Intranet. Gracias -06/09/2004 (15:46)

5. definción del nacionalismo cultural, en especial lo que significa para el Movimiento Chicano- mexicanoamericano- de finales de los sesenta. muchas gracias. --06/09/2004 (16:47)

6. Buenas, se qué significa ISBN pero... ¿qué significa ASIN en un libro? Gracias --06/09/2004 (17:13)

7. quisiera saber cuales son los nombres de catálogos mas utilizados en bibliotecas universitarias Gracias -$06 / 09 / 2004(17: 18)$

s. Me gustaría saber cual es el sistema integrado de gestión bibliotecaria de la B Nacional española Gracias $-06 / 09 / 2004(17: 18)$

9. Si catalogamos una publicación periódica, el director debe nombrarse en la mención de responsabilidad? Es obligatorio? --06/09/2004 (17:31)

10. Reglas para la colocacion de valores gubernamentales --06/09/2004 (17:33)

contestar | rechazar | redirigir a biblioteca local | borrar repetidas

Fig. 3.14. Página interna de preguntas recibidas en un turno 
Para simplificar el trabajo de los profesionales que atienden el servicio se elaboraron una serie de respuestas modelo, cuyo uso está indicado para preguntas inapropiadas o que no se ajustan a los objetivos del servicio; así como para cuestiones para las que no se ha podido encontrar una respuesta y consultas que sólo se han podido resolver de forma parcial. Las bibliotecas respondían a partir del siguiente formulario.

\section{Gestión de respuestas:}

4

Texto de la consulta:

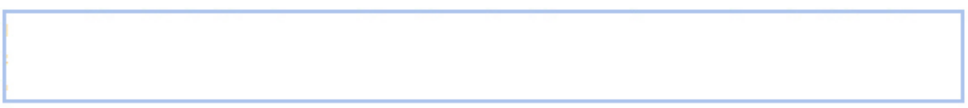

Datos del usuario

Nombre: $\quad$ Correo electrónico: Edad: Procedencia:

Respuesta

Tema

Fuentes de información

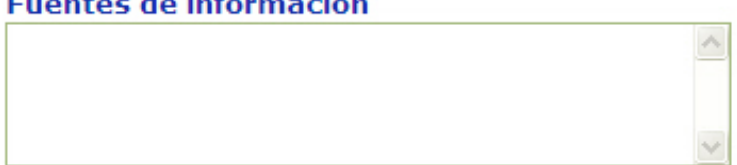

Fuentes para ampliar

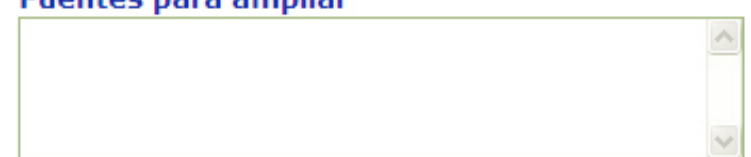

Respuestas modelo

No hemos encontrado nada

Pregunta no apropiada

Respuesta incompleta

Preguntas de 1 en 1

Consultorio bibliotecario

Acumulacion de preguntas

Pregunte poco precisa o muy genérica

Más acerca de las respuestas modelo.

Si considera que ésta es una consulta "ejemplo", pulse sobre la siguiente casilla

Fig. 3.15. Página interna para elaborar la respuesta 
Es interesante constatar la doble opción que se presenta a la hora de ofrecer fuentes de información, ya que, por una parte, se trataba de recoger cuáles habían sido las utilizadas para redactar la consulta y, por otra, cuáles podrían servir de complemento a la respuesta dada. Al tratarse de campos opcionales, sólo se rellenaban cuando las bibliotecas lo quieren o lo consideran necesario. En muchos casos, estos campos ayudaban a resolver las limitaciones que presenta el sistema en cuanto al número de caracteres que puede tener una respuesta.

Las respuestas modelo se detallaban en una pantalla de ayuda, en la que se mostraba el texto completo de la respuesta que se ofrecía en función de la consulta solicitada.

El bibliotecario seleccionará, si procede, una o varias respuestas modelo, prediseñadas por el sistema, para añadir al mensaje de respuesta.

Actualmente, los textos de las respuestas modelo que puede añadir son:

No hemos encontrado nada - Sintiendolo mucho no hemos logrado encontrar una respuesta precisa a la pregunta que nos planteo. Le rogamos que si en otro momento encuentra algun dato mas sobre el tema, nos vuelva a remitir la pregunta

Pregunta no apropiada - Su pregunta no se ajusta al proposito de nuestro servicio, por lo que aconsejamos que se ponga en contacto con otro centro de informacion para resolverla

Respuesta incompleta - La respuesta que le enviamos no se ajusta exactamente a lo que usted solicito, pero no hemos podido encontrar informacion mas precisa. Consulte alguna de las obras que le recomendamos en la bibliografia anexa

Preguntas de 1 en 1 - Aprovechamos para recordarle que para facilitar la elaboracion de las respuestas nos envie sus consultas de una en una.

Consultorio bibliotecario - En relación con su pregunta demandando información sobre cuestiones bibliotecario-documentales, ponemos en su conocimiento que el servicio «Pregunte, las bibliotecas responden* es un servicio de referencia de carácter enciclopédico y por tanto no figura entre sus objetivos la consultoría sobre tales aspectos. Sin embargo, le facilitamos algunas información general que puede serle de utilidad.

Acumulacion de preguntas - Por favor no realice demasiadas preguntas en el mismo momento, porque puede saturar al personal que atiende el servicio. Busque una fórmula genérica para plantear sus cuestiones.

Pregunte poco precisa o muy genérica - El tema de su pregunta resulta amplísimo e impreciso para los límites de este servicio y la respuesta a la misma supondría no solo la consulta de las numerosas fuentes de información existentes, sino también la elaboración de un informe que en cualquier caso excede nuestras posibilidades.

Fig. 3.16. Opciones de respuestas predeterminadas

Al término de la respuesta se asignaba a la misma una de estas calificaciones:

- POSITIVA:

- NEGATIVA:

pregunta que se considera contestada

- INAPROPIADA: pregunta que no se pudo resolver

- INCOMPLETA:

pregunta rechazada por no ajustarse al servicio

pregunta resuelta parcialmente 
Las opciones "Negativa" e "Inapropiada" permitían que se pueda mantener un seguimiento de la consulta y enviar posteriormente una respuesta satisfactoria, si ha sido posible encontrarla.

También se debía asignar a cada respuesta una materia, de las 16 que se aprobaron y que están en vigor desde julio de 2002. Se establecieron estos grandes grupos en función de los temas más consultados. A cada pregunta se le asignaba obligatoriamente un tema, sobre todo a efectos de control estadístico.

El bibliotecario seleccionará uno de los temas presentes en la lista desplegable, de manera que sea posible clasificar de alguna manera la consulta realizada por el usuario.

La selección del tema es imprescindible si se desea que una consulta sea guardada en el sistema como ejemplo a seguir a la hora de consultar.

Los temas incluidos hasta el momento son:

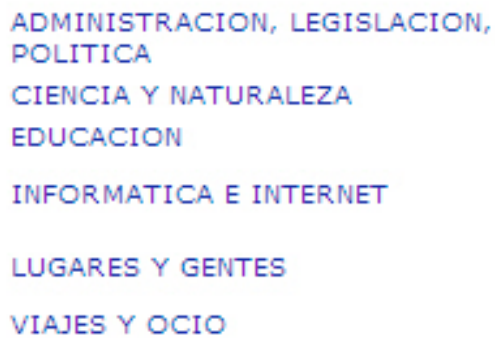

ARTE

CIENCIAS SOCIALES EMPLEO Y TRABAJO

INGENIERIA, TECNOLOGIAS PENSAMIENTO $Y$ RELIGIONES
BIBLIOTECAS Y

DOCUMENTACION

ECONOMIA Y EMPRESAS

HISTORIA

LENGUAS Y LITERATURA

SALUD, MEDICINA y ocio

VOLVER AL FORIMULARIO

Fig. 3.17. Asignación de un tema a la pregunta

Una vez enviada la respuesta, el usuario recibía el texto de la contestación en un correo electrónico:

\begin{tabular}{|ll|}
\hline $\begin{array}{l}\text { De: } \\
\text { Fecha: }\end{array}$ & respuestas.pregunte@carm.es \\
$\begin{array}{l}\text { Para: } \\
\text { Asunto: }\end{array} \quad$ seteron@jet.es & Las bibliotecas responden: Respuesta a su pregunta de 22/03/2004 \\
\hline & \\
Estimado/a amigo/a \\
$\begin{array}{l}\text { Este mensaje contiene la respuesta a la pregunta que formuló al servicio } \\
\text { 'Pregunte, las bibliotecas responden' el dia 22/03/2004. }\end{array}$
\end{tabular}

Fig. 3.18. Cabecera del correo automático de respuesta

Las preguntas que no habían podido solventarse pasan al archivo de preguntas sin resolver. En estos casos, el usuario no recibía contestación alguna, ni siquiera en sentido negativo. Estas respuestas se podían 
consultar desde una de las opciones de las páginas internas y junto a las mismas se ofrecía la posibilidad de responderlas.

$\rightarrow \quad$ Estoy buscando un artículo de Benjamin Franklin, \'Morals of Chess \',que creo pertenece al libro \'The Big Book Brunch \'. ¿Existe una traducción al español? Gracias.

$\rightarrow \quad$ Bibliografia sobre la primera plaza de toros en Blanca (Murcia). Segun la Gran Enciclopedia de la Region murciana se dice (Antonio Gonzalez Barnes) que la primera plaza de toros se construyo en 1658 en Blanca con una capacidad de 2000 espectadores. Era la primera en Murcia y el sexto en España. PERO DONDE ESTA LA REFERENCIA O BIBLIOGRAFIA QUE PRUEBA AQUELLO??

$\rightarrow \quad$ ¿ QUE SON LOS PLANES DE ALOJAMIENTO ? ¿ COMO PUEDE ORDENARCE EL SERVICIO DE HOSPEDAJE, POR SU OPERACION Y FUNCIONAMIENTO ? ¿ CUANTOS PLANES DE ALOJAMIENTO SON CONOCIDOS EN MEXICO? ¿ QUE SISTEMAS EXISTEN PARA CLASIFICAR LOS HOTELES ? ¿ COMO SE CLASIFICAN LOS HOTELES,ATENDIENDO A LA CALIDAD DE SUS SERVICIOS ? ¿ EN QUE CONSISTE EL SISTEMA DE ESTRELLAS ? ¿ QUE ES UN HOTEL CASINO ?

Fig. 3.19. Página interna del archivo de preguntas pendientes de resolver

Como ya se comentó, las respuestas enviadas a direcciones de correo electrónico erróneas, una vez devueltas al sistema, eran almacenadas en la página de respuestas perdidas, para que los usuarios que las plantearon pudieran conocer la contestación dada.

\section{las bibliotecas responden respuestas perdidas}

En esta pagina se almacenan las preguntas y respuestas que no se har direccion de correo electronico que los usuarios nos proporcionan.

CONSULTA: (NIC: 25495, 25/08/2004) CUALES SON LOS CASOS ESPECIALES D ORTOGRAFIA

dentro de este mismo programa hay un buscador interno (consultas)que responde muchas veces a preguntas similares. Se escribe ortografia y en una de ellas sale su pregunta. También hay paginas web como la de la real academia española. Los casos o aspectos más famosos se deben a que en español no solemos vocalizar o diferencial foneticamente, por ejemplo la b y la $v$., también caso de $g \mathrm{y} \mathrm{j}$, etc.

Fuentes: internet, lenguaje.com., pagina de la real academia lengua española, localizar por google y buscar en consultas del español, están las normas

Para ampliar: martinez sousa la nueva ortografia.- ortocard. Reglas de... Barcelona, Castellnou, 1995

Fig. 3.20. Página pública de preguntas perdidas (direcciones de correo erróneas)

El número de personas encargadas de dar respuesta a las consultas recibidas variaba mucho entre unas bibliotecas y otras, ya que hay casos en los que un solo bibliotecario era el responsable del servicio, mientras que en otras había equipos de una decena de personas. En cada biblioteca 
participante existe un coordinador, quien, además de contestar las preguntas, se encarga de recibirlas, de organizar la distribución de las mismas entre los profesionales de esa biblioteca y de recoger las respuestas para su redacción definitiva y envío.

El proceso era más complejo en unas bibliotecas que en otras, ya que en algunas el grupo encargado de contestar las preguntas, las debatía y las repartía según la afinidad del tema y del personal. Por el contrario, en bibliotecas con menos personal, el responsable del servicio se encargaba de todo el proceso: recoger las preguntas, seleccionar las fuentes, contestarlas y enviarlas. Este proceso fue motivo de pregunta en la encuesta que se realizó a los profesionales.

En cuanto a los manuales y a textos redactados para la prestación del servicio, no eran muchos los documentos que se habían producido para normalizar el servicio «Pregunte: las bibliotecas responden». En el momento de aplicar la evaluación que se está presentando en esta tesis doctoral había tres herramientas que empleaban todas las bibliotecas participantes:

1. Manual de instrucciones y procedimientos

2. Manual técnico del servidor

3. Cuadro de materias

El Manual de instrucciones y procedimientos y el Manual técnico del servidor, en la versión que se empleaba en ese momento, habían sido editado en el año 2000. La redacción corrió a cargo del Grupo de Trabajo formado por representantes de las Comunidades Autónomas y del Ministerio de Cultura. El borrador fue elaborado por la Subdirección General de Coordinación Bibliotecaria. Ambos manuales se difundieron juntos, como dos bloques del mismo documento. El primero de estos bloques era el que aparecía también en línea, en las páginas internas del servidor destinadas a las bibliotecas que participaban en el servicio.

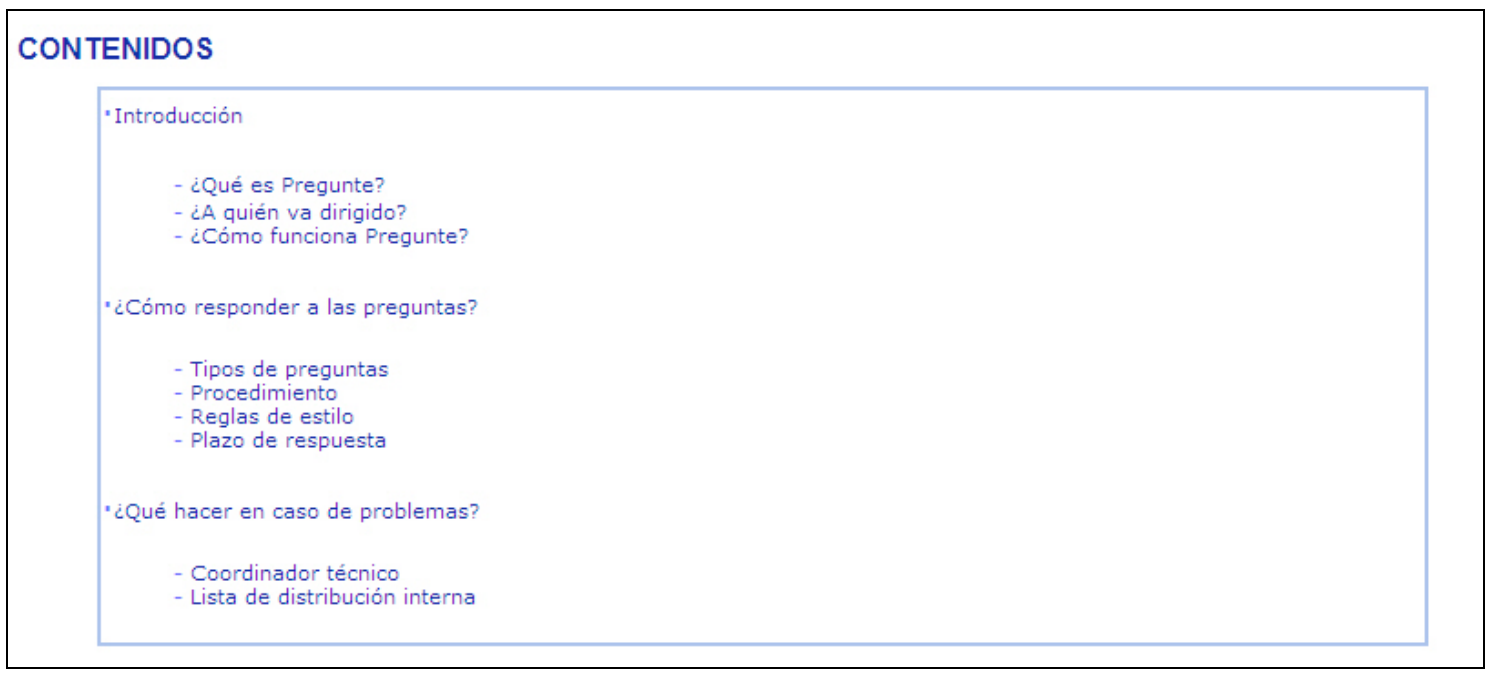

Fig. 3.21. Manual de instrucciones y procedimientos 
En la parte inicial del documento (manual de procedimiento) se definía el servicio, se ofrecían recomendaciones acerca de cómo responder a las preguntas y de cómo resolver los problemas que pudieran surgir.

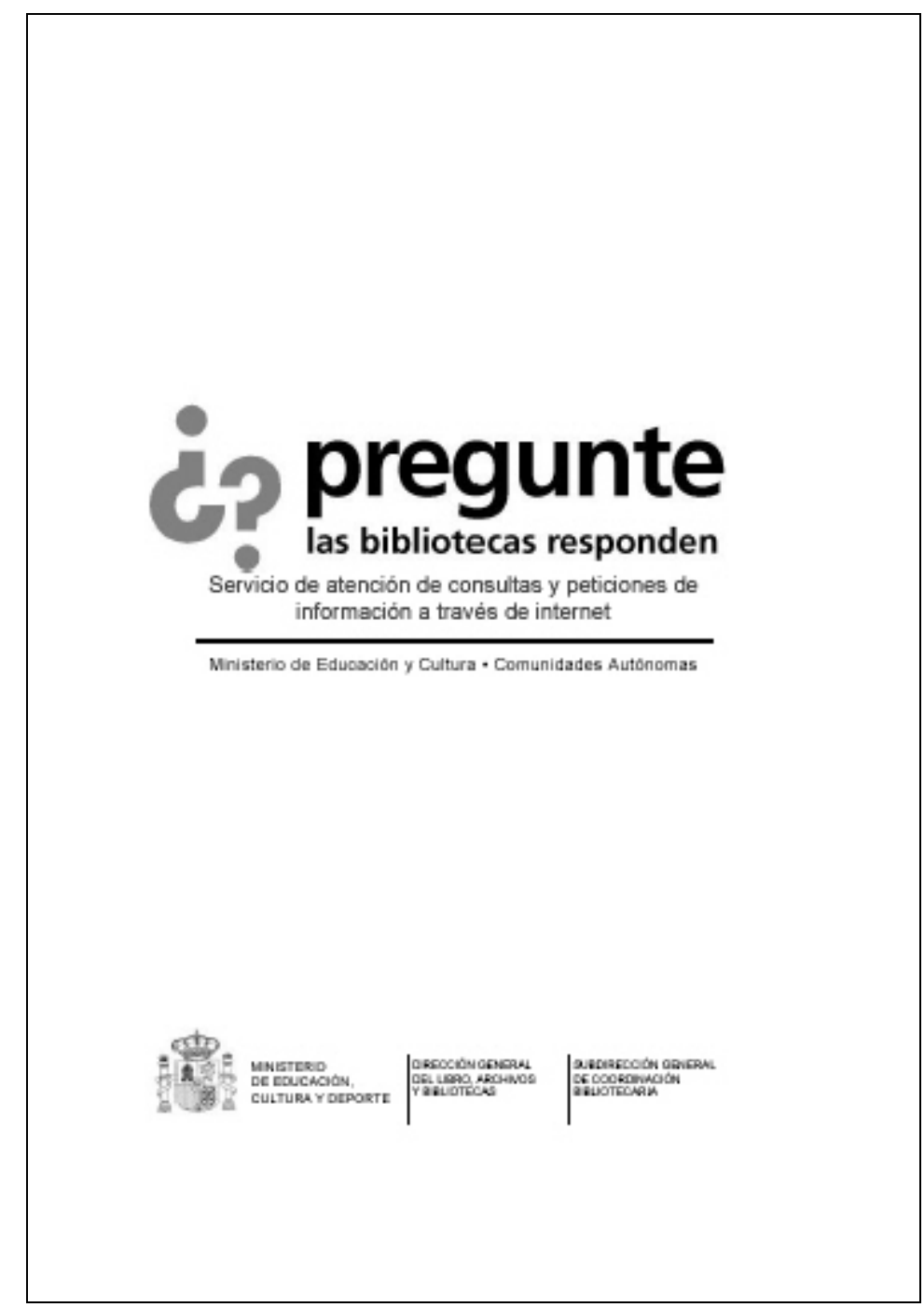

Fig. 3.22. Manual de procedimiento

Hay que reconocer el evidente esfuerzo realizado para la redacción de este manual de procedimiento, sobre todo en lo referente a su normalización y definición. No obstante, transcurridos varios años desde la puesta en funcionamiento del servicio, era necesario volver a redactar el manual de procedimiento, replanteando la misión del servicio, reorientando a las bibliotecas sobre cómo contestar e incluyendo todas las novedades que surgieron en el servidor y en las páginas de acceso a «Pregunte». En el periodo de evaluación se estaba ofreciendo información desfasada, sobre todo la referente a las direcciones web y a los datos de la coordinación técnica.

La segunda parte del manual se destinaba a explicar cómo trabajar con el servidor (Manual técnico). En primer lugar, se explicaban las páginas públicas, es decir, las que utilizan los usuarios para realizar preguntas, registrarse, buscar en la base de datos de preguntas, etc. A continuación, se 
detallaban las páginas y opciones a las que sólo tenían acceso las bibliotecas participantes, explicando todas las posibilidades que éstas les ofrecían y la información que podían obtener en ellas: turnos, recepción de preguntas y gestión de respuestas, ayuda en línea, información sobre las bibliotecas participantes, buscador interno y realización de estadísticas. El manual técnico finalizaba con algunas observaciones relativas a la configuración de pantalla, tipo de navegador y otras cuestiones de tipo tecnológico. También se daban consejos para enlazar el servicio desde los servidores web de los participantes en el proyecto.

Existía otro documento titulado Manual técnico + Manual de coordinación, que fue producido por el Servicio de Informática de la Universidad de Murcia en el año 2000, con la intención de aportar "información útil para la coordinación del sistema y para posibles mantenimientos técnicos posteriores". Este manual estaba orientado como una guía de uso del sistema informático empleado, en la que se describían todos los componentes del mismo y se explicaba cómo proceder para realizar las distintas operaciones posibles. El Manual técnico + Manual de coordinación no se difundía entre las bibliotecas, ya que sólo era de interés para la coordinación técnica, es decir, para quien operaba directamente con el servidor donde estaba almacenada toda la información de «Pregunte: las bibliotecas responden».

El tercero de los materiales de trabajo es el Cuadro de materias, que fue modificado a los dos años de entrar el servicio en funcionamiento. La clasificación que se utilizó para la evaluación se emplea desde julio de 2002 y se creó para reorganizar la sistematización de las preguntas, ya que existía mucho desequilibrio entre unas materias y otras. Se establecieron dieciséis grandes grupos de materias, informado además de los encabezamientos de materias y notaciones de la Clasificación Decimal Universal que están contenidas en cada término admitido.

\section{CUADRO DE MATERIAS EMPLEADAS EN EL SERVICIO "PREGUNTE, LAS BIBLIOTECAS RESPONDEN" (desde julio 2002)}

TÉRMINO ADMITIDO CORRESPONDENCIA ALFABÉTICA

NOTACIÓN CDU

\begin{tabular}{|c|c|c|}
\hline $\begin{array}{l}\text { Administración, } \\
\text { Legislación } \\
\text { Política }\end{array}$ & 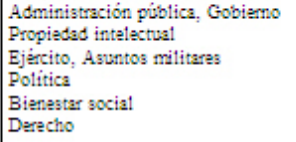 & 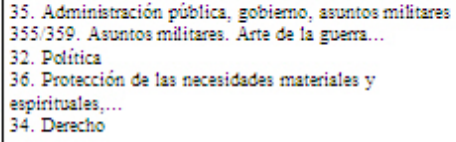 \\
\hline
\end{tabular}

Fig. 3.23. Cuadro de clasificación 
Cualquier usuario podía hacer llegar sus sugerencias para la mejora del servicio. Para ello se había habilitado un formulario específico, que permitía redactar de forma libre la sugerencia y enviarla a la coordinación técnica. La sugerencia se recibía en forma de correo electrónico, con el tema "Sugerencia al sistema". El formulario de sugerencias era el siguiente:

\section{las bibliotecas responden sugerencias}

Escriba aquí su sugerencia

Estos datos se enviarán por correo electrónico a las personas encergadas de la coordinación del sistema.

Dirección de correo electrónico

(opcional)

Nombre del remitente

(opcional)

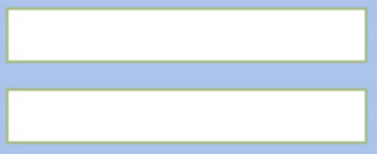

ENVIAR $\Longrightarrow$ BORRAR $\Longrightarrow$

Fig. 3.24. Página pública de sugerencias

Si el usuario no estaba de acuerdo con la respuesta dada o necesitaba más datos también podía manifestarlo a la coordinación del servicio. Para ello, al final de los mensajes de respuesta a una consulta se incluía un texto estándar, en el que se informaba al usuario de cómo debía proceder para solicitar una ampliación de la consulta o para expresar sugerencias.

Este método generaba que un usuario recibiera contestaciones diferentes para preguntas similares, ya que cada vez que pedía una ampliación o concretar una pregunta debía hacerlo como si se tratase de una nueva cuestión. Si las bibliotecas no consultaban el buscador interno no podían saber el proceso que esa pregunta estaba siguiendo. 


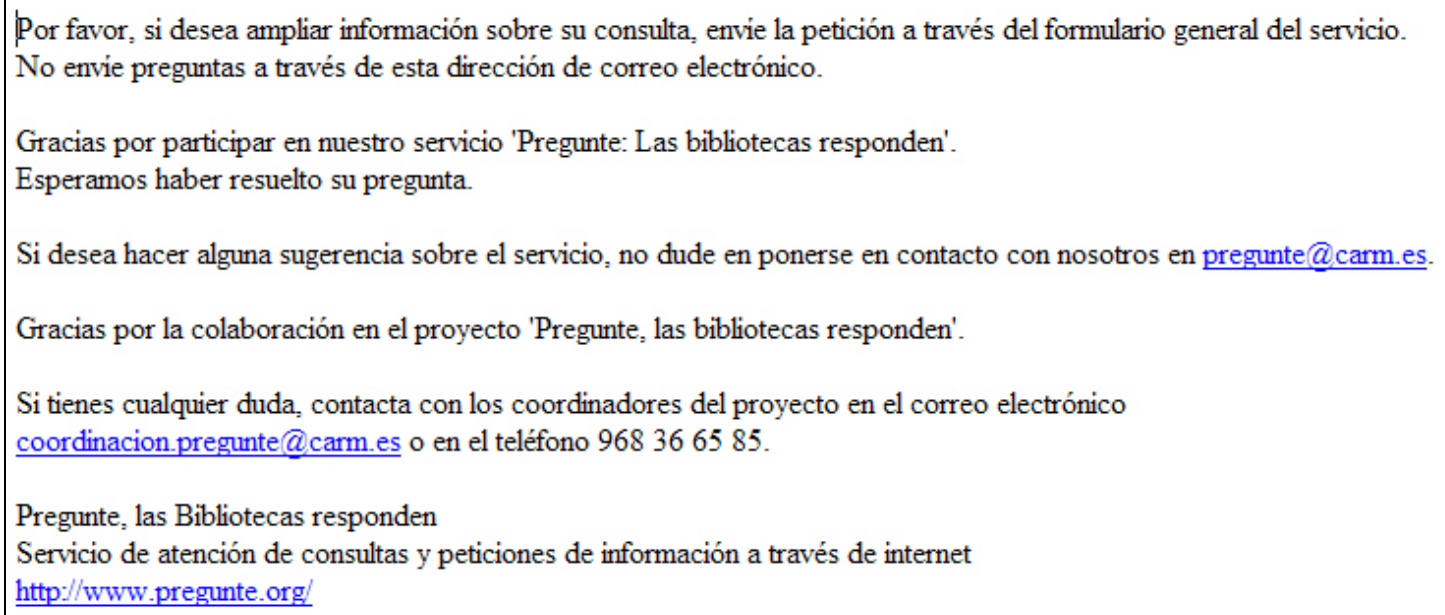

Fig. 3.25. Cierre de los correos electrónicos de respuesta

El sistema permitía que los usuarios realizaran un seguimiento de sus consultas. Para ello debían registrarse y así poder acceder a la información sobre todas las preguntas que hubieran realizado al servicio. Para registrarse era necesario completar un formulario con datos como nombre, correo electrónico, edad y provincia de residencia.

\section{las bibliotecas responden registro de usuarios}

Al registrarse como usuario y obtener una clave, podra consultar preguntas/respuestas que haya enviado a nuestro servicio.
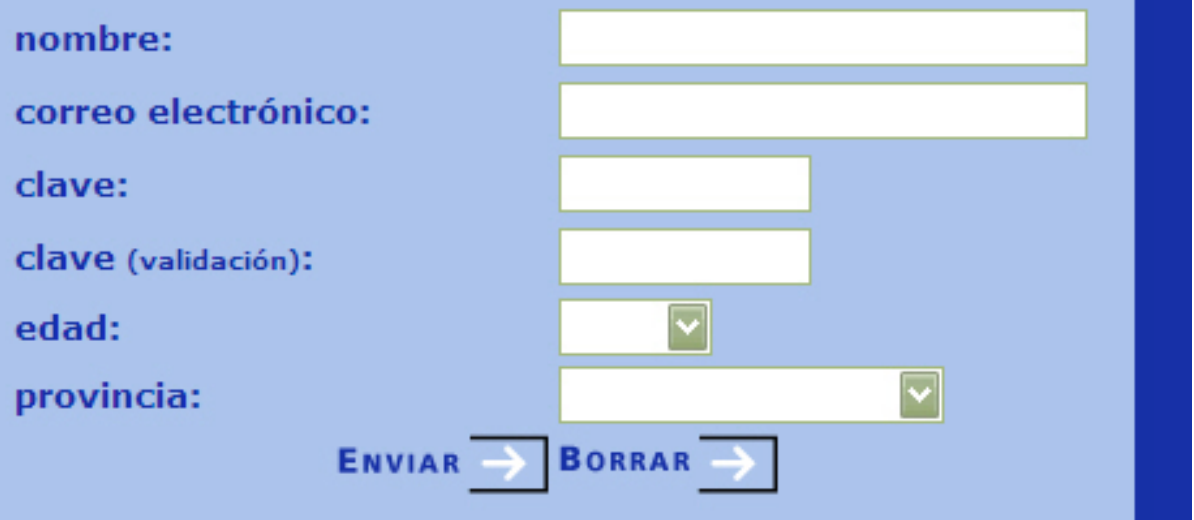

Fig. 3.26. Sistema de registro de usuarios

El usuario elegía la clave con la que sería registrado en el sistema y que, junto a su dirección de correo electrónico, le permitiría conocer el estado de sus preguntas, consultar las ya resueltas y presentar alguna queja 0 reclamación sobre las respuestas dadas. 
A la sección de servicios personalizados se accedía desde la página principal de «Pregunte: las bibliotecas responden», aunque también había enlaces desde cualquiera de las páginas secundarias.

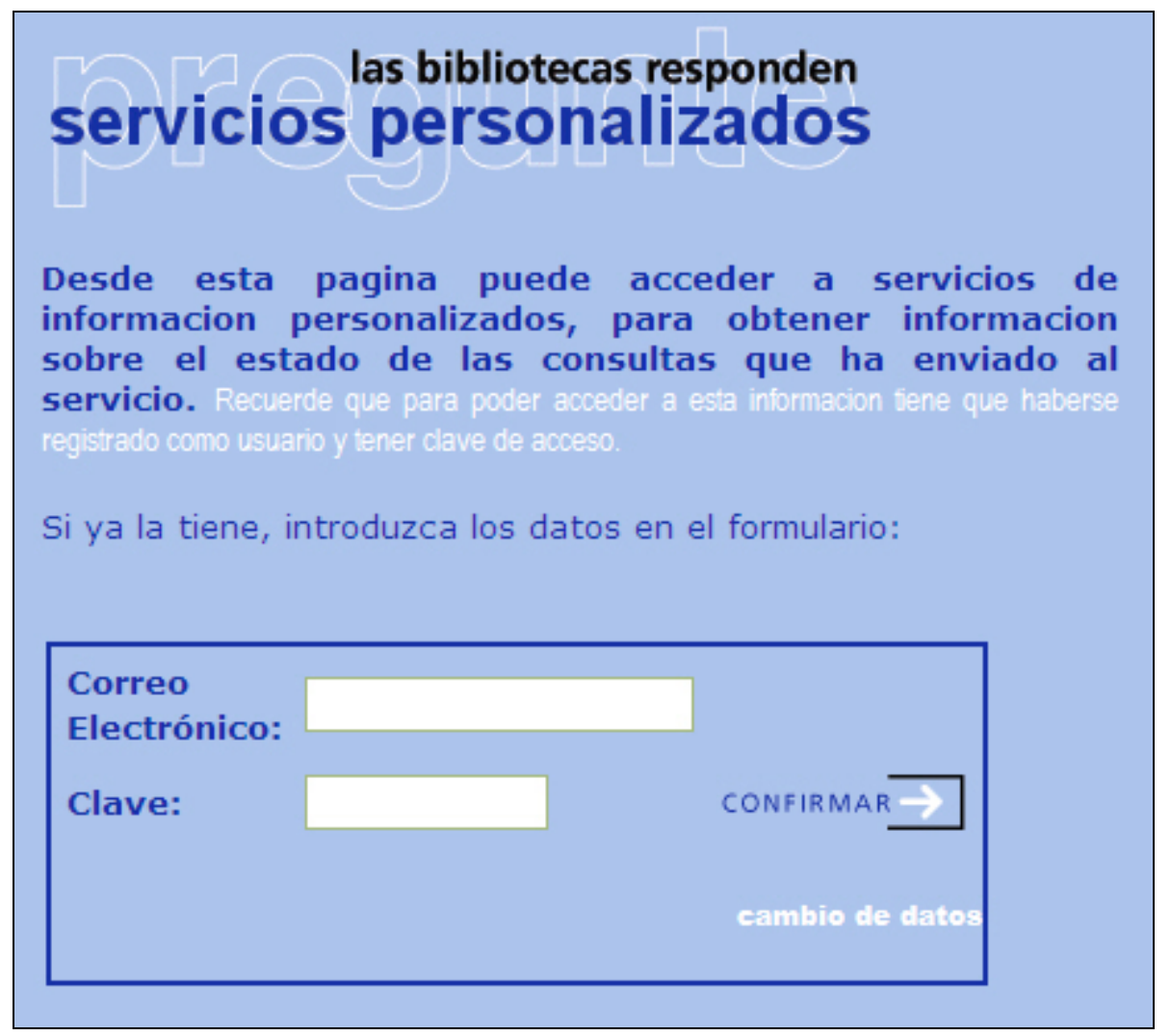

Fig. 3.27. Sistema de acceso para usuarios registrados

Una vez identificados se mostraban las preguntas ya resueltas, las pendientes y el formulario que debería emplear para realizar las quejas relativas a cualquiera de las preguntas planteadas.

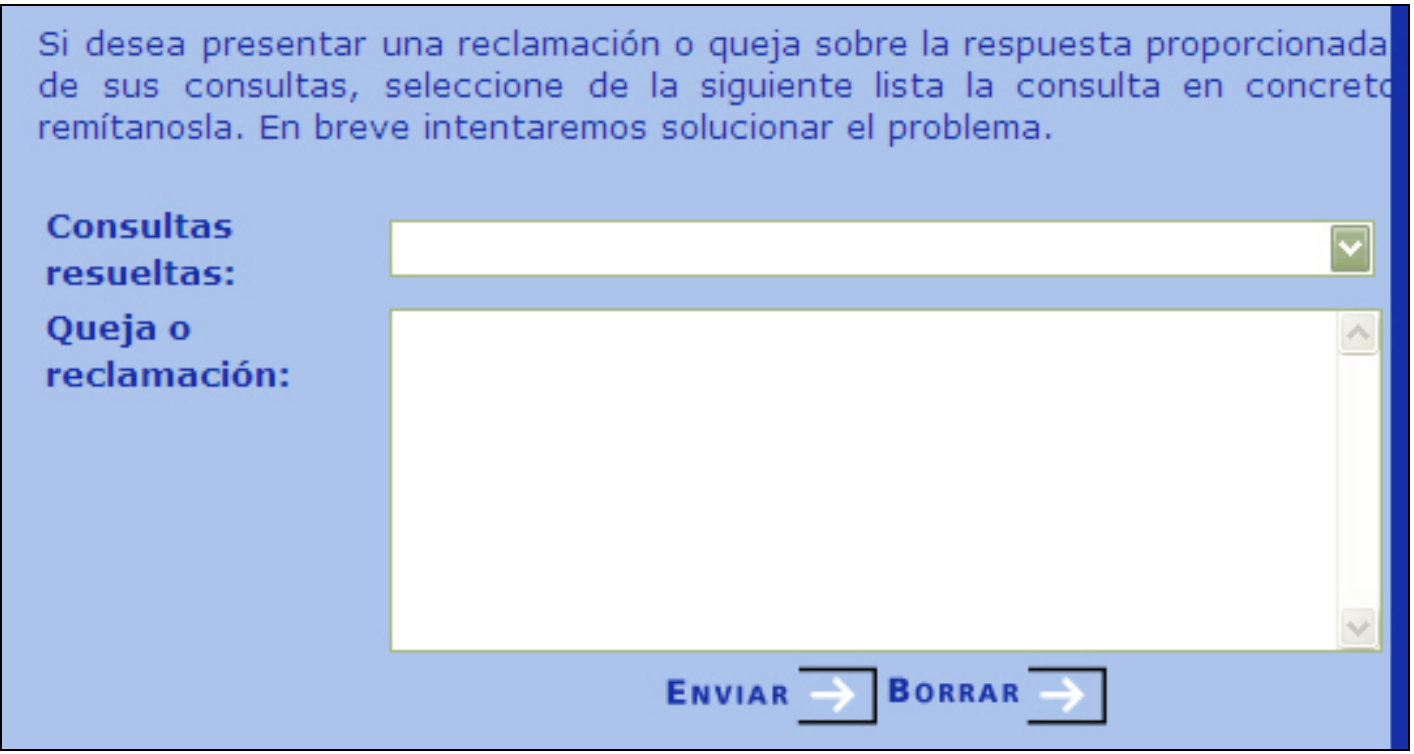

Fig. 3.28. Sistema de quejas para usuarios registrados 
Las reclamaciones enviadas por este medio también eran recibidas por la coordinación técnica, a través de un mensaje de correo electrónico, con el tema "Reclamación o queja al sistema", con el NIC de la consulta, el texto de la reclamación y los datos de la pregunta, la respuesta y la biblioteca que la había contestado.

A pesar de que este método existía, por lo general, los usuarios que deseaban plantear alguna cuestión al servicio solían hacerlo a través de la dirección de correo electrónico de la coordinación técnica, que aparecía en todas las páginas, con la leyenda "Contacte con nosotros". También empleaban el formulario de "Sugerencias", ya que era mucho más visible.

En relación a las estadísticas, las bibliotecas podían conocer el desarrollo de las consultas atendidas de forma sencilla, aunque no excesivamente completa. El sistema generaba automáticamente un sucinto resumen estadístico relativo a todo el servicio y a una biblioteca en concreto. En este primer balance se informaba de las preguntas gestionadas por una biblioteca, de las que contestó fuera de plazo y los días que ha estado en el turno general hasta la fecha de consulta. Estos últimos datos se presentaban de forma distinta, puesto que las bibliotecas sólo podían conocer por esta vía sus propios resultados.

El primer resumen también ofrecía una serie de datos generales, sobre el total de usuarios, de preguntas, plazos medios de respuesta, media de consultas por día, etc.

\section{Estadísticas del sistema}

Breve resumen estadístico del sistema Pregunte.

Información de la Biblioteca Regional de Murcia/Biblioteca Pública del Estado en Murcia

No de preguntas gestionadas: 896

No de respuestas fuera de plazo: 49

No de días de turno: 70

Datos generales

No total de preguntas recibidas: 25622

Preguntas no apropiadas: 978 ( $3.81 \%$ del total)

Respuestas negativas: 1120 (4.37\% del total)

Respuestas perdidas: 1061 ( $4.14 \%$ del total)

Total de usuarios: 16684

Máximo de consultas en un día: 97

Media de consultas por día: 15.50

Tiempo medio de respuesta: 1.65 días

$\rightarrow$ ESTAdístICAS PROPIAS

Fig. 3.29. Información estadística en la intranet 
Si se deseaba un mayor nivel de detalle se debía elegir la opción "Estadísticas propias", desde la que se volvían a resumir los datos generales de la biblioteca que realizaba la consulta: número de preguntas gestionadas, consultas pendientes y preguntas atendidas en otras lenguas.

El interés de esta sección de las estadísticas es que permitía obtener cifras e informaciones de las consultas atendidas por una biblioteca en el plazo que se le indicara al sistema. Los resultados incluían el número de respuestas positivas, negativas, inapropiadas e incompletas.

Asimismo, el sistema posibilitaba conseguir otra información relevante, como los temas más demandados, los grupos de edad a los que pertenecen los usuarios atendidos o las localidades desde las que se hicieron las preguntas. Si se deseaba también se puede conseguir información sobre el tiempo que se estaba tardando en ofrecer respuesta a las consultas.

\section{Estadísticas del sistema}

En esta sección podrá conocer distintas estadísticas acerca de su uso del sistema.

\section{SEGUIMIENTO}

$\rightarrow$ Consultas realizadas al sistema: $\mathbf{8 9 6}$ (de un total de 25622)

$\rightarrow$ Consultas pendientes en el sistema: $\mathbf{0}$ (de un total de 0)

POR IDIOMAS:

Total de consultas en idiomas: 1 (Catalán: 1 -- Euskera: 0 -- Gallego:0)

Total de consultas generales: 895

\section{ESTADÍSTICAS ACERCA DE MIS CONSULTAS}

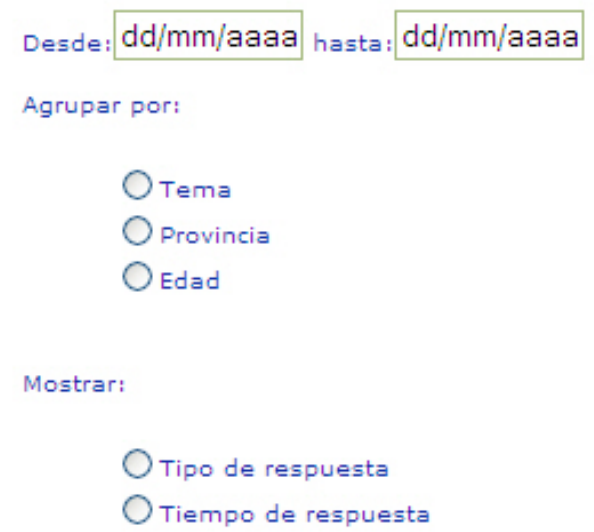

Fig. 3.30. Consulta a las estadísticas de una biblioteca en la intranet

Existía la posibilidad de interrogar al servidor para conseguir estadísticas más detalladas y para conocer la evolución del servicio, pero estas opciones se tienen que manejar desde el propio servidor, con órdenes diferentes. 
«Pregunte» es un excelente recurso de información, ya que todas las consultas satisfechas se ponen a disposición de profesionales y usuarios. Si se accedía a la base de datos de preguntas-respuestas desde las páginas de acceso restringido a las bibliotecas participantes, las opciones de consulta eran:

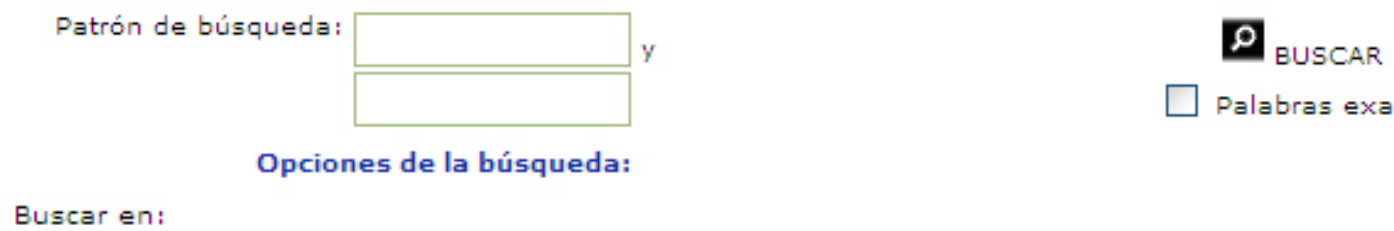

$\rho$ BusCAR

Opciones de la búsqueda:

Buscar en:

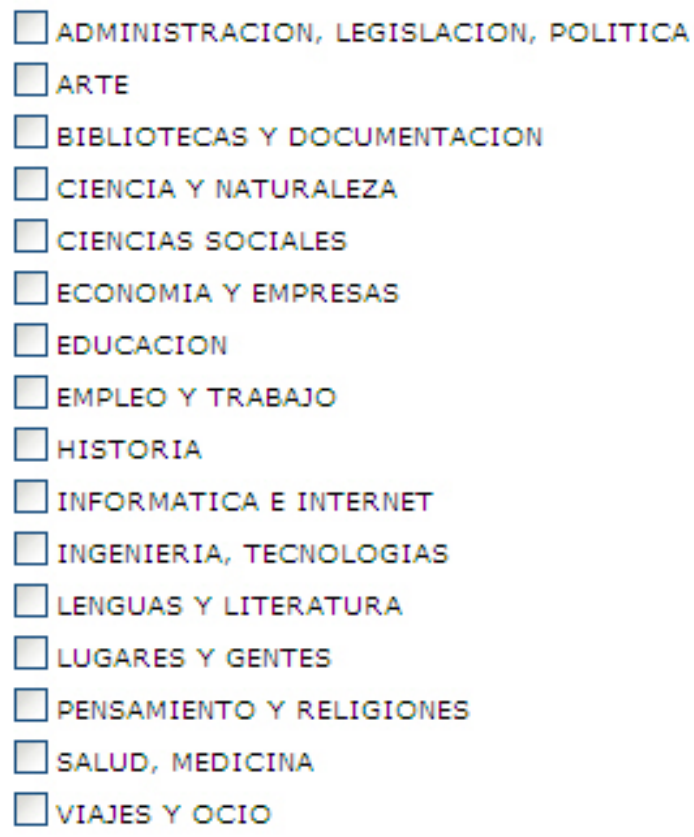

Fig. 3.31. Sistema de consultas desde la intranet 
Como se aprecia, la búsqueda se podía limitar de forma temática o bien cronológica. Los resultados se podían ordenar por tema, fecha en la que se hizo una pregunta o fecha en la que la misma fue resuelta. Lo cierto es que el sistema no presentaba demasiadas posibilidades de consulta. Por el contrario, en él se podían encontrar fallos de recuperación y limitaciones en la consulta. Por ejemplo, era obligatorio incluir algún carácter en las casillas de "Palabras a buscar", por lo que, si se quería obtener el número de preguntas efectuadas sobre un tema en un periodo concreto, había que escribir un carácter que pueda estar en una pregunta o respuesta. En las consultas realizadas en la evaluación se tecleó siempre un espacio. Si la consulta se realiza desde el buscador de las páginas públicas las limitaciones son mucho mayores, ya que sólo se ofrece la opción de buscar por palabras y delimitar por materias. La consulta de la misma palabra y/o materia en la web pública y en la restringida podía dar resultados distintos, a pesar de trabajar sobre la misma base de datos.

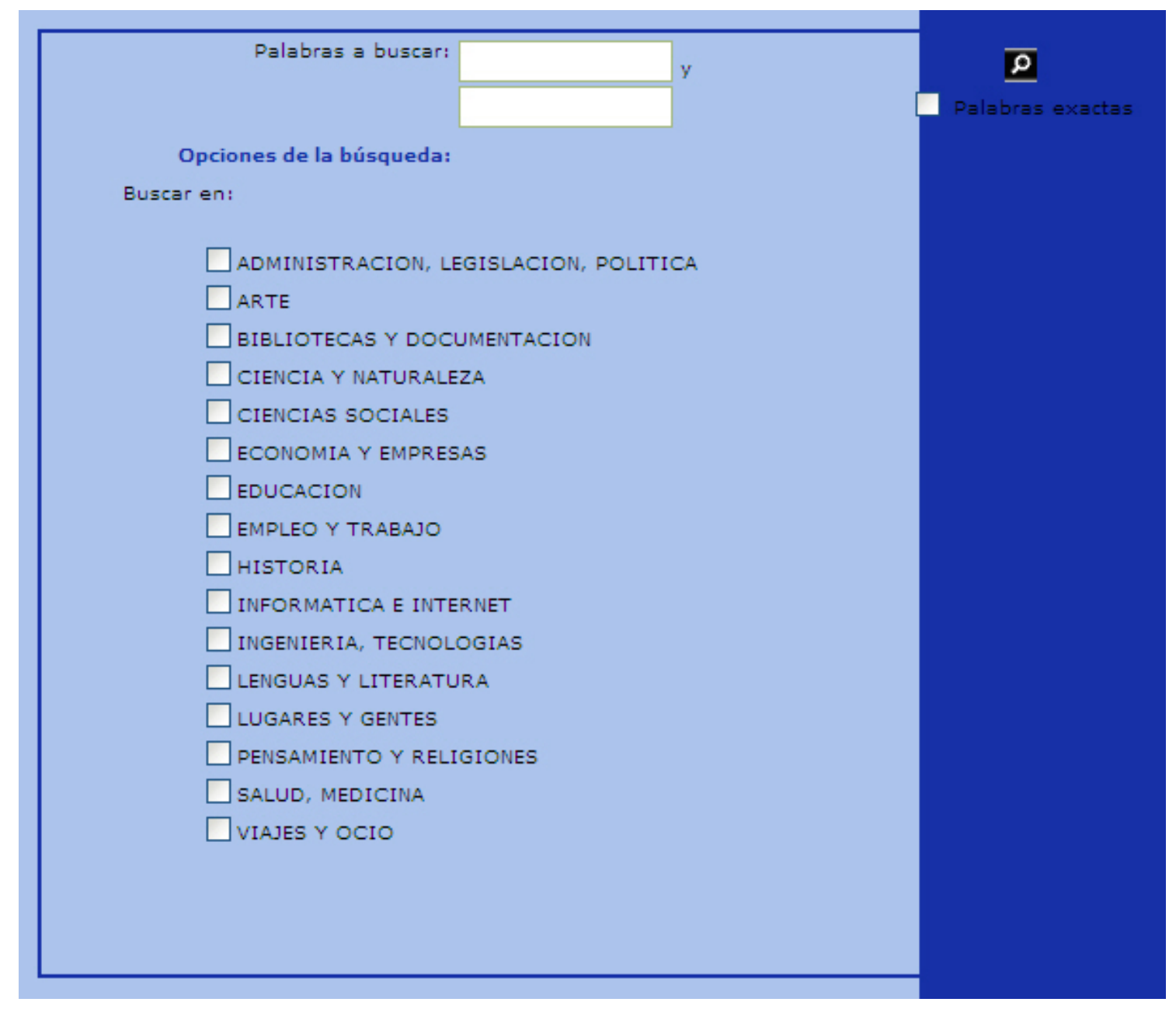

Fig. 3.32. Sistema de consultas desde Internet

En la web pública, los resultados de la consulta se ofrecían en una relación ordenada por materias. Bastaba con elegir una pregunta para ver su 
contenido completo. El funcionamiento es idéntico en la web de acceso limitado a las bibliotecas participantes, aunque no los resultados. En la consulta que se hacía de forma pública la fecha aparecía en los primeros resultados de la búsqueda, mientras que las páginas restringidas se especificaba en cada registro las fechas de consulta y respuesta.

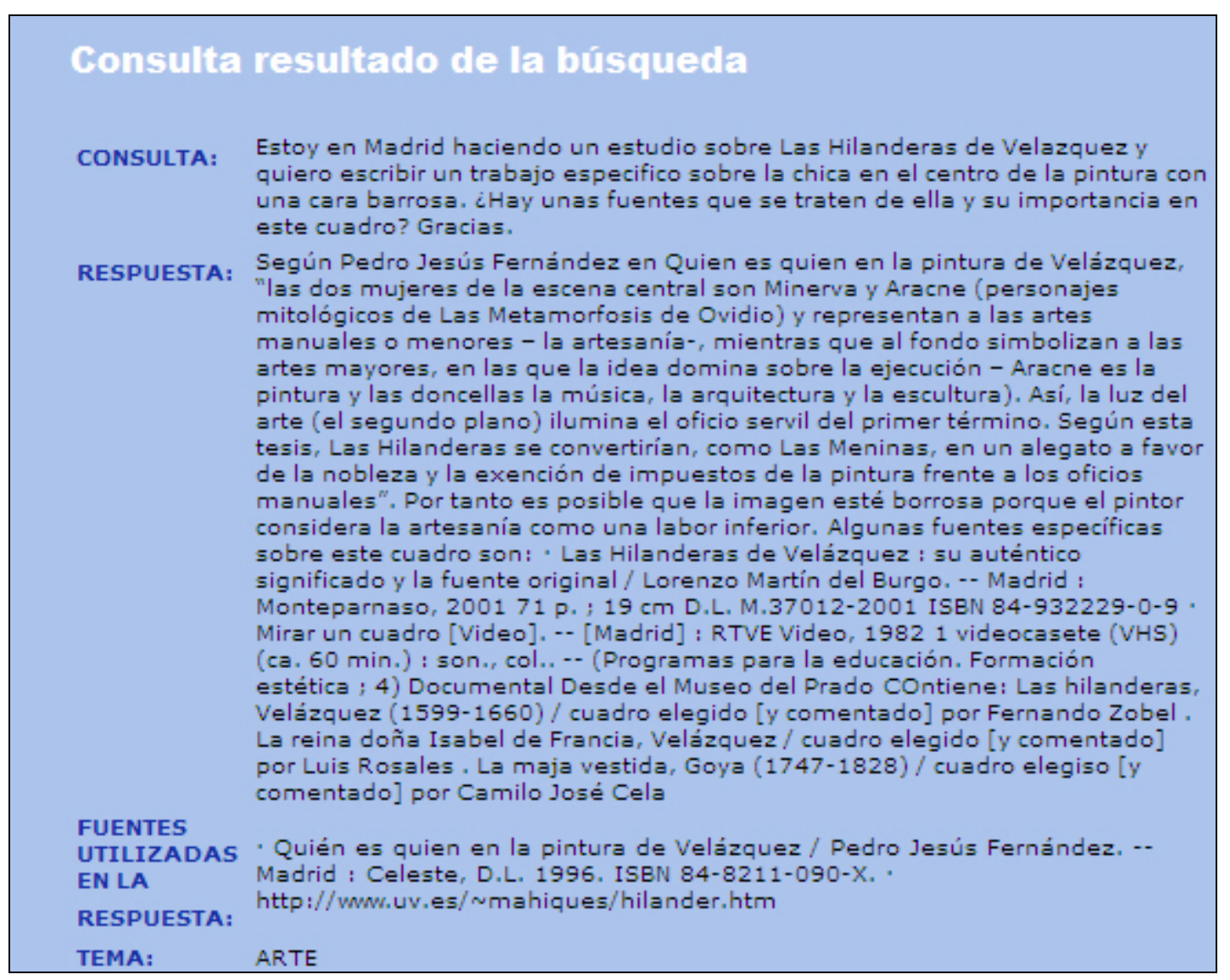

Fig. 3.33. Modelo de preguntas/respuestas en el archivo público

Desde el sitio web del servicio, se pueden realizar consultas de forma abierta, empleando palabras del lenguaje natural, que serán localizadas como texto libre, es decir, en cualquiera de los campos que componen cada registro de una consulta. El formulario realiza de forma automática la búsqueda booleana (operador de intersección), combinando los términos que el usuario introduzca en las dos casillas del formulario diseñadas a tal efecto. De igual forma, se puede realizar una búsqueda exacta, habilitando la opción "Palabras exactas" del formulario de consulta.

Al contrario que en la intranet, el archivo público de las consultas apenas ofrecía opciones de recuperación, algo que fue solucionado en el nuevo sistema puesto en funcionamiento en octubre de 2007, donde el usuario cuenta con mayores posibilidades de recuperación. En el nuevo sistema de recuperación se han establecido dos formularios de búsqueda (sencillo y avanzado), que ofrecen las siguientes posibilidades de búsqueda, que pueden ser combinadas entre sí: 
Búsqueda sencilla:

- texto libre, una casilla, desde donde se elige el campo en el que se quiere localizar la/s palabra/s: pregunta, respuesta o ambos.

- tema, seleccionando uno o varios de los grandes grupos bajo los que se clasifican las preguntas: administración, legislación, política; arte; bibliotecas y documentación; ciencias sociales; ciencia y naturaleza; economía y empresas; educación; empleo y trabajo; historia; informática e internet; ingeniería, tecnologías; lenguas y literatura; lugares y gentes; pensamiento y religiones; salud, medicina; viajes y ocio.

- fecha, indicando periodos en los cuales enmarcar cronológicamente la consulta.

Búsqueda avanzada:

- texto libre, dos casillas que se combinan entre sí mediante los operadores de unión o intersección, seleccionando el campo en el que se realizará la búsqueda: pregunta, respuesta o ambos; además, se permite establecer límites, mediante operadores de exactitud y negación: contiene, no contiene y frase exacta.

- tema, a partir de los epígrafes de la clasificación empleada en el servicio: administración, legislación, política; arte; bibliotecas y documentación; ciencias sociales; ciencia y naturaleza; economía y empresas; educación; empleo y trabajo; historia; informática e internet; ingeniería, tecnologías; lenguas y literatura; lugares y gentes; pensamiento y religiones; salud, medicina; viajes y ocio.

- fechas, delimitando el marco temporal de la consulta. 


\section{Evaluación del servicio de referencia digital «Pregunte: las bibliotecas responden»}

Poner en práctica la teoría es la intención principal de este apartado. La convergencia de intereses entre el doctorando y los responsables del servicio posibilitó que la investigación se hiciese con una doble perspectiva, ya que no se quería enfocar simplemente con un trabajo universitario conducente a la obtención del grado de doctor, sino que se quiso también realizar un trabajo de consultoría que permitiera aplicar en la medida de lo posible las mejoras sugeridas a partir de la evaluación que se realizara del servicio público de referencia en línea español.

El análisis del servicio y la evaluación de su funcionamiento, así como de la consecución de sus objetivos constituyen el grueso de esta investigación. Por este motivo, se han realizado distintos exámenes sectoriales, con la intención de obtener datos de los principales agentes participantes (profesionales y usuarios). Por otra parte, se han realizado análisis desde otras perspectivas, como son las incidencias que se reciben en la coordinación del servicio, el análisis de los tipos de respuestas dadas, la homogeneidad de las contestaciones ofrecidas a una serie de preguntas o la presencia de «Pregunte» en la bibliografía profesional y en Internet.

Los siguientes subapartados describen pormenorizadamente la aplicación práctica realizada, comenzando por la explicación de las metodologías empleadas, en muchos casos novedosas y establecidas a partir de esta tesis. Además, se explican los diferentes estudios parciales realizados: estudio de profesionales, estudio de usuarios, estudio de incidencias, estudio de preguntas y respuestas (estadísticas generales, análisis por clasificación, análisis de respuestas, homogeneidad de las respuestas), estudio de visibilidad y estudio bibliográfico. Al final de este bloque, se presentan agrupadas las diferentes conclusiones obtenidas, que suponen un diagnóstico objetivo de la situación del servicio de referencia digital en el momento en el que se evaluó.

\subsection{Estudios y metodología}

Como se explicó en los párrafos anteriores, se han realizado diversos estudios específicos para cada uno de los aspectos que interesaba evaluar. La diversidad de informaciones que se necesitaba recoger han determinado las diferentes metodologías empleadas. En algunos casos, la observación directa ha sido la única fuente de información, mientras que en otras ocasiones se ha preferido emplear encuestas, como el método más fiable de recogida de datos. En este apartado, se ofrecen los resultados y comentarios de los seis estudios parciales efectuados. La suma de resultados parciales aportaron diferentes indicadores que fueron empleados de forma conjunta para establecer las conclusiones y ofrecer propuestas de mejora. 


\section{1/ Estudio de profesionales}

Encuesta enviada al personal que trabajaba o había trabajado en «Pregunte», coordinando el servicio en sus respectivas bibliotecas, recibiendo las preguntas y ofreciendo sus respuestas, así como personal de apoyo en las distintas fases del proceso de recepción de las preguntas, resolución de las mismas y envío de las respuestas. Las encuestas se enviaron por correo electrónico y las respuestas se recogieron por el mismo procedimiento.

\section{2/ Estudio de usuarios}

Encuesta enviada a los usuarios registrados en el servicio «Pregunte: las bibliotecas responden». El sistema informático permitía que el usuario introdujera sus datos para registrarse y así el interesado podía conocer las informaciones relativas a las consultas que hubiera efectuado. La encuesta se envió a usuarios españoles y no españoles. Se hizo una depuración sobre los correos electrónicos, ya en muchos casos no eran válidos (por ejemplo, ausencia de arrobas) o en otros casos el usuario se había registrado varias veces.

\section{3/ Estudio de incidencias}

Análisis de las incidencias remitidas al coordinador del servicio por correo electrónico a lo largo de todo el año 2003, tanto por los profesionales que trabajaban en «Pregunte» como por los usuarios. Las incidencias se clasificaron para conocer cuáles eran los principales problemas que generaba un servicio como éste.

\section{4/ Estudios de preguntas y respuestas}

Envío de preguntas a través del formulario principal de «Pregunte». Se remitieron diversas cuestiones, generalmente repetidas a lo largo de varios días para conocer el tiempo de respuesta, la calidad de la información recibida, la homogeneidad en las respuestas, el tipo de fuentes de información empleadas y la uniformidad en la redacción de las respuestas. Se analizaron también las respuestas dadas a lo largo de un turno completo, para ver el tipo de contestación y las fuentes empleadas.

\section{5/ Estudio de visibilidad}

Consulta a través de los sistemas avanzados de los principales buscadores de Internet de los sitios web que ofrecen algún enlace a cualquiera de los servidores que remiten a «Pregunte: las bibliotecas responden». Los mejores motores permiten conocer qué webs enlazan con una URL concreta. Se integraron y depuraron los resultados para conocer el número de enlaces y las instituciones que dan acceso a «Pregunte» desde sus páginas. 


\section{6/ Estudio bibliográfico}

Consulta a bases de datos especializadas en bibliotecas, españolas e internacionales, para conocer cuántos documentos han estudiado o difundido el servicio de referencia en línea «Pregunte». El número de documentos y la tipología de los mismos permitió detectar el grado de conocimiento que se tenía de «Pregunte».

En los siguientes apartados se detallarán cada uno de los estudios, exponiendo la metodología empleada y comentando los principales resultados obtenidos.

\subsection{Estudio de profesionales}

Para conocer el perfil de los profesionales que trabajan o han trabajado en «Pregunte: las bibliotecas responden» se optó por confeccionar una encuesta en la que a través de 50 preguntas se recogieron datos sobre las personas que están al cargo del servicio (categoría laboral, formación, etc.), dedicación al servicio (parcial, total), formación (biblioteconomía, fuentes de información, etc.), procedimientos (metodología, recursos, etc.), servicio (organización, orientación, sistema, documentación, etc.), calidad (servicio, respuestas), reformas (chat, documentos adjuntos, etc.), opinión (problemas, difusión, etc.). Según los datos facilitados por los coordinadores en otro cuestionario, en el momento de realizar la investigación había 148 profesionales trabajando en el servicio, por lo que la muestra empleada fue muy significativa, al haberse obtenido 114 cuestionarios válidos, aunque la encuesta también fue contestada por algunas personas que ya no están trabajando en «Pregunte».

Los datos concretos de la encuesta y sus resultados se exponen a continuación, indicando pregunta a pregunta los resultados porcentuales y algunos comentarios en tiempo presente, que se ofrecen en cursiva para contextualizar los datos más significativos, los cuales no se valoran en este apartado, ya que el análisis de todos los resultados se hace en el apartado correspondiente a las conclusiones, que se encuentra al final de este bloque de la tesis doctoral.

\begin{tabular}{|ll|}
\hline Ámbito: & $\begin{array}{l}\text { Referencistas de «Pregunte» y personas que habían } \\
\text { estado en el servicio }\end{array}$ \\
Categorías: & Todas las categorías profesionales \\
Técnica: & Envío y recepción de formularios por correo electrónico \\
Muestra: & $\begin{array}{l}114 \text { personas } \\
\text { Fechas: }\end{array}$ \\
$\begin{array}{l}\text { Trabajo de campo (envío y recepción de los formularios) } \\
\text { realizado entre febrero y marzo de 2004 }\end{array}$ \\
Observaciones: $\begin{array}{l}\text { Se enviaron los cuestionarios a las personas que actúan } \\
\text { como coordinadores de «Pregunte» en cada biblioteca, } \\
\text { quienes se encargaron de distribuirlos entre el personal } \\
\text { de cada centro. }\end{array}$ \\
\hline
\end{tabular}




\section{Preguntas y resultados:}

1 ¿Qué categoría profesional tiene?

La mayoría de las personas que participan en «Pregunte» pertenecen al Grupo B de la administración, independientemente de su denominación. Existe un pequeño porcentaje de profesionales de los grupos inferiores al C que también trabajan en el servicio.

\section{Categoría laboral (\%)}

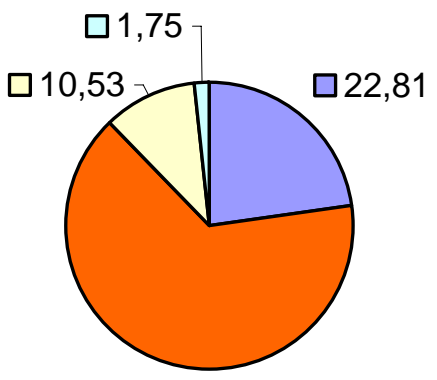

$\square$ Grupo A

$\square$ Grupo B

$\square$ Grupo C

$\square$ Otros

64,91

Figura 3.34. Encuesta a profesionales: categoría laboral

2 ¿Cuál es su responsabilidad en su biblioteca en relación al servicio «Pregunte»?

Por lo general quienes respondieron la encuesta se encargan de la resolución de las preguntas. El siguiente grupo lo constituyen quienes compatibilizan las tareas de coordinación con las labores de respuesta.

\section{Tareas (\%)}

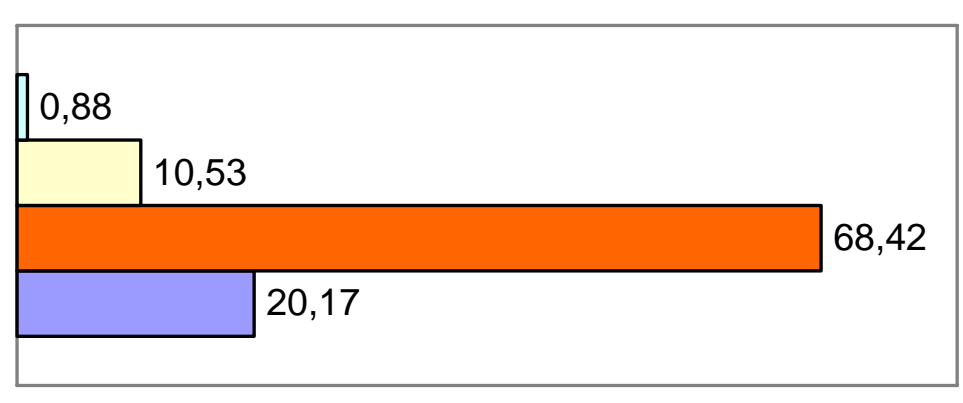

$\square$ Resolución de preguntas y apoyo a la coordinación

$\square$ Apoyo

$\square$ Resolución de preguntas

$\square$ Coordinación y resolución de preguntas

Fig. 3.35. Encuesta a profesionales: tareas desempeñadas

3 ¿Desde qué fecha lleva usted en el servicio «Pregunte»?

El tiempo de permanencia en «Pregunte» es un dato significativo para poder valorar la familiarización de los profesionales con el servicio. Dado que en los últimos meses han sido varias las bibliotecas que se han incorporado al proyecto se ha obtenido un porcentaje muy alto de personas que llevan en el servicio menos de un año. 


\section{Meses en «Pregunte» (\%)}

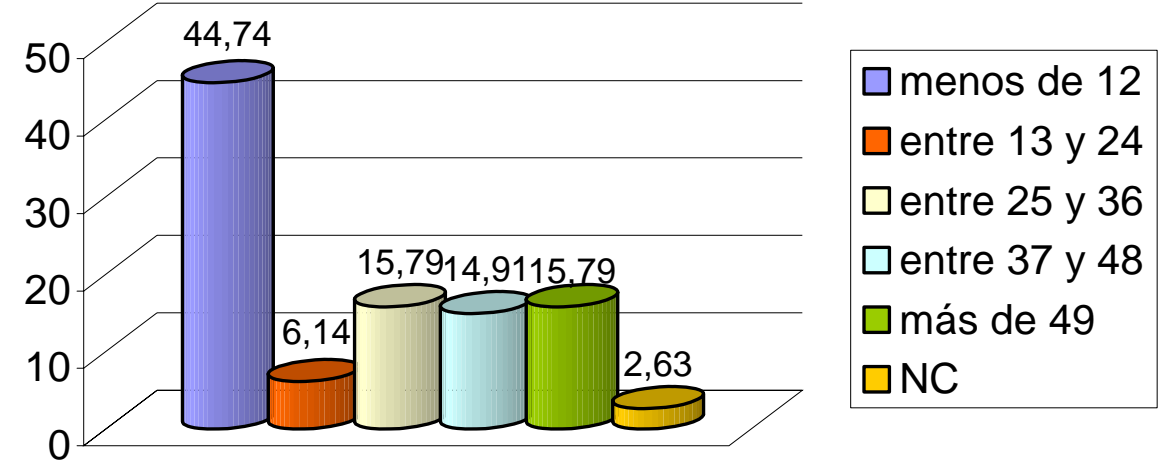

Fig. 3.36. Encuesta a profesionales: tiempo en el servicio

4 ¿Qué porcentaje de la jornada laboral dedica a «Pregunte» cuando su biblioteca tiene el turno de respuestas?

Es muy significativo que los profesionales dedican al servicio -en su mayoría- sólo el tiempo que tardan en ofrecer las respuestas. Una quinta parte, sin embargo, emplea toda la jornada en cuestiones relacionadas con «Pregunte».

\section{Dedicación (\%)}

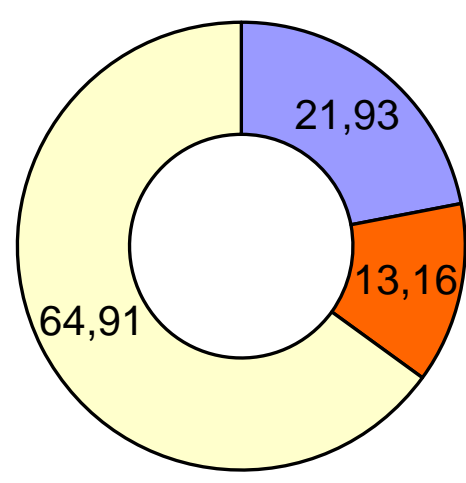

Toda la jornada laboral

Parte de la jornada laboral

$\square$ El tiempo que tarde en responder las preguntas

Fig. 3.37. Encuesta a profesionales: dedicación al servicio

El 13,16\% que dedica al servicio parte de la jornada laboral distribuye su tiempo entre el servicio de referencia y otras tareas de la biblioteca. En este caso un $26 \%$ dedican un $80 \%$ de su tiempo a «Pregunte» y el otro $20 \%$ a cuestiones de su biblioteca. El segundo grupo más numeroso es el $20 \%$ que divide a partes iguales su jornada entre el servicio de referencia y otros servicios. El resto de los datos se encuentran en el siguiente gráfico. 
Dedicación parcial (\%)

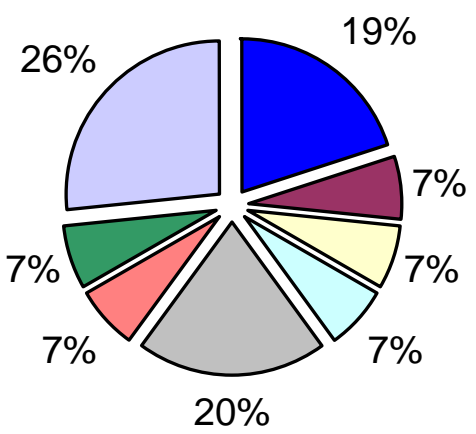

$\square \mathrm{NC}$

$\square 15-20 \%$

$\square 20 \%$

$\square 25-50 \%$

$\square 50 \%$

$\square 70 \%$

$75 \%$

$80 \%$

Fig. 3.38. Encuesta a profesionales: distribución de la jornada laboral

5 ¿Compatibiliza sus tareas profesionales habituales con «Pregunte» cuando su biblioteca tiene el turno de respuestas?

Como es de esperar en un servicio como éste, en el que las bibliotecas participan de forma desinteresada, la amplia mayoría de los profesionales compatibiliza sus tareas habituales con la resolución de las preguntas. Muy pocos son los bibliotecarios que pueden dedicarse en exclusiva a «Pregunte» cuando su biblioteca está en el turno de respuestas.

\section{Compatibilidad de tareas (\%)}

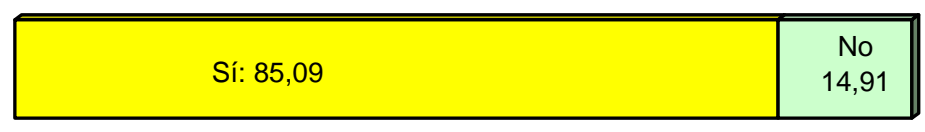

Fig. 3.39. Encuesta a profesionales: compatibilidad de actividades

6 ¿Cuánto tiempo de media tarda en resolver una pregunta que no requiera una investigación extraordinaria?

El tiempo que tardan las profesionales de «Pregunte» en resolver una demanda de información es bajo, ya que por lo general (73,69\%), es menos de una hora. El restante 26,32\% tarda más de una hora. Estos datos son bastante reveladores, ya que en una jornada laboral pueden quedar resueltas la mayoría de las preguntas que una biblioteca recibe en su día de turno. 
Tiempo de resolución (\%)

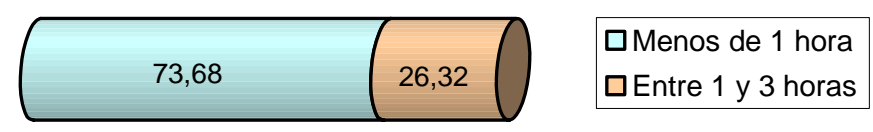

Fig. 3.40. Encuesta a profesionales: tiempo de resolución de preguntas

7 ¿Cómo valoraría su formación en biblioteconomía?

La formación profesional de quienes atienden el servicio de referencia en línea es normal o buena en su mayoría, aunque sólo un 3,51\% la califica como excelente. Son preocupantes los datos de ese diez por ciento que opina que su formación en aspectos bibliotecarios es escasa o suficiente, los dos grados más bajos de las posibilidades de respuesta que se ofrecían.

\section{Formación en biblioteconomía (\%)}

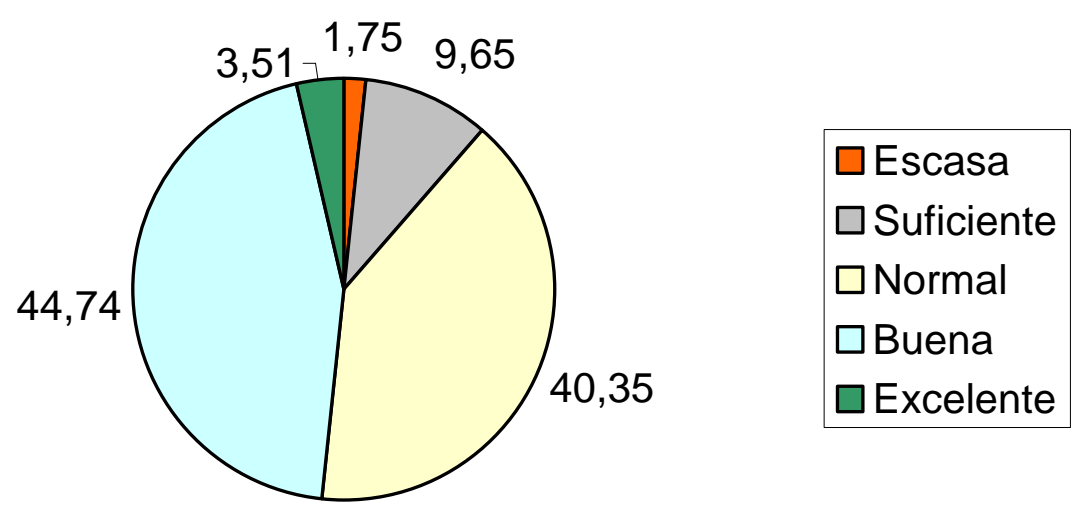

Fig. 3.41. Encuesta a profesionales: formación profesional en biblioteconomía

8 ¿Cómo valoraría sus conocimientos de fuentes de información?

El conocimiento de recursos de información es esencial en el trabajo de referencia. Según los datos de la encuesta, el porcentaje mayor de quienes gestionan «Pregunte» denominan su formación en fuentes de información y en recursos documentales como normal. También es significativo el hecho de que nadie haya calificado como excelentes sus conocimientos en fuentes de referencia. 


\section{Formación en fuentes (\%)}

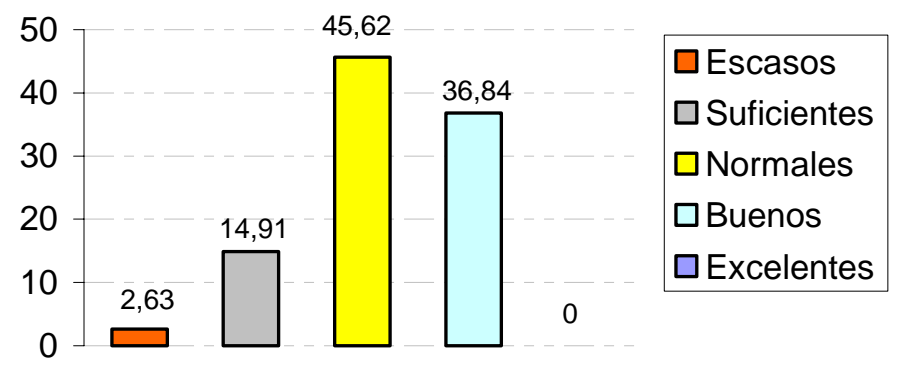

Fig. 3.42. Encuesta a profesionales: formación profesional en fuentes de información

9 ¿Cómo valoraría sus conocimientos de Internet?

Internet es un recurso de información de primer orden y mucho más en los servicios de referencia; por ello, es primordial que se conozca su funcionamiento, sus sistemas de recuperación y el acceso a la información disponible en los servidores conectados a esta red. Sin embargo, como ocurría en la pregunta anterior no son muchos quienes opinan que sus conocimientos son buenos o excelentes.

\section{Conocimientos de Internet (\%)}

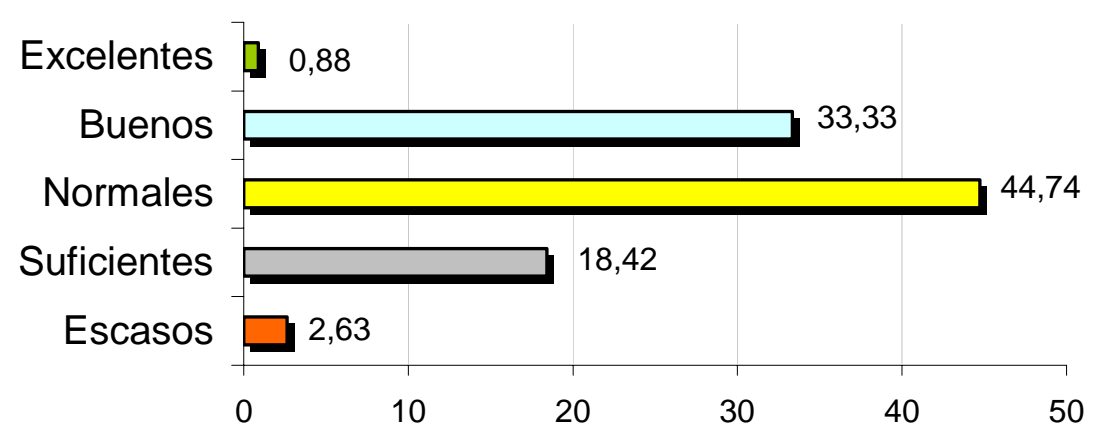

Fig. 3.43. Encuesta a profesionales: conocimientos de Internet

10 ¿Qué fuentes de información emplea principalmente para la resolución de las consultas?

El valor de esta pregunta está vinculado a la anterior. Un porcentaje muy alto emplea Internet de forma frecuente, junto a la disponible en la colección de referencia propia. Incluso, casi la quinta parte $(18,42 \%)$ utiliza fundamentalmente Internet para la resolución de las preguntas. 


\section{Fuentes empleadas (\%)}

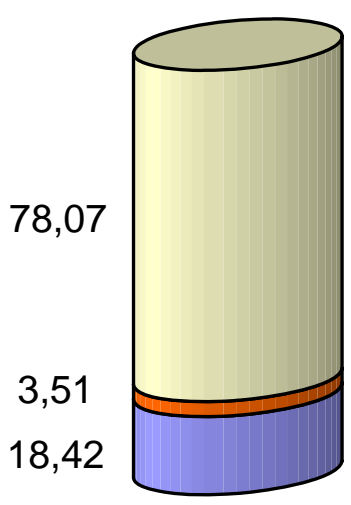

\begin{tabular}{|l|}
\hline Indistintamente \\
Internet y la \\
colección de \\
referencia propia \\
$\square$ Principalmente la \\
colección de \\
referencia propia \\
$\square$ Fundamentalmente \\
Internet \\
\hline
\end{tabular}

Fig. 3.44. Encuesta a profesionales: tipos de recursos empleados

11 ¿Cuándo emplea buscadores, utiliza las búsquedas avanzadas?

También se consideró interesante conocer el grado de uso de las posibilidades de recuperación avanzada que presentan los buscadores de Internet. Se parte de la idea de que a través de las opciones de búsqueda experta se consiguen resultados más afines y pertinentes. Sin embargo, los profesionales de «Pregunte» en su mayoría sólo emplean estas posibilidades de forma ocasional. Un cuarenta por ciento las utiliza siempre o habitualmente.

\section{Uso de búsquedas avanzadas (\%)}

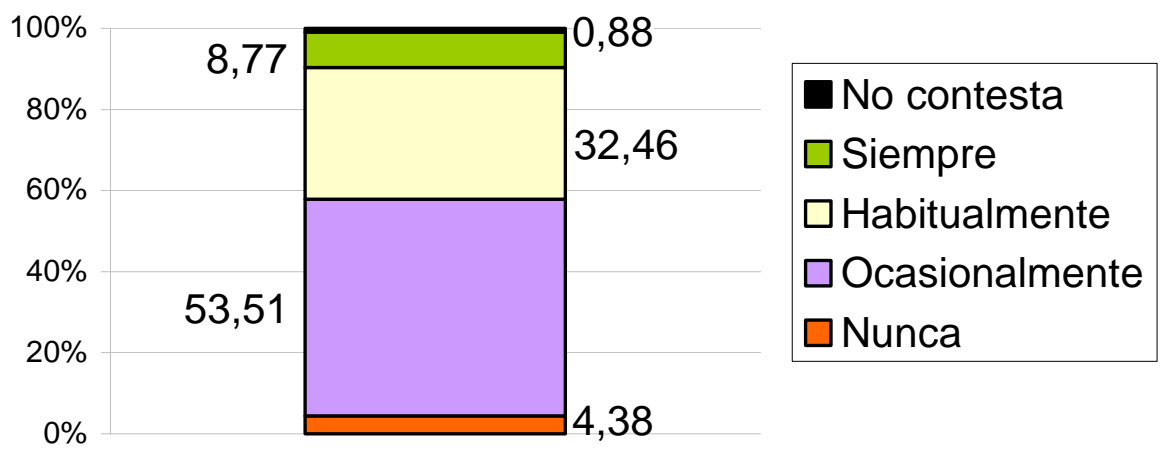

Fig. 3.45. Encuesta a profesionales: uso de búsquedas avanzadas

12 ¿Le parece adecuado el sistema informático empleado por «Pregunte»?

Más de la mitad de los encuestados están contentos con el sistema informático que se emplea para la recepción de las preguntas, el reenvío a las bibliotecas a las que corresponde el turno, la resolución de las consultas y el posterior envío a los usuarios. Sin embargo, un 42,98\% haría cambios en el mismo. 


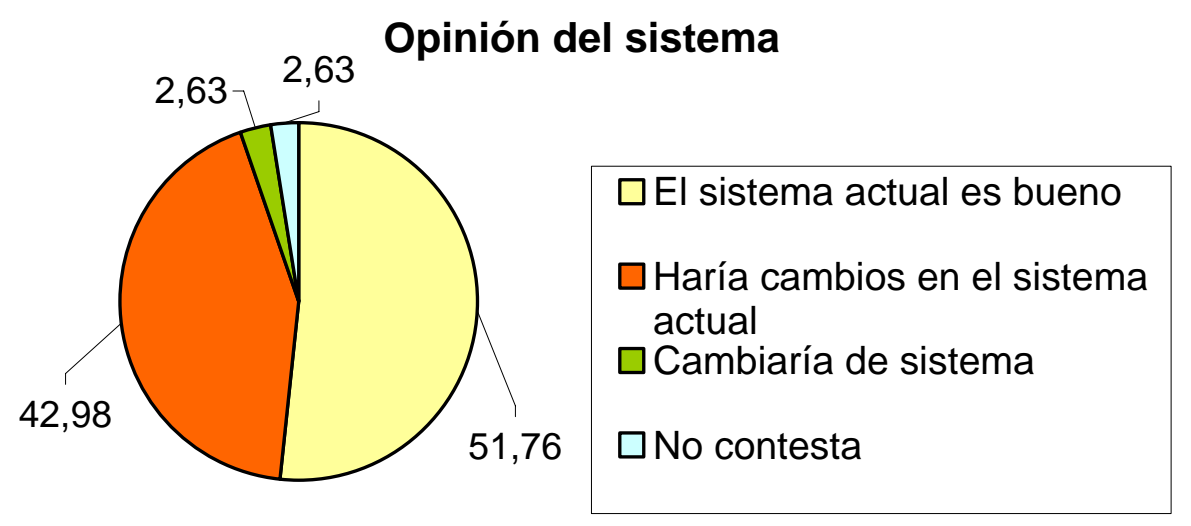

Fig. 3.46. Encuesta a profesionales: opinión sobre el sistema informático

13 ¿Qué opina del servidor empleado por «Pregunte»?

El funcionamiento del servidor donde reside el sistema y donde se almacenan las respuestas es problemático para una tercera parte de los profesionales, aunque un alto porcentaje $(68,42 \%)$ piensa que es correcto. Nadie ha opinado que el servidor funciona de forma excelente.

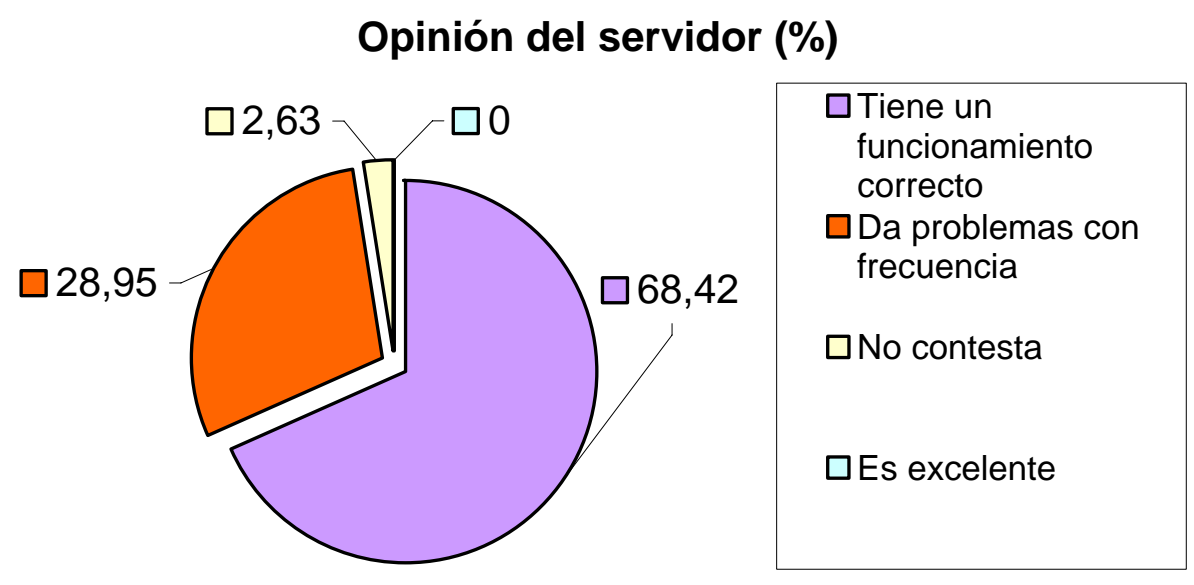

Fig. 3.47. Encuesta a profesionales: opinión acerca del servidor

14 ¿Le parece suficiente el espacio disponible para responder?

En esta pregunta se muestra de forma evidente la disparidad de opiniones sobre el espacio con el que se cuenta para ofrecer las respuestas, ya que casi la mitad piensa que el número de caracteres disponibles es suficiente, mientras que la otra mitad opina que debería ampliarse o que debería ser ilimitado. 


\section{Opinión sobre el espacio de respuesta (\%)}

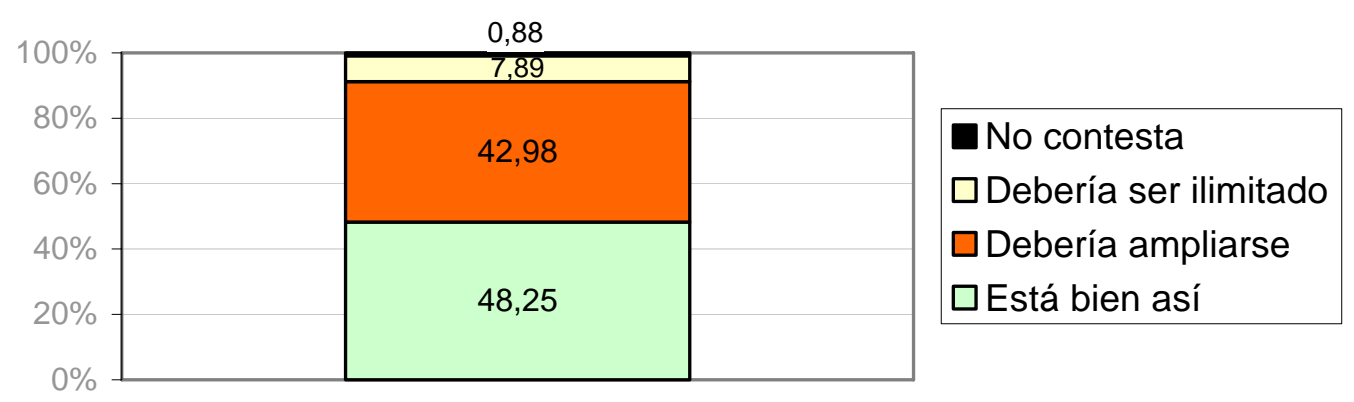

Fig. 3.48. Encuesta a profesionales: opinión sobre límites para la respuesta

15 ¿Le parecería adecuado que se pudiesen adjuntar documentos a la respuesta?

Una de las modificaciones que se pueden hacer en el sistema actual es la posibilidad de adjuntar documentos a las respuestas, con la intención de ofrecer contestaciones más amplias y precisas. Una amplia mayoría (71,93\%) está de acuerdo con que se puedan adjuntar documentos a las respuestas.

\section{Opinión sobre documentos adjuntos (\%)}

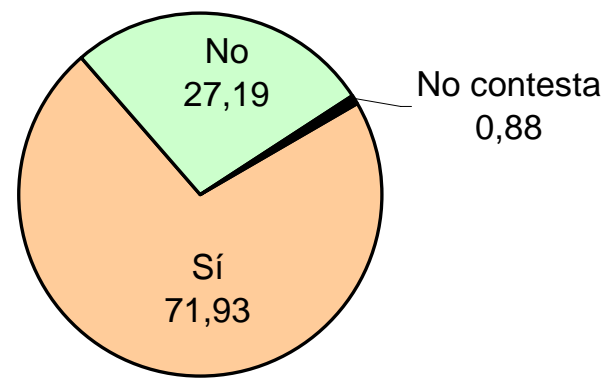

Fig. 3.49. Encuesta a profesionales: opinión sobre posibilidad de adjuntar archivos

16 ¿Está de acuerdo con las limitaciones (preguntas que no se admiten) realizadas en los tipos de preguntas que se permiten formular?

El manual de instrucciones y procedimientos de «Pregunte» ofrece ejemplos de tipos de preguntas que no deben ser admitidas (cuestiones hipotéticas, investigaciones científicas, cuestiones médicas, etc.). Un amplio grupo $(61,40 \%)$ opina que las limitaciones son oportunas, aunque también es importante el número de personas $(36,84 \%)$ que piensan que debería replantearse el tipo de preguntas que se rechazan. 


\section{Opinión sobre limitaciones a preguntas (\%)}

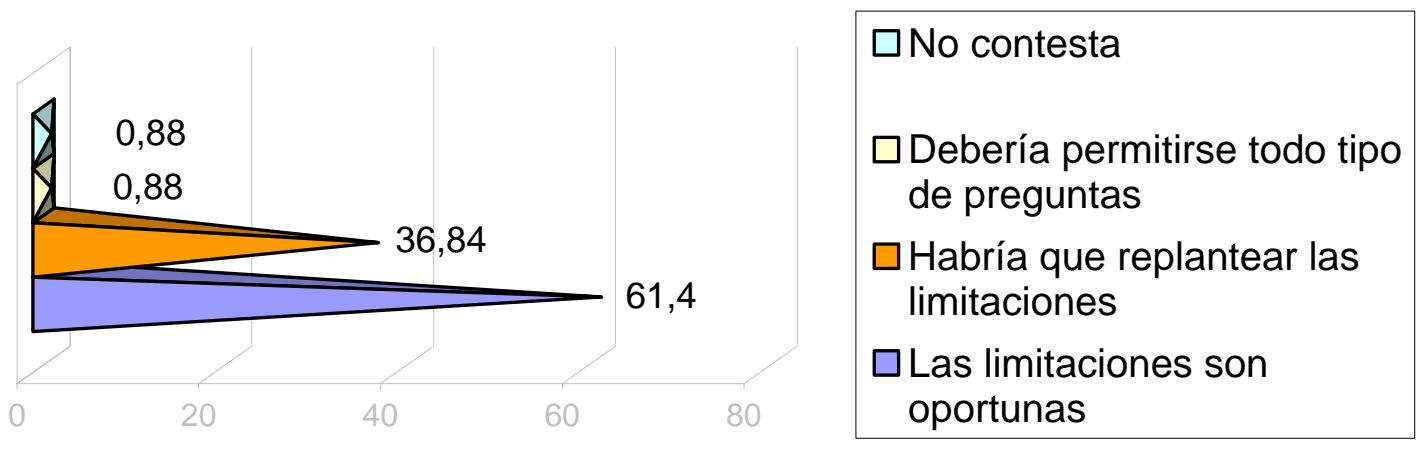

Fig. 3.50. Encuesta a profesionales: opinión sobre limitaciones a preguntas

17 Indique las distintas fases que realiza desde que recibe una pregunta hasta que envía la respuesta. (Incluya todas las fases o procesos que usted realice)

Esta pregunta se presentaba de forma abierta, por lo que los resultados han sido muy dispares y difíciles de cuantificar. Se trataba de conocer cuántas y cuáles eran las fases en las que los bibliotecarios del servicio de referencia estructuraban su trabajo, desde que recibían una pregunta. Lo que a continuación se expone es el resultado obtenido de forma global, es decir las distintas operaciones que se han recogido en la encuesta. El orden en el que aparecen es por la frecuencia de respuesta. Existen operaciones repetidas, ya que hay quien ha especificado el proceso y hay quien lo expone de forma general.

1. Lectura y análisis de las preguntas

2. Consultar fuentes de la colección local

3. Consultar fuentes externas

4. Búsqueda (en general)

5. Redacción definitiva de la respuesta

6. Envío de la respuesta

7. Consultar otros servicios y fuentes

8. Comentario con equipo y reparto de preguntas

9. Consulta o envío al coordinador del servicio en la biblioteca

10. Buscar en el archivo de preguntas

11. Primera redacción, evaluación y/o síntesis de la respuesta

12. Archivo y/o impresión de la respuesta

13. Selección, reenvío, descarte de preguntas

14. Agrupación de las preguntas por temas o por el grado de dificultad

15. Inclusión de fuentes complementarias

16. Hacer o completar estadísticas propias

18 ¿Consulta a otras bibliotecas, participen o no en «Pregunte», si cree que pueden ayudar en la resolución de las preguntas? 
La opción más frecuente es que se consulta a otras bibliotecas sólo de forma ocasional, de lo que se deduce que lo normal es que las bibliotecas resuelvan las demandas de información por sus propios medios, algo que es lógico. Simplemente se trataba de conocer si esta solución era contemplada por los profesionales referencistas.

\section{Consulta a otras bibliotecas (\%)}

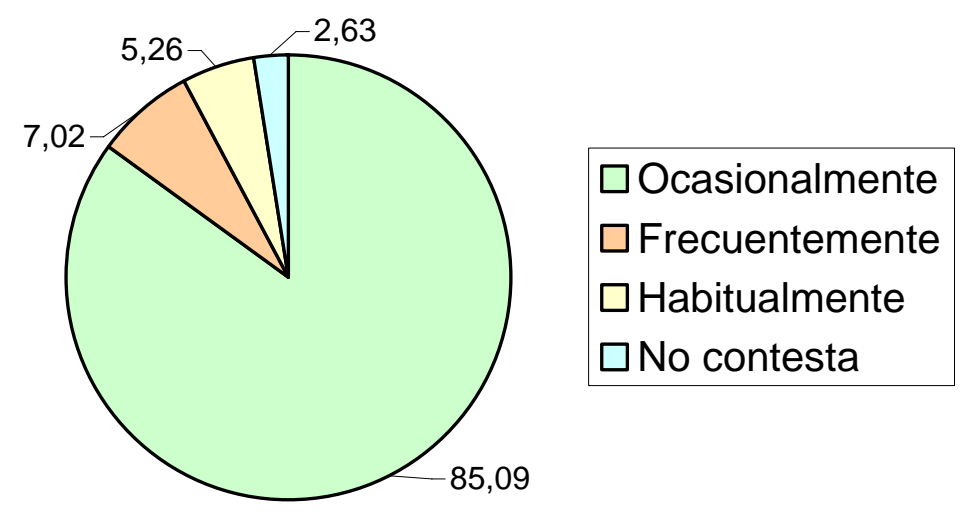

Fig. 3.51. Encuesta a profesionales: consulta a otras bibliotecas

19 ¿Suele consultar el archivo de consultas realizadas a «Pregunte»?

El archivo de preguntas planteadas y resueltas es una gran fuente de información, ya que muchas de las cuestiones que llegan a «Pregunte» ya han sido solucionadas. Sin embargo, la mayoría de los profesionales $(65,78 \%)$ sólo consultan esta base de datos de forma esporádica.

\section{Consulta del archivo (\%)}

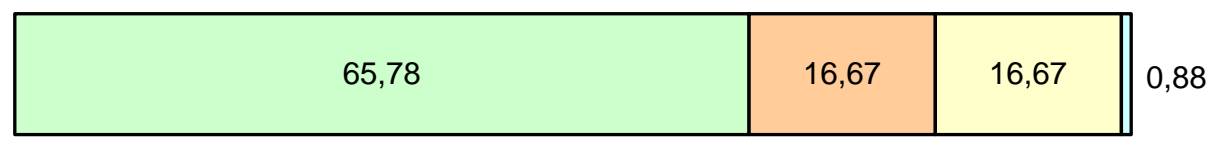

$\square$ Ocasionalmente $\square$ Frecuentemente $\square$ Habitualmente $\square$ No contesta

Fig. 3.52. Encuesta a profesionales: consulta al archivo de preguntas

20 ¿Tiene una selección de recursos favoritos que utiliza para responder las preguntas?

Otra cuestión que se consideró de interés fue conocer si quienes atienden las consultas de los usuarios emplean una selección de recursos elaborados por ellos mismos. La respuesta más amplia fue la afirmativa, ya que el $75,44 \%$ de las respuestas indican que han realizado una selección específica de fuentes de información de utilidad. 
Selección de recursos propia (\%)

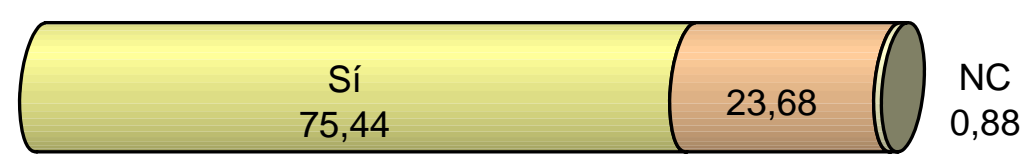

Fig. 3.53. Encuesta a profesionales: selección propia de recursos informativos

21 ¿Cómo calificaría la colección de referencia de su biblioteca?

Sin una colección de fuentes de información es imposible atender de forma correcta un servicio de referencia. A pesar de esto un tercio de los encuestados afirma que sus fondos de información son escasos, mientras que otro tercio sólo estiman su colección como "normal". Sólo un 4,39\% opina que su sección de referencia está dotada de forma excelente.

\section{Colección de referencia propia (\%)}

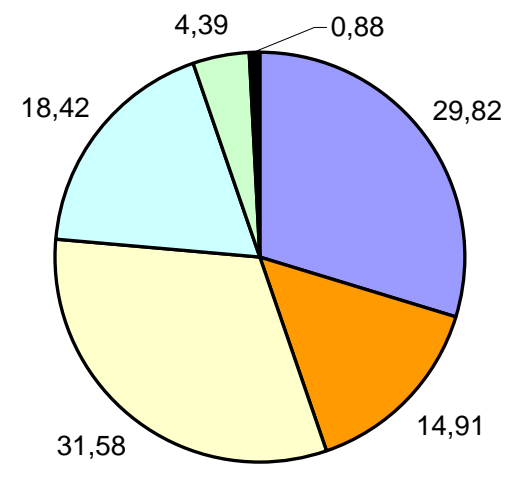

Escasa $\square$ Suficiente $\square$ Normal $\square$ Buena $\square$ Excelente - No contesta

Fig. 3.54. Encuesta a profesionales: opinión sobre la colección de referencia

22 ¿Cómo valoraría la edad media de su colección de referencia?

La colección de referencia sólo es útil si es actual, ya que este tipo de fondos tienen un alto grado de obsolescencia. Según los datos extraídos de las encuestas, el porcentaje mayor corresponde a quienes califican sus fondos de información como "actuales", aunque no es desdeñable la cifra de quienes piensan que es poco actual. 


\section{Edad de la colección de referencia local (\%)}
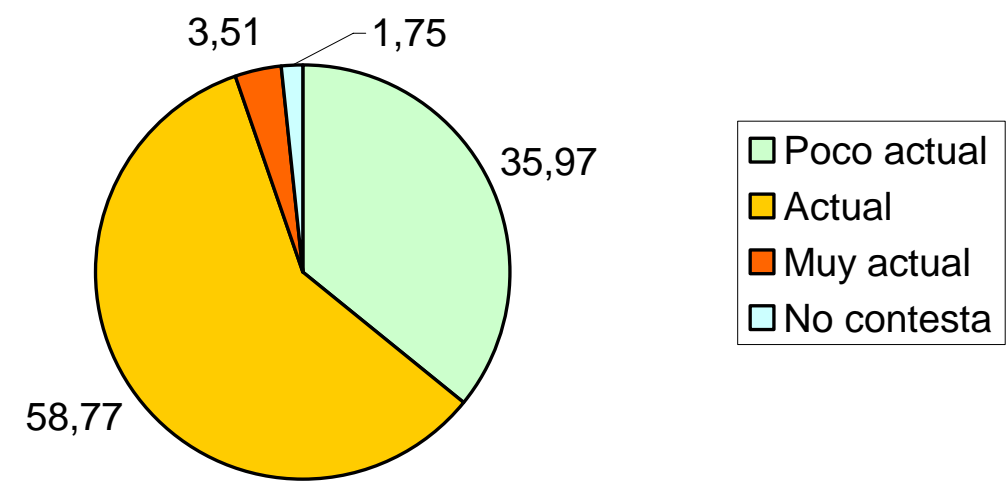

Fig. 3.55. Encuesta a profesionales: edad de la colección de referencia

23 ¿Cómo valora la documentación (manuales, clasificación, normativas, etc.) de que disponen las bibliotecas participantes en «Pregunte»?

Un servicio cooperativo necesita documentos que marquen los procesos que se deben seguir e instrumentos que unifiquen los criterios. En «Pregunte» existen una serie de materiales (manual de procedimiento, manual técnico, clasificación, etc.) que apoyan el trabajo de los referencistas; sin embargo, la opinión sobre esta documentación es muy dispar, como puede observarse en los resultados.

\section{Opinión de la documentación (\%)}

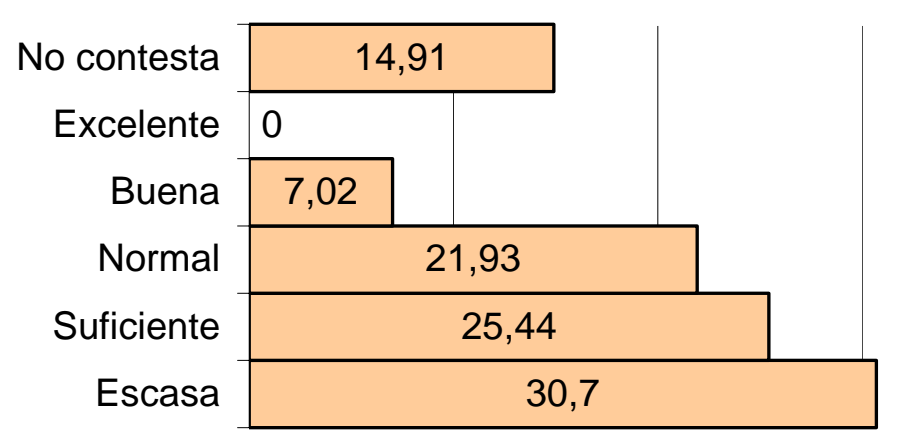

Fig. 3.56. Encuesta a profesionales: opinión sobre la documentación del servicio

24 ¿Qué documentación (manuales, clasificación, normativas, etc.) considera que se debería reelaborar de la que disponen las bibliotecas participantes en «Pregunte»?

La división de opiniones es evidente en cuanto a si es necesario reelaborar la documentación. Se dejó esta pregunta abierta, para que los encuestados respondieran según sus pareceres. La mitad de los profesionales piensan que los materiales de apoyo son correctos, mientras que la otra mitad cree que hay parte de la documentación que necesita ser modificada. 


\section{Cambios en la documentación (\%)}

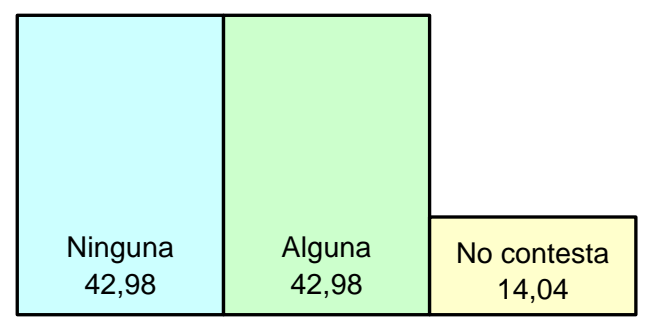

Fig. 3.57. Encuesta a profesionales: opinión sobre cambios en los manuales

La normativa básica o manual de procedimiento fue la respuesta más común entre quienes opinaron que era necesario modificar parte de la documentación. A continuación, se encuentran quienes piensan que hay que modificar la clasificación temática que se está empleando. Les siguen, en proporciones mucho más bajas, quienes incluyen entre los materiales susceptibles de ser modificados los tipos de preguntas no pertinentes o los modelos de respuestas. Los porcentajes que se reproducen a continuación se han hecho a partir del número total de respuestas que contestaron que habría que modificar parte de la documentación.

\section{Documentación que cambiaría (\%)}

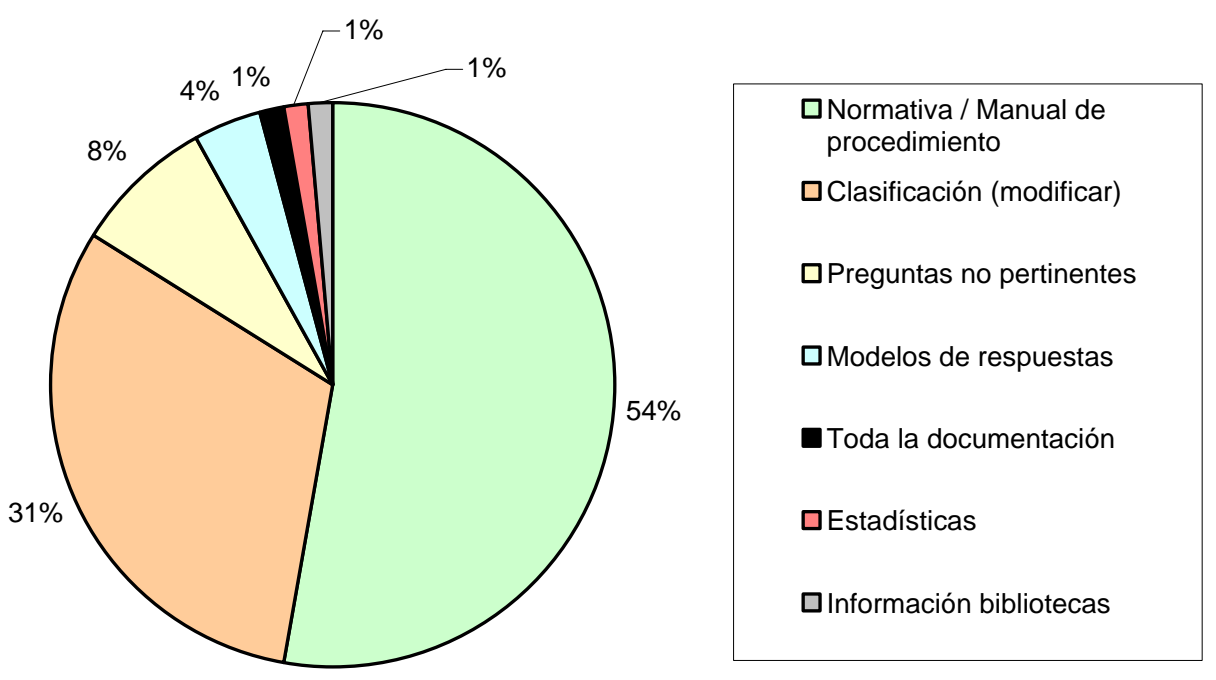

Fig. 3.58. Encuesta a profesionales: opinión sobre documentos susceptibles de mejora

25 ¿Qué documentación considera que debería elaborarse para incorporarla a la hasta ahora existente?

Los resultados de la pregunta anterior se complementan con la presente. Se trataba de conocer, en primer lugar, si era necesario elaborar materiales nuevos $y$, en caso afirmativo, qué documentación de apoyo se echaba en 
falta. Como ocurría en la pregunta pasada la opinión de los profesionales que opinan que no es necesario documentación nueva y la de quienes consideran lo contrario dio como resultado porcentajes muy similares.

\section{Documentación nueva (\%)}

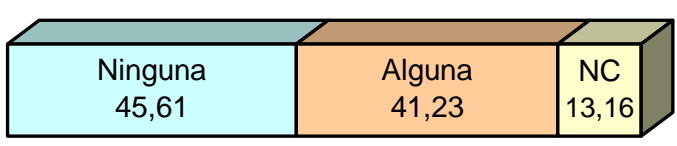

Fig. 3.59. Encuesta a profesionales: opinión sobre nueva documentación

Esta cuestión también estaba abierta, por lo que quienes consideraban que era necesario incluir nuevos materiales podían completar su respuesta con el tipo de documentación que requerían. Los pareceres han sido múltiples, como se observa en la tabla siguiente. Es importante destacar el volumen de las respuestas que indican la necesidad de crear selecciones de fuentes de información en Internet, así como la cifra de quienes dicen necesitar manuales de obras de referencia. Como en el caso anterior los porcentajes se toman a partir del número total de respuestas que indicaron que se deberían incluir materiales nuevos, no del total del número de encuestas recogidas.

\section{Documentación nueva (\%)}

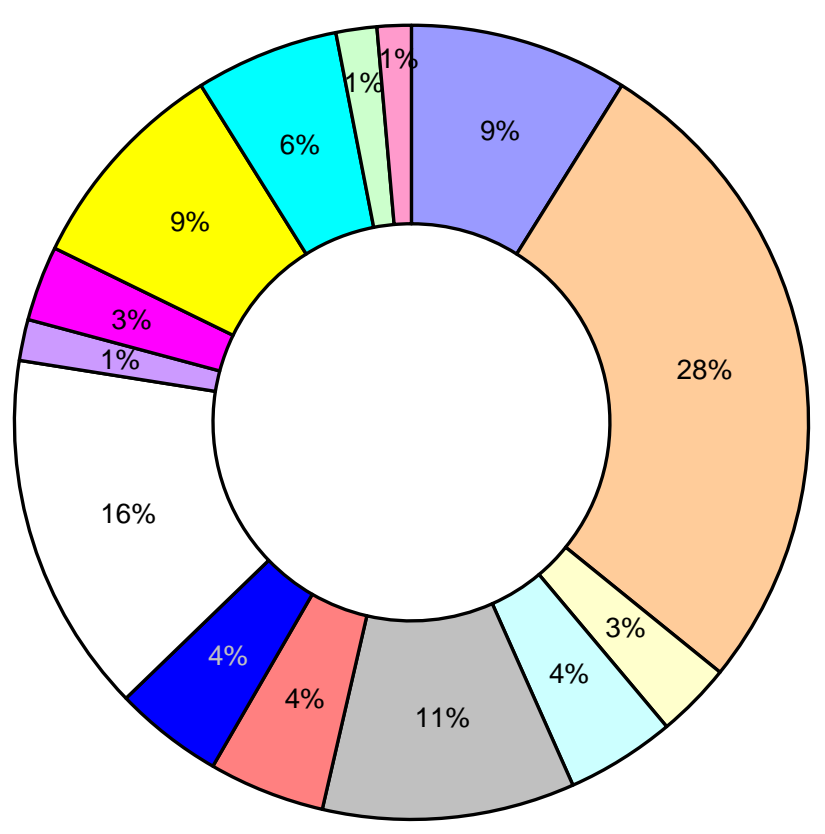

$\square$ Normativa

$\square$ Fuentes información en Internet

$\square$ Cómo buscar en Internet

$\square$ Clasificación (reelaborar)

$\square$ Manual de estilo

$\square$ Criterios para describir fuentes

Bases de datos

$\square$ Obras de referencia

$\square$ Manual de indización

口Formulario de satisfacción

$\square$ Manual de cómo preguntar

$\square$ Extensión de la respuesta

$\square$ Archivo de preguntas dificiles

$\square$ Informes sobre el servicio

Fig. 3.60. Encuesta a profesionales: opinión sobre nueva documentación 
26 ¿Considera conveniente que se ofrezcan cursos de formación específicos a quienes participan en «Pregunte»?

La formación en fuentes de información y métodos de recuperación es muy valorada por los profesionales que atienden «Pregunte», como no podría ser de otra manera. Un elevado porcentaje de las respuestas consideran conveniente o muy conveniente la organización de cursos de formación específicos, orientados hacia el personal que atiende el servicio y que, por tanto, necesita conocer los recursos más útiles y los métodos para localizar la información en estas fuentes.

\section{Cursos de formación (\%)}

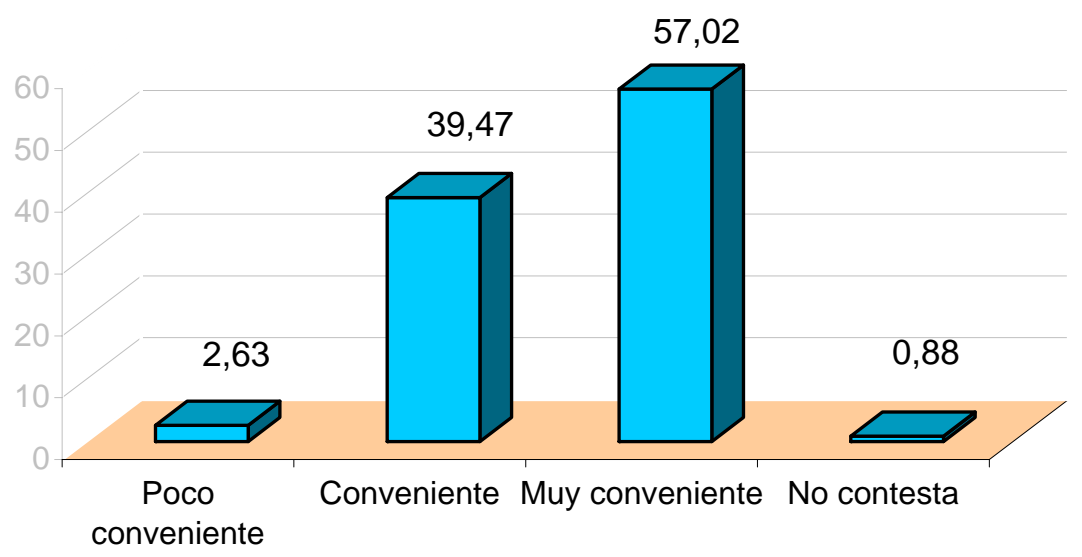

Fig. 3.61. Encuesta a profesionales: opinión sobre formación continua

27 ¿Considera conveniente que las distintas bibliotecas participantes se especialicen en un tema para dar mejor servicio en «Pregunte»?

Un posible método de organización de un servicio cooperativo como éste podría ser la distribución de las preguntas entre los participantes en función del tema de las mismas. Sin embargo, esta idea no se considera viable por quienes trabajan en «Pregunte», ya que más de la mitad de los referencistas consideran poco conveniente esta iniciativa.

Este dato es importante, para evitar reformas que después no surtan el efecto deseado, por innecesarias o inútiles. No obstante, hay que tener en cuenta que el cuarenta por cien de los encuestados creen que la especialización en materias por bibliotecas es algo conveniente o muy conveniente. 


\section{Especialización (\%)}

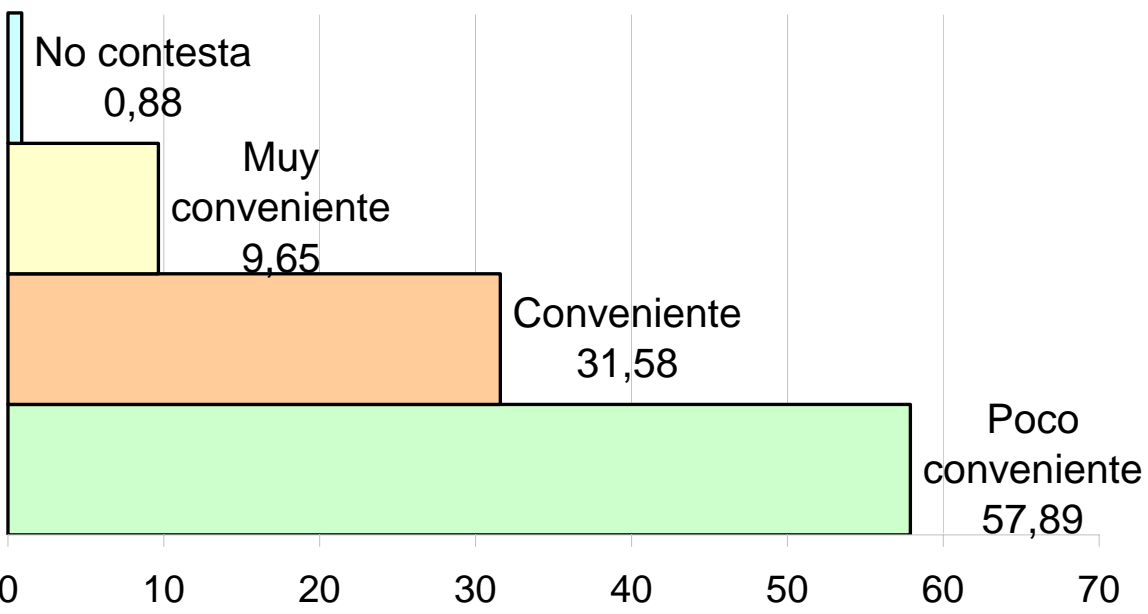

Fig. 3.62. Encuesta a profesionales: opinión sobre especialización

28 ¿Considera conveniente que se elabore un formulario de evaluación de la respuesta para que el usuario, si lo desea, muestre su grado de satisfacción con la contestación recibida?

Hasta el momento no existen sistemas para conocer el grado de satisfacción del usuario. Por ello se han incluido una serie de preguntas sobre la oportunidad de incluir algún tipo de formulario para conocer datos, como en este caso, la valoración de la respuesta que ha recibido un usuario. Como se observa en los resultados siguientes, una elevado volumen de respuestas indica que sí es conveniente incluir algún tipo de formulario en el que se exprese el grado de satisfacción causado por la respuesta recibida.

\section{Evaluación de la respuesta (\%)}

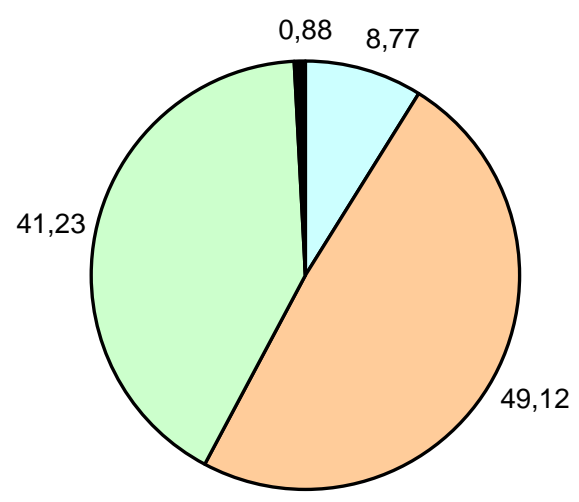

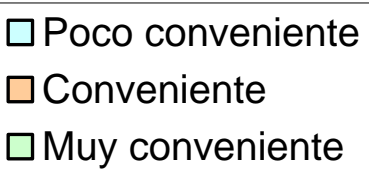

No contesta

Fig. 3.63. Encuesta a profesionales: opinión sobre evaluación de las respuestas 
29 ¿Considera conveniente que se elabore un formulario de evaluación de «Pregunte» para que el usuario, si lo desea, muestre su grado de satisfacción con el servicio?

Siguiendo con la eventualidad de recoger en un formulario la opinión del usuario, también se preguntó por el grado de satisfacción general que el servicio le había causado, ya que la respuesta puede no ser plenamente satisfactoria, pero sí los plazos, las fuentes o las informaciones facilitadas. Una amplia mayoría creen que también debe preguntarse al usuario sobre su opinión respecto a «Pregunte».

\section{Evaluación del servicio (\%)}

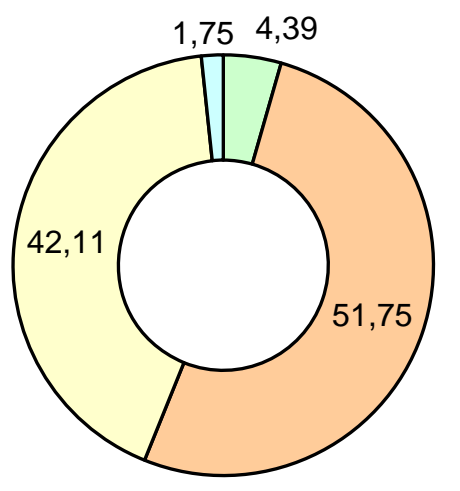

$\square$ Poco conveniente
$\square$ Conveniente
$\square$ Muy conveniente
$\square$ No contesta

Fig. 3.64. Encuesta a profesionales: opinión sobre evaluación del servicio

30 ¿Cómo valoraría la incorporación de un servicio de chat a «Pregunte»?

El siguiente bloque de preguntas se centró en posibles cambios en «Pregunte». Las tendencias en los servicios de referencia telemáticos están incluyendo en los mismos la posibilidad de plantear determinadas cuestiones a través de servicios de comunicación instantáneos, sobre todo a partir de chat.

La posibilidad de ofrecer un servicio de este tipo es considerada por la mayoría (53,51\%) como "interesante", aunque pocos lo consideran urgente o necesario. 


\section{Inclusión de chat (\%)}

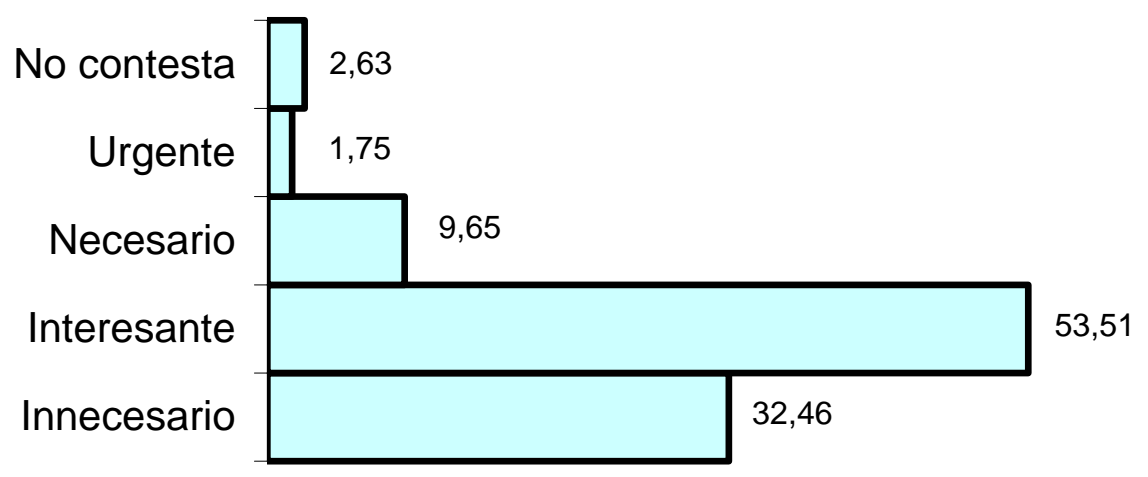

Fig. 3.65. Encuesta a profesionales: opinión sobre inclusión de chat

31 ¿Cómo valoraría la inclusión de una selección de recursos de información de Internet en la página principal de «Pregunte»?

Una modificación posible del servicio actual es la inclusión de una selección de recursos de información accesibles a través de Internet, que sirviera como complemento al servicio de respuesta personalizado que ahora se ofrece. La opinión es unánime en este sentido, ya que nadie considera este nuevo servicio innecesario, sino todo lo contrario.

\section{Selección de recursos (\%)}

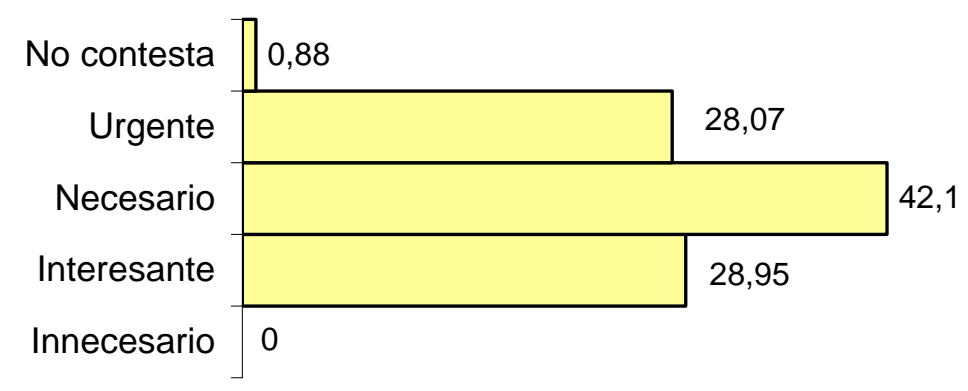

Fig. 3.66. Encuesta a profesionales: opinión sobre inclusión de recursos

32 ¿Cómo valoraría la elaboración de documentos acerca de cómo buscar o guías de recursos comentados para incorporar a la página principal de «Pregunte»?

También la mayoría de los profesionales que están al cargo de «Pregunte» estiman necesario y/o urgente la realización de tutoriales sobre técnicas de búsqueda y guías acerca de cómo emplear determinados recursos de información. En esta modificación junto con la resultante de la anterior pregunta los bibliotecarios están de acuerdo, por lo que sería lógico ponerlas en marcha cuanto antes. 


\section{Guías de recursos (\%)}

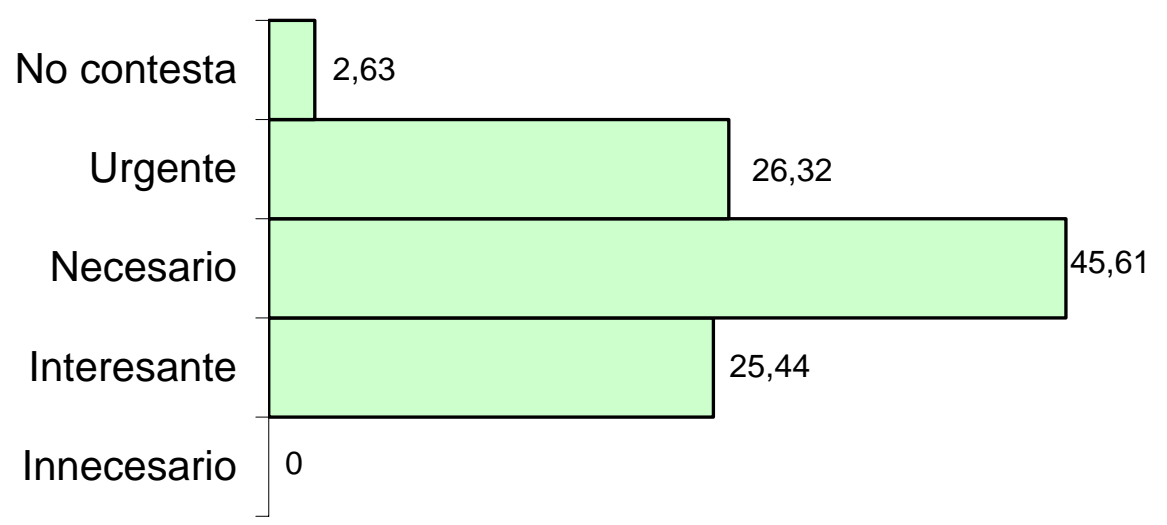

Fig. 3.67. Encuesta a profesionales: opinión sobre inclusión de tutoriales

33 ¿Cómo valoraría la contratación cooperativa de recursos electrónicos de referencia para las bibliotecas participantes en «Pregunte»?

Otra solución en la que se está de acuerdo es la contratación de recursos electrónicos para su uso cooperativo. La urgencia de esta medida se demuestra en los resultados obtenidos en la encuesta.

\section{Recursos cooperativos (\%)}

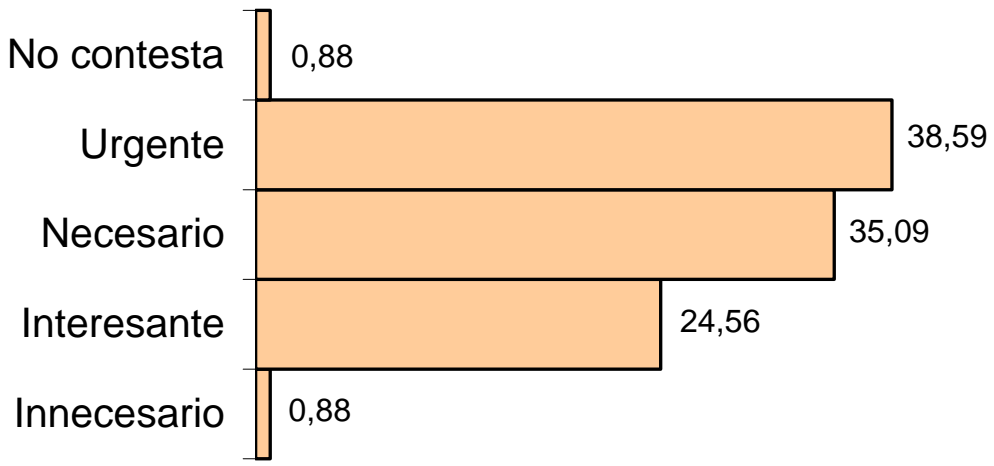

Fig. 3.68. Encuesta a profesionales: opinión sobre contratación de recursos comunes

34 ¿Considera conveniente que se pida obligatoriamente alguna identificación al usuario para poder responder mejor a su preguntas?

Hasta el momento la identificación del usuario (edad, localidad, etc.) sólo se hacía si éste voluntariamente lo indicaba. No obstante, se puede considerar necesario conocer de antemano ciertos datos de quien realiza una pregunta, con la intención de ofrecerle una respuesta más afín. Parece que así piensan la mayoría de los profesionales de «Pregunte», quienes estiman 
conveniente $(45,61 \%)$ o muy conveniente $(34,21 \%)$ que se pidan algunos datos de los usuarios.

\section{Identificación del usuario (\%)}

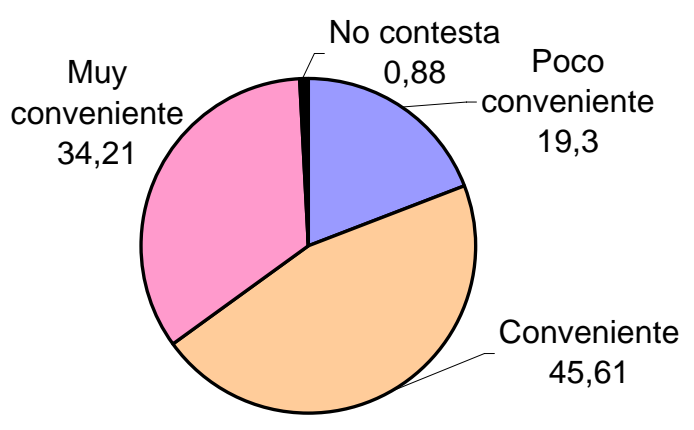

Fig. 3.69. Encuesta a profesionales: opinión sobre la identificación del usuario

35 ¿Si se pidiera alguna identificación obligatoria al usuario cree que la localidad debería ser uno de estos datos?

Los datos de localidad en la que reside el usuario parece que son determinantes $y$, en el caso de incluir la obligatoriedad de responder a ciertas cuestiones de identificación, esta información sería una de las necesarias, según los bibliotecarios de «Pregunte».

\section{Identificación de la localidad (\%)}

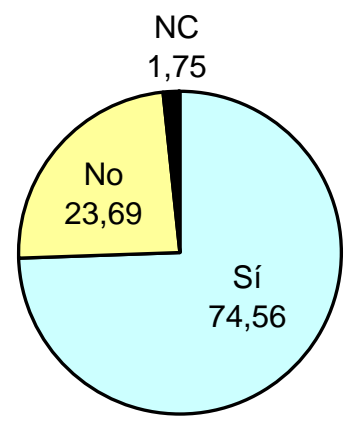

Fig. 3.70. Encuesta a profesionales: opinión sobre la identificación de la localidad

36 ¿Si se pidiera alguna identificación obligatoria al usuario cree que la edad debería ser uno de estos datos?

También se está de acuerdo en que conocer la edad del usuario es importante, de ahí que un 82,46\% hayan escogido esta opción. No es igual contestar una pregunta a un niño que a un universitario. 


\section{Edad del usuario (\%)}

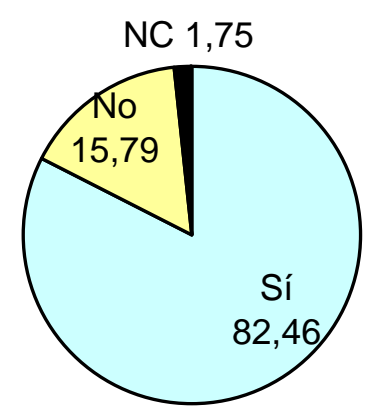

Fig. 3.71. Encuesta a profesionales: opinión sobre la petición de la edad

37 ¿Si se pidiera alguna identificación obligatoria al usuario cree que el motivo de la consulta (trabajo, estudio, personal) debería ser uno de estos datos?

Por último, además de los datos anteriores se está también de acuerdo, aunque en menor medida (78,07\%) en que el motivo de la consulta es un dato que habría que incluir en una hipotética identificación del usuario. Se trata de conocer de forma básica (trabajo, estudio u motivación personal), cuál es la origen de la pregunta, para poder enfocar de forma más pertinente la respuesta.

\section{Motivo de la consulta (\%)}

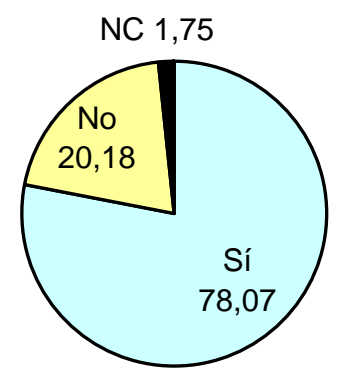

Fig. 3.72. Encuesta a profesionales: opinión sobre la petición del motivo de la consulta

38. ¿Cree que «Pregunte» debería ofrecerse sólo a usuarios españoles?

Es difícil determinar el usuario a quien va dirigido un servicio como «Pregunte». Entre las pocas limitaciones que se ponen está la obligación de realizar las consultas en lenguas españolas, por lo que también interesaba conocer la opinión de los profesionales en este sentido. Además, las estadísticas muestran que existe un porcentaje alto de usuarios que efectúan consultas desde fuera de España. Como se observa en los resultados obtenidos, el porcentaje mayor $(63,16 \%)$ corresponde a quienes creen que el servicio debe ofrecerse a usuarios que usen lenguas españolas, independiente del lugar desde el que pregunte. También es 
significativo el número $(22,81 \%)$ de quienes piensan que ni lengua ni el país deben ser limitaciones para usar «Pregunte».

\section{Usuarios (\%)}

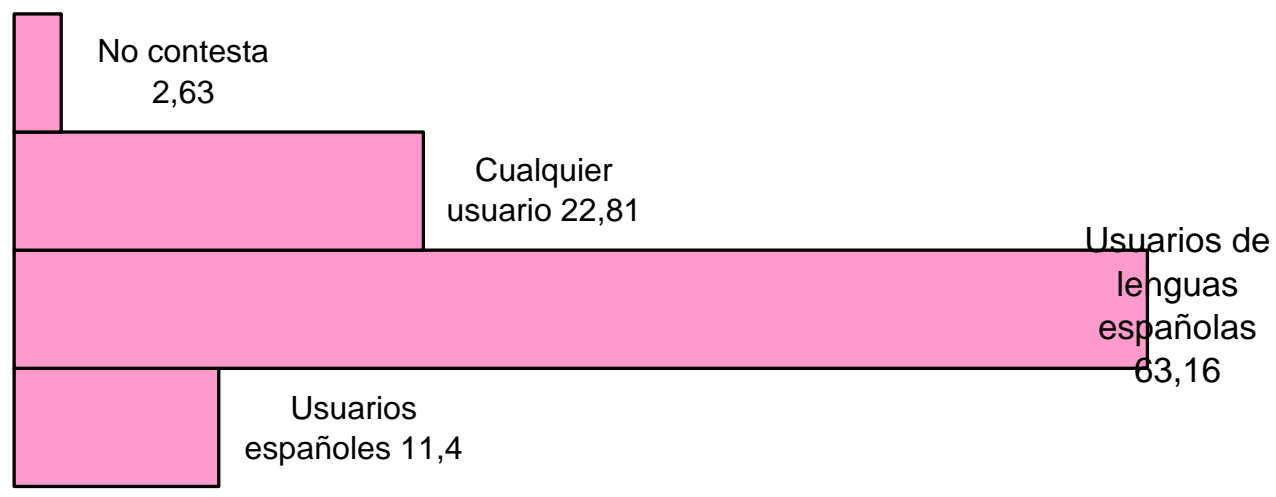

Fig. 3.73. Encuesta a profesionales: usuarios del servicio

39 ¿Cómo valoraría la utilidad del servicio «Pregunte»?

La opinión sobre si el trabajo que se está desempeñando es útil es esencial en la valoración del servicio. Si el servicio es útil, la actividad realizada también lo será y viceversa. La mayor parte de quienes atienden «Pregunte» lo consideran útil $(58,77 \%)$, seguidos de quienes lo creen muy útil $(28,95 \%)$. Por tanto, los bibliotecarios implicados en el servicio están convencidos de su eficacia.

\section{Utilidad de «Pregunte» (\%)}

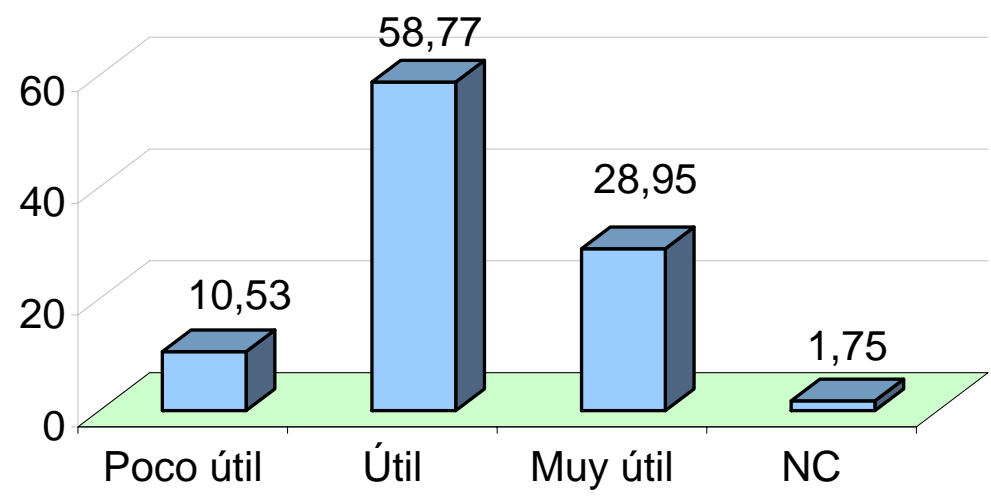

Fig. 3.74. Encuesta a profesionales: utilidad del servicio

40 ¿Considera que la autosuficiencia de los usuarios para buscar en información disminuye la utilidad de «Pregunte»?

Una de los posibles causas de la disminución en el uso de «Pregunte» podría ser que los usuarios de Internet cada vez son más autosuficientes y 
resuelven sus dudas por sí mismo. Entonces, un servicio como éste deja de ser tan útil, ya que los propios usuarios encuentran solución a sus demandas informativas. Ante esta cuestión los resultados vuelven a ser totalmente contrarios, ya que son tantos quienes consideran que «Pregunte» es menos útil, como quienes consideran que nada cambia ante la mejor formación de los usuarios en hábitos de información.

\section{Autosuficiencia del usuario / Interés del servicio (\%)}

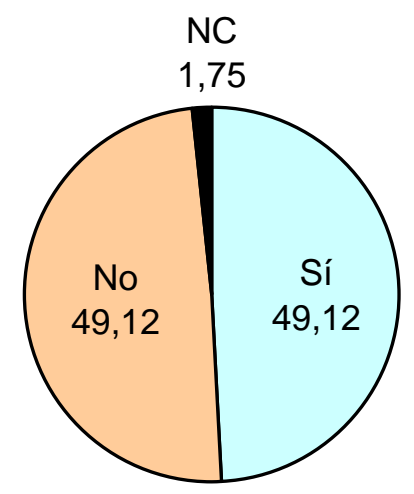

Fig. 3.75. Encuesta a profesionales: autosuficiencia del usuario

41. ¿Cómo valoraría el grado de coordinación entre las bibliotecas que participan en «Pregunte»?

Un servicio cooperativo debe estar coordinado. En esta pregunta se quería conocer la impresión de los profesionales de este servicio de referencia acerca del grado de coordinación. Como en otros casos, la escala de valores daba cinco posibilidades, siendo el valor medio el más frecuente (54\%), pero seguido de quienes opinan que la coordinación no es satisfactoria (21,05\% y 4,39\%).

\section{Grado de coordinación (\%)}

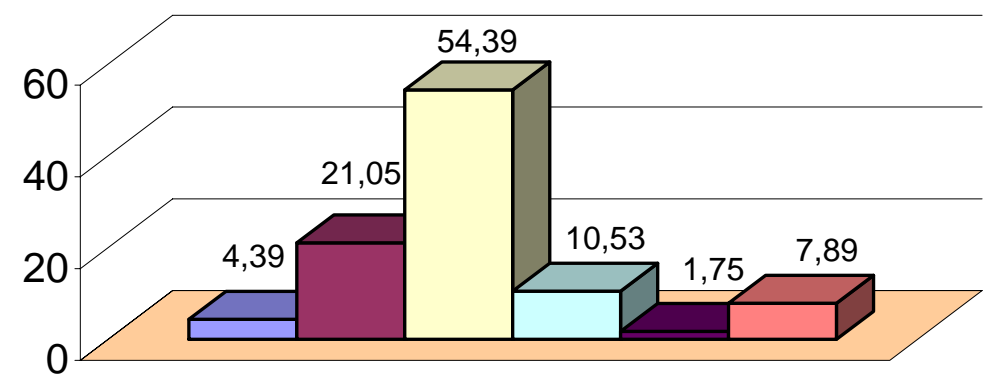

$\square$ Muy malo $\square$ Malo $\square$ Normal $\square$ Bueno $\square$ Muy bueno $\square$ No contesta

Fig. 3.76. Encuesta a profesionales: grado de coordinación 
42. ¿Cómo valoraría el traslado del servidor de «Pregunte» y la coordinación del proyecto a la Subdirección General de Coordinación Bibliotecaria?

Cuando se estaba elaborando esta encuesta se encontraba en fase de ejecución el traslado del servidor que emplea el servicio a las dependencias de la Subdirección General de Coordinación Bibliotecaria, algo que la mayor parte de los encuestados (55,26\%) consideraban necesario. En esta pregunta también es valorable el alto porcentaje alcanzado por quienes no contestaron a esta cuestión, lo que puede ser interpretado como una falta de información acerca del proceso de cambio de ubicación del servidor.

\section{Traslado servidor/coordinación (\%)}

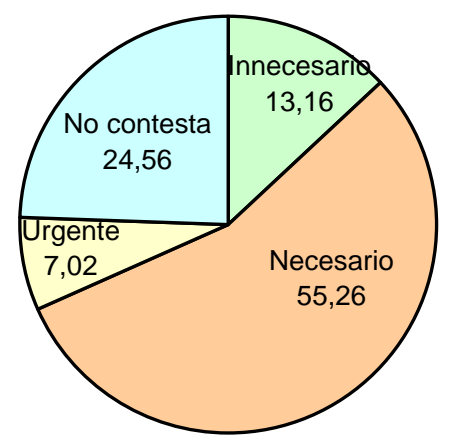

Fig. 3.77. Encuesta a profesionales: opinión sobre el traslado del servidor

43. ¿Cree que el número de bibliotecas participantes en el proyecto es suficiente?

La participación en «Pregunte» es voluntaria. La responsabilidad de dar respuesta a las cuestiones recibidas se distribuye de forma periódica entre las bibliotecas que integran este proyecto. A juzgar por los resultados recopilados un número elevado de profesionales $(71,93 \%)$ piensan que deberían ser más las bibliotecas integradas en este servicio.

\section{Número de bibliotecas (\%)}

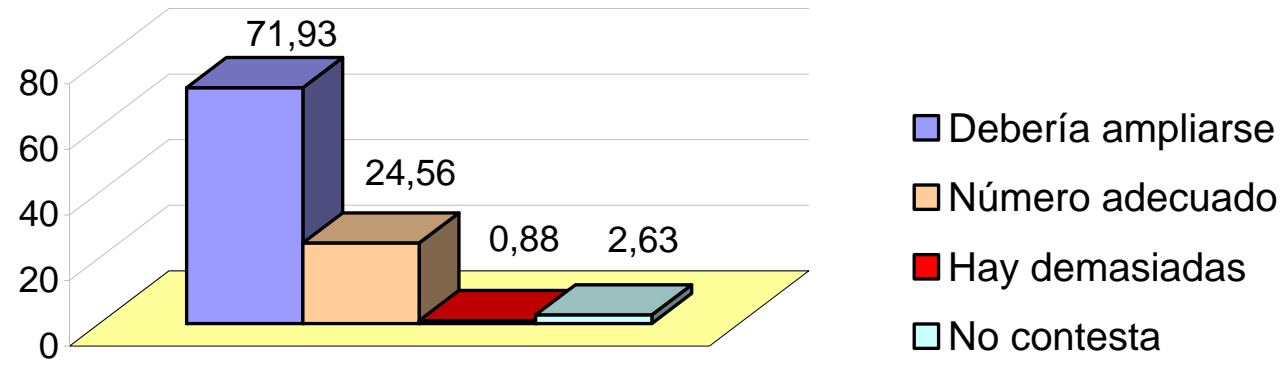

Fig. 3.78. Encuesta a profesionales: opinión sobre el número de centros 
44. ¿Cree que el sistema actual de turnos (un turno +/- al mes) es adecuado?

El número de bibliotecas participantes permite que una vez al mes, aproximadamente, un centro sea el responsable de recibir las preguntas y de darles solución. Esta distribución es adecuada para la mayoría de los encuestados (58,77\%), aunque tampoco es desdeñable la opinión de quienes valorarían positivamente la organización de turnos más espaciados.

Turnos (\%)

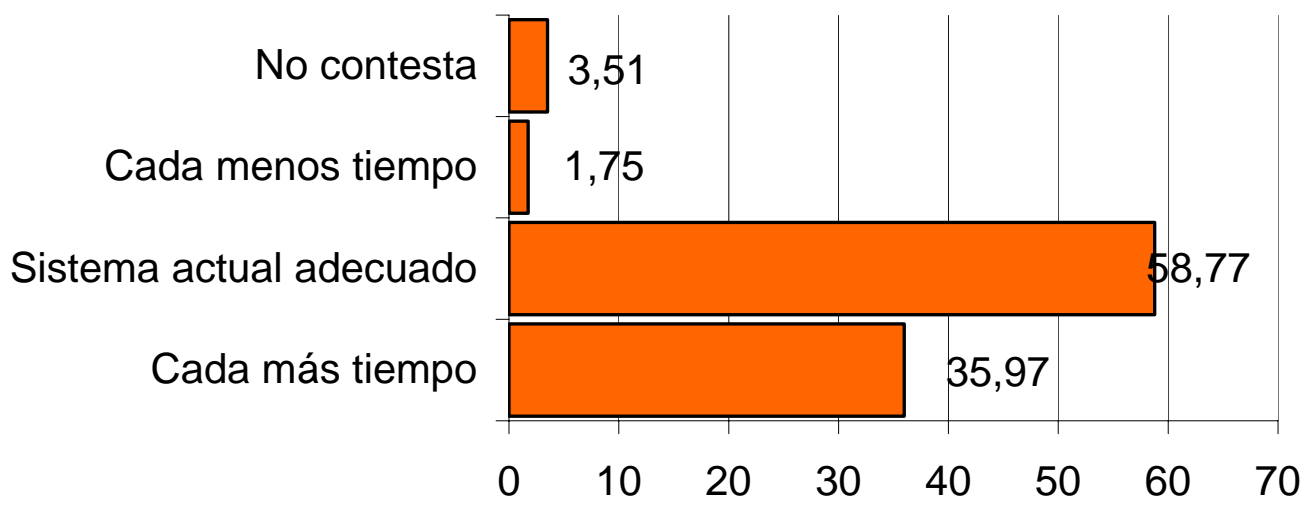

Fig. 3.79. Encuesta a profesionales: opinión sobre el sistema de turnos

45 ¿Cómo valoraría la calidad de las respuestas que se dan en «Pregunte»?

La consideración más generalizada en cuanto a la calidad de las respuestas es que éstas son buenas (46,49\%), seguida de quienes creen que es la normal $(42,10 \%)$. Es destacable que nadie piense que es muy buena.

\section{Calidad de las respuestas (\%)}

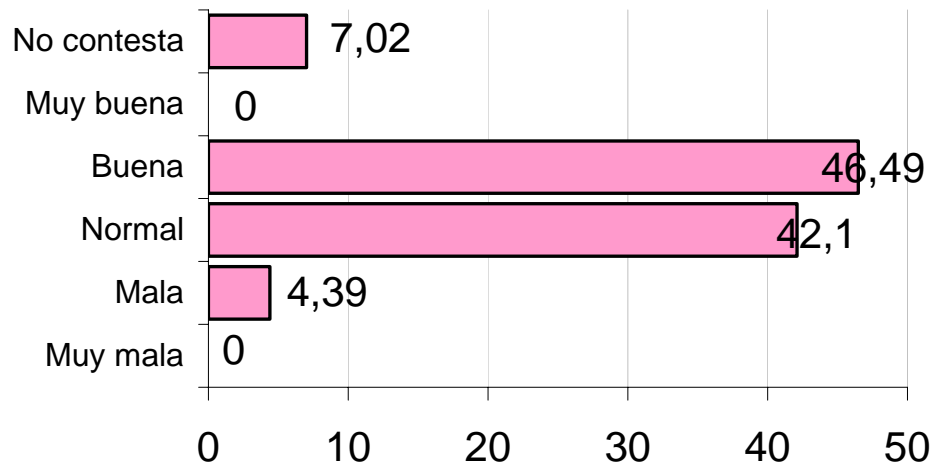

Fig. 3.80. Encuesta a profesionales: opinión sobre la calidad de las respuestas 
46 ¿Cómo valoraría la cantidad de preguntas que recibe su biblioteca?

Tampoco parece haber problemas con el número de preguntas que se reciben en cada turno, ya que casi todos $(70,18 \%)$ opinan que el volumen de cuestiones que tienen que resolver es normal.

\section{Cantidad de preguntas (\%)}

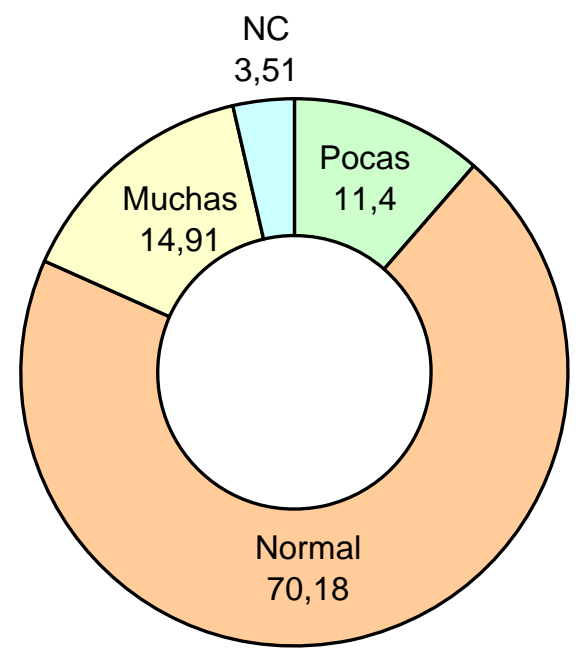

Fig. 3.81. Encuesta a profesionales: opinión sobre la cantidad de preguntas

47- ¿Cree que el tiempo de respuesta de «Pregunte» es el adecuado?

Las normas del servicio indican que las respuestas deben ofrecerse en un máximo de tres días. La opinión más extendida $(76,31 \%)$ es que los plazos marcados son los correctos, por lo que no deben modificarse.

\section{Tiempo de respuesta}

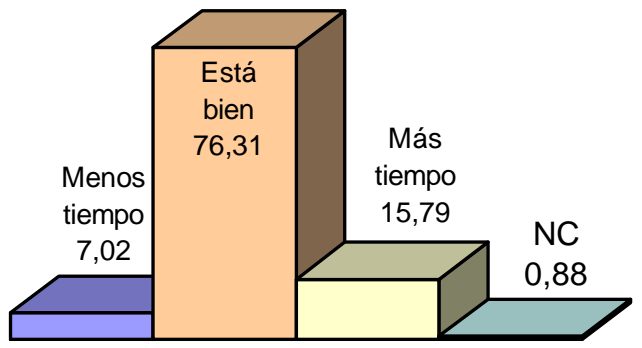

Fig. 3.82. Encuesta a profesionales: opinión sobre el tiempo de respuesta

48 ¿Cree que el servicio «Pregunte» es conocido fuera de la profesión bibliotecaria? 
Una cantidad elevada de encuestados (86,84\%) creen que el servicio «Pregunte» es poco conocido entre los profesionales bibliotecarios, algo que implicaría que todavía lo será menos entre las personas ajenas a la profesión. Nadie piensa que el servicio es muy conocido entre quienes trabajan en las bibliotecas.

\section{Conocimiento de «Pregunte» (\%)}

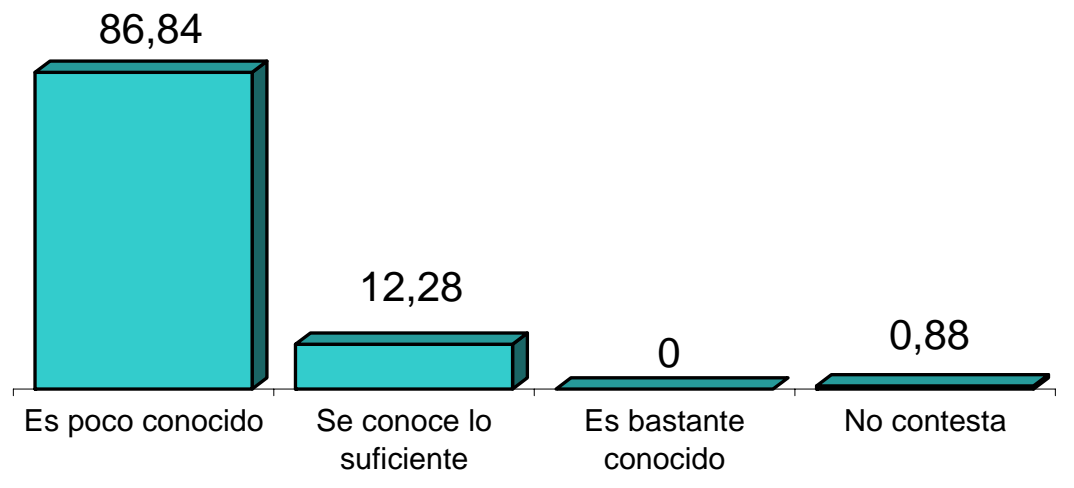

Fig. 3.83. Encuesta a profesionales: opinión sobre el conocimiento del servicio

49. ¿Qué le parecería la realización de una campaña de promoción de «Pregunte»?

Una solución al posible desconocimiento de la existencia de «Pregunte» es la realización de una campaña de difusión. Esta medida es considerada necesaria por un amplio grupo $(59,65 \%)$ y urgente por otra significativa proporción $(22,81 \%)$.

\section{Campaña de difusión (\%)}
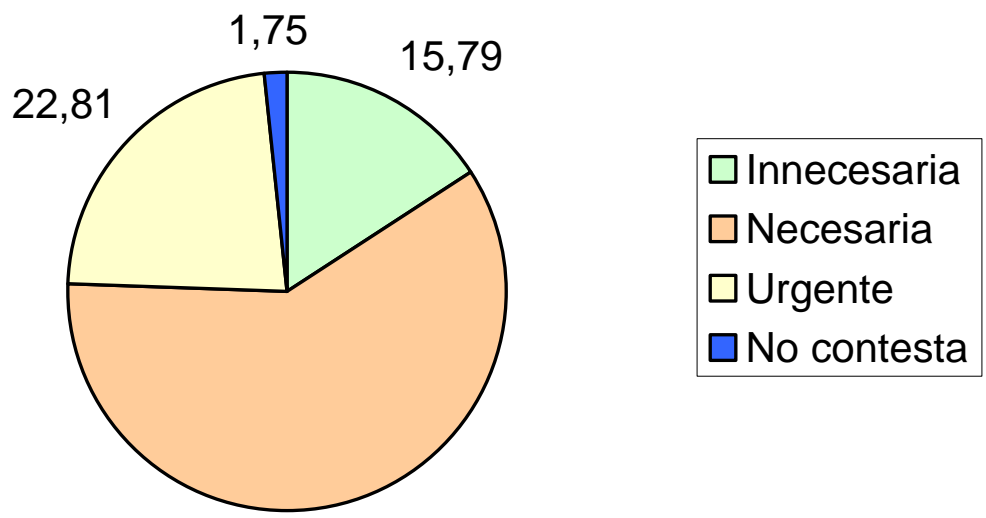

59,65

Fig. 3.84. Encuesta a profesionales: opinión sobre la necesidad de difusión 
50. ¿Cuáles son, a su juicio, los problemas de «Pregunte» que necesitan una solución más urgente? (Indique todos aquellos que considere)

Una última y comprometida pregunta se hacía de forma abierta para conocer las opiniones de cuáles son, a juicio de los encuestados, los problemas que afectan a «Pregunte» y que requieran una solución más urgente. Un 0,88\% no contestó a esta pregunta, un $25,44 \%$ indicó que no encontraba problemas urgentes y el restante $73,68 \%$ sí expresó al menos un problema. En total se recogieron 277 problemas en las 114 encuestas válidas. Los problemas expresados se han agrupado en categorías, en función de los temas a los que se refieren. Los porcentajes corresponden al total de problemas planteados.

\begin{tabular}{|l|l|}
\hline Tema & $\%$ \\
\hline Ayudas: apoyo de las CCAA o de entidades bibliotecarias & 2,89 \\
\hline Bibliotecas: coordinación entre las bibliotecas, organización, etc. & 16,97 \\
\hline $\begin{array}{l}\text { Recursos: colección, necesidad de realizar selecciones de } \\
\text { recursos, etc. }\end{array}$ & 11,19 \\
\hline Difusión: campaña de promoción del servicio & 5,41 \\
\hline Normativa: revisión de los materiales de trabajo & 6,86 \\
\hline Personal: formación, compatibilidad de tareas, etc. & 10,83 \\
\hline Preguntas: tipo de preguntas, idoneidad, reenvíos, etc. & 15,52 \\
\hline Respuestas: calidad, tipos, contenido, etc. & 11,55 \\
\hline Sistema: servidor, programa, páginas web, archivos, etc. & 9,03 \\
\hline Usuarios: identificación, tipos, satisfacción, etc. & 9,75 \\
\hline
\end{tabular}

El siguiente gráfico expresa de forma visual el resultado obtenido al agrupar en grandes categorías los distintos problemas reflejados por los profesionales que trabajan en «Pregunte».

\section{Problemas (\%)}

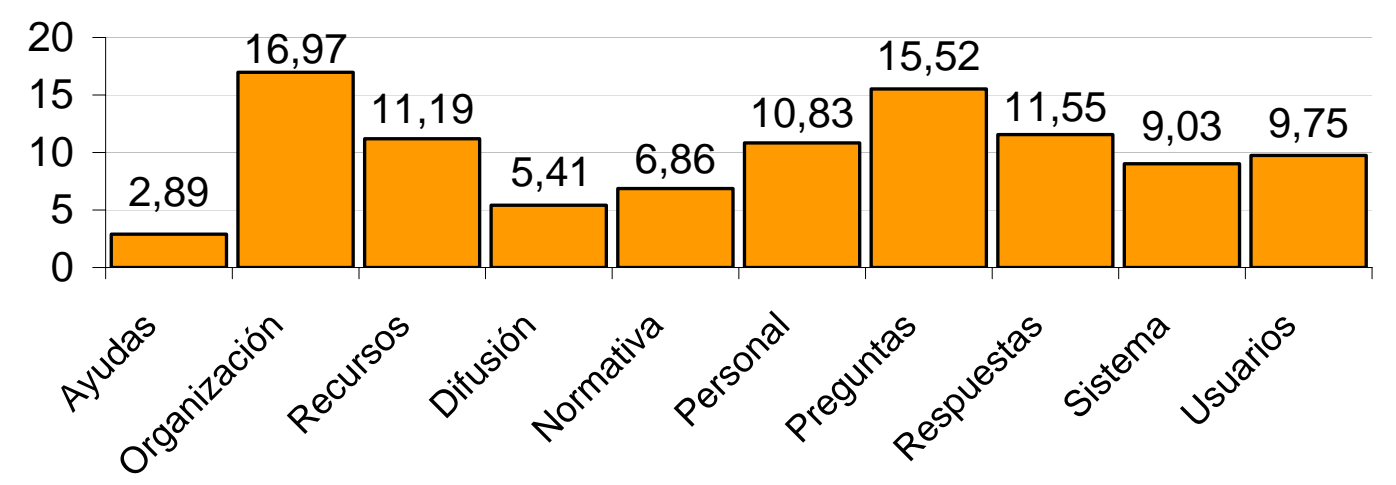

Fig. 3.85. Encuesta a profesionales: opinión sobre principales problemas del servicio

Pero es interesante conocer cuáles son los 277 problemas expresados por los bibliotecarios de referencia en las 114 encuestas, por lo que en la siguiente tabla se relacionan dichos problemas, ordenados por su índice de 
frecuencia e informando además de la categoría temática a la que se han adscrito en la tabla y gráfico anteriores.

\begin{tabular}{|c|c|c|}
\hline $\begin{array}{l}\text { Problema } \\
\end{array}$ & $\mathbf{N}^{\mathbf{o}}$ & Tema \\
\hline Tipo de preguntas, idoneidad y concreción & 23 & Preguntas \\
\hline Mejora de la colección y selección de fuentes & 22 & Recursos \\
\hline Formación específica & 21 & Personal \\
\hline Coordinación, cooperación entre participantes & 15 & Bibliotecas \\
\hline Campaña de promoción del servicio & 15 & Difusión \\
\hline Poca definición del servicio & 11 & Bibliotecas \\
\hline Poca calidad o claridad en las respuestas & 11 & Respuestas \\
\hline Mayor información de los usuarios & 11 & Usuarios \\
\hline Problemas con el servidor & 10 & Sistema \\
\hline Filtrado de preguntas & 9 & Preguntas \\
\hline Selección de recursos de Internet & 8 & Recursos \\
\hline Más explicaciones al usuario antes de que pregunte & 8 & Usuarios \\
\hline Manual poco realista / Normativa poco clara & 7 & Normativa \\
\hline Revisión del manual & 7 & Normativa \\
\hline Replantear turnos en otras lenguas & 6 & Bibliotecas \\
\hline Personal: número y grupos & 6 & Personal \\
\hline Tamaño de la respuesta muy breve & 6 & Respuestas \\
\hline Lentitud del servidor & 6 & Sistema \\
\hline Compartir recursos y experiencias & 5 & Bibliotecas \\
\hline Reenvío de preguntas a otras bibliotecas pertinentes & 5 & Preguntas \\
\hline Unificación de criterios en las respuestas & 5 & Respuestas \\
\hline Nuevas bibliotecas & 4 & Bibliotecas \\
\hline Modificar la clasificación & 4 & Normativa \\
\hline Mayor implicación de las CCAA e Instituciones & 3 & Ayudas \\
\hline Apoyo de bibliotecas especializadas & 3 & Ayudas \\
\hline Limitar el servicio a días laborales & 3 & Bibliotecas \\
\hline Incompatibilidad tareas profesionales y de referencia & 3 & Personal \\
\hline Más tiempo de respuesta & 3 & Respuestas \\
\hline Actualización página web & 3 & Sistema \\
\hline Interacción con el usuario & 3 & Usuarios \\
\hline Dos o más bibliotecas de turno & 2 & Bibliotecas \\
\hline Explicación del motivo de la consulta & 2 & Preguntas \\
\hline Varias preguntas en una / Limitar las preguntas & 2 & Preguntas \\
\hline Adjuntar archivos & 2 & Respuestas \\
\hline Elevado número de preguntas sin respuesta & 2 & Respuestas \\
\hline Mejor mantenimiento informático & 2 & Sistema \\
\hline Información de las posibilidades reales del servicio & 2 & Usuarios \\
\hline Conocer la satisfacción de los usuarios & 2 & Usuarios \\
\hline Ayudas económicas & 1 & Ayudas \\
\hline Servicio específico para preguntas de Biblioteconomía & 1 & Ayudas \\
\hline Responsabilidad de las bibliotecas para sus preguntas & 1 & Bibliotecas \\
\hline Elaboración de guías de recursos & 1 & Recursos \\
\hline Redefinición del ámbito geográfico & 1 & Normativa \\
\hline Acumulación de preguntas en una sola biblioteca & 1 & Preguntas \\
\hline Selección preguntas incontestables & 1 & Preguntas \\
\hline Tipo de respuesta (dar sólo fuentes) & 1 & Respuestas \\
\hline
\end{tabular}




$\begin{array}{rll}\text { Rebajar el tiempo de respuesta } & 1 & \text { Respuestas } \\ \text { Posibilidad de recuperar preguntas } & 1 & \text { Respuestas } \\ \text { No se pueden buscar preguntas por días } & 1 & \text { Sistema } \\ \text { Programa de gestión genera spam } & 1 & \text { Sistema } \\ \text { Mejora de las estadísticas } & 1 & \text { Sistema } \\ \text { Archivo de preguntas poco práctico } & 1 & \text { Sistema } \\ \text { No atender a usuarios no españoles } & 1 & \text { Usuarios }\end{array}$

Existen algunas respuestas en las que coinciden varios de los encuestados, por lo que se pueden considerar como los problemas más urgentes o al menos las cuestiones que hay que solucionar de las que se tiene más consciencia. Parece necesario que exista una mayor información sobre el tipo de preguntas que se deben responder, así como la necesidad de mejorar la colección de referencia y de una formación específica. Otras cuestiones en las que se está de acuerdo es la urgencia de una campaña de difusión, en la idoneidad de recoger datos del usuario o en la definición y coordinación del servicio.

\subsection{Estudio de usuarios}

La evaluación de cualquier servicio requiere preguntar a los usuarios del mismo su opinión y grado de satisfacción. En «Pregunte», como es lógico, los datos del usuario son anónimos y en el archivo de preguntas no se almacenan los correos electrónicos ni su perfil (ciudad, edad, etc.). Pero existe una posibilidad de registrarse voluntariamente como usuario del sistema, lo que les permite interrogar al mismo, para conocer el estado de sus preguntas, tanto resueltas como en proceso de contestación. Esta base de datos de usuarios registrados sí incluye el correo electrónico y es la que se ha empleado para hacer llegar un breve cuestionario en el que se recogen datos básicos como el tamaño de la población o de si se trata de estudiantes, trabajadores o pensionistas. De igual forma, se plantean en el formulario preguntas sobre el servicio y su calidad.

En la base de datos de usuarios registrados se puede saber también las edades y las ciudades de origen de quienes han empleado este sistema, excepto para usuarios no españoles, que aparecen todos reunidos bajo un mismo código, independientemente del país desde el que consulten.

En primer lugar se tomaron los datos de los usuarios españoles y se efectuó una depuración de la base de datos, ya que se percibía que existían muchos usuarios registrados de forma incompleta, así como duplicados. Por este motivo se seleccionaron sólo aquellas personas que indicaban la edad y la localidad. A estos usuarios, cuyo número se elevaba a 1.189 se les envió un correo electrónico el día 4 de febrero de 2004, en cuyo cuerpo del mensaje aparecían las 15 preguntas del cuestionario. Sólo se trataba de responder el mensaje, marcando las opciones que estimasen.

Las edades de estos 1189 usuarios se pueden conocer, ya que éste es uno de los datos que se piden en el formulario de registro: 


$\begin{array}{ll}\text { Edad } & \text { Usuarios registrados españoles } \\ \text { 1: } \text { Menos de } 10 \text { años } & 6 \\ \text { 2: } 11-20 \text { años } & 131 \\ \text { 3: } 21-30 \text { años } & 380 \\ \text { 4: } 31-40 \text { años } & 356 \\ \text { 5: } 41-50 \text { años } & 211 \\ \text { 6: } 51-60 \text { años } & 74 \\ \text { 7: Más de } 60 \text { años } & 31\end{array}$

TOTAL: 1189

De igual forma, también se solicita que se indique la provincia de residencia. La recogida de estos datos se realiza a partir de los códigos postales empleados en España. Para los usuarios no españoles, cuyos datos se expondrán en otra tabla, el indicador de localidad es 00 , indiferentemente del país de origen.

\begin{tabular}{|c|c|c|}
\hline \multicolumn{3}{|c|}{ Provincias de los usuarios registrados } \\
\hline CP & Provincia & Usuarios \\
\hline 01 & Álava & 17 \\
\hline 02 & Albacete & 33 \\
\hline 03 & Alicante & 34 \\
\hline 04 & Almetía & 9 \\
\hline 05 & Ávila & 6 \\
\hline 06 & Badajoz & 19 \\
\hline 07 & Baleares & 11 \\
\hline 08 & Barcelona & 147 \\
\hline 09 & Burgos & 9 \\
\hline 10 & Cáceres & 9 \\
\hline 11 & Cádiz & 18 \\
\hline 12 & Castellón & 9 \\
\hline 13 & Ciudad Real & 8 \\
\hline 14 & Córdoba & 11 \\
\hline 15 & La Coruña & 19 \\
\hline 16 & Cuenca & 7 \\
\hline 17 & Gerona & 24 \\
\hline 18 & Granada & 23 \\
\hline 19 & Guadalajara & 8 \\
\hline 20 & Guipúzcoa & 28 \\
\hline 21 & Huelva & 5 \\
\hline 22 & Huesca & 1 \\
\hline 23 & Jaén & 9 \\
\hline 24 & León & 10 \\
\hline 25 & Lérida & 10 \\
\hline 26 & La Rioja & 13 \\
\hline 27 & Lugo & 4 \\
\hline 28 & Madrid & 145 \\
\hline 29 & Málaga & 12 \\
\hline 30 & Murcia & 91 \\
\hline 31 & Navarra & 38 \\
\hline 32 & Orense & 6 \\
\hline 33 & Asturias & 36 \\
\hline 34 & Palencia & 3 \\
\hline 35 & Las Palmas de Gran Canaria & 12 \\
\hline 36 & Pontevedra & 15 \\
\hline
\end{tabular}




\begin{tabular}{|l|l|l|}
\hline 37 & Salamanca & 16 \\
\hline 38 & Tenerife & 24 \\
\hline 39 & Cantabria & 14 \\
\hline 40 & Segovia & 3 \\
\hline 41 & Sevilla & 34 \\
\hline 42 & Soria & 4 \\
\hline 43 & Tarragona & 30 \\
\hline 44 & Teruel & 2 \\
\hline 45 & Toledo & 12 \\
\hline 46 & Valencia & 98 \\
\hline 47 & Valladolid & 9 \\
\hline 48 & Vizcaya & 41 \\
\hline 49 & Zamora & 5 \\
\hline 50 & Zaragoza & 37 \\
\hline 51 & Ceuta & 1 \\
\hline 52 & Melilla & 0 \\
\hline & & $\mathbf{1 1 8 9}$ \\
\hline
\end{tabular}

A lo largo de los días siguientes se fueron recibiendo mensajes devueltos, dada la inexistencia de los correos indicados por algunos usuarios. Eliminados estos mensajes hay que tomar como dato que se enviaron y recibieron de forma correcta 1.025 cuestionarios. Posteriormente se realizó esta misma operación con los usuarios no españoles, a cuyo cuestionario se añadió una pregunta, para conocer el país desde el que se consultaba el servicio. El procedimiento fue el mismo que en el caso anterior. El 2 de marzo de 2004 se enviaron 537 mensajes con las preguntas a quienes habían completado su registro de usuario de forma completa. Como ocurrió en el caso anterior, llegaron mensajes devueltos por problemas con las direcciones de correo, por lo que la cifra de mensajes que llegaron de forma correcta fue de 508.

Los datos de edad de los usuarios registrados no españoles a los que se envió el cuestionario de evaluación son los siguientes:

$\begin{array}{ll}\text { Edad } & \text { Usuarios registrados no españoles } \\ \text { 1: Menos de } 10 \text { años } & 4 \\ \text { 2: } 11-20 \text { años } & 91 \\ \text { 3: } 21-30 \text { años } & 188 \\ \text { 4: } 31-40 \text { años } & 124 \\ \text { 5: } 41-50 \text { años } & 69 \\ \text { 6: } 51-60 \text { años } & 46 \\ \text { 7: Más de } 60 \text { años } & 15\end{array}$

TOTAL: 537

Los países de origen no se pueden conocer, ya que en el formulario de inscripción como usuarios registrados sólo se recogen códigos geográficos para quienes están domiciliados en España. Los que tienen su localidad fuera del estado español se codifican de forma única con un doble cero (00).

Excluyendo los mensajes que fueron devueltos por inexistencia de la dirección de correo electrónico, el número total de cuestionarios enviados y 
recibidos de forma correcta fue de 1.533 , sumando los remitidos a usuarios españoles (1.025) y no españoles (508).

La cifra de cuestionarios contestados de forma válida, con la evaluación realizada, fue de 216 personas, tanto españolas como no españolas, lo que supone que se trabajará con una muestra del $14,10 \%$ de las encuestas solicitadas, una cifra mucho menor que la que se obtuvo de los profesionales, aunque válida con fines estadísticos $\mathrm{y}$, sobre todo, útil para conocer las opiniones de los usuario del servicio.

Los datos de la encuesta y los resultados obtenidos en la misma se desarrollan en los siguientes párrafos. A las cifras obtenidas se han adjuntado algunos comentarios sobre los datos más significativos. El análisis de la encuesta se abordará de forma conjunta con el resto de las evaluaciones realizadas en el apartado correspondiente a las conclusiones de la investigación.

\begin{tabular}{|ll|}
\hline Ámbito: & Usuarios registrados en el sistema \\
Categorías: & Usuarios españoles y no españoles \\
Técnica: & Envío y recepción de formularios por correo electrónico \\
Muestra: & 216 personas \\
Fechas: & Trabajo de campo (envío y recepción de cuestionarios) \\
& realizado entre febrero y marzo de 2004 \\
Observaciones: & Se empleó la base de datos de usuarios registrados, \\
& haciendo llegar el cuestionario a través de correo \\
& electrónico, incluyendo las preguntas en el cuerpo del \\
& mensaje. No se enviaron los cuestionarios a todos los \\
& usuarios, sino sólo a aquellos que indicaban edad y \\
& localidad. En el caso de estar registrados varias veces \\
& sólo se utilizó una de las direcciones para el envío del \\
& cuestionario. El número total de cuestionarios enviados y \\
& recibidos por los usuarios de forma válida es de 1533, de \\
& los que 216 se devolvieron contestados de forma \\
& correcta y son los que se han tomado como muestra. \\
\hline
\end{tabular}




\section{Preguntas y resultados:}

1 ¿A qué categoría de las siguientes perteneces?

El porcentaje mayor de los usuarios registrados corresponde a trabajadores o desempleados $(68,52 \%)$.

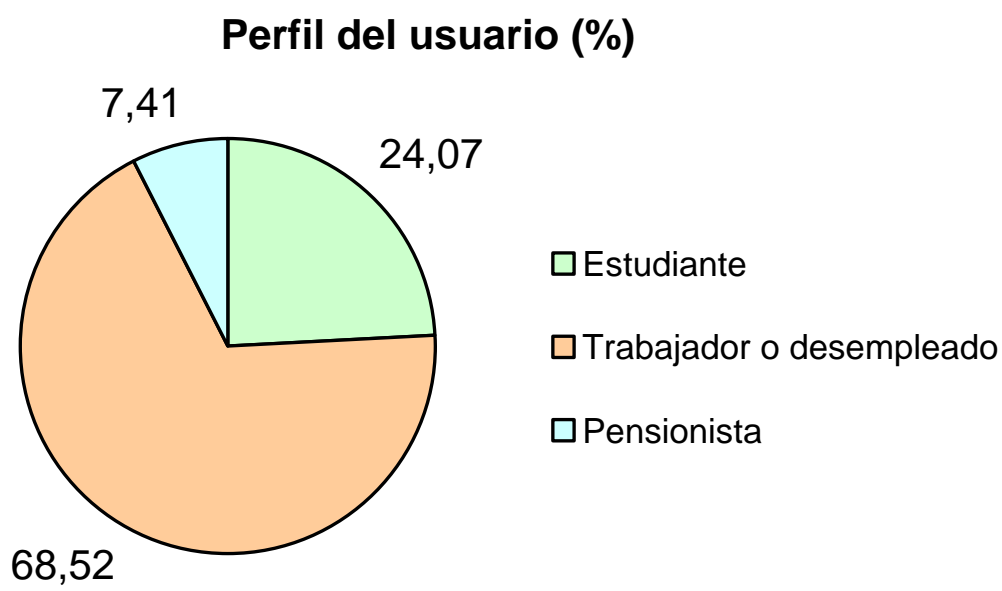

Fig. 3.86. Encuesta a usuarios: perfiles

2 ¿Qué tamaño tiene la población en la que vives?

El mayor porcentaje (31,02\%) corresponde a usuarios que habitan en grandes ciudades, mayores de 750.000 habitantes. A continuación se encuentra el grupo de quienes viven en localidades de entre 100.000 y 250.000 habitantes $(23,15 \%)$.

\section{Población de la localidad (\%)}

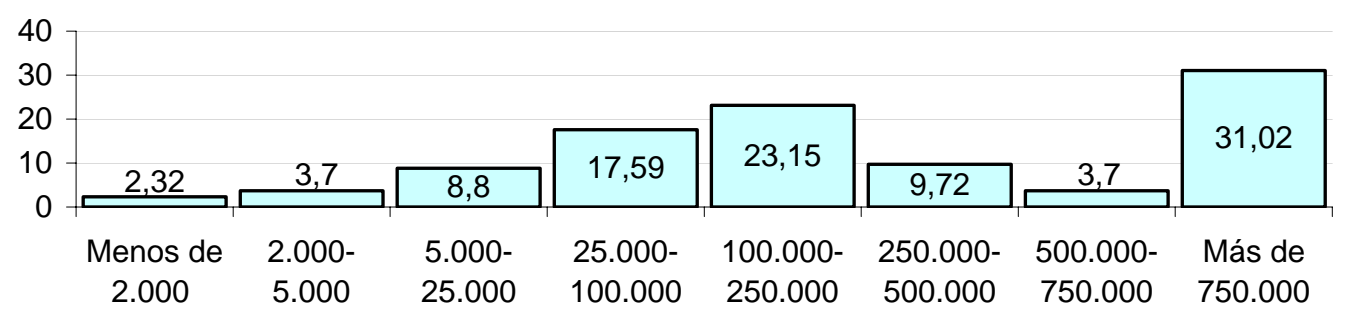

Fig. 3.87. Encuesta a usuarios: población de sus localidades

3 ¿Cuántas veces has usado el servicio «Pregunte: las bibliotecas responden»?

La mayor parte de los usuarios registrados ha empleado varias veces el servicio «Pregunte». Sólo una tercera parte de los encuestados lo había usado sólo una vez. 


\section{Número de preguntas 8\%)}

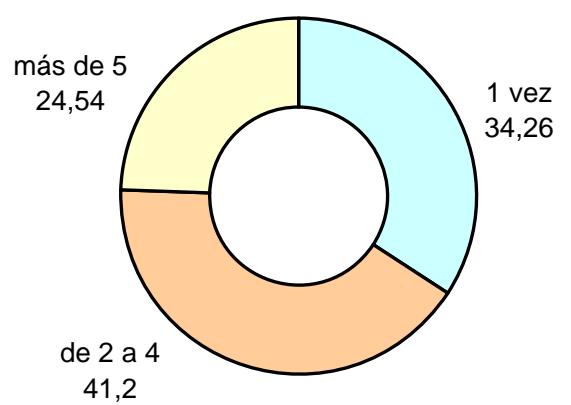

Fig. 3.88. Encuesta a usuarios: preguntas realizadas

4. ¿Tuviste algún problema de conexión con el servidor de «Pregunte»?

Los problemas de conexión con el servidor parecen no haber sido un problema a la hora de realizar una consulta, ya que el $85,65 \%$ indica que no hubo fallos en la conexión.

\section{Problemas con el servidor (\%)}

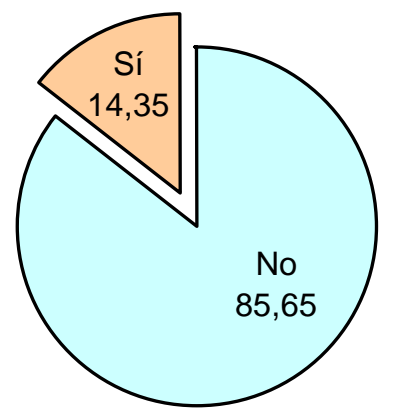

Fig. 3.89. Encuesta a usuarios: problemas de conexión

5 ¿Cuáles fueron los motivos por los que usaste el servicio «Pregunte: las bibliotecas responden»? (Elige sólo una opción, la que consideres mayoritaria)

Por lo general, el empleo de los servicios de referencia obedece a cuestiones profesionales, formativas o personales. En el caso de «Pregunte» se demuestran estas tres finalidades, aunque los motivos educacionales son más frecuentes $(42,13 \%)$ que los restantes. 


\section{Motivos de la consulta (\%)}

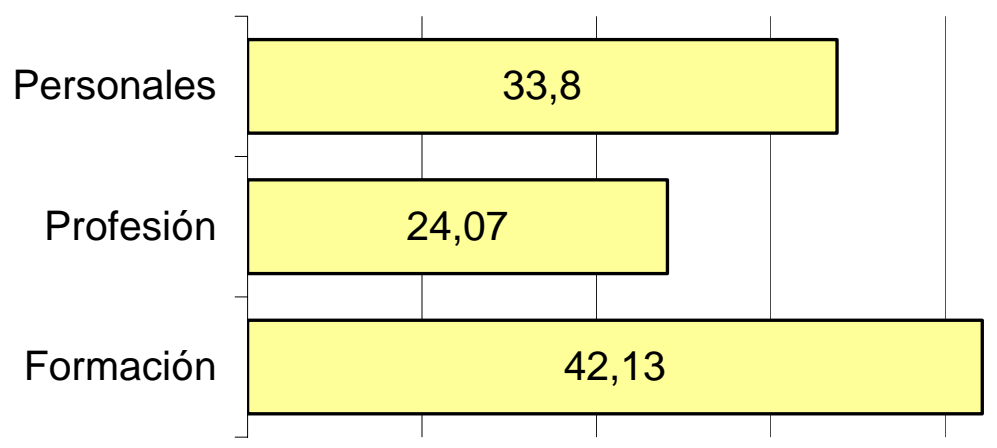

Fig. 3.90. Encuesta a usuarios: motivos de la consulta

6. ¿Cómo valorarías la respuesta que se dio a tu/s pregunta/s? (Elige sólo una opción, la que consideres mayoritaria)

La utilidad de las respuestas dadas es evidente, ya que casi la mitad $(49,07 \%)$ así las califican, mientras que para cerca de la tercera parte $(32,41 \%)$ las consideró de mucha utilidad. También hay que tener en cuenta el dato de que un 18,06\% estimó de poca utilidad las respuestas recibidas.

\section{Utilidad de la respuesta (\%)}

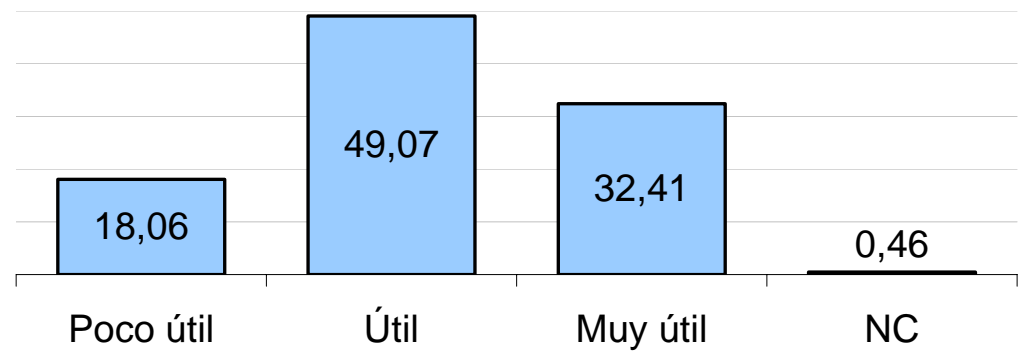

Fig. 3.91. Encuesta a usuarios: utilidad de la respuesta

7. ¿Cómo valorarías el tiempo que se tardó en ofrecerte la respuesta? (Elige sólo una opción, la que consideres mayoritaria)

Las opiniones acerca del tiempo transcurrido hasta que se recibió la respuesta también son satisfactorias en su mayoría, ya que sólo un 12,96\% cree que se tardó mucho en contestar su demanda. 


\section{Tiempo de respuesta (\%)}

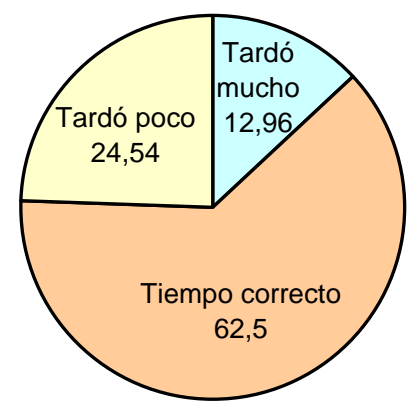

Fig. 3.92. Encuesta a usuarios: tiempo de respuesta

8 ¿Intentaste localizar la respuesta por ti mismo antes de utilizar el servicio «Pregunte: las bibliotecas responden»?

Una información importante es la que se deriva de esta pregunta, ya que un elevado porcentaje de los usuarios del servicio lo emplearon al no encontrar por sí mismos la respuesta a sus demandas de información. Únicamente una décima parte de los encuestados (10,65\%) empleó «Pregunte» como primera opción para resolver sus cuestiones.

\section{Búsqueda previa (\%)}

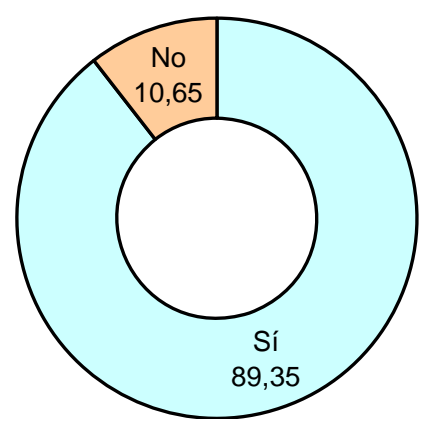

Fig. 3.93. Encuesta a usuarios: búsqueda previa de la información

9 ¿Volverías a usar «Pregunte: las bibliotecas responden»?

Una forma de conocer el grado de satisfacción de un servicio es si vuelve a emplear. Como se vio en una pregunta anterior muchos de los usuarios lo han utilizado de forma reiterada. En el dato actual se comprueba que una inmensa mayoría $(96,30 \%)$ volvería a usar «Pregunte». 


\section{Volver a usar (\%)}

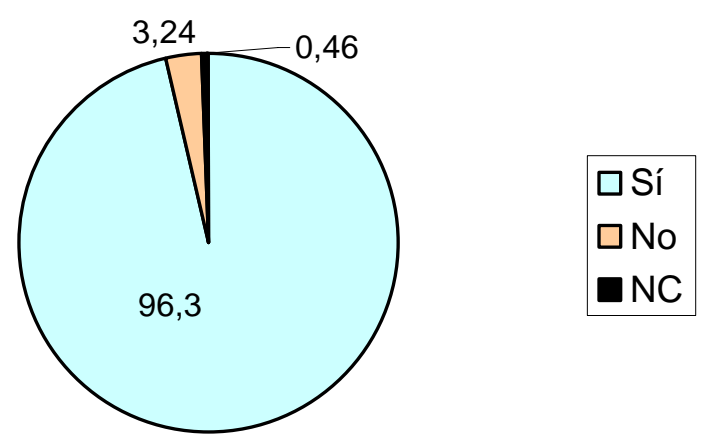

Fig. 3.94. Encuesta a usuarios: fidelización

10 ¿Has recomendado o recomendarías el servicio «Pregunte: las bibliotecas responden»?

Un usuario hace otro usuario y así se puede comprobar en los resultados de esta pregunta, donde un grupo amplio (76,85\%) dice haber recomendado «Pregunte» o estar en disposición de hacerlo. Puede ser preocupante que uno de cada cinco usuarios $(20,83 \%)$ ni ha recomendado el servicio ni piensa hacerlo.

\section{Recomendación del servicio (\%)}

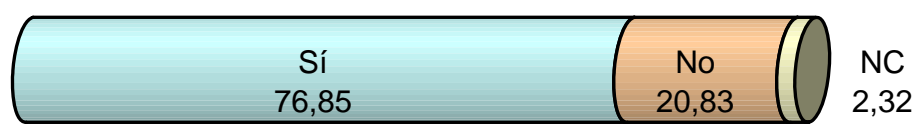

Fig. 3.95. Encuesta a usuarios: promoción del servicio

11. ¿Cómo conociste la existencia del servicio «Pregunte: las bibliotecas responden»? (Elige sólo una opción)

Es interesante conocer cuál es la fuente de información por la que los usuarios conocieron la existencia del servicio. Los enlaces y las recomendaciones en webs son el principal origen, con un 32\%, seguido de recomendaciones hechas en centros de estudio, trabajo y bibliotecas. 


\section{Cómo conoció «Pregunte» (\%)}

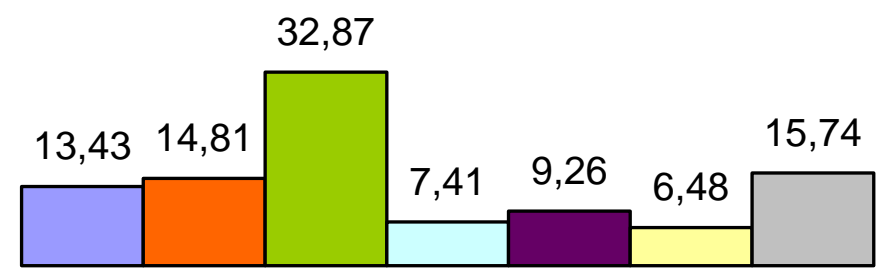

$\square$ Recomendación de una biblioteca

$\square$ Recomendación de mi centro de estudios o trabajo

$\square$ Recomendación en un web

$\square$ Recomendación en una revista o periódico

$\square$ Recomendación de un amigo

$\square$ Recomendación en una lista de noticias o de distribución

$\square$ Otro

Fig. 3.96. Encuesta a usuarios: conocimiento del servicio

Existe un grupo significativo de personas (15,74\%) que no escogieron ninguna de las opciones propuestas y que escogieron la respuesta "Otro", que se encontraba abierta para que el encuestado indicara cómo conoció «Pregunte». Tomando como base ese 15,74\%, la mayoría de quienes eligieron otras opciones la integraban quienes conocieron el servicio navegando por Internet (64,72\%), seguidos de forma distanciada por quienes lo conocieron por su profesión, generalmente bibliotecarios $(8,82 \%)$ y por quienes no recuerdan cómo supieron de «Pregunte» (8,82\%). Otras causas fueron la recomendación de un especialista $(5,88 \%)$, la preparación de oposiciones (5,88\%), la difusión institucional realizada por los responsables ministeriales $(2,94 \%)$ o en la radio $(2,94 \%)$.

12. ¿Qué te parecía la inclusión de un chat en «Pregunte» para hacer preguntas en tiempo real?

Diferentes propuestas de modificación del servicio fueron planteadas a los usuarios para conocer su opinión. La posible inclusión de un chat para recoger en tiempo real las preguntas del usuario y ser contestadas con la mayor brevedad fue calificada como "interesante" por la mayoría (60,65\%), pareciendo algo innecesario a poco más de la décima parte (11,57\%). 


\section{Inclusión de chat (\%)}

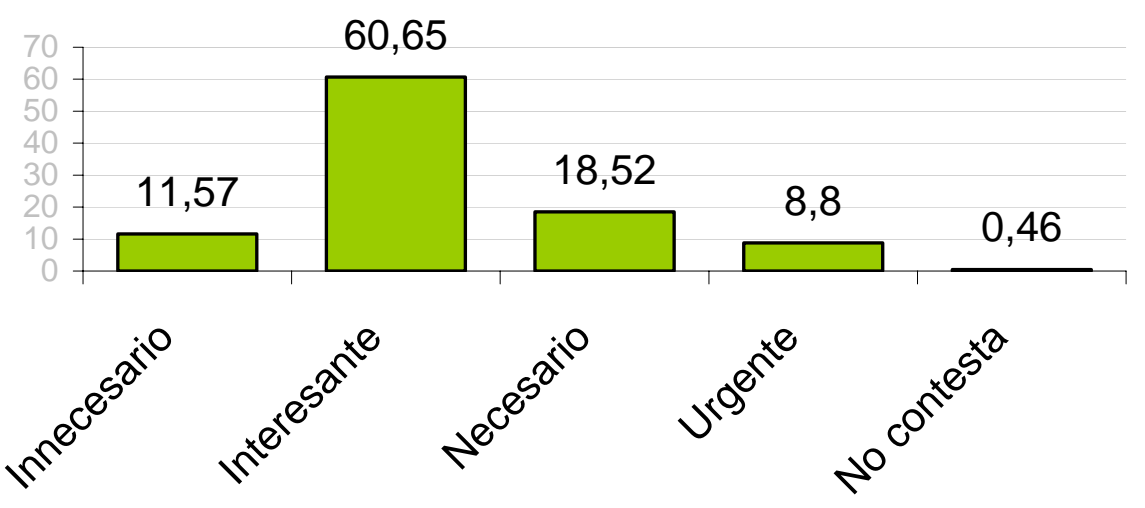

Fig. 3.97. Encuesta a usuarios: inclusión de chat

13. ¿Qué te parecía la inclusión de tutoriales sobre cómo buscar en Internet u otros temas?

Acompañar al formulario de consulta de materiales para enseñar a buscar en Internet o a localizar información en determinados recursos fue una propuesta bien valorada por los usuarios registrados, ya que más de la mitad la consideran necesaria o urgente.

\section{Inclusión de tutoriales (\%)}

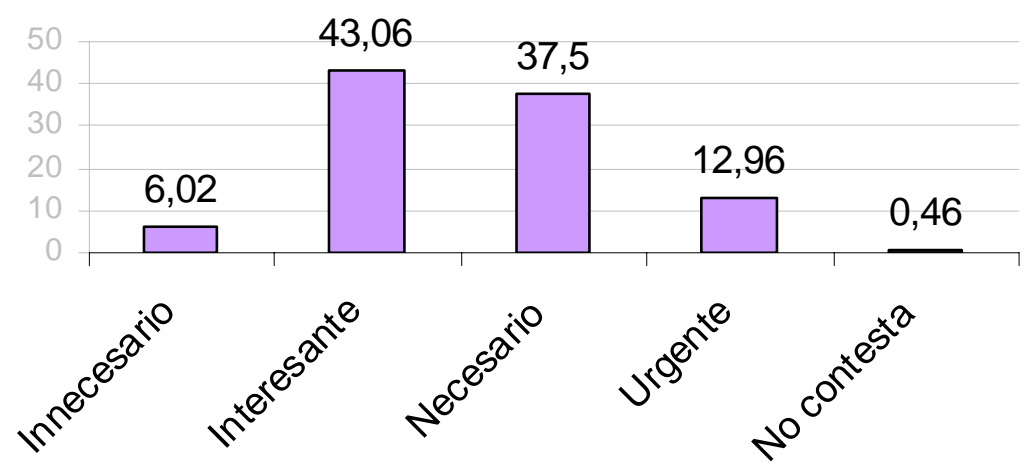

Fig. 3.98. Encuesta a usuarios: inclusión de tutoriales

14. ¿Qué te parecería incluir en «Pregunte» selecciones de recursos de Internet?

Porcentajes muy similares a los obtenidos en la pregunta anterior son los que aparecen en la presente, ya que también la mitad de los encuestados estima que es necesario o urgente incluir una selección de recursos accesibles a través de Internet, que complete la oferta informativa del servicio. 
Inclusión de selecciones de recursos (\%)

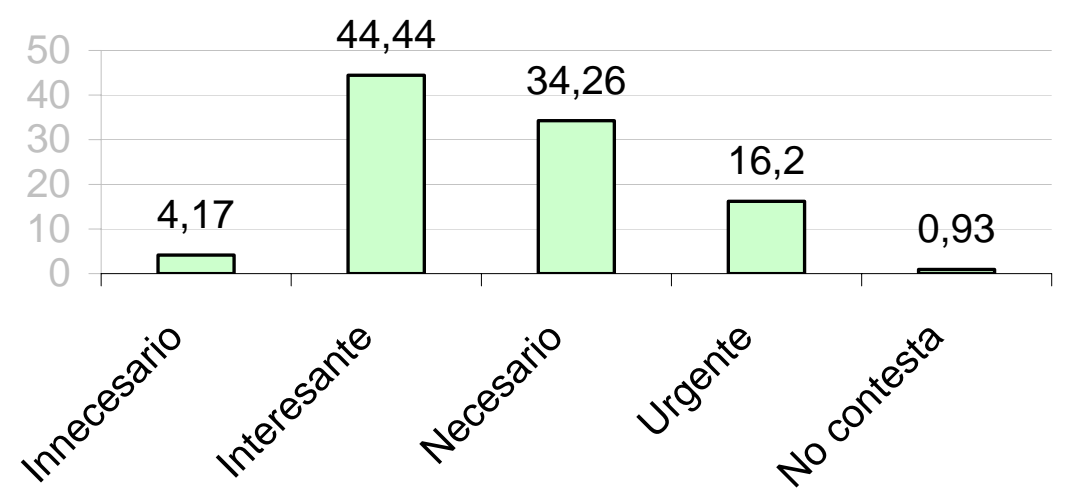

Fig. 3.99. Encuesta a usuarios: inclusión de recursos seleccionados

15. ¿En líneas generales, cómo valorarías el servicio «Pregunte»?

También se pidió al usuario una valoración global del servicio. En su mayoría (55,09\%) opinan que «Pregunte» es muy útil, mientras que un 39,36\% lo definen como "útil". Sólo un 5,09\% dicen del servicio que es poco útil.

\section{Utilidad de «Pregunte» (\%)}

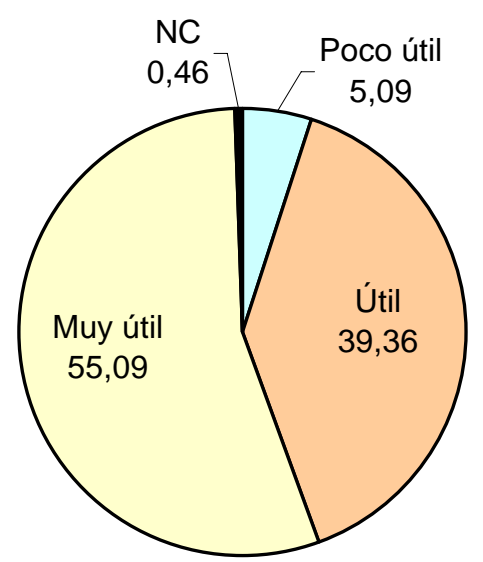

Fig. 3.100. Encuesta a usuarios: valoración del servicio 


\subsection{Estudio de incidencias}

Una buena fuente de información para valorar el servicio es su archivo de incidencias. Ángel Peñalver Martínez, referencista de la Biblioteca Regional de Murcia, era el responsable de la coordinación de «Pregunte» y, por tanto, la persona que se encargaba de resolver las cuestiones técnicas u organizativas que se derivan del servicio. Todos los mensajes enviados por las bibliotecas participantes o por los usuarios son archivados por el coordinador, quien ha facilitado para esta tesis las 332 incidencias del servicio correspondientes al año 2003, año completo más cercano al periodo en el que se estaba realizando la evaluación. A pesar del periodo transcurrido, el contenido de las incidencias fue válido para conocer de primera mano los problemas que generaba este servicio y, sobre todo, sus debilidades. Una vez más el doctorando agradece al entonces coordinador que haya facilitado este material, ya que supone una excelente herramienta de evaluación, que permite conocer los problemas internos y las cuestiones que los usuarios hacen llegar a los responsables del servicio.

Los procedimientos por los que se habían recibido las incidencias son los siguientes:

- Correo: mensaje a la dirección personal del coordinador de «Pregunte» y de los profesionales del servicio en la Biblioteca Regional de Murcia, así como de las direcciones corporativas de «Pregunte»:

referencia-brmu@listas.carm.es

pregunte@listas.carm.es.

- Lista: mensajes enviados desde el foro de «Pregunte», que son recibidos por todos los participantes

- Queja: mensaje enviado a través del formulario de Quejas o reclamaciones y que se redirige al coordinador desde pregunte@listas.carm.es, con el tema "Reclamación o queja al sistema".

- Redirección: mensaje enviado a través del sistema de resolución de preguntas y que se redirige al coordinador desde pregunte@listas.carm.es, con el tema "Las bibliotecas responden: Redirección de consulta".

- Sin respuesta: mensaje enviado a través del sistema de contestación de Preguntas sin respuesta y que se redirige al coordinador desde pregunte@listas.carm.es, con el tema "Las bibliotecas responden: Preguntas sin respuesta".

- Sugerencia: mensaje enviado a través del formulario de Sugerencias y que se redirige al coordinador desde pregunte@listas.carm.es, con el tema "Sugerencia al sistema". 
En el siguiente gráfico se aprecia la distribución de los diferentes sistemas mediante los que se han hecho llegar los mensajes al coordinador del servicio. Se observa que el correo electrónico $(46,08 \%)$ y el formulario de sugerencias $(38,86 \%)$ son los métodos más usados. El correo electrónico es empleado tanto por los usuarios como por las bibliotecas participantes, mientras que la totalidad de las incidencias recibidas a través del formulario de sugerencias disponible en las páginas web del servicio corresponden a usuarios.

También es necesario comentar el escaso uso que se realiza de la lista de distribución interna, que sólo ha sido empleada en el 1,81\% de las incidencias. Este dato es lógico, ya que se está tomando como referencia el total de los mensajes enviados al coordinador, por lo que también se contabilizan los remitidos por los usuarios. Pero, si tenemos en cuenta sólo las incidencias de las bibliotecas, se puede seguir afirmando que el uso de la lista de distribución es bajo, ya que sólo se utilizó para el 4,54\% de las incidencias notificadas por los responsables de las bibliotecas participantes.

\section{Envío de incidencias (\%)}

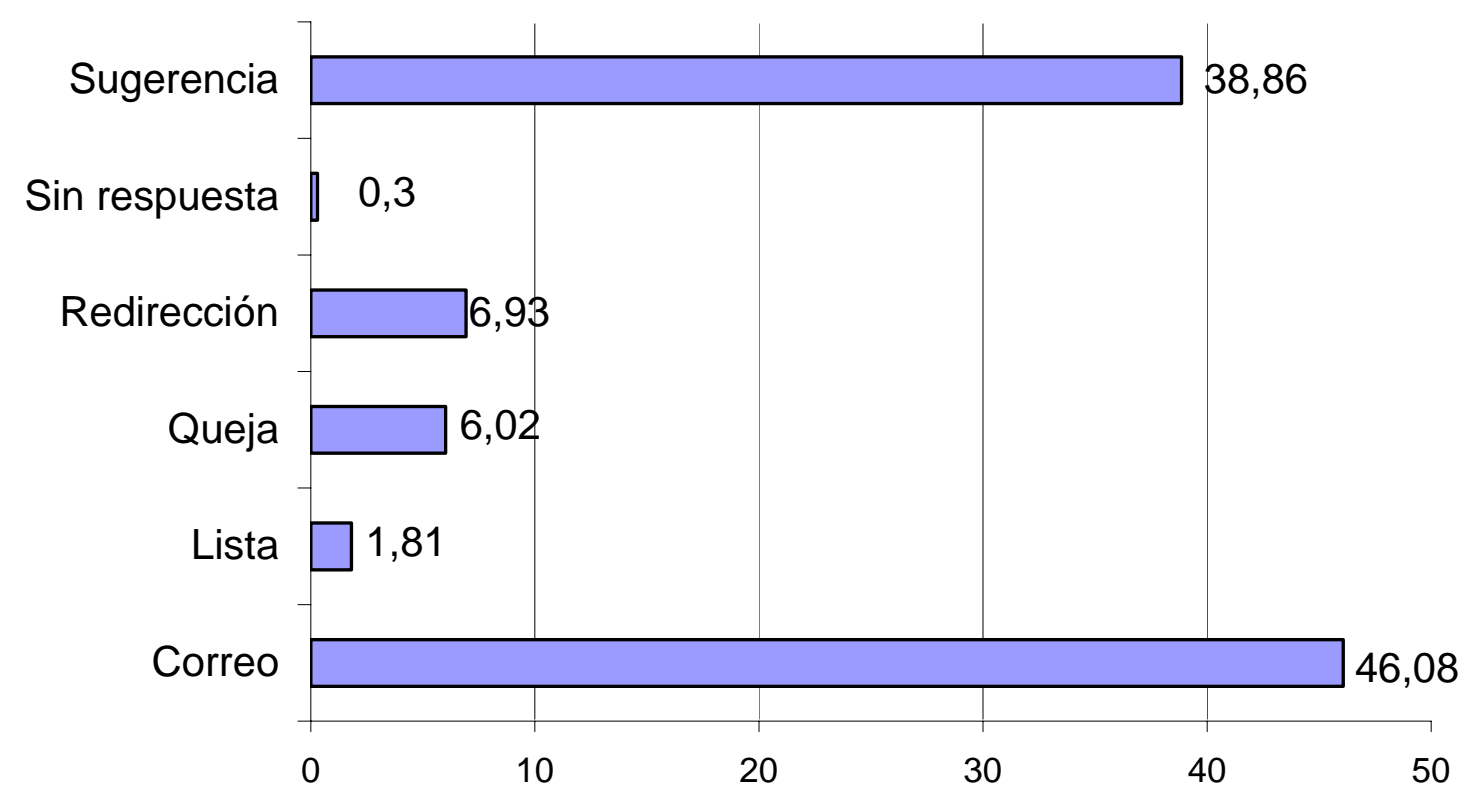

Fig. 3.101. Incidencias: forma de envío

Los remitentes de los mensajes tomados como incidencias son los siguientes:

- Coordinador: responsable de la coordinación entre las bibliotecas participantes.

- Biblioteca: bibliotecas participantes en el servicio

- Usuario: personas no vinculadas al servicio, que hacen uso del mismo 
- Otro: servicio de informática y responsables de la Subdirección General de Coordinación Bibliotecaria.

La representación gráfica del volumen de mensajes enviados por cada categoría de remitentes es la siguiente:

\section{Remitentes de las incidencias (\%)}

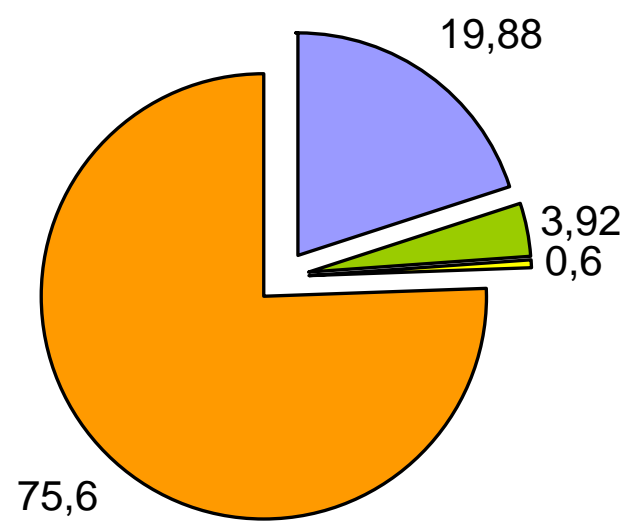

$\square$ Biblioteca $\quad \square$ Coordinador $\quad \square$ Otros $\quad \square$ Usuarios

Fig. 3.102. Incidencias: identificación de remitentes

Como puede apreciarse, las tres cuartas partes $(75,60 \%)$ de los mensajes que recibe el coordinador son enviados por los usuarios, correspondiendo la siguiente proporción a las bibliotecas participantes en «Pregunte» (19,88\%).

Ahora bien, se está entendiendo como incidencia cualquier cuestión remitida al coordinador del servicio o bien los mensajes enviados a todas las bibliotecas que integran el proyecto. Los temas que tratan estas incidencias pueden ser sistematizados en las siguientes categorías:

- Aclaración: datos que complementan a una pregunta efectuada.

- Agradecimiento: mensajes de gratitud por las respuestas remitidas.

- Organización: problemas con consultas, cuestiones de procedimiento, petición de estadísticas y materiales, cambios de turnos, modificación de los datos de una biblioteca o participante o incorporación de los mismos etc.

- Pregunta: consulta enviada al coordinador y no al formulario.

- Pregunta sin respuesta: pregunta contestada por un usuario. 
- Reclamación: queja de un usuario por la respuesta entregada o por cualquier otra cuestión.

- Redirección: envío de preguntas que se consideran más afines a la Biblioteca Regional de Murcia.

- Sistema: cuestiones relacionadas con la tecnología de «Pregunte».

- Sugerencia: indicaciones de cambios y mejoras en «Pregunte».

La distribución de los mensajes según el contenido de los mismos, una vez divididos en las nueve categorías anteriores ofrece los siguientes datos:

\section{Categorías de las incidencias (\%)}

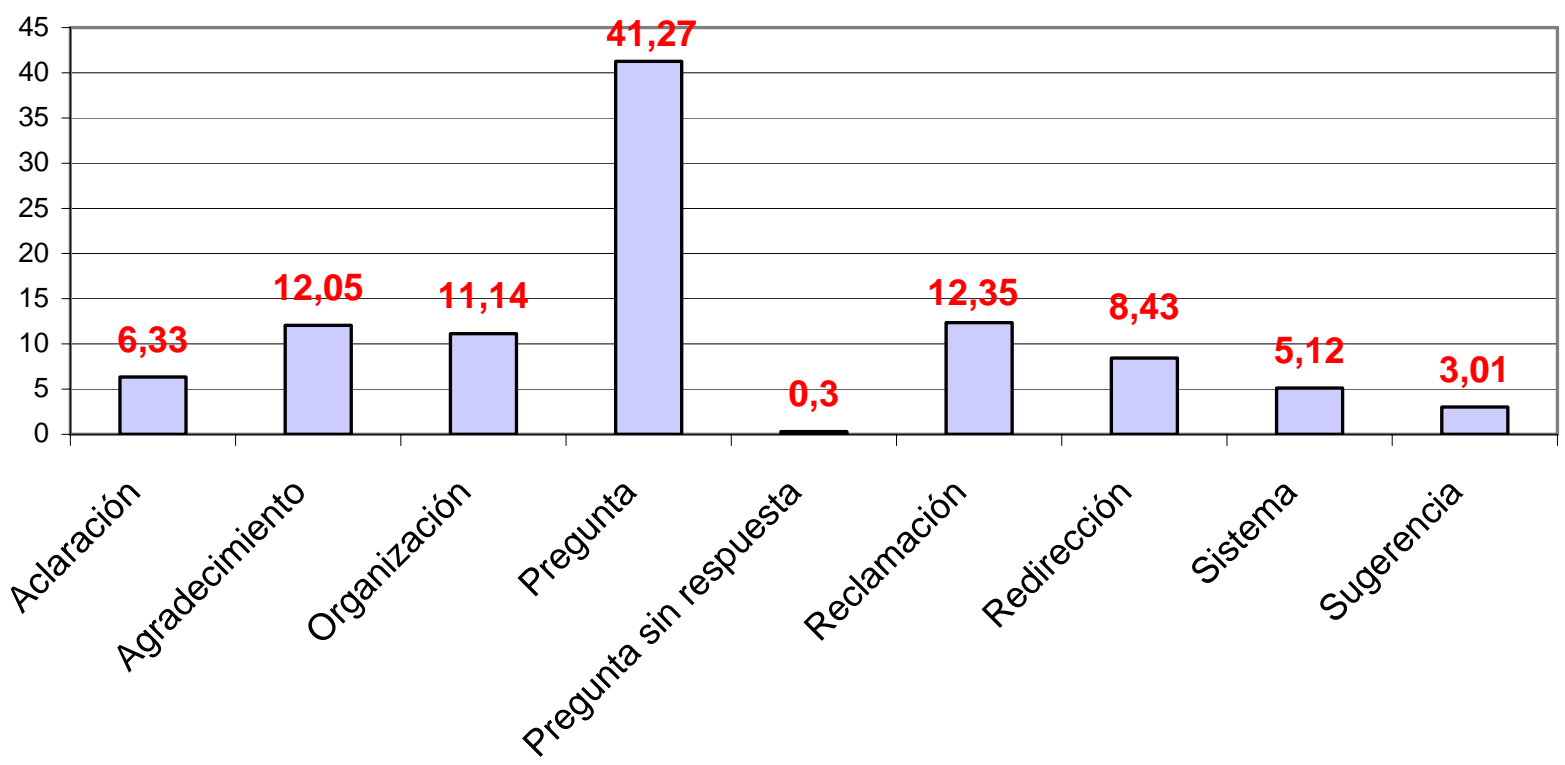

Fig. 3.103. Incidencias: sistematización

Existen datos deducibles de estas estadísticas que merecen ser destacados. Uno de ellos es el elevado porcentaje de consultas $(41,27 \%)$ que se reciben a través del correo electrónico o de los formularios de sugerencias. El usuario tiene bien indicado cuál es el procedimiento para realizar una consulta, sin embargo, emplea otros medios.

Los datos correspondientes a este $41,27 \%$ de preguntas que se hacen llegar al coordinador y que no tienen que ver con el sistema se envían fundamentalmente a través del formulario de sugerencias $(72,26 \%)$, seguido del correo electrónico $(23,36 \%)$ y del formulario de quejas y reclamaciones $(4,38 \%)$, como se muestra en el gráfico siguiente: 


\section{Incidencias: envío de preguntas (\%)}

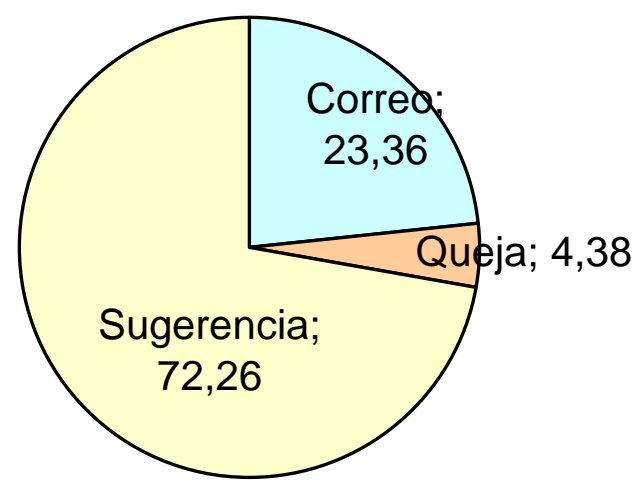

Fig. 3.104. Preguntas enviadas por procedimientos incorrectos

También merece la pena examinar de forma independiente los tipos de incidencias que envían todos aquellos agentes que no son usuarios, es decir, el coordinador, las bibliotecas participantes y otras personas vinculadas a «Pregunte», como son los técnicos informáticos o el personal de la Subdirección General de Coordinación Bibliotecaria.

El $24,40 \%$ de las incidencias corresponde a este tipo de remitentes, vinculados todos ellos a «Pregunte: las bibliotecas responden», en distintos ámbitos. Tomando sólo los mensajes generados por estas personas se pueden extraer los temas más relevantes tratados en sus mensajes. Esta información será importante para conocer los principales problemas con lo que el personal se encuentra.

Las incidencias que han remitido las diferentes bibliotecas o el resto de las personas que no se pueden considerar como usuarios se han clasificado en ocho grupos, en función de los principales asuntos de los que tratan. Las categorías bajo las que se han reunido son las siguientes:

- Consultas: aclaración, resolución, etc. de preguntas realizadas por los usuarios y que necesitan ser completadas, que se contestan de forma personal y cualquier otra circunstancia relacionadas con consultas que no sean sobre el servicio y que no hayan sido remitidas a través del formulario principal de «Pregunte».

- Datos: incorporación, modificación, etc. de los datos de las bibliotecas, como correos electrónicos o direcciones web. También se incluyen aquí los mensajes sobre la incorporación de nuevas bibliotecas al servicio.

- Documentación: petición de estadísticas, materiales, actas, etc. del servicio. 
- Procedimientos: información sobre métodos para realizar determinadas operaciones en «Pregunte».

- Quejas: respuestas, resoluciones y otros mensajes relacionados con las quejas presentadas por los usuarios.

- Redirección: reenvío de consultas que han sido remitidas a una biblioteca y que ésta, a su vez, considera que debe ser contestada o redistribuida por la Biblioteca Regional de Murcia.

- Servidor: problemas con el acceso, modificación de las páginas, traducción a otras lenguas del estado, migración de la información, etc.

- Turnos: modificación de los turnos, incorporación de nuevas bibliotecas a turnos ya establecidos, petición de información sobre fiestas locales para organización de turnos, etc.

Una vez analizadas este tipo de incidencias se puede comprobar que el mayor porcentaje $(32,10 \%)$ corresponde a las preguntas que se redirigen desde las distintas bibliotecas que participan en el servicio a la Biblioteca Regional de Murcia, ya sea porque se considera más idónea para su resolución o para que las remita a las bibliotecas que estime más afines.

También son frecuentes $(16,05 \%)$ las incidencias relacionadas con preguntas hechas por un usuario y que generan posteriores comunicaciones con el mismo. El proceso suele ser el siguiente:

a/ un usuario realiza una pregunta a través del formulario.

b/ la biblioteca a la que corresponde el turno le pide una aclaración de la misma, para poder contestarla de forma positiva.

c/ el usuario envía esta aclaración al correo electrónico que se le indica, que es el del servicio, pregunte@carm.es.

$\mathrm{d} /$ el coordinador recibe este mensaje y lo contesta o lo vuelve a enviar a la biblioteca a la que le fue hecha la consulta.

Los mensajes clasificados como "consultas" se refieren a los apartados c y d de este proceso.

En el mismo porcentaje (16,05\%) se encuentran las incidencias en las que las bibliotecas envían al coordinador y a los restantes miembros del grupo las modificaciones de sus datos, como cambios en los correos electrónicos o en las direcciones web de sus páginas. Además, se engloban en este apartado los mensajes que informan de la incorporación de nuevas bibliotecas al proyecto. 
El siguiente grupo de incidencias dignas de destacar por el volumen que alcanzan $(13,58 \%)$ son los mensajes relacionados con los turnos en los que se organiza a qué bibliotecas corresponde responder las preguntas de cada día. Estas incidencias consisten en: solicitud de cambios de turno, modificaciones en los calendarios establecidos o en la petición de información para confeccionar la distribución de la atención de «Pregunte» entre los centros que participan en el proyecto.

\section{Temas incidencias no usuarios (\%)}

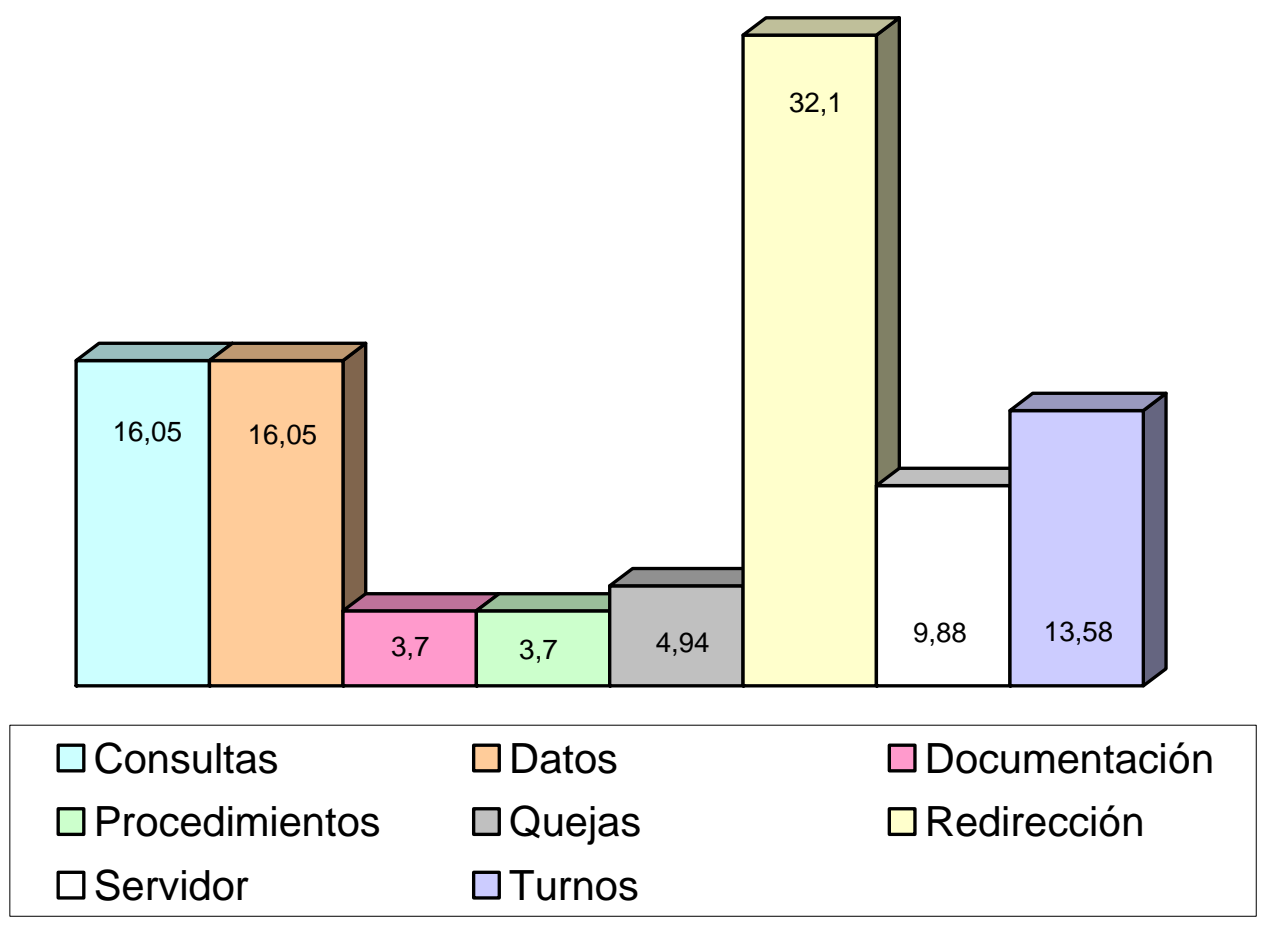

Fig. 3.105. Incidencias: temática

\subsection{Estudio de preguntas y respuestas}

Una de las metodologías más empleadas para la evaluación de un servicio de referencia, ya sea presencial o en línea, es la que analiza la calidad de las respuestas. En la investigación aplicada a «Pregunte» también se ha efectuado un análisis cuantitativo y cualitativo de las preguntas recibidas y de las respuestas ofrecidas. Las teorías expuestas por el doctorando en el apartado correspondiente a la evaluación de los servicios de referencia se ponen en práctica en esta sección, empleando tres metodologías diferentes:

- estadísticas generales: datos cuantitativos de la evolución del número de preguntas recibidas.

- análisis por clasificación: datos cuantitativos para conocer las materias que son objeto de un mayor número de preguntas. 
- análisis de respuestas: estudio cualitativo de la calidad de las informaciones ofrecidas a las consultas de los usuarios.

- homogeneidad de las respuestas: análisis cualitativo para concluir si antes preguntas idénticas las respuestas eran similares.

\subsubsection{Estadísticas generales}

Conocer qué se pregunta y qué se responde es esencial en la evaluación de un servicio de referencia. La forma correcta de afrontar un estudio de este tipo es analizar cada pregunta, sistematizando su contenido y valorando cómo y con qué se ha respondido. Este trabajo merece ser objeto de un estudio independiente, dado su valor informativo y el esfuerzo que requiere. No es éste exactamente el estudio de las preguntas y respuestas que se ha hecho en estas páginas. En esta investigación se ha intentado, por una parte, un acercamiento cuantitativo a la evolución numérica de las preguntas realizadas al servicio en los cuatro primeros años de funcionamiento. Las cifras se refieren al volumen total de preguntas realizadas y también a las materias asignadas a las cuestiones planteadas en «Pregunte».

Existen graves problemas para interrogar la base de datos del servicio, dadas sus limitaciones y los errores de recuperación que se han observado en las diferentes búsquedas realizadas, hasta el punto de que los resultados son diferentes si se consulta la base de datos desde el formulario público o desde el buscador interno, al que sólo acceden las bibliotecas participantes. Esto no debería ser extraño, pero la base de datos es la misma y, hasta cierto punto, los formularios de búsqueda también. A pesar de estos inconvenientes se han realizado distintas consultas, desde el buscador interno, indicando las fechas de junio de un año a mayo del siguiente. El motivo de haber elegido estas fechas es que «Pregunte» se hizo público en el mes de junio de 2000 y que la investigación de esta parte de la tesis doctoral se efectuó en el verano de 2004, por lo que se podía disponer de los datos de cuatro años completos.

Puesto que el formulario de consulta obligaba a introducir algún carácter, las búsquedas se realizaron introduciendo un espacio en el formulario, además de acotando por las distintas fechas de interés. Los resultados obtenidos fueron los siguientes:

\begin{tabular}{|c|c|c|c|}
\hline $\mathbf{0 1 / 0 6 / 2 0 0 0}$ & $\mathbf{0 1 / 0 6 / 2 0 0 1}$ & $\mathbf{0 1 / 0 6 / 2 0 0 2}$ & $\mathbf{0 1 / 0 6 / 2 0 0 3}$ \\
$\mathbf{3 1 / 0 5 / 2 0 0 1}$ & $\mathbf{3 1 / 0 5 / 2 0 0 2}$ & $\mathbf{3 1 / 0 5 / 2 0 0 3}$ & $\mathbf{3 1 / 0 5 / 2 0 0 4}$ \\
\hline 7839 & 5990 & 4596 & 5417 \\
\hline
\end{tabular}

Estos datos son preocupantes, ya que la cifra más elevada se muestra el primer año de funcionamiento, a partir del cual las cifras fueron decreciendo, aunque con un esperanzador ascenso en el último año. El porqué de estos resultados es uno de los alicientes de esta investigación, que consiguió 
argumentar las debilidades en sus conclusiones y a partir del cual se propusieron soluciones para mejorar los puntos débiles del servicio, tal y como ha ocurrido posteriormente, ya que en 2007 se ha mejorado el servicio teniendo en cuenta la serie de observaciones extraídas de las distintas evaluaciones realizadas en este estudio.

\subsubsection{Análisis por clasificación}

Otro análisis cuantitativo llevado a cabo se refiere a las categorías temáticas a las que pertenecen las preguntas recibidas en «Pregunte». Como ocurrió para obtener los datos totales, hubo problemas para conseguir estas cifras. Con el fin de poder contar con información cuantificable se realizaron consultas al servidor desde el buscador interno, indicando los mismos periodos cronológicos (junio a mayo) e introduciendo un espacio en blanco como único carácter de la consulta, entendiendo que en todas las preguntas habrá al menos un espacio.

Los resultados pertenecen a las categorías que se empleaban en esas fechas, ya que el sistema de clasificaciones varió en julio de 2002. No obstante, los datos totales pueden ser significativos. Puesto que los resultados absolutos presentaron incongruencias, dependiendo de si se realizaba la consulta en el buscador interno o en el público, se ha preferido extraer los datos porcentuales de la clasificación temática actual, teniendo en cuenta que hasta julio de 2002 no existían las categorías de "Bibliotecas y documentación", "Lugares y gentes" y "Pensamiento y religiones". Hasta ese año estos temas se encontraban clasificados en otras categorías, como "Arte y Humanidades". Asimismo, en esa fecha desaparecieron otras categorías como "Cine", "Música" y "Deportes".

Las búsquedas de los cuatro primeros años, objeto de esta investigación, dieron los siguientes resultados:

\begin{tabular}{|l|r|}
\hline \multicolumn{1}{|c|}{ Tema } & \multicolumn{1}{c|}{$\%$} \\
\hline Administración, legislación, política & 7,06 \\
\hline Arte & 14,78 \\
\hline Bibliotecas y documentación & 8,94 \\
\hline Ciencia y naturaleza & 3,11 \\
\hline Ciencias Sociales & 5,17 \\
\hline Economía y empresas & 4,82 \\
\hline Educación & 5,4 \\
\hline Empleo y trabajo & 2,24 \\
\hline Historia & 11,9 \\
\hline Informática e Internet & 4,17 \\
\hline Ingeniería, tecnologías & 7,38 \\
\hline Lenguas y literatura & 13,51 \\
\hline Lugares y gentes & 2,01 \\
\hline Pensamiento y religiones & 1,09 \\
\hline Salud, medicina & 3,47 \\
\hline Viajes y ocio & 4,95 \\
\hline
\end{tabular}


En los porcentajes de este periodo se observa que existen dos grandes áreas que destacan: "Arte" y "Lenguas y literatura". No obstante, hay que tener en cuenta que estos porcentajes no pueden ser tenidos en cuenta en su totalidad, ya que, como se dijo, existen categorías que no existían hasta julio de 2002, cuyas preguntas aparecen en otras materias.

Gráficamente, la tabla anterior se expresaría de la siguiente forma:

Temática de las preguntas (\%)

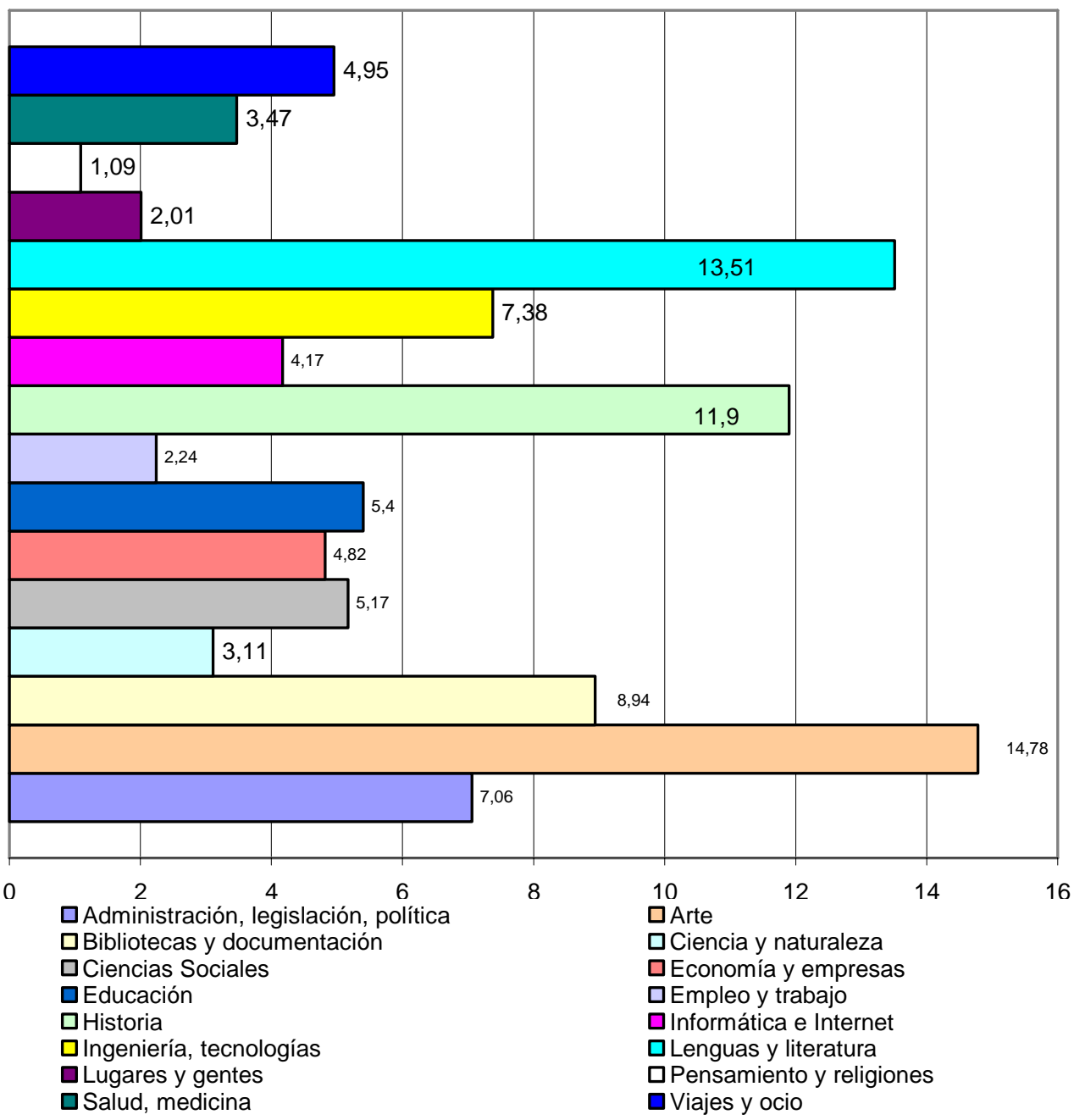

Fig. 3.106. Temática de las preguntas

Para interpretar de forma correcta los datos que se exponen en esta tabla hay que recordar que algunas categorías temáticas se desestimaron en el verano de 2002, mientras que otras aparecieron y otras fueron reestructuradas. En la actualidad es imposible recuperar por las categorías que ya no existen, por lo que el desarrollo diacrónico de las preguntas no puede ser analizado a partir del sistema de recuperación que ahora se utiliza. No obstante, existieron algunos estudios e informe previos cuyos datos pueden ser útiles en el análisis temático de las preguntas que ahora se está haciendo. 
En el I Congreso Nacional de Bibliotecas Públicas, celebrado en Valencia en el año 2002, se presentó una comunicación titulada "Evaluación de fuentes de información para servicios de referencia en Internet: una propuesta a partir de «Pregunte: las bibliotecas responden»", que fue elaborada por María Dolores Ayuso García, Ángel Peñalver Martínez y Victoria Martínez Navarro. En dicha comunicación se reproducen los datos numéricos de las consultas realizadas al servicio desde el 1 de junio de 2000 hasta el 31 de mayo de 2002.

Las cifras se recogieron por los temas que se empleaban en el momento de redactar la ponencia, que fue justo antes de que se procediera a un cambio en la clasificación. Por este motivo es importante dejar constancia de los resultados obtenidos, antes de ofrecer las cifras de los temas actuales. La tabla que se reproduce a continuación está extraída de la comunicación presentada por Ayuso, Peñalver y Martínez al I Congreso Nacional de Bibliotecas Públicas. La ordenación de las materias se ha hecho en función de las más demandas hasta mayo de 2002.

$\begin{array}{lr}\text { Tema } & \text { Preguntas } \\ \text { Arte y Humanidades } & 2391 \\ \text { Lenguas y Literatura } & 1790 \\ \text { Historia } & 1760 \\ \text { Ciencia y Tecnología } & 1375 \\ \text { Derecho, Gobierno y Ciencias Políticas } & 1016 \\ \text { Educación } & 848 \\ \text { Actualidad } & 759 \\ \text { Economía y negocios } & 723 \\ \text { Informática e Internet } & 571 \\ \text { Salud y Ciencias Médicas } & 485 \\ \text { Formación y empleo } & 382 \\ \text { Sin tema } & 368 \\ \text { Tiempo libre y ocio } & 305 \\ \text { Música } & 280 \\ \text { Viajes / Turismo } & 238 \\ \text { Deportes } & 173 \\ \text { Ecología } & 162 \\ \text { Beber y comer } & 133 \\ \text { Cine } & 115\end{array}$

Como puede apreciarse es lógico que se hiciese una reforma de las materias, ya que muchas eran excesivamente amplias (Arte y Humanidades) y otras demasiado específicas, como ocurría con cine, música o deportes. En estos resultados sorprende el elevado número de cuestiones que se recibieron de contenido humanístico, ya que sólo tres categorías ("Arte y Humanidades", "Lenguas y Literatura" e "Historia") constituyen más del $40 \%$ del total de las consultas realizadas.

Para poder aportar los datos correspondientes al momento del estudio se interrogó la base de datos de preguntas por las distintas materias que se 
empleaban en ese momento, delimitando la consulta por periodos anuales que van desde el 1 de junio de un año, hasta el 31 de mayo del año siguiente. Las cifras que se aportan son datos absolutos. Los datos correspondientes a la opción "Sin tema" se han obtenido de la diferencia entre el número de respuestas anuales totales resultantes de la búsqueda por fechas (sin delimitar tema) y la suma de las consultas de cada uno de los temas. Es decir, primero se interrogó a la base de datos por fechas y luego por esas mismas fechas, pero delimitando tema a tema. Se entendió que la diferencia entre ambos resultados correspondía a las preguntas a las que no se les había asignado un tema.

Los datos que se pudieron extraer de las consultas anuales (1 de junio a 31 de mayo) son los que se exponen a continuación:

\begin{tabular}{|l|l|l|l|l|}
\hline \multicolumn{1}{|c|}{ Temas actuales } & \multicolumn{1}{|c|}{$\begin{array}{c}\text { 2000I } \\
\mathbf{2 0 0 1}\end{array}$} & \multicolumn{1}{|c|}{$\begin{array}{c}\mathbf{2 0 0 1} \text { (2002 } \\
\text { 20002I }\end{array}$} & \multicolumn{1}{|c|}{$\begin{array}{c}\mathbf{2 0 0 3} \text { (2003 } \\
\mathbf{2 0 0 4}\end{array}$} \\
\hline Administración, legislación, política & 587 & 426 & 284 & 352 \\
\hline Arte & 1402 & 1373 & 444 & 251 \\
\hline Bibliotecas y documentación & 0 & 0 & 686 & 1183 \\
\hline Ciencia y naturaleza & 92 & 70 & 216 & 349 \\
\hline Ciencias Sociales & 397 & 356 & 246 & 284 \\
\hline Economía y empresas & 394 & 328 & 206 & 216 \\
\hline Educación & 521 & 325 & 173 & 240 \\
\hline Empleo y trabajo & 224 & 158 & 90 & 79 \\
\hline Historia & 957 & 794 & 605 & 484 \\
\hline Informática e Internet & 343 & 228 & 197 & 214 \\
\hline Ingeniería, tecnologías & 782 & 589 & 187 & 178 \\
\hline Lenguas y literatura & 981 & 808 & 638 & 724 \\
\hline Lugares y gentes & 0 & 0 & 162 & 297 \\
\hline Pensamiento y religiones & 0 & 0 & 82 & 165 \\
\hline Salud, medicina & 303 & 182 & 137 & 181 \\
\hline Viajes y ocio & 491 & 353 & 172 & 136 \\
\hline Sin clasificar & 365 & 0 & 71 & 84 \\
\hline TOTAL & 7839 & 5990 & 4596 & 5417 \\
\hline
\end{tabular}

Si se desean obtener datos significativos sólo habría que valorar los dos últimos años ofrecidos, ya que fue cuando se introdujo la clasificación vigente. Las tendencias del periodo 2002/2003 se mantienen en el correspondiente a 2003/2004, notándose algunos movimientos a la baja importantes, como el correspondiente a las preguntas sobre arte o historia. Por otra parte, se observan otras progresiones en ascenso significativas, sobre todo la del grupo de "Bibliotecas y documentación", que se ha incrementado de manera notable. Algo similar ocurrió con el grupo "Pensamiento y religiones", que ha duplicado el número de preguntas en un año.

La situación en el último año es que las preguntas sobre "Bibliotecas y documentación" son las más numerosas, seguidas de forma lejana, por las de los grupos "Lenguas y literatura" e "Historia". El alto grado de conocimiento del servicio entre profesionales de las bibliotecas y estudiantes 
de Biblioteconomía son una posible causa de que ésta sea la materia más demandada.

En el siguiente gráfico se expone visualmente la situación actual en cuanto a qué categorías temáticas pertenecen las preguntas que se han recibido en «Pregunte» en el último año del periodo de la investigación.

Consultas por temas (2003/2004)

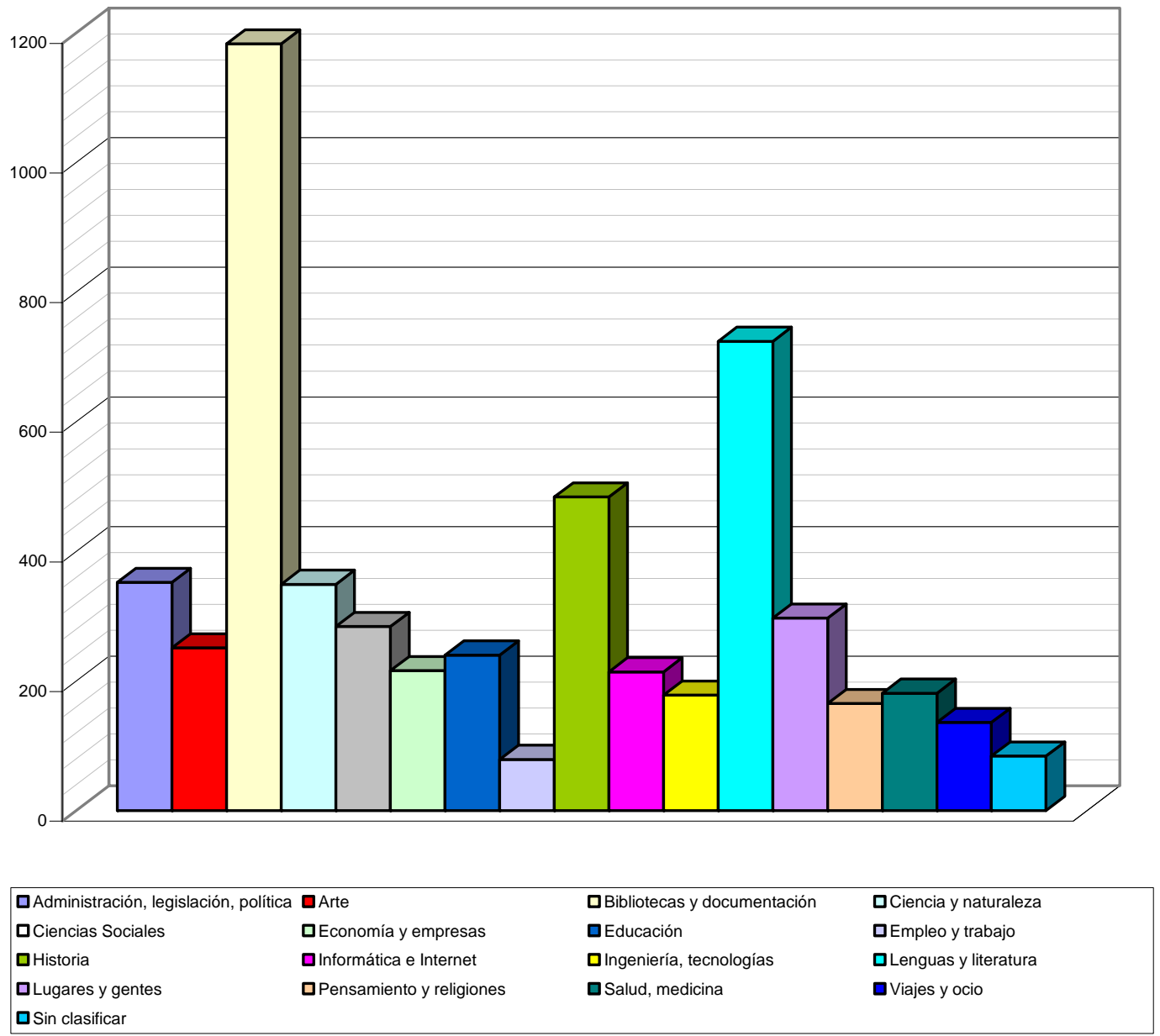

Fig. 3.107. Número de preguntas por temas (2003/2004)

Por lo que respecta a la evolución de los temas que más han variado en los dos últimos años del estudio, la representación gráfica sería la siguiente: 
Temas 2002/03-2003/04

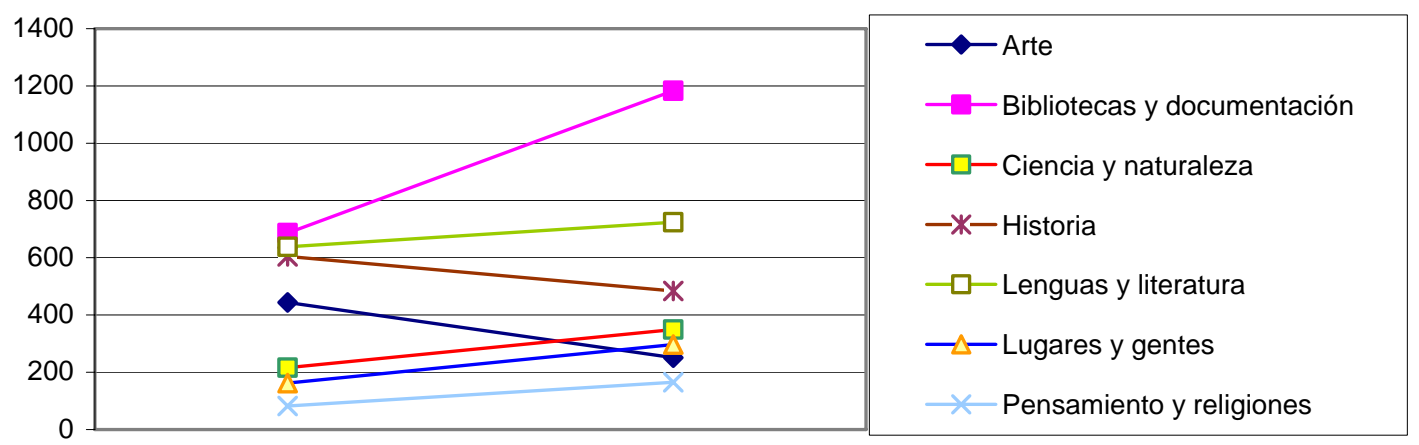

Fig. 3.108. Evolución de la preguntas por temas (2002-2004)

\subsubsection{Análisis de respuestas}

El estudio cualitativo de «Pregunte: las bibliotecas responden» es la única opción para conocer la calidad de las respuestas dadas y de la información complementaria facilitada. Ante una pregunta procedente, interesa conocer aspectos como: si la pregunta se contesta, si es contestada correctamente o si se ofrecen fuentes complementarias. Además, para una completa evaluación y un análisis exhaustivo del servicio habría que valorar qué fuentes de información se han empleado. Otra cuestión importante, imposible de valorar con el sistema actual, sería si el usuario está satisfecho con la respuesta dada. Pero lo que sí es evaluable es el tipo de respuesta que se ha dado al usuario. Para ello se optó por analizar un turno completo del servicio, el que transcurrió entre el 1 de marzo de 2004 y el 3 de abril del mismo año, ambos inclusive. Se han elegido estas fechas porque es el mes en el que se estaban recogiendo y procesando las encuestas de profesionales y usuarios, por lo que algunas cuestiones de las contestadas en los formularios están vinculadas a las respuestas que se ofrecen a las preguntas de los usuarios y reflejadas en las mismas (necesidades de formación, de colecciones, de enlaces de Internet, etc.). Como incidencia hay que tener en cuenta que en este periodo existieron varios días festivos, sobre todo los pertenecientes a la Semana Santa. No obstante, esto es interesante para el estudio, ya que se reflejará cómo se comporta el servicio en días feriados, en relación a los días laborales. Los datos de este estudio de respuestas son los siguientes:

Fechas: $\quad 1$ de marzo de 2004 a 3 de abril de 2004

Turnos: 1 (34 bibliotecas)

Preguntas: 581

Evaluación: Se analizaron en cada pregunta los siguientes aspectos:

a/ Tipo de respuesta

b/ Fuentes empleadas

c/ Fuentes para ampliar

d/ Días transcurridos entre la pregunta y la respuesta

e/ Validez de la respuesta

f/ Temática de la preguntas 
A continuación se exponen y comentan los resultados obtenidos en el análisis de las respuestas de este periodo.

a/ Tipo de respuesta

Se establecieron cuatro categorías en el tipo de respuesta que se da a una pregunta:

- Texto: la respuesta se ofrece mediante uno varios o párrafos explicativos

- Fuentes: no se ofrece una respuesta, sino que se dan las fuentes para encontrarla

- Texto y fuentes: se ofrece la respuesta en un texto y se indican fuentes relacionadas

- No contestada: la pregunta se deja sin repuesta, bien porque se considera improcedente o porque no se pudo contestar y tampoco se envió mensaje al usuario

Los resultados obtenidos muestran que la mayoría de las respuestas (58\%) se ofrecen mediante un texto explicativo. Aquí se incluyen también las contestaciones que indican al usuario que matice o concrete su pregunta y las que informan de que no se ha podido encontrar nada.

\section{Tipo de respuesta (\%)}

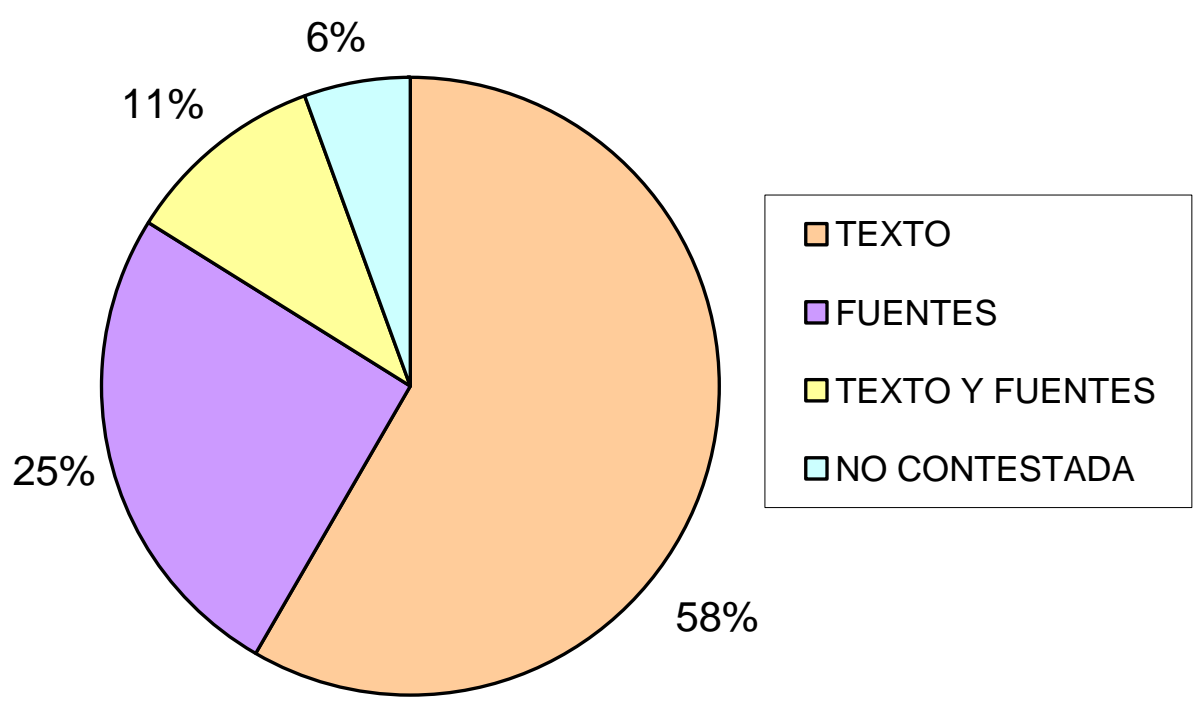

Fig. 3.109. Estudio de respuestas: tipología 
b/ Fuentes empleadas

En este apartado se valoró el tipo de fuentes que se utilizaron para la resolución de la consulta, siempre que se rellenara este campo. En muchas ocasiones las fuentes se dan como parte de la respuesta; en este caso no se contabilizaron como fuentes empleadas, sino como tipo de respuesta. Así pues, las categorías empleadas para valorar las fuentes empleadas son:

- Impresas: monografías, obras de referencia y otros recursos en papel

- Electrónicas: CD-ROM, OPAC, recursos de Internet

- Personales: consultas a personas o instituciones

- Ninguna: el campo "Fuentes de información" aparece en blanco

- Varias: uso conjunto de fuentes impresas, electrónicas o personales

- No procede: pregunta sin responder

En la distribución por categorías de las preguntas y respuestas examinadas se evidencia el alto porcentaje $(53,56 \%)$ de preguntas que se solucionan tras la consulta de fuentes electrónicas y/o telemáticas. También es significativo el promedio de respuestas que no incluyen las fuentes empleadas $(19,10 \%)$.

\section{Fuentes empleadas (\%)}

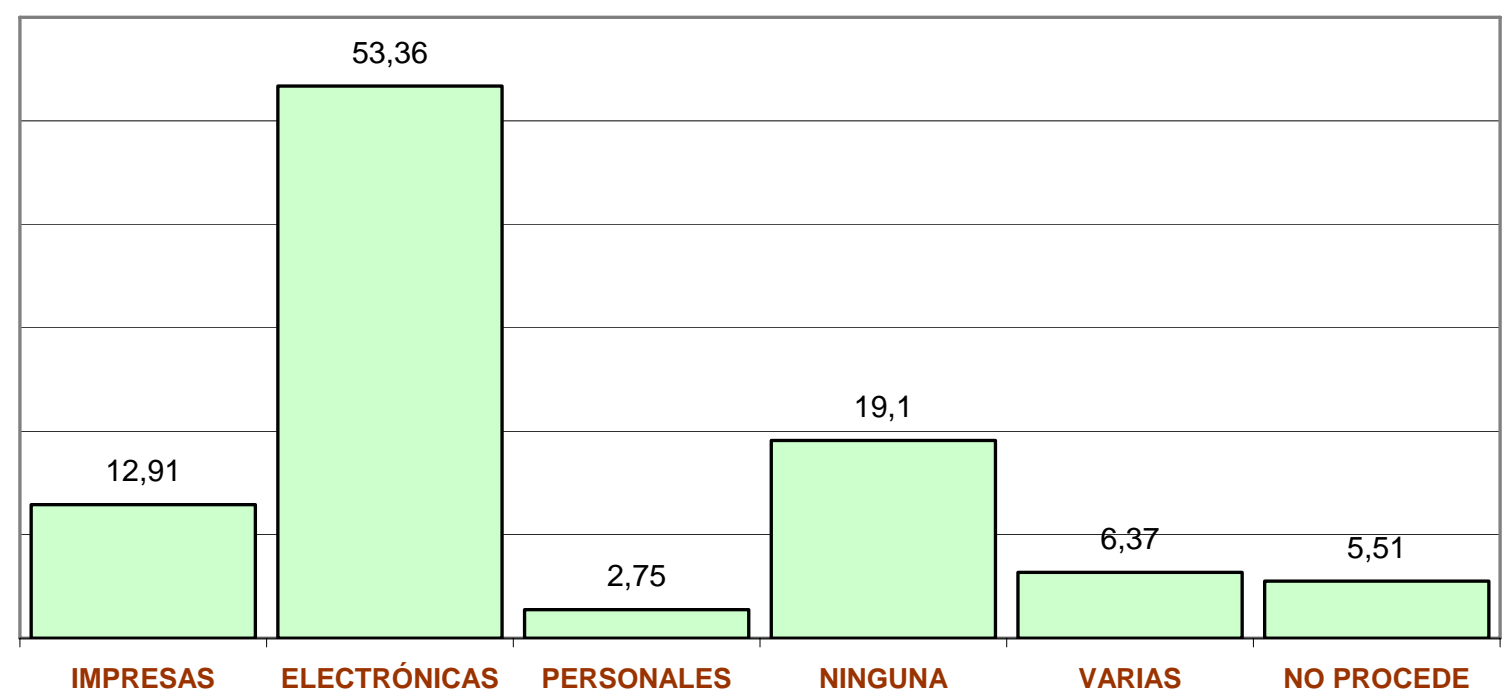

Fig. 3.110. Estudio de respuestas: fuentes empleadas 
c/ Fuentes para ampliar

La inclusión de fuentes para ampliar es una recomendación del manual de procedimiento de «Pregunte; las bibliotecas responden». En esta ocasión, se ha cuantificado el número de preguntas que añadían fuentes a sus respuestas, sin entrar a valorar ni a sistematizar qué tipo ni su calidad.

Los grupos establecidos en esta categoría son:

- Sí: la respuesta incluye fuentes para ampliar

- No: la respuesta no incluye fuentes para ampliar

- No procede: la pregunta no se contestó

\section{Fuentes para ampliar (\%)}

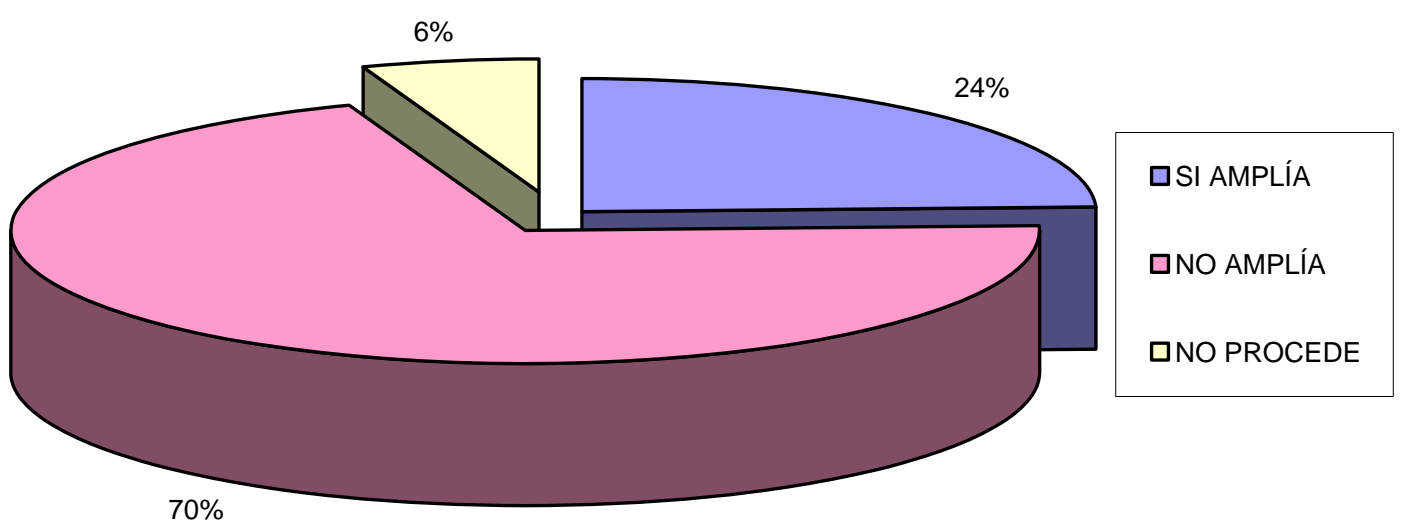

Fig. 3.111. Estudio de respuestas: inclusión de fuentes complementarias

Como puede verse en el gráfico los profesionales que atienden «Pregunte» no acostumbran a incluir fuentes para ampliar, ya que sólo en un $24 \%$ de las respuestas analizadas se ha rellenado este campo.

También es cierto que en muchas preguntas no es necesario ofrecer fuentes complementarias, ya que la respuesta dada contesta plenamente la cuestión planteada por el usuario.

No obstante, debería concretarse el alcance de este campo, delimitando qué uso se le quiere dar y qué tipo de información deberá contener. 
d/ Días transcurridos entre la pregunta y la respuesta

El servicio se compromete a contestar una pregunta en un máximo de tres días. Las estadísticas globales de «Pregunte» indican que en más del $90 \%$ de los casos las respuestas se ofrecen en el plazo marcado.

No obstante, se ha querido tomar una muestra del número de días que transcurren desde que el usuario hace una consulta al servicio hasta que recibe un correo con la respuesta.

En la siguiente tabla se han tomado las fechas que aparecen en el buscador interno de «Pregunte» (archivo de preguntas). Aquí, las respuestas improcedentes aparecen con una fecha de recepción y otra de resolución. Esta última es la del día en que se envió la opción automática de "Rechazar", con la que se encuentran las bibliotecas responsables del turno. Por tanto, en esta ocasión sí se han cuantificado las preguntas sin respuesta. Los datos resultantes, que se ofrecen en cifras absolutas, son los siguientes:

\section{Días transcurridos Pregunta / Respuesta}

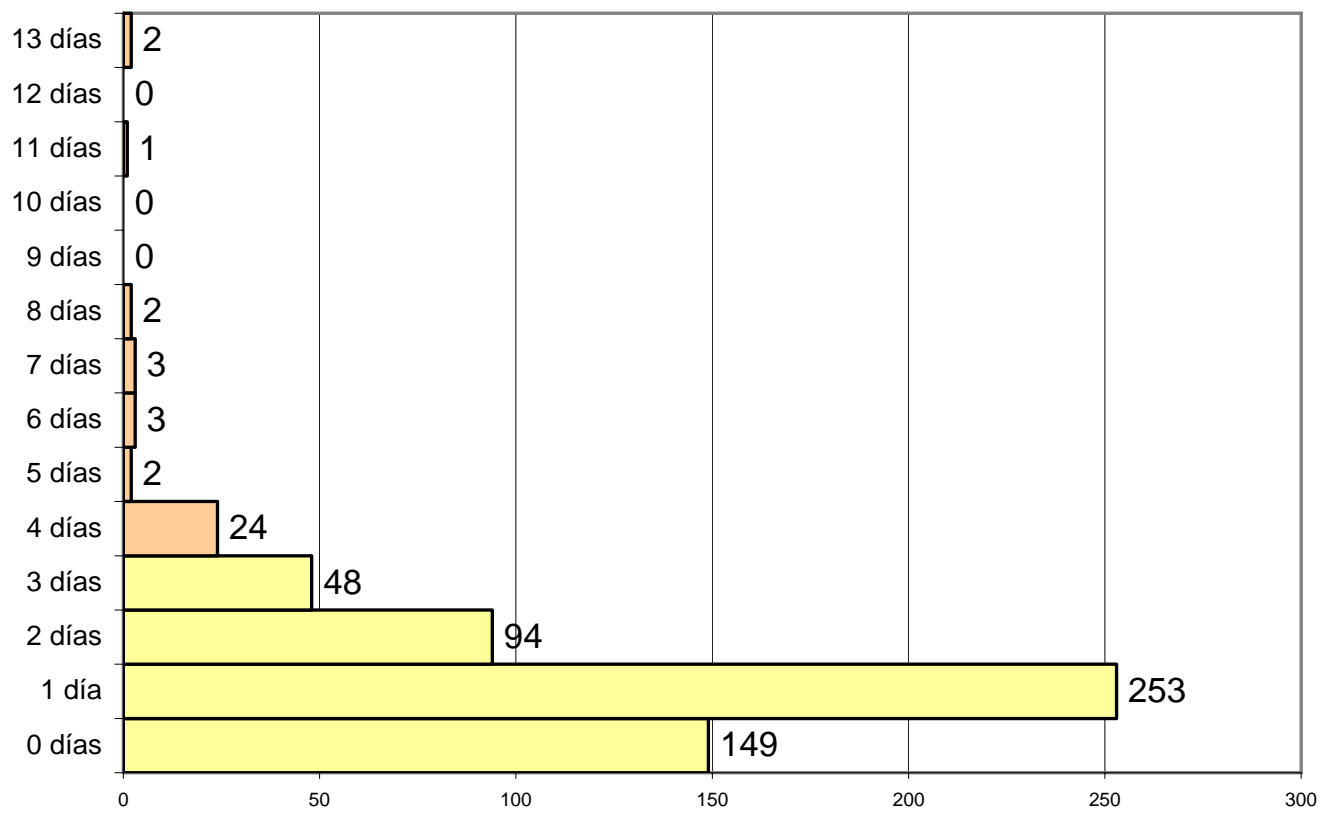

Fig. 3.112. Estudio de respuestas: plazos de respuestas

Es muy estimulante comprobar cómo el número más alto corresponde a las preguntas que se contestan en un sólo día, seguidas de las que se resuelven en el mismo día.

Hay lamentables excepciones, que corresponden a preguntas realizadas en periodos vacacionales, lo que demuestra la necesidad de buscar alternativas para cuando una biblioteca no va a poder responder en el plazo marcado. 
No obstante, si se analiza de forma conjunta las respuestas entregadas en menos de 72 horas se podrá comprobar que el nivel de efectividad es muy alto, ya que sólo el $6 \%$ de las preguntas no resolvieron en el plazo estipulado.

\section{Respuestas en plazo}

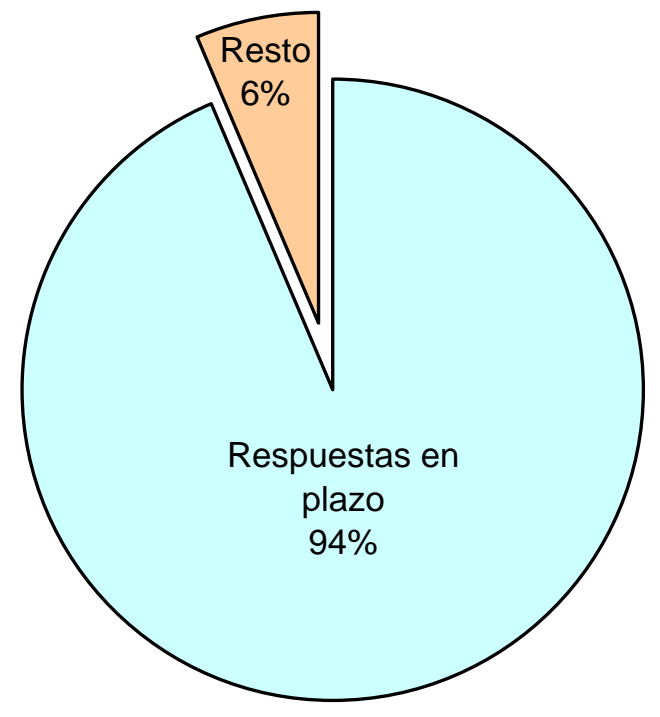

Fig. 3.113. Estudio de respuestas: cumplimiento de plazos

e/ Validez de la respuesta

Otra cuestión que se consideró de interés es saber qué porcentaje de las respuestas se contestaban de forma pertinente, esto es, que el contenido de la respuesta se ajustaba a lo preguntado por el usuario. En esta ocasión, conscientes del peligro de que el analista cayese en criterios subjetivos, se valoró que se contestara a lo que se preguntaba.

Las categorías, lógicamente, sólo fueron dos:

- Sí: el contenido de la respuesta se ajustaba a la pregunta

- No: no se respondía a lo que se preguntaba

Las preguntas que quedaron sin contestar se han valorado como "No", ya que no se ha ofrecido al usuario una respuesta, aunque fuese informando de que la pregunta no se ajustaba a los fines del servicio.

Las respuestas cuyo contenido es válido, es decir, que se contesta una pregunta de forma pertinente, son mayoritarias $(88,47 \%)$, mientras que más de la décima parte $(11,53 \%)$ no se contestan de forma apropiada o simplemente no se contestan. 


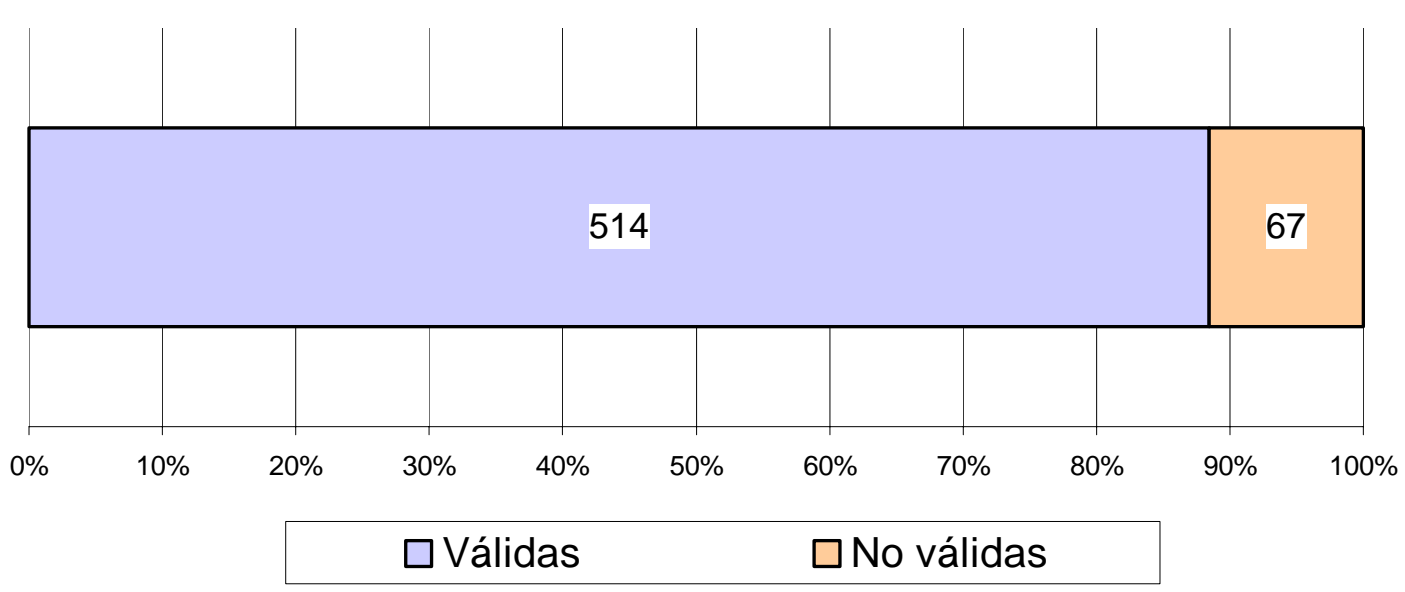

Fig. 3.114. Estudio de respuestas: validez de las respuestas

f/ Temática de las preguntas

Este último apartado no obedece a una evaluación subjetiva, sino que se ha consultado directamente en la base de datos y se ha extraído la clasificación asignada a cada una de las preguntas realizadas en el periodo de estudio.

El número de preguntas obtenido en cada materia en el periodo de análisis (1 de marzo a 3 de abril de 2004) fue el siguiente:

\begin{tabular}{lr}
\hline Materias & Preguntas \\
\hline ADMINISTRACIÓN, LEGISLACIÓN, POLÍTICA & 45 \\
\hline ARTE & 33 \\
\hline BIBLIOTECAS Y DOCUMENTACIÓN & 150 \\
\hline CIENCIA Y NATURALEZA & 34 \\
\hline CIENCIAS SOCIALES & 23 \\
\hline ECONOMÍA Y EMPRESAS & 13 \\
\hline EDUCACIÓN & 26 \\
\hline EMPLEO Y TRABAJO & 86 \\
\hline HISTORIA & 18 \\
\hline INFORMÁTICA E INTERNET & 17 \\
\hline INGENIERÍA, TECNOLOGÍAAS & 77 \\
\hline LENGUAS Y LITERATURA & 32 \\
\hline LUGARES Y GENTES & 18 \\
\hline PENSAMIENTO Y RELIGIONES & 12 \\
\hline SALUD, MEDICINA & 16 \\
\hline VIAJES Y OCIO & 23 \\
\hline SIN TEMA &
\end{tabular}


Una representación gráfica de los porcentajes de cada una de las materias muestra la gran diferencia existente entre unas categorías y otras. Las preguntas del grupo "Bibliotecas y documentación" suponen la cuarta parte del total $(25,82 \%)$. Teniendo en cuenta que las preguntas se clasificaban en 16 categorías es evidente la desproporción existente.

\section{Temática de las preguntas (\%)}

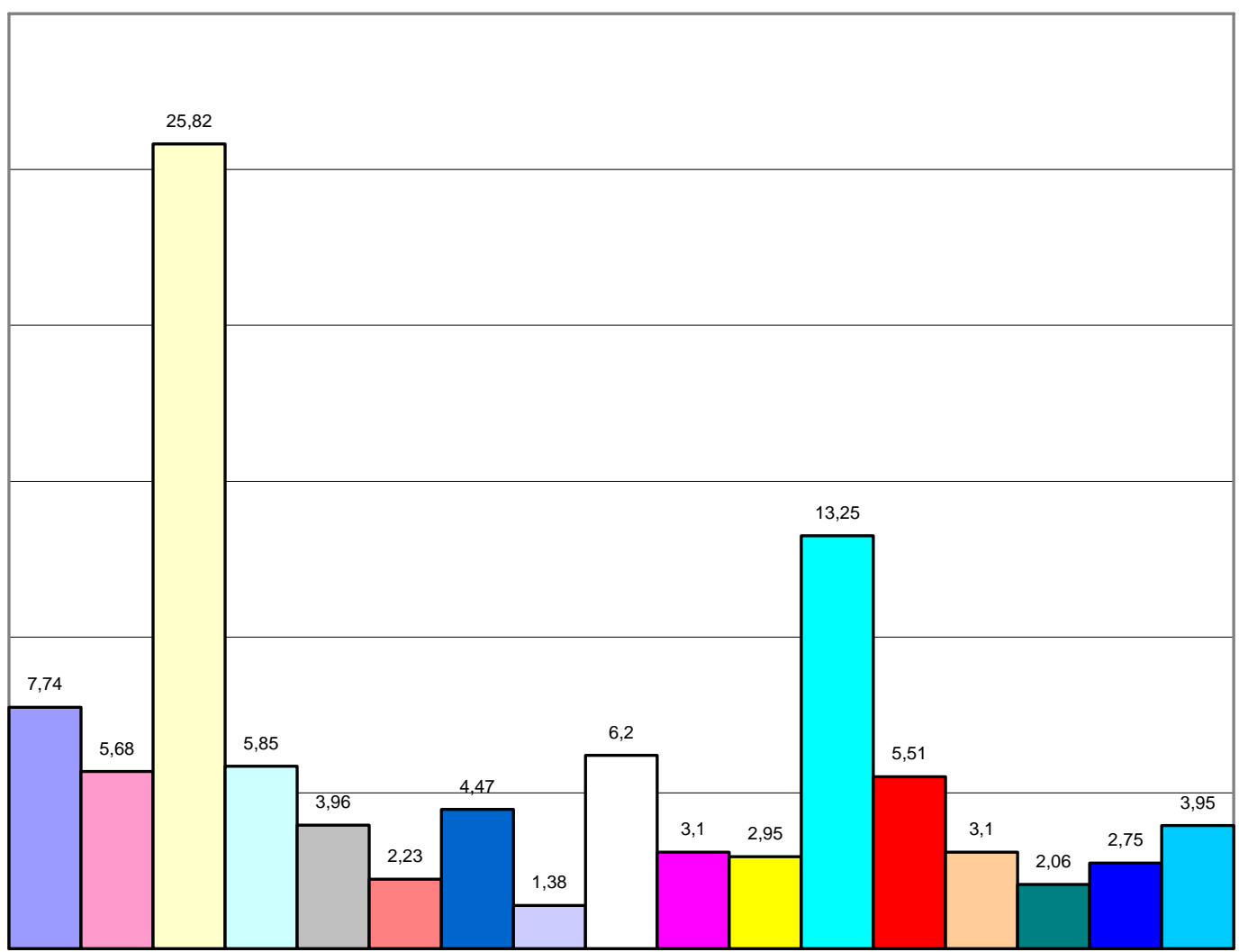

\begin{tabular}{|c|c|}
\hline 口ADMINISTRACION, LEGISLACION, POLITICA & 口ARTE \\
\hline 口BIBLIOTECAS Y DOCUMENTACION & 口CIENCIA Y NATURALEZA \\
\hline 口CIENCIAS SOCIALES & 口ECONOMIA Y EMPRESAS \\
\hline DEDUCACION & 口EMPLEO Y TRABAJO \\
\hline 口HISTORIA & DINFORMATICA E INTERNET \\
\hline 口INGENIERIA, TECNOLOGIAS & 口LENGUAS Y LITERATURA \\
\hline 口LUGARES Y GENTES & 口PENSAMIENTO Y RELIGIONES \\
\hline 口SALUD, MEDICINA & DVIAJES Y OCIO \\
\hline 口SIN TEMA & \\
\hline
\end{tabular}

Fig. 3.115. Estudio de respuestas: temática de las preguntas 


\subsubsection{Homogeneidad de las respuestas}

Un análisis cualitativo más que se consideró interesante fue conocer si ante preguntas iguales se contestaba de forma homogénea. Se pretendía comparar las informaciones entregadas a los usuarios por diferentes bibliotecas ante idénticas preguntas.

Del total de las preguntas planteadas en el periodo que se está manejando en esta parte de la tesis (1 de marzo a 3 de abril de 2004), que corresponde a un turno completo de bibliotecas, se han extraído las preguntas que cumplían esta condición:

- el contenido de la pregunta se repetía

- la pregunta se realizó en días distintos

Doce cuestiones cumplían estas dos condiciones, de las cuales algunas fueron realizadas por el doctorando, consciente de que éste era un método que permitía conocer la uniformidad de las respuestas. Las restantes preguntas que se reproducen en las páginas siguientes fueron extraídas de los resultados obtenidos en el buscador interno, al acotar la consulta por fechas y seleccionar de forma manual las preguntas duplicadas.

Los resultados no son de utilidad estadística, al manejar tan bajo volumen de preguntas, pero sí a efectos informativos, ya que se intuyen las tendencias más acusadas, al menos en los días estudiados. También es posible que los resultados fueran diferentes, si son evaluados por otro investigador, por lo que se ha considerado conveniente incluir los textos de las preguntas, sus respuestas y el resto de los datos al final de este apartado.

De cada pregunta se han analizado tres aspectos:

a/ Contenido: respuesta dada a la pregunta

b/ Estilo / Exposición: forma de redactar la respuesta

c/ Fuentes: recursos empleados y recomendados

La comparación entre preguntas iguales se ha calificado de la siguiente forma:

- Igual: la información dada es la misma o muy parecida

- Parecido: la información es similar, pero con diferencias

- Distinto: la información es diferente

A continuación se reproduce gráficamente la valoración global del autor del informe a partir de las doce preguntas seleccionadas. 
a/ Contenido

\section{Contenido}

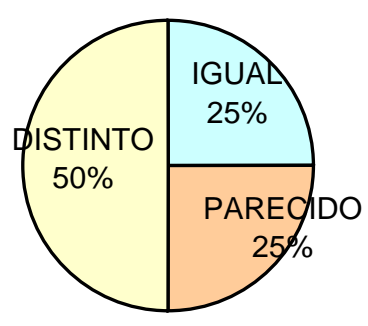

Fig. 3.116. Homogeneidad de las respuestas: contenido

b/ Estilo / Exposición
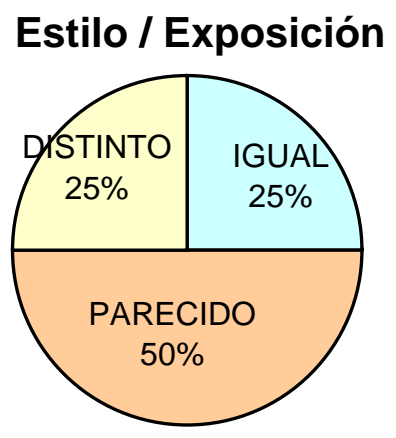

Fig. 3.117. Homogeneidad de las respuestas: estilo y exposición

cl Fuentes

\section{Fuentes}

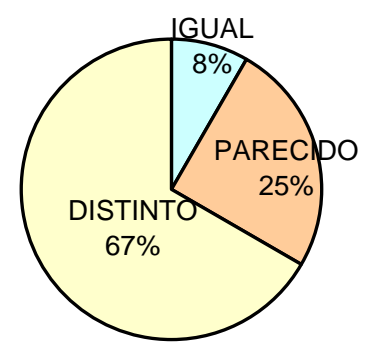

Fig. 3.118. Homogeneidad de las respuestas: fuentes empleadas

Sorprende encontrarse con que la mitad de las respuestas no se han elaborado de forma uniforme en cuanto a su contenido, ya que hay bibliotecas que optan por dar explicaciones y otras fuentes. También hay que incluir aquí que se ofrecen informaciones diferentes dependiendo de qué biblioteca haya redactado la respuesta. 
El estilo de las respuestas es similar, algo que hay que valorar positivamente. También es un elemento de reflexión que ante preguntas iguales se opte por usar fuentes diferentes. Aunque esto tampoco tiene por qué ser preocupante, ya que existen multitud de recursos distintos para encontrar una información, sería aconsejable que se establecieran repertorios de fuentes de información, que facilitaran el trabajo y que permitieran a los profesionales ofrecer información fiable de forma rápida.

En el anexo 2 se reproducen las preguntas empleadas en el análisis realizado en este apartado. Se ofrece su número de identificación de consulta (NIC), la consulta tal cual fue hecha, la respuesta enviada al usuario (si se envió alguna), las fuentes utilizadas en la respuesta, las fuentes para ampliar (si se redactaron) y las fechas de solicitud y resolución.

\subsection{Estudio de visibilidad}

El concepto de visibilidad se emplea aquí como la cantidad de enlaces que una página, un sitio web o un servidor reciben desde otras páginas. Se deduce que a mayor visibilidad mayor grado de difusión y calidad, ya que si una web es muy recomendada será porque es considerada de utilidad.

Existen diferentes maneras de medir la visibilidad de un sitio web. La mayoría de los buscadores disponen de una opción avanzada para recuperar las URL que enlazan con una dirección web indicada. Esta búsqueda experta se puede introducir tanto en el formulario de consulta avanzada como a través de los operadores específicos desde el formulario principal.

Por ejemplo, para encontrar los enlaces a http://www.pregunte.org en el buscador Google se puede hacer directamente en el formulario mediante la instrucción: link:www.pregunte.org. En el resto de los motores de búsqueda estas consultas se realizan de forma similar, bien mediante operadores concretos, bien mediante formularios de búsquedas avanzadas.

No obstante, estos sistemas requieren introducir las distintas direcciones de un servidor para obtener una panorámica completa de cuántos enlaces existen hacia un mismo sitio web. Por este motivo, se hace necesario ampliar las consultas a otros tipos de operadores, como los de exactitud, para conseguir reunir el mayor número posible de enlaces hacia un web.

A lo largo de la segunda semana del mes de abril de 2004 se consultaron los buscadores que se consideran de mayor utilidad (Altavista, AskJeeves, Google, Metacrawler, Teoma y Yahoo), empleando tanto las opciones de búsqueda exacta ("Pregunte: las bibliotecas responden") como las posibilidades de localizar las páginas que enlazaran con una dirección dada. El 18 de abril de 2004 se finalizaron las consultas, se eliminaron los duplicados y se depuraron los datos con los que se ha trabajado en esta sección del informe. 
El servicio «Pregunte» tuvo distintas direcciones desde las que se puede acceder al mismo, por lo que se interrogó tanto por las direcciones alojadas en pregunte.carm.es, como en www.pregunte.org, ya que existen muchos enlaces a páginas desde las cuales se reenvía al servidor actual.

Los resultados que se obtuvieron en ese momento fueron los siguientes:

- Número de páginas que enlazan con «Pregunte»:

- Número de servidores donde se alojan esas páginas:

Estos datos tampoco son muy significativos si no se comparan con otros similares. Pero sí se puede decir que son muy bajos, tratándose de un servicio de estas características.

Sí es de interés conocer qué organismos son los que recomiendan «Pregunte: las bibliotecas responden» desde sus propias páginas web. Para ello se procedió al análisis y sistematización de cada uno de los servidores en los que se encontró un enlace al servicio. La división que se hizo fue la siguiente:

- Administración Pública: instituciones pertenecientes a los distintos niveles de la Administración: local, regional, nacional.

- Bibliotecas públicas: bibliotecas municipales, regionales y públicas en general

- Bibliotecas universitarias: bibliotecas de centros de enseñanza superior

- Centros de investigación y documentación: instituciones de investigación, centros de documentación y bibliotecas especializadas

- Universidades y centros educativos: centros de enseñanza reglada de todos los niveles (no sus bibliotecas)

- Empresas privadas: webs de empresas

- Organismos profesionales: colegios, asociaciones y entidades de tipo profesional

- Formación no reglada: empresas y entidades dedicadas a la enseñanza no oficial

- Organizaciones socioculturales: instituciones de tipo social, cultural y económico (no empresas) 
- Páginas personales: páginas de personas que aportan una información no vinculada a una institución

- Publicaciones periódicas: noticias de diarios, artículos de revistas, boletines informativos, etc.

- Directorios y servidores de información: buscadores, índices temáticos, portales, directorios, etc.

- Weblogs: informaciones personales con actualización periódica

Esta categorización permitió agrupar las instituciones de forma clara. El resultado que se obtuvo se refleja en el gráfico que se reproduce a continuación.

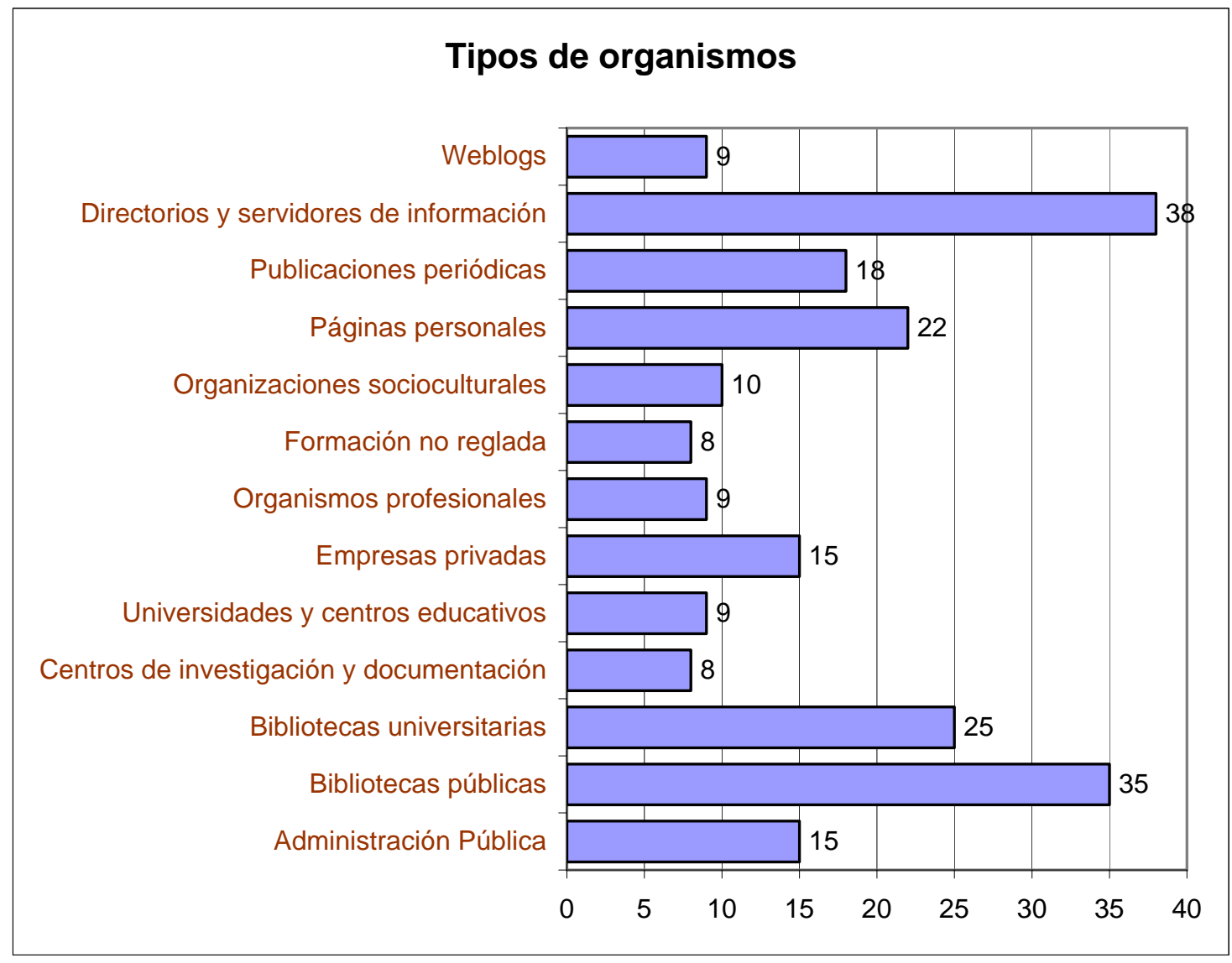

Fig. 3.119. Estudio de visibilidad: organismos con enlaces al servicio

Como puede observarse, el mayor número de enlaces se hace desde buscadores y directorios temáticos, seguido de los procedentes de las bibliotecas públicas y universitarias.

La distribución geográfica de estos servidores también es un dato importante. En el momento de hacer las consultas se ofrecían enlaces desde 
veintitrés países distintos. Los servidores de dominios no geográficos se analizaron también para conocer cuál era su lugar de origen.

Para simplificar los resultados se han agrupado en tres grandes áreas los estados desde donde hay enlaces al servicio «Pregunte». Además de España, se han contabilizados juntos los países americanos de habla hispana y, en un tercer grupo, Estados Unidos y los países europeos.

El predominio, lógicamente, es de los servidores españoles y en porcentajes similares las otras dos áreas, como puede verse en el gráfico.

\section{Distribución geográfica (\%)}

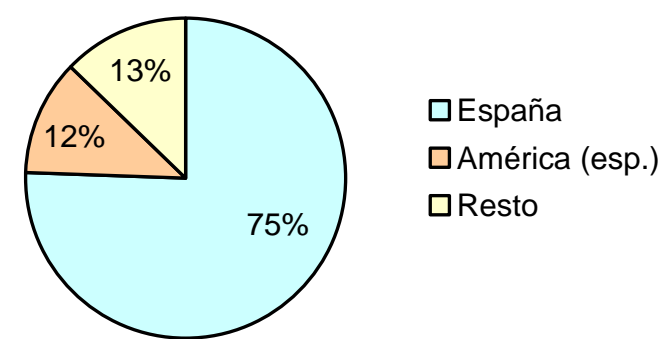

Fig. 3.120. Estudio de visibilidad: distribución geográfica

La relación completa de los países en los que se encuentran los servidores, junto al número de los mismos es: Alemania (8), Argentina (12), Bélgica (1), Bolivia (1), Chile (1), Colombia (1), Cuba (2), Dinamarca (1), España (167), Estados Unidos (7), Estonia (1), Francia (3), Hungría (1), Italia (2), México (4), Países Bajos (1), Perú (2), Portugal (1), Reino Unido (1), República Dominicana (1), Rusia (1), Uruguay (1) y Venezuela (1). El grado de visibilidad también dependerá del lugar en el que se encuentre el enlace a un determinado sitio web. Por este motivo, se analizó también si existían enlaces a «Pregunte» desde las páginas de las Bibliotecas Públicas del Estado y las restantes bibliotecas que participan en el servicio, siempre y cuando posean información web. Se establecieron tres niveles: sin enlace, enlace en la página principal y enlaces en páginas secundarias. El resultado fue que, de 28 sitios web analizados, había tantas bibliotecas con enlace en su primera página web, como centros que no ofrecían ningún tipo de enlace. La distribución fue la siguiente.

\section{Enlaces desde Bibliotecas Públicas (\%)}

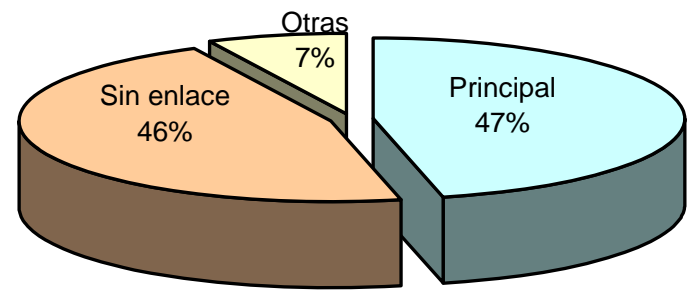

Fig. 3.121. Estudio de visibilidad: enlaces en bibliotecas públicas del servicio 


\subsection{Estudio bibliográfico}

Otro indicador del grado de difusión de un servicio es el número de ocasiones que ha sido mencionado en la bibliografía profesional y en reuniones científicas. En esta última sección se ofrece el resultado de la investigación bibliográfica realizada para conocer en qué publicaciones profesionales se ha hablado de «Pregunte: las bibliotecas responden». Para obtener esta información se han interrogado bases de datos de biblioteconomía y documentación, así como los principales buscadores. También ha servido de mucha ayuda la información facilitada por los responsables del servicio.

Para saber si las distintas bibliotecas participantes habían difundido en los medios de comunicación locales la existencia del servicio se preguntó a los coordinadores de cada biblioteca. En la mayoría de los casos (60\%) se indicó que no se había publicado nada sobre «Pregunte» en los periódicos locales, mientras que en poco más de la cuarta parte (26\%) el servicio sí apareció en los medios de comunicación de la provincia.

\section{Difusión en prensa}

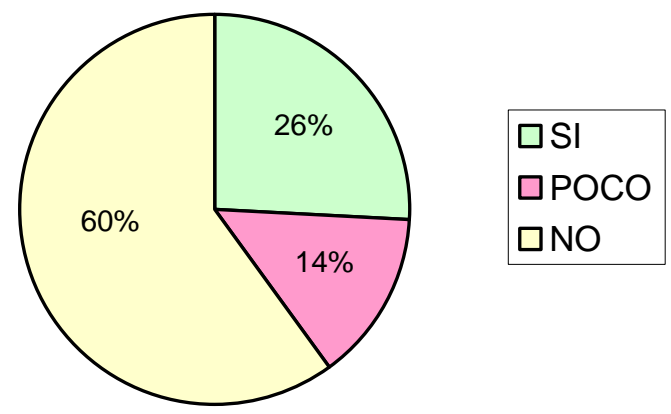

Fig. 3.122. Estudio bibliográfico: difusión en prensa

Una vez localizados los artículos se revisaron para saber si sólo se mencionaba el servicio «Pregunte: las bibliotecas responden» o bien se dedicaban algunas líneas al mismo. Las referencias bibliográficas que se exponen a continuación corresponden a aquellos artículos donde «Pregunte» ha sido comentado con alguna profundidad.

Como se podrá comprobar el número de textos aparecidos en publicaciones periódicas especializadas no era muy grande. La mayoría han sido publicados en España y en sólo dos de ellos «Pregunte» es tratado de forma exhaustiva. Esto indicaba que se hacía necesario realizar más trabajos sobre el servicio, para difundirlos entre los profesionales españoles y extranjeros.

Los artículos de publicaciones profesionales en las que se han editado trabajos sobre el servicio «Pregunte» son los siguientes: 
- Ayuso García, María Dolores; Peñalver Martínez, Ángel; Martínez Navarro, Victoria. Evaluación de fuentes de información para servicios de referencia en Internet. Una propuesta a partir de "Pregunte, las bibliotecas responden". En Congreso Nacional de Bibliotecas Públicas (1. 2002. Valencia). La biblioteca pública: portal de la sociedad de la información. Madrid: Ministerio de Educación, Cultura y Deporte, 2002, p. 13-25. Disponible en http://travesia.mcu.es/documentos/actas/com_ 013.pdf.

- Merlo Vega, José Antonio. El servicio de referencia. Anales de documentación, 2000, n.3, p. 93-126. Disponible en http://www.um.es/fccd/anales/ad03/AD07-2000.PDF

- Merlo Vega, José Antonio; Sorli Rojo, Ángela. Pregunte a un bibliotecario: servicios de referencia en línea. Revista española de documentación científica, en.-marzo 2003, vol. 26, n. 1, p. 91-101.

- Pregunte: las bibliotecas responden, nueva sesión del Foro de Libros, Archivos y Bibliotecas. Anaquel, en.-marzo 2002, n. 17, p. 11.

- Pregunte, las bibliotecas responden: nuevo servicio cooperativo de información en Internet, Correo Bibliotecario, junio 2000, n. 43, p. 5.

- Quiroga Iglesias, María. Las bibliotecas y la sociedad de la información [en línea]. Feria Internacional del Libro de Centroamérica (5. 2001. Panamá). Jornadas profesionales, 2 de agosto de 2001 [Consulta 1 de septiembre de 2004]. Disponible en http://www.arrakis.es/ byblos/txt/ mquiroga.html.

- Ruiz Felipe, José Ángel. Las bibliotecas responden: servicios de referencia en línea [en línea]. Sociedad de la información, 2001 [consulta 1 abril 2004]. Disponible en http://www.sociedaddelainformacion.com/ 20010901/Bibliotecas/Pregunte.htm.

- Sánchez Remón, Dinorah. El servicio de referencia virtual en la gestión de la información [en línea]. Revista Acimed, 2003 vol. 11, n. 2 [consulta 1 septiembre 2004]. Disponible en http://www.infomed.sld.cu/revistas/ aci/vol11_2_03/aci040203.htm.

- Saorín, Tomás. Una fórmula para Internet: productos cooperativos. La experiencia de "Pregunte, las bibliotecas responden". Educación y biblioteca, abril 2001, vol. 13, n. 122, p. 44-50. 


\subsection{Propuestas de mejora}

Las conclusiones de los diferentes estudios realizados se materializan en diversas propuestas de mejora del servicio. Cada una de las sugerencias planteadas en este bloque se deriva de los resultados de la evaluación llevada a cabo. Existen grandes coincidencias en las opiniones de usuarios y profesionales que han generado algunas de las propuestas. De igual forma, el resto de los análisis han puesto de manifiesto algunas carencias y necesidades que han sido la fuente para las restantes propuestas.

Todas las recomendaciones que se indican, por tanto, están avaladas por los diferentes análisis efectuados. Una vez realizados los diferentes estudios de evaluación y extraídas las conclusiones oportunas, se pueden ofrecer diferentes sugerencias para la mejora del servicio de referencia en línea «Pregunte: las bibliotecas responden». Estas propuestas se han organizado en función de diferentes categorías, con la intención de determinar de forma más precisa el alcance de las recomendaciones efectuadas.

Para la elaboración de las propuestas de mejora se ha partido de tres ideas previas:

- El proyecto «Pregunte» es uno de los inhabituales ejemplos de cooperación entre bibliotecas públicas de las diferentes comunidades autónomas españolas. Si el proyecto se mantiene en marcha es por la participación desinteresada de profesionales que entienden la utilidad de un servicio como el que se está ofreciendo. Cualquier sugerencia de cambio en la organización de «Pregunte» sólo será posible si se respeta el sistema de funcionamiento actual. La flexibilidad del modelo vigente origina problemas en la prestación del servicio, pero también es una de las causas que permiten que éste exista.

- La opinión de quienes participan en el servicio es fundamental ante cualquier propuesta de cambio que se realice. Nadie mejor que quien está directamente vinculado a un servicio podrá conocer los problemas de dicho servicio. No sería viable, por tanto, sugerir modificaciones con las que una amplia mayoría no estuviese de acuerdo.

- La investigación tenía como finalidad analizar las debilidades y fortalezas del servicio y ofrecer unos resultados que sirvieran a los responsables del mismo para que tomasen las decisiones que considerasen adecuadas y posibles, pero también fue un objetivo proponer las mejoras que se estimasen oportunas, en aras de conseguir un servicio más útil y de mayor calidad. Por tanto, se ofrecieron también algunas sugerencias que modificaban el servicio tal y como se estaba prestando en esos momentos.

Los bloques bajo los que se agruparon las sugerencias son:

1. Servicio: utilidad, alcance, orientación, participantes, etc.

2. Organización: coordinación, turnos, procedimientos, etc.

3. Profesionales: perfil, formación, dedicación, etc. 
4. Documentación: materiales de trabajo, normativa, etc.

5. Sistema: servidor, sitio web, programa informático, etc.

6. Información: información que se ofrece y puede ofrecer.

7. Recursos: medios, fuentes de información, etc.

8. Difusión: actividades de promoción del servicio.

Como se ha ido explicando, esta investigación tiene una doble finalidad; por una parte, se han querido poner en práctica las teorías planteadas a partir de la investigación realizada para esta tesis doctoral y, por otra parte, aplicar la evaluación para las mejoras de un servicio público específico, que se estaba ofreciendo desde años atrás y que necesitaba un análisis de su funcionamiento, del que se obtuvieran propuestas de mejora. En los siguientes subapartados se ofrecen estas sugerencias de mejoría, redactadas en tiempo presente, para que la descripción de las mismas esté cercana a la realidad de la situación en el momento de la investigación. Todas las sugerencias se han numerado de forma consecutiva, aunque se hayan estructurado en función de bloques temáticos específicos. Esta numeración es empleada como referencia en otras partes de la tesis doctoral.

\section{Servicio}

«Pregunte: las bibliotecas responden» es un servicio de utilidad, por lo que sería recomendable mantenerlo en funcionamiento con el mismo esquema con el que trabaja en la actualidad: distintas bibliotecas cooperan de forma desinteresada para atender las consultas recibidas por usuarios españoles y de otros países. Es necesario que las entidades participantes se replanteen la filosofía general del servicio, estableciendo de forma concreta: qué servicio informativo se quiere ofrecer, qué tipo de información se ofrecerá, cómo se contestarán las preguntas o qué tipo de usuarios se atenderán.

1. «Pregunte» debe ser un servicio abierto a cualquier persona que se comunique en alguna de las lenguas españolas, independientemente de su edad, de su lugar de residencia y de los fines de la consulta.

2. «Pregunte» debe atender cuestiones de carácter temático, bibliográfico, institucional y personal.

3. «Pregunte» no debe atender cuestiones subjetivas, hipotéticas, de investigación, ni en las que se pida la opinión o el asesoramiento del personal que atiende el servicio.

4. «Pregunte» debe dar respuesta a cualquier consulta, aunque sea para informar al usuario de que no se ha encontrado información o de que la pregunta es inapropiada o improcedente.

5. Se debe seguir un estilo y esquema de respuesta común, en el que se ofrezcan los siguientes datos: encabezamiento (saludo), respuesta, fuentes empleadas e informaciones complementarias (otras fuentes, bibliotecas 
cercanas, etc.), sistema de queja y ampliación de la consulta. Cada dato debe estar separado de forma conveniente, no incorporando las fuentes a la respuesta.

6. Se debe ampliar el espacio destinado a las respuestas en el sistema informático, ya que muchas de ellas necesitan mayor número de caracteres, debido a la singularidad de algunas preguntas.

7. «Pregunte» no puede ser solamente un servicio de respuestas, también debe ofrecer recursos para que el usuario satisfaga sus necesidades de información. Se deberán incluir otros servicios e informaciones, como selecciones de recursos presentes en Internet o elaboración de tutoriales de fuentes de información.

\section{Organización}

El sistema mediante el que se está organizando «Pregunte: las bibliotecas responden» está funcionando de forma correcta, por lo que no será prioritario iniciar reformas en este sentido. No obstante, se han encontrado algunos fallos de procedimiento y posibilidades de mejora que se comentan en los párrafos siguientes.

8. La información existente sobre los miembros de «Pregunte» está desactualizada, por lo que será necesario completarla y ponerla al día.

9. La calidad de «Pregunte» y su sistema de funcionamiento mejorarían con la presencia de un coordinador o grupo de coordinadores que se encargaran de validar las preguntas antes de proceder a su respuesta y de contestar las improcedentes e inapropiadas.

10. El servicio debería reducir el tiempo de respuesta a dos días laborales.

11. El servicio debería comunicar a los usuarios que su pregunta no se podrá resolver en el tiempo estipulado, cuando sea imposible cumplir los plazos.

12. El foro de comunicación de los participantes en «Pregunte» debería considerarse como una herramienta más para solicitar asesoramiento o recursos.

13. Los miembros de «Pregunte» deberían considerar como una responsabilidad común las respuestas recibidas, pudiendo resolver las preguntas sin respuesta y las que una biblioteca considere complejas.

14. El sistema de turnos debe ser replanteado para permitir a las bibliotecas participantes que opinen sobre cómo debe ser la distribución de las preguntas.

15. «Pregunte» debería contar con una red de asesores que ayuden a resolver las cuestiones para las que no se han encontrado respuestas. En 
esta red deberían incluirse bibliotecas sustentadas con fondos públicos, como son la Biblioteca Nacional o las pertenecientes al Consejo Superior de Investigaciones Científicas. Se recomienda establecer acuerdos de cooperación con este tipo de centros.

\section{Profesionales}

Los profesionales que atienden el servicio son quienes tienen en su mano que la calidad de «Pregunte» sea la esperada y que su funcionamiento sea ágil y eficaz. Por ello, se plantean una serie de medidas que les afectan.

16. Se deben seguir realizando actividades de formación especialmente destinadas a las personas que atienden «Pregunte». La oferta debe incluir cursos generales sobre servicios de referencia, técnicas de búsqueda de documentos y recuperación de información y fuentes de información en las diferentes disciplinas del conocimiento.

17. Sería muy útil la elaboración de manuales y repertorios de obras de referencia, especialmente enfocados a bibliotecas públicas españolas.

18. Se deberían realizar tutoriales o guías de uso de determinadas fuentes de información, así como de técnicas bibliográficas (cómo citar, por ejemplo).

19. Aunque los profesionales que atienden «Pregunte» deben ser los bibliotecarios que trabajan en las bibliotecas participantes en el proyecto, se deberán establecer contactos con especialistas en diferentes materias para que ofrezcan asesoramiento al servicio.

\section{Documentación}

Las herramientas de trabajo de quienes participan en «Pregunte» no son numerosas ni están actualizadas, por lo que son necesarias una serie de reformas.

20. Se debe volver a elaborar el "Manual de procedimiento", para actualizarlo y adaptarlo a las reformas que se realicen.

21. Se debería redactar un "Manual de «Pregunte»", más amplio que el "Manual de procedimiento", donde se recojan todas las cuestiones relativas al servicio, tanto las procedimentales, como las que se refieran a la filosofía general de «Pregunte», forma de organización, tipos de cuestiones que se atienden, tipos de respuestas que se deben dar, estilo de redacción de las respuestas, directorio de participantes y colaboradores, manejo del servidor, etc.

22. Se debe redactar un documento explicando la forma de proceder ante una pregunta: etapas, fuentes, estilo de la respuesta, etc. La información que 
debe llevar una respuesta y los datos que aparecerán en la misma debe ser uniforme.

23. La clasificación se considera válida para organizar temáticamente las preguntas recibidas, pero se debería emplear un tesauro o una lista de encabezamientos de materia para adjudicar una serie de palabras clave a cada pregunta/respuesta, para poder recuperar de forma más precisa.

24. Se debería redactar un documento específico con tipos de respuestas ejemplares, tanto para preguntas procedentes como para las inadecuadas 0 para las que no se ha conseguido información.

25. El servicio necesita una guía de las fuentes de información más útiles en cada materia.

26. «Pregunte» debería contar con un directorio de bibliotecas públicas actualizado, porque muchas consultas se resuelven orientando al usuario hacia documentos impresos e informando de dónde puede consultarlo.

27. Se debería elaborar una guía de expertos, en la que se recogieran entidades, centros de información especializados y especialistas en distintas disciplinas, para contactar con los mismos en caso de recibir cuestiones difíciles de resolver con los recursos de las bibliotecas participantes.

\section{Sistema}

El sistema informático es la columna vertebral de «Pregunte», ya que sobre el mismo recae todo el peso del funcionamiento de este servicio de referencia en línea. Hay que reconocer las ventajas de este sistema, creado ad hoc para «Pregunte», pero también se hacen necesarias una serie de mejoras y modificaciones.

28. El diseño de «Pregunte» debe ser modificado, ya que provoca problemas de lectura, además de identificación del servicio. Se deberán seguir los principios estéticos más acordes con las bibliotecas participantes.

29. Se debe establecer un diseño que permita que los usuarios que usan «Pregunte» desde una biblioteca distingan claramente que se trata de un servicio externo.

30. Se debe preparar una nueva página de acogida, en la que se ofrezcan las diferentes modalidades de información ofrecidas: 1) recursos seleccionados y comentados de Internet; 2) tutoriales de fuentes de información y sistemas de búsqueda; 3) formularios de recuperación en el archivo de respuestas; 4) formulario para enviar una pregunta a las bibliotecas del proyecto «Pregunte». 
31. El sistema debe permitir que el usuario se identifique antes de realizar su consulta. En esta identificación deberán incluirse obligatoriamente datos de edad, de lugar de residencia y de finalidad de la consulta.

32. El sistema debe posibilitar que antes de realizar una consulta se recuerde obligatoriamente al usuario qué tipo de cuestiones no se responden.

33. Se deberá incorporar al sistema un método de evaluación de la calidad del servicio y la satisfacción del usuario. Un procedimiento podría ser un enlace en el mensaje de correo electrónico de la respuesta, desde el que se abriera una página con un sencillo formulario de evaluación.

34. El sistema debería permitir que se envíen archivos adjuntos, cuando los profesionales lo estimen oportuno.

35. El sistema deberá permitir el seguimiento de las diferentes consultas que provoque una pregunta: consulta, primera respuesta, ampliación de la pregunta, segunda respuesta, etc. En estos momentos las matizaciones a una pregunta suelen tomarse como preguntas independientes, por lo que se responde de forma diferente.

36. El sistema de búsqueda de preguntas ya respondidas obliga a introducir un carácter en el formulario de consulta con lo que no se puede recuperar de forma fiable todas las cuestiones recibidas sobre una materia o en plazo de tiempo determinado.

37. El sistema de búsqueda de preguntas ya respondidas ofrece muy pocas posibilidades a los usuarios, por lo que se deberían incluir otras opciones, como acotar fechas, elegir lenguas, etc. No deberían ser distintos los sistemas de recuperación interno (bibliotecas participantes) y externo (usuarios que se conectan sin contreseña).

38. El archivo de preguntas y respuestas deberá ser consultado antes de ofrecer una respuesta, ya que existen muchas preguntas que se plantean varias veces.

39. El sistema de quejas y reclamaciones, así como el de sugerencias deberán ser modificados, ya que los usuarios confunden los diferentes formularios y los emplean indistintamente. El formulario de quejas no debería limitarse sólo a usuarios registrados. Cualquier usuario debería poder interesarse por una pregunta realizado con sólo indicar el Número de Identificación de la Consulta (NIC). El sistema de quejas debería separarse del de seguimiento de una consulta.

40. El sistema de usuarios registrados no aporta excesiva información, por lo que debería replantearse o incluso eliminarse. «Pregunte» podría disponer de una lista de distribución al servicio de estos usuarios, en la que se informe de fuentes de información y recursos de interés. 


\section{Información}

La información que hasta ahora ofrece «Pregunte» viene delimitada por el tipo de consultas que se están realizando. No obstante, la concepción del servicio de una forma más amplia, como un proyecto desde el que se ofrezca información, incluso sin ser solicitada, conllevaría un giro interesante, que tanto usuarios como bibliotecarios desean.

41. «Pregunte» debe ser un servicio de información amplio, que permita a un usuario encontrar por sí mismo una información o bien remitir una consulta a profesionales bibliotecarios.

42. «Pregunte» debe seguir permitiendo que se envíen consultas de cualquier disciplina y tipología: informaciones sobre cualquier materia, informaciones bibliográficas, datos de instituciones, datos biográficos. No se informará sobre cuestiones de carácter subjetivo (hipótesis, impresiones), profesional (orientaciones, dictámenes, diagnósticos) ni comerciales (consejos, información mercantil).

43. La base de datos de preguntas / respuestas debe ser considera una fuente de información de gran valor, por lo que se ofrecerá de forma sencilla desde la primera página del servicio.

44. Se debe incluir en la página principal de «Pregunte» el acceso a recursos gratuitos accesibles en Internet organizados por temas, tipos y lugares. Esta selección deberá ir acompañada de comentarios. La recopilación deberá ser mantenida por las bibliotecas participantes. Se debería comenzar de inmediato con una selección pensada en usuarios de bibliotecas públicas españolas.

45. Además del formulario de consulta, de la base de datos de preguntas y de la selección de recursos se ofrecerá también una serie de tutoriales sobre cómo y dónde buscar: motores de búsqueda, recursos bibliográficos, legislativos, etc.

46. La oferta de estos cuatro tipo de informaciones (consultas, archivo de preguntas, selección de recursos y tutoriales) requerirá un cambio en el servidor, tanto en su estructura como en su diseño.

47. La información de carácter local es importante, por lo que se incluirá en la selección de recursos, debiéndose elaborar con la colaboración de bibliotecas de las distintas Comunidades Autónomas.

48. La información especializada no debe rechazarse. Se deberá pedir apoyo a bibliotecas científicas y universitarias, así como a expertos.

49. La información de tipo escolar tampoco debe rechazarse. Además de ofrecer la respuesta, se orientará al usuario hacia recursos educativos.

50. La información especializada en bibliotecas abunda en estos momentos, por lo que sería recomendable establecer un grupo de expertos o bien contar 
con los servicios de una biblioteca especializada para resolver estas cuestiones. Se puede solicitar la cooperación de la Biblioteca Nacional y de bibliotecas universitarias de centros en los que se imparta Biblioteconomía y/o Documentación.

\section{Recursos}

Los recursos más empleados por los profesionales de «Pregunte» son los que se encuentran en Internet. Las colecciones de referencia locales se consideran útiles, pero no suficientes.

51. Las colecciones de referencia de cada biblioteca deberán ser actualizadas y mejoradas, por lo que sigue siendo importante la colaboración económica del Ministerio de Cultura, aunque la selección de los documentos deberá ser consultada con los interesados para evitar la compra de duplicados.

52. Se deberán contratar recursos electrónicos para su uso cooperativo por las bibliotecas participantes en el proyecto «Pregunte». En estos recursos se consideran indispensables los de tipo enciclopédico: Enciclonet, Ocenet, Britannica, etc., así como algunas bases de datos que puedan ser de utilidad en bibliotecas públicas: Aranzadi, CINDOC, etc.

53. La selección de recursos que se pondrá a disposición de los usuarios deberá ser también útil para los referencistas, por lo que se establecerán criterios comunes de selección y descripción, así como un procedimiento técnico sencillo para su mantenimiento y la incorporación de nuevos recursos.

54. Se deberá establecer contactos con otras bibliotecas y centros de información para poder consultar sus recursos o solicitar informaciones cuando las colecciones y fuentes de los centros participantes en «Pregunte» sean insuficientes.

\section{Difusión}

El uso de «Pregunte» debería potenciarse, por lo que debería ser más difundido, tanto en medios generales como profesionales. La evidente utilidad del servicio, así como su carácter gratuito, obliga a que éste sea promocionado de forma conveniente.

55. Una vez realizadas las modificaciones que se hayan considerado interesantes, se deberá iniciar una campaña de promoción, que permita dar a conocer «Pregunte», sur servicios y utilidad.

56. El Ministerio de Cultura y las consejerías de las con competencias en materia de bibliotecas en las Comunidades Autónomas deberían emitir notas de prensa explicativas. 
57. Se deberá pedir a los sistemas públicos de bibliotecas que promocionen el servicio en sus recintos y servicios telemáticos.

58. Se debería solicitar a las bibliotecas públicas españolas y aquellas que se consideren oportunas, que incluyan un enlace a «Pregunte» en sus sitios web.

59. Los profesionales que trabajan en «Pregunte» deberían promocionar el servicio en reuniones científicas y profesionales, mediante la presentación de ponencias, así como en revistas especializadas, a través de artículos y reseñas.

60. «Pregunte» debería ser presentado a organizaciones de tipo educativo y cultural. 


\section{El servicio público de referencia digital «Pregunte: las bibliotecas responden» en la actualidad}

En esta última parte dedicada al servicio público de referencia digital español se ofrece el estado de la cuestión en agosto de 2007. Tras la evaluación que se ha mostrado como núcleo central de esta tesis doctoral, conviene dejar constancia de cuál ha sido el desarrollo de este sistema de información. El Grupo de Trabajo de Referencia digital, coordinado por la Subdirección General de Coordinación Bibliotecaria del Ministerio de Cultura e integrado por representantes de las diferentes Comunidades Autónomas implicadas en el proyecto, ha trabajado durante dos años para la renovación de la tecnología en la que sustenta el servicio, así como en la elaboración de nuevos manuales de procedimiento que se ajustara a una nueva política del servicio. Los frutos de este trabajo han sido tangibles de forma reciente. En junio de 2006 se aprueba el nuevo manual de «Pregunte», que se adapta a la situación presente y que sustituye al elaborado en los inicios del servicio, a finales de 1999, época de la fase de pruebas. Otra reforma importante es la puesta en funcionamiento, en marzo de 2007, de la nueva herramienta de gestión automatizada, que parte de los módulos de la realizada por informáticos de la Universidad de Murcia, pero que actualiza funciones, corrige problemas y se adapta a requisitos técnicos, tecnológicos y legales contemplados por el grupo de profesionales que participan en el proyecto.

En los apartados de este capítulo, se actualiza la nómina de las bibliotecas que están prestando servicio en «Pregunte», presentando algunos de los datos más importantes de las mismas. Los datos han sido recopilados a partir de la intranet del servicio, gracias a la colaboración de los coordinadores del mismo, que han permitido la realización de las consultas en su sección del servidor que es de uso exclusivo para los profesionales que atienden las consultas. Desde estas líneas se vuelve a agradecer a los responsables del servicio las facilidades prestadas. Partiendo de la intranet de «Pregunte» han sido obtenidas también las estadísticas evolutivas que se incluyen en el siguiente apartado, donde se ofrecen datos más detallados, como el número de preguntas contestadas fuera de plazo o aquellas que ha quedado sin resolver. Las estadísticas temáticas se han elaborado a partir de consultas realizadas en el buscador público, que permite la opción de delimitar los periodos temporales y la temática.

Por último, en este bloque de la tesis doctoral se comentan los nuevos manuales de procedimiento en los que se sustenta el servicio «Pregunte: las bibliotecas responden», así como otros documentos de uso interno que rigen la administración de este proyecto cooperativo. Se comentarán los manuales de usuario y de procedimiento, así como la tabla clasificatoria, que se utiliza para asignar categorías a las preguntas recibidas, y el documento de seguridad redactado al amparo de la Ley 15/1999 de Protección de Datos de Carácter Personal, en el que se detallan los niveles de confidencialidad de la información archivada en el servidor del proyecto. 


\subsection{Bibliotecas participantes: datos generales}

Tras las reformas comentadas en relación a las políticas de desarrollo y de gestión automatizada, «Pregunte: las bibliotecas responden» es un proyecto cooperativo en el que trabajan activamente 42 bibliotecas públicas españolas $^{465}$. A este conjunto habría que añadir a la Subdirección General de Coordinación Bibliotecaria, cuya sección de Proyectos, coordina la actividad de este servicio, ejemplo de cooperación interautonómica en materia bibliotecaria. Varias bibliotecas han pertenecido al proyecto y lo abandonaron por diferentes razones a lo largo de los siete años de trayectoria del servicio. La relación de los centros que han pertenecido al proyecto se puede consultar en la cronología que se presenta al comienzo de esta tercera parte de la tesis doctoral. El mayor número de bibliotecas que participa en «Pregunte: las bibliotecas responden» son Bibliotecas Públicas del Estado, algunas de ellas también Bibliotecas Regionales. Además, se han incorporado también algunas bibliotecas municipales, sobre todo en Comunidades bilingües. El desglose de las bibliotecas por turno es el siguiente:

$\begin{array}{ll}\text { Turno general (castellano) } & 42 \text { bibliotecas } \\ \text { Turno catalán: } & 8 \text { bibliotecas } \\ \text { Turno gallego: } & 3 \text { bibliotecas } \\ \text { Turno vasco: } & 4 \text { bibliotecas }\end{array}$

Las cifras generales del servicio, desde su etapa en pruebas a finales de 1999 hasta el 18 de agosto de 2007 son las siguientes:

$\begin{array}{ll}\text { Entradas al servidor: } & 383.472 \\ \text { Preguntas recibidas: } & 41.026 \\ \text { Preguntas respondidas: } & 40.912 \\ \text { Usuarios distintos: } & 26.628\end{array}$

El desglose correspondiente al número de preguntas respondidas por año, así como el total de las recibidas y el porcentaje de las mismas que han sido contestadas puede consultarse en la siguiente tabla

$\begin{array}{rl}\text { Año } & \text { Respondidas / Recibidas (\%) } \\ 1999 & 30 / 34(88,24 \%) \\ 2000 & 4352 / 4376(99,45 \%) \\ 2001 & 7687 / 7686(100,01 \%) \\ 2002 & 4893 / 4878(100,31 \%) \\ 2003 & 4823 / 4870(99,03 \%) \\ 2004 & 5703 / 5651(100,92 \%) \\ 2005 & 5681 / 5691(99,82 \%) \\ 2006 & 4968 / 5040(98,57 \%) \\ 2007 & 2775 / 2800(99,11 \%) \\ & \\ \text { Total } & 40912 / 41026(99,72 \%)\end{array}$

${ }^{465}$ Dato de 30 de noviembre de 2007. 
Hay que tener presente que hasta junio de 2000 el servicio no se lanza con normalidad, por lo que las estadísticas deben interpretarse teniendo en cuenta que en el año 2000 sólo fueron operativos seis meses; además, las estadísticas correspondientes a 2007 sólo abarcan hasta el mes de agosto, mes en el que se tomaron los datos para la redacción de este apartado de la tesis doctoral. La relación de las bibliotecas, por Comunidades Autónomas, que están en el servicio en agosto de 2007 es la siguiente:

\begin{tabular}{|c|c|}
\hline Andalucía & $\begin{array}{l}\text { - Biblioteca Pública del Estado en Córdoba } \\
\text { - Biblioteca Pública del Estado en Almería } \\
\text { - Biblioteca Pública del Estado en Huelva } \\
\text { - Biblioteca de Andalucía }\end{array}$ \\
\hline Aragón & $\begin{array}{l}\text { - Biblioteca Pública del Estado en Teruel } \\
\text { - Biblioteca Pública del Estado en Huesca } \\
\text { - Biblioteca Pública del Estado en Zaragoza }\end{array}$ \\
\hline Baleares & $\begin{array}{l}\text { - Biblioteca Pública del Estado en Maó } \\
\text { - Biblioteca Pública del Estado en Palma de Mallorca }\end{array}$ \\
\hline Canarias & - Biblioteca Pública del Estado en Santa Cruz de Tenerife \\
\hline Cantabria & $\begin{array}{l}\text { - Biblioteca Central de Cantabria/Biblioteca Pública del Estado } \\
\text { en Santander }\end{array}$ \\
\hline Castilla y León & $\begin{array}{l}\text { - Biblioteca Pública del Estado en Soria } \\
\text { - Biblioteca Pública del Estado en León } \\
\text { - Biblioteca Pública del Estado en Salamanca } \\
\text { - Biblioteca de Castilla y León/Biblioteca Pública del Estado en } \\
\quad \text { Valladolid } \\
\text { - Biblioteca Pública del Estado en Burgos } \\
\text { - Biblioteca Pública del Estado en Segovia }\end{array}$ \\
\hline Castilla-La Mancha & $\begin{array}{l}\text { - Biblioteca Pública del Estado en Cuenca } \\
\text { - Biblioteca Pública del Estado en Albacete } \\
\text { - Biblioteca de Castilla-La Mancha/Biblioteca Pública del Estado } \\
\text { en Toledo }\end{array}$ \\
\hline Cataluña & $\begin{array}{l}\text { - Biblioteca Pública del Estado en Girona } \\
\text { - Biblioteca Pública del Estado en Tarragona } \\
\text { - Biblioteca Pública del Estado en Lleida }\end{array}$ \\
\hline Comunidad Valenciana & $\begin{array}{l}\text { - Biblioteca Valenciana } \\
\text { - Biblioteca Pública del Estado en Valencia } \\
\text { - Biblioteca Pública del Estado en Alicante }\end{array}$ \\
\hline Extremadura & $\begin{array}{l}\text { - Biblioteca Pública del Estado en Badajoz } \\
\text { - Biblioteca Pública del Estado en Mérida } \\
\text { - Biblioteca Pública del Estado en Cáceres }\end{array}$ \\
\hline Galicia & $\begin{array}{l}\text { - Biblioteca Nodal de Pontevedra } \\
\text { - Servicio Municipal de Bibliotecas de A Coruña } \\
\text { - Biblioteca Municipal de Estudos Locais da Coruña }\end{array}$ \\
\hline La Rioja & $\begin{array}{l}\text { - Biblioteca Central de La Rioja/Biblioteca Pública del Estado en } \\
\text { Logroño }\end{array}$ \\
\hline Madrid & $\begin{array}{l}\text { - Biblioteca Regional de Madrid Joaquín Leguina } \\
\text { - Ministerio de Cultura- SG Coordinación Bibliotecaria } \\
\text { - Biblioteca Pública Central de Madrid } \\
\text { - Biblioteca Pública de Latina-Antonio Mingote (Madrid) }\end{array}$ \\
\hline Murcia & $\begin{array}{l}\text { - Biblioteca Regional de Murcia/Biblioteca Pública del Estado en } \\
\text { Murcia }\end{array}$ \\
\hline Navarra & - Biblioteca General de Navarra \\
\hline País Vasco & $\begin{array}{l}\text { - Red de Bibliotecas Municipales de Bilbao } \\
\text { - Biblioteca Pública del Estado en Vitoria Casa de Cultura } \\
\text { Ignacio Aldecoa } \\
\text { - Biblioteca Municipal Central de San Sebastián }\end{array}$ \\
\hline Principado de Asturias & - Biblioteca de Asturias \\
\hline
\end{tabular}


La nueva versión de «Pregunte: las bibliotecas responden» se lanza a la web en marzo de 2007. Se trata de un nuevo diseño estético que comporta otra serie de cambios importantes. La versión actual de la aplicación ya no está instalada en un servidor de la Comunidad de Murcia, sino en el Ministerio de Cultura, cuyos informáticos han adaptado el programa para ajustarlo a las reformas propuestas por el Grupo de Trabajo de Referencia Virtual, así como a los requisitos legales a los que obliga la legislación en materia de protección de datos. Tras un largo periodo de planificación y unos meses de coexistencia de los dos sistemas, en los que se fue probando la versión beta de la nueva aplicación, el 26 de marzo de 2007 los usuarios que querían enviar sus usuarios a «Pregunte» ya se encontraron con la nueva presentación. La interfaz principal que se preparó es la que se muestra en la siguiente imagen:

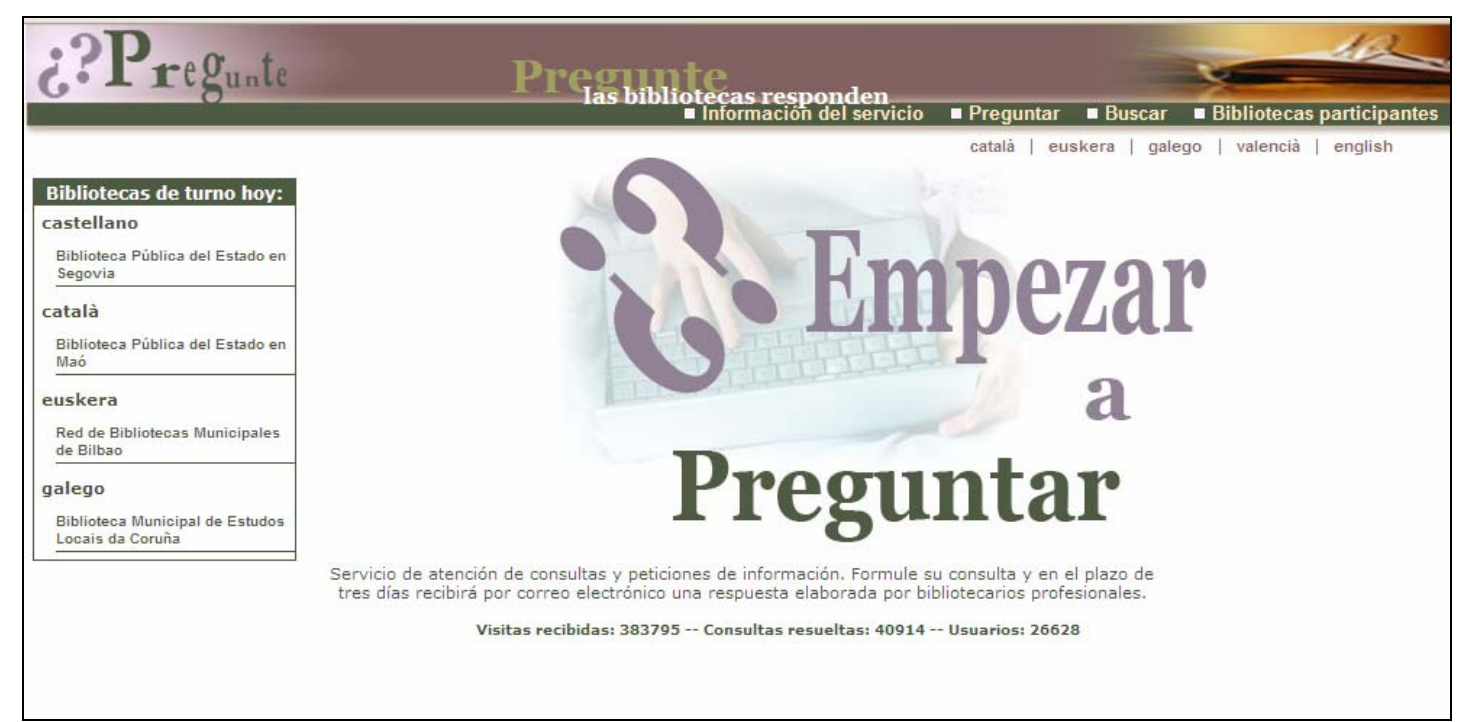

Fig. 3.123. Interfaz del servicio (marzo 2007)

Se ofrece una primera página en la que se describe someramente el servicio, al tiempo que se informa de qué bibliotecas son las que atenderán la consulta que se realice ese día. Asimismo, se pueden visualizar las principales estadísticas del sistema: entradas al servidor, número de preguntas resueltas y número de usuarios atendidos. Las páginas del servicio se pueden consultar en castellano, catalán, gallego, inglés, valenciano y vasco, aunque las preguntas sólo se contestan en las cuatro lenguas españolas oficiales.

En la página de información del servicio se detalla qué es «Pregunte: las bibliotecas responden», destacando los objetivos del servicio, los compromisos y su carácter abierto y público:

"Las bibliotecas responden" funciona 24 horas, 365 días al año, y se compromete a contestar en un plazo máximo de tres días. Las preguntas pueden tratar sobre cualquier tema puntual y concreto. Está abierto a todos los ciudadanos. 
Desde esta sección de información se describe cómo funciona el servicio, dejando claro que se trata de un proyecto rotatorio, en el que se la responsabilidad de las respuestas recae cada día en una de las bibliotecas participantes. También se determina qué tipo de respuestas ofrece: "El servicio «Pregunte» debe atender todo tipo de preguntas, consultas y peticiones de información, tanto las de carácter práctico como las temáticas, bibliográficas y culturales, de índole general y sobre todas las materias. Proporciona respuestas concretas a preguntas concretas o bien referencias para que el usuario encuentre por sí mismo la información que busca. No proporciona información elaborada, como informes, trabajos, etc." Además, ofrece sugerencias para la redacción de las preguntas y muestra ejemplos de consultas reales realizadas al servicio.

En la página en la que se han recogido los consejos para preguntar se insiste en cuestiones esenciales, como no realizar preguntas sobre una biblioteca concreta o la necesidad de comprobar la dirección de correo electrónico que se dé como contacto. No obstante, se informa de la existencia de una página para las respuestas perdidas, en la que se alojan los correos de respuesta que son devueltos al sistema. En otra de las páginas informativas se puede consultar la relación completa de las bibliotecas que participan en el proyecto, con acceso a los servidores de las mismas.

El formulario web desde el que se envían las consultas es sencillo de utilizar. Solicita una serie de datos obligatorios, como el correo electrónico y otros opcionales, como el nombre, la franja de edad y la localidad desde la que se escribe. El hecho de pedir la localidad obedece a que en muchos casos la respuesta puede estar en algún documento impreso disponible en alguna biblioteca de la localidad de domicilio del solicitante. El formulario de la consulta tiene limitados los caracteres y junto al mismo se pide la elección de la lengua de respuesta: castellano, catalán, gallego o vasco. Una vez realizada la pregunta, aparece una pantalla de confirmación, en la que se informa al usuario del número de identificación de la consulta (NIC) que se le ha asignado a la misma.

Por último, el servidor ofrece la posibilidad de consultar la base de datos de preguntas y respuestas. Se trata de un excelente recurso de información, ya que permite acceder a todas las consultas realizadas desde la creación del servicio, cifra que ya ha sobrepasado las cuarenta mil respuestas. Las posibilidades de interrogación son dos: búsqueda por defecto y buscador avanzado. En la primera de ellas, la que facilita directamente el sistema al elegir la opción Buscar desde cualquier página, envía a un formulario muy sencillo, en la que se pueden combinar tres argumentos: palabra (en pregunta, respuesta o ambas) tema (uno o todos) y fecha. La búsqueda avanzada amplia las posibilidades, ya que permite combinar dos términos con los operadores booleanos básicos, teniendo también la posibilidad de delimitar la consulta por temas o por rangos de fechas. La siguiente imagen muestra el formulario de búsqueda avanzada. 


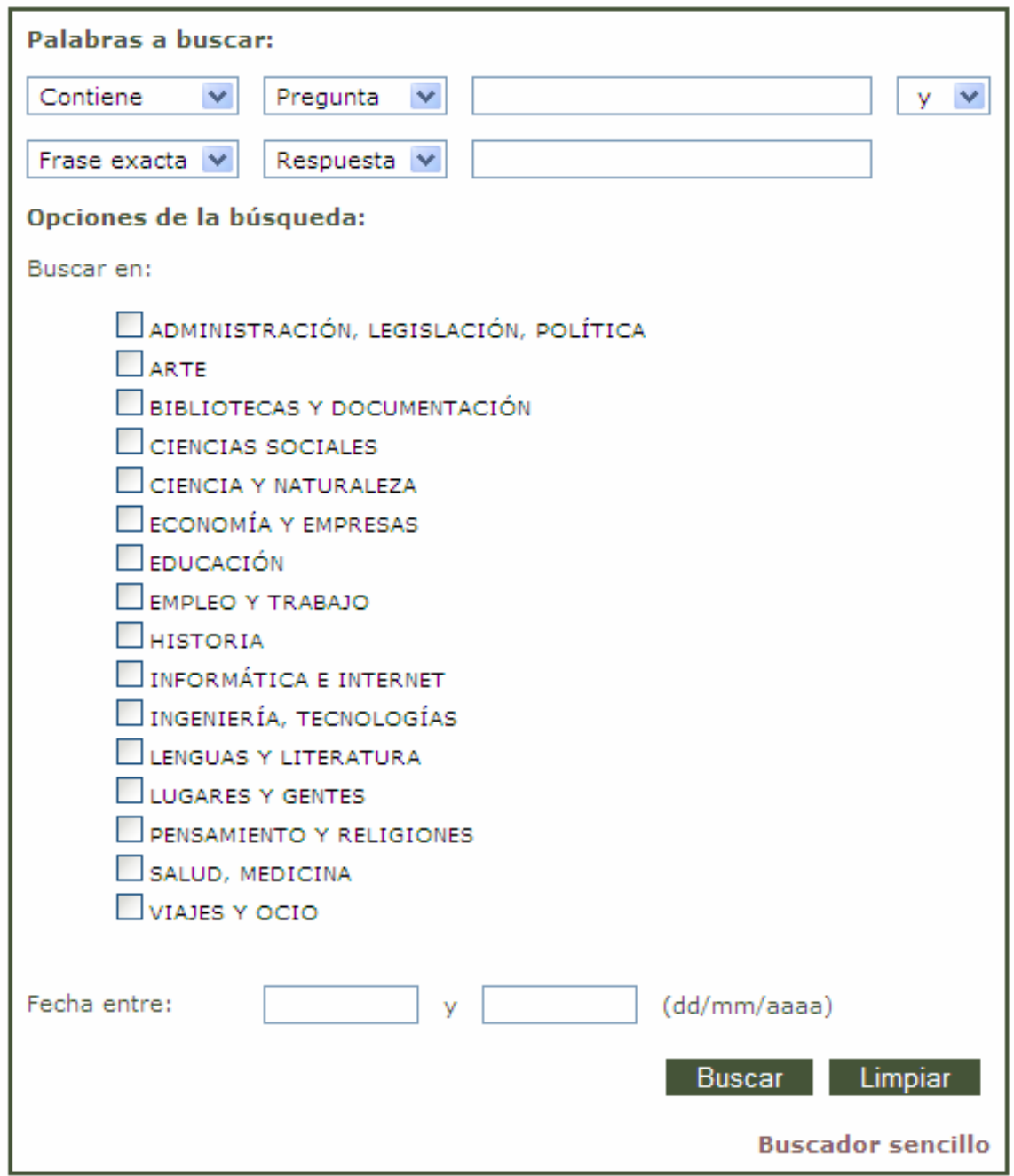

Fig. 3.124. Sistema de búsqueda (intranet)

Como se ha dicho unas líneas más arriba, la interfaz del servicio público de referencia digital española cambió de diseño a principio de 2007. La estética con la que comenzó la nueva etapa es la que se muestra en la figura 123.

No obstante, no se trataba de la interfaz definitiva, ya que estaba pendiente de finalizarse el diseño final, que es el que se muestra a continuación y que fue puesto en línea de forma definitiva el 1 de octubre de 2007, una vez que se modificaron algunos aspectos del sitio web, aunque todavía está proyecto incluir algunas secciones nuevas, como los recursos de información, así como otros ajustes en la navegación y la introducción de nuevos contenidos $^{466}$.

La imagen actual de «Pregunte: las bibliotecas responden» ofrece un diseño muy atractivo, con una estética contemporánea con la que mejoran las dos interfaces anteriores bajo las que se ha presentado el servicio.

\footnotetext{
${ }^{466}$ La presentación pública de la nueva web fue realizada por parte de la Subdirección General de Coordinación Bibliotecaria a través de su revista Correo Biblioteca, en el número 98, correspondiente a octubre de 2007.
} 


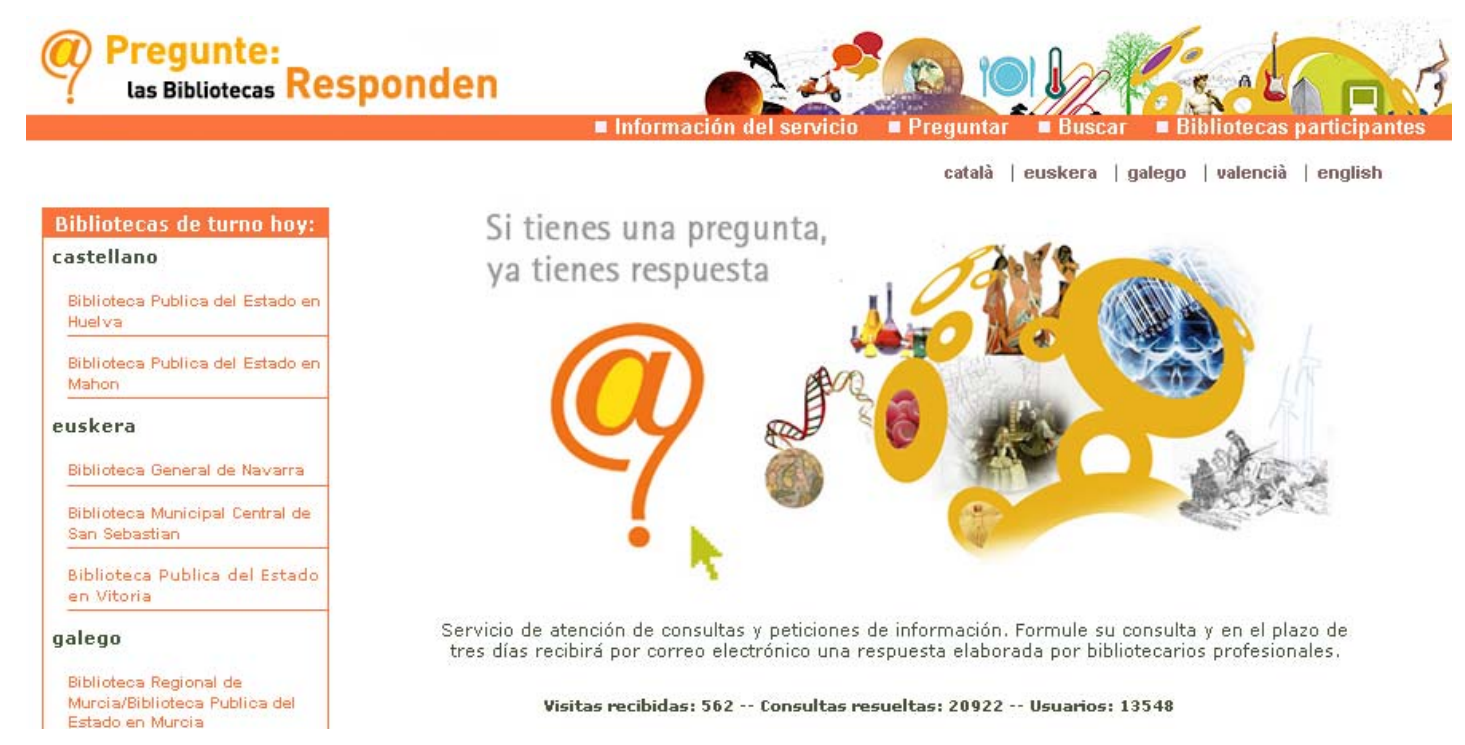

Fig. 3.125. Interfaz del servicio (octubre 2007)

La información se ofrece distribuida en varias áreas. Desde la imagen central los usuarios podrán acceder directamente al formulario desde el que se realizan las consultas. Bajo la imagen se encuentra una breve explicación del sistema y las estadísticas básica. En la pantalla central también se informa de qué bibliotecas están atendiendo el servicio en ese día.

La sección horizontal actúa como menú general. Aunque en la figura 3.125 se ofrece la imagen de la pantalla de bienvenida en el momento de su renovación (octubre de 2007), en la actualidad, las secciones en las que se estructura el sitio web de «Pregunte: las bibliotecas responden» son las siguientes:

Información del servicio: datos sobre qué es «Pregunte», cómo funciona y consejos para preguntar.

Preguntar: acceso al formulario de consulta, que se divide en diferentes secciones, obligatorias u opcionales.

Buscar: consulta del archivo de preguntas y respuestas, así como a la página de preguntas perdidas y ejemplos de búsquedas.

Bibliotecas participantes: relación de bibliotecas que atienden el servicio, ordenadas por Comunidades Autónomas.

Recursos en línea: acceso a diferentes variantes de la enciclopedia Ocenet, que se ofrece gratuitamente si se consulta desde esta web. 


\subsection{Manuales de procedimiento y otros documentos}

La reforma del servicio, que culminó en marzo de 2007, también ha implicado un cambio en los manuales y documentos sobre los que asienta el desarrollo de «Pregunte: las bibliotecas responden». Era lógico que, después de los primeros años de existencia, fuera necesario una revisión de sus procedimientos y filosofía de trabajo. Como se apreció en la evaluación presentada en el capítulo 13 de esta investigación, eran necesarios ciertos reenfoques en la filosofía general del servicio, además de algunas precisiones en el tipo de preguntas que se atienden y en la forma de ofrecer las respuestas. Todo ello ha sido revisado durante los dos últimos años y ha visto su culminación en el primer trimestre de 2007.

El servicio de referencia digital que ofrecen de forma coordinada y cooperativa 42 bibliotecas públicas españolas se organiza en torno a una aplicación informática común, elaborada de forma específica para este proyecto. Las bibliotecas emplean una serie de documentos comunes, que marcan la política y los procedimientos. En los siguientes párrafos se describen los cuatro documentos más importantes de uso interno del servicio: el Manual del usuario, el documento de Publicación del servicio, el Manual de procedimiento, el Cuadro de materias y el Documento de seguridad. Aunque los manuales son de uso interno han sido facilitados al doctorando por el equipo de responsables del servicio, hecho que debe ser agradecido, ya que permite que la visión que se está dando del proyecto sea completa.

El Manual del usuario es el documento más extenso e importante. Fue elaborado de forma conjunta por los miembros del Grupo de Trabajo de Referencia Virtual, que debatieron los contenidos, repartieron los diferentes apartados para su redacción individual, pusieron en común los trabajos particulares, consensuaron las modificaciones y aprobaron por unanimidad. El manual está dividido en once puntos:

1. Pregunte: las bibliotecas responden. Información sobre los orígenes y objetivos del servicio e introducción a los módulos de la aplicación informática (público e interno). Se describen las áreas relacionadas con el multilingüismo, la información básica del servicio que se ofrece al usuario, así como sobre las bibliotecas participantes. También se describen someramente las áreas de envío de consultas y el buscador.

2. Consultas y sugerencias: ¿qué ocurre cuando el ciudadano solicita estos servicios? Explicación del proceso que se sigue cuando un usuario realiza una consulta. Se muestra un modelo de consulta y notificación automática, tanto para el usuario como la que recibe la biblioteca a la que se le asigna la demanda. También se muestra el sistema de recepción de sugerencias. Una novedad del sistema son las consultas anidadas, es decir, que un usuario pueda volver a pedir información a partir de una respuesta. El sistema reenvía la consulta a la misma 
biblioteca que redactó la primera respuesta, algo que era un déficit claro del sistema anterior.

3. Autenticarse, desconectar y cambio de contraseña. Indicaciones para entrar el sistema de forma correcta, a partir de las diferentes contraseñas asignadas en función de los niveles de responsabilidad asignados. También se explica el sistema para el cambio de contraseñas.

4. Gestionar las consultas pendientes. Administración de las consultas que una biblioteca tiene pendiente de resolver, explicando las diferentes actuaciones posibles: contestar la consulta, rechazarla o redirigirla. Se describen los aspectos indispensables necesarios para contestar una pregunta, ya que, además de la respuesta en sí, se deben asignar temas, incluir las fuentes de información empleadas y las sugeridas para ampliar información. Asimismo, se detallan las diferentes modelo, es decir, los textos ya redactados que sirven para preguntas ya resueltas, para las que no tienen respuesta, para las que se consideran inapropiadas y para las que se contestan de forma parcial. En el caso de tratarse de una pregunta inapropiada se explica cómo seleccionar una respuesta modelo acorde para contestar. De igual forma, si se decide redirigir una pregunta se explica cómo asignar esta pregunta a la biblioteca más acorde. Por último, se explica someramente la necesidad de indicar el estado de la consulta: respondida, perdida, dentro o fuera de plazo.

5. Buscador: localizar y gestionar la consulta. Descripción del buscador interno, incidiendo en los criterios de búsqueda disponibles y en los sistemas de navegación por los resultados obtenidos. El buscador interno (no el público) permite obtener información detallada de las preguntas, incluso contestar las pendientes. Todo ello se explica también en esta parte del manual.

6. Estadísticas. Información sobre las posibilidades de explotación de las estadísticas que genera el sistema, exportación y visualización. Las estadísticas se agrupan por las consultas recibidas, por estado y por tipo. El manual detalla qué incluye cada uno de estos subtipos y cómo se deben consultar estas estadísticas. Además, se pueden realizar dos tipos de análisis estadísticos, uno general del sistema y otro por periodos y criterios seleccionados por el interesado.

7. Bibliotecas y perfiles de acceso. El sistema delimita diferentes tipos de perfil: bibliotecario, coordinador de biblioteca y coordinador general. En esta parte del manual se pueden ver las posibilidades de acceso al sistema de cada uno de ellos. Además, se indica cómo mantener actualizados los datos de cada centro, añadir o dar de baja bibliotecas, incluir usuarios en el sistema y gestionar días de fiesta 0 bajas temporales de bibliotecas. 
8. Control de turnos. Dado que «Pregunte funciona de forma cooperativa, mediante el trabajo rotatorio de las bibliotecas participantes, es necesario coordinar de forma muy detallada el sistema de control de turnos. En este capítulo se explica cómo se consultan los turnos, cómo se realizan los cambios de forma manual, cómo se actualizan los turnos si hay cambios y cuál es el procedimiento de asignación automática de los turnos.

9. Tipos de respuesta y gestión de respuestas modelo. Aunque ya se incluye información sobre las respuestas en el capítulo cuatro de este manual, se amplía el procedimiento y los tipos posibles en este apartado. Se diferencian las respuestas entre apropiadas y completadas, no apropiada o rechazada, incompleta y sin respuesta. Se explica cómo crear una respuesta modelo, así como la forma de modificarla o eliminarla. Se entiende por respuesta modelo aquella que sirve para responder consultas ya planteadas, incompletas, inapropiadas, etc.

10. Foro, información de participantes y documentación. El sistema dispone de un sistema de comunicación colectivo. En este apartado se explica la forma de enviar mensajes al foro, así cómo obtener información detallada de las bibliotecas participantes. También se remite a la sección en la que se encuentran los diferentes manuales del servicio.

11. Requisitos técnicos para el uso de Pregunte. El último apartado del manual del usuario se destina a las condiciones más adecuadas para el uso del servidor con los diferentes navegadores, sobre todo requisitos técnicos relativos a archivos temporales y privacidad.

A este manual del usuario se le acompaña del denominado Publicación del servicio: procedimiento de trabajo de las bibliotecas, que se redactó por dos razones; en primer lugar, para asegurar que el cambio de servidor y sistema se realizaba de forma correcta y, en segundo lugar, para que las bibliotecas que se incorporaban al servicio -así como las futuras- tuvieran un documento de referencia sobre cómo comenzar a trabajar en el mismo. La migración del sistema desde la Biblioteca Regional de Murcia al Ministerio de Cultura implicaba importantes cambios que era importante dar a conocer, ya que la nueva aplicación sólo incluía un usuario por biblioteca, el coordinador, a quien se encargaba de dar de alta a los restantes miembros del equipo, en función de los distintos perfiles y niveles de responsabilidad asignados y que se detallaban en éste y otros documentos que se explicarán en este apartado, como el denominado Documento de seguridad. Este breve documento, por tanto, está dirigido a los coordinadores del servicio en cada biblioteca y en el mismo se explica como actualizar los datos relativos a la biblioteca, al coordinador de la biblioteca, la lista de usuarios de la biblioteca y cómo modificar la contraseña.

El Manual de procedimiento es el documento en el que se recoge la filosofía del servicio, así como algunas normas básicas de actuación relativas a cómo actuar desde que se recibe una pregunta hasta que se da por solucionada, 
qué procesos internos se deben seguir, qué estilo es conveniente emplear para la redacción de las respuestas o cómo tratar las fuentes de información, incluyendo normas para la redacción de referencias bibliográficas. La última versión de este manual de procedimiento lleva la fecha del 15 de junio de 2007. Como se explicaba, es éste el documento en el que se constata detalladamente la filosofía de base del servicio, como se refleja en los siguientes párrafos extraídos del documento que se está describiendo:

Pregunte, las bibliotecas responden es un servicio de atención de consultas y peticiones de información a través de Internet. Cualquier ciudadano puede plantear su pregunta en la página Web del servicio Pregunte y, antes de 72 horas, recibirá por correo electrónico la respuesta, elaborada por profesionales de la búsqueda y organización de la información.

Cualquier persona puede usar Pregunte. Sólo se necesita poder utilizar un acceso a Internet y una cuenta de correo electrónico (las bibliotecas públicas españolas proporcionan acceso libre y gratuito a Internet a través de más de 7.432 puestos). EI servicio Pregunte proporciona respuestas concretas a preguntas concretas o bien referencias para que el usuario encuentre por sí mismo la información que busca. No proporciona información elaborada como informes, trabajos, etc.

Los destinatarios primeros del servicio son los habitantes de España, pero el alcance global de la herramienta usada, Internet, y la capacidad de proyección y de respuesta que ofrecen las instituciones implicadas en su prestación, hace que el servicio sea capaz de atender todas las consultas recibidas, siempre que éstas se hayan formulado en cualquiera de las lenguas oficiales de España, independientemente del lugar desde donde se realicen o la nacionalidad de quien formula la pregunta.

El servicio es proporcionado por un conjunto de 40 bibliotecas públicas españolas, cuyo personal especializado atiende, en turnos diarios, las preguntas formuladas por los ciudadanos, y cuenta con el apoyo del Ministerio de Cultura, a través de la Subdirección General de Coordinación Bibliotecaria.

El servicio Pregunte, las bibliotecas responden, se plantea como sus principales objetivos los siguientes:

Satisfacer, mediante un servicio público y gratuito, las necesidades de información concreta y referencial que puedan tener los ciudadanos y quienes se expresan en las lenguas oficiales de España.

Promover el papel de las bibliotecas públicas en la Sociedad de la Información y el Conocimiento, como centros activos y actualizados, capaces de proveer información de calidad para cualquier necesidad de los ciudadanos.

Favorecer el establecimiento y desarrollo de sistemas de trabajo cooperativo entre bibliotecas de diferente titularidad y gestión, con el fin de obtener unos mejores y más amplios servicios a los ciudadanos.

Intensificar la prestación de servicios de biblioteca mediante la utilización de las tecnologías de la información y la comunicación.

Pregunte constituye una extensión natural de lo servicios de información y referencia de las bibliotecas públicas, aunque con algunas peculiaridades.

El concepto actual de la biblioteca como organización humana que facilita el acceso a la información y la cultura tiene variadas implicaciones. Por una parte, supone el reconocimiento de la importancia de la persona como soporte de la organización, frente a la visión patrimonial de siglos anteriores. Por otra, consagra el servicio de Información y Referencia como el núcleo de la atención al público. En la misma línea, los sistemas de información local incorporan a la biblioteca pública una nueva 
dimensión del servicio que nunca han dejado de dar: el de centros de información para la comunidad a la que sirven.

Dentro de este marco, pero también en un entorno cooperativo en el ámbito nacional, Pregunte supone la extrapolación del servicio de referencia hacia una comunidad virtual, no presencial y que no tiene por qué coincidir con el público objetivo habitual de las bibliotecas públicas. Esta circunstancia obliga al mismo tiempo a desarrollar y aplicar al máximo las habilidades y conocimientos bibliotecarios para conseguir comprender la pregunta, encontrar la información y concretar la respuesta adecuada, sin el apoyo que supone la habitual entrevista de referencia, o en el resto de los procedimientos, sean presenciales, telefónicos, de chat, etc...

El Cuadro de materias empleadas en el servicio «Pregunte: las bibliotecas responden» es otro de los documentos técnicos elaborados en el proyecto y que es de uso común para todas las bibliotecas que participan en el mismo. Como se ha detallado en esta parte de la tesis doctoral, a todas las consultas se le debe adjudicar una materia. Son los profesionales referencistas quienes tienen esa obligación, a fin de poder reunir en un mismo archivo temático todas las cuestiones afines. Para ello, se emplea una clasificación sintética, que agrupa todas las disciplinas del conocimiento en dieciséis grandes categorías. Para su mejor compresión y manejo, el cuadro clasificatorio empleado en el servicio ofrece, en primer lugar, la relación de los términos admitidos y, acompañando a cada uno de ellos, la correspondencia de materias que se engloban en cada grupo y las notaciones de la CDU que se deben incluir en los respectivos bloques. Se muestra el ejemplo de la primera categoría para ilustrar de forma más adecuada cómo es la presentación de esta clasificación:

\begin{tabular}{|c|l|l|}
\hline TÉRMINO ADMITIDO & \multicolumn{1}{|c|}{$\begin{array}{c}\text { CORRESPONDENCIA } \\
\text { ALFABÉTICA }\end{array}$} & \multicolumn{1}{c|}{ NOTACIÓN CDU } \\
\hline $\begin{array}{c}\text { Administración, } \\
\text { Legislación, } \\
\text { Política }\end{array}$ & $\begin{array}{l}\text { Administración pública, Gobierno } \\
\text { Propiedad intelectual } \\
\text { Ejército, Asuntos militares }\end{array}$ & $\begin{array}{l}\text { 35. Administración pública, } \\
\text { gobierno, asuntos militares } \\
\text { Política } \\
\text { Bienestar social } \\
\text { Derecho }\end{array}$ \\
& & $\begin{array}{l}\text { Arte de la guerra... } \\
\text { 32. Política }\end{array}$ \\
& & $\begin{array}{l}\text { 36. Protección de las } \\
\text { necesidades materiales y } \\
\text { espirituales } \\
\text { 34. Derecho }\end{array}$ \\
& & \\
\hline
\end{tabular}

La relación completa de las categorías bajo las que se clasifican todas las consultas enviadas al servicio «Pregunte: las bibliotecas responden» es la siguiente:

Administración, Legislación, Política

Arte

Bibliotecas y Documentación

Ciencia y Naturaleza

Ciencias Sociales

Economía y Empresas

Educación

Empleo y Trabajo
Historia

Informática e Internet

Ingeniería, Tecnologías

Lenguas y Literatura

Lugares y Gentes

Pensamiento y Religiones

Salud, Medicina

Viajes y Ocio 
El traslado del servidor al Ministerio de Cultura conllevó ciertos cambios en la organización técnica del servicio. Al ser responsabilidad por entero del Ministerio de Cultura, se aumentaron las medidas de confidencialidad y se vigiló de forma exhaustiva el cumplimiento de la normativa legal en relación a la protección e intercambio de datos almacenados en medios digitales. En agosto de 2006 se redacta por primera vez el Documento de seguridad, cuya última modificación corresponde al mes de agosto de 2007. Este texto es una exigencia de la Ley Orgánica 15/1999 de Protección de Datos de Carácter Personal.

Al tratarse de una base de datos en la que se incluyen informaciones particulares, como es la dirección de correo electrónico, es necesario un documento como éste, en el que se detalle el funcionamiento de los módulos interno y público del sistema, así como las medidas, normas, procedimientos y reglas de seguridad.

Además de en el manual del usuario, en este documento se explica de forma pormenorizada cuáles son las funciones y obligaciones del personal relacionado con el servicio y cuáles son sus funciones sobre el fichero o archivo general del servicio. Se establecen perfiles muy diferenciados, según la responsabilidad que se les asigne y el tipo de datos a los que se tenga acceso. La relación de perfiles del sistema es la siguiente:

\begin{tabular}{|c|c|c|}
\hline Función sobre el fichero & $\begin{array}{l}\text { Perfil de usuario } \\
\text { Pregunte }\end{array}$ & Personal \\
\hline Responsable del Fichero & Ninguno & $\begin{array}{l}\text { Director General del Libro, Archivos y } \\
\text { Bibliotecas } \\
\quad \text { Ministerio de Cultura }\end{array}$ \\
\hline Grupo Coordinador General & $\begin{array}{l}\text { Coordinador } \\
\text { General }\end{array}$ & $\begin{array}{l}\text { SG Coordinación Bibliotecaria } \\
\text { Usuarios registrados con perfil } \\
\text { coordinador general y } \\
\text { asociados al Ministerio de } \\
\text { Cultura } \\
\end{array}$ \\
\hline $\begin{array}{l}\text { Grupo Coordinador de } \\
\text { Biblioteca }\end{array}$ & $\begin{array}{l}\text { Coordinador de } \\
\text { Biblioteca }\end{array}$ & $\begin{array}{l}\text { Bibliotecas } \\
\text { Usuarios registrados con perfil } \\
\text { coordinador de biblioteca, } \\
\text { asociados a alguna de las } \\
\text { bibliotecas de la tabla } \\
\text { Bibliotecas } \\
\end{array}$ \\
\hline Grupo Bibliotecario & Bibliotecario & $\begin{array}{l}\text { Bibliotecas } \\
\text { Usuarios registrados con perfil } \\
\text { bibliotecario, asociados a } \\
\text { alguna de las bibliotecas de la } \\
\text { tabla Bibliotecas }\end{array}$ \\
\hline $\begin{array}{l}\text { Administración técnica de } \\
\text { PREGUNTE }\end{array}$ & Ninguno & $\begin{array}{l}\text { SG de Tecnologías y Sistemas de } \\
\text { Información } \\
\text { Ministerio de Cultura }\end{array}$ \\
\hline
\end{tabular}

En este documento se expone también la estructura de los ficheros con datos de carácter personal y se describen los sistemas que los tratan. La base de datos se encuentra en un servidor Oracle v.9.2. Todos los datos referentes a las conexiones son almacenados en un fichero XML, que está restringido a los administradores del servidor de aplicaciones, como se 
explica en este documento de seguridad, en el que también se incluye información acerca de cómo gestionar incidencias y el procedimiento para la realización de copias de respaldo y recuperación de los datos. En un documento anexo se recogen las obligaciones del personal con perfil de coordinador (general o de biblioteca), así como las del responsable del fichero, en virtud de la Ley Orgánica 15/1999. Por ejemplo, la persona que en una de las 42 bibliotecas actuales pertenecientes al proyecto ostente la coordinación del mismo en su centro, está obligada por esta ley a lo siguiente, como se refleja en el anexo al documento de seguridad que se está describiendo:

1- Está obligado al cumplimiento de la normativa de seguridad que se recoge en el Documento de Seguridad. Por ello, debe conocer el Documento de Seguridad y las consecuencias de su incumplimiento.

2- Debe mantener en secreto su contraseña de acceso al fichero PREGUNTE y poner todos los medios para impedir que otra persona utilice su acceso: guardar secreto sobre la misma, cambiar la contraseña cuando así se le indique y cuando considere que alguien pueda conocerla.

3- Debe cerrar la aplicación PREGUNTE siempre que se ausente de su puesto de trabajo.

4- Deberá recoger en el fichero PREGUNTE sólo datos personales que sean adecuados, pertinentes y no excesivos en relación con su finalidad.

5- No podrá utilizar los datos para finalidades diferentes para las que hubieran sido recogidos.

6- Estará obligado al secreto profesional respecto a los datos registrados y al deber de guardarlos, obligaciones que subsistirán aun después de finalizar su relación con el fichero PREGUNTE.

7- Los listados y formularios impresos en soporte papel cuyos datos no estén sometidos a un proceso de disociación (sin nombre, correo electrónico o cualquier otro campo que identifique a la persona) sólo podrán utilizarse para las funciones que fueron creados y mantenerse en lugar seguro para evitar acceso a los mismos a personas no autorizadas. En ningún caso estos documentos deberán salir fuera de las dependencias del puesto de trabajo ni facilitarse original o copia a otra persona sin el consentimiento del Responsable del Fichero.

8- Remitirá al Responsable del Fichero las peticiones del interesado respecto a sus derechos de acceso, rectificación y cancelación.

9- Mantendrá actualizada la relación de usuarios de la biblioteca con permiso de acceso al sistema Pregunte y deshabilitará dicho permiso cuando el usuario deje de ejercer funciones sobre el mismo. 
14.3. Estadísticas del servicio de referencia digital «Pregunte: las bibliotecas responden»: $\mathbf{2 0 0 0 - 2 0 0 7}$

A lo largo de esta tesis doctoral se han querido recoger todos los aspectos que tienen relación con los servicios de referencia digital, comenzando por los aspectos genéricos de las secciones de información de las bibliotecas, continuando por las cuestiones relativas a los sistemas de consulta basados en Internet, desarrollando los aspectos vinculados a la evaluación de servicios de referencia locales y telemáticos y presentando minuciosamente el proyecto cooperativo español, que se enmarca entre los grandes sistemas nacionales de referencia en línea. Lejos han quedado las tímidas experiencias iniciadas en 1999, que dieron como resultado un servicio compacto y consolidado.

En los siguientes párrafos se quiere finalizar esta parte -la más voluminosa de la investigación- ofreciendo las principales cifras que muestren la evolución del servicio desde su creación hasta la actualidad. Para poder disponer de datos comparativos entre sí se han establecido periodos de un año, desde el junio de un año hasta el 30 de mayo del siguiente. «Pregunte» comenzó a ser un servicio público a principios de junio de 2000, por eso se toma esa fecha como referente inicial. Los datos que se muestran se han tomado en agosto de 2007, pero para obtener secuencias completas y homogéneas, las estadísticas que se ofrecen se cierran en junio de 2007, a fin de tener series anuales análogas.

Todas las estadísticas que se presentan aquí han sido extraídas de la intranet del servicio. Entre las funcionalidades de que dispone se encuentra la consulta a los datos estadísticos, ya sea de una biblioteca o de todo el conjunto. Las consultas pueden limitarse por periodos temporales, como se ha hecho para esa tesis doctoral. De igual forma, el sistema permite la obtención de tres tipos de informes:

- Consultas: ofrece datos de las consultas recibidas, pendientes y de las redirigidas.

- Estado: informa de las consultas recibidas, de las respondidas en plazo y fuera de plazo, de las perdidas fuera y dentro de plazo y de las cuestiones que están sin resolver.

- Tipo: muestra las consultas recibidas, las respondidas, las resueltas, las contestadas sin respuesta, las consultas no apropiadas 0 rechazadas y las respuesta incompletas.

Las estadísticas correspondientes a la temática de las preguntas, sin embargo, no han sido elaboradas a partir de la intranet, sino de la web pública, a partir del buscador avanzado. Se han realizado las consultas necesarias, indicando los periodos anuales establecidos y seleccionado cada uno de los temas bajo los que «Pregunte» archiva sus consultas. De esta forma se han obtenido los datos de cada tema y año, aunque hay algunas categorías temáticas que no estaban en los primeros años del 
servicio. No obstante, el servicio dispone ya de suficiente trayectoria como para considerar como significativa la evolución que se muestra en las estadísticas temáticas que arroja el servicio.

Todas las estadísticas se han combinado y tabulado de manera conjunta, uniendo los datos extraídos por los distintos métodos de recuperación, para poder ofrecer esta panorámica sobre la evaluación del servicio desde 2000 hasta 2007.

En primera lugar, se puede observar el incremento del número de bibliotecas que participan en el servicio de referencia digital «Pregunte». En el primer año, el de mayo afluencia de preguntas, el proyecto se gestionó con 21 centros, número que rápidamente se constató que era insuficiente, por lo que poco a poco, a medida que ha sido necesario, se han ido sumando nuevas bibliotecas al proyecto. Aunque en el último año de la siguiente figura aparecen 39 bibliotecas, en la actualidad hay 42 prestando servicio, ya que las estadísticas recogen periodos anuales que se inician el 1 de junio y terminan el 30 de mayo. En junio de 2007 se han sumado al proyecto tres nuevas bibliotecas, por lo que la cifra actual es de 42 bibliotecas, más la Subdirección General de Coordinación Bibliotecaria, del Ministerio de Cultura, que actúa como coordinadora del servicio.

Así pues, pues la evolución cronológica del número de bibliotecas que atienden o han atendido el servicio público de referencia español ha ido evolucionando desde las 21 que inicialmente atendían las consultas de los usuarios a las 42 que integran la red en la actualidad. Si se muestra gráficamente la evolución tomando los periodos anuales completos, el resultado sería el siguiente:

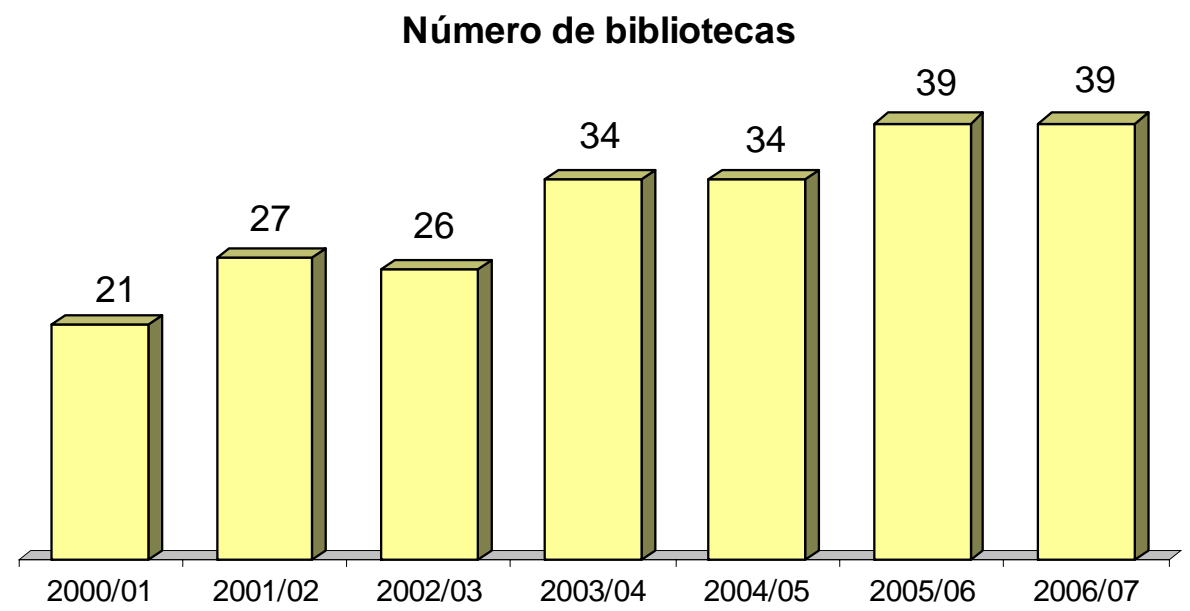

Fig. 3.126. Evolución estadística: número de bibliotecas

El número de preguntas se mantiene en torno a las 5.500, aunque en el último año ha habido una caída preocupante, ya que se recibieron poco más de 4.500 cuestiones. Como se reflejó en la evaluación que se ha presentado en esta parte de la tesis doctoral, siguen siendo necesarias diversas medidas de promoción del servicio, ya que una de las principales causas de que un proyecto tan sólido y estructurado como éste no se emplee, es, 
probablemente, el desconocimiento de su existencia. Es evidente que en estos momentos, una vez realizados los ajustes necesarios, corregidos los errores y mejorada la aplicación informática, el servicio debe ser relanzado, mediante una campaña informativa que tenga como protagonistas a las bibliotecas, principales centros informadores. En la siguiente figura se muestra de forma gráfica la evolución del número de cuestiones que se han recibido en «Pregunte», una vez más, empleando como periodo temporal el año que transcurre desde el 1 de junio hasta el 30 de mayo del año siguiente. Como se explicó, en junio de 2000 se inicia el servicio, por lo que cerrar el plazo en junio de 2007 permite disponer de secuencias temporales homogéneas y comparables.

\section{Consultas recibidas}

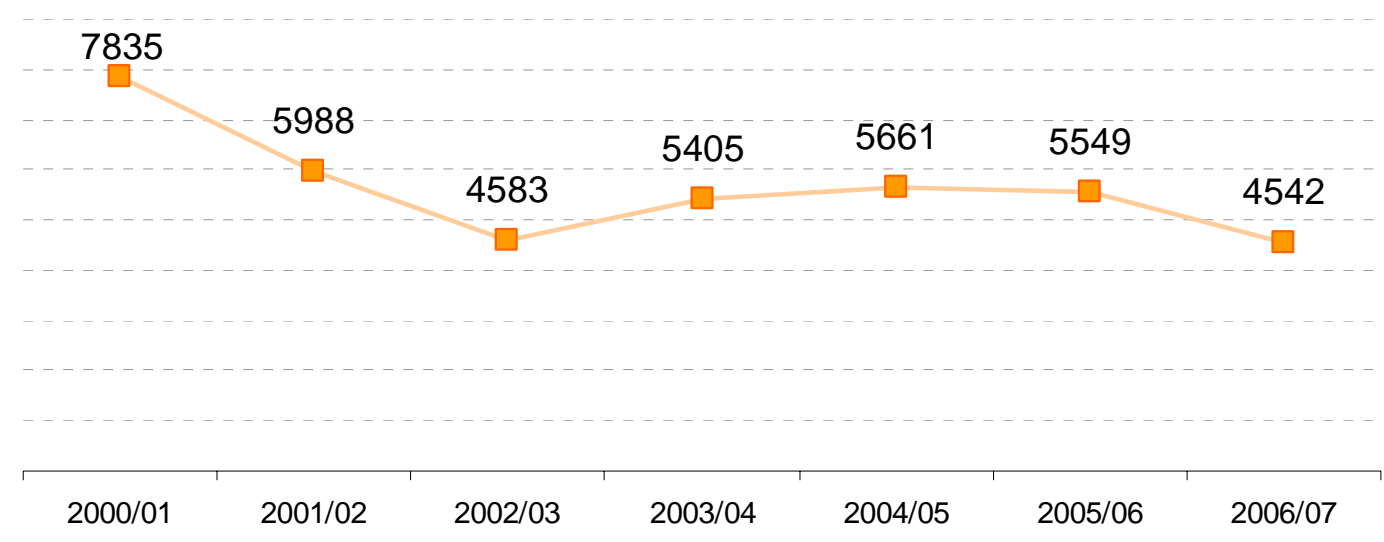

Fig. 3.127. Evolución estadística: consultas recibidas

En los distintos apartados del capítulo 12 se describió la identificación de las preguntas que realizan los profesionales referencistas en función de las contestaciones que se den a las demandas recibidas. Así, es posible encontrarse con la siguiente tipología de cuestiones:

- consultas recibidas: todas las que llegan a través del formulario web

- consultas respondidas: las que son contestadas, ofreciendo o no la respuesta a la pregunta formulada

- consultas resueltas: las que responden a la pregunta

- consultas redirigidas: cuestiones que tratan de temas locales y que se remiten a otra biblioteca más afín

- contestadas sin respuesta: aquéllas que ofrecen una contestación al usuario, pero no la respuesta a su pregunta

- consultas rechazadas: las que se contestan indicando que no se responderán por no ajustarse a la política del servicio 
- respuestas incompletas: las que se contestan respondiendo de forma parcial, indicando al usuario que no se ha podido obtener la respuesta a su pregunta, pero ofreciendo informaciones relacionadas

Las consultas recibidas en «Pregunte: las bibliotecas responden» deben ser respondidas en menos de 72 horas, ése el plazo que se ha marcado el servicio y ése el compromiso que aceptan todas las bibliotecas participantes en el proyectos. Como puede observarse en la figura que se muestra a continuación, un gran porcentaje de las preguntas se responden en menos de los tres días marcados, sólo una cifra menor se contesta fuera de este periodo, aunque lo idóneo sería que el número de las respuestas enviadas transcurrido el plazo fuera inexistente.

Plazos de respuesta

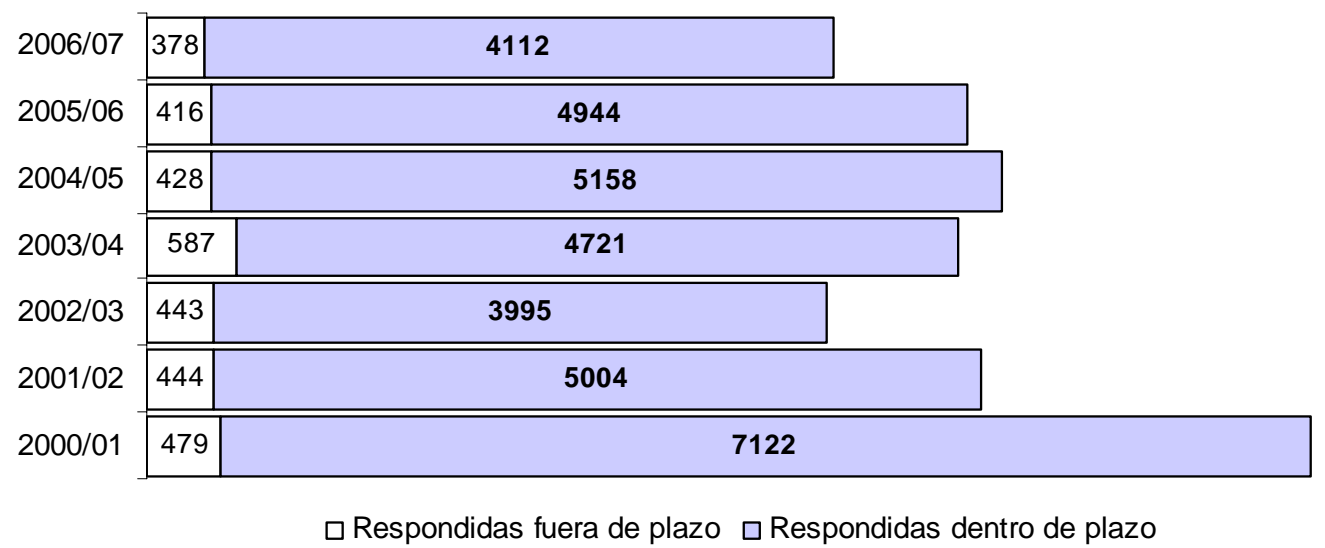

Fig. 3.128. Evolución estadística: plazos de respuesta

Para finalizar la parte dedicada al servicio público de referencia digital «Pregunte: las bibliotecas responden» se han recopilado los datos referentes a la temática de las consultas realizadas por los usuarios. El manual de procedimiento indica que a cada pregunta recibida se le adjudica un tema de entre los dieciséis en los que organiza el conocimiento este servicio. De esta manera, los archivos pueden consultarse por las preguntas recibidas sobre un tema concreto; además, esta clasificación permite realizar análisis estadísticos acerca de los temas más demandados en el servicio. La figura con la que se termina este bloque suma las consultas asignadas a cada tema en los periodos que se están manejando durante todo este capítulo, es decir, desde el 1 de junio de 2000 hasta el 30 de mayo de 2007. Algunas de las categorías actuales no estaban presentes en los dos primeros años, como ocurre con Bibliotecas y documentación, Lugares y gentes y Pensamiento y religiones.

No obstante, en la siguiente gráfica se puede comprobar cómo las preguntas relativas a bibliotecas son las más frecuentes, a pesar de haber comenzado a computarse como categoría independiente en 2002. Existe una razón muy clara para que existan más preguntas sobre esta materia. Quienes mejor conocen el servicio son quienes están trabajan en un puesto relacionado con la biblioteconomía o la documentación. o quienes se preparan para el 
acceso a la función pública en una plaza de bibliotecario. Un alto porcentaje de las cuestiones de esta categoría corresponden a opositores y estudiantes, quienes saben de la existencia del servicio y que está atendido por bibliotecarios profesionales. Además, es significativo el número de preguntas relacionadas con las humanidades, ya sea lengua, literatura 0 historia, que ocupan los siguientes lugares en la frecuencia de preguntas, como se aprecia en la ilustración siguiente.

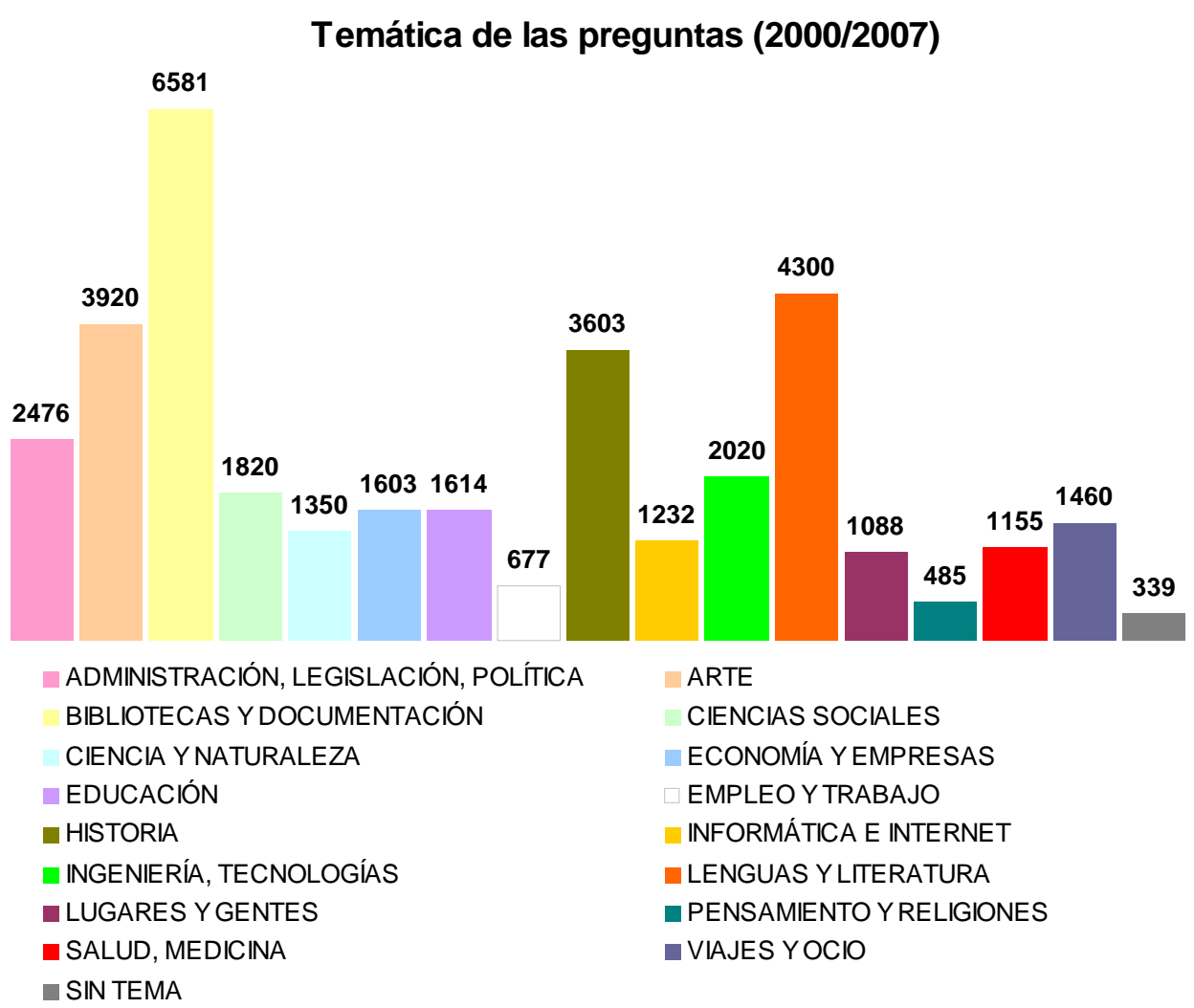

Fig. 3.129. Evolución estadística: temática de las preguntas

A fin de poder obtener una visión de conjunto lo más completa posible, se reproducen en la tabla siguiente los datos correspondientes a los siete años completos de existencia de «Pregunte: las bibliotecas responden». Como puede observarse, el mayor porcentaje de las preguntas recibidas se responde de forma completa, algo que se puede considerar como un indicador de calidad.

$\begin{array}{rccccccc} & \begin{array}{c}\text { Consultas } \\ \text { recibidas }\end{array} & \begin{array}{c}\text { Consultas } \\ \text { respondidas }\end{array} & \begin{array}{c}\text { Consultas } \\ \text { resueltas }\end{array} & \begin{array}{c}\text { Consultas } \\ \text { redirigidas }\end{array} & \begin{array}{c}\text { Contestadas } \\ \text { sin respuesta }\end{array} & \begin{array}{c}\text { Consultas } \\ \text { rechazadas }\end{array} & \begin{array}{c}\text { Respuestas } \\ \text { incompletas }\end{array} \\ 2000 / 01 & 7835 & 7835 & 7132 & 0 & 283 & 299 & 121 \\ 2001 / 02 & 5988 & 5988 & 5539 & 0 & 198 & 172 & 79 \\ 2002 / 03 & 4583 & 4583 & 3836 & 285 & 241 & 158 & 348 \\ 2003 / 04 & 5405 & 5405 & 4541 & 427 & 294 & 245 & 325 \\ 2004 / 05 & 5661 & 5661 & 4611 & 551 & 331 & 349 & 370 \\ 2005 / 06 & 5549 & 5549 & 4368 & 635 & 346 & 412 & 423 \\ 2006 / 07 & 4542 & 4542 & 3758 & 710 & 224 & 265 & 295 \\ \text { Total } & 39563 & 39563 & 33785 & 2608 & 1917 & 1900 & 1961\end{array}$


La evolución de los siete primeros años completos del servicio de referencia digital español refleja un periodo de estancamiento prolongado, ya que es preocupante que el número más elevado de preguntas se recibieran en el primer año del servicio y, desde entonces, las cifras han ido en descenso, exceptuando algunos periodos de cierto alza. En la siguiente figura se puede comprobar la trayectoria del número de preguntas recibidas y de las consultas que han sido resueltas.

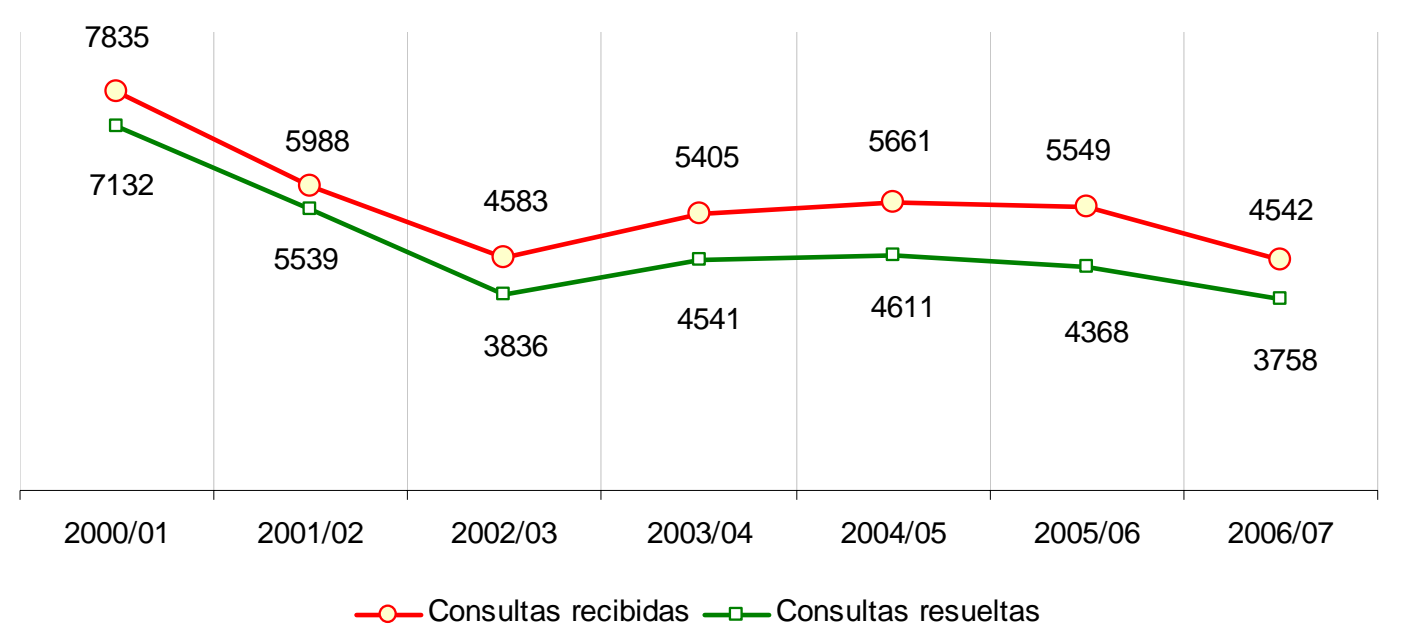

Fig. 3.130. Evolución estadística: consultas 


\section{Análisis de resultados: conclusiones}

Tras la exposición de los estudios realizados se presentan en este apartado las conclusiones que se pueden extraer del análisis de las distintas evaluaciones realizadas, a fin de obtener una visión global de los que se han considerado los principales aspectos de descripción del servicio, como son sus fortalezas y debilidades, el grado de satisfacción de los usuarios y los profesionales que atienden «Pregunte», la documentación empleada, su sistema de organización, etc.

En los siguientes párrafos, se exponen de forma consecutiva las conclusiones extraídas a partir de los diferentes análisis y evaluaciones llevados a cabo en los apartados anteriores de esta tesis doctoral. Se ha preferido realizar una exposición numérica de las conclusiones, en vez de una agrupación por categorías, ya que muchas de las cuestiones que se presentan afectan a diferentes aspectos de «Pregunte» (servidor, organización, recursos, profesionales, etc.) de forma simultánea. No obstante, las sugerencias de mejora que se plantearán en el siguiente apartado, que están motivadas por estas conclusiones, sí se ofrecerán organizadas por las categorías a las que se refieren.

Hay que tener presente que las conclusiones corresponden a los diferentes estudios expuestos, los cuales fueron realizados en fechas pasadas. Muchas de las conclusiones que aquí se exponen y de las sugerencias correspondientes que se verán en el apartado siguiente, han sido reflejadas en la nueva versión del servidor del servicio, hecha pública el 26 de marzo de 2007. De igual forma, los nuevos manuales de procedimiento tienen en cuenta los aspectos que se derivaron de la investigación y que se relacionan en las siguientes líneas.

1. La utilidad del servicio «Pregunte» es incontestable, por lo que cualquier modificación del mismo debe orientarse hacia una mejor organización y hacia la consecución de mayor calidad en sus respuestas. La opinión de los usuarios sobre la utilidad del servicio es muy positiva, así como la de los profesionales. Las diferentes consultas realizadas demuestran que la calidad general de «Pregunte» es buena, a pesar de la disparidad en la forma de responder. Se debe procurar la homogeneización de las respuestas ante preguntas similares, así como el uso de un formato único de contestación.

2. La filosofía general del servicio (qué se pretende ofrecer y cómo se ofrece) debería ser debatida entre las bibliotecas participantes, ya que existen diferencias significativas, por ejemplo, entre el modo en que unas y otras bibliotecas responden. Es esencial que se determine cuál es el objetivo principal de «Pregunte», a quién se quiere atender, qué tipo de consultas se deben responder y cómo se realizarán las 
respuestas. Se considera necesario y urgente delimitar en un reglamento consensuado los fines y procedimientos del servicio.

3. No se sigue un mismo esquema de respuesta. Dependiendo de qué biblioteca conteste se ofrecerá la respuesta elaborada o sólo las fuentes de información y se incluirán fuentes o no. Es necesario unificar los criterios de respuesta y las formas de redacción de las mismas.

4. Las preguntas inadecuadas y las que no se ajustan a las normas del servicio muchas veces quedan sin contestar. Es necesario que se establezcan métodos homogéneos para responder estas cuestiones, aunque sea con fórmulas de cortesía informando de por qué no se da una respuesta a las mismas.

5. La forma de citar las fuentes empleadas y las recomendadas es muy diferente entre unas bibliotecas y otras. Es conveniente incluir en el manual de procedimiento qué información debe aparecer en estos campos y cómo se expresará. Por ejemplo, no se puede poner "Internet" como fuente, algo muy común en las respuestas dadas, ya que se deberá informar de qué servicio o servidor de Internet se ha empleado.

6. Es conveniente que el servicio se ofrezca sólo para usuarios que empleen las lenguas españolas, independientemente de su país de residencia. La mayoría de los profesionales que atienden «Pregunte» opinan de esta forma, por lo que no sería correcto plantear cambios en este sentido. Sí sería útil establecer contactos con otros servicios públicos de referencia en línea para el reenvío de preguntas relacionadas con otros países.

7. Muchas preguntas obedecen a cuestiones personales y genealógicas. Se deberá establecer cuál es el grado de información que el servicio puede prestar en estos temas y reforzar, en su caso, las fuentes de información biográficas existentes en las bibliotecas integrantes de «Pregunte».

8. Existe un porcentaje no desdeñable de respuestas que se redactan de forma muy subjetiva: "creemos que...", "entendemos que...". El servicio debería plantearse con informaciones objetivas en el que el referencista sólo sea un intermediario entre la pregunta y su respuesta.

9. Muchos usuarios repiten una pregunta, a la vez que existen muchas preguntas que se hacen de forma periódica. El personal que atiende «Pregunte» debería consultar siempre el archivo de consultas, algo que no es común, para ofrecer respuestas idénticas ante preguntas iguales. 
10. La variedad de fuentes empleadas no es excesiva, por lo que se puede deducir del análisis de la base de datos de respuestas. Sin embargo, ante preguntas del mismo tipo, por ejemplo bibliográficas 0 normativas, en muchos casos se usan recursos muy dispares, que provocan resultados diferentes. Habría que establecer una serie de fuentes de información esenciales, que serían las que se consulten en primer lugar.

11. No se considera urgente la posibilidad de recibir y responder preguntas de forma inmediata, sobre todo si se parte de la actual estructura descentralizada del servicio. Sin embargo, la tendencia en proyectos nacionales de este tipo es la implantación de sistemas de chat 0 mensajería instantánea, siempre que se den las condiciones para atender un servicio de estas características. Sería útil analizar cómo se está planteando este servicio en países donde ya se ofrece con éxito.

12. Poco menos de la mitad de los profesionales está conforme con el espacio disponible para ofrecer las respuestas. Sin embargo, la mayoría opina que debería ofrecerse la posibilidad de adjuntar archivos, para desarrollar la respuesta o enviar documentos complementarios. El número de caracteres máximo o el permitir adjuntar documentos dependerá del tipo de respuestas que el servicio quiera ofrecer, por lo que sería recomendable establecer una normativa clara acerca de qué tipo de preguntas se atienden y cómo se contestan, antes de decidir ampliar el número de caracteres o de permitir enviar archivos adjuntos.

13. Se considera conveniente establecer un sistema de evaluación, a través del cual se conozca el grado de satisfacción del usuario acerca de las respuestas recibidas y del servicio en general. Muchos usuarios usan por error el sistema de quejas y sugerencias para mostrar su agradecimiento o disconformidad. Se estima necesario un método que permita recoger estas valoraciones.

14. No existe un sistema de evaluación cualitativa del servicio en el que participen todas las bibliotecas del proyecto. Sí existen indicadores cuantitativos, pero que no permiten conocer el tipo de preguntas, respuestas y fuentes, ni tampoco la calidad del servicio ni la satisfacción del usuario.

15. La metodología actual de distribución de turnos posibilita que las bibliotecas resuelvan las preguntas que reciben de forma cómoda. Por lo general, se está de acuerdo con el método de organización, con el número de respuestas que se recibe y con el tiempo de que se dispone para responder.

16. En su gran mayoría el tiempo que se tarda en resolver una pregunta es inferior a una hora. Si la media de preguntas por turno es 15,56 y la 
media de respuesta es de 1,67 días, sería posible reducir el periodo de 72 horas establecido para contestar una pregunta.

17. Los preguntas enviadas en fin de semana deben ser contestadas en un sólo día si no se quieren enviar fuera de plazo. Sería más equilibrado establecer los plazos en días laborables, puesto que no hay profesionales que atiendan el servicio en días festivos. Esto no impediría que las preguntas se recogieran 24 horas al día, los 7 días de la semana.

18. Muchas preguntas no se contestan en el plazo establecido. En ocasiones esto ocurre por problemas con el personal (bajas, vacaciones, exceso de trabajo, etc.), aunque en otros casos es la dificultad de la respuesta la que provoca el retraso. El procedimiento debería contemplar la posibilidad de una primera comunicación en la que se indique al usuario que la pregunta se ha recibido y que se enviará su respuesta próximamente.

19. Habría que valorar que en las bibliotecas con doble turno (dos lenguas) se dispusiera de más días entre un turno y otro, en función del número de consultas que reciben.

20. La información sobre el servicio (manuales, directorio, etc.) necesita ser reelaborada, ya que existen muchos cambios en los datos de las personas y las bibliotecas que participan en el proyecto. De igual forma, el manual de procedimiento debería volver a redactarse, para adaptarse al tipo de preguntas que se hacen en la actualidad y al modo en el que se están atendiendo.

21. Hay una sensación de que existe escasa coordinación entre las bibliotecas. Esto se solventaría con la existencia de un centro coordinador con atribuciones sobre el filtrado y validación de las preguntas y respuestas. El supuesto centro coordinador también se podría responsabilizar de las cuestiones que quedan sin respuesta, del establecimiento de los turnos y del asesoramiento de todas las bibliotecas que integran el servicio.

22. Sería aconsejable establecer un procedimiento para que una biblioteca que quiera ampliar o mejorar una respuesta pueda recuperar la pregunta para reenviar la contestación al usuario.

23. Las preguntas sin respuesta se están acumulando de forma preocupante. Nadie parece tener responsabilidad sobre las mismas, por lo que habrá que establecer una metodología de respuesta, una normativa de responsabilidad de las respuestas o un sistema cooperativo más eficaz para que ninguna pregunta quede sin contestación. 
24. Algunas categorías temáticas están recibiendo una proporción elevada de preguntas, por lo que sería muy útil contar con bibliotecas que se especializasen en esos temas o bien llegar a acuerdos con bibliotecas o entidades especializadas para el apoyo en la resolución de estas cuestiones. El proyecto ganaría en calidad y recursos si se incorporasen otras entidades bibliotecarias públicas, como la Biblioteca Nacional, bibliotecas de investigación del CSIC 0 bibliotecas de universidades públicas.

25. La lista de distribución interna no se emplea. Por lo general no hay comunicaciones entre bibliotecas, sino entre la coordinación y los centros participantes. El foro es una evidente herramienta de cooperación que debería ser empleada para el intercambio de experiencias, recursos y, por qué no, de dificultades.

26. El número de profesionales bajo cuya responsabilidad está «Pregunte» es significativo, ya que unas 150 personas, entre las 34 bibliotecas pertenecientes al proyecto, se encargan de atender las consultas de los usuarios. Aunque no es una cifra pequeña debería estudiarse la posibilidad de incorporar nuevas bibliotecas, aunque sólo fueran de las Comunidades Autónomas menos representadas.

27. Internet es una herramienta muy utilizada por el personal que atiende «Pregunte», aunque apenas se utiliza de forma experta, por lo que se deben enseñar técnicas avanzadas de recuperación de información en Internet. Dado el número de personas vinculadas a «Pregunte», se debería optar preferentemente por elaborar publicaciones de divulgación en las que se expliquen los principales métodos, sistemas y herramientas de localización de información en Internet.

28. La mayoría de los profesionales que atienden el servicio «Pregunte» destinan al mismo sólo el tiempo que tardan en responder las preguntas. De igual forma, es elevado el porcentaje de bibliotecarios que compatibiliza las tareas de referencia con otras labores profesionales.

29. Los profesionales que atienden «Pregunte» califican como "normales" sus conocimientos profesionales, tanto los relativos a las técnicas bibliotecarias, como los relacionados con fuentes de información e Internet. Los bibliotecarios referencistas deben ser expertos en la localización de información, por lo que serían recomendables acciones formativas específicas para quienes estén al cargo de este servicio.

30. Los cursos de formación son considerados convenientes o muy convenientes por la gran mayoría. Las administraciones implicadas en «Pregunte» deberán organizar actividades de formación especificas para quienes atienden las consultas de los usuarios. Estos cursos 
deberán orientarse hacia técnicas de búsqueda y fuentes de información.

31. La formación continua de los profesionales en materia de referencia es algo necesario. Además de programarse los cursos que regularmente se convocan se deberían ofrecer cursos presenciales o a distancia, a partir de las sugerencias que hagan los referencistas que trabajan para «Pregunte».

32. La mayoría de la documentación que se ofrece a las bibliotecas fue realizada en la primera época del servicio; habría que utilizar la experiencia acumulada para volver a elaborar la documentación que se ha de emplear: normativa general, organización, modelos de respuestas, clasificación, etc.

33. La documentación de trabajo de «Pregunte» es muy escasa, ya que se limita a un manual de procedimiento y de uso del servidor y a una clasificación. Aparte de la necesidad de actualizar y mejorar la documentación existente, los profesionales requieren normativas específicas para la redacción de respuestas o para citar las fuentes, entre otras cuestiones.

34. Aparte de la normativa de trabajo, son muchos quienes consideran que se debe ofrecer documentación de apoyo, fundamentalmente tutoriales sobre fuentes de información, recursos en Internet, técnicas de búsquedas o redacción de referencias. Es aconsejable incorporar este tipo de materiales para la mejor formación de los profesionales y, por tanto, para una mejor calidad del servicio.

35. Por lo general, el funcionamiento del sistema informático es correcto, aunque una tercera parte opina que da problemas con frecuencia. Se deberá procurar que no existan cortes en el acceso al servidor y que el funcionamiento del sistema informático sea perfecto.

36. Se hace necesario un nuevo diseño y reestructuración de las páginas web de «Pregunte», en donde se establezcan dos grandes áreas, una para la consulta autónoma de los usuarios y otra para la realización de las consultas que se quieran plantear a los profesionales que atienden el servicio. La sección de consulta independiente debería disponer de un sistema sencillo de interrogación a los recursos temáticos y locales seleccionados. Las páginas específicas del servicio de referencia deberían incluir el archivo de preguntas y las distintas ventanas desde las que los usuarios podrán hacer sus preguntas.

37. El sistema de consulta actual permite que el usuario envíe su pregunta de forma poco delimitada, por lo que es habitual que se produzcan errores de interpretación o que sean necesarias posteriores comunicaciones con el mismo para establecer el contenido de la 
consulta. Sería oportuno incluir páginas o ventanas previas de información para el usuario, en las que se le guíe en el proceso que se realiza para enviar una pregunta.

38. El buscador interno, al que se accede tanto desde las páginas restringidas como desde el web público, debería programarse para que permitiera recuperar información por categorías temáticas y fechas, sin necesidad de escribir nada en el formulario principal. De esta forma se podrían recuperar todas las preguntas hechas sobre un tema o en un periodo de tiempo concreto.

39. El archivo de preguntas contestadas es muy poco usado. Debería ser rediseñado para que fuese más útil para usuarios y bibliotecarios. La base de datos de preguntas resueltas sería más útil en un nuevo diseño del web, junto a recursos seleccionados y el formulario de consulta. Debería establecerse un procedimiento normalizado para que se siguieran las mismas etapas en la confección de una respuesta, en el que se tuviese en cuenta, necesariamente, el archivo de consultas.

40. El diseño del web provoca problemas en la visualización de las páginas según el tipo y versión de los navegadores y la configuración de la pantalla del usuario. Si se realiza una modificación del diseño deberá tenerse en cuenta este inconveniente. El rediseño del web debería hacerse partiendo de los estándares internacionales y las indicaciones institucionales.

41. Muchos usuarios creen que «Pregunte» es un servicio de su biblioteca, ya que no identifican el proyecto como un servicio cooperativo. El rediseño del web podría dejar claro este problema con información suficiente. También se resolvería informando de que no hay que emplear «Pregunte» para cuestiones relacionadas con los fondos y servicios de una biblioteca en concreto.

42. El método actual de consulta, en el que el usuario puede realizar sus preguntas sin necesidad de conocer los límites del servicio ni su normativa, permite que se reciban muchas preguntas inapropiadas, incompletas o que no se ajustan al reglamento, por lo que sería necesario un sistema que guíe al usuario.

43. Muchas preguntas no se resuelven con un mensaje de respuesta, ya que requieren matizaciones del usuario o bien éste amplía los datos de su pregunta. El sistema actual no facilita que una biblioteca se haga cargo de una consulta hasta que el usuario la dé por satisfecha.

44. Se considera necesario disponer de los datos básicos del usuario que emplea «Pregunte», con la intención de poder acomodar la respuesta a su perfil. Se requiere conocer la edad del usuario y el motivo de la consulta para delimitar el alcance de la respuesta que se ofrezca. De 
igual forma, es útil conocer la localidad de residencia, para poder orientar al usuario sobre documentos que pueda consultar en las bibliotecas de su municipio.

45. El sistema de quejas es complicado, ya que el formulario habilitado para este fin sólo se ofrece a los usuarios registrados. Esto provoca que el correo electrónico y los formularios de consulta y sugerencias se usen para también para recibir reclamaciones. Habrá que solucionar este problema, permitiendo que un usuario no registrado explique su queja desde un lugar habilitado para ello y fácilmente reconocible y accesible.

46. La base de datos de usuarios registrados no aporta información excesiva al servicio. Habría que replantearse para qué se quiere contar con este grupo de usuarios y qué servicios se les puede ofrecer.

47. Existen muchas preguntas sin respuesta. El sistema es demasiado individualista, ya que si una biblioteca no se hace responsable de una pregunta ésta se perderá. Sería necesario reestructurar el procedimiento, para que todas las preguntas sin contestar permanecieran juntas, aún indicando la biblioteca a la que se envió, y para que se fueran respondiendo de forma cooperativa.

48. Los usuarios valoran positivamente el potencial informativo de «Pregunte». Usuarios y bibliotecarios piensan que el servicio debe convertirse en una amplia fuente de información, ofreciendo dos posibilidades de encontrar una información. Por una parte, se debe facilitar la consulta a los profesionales, para que ellos resuelvan las dudas que se les planteen, como hasta ahora está ocurriendo; pero, por otro lado, se deben ofrecer una serie de recursos para que el usuario localice por sí mismo la información que necesite. Para que «Pregunte» sea un verdadero portal informativo se deberán seleccionar recursos de Internet, describiéndolos y comentando qué información se puede conseguir en los mismos.

49. Es elevado el número de usuarios en periodo de estudios y que realizan preguntas por motivos formativos. Se deberá tener en cuenta este perfil a la hora de redactar las respuestas. Es conveniente delimitar si el servicio, en estos casos, debe ofrecer fuentes para que el usuario elabore la información o facilitarle los datos ya preparados.

50. La información a la comunidad es esencial en las bibliotecas públicas, por lo que muchos usuarios emplean «Pregunte» para cuestiones locales. Además de redirigir las consultas a las bibliotecas más apropiadas, el servicio debería ofrecer desde su web enlaces de tipo administrativo y local de utilidad informativa. La selección de estos recursos podría ser solicitada a bibliotecas públicas de los diferentes municipios. 
51. La mayoría de los profesionales vinculados a «Pregunte» han realizado una selección de recursos de información para su uso particular. Sería apropiado diseñar un sistema para intercambiar esta información y ponerla a disposición de todas las bibliotecas que integran el servicio.

52. Se necesita elaborar una base de datos de recursos disponibles en Internet que pudiese ser consultada directamente por los usuarios a través de una interfaz sencilla, en la que al menos se permitiera interrogar por temas, ámbitos geográficos y tipología documental.

53. Los agentes que intervienen en «Pregunte»-usuarios y bibliotecarios referencistas- consideran útil la elaboración de tutoriales o guías de uso de determinadas fuentes o tipologías documentales (buscadores, servidores bibliográficos, jurídicos, etc.). Esta información sería muy provechosa en un servicio como éste.

54. La selección de fuentes telemáticas de utilidad para usuarios y bibliotecarios deberá ir acompañada de la contratación de recursos electrónicos para su uso cooperativo. Se estima oportuno contratar varias licencias para el acceso a recursos de referencia, como enciclopedias y bases de datos. Existen en el mercado diferentes colecciones de recursos electrónicos que serían de utilidad para las bibliotecas que colaboran en «Pregunte» y cuya contratación sería muy provechosa para el servicio.

55. Muchas de las preguntas que se reciben requieren una especialización, tanto en las fuentes que se deben utilizar, como en el contenido de las mismas. Por este motivo es recomendable redactar una guía de expertos a los que se pudiera enviar las preguntas sobre un tema de difícil resolución. En esta misma línea se inscribirían los contactos con servicios de referencia de bibliotecas especializadas y universitarias a las que se pueda consultar las cuestiones cuya complejidad haga imposible su resolución mediante los canales habituales de «Pregunte».

56. Un porcentaje elevado de las cuestiones recibidas tienen su origen en trabajos escolares, por lo que sería recomendable contar con recursos educativos suficientes y contactar con organismos vinculados a la educación primaria y secundaria para el apoyo en la resolución de este tipo de consultas.

57. Sólo la cuarta parte de los profesionales consideran que sus colecciones de referencia son buenas o excelentes, por lo que habría que reforzar el fondo de este tipo en las bibliotecas que participan en el servicio. Sería útil disponer de un manual de fuentes de información para bibliotecas públicas, en el que se seleccionaran y comentara los principales recursos de información de utilidad para las bibliotecas públicas españolas. 
58. Los estudios de visibilidad en Internet y de la presencia de «Pregunte» en la bibliografía profesional demuestran que el servicio es poco conocido, por lo que debería ser relanzado a través de una campaña de promoción, una vez que se hayan realizado los cambios que se consideren necesarios.

59. Las entidades y centros implicados en «Pregunte» apenas han difundido el servicio, excepto en los primeros meses de existencia. Sería necesaria mayor implicación en su conocimiento, a través de notas en boletines y en prensa, así como estudios en revistas profesionales y reuniones científicas, nacionales e internacionales.

60. Apenas existen enlaces al servicio desde los webs de las entidades autonómicas bibliotecarias, ni de las bibliotecas públicas, por lo que es una labor urgente proponer la inclusión de enlaces a «Pregunte» desde los sitios web de tipo bibliotecario. 


\section{Parte IV}

\section{Recursos de información}

La última parte de la tesis doctoral recoge las referencias de los documentos con los que se ha trabajado en esta investigación, estableciendo tres grandes de bloques temáticos, que son a su vez subdivididos en función de su especificidad. Las tres grandes secciones en las que se han categorizado los recursos son, en primer lugar, los documentos que tratan sobre servicios de referencia en general, desde una perspectiva tradicional o actual, pero no centrados en referencia digital; en segundo lugar, los textos publicados sobre fuentes de información y colecciones de referencia; y, en tercer lugar, los documentos que versan sobre cualquier aspecto relacionado con los servicios y sistemas de referencia que las bibliotecas ofrecen a través de sistemas de comunicación digitales. Este tercer bloque es el más numeroso, porque es el único donde se ha pretendido ser exhaustivo, mientras que en los otros dos sólo se han seleccionado aquellas referencias que están relacionadas directamente con el tema de la tesis doctoral. Asimismo, en los tres apartados se ha establecido una sección bibliográfica para aspectos relativos a la evaluación, tanto de servicios de referencia, como de colecciones o fuentes de información, como prácticas o métodos de evaluación de la referencia digital. La selección bibliográfica se cerró a finales de diciembre de 2007, por lo que todas las referencias son anteriores a esa fecha. Todas las referencias siguen el estilo de la Norma ISO 690 y están ordenadas alfabéticamente, a partir de su punto de acceso principal. 


\section{Parte IV. RECURSOS DE INFORMACIÓN}

16. Servicios de referencia: recursos bibliográficos

16.1. Manuales sobre servicios de referencia

16.2. Evaluación de servicios de referencia

16.3. Servicios de referencia en entornos digitales

16.4. Recursos y tecnología web en los servicios de referencia

16.5. Bibliografía complementaria sobre servicios de referencia

17. Fuentes de información: recursos bibliográficos

17.1. Manuales sobre fuentes de información y colecciones de referencia

17.2. Evaluación de fuentes de información

17.3. Bibliografía complementaria sobre fuentes de información

18. Referencia digital: recursos bibliográficos

18.1. Manuales y bibliografía esencial sobre referencia digital

18.2. Evaluación de la referencia digital

18.3. Conceptualización de la referencia digital

18.4. Procesos de la referencia digital

18.5. Sistemas de referencia digital

18.6. Servicios públicos de referencia digital

18.7. Servicios especializados de referencia digital 


\section{Servicios de referencia: recursos bibliográficos}

En esta primera parte de la bibliografía se recogen textos y documentos relativos a los servicios bibliotecarios de referencia, excluyendo aquellas obras y artículos que tratan exclusivamente de los servicios de referencia digitales. Por tanto, en esta sección se localizan, manuales generales sobre servicios de referencia, documentos sobre la evaluación de estos servicios, ya que es un tema vinculado al núcleo de esta tesis y bibliografía complementaria. En este último caso, las referencias han sido seleccionadas en función del interés que los diferentes textos reunidos aquí tienen en relación al tema de la tesis. Conscientemente, se han eliminado referencias que trataban sobre los servicios bibliotecarios de referencia, pero que no tenían vinculación con alguno de los aspectos estudiados en este trabajo de investigación.

La relación de las tecnologías con los servicios de referencia se recoge en dos apartados diferentes de esta sección bibliográfica. Por una parte, se han agrupado las referencias que tratan sobre los diferentes ámbitos de la automatización en los servicios de referencia: sistemas, documentación electrónica, aplicaciones informáticas, etc.; por otra parte, se ofrecen una serie de artículos, cuya selección se restringe a los que tratan del uso de Internet y la tecnología web en los servicios bibliotecarios de información. Es conveniente incidir en que todos los documentos relativos a la referencia digital (interacción usuario-biblioteca) se encuentran en otro apartado de esta tesis doctoral, concretamente en el número 18.

Las referencias bibliográficas que se recogen en este apartado están agrupadas en función de estas categorías:

1. Manuales sobre servicios de referencia: monografías y documentos monográficos que versan sobre la creación de los servicios bibliotecarios de información, así como capítulos de manuales de biblioteconomía en los que se traten estos temas.

2. Evaluación de servicios de referencia: análisis del rendimiento de los servicios bibliotecarios de referencia.

3. Servicios de referencia en entornos digitales: aplicaciones de las tecnologías en los servicios de referencia, excluyendo los que tratan de Internet como recurso de información y los específicos de referencia digital.

4. Recursos y tecnología web en los servicios de referencia: uso y valor de Internet en los servicios bibliotecarios de referencia.

5. Bibliografía complementaria sobre servicios de referencia: documentos sobre servicios de referencia que no correspondan a alguna de las categorías anteriores. 


\subsection{Manuales sobre servicios de referencia}

16.1.1. AGHEMO, Aurelio. Informare in biblioteca. Milano: Editrice Bibliografica, 1992.

16.1.2. ANDERSON, Byron; WEBB, Paul T. (eds.). New directions in reference. Binghamton, NY: The Haworth Information Press, 2006.

16.1.3. ARTHUR, Gwen (ed. ). Get Them Talking: Managing Change through Case Studies and Case Study Discussion. Chicago, IL: American Library Association, Reference and User Services Association, 2000.

16.1.4. AUSTER, Ethel (ed.). Managing online reference services. New York: NealSchuman, 1986.

16.1.5. BOPP, Richard E.; SMITH, Linda C. Introducción general al servicio de consulta. México D.F.: Universidad Nacional Autónoma de México, 2000.

16.1.6. BOPP, Richard E.; SMITH, Linda C. (eds. ). Reference and information services: an introduction . 4th ed. Englewood, CO: Libraries Unlimited, 2007.

16.1.7. BRUMLEY, Rebecca. The Reference Librarian's Policies, Forms, Guidelines, and Procedures. Nw York: Neal-Schuman Publishers, 2006.

16.1.8. CALENGE, Bertrand. Accueillir, orienter, informer: I'organisation des services aux publics dans les bibliothèques. Paris: Edition du Cercle de la librairie, 1996.

16.1.9. CARANDE, Robert. Automation in library reference services: a handbook. Westport (Connecticut): Greenwook Press, 1992.

16.1.10. CASSELL, Kay Ann; HIREMATH, Uma. Reference and information services in the 21st century: an introduction. London: Facet, 2006.

16.1.11. COHEN, Laura B. (ed.). Reference services for archives and manuscripts. Binghamton, NY: The Haworth Information Press, 1997.

16.1.12. CONNOR, Elizabeth (ed.). An Introduction to Reference Services in Academic Libraries. Binghamton, NY: The Haworth Information Press , 2006.

16.1.13. CORDÓN GARCíA, José Antonio. Servicios de información y referencia. En Orera Orera, Luisa (ed.). Manual de biblioteconomía. Madrid: Síntesis, 1996, p. 265287.

16.1.14. $\mathrm{DI}, \mathrm{Su}$ (ed.). Evolution in reference and information services: the impact of the Internet. Binghamton, NY: The Haworth Information Press, 2002.

16.1.15. DOMÍNGUEZ SANJURJO, María Ramona. Nuevas formas de organización y servicios en la biblioteca pública . Gijón: Trea, 1996 .

16.1.16. EDWARDS, John D. (ed.). Emerging Solutions in Reference Services: Implications for Libraries in the New Millennium. Binghamton, NY: The Haworth Information Press, 2001.

16.1.17. ENSOR, Pat (ed.). The Cybrarian's Manual 2. Chicago: American Library Association, 2000.

16.1.18. FARMER, Lesley S. J. The Human Side of Reference and Information Services in Academic Libraries: Adding Value in the Digital World. Oxford: Chandos Publishing, 2007.

16.1.19. FRALEY, Ruth A.; KATZ, William A. (eds.). Finance, budget, and management for reference services. Binghamton, NY: The Haworth Information Press, 1988. 
16.1.20. GLEAVES, Edwin S. et al. Reference services and library education: essays in honor of Frances Neel Cheney. Lexington, Massachusetts etc.: Lexington Books, 1983.

16.1.21. GÓMEZ HERNÁNDEZ, José Antonio. La definición de los usuarios y los servicios básicos. En Gómez Hernández, José AntonioGestión de bibliotecas. Murcia: DM, ICE, 2002, p. 171-191.

16.1.22. GORMAN, G. E. (ed.). Information services in an electronic environment. London: Facet, 2001.

16.1.23. GOSLING, Mary. Servicio de referencia. Bogotá: Rojas Eberhard, 2001.

16.1.24. GROGAN, Denis. Practical reference work. $2^{\text {nd }}$. ed. London: Library Association, 1992.

16.1.25. HUANG, Samuel T. (ed.). Modern library technology and reference services. Binghamton, NY: The Haworth Information Press, 1993.

16.1.26. IRVING, Richard D.; KATZ, William A. (eds.). Reference services and public policy. Binghamton, NY: The Haworth Information Press, 1988.

16.1.27. JANES, Joseph. Introduction to reference work in the digital age. New York: Neal-Schuman, 2003.

16.1.28. KATZ, Bill (ed.). Community college reference services: a working guide for and by librarians. Metuchen, N.J.: Scarecrow Press, 1992.

16.1.29. KATZ, Bill (ed.). Continuing Education of Reference Librarians. Binghamton, NY: The Haworth Information Press, 1990.

16.1.30. KATZ, Bill (ed.). New technologies and reference services. Binghamtom, NY: The Haworth Information Press, 2000.

16.1.31. KATZ, Bill (ed.). Reference and information services: a reader for the nineties. Metuchen, N.J.: Scarecrow Press, 1991.

16.1.32. KATZ, Bill (ed.). The reference library user: Problems and solutions. Binghamton, NY: The Haworth Information Press, 1991.

16.1.33. KATZ, Bill (ed.). Reference service expertise. Binghamton, NY: The Haworth Information Press, 1993.

16.1.34. KATZ, Bill; FRALEY, Ruth A. (eds.). Conflicts in reference services. Binghamton, NY: The Haworth Information Press, 1985.

16.1.35. KATZ, Bill; FRALEY, Ruth A. ( eds.). Ethics and reference services. Binghamton, NY: The Haworth Information Press, 1982.

16.1.36. KATZ, Bill; FRALEY, Ruth A. ( eds.). International aspects of reference and information services. Binghamton, NY: The Haworth Information Press, 1987.

16.1.37. KATZ, Bill; FRALEY, Ruth A. ( eds.). Reference services administration and management. Binghamton, NY: The Haworth Information Press , 1982.

16.1.38. KATZ, Bill; FRALEY, Ruth A. ( eds.). Reference services today: from interview to burnout. Binghamton, NY: The Haworth Information Press , 1987.

16.1.39. KATZ, W. A. Cuneiform to computer: a history of reference sources. Lanham, Md.: Scarecrow, 1998. 
16.1.40. KATZ, William (ed.). Opportunities for Reference Services: The Bright Side of Reference Services in the 1990's. Binghamton, NY: The Haworth Information Press, 1991.

16.1.41. KATZ, William A. Introduction to reference work. 8th ed. New York: McGraw-Hill, 2002.

16.1.42. KATZ, William A.; CLIFFORD, Anne (eds.). Reference and online services handbook: guidelines, policies, and procedures for libraries. New York: NealSchuman, 1982.

16.1.43. KATZ, William A.; FRALEY, Ruth A. (eds.). Library instruction and reference services. Binghamton, NY: The Haworth Information Press , 1984.

16.1.44. KATZ, William A.; FRALEY, Ruth A. (eds.). Personnel issues in reference services. Binghamton, NY: The Haworth Information Press , 1986.

16.1.45. KATZ, William A.; FRALEY, Ruth A. (eds.). Reference services for children and young adults. Binghamton, NY: The Haworth Information Press, 1983.

16.1.46. KATZ, William A. ed; FRALEY, Ruth A. (eds.). Video to online: reference services and the new technology. Binghamton, NY: The Haworth Information Press, 1983.

16.1.47. KINDER, Robin (ed.). Librarians on the Internet: impact on reference services. Binghamton, NY: The Haworth Information Press, 1994.

16.1.48. KINDER, Robin; KATZ, William A. (ed.). Information brokers and reference services. Binghamton, NY: The Haworth Information Press, 1998.

16.1.49. KINDER, Robin; KATZ, William A. (ed.). Serials and reference services. London: The Haworth Information Press, 1990.

16.1.50. KOHL, David F. Reference services and library instruction. Santa Barbara (California) ; Oxford (England): ABC-Clio, 1985.

16.1.51. KUHLTHAU, Carol Collier. Seeking meaning: a process approach to library and information services. Noewood: Ablex, 1992.

16.1.52. LANKES, R. David. Building and maintaining Internet information services. Syracuse, New York: Syracuse University, 1998.

16.1.53. LECLERC-REYNAUD, Sylvie. Pour une documentation créative: l'apport de la philosophie de Raymond Ruyer. Paris: ADBS, 2006.

16.1.54. LEWE, Brunhilde. Informationsdienst in Offentlichen Bibliotheken. Grundlagen fur Planung und Praxis. Koln: 1999.

16.1.55. LIBRARY ASSOCIATION. Guidelines for reference and information services in public libraries. London: Library Association, 1999.

16.1.56. LOW, Kathleen (ed.). The roles of reference librarians: today and tomorrow. Binghamton, NY: The Haworth Information Press, 1996.

16.1.57. MABRY, Celia Hales (ed.). Cooperative reference: social interaction in the workplace. Binghamton, NY: The Haworth Information Press , 2003.

16.1.58. MABRY, Celia Hales (ed.). Doing the work of reference: practical tips for excelling as a reference librarian. Binghamton, NY: The Haworth Information Press, 2001. 
16.1.59. MABRY, Celia Hales (ed.). Philosophies of reference service. Binghamton, NY: The Haworth Information Press, 1997.

16.1.60. MAGÁN WALS, José Antonio. Los servicios de información y referencia bibliográfica: situación actual y aprovechamiento de los recursos. En Magán Wals, José Antonio (ed.). Tratado básico de biblioteconomía. Madrid: Editorial Complutense, 1996, p. 341-364.

16.1.61. MCDERMOTT, Irene E. The librarian's Internet survival guide: strategies of the high-tech reference desk. Medford: Information Today, 2002.

16.1.62. MCMENEMY, David; POULTER, Alan. Delivering Digital Services: A Handbook for Public Libraries and Learning Centres. London: Facet, 2005.

16.1.63. MERRILL, Martha (ed.). Reference services and media. Binghamton (NY): The Haworth Information Press, 1999.

16.1.64. MIDDLETON, Marcia Stucklen; KATZ, William A. (eds.). Information and referral in reference services. Binghamton, NY: The Haworth Information Press, 1988.

16.1.65. MILLER, William; PELLEN, Rita M. (eds.). Improving internet reference services to distance learners. Binghamton, NY: The Haworth Information Press, 2005.

16.1.66. MORALES CAMPOS, Estela. El servicio de consulta . 2. ed. corr. y aum. Mexico, D.F.: Universidad Nacional Autonoma de México, 1993.

16.1.67. MOUREN, Raphaële; PEIGNET, Dominique (dirs.). Le métier de bibliothécaire. 11eme éd. Paris: Electre; Cercle de la Librairie, 2007.

16.1.68. NESBEITT, Sarah L.; GORDON, Rachel Singer. The information professional's guide to career development online. Medford (New Jersey) : Information Today, 2001.

16.1.69. OWEN, Tim Buckley. Success at the Enquiry Desk. $5^{\text {th }}$ ed. London: Facet, 2006.

16.1.70. PUCCIO, J. A. Serials reference work. Englewood, Colo.: Libraries Unlimited, 1989.

16.1.71. PUGH, Mary Jo. Providing Reference Services for Archives and Manuscripts. Lanham, MD: Scarecrow Press, 2005.

16.1.72. RIECHEL, Rosemarie. Reference services for children and young adults. Hamden, Connecticut: Library Professional Publications, 1991.

16.1.73. ROSS, Catherine Sheldrick; NILSEN, Kirsti; DEWDNEY, Patricia. Conducting the reference interview: a how-to-do-it manual for librarians. New York: Neal-Schuman, 2002.

16.1.74. ROWLAND, Arthur Ray (ed.). The librarian and reference service. Hamden, Connecticut: Shoe String, 1977.

16.1.75. ROWLAND, Arthur Ray (ed.). Reference services: contributions to Library Literature. Hamden, Connecticut: The Shoe String Press, Inc., 1964.

16.1.76. ROYSDON, Christine; WHITE, Howard D. (eds.). Expert systems in reference services. Binghamton, NY: The Haworth Information Press, 1989.

16.1.77. SABOR, Josefa E. Servicio de referencia. En (ed). Manual de bibliotecología. México D.F.: Kapelusz, 1984, p. 191-213.

16.1.78. SAORÍN PÉREZ, Tomás. Los portales bibliotecarios. Madrid: Arco/Libros, 2004. 
16.1.79. SARKODIE-MENSAH, Kwasi (ed.). Managing the Twenty-First Century Reference Department: Challenges and Prospects. Binghamton, NY: The Haworth Information Press, 2004.

16.1.80. SARKODIE-MENSAH, Kwasi (ed.). Reference Services for the Adult Learner: Challenging Issues for the Traditional and Technological Era. Binghamton, NY: The Haworth Information Press, 2000.

16.1.81. SMITH, Susan Sharpless. Web-Based instruction: a guide for libraries. Chicago: American Library Association, 2001.

16.1.82. SOLIMINE, Giovanni. L'informazione in biblioteca: introduzione ai problemi dell'informazione bibliografica. Milano: Editrice Bibliografica, 1985.

16.1.83. STEVENSON, Gordon; STEVENSON, Sally (eds.). Reference services and technical services: interactions in library practice. Binghamton, NY: The Haworth Information Press, 1984.

16.1.84. TARR, Andrea; KATZ, William A. (eds.). Reference and information services: a reader. Metuchen (N.J.): The Scarecrow Press, 1978.

16.1.85. THOMSEN, Elizabeth. Rethinking reference: the reference librarian's practical guide for surviving constant change. New York: Neal-Schuman, 1999.

16.1.86. TRUETT, Carol (eds.). School library reference services in the 90s: where we are, where we're heading. Binghamton, NY: The Haworth Information Press, 1994.

16.1.87. TUNNICLIFF, Myriam Forney; SOENEN, Susan Sheldon. The reference information skills game. Englewood, Colorado: Libraries Unlimited, 1995.

16.1.88. VERRY-JOLIVET, Cornne (dir.). Creer et gerer un service de référence. Villeurbanne: Institut de Formation des Bibliothecaires, 1996.

16.1.89. WEBB, S. P. Creating an information service. 2nd ed. London: Aslib, 1992.

16.1.90. WEST, Jessamyn (ed.). Digital versus non-digital reference: ask a librarian online and offline. Binghamton, NY: The Haworth Information Press, 2004.

16.1.91. WHALEN, Lucille (ed.). Reference services in archives. Binghamton, NY: The Haworth Information Press, 1986.

16.1.92. WHITEHALL, Tom. Practical current awareness services from libraries. Hants, England: Gower, 1986.

16.1.93. WHITLATCH, Jo Bell (ed.). Library users and reference services. Binghamton, NY: The Haworth Information Press, 1995.

16.1.94. WHITLATCH, Jo Bell. The role of the academic reference librarian. New York: Greenwood, 1990.

16.1.95. ZLATOS, Christy (ed.). Coming of age in reference services: a case history of the Washington State University Libraries. Binghamton, NY: The Haworth Information Press, 1999. 


\subsection{Evaluación de servicios de referencia}

16.2.1. AMERICAN LIBRARY ASSOCIATION. REFERENCE AND ADULT SERVICES DIVISION. The reference assessment manual. Ann Arbor (Michigan): Pierian Press, 1995.

16.2.2. ARNOLD, Julie; KASKE, Neal K. Evaluating the quality of a chat service. Portal: Libraries and the Academy, 2005, vol. 5, n. 2, p. 177-193.

16.2.3. BORIN, Jacqueline. Training, Supervising, and Evaluating Student Information Assistants. The Reference Librarian, 2001, n. 72, p. 195-206.

16.2.4. CARTER, David S.; JANES, Joseph. Unobtrusive Data Analysis of Digital Reference Questions and Service at the Internet Public Library: An Exploratory Study . Library trends, 2000, vol. 49, n. 2.

16.2.5. CHANG, Hye Rhan; HOLLAND, Maurita Peterson. User satisfaction survey of ask-a-question service at the internet public library. Internet Reference Services Quarterly, 2005, vol. 10, n. 2, p. 61-73.

16.2.6. COVI, Lisa M.; CRAGIN, Melissa H. Reconfiguring Control in Library Collection Development: A Conceptual Framework for Assessing the Shift Toward Electronic Collections. Journal of the American Society for Information Science and Technology, 2004, vol. 55, n. 4, p. 312-325.

16.2.7. DE GROOTE, S. L.; HITCHCOCK, K.; MCGOWAN, R. Trends in Reference Usage Statistics in an Academic Health Sciences Library. Journal of the Medical Library Association, 2007, vol. 95, n. 1, p. 23-30.

16.2.8. DEE, Cheryl; ALLEN, Maryellen. A survey of the usability of digital reference services on academic health science library Web sites. The Journal of Academic Librarianship, 2006, vol. 32, n. 1, p. 69-78.

16.2.9. DELGADO LÓPEZ-CÓZAR, Emilio. La investigación en biblioteconomía y documentación. Gijón: Trea, 2002.

16.2.10. DILEVKO, Juris. Unobtrusive Evaluation of Reference Service and Individual Responsibility: The Canadian Experience. Westport CT: Greenwood Publishing, 2000.

16.2.11. ESCALONA RíOS, Lina. La evaluación del servicio de consulta ¿cantidad o calidad? Biblioteca universitaria: revista de la Dirección General de Bibliotecas, 2004, vol. 7, n. 1, p. 12-22.

16.2.12. FIELDS, Anne M. III-structured problems and the reference consultation: The librarian's role in developing student expertise. Reference Services Review, 2006, vol. 34, n. 3, p. 405-420.

16.2.13. FRICKÉ, Martin; FALLIS, Don. Indicators of Accuracy for Answers to Ready Reference Questions on the Internet. Journal of the American Society for Information Science and Technology, 2004, vol. 55, n. 3, p. 238-245.

16.2.14. GROSS, M. Imposed versus self-generated questions: implications for reference practice. Reference and User Services Quarterly, 1999, vol. 39, n. 1, p. 53-61.

16.2.15. GROSS, Melissa; MCCLURE, Charles R.; LANKES, R. David. Costing reference: issues, approaches, and directions for research. The Reference Librarian, 2006, vol. 46, n. 95/96, p. 173-186.

16.2.16. HEAD, Michael C.; MARCELLA, Rita. A Testing Question: The Quality of 
Reference Services in Scottish Public Libraries. Library Review , 1993, vol. 42, n. 6.

16.2.17. HEAD, Michael C.; MARCELLA, Rita; SMITH, Judith M. Are you being served? The quality of business information provision in Scottish public libraries. Library Review, 1995, vol. 44, n. 2, p. 28-37.

16.2.18. HERNON, Peter; MCCLURE, Charles. Unobstrusive reference testing: the 55 percent rule. Library Journal, 1986, n. 111, p. 37-41.

16.2.19. HILLER, Steve; SCHILLIE, Jane; SELF, Jim. Evaluación de la Comunidad: Parte esencial de las herramientas del bibliotecario referencista. En IFLA General Conference and Council (70. 2004. Buenos Aires). Buenos Aires: IFLA, 2004. Disponible en http://www.ifla.org/IV/ifla70/papers/029s_trans-Hiller_Schillie_Self.pdf [consultado el 17/07/2007].

16.2.20. HOIVIK, Tord. Why do you ask? Reference statistics for library planning. Performance Measurement and Metrics, 2003, vol. 4, n. 1, p. 28-37.

16.2.21. HOIVIK, Tord. Why is quality control so hard? Reference studies and reference quality in public libraries: the case of Norway. En IFLA General Conference and Council (69. 2003. Berlín). Berlín: IFLA, 2003.

16.2.22. KATZ, Bill; FRALEY, Ruth A. ( eds.). Evaluation of reference services. Binghamton, NY: The Haworth Information Press, 1985.

16.2.23. KURUPPU, Pali U. Evaluation of Reference Services: A Review. The Journal of Academic Librarianship, 2007, vol. 33, n. 3, p. 368-381.

16.2.24. LAMY, Jean-Philippe. Evaluer un service de référence: quelques outils. Bulletin des Bibliothèques de France, 2001, vol. 46, n. 4, p. 82-88.

16.2.25. LEVASSEUR, D. L'Internet et les services de reference: une enquete dans les etablissements universitaires du Quebec. Argus, 1996, vol. 25, n. 1, p. 5-12.

16.2.26. LOCHORE, Stephen. How good are the free digital reference services? A comparison of library-based and expert services. Library Review, 2004, vol. 53, n. 1, p. 24-29.

16.2.27. MALLIARI, Aphrodite; KYRIAKI-MANESSI, Daphne. Users' behaviour patterns in academic libraries' OPACs: a multivariate statistical analysis. New Library World, 2007, vol. 108, n. 3/4, p. 107-122.

16.2.28. MANUEL, K.; HORN, J. Association of College and Research Libraries Tenth National Conference. Library Hi Tech News, 2001, vol. 18, n. 5, p. 29-32.

16.2.29. MASSíSSIMO, Ángels. Avaluació de serveis de referència. Item, 1994, n. 15, p. 104-117.

16.2.30. MATUS SEPÚLVEDA, Gladys; MOLINA LUQUE, Fidel. Metodología cualitativa: un aporte de la Sociología para investigar en Bibliotecología. Valparaíso: Universidad de Playa Ancha, 2006.

16.2.31. MIWA, Makiko. Situatedness in users' evaluation of information and information services. New Review of Information Behaviour Research: New Review of Information Behaviour Research, 2003, vol. 4, n. 1, p. 207-224.

16.2.32. MURGAI, Sarla R.; AHMADI, Mohammad. A multiple regression model for predicting reference desk staffing requirements. The Bottom Line: Managing Library Finances, 2007, vol. 20, n. 2 , p. 69-76. 
16.2.33. NICHOLAS, David; HUNTINGTON, Paul; JAMALI, Hamid R.; DOBROWOLSKI, Tom. Characterising and evaluating information seeking behaviour in a digital environment: Spotlight on the 'bouncer'. Information Processing and Management, 2007, vol. 43, n. 4, p. 1085-1102.

16.2.34. NOVOTNY, Eric. Evaluating electronic reference services: issues, approaches and criteria. The Reference Librarian, 2001, n. 74, p. 103-120.

16.2.35. ODER, Norman. Reference Report Raises Questions. Library Journal, 2001, vol. 126, n. 15, p. 18.

16.2.36. OTT, Katherine; CHHIU, Sueling. The first wave: Floating in the Florida State University Strozier Library, Florida State University, Tallahassee, Florida. New Library World, 2007, vol. 108, n. 3/4, p. 165-176.

16.2.37. PICKARD, Alison Jane. Research methods in information. London: Facet, 2007.

16.2.38. POLL, Roswitha. Performance measures for library networked services and resources. The Electronic Library, 2001, vol. 19, n. 5, p. 307-314.

16.2.39. POWELL, Ronald R.; CONNAWAY, Lynn Silipigni. Basic research methods for librarians. 4th ed. Westport (Connecticut); London: Libraries Unlimited, 2004.

16.2.40. RACHEL CHENG; STEVE BISCHOF; ALAN J NATHANSON. Data collection for user-oriented library services: Wesleyan University Library's experience. OCLC Systems \& Services, 2002, vol. 18, n. 4, p. 195-204.

16.2.41. RICHARDSON, J. V.; REYES, R. B. Government information expert systems: a quantitative evaluation. College and Research Libraries, 1995, vol. 56, n. 3, p. 235247.

16.2.42. RIMLAND, Emily L. Do We Do It Well? A Bibliographic Essay on the Evaluation of Reference Effectiveness. The Reference Librarian, 2007, vol. 47, n. 98, p. 41-55.

16.2.43. ROGERS, Michael; KENNEY, Brian. Academic Libraries Test Web-Based Reference. Library Journal, 2001, vol. 126, n. 12, p. 25.

16.2.44. ROSS, Catherine S.; NILSEN, Kirsti. Has the Internet changed anything in reference? The library visit study, Phase 2. Reference and User Services Quarterly, 2000, vol. 40, n. 2, p. 147-155.

16.2.45. SAXTON, Matthew L.; NAUMER, Charles M.; FISHER, Karen E. 2-1-1 Information services: Outcomes assessment, benefit-cost analysis, and policy issues. Government Information Quarterly, 2007, vol. 24, n. 1, p. 186-215.

16.2.46. SMITH, J. M.; TEMPLETON, E. J. A comparison of the range and value of use of the Internet with traditional reference sources in Scottish public libraries. Journal of Information Science, 1999, vol. 25, n. 1, p. 27-33.

16.2.47. SMITH, Michael M. A tool for all places: a web-based reference statistics system. Reference Services Review, 2006, vol. 34, n. 2, p. 298-315.

16.2.48. STOFFEL, Bruce; TUCKER, Toni. E-mail and chat reference: assessing patron satisfaction . Reference Services Review, 2004, vol. 32, n. 2, p. 120-140.

16.2.49. STOVER, Mark. Reference librarians and the Internet: a qualitative study. Reference Services Review, 2000, vol. 28, n. 1, p. 39-49.

16.2.50. SU, S. F; LANCASTER, F. W. Evaluation of expert systems in reference service applications. $R Q, 1995$, vol. 35, n. 2, p. 219-228. 
16.2.51. SYRKIN, Darby. At the desk or online: reference training, measurements, and guidelines. Public Services Quarterly, 2006, vol. 2, n. 2/3, p. 191-192.

16.2.52. TENOPIR, Carol. Reference use statistics. Library Journal, 1998, vol. 123, n. 8, p. 32.

16.2.53. TSCHANG, Virginia. Assessment of HyperCard program at Penrose Library, the University of Denver. Reference Services Review, 1991, vol. 19, n. 1, p. 39-48.

16.2.54. VALENTIM, Marta Ligia Pomim. Métodos cualitativos de pesquisa em Ciencia da informaçao. Sao Paulo: Polis, 2005.

16.2.55. WELCH, Jeanie M. Click and Be Counted: A New Standard for Reference Statistics. The Reference Librarian, 2007, vol. 47, n. 97, p. 95-104.

16.2.56. WELCH, Jeanie M. Laser lights or dim bulbs? Evaluating reference librarians' use of electronic sources. Reference Services Review, 1999, vol. 27, n. 1, p. 73-77.

16.2.57. WELCH, Jeanie M. Who says we're not busy? Library web page usage as a measure of public service activity. Reference Services Review, 2005, vol. 33, n. 4, p. 371-379.

16.2.58. WHITLATCH, Jo Bell. Evaluating Reference Services: A Practical Guide. Chicago: American Library Association, 2000.

16.2.59. WHITLATCH, Jo Bell. Evaluating reference services in the electronic age. Library Trends, 2001, vol. 50, n. 2, p. 207-217.

\subsection{Servicios de referencia en entornos digitales}

16.3.1. ABELS, Eileen. Information Seekers' Perspectives of Libraries and Librarians. Advances In Librarianship, 2004, vol. Volume 28, p. 151-170.

16.3.2. AHMED, Terry; GLAZER, Adam; MOORE, Mary. Using an automated knowledge agent for reference and customer service. Journal of the Medical Library Association, 2004, vol. 92, n. 2, p. 271-273.

16.3.3. ARNOLD, Judith M.; CSIR, Floyd; SIAS, Jennifer; ZHANG, Jingping. Does anyone need help out there? Lessons from designing online help. Internet Reference Services Quarterly, 2005, vol. 9, n. 3-4, p. 115-134.

16.3.4. BAILEY, Charles W. Jr. The role of reference librarians in institutional repositories. Reference Services Review, 2005, vol. 33, n. 3, p. 259-267.

16.3.5. BELL, Suzanne; FOSTER, Nancy Fried; GIBBONS, Susan. Reference librarians and the success of institutional repositories. Reference Services Review, 2005, vol. 33 , n. 3, p. 283-290.

16.3.6. BERTOT, John Carlo. Libraries and networked information services: issues and consideration in measurement. Performance Measurement and Metrics, 2004, vol. 5, n. 1, p. 11-19.

16.3.7. BONTENBAL, K. F. Challenges faced by reference librarians in familiarizing adult students with the computerized library of today: the Cuesta College experience. The Reference Librarian, 2000, n. 69/70, p. 69-76.

16.3.8. BRADBURN, Jean. Virtual or traditional: the impact of change on information 
services. Refer, 2006, vol. 22, n. 3, p. 4-7.

16.3.9. BRADFORD, Jane T.; COSTELLO, Barbara; LENHOLT, Robert. Reference service in the digital age: an analysis of sources used to answer reference questions. The Journal of Academic Librarianship, 2005, vol. 31, n. 3, p. 263-272.

16.3.10. BRUNVAND, Amy. Integrating library reference services in an online information literacy course: the internet navigator as a model. Internet Reference Services Quarterly, 2005, vol. 9, n. 3-4, p. 159-177.

16.3.11. BUCKLEY, Chad E. Golden rule reference: Face-to-face and virtual. The Reference Librarian, 2006, n. 93, p. 129-136.

16.3.12. BUEHLER, Marianne A.; BOATENG, Adwoa. The evolving impact of institutional repositories on reference librarians. Reference Services Review, 2005, vol. 33, n. 3, p. 291-300.

16.3.13. BUTKOVICH, Nancy J.; BROWNING, Marilyn M.; TAYLOR, Kathryn L. The Reference Expert: a computerized database utilizing INMAGIC and a WORM drive. Database, 1991, vol. 14, n. 6, p. 35-38.

16.3.14. CARLO, Jessica Luo; YOO, Youngjin. How may I help you?: Politeness in computer-mediated and face-to-face library reference transactions. Information and Organization, 2007 , vol. en prensa.

16.3.15. CASEY, Anne Marie. A historical overview of internet reference services for distance learners. Internet Reference Services Quarterly, 2005, vol. 9, n. 3-4, p. 5-17.

16.3.16. CHAN, Diana L. H.; KWOK, Catherine S. Y.; YIP, Steve K. F. Changing roles of reference librarians: the case of the HKUST Institutional Repository. Reference Services Review, 2005, vol. 33, n. 3, p. 268-282.

16.3.17. CHISMAN, Janet; TREAT, William. An online reference system. RQ, 1984, vol. 23, n. 4, p. 438-445.

16.3.18. CHOI, Youngok. Reference services in digital collections and projects. Reference Services Review, 2006, vol. 34, n. 1, p. 129-147.

16.3.19. CHOWDHURY, Gobinda G. Digital libraries and reference services: present and future. Journal of Documentation, 2002, vol. 58, n. 3, p. 258-283.

16.3.20. CLINE, P. Confessions of a reference technophile. The Reference Librarian, 1993, n. 39, p. 5-11.

16.3.21. COLE, C.; KENNEDY, L.; CARTER, S. The optimization of online searches through the labelling of a dynamic, situation-dependent information need: the reference interview and online searching for undergraduates doing a social-science assignment. Information Processing and Management, 1996, vol. 32, n. 6, p. 709-717.

16.3.22. CUENCA, Angela Maria Belloni; ALVAREZ, Maria do Carmo Avamilano; FERRAZ, Maria Lucia Evangelista de Faria; GARBIN, Vanda Lucia. O usuario remoto de uma biblioteca academica na area de saude publica. Informaçao \& Sociedade: Estudos, 2003, vol. 13, n. 2.

16.3.23. CULLEN, Rowena. Only connect . . . a survey of reference services -past, present and future. En Gorman, G. E. (ed.). Information services in an electronic environment. London: Facet, 2001.

16.3.24. CULLEN, Rowena; HUANWEN, Cheng. The use of new technologies in reference and information work: A survey of training needs in China and New Zealand. 
Asian Libraries, 1999, vol. 8, n. 6, p. 195-214.

16.3.25. CURRY, Evelyn L. The reference interview revisited: Librarian-patron interaction in the virtual environment. SIMILE: Studies in Media \& Information Literacy Education, 2005, vol. 5, n. 1.

16.3.26. DETINGER, Sue. EL production support: The SilverPlatter electronic reference library-servers, clients and data. Library hi tech, 1998, vol. 16, n. 3-4.

16.3.27. ERTEL, M. Brave New World: what a working librarian should know about living on the Internet. Searcher, 1995, vol. 3, n. 3, p. 28-33.

16.3.28. ETKIN, C. Creating a core knowledge for electronic reference services. Tennessee Librarian, 1996 , vol. 48, n. 1, p. 16-28.

16.3.29. FARHAT, Jihad; GIRARD, Luc. L'avenir des services de reference des bibliotheques universitaires. Argus, 2004, vol. 33, n. 2.

16.3.30. FENNEWALD, Joseph. Same Questions, Different Venue: An Analysis of InPerson and Online Questions. The Reference Librarian, 2006, vol. 46, n. 95/96, p. 2135.

16.3.31. GIACCAI, S.; BORETTI, E. Vuoi diventare un virtual reference librarian? Biblioteche Oggi, 1995, vol. 13, n. 10, p. 88-89.

16.3.32. GOH, Dion H.; CHAN, Roy L. The National Archives of Singapore Reference Enquiry Database. The Electronic Library, 2003, vol. 21, n. 4, p. 316-321.

16.3.33. GREALY, Deborah S. Technological mediation: reference and the non-traditional student. The Reference Librarian, 2000, n. 69/70, p. 63-68.

16.3.34. HARZBECKER, J. H. DNA sequences over the Internet provide greater speed and accuracy for health sciences reference librarians. Microcomputers for Information Management, 1993, vol. 10, n. 1, p. 43-54.

16.3.35. HUWE, Terrence K. Casting a Wider Net with Roving Reference. Computers in Libraries, 2003, vol. 23, n. 3 , p. 34.

16.3.36. IACCARINO, G. A look at Internet privacy and security issues and their relationship to the electronic job search: implications for librarians and career services professionals. The Reference Librarian, 1996, n. 55, p. 107-113.

16.3.37. JANE, Catherine; MCMILLAN, Dawn. Online in real-time? Deciding whether to offer a real-time virtual reference service: Winds of change: libraries in the twenty-firt century. The Electronic Library, 2003, vol. 21, n. 3, p. 240-246.

16.3.38. JANES, Joseph; HILL, Chrystie. Finger on the pulse: librarians describe evolving reference practice in an increasingly digital world. Reference and User Services Quarterly, 2003, vol. 42, n. 1, p. 54-65.

16.3.39. JENKINS, Barbara; BREAKSTONE, Elizabeth; HIXSON, Carol. Content in, content out: the dual roles of the reference librarian in institutional repositories. Reference Services Review, 2005, vol. 33, n. 3, p. 312-324.

16.3.40. JENKINS, L. The information superhighway, the community college and the real world: reflections on the impact of technology on reference work. Community and Junior College Libraries, 1999, vol. 8, n. 2, p. 45-49.

16.3.41. JOHNSON, C. Electronic technology and its impact on libraries. Journal of Librarianship and Information Science, 1998, vol. 30, n. 1, p. 7-24. 
16.3.42. JORDAN, W. My Gateway at the University of Washington Libraries. Information Technology and Libraries, 2000, vol. 19, n. 4, p. 180-185.

16.3.43. KATZ, Bill. Long live old reference services and new technologies. Libraries trends, 2001, vol. 50, n. 2 , p. 263-285.

16.3.44. KETCHELL, D. S. Too many channels: making sense out of portals and personalization. Information Technology and Libraries, 2000, vol. 19, n. 4, p. 175-179.

16.3.45. KIELEMA, Eddy. Beperkt slechte presentatie gebruik digitale bestanden?= An inadequate way of setting out access to online resources? BibliotheekBlad, 2004, vol. 8, n. 8, p. $14-15$.

16.3.46. KILLE, Angela. Wikis in the workplace: how wikis can help manage knowledge in library reference services. LIBRES, 2006, vol. 16, n. 1.

16.3.47. KING COUNTY LIBRARY SYSTEM; UNIVERSITY OF WASHINGTON. Virtual reference services: marketing guidelines. KGLS; University of Washington, 2002.

16.3.48. KUMAR, S. From reference service to information retrieval. Library Science with a Slant to Documentation, 1992, vol. 29, n. 4, p. 165-168.

16.3.49. LAKOS, A.; GRAY, C. Personalized library portals as an organizational culture change agent: reflections on possibilities and challenges. Information Technology and Libraries, 2000, vol. 19, n. 4, p. 169-174.

16.3.50. LAWAL, Ibironke O. Electronic reference works and library budgeting dilemma. Acquisitions Librarian, vol.19, no.37/38, pp.46-62, 2006, vol. 19, n. 37/38, p. 46-62.

16.3.51. LILLARD, Linda L.; DINWIDDIE, Mollie. If you build it, they will come, but then what: a look at issues related to using online course software to provide specialized reference services. Internet Reference Services Quarterly, 2005, vol. 9, n. 3-4, p. 135145.

16.3.52. LORENZEN, E. A. The librarian's role in the job search of the future: issues and ethics in the electronic environment. The Reference Librarian, 1996, n. 55, p. 1-6.

16.3.53. MACHALOW, Robert. Using Lotus and Excel for a reference file. Computers in Libraries, 1990, vol. 10, n. 2, p. 44-47.

16.3.54. MANN, T. Reference service, human nature, copyright, and offsite service: in a 'digital age'? Reference and User Services Quarterly, 1999, vol. 38, n. 1, p. 55-61.

16.3.55. MANSO RODRÍGUEZ, Ramón Alberto. Del escritorio tradicional al virtual: nuevas posibilidades para el servicio de referencia. ACIMED, 2007, vol. 15, n. 2.

16.3.56. MARCUM, Deanna B. Research Questions for the Digital Era Library. Library Trends, 2003, vol. 51, n. 4, p. 636.

16.3.57. MARTín CASTILLA, Sonia; ALONSO ARÉVALO, Julio. Uso de Internet en las bibliotecas: información estática y dinámica como herramienta de información. Coloquio de la Asociación Internacional de Bibliología, 2000, vol. 15.

16.3.58. MARTIN, S. K. A new kind of audience. The Journal of Academic Librarianship, 1998, vol. 24, n. 6, p. 469.

16.3.59. MAXWELL, D. Jackson. Digital versus print: The current state of reference affairs in school Libraries. The Reference Librarian, 2005, vol. 44, n. 91/92, p. 53-68.

16.3.60. MCCLURE, Charles. A planning primer for online reference services in a public 
library. Online, 1980, vol. 4, n. 2, p. 57-65.

16.3.61. MCDERMOTT, I. E. Reference and the bottom line in the city of industry. Searcher, 1998, vol. 6, n. 7, p. 23-27.

16.3.62. MICCO, Mary; SMITH, Irma. Designing a workstation for information seekers. The Reference Librarian, 1989, n. 23, p. 135-152.

16.3.63. MINER, S. Success at the reference desk: helping patrons overcome computer anxiety. Legal Reference Services Quarterly, 2001, vol. 19, n. 3/4, p. 95-103.

16.3.64. MORGAN, E. L. MyLibrary in your library could make for satisfied patrons. Computers in Libraries, 1998, vol. 18, n. 5, p. 40-41.

16.3.65. MOYO, Lesley; ROBINSON, Ashley. Beyond research guidance: the Gateway Library Research Mentoring Program. Library Management, 2001, vol. 22, n. 8/9, p. 343-350.

16.3.66. MURRAY, Janet; TSCHERNITZ, Cindy. The impact of electronic information delivery on reference enquiries. Online Information Review, 2005, vol. 29, n. 2, p. 157167.

16.3.67. NARDI, B. A.; O'DAY, V. L. Application and implications of agent technology for libraries. The Electronic Library, 1998, vol. 16, n. 5, p. 325-337.

16.3.68. NILSEN, Kirsti. Virtual versus Face-to-Face Reference. Refer, 2005, vol. 21, n. 3, p. 12-19.

16.3.69. NILSEN, Kirsti. Virtual versus Face-to-Face Reference: Comparing Users' Perspectives on Visits to Physical and Virtual Reference Desks in Public and Academic Libraries. En IFLA General Conference and Council (71. 2005. Os/o). Oslo: IFLA, 2005. Disponible en http://www.ifla.org/IV/ifla71/papers/027e-Nilsen.pdf [consultado el 17/07/2007].

16.3.70. OSA, Justina O. Managing the 21st Century Reference Department: Competencies. The Reference Librarian, 2003, vol. 39, n. 81, p. 33-50.

16.3.71. OUNANIAN, L. A. Adding value: using a Lotus Notes database to improve reference service. Business Information Review, 1996, vol. 13, n. 4, p. 259-278.

16.3.72. PANTRY, Sheila; GRIFFITHS, Peter. Introducing the concept of an electronic information service. Business Information Review, 2002, n. 19, p. 29-39.

16.3.73. PHILLIPS, Holly; CARR, Richard; TEAL, Janis. Leading roles for reference librarians in institutional repositories: one library's experience. Reference Services Review, 2005, vol. 33, n. 3, p. 301-311.

16.3.74. PINILLO LEÓN, Ana Luisa; GALINDO PINILLO, Niurys; CANTO ENRÍQUEZ, Alina del. El servicio de referencia de la Biblioteca Médica Nacional: de lo clásico a lo virtual. $A C I M E D, 2002$, vol. 10, n. 6.

16.3.75. POTTER, L. A. A systematic approach to finding answers over the Internet. Bulletin of the Medical Library Association, 1995, vol. 83, n. 3, p. 280-285.

16.3.76. PURCELL, Royal. Computers and reference service. Library Software Review, 1989 , vol. 8, n. 5, p. 256-264.

16.3.77. QUINN, B. Overcoming technostress in reference services to adult learners. The Reference Librarian, 2000, n. 69/70, p. 49-62. 
16.3.78. REGER, N. K. Redefining reference services. Transitioning at one public library. Reference and User Services Quarterly, 1999, vol. 38, n. 1, p. 73-75.

16.3.79. RETTIG, James. Technology, cluelessness, anthropology, and the memex: the future of academic reference service. Reference Services Review, 2003, vol. 31, n. 1, p. $17-21$.

16.3.80. RICE, James. The golden age of reference service: is it really over? Wilson Library Bulletin, 1986, vol. 61, n. 4, p. 17-19.

16.3.81. RICHARDSON, John V. Jr. The future of reference: the intersection of information resources, technology and users. Reference Services Review, 2003, vol. 31 , n. 1, p. 43-45.

16.3.82. RIGGS, Colby. Reference services: virtual, digital and in-library. Library Hi Tech News, 2003, vol. 20, n. 5, p. 6-7.

16.3.83. ROBERTS, Gary. Groupware as a knowledge repository. Computers in Libraries, 2005, vol. 25, n. 4, p. 29-31.

16.3.84. RODKEWICH, Patricia J. M.; DEVRIES, JoAnn. Taking Control: A Reference Approach to the Internet. The Reference Librarian, 2001, n. 72, p. 113-122.

16.3.85. RUAN, Lian. Designing and developing Internet reference services to support firefighter distance learners in Illinois. Internet Reference Services Quarterly, 2005, vol. 9, n. 1/2, p. 147-172.

16.3.86. SAINT-ONGE, J. Les services de reference et l'acces libre aux sources electroniques dans une bibliotheque de recherche. Documentation et bibliothèques, 1994, vol. 40, n. 3, p. 149-152.

16.3.87. SCHLOMAN, B. F. Managing reference services in an electronic environment. The Reference Librarian, 1993, n. 39, p. 99-109.

16.3.88. SCHNEIDER, Karen G. The Distributed Librarian: Live, Online, Real-Time Reference. American Libraries, 2000, vol. 31, n. 10, p. 64.

16.3.89. SENDI, K.; REIMAN, D. Point-and-click at the reference desk. Online, 1995, vol. 19, n. 4, p. 76-78.

16.3.90. SHAMEL, C. L. Centralized library and learning resources: a remote access demonstration project. Community and Junior College Libraries, 2001, vol. 10, n. 4, p. 13-28.

16.3.91. SHENTON, Andrew K. Viewing information needs through a Johari Window. Reference Services Review, 2007, vol. 35, n. 3, p. 487-496.

16.3.92. SIMMONDS, Patience L. The 21st Century Reference Department: Working to Provide Quality: Service to Users. The Reference Librarian, 2003, vol. 39, n. 81, p. 89103.

16.3.93. SINGH, Sewa. Reference service and automation. Lucknow Librarian, 1983, vol. 15, n. 4, p. 125-134.

16.3.94. SLATER, Robert. Reference desk notes: an online knowledge management system. Internet Reference Services Quarterly, 2006, vol. 11, n. 3, p. 69-83.

16.3.95. SMITH, Dana E. The Information Station. Small Computers in Libraries, 1987, vol. 7 , n. 6 , p. 26-27. 
16.3.96. SMITH, Dana E. Reference expert systems: humanizing depersonalized service. The Reference Librarian, 1989, n. 23, p. 177-190.

16.3.97. SMITH, Karen F. Robot at the reference desk? College and Research Libraries, 1986, vol. 47, n. 5, p. 486-490. bibliog.

16.3.98. SONG, Yoo-Seong. International business students: a study on their use of electronic library services. Reference Services Review, 2004, vol. 32, n. 4, p. 366-371.

16.3.99. SOTTONG, S. P. A menu-driven ready reference file using dBase 3 Plus or dBase 4. Library Software Review, 1993, vol. 12, n. 3, p. 36-41.

16.3.100. SOWARDS, Steven W. Reference collections, reference services, and the change from text to technology. New Library World, 2003, vol. 104 , n. 4/5, p. 135-141.

16.3.101. SPINK, Amanda. Mediated online searching and digital reference. The Reference Librarian, 2002-2003, vol. 38, n. 79/80, p. 57-65.

16.3.102. STALKER, J. C.; MURFIN, M. E. Frequently asked questions: an effective way to store and retrieve reference information? Reference Services Review, 1996, vol. 24, n. 4 , p. 31-40.

16.3.103. STILL, J.; ALEXANDER, J. Integrating Internet into reference: policy issues. College and Research Libraries News, 1993, vol. 54, n. 3, p. 139-140.

16.3.104. STOVER, Mark. Making tacit knowledge explicit: the Ready Reference Database as codified knowledge. Reference Services Review, 2004, vol. 32, n. 2, p. 164-173.

16.3.105. STRAW, Joseph E. From magicians to teachers: The development of electronic reference in libraries: 1930-2000. The Reference Librarian, 2001, n. 74, p. 1-12.

16.3.106. TALAVERA IBARRA, Ana María. El bibliotecario electrónico: Consideraciones en torno al Servicio de Referencia en la Era Digital. Biblios, 2000, vol. 1, n. 3.

16.3.107. TENOPIR, C.; NEUFANG, R. Electronic reference options: tracking the changes. Online, 1995, vol. 19, n. 4, p. 67-73.

16.3.108. THOMAS, J.; SOTTONG, S. P. Automating your ready-reference file. Reference Services Review, 1994 , vol. 22, n. 1, p. 89-93.

16.3.109. TRAUTMAN, Rodes; GOTHBERG, Helen M. A reference tools database: a proposed application for a microcomputer at the reference desk. The Reference Librarian, 1982, n. 5/6, p. 195-198.

16.3.110. WILDE, Erik. References as knowledge management. Issues in Science and Technology Librarianship, 2004, n. 41.

16.3.111. WU, Qi. Win-win strategy for the employment of reference graduate assistants in academic libraries. Reference Services Review, 2003, vol. 31, n. 2, p. 141-153.

16.3.112. YOUNG, Courtney L.; DIAZ, Karen R. E-reference: incorporating electronic publications into reference. Library Hi Tech, 1999, vol. 17, n. 1, p. 55-62.

16.3.113. YU, Holly; ZHANG, Ying; BISHOP, Corinne. Content and workflow management for library web sites: case studies: Project-management tools for libraries: a planning and implementation model using Microsoft Project 2000. Information Technology and Libraries, 2005, vol. 24, n. 3, p. 259-147, 152. 


\subsection{Recursos y tecnología web en los servicios de referencia}

16.4.1. ADALIAN, Paul T.; SWANSON, Judy. Locally developed Web-enabled databases: new roles and opportunities for libraries. Reference Services Review, 2001, vol. 29, n. 3, p. 238-253.

16.4.2. ADAMS, M. Meeting reference responsibilities through library Web sites. The Reference Librarian, 2001, n. 74, p. 91-101.

16.4.3. BERNIER, Roxane; BOWEN, Jonathan P. Web-based discussion groups at stake: the profile of museum professionals online. Program, 2004, vol. 38, n. 2, p. 120137.

16.4.4. BORDEIANU, Sever; CARTER, Christina E.; DENNIS, Nancy K. Delivering electronic resources with Web OPACs and other Web-based tools: needs of reference librarians. Reference Services Review, 2000, vol. 28, n. 2, p. 111-119.

16.4.5. CANNON, Nancy. Yahoo! Do you Google? Virtual reference overview. The Reference Librarian, 2002, vol. 38, n. 77, p. 31-37.

16.4.6. COLLINS, S. L. Developing Web resource guides for local history: a Pittsburgh example. Public Services Quarterly, 2002, vol. 1, n. 2, p. 67-78.

16.4.7. CRAWFORD, G. A.; WHITE, G. W. Migrating to Internet-based reference services: issues for the smaller academic library. Internet Reference Services Quarterly, 1998, vol. 3, n. 4, p. 3-18.

16.4.8. CROOK, E. The role of the Internet in public libraries. LASIE, 2000, vol. 31, n. 1, p. $28,31,34-6$.

16.4.9. DARRIES, Fatima. Internet access and use in reference services in higher education institutions in South Africa. South African Journal of Libraries and Information Science, 2004, vol. 70, n. 2, p. 72-85.

16.4.10. DI SU. Electronic Stacks: Using Web Sources in Reference Service. The Reference Librarian, 1999, n. 65, p. 161-176.

16.4.11. DIAZ, K. R.; O'HANLON, N. Hot topics on the Web: strategies for research. Reference and User Services Quarterly, 2001, vol. 41, n. 1, p. 25-29.

16.4.12. ENGEL, Debra; ROBBINS, Sarah. Improving reference services through a library website: strategies for collaborative change. The Reference Librarian, 2003, vol. 40, n. 83/84, p. 157-173.

16.4.13. FRÍAS, Amparo; LORENTE, Magdalena. La web de la biblioteca como escaparate de la biblioteca física: análisis de las webs de las bibliotecas públicas. BiD: textos universitaris de biblioteconomia i documentació, 2003, n. 10.

16.4.14. GARCÍA GÓMEZ, Francisco Javier. Las bibliotecas públicas españolas en Internet: ¿qué servicios ofrecen? Boletín de la Asociación Andaluza de Bibliotecarios, 2002, n. 68, p. 22-36.

16.4.15. GARCÍA MARCO, Francisco Javier. Servicios de información en la World Wide Web: una nueva frontera para los docentes del área de Biblioteconomía y Documentación. Cuadernos de documentación multimedia, 1998, vol. 6-7.

16.4.16. GUPTA, Rajiv; KUMAR, Vijai; SINGH, Sanjay Kumar; SINGH, Manoj. A typical approach to develop a comprehensive library web. SRELS Journal of Information Management, 2004, vol. 41, n. 1, p. 19-27. 
16.4.17. HOLLIS, Deborah R.; JOBE, Margaret M. Publishing on the Web: creating a local reference tool. Library Hi Tech, 1999, vol. 17, n. 1, p. 63-74.

16.4.18. HOPE, Charity B.; KAJIWARA, Sandra; MENGXIONG LIU. The Impact of the Internet: Increasing the Reference Librarian's Role as Teacher. The Reference Librarian, 2001, n. 74, p. 13-36.

16.4.19. HUBBARD, William J.; NIU, Guiling; WANG, Hanrong. Current status of reference services in academic libraries in mainland China: a web analysis. The International Information and Library Review, 2004, vol. 36, n. 2, p. 105-110.

16.4.20. HUNDIE, Kebede. Library operations and Internet resources. The Electronic Library, 2003, vol. 21, n. 6, p. 555-564.

16.4.21. JAY, Margaret; WEBBER, Sheila. Impact of the internet on delivery of reference services in English public libraries. Program: electronic library and information systems, 2005, vol. 39, n. 1, p. 25-38.

16.4.22. JOHNSON, R.; MCKIBBEN, J.; RUSTOMFRAM, P. Everything matters: creating a reference web page, the university of Memphis library experience. Tennessee Librarian, 1997, vol. 49, n. 2, p. 5-11.

16.4.23. JOINT, Nick; LAW, Derek. The electronic library: a review. Library Review, 2000, vol. 49, n. 9, p. 428-435.

16.4.24. JONES, J. E. Internet success stories from the Lewis and Clark Library System. Illinois Libraries, 1996, vol. 78, n. 3, p. 127-140.

16.4.25. KENNEDY, S. D. The Web makes its way mainstream: what kinds of everyday uses are you putting the Web to? Information Today, 1999, vol. 16, n. 10, p. 30-32.

16.4.26. KENNEY, Anne R.; MCGOVERN, Nancy Y.; MARTINEZ, Ida T.; HEIDIG, Lance J. Google Meets eBay: What Academic Librarians Can Learn from Alternative Information Providers . D-Lib Magazine, 2003, vol. 9, n. 6.

16.4.27. KONDRUP, Ruth. Internet as a tool for reference work Experiences from the IFLA/Danida trial project in Ghana. En IFLA General Conference and Council (68. 2002. Glasgow). Glasgow: IFLA, 2002. Disponible en http://www.ifla.org//V/ifla68/papers/002-128e.pdf [consultado el 17/07/2007].

16.4.28. KONDRUP, Ruth. Reference work in a library system without national bibliographies and union catalogues. Internet as a tool for reference work Experiences from the IFLA/Danida trial project in Ghana. En IFLA General Conference and Council (68. 2002. Glasgow). Glasgow: IFLA, 2002. Disponible en http://www.ifla.org//V/ifla68/papers/002-128e.pdf [consultado el 17/07/2007].

16.4.29. KOUTNIK, C. The World Wide Web is here: is the end of printed reference sources near? RQ, 1997, vol. 36, n. 3, p. 422-429.

16.4.30. KOVACS, D. K.; SCHLOMAN, B. F.; MCDANIEL, J. A. A model for planning and providing reference services using Internet resources. Library Trends, 1994, vol. 42, n. 4, p. 638-647.

16.4.31. LADNER, S. J.; TILLMAN, H. N. Using the internet for reference. Online, 1993, vol. 17, n. 1, p. 45-51.

16.4.32. MCGLAMERY, Susan; COFFMAN, Steve. Moving reference to the web. Reference and User Services Quarterly, 2000, vol. 39, n. 4, p. 380-386.

16.4.33. MELLENDORF, S. A. Automating access to Internet resources at the reference 
desk. Online, 1994 , vol. 18, n. 5, p. 69-73.

16.4.34. MERLO VEGA, José Antonio. El servicio de Internet en la biblioteca pública. Boletín de la AABADOM, 2003, n. 1-2, p. 53-55.

16.4.35. MERLO VEGA, José Antonio; SORLI ROJO, Angela. Pregunte a un bibliotecario: servicios de referencia en línea. Revista española de documentación científica, 2003, vol. 26 , n. 1.

16.4.36. MITCHELL, Eleanor; WATSTEIN, Sarah Barbara. Web researchers wanted. Reference Services Review, 2006, vol. 34, n. 3, p. 329-332.

16.4.37. MOORE, Sheryl. Weaving the Web: the impact of the Internet and other electronic technologies on reference service. Louisiana Library Association Bulletin, 1998 , n. 60 , p. $114-118$.

16.4.38. MORIN, Nicolas. Contenus et services des sites web des bibliothèques. Bulletin des Bibliothèques de France, 2003, vol. 48, n. 4, p. 9-13.

16.4.39. MOYO, L. M. Electronic Libraries and the Emergence of New Service Paradigms. The Electronic Library, 2004, vol. 22, n. 3, p. 220-230.

16.4.40. MULAC, C. M. Nothing but Net: a selected bibliography of using the Internet for reference. Illinois Libraries, 1996, vol. 78, n. 1, p. 15-16.

16.4.41. POMERANTZ, Jeffrey; STUTZMAN, Frederic. Collaborative reference work in the blogosphere. Reference Services Review, 2006, vol. 34, n. 2, p. 200-212.

16.4.42. REVILL, Don. Information services in an electronic environment: a review. New Library World, 2002, vol. 103, n. 1180, p. 336-339.

16.4.43. RYAN, S. Reference service for the Internet community: a case study of the Internet Public Library Reference Division. Library and Information Science Research, 1996, vol. 18, n. 3, p. 241-259.

16.4.44. SAWYER, D. A matter of confidence: asking reference questions over the Internet. Online, 1993 , vol. 17, n. 4, p. 8-9.

16.4.45. SCHMIDT, Janine. Promoting library services in a Google world. Journal: Library Management, 2007 , vol. 28, n. 6/7, p. 337-346.

16.4.46. STERN, D. Expert systems: HTML, the WWW, and the librarian. Computers in Libraries, 1995, vol. 15, n. 4, p. 56-58.

16.4.47. TENOPIR, Carol. Internet issues in reference. Library Journal, 1995, vol. 120, n. 16.

16.4.48. WHITLATCH, Jo Bell. Reference futures: outsourcing, the Web, or Knowledge counseling. Reference services review, 2003, vol. 31, n. 1, p. 26-30.

16.4.49. $\mathrm{YU}, \mathrm{X}$. Advancing reference information systems on the Web. Internet Reference Services Quarterly, 1996, vol. 1, n. 3, p. 67-74.

16.4.50. ZUMALT, Joseph R. Cost-of-Living Calculators on the Web: An Empirical Snapshot. Reference and User Services Quarterly, 2003, vol. 43, n. 2.

16.4.51. ZUMALT, Joseph R.; PASICZNYUK, Robert W. The Internet and reference services: a real-world test of Internet utility. Reference and User Services Quarterly, 1998, vol. 38, n. 2, p. 165-172. 


\subsection{Bibliografía complementaria sobre servicios de referencia}

16.5.1. AFOLABI, Michael. Application of diagnostic constructs to query negotiation in reference service. Library Review, 1996, vol. 45, n. 8, p. 25-32.

16.5.2. AKED, Michael J.; PHILLIPS, John C.; REIMAN-SENDI, Karen; RISNER, Kevin; VOIGT, Kathleen J.; WIESLER, Judy. Faculty use of an academic library reference collection. Collection Building, 1998, vol. 17, n. 2, p. 56-64.

16.5.3. ANELLO, Karen; BONFIELD, Brett. Providing Reference Service in Our Sleep. Reference and User Services Quarterly, 2007, vol. 46, n. 3, p. 28-33.

16.5.4. ANGELO, Barbara J. D'. If They Build It Will They Come? Cooperation and Collaboration to Create a Customized Library. The Reference Librarian, 2003, vol. 40, n. 83-84, p. 237-250.

16.5.5. BARLOW, Diane L.; AVERSA, Elizabeth. Library Professionals for the 21st Century Academy . Advances In Librarianship, 2006, vol. Volume 30 , p. 327-364.

16.5.6. BARNES, Newkirk. Doing It All: First Year Challenges for New Academic Reference Librarians. The Reference Librarian, 2007, vol. 47, n. 97, p. 51-61.

16.5.7. BASCO, Buenaventura B.; GODA, Donna; KILLINGSWORTH, Elizabeth K. University of Central Florida Librarians on Location. Public Services Quarterly, 2002, vol. 1, n. 3, p. 13-19.

16.5.8. BATT, C. Creating the Clapham Junction of knowledge. Library Manager, 1995, n. 3, p. 5.

16.5.9. BECK, Susan E.; TURNER, Nancy B. On the Fly BI: Reaching and Teaching from the Reference Desk. The Reference Librarian, 2001, n. 72, p. 83-96.

16.5.10. BEJUNE, Matthew; KINKUS, Jane. Creating a composite of user behavior to inform decisions about new and existing library services. Reference Services Review, 2006, vol. 34, n. 2, p. 185-192.

16.5.11. BLOCKS, D.; CUNLIFFE, D.; TUDHOPE, D. A Reference Model for User-System Interaction in Thesaurus-Based Searching. Journal of the American Society for Information Science and Technology, 2006, vol. 57, n. 12.

16.5.12. BOSQUE, Darcy Del; CHAPMAN, Kimberly. Your place or mine? Face-to-face reference services across campus. New Library World, 2007, vol. 108, n. 5/6, p. 247262.

16.5.13. BROWN, Deborah; LEITH, Dean. Integration of the research library service into the editorial process: Embedding the librarian into the media. Aslib Proceedings, 2007, vol. 59 , n. 6 , p. 539-549.

16.5.14. BURKE, Cynthia; GREENBERG, Stephen; AHMED, Terry. Serving our colleagues: reference and history of medicine services from the National Library of Medicine. Medical Reference Services Quarterly, 2007.

16.5.15. CALALUCA, Eric M. Reference Universe: unlocking libraries' reference collections. Against the Grain, 2006, vol. 18, n. 6, p. 36-38.

16.5.16. CARANDE, Robert. Reference Advisory Systems (RAS): some practical issues. Reference Services Review, 1989, vol. 17, n. 3, p. 87-90.

16.5.17. CARDWELL, C.; FURLONG, K.; O'KEEFFE, J. My librarian: personalized 
research clinics and the academic library. Research Strategies, 2001, vol. 18, n. 2, p. $97-111$.

16.5.18. CHANDLER, Yvonne J. Reference in library and information science education. Library trends, 2001, vol. 50, n. 2, p. 245-262.

16.5.19. COPPOLA, Elaine. Do You Have Any Information on the Goth Lifestyle? The Reference Librarian, 2001, n. 72, p. 171-177.

16.5.20. CROWE, Kathryn M. Collaborative Leadership: A Model for Reference Services. The Reference Librarian, 2003, vol. 39, n. 81, p. 59-69.

16.5.21. CURTIS, S.; MANN, B. Cooperative reference: is there a consortium model? Reference and User Services Quarterly, 2002, vol. 41, n. 4, p. 344-349.

16.5.22. DALLIS, Diane; WALTERS, Carolyn. Reference services in the commons environment. Reference Services Review, 2006, vol. 34, n. 2, p. 248-260.

16.5.23. DARBY, Della H.; NORTHRUP, Lori A.; WADDELL, Carla T.; WATTERS, Heather F. Cooperation in a Multi-Faceted Reference Department: Blending Resources, Personnel, and Services of Reference, Instruction, Interlibrary Loan, and Government Documents . The Reference Librarian, 2003, vol. 40, n. 83-84, p. 119130.

16.5.24. DE GROOTE, Sandra L. Questions asked at the virtual and physical health sciences reference desk: how do they compare and what do they tell us? Medical reference services quarterly, 2005, vol. 24, n. 2, p. 11-23.

16.5.25. DEW, S. H.; BUCHANAN, N. L.; KNIGHT, L. A. Twenty years of MARS in print: an annotated bibliography. $R Q, 1997$, vol. 36, n. 3, p. 382-392.

16.5.26. DILEVKO, Juris; LISA GOTTLIEB. Reading and the Reference Librarian: The Importance to Library Service of Staff Reading Habits. Jefferson NC: McFarland, 2003.

16.5.27. DUCKETT, Bob. From reference library to information service: services in danger. Library Review, 2004, vol. 53, n. 6, p. 301-308.

16.5.28. DUCKETT, Bob. Paradise Lost? The Retreat from Reference. Library Review, 1992, vol. 41, n. 1.

16.5.29. DUCKETT, Bob. Reference and information services. Library Review, 2000, vol. 49 , n. 9 , p. $454-461$.

16.5.30. DUFFY, Amanda. IFLA Reference and Information Services Section 2005. Refer, 2005, vol. 21, n. 3, p. 9-11.

16.5.31. ENGLE, S. Reference services and issues in resource sharing via NREN. Current Studies in Librarianship, 1992, vol. 16, n. 1, p. 83-93.

16.5.32. EZZELL, J. R. It was the most uncertain of times: academic reference librarianship at the end of the Twentieth Century. North Carolina Libraries, 1998, vol. 56, n. 3, p. 96-99.

16.5.33. FRITCH, John W.; MANDERNACK, Scott B. The emerging reference paradigm: a vision of reference services in a complex information environment. Library trends, 2001, vol. 50, n. 2, p. 286-305.

16.5.34. GALLUZZI, Anna. II reference che verrà. Bollettino AIB, 2004, vol. 44, n. 2, p. 183-195. 
16.5.35. GALVIN, Jeanne. Alternative Strategies for Promoting Information Literacy. The Journal of Academic Librarianship, 2005, vol. 31, n. 4, p. 352-357.

16.5.36. GANDHI, Smiti. Knowledge management and reference services. The Journal of Academic Librarianship, 2004, vol. 30, n. 5, p. 368-381.

16.5.37. GORMAN, Michael. Values for human-to-human reference. Library trends, 2001, vol. 50, n. 2, p. 168-182.

16.5.38. HARLEY, Bruce; DREGER, Megan; KNOBLOCH, Patricia. The postmodern condition: students, the Web, and academic library services. Reference Services Review, 2001, vol. 29, n. 1, p. 23-32.

16.5.39. HARMON, Glynn. Toward expert inquiry systems. The Reference Librarian, 1987, n. 18, p. 95-106.

16.5.40. HARRISON, L. Stress relief: help for the technophobic patron from the reference desk. The Reference Librarian, 2000, n. 69/70, p. 31-47.

16.5.41. HAYDEN, K. Alix; LEE, Jennifer; MACMILLAN, Don . I wouldn't have asked for help if I had to go to the Library: reference services on site. Issues in Science and Technology Librarianship, 2004, n. 41.

16.5.42. HEIN, Karen K. Information uncommon: public computing in the life of reference. Reference Services Review, 2006, vol. 34, n. 1, p. 33-42.

16.5.43. HENNER, Terry. Reference practice. Medical Reference Services Quarterly, 2006, vol. 25, n. 3, p. 98-99.

16.5.44. HERIARD, R. Ethical issues facing reference service providers in a cooperative state-wide multi-type library network. LLA Bulletin, 1995, vol. 58, n. 1, p. 10-14.

16.5.45. HOGAN, D. R. Cooperative reference services and the referred reference question: an annotated bibliography, 1983-1994. Reference services review, 1996, vol. 24, n. 1, p. 57-64.

16.5.46. HOWZE, Philip C. Training the New Head of Reference: Focusing on the Supervising Relationship as Technique. The Reference Librarian, 2003, vol. 39, n. 81, p. 51-58.

16.5.47. HULL, Tracy L.; TAYLOR, Natalia. Crossing Three Bridges: Linking Librarianship and Teaching Across the P-16 Educational Continuum . The Reference Librarian, 2003, vol. 40, n. 83-84, p. 83-96.

16.5.48. HYOKYOUNG YI. Korean collections consortium of North America: Ten years and after. Journal of East Asian Libraries, 2007, n. 142, p. 25-36.

16.5.49. JANES, Joseph. What is reference for? Reference Services Review, 2003, vol. 31, n. 1, p. 22-25.

16.5.50. JANTZ, Ron. Knowledge management in academic libraries: special tools and processes to support information professionals. Reference Services Review, 2001, vol. 29, n. 1, p. 33-39.

16.5.51. JUZNIC, Primoz; URBANIJA, Jose; GRABRIJAN, Edvard; MIKLAVC, Stasoa; OSLAJ, Damijana; SVOLJSAK, Sonja. Excuse me, how do I commit suicide? Access to ethically disputed items of information in public libraries. Library Management, 2001, vol. 22, n. 1/2, p. 75-80.

16.5.52. KING, Valery. Cooperative Reference Desk Scheduling and Its Effects on 
Professional Collegiality . The Reference Librarian, 2003, vol. 40, n. 83-84, p. 97-118.

16.5.53. KLUEGEL, Kathleen; ROSS, Catherine Sheldrick. The Reference Interview. Reference and User Services Quarterly, 2003, vol. 43, n. 1, p. 37-43.

16.5.54. LAMY, Jean-Philippe. Les espaces d'information: éléments de programmation. Bulletin des Bibliothèques de France, 2000, vol. 45, n. 3, p. 83-88.

16.5.55. LANDESMAN, Margaret. Getting it right: the evolution of reference collections. The Reference Librarian, 2005, vol. 44, n. 91/92, p. 5-22.

16.5.56. LASKOWSKI, Mary S.; FENNELL, Chad. Retooling Access to Academic Media Collections. Technical Services Quaterly, 2006, vol. 23, n. 3.

16.5.57. LEAHY, Lynda. Managing an Academic Reference Department. The Reference Librarian, 2003, vol. 39, n. 81, p. 5-15.

16.5.58. LIBERATORE, Gustavo. Los servicios bibliotecarios en línea y la formación universitaria a distancia en la Argentina: acceso a la información y formación. En IFLA General Conference and Council (70. 2004. Buenos Aires). Buenos Aires: IFLA, 2004. Disponible en http://www.ifla.org/IV/ifla70/papers/172s-Liberatore.pdf [consultado el 17/07/2007].

16.5.59. LIPOW, Anne Grodzins. The future of reference: point-of-need reference service: no longer an afterthought. Reference Services Review, 2003, vol. 31, n. 1, p. 31-35.

16.5.60. LIPOW, Anne Grodzins. The librarian has left the building: But to where? Internet reference services quarterly, 2003, vol. 8, n. 1-2, p. 9-18.

16.5.61. MALENFANT, Chuck; DEMERS, Nora Egan. Collaboration for point-of-need library instruction. Reference Services Review, 2004, vol. 32, n. 3, p. 264-273.

16.5.62. MATYLONEK, J. C.; OTTOW, C.; REESE, T. Organizing ready reference and administrative information with the reference desk manager. D-Lib Magazine, 2001, vol. 7, n. 11.

16.5.63. MCCLARE, Christel L. Serials reference services at the National Library of New Zealand. Serials Librarian, 1991, vol. 20, n. 4, p. 35-45.

16.5.64. MERLO VEGA, José Antonio. El servicio de referencia. Anales de documentación, 2000, n. 3, p. 93-126.

16.5.65. MITCHELL, Eleanor; WATSTEIN, Sarah Barbara. Further thoughts about putting the user at the center. Reference Services Review, 2007, vol. 35, n. 1, p. 5-7.

16.5.66. MORENO TORRES, R. El bibliotecario de referencia: técnica y entorno espacial. Revista Española de Documentación Científica, 1991, vol. 14, n. 3, p. 289-290.

16.5.67. NGIAN, Lek Choh. The re-invention of the reference enquiry service: a case study of the National Library Board, Singapore. En IFLA General Conference and Council (71. 2005. Os/o). Oslo: IFLA, 2005. Disponible en http://www.ifla.org/IV/ifla71/papers/031e-Ngian.pdf [consultado el 17/07/2007].

16.5.68. NILSEN, Kirsti. Comparing users' perspectives of in-person and virtual reference. New Library World, 2006, vol. 107, n. 3/4, p. 91-104.

16.5.69. NOFSINGER, Mary M. Training and Retraining Reference Professsionals: Core Competencies for the 21st Century. The Reference Librarian , 1999, n. 64, p. 9-19.

16.5.70. PARROTT, James R. REFSIM: a bimodal knowledge-based reference training 
and consultation system. Reference Services Review, 1988, vol. 16, n. 1-2, p. 61-68.

16.5.71. POMERANTZ, Jeffrey. Collaboration as the Norm in Reference Work. Reference and User Services Quarterly, 2006, vol. 46, n. 1, p. 45-55.

16.5.72. POMERANTZ, Jeffrey. A linguistic analysis of question taxonomies. Journal of the American Society for Information Science and Technology, 2005, vol. 56, n. 7, p. 715-728.

16.5.73. PYATI, Ajit. Limited English proficient users and the need for improved reference services . Reference Services Review, 2003, vol. 31, n. 3, p. 264-271.

16.5.74. QUINLAN, Nora J.; TUNON, Johanna. Providing reference in a joint-use library. Internet Reference Services Quarterly, 2005, vol. 9, n. 1/2, p. 111-128.

16.5.75. QUINN, Brian. Cooperation and Competition at the Reference Desk. The Reference Librarian, 2001, vol. 34, n. 72, p. 65-82.

16.5.76. REENSTJERNA, Frederick R. Thinking About Reference Service Paradigms and Metaphors. The Reference Librarian, 2001, vol. 34, n. 72, p. 97-111.

16.5.77. REFERENCE SPECIAL AND INFORMATION SECTION OF THE LIBRARY ASSOCIATION. Is there a future for Reference Libraries? A discussion document. Refer, 2006, vol. 22, n. 1, p. 13-16.

16.5.78. REICHARDT, Randy. Moore's law and the pace of change. Internet Reference Services Quarterly, 2006, vol. 11, n. 3, p. 117-124.

16.5.79. RETTIG, James. Reference Service: From Certainty to Uncertainty. Advances In Librarianship, 2006 , vol. Volume 30, p. 105-143.

16.5.80. REVELLI, Carlo. Providing information: in what way, and how much of it? Biblioteche Oggi, 2005, vol. 23, n. 10, p. 54-60.

16.5.81. ROBINSON, Catherine M.; REID, Peter. Do academic enquiry services scare students? Reference Services Review, 2007, vol. 35, n. 3, p. 405-424.

16.5.82. ROCKMAN, Ilene F. Distinct and expanded roles for reference librarians. Reference Services Review, 2005, vol. 33, n. 3, p. 257-258.

16.5.83. RODWELL, John. Dinosaur or dynamo? The future for the subject specialist reference librarian. New Library World, 2001, vol. 102, n. 1/2, p. 48-52.

16.5.84. ROLLÁN MALMIERCA, A. El servicio de referencia y el bibliotecario referencista. Boletín de la Asociación Andaluza de Bibliotecarios, 1998, n. 51, p. 9-26.

16.5.85. RUSA. Competències professionals per als bibliotecaris dels serveis de referència i atenció a l'usuari. Presentació i traducció de Nora Vela. BiD: textos universitaris de biblioteconomia i documentació, 2003, n. 11.

16.5.86. SAMSON, Sue; OELZ, Erling. The Academic Library as a Full-Service Information Center. The Journal of Academic Librarianship, 2005, vol. 31, n. 4, p. 347351.

16.5.87. SHIPMAN, Jean $P$. Why emerging roles for health sciences librarians? Reference Services Review, 2004, vol. 32, n. 1, p. 9-12.

16.5.88. SILBURN, Ruth. The reference library is alive. Refer , 2006, vol. 22, n. 3, p. 8-9.

16.5.89. SPANG, Lothar; BAKER, Lynda M. Healthcare information delivery in public 
libraries: implications for academic reference librarians. Reference Services Review, 2000, vol. 28, n. 1, p. 81-94.

16.5.90. STALKER, J. C.; MURFIN, M. E. Why reference librarians won't disappear: a study of success in identifying answering sources for reference questions. RQ, 1996, vol. 35, n. 4, p. 489-503.

16.5.91. STANDERFER, Amanda E. Reference Services in Rural Libraries. The Reference Librarian, 2006, vol. 45, n. 93, p. 137-149.

16.5.92. STODDART, R. A.; BRYANT, T. W.; BAKER, A. L.; LEE, A.; SPENCER, B. Going Boldly Beyond the Reference Desk: Practical Advice and Learning Plans for New Reference Librarians Performing Liaison Work. The Journal of Academic Librarianship, 2006, vol. 32, n. 4.

16.5.93. STRAW, Joseph E. When the Walls Came Tumbling Down: The Development of Cooperative Service and Resource Sharing in Libraries: 1876-2002. The Reference Librarian, 2003, vol. 40, n. 83-84, p. 263-276.

16.5.94. TENOPIR, Carol. Reference services from RLG. Library Journal, 1995, vol. 120, n. 8, p. 28.

16.5.95. TOBIN, Carol M. The future of reference: an introduction. Reference Services Review, 2003, vol. 31, n. 1 , p. 9-11.

16.5.96. TOWLSON, Kaye. Information in Business: a model of co-operation. Library Management, 1995, vol. 16, n. 3, p. 9-14.

16.5.97. TUCKER, James Cory. Getting down to business: library staff training. Reference Services Review, 2004, vol. 32, n. 3, p. 293-301.

16.5.98. TYCKOSON, David A. On the desirableness of personal relations and readers: the past and future of reference service. Reference services review, 2003, vol. 31, n. 1, p. 12-16.

16.5.99. TYCKOSON, David A. What is the best model of reference service? Library trends, 2001, vol. 50, n. 2, p. 183-196.

16.5.100. TYKOSON, David. References at Its Core: The Reference Interview. Reference and User Services Quarterly, 2003, vol. 43, n. 1, p. 49-51.

16.5.101. ULVIK, Synnove; SALVESEN, Gunhild. Ethical reference practice. New Library World, 2007, vol. 108, n. 7/8, p. 342-353.

16.5.102. WATSTEIN, Sarah Barbara. Emerging roles of health sciences librarians: academic library centrality. Reference Services Review, 2004, vol. 32, n. 1, p. 13-15.

16.5.103. WATSTEIN, Sarah Barbara. Scenario planning for the future of reference: five white papers posit the future and raise the bar for us all. Reference Services Review, 2003, vol. 31, n. 1, p. 36-38.

16.5.104. WHITE, M. D. Questions in reference interviews. Journal of Documentation, 1998, vol. 54, n. 4, p. 443-465.

16.5.105. WILLEMSE, L. Wie haalde de top 40 niet?= Who didn't make the top 40 ? BibliotheekBlad, 2002, vol. 6, n. 22/23, p. 17.

16.5.106. YEE, Jordan G. Librarians as matchmakers: connecting seniors in their Capstone semester. Reference Services Review, 2007, vol. 35, n. 2, p. 257-264. 
16.5.107. YI, Hua. Individual research consultation service: an important part of an information literacy program. Reference Services Review, 2003 , vol. 31, n. 4, p. 342350.

16.5.108. YU, L. Geographic Information Systems in library reference services: development and challenge. The Reference Librarian, 1998, n. 60, p. 87-110.

16.5.109. ZAINIB, A. N.; ZAID, N. E. M. Introducing Maklum: the general reference expert adviser developed for a university library. Malaysian Journal of Library and Information Science, 1996, vol. 1, n. 1, p. 93-107.

16.5.110. ZHANG, Li. Communication in academic libraries: an East Asian perspective. Reference Services Review, 2006, vol. 34, n. 1, p. 164-176.

16.5.111. ZUMALT, J. R.; SMITH, R. A. Internet reference service: general sources and trends. Journal of Library Administration, 2000, vol. 30, n. 3/4, p. 335-350. 


\section{Fuentes de información: recursos bibliográficos}

La bibliografía sobre fuentes de información es extensa, pero, al no ser éste el tema central de la tesis doctoral aquí sólo se contempla de forma tangencial, como uno de los aspectos que tienen relación con la referencia digital, ya que los servicios de referencia, sean presenciales o en línea, necesitan colecciones de calidad para poder dar respuesta a las consultas que les hagan llegar los usuarios.

En este capítulo se recogen, pues, referencias bibliográficas sobre fuentes y colecciones de referencia, siempre desde la perspectiva de su valor para una biblioteca, concretamente para sus servicios de información. La selección se ha realizado partiendo de su relación con alguno de los capítulos de la tesis doctoral; así, es posible encontrarse con manuales de fuentes de información, con algunos repertorios, con documentos que tratan sobre aspectos de evaluación y otras referencias de menor interés pero que es lícito que se presenten también en esta recopilación bibliográfica.

Se pueden encontrar en esta sección bibliográfica importantes referencias sobre evaluación de la información telemática, que ha sido agrupadas junto a las que tratan de la calidad de las colecciones de referencia. Esto es así, porque en distintas partes de la tesis se trata de evaluación de servicios de referencia y colecciones de referencia, evaluación de la información telemática. En la sección bibliográfica del capítulo 18 se incluyen las referencias sobre la evaluación de los servicios de referencia digital.

Dado que éste no es el apartado central de la tesis doctoral sólo se han establecido tres subcategorías, en función de la especificidad de los contenidos de las mismas. Se trata de los siguientes grupos:

1. Manuales sobre fuentes de información y colecciones de referencia: monografías y documentos monográficos que tratan sobre fuentes de información y colecciones bibliotecarias de referencia, desde una perspectiva teórico-práctica.

2. Evaluación de fuentes de información: manuales y artículos de publicaciones periódicas especializadas que traten sobre criterios para la medición de calidad de la información, así como metodologías de evaluación de fuentes de información e indicadores específicos para el análisis de obras de referencia, preferentemente desde una perspectiva biblioteconómica.

3. Bibliografía complementaria sobre fuentes de información: aspectos específicos de determinadas fuentes de información y documentos sobre recursos informativos que no se puedan integrar en alguna de las dos categorías anteriores. 


\subsection{Manuales sobre fuentes de información y colecciones de referencia}

17.1.1. ADBS. Répertoire des banques de données professionnelles: banques et services d'information en ligne. 15éme ed. Paris: ADBS, 1996.

17.1.2. ALÍA MIRANDA, Francisco. Fuentes de información para historiadores: obras de referencia y bibliografías. Gijón: Trea, 1998.

17.1.3. ASOCIACIÓN EDUCACIÓN Y BIBLIOTECAS. Obras de referencia: repertorio bibliográfico para bibliotecas públicas. $2^{\mathrm{a}}$ ed. Madrid: Tilde Servicios Editoriales, 1996.

17.1.4. BAXTER, Pam M. (ed.). Social science reference services. Binghamton, NY: The Haworth Information Press, 1995.

17.1.5. BEAUDIQUEZ, Marcelle; BÉTHERY, Annie; ALBARIC, Michel. Ouvrages de référence pour les bibliothèques: répertoire bibliographique. 4eme ed. Paris: Cercle de la Librairie, 1995.

17.1.6. BÉTHERY, Annie (dir.). Développer un fonds de référence en bibliothèque: imprimés, cédéroms, sites Internet. $5^{\mathrm{eme}}$. Paris: Cercle de la librairie, 2001.

17.1.7. BLAZEK, R.; AVERSA, E. The Humanities: A Selective Guide to Information Sources . 5th ed. Englewood, CO: Libraries Unlimited, 2000.

17.1.8. BOPP, Richard E.; SMITH, Linda C. Introducción general al servicio de consulta. México D.F.: Universidad Nacional Autónoma de México, 2000.

17.1.9. BOPP, Richard E.; SMITH, Linda C. (eds. ). Reference and information services: an introduction . 4th ed. Englewood, CO: Libraries Unlimited, 2007.

17.1.10. CALVA GONZÁLEZ, Juan José. Las necesidades de información: fundamentos teóricos y métodos. México: UNAM, 2004.

17.1.11. CARRIZO, Gloria; IRURETA-GOYENA, Pilar; LÓPEZ DE QUINTANA, Eugenio. Manual de Fuentes de Información. Madrid: CEGAL, 1994.

17.1.12. CARRIZO SAINERO, Gloria. La información en ciencias sociales. Gijón: Trea, 2000.

17.1.13. CASSELL, Kay Ann. Developing reference collections and services in an electronic age: A how-t-do-it manual for librarians. New York: Neal-Schuman, 1999.

17.1.14. CASSELL, Kay Ann; HIREMATH, Uma. Reference and information services in the 21st century: an introduction. London: Facet, 2006.

17.1.15. CEBRIÁN, Bernandino. J. Fuentes de consulta para la documentación informativa. Madrid: Universidad Europea CEEE, 1997.

17.1.16. CORDÓN GARCÍA, José Antonio; LÓPEZ LUCAS, Jesús; VAQUERO PULIDO, Raúl. Manual de investigación bibliográfica y documental. Madrid: Pirámide, 2001.

17.1.17. DIAZ, Karen R. (ed.). Reference sources on the Internet: off the shelf and onto the Web. Binghamton, NY: The Haworth Information Press, 1997.

17.1.18. DUCKETT, Bob; WALKER, Peter; DONNELLY, Christinea. Know It All, Find It Fast: An A-Z source guide for the enquiry desk. $2^{\text {nd }}$. London: Facet, 2004.

17.1.19. FROST, William J. (ed.). The reference collection: from the shelf to the Web. 
Binghamton, NY: The Haworth Information Press, 2005.

17.1.20. GARZA MERCADO, Ario. Obras de consulta para estudiantes de ciencias sociales y humanidades. México: El Colegio de México, 1992.

17.1.21. HERRON, Nancy et al. The social sciences: a cross disciplinary guide to selected sources . 3rd edition. Englewood: Libraries Unlimited , 2002.

17.1.22. HURT, C. D. (ed.). Information sources in science and technology . 3rd ed. Englewood: Libraries Unlimited, 1998.

17.1.23. JACOBS, Neil; HUXLEY, Lesly (eds.). Online information services in the Social Sciences. Oxford: Chandos, 2004.

17.1.24. KATZ, William A. Introduction to reference work. 8th ed. New York: McGraw-Hill, 2002.

17.1.25. KOVACS, D. K.; FLEMING, M. (eds.). Internet resources and Humanities Reference Service: Proceedings of the Clinic on Library Applications of Data Processing, Illinois University at Urbana-Champaign, 4-6 Apr 1993. Illinois: Illinois University at Urbana-Champaign, Graduate School of Library and Information Science, 1994.

17.1.26. KOVACS, Diane; KARA ROBINSON. The Kovacs Guide to Electronic Library Collection Development: Essential Core Subject Collections, Selection Criteria, and Guidelines. New York: Neal-Schuman, 2004.

17.1.27. LAFOND, Deborah M.; WALSH, Gretchenguest (eds.). Research, reference service, and resources for the study of Africa. Binghamton, NY: The Haworth Information Press, 2004.

17.1.28. LEA, Peter; DAY, Alan (eds.). The reference sources handbook: (previously Printed reference material). $4^{\mathrm{a}}$ ed. London: Library Association Publishing, 1996.

17.1.29. LESTER, Ray (ed.). New Walfords Guide to Reference Sources. London: Facet, 2005-.

17.1.30. LIBRARY ASSOCIATION (ed.). Walford's guide to reference material. London: Library Association, 1994-1997.

17.1.31. LÓPEZ YEPES, José. Los caminos de la información. Madrid: Fragua, 1997.

17.1.32. LOW, Kathleen. Legislative reference services and sources. Binghamton, NY: The Haworth Information Press, 1995.

17.1.33. MALDONADO MARTÍNEZ, Ángeles; RODRÍGUEZ YUNTA, Luis (coords.). La información especializada en Internet: directorio de recursos de interés académico y profesional. 2a ed. corr. y aum. Madrid: CSIC, 2006.

17.1.34. MALINOWSKY, R. H. Reference sources in science, engineering, medicine, and agriculture . Phoenix: Oryx, 1994.

17.1.35. MARTíN VEGA, Arturo. Fuentes de información general. Gijón: Trea, 1995.

17.1.36. MCILWAINE, Ia C.; HILL, Michael W.; WILLIAMSON, Nancy (eds.). Guides to information sources... [repertorios monográficos sobre diversos temas]. München: K.G.Saur.

17.1.37. MELNIK, Diana. Principios de referencia: fuentes y servicios de consulta. Buenos Aires: Alfagrama, 2005. 
17.1.38. MERLO VEGA, José Antonio; SORLI ROJO, Ángela. Biblioteconomía y Documentación en Internet. Madrid: CSIC, CINDOC, 1996.

17.1.39. MILLER, William; PELLEN, Rita M. (eds.). Evolving Internet Reference Resources. Binghamton, NY : The Haworth Information Press, 2006.

17.1.40. NIXON, Carol; BURMOOD, Jennifer (comps.). Internet Librarian 2001. Proceedings of the Internet Librarian Conference (5. Pasadena, California. November 6-8, 2001). Pasadena, CA: Internet Librarian Conference, 2001.

17.1.41. NOLAN, Christopher W. Managing the reference collection. Chicago: American Library Association, 1999.

17.1.42. O'GORMAN, Jack (ed.). Reference Sources for Small and Medium-sized Libraries. $7^{\text {th }}$ ed. Chicago: American Library Association, 2007.

17.1.43. POULTER, Alan; MCMENEMY, David; HIOM, Deborah. The Library and Information Professional's Internet Companion: A practical resource for library and information professionals. London: Facet, 2005.

17.1.44. PURCELL, Gary R.; SCHLACHTER, Gail A.; BUNGE, Charles A. Reference sources in library and information services: a guide to the literature. Santa Barbara, California: ABC-Clio Information Services, 1984.

17.1.45. REYNOLDS, Judy (ed.). Reference services in the humanities. Binghamton, NY: The Haworth Information Press, 1994.

17.1.46. ROMANOS DE TIRATEL, Susana. Guía de fuentes de información especializadas: Humanidades y Ciencias Sociales. Buenos Aires: EB Publicaciones, 2001.

17.1.47. SADER, Marion (ed.). General reference books for adults: authoritative, evaluations of encyclopedias, atlases, and dictionaries. New York: Bowker, 1988.

17.1.48. SALVADOR OLIVÁN, J. A.; ANGÓS ULLATE, J. M. Directorio de bases de datos internacionales. Zaragoza: Universidad de Zaragoza, 2001.

17.1.49. SAUERS, Michael P. Using the internet as a reference tool: a how-to-do-it manual for librarians. New York: Neal-Schuman, 2001.

17.1.50. SHELFER, Katherine M. (ed.). Business reference services and sources: how end users and librarians work together. Binghamton, NY: The Haworth Information Press, 1997.

17.1.51. SLAVENS, Thomas P. (ed.). Library problems in the humanities: case studies in reference services, collection building, and management. K.G. Saur: Paris, 1981.

17.1.52. THOMPSON, E. Reference and collections development on the Internet. New York: Neal-Schuman, 1996.

17.1.53. THOMSEN, Elizabeth. Reference collection development on the Internet: A howto-do-it manual. New York: Neal-Schuman, 1996.

17.1.54. TORRES, Isabel de (dir.). Las fuentes de Información: estudios teórico-prácticos. Madrid: Síntesis, 1998.

17.1.55. TZE-CHUNG, Li. Social science reference sources: a practical guide . 3rd ed. New York: Greenwood Press, 2000.

17.1.56. VILLASEÑOR, Isabel. Las fuentes de información. En López Yepes, José (ed.). 
Manual de información y documentación. Madrid: Pirámide, 1996, p. 200-228.

\subsection{Evaluación de fuentes de información}

17.2.1. ALEXANDER, J.; TATE, M. A. Web wisdom: how to evaluate and create information quaity on the Internet. Mahwah: Lawrence Erlbaum Associates, 1999.

17.2.2. AYUSO GARCÍA, María Dolores; MARTÍNEZ NAVARRO, Victoria. Evaluación de calidad de fuentes y recursos digitales: guía de buenas prácticas. Anales de documentación, 2006, n. 9, p. 17-42.

17.2.3. CANEPI, K. Information access through electronic databases for rural public libraries. Rural Libraries, 1997, vol. 17, n. 1, p. 7-34.

17.2.4. CAYWOOD, C. Library selection criteria for WWW resources [en línea]. Public libraries, 1996, p. 169.

17.2.5. CLARK, J. M.; CARY, K. An approach to the evaluation of ready reference collections. Reference services review, 1996, vol. 23, n. 1, p. 39-43.

17.2.6. CODINA, Lluis. Evaluación de recursos digitales en línea: conceptos, indicadores y métodos. Revista Española de Documentación Científica, 2000, vol. 23, n. 1, p. 9-44.

17.2.7. CODINA, Lluis. Parámetros e indicadores de calidad para la evaluación de recursos digitales. En Jornadas Españolas de Documentación (7. 2000. Bilbao). Bilbao: Universidad del País Vasco, 2000, p. 135-144.

17.2.8. COLLINS, Boyd R. Beyond cruising: reviewing. Library Journal, 1996, vol. 121, n. 3.

17.2.9. COOKE, A. Authoritative guide to evaluating information on the Internet. New York: Neal-Schuman, 1999.

17.2.10. GARNES, D.; MILLS, C. Finding and evaluating health sources on the Internet: an overview. The Reference Librarian, 2001, n. 74, p. 177-186.

17.2.11. JIMÉNEZ PIANO, Marina; ORTIZ-REPISO JIMÉNEZ, Virginia. Evaluación y calidad de sedes web. Gijón: Trea, 2007.

17.2.12. KAPOUN, J. Teaching undergrads WEB evaluation: a guide for library instruction [en línea]. C\&RL News, 1998, vol. 59, n. 7.

17.2.13. MURRAY, Janet; TSCHERNITZ, Cindy. The Internet myth: emerging trends in reference enquiries. Australasian Public Libraries and Information Services, 2004, vol. 17 , n. 2, p. $80-87$.

17.2.14. NARDI, B. A.; O'DAY, V. Intelligent agents: what we learned at the library. Libri: International Journal of Libraries and Information Services, 1996, vol. 46, n. 2, p. 5988.

17.2.15. NAVARRETE-CORTÉS, José; FERNÁNDEZ LÓPEZ, Juan Antonio; CHAICHIO, Juan Antonio. Recursos informativos en la web: aplicación de técnicas bibliométricas para medir su uso. Revista española de documentación científica, 2007, vol. 30, n. 4, p. 492-502.

17.2.16. OLIVER, K. M. Wilkinson G. L. Bennet L. T. Evaluating the quality of Internet 
information sources [en línea]. En ED-MEDIA/ED-TELECOM (Calgary, Alberta, Canada, 1997). Washington: ERIC, 1997. Disponible en http://www.eric.ed.gov [consultado el 17/07/2007].

17.2.17. RITCHIE, Ann; GENONI, Paul. Print v. electronic reference sources: implications of an Australian study. The Electronic Library, 2007, vol. 25, n. 4, p. 440-452.

17.2.18. SEBEK, Robert; AUER, Nicole. Bibliography on evaluating web information [en línea]. Emergency Librarian, 1988, vol. 25, n. 5, p. 23-24.

17.2.19. SMITH, Alastair. Evaluation of information sources [en línea]. En Ciolek, Matthew; GOLTZ, IRENA M. (eds.). Information Quality WWW Virtual Library [en línea]. Canberra: Ciolek, 2006.

17.2.20. SMITH, Alastair G. Testing the Surf: Criteria for Evaluating Internet Information Resources. The Public-Access Computer Systems Review, 1997, vol. 8, n. 3.

17.2.21. SOWARDS, Steven W. Visibility as a factor in library selection of ready reference web resources. Reference Services Review, 2005, vol. 33, n. 2, p. 161-172.

17.2.22. SVEUM, Tor. Quality information on the internet: Norwegian library students on the search. New Library World, 2007, vol. 108, n. 7/8, p. 332-341.

17.2.23. TOMAÉL, Maria Inês; VALENTIM, Marta Lígia Pomim (eds.). Avaliação de fontes de informação na internet. Londrina: EDUEL, 2004.

\subsection{Bibliografía complementaria sobre fuentes de información}

17.3.1. ADAMSON, Shaun; WEINGART, Sandra. Creation and evolution of a Webbased reference collection for an academic community. Campus-Wide Information Systems, 1999, vol. 16, n. 5, p. 157-161.

17.3.2. ALBITZ, Rebecca S. From celluloid to digital: electronic resources for film studies. Journal of Library Administration, 2005, vol. 43, n. 3/4, p. 55-63.

17.3.3. ANDERSON, B. The Internet as career, job, and employment resource: transition, assimilation, instruction. The Reference Librarian, 1996, n. 55, p. 7-17.

17.3.4. ARDIS, Susan B. Internet engineering reference: an academic strategy . The Reference Librarian, 2001, n. 74, p. 75-90.

17.3.5. BALLARD, T. Internet reference: just the good stuff here's how to offer quick access to good reference resources on the Web. Information Today, 1997, vol. 14, n. 11, p. 51.

17.3.6. BASU, G. Using Internet for reference: myths versus realities. Computers in Libraries, 1995, vol. 15, n. 2, p. 38-40.

17.3.7. BIVENS-TATUM, W. Expert services on the Web. College and Research Libraries News, 2001, vol. 62, n. 7, p. 714-716.

17.3.8. BLOCK, Karla J.; KELLY, Julia A. Integrating Informal Professional Development into the Work of Reference. The Reference Librarian, 2001, n. 72, p. 207-217.

17.3.9. BRADLEY, P.; CHAMBERS, L. Growth and use of the Internet. Assignation, 1995, vol. 12, n. 2, p. 26-28. 
17.3.10. BRONARS, Lori. Science Reference on the Internet. The Reference Librarian, 2005, vol. 44, n. 91/92, p. 175-196.

17.3.11. BUTLER, Brett. KnowledgeBit: A Database Format for Reference: Version 2.0 . Annual Digital Reference Conference, 2000, n. 2.

17.3.12. CAMPILLO, R. R. La informacion referencial en bibliotecas especializadas: un futuro orientado electronicamente. Boletín de la Asociación Andaluza de Bibliotecarios, 1994, vol. 10, n. 36, p. 51-55.

17.3.13. CARR, A. F.; STIBRAVY, R. Designing a Web bookmarks page for reference desk use. Bulletin of the Medical Library Association, 1999, vol. 87, n. 1, p. 80-82.

17.3.14. COX, Jennifer L.; SKARL, Susie A. Government information education and training: a selected annotated bibliography. Reference Services Review, 2004, vol. 32, n. 3, p. 313-319.

17.3.15. CRAMER, Jane. Free online government information: a resource guide. Collection Building, 2002, vol. 21, n. 2, p. 53-59.

17.3.16. DICKSTEIN, R.; GREENFIELD, L.; ROSEN, J. Using the World Wide Web at the reference desk. Computers in Libraries, 1997, vol. 17, n. 8, p. 61-65.

17.3.17. DILLON, Dennis. Internet Reference Sources in the Humanities. The Reference Librarian, 2005, vol. 44, n. 91/92, p. 161-174.

17.3.18. DUVAL, B. K.; MAIN, L. Searching the Internet: part 2 trail-blazers. Library Software Review, 1997, vol. 16, n. 2, p. 89-98.

17.3.19. FERRARI, Roberto C. Researching art(ists) on the Internet. Journal of Library Administration, 2005, vol. 43, n. 3/4, p. 9-25.

17.3.20. FRISCH, Paul A. Popular Web-based reference sources for United States history. Journal of Library Administration, 2005, vol. 43, n. 3/4, p. 65-74.

17.3.21. GOLDERMAN, Gail M.; CONNOLLY, Bruce. Briefcases and Databases: WebBased Reference Sources for Business Librarians and Their Client Communities. The Reference Librarian, 2005, vol. 44, n. 91/92, p. 235-261.

17.3.22. GREENBLATT, Ellen. Exploring LGBTQ online resources. Journal of Library Administration, 2005, vol. 43, n. 3/4, p. 85-101.

17.3.23. GUST, Kara J.; FLYNN, Holly A. Finding your future: college and career information on the Internet. Journal of Library Administration, 2005, vol. 43, n. 3/4, p. 227-245.

17.3.24. GUST, Samantha J. Librarian-recommended sites. Internet reference services quarterly, 2003, vol. 8, n. 1-2, p. 195-200.

17.3.25. HERNANDEZ, M. N.; TALLMAN, K. D. Using the World Wide Web for art and humanities reference services. Internet Reference Services Quarterly, 1998, vol. 3, n. 4, p. 21-33.

17.3.26. HERNANDEZ, Mary N.; TALLMAN, Karen Dalziel. Untangling the Web: Using the World Wide Web for Art and Humanities Reference Services. Untangling the Web, 1996.

17.3.27. HSIEH-YEE, I. The retrieval power of selected search engines: how well do they address general reference questions and subject questions? The Reference Librarian, 1998 , n. 60, p. 27-47. 
17.3.28. HUNDIE, Kebede. A guide to selected and freely searchable bibliographic and full-text databases on the Web. Collection Building, 2002, vol. 21, n. 1, p. 13-21.

17.3.29. ISAACSON, David. New Word Sources: A Selective Annotated Bibliography. Reference Services Review, 1997, vol. 25, n. 2, p. 53-64.

17.3.30. JACSÓ, Péter. Browsing indexes of cited references. Online Information Review, 2005, vol. 29, n. 1, p. 107-112.

17.3.31. JACSÓ, Péter. Google Scholar: the pros and the cons. Online Information Review, 2005, vol. 29, n. 2, p. 208-214.

17.3.32. JACSÓ, Péter. Open access ready reference suites. Online Information Review, 2006, vol. 30, n. 6, p. 737-743.

17.3.33. JONES, Reinette F. Creating a Web resource: African American Kentuckian profiles. Journal of Library Administration, 2005, vol. 43, n. 3/4, p. 149-159.

17.3.34. KANEMUNE, Susumu. Digital reference services: Wikipedia as a digital reference tool. Journal of Information Science and Technology Association, 2006, vol. 56, n. 3, p. 10-107.

17.3.35. KEERAN, Peggy. Humanities Reference Librarians in the Electronic Age. The Reference Librarian, 2001, n. 72, p. 123-136.

17.3.36. KESSELMAN, Martin; WATSTEIN, Sarah Barbara. Google Scholar and libraries: point/counterpoint. Reference Services Review, 2005, vol. 33, n. 4, p. 380-387.

17.3.37. KLOPFER, Lisa. Internet reference sources for Asian Studies. Journal of Library Administration, 2005, vol. 43, n. 3/4, p. 119-128.

17.3.38. KOTTER, Wade R. Evolving Internet reference in anthropology: what our patrons want and how we can help them find it. Journal of Library Administration, 2005, vol. 43, n. $3 / 4$, p. $75-83$.

17.3.39. MACHALOW, R. Government information on the Web. The Reference Librarian, 2001, n. 74, p. 165-175.

17.3.40. MARTín VEGA, Arturo. La colección de referencia. Boletín de la Asociación Andaluza de Bibliotecarios, 1997, n. 48, p. 49-85.

17.3.41. MCCALLIPS, Cheryl. Eldercare and caregivers: building a basic collection. Reference and User Services Quarterly, 2006, vol. 45, n. 3, p. 190-199.

17.3.42. MCDERMOTT, I. E. Homework help on the Web. Searcher, 2002, vol. 10, n. 4, p. 10.

17.3.43. MCMILLAN, Gary A. Medical Reference Sources on the Internet: An Evolving Information Forum and Marketplace. The Reference Librarian, 2005, vol. 44, n. 91/92, p. 197-209.

17.3.44. MERLO VEGA, José Antonio. Colecciones de referencia en línea. Educación y Biblioteca, 2001, vol. 13, n. 122.

17.3.45. MERLO VEGA, José Antonio; SORLI ROJO, Angela. Directorios de fuentes de información y referencia en Internet. Revista española de documentación científica, 1999, vol. 23, n. 3.

17.3.46. MINKEL, W. Searching for kid's sites. Library Journal, 2002, vol. Net, p. 30-31. 
17.3.47. MIZZY, Danianne; MAHONEY, Elizabeth Tillapaugh. Stocking the Virtual Ready Reference Collection . The Reference Librarian, 2002, vol. 38, n. 79-80, p. 67-99.

17.3.48. MOLLOY, Molly. The Internet in Latin America: development and reference sources. Journal of Library Administration, 2005, vol. 43, n. 3/4, p. 129-147.

17.3.49. MORSE, Lori. 100 best free reference websites: a selected list. The Reference Librarian, 2005, vol. 44, n. 91/92, p. 279-295.

17.3.50. MUDROCK, T. Revising ready reference sites: listening to users through server statistics and query logs. Reference and User Services Quarterly, 2002, vol. 42, n. 2, p. $155-163$.

17.3.51. NOËL, É. Sélectionner des sites Internet. Bulletin des Bibliothèques de France, 2001 , vol. 46, n. 1, p. 96-104.

17.3.52. NOTESS, G. R. Internet ready reference resources. Database, 1996, vol. 19, n. 2, p. 88-91.

17.3.53. PAGLIERO POPP, Mary; FAZLE KABIR, A. F. M.; PAGLIERO POPP, M. CDROM sources in the reference collection: issues of access and maintenance. The Reference Librarian, 1990, n. 29, p. 77-91.

17.3.54. PORARINSDOTTIR, P. T. Netid sem heimild $=$ The Internet as a reference source. Bokasafnid, 1999, n. 23, p. 4-6.

17.3.55. QUINN, Brian. Web-Based Reference Resources for the Social Sciences. The Reference Librarian, 2005, vol. 44, n. 91/92, p. 211-234.

17.3.56. RAMPEY, L. C. Use it! Usenet as a reference tool. College and Research Libraries News, 1996, vol. 57, n. 5, p. 294-296.

17.3.57. RICHEY, Debora; KRATZERT, Mona. I too dislike it: the evolving presence of poetry on the Internet. Journal of Library Administration, 2005, vol. 43, n. 3/4, p. 41-54.

17.3.58. RIGGS, Colby. New Technologies: A New Reference Search Service and a Couple of Web Browsers. Library Hi Tech News, 2005, vol. 22, n. 3, p. 15-17.

17.3.59. ROBBIO, Antonella De. Online Resources for Mathematics in the Scientific Virtual Reference Desk. Libraries Webzine , 2001, n. 3.

17.3.60. ROY, Loriene; HALLMARK, Beth; TRAVISS, Amanda. WebJunction.org: where minds meet to support public access computing. The Electronic Library, 2004, vol. 22, n. 4.

17.3.61. RUSA, Machine-Assisted Reference Section. Best free reference Web sites: eighth annual list. Reference and User Services Quarterly, 2006, vol. 46, n. 1, p. 3439.

17.3.62. SIMS, Lee. Academic law library web sites: a source of service to the pro se user. Legal Reference Services Quarterly, 2004, vol. 23, n. 4, p. 1-28 .

17.3.63. SMITH, C. Brian. In search of blessed bots. Library Journal, 2002, vol. Net, p. 3435.

17.3.64. SMITH, J. C. Using the Web to answer legal reference questions. Public Services Quarterly, 2002, vol. 1, n. 1, p. 65-70.

17.3.65. SOWARDS, Steven W. Structures and Choices for Ready Reference Web Sites. The Reference Librarian, 2005, vol. 44, n. 91/92, p. 117-138. 
17.3.66. SPENCER, Brett. Harnessing the Deep Web: a practical plan for locating free specialty databases on the web. Reference Services Review, 2007, vol. 35, n. 1, p. 71-83.

17.3.67. STEWART, Lou Ann. Choosing Between Print and Electronic Resources: The Selection Dilemma. The Reference Librarian, 2000, vol. 34, n. 71, p. 79-97.

17.3.68. TORRES RAMÍREZ, Isabel de. Las fuentes de información: metodología del repertorio bibliográfico. En López Yepes, José (coor.). Manual de Ciencias de la Documentación. Madrid: Pirámide, 2002, p. 317-336.

17.3.69. VAN EPPS, Amy S. The evolution of electronic reference sources. Library Hi Tech, 2005, vol. 23, n. 2, p. 287-298.

17.3.70. VILENO, Luigina. From paper to electronic, the evolution of pathfinders: a review of the literature. Reference Services Review, 2007, vol. 35, n. 3, p. 434-451.

17.3.71. WEBER, Linda. Internet Reference Sources in Education. The Reference Librarian, 2005, vol. 44, n. 91/92, p. 263-277. 


\section{Referencia digital: recursos bibliográficos}

Como no podría ser de otra manera, en este apartado se encuentra el grueso de las referencias bibliográficas de interés en esta tesis doctoral. Se ha intentando conseguir un repertorio exhaustivo de la producción científica sobre servicios y sistemas de referencia digital en bibliotecas. Para ello, se han consultado numerosas fuentes de información, analizado otras bibliografías y revisado un importante número de documentos. Las relaciones de documentos de este capítulo corresponden a las referencias de aquellos artículos directamente vinculados con los procedimientos empleados por las bibliotecas para ofrecer de forma telemática servicios de información.

La relación inicial de artículos recopilados fue menguando en función de diversos criterios, como la pertinencia de su contenido, la facilidad de acceso o consulta del mismo y la lengua en la que se han publicado. Así, se eliminaron referencias que, si bien se era consciente de la afinidad de sus textos, no fue posible encontrar un sistema de traducción o un resumen en otra lengua. Así, se han eliminado referencias en japonés, polaco o ruso, por ejemplo. No obstante, se han mantenido algunas en idiomas menos comunes, ya que se ha podido conocer su contenido, ya sea con la ayuda de traductores o con elementos informativos, como los resúmenes. Por este motivo, se podrán encontrar un pequeño grupo de referencias en croata, húngaro, finlandés, danés o islandés. No obstante, como se mostró en la parte inicial de esta investigación, el porcentaje más elevado de las referencias está en inglés $y$, de igual forma, las principales revistas recogidas están accesibles en las principales bibliotecas y en los servicios de acceso al documento más empleados.

En esta ocasión se ha querido establecer una mayor subdivisión entre los documentos contenidos en este bloque temático, para poder trabajar de forma más ágil con la bibliografía y para facilitar su consulta. Se han hecho siete subgrupos, en los que se han clasificado todos los documentos de esta sección, aunque en algunos casos se han dado dos subcategorías, ya que el documento presentaba claramente dos enfoques en los que ser sistematizado. Esto ha ocurrido, por ejemplo, en las experiencias de evaluación de servicios digitales concretos, que han sido catalogados dentro del grupo 2 y del 6 o 7, dependiendo del tipo de servicio. También ha ocurrido en los documentos teóricos, que ofrecían una perspectiva conceptualizadora, por tanto, asignable al grupo, junto a otras más relacionadas con procesos, sistemas o servicios.

En los siguientes párrafos se describirán los contenidos que se pueden encontrar en estos siete subgrupos, teniendo en cuenta que algunos documentos pueden pertenecer a dos categorías diferentes, aunque también pueden estar recogidos en una categoría de este bloque y en otra de algunos de los dos grandes bloques temáticos anteriores. En estos casos, la 
referencia aparecerá duplicada, con la intención de facilitar la consulta simultánea de los documentos afines a cada grupo.

En definitiva, las categorías de este tercer y último bloque, el más importante y específico sobre servicios de referencia digital, tratan los siguientes temas:

1. Manuales y bibliografía esencial sobre referencia digital: documentos monográficos sobre cualquier aspecto de la referencia digital; colecciones de escritos y actas de congresos; informes y textos amplios en los que se asienten las bases de la referencia digital.

2. Evaluación de la referencia digital: metodología para la evaluación de servicios de referencia digital; experiencias de evaluación llevadas a cabo en los servicios de información telemáticos de bibliotecas y redes cooperativas de referencia en línea.

3. Conceptualización de la referencia digital: artículos de publicaciones periódicas y comunicaciones de congresos 0 reuniones científicas en las que se ofrezca teoría sobre la referencia digital o se presenten estos servicios desde una perspectiva eminentemente teórica.

4. Procesos de la referencia digital: documentos que tratan de aspectos como la entrevista de referencia, la política de los servicios de información digital, las competencias profesionales del personal referencista y la cooperación en la prestación de servicios de información por medios telemáticos.

5. Sistemas de referencia digital: textos relativos de forma prioritaria a los aspectos tecnológicos de la referencia digital; sistemas telemáticos empleados para el intercambio de preguntas y respuestas; servicios de Internet hábiles para la referencia; aplicaciones informáticas empleadas en la referencia digital.

6. Servicios públicos de referencia digital: documentos sobre servicios ofrecidos por bibliotecas públicas y entidades bibliotecarias pertenecientes a los diferentes niveles de la administración; servicios de referencia abiertos a todos los ciudadanos.

7. Servicios especializados de referencia digital: documentos sobre servicios de información ofrecidos por universidades, organismos especializados o cualquier centro que no sean bibliotecas públicas; referencia telemática en universidades. 


\subsection{Manuales y bibliografía esencial sobre referencia digital}

18.1.1. ANDERSON, Byron; WEBB, Paul T. (eds.). New directions in reference. Binghamton, NY: The Haworth Information Press, 2006.

18.1.2. BERNET, B. Developing an Internet-based reference service. En Ensor, Pat (ed.). The Cybrarian's Manual 2. Chicago: American Library Association, 2000, p. 159169.

18.1.3. BRADLEY, Phil. How to Use Web 2.0 in Your Library. London: Facet, 2007.

18.1.4. CASSELL, Kay Ann. Developing reference collections and services in an electronic age: A how-t-do-it manual for librarians. New York: Neal-Schuman, 1999.

18.1.5. COFFMAN, Steve. Going live: Starting and running a virtual reference service. Chicago: American Library Association, 2003.

18.1.6. IFLA, Reference and Information Services Section. IFLA Digital Reference Guidelines. The Hague: IFLA, 2004.

18.1.7. IFLA. Recomendaciones para el servicio de referencia digital. Madrid: ANABAD, 2004.

18.1.8. JANES, Joseph. Introduction to reference work in the digital age. New York: Neal-Schuman, 2003.

18.1.9. JING, Guo; WEI, Pan; QIAOYING, Zheng; MIN, Huang; ZONGYING, Yang; YING, Ye. Design an ideal Digital Reference Service (DRS): model for academic libraries . En Digital Libraries: International Collaboration and Cross-Fertilization. Berlin: Springer , 2004, p. 668-669.

18.1.10. KATZ, William A. (ed.). Digital Reference Services. Binghamton, NY: The Haworth Information Press, 2004.

18.1.11. KIMMEL, Stacey; HEISE, Jennifer (eds.). Virtual reference services: Issues and trends. Binghamton, NY: The Haworth Information Press , 2003.

18.1.12. KOVACS, Diane K. The virtual reference handbook: interview and information delivery techniques for the chat and e-mail environments. London: Facet, 2007.

18.1.13. LANKES, R. David; ABELS, Eileen; WHITE, Marilyn; HAQUE, Saira N. (eds.). The virtual reference desk: creating a reference future. London: Facet, 2006.

18.1.14. LANKES, R. David; COLLINS, John W.; KASOWITZ, Abby S. (eds.). Digital reference service in the new millennium: planning, management, and evaluation. New York, London: Neal-Schuman, 2000.

18.1.15. LANKES, R. David; JANES, Joseph; SMITH, Linda C.; FINNERAN, Christina M. (eds.). The virtual reference experience: integrating theory into practice. New York: Neal-Schuman, 2004.

18.1.16. LANKES, R. David; KASOWITZ, Abby S. The AskA starter kit: How to build and maintain digital reference services. Syaracuse, New York: Syracuse University, 1998.

18.1.17. LANKES, R. David; MCCLURE, Charles R.; GROSS, Melissa; POMERANTZ, Jeffrey (eds.). Implementing digital reference services: setting standards and making it real. New York: Neal-Schuman, 2003.

18.1.18. LANKES, R. David; NICHOLSON, Scott; RADFORD, Marie L.; WESTBROOK, 
Lynn; SILVERSTEIN, Joanne L.; NAST, Philip (eds.). Virtual reference service: From competencies to assessment. New York: Neal-Schuman, 2007.

18.1.19. LIPOW, Anne Grodzins. The Virtual Reference Librarian's Handbook. New York: Neal-Schuman, 2003.

18.1.20. MCMENEMY, David; POULTER, Alan. Delivering Digital Services: A Handbook for Public Libraries and Learning Centres. London: Facet, 2005.

18.1.21. MEOLA, Marc; STORMONT, Sam. Starting and Operating Live Virtual Reference Services: A How-to-Do-It Manual for Librarians. New York: Neal-Schuman, 2002.

18.1.22. PANTRY, Sheila. Creating a successful e-information service . London: Facet, 2002.

18.1.23. REFERENCE AND USER SERVICES ASSOCIATION. Virtually yours: models for managing electronic resources and services: proceedings of the Joint Reference and User Services Association and Association for Library Collections and Technical Services Institute, Chicago, Illinois, October 23-25, 1997. Chicago: American Library Association, 1999.

18.1.24. RODRÍGUEZ BRIZ, Fernanda. Los servicios de referencia virtual: surgimiento, desarrollo y perspectivas a futuro. Buenos Aires: Alfagrama, 2005.

18.1.25. RONAN, Jana Smith. Chat reference: a guide to live virtual reference services. Westport, Conn.: Libraries Unlimited, 2003.

18.1.26. VIRTUAL REFERENCE DESK (1. CAMBRIDGE. 1999). Reference in the New Millenium: Virtual Reference Desk: Digital Reference Conference 1999. Seattle; Dublin: Web Junction, 1999.

18.1.27. VIRTUAL REFERENCE DESK (2. SEATTLE. 2000). Facets on digital reference: The Virtual Reference Desk: 2nd Annual Digital Reference Conference. Seattle; Dublin: Web Junction, 2000.

18.1.28. VIRTUAL REFERENCE DESK (3. ORLANDO. 2001). Setting standards and making it real: 3rd VRD Conference. Seattle; Dublin: Web Junction, 2001.

18.1.29. VIRTUAL REFERENCE DESK (4. CHICAGO. 2002). Charting the course for reference roundup: toward a preferred future: Virtual Reference Desk Conference . Seattle; Dublin: Web Junction, 2002.

18.1.30. VIRTUAL REFERENCE DESK (5. SAN ANTONIO. 2003). The reference roundup: Annual Virtual Reference Desk Conference . Seattle; Dublin: Web Junction, 2003.

18.1.31. VIRTUAL REFERENCE DESK (6. CINCINNATI. 2004). Creating a reference future: Annual Virtual Reference Desk Conference . Seattle; Dublin: Web Junction, 2004.

18.1.32. VIRTUAL REFERENCE DESK (7. SAN FRANCISCO. 2005). Annual Virtual Reference Desk Conference. Seattle; Dublin: Web Junction, 2005.

18.1.33. WEST, Jessamyn (ed.). Digital versus non-digital reference: ask a librarian online and offline. Binghamton, NY: The Haworth Information Press, 2004.

18.1.34. WOOD, M. Sandra. Medical Librarian 2.0: Use of Web 2.0 Technologies in Reference Services. Binghamton: The Haworth Press, 2007. 


\subsection{Evaluación de la referencia digital}

18.2.1. AENOR. UNE-ISO/TR 20983 IN: Información y documentación: Indicadores para los servicios bibliotecarios electrónicos (ISO/TR 20983:2003). Madrid: AENOR, 2006.

18.2.2. AYUSO GARCÍA, María Dolores; PEÑALVER MARTÍNEZ, Ángel; MARTÍNEZ NAVARRO, Victoria. Evaluación de fuentes de información para servicios de referencia en Internet. Una propuesta a partir de Pregunte, las bibliotecas responden: La biblioteca pública: portal de la sociedad de la información. En Congreso Nacional de Bibliotecas Públicas (1. 2002. Valencia). Madrid: Ministerio de Educación, Cultura y Deporte, 2002, p. 13-25 . Disponible en http://travesia.mcu.es/documentos/actas/com_013.pdf [consultado el 17/07/2007].

18.2.3. BENNETT, A. B; KASOWITZ, a.; LANKES, R. D. Digital reference quality criteria. En Lankes, R. D.; COLLINS III, J. W.; KASOWITZ, A. S. (eds.). Digital Reference Service in the New Millennium: Planning, Management, and Evaluation. New York: Neal-Schuman, 2000, p. 69-80.

18.2.4. CORNWELL, Gary; REAKES, Patrick; RONAN, Jana. Evaluating online real-time reference in an academic library: obstacles and recommendations. The Reference Librarian, 2002-2003, vol. 38, n. 79/80, p. 225-240.

18.2.5. DE GROOTE, Sandra L. Questions asked at the virtual and physical health sciences reference desk: how do they compare and what do they tell us? Medical reference services quarterly, 2005, vol. 24, n. 2, p. 11-23.

18.2.6. DOLENCE, Travis; GILMOUR, Ron. Libraries, Information, and Amateur Scientists. Technical Services Quaterly, 2006, vol. 23, n. 3.

18.2.7. DURCAN, A. A Reference Library Talks to its Users. European Journal of Marketing, 1984, vol. 18, n. 2, p. 65-71.

18.2.8. FLANAGAN, Patricia A.; HELMAN, Deborah L.; HOROWITZ, Lisa R. The viability of live online reference: an assessment. Portal: Libraries and the Academy, 2005, vol. 5, n. 2, p. 239-258.

18.2.9. GILBERT, Lauren Miranda; MENGXIONG, Liu; MATOUSH, Toby; WHITLATCH, Jo Bell. Assessing Digital Reference and Online Instructional Services in an Integrated Public/University Library. The Reference Librarian, 2006, vol. 46, n. 95, p. 149-172.

18.2.10. GRANFIELD, Diane. Getting help and doing research: what do patrons want? An exploratory study comparing desk users with virtual reference users. En Flaten, Trine Kolderup (ed.). Management, marketing and promotion of library services based on statistics, analyses and evaluation. München: K.G. Saur, 2006, p. 246-256.

18.2.11. GUISE, Janneka L. Toward a template for systematic reference and instruction programme analysis. New Library World, 2005, vol. 106, n. 1/2, p. 29-42.

18.2.12. HENDRICKS, Arthur. A cost-effective virtual reference service: are users satisfied? Journal of Library and Information Science, 2005, vol. 31, n. 1, p. 79-86.

18.2.13. HILL, J. B.; MADARASH-HILL, Cherie; ALLRED, Alison. Outsourcing Digital Reference: The User Perspective. The Reference Librarian, 2007, vol. 47, n. 98, p. 57-74.

18.2.14. HILL, J. B.; MADARASH-HILL, Cherie; BICH, Ngoc Pham Thi. Digital Reference Evaluation: Assessing the Past to Plan for the Future . Electronic Journal of Academic and Special Librarianship, 2003, vol. 4, n. 2-3. 
18.2.15. HIRKO, Buff. VET: The Virtual Evaluation Toolkit. The Reference Librarian, 2006, vol. 46, n. 95/96, p. 125-148.

18.2.16. HODGES, Ruth A. Assessing digital reference. Libri: International Journal of Libraries and Information Services, 2002, vol. 52, n. 3, p. 157-168.

18.2.17. HOULSON, Van; MCCREADY, Kate; STEINBERG PFAHL, Carla. A window into our patron's needs: analyzing data from chat transcripts. Internet Reference Services Quarterly, 2006 , vol. 11, n. 4, p. 19-39.

18.2.18. HYDE, Loree; TUCKER-RAYMOND, Caleb. Benchmarking Librarian Performance in Chat Reference. The Reference Librarian, 2006, vol. 46, n. 95/96, p. 5-19.

18.2.19. JERMEY, Jonathan. Enquire within on everything: getting questions answered on the Internet . Online Currents, 2003, vol. 18, n. 2, p. 1-6.

18.2.20. JIA, Liu. The evaluation of worldwide digital reference services in libraries. Oxford: Chandos Publishing, 2007.

18.2.21. JIA, Liu. Is the collaborative service always superior to the single library service? A project for evaluating the chat reference services in USA. Bibliothek Forschung und Praxis, 2006, vol. 30, n. 3, p. 353-366.

18.2.22. KASOWITZ, Abby; BENNETT, Blythe; LANKES, R. David. Quality standards for digital reference consortia. Reference and User Services Quarterly, 2000, vol. 39, n. 4.

18.2.23. KAWAKAMI, Alice; SWARTZ, Pauline. Digital reference: training and assessment for service improvement. Reference Services Review, 2003, vol. 31, n. 3, p. 227-236.

18.2.24. KERN, M. Kathleen. Looking at the bigger picture: An integrated approach to evaluation of chat reference services. The Reference Librarian, 2006, vol. 46, n. 95/96, p. 99-112.

18.2.25. KLOSS, Louise; ZHANG, Yin. An evaluative case study of a real-time online reference service. The Electronic Library, 2003, vol. 21, n. 6, p. 565-575.

18.2.26. KWON, Nahyun. User satisfaction with referrals at a collaborative virtual reference service. Information Research, 2006, vol. 11, n. 2.

18.2.27. LANKES, R; MCCLURE, Charles R; GROSS, Melissa; AVERSA, Elizabeth; MANLEY, Cynthia. Assessing quality in digital reference services. En Annual Meeting of the American Society for Information Science and Technology (64. 2001. Washington). Silver Spring, Maryland: ASIST, 2001, p. 323-329.

18.2.28. LANKES, R. David; GROSS, Melissa; MCCLURE, Charles R. Cost, statistics, measures, and standards for digital reference services: A preliminary view. Library trends, 2003, vol. 51, n. 3, p. 401-413.

18.2.29. LANKES, R. David; NICHOLSON, Scott; RADFORD, Marie L.; WESTBROOK, Lynn; SILVERSTEIN, Joanne L.; NAST, Philip (eds.). Virtual reference service: From competencies to assessment. New York: Neal-Schuman, 2007.

18.2.30. MCCLURE, Charles R.; LANKES, R. David; GROSS, Melissa; CHOLTCODEVLIN, Beverly. Statistics, Measures and Quality Standards for Assessing Digital Reference Library Services: Guidelines and Procedures. Syracuse, New York ; Tallahassee, Florida: Information Institute of Syracuse; School of Information Studies, 2002. 
18.2.31. MCCREA, Richard. Evaluation of two library-based and one expert reference service on the Web. Library Review, 2004, vol. 53, n. 1, p. 11-16.

18.2.32. MCGRAW, Kathleen A.; HEILAND, Jennifer; HARRIS, Julianna C. Promotion and evaluation of a virtual live reference service. Medical Reference Services Quarterly, 2003, vol. 22, n. 2, p. 41-56.

18.2.33. MON, Lorri; JANES, Joseph. The Thank You Study: Research on User Satisfaction with Digital Reference Services . Annual Digital Reference Conference, 2003, n. 5.

18.2.34. MON, Lorri; JANES, Joseph W. The Thank You Study. Reference and User Services Quarterly, 2007, vol. 46, n. 4, p. 53-59.

18.2.35. MOYO, Lesley M. Virtual Reference Services and Instruction: An Assessment. The Reference Librarian, 2006, vol. 46, n. 95/96, p. 213-230.

18.2.36. NILSEN, Kirsti. The Library Visit Study: user experiences at the virtual reference desk. Information Research, 2004, vol. 9, n. 2.

18.2.37. NILSEN, Kirsti; ROSS, Catherine Sheldrick. Evaluating Virtual Reference from the Users' Perspective. The Reference Librarian, 2006, vol. 46, n. 95/96, p. 53-79.

18.2.38. NOVOTNY, Eric (ed.). Assessing reference and user services in a digital age. Binghamton, NY: The Haworth Information Press, 2006.

18.2.39. NOVOTNY, Eric. Developing meaningful measures for electronic reference services. Northumbria International Conference on Performance Measurement in Libraries \& Information Services, 2002, vol. 4.

18.2.40. PERRY, Leanne; MCELHILL, Maggie. So, what's the difference: an evaluation of the AskNow! live reference service. En Information Online Conference (13. 2007. Sydney). Sydney: ALIA, 2007. Disponible en http://www.sl.nsw.gov.au/staff/pdfs/asknow_paper.pdf [consultado el 17/07/2007].

18.2.41. PETERS, T. A. Current opportunities for the effective meta-assessment of online reference services. Library Trends, 2000 , vol. 49, n. 2, p. 334-349.

18.2.42. POMERANTZ, Jeffrey. Factors influencing digital reference triage: a think-aloud study. Library Quarterly, 2004, vol. 74, n. 3, p. 235-264.

18.2.43. POMERANTZ, Jeffrey; LUO, Lili. Motivations and uses: evaluating virtual reference service from the users' perspective. Library and Information Science Research, 2006, vol. 28, n. 3, p. 350-373.

18.2.44. POMERANTZ, Jeffrey; LUO, Lili; MCCLURE, Charles R. Peer review of chat reference transcripts: Approaches and strategies. Library and Information Science Research, 2006, vol. 28, n. 1.

18.2.45. POMERANTZ, Jeffrey; MCCLURE, Charles. Evaluation of a Statewide Collaborative Chat based Reference Service: Approaches and Directions. En Proceedings of the 67th Annual Meeting of the American Society for Information Science and Technology . Medford, NJ: Information Today, 2004, p. 102-109.

18.2.46. POMERANTZ, Jeffrey; NICHOLSON, Scott; BELANGER, Yvonne; LANKES, David R. The current state of digital reference: validation of a general digital reference model through a survey of digital reference services. Information Processing and Management, 2004, vol. 40, n. 2, p. 347-363.

18.2.47. POMERANTZ, Jeffrey; NICHOLSON, Scott; LANKES, R. David. Digital 
Reference Triage: Factors Influencing Question Routing and Assignment. Library Quarterly, 2003, vol. 73, n. 2.

18.2.48. POWELL, Ronald R. Measurement and evaluation of electronic information services. En Gorman, G. E. (ed.). Information services in an electronic environment. London: Facet, 2001, p. 323-342.

18.2.49. PRESTON, L. A. A model for analysis of usage patterns of online databases as reference desk tools. En Thirteenth National Online Meeting. Medford,New Jersey: Learned Information, Inc, 1992, p. 263-273.

18.2.50. PROBST, Laurie; PELIKAN, Michael. Listening to Our Users: System Migration and the Evaluation of Web-Based Library Services. The Reference Librarian, 2006, vol. 46, n. 95/96, p. 37-51.

18.2.51. QAYYUM, M. A. Internet reference services and the reference desk: does the nature of a user's query really change. Internet Reference Services Quarterly, 2002, vol. 7, n. 3, p. 15-22.

18.2.52. RADFORD, Marie. In Synch? Evaluating Chat Reference Transcripts . Annual Digital Reference Conference, 2003, n. 5.

18.2.53. RADFORD, Marie L. Encountering virtual users: a qualitative investigation of interpersonal communication in chat reference. Journal of the American Society for Information Science and Technology, 2006, vol. 57, n. 8, p. 1046-1059.

18.2.54. RADFORD, Marie L.; KERN, M. Kathleen. A multiple-case study investigation of the discontinuation of nine chat reference services. Library and Information Science Research, 2006, vol. 28, n. 4.

18.2.55. RICHARDSON, J. V. Question Master: an evaluation of a Web-based decisionsupport system for use in reference environments. College and Research Libraries, 1998, vol. 59, n. 1, p. 29-37.

18.2.56. RIGBY, Alison; SMITHERS, Amanda. From service to survey: The UNISON Digital Reference Key Performance Indicators Project. En Information Online 2007. 2007: Australia Library and Information Association, 2007. Disponible en http://www.information-online.com.au/docs/Presentations/oncon.pdf [consultado el 17/07/2007].

18.2.57. RIGBY, Alison; ZHANG, Susan; SMITHERS, Amanda. Digital reference: key performance indicators. inCite, 2006, vol. 27, n. 6, p. 7.

18.2.58. ROBINS, David; MILLER, Jonathan. Information Architecture/User Experience Perspective: Design of a Study and Preliminary Results . Annual Digital Reference Conference, 2003, n. 5.

18.2.59. RÖSCH, Herman. Digital reference services: state of the art in the focus of quality. En IFLA General Conference and Council (72. 2006. Seúl). Seúl: IFLA, 2006. Disponible en http://www.ifla.org/IV/ifla72/papers/098-Roesch-en.pdf [consultado el 17/07/2007].

18.2.60. RUPPEL, Margie; FAGAN, Jody Condit. Instant messaging reference: users' evaluation of library chat. Reference Services Review, 2002, vol. 30, n. 3, p. 183-197.

18.2.61. SEARS, J. Chat reference service: an analysis of one semester's data. Issues in Science and Technology Librarianship, 2001, n. 32.

18.2.62. SHACHAF, Pnina; MEHO, Lokman I.; HARA, Noriko. Cross-cultural Analysis of E-mail Reference. The Journal of Academic Librarianship, 2007, vol. 33, n. 2, p. 243- 
253.

18.2.63. SHIMING, Guo. On Quality Evaluation of Digital Referential Consulting Service. Journal of the China Society for Scientific and Technical Information, 2006, vol. 25, n. 3, p. 326-329.

18.2.64. SMYTH, Joanne B.; MACKENZIE, James C. Comparing Virtual Reference Exit Survey Results and Transcript Analysis: A Model for Service Evaluation. Public Services Quarterly, 2006 , vol. 2, n. 2/3, p. 85-99.

18.2.65. SYRKIN, Darby. At the desk or online: reference training, measurements, and guidelines. Public Services Quarterly, 2006, vol. 2, n. 2/3, p. 191-192.

18.2.66. TENOPIR, Carol; ENNIS, Lisa. The digital reference work of academic libraries. Online, 1998, vol. 22, n. 4, p. 22-24.

18.2.67. VANDECREEK, Leanne. E-Mail reference evaluation: using the results of a satisfaction survey. The Reference Librarian, 2006, vol. 45, n. 93, p. 99-108.

18.2.68. WALTER, Virginia A.; MEDIAVILLA, Cindy. Teens are from Neptune, librarians are from Pluto: an analysis of online reference transactions. Library Trends, 2005, vol. 54, n. 2 , p. 209-227.

18.2.69. WARD, David. Measuring the completeness of reference transactions in online chats. Results of an unobtrusive study. Reference and User Services Quarterly, 2004, vol. 44, n. 1, p. 46-56.

18.2.70. WEBSTER, Ruiha; WILLIAMS, Peter. An evaluation of the NHS Direct online health information e-mail enquiry service: Quality of health information on the internet . Aslib Proceedings, 2005, vol. 57, n. 1.

18.2.71. WELCH, Jeanie M. Click and Be Counted: A New Standard for Reference Statistics. The Reference Librarian, 2007, vol. 47, n. 97, p. 95-104.

18.2.72. WHITE, Marilyn Domas. Digital reference services: Framework for analysis and evaluation. Library and Information Science Research, 2001, vol. 23, n. 3, p. 211-231.

18.2.73. WHITE, Marilyn Domas; ABELS, Eileen G.; KASKE, Neal. Evaluation of Chat Reference Service Quality. D-Lib Magazine, 2003, vol. 9, n. 2.

18.2.74. WHITLATCH, Jo Bell. Evaluating Reference Services: A Practical Guide. Chicago: American Library Association, 2000.

18.2.75. XIE, Hong. Evaluation of digital libraries: Criteria and problems from users' perspectives . Library and Information Science Research , 2006, vol. 28, n. 3, p. 433452.

18.2.76. XUE-MING, Bao. A study of Web-based interactive reference services via academic library home pages. Reference and User Services Quarterly, 2003, vol. 42, n. 3 , p. $250-256$. 


\subsection{Conceptualización de la referencia digital}

18.3.1. ACCART, Jean-Philippe. Les services d'information et de référence: l'avenir est virtuel. Arbido, 2005, n. 6, p. 3-4.

18.3.2. ALBANESE, Andrew Richard. Reference 2005: The reference evolution. Library Journal, 2004, vol. 129, p. 10-12.

18.3.3. ALVES, Ana Paula Meneses; VIDOTTI, Silvana Aparecida Borsetti Gregório. O serviço de referência e informação digital. Biblionline, 2006, vol. 2, n. 2.

18.3.4. ALVESTRAND, Viveka. Librarians beat Google in quest for answers. Information World Review, 2003, n. 196, p. 8.

18.3.5. ANDERSON, Charles R. Reference librarianship: a guides for the 21st Century. The Reference Librarian, 2006, vol. 34, n. 72, p. 5-19.

18.3.6. ARELLANO, Miguel Ángel Márdero. Serviços de referência virtual. Ciência da informaçao, 2001, vol. 30, n. 2.

18.3.7. BAILEY-HAINER, Brenda. Virtual reference: alive and well. Library Journal, 2005, vol. 130 , n. 1, p. 46-47.

18.3.8. BAKHOUM, Nafissatou. Services à distance et services de proximité en milieu africain: quels défis pour le bibliothécaire en tant que vecteur de développement ? En IFLA General Conference and Council (68. 2002. Glasgow). Glasgow: IFLA, 2002. Disponible en http://www.ifla.org/IV/ifla68/papers/017-114f.pdf [consultado el 17/07/2007].

18.3.9. BANG, T.; HARBO, K. Winds of change: research libraries. New Library World, 2002, vol. 103, n. 1175/1176, p. 150-155.

18.3.10. BARBIER, Pat; WARD, Joyce. Ensuring quality in a virtual reference environment. Community and Junior College Libraries, 2004, vol. 13, n. 1, p. 55-71.

18.3.11. BEALES, Donna I. Cyber Libraries: building the perfect beast. Medical reference services quarterly, 2002, vol. 21, n. 4, p. 49-56.

18.3.12. BERGER, Sika; CHENG, Rachel J.; HANSEN, Beth; MACFARLANE, Heather; NATHANSON, Alan J. Collaborative digital reference in small academic liberal arts college libraries: Connecticut College, Smith College and Wesleyan University, 20012002. Resource Sharing and Information Networks, 2002, vol. 16, n. 2, p. 169-188.

18.3.13. BERUBE, Linda. Digital Reference Overview. Bath: UKLON, Networked Services Policy Task Group, 2003.

18.3.14. BOSANDIC, Boris. Put k povezivanju: usluga pitajte knjiznicara na mreznim stranicama narodnih knjiznica=Towards achieving co-operation: the ask a librarian service on public libraries' web-sites. Vjesnik Bibliotekara Hrvatske, 2003, vol. 46, n. 34, p. 80-92.

18.3.15. BOSS, Richard W. Virtual Reference. Public Library Association Tech Notes, 2004, n. 30 dec.

18.3.16. BOSSEAU, D. L. Digital reference services: virtual or real? Information Management Report, 2001, vol. Oct, p. 1-4.

18.3.17. BREEDING, M. Providing virtual reference service. Information Today, 2001, vol. 18 , n. 4 , p. $42-43$. 
18.3.18. BUCKLEY, Chad E. Golden rule reference: Face-to-face and virtual. The Reference Librarian, 2006, n. 93, p. 129-136.

18.3.19. CALZONETTI, Jo Ann; DECHAMBEAU, Aimee. Virtual reference: a telecommuting opportunity? Information Outlook, 2003, vol. 7, n. 10, p. 34-36.

18.3.20. CAVALERI, Piero. Servizi personalizzati online della biblioteca. Biblioteche Oggi, 2001, vol. 19, n. 7, p. 70-90.

18.3.21. CHASE, Darren. Papa's got a brand new (virtual) bag: real-time chat and reference discourse. E-JASL: The Electronic Journal of Academic and Special Librarianship, 2005, vol. 6, n. 1-2, p. [n].

18.3.22. CHOWDHURY, Gobinda G. Digital libraries and reference services: present and future. Journal of Documentation, 2002, vol. 58, n. 3, p. 258-283.

18.3.23. CHURCH, Audrey. Your library goes virtual: Promoting Reading and Supporting Research. Library Media Connection, 2006, vol. 25, n. 3, p. 10-13.

18.3.24. CICCONE, Karen. Virtual Reference, Today and Tomorrow. Information Technology and Libraries, 2001, vol. 20, n. 3, p. 120.

18.3.25. CLIFFORD, Christine. Why Couldn't They Find It?: Improving your Website through VR Transactions . En Virtual Reference Desk Conference (5. 2003. San Antonio). Seattle : Web Junction, 2003. Disponible en http://www.webjunction.org [consultado el 17/07/2007].

18.3.26. CLOUGHLEY, Karen. Digital reference services: how do the library-based services compare with the expert services? Library Review, 2004, vol. 53, n. 1, p. 1723.

18.3.27. COON, B.; WOJTOWICZ, R. Electronic reference: trends and considerations. PNLA Quarterly, 2002, vol. 67, n. 1, p. 17-19.

18.3.28. CORTEZ, E.; RICE, R. An investigation into the role of public libraries with online reference service. Public Library Quarterly, 1994, vol. 14, n. 2/3, p. 7-21.

18.3.29. DEE, Cheryl R. Digital reference service: trends in academic health science libraries. Medical reference services quarterly, 2005, vol. 24, n. 1, p. 19-27.

18.3.30. DEVINE, S.; WOODS, D. Internet-based reference services and community libraries: a need for new models and strategies. The Electronic Library, 1996, vol. 14, n. 4 , p. 299-302.

18.3.31. DILEVKO, Juris. An ideological analysis of digital reference service models. Library Trends, 2001, vol. 50, n. 2, p. 218-244.

18.3.32. DONLAN, Rebecca. Decision Points for Going E-Only: Beware the Fallacy of the Single Solution. The Reference Librarian, 2007, vol. 47, n. 97, p. 121-124.

18.3.33. DOUGHERTY, R. M. Reference around the clock: is it in your future? American Libraries, 2002, vol. 33, n. 5, p. 44.

18.3.34. DUNCAN, Vicky; FICHTER, Darlene M. What words and where? Applying usability testing techniques to name a new live reference service. Journal of the Medical Library Association, 2004, vol. 92, n. 2, p. 218-225.

18.3.35. EVANS, A. K. Electronic reference services: mediation for the 1990s. The Reference Librarian, 1992, n. 37, p. 75-86. 
18.3.36. FADELL, Jeff; MEYERS, Judy E. The information machine: a microcomputerbased reference service. The Reference Librarian, 1989, n. 23, p. 75-112.

18.3.37. FENSKE, R.; O'CONNOR, P.; COFFMAN, S.; MCCLURE, C.; SLOAN, B. Virtual Reference: Evolution, Evaluation, Optimizing the Link Between Providers and Users. En Proceedings of the American Society for Information Science and Technology. Silver Spring, Maryland : ASIST, 2002, p. 505-507. Disponible en ISI:000180277800085 [consultado el 17/07/2007].

18.3.38. FERNANDEZ, Joe. Facing live reference. Online, 2004, vol. 28, n. 3, p. 37-40.

18.3.39. FIELDS, Mary Alice; SZYMANSKI, Gerald. Virtual reference in the music library. Notes, 2005, vol. 61, n. 3, p. 634-658.

18.3.40. FORCE, R. Planning online reference services for the 90s. The Reference Librarian, 1994, n. 43, p. 107-115.

18.3.41. GARCÍA DELGADO, Purificación. El servicio de referencia digital. El profesional de la información, 2003, vol. 12, n. 4, p. 320-330.

18.3.42. GRAY, S. M. Virtual reference services: Directions and agendas. Reference and User Services Quarterly, 2000, vol. 39, n. 4, p. 365-375.

18.3.43. HEISE, Jennifer; KIMMEL, Stacey. Reading the river: the state of the art of realtime virtual reference. Internet Reference Services Quarterly, 2003, vol. 8, n. 1/2, p. 17.

18.3.44. HENSON, B.; TOMAJKO, K. G. Electronic reference services: opportunities and challenges. Journal of Educational Media and Library Sciences, 2000, vol. 38, n. 2, p. 113-121.

18.3.45. HIRKO, Buff; ROSS, Mary Bucher. Virtual reference training: the complete guide to providing anytime, anywhere answers. Chicago: American Library Association, 2004.

18.3.46. HOHMANN, L. K. Providing reference services over the Internet. Colorado Libraries, 2000, vol. 26, n. 2, p. 16-18.

18.3.47. HORN, Judy. The future is now: reference services for the electronic era. En Crossing the divide: ACRL Tenth National Conference. Denver: ACRL, 2001, p. 320327.

18.3.48. HOSKISSON, Tam; WENTZ, Deleyne. Simplifying electronic reference: a hybrid approach to one-on-one consultation. College and Undergraduate Libraries, 2001, vol. 8, n. 2, p. 89-102.

18.3.49. HOUGHTON, Sarah. Virtual Reference @ Your Library. Knowledge Quest, 2005, vol. 33, n. 3.

18.3.50. JACKSON, Michael G. A rush to serve: Digital reference services and the commitment to 24/7 . Advances In Librarianship, 2002, vol. Volume 26 , p. 299-317.

18.3.51. JACSÓ, Péter. Virtual Reference Service and Disservice. Computers in libraries, 2003, vol. 23, n. 4.

18.3.52. JAGMAN, H. An introduction to the next steps in online reference services. Public Services Quarterly, 2002, vol. 1, n. 2, p. 5-13.

18.3.53. JANE, Catherine; MCMILLAN, Dawn. Online in real-time? Deciding whether to offer a real-time virtual reference service: Winds of change: libraries in the twenty-firt 
century. The Electronic Library, 2003, vol. 21, n. 3, p. 240-246.

18.3.54. JANES, Joe. Live reference: too much, too fast? Library Journal Net Connect, 2002, p. 12-14.

18.3.55. JANES, Joseph. What is reference for? Reference Services Review, 2003, vol. 31, n. 1, p. $22-25$.

18.3.56. JANES, Joseph; CARTER, David; MEMMOTT, Patricia. Digital reference services in academic libraries. Reference and User Services Quarterly, 1999, vol. 39, n. 2, p. $145-150$.

18.3.57. JIA, Peijun. Distance referencing: real-time conference tools. Community and Junior College Libraries, 2003, vol. 11, n. 3, p. 35-41.

18.3.58. JIN, Yi; HUANG, Min; LIN, Haoming; GUO, Jing. Study on the collaboration mechanism of the virtual reference service. The Electronic Library, 2007, vol. 25, n. 6, p. 733-740.

18.3.59. KATZ, Bill. Digital reference: an overview. The Reference Librarian, 2002-2003, vol. 38, n. $79 / 80$, p. 1-17.

18.3.60. KAWAKAMI, Alice K. Delivering digital reference. Library Journal, 2002, vol. Net, p. 28-29.

18.3.61. KENNEY, Brian. An LJ Round Table Live, Digital Reference: A close look at libraries' exciting new service. Library Journal, 2002, vol. 127 , n. 16, p. 46.

18.3.62. KHAN, Asad. Digital/virtual reference services in libraries: an Internet based reference service. Pakistan Library \& Information Science Journal, 2006, vol. 37, n. 1, p. 13-18.

18.3.63. KIBBEE, Jo. Librarians without Borders? Virtual Reference Service to Unaffiliated Users. The Journal of Academic Librarianship, 2006, vol. 32, n. 5, p. 467-473.

18.3.64. KRESH, Diane. Virtually yours: thoughts on where we have been and where we are going with virtual reference services in libraries. The Reference Librarian, 20022003, vol. 38, n. 79/80, p. 19-34.

18.3.65. KRESH, Diane Nester. From Sshh to Search Engine: Reference.net on the World Wide Web . Information technology and libraries, 2001, vol. 20, n. 3, p. 139142.

18.3.66. LAGUARDIA, Cheryl. The future of reference: get real! Reference Services Review, 2003, vol. 31, n. 1, p. 39-42.

18.3.67. LANKES, R. D. Digital Reference Research - Fusing Research and Practice. Reference and User Services Quarterly, 2005, vol. 44, n. 4, p. 320-326.

18.3.68. LANKES, R. D.; NICHOLSON, S.; GOODRUM, A. (eds.). The Digital Reference Research Agenda. Chicago: Association of College and Research Libraries, 2003.

18.3.69. LANKES, R. David. Current State of Digital Reference in Primary and Secondary Education. D-Lib Magazine, 2003, vol. 9, n. 2.

18.3.70. LANKES, R. David. The digital reference fallacy. The Reference Librarian, 20022003, vol. 38, n. 79/80, p. 35-44.

18.3.71. LANKES, R. David. The digital reference research agenda. Journal of the American Society for Information Science and Technology, 2004, vol. 55, n. 4, p. 301- 
311.

18.3.72. LANKES, R. David. Impact and Opportunity of Digital Reference in Primary and Secondary Education. En Digital Reference Research Symposium. Cambridge, Massachusetts: Digital Reference Research Symposium, 2002.

18.3.73. LANKES, R. David. The Roles of Digital Reference in a Digital Library Environment. En International Conference of Digital Library-Advance the Efficiency of Knowledge Utilization. Beijing, China: ICDL, 2004. Disponible en http://data.webjunction.org/wj/documents/11895.pdf [consultado el 17/07/2007].

18.3.74. LANKES, R. David; SHOSTACK, Pauline. The necessity of real-time: fact and fiction in digital reference systems. Reference and User Services Quarterly, 2002, vol. 41, n. 4, p. 350-355.

18.3.75. LANKES, R. David; SILVERSTEIN, Joanne. The Birth Cries of Digital Reference. Reference and User Services Quarterly, 2000, vol. 39, n. 4.

18.3.76. LAUER, Jonathan D.; MCKINZIE, Steve. Bad Moon Rising: A Candid Examination of Digital Reference and What It Means to the Profession. The Reference Librarian, 2002-2003, vol. 38, n. 79-80, p. 45-56.

18.3.77. LAVENDER, Kenneth; NICHOLSON, Scott; POMERANTZ, Jeffrey. Building bridges for collaborative digital reference between libraries and museums through an examination of reference in special collections. The Journal of Academic Librarianship, 2005, vol. 31, n. 2, p. 106-118.

18.3.78. LÉTOURNEAU, Alain. La référence virtuelle. Documentation et bibliothèques, 2003, vol. 49, n. 1, p. 41-43.

18.3.79. LILFENG, Han; GOLUDING, Anne. Information and reference services in the digital library. Information services and use, 2003, vol. 23, n. 4, p. 251-262.

18.3.80. LINDBLOOM, Mary-Carol; YACKLE, Anna; BURHANS, Skip; PETERS, Tom; BELL, Lori. Virtual Reference: A Reference Question Is a Reference Question? Or Is Virtual Reference a New Reality? New Career Opportunities for Librarians. The Reference Librarian, 2006, vol. 45, n. 93, p. 3-22.

18.3.81. LOINTIER, Cecile. La référence virtuelle: definition, typologie et normes. Argus, 2004, vol. 33, n. 1.

18.3.82. LUDTKE, H. Taking the reference desk to cyberspace. Buch und Bibliothek, 2001, vol. 53, n. 9, p. 544-552.

18.3.83. LUPIEN, Pascal. La reference virtuelle en temps reel: avantages et defis. Argus, 2004, vol. 33, n. 1 .

18.3.84. MANSO RODRÍGUEZ, Ramón Alberto; LORENZO RODRÍGUEZ, Marilyn; ANTÓN YEBRA, Ángel Ernesto. El servicio de referencia en el entorno digital. En Info: Congreso Internacional de Información. La Habana: Info, 2004. Disponible en http://www.congreso-info.cu/UserFiles/File/Info/Info2004/Ponencias/187.pdf [consultado el 17/07/2007].

18.3.85. MARKGREN, Susanne. Digital Reference Services Bibliography. Public Services Quarterly, 2006, vol. 2, n. 2/3, p. 194-195.

18.3.86. MARSTELLER, Matthew R.; SCHMITT-MARSTELLER, Jackie. Opportunities for real-time digital reference service. The Reference Librarian, 2002, vol. 38, n. 79/80, p. 163-181. 
18.3.87. MARVIN, Stephen. Discovering corporate virtual reference services. Information Outlook, 2003, vol. 7, n. 9, p. 20-22.

18.3.88. MAXWELL, D. Jackson. Digital versus print: The current state of reference affairs in school Libraries. The Reference Librarian, 2005, vol. 44, n. 91/92, p. 53-68.

18.3.89. MAXYMUK, J. The investment in providing virtual reference: what sources are available? Bottom Line, 2002, vol. 15, n. 2, p. 79-83.

18.3.90. MCCLENNEN, M.; MEMMOTT, P. Roles in digital reference. Information Technology and Libraries, 2001, vol. 20, n. 3, p. 143-148.

18.3.91. MCDERMOTT, I. E. Virtual reference for a real public. Searcher, 1998, vol. 6, n. 4, p. 25-31.

18.3.92. MCGRANAHAN, Jamen. Virtual reference. Library Mosaics, 2005, vol. 16, n. 1, p. 16.

18.3.93. MCKINZIE, Steve; LAUER, Jonathan D. Digital reference: a new library paradigm or the emperor's new clothes. Against the Grain, 2002, vol. 14, n. 4, p. 34-38.

18.3.94. MCKINZIE, Steve; LAUER, Jonathan D. Le travail de reference virtuel: un service surestime, gonfle et pas meme reel. Bulletin des Bibliothèques de France, 2003, vol. 48, n. 4, p. 63-65.

18.3.95. MCKINZIE, Steve; LAUER, Jonathan D. Virtual reference: overrated, inflated, and not even real. Charleston Advisor, 2002, vol. 4, n. 2, p. 56-57.

18.3.96. MILLER, William; GRATCH, Bonnie. Making connections: computerized reference services and people. Library Trends, 1989, vol. 37, n. 4, p. 387-401.

18.3.97. MINETTO, Sonia. L'evoluzione del reference nella biblioteca elettronica: informazione e formazione dell'utente finale come progetto permanente per un servizio efficace. Bollettino AIB, 1998, vol. 38, n. 4.

18.3.98. MON, Lorri. Digital reference service. Government Information Quarterly, 2000, vol. 17, n. 3, p. 309-318.

18.3.99. MOYO, L. M. Electronic Libraries and the Emergence of New Service Paradigms. The Electronic Library, 2004, vol. 22, n. 3, p. 220-230.

18.3.100. NGUYEN, Claire. Mettre en place et développer un service de référence virtuelle dans une perspective d'integration à un réseau collaboratif: Analysis comparées et propositions à partir de l'exemple de l'Université de Montréal: Mémoirte d'étude. Villeurbanne : ENSSIB, 2006.

18.3.101. NGUYEN, Claire. Les services de reference virtuels en bibliotheque universitaire: Enjeux, perspectives, debats. Bulletin des bibliothèques de France, 2006, vol. 51, n. 3, p. 54-57.

18.3.102. NILSEN, Kirsti. Service de référence en ligne contre service de référence sur place: une comparaison des pratiques de service de référence dans les bibliothèques publiques et académiques. En IFLA General Conference and Council (71. 2005. Os/o). Oslo: IFLA, 2005. Disponible en http://www.ifla.org/IV/ifla71/papers/027f_transNilsen.pdf [consultado el 17/07/2007].

18.3.103. NILSEN, Kirsti. Virtual versus Face-to-Face Reference. Refer, 2005, vol. 21, n. 3, p. 12-19.

18.3.104. NOFSINGER, Mary M. Training and Retraining Reference Professsionals: Core 
Competencies for the 21st Century. The Reference Librarian , 1999, n. 64, p. 9-19.

18.3.105. NOGUCHI, Sachie. Digital reference services: trends and issues. Joho Kanri, 2003, vol. 45, n. 10, p. 696-706.

18.3.106. NUNES, Manuela Barreto. Novos serviços em Bibliotecas Universitarias: a referencia electrónica. Encontro das Bibliotecas do Ensino Superior, 2003, vol. 1.

18.3.107. OBERHELMAN, David D. Reference service and resources in the age of instant messaging. Reference Reviews, 2007, vol. 21, n. 2, p. 7-8.

18.3.108. ODER, N. The shape of e-reference. Library Journal, 2001, vol. 126, n. 2, p. 4650.

18.3.109. PENKA, Jeffrey T. The Technological Challenges of Digital Reference. D-Lib Magazine, 2003, vol. 9, n. 2.

18.3.110. PETERS, Tom; BELL, Lori. Virtual reference services for the print impaired: separate, but not equal. Computers in Libraries, 2006, vol. 26, n. 10, p. 24-27.

18.3.111. POMERANTZ, Jeffrey. Integrating Digital Reference Service into the Digital Library Environment. En Lankes, R. D.; NICHOLSON, S.; GOODRUM, A. (eds.). The Digital Reference Research Agenda. Chicago: Association of College and Research Libraries, 2003, p. 23-47.

18.3.112. POMERANTZ, Jeffrey; MARCHIONINI, Gary. The digital library as place. Journal of Documentation, 2007, vol. 63, n. 4, p. 505-533.

18.3.113. POON, Pwt. Live Digital Reference Service: Its Present and Future. En Digital Libraries: International Collaboration and Cross-Fertilization. Berlin: Springer, 2004, p. 636-639.

18.3.114. QUIROGA IGLESIAS, María. Las bibliotecas y la sociedad de la información [en línea]: Jornadas profesionales, 2 de agosto de 2001. En Feria Internacional del Libro de Centroamérica (5. 2001. Panamá). Panamá: Feria Internacional del Libro de Centroamérica, 2001. Disponible en http://www.arrakis.es/ byblos/txt/mquiroga.html. [consultado el 17/07/2007].

18.3.115. REICHARDT, Randy. Digital Reference Overload: Thoughts on How To Deal. Internet Reference Services Quarterly, 2006, vol. 11, n. 2, p. 105-112.

18.3.116. RICE, Kimberley. Moving out. Australian Library Journal, 2006, vol. 55, n. 4, p. 374.

18.3.117. RIGGS, C. Virtual reference services... what, why and how? a report on a teleconference. Library Hi Tech News, 2002, vol. 19, n. 4, p. 7-9.

18.3.118. RIGGS, Colby. Reference services: virtual, digital and in-library. Library Hi Tech News, 2003, vol. 20, n. 5, p. 6-7.

18.3.119. ROBERTS, Brent. What libraries do best: bringing warmth to virtual reference. PNLA Quarterly, 2004, vol. 68, n. 3, p. 8-9, 22.

18.3.120. ROCKMAN, Ilene F. Visionary pragmatism in an e-library environment. Reference Services Review, 2001, vol. 29, n. 3, p. 169-170.

18.3.121. RONCEVIC, Mirela. The e-ref invasion. Library Journal, 2005, vol. 130, n. 19, p. 8-10, 13.

18.3.122. RÖSCH, Herman. Digital reference services: state of the art in the focus of 
quality. En IFLA General Conference and Council (72. 2006. Seúl). Seúl: IFLA, 2006. Disponible en http://www.ifla.org/IV/ifla72/papers/098-Roesch-en.pdf [consultado el 17/07/2007].

18.3.123. RUIZ FELIPE, Jose Angel. Las bibliotecas responden: servicios de referencia en línea. Sociedad de la información, 2001, n. 1.

18.3.124. SÁNCHEZ REMÓN, Dinorah. El servicio de referencia virtual en la gestión de información. ACIMED, 2003, vol. 11, n. 2.

18.3.125. SEN-ROY, Mita. The social life of digital reference: what the technology affords. The Reference Librarian, 2004, n. 85, p. 127-137.

18.3.126. SHACHAF, Pnina; HOROWITZ, Sarah. Are virtual reference services color blind? Library and Information Science Research, 2006, vol. 28, n. 4.

18.3.127. SHACHAF, Pnina; SNYDER, Mary. The Relationship Between Cultural Diversity and User Needs in Virtual Reference Services. The Journal of Academic Librarianship, 2007, vol. 33, n. 3, p. 361-367.

18.3.128. SHARMA, Sumati; KUMAR, Ashok; SINGH, Mohinder. Digital Reference Service. DESIDOC Bulletin of Information Technology, 2004, vol. 24, n. 6, p. 11-18.

18.3.129. SLOAN, Bernie. Electronic reference services: some suggested guidelines. Reference and User Services Quarterly, 1998, vol. 38, n. 1, p. 77-81.

18.3.130. SLOAN, Bernie. Service perspectives for the digital library remote reference services. Library Trends, 1998, vol. 47, n. 1, p. 117-143.

18.3.131. SLOAN, Bernie. Twenty years of virtual reference. Internet Reference Services Quarterly, 2006, vol. 11, n. 2, p. 91-95.

18.3.132. SMITH, R. M.; RACE, S. F.; AULT, M. Virtual desk: real reference. Journal of Library Administration, 2001, vol. 32, n. 1/2, p. 371-382.

18.3.133. SROKA, Marek; NIXON, Carol; BURMOOD, Jennifer. International virtual reference desk: current status and challenges. Internet Librarian 2002: Collected Presentations, 2002, p. 259-262.

18.3.134. STAHL, J. R.; KRESH, D. N. Online, virtual, e-mail, digital, real time: the next generation of reference services. Art Documentation, 2001, vol. 20, n. 1, p. 26-30.

18.3.135. STORMONT, S. Here, there and everywhere - live virtual reference. Collection Management, 2001, vol. 26, n. 2, p. 79-87.

18.3.136. STORMONT, Sam. Going where the users are: live digital reference. Information Technology and Libraries, 2001, vol. 20, n. 3, p. 129-134.

18.3.137. STRAW, Joseph E. From magicians to teachers: The development of electronic reference in libraries: 1930-2000. The Reference Librarian, 2001, n. 74, p. 1-12.

18.3.138. STRONG, Gary E. If we change it - will they come? Reference Services Review, 2006, vol. 34, n. 3, p. 333-339.

18.3.139. TENNANT, Roy. Revisiting Digital Reference. Library Journal, 2003, vol. 128, n. 1, p. 38.

18.3.140. TENNANT, Roy; OBERG, Steve; SLOAN, Bernie; LESTER, Dan; JARVIS, Hugh; TIESS, Robert. Que reproche-t-on au travail de référence virtuel ? Bulletin des Bibliothèques de France, 2003, vol. 48, n. 4, p. 66-71. 
18.3.141. TENOPIR, Carol. Rethinking virtual reference. Library Journal, 2004, vol. 129, n. 18, p. 34.

18.3.142. TENOPIR, Carol. Virtual reference services in a real world. Library Journal, 2001, vol. 126, n. 12, p. 38.

18.3.143. TENOPIR, Carol; ENNIS, Lisa. A Decade of Digital Reference: 1991-2001. Reference and User Services Quarterly, 2002, vol. 41, n. 3.

18.3.144. THOMAS, Margaret. Scrutinizing Virtual Reference. Alki, 2005, vol. 21, n. 2, p. 16-18.

18.3.145. TORRES VARGAS, Georgina Araceli; SÁNCHEZ AVILLANEDA, María Del Rocío. El servicio de referencia en la biblioteca digital. Investigación Bibliotecológica, 2005, vol. 19, n. 39.

18.3.146. TRUMP, J. F.; TUTTLE, I. P. Here, there, and everywhere: reference at the point-of-need. The Journal of Academic Librarianship, 2001, vol. 27, n. 6, p. 464-466.

18.3.147. TUNENDER, H. Digital reference: trends, techniques and changes. Library Hi Tech News, 2002, vol. 19, n. 4, p. 5-6.

18.3.148. UCAK, Nazan. Elektronik danisma hizmetleri= Digital reference services. Bilgi Dunyasi / Information World, 2003, vol. 4, n. 2, p. 103-121.

18.3.149. VIJAYAKUMAR, Manju; VIJAYAKUMAR, J. K. Digital Reference Service: Libraries Online 24/7. En Proceedings of SIS-2005. Visakhapatanam: SIS, 2005, p. 212-218.

18.3.150. WALMSLEY, Andrew. Developing reference services in the electronic age. Library + Information Update, 2007, vol. 6, n. 1-2, p. 40-44.

18.3.151. WASIK, Joann M. AskA Services and Funding: An Overview. The Virtual Reference Desk, 1998.

18.3.152. WASIK, Joann M. Building and Maintaining Digital Reference Services. Syracuse, NY: ERIC Clearinghouse on Information and Technology, 1999.

18.3.153. WAYNE DANIELS; KATHY SCARDELLATO. Past into future: capturing library expertise in a virtual library. Library Hi Tech, 1999, vol. 17, n. 2, p. 181-188.

18.3.154. WESSELING, M. Het virtuele inlichtingenbureau= The virtual enquiry desk. Informatie Professional, 2002, vol. 6, n. 10, p. 42-43.

18.3.155. WEST, Jessamyn. The Librarian Is In, and Online! Computers in libraries, 2003, vol. 23, n. 9.

18.3.156. WILLIAMSON, J. The reality of virtual reference: a view from the edge. Feliciter, 2002, vol. 48, n. 3, p. 110-111.

18.3.157. ZANIN-YOST, Alessia. Digital Reference: What the Past Has Taught Us and What the Future Will Hold. Library Philosophy and Practice, 2004, vol. 7, n. 1, p. 1-16. 


\subsection{Procesos de la referencia digital}

18.4.1. BACKHUS, Sherry Hawkins; SUMMEY, Terri Pedersen. Collaboration: The Key to Unlocking the Dilemma of Distance Reference Services. The Reference Librarian, 2003 , vol. 40, n. 83-84, p. 193-202.

18.4.2. BISHOP, Bradley Wade; TORRENCE, Matt. Virtual reference services: consortium versus stand-alone. College and Undergraduate Libraries, 2006, vol. 13, n. 4, p. 117-127.

18.4.3. BORETTI, Elena. Communicare con l'utente remoto. Biblioteche Oggi, 2001, vol. 19, n. 6 , p. $54-60$.

18.4.4. BORIN, Jacqueline. E-Problems, E-Solutions: electronic reference and the problem patron in the academic library . The Reference Librarian, 2002, vol. 36, n. 7576 , p. $149-162$.

18.4.5. BOWMAN, Vibiana. The virtual librarian and the electronic reference interview. Internet Reference Services Quarterly, 2002, vol. 7, n. 3, p. 3-14.

18.4.6. BREIDENBAUGH, Andrew. Budget planning and performance measures for virtual reference services. The Reference Librarian, 2006, vol. 46, n. 95/96, p. 113124.

18.4.7. BREZNAY, Ann Marie; HAAS, Leslie M. A checklist for starting and operating a digital reference desk. The Reference Librarian, 2002-2003, vol. 38, n. 79/80, p. 101112.

18.4.8. BRONSHTEYN, Karen. Using NetLibrary eBooks at the reference desk. Reference Services Review, 2007, vol. 35, n. 4, p. 560-570.

18.4.9. BROUGHTON, K.; HUNKER, S. D.; SINGER, C. A. Why use Web contact center software for digital reference? Internet Reference Services Quarterly, 2001, vol. 6, n. 2, p. 1-12.

18.4.10. BURKE, Adam; JOHNSO, Wendell. Invoking digital reference: creation and implementation. Community and Junior College Libraries, 2004, vol. 12, n. 1, p. 35-43.

18.4.11. CALDWELL, Tracey. Sun rises on health sector path-finder site. Information World Review, 2005, n. 211, p. 10.

18.4.12. CARLO, Jessica Luo; YOO, Youngjin. How may I help you?: Politeness in computer-mediated and face-to-face library reference transactions. Information and Organization, 2007 , vol. en prensa.

18.4.13. CAUFIELD, James. Tricky devil: a humorous training technique for the chat reference environment. The Electronic Library, 2005, vol. 23, n. 4, p. 377-382.

18.4.14. CICCONE, K.; VANSCOY, A. Managing an established virtual reference service. Internet Reference Services Quarterly, 2003, vol. 8, n. 1/2, p. 95-105.

18.4.15. COFFMAN, Steve. Distance Education and Virtual Reference: Where Are We Headed? Computers in libraries, 2001, vol. 21, n. 4.

18.4.16. COOK, Hope Marie. The emerging technology: twenty first century Web based environments and their resultant effect on the work responsibilities of academic reference librarians. Were the predictions correct? E-JASL: The Electronic Journal of Academic and Special Librarianship, 2006, vol. 7, n. 2. 
18.4.17. COX, Christopher Nelson. Think Before You Collaborate. Charleston Advisor, 2006, vol. 7, n. 3, p. 51-52.

18.4.18. CUMMINGS, J.; CUMMINGS, L.; FREDERIKSEN, L. User Preferences in Reference Services: Virtual Reference and Academic Libraries. Portal-Libraries and the Academy, 2007, vol. 7, n. 1, p. 81-96.

18.4.19. DE GROOTE, Sandra L.; DORSCH, Josephine L.; COLLARD, Scott; SCHERRER, Carol. Quantifying cooperation: collaborative digital reference service in the large academic library. College and Research Libraries, 2005, vol. 66, n. 5, p. 436454.

18.4.20. DEVLIN, Frances A.; BURICH, Nancy J.; STOCKHAM, Marcia G.; PEDERSEN SUMMEY, Terri; TURTLE, Elizabeth C. Getting beyond institutional cultures: when rivals collaborate. Journal of Library Administration, 2006, vol. 45, n. 1/2, p. 149-168.

18.4.21. DINWIDDIE, Mollie; LILLARD, Linda L. At the crossroads: library and classroom. Journal of Library Administration, 2002, vol. 37, n. 1/2, p. 251-267.

18.4.22. DUFF, W. M.; JOHNSON, C. A. A virtual expression of need: an analysis of email reference questions. American Archivist, 2001, vol. 64, n. 1.

18.4.23. ELIAS, Tana; MORRILL, Stef. Our virtual reference training camp: testing the players before signing them on. Computers in Libraries, 2003, vol. 23, n. 4, p. 10.

18.4.24. ELLIS, Lisa; FRANCOEUR, Stephen. Appliquer la compétence de l'information à la référence numérique. En IFLA General Conference and Council (67. 2002. Boston). 2002: IFLA, 2002. Disponible en http://www.ifla.org/IV/ifla67/papers/057-98f.pdf [consultado el 17/07/2007].

18.4.25. ELLIS, Lisa; FRANCOEUR, Stephen. Applying Information Competency to Digital Reference. En IFLA General Conference and Council (67. 2001. Boston). Boston: IFLA, 2001. Disponible en http://www.ifla.org/IV/ifla67/papers/057-98e.pdf [consultado el 17/07/2007].

18.4.26. ELLIS, Lisa A. Approaches to teaching through digital reference. Reference Services Review, 2004 , vol. 32, n. 2, p. 103-119.

18.4.27. ERCEGOVAC, Zorana. Collaborative E-Reference: A Research Agenda. En IFLA General Conference and Council (67. 2001. Boston). Boston: IFLA, 2001. Disponible en http://www.ifla.org/IV/ifla67/papers/058-98e.pdf [consultado el 17/07/2007].

18.4.28. FARMER, Lesley S. Virtual reference service for K-12 students. Knowledge Quest, 2005, vol. 33, n. 3, p. 22-24.

18.4.29. FENNEWALD, Joseph. Same Questions, Different Venue: An Analysis of InPerson and Online Questions. The Reference Librarian, 2006, vol. 46, n. 95/96, p. 2135.

18.4.30. FRANK, Rivkah. Improving Internet reference services to distance learners. Medical Reference Services Quarterly, 2006, vol. 25, n. 3, p. 108-109.

18.4.31. FULLERTON, Vera. VR in a Consortium: Planning, Implementation \& Evaluation. Annual Digital Reference Conference, 2002, n. 4.

18.4.32. GINANNI, Katy; DAVIS, Susan; ARTHUR, Michael A. Talk About: E-Resources Librarian to the Rescue? Creating the Über Librarian: Turning Model Job Descriptions into Practical Positions. Serials Librarian, 2006, vol. 50, n. 1/2, p. 173-177. 
18.4.33. GOODRUM, Abby A. Visual resource reference: collaboration between digital museums and digital libraries. D-Lib Magazine, 2003, vol. 9, n. 2.

18.4.34. GORMAN, Michael. Privacy in the Digital environment: issues for libraries. En IFLA General Conference and Council (67. 2001. Boston). Boston: IFLA, 2001. Disponible en http://www.ifla.org//V/ifla67/papers/145-083e.pdf [consultado el 17/07/2007].

18.4.35. HARIDASAN, Sudharma. Collaborative Digital Reference Service for the Post Industrial Society. Journal of Library and Information Science, 2006, vol. 31, n. 2, p. 135-140.

18.4.36. HEDONG, Yang; SHIJIONG, Lu; ZHIPING, Zhang. Construction of online reference system. Journal of the China Society for Scientific and Technical Information, 2006, vol. 25, n. 1, p. 94-98.

18.4.37. HELMAN, D. L. Bringing the human touch to digital library services. Science and Technology Libraries, 2001, vol. 20, n. 2/3, p. 83-96.

18.4.38. HERT, Carol A. Information Seeking and User-Intermediary Interactions: Informing the Design of Digital Reference Services . Annual Digital Reference Conference, 2000, n. 2.

18.4.39. HIDER, Philip M. Search goal redefinition through user-system interaction. Journal of Documentation, 2007, vol. 63, n. 2, p. 188-203.

18.4.40. HILL, J. B.; MADARASH-HILL, Cherie; ALLRED, Alison. Outsourcing Digital Reference: The User Perspective. The Reference Librarian, 2007, vol. 47, n. 98, p. 57-74.

18.4.41. HIRKO, Buff; ROSS, Mary Bucher. Virtual reference training: the complete guide to providing anytime, anywhere answers. Chicago: American Library Association, 2004.

18.4.42. JAMES-CATALANO, C. Cyberlibrarian. Internet World, 1995, vol. 6, n. 4, p. $92-$ 93.

18.4.43. JANES, Joseph. Digital reference: reference librarians' experiences and attitudes. Journal of the American Society for Information Science and Technology, 2002, vol. 53, n. 7, p. 549-566.

18.4.44. JANES, Joseph; SILVERSTEIN, Joanne. Question Negotiation and the Technological Environment. D-Lib Magazine, 2003, vol. 9, n. 2.

18.4.45. JENSEN, Bruce. The case for non-intrusive research: a virtual reference librarian's perspective. The Reference Librarian, 2004, n. 85, p. 139-149.

18.4.46. JOHNSON, Carolyn; URY, Connie. Reference beyond the walls of the library: interacting with faculty and students in the 21st century. The Reference Librarian, 2003, vol. 40 , n. 83/84, p. 203-218.

18.4.47. JOHNSTON, Patricia E. Digital reference as an instructional tool: Just in time and just enough. Searcher, 2003, vol. 11, n. 3, p. 31-33.

18.4.48. JONES, Marie F. Internet reference services for distance education: guidelines comparison and implementation. Internet Reference Services Quarterly, 2005, vol. 9, n. 3-4, p. 19-32.

18.4.49. KERN, M. Kathleen. Communication, patron satisfaction, and the reference Interview. Reference and User Services Quarterly, 2003, vol. 43, n. 1, p. 47-49. 
18.4.50. KING, Valery; NICHOLS, Jane; PADILLA, Greg. Moving back to campus: creating a local virtual reference service. Internet Reference Services Quarterly, 2006, vol. 11, n. 3, p. 1-17.

18.4.51. KLAISS, B. A. Using resource-sharing consortiums to extend automated reference resources to rural and small libraries. Current Studies in Librarianship, 1996, vol. 20 , n. $1 / 2$, p. $64-81$.

18.4.52. KLUEGEL, Kathleen; ROSS, Catherine Sheldrick; RONAN, Jana; KERN, Kathleen; TYCKOSON, David. The reference interview: Connecting in person and in cyberspace: presentations and responses from the RUSA president's program, 2002 ALA Annual Conference, Atlanta, June 17, 2002. Reference and User Services Quarterly, 2003, vol. 43, n. 1, p. 37-51.

18.4.53. KRATZERT, M.; RICHEY, D.; WASSMANN, C. Tips and snags of academic cyberreference. College and Undergraduate Libraries, 2001, vol. 8, n. 2, p. 73-82.

18.4.54. KRESH, Diane. High touch or high tech: The collaborative digital reference service as a model for the future of reference. Advances In Librarianship, 2002, vol. 26, p. $149-173$.

18.4.55. KRESH, Diane Nester; NIXON, Carol. High touch, high tech or high noon?: the cost and promise of building collaborative networks. En Annual Computers in Libraries Conference (17. 2002. Washington). Medford, NJ: Information Today, 2002, p. 192201.

18.4.56. KUPERSMITH, John. Technostress and the reference librarian. Reference Services Review, 1992, vol. 20, n. 2, p. 7-14,50.

18.4.57. LAGACE, N.; MCCLENNEN, M. Managing an Internet-based distributed reference service. Computers in Libraries, 1998, vol. 18, n. 2, p. 24-27.

18.4.58. LANKES, R. David. AskA's. Lesson learned from K-12 Digital Reference Services. Reference and User Services Quarterly, 1999, vol. 38, n. 1, p. 63-71.

18.4.59. LANKES, R. David. Building the virtual reference desk. The Virtual Reference Desk, 1998.

18.4.60. LANKES, R. David; GROSS, Melissa; MCCLURE, Charles R. Cost, statistics, measures, and standards for digital reference services: A preliminary view. Library trends, 2003, vol. 51, n. 3, p. 401-413.

18.4.61. LEE, Seongsin. Vroom's expectancy theory and the public library customer motivation model. Library Review, 2007, vol. 56, n. 9, p. 788-796.

18.4.62. LIPOW, Anne G. Are you ready for real-time remote reference? New questionhandling skills and library policies needed to move the desk (and you) to the web. En IFLA General Conference and Council (67. Boston. 2001). Boston: IFLA, 2001.

18.4.63. LUNNEBORG, Eva. Utilizing Virtual Reference to Serve Multitype Library Patrons The Experiences of Collaborative Services in Sweden and Florida. En IFLA General Conference and Council (71. 2005. Os/o). Oslo: IFLA, 2005. Disponible en http://www.ifla.org/IV/ifla71/papers/029e-Lunneborg_Mariner.pdf [consultado el 17/07/2007].

18.4.64. MARSTELLER, Matthew R.; MIZZY, Danianne. Exploring the synchronous digital reference interaction for query types, question negotiation, and patron response. Internet Reference Services Quarterly, 2003, vol. 8, n. 1/2, p. 149-165.

18.4.65. MARVIN, Stephen; NIXON, Carol; BURMOOD, Jennifer. Process for developing 
e-reference services. InfoToday 2002 Collected Presentations, 2002, p. 255-258.

18.4.66. MAXWELL, Nancy Kalikov. Establishing and mantaining live online reference service. Library Technology Reports, 2002, vol. 38, n. 4, p. 1-68.

18.4.67. MCADAM, Barbara; GRAY, Suzanne. A Management Model for Digital Reference: Services In Large Institutions. Annual Digital Reference Conference, 2000, n. 2.

18.4.68. MCELFRESH, Laura Kane. And some have patron service greatness thrust upon them. Technicalities, 2005 , vol. 25, n. 5, p. 1, 8-10.

18.4.69. MCGRAW, Kathleen A.; HEILAND, Jennifer; HARRIS, Julianna C. Promotion and evaluation of a virtual live reference service. Medical Reference Services Quarterly, 2003, vol. 22, n. 2, p. 41-56.

18.4.70. MELOCHE, Joseph A. The Importance of Digital Reference in Supporting Critical Thinking in Distance Education . Annual Digital Reference Conference, 2000, n. 2.

18.4.71. MINOR, Carolyn; DUNNING, Beth. Making virtual library staffing a reality. Information Outlook, 2006, vol. 10, n. 7, p. 29-32.

18.4.72. MON, Lorri. Digital reference and ubiquitous computing in the classroom. Knowledge Quest, 2006, vol. 34, n. 3, p. 20-23.

18.4.73. MOSS, Molly M. Reference Services for Remote Users . Katharine Sharp Review, 1997, n. 5.

18.4.74. NEEDLEMAN, M. NISO's Networked References Standards Committee. Serials Review, 2002, vol. 28, n. 4, p. 342-343.

18.4.75. NEUHAUS, Chris. Flexibility and feedback: a new approach to ongoing training for reference student assistants. Reference Services Review, 2001, vol. 29, n. 1, p. 53-64.

18.4.76. NEUHAUS, P. Privacy and Confidentiality in Digital Reference. Reference and User Services Quarterly, 2003, vol. 43, n. 1, p. 26-36.

18.4.77. NILSEN, Kirsti. Comparing users' perspectives of in-person and virtual reference. New Library World, 2006, vol. 107, n. 3/4, p. 91-104.

18.4.78. NILSEN, Kirsti. Virtual versus Face-to-Face Reference: Comparing Users' Perspectives on Visits to Physical and Virtual Reference Desks in Public and Academic Libraries. En IFLA General Conference and Council (71. 2005. Os/o). Oslo: IFLA, 2005. Disponible en http://www.ifla.org/IV/ifla71/papers/027e-Nilsen.pdf [consultado el 17/07/2007].

18.4.79. OSA, Justina O. Managing the 21st Century Reference Department: Competencies. The Reference Librarian, 2003, vol. 39, n. 81, p. 33-50.

18.4.80. PAPANDREA, V. A. Managing reference services in the electronic age: a competing values approach to effectiveness. The Reference Librarian, 1998, n. 60, p. 111-126.

18.4.81. PARROTT, James R. Simulation of the reference process. The Reference Librarian, 1988, n. 21, p. 189-207.

18.4.82. PARROTT, James R. Simulation of the reference process, Part 2: REFSIM, an implementation with expert system and ICAI modes. The Reference Librarian, 1989, n. 23 , p. 153-176. 
18.4.83. PENZHORN, Cecilia. Training for digital reference: a South African experience. Libri, 2007, vol. 57, n. 2, p. 76-83.

18.4.84. PETERS, Thomas A. E-reference: how consortia add value. The Journal of Academic Librarianship, 2002, vol. 28, n. 4, p. 248-250.

18.4.85. POMERANTZ, Jeffrey; TOMS, Elaine G. Question types in digital reference: an evaluation of question taxonomies. En Information, Connections, and Community: Proceedings of the 65th Conference of the American Society for Information Science \& Technology. Medford, NJ : Information Today, 2002, p. 542.

18.4.86. QUAN, Cheng; YUAN, Chen. Construction of sharing platform of distributed collaborative reference service system. Journal of the China Society for Scientific and Technical Information, 2005, vol. 24, n. 1, p. 93-99.

18.4.87. RADER, Hannelore B. Information literacy in the reference environment: preparing for the future. The Reference Librarian, 2000, n. 71, p. 25-33.

18.4.88. RAMSAY, Karen M.; KINNIE, Jim. The embedded librarian. Library Journal, 2006, vol. 131, n. 6, p. 34-35.

18.4.89. REFERENCE AND USER SERVICES ASSOCIATION . Guidelines for implementing and maintaining virtual reference services. Reference and User Services Quarterly, 2004, vol. 44, n. 1, p. 9-13.

18.4.90. RICHARDSON, J.; FLETCHER, J.; HUNTER, A.; WESTERMAN, P. 'Ask a librarian' electronic reference services: the important of corporate culture, communication and service attitude. LASIE, 2000, vol. 31, n. 4, p. 25-37.

18.4.91. RONAN, Jana. The Reference Interview Online. Reference and User Services Quarterly, 2003, vol. 43, n. 1, p. 43-47.

18.4.92. RUSA. Guidelines for Implementing and Maintaining Virtual Reference Services. Chicago: ALA, RUSA, 2004.

18.4.93. SALZMANN, Katharine A. Contact us: archivists and remote users in the digital age. The Reference Librarian, 2004, n. 85, p. 43-50.

18.4.94. SCHNEIDER, Karen G. The Distributed Librarian: Live, Online, Real-Time Reference. American Libraries, 2000, vol. 31, n. 10, p. 64.

18.4.95. SCHWARTZ, Jennifer. Toward a typology of e-mail reference questions. Internet Reference Services Quarterly, 2003, vol. 8, n. 3, p. 1-15.

18.4.96. SENNEMA, Greg. Managing the reference desk online. Reference Services Review, 2003, vol. 31, n. 3, p. 257-263.

18.4.97. SILVERSTEIN, Joanne. Just Curious: Children's Use of Digital Reference for Unimposed Queries and Its Importance in Informal Education. Library Trends, 2005, vol. 54, n. 2, p. 228-244.

18.4.98. SNAVELY, L. Building the virtual reference shelf: how to get the most for your money. Information Outlook, 1997, vol. 1, n. 7, p. 24-28.

18.4.99. SREENIVASULU, $\vee$. The role of a digital librarian in the management of digital information systems (DIS). The Electronic Library, 2000, vol. 18, n. 1, p. 12-20.

18.4.100. STEMPER, James A.; BUTLER, John T. Developing a model to provide digital reference services. Reference Services Review, 2001, vol. 29, n. 3, p. 172-189. 
18.4.101. STEPHENS, Michael; NIXON, Carol; BURMOOD, Jennifer. Technology skills for live librarians: pre-training for results. Internet Librarian 2002: Collected Presentations, 2002, p. 279-286.

18.4.102. STIRLING, Dale A. Virtual reference training: The complete guide to providing anytime anywhere answers. Journal of the American Society for Information Science and Technology, 2005, vol. 56, n. 11, p. 1238-1239.

18.4.103. STRAW, Joseph E. A Virtual Understanding: The Reference Interview and Question Negotiation in the Digital Age. Reference and User Services Quarterly, 2000, vol. 39, n. 4.

18.4.104. STRAW, Joseph E.; COX, Christopher N. Using Canned Messages in Virtual Reference Communication. Internet Reference Services Quarterly, 2006, vol. 11, n. 1, p. 39-49.

18.4.105. SUMMERS, Robin. Meeting Education Information Needs Through Digital Reference. Art Documentation, 1998, vol. 17, n. 1, p. 3-68.

18.4.106. SUMMEY, Tern Pedersen; AKERS, Cynthia. From IM to Collaboration: Providing Virtual Reference Services at a Medium-Sized Institution. College and Undergraduate Libraries, 2006, vol. 13, n. 4, p. 75-93.

18.4.107. TADDEO, Laura; HACKENBERG, Jill M. The nuts, bolts, and teaching opportunities of real-time reference. College and Undergraduate Libraries, 2006, vol. 13 , n. 3, p. 63-85.

18.4.108. TAHER, M. Real-time (synchronous interactive) reference interview: a select bibliography. Internet Reference Services Quarterly, 2002, vol. 7, n. 3, p. 35-41.

18.4.109. TAHER, M. The reference interview through asynchronous e-mail and synchronous interactive reference: does it save the time of the interviewee? Internet Reference Services Quarterly, 2002, vol. 7, n. 3, p. 23-34.

18.4.110. TAYLOR, D.; PORTER, G. S. The problem patron and the academic library Web site as virtual reference desk. The Reference Librarian, 2002, vol. 36, n. 75/76, p. 163172.

18.4.111. TENOPIR, Carol. Electronic reference and reference librarians: a look through the 1990s. Reference Services Review, 1999, vol. 27, n. 3, p. 276-280.

18.4.112. TOMAIUOLO, N. G.; PACKER, J. G. Aska' do's, don'ts, and how-to's: lessons learned in a library. Searcher, 2000, vol. 8, n. 3, p. 32-35.

18.4.113. TRUELSON, Judith A. Creating Successful E-mail/Chat Documentation: The Process Flow Diagram Approach. Annual Digital Reference Conference, 2002, n. 4.

18.4.114. TUCKER, James Cory. Developing a chat reference training program. Internet Reference Services Quarterly, 2004, vol. 8, n. 4, p. 11-25.

18.4.115. TURNAGE, Marthea; CARTER, Wade; MCDONALD, Randy. Keep it simple: internet reference support for distance learners. Internet Reference Services Quarterly, 2005, vol. 9, n. 3-4, p. 43-54.

18.4.116. VAN FLEET, C.; WALLACE, D. P. Virtual Libraries - Real Threats - Technostress and Virtual Reference. Reference and User Services Quarterly, 2003, vol. 42, n. 3, p. 188-191.

18.4.117. VILELLE, Luke. Marketing virtual reference: What academic libraries have done. College and Undergraduate Libraries, 2005, vol. 12, n. 1/2, p. 65-79. 
18.4.118. WALTERS, Tyler O.; WILLIAMS, Clara R. Reference and instruction services go virtual as a form of outreach: case studies from academic libraries. Information Outlook, 2003, vol. 7, n. 8, p. 20-24.

18.4.119. WARD, David. Using virtual reference transcripts for staff training. Reference Services Review, 2003, vol. 31, n. 1, p. 46-56.

18.4.120. WARD, Joyce; MERVAR, Dana; LOVING, Matthew; KRONEN, Steve. Going It Alone: can a small/medium-sized library manage live online reference? The Reference Librarian, 2002-2003, vol. 38, n. 79-80, p. 311-322.

18.4.121. WARE, Susan A.; HOWE, Patricia S.; SCALESE, Rosemary G. Interactive reference at a distance: a corporate model for academic libraries. The Reference Librarian, 2000, n. 69-70.

18.4.122. WEBBER, Sheila Anne Elizabeth. Pricing and marketing online information services. Annual Review of Information Science and Technology (ARIST), 1998, vol. 33.

18.4.123. WESTBROOK, Lynn. Virtual reference training: the second generation. College and Research Libraries, 2006, vol. 67, n. 3, p. 249-259.

18.4.124. YAKEL, Elizabeth. Inviting the user into the virtual archives. OCLC Systems \& Services, 2006, vol. 22, n. 3, p. 159-163.

18.4.125. YI, Jin; MIN, Huang; HAOMING, Lin; JING, Guo. Study on the collaboration mechanism of the virtual reference service. The Electronic Library, 2007, vol. 25, n. 6, p. $733-740$.

\subsection{Sistemas de referencia digital}

18.5.1. ABELS, Eileen G. The e-mail reference interview. RQ, 1996, vol. 35, n. 3, p. 345358.

18.5.2. ABRAM, Stephen. Three ways to understand professional-grade virtual reference. Information Outlook, 2005, vol. 9, n. 7, p. 34-35.

18.5.3. ALVESTRAND, Viveka. Online reference service creates visualisation tool. Information World Review, 2003, n. 196, p. 4.

18.5.4. ARANT-KASPAR, Wendi; CARTER, Henry; DESAI, Sheetal; BYRD, John; HAHN, Douglas. ResDesk: An automated solution for course reserves request tracking and process management. Library Hi Tech, 2007, vol. 25, n. 2, p. 197-210.

18.5.5. ARNOLD, Julie; KASKE, Neal; NIXON, Carol. Chat with a librarian. En Annual Computers in Libraries Conference (17. 2002. Washington). Medford, NJ: Information Today, 2002, p. 1-6.

18.5.6. ARRET, Linda; COFFMAN, Steve. To chat or not to chat: taking another look at virtual reference. Searcher, 2004, vol. 12, n. 7, p. 38-46.

18.5.7. BAIGET, Tomas. Programa work-flow para un servicio de consultas a medida. El Profesional de la Informacion, 2006, vol. 15, n. 5, p. 364-372.

18.5.8. BAKKER, T. Virtual reference service: connecting users with experts and supporting the development of skills. Liber Quarterly : the Journal of European Research Libraries, 2002 , vol. 12, n. 2/3, p. 124-137. 
18.5.9. BARCELLOS, Sílvia. Understanding Intermediation in a Digital Environment: An Exploratory Case Study . Annual Digital Reference Conference, 2000, n. 2.

18.5.10. BARR, Belinda; CONLEY, Jerome; GOODE, Joanne. Chat is now: administrative issues. Internet Reference Services Quarterly, 2003, vol. 8, n. 1/2, p. 19-25.

18.5.11. BARTON, Emily; WESMANTEL, Arlene. Ref logs now: internal web logs can rejuvenate reference . Library Journal, 2006, vol. 131, n. 16, p. 28-30.

18.5.12. BELL, Steven. Thinking Thoughtfully: About Reference Technology. The Reference Librarian, 2007, vol. 47, n. 97, p. 125-128.

18.5.13. BELL, Steven J. Time to Lose the Sticky and Try a Wiki. The Reference Librarian, 2007, vol. 47, n. 98, p. 101-105.

18.5.14. BENNETT, Blythe Allison. Virtual Reference Desk Incubator: A Demo . Annual Digital Reference Conference, 2000, n. 2.

18.5.15. BENNETT, David; CORINTH, Jackie; NIXON, Carol. Verbots for library Web sites. En Annual Computers in Libraries Conference (17. 2002. Washington). Medford, NJ: Information Today, 2002, p. 7.

18.5.16. BENNETT, Denise Beaubien; CENZER, Pamela S.; KIRK, Paul. A class assignment requiring chat-based reference. Reference and User Services Quarterly, 2004 , vol. 44, n. 2, p. $149-163$.

18.5.17. BOBROWSKY, Tammy; BECK, Lynne; GRANT, Malaika. The chat reference interview: practicalities and advice. The Reference Librarian, 2005, n. 89/90, p. 179191.

18.5.18. BRAXTON, Susan M.; BRUNSDALE, Maureen. Email Reference as Substitute for Library Receptionist. The Reference Librarian, 2004, vol. 41, n. 85, p. 19-31.

18.5.19. BROUGHTON, Kelly. Our Experiment in Online, Real-Time Reference . Computers in libraries, 2001, vol. 21, n. 4.

18.5.20. BROWN, Mitchell. Library toolbars for use and development. Library Hi Tech News, 2007, n. 8, p. 33-35.

18.5.21. BURICH, Nancy J.; DEVLIN, Frances A. Hawkhelp: from chat to a student services portal. Internet Reference Services Quarterly, 2005, vol. 9, n. 3-4, p. 81-98.

18.5.22. CAMPBELL, Kathy A.; JONES, Marie F.; SHUTTLE, Jerry. Chat reference: one university's experience. The Reference Librarian, 2002-2003, vol. 38, n. 79/80, p. 297309.

18.5.23. CAMPBELL, Sandra. Oxford Reference Online and Xreferplus: a comparison. Refer, 2007, vol. 23, n. 1, p. 2-6.

18.5.24. CARRAWAY, Shawn; PAYNE, Susan. Implementing RAKIM open source chat reference software. Computers in Libraries, 2005, vol. 25, n. 5, p. 10, 12, 14-15.

18.5.25. CARTER, David S. Hurry up and wait: observations and tips about the practice of chat reference. The Reference Librarian, 2002-2003, vol. 38, n. 79/80, p. 113-120.

18.5.26. CATHCART, Rachael A. Podcasting and Reference: Friend or Foe? The Reference Librarian, 2007, vol. 47, n. 97, p. 119-120.

18.5.27. CERVONE, H. Frank. Open source software to support distance learning library services. Internet Reference Services Quarterly, 2005, vol. 9, n. 3-4, p. 147-158. 
18.5.28. CICHANOWICZ, Edana McCaffery. Live reference chat from a customer service perspective. Internet Reference Services Quarterly, 2003, vol. 8, n. 1/2, p. 27-32.

18.5.29. CICHANOWICZ, Edana Mccaffery; NAN, Chen. Planning for multilingual chat reference service in a suburban public library system. The Reference Librarian, 2004, n. 85 , p. $115-126$.

18.5.30. CIGALE, George. Partners in advocacy. Library Journal, 2005, vol. 130, n. 13, p. 46-48.

18.5.31. COERS, R. Binnenkort: de chattende inlichtingenmedewerker= Coming soon: the chatting information service. BibliotheekBlad, 2001, vol. 5, n. 14, p. 9.

18.5.32. COFFMAN, Steven. We'll take it from here: further developments we'd like to see in virtual reference software. Information Technology and Libraries, 2001, vol. 20, n. 3, p. $149-153$.

18.5.33. CONNOR, E. Real-time reference: the use of chat technology to improve point of need assistance. Medical reference services quarterly, 2002, vol. 21, n. 4, p. 1-14.

18.5.34. COURTNEY, Nancy (ed.). Library 2.0 and beyond: innovative technologies and tomorrow's user. Westport: Libraries Unlimited, 2007.

18.5.35. CROFT, Rosie; EICHENLAUB, Naomi. E-mail reference in a distributed learning environment: best practices, user satisfaction, and the reference services continuum. Journal of Library Administration, 2006, vol. 45, n. 1/2, p. 117-147.

18.5.36. CURTIS, Donnelyn; GREENE, Araby. A university-wide, library-based chat service. Reference Services Review, 2004, vol. 32, n. 3, p. 220-233.

18.5.37. DAVIS, Kate. AskNow Instant Messaging: innovation in virtual reference. Australian Library Journal, 2007, vol. 56, n. 2, p. 152-174.

18.5.38. DE JONG, M. Chattende inlichtingenwerker? =Chatting with the reference librarian? BibliotheekBlad, 2001, vol. 5, n. 15/16, p. 15.

18.5.39. DEE, Cheryl R.; NEWHOUSE, Joshua D. Digital chat reference in health science libraries: challenges in initiating a new service. Medical reference services quarterly, 2005, vol. 24, n. 3, p. 17-27.

18.5.40. DESAI, Christina M. Instant messaging reference: how does it compare? The Electronic Library, 2003, vol. 21, n. 1, p. 21-30.

18.5.41. DESAI, Christina M; FAGAN, Jody; NIXON, Carol. Instant messaging reference. En Annual Computers in Libraries Conference (17. 2002. Washington). Medford, NJ: Information Today, 2002, p. 52-59.

18.5.42. DESAI, Christina M.; GRAVES, Stephanie J. Instruction via Instant Messaging reference: what's happening? The Electronic Library, 2006, vol. 24, n. 2, p. 174-189.

18.5.43. DINBERG, Donna; GORDON, Cary; MCCLENNEN, Michael; PENKA, Jeffrey. Gearing up for NetRef. Annual Digital Reference Conference, 2003, n. 5.

18.5.44. DOAN, Tomalee; FERRY, Kristine. Instant messaging (IM): providing services and enhancing communication. Journal of Business and Finance Librarianship, 2006, vol. 12, n. 2, p. 17-22.

18.5.45. DOEK, Alice. Chatten met de informatiebalie: een-op-een= Chatting to the information desk: one to one. Informatie Professional, 2004, vol. 8, n. 7/8, p. 18-20. 
18.5.46. ENGLE, M. O. Using World Wide Web software for reference and instruction. Internet Reference Services Quarterly, 1996, vol. 1, n. 2, p. 7-15.

18.5.47. ERDMAN, Jacquelyn. Reference in a 3-D Virtual World: Preliminary Observations on Library Outreach in "Second Life". The Reference Librarian, 2007, vol. 47 , n. 98, p. 29-39.

18.5.48. EVANS, Beth. Your Space or MySpace? Library Journal Net Connect, 2006, vol. 131 , p. 8-12.

18.5.49. FAGAN, J. C.; CALLOWAY, M. Creating an instant messaging reference system. Information Technology and Libraries, 2001, vol. 20, n. 4, p. 202-212.

18.5.50. FAGAN, Jody Condit. Site search and instant messaging reference: a comparative study. Internet Reference Services Quarterly, 2003, vol. 8, n. 1/2, p. 167182.

18.5.51. FAGAN, Jody Condit. Virtual reference software comparative review. The Charleston Advisor, 2004, vol. 6, n. 4, p. 16.

18.5.52. FAGAN, Jody Condit; DESAI, Christina M. Communication strategies for instant messaging and chat reference services. The Reference Librarian, 2002-2003, vol. 38, n. $79 / 80$, p. $121-155$.

18.5.53. FALCATO, Pedro. Sistema de ayuda para la redacción de mensajes en un servicio de referencia por correo electrónico. Información, cultura y sociedad, 2005, n. 13, p. 11-28.

18.5.54. FARKAS, Meredith G. Tools for synchronous online reference. En Farkas, Meredith G.Social software in libraries. Medford: Informarion Today, 2007, p. 149-166.

18.5.55. FISHMAN, D. L. Managing the virtual reference desk: how to plan an effective reference e-mail system. Medical reference services quarterly, 1998, vol. 17, n. 1, p. 1-10.

18.5.56. FLYNN, David A. Seeking peer assistance: Use of e-mail to consult weak and latent ties. Library and information science research, 2005, vol. 27, n. 1.

18.5.57. FORSTER, Shirley. Using instant messaging for online reference service. Australian Library Journal, 2006, vol. 55, n. 2, p. 147-158.

18.5.58. FORSYTH, Ellen. Using wireless devices to enhance reference and information services. Australian Library Journal, 2006, vol. 55, n. 4, p. 317-324.

18.5.59. FRANCOEUR, Stephen. An analytical survey of chat reference services. Reference Services Review, 2001, vol. 29, n. 3, p. 189-204.

18.5.60. GAMBLES, A. The development and launch of the HeadLine Personal Information Environment. Information Technology and Libraries, 2000, vol. 19, n. 4, p. 199-205.

18.5.61. GARNSEY, A. Beth; POWEL, Ronald R. Los servicios de referencia a través del correo electrónico en la biblioteca pública. Boletín de la Asociación Andaluza de Bibliotecarios, 2003, vol. 18, n. 71, p. 57-76.

18.5.62. GILES, Nicola; GREY-SMITH, Sue. Txting librarians @ Curtin. En Information Online 2005. Sydney: Australian Library and Information Association, 2005. Disponible en http://conferences.alia.org.au/online2005/papers/a12.pdf [consultado el 17/07/2007]. 
18.5.63. GRAVES, Stephanie J.; DESAI, Christina M. Instruction via chat reference: does co-browse help? Reference Services Review, 2006, vol. 34, n. 3, p. 340-357.

18.5.64. HAINES, A.; GRODZINSKI, A. Web forms: improving, expanding, and promoting remote reference services. College and Research Libraries News, 1999, vol. 60, n. 4, p. 271-272.

18.5.65. HERMAN, Sonia. SMS reference: keeping up with your clients. The Electronic Library, 2007, vol. 25, n. 4, p. 401-408.

18.5.66. HIBNER, Holly. The Wireless Librarian: Using Tablet PCs for Ultimate Reference and Customer Service: A Case Study. Library Hi Tech News, 2005, vol. 22, n. 5, p. 19-22.

18.5.67. HILL, J. B.; MADARASH-HILL, Cherie; SHERMAN, Dayne. Text Messaging in an Academic Library: Integrating SMS into Digital Reference. The Reference Librarian, 2007, vol. 47, n. 97, p. 17-29.

18.5.68. HILLYER, Nora; PARKER, Linda L. Video reference: it's not your typical virtual reference: video reference services for South Campus at the University of Nebraska at Omaha. Internet Reference Services Quarterly, 2006, vol. 11, n. 4, p. 41-54.

18.5.69. HIRKO, Buff. Get Vendor Savvy. Library Journal Net Connect, 2004, vol. 129, p. 12-14.

18.5.70. HIRKO, Buff. Live, Digital Reference Marketplace. Library Journal Net Connect, 2002, n. 15 oct.

18.5.71. HOAG, T. J.; CICHANOWICZ, E. M. Going prime time with live chat reference. Computers in Libraries, 2001, vol. 21, n. 8, p. 40-44.

18.5.72. HUTCHINSON, A. R. Xreferplus: digital reference library. Choice: Current Reviews for Academic Libraries, 2006, vol. 43, n. 8, p. 1368.

18.5.73. JESUDASON, Melba. Outreach to student-athletes through e-mail reference service. Reference Services Review, 2000, vol. 28, n. 3, p. 262-268.

18.5.74. JUNTUMAA, Jouni. Kysy mita vain radiossa= Ask anything on the radio. Kirjastolehti, 2004, n. 2, p. 20.

18.5.75. KASKE, Neal; ARNOLD, Julie. Lessons Learned by Chat Service Providers Regarding the Quality and Type of Service Provided. Annual Digital Reference Conference, 2003, n. 5.

18.5.76. KAZMER, Michelle M.; BURNETT, Gary; DICKEY, Michael H. Identity in customer service chat interaction: Implications for virtual reference. Library and Information Science Research, 2007, vol. 29, n. 1.

18.5.77. KERN, M. Kathleen. Chat it up! Extending reference services to assist offcampus students. Journal of Library Administration, 2004, vol. 41, n. 1/2, p. 217-226.

18.5.78. KHOO, Christopher S. G.; POO, Danny C. C.; TECK-KANG TOH . E-Referencer: Transforming Boolean OPACs to Web Search Engines. En IFLA General Conference and Council (65. 1999. Bangkok). Bangkok: IFLA, 1999. Disponible en http://www.ifla.org/IV/ifla65/papers/010-143e.htm [consultado el 17/07/2007].

18.5.79. KIMMEL, S.; HEISE, J. Being there: tools for online synchronous reference. Online, 2001, vol. 25, n. 6, p. 30, 6,38-9.

18.5.80. KLASSEN, T. Usenet as a reference tool. Reference Services Review, 1995, vol. 
23, n. 2, p. 13-16.

18.5.81. KWON, Nahyun. Public library patrons' use of collaborative chat reference service: The effectiveness of question answering by question type. Library and Information Science Research, 2007, vol. 29, n. 1.

18.5.82. LADENSON, Sharon. E-Mail Reference: Improving Service by Working Cooperatively . The Reference Librarian, 2003, vol. 40, n. 83-84, p. 183-191.

18.5.83. LEDERER, Naomi. E-mail reference: who, when, where, and what is asked. The Reference Librarian, 2001, n. 74, p. 55-73.

18.5.84. LEE, Ian J. Do virtual reference librarians dream of digital reference questions?: a qualitative and quantitative analysis of e-mail and chat reference. AARL Australian Academic \& Research Libraries, 2004, vol. 35, n. 2.

18.5.85. LUKASIEWICZ, Adrianna. Exploring the role of digital academic libraries: Changing student needs demand innovative service approach. Library Review, 2007, vol. 56, n. 9, p. 821-827.

18.5.86. LUO, Lili. Chat reference competencies: identification from a literature review and librarian interviews. Reference Services Review, 2007, vol. 35, n. 2, p. 195-209.

18.5.87. LUPIEN, Pascal. Virtual reference in the age of pop-up blockers, firewalls, and Service Pack 2. Online, 2006, vol. 30, n. 4, p. 14-19.

18.5.88. MANUEL, Sue. Weblog use in information and enquiries service provision. Assignation, 2005, vol. 22, n. 2, p. 5-7.

18.5.89. MARTÍNEZ USERO, José Ángel. Nuevas tecnologías para nuevas bibliotecas: desarrollo de servicios de información electrónica. Buenos Aires: Alfagrama, 2007.

18.5.90. MATHEWS, Brian S. Libraries' Place in Virtual Social Networks . Journal of Web Librarianship, 2007, vol. 1, n. 2, p. 71-74.

18.5.91. MCGEACHIN, R. B. Videoconferencing and remote application sharing for distant reference service. The Reference Librarian, 1999, n. 65, p. 51-60.

18.5.92. MEOLA, Marc; STORMONT, Sam. Real-Time reference service for the remote user: from the telephone and electronic mail to Internet chat, instant messaging, and collaborative software. The Reference Librarian, 1999, n. 67-68.

18.5.93. MERLO VEGA, José Antonio. Bibliotecas y web social. Educación y biblioteca, 2007, n. 161, p. 62-124.

18.5.94. NELSON, Megan S. Initiating engineering outreach reference services: background and practice. Reference Services Review, 2007, vol. 35, n. 2, p. 265-284.

18.5.95. NYBRATEN, Frank Robert; ARNTZEN, Jonas Svartberg. Participation and interaction. Scandinavian Public Library Quarterly, 2007, vol. 40, n. 1, p. 14-15.

18.5.96. OLIVARES, Olivia. Helping You Buy: Virtual Reference Systems. Computers in Libraries, 2004, vol. 24, n. 5, p. 25-29.

18.5.97. OVADIA, Steven. Real-time chat reference and the importance of text-chat. The Reference Librarian, 2002-2003, vol. 38, n. 79/80, p. 157-161.

18.5.98. PEARCE, Linda. Reserving workstations on a local area network: development of a LAN booking system. Campus-Wide Information Systems, 1993, vol. 10, n. 2. 
18.5.99. POMERANTZ, Jeffrey. A conceptual framework and open research questions for chat-based reference service. Journal of the American Society for Information Science and Technology, 2005, vol. 56, n. 12, p. 1288-1302.

18.5.100. POMERANTZ, Jeffrey; STUTZMAN, Frederic. Lyceum: A Blogsphere for Library Reference. Chapel Hill, NC: University of North Carolina at Chapel Hill, School of Information and Library Science, 2004.

18.5.101. PORTER, Susan. Chat: from the desk of a subject librarian. Reference Services Review, 2003, vol. 31, n. 1, p. 57-67.

18.5.102. POWELL, Carol A.; BRADIGAN, Pamela S. E-Mail reference services: characteristics and effects on overall reference services at an academic health sciences library. Reference and User Services Quarterly, 2001, vol. 41, n. 2, p. 170178.

18.5.103. PREVIDI, Fabio; FERRARIN, Maurizio; SAVARESI, Sergio M.; BITTANTI, Sergio. Closed-loop control of FES supported standing up and sitting down using Virtual Reference Feedback Tuning: Modelling and Control of Biomedical Systems. Control Engineering Practice, 2005, vol. 13, n. 9, p. 1173-1182.

18.5.104. PULLIAM, Beatrice R.; MCMULLEN, Susan. RYT: are you there? A consortium's switch to IM reference. College and Undergraduate Libraries, 2006, vol. 13, n. 4, p. 55-74.

18.5.105. RADFORD, Marie L.; CONNAWAY, Lynn S. Are we warner? Query clarification in chat reference. En Library Research Roundtable. Washington: ALA Annual Conference, 2007.

18.5.106. REEVES, Linda Andrews. Trying it on for size: piloting synchronous online reference service with Elluminate vClass. Internet Reference Services Quarterly, 2005, vol. 10, n. 2, p. 19-33.

18.5.107. RIOS, Gabriel R. PDA librarian. Reference Services Review, 2004, vol. 32, n. 1, p. 16-20.

18.5.108. ROBINSON, Kathryn. Point-of-need customer service: Mobile service using wireless technology. Journal of access services, 2005, vol. 3, n. 2, p. 1-14.

18.5.109. RONAN, Jana; REAKES, Patrick; OCHOA, Marilyn. Application of reference guidelines in chat reference interactions: a study of online reference skills. College and Undergraduate Libraries, 2006, vol. 13, n. 4, p. 3-30.

18.5.110. SALA, Antonio. Integrating virtual reference feedback tuning into a unified closed-loop identification framework. Automatica, 2007, vol. 43, n. 1, p. 178-183.

18.5.111. SALA, Antonio; ESPARZA, Alicia. Extensions to virtual reference feedback tuning: A direct method for the design of feedback controllers. Automatica, 2005, vol. 41, n. 8, p. 1473-1476.

18.5.112. SCHNEIDER, Karen G. My Patron Wrote Me a Letter: The Joy of E-Mail Reference. American Libraries, 2000, vol. 31, n. 1, p. 96.

18.5.113. SCHNELL, E. H. A Gopher on the reference desk. Medical reference services quarterly, 1994, vol. 13, n. 4 , p. 1-12.

18.5.114. SEADLE, Michael. Mental models for personal digital assistants (PDAs) . Library hi tech, 2003, vol. 21, n. 4.

18.5.115. SMITH, Michael M.; PIETRASZEWSKI, Barbara A. Enabling the roving reference 
librarian: wireless access with tablet PCs. Reference Services Review, 2004, vol. 32, n. 3, p. 249-255.

18.5.116. STEINER, Sarah K.; LONG, Casey M. What Are We Afraid of? A Survey of Librarian Opinions and Misconceptions Regarding Instant Messenger. The Reference Librarian, 2007, vol. 47, n. 97, p. 31-50.

18.5.117. STEPHENS, Michael; GORDON, Rachel Singer. IM-FASTER virtual reference on the cheap! Computers in Libraries, 2006, vol. 26, n. 4, p. 36-37.

18.5.118. STRAUBER, Christopher. Handhled computers in libraries. En Courtney, Nancy (ed.). Library 2.0 and beyond: innovative technologies and tomorrow's user. Westport: Libraries Unlimited, 2007, p. 49-61.

18.5.119. TANG, R; CALARCO, Pv; FAGAN, Jc; STORMONT, S; CASSON, R. Virtual Reference Services: Exploring the Open Source Options. En Proceedings of the American Society for Information Science and Technology. Silver Spring, Maryland : ASIST, 2002, p. 496. Disponible en ISI:000180277800080 [consultado el 17/07/2007].

18.5.120. TINNIN, N.; BUCKSTEAD, J.; RICHARDSON, K. Remote reference by microcomputer: setup and installation. En Conference Proceedings. Central Michigan University (Mount Pleasant, Michigan. 1998). Mount Pleasant, Michigan: Central Michigan University , 1998.

18.5.121. TOMAIUOLO, Nicholas G. Answers.com and Xrefer: the Chevy and Bimmer of ready reference. Searcher, 2005, vol. 13, n. 1, p. 44-50.

18.5.122. VINE, R. Cyberpulse: software for interactive online reference service. Bibliotheca Medica Canadiana, 1998, vol. 20, n. 2, p. 83-84.

18.5.123. WALLACE, Valeri; GEOGHEGAN, Bob. Secure Virtual Reference From Home: Fast, Easy \& Cheap . Annual Digital Reference Conference, 2003, n. 5.

18.5.124. WALLACE, Valeri; GEOGHEGAN, Bob. Swapping Horses: Considerations for Switching Digital Reference Software . Annual Digital Reference Conference, 2003, n. 5.

18.5.125. WARD, David. Chat reference: new challenges for a new service. Internet Reference Services Quarterly, 2005, vol. 10, n. 1, p. 95-97.

18.5.126. WARD, David. How much is enough? Managing chat length. Internet Reference Services Quarterly, 2005, vol. 10, n. 2, p. 89-93.

18.5.127. WARD, David. Instant Messaging and chat reference. Internet Reference Services Quarterly, 2006, vol. 11, n. 1, p. 103-106.

18.5.128. WARD, David. Why users choose chat: a survey of behavior and motivations. Internet Reference Services Quarterly, 2005, vol. 10, n. 1, p. 29-46.

18.5.129. WASIK, Joann M. Commercial Digital Reference and AskA Services. The Virtual Reference Desk, 1998.

18.5.130. WESTBROOK, Lynn. Chat reference communication patterns and implications: applying politeness theory. Journal of Documentation, 2007 , vol. 63, n. 5, p. 638-658.

18.5.131. WOOD, M. Sandra. Medical Librarian 2.0: Use of Web 2.0 Technologies in Reference Services. Binghamton: The Haworth Press, 2007.

18.5.132. YUE, Joseph. The Use Of ICQ In Providing Real Time Reference Services . Annual Digital Reference Conference, 2000, n. 2. 


\subsection{Servicios públicos de referencia digital}

18.6.1. ABCARTOS, Jean-Pascal. Le bureau d'assistance centralisé: une hot-line á la Bibliothéque Nationale de France? Bulletin des bibliothèques de France, 2000, vol. 45, n. 4.

18.6.2. ACCART, Jean-Philippe. Le Guichet virtuel sur la Suisse : valoriser les compétences et les ressources. Arbido, 2007, n. 2, p. 61-63.

18.6.3. ACCART, Jean-Philippe. Guichets virtuels: haut niveau de références. Archimag, 2004-2005, n. 180, p. 32-33.

18.6.4. ACCART, Jean-Philippe. A question about Switzerland? SwissInfoDesk. En IFLA General Conference and Council (71. 2005. Oslo). Oslo: IFLA, 2005. Disponible en http://www.ifla.org/IV/ifla71/papers/030e_trans-Accart.pdf [consultado el 17/07/2007].

18.6.5. ACCART, Jean-Philippe. The SwissInfoDesk experiment: the building of a website subject gateway as a contributive part of a virtual reference desk. Collection Building, 2006, vol. 25, n. 4, p. 134-138.

18.6.6. ACCART, Jean-Philippe. SwissInfoDesk: the Virtual Reference Desk Project of the Swiss National Library. New Library World, 2006, vol. 107 , n. 5/6, p. 228-237.

18.6.7. ACCART, Jean-Philippe. Une question sur la Suisse ?: SwissInfoDesk. En IFLA General Conference and Council (71. 2005. Oslo). Oslo: IFLA, 2005. Disponible en http://www.ifla.org/IV/ifla71/papers/030f-Accart.pdf [consultado el 17/07/2007].

18.6.8. AHMED, Terry T.; WILLARD, Carolyn. Automated customer service at the National Library of Medicine. First Monday, 2006, vol. 11, n. 11.

18.6.9. ANDRESEN, Leif. Bibliotek.dk Visit your library from home: Better quality and more information. Scandinavian Public Library Quarterly, 2002, vol. 35, n. 1.

18.6.10. BAILEY-HAINER, Brenda. Collaborative virtual reference in Colorado. Colorado Libraries, 2003, vol. 29, n. 1, p. 15-18.

18.6.11. BANHEGYI, Zsolt. Digital reference in the USA . Konyvtari Figyelo (Library Review), 2001, vol. 2001, n. 4, p. 694-698.

18.6.12. BARTOLINI, Laurie. The evolution of virtual reference in Illinois. Illinois Libraries, 2005, vol. 85, n. 4, p. [n].

18.6.13. BAUM, Jenny; LYONS, Kate. Predicting the success of commercial AskA services in the United States and abroad. The Reference Librarian, 2004, n. 85, p. 8189.

18.6.14. BAZIN, Patrick. Le Guichet du Savoir. Arbido, 2005, vol. 20, n. 6, p. 9-11.

18.6.15. BAZIN, Patrick. The Guichet du Savoir: A service for knowledge sharing and a driving force for change. Library Management, 2006, vol. 27, n. 5, p. 423-429.

18.6.16. BELL, Lori; PETERS, Tom; RUDA, Sharon; SUSSMAN, Diana Brawley. InfoEyes: a virtual reference service for the visually impaired. Library Hi Tech News, 2004 , vol. 21 , n. 6 , p. 5-11.

18.6.17. BENEDETTI, Fabrizia. Chiedilo al bibliotecario. Biblioteche Oggi, 2003, vol. 21, n. 2, p. 15-23.

18.6.18. BERUBE, Linda. Ask Live! UK public libraries and virtual collaboration. Library 
and Information Research News, 2003, vol. 27, n. 86, p. 43-50.

18.6.19. BERUBE, Linda. Collaborative digital reference: an Ask a Librarian (UK) overview. Program, 2004, vol. 38, n. 1, p. 29-41.

18.6.20. BERUBE, Linda. People'e Network Enquire: virtual reference in England. En IFLA General Conference and Council (71. 2005. Os/o). Oslo: IFLA, 2005. Disponible en http://www.ifla.org/IV/ifla71/papers/028e-Berube.pdf [consultado el 17/07/2007].

18.6.21. BIERMA, L. The Illinois FirstSearch project. Illinois Libraries, 1995, vol. 77, n. 4, p. $210-217$.

18.6.22. BOBOWSKI, Alan; MEIZNER, Kathie; GILMAN, Franice; NIXON, Carol. Collaborative IT planning at Montgomery County Public Library, Maryland. En Annual Computers in Libraries Conference (17. 2002. Washington). Medford, NJ: Information Today, 2002, p. 8.

18.6.23. BRANDORFF, Gunter. AI@din weiss alles. Drei Jahre erfolgreicher Informationsdienst der niederlandischen Bibliotheken= Al@din knows everything: three years of successful information service by the Netherlands libraries. BuB Forum Bibliothek und Information, 2005, vol. 57, n. 11/12, p. 780-782.

18.6.24. BROMBERG, P. Managing a statewide virtual reference service: how $Q$ and $A$ NJ works. Computers in Libraries, 2003, vol. 23, n. 4, p. 26-31.

18.6.25. BROMBERG, Peter; HYMAN, Karen. I Am Ecstatic About the Whole Darn Thing!: Customer feedback and lessons learned at Q and A NJ, New Jersey's 24/7 live virtual reference service. Annual Digital Reference Conference, 2003, n. 5.

18.6.26. BURY, Stephen. The British Library Experience. Annual Digital Reference Conference, 2001, n. 3.

18.6.27. CHAN, Ben. 24-Hour Reference Service. Library + Information Update, 2005, vol. 4 , n. 6 , p. 24-26.

18.6.28. CHAUDHRY, Abdus Sattar; JEANNE, Chua. Call centres for enhanced reference services: a comparison of selected library call centres and the Reference Point at National Library of Singapore. Library Review, 2004, vol. 53, n. 1, p. 37-49.

18.6.29. COERS, Rob. Chatservice in Delft= Chatroom services at Delft. BibliotheekBlad, 2003, vol. 7, n. 21/22, p. 19.

18.6.30. COERS, Rob. Plinklet en chat: Vredespaleis opent haar deuren= Plinklet and chat: the Peace Palace opens its doors. BibliotheekBlad, 2004, vol. 8, n. 7, p. 11.

18.6.31. COLSTON, Dale E.; LISA, David M.; SWEET, Marianne F. Q and A NJ: service design and impact. Internet Reference Services Quarterly, 2003, vol. 8, n. 1/2, p. 4969.

18.6.32. COLVIN, Gloria. Florida libraries go live: a look at chat reference services. Internet Reference Services Quarterly, 2003, vol. 8, n. 1/2, p. 107-116.

18.6.33. DALGAARD, Birgitte. Stor success med sma skonhedsfejl= Great success with small imperfections. Bibliotekspressen, 2005, vol. 26, n. 2, p. 6-9.

18.6.34. DAUGAARD, Vera. The Co-operation Across Cultures in Public And Stientific Libraries: The Cooperation In Net Librarian / BiblioteksVagten: A Danish Ask The Librarian Service. En IFLA General Conference and Council (69. 2003. Berlín). Berlín: IFLA, 2003. 
18.6.35. DAUGAARD, Vera. Net Librarian: A Danish National Online Information Service. Annual Digital Reference Conference, 2000, n. 2.

18.6.36. DAUGAARD, Vera; KRAG, S. D. Net Librarian.dk: a joint project. Scandinavian Public Library Quarterly, 2003, vol. 36, n. 1, p. 8-11.

18.6.37. DAVIS, Kate. AskNow Instant Messaging: innovation in virtual reference. Australian Library Journal, 2007, vol. 56, n. 2, p. 152-174.

18.6.38. DE JONG, Martin. Welke gevolgen heeft al@din voor bibliotheken?=What effects will AI@din have on public libraries? BibliotheekBlad, 2003, vol. 7, n. 25/26, p. 13.

18.6.39. DUAGAARD, Vera. Net librarian: Danish net based information service. Scandinavian Public Library Quarterly, 2000, vol. 33, n. 2, p. 7-9.

18.6.40. DYRBYE, Holger; ERLANDSEN, Poul; POULSEN, Gert; SONDERGAARD, Peter. Virtuel reference og biblioteker i USA $=$ Virtual reference and libraries in the USA. DF Revy, 2005, vol. 28, n. 2, p. 4-9.

18.6.41. EASTELL, Ciara. Answers Now: from Somerset to. Public Library Journal, 2004, vol. 19, n. 4, p. 27-29.

18.6.42. EIK, Solveig. Hi, what can I do for you? New roles for the librarian behind the scenes at the library. Scandinavian Public Library Quarterly, 2003, vol. 36, n. 1, p. 4-7.

18.6.43. FENNEWALD, Joseph; MOYO, Lesley M.; PROBST, Laura K.; WARE, Susan A. Ask a Penn State librarian, live: virtual reference service at Penn State. The Reference Librarian, 2002-2003, vol. 38, n. 79/80, p. 281-295.

18.6.44. FLAGG, Gordon. Libraries Launch 24/7 E-Reference Service. American Libraries, 2001, vol. 32, n. 7, p. 16.

18.6.45. FREDERIKSEN, L. Ask a Librarian: implementing a virtual reference project in Washington State. PNLA Quarterly, 2003, vol. 67, n. 3, p. 5.

18.6.46. FULLERTON, Vera. E-mail Reference: Refocus and Revise. Experiences from Gelman Library. En IFLA General Conference and Council (67. Boston. 2001). Boston: IFLA, 2001. Disponible en http://www.ifla.org/IV/ifla67/papers/056-98e.pdf [consultado el 17/07/2007].

18.6.47. GAUDER, B.; HERMES, F.; KRESH, D.; HIRKO, D.; O'NEILL, N. Reference cooperative expands with QuestionPoint. OCLC Newsletter, 2002, n. 258, p. 4-11.

18.6.48. GAUDER, Brad. Bringing virtual reference to library users in Canada. OCLC Newsletter, 2003, n. 261, p. 21-23.

18.6.49. GAUDET, Franceen. Virtual Reference Canada (VRC): A Canadian service in a multicultural environment. En IFLA General Conference and Council (68. 2002. Glasgow). Glasgow: IFLA, 2002. Disponible en http://www.ifla.org//V/ifla68/papers/004-128e.pdf [consultado el 17/07/2007].

18.6.50. GENTILINI, Virginia; MENARBIN, Enrica. Quali domande? Biblioteche Oggi, 2003, vol. 21, n. 2, p. 23-27.

18.6.51. GOTTESMAN, Laura; KRESH, Diane; TAKAGI, Kazuko . QuestionPoint: collaboration between the Library of Congress and the Online Computer Library Center (OCLC): an update. Journal of Information Processing and Management, 2004 , vol. 47, n. 8, p. 535-540. 
18.6.52. GREENE, Louise; THOMPSON, Joseph. What Went Right? Customer Service and Repeat Users at Maryland AskUsNow! Annual Digital Reference Conference, 2003, n. 5.

18.6.53. HAKLI, P. The Virtual Reference Station Concept in Finland - a Case Study. Survey Review, 2007, vol. 39, n. 304, p. 145-155.

18.6.54. HATTERY, M. Computers in libraries: virtual reference plus dead and emerging technologies. Information Retrieval and Library Automation, 2002, vol. 37, n. 11, p. 15.

18.6.55. HATTERY, M. Reference service in a digital age: three projects. Information Retrieval and Library Automation, 1999, vol. 34, n. 9, p. 1-2.

18.6.56. HELFER, D. S. Virtual reference in libraries: remote patrons heading your way? Searcher, 2001, vol. 9, n. 2, p. 67-70.

18.6.57. HERMOSILLA MORENO, Antonia Dolores; PEÑALVER MARTíNEZ, Ángel. ¿Bibliotecarios respondiendo a bibliotecarios?: las consultas y fuentes de información sobre bibliotecas y documentación en Pregunte, las bibliotecas responden. Congreso Nacional de Bibliotecas Públicas, 2006, vol. 3.

18.6.58. HERZOG, Susan; WISE, Suzanne. Integrating a New Service: One Library's Experience with Digital Reference. North Carolina Libraries, 2003, vol. 61, n. 4, p. 152-153.

18.6.59. HIRKO, Buff. Building networks, building trust: Statewide Virtual Reference. Advances In Librarianship, 2005, vol. 29, p. 159-186.

18.6.60. HOIVIK, Tord. Public libraries in the Norwegian reference market. New Library World, 2007, vol. 108, n. 9/10, p. 396-406.

18.6.61. HORNIG, Leo. Al@din: de digitale informatiedienst van openbare bibliotheken = Al@din: the digital information service from public libraries. Informatie Professional, 2003, vol. 7, n. 1 , p. 18-21.

18.6.62. IRWIN, K. R. Professional reference service at the Internet Public Library with 'freebie' librarians. Searcher, 1998, vol. 6, n. 9, p. 21-23.

18.6.63. IVANYI, Kristof; TOTH, Ferenc Tibor. Az informacioszolgaltatastol a tartalomszalgaltatasig: a LibInfo jelene es jovoje $=$ From information service to content providing: the present and future of Libinfo. Tudomanyos es Muszaki Tajekoztatas, 2004, vol. 51, n. 7, p. 271-275.

18.6.64. JIANZHONG, Wu; JIN, Xiaoming. A Dynamic Gateway to Information: electronic services at the Shanghai Library. Information Development, 2004, n. 20, p. 111-116.

18.6.65. JONSBY, E. The virtual librarian answers your questions. Scandinavian Public Library Quarterly, 2000, vol. 33, n. 3, p. 20-22.

18.6.66. JOSHI, I. AskUsQuestions.com. Live experienced librarians available over the Web. Unabashed Librarian, 2001, n. 118, p. 9-13.

18.6.67. KASOWITZ, Abby S. AskA Service Question Submission Forms. The Virtual Reference Desk, 1998.

18.6.68. KEYS, Jacki; WILSON, Fran. AskNow! Evaluating an Australian collaborative chat reference service: a project manager's perspective. Australian Academic and Research Libraries, 2004, vol. 35, n. 2, p. 81-94. 
18.6.69. KIERKEGAARD, E. Ugletip: en laesesal paa nettet. 'Owltips': a reference room on the Net. Bibliotekspressen, 2003, n. 6, p. 218-219.

18.6.70. KLITKOU, N. QuestionPoint is the new concept in the field of reference work. Synopsis, 2002, vol. 33, n. 3, p. 159-162.

18.6.71. KOFSKY, Charna. On-line reference service-Scarborough Public Library. Ontario Library Review, 1980, vol. 64, n. 4, p. 293-298.

18.6.72. KRESH, Diane N. High touch and high tech: QuestionPoint as a model for the future of reference. Joho Kanri, 2002, vol. 45, n. 8, p. 553-564.

18.6.73. KRESH, Diane Nester. Follow-up on the Collaborative Digital Reference Service Project. En IFLA General Conference and Council (67. 2001. Boston). Boston: IFLA, 2001.

18.6.74. KRESH, Diane Nester. Library quality reference meets the World Wide Web. En IFLA General Conference and Council (67. 2001. Boston). Boston: IFLA, 2001. Disponible en http://www.ifla.org//V/ifla67/papers/131-151e.pdf [consultado el 17/07/2007].

18.6.75. KRESH, Diane Nester. Offering high quality reference service on the Web. The Collaborative Digital Reference Service (CDRS). D-Lib Magazine, 2000, vol. 6, n. 6.

18.6.76. LAERKES, Berit; NIXON, Carol. Ask Olivia (Sporg Olivia): www.spoergolivia.dk: an Internet answering service for children. Internet Librarian International 2003 Collected Presentations, 2003, p. 236-240.

18.6.77. LANKES, R. David. The Virtual Reference Desk: Building a Network of Expertise for America's Schools . The Virtual Reference Desk, 1998.

18.6.78. LANKES, R. David. The Virtual Reference Desk: Question Interchange Profile. The Virtual Reference Desk, 1999.

18.6.79. LONG, S. Partnerships: 'Q and A NJ' handles reference 24/7. Interface, 2002, vol. 24, n. 2 , p. 4.

18.6.80. LONGO, Brunella. I servizi di reference nell'era dell'accesso. Biblioteche Oggi, 2001, vol. 19, n. 3, p. 42-58.

18.6.81. MARTín PERTíÑEZ, Francisco J.; ROSALES UARO, María Helena. Nuevos sistemas de acceso a la información y referencia en bibliotecas: La Biblioteca Responde. En Jornadas Bibliotecarias de Andalucía (11. 2000. Sevilla). Sevilla: Asociación Andaluza de Bibliotecarios, 2000, p. 191-201.

18.6.82. MCCLELLAN, Cynthia S. Live reference in an Academic Health Sciences Library: the Q and A NJ experience at the University of Medicine and Dentistry of New Jersey Health Sciences Library at Stratford. Internet Reference Services Quarterly, 2003, vol. 8, n. 1/2, p. 117-126.

18.6.83. MCGLAMERY, Susan; ULRICH, Paul S. Serving Patrons in Their Language, Not Just Ours. En IFLA General Conference and Council 73. 2007. Durban). Durban: IFLA, 2007. Disponible en http://www.ifla.org/IV/ifla73/papers/128-McGlamery_Ulrichen.pdf [consultado el 17/07/2007].

18.6.84. MCINERNY, Carmel; FIELDING, Elizabeth. A big Ask! Reference: time zones and the art of the cooperation. En Click 06 : ALIA 2006 Biennial Conference. Perth: ALIA, 2006. Disponible en http://conferences.alia.org.au/alia2006/presentations/McInerny_Fielding.pdf [consultado el 17/07/2007]. 
18.6.85. MERCER, Prue; DRACOULIS, Elizabeth. Creating National Collaborative Reference Services in Australia. En Creating a reference future: Annual Virtual Reference Desk Conference . Seattle; Dublin: Web Junction, 2004. Disponible en http://webjunction.org [consultado el 17/07/2007].

18.6.86. MERLO VEGA, José Antonio; SORLI ROJO, Angela. Pregunte a un bibliotecario: servicios de referencia en línea. Revista española de documentación científica, 2003, vol. 26, n. 1.

18.6.87. MORIN, Alison. Approaching Best Practices and Guidelines for Digital Reference: From Virtual to Real - Lessons Learned from the Library of Congress . Annual Digital Reference Conference, 2003, n. 5.

18.6.88. MORIN, Nicolas. Un service de référence en ligne en temps réel. Biblioacid, 2005 , vol. 2, n. 2, p. 13-17.

18.6.89. MORTENSEN, M.; KRESH, D. I fingerspidskontakt med verden= In fingertip contact with the world. Bibliotekspressen, 2002, n. 11, p. 326-329.

18.6.90. MOYO, L. M. Reference anytime anywhere: towards virtual reference services at Penn State. The Electronic Library, 2002, vol. 20, n. 1, p. 22-28.

18.6.91. NIELSEN, Ellen. Research libraries in BiblioteksVagten.dk. DF Revy, 2004, vol. 27, n. 1 , p. 24-25.

18.6.92. NOTARIO URANGO, Juan. La Biblioteca de Castilla-La Mancha colaborará con la Biblioteca Central y Regional de Berlín en la prestación de servicios multilíngües de referencia virtual. Anaquel, 2007, n. 39, p. 26.

18.6.93. Nueva versión de Pregunte, las bibliotecas responden. Correo bibliotecario, 2007, n. 98, p. 26-27.

18.6.94. O'LEARY, Mick. QuestionPoint fortifies libraries in Internet Age. Online, 2003, vol. 27, n. 3, p. 70-72.

18.6.95. ORMES, S. You only had to ask. Library Technology, 1998, vol. 3, n. 2, p. 39-40.

18.6.96. PACILLO, Angela. Chiedi @lla tua biblioteca. Biblioteche Oggi, 2006, vol. 24, n. 8, p. 45-54.

18.6.97. PEARCE, Liz. IT for Me: Personalising Access to Online Resources in Public Libraries. Library and information research, 2004-, vol. 28 , n. 88, p. 56-58.

18.6.98. PERRY, Leanne; MCELHILL, Maggie. So, what's the difference: an evaluation of the AskNow! live reference service. En Information Online Conference (13. 2007. Sydney). Sydney: ALIA, 2007. Disponible en http://www.sl.nsw.gov.au/staff/pdfs/asknow_paper.pdf [consultado el 17/07/2007].

18.6.99. PETERSEN, J. B.; TINDBAEK, B.; SOLBERG, G. Fra internetdialog til Sport Biblioteket: en national landsdaekkende stumperservice= From Internet dialogue to Ask the Library: a national countrywide stumper service. Bibliotekspressen, 1999, n. 2, p. 69-70.

18.6.100. PIETRO, Christelle di; CALENGE, Bertrand. Le Guichet du Savoir: Répondre aux demandes de contenus. Bulletin des Bibliothèques de France, 2005, vol. 50, n. 4, p. 38-42.

18.6.101. Pregunte. Anaquel, 2002, n. 17, p. 11.

18.6.102. Pregunte, las bibliotecas responden: nuevo servicio cooperativo de información 
en Internet. Correo Bibliotecario, 2000, n. 43, p. 5.

18.6.103. PRICE, A.; KRESH, D. The truth is out there: QuestionPoint, en global digital referencetjeneste $=$ The truth is out there: QuestionPoint, a global digital reference service . DF Revy, 2002, vol. 25, n. 5, p. 113-114.

18.6.104. PRIMARY RESEARCH GROUP; PROBST, Laura K. Creating the virtual reference service: Digital reference management: a Penn State case study. Internet Reference Services Quarterly, 2003, vol. 10, n. 2, p. 79-43, 59.

18.6.105. QUINN, Todd; BRIGGS SIMON, Lea. Small collaboration, big effort: the realities of a small statewide collaborative virtual reference service. College and Undergraduate Libraries, 2006, vol. 13, n. 4, p. 97-116.

18.6.106. QUINT, B. QuestionPoint marks new era in virtual reference. Information Today, 2002, vol. 19, n. 7, p. 50.

18.6.107. RAMIREZ, J. L. Reference rover: the hesitant patron's best friend. College and Research Libraries News, 1994, vol. 55, n. 6, p. 354-7.

18.6.108. ROGERS, Michael. Colorado State Library Talks Virtual Reference. Library Journal, 2005, vol. 130, n. 15, p. 25.

18.6.109. RÖSCH, Hermann. Digital Reference in Germany: an overview and experiences on the need for qualifications. En IFLA General Conference and Council (69. 2003. Berlín). Berlín: IFLA, 2003. Disponible en http://www.ifla.org//V/ifla69/papers/107e_trans-Roesch.pdf [consultado el 17/07/2007].

18.6.110. RYDER, M. A.; NEBEKER, B. Implementing an 'Ask a Librarian' electronic reference service. Community and Junior College Libraries, 1999, vol. 9, n. 1, p. 2134.

18.6.111. SACHS, Diana. Ask a librarian: Florida's virtual reference service. Community and Junior College Libraries, 2004, vol. 12, n. 4, p. 49-58.

18.6.112. SAORÍN PÉREZ, Tomás. Una fórmula para Internet: productos cooperativos: La experiencia de 'Pregunte, las bibliotecas responden'. Educación y Biblioteca, 2001 , vol. 13, n. 122.

18.6.113. SAUNDERS, Laverna. Building the Virtual Reference Desk. Information Today, 2001, vol. 18, n. 3, p. 25.

18.6.114. SCHOUTEN, Jaap. Najaarscampagne al@din: vernieuwend en dynamisch imago communiceren= An Autumn campaign for Al@din: putting across an innovative and dynamic image. BibliotheekBlad, 2003, vol. 7, n. 20, p. 10-12.

18.6.115. SILVERIA, J. B.; HOLMER, S. Serving up information at the QandAcafe: virtual reference in a multitype library consortium. Public Services Quarterly, 2002, vol. 1, n. 2, p. 15-27.

18.6.116. SILVERSTEIN, Joanne L.; LANKES, R. David. Digital Reference Services and Centers at the United States Department of Education: Analysis and Recommendations. Syracuse, NY: Virtual Reference Desk Project; Information Institute of Syracuse, 1999.

18.6.117. SISLER, Eric; SMITH, Veronica. Building a Library Network from Scratch: Eric \& Veronica's excellent adventure. Computers in Libraries, 2000, vol. 20, n. 9, p. 44.

18.6.118. SLOAN, Bernie. Reference service in the digital library: a report on the Ready for Reference project. Library Hi Tech News, 2001, vol. 18, n. 10, p. 14-19. 
18.6.119. STERLING, Rayette. The Washington State VRef Lab. Alki, 2005, vol. 21, n. 2, p. 17.

18.6.120. STOCKHAM, Marcia; TURTLE, Elizabeth; HANSEN, Eric. KANAnswer: a collaborative statewide virtual reference pilot project. The Reference Librarian, 20022003, vol. 38, n. 79/80, p. 257-266.

18.6.121. STROM, Nina. Ask the Library: information literacy among users and librarians is promoted by digital reference services. Scandinavian Public Library Quarterly, 2004, n. 3, p. 8-11.

18.6.122. SULLIVAN, Doreen. Characteristics of E-mail Reference Services in Selected Public Libraries, Victoria, Australia . The Reference Librarian, 2004, vol. 41, n. 85, p. 51-80.

18.6.123. TAYLOR, M. A digital reference library emerges at Stanton Library. Australasian Public Libraries and Information Services, 2001, vol. 14, n. 3, p. 97-100.

18.6.124. THOMPSON, Joseph. After School and Online. Library Journal, 2003, vol. 128, n. 1, p. 35-37.

18.6.125. TILLOTSON, Dianne. AskNow!: but wait for the answer! Online Currents, 2002, vol. 17, n. 10, p. 4-7.

18.6.126. TIPTON, Carol J.; EARP, Vanessa J. One school's experience with virtual reference. Internet Reference Services Quarterly, 2004, vol. 9, n. 3/4, p. 99-114.

18.6.127. TOKAJI-NAGY, Erzsebet; TOTH, Ferenc Tibor. LibInfO, the Internet reference service of Hungarian libraries. Tudomanyos es Muszaki Tajekoztatas, 2002, vol. 49, n. 12, p. 463-469.

18.6.128. TRAIN, Mary Beth. Answers at your fingertips: live Internet reference for teachers, students, parents, and library media specialists. Knowledge Quest, 2005, vol. 33, n. 3, p. 19-21.

18.6.129. TRUELSON, Judith A. Partnering on virtual reference using QuestionPoint: guidelines for collaboration between academic libraries in Australia/New Zealand and the US. AARL Australian Academic \& Research Libraries , 2004, vol. 35, n. 4.

18.6.130. ULRICH, P. S. It works: die Arbeit des Collaborative Digital Reference Service (CDRS)= It works: the work of the Collaborative Digital Reference Service (CDRS). Buch und Bibliothek, 2002, vol. 54, n. 4, p. 238-242.

18.6.131. ULRICH, Paul S. Einsatz und Erfahrungen mit QuestionPoint in der Zentral- und Landesbibliothek Berlin= Implementation of QuestionPoint and experience with this product in the Central- and Land Library, Berlin. Bibliotheksdienst, 2004, vol. 38, n. 1, p. 54-60.

18.6.132. VAN HOUTEN, Carol. Wired New Jersey: Q and A NJ. The Reference Librarian, 2004, n. 85, p. 91-100.

18.6.133. VONDRACEK, Ruth. Balancing Statewide and Local Digital Reference Service. The Reference Librarian, 2006, vol. 46, n. 95/96, p. 81-98.

18.6.134. WAGONER, Mary T. Live Homework Help online. Texas Library Journal, 2005, vol. 81, n. 4, p. 136, 138-139.

18.6.135. WILLEMSE, Leo. AI@din snel en betrouwbaar= Al@din is fast and reliable. BibliotheekBlad, 2003, vol. 7, n. 10/11, p. 28-29. 
18.6.136. WÖHNER, Bodil. The Public Library's Role in the Danish Information Society: demand for new competencies? En IFLA General Conference and Council (67. 2001. Boston). Boston : IFLA, 2001. Disponible en http://www.ifla.org//V/ifla67/papers/05998e.pdf [consultado el 17/07/2007].

18.6.137. YODA, Norihisa. Digital Reference Service on Collaborative Reference Database project of the National Diet Library. Journal of Information Science and Technology Association, 2006, vol. 56, n. 3, p. 90-95.

18.6.138. YODA, Norihisa. An introduction to the Collaborative Reference Database Project: how to utilize the database and what is expected of pharmaceutical libraries. Pharmaceutical Library Bulletin, 2006, vol. 51, n. 3, p. 220-226.

18.6.139. ZHAN, Jenny. Virtual reference services: Taking up the challenge in Swiss libraries . Arbido, 2005, vol. 20, n. 6, p. 5-6.

18.6.140. ZHENG, Songhui. Virtual reference services in China: helping the informationpoor. The Electronic Library, 2006, vol. 24, n. 6, p. 763-773.

\subsection{Servicios especializados de referencia digital}

18.7.1. ABDOULAYE, Kaba; MAJID, Shaheen. Use of the Internet for reference services in Malaysian academic libraries. Online Information Review, 2000, vol. 24, n. 5, p. 381-389.

18.7.2. ALBANESE, Andrew Richard. A Tale of Three Libraries. Library Journal, 2004, vol. 129, p. 12-14.

18.7.3. ANDERSON, Eric; BOYER, Josh; CICCONE, Karen. Remote Reference Services at the North Carolina State University Libraries . Annual Digital Reference Conference, 2000, n. 2.

18.7.4. ASCHER, Marie T.; CROW, Suzanne J.; LOUGEE-HEIMER, Haldor; MARKGREN, Susanne. Asked and answered-online: how two medical libraries are using OCLC's QuestionPoint to answer reference questions. Medical reference services quarterly, 2004, vol. 23, n. 1, p. 13-28.

18.7.5. BAINS, Simon. The OCLC QuestionPoint electronic reference service: experiences of a group of CURL libraries. SCONUL Newsletter, 2003, n. 29, p. 21-26.

18.7.6. BAINS, Simon. Testing collaborative electronic reference services: The experience of UK University Research Libraries in the use of OCLC's QuestionPoint. Annual Digital Reference Conference, 2002, n. 4.

18.7.7. BALLESTE, R.; RUSSELL, G. Implementing virtual reference: Hollywood technology in real life. Computers in Libraries, 2003, vol. 23, n. 4, p. 14-16.

18.7.8. BEARD, Jill; BOTTOMLEY, Neil; GEESON, Rachel; SPENCER, Stuart. ASK: a virtual enquiry desk - a case study. The Electronic Library, 2003, vol. 21, n. 6, p. 601608.

18.7.9. BELANGER, Yvonne; LANKES, R. David; SHOSTACK, Pauline Lynch. Managing data collection for real-time reference: lessons from the AskERIC Live! experience. Internet Reference Services Quarterly, 2003, vol. 8, n. 1/2, p. 137-148.

18.7.10. BENNETT, T. M. G. Appalachian State University Libraries' Ask A Librarian: a reference service for ASU students, faculty, staff, and alumni. Internet Reference Services Quarterly, 2002, vol. 7, n. 1/2, p. 89-98. 
18.7.11. BLANK, Phil. Virtual reference at Duke: an informal history. The Reference Librarian, 2002-2003, n. 79/80, p. 215-224.

18.7.12. BOBAL, Alison M.; COX, Roxanne; SCHMIDT, Cynthia M. One library's experience with live, virtual reference. Journal of the Medical Library Association, 2005, vol. 93, n. 1, p. 123-125.

18.7.13. BORUFF-JONES, Polly D. Our experience with two virtual reference services at IUPUI University Library . The Reference Librarian, 2002-2003, vol. 79-80, n. 38, p. 241-255.

18.7.14. BOYER, Joshua. Virtual reference at the NCSU Libraries: the first one hundred days. Information Technology and Libraries, 2001, vol. 20, n. 3, p. 122-128.

18.7.15. BRADBURY, D.; PAYNE, G. OPAL: building a 24/7 automated enquiry service for Open University Distance Learners. Assignation, 2002, vol. 19, n. 3, p. 36-39.

18.7.16. BRADBURY, D.; PAYNE, G. The OPAL project: developing an online digital reference service for distance learners. Library Hi Tech News , 2001, vol. 18, n. 9, p. 28-29.

18.7.17. BROUGHTON, Kelly M. Usage and user analysis of a real-time digital reference service. The Reference Librarian, 2002-2003, vol. 38, n. 79/80, p. 183-200.

18.7.18. BROWN, Elizabeth; MAXIMIEK, Sarah; RUSHTON, Erin E. Connecting to students: launching instant messaging reference at Binghamton University. College and Undergraduate Libraries, 2006, vol. 13, n. 4, p. 31-42.

18.7.19. BUTKOVICH, Nancy J.; TAYLOR, Kathryn L.; DENT, Sharon H.; MOORE, Anne $\mathrm{S}$. An expert system at the reference desk: impressions from users. The Reference Librarian, 1989, n. 23, p. 61-74.

18.7.20. CHAPMAN, Kimberly; BOSQUE, Darcy Del. Ask a UT system librarian: a multicampus chat initiative supporting students at a distance. Internet Reference Services Quarterly, 2005 , vol. 9, n. 3-4, p. 55-79.

18.7.21. CHASON, Leslie. Giving patrons what they want: creating the Florida psychiatric facilities list. Behavioral and Social Sciences Librarian, 2003, vol. 21, n. 2, p. 49-55.

18.7.22. CHOWDHURY, Gobinda; MARGARITI, Simone. Digital reference services: a snapshot of the current practices in Scottish libraries. Library Review, 2004, vol. 53, n. 1 , p. 50-60.

18.7.23. COERS, Rob. Google Answers: betaalde vraagbeantwoording= Google Answers: a paid enquiry service. BibliotheekBlad, 2003, vol. 7, n. 14, p. 9.

18.7.24. COFFMAN, Steve; MCGLAMERY, Susan. The Librarian and Mr. Jeeves. American Libraries, 2000, vol. 31, n. 5, p. 66.

18.7.25. COHEN, S.; FEREIRA, J.; HORNE, A.; KIBBEE, B.; MISTLEBAUER, H.; SMITH, A. MyLibrary: personalized electronic services in the Cornell University Library. D-Lib Magazine, 2000, vol. 6, n. 4.

18.7.26. CREPUQ. Un service de référence virtuelle pour les bibliothèques universitaires québécoises. Montréal: CREPUQ, 2006.

18.7.27. CURTIS, Dorothy; MARTIN, Kath; PETERSONT, Mary; ROCKLIFF, Sue. Chasing the sun: a virtual reference service between SAHSLC (SA) and SWICE (UK). Health Information and Libraries Journal, 2005, vol. 22, n. 2, p. 117-123. 
18.7.28. DANKERT, Holly Stec; DEMPSEY, Paula R. Building reference strengths through peer training . Reference Services Review, 2002, vol. 30, n. 4, p. 349-354.

18.7.29. DAVENPORT, E.; PROCTER, R.; GOLDENBERG, A. Distributed expertise: remote reference service on a metropolitan area network. The Electronic Library, 1997, vol. 15, n. 4, p. 271-278.

18.7.30. DAVIS, Keith; SCHOLFIELD, Sally. Beyond the virtual shore: an Australian digital reference initiative with a global dimension. Library Review, 2004, vol. 53, n. 1, p. $61-65$.

18.7.31. DIAMOND, Wendy; PEASE, Barbara. Digital reference: a case study of question types in an academic library. Reference Services Review, 2001, vol. 29, n. 3, p. 210219.

18.7.32. DUNN, Kathleen; MORGAN, Ann. Going where the students are: live/Web reference at Cal Poly Pomona. The Reference Librarian, 2002-2003, vol. 38, n. 79/80, p. 201-213.

18.7.33. EDWARDS, Phillip M. Characterization of Volunteer Expertise Within the Internet Public Library Reference Service. Annual Digital Reference Conference, 2002, n. 4.

18.7.34. FARHA, Aida. End-user training in a virtual medical library setting: a case study of an academic medical library in Lebanon. Library Management, 2001, vol. 22, n. 8/9, p. 351-356.

18.7.35. FOLEY, M. Instant messaging reference in an academic library: a case study. College and Research Libraries, 2002, vol. 63, n. 1, p. 36-45.

18.7.36. FRANK, I. E-mail reference service at the University of South Florida: a well-kept secret. Art Documentation, 1998, vol. 17, n. 1, p. 8-9.

18.7.37. FRANKE, Fabian. Ask the UB: the query management system of Wurzburg University Library. Bibliotheksforum Bayern, 2005, vol. 33, n. 3, p. 223-235.

18.7.38. GARDNER, Melanie A.; VRIES, JoAnn De; KAAG, Cindy. How Many Trees in a Forest: Creating Digital Reference Services in Agriculture . Annual Digital Reference Conference, 2000, n. 2.

18.7.39. GHAPHERY, J.; REAM, D. VCU's My Library: librarians love it. . . users? Well, Maybe. Information Technology and Libraries, 2000, vol. 19, n. 4, p. 186-190.

18.7.40. GLEADHILL, D. Does the Nerd have the answer? Library Technology, 1997, vol. 2, n. 2, p. 34-36.

18.7.41. GUIJARRO, Mercedes; VÉLEZ, Soledad; CARRILLO, Cristina. El servicio de referencia en bibliotecas digitales: La experiencia de la Biblioteca Virtual Miguel de Cervantes. En Jornadas de Bibliotecas Digitales (4. 2003. Alicante). 2003. Disponible en http://imhotep.unizar.es/jbidi/jbidi2003/08_2003.pdf [consultado el 17/07/2007].

18.7.42. GUILLOT, Ladonna; STAHR, Beth. A tale of two campuses: Providing Virtual Reference to distance nursing students. Journal of library administration, 2004, vol. 41, n. 1-2, p. 139-152.

18.7.43. HANFMAN, Deborah. AquaRef: an expert advisory system for reference support. The Reference Librarian, 1989, n. 23, p. 113-133.

18.7.44. HARDY, G. Qjumper: a Hypercard library information system. Australian Library Review, 1993, vol. 10, n. 1, p. 41-44. 
18.7.45. HARRIS, Lydia Eato. Digital Reference Education Initiative. Public Services Quarterly, 2006, vol. 2, n. 2/3, p. 195-196.

18.7.46. HATTERY, Maxine. Welcome to the library: Julia is not just a pretty interface. Information Retrieval and Library Automation, 2002, vol. 37, n. 12, p. 1-2.

18.7.47. HAYASHI, Takanori; MATSUYAMA, Tatsuhiko; NIMOTO, Kimihiro. Digital reference services: QuestionPoint, case studies and future plans. Journal of Information Science and Technology Association, 2006, vol. 56, n. 3, p. 96-102.

18.7.48. HENLEY, Caroline. Digital reference services for young library users: a comparison of four services. Library Review, 2004, vol. 53, n. 1, p. 30-36.

18.7.49. HOWARD, Ellen H.; JANKOWSKI, Terry Ann. Reference services via electronic mail. Bulletin of the Medical Library Association, 1986, vol. 74, n. 1, p. 300-204.

18.7.50. HUANG, Min; LIN, Haoming; JIN, Yi. The Distributed Collaborative Virtual Reference System and Its Scheduler Mechanism for Chinese University Libraries. Digital Libraries: International Collaboration and Cross-Fertilization, 2004, p. 124-132.

18.7.51. IBEGBULAM, I. J. Use of ICT for reference services in Nigerian university libraries: results of a survey. Program, 2000, vol. 34, n. 3, p. 297-302.

18.7.52. JIMÉNEZ LÓPEZ, Angels. Servicios de referencia virtuales: consideraciones generales y estado de desarrollo en las bibliotecas universitarias españolas. En Info: Congreso Internacional de Información (5. 2004. La Habana). La Habana: INFO, 2004. Disponible en http://www.congresoinfo.cu/UserFiles/File/Info/Info2004/Ponencias/017.pdf [consultado el 17/07/2007].

18.7.53. JIN, Yi; HUANG, Min; LIN, Haoming; GUO, Jing. Towards collaboration: the development of collaborative virtual reference service in China. The Journal of Academic Librarianship, 2005, vol. 31, n. 3, p. 287-291.

18.7.54. JOHNSON, Corey M. Online chat reference: survey results from affiliates of two universities. Reference and User Services Quarterly, 2004, vol. 43, n. 3, p. 237-247.

18.7.55. KIBBEE, Jo; WARD, David; WE, Ma. Virtual service, real data: results of a pilot study. Reference Services Review, 2002, vol. 30, n. 1, p. 25-36.

18.7.56. LAGACE, N. The Internet Public Library's 'Ask a question worldwide reference service'. Art Documentation, 1998, vol. 17, n. 1, p. 5-7.

18.7.57. LAMY, Rudolf $B$. The odds don't end in legal reference: a brief review of the email at a State Public Law Library. Legal Reference Services Quarterly, 2005, vol. 24, n. $1 / 2$, p. 183-189.

18.7.58. LUPIEN, Pascal. Bilingual virtual reference: its better than searching the Open Web. Computers in Libraries, 2004, vol. 24, n. 5, p. 6, 8, 53-54, 56.

18.7.59. MARTIN, Julie. Ask a librarian virtual reference services at the Boeing library. Internet Reference Services Quarterly, 2003, vol. 8, n. 1/2, p. 127-135.

18.7.60. MATHESON, Scott. Library LAWLINE: Collaborative Virtual Reference in a Special Library Consortium . The Reference Librarian, 2004, vol. 41, n. 85, p. 101114.

18.7.61. MAXEY-HARRIS, Charlene. Chat reference service pilot. Nebraska Library Association Quarterly, 2003, vol. 34, n. 2, p. 6-8.

18.7.62. MCCULIEY, Lucretia; REINAUER, Olivia. Connecting with AIM: The Search for a 
Virtual Reference Niche. College and Undergraduate Libraries, 2006, vol. 13, n. 4, p. 43-54.

18.7.63. MCDONALD, Karen I.; VANDUINKERKEN, Wyoma. Distance education and virtual reference: implementing a marketing plan at Texas A\&M University. Journal of Library and Information Services in Distance Learning, 2005, vol. 2, n. 4, p. 29-40.

18.7.64. MILLER, J. E. Developing a career information gopher: the University of Michigan experience. The Reference Librarian, 1996, n. 55, p. 83-97.

18.7.65. MOELLER, Sherry Engle. Ask-A-Librarian: an analysis of an e-mail reference service at a large academic library. Internet Reference Services Quarterly, 2003, vol. 8, n. 3, p. 47-61.

18.7.66. MORGAN, K.; READE, T. Pioneering portals: MyLibrary@NCState. Information Technology and Libraries, 2000, vol. 19, n. 4, p. 191-198.

18.7.67. NEUHAUS, P.; MARSTELLER, M. R. Chat reference at Carnegie Mellon University. Public Services Quarterly, 2002, vol. 1, n. 2, p. 29-41.

18.7.68. NICHOLSON, Scott; LANKES, R. David. The Digital Reference Electronic Warehouse Project: creating the infrastructure for digital reference research through a multidisciplinary knowledge base. Reference and User Services Quarterly, 2007, vol. 46, n. 3, p. 45-59.

18.7.69. NOVOTNY, Eric; RIMLAND, Emily. Using the Wisconsin-Ohio Reference Evaluation Program (WOREP) to Improve Training and Reference Services. The Journal of Academic Librarianship, 2007, vol. 33, n. 3, p. 382-392.

18.7.70. O'SHEA, Anne; WONG, Sandra. Librarians have left the building: Ask Us HERE! At Simon Fraser University. Feliciter, 2004, vol. 50, n. 3, p. 90-92.

18.7.71. PATRICK, S.; MATTHEWS, C. Ask a Librarian LIVE. College and Research Libraries News, 2002, vol. 63, n. 4 , p. 280-281.

18.7.72. PATTERSON, R. Live virtual reference: more work and more opportunity. Reference Services Review, 2001, vol. 29, n. 3, p. 204-209.

18.7.73. PAYNE, G.; PERROTT, M. Librarians On Call: an instant messaging enquiry service for Open University distance learners. Library and Information Research News, 2003, vol. 27, n. 85, p. 11-21.

18.7.74. PAYNE, G. F.; BRADBURY, D. An automated approach to online digital reference: the Open University Library OPAL Project. Program, 2002, vol. 36, n. 1, p. 5-12.

18.7.75. PAYNE, Georgina; BRADBURY, David. The OPAL Project: Developing An Automated Online Reference System For Distance Learners . D-Lib Magazine, 2001, vol. 7, n. 6 .

18.7.76. PFANDER, J. L. Meeting rangeland information needs through a Web-based reference service: the Arizona AgNIC experience. Journal of Agricultural and Food Information, 2002, vol. 4, n. 2 , p. 33-41.

18.7.77. PLUMB, Abigail. The Internet Public Library as a Teaching Tool for Shockingly Tradional Reference Skills. The Reference Librarian, 2004, vol. 41, n. 85, p. 33-41.

18.7.78. PROENZA, Francisco J.; MEZA, Sergio Ivan Salas; ALETER, Abdulla; PEREZTREJO, Francisco; JAFF, Kayan. The future of extension: Chile's advice online service: view from practice. Information Technology for Development, 2006, vol. 12, n. 
1, p. 77-86.

18.7.79. QUINT, B. Some advice for Google Answers. Information Today, 2002, vol. 19, n. 6, p. 8.

18.7.80. RONAN, Jana Smith. Staffing a real-time reference service: The University of Florida experience. Internet reference services quarterly, 2003, vol. 8, n. 1-2, p. 33-47.

18.7.81. SANTOVENIA DÍAZ, Javier; CAÑEDO ANDALIA, Rubén. Servicio de asistencia bibliográfica y referencia virtual en bibliotecología y ciencias de la información. Acimed, 2006, vol. 14, n. 3.

18.7.82. SCHAAKE, Glenda; SATHAN, Eleanor. We Jumped on the Live Reference Bandwagon, and We Love the Ride! Computers in libraries, 2003, vol. 23, n. 4, p. 2025.

18.7.83. SIMON, Ingeborg. Warum verstecken Sie sich? Warum fragen Sie nicht? Die EMail-Auskunft an deutschen Universitatsbibliotheken= Why do you hide yourself? Why do you not ask? E-mail reference services in Germany university libraries. Bibliothek Forschung und Praxis, 2006, vol. 30, n. 3, p. 367-371.

18.7.84. SIMS, Melanie E. Virtual reference services: the LSU libraries experience. The Reference Librarian, 2002-2003, vol. 38, n. 79/80, p. 267-279.

18.7.85. SMYTH, J. Virtual reference transcript analysis: a few models. Searcher, 2003, vol. 11, n. 3, p. 26-30.

18.7.86. STACY-BATES, Kristine. E-mail Reference Responses from Academic ARL Libraries: An Unobtrusive Study . Reference and User Services Quarterly, 2003, vol. 43, n. 1.

18.7.87. STACY-BATES, Kristine K. Ready-Reference Resources and E-mail Reference on Academic ARL Web Sites . Reference and User Services Quarterly, 2001, vol. 40, n. 1.

18.7.88. STAHL, J. Have a question? Click here: electronic reference at the National Museum of American Art. Art Documentation, 1998, vol. 17, n. 1, p. 10-12.

18.7.89. STALEY, L. E-mail reference: experiences at City University. PNLA Quarterly, 1998, vol. 62, n. 4, p. 20-21.

18.7.90. STORMONT, Sam. Interactive Reference Project - Assessment After Two Years . Annual Digital Reference Conference, 2000, n. 2.

18.7.91. TICKLE, Teresa E. Expanding outreach to a unique user community: the Slavic Reference Service and the Internet. The Reference Librarian, 1999, n. 67-68.

18.7.92. VANSCOY, Amy. Page us: combining the best of in-person and virtual reference service to meet in-library patron needs. Internet Reference Services Quarterly, 2006, vol. 11, n. 2, p. 15-25.

18.7.93. WANSERSKI, John. From AskWendt live to QuestionPoint: a chronology of the development of a persistently virtual reference product and service. Internet Reference Services Quarterly, 2003, vol. 8, n. 1/2, p. 71-94.

18.7.94. WASIK, Joann M. The Present State of Chemistry AskA Services. The Virtual Reference Desk, 1998.

18.7.95. WASIK, Joann M. A Report of Art and Art Education AskA Services. The Virtual Reference Desk, 1998. 
18.7.96. WASIK, Joann M. A Report of Library-Related AskA Services. The Virtual Reference Desk, 1998.

18.7.97. WASIK, Joann M. A Report of Paleontology AskA Services. The Virtual Reference Desk, 1998.

18.7.98. WASIK, Joann M. A Report on Construction \& Structural Engineering AskA Services. The Virtual Reference Desk, 1998.

18.7.99. WEST, Kathy. Managing and staffing a virtual reference service pilot project. Feliciter, 2002, vol. 48, n. 2, p. 64-65.

18.7.100. WHITE, Marilyn Domas. Diffusion of an innovation: digital reference service in Carnegie Foundation master's -comprehensive- academic institution libraries. The Journal of Academic Librarianship, 2001, vol. 27, n. 3, p. 173-187.

18.7.101. WHITRIDGE, Kate; JESKE, Margo. PARLREF: Digitizing the Reference Request Process . Annual Digital Reference Conference, 2000, n. 2.

18.7.102. XIAOXIA, Yao; LING, Chen. Exploring the services provided by CALIS: meeting the needs of member libraries. Library Management, 2005, vol. 26, n. 8/9, p. 471-477.

18.7.103. YAO, XiaoXia; CHEN, Ling; DAI, LongJi. Current situation and future development of CALIS. Library Management, 2004, vol. 25, n. 6/7.

18.7.104. YASUI, Yumiko. Digital reference services of university libraries in Japan: results and analysis of questionnaire research. Journal of College and University Libraries, 2004, n. 72, p. 18-29.

18.7.105. ZHENG, Ye Yang. Improving Turnaround Time for Document Delivery of Materials Owned But Not on the Shelf: A Case Study From an Academic Library. The Journal of Academic Librarianship, 2006, vol. 32, n. 2, p. 200-204. 


\section{Anexos}

\section{Documentos complementarios}

La evaluación que se ha realizado del servicio público de referencia digital «Pregunte: las bibliotecas responden» requirió la elaboración de una serie de materiales que se emplearon para la aplicación práctica del análisis de este servicio cooperativo. La recogida de datos sobre el servicio, así como el registro de las opiniones de los profesionales que atienen el servicio y de los usuarios del mismo, se realizó mediante encuestas. En estos anexos se reproducen los formularios empleados en esta evaluación. De igual forma, se incluyen las preguntas que se realizaron para la evaluación cualitativa, así como las respuestas que fueron entregadas por las diferentes bibliotecas que atendían el servicio los diferentes días en los que se hizo el muestreo. Los documentos que se incluyen en estos anexos complementan los procesos que se explican en los apartados 13.2. y 13.3, en el caso de las encuestas y en el apartado 13.5., en el caso de las preguntas y las respuestas. No obstante, en las páginas siguientes se vuelven a contextualizar los documentos anejos. 


\section{Anexos. DOCUMENTOS COMPLEMENTARIOS}

Anexo 1. Encuestas empleadas en la evaluación de «Pregunte: las bibliotecas responden»

Cuestionario 1: Coordinadores

Cuestionario 2: Profesionales

Cuestionario 3: Usuarios

Anexo 2. Consultas realizadas en la evaluación de «Pregunte: las bibliotecas responden» 


\section{Anexo 1. Encuestas empleadas en la evaluación de «Pregunte: las bibliotecas responden»}

La evaluación realizada al servicio de referencia que prestan de forma cooperativa bibliotecas públicas españolas incluía una serie de encuestas, con las que se pretendía recoger de forma directa las opiniones de los agentes implicados en este servicio de referencia digital. Por una parte, se contactó con los coordinadores del servicio en cada biblioteca, para recoger datos sobre el funcionamiento a nivel local; además, se envió a cada biblioteca una encuesta anónima, para ser cumplimentada por todas las personas que estaba o habían estado implicadas en el proceso de recepción de las consultas y resolución de las mismas. Esta encuesta estaba compuesta por medio centenar de preguntas, con las que se quería su formación, procedimientos, opiniones y sugerencias. Por último, se realizó otra encuesta entre los usuarios que habían empleado el servicio y que se encontraban registrados en la base de datos. A continuación, se ofrece la descripción de los pormenores de cada una de estas encuestas:

Encuesta a los coordinadores del servicio: destinada únicamente a la persona responsable de coordinar la actividad del servicio en cada una de las bibliotecas participantes en el proyecto; se pretendía recabar información sobre la implicación de las diferentes bibliotecas en el proyecto global, conociendo sus principales datos, su organización interna, así como la participación en proyectos locales similares. La encuesta fue cumplimentada por los responsables de las 34 bibliotecas integradas en la red en el momento de la evaluación.

Encuesta a los profesionales: dirigida a los bibliotecarios referencistas que estaban implicados en el servicio o lo habían estado anteriormente; se realizaron cincuenta preguntas, entre las que había preguntas relativas a su situación laboral, tiempo de trabajo destinados en el servicio, formación en biblioteconomía y en fuentes de información, destrezas con Internet, opinión sobre el sistema, sugerencias sobre posibles cambios, descripción de problemas, etc.; se trató de una encuesta exhaustiva en la que se basan fundamentalmente los resultados de la evaluación. La encuesta fue cumplimentada por 114 profesionales, de los 148 que estaban trabajando en el servicio cuando se efectuó la evaluación.

Encuesta a los usuarios: dirigida a usuarios registrados en el servicio con la intención de conocer su opinión acerca de la calidad de las respuestas, los plazos transcurridos y las posibles mejoras; se efectuaron dos oleadas, una sólo a usuarios residentes en España y una segunda en la que se incluyeron usuarios extranjeros. El número de cuestionarios válidos fue de 216.

En las siguientes páginas se reproducen los cuestionarios tal y como se hicieron llegar a los destinatarios. Los envíos se realizaron por correo electrónico y la recepción fue en su amplia mayoría por el mismo medio. 


\title{
Cuestionario 1: Coordinadores
}

\author{
«PREGUNTE: LAS BIBLIOTECAS RESPONDEN"
}

\section{ENCUESTA A LOS COORDINADORES DEL SERVICIO}

1.- ¿Cuántas personas trabajan en la actualidad en «Pregunte» en tu biblioteca? ¿Qué categoría laboral/profesional tienen?

2.- ¿Qué tareas profesionales desempeñan habitualmente las personas que trabajan en «Pregunte» en tu biblioteca? ¿Trabajan en el servicio de referencia? ¿Compaginan las tareas de referencia con otras?

3.- ¿Participar en «Pregunte» ha supuesto un gasto económico extra a tu biblioteca?

4. ¿Tiene tu biblioteca servicio de referencia en línea, además de «Pregunte»? ¿Participa en algún proyecto similar, ya sea local o regional?

5. ¿Vuestra colección de referencia es suficiente para trabajar en «Pregunte»o necesitáis acudir habitualmente a fuentes externas, además de a Internet?

6. ¿El servicio «Pregunte» depende de la dirección de la biblioteca?¿Cómo se coordina?

7. ¿Se ha difundido en los medios de comunicación locales la participación de tu biblioteca en «Pregunte»?

8. En el servidor de «Pregunte», en el apartado "Estadísticas del sistema" se pueden saber los siguientes datos de la participación de tu biblioteca en el servicio, que te pido que me copies:

$\mathrm{N}^{\circ}$ de preguntas gestionadas:

$\mathrm{N}^{\circ}$ de respuestas fuera de plazo:

$N^{\circ}$ de días de turno:

Fecha en la que hiciste la consulta: 


\title{
Cuestionario 2: Profesionales
}

\author{
«PREG U N TE: LAS B I B L IO TE C A S \\ RES P O N D E N
}

\section{ENCUESTA A PROFESIONALES QUE PARTICIPAN EN EL SERVICIO}

Esta encuesta está dirigida a los profesionales que trabajan en el servicio de referencia en línea «Pregunte: las bibliotecas responden». Su objetivo es conocer las opiniones de quienes participan en este proyecto para detectar los posibles problemas y establecer acciones para su mejora.

Esta encuesta ha de ser anónima. No incluya en ella datos que identifiquen a quien la contesta ni a la biblioteca donde trabaja. Una vez recibida la encuesta se confirmará su recepción y se borrará el mensaje del remitente.

Cuando haya completado el cuestionario envíelo a la siguiente dirección de correo electrónico:

$$
\text { merlo@usal.es }
$$

\section{IMPORTANTE}

- Ponga una $\mathbf{X}$ delante de la opción que considere más adecuada en su opinión

- Sólo debe elegir una opción, a menos que se informe de lo contrario

- Procure devolver el cuestionario no más de una semana después de su recepción

1 ¿Qué categoría profesional tiene?

[ ] a) Facultativo

[ ] b) Ayudante

[ ] c) Auxiliar

[ ] d) Otra (indíquese):

2 ¿Cuál es su responsabilidad en su biblioteca en relación al servicio «Pregunte»?

[ ] a) Coordinación y resolución de preguntas

[ ] b) Resolución de preguntas

[ ] c) Apoyo

[ ] d) Otra (indíquese): 
3 ¿Desde qué fecha lleva usted en el servicio «Pregunte»?

[ ] a) Desde mes: año: hasta la actualidad

[ ] b) Desde mes: año: hasta mes: año:

4 ¿Qué porcentaje de la jornada laboral dedica a «Pregunte» cuando su biblioteca tiene el turno de respuestas?

[ ] a) Toda la jornada laboral

[ ] b) Parte de la jornada laboral (indica el porcentaje):

[ ] c) El tiempo que tarde en responder las preguntas

5 ¿Compatibiliza sus tareas profesionales habituales con «Pregunte» cuando su biblioteca tiene el turno de respuestas?

[ ] a) Sí

[ ] b) No

6 ¿Cuánto tiempo de media tarda en resolver una pregunta que no requiera una investigación extraordinaria?

[ ] a) Menos de 1 hora

[ ] b) Entre 1 y 3 horas

[ ] c) Entre 3 y 5 horas

[ ] d) Más de 5 horas

7 ¿Cómo valoraría su formación en biblioteconomía?

[ ] a) Escasa

[ ] b) Suficiente

[ ] c) Normal

[ ] d) Buena

[ ] e) Excelente

8 ¿Cómo valoraría sus conocimientos de fuentes de información?

[ ] a) Escasos

[ ] b) Suficientes

[ ] c) Normales

[ ] d) Buenos

[ ] e) Excelentes

9 ¿Cómo valoraría sus conocimientos de Internet?

[ ] a) Escasos

[ ] b) Suficientes

[ ] c) Normales

[ ] d) Buenos

[ ] e) Excelentes 
10 ¿Qué fuentes de información emplea principalmente para la resolución de las consultas?

[ ] a) Fundamentalmente Internet

[ ] b) Principalmente la colección de referencia propia

[ ] c) Indistintamente Internet y la colección de referencia propia

11 ¿Cuándo emplea buscadores, utiliza las búsquedas avanzadas?
[ ] a) Nunca
[ ] b) Ocasionalmente
[ ] c) Habitualmente
[ ] d) Siempre

12 ¿Le parece adecuado el sistema informático empleado por «Pregunte»?

[ ] a) El sistema actual es bueno

[ ] b) Haría cambios en el sistema actual

[ ] c) Cambiaría de sistema

13 ¿Qué opina del servidor empleado por «Pregunte»?

[ ] a) Da problemas con frecuencia

[ ] b) Tiene un funcionamiento correcto

[ ] c) Es excelente

14 ¿Le parece suficiente el espacio disponible para responder?

[ ] a) Está bien así

[ ] b) Debería ampliarse

[ ] c) Debería ser ilimitado

15 ¿Le parecería adecuado que se pudiesen adjuntar documentos a la respuesta?

[ ] a) Sí

[ ] b) No

16 ¿Está de acuerdo con las limitaciones (preguntas que no se admiten) realizadas en los tipos de preguntas que se permiten formular?

[ ] a) Las limitaciones son oportunas

] b) Habría que replantear las limitaciones

[ ] c) Debería permitirse todo tipo de preguntas 
17 Indique las distintas fases que realiza desde que recibe una pregunta hasta que envía la respuesta. (Incluya todas las fases o procesos que usted realice)
1)
2)
3)
4)
5)

18 ¿Consulta a otras bibliotecas, participen o no en «Pregunte», si cree que pueden ayudar en la resolución de las preguntas?
[ ] a) Ocasionalmente
[ ] b) Frecuentemente
[ ] c) Habitualmente

19 ¿Suele consultar el archivo de consultas realizadas a «Pregunte»?
[ ] a) Ocasionalmente
[ ] b) Frecuentemente
[ ] c) Habitualmente

20 ¿Tiene una selección de recursos favoritos que utiliza para responder las preguntas?
[ ] a) Sí
[ ] b) No

21 ¿Cómo calificaría la colección de referencia de su biblioteca?
[ ] a) Escasa
[ ] b) Suficiente
[ ] c) Normal
[ ] d) Buena
[ ] e) Excelente

22 ¿Cómo valoraría la edad media de su colección de referencia?

[ ] a) Poco actual

[ ] b) Actual

[ ] c) Muy actual

23 ¿Cómo valora la documentación (manuales, clasificación, normativas, etc.) de que disponen las bibliotecas participantes en «Pregunte»?
[ ] a) Escasa
[ ] b) Suficiente
[ ] c) Normal
[ ] d) Buena
[ ] e) Excelente 
24 ¿Qué documentación (manuales, clasificación, normativas, etc.) considera que se debería reelaborar de la que disponen las bibliotecas participantes en «Pregunte»?

[ ] a) Ninguna

[ ] b) La/s siguiente/s (indique cual):1)

5)

25 ¿Qué documentación considera que debería elaborarse para incorporarla a la hasta ahora existente?

[ ] a) Ninguna

[ ] b) La/s siguiente/s (indique cual):1)

3)

4)

5)

26 ¿Considera conveniente que se ofrezcan cursos de formación específicos a quienes participan en «Pregunte»?

[ ] a) Poco conveniente

[ ] b) Conveniente

[ ] c) Muy conveniente

27 ¿Considera conveniente que las distintas bibliotecas participantes se especialicen en un tema para dar mejor servicio en «Pregunte»?

[ ] a) Poco conveniente

[ ] b) Conveniente

[ ] c) Muy conveniente

28 ¿Considera conveniente que se elabore un formulario de evaluación de la respuesta para que el usuario, si lo desea, muestre su grado de satisfacción con la contestación recibida?

[ ] a) Poco conveniente

[ ] b) Conveniente

[ ] c) Muy conveniente

29 ¿Considera conveniente que se elabore un formulario de evaluación de «Pregunte» para que el usuario, si lo desea, muestre su grado de satisfacción con el servicio?

[ ] a) Poco conveniente

[ ] b) Conveniente

[ ] c) Muy conveniente 
30 ¿Cómo valoraría la incorporación de un servicio de chat a «Pregunte»?

[ ] a) Innecesario

[ ] b) Interesante

[ ] c) Necesario

[ ] d) Urgente

31 ¿Cómo valoraría la inclusión de una selección de recursos de información de Internet en la página principal de «Pregunte»?

[ ] a) Innecesario

[ ] b) Interesante

[ ] c) Necesario

[ ] d) Urgente

32 ¿Cómo valoraría la elaboración de documentos acerca de cómo buscar o guías de recursos comentados para incorporar a la página principal de «Pregunte»?
[ ] a) Innecesario
[ ] b) Interesante
[ ] c) Necesario
[ ] d) Urgente

33 ¿Cómo valoraría la contratación cooperativa de recursos electrónicos de referencia para las bibliotecas participantes en «Pregunte»?
[ ] a) Innecesario
[ ] b) Interesante
] c) Necesario
[ ] d) Urgente

34 ¿Considera conveniente que se pida obligatoriamente alguna identificación al usuario para poder responder mejor a su preguntas?

[ ] a) Poco conveniente

[ ] b) Conveniente

[ ] c) Muy conveniente

35 ¿Si se pidiera alguna identificación obligatoria al usuario cree que la localidad debería ser uno de estos datos?
[ ] a) Sí
[ ] b) No

36 ¿Si se pidiera alguna identificación obligatoria al usuario cree que la edad debería ser uno de estos datos?

[ ] a) Sí
[ ] b) No 
37 ¿Si se pidiera alguna identificación obligatoria al usuario cree que el motivo de la consulta (trabajo, estudio, personal) debería ser uno de estos datos?

[ ] a) Sí

[ ] b) No

38. ¿Cree que «Pregunte» debería ofrecerse sólo a usuarios españoles?

[ ] a) Sólo debería ofrecerse a usuarios españoles

[ ] b) Debería ofrecerse a usuarios que pregunten en lenguas españolas

[ ] c) Debería ofrecerse a cualquier usuario, independientemente de la lengua

39 ¿Cómo valoraría la utilidad del servicio «Pregunte»?

[ ] a) Poco útil

[ ] b) Útil

[ ] c) Muy útil

40 ¿Considera que la autosuficiencia de los usuarios para buscar en información disminuye la utilidad de «Pregunte»?

$$
\begin{aligned}
& \text { [ ] a) Sí } \\
& \text { [ ] b) No }
\end{aligned}
$$

41. ¿Cómo valoraría el grado de coordinación entre las bibliotecas que participan en «Pregunte»?
[ ] a) Muy malo
[ ] b) Malo
[ ] c) Normal
[ ] d) Bueno
[ ] e) Muy bueno

42. ¿Cómo valoraría el traslado del servidor de «Pregunte» y la coordinación del proyecto a la Subdirección General de Coordinación Bibliotecaria?
[ ] a) Innecesario
[ ] b) Necesario
[ ] c) Urgente

43. ¿Cree que el número de bibliotecas participantes en el proyecto es suficiente?

[ ] a) Debería ampliarse a más bibliotecas

[ ] b) El número de bibliotecas participantes es adecuado

[ ] c) Hay demasiadas bibliotecas en el proyecto 
44. ¿Cree que el sistema actual de turnos (un turno $+/$ - al mes) es adecuado?

[ ] a) Sería mejor cada más tiempo

[ ] b) El sistema actual es adecuado

[ ] c) Sería mejor cada menos tiempo

45 ¿Cómo valoraría la calidad de las respuestas que se dan en «Pregunte»?

[ ] a) Muy mala

[ ] b) Mala

[ ] c) Normal

[ ] d) Buena

[ ] e) Muy buena

46 ¿Cómo valoraría la cantidad de preguntas que recibe su biblioteca?

[ ] a) Pocas

[ ] b) Normal

[ ] c) Muchas

47- ¿Cree que el tiempo de respuesta de «Pregunte» es el adecuado?

[ ] a) Debería contestaste en menos tiempo

[ ] b) Está bien en estos momentos

[ ] c) Debería disponerse de más tiempo para contestar

48 ¿Cree que el servicio «Pregunte» es conocido fuera de la profesión bibliotecaria?

[ ] a) Es poco conocido

[ ] b) Se conoce lo suficiente

[ ] c) Es bastante conocido

49. ¿Qué le parecería la realización de una campaña de promoción de «Pregunte»?

[ ] a) Innecesaria

[ ] b) Necesaria

[ ] c) Urgente

50. ¿Cuáles son, a su juicio, los problemas de «Pregunte» que necesitan una solución más urgente? (Indique todos aquellos que considere)
1)
2)
3)
4)
5) 


\section{Cuestionario 3: Usuarios \\ A/ Usuarios con domicilio indicado en España \\ «PREGUNTE: LAS B I B LIOTECAS \\ RES P O N D E N »}

\section{ENCUESTA A USUARIOS REGISTRADOS}

\section{Estimado/a amigo/a:}

Me dirijo a ti como usuario/a registrado/a del servicio «Pregunte: las bibliotecas responden», que ofrecen las Bibliotecas Públicas del Estado, para pedirte que colabores en la evaluación de este servicio, contestando a las preguntas que figuran en este mensaje.

Sólo te llevará un par de minutos.

Las respuestas han de ser anónimas. No incluyas en ella datos que te identifiquen. Tu correo electrónico ha sido extraído de la base de datos de «Pregunte», pero sólo se empleará para esta comunicación. Tus datos son confidenciales.

Simplemente devuelve este mensaje, poniendo una $\mathbf{X}$ delante de la opción que consideres más adecuada en tu opinión. Sólo debes elegir una opción para cada pregunta.

1 ¿A qué categoría de las siguientes perteneces?

[ ] a) Estudiante

[ ] b) Trabajador o desempleado

[ ] c) Pensionista

2 ¿Qué tamaño tiene la población en la que vives?

[ ] a) Menos de 2.000 habitantes

] b) Entre 2.000 y 5.000 habitantes

] c) Entre 5.000 y 25.000 habitantes

] d) Entre 25.000 y 100.000 habitantes

] e) Entre 100.000 y 250.000 habitantes

] f) Entre 250.000 y 500.000 habitantes

] g) Entre 500.000 y 750.000 habitantes

] h) Más de 750.000 habitantes 
3 ¿Cuántas veces has usado el servicio «Pregunte: las bibliotecas responden»?

[ ] a) Sólo 1 vez

[ ] b) Entre 2 y 4 veces

[ ] c) Más de 5 veces

4. ¿Tuviste algún problema de conexión con el servidor de «Pregunte»?

[ ] a) No

[ ] b) Sí

5 ¿Cuáles fueron los motivos por los que usaste el servicio «Pregunte: las bibliotecas responden»? (Elige sólo una opción, la que consideres mayoritaria)

[ ] a) Formación: trabajo de clase, estudios, etc.

[ ] b) Profesión: necesidades laborales

[ ] c) Personales: motivos no profesionales ni de formación

6. ¿Cómo valorarías la respuesta que se dio a tu/s pregunta/s? (Elige sólo una opción, la que consideres mayoritaria)

[ ] a) Poco útil

[ ] b) Útil

[ ] c) Muy útil

7. ¿Cómo valorarías el tiempo que se tardó en ofrecerte la respuesta? (Elige sólo una opción, la que consideres mayoritaria)

[ ] a) Tardó mucho

[ ] b) El tiempo fue correcto

[ ] c) Tardó poco

8 ¿Intentaste localizar la respuesta por ti mismo antes de utilizar el servicio «Pregunte: las bibliotecas responden»?

[ ] a) Sí

[ ] b) No

9 ¿Volverías a usar «Pregunte: las bibliotecas responden»?

[ ] a) Sí

[ ] b) No

10 ¿Has recomendado o recomendarías el servicio «Pregunte: las bibliotecas responden»?

[ ] a) Sí

[ ] b) No 
11. ¿Cómo conociste la existencia del servicio «Pregunte: las bibliotecas responden»? (Elige sólo una opción)

[ ] a) Recomendación de una biblioteca

[ ] b) Recomendación de mi centro de estudios o trabajo

[ ] c) Recomendación en un web

[ ] d) Recomendación en una revista o periódico

[ ] e) Recomendación de un amigo

[ ] f) Recomendación en una lista de noticias o de distribución

[ ] g) Otro (indíquese):

12. ¿Qué te parecería la inclusión de un chat en «Pregunte» para hacer preguntas en tiempo real?
[ ] a) Innecesario
[ ] b) Interesante
[ ] c) Necesario
[ ] d) Urgente

13. ¿Qué te parecería la inclusión de tutoriales sobre cómo buscar en Internet u otros temas?
[ ] a) Innecesario
[ ] b) Interesante
[ ] c) Necesario
[ ] d) Urgente

14. ¿Qué te parecería incluir en «Pregunte» selecciones de recursos de Internet?
[ ] a) Innecesario
[ ] b) Interesante
[ ] c) Necesario
[ ] d) Urgente

15. ¿En líneas generales, cómo valorarías el servicio «Pregunte»?
[ ] a) Poco útil
[ ] b) Útil
[ ] c) Muy útil

Muchas gracias por tu cooperación. 


\section{Cuestionario 3: Usuarios \\ B/ Usuarios con domicilio indicado fuera de España \\ «PREGUNTE: LAS BIBLIOTECAS RESPONDEN» \\ ENCUESTA A USUARIOS REGISTRADOS \\ Tiempo estimado de respuesta: 2 minutos}

Estimado/a amigo/a:

Me dirijo a ti como usuario/a registrado/a del servicio «Pregunte: las bibliotecas responden», que ofrecen las Bibliotecas Públicas del Estado, para pedirte que colabores en la evaluación de este servicio, contestando a las preguntas que figuran en este mensaje.

Las respuestas han de ser anónimas. No incluyas en ella datos que te identifiquen. Tu correo electrónico ha sido extraído de la base de datos de «Pregunte», pero sólo se empleará para esta comunicación. Tus datos son confidenciales.

Simplemente devuelve este mensaje, poniendo una $X$ delante de la opción que consideres más adecuada en tu opinión. Sólo debes elegir una opción para cada pregunta.

1 ¿A qué categoría de las siguientes perteneces?

[ ] a) Estudiante

[ ] b) Trabajador o desempleado

[ ] c) Pensionista

2 ¿En qué país vives y qué tamaño tiene tu localidad de residencia?

País:

Población (elige una opción):

[ ] a) Menos de 2.000 habitantes

[ ] b) Entre 2.000 y 5.000 habitantes

[ ] c) Entre 5.000 y 25.000 habitantes

[ ] d) Entre 25.000 y 100.000 habitantes

[ ] e) Entre 100.000 y 250.000 habitantes

[] f) Entre 250.000 y 500.000 habitantes

[ ] g) Entre 500.000 y 750.000 habitantes

[ ] h) Más de 750.000 habitantes 
3 ¿Cuántas veces has usado el servicio «Pregunte: las bibliotecas responden»?

[] a) Sólo 1 vez

[] b) Entre 2 y 4 veces

[] c) Más de 5 veces

4. ¿Tuviste algún problema de conexión con el servidor de «Pregunte»?

[] a) No

[ ] b) Sí

5 ¿Cuáles fueron los motivos por los que usaste el servicio «Pregunte: las bibliotecas responden»? (Elige sólo una opción, la que consideres mayoritaria)

[ ] a) Formación: trabajo de clase, estudios, etc.

[ ] b) Profesión: necesidades laborales

[ ] c) Personales: motivos no profesionales ni de formación

6. ¿Cómo valorarías la respuesta que se dio a tu/s pregunta/s? (Elige sólo una opción, la que consideres mayoritaria)

[ ] a) Poco útil

[ ] b) Útil

[ ] c) Muy útil

7. ¿Cómo valorarías el tiempo que se tardó en ofrecerte la respuesta? (Elige sólo una opción, la que consideres mayoritaria)

[] a) Tardó mucho

[ ] b) El tiempo fue correcto

[] c) Tardó poco

8 ¿Intentaste localizar la respuesta por ti mismo antes de utilizar el servicio «Pregunte: las bibliotecas responden»?
[] a) Sí
[] b) No

9 ¿Volverías a usar «Pregunte: las bibliotecas responden»?

[ ] a) Sí

[ ] b) No 
10 ¿Has recomendado o recomendarías el servicio «Pregunte: las bibliotecas responden»?
[] a) Sí
[] b) No

11. ¿Cómo conociste la existencia del servicio «Pregunte: las bibliotecas responden»? (Elige sólo una opción)
[] a) Recomendación de una biblioteca
[ ] b) Recomendación de mi centro de estudios o trabajo
[ ] c) Recomendación en un web
[ ] d) Recomendación en una revista o periódico
[ ] e) Recomendación de un amigo
[ ] f) Recomendación en una lista de noticias o de distribución
[ ] g) Otro (indíquese):

12. ¿Qué te parecía la inclusión de un chat en «Pregunte» para hacer preguntas en tiempo real?
[] a) Innecesario
[ ] b) Interesante
[] c) Necesario
[] d) Urgente

13. ¿Qué te parecía la inclusión de tutoriales sobre cómo buscar en Internet u otros temas?
[] a) Innecesario
[ ] b) Interesante
[] c) Necesario
[ ] d) Urgente

14. ¿Qué te parecería incluir en «Pregunte» selecciones de recursos de Internet?
[ ] a) Innecesario
[ ] b) Interesante
[ ] c) Necesario
[] d) Urgente

15. ¿En líneas generales, cómo valorarías el servicio «Pregunte»?
[] a) Poco útil
[] b) Útil
[] c) Muy útil

Muchas gracias por tu cooperación. 


\section{Anexo 2. Consultas realizadas en la evaluación de «Pregunte: las bibliotecas responden»}

La homogeneidad de las respuestas ofrecidas en «Pregunte: las bibliotecas responden» fue objeto de uno de los análisis que se realizaron en el seno de esta investigación doctoral. Los pormenores de esta evaluación se detallan en el apartado 13.5.4. Se quería comparar las respuestas ofrecidas por distintas bibliotecas ante preguntas idénticas.

Las preguntas fueron enviadas entre el 1 de marzo y el 3 de abril de 2004, periodo en el que se realizó el grueso de la evaluación del servicio.

Se analizaron las preguntas realizadas al sistema en un turno completo, seleccionándose aquellas que cumplían una doble condición: el contenido de la consulta se repetía y la pregunta se realizaba en días distintos. Las preguntas que cumplían estas condiciones fueron doce, algunas planteadas por el doctorando, como parte del estudio discreto que se estaba llevando a cabo.

Las preguntas sirvieron para valorar de forma cualitativa algunas cuestiones: su contenido, es decir, la respuesta dada a la pregunta; el estilo empleado para redactar la respuesta; y las fuentes o recursos empleados y recomendados.

Como se podrá comprobar en la sección mencionada de la tesis doctoral, a partir de la comparación se calificaron las respuestas como iguales, parecidas o distintas, estableciéndose los porcentajes de homogeneidad en las mismas.

En los siguientes párrafos se reproducen todos los datos de las consultas empleadas para esta parte de la evaluación: número de identificación de la consulta (NIC), consulta, respuesta, fuentes utilizadas en la respuesta, fuentes para ampliar, fecha de solicitud y fecha de resolución.

Los textos se transcriben de forma literal, tanto en lo concierte a las preguntas, como en lo relativo a las respuestas. En algunos casos se han encontrado errores ortográficos o tipográficos, que no han sido corregidos, dado el carácter de los ejemplos que se aportan. 


\section{Pregunta 1}

NIC: 23142

CONSULTA: Estimados señores: Me gustaría saber ¿por qué a las bibliotecas escolares en EEUU se denominan K-12? Enhorabuena por su servicio

RESPUESTA: K-12: estudiantes de kinder hasta el deudécimo año. K=kinder hasta el 12 curso

FUENTES UTILIZADAS EN LA RESPUESTA:

http://www.clarku.edu/faculty/marcano/cig/proyecto.html

http://emma.la.asu.edu/TESNEWS/SPAN/1VOL/1NO/educ.html

FECHA DE SOLICITUD: 22/03/2004

FECHA DE RESOLUCIÓN: 23/03/2004

NIC: 23164

CONSULTA: Estimados señores: Me gustaría saber ¿por qué las bibliotecas escolares en EEUU se denominan K-12? Enhorabuena por su servicio

RESPUESTA: En Estados Unidos la educación desde el jardin de infancia (Kindergarden) hasta el doceavo grado se la denomina k-12, por lo que las bibliotecas de dichos centros docentes se llaman bibliotecas del k-12.

FUENTES UTILIZADAS EN LA RESPUESTA:

http://www.hispanicprwire.com/spa/release_Milken_SP.htm

FECHA DE SOLICITUD: 23/03/2004

FECHA DE RESOLUCIÓN: 25/03/2004

Pregunta 2

NIC: 23165

CONSULTA: Buenas tardes: Me podrían informar de en qué universidad española es posible realizar un doctorado en enseñanza de español como lengua extranjera. Muchas gracias

RESPUESTA: Varias son las universidadds españolas que ofrecen estudios de postgrado de la enseñanza del español como lengua extranjera. Entre los cuales destacamos: Universidad de Alcalá de Henares Departamento de Filología MÁSTER EN ENSEÑANZA DE ESPAÑOL COMO LENGUA EXTRANJERA http://www.unirioja.es/Prensa/Noticias/espanolELE.html Universidad de la Rioja Diversas iniciativas http://www.unirioja.es/Prensa/Noticias/espanolELE.html Universidad Antonio de Nebrija Másters y doctorados Doctorado en Lingüística Aplicada a la Enseñanza del Español como Lengua Extranjera http://www.nebrija.com/titulaciones/postgrado.htm Universidad Autónoma de Madrid Doctorado http://www.ffil.uam.es/filoespa/doctorad.htm Universidad de Granada: Doctorado http://www.ugr.es/ filoespa/doctorado.htm Universitat de Barcelona: Master http://www.ub.es/filhis/tmast97.htm Instituto de España http://cvc.cervantes.es/aula/formacion/

FUENTES UTILIZADAS EN LA RESPUESTA: Registro Nacional de Universidades de España del Ministerio de Educación en el que se puede buscar por titulaciones:

http://wwwn.mec.es/educa/jsp/plantilla.jsp?area=ccuniv\&id=802\&contenido=/ ccuniv/html/Registro_Nacional_de_Universidades_centros_y_ensenanzas/in dex.html Y la obra: Dices 2003-2004 : directorio de centros de formación. Madrid: Círculo de Progreso, 2003. 3 v.: t.1. Guía de colegios privados en España, t. 2. Guía de carreras y estudios superiores : directorio de centros 
de formación superior en España, t. 3. Guía de master y cursos de postgrado : directorio de centros de postgrado

FUENTES PARA AMPLIAR: Creeemos que le será de gran utilidad el portal de la web de la Universidad de Granada destinado al Español como Segunda Lengua: Español como Segunda Lengua http://www.ugr.es/ ftsaez/espl2.htm

FECHA DE SOLICITUD: 23/03/2004

FECHA DE RESOLUCIÓN: 24/03/2004

NIC: 23177

CONSULTA: Buenas días: Me podrían informar de en qué universidad española es posible realizar un doctorado en enseñanza de español como lengua extranjera. Muchas gracias

RESPUESTA: Puedes estudiarlo en la Universidad Antonio de Nebrija, en Madrid. Puedes encontrar más información en las páginas: http://cv1.cpd.ua.es/estudiosxxi/OHOME0/SU2PPESII1EE1/ http://www.universia.net.mx/contenidos/estudios/

FUENTES UTILIZADAS EN LA RESPUESTA: www.google.com

FECHA DE SOLICITUD: $24 / 03 / 2004$

FECHA DE RESOLUCIÓN: 31/03/2004

NIC: 23143

CONSULTA: Buenas tardes: Me podrían informar de en qué universidad española es posible realizar un doctorado en enseñanza de español como lengua extranjera. Muchas gracias

RESPUESTA: Los Diplomas de Español como Lengua Extranjera (D.E.L.E.) son títulos oficiales, acreditativos del grado de competencia y dominio del idioma español, que otorga el Ministerio de Educación, Cultura y Deporte de España. El Instituto Cervantes es el organismo encargado de organizar las convocatorias de los exámenes, mientras que la Universidad de Salamanca en España, es la encargada de la elaboración, corrección y evaluación final de todos los exámenes. Puedes encontrar mas información en la web:http://www.dele.org/dele/index.asp

FUENTES UTILIZADAS EN LA RESPUESTA: http://www.dele.org/dele/index.asp

FECHA DE SOLICITUD: 22/03/2004

FECHA DE RESOLUCIÓN: 25/03/2004

Pregunta 3

NIC: 23168

CONSULTA: Quisiera saber dónde informarse sobre cómo convalidar títulos universitarios obtenidos fuera de España

RESPUESTA: Puedes encontrar informacion en: * Servicios de HOMOLOGACIÓN de Estudios Extranjeros Universitarios y NO Universitarios Subdirección General de Títulos Convalidaciones y Homologaciones (MECD) Paseo del Prado, 28 (28071 MADRID) - Tfno: 915065600 - Fax: 9065706 * Delegación del gobierno en sevilla: 955569201 * Subdelegacion del Gobierno en Córdoba: Pza de la COnstitución, 1. 14071 Córdoba. Tlf: 957 989222 También en: Ministerio de Educación, Cultura y Deporte: Centro de Información y Atención al Ciudadano (Sección de Información educativa): C/ Alcalá, 36. 28071-Madrid Tel. directos: 902218500 Fax: 917018648 y 91 7018600 o en la página web del ministerio de Educación: http://www.mecd.es/consejou/webconsejo/index.html te metes en Títulos Universitarios.

FUENTES UTILIZADAS EN LA RESPUESTA: www.google.com 
FECHA DE SOLICITUD: 24/03/2004

FECHA DE RESOLUCIÓN: 31/03/2004

NIC: 23198

CONSULTA: Quisiera saber dónde informarse sobre cómo convalidar títulos universitarios obtenidos fuera de España

RESPUESTA: En esta página del Ministerio de Educación, Cultura y Deporte aparece toda la información sobre el tema que le interesa:

http://wwwn.mec.es/mecd/jsp/plantilla.jsp?id=6\&area=titulos Existe igualmente una opción de consulta electrónica para ciudadanos y una dirección de correo:

http://wwwn.mec.es/mecd/jsp/plantilla.jsp?id=21\&area=atencion informa.admini@sgt.mcu.es También podrán darle cumplida información sobre este tema en las Subdelegaciones del Gobierno de cada capital de provincia, así como en los Servicios o Direcciones provinciales de Educación.

FUENTES UTILIZADAS EN LA RESPUESTA: Página web del Ministerio de Educación, Cultura y Deporte

FECHA DE SOLICITUD: 25/03/2004

FECHA DE RESOLUCIÓN: 25/03/2004

NIC: 23225

CONSULTA: Quisiera saber dónde informarse sobre cómo convalidar títulos universitarios obtenidos fuera de España

RESPUESTA: En la página del Ministerio de Educación, Cultura y Deportes (http://www.mecd.es/), dentro de Universidades (http://www.univ.mecd.es/) y dentro de legislación, donde se informa de los títulos oficiales, aparecen toda la normativa relativa a la homologación de títulos universitarios extranjeros (http://www.univ.mecd.es/univ/jsp/plantilla.jsp?id=1850) Además, en la misma página aparece un nuevo número de información telefónica al ciudadano: 902-218-500 (de lunes a viernes de 9 a 14,30 horas), para temas de educación. También en la Universidad de Córdoba puede solicitar información sobre el tema, concretamente en la Oficina de Información (http://www.uco.es/servicios/informacion/), en el Recinto C.M. Nuestra Señora de la Asunción, Av. Menéndez Pidal, s/n, 14004 Córdoba, Tfno. 957218-034 / 218-203, fax. 957-218-222, (www.uco.es/estudia/), c.e. informacion@uco.es

FECHA DE SOLICITUD: 26/03/2004

FECHA DE RESOLUCIÓN: 26/03/2004

\section{Pregunta 4}

NIC: 23185

CONSULTA: Estimados señores: Espero que esta pregunta no se salga de los objetivos de su servicio. ¿Podrían indicarme cinco títulos de novelas infantiles (alumnos de primaria) en las que se trate el tema de la discapacidad? Muchas gracias

RESPUESTA: Recientemente la FEAPS ha publicado una colección de libros para niños donde se trata el tema de la discapacidad: Ori y su mascota / de Vicent Josep Escartí ; ilustraciones de Joan Millet También hay otros como: 'El hogar de los pequesolos', María y José.Madrid:Intermón y Bruño, 1999 'El saltamontes verde', Ana María Matute. Editorial Lumen. 'Un niño como los demás', J.Carrete. Editorial Sígueme. Salamanca 'Suelta el globo', I.Southall. SM Madrid. A parti de 12 años. Puedes encontrar una amplia bibliografía en el siguiente libro: 'Lectura y libros par niños especiales', 
Gabriel Comes Nolla.Ed. CEAC. Lo puedes encontrar en la bibliteca más cercana. Está disponible en: Biblioteca Pública Provincial de Córdoba Amador de los Ríos s/n 14004 Córdoba Tfno. 957475556

FUENTES UTILIZADAS EN LA RESPUESTA: Red de bibliotecas Públicas del Estado Red de Lectura Pública de Andalucía

FECHA DE SOLICITUD: 24/03/2004

FECHA DE RESOLUCIÓN: 30/03/2004

NIC: 23199

CONSULTA: ¿Me podrían aconsejar cinco novelas infantiles (nivel primaria) en las que se trate el tema de la discapacidad?

RESPUESTA: Le enviamos la bibliografia solicitada: "El vecino prohibido" de Xavier Bertran, Edebé, Barcelona, 1994. Plantea el tema de la marginación y automarginación debido al rechazo que genera la discapacidad de uno de los niños protagonistas. En SM hay un libro bellísimo que se llama 'Jacobo no es un pobre diablo' de Gabriele Heiser-Korioth sobre un albatros que no puede volar. La autora lo escribió para su hijo minusválido de 5 años. "Inés crece despacio : La historia de Inés, niña con síndrome de Down" / Claude Heleft . -- Barcelona : Serres, cop. 2003 : Acaba de nacer un bebé en la maternidad. El médico explica que "ha habido un accidente genético" y que "Inés es portadora del síndrome de Down". Este libro, de la colección "El árbol de la vida" evoca el difícil trayecto de un niño disminuido y de su familia. Más sobre la enfermedad que sobre la incapacidad es 'La gorra', editado por La Galera, en la colección Grumetes Parchís: Trata de un niño que por su tratamiento de cáncer ha perdido el pelo y no quiere que los demás se enteren. Existen además los libros del colectivo B.A.T.A. , asociación que presta servicios a personas con Autismo y otros trastornos generalizados del desarrollo. Son de la colección Makakiños y los publica en Pontevedra la editorial Kalandraka. Hasta ahora lleva publicados "La ratita presumida" y "El conejo blanco

FUENTES UTILIZADAS EN LA RESPUESTA: El catálogo de nuestra biblioteca

FECHA DE SOLICITUD: 25/03/2004

FECHA DE RESOLUCIÓN: 26/03/2004

NIC: 23226

CONSULTA: ¿Me podrían aconsejar cinco novelas infantiles (nivel primaria) en las que se trate el tema de la discapacidad?

RESPUESTA: Estamos seguros de que existen muchos títulos interesantes sobre el tema de la discapacidad, le enviamos unos pocos, esperamos que le sean útiles. Andrés y el niño nuevo / Nancy Carlson ; traducción de Pablo Gervás. -- Madrid : Espasa-Calpe, D.L. 1991 Inés crece despacio : La historia de Inés, niña con síndrome de Down / Claude Heleft ; ilustraciones de Madeleine Brunelet ; prefacio de Anne Sylvestre. -- 1 ed. -- Barcelona : Serres, 2003 Los mejores amigos / Rachel Anderson ; traducción de P. Rozarena ; ilustraciones de Shelagh McNicholas. -- $\left[1\right.$ ed. $8^{a}$ reimp.]. -Madrid : Alfaguara, 2000 Juan es diferente / Marleen Vanvuchelen ; ilustraciones, Ingrid Godon ; traducción, María Lerma. -- Zaragoza : Edelvives, [2003] La sonrisa de Carlos / Teresa Sabaté ; [adaptación e ilustraciones] Carme Solà. -- 1 ed. -- Barcelona : Salvatella, 2002 Jacobo no es un pobre diablo / Gabriele Heiser. -- [5a ed.]. -- Madrid : SM, 1991

FUENTES UTILIZADAS EN LA RESPUESTA: http://www.mcu.es/cgibin/cbpe_b/BRSCGI?CMD=VERPAG\&PAG=ForCBPE\&SEC=CBPE

FECHA DE SOLICITUD: 26/03/2004

FECHA DE RESOLUCIÓN: 29/03/2004 


\section{Pregunta 5}

NIC: 23200

CONSULTA: Hola, buenos días. Desearía saber en qué consiste la 'prostatitis crónica no bacteriana'. Al denominarse 'crónica', ¿quiere decir que se padecerá toda la vida o temporalmente? Muchas gracias por ofrecer un servicio tan interesante.

RESPUESTA: En respuesta a su pregunta, le podemos contestar que la prostatitis crónica no bacteriana es la más común y menos conocida. Se calcula que es ocho veces más común que la prostatitis bacteriana. Suele ser crónica y dolorosa, y aparece en hombres de cualquier edad. Los síntomas suelen desaparecer y reaparecer sin previo aviso. La orina y los fluidos provenientes de la próstata no muestran evidencia de poseer ningún organismo infeccioso conocido, pero el semen y algunos otros fluidos de la próstata contienen glóbulos blancos. Los médicos usualmente tratan la prostatitis no bacteriana con antibióticos y medicamentos que relajan los músculos de la próstata. Este tipo de prostatitis puede asociarse a otras enfermedades, como la artritis reactiva (Enfermedad de Reiter). Algunas veces se recetan medicamentos antiinflamatorios como el ibuprofeno y el naproxeno para aliviar el dolor.

FUENTES UTILIZADAS EN LA RESPUESTA:

http://www.urologia.tv/icua/enfermedades.asp?cod=3 Diccionario médico. -$2^{\mathrm{a}}$ ed., $2^{\mathrm{a}}$ Reimp. -- Barcelona : Salvat, 1989 Diccionario de Medicina. -Madrid : Cultural, 2000

FECHA DE SOLICITUD: 25/03/2004

FECHA DE RESOLUCIÓN: 25/03/2004

NIC: 23256

CONSULTA: Me gustaría saber en qué consiste la prostatitis crónica no bacteriana. Al denominarse 'crónica', ¿quiere decir que se padecerá toda la vida?

RESPUESTA: Le enviamos direcciones de Internet donde podrá encontrar información sobre el tema de su consulta: -

www.entornomedico.org/salud/saludyenfermedades/alfaomega/prostatitisnobac.html www.esmas.com/salud/enfermedades/infecciosas/346839.html www.intermedicina.com/Avances/Interes_General/AIG13.htm www.nlm.nih.gov/medlineplus/spanish/ency/article/000524.htm

FUENTES UTILIZADAS EN LA RESPUESTA: Internet

FECHA DE SOLICITUD: $28 / 03 / 2004$

FECHA DE RESOLUCIÓN: 29/03/2004

Pregunta 6

NIC: 23257

CONSULTA: Quisiera saber quién inventó el lapicero y algo de historia de esta herramienta.

RESPUESTA: Le envío algunas direcciones de páginas web donde encontrará información sobre el tema de su consulta: -

www.educar.org/inventos/lapiz.asp -

http://webs.sinetics.com.ar/mcagliani/hlapiz.htm -

www.mujeresdeempresa.com/networking/networking020101.htm

FUENTES UTILIZADAS EN LA RESPUESTA: Internet

FECHA DE SOLICITUD: 28/03/2004

FECHA DE RESOLUCIÓN: 29/03/2004 
NIC: 23227

CONSULTA: Me gustaría saber quién inventó el lapicero y un poco de historia de esta útil herramienta.

RESPUESTA: LAPICERO: Instrumento en que se pone el lápiz para servirse de él. LÁPIZ: Barra de grafito encerrada en un cilindro o prisma de madera, que sirve para escribir o dibujar... Conrad Gesner, de Zurich, se refería ya en 1565 a un lápiz inglés, hecho probablemente con grafito procedente de la mina de Borrowdale, donde se descubrió esta sustancia por primera vez (1554)... Los primeros lápices se fabricaron en Inglaterra. De los bloques de grafito descubiertos en 1564 en Borrowdale (condado de Cumberland) se sacaron primero placas que se pulieron y serraron hasta obtener varillas prismáticas de sección cuadrada que se sujetaron por pinzas de madera. Más tarde, se emplearon los residuos y grafitos de calidad inferior. Se pulverizaba el grafito y con cola, colofonia, goma, azufre, etc., se formaba una masa de la que se sacaban las minas. Pero estos aglutinantes no dieron resultado alguno, hasta que a Jacques Conté (1795) se le ocurrió el empleo de la arcilla. En 1761 se fundó en Alemania la conocida fábrica Faber, en Stein, cerca de Nuremburgo. En 1847, agotada ya la mina de grafito inglesa, descubrióse por Alibert otra excelente en Siberia. Hoy, todas las minas de lápices de buena calidad son siberianas... En 1812, el ebanista e inventor William Monroe, de Concord, Massachussetts, Estados Unidos, fabricó una máquina que producía estrechas tablitas semicilíndricas de madera de 16 a 18 centímetros de longitud. A lo largo de cada tablilla, al aparato producía estrías justo en la mitad del grosor del delgado semicilindro moldeado. A continuación, Monroe unía con cola las dos secciones de madera, pegándolas estrechamente en torno al grafito y así fue como nació el lápiz tal y como lo conocemos en la actualidad... El lápiz automático o estilográfico fue introducido por Hawkins y Mordan en 1822... El lápiz resultó útil, económico, portátil, versátil y adaptable a la mayor parte de las culturas de la Tierra. Ahora se producen más de 300 tipos de lápices...

FUENTES UTILIZADAS EN LA RESPUESTA: http://www.rae.es/ Enciclopedia universal ilustrada : europeo-americana. -- Madrid : Espasa-Calpe, D.L. 1958-. - T. 29, p. 775 Nueva enciclopedia Durvan / dirección general Lorenzo Portillo Sisniega ; dirección editorial, Jesús Moya ; dirección de producción, Luis Rodrigo Ibarra ; prólogo general, Julián Marías. -- $3^{\mathrm{a}}$ ed. -Bilbao : Durvan, [1998]. - T. 16, p. 6385 www.oei.org.co/sii/entrega17/art08.htm http://www.juvenilweb.com/HOB/COLECCIONES/lapiz.html http://www.centrovision.cu/semblanzas/confoto.php?rec=96

FECHA DE SOLICITUD: 26/03/2004

FECHA DE RESOLUCIÓN: 29/03/2004

NIC: 23275

CONSULTA: Quisiera saber quién inventó el lapicero y algo de historia de esta herramienta

RESPUESTA: La definición de lapicero es polisémica en español, pudiendo significar lo siguiente según la Real Academia Española : lapicero. 1. m. Instrumento en que se pone el lápiz para servirse de él. 2. m. lápiz (\| barra de grafito). 3. m. C. Rica, Guat. y Hond. bolígrafo. 4. m. Méx. portaminas. La historia del instrumento en que se pone el lápiz no la hemos localizado, pero sí la historia del lápiz : En 1795 se inventó una fórmula de mezclar polvo de grafito con arcilla, cortando el producto resultante en pequeñas barras que luego se cocían. La dureza de estos lápices depende de la proporción entre grafito y arcilla: cuanto más grafito se utilice, más blando u oscuro es el trazo del lápiz. En 1812 el estadounidense William Monroe ideó un proceso, que 
aún se emplea en la actualidad, mediante el cual se podía embutir la mezcla grafito-arcilla entre dos trozos de madera de cedro. El portaminas, patentado en 1877, está formado por una barrita cilíndrica de mina insertada en un cilindro metálico o plástico y empujado por un émbolo que al girar va expulsando la punta de la mina. El diseño básico del portaminas apenas sufrió alteraciones hasta que en 1976 se introdujo una modificación notable. El nuevo utensilio, con capacidad hasta 12 minas, va haciendo salir la mina por efecto de la gravedad desde el depósito a través de un fino tubo de metal. La mina queda sujeta por una mordaza de muelle enrollada a su alrededor. Este mecanismo ha permitido la utilización de minas de un grosor de hasta $0,3 \mathrm{~mm}$ de diámetro, que se partirían en cualquier otro portaminas mecánico. Comercializado inicialmente como una herramienta profesional para ingenieros, delineantes y artistas, el portaminas goza de una difusión casi universal

FUENTES UTILIZADAS EN LA RESPUESTA: Internet, Diccionarios

FECHA DE SOLICITUD: 29/03/2004

FECHA DE RESOLUCIÓN: 29/03/2004

Pregunta 7

NIC: 23276

CONSULTA: Hola, necesito una síntesis histórica de la construcción de la catedral de Burgos. Muchas gracias.

RESPUESTA: A continuación le detallamos algunas direcciones de páginas web para que usted pueda eleborar una síntesis histórica de la construcción de la catedral de Burgos, asi como otras páginas para ampliar la informacióbn sobre la misma.

FUENTES UTILIZADAS EN LA RESPUESTA:

http://centros5.pntic.mec.es/ies.juana.de.castilla/burgos.htm http://www3.planalfa.es/catedralburgos/ http://web.jet.es/vliz/catedral.htm http://www.archiburgos.org/catedral/visita.htmhttp://html.rincondelvago.com/c atedral-de-burgos.html

FUENTES PARA AMPLIAR: http://web.jet.es/vliz/catebur.htm http://campaners.com/gcv/t138a.htm http://www.artehistoria.com/frames.htm?http://www.artehistoria.com/historia/ obras/9417.htm http://www.mappinginteractivo.com/plantillaante.asp?id_articulo $=168$

FECHA DE SOLICITUD: 29/03/2004

FECHA DE RESOLUCIÓN: 29/03/2004

NIC: 23302

CONSULTA: Hola, necesito una síntesis histórica de la construcción de la catedral de Burgos. Muchas gracias.

RESPUESTA: Se inició el 20 julio 1221, asentándose sobre el antiguo templo románico erigido en reinado de Alfonso VI (1065-1109). Pusieron la primera piedra Fernando III y el obispo Mauricio que en sus viajes a Europa conoció el estilo gótico desarrollado en Francia. Las obras avanzaron con rapidez y en 1257 la cabecera con girola debía estar acabada. se consagra en 1260. Las naves completan fines XIII como el claustro. El 1er arquitecto conocido es M. Enrique, al que semenciona en 1261, hasta su muerte (1277). Continua Juan Pérez (+1296)Los trabajos llegan a la fachada, con tres portadas y torres, mientras q fachadas de crucero lo hacen con portada única, Sarmental Sur y Coronería Norte. El Claustro en el sur, con 2 pisos, bóveda crucería simple. En XIV trabajos lentos, se construyen capillas zona 
este del claustro, destaca la de S. Catalina con bóveda estrellada. En XV obras cobran impulso con Juan y Simón Colonia, alemanes llegados por iniciativa de Alonso de Cartagena. Su actividad trae renovación estilística que sustituye influencia francesa por gótico germánico y flamencos. Juan diseña remate torres en aguja calada (1442-1458) y capillas de Visitación y S Ana y traza el cimborrio primitivo. Simón realizó (1482-1491) capilla Condestables, de planta octogonal, mezcla formas flamígeras y elementos tradición islámica. En XVI se combina gótico final y renacimiento. Trabajan Francisco Colonia que realiza puerta Pellejería norte del crucero) en estilo transición a Renacimiento. Diego Siloé construye (1519-1526 Escalera Dorada, obra renacentista española. Juan Vallejo hace $n$ cimborrio crucero (1339-1568)destruido el primitivo. conr cúpula estrella ocho puntas,pechinas,influencia musulmana. $2^{\mathrm{a}} \mathrm{XVI}$ deja de utilizarse bóveda gótica en Cap Natividad en girola por Martín de Bérriz En época barroca se produce el cerramiento del Coro (1599-1604) y la Capilla San Enrique.S. XVIII Cap Sta Tecla, de Andrés Collado y Reliquias

FUENTES UTILIZADAS EN LA RESPUESTA: Andrés Ordax, Salvador. La Catedral de Burgos : patrimonio de la Humanidad. León : Edilesa, 1993 López Martínez, Nicolás. Catedral de Burgos, guía básica. Burgos : Cabildo de la Catedral, 1999 Rico Santamaría, Marcos. La Catadral de Burgos ; Patrimonio del mundo, 1993 Burgos : guía visual. Burgos : Ayuntamiento, 2003

FUENTES PARA AMPLIAR: http://www.archiburgos.org/catedral/contenido.htm

FECHA DE SOLICITUD: 30/03/2004

FECHA DE RESOLUCIÓN: 02/04/2004

\section{Pregunta 8}

NIC: 23277

CONSULTA: Buenos días. Soy un estudiante de derecho y me gustaría que me dijeran cuáles son las pruebas que se realizan en las oposiciones para registradores de la propiedad,ya que estoy pensando en hacer esta oposición. Les agredeceré que simplemente me enumeren las pruebas y que me digan el contenido de cada una. Muchísimas gracias por su servicio.

RESPUESTA: Le remito a la página web del Colegio de Registradores y Mercantiles de España, donde le indican las bases así como las convocatorias:

http://www.registradores.org/castellano/comunes/frames.html?objeto=turbina 1N2\&opcion=0\&elem=1 En cuanto a las pruebas a realizar están enumeradas en el Convenio de Registradores y Mercantiles de España, en un anexo titulado: PRUEBAS DE APTITUD PARA INGRESO Y PROMOCION DE LOS AUXILIARES Y OFICIALES, cuya página web es: http://www.comfia.net/acuerdo/serviadmi/registra.htm

FUENTES UTILIZADAS EN LA RESPUESTA: http://www.der.uva.es/orientate/publico/registradores.html

FECHA DE SOLICITUD: 29/03/2004

FECHA DE RESOLUCIÓN: 29/03/2004

NIC: 23303

CONSULTA: Buenos días. Soy un estudiante de derecho y me gustaría que me dijeran cuáles son las pruebas que se realizan en las oposiciones para registradores de la propiedad,ya que estoy pensando en hacer esta oposición. Les agredeceré que simplemente me enumeren las 
pruebas y que me digan el contenido de cada una. Muchísimas gracias por su servicio.

RESPUESTA: Las oposiciones al Cuerpo de Registradores de la Propiedad, Bienes Muebles y Mercantiles se publican en el Boletín Oficial del Estado (www.boe.es) en la Sección II, Autoridades y Personal dentro de Ministerio de Justicia. En el BOE del 10 de enero de 2003 puede Vd. consultar en el Anexo el Temario de una de las convocatorias.

FUENTES UTILIZADAS EN LA RESPUESTA: Internet. www.boe.es

FUENTES PARA AMPLIAR: Dirección General de los Registros y del Notariado: www.mju.es/rnotariado1.htm

FECHA DE SOLICITUD: 30/03/2004

FECHA DE RESOLUCIÓN: 31/03/2004

NIC: 23319

CONSULTA: Buenos días. Soy un estudiante de derecho y me gustaría que me dijeran cuáles son las pruebas que se realizan en las oposiciones para registradores de la propiedad,ya que estoy pensando en hacer esta oposición. Les agredeceré que simplemente me enumeren las pruebas y que me digan el contenido de cada una. Muchísimas gracias por su servicio.

RESPUESTA: Estimado amigo: Según la Resolución de 12 de diciembre de 2002, publicada en el BOE de 10 de enero de 2003, por la que se convocan oposiciones al cuerpo de aspirantes de registradores de la propiedad, los ejercicios de la oposición y la forma de calificación se ajustarán a lo dispuesto en el artículo 506 del Reglamento Hipotecario (publicado en el BOE de 16 de abril de 1947 y modificado en el BOE de 29 de septiembre de 1998). Según este artículo los ejercicios de la oposición serán cuatro: 1.Contestar verbalmente y en el tiempo máximo de una hora cinco temas sacados a la suerte de los comprendidos en el programa que se cite en la convocatoria de las siguientes materias: tres de derecho civil, común y foral, uno de derecho mercantil y uno de derecho administrativo o procesal. 2.Contestar verbalmente y en el tiempo máximo de una hora cinco temas sacados a la suerte del mismo programa de las siguientes materias: tres de derecho hipotecario, uno de derecho fiscal y uno de derecho notarial. (EI temario se publicó en el BOE de 25 de abril de 1996, modificado en el BOE del 10 de enero de 2003, fecha de la última convocatoria). 3.- Calificar un documento y la redacción del informe en defensa de la nota, en el tiempo máximo de seis horas. 4.- Practicar, en el tiempo máximo de seis horas, las operaciones procedentes de liquidación y registro, hasta dejar inscrito o anotado un documento, o denegada o suspendida la inscripción o anotación.

FUENTES UTILIZADAS EN LA RESPUESTA: www.boe.es www.aranzadi.es

FUENTES PARA AMPLIAR: www.map.es/seap/dgfp/dgfp.htm

FECHA DE SOLICITUD: $31 / 03 / 2004$

FECHA DE RESOLUCIÓN: 01/04/2004

\section{Pregunta 9}

NIC: 23304

CONSULTA: ¿Es bueno dar la leche a los gatos? Hay quien dice que sólo de pequeños, pero que luego les sienta mal.

RESPUESTA: Los perros y gatos no poseen las enzimas adecuadas para desdoblar el glucosacárido propio de la leche llamado lactosa. Esto es común en algunas personas, ellos también carecen de lactasa que es la enzima que desdobla a la lactosa en glucosa y de esta manera puede ser absorbida en el tracto intestinal, tanto las personas o animales que no poseen la enzima que desdobla a la lactosa, la leche permanece sin digerir, 
fermenta y es causa de diarrea. Algunos animales pueden tolerar un poco la leche, otros, en absoluto. Si su animal disfruta y parece tolerar la leche, se le puede administrar en cantidades pequeñas y tibia, nunca fría.

FUENTES UTILIZADAS EN LA RESPUESTA: Internet: Revista Mascotia en Www.mascotia.com

FECHA DE SOLICITUD: 30/03/2004

FECHA DE RESOLUCIÓN: 31/03/2004

NIC: 23318

CONSULTA: ¿Es bueno dar la leche a los gatos? Hay quien dice que sólo de pequeños, pero que luego les sienta mal.

RESPUESTA: Los gatos no poseen las enzimas adecuadas para desdoblar el glucosacárido propio de la leche llamado lactosa. Cuando no se posee esta enzima de la lactasa la leche permanece sin digerir, fermenta y es causa de diarrea. La leche de vaca no es una bebida apropiada, pues en la mayoría de los gatos adultos su lactosa origina diarreas (la leche materna de las gatas no contiene lactosa). Para las hembras en gestación o para las que están dando de mamar y, están habituadas a ella, la leche es un alimento suplementario rico en calorías y de gran valor. Sí puede suministrarse tranquilamente productos lácteos fermentados, como leche condensada, cuajadas y yogures, pues no contienen lactosa. Los cachorros deben de ser alimentados con una leche especial para ellos.

FUENTES UTILIZADAS EN LA RESPUESTA: Gatos : guía práctica para una convivencia feliz / Gerd Ludwig ; fotografías de reconocidos profesionales especialistas en animales ; ilustraciones, Renate Holzner ; [traducción, Ambrosio Berasaín Villanueva]. -- León : Everest, [2002 http://www.mascotia.com

FUENTES PARA AMPLIAR: Nutrición de perros y gatos : manual para estudiantes, veterinarios, criadores y propietarios / director, A.T.B. Edney ; traducido del inglés por el Dr. Rafael Sanz Arias. -- Zaragoza : Acribia, D.L. 1986 El veterinario en casa : como prevenir y curar trastornos y enfermedades de perros y gatos / Roberto Gianinetti. -- Barcelona : Ediciones del Drac, 1993 http://www.bigshotcats.com/leche_para_cachorros.htm

FECHA DE SOLICITUD: 31/03/2004

FECHA DE RESOLUCIÓN: 01/04/2004

\section{Pregunta 10}

NIC: 23040

CONSULTA: ¿Es lo mismo Centro de Documentación que Biblioteca Especializada? . Sino es así podrían decirme las similitudes y diferencias.

RESPUESTA: No es lo mismo a continuación le indicamos alguna definición sobre el tema y bibliografía. Centro de Documentación: es aquella unidad de información que se dedica al análisis o descripción del contenido de los documentos y la difusión de la información. Biblioteca especializada: mantenida y administradad por una firma comercial, una corporación privada, una asociación, un organismo estatal u otro grupo o entidad que tienen interés por una materia específica para atender las necesidades de información de sus miembros o personal y alcanzar los objetivos de la organización...

FUENTES UTILIZADAS EN LA RESPUESTA: MANUAL de bibliotecas.Madrid: Síntesis, 1996 pg. 69 MANUAL de Ciencias de la Documentación. Madrid: Pirámide, 2002 pág. 207

FECHA DE SOLICITUD: $15 / 03 / 2004$

FECHA DE RESOLUCIÓN: 15/03/2004 
NIC: 23052

CONSULTA: ¿Es lo mismo centros de documentacion y bibliotecas especializadas?. Sino es así cuales son las diferencias

RESPUESTA: Como podemos observar, ambos conceptos son muy similares Centro de documentación: Organismo que adquiere, organiza, almacena, recupera y difunde documentación para atender a demandas concretas de información. Véase además Biblioteca especial Biblioteca especial: Biblioteca que reúne información sobre una determinada rama del conocimiento y generalmentea actúa como centro de documentación en la misma. Véase además centro de documentación, biblioteca científica, biblioteca de empresa, biblioteca general, biblioteca técnica.

FUENTES UTILIZADAS EN LA RESPUESTA: Diccionario del archiverobibliotecario : terminología de la elaboración, tratamiento y utilización de los materiales propios de los centros documentales / Luis García Ejarque. -Gijón : Trea, 2000 XIV, 442 p. ; 24 cm. -- (Biblioteconomía y administración cultural ; 42) ISBN 84-95178-83-4

FECHA DE SOLICITUD: $16 / 03 / 2004$

FECHA DE RESOLUCIÓN: 16/03/2004

NIC: 23092

CONSULTA: ¿Es lo mismo Centros de Documentación que Bibliotecas Especializadas? ¿Cuales son las diferencias?

RESPUESTA: Según el diccionario de Bibliología y ciencias afines de José Martínez de Sousa, Centro de Documentación es el organismo que desarrolla tareas de documentación e información, y cuya función no es la de archivar, sino la de distribuir. Mientras que define a la biblioteca especializada como aquella que está formada por obras correspondientes a una sola disciplina o rama de conocimiento. Consultado el Manual de Biblioteconomía editado por Luisa Orera, la biblioteca especializada responde a aquellas bibliotecas, centros de documentación o centros de información que aglutinan, tratan y difunden información relativa a un tema o a un grupo de temas afines. Normalmente se tratará de bibliotecas vinculadas a centros de investigación, organizaciones industriales 0 culturales, y todo tipo de instituciones que desarrollan su trabajo en un ámbito determinado, siendo su principal misión proporcionar información a las personas que trabajen en esos centros. La misión primaria de una biblioteca es la de recopilar y ser depositarios de documentos, mientras que la de un Centro de Documentación es conocer en profundidad y estar al día sobre la producción científica relativa a un cierto tema, produciendo nuevos documentos (secundarios) que permitan extractar su contenido informativo. Según Riera Masgrauy Sastre Domenech, es misión primordial de los centros de documentación, tener localizada la documentación completa sobre una materia determinada y poder acceder a ella en cualquier momento. Se puede decir como característica de los centros de documentación que lo diferencian de otras instituciones documentales que en ellos prepondera el análisis de la documentación, tanto en lo relativo a su identificación física como a su ordenación temática y a la descripción del contenido; y que los documentos propios de estos Centros comparten rasgos comunes con los de una biblioteca o de un archivo, pero que se diferencian por ser fruto de una recopilación voluntaria y deliberada.

FUENTES UTILIZADAS EN LA RESPUESTA: * MANUAL de biblioteconomía / Luisa Orera Orera (editora). Síntesis, 1998 * MARTINEZ COMECHE, Juan Antonio. Teoría de la información documental y de las instituciones documentales . Síntesis, 1995 * MARTINEZ DE SOUSA, José. Diccionario de bibliología y ciencias afines. Fundación Germán Sánchez Ruipérez, 1993 
FECHA DE SOLICITUD: $18 / 03 / 2004$

FECHA DE RESOLUCIÓN: 18/03/2004

\section{Pregunta 11}

NIC: 23106

CONSULTA: Cual es la función de las Bibliotecas Universitarias?

RESPUESTA: Según José Antonio Gómez Hernández en el Manual de Biblioteconomía, concreta las misiones o funciones de la biblioteca universitaria como las de proporcionar una colección básica de acuerdo a las necesidades de introducción en el conocimiento científico que tengan los estudiantes; mantener una colección de referencia bajo cualquier soporte, que pueda ser base de información y medio didactico y metodologico en el proceso de aprendizaje y adquisicion de habitos investigadores; contar con una colección documental especializada en las materias que cubran los Planes de Estudio y los proyectos de investigación; ser un servicio de información, orientación, referencia y formación de usuarios, que promueva y mejore los hábitos de uso de la biblioteca, para un optimo aprovechamiento de sus recursos; ser un servicio de apoyo a la investigación especializada que cumpla las funciones de acceso a bases de datos internacionales, orientación bibliografica especializada y obtención del documento original y favorecer el acceso a la cultura del entorno y la época, a través de una colección documental diversa relacionada con las manifestaciones espirituales, y de la programación de actividades de difusión de la ciencia y la cultura.

FUENTES UTILIZADAS EN LA RESPUESTA: Manual de biblioteconomía / Luisa Orera Orera (editora). Síntesis, 1998

FECHA DE SOLICITUD: $18 / 03 / 2004$

FECHA DE RESOLUCIÓN: 18/03/2004

NIC: 23111

CONSULTA: ¿Cual es la funcion de las bibliotecas universitarias?

RESPUESTA: Segun la ALA, la biblioteca universitaria es una conbinación orgánica de personal, colecciones e instalaciones cuyo propósito es ayudar a sus usuarios en el proceso de transformar la información en conocimiento. Según la Association of University Teachers (1964) la función primordial de la biblioteca universitaria es 'facilitar el estudio y la investigación a los miembros de su propia institución'. Segun REBIUN (Red de Bibliotecas Universitarias) el objetivo primordial de la biblioteca universitaria es satisfacer las necesidades de información de la comunidad universitaria. Los servicios de la biblioteca son, juntamente con sus recursos y su personal, los instrumentos que permiten conseguir el objetivo mencionado.

FUENTES UTILIZADAS EN LA RESPUESTA: -REBIUN. Normas y directrices para bibliotecas universitarias y científicas. Madrid : Ministerio de Educación y Cultura. 1999. -James Thompson, Reg Carr. La biblioteca universitaria: introducción a su gestión. Madrid : Funadación Germán Sánchez Ruipérez, 1990. -Luisa Orera Orera (ed.). Manual de biblioteconomía. Madrid : Síntesis, 1996.

FUENTES PARA AMPLIAR: Las mismas obras

FECHA DE SOLICITUD: $19 / 03 / 2004$

FECHA DE RESOLUCIÓN: 20/03/2004

NIC: 23122

CONSULTA: ¿Cual es la función de las bibliotecas universitarias? 
RESPUESTA: Buenos dias: tiene un libro que le orientará sobre el tema cuyo título es: 'Biblioteca universitaria: introducción a su gestión' autor James Thompson, edit. Fundación Germán Sanchez Ruipérez. También, 'Temas de biblioteconomía universitaria y general' Edit. Complutense. Por otro lado, cualquier libro sobre las bibliotecas en general le dará nociones sobre este tema.

FECHA DE SOLICITUD: 21/03/2004

FECHA DE RESOLUCIÓN: 22/03/2004

NIC: 23127

CONSULTA: ¿Cual es la función de las bibliotecas universitarias?

RESPUESTA: Tienes las funcines en las web: http://web.usal.es/ alar/Bibweb/Temario/Univer.PDF http://www.ucm.es/BUCM/pruebas/apuntes/bu01.pdf

FUENTES UTILIZADAS EN LA RESPUESTA: http://web.usal.es/ alar/Bibweb/Temario/Univer.PDF http://www.ucm.es/BUCM/pruebas/apuntes/bu01.pdf

FECHA DE SOLICITUD: 22/03/2004

FECHA DE RESOLUCIÓN: 23/03/2004

NIC: 23189

CONSULTA: ¿Cual es la funcion de las bibliotecas universitarias?

RESPUESTA: La Biblioteca Universitaria es el corazón de la Universidad, ocupando un lugar central y básico. Se ocupa y sirve a todas las funciones de la Universidad: enseñanza e investigación, creación de conocimiento y la trasmisión a la posteridad de la ciencia y la cultura. Funciona como un instrumento dinámico de información animando al estudiante a la búsqueda personal e individual del conocimiento y del saber.Así, tiene una clara función en la formación; y por tanto es importante que a los lectores se les informe sobre su uso. De esta manera, podemos decir que son funciones de las Biliotecas Universitarias las siguientes: a) Gestionar la adquisición de los fondos bibliográficos y documentales solicitados por los diversos servicios, de acuerdo con las líneas de estudio e investigación de la Universidad. b) Conservar, procesar y difundir los fondos bibliográficos, documentales y audiovisuales de la Universidad de Cádiz. c) Garantizar el conocimiento y uso de sus propios fondos. d) Facilitar a la comunidad universitaria y a la sociedad el acceso a la información bibliográfica y documental. e) Facilitar el acceso a la información actualizada de otras bibliotecas, centros de información o bancos de datos.

FUENTES UTILIZADAS EN LA RESPUESTA: www.google.com

FUENTES PARA AMPLIAR: Reglamentos de las bibliotecas de las distintas universidades

FECHA DE SOLICITUD: 24/03/2004

FECHA DE RESOLUCIÓN: 24/03/2004

NIC: 23170

CONSULTA: ¿Cual es la función de las bibliotecas universitarias?

FECHA DE SOLICITUD: 23/03/2004

FECHA DE RESOLUCIÓN: 24/03/2004 


\section{Pregunta 12}

NIC: 23204

CONSULTA: Estimados sres.les gracederia por tener gran interes en mis origenes alguna informacion sobre el apellido GRANIZO,que por mis noticias es un apellido castellano.

RESPUESTA: Sintiendolo mucho no hemos logrado encontrar una respuesta precisa a la pregunta que nos planteó. Le rogamos que si en otro momento encuentra algun dato mas sobre el tema, nos vuelva a remitir la pregunta

FECHA DE SOLICITUD: 25/03/2004

FECHA DE RESOLUCIÓN: 26/03/2004

NIC: 23232

CONSULTA: Estimados Sres. Les agradeceria por tener gran interes en mis origenes alguna informacion sobre el apellido GRANIZO, que por mis noticias es un apellido castellano o extremeño

RESPUESTA: Existen multitud de páginas web sobre heráldica y genealogía, pero la mayoría son de pago o se accede mediante contraseña. También hay muchos foros donde se intercambia información, facilitando la comunicación entre aficionados al tema de la Genealogía y en especial a aquellos que buscan sus raíces, de forma totalmente altruista, p. e.: http://www.rediris.es/list/info/genealogia.es.html En el Centro Español de Investigación Heráldica (http://www.ceih.com/) no disponen de los datos de la Historia correspondiente al apellido GRANIZO, pero si disponen de los datos del Blasón de Armas correspondiente al Apellido GRANIZO. Granizo: escudo: en azur, un grifo de plata (http://www.heraldaria.com/armorial.php)

FUENTES UTILIZADAS EN LA RESPUESTA: http://www.ldelpino.com/recursos.html http://www.heraldaria.com/enlaces.php

FECHA DE SOLICITUD: 26/03/2004

FECHA DE RESOLUCIÓN: 29/03/2004

NIC: 23350

CONSULTA: Estimados Sres: Por medio de la presente, nos gustaría conocer bibliografías para obtener información sobre el Apellido GRANIZO. Saludos

FECHA DE SOLICITUD: 02/04/2004

FECHA DE RESOLUCIÓN: 02/04/2004 